\title{
Drop Analysis of the
} Advanced Test Reactor Fresh Fuel Shipping Container with Heavier Low-Enriched Uranium Fuel Contents

\section{November 2020}

ECAR-5224

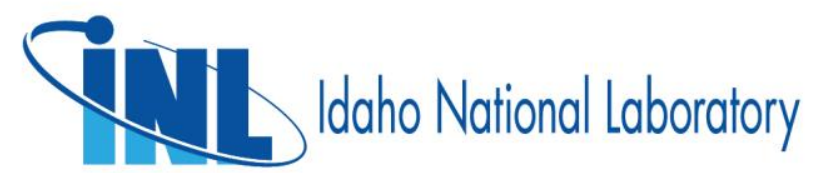




\section{DISCLAIMER}

This information was prepared as an account of work sponsored by an agency of the U.S. Government. Neither the U.S. Government nor any agency thereof, nor any of their employees, makes any warranty, expressed or implied, or assumes any legal liability or responsibility for the accuracy, completeness, or usefulness, of any information, apparatus, product, or process disclosed, or represents that its use would not infringe privately owned rights. References herein to any specific commercial product, process, or service by trade name, trade mark, manufacturer, or otherwise, does not necessarily constitute or imply its endorsement, recommendation, or favoring by the U.S. Government or any agency thereof. The views 


\title{
Drop Analysis of the Advanced Test Reactor Fresh Fuel Shipping Container with Heavier Low-Enriched Uranium Fuel Contents
}

\author{
ECAR-5224
}

November 2020

Idaho National Laboratory

Idaho Falls, Idaho 83415

http://www.inl.gov

\author{
Prepared for the \\ U.S. Department of Energy \\ Under DOE Idaho Operations Office \\ Contract DE-AC07-05ID14517
}


Page intentionally left blank 
Drop Analysis of the Advanced Test Reactor Fresh Fuel Shipping Container with Heavier Low-Enriched Uranium Fuel Contents

\begin{tabular}{|l|l|l|}
\hline 1. Effective Date & $12 / 07 / 20$ & $\begin{array}{l}\text { Professional Engineer's Stamp } \\
\text { Not required per LWP-10010 (2019) } \\
\text { Section 4.1. }\end{array}$ \\
\cline { 1 - 2 } $\begin{array}{l}\text { 2. Does this ECAR involve a } \\
\text { Safety SSC? }\end{array}$ & Yes & \\
\cline { 1 - 2 } $\begin{array}{l}\text { 3. Safety SSC Determination } \\
\text { Document ID }\end{array}$ & STC-000160 & \\
\cline { 1 - 2 } 4. SSC ID & USA/9330/AF-96 & \\
\cline { 1 - 2 } 5. Project No. & Docket No. 71-9330 & \\
\cline { 1 - 2 } 6. Engineering Job (EJ) No. & N/A & \\
\cline { 1 - 2 } 7. Building & Various & ATR Complex \\
\cline { 1 - 2 } 8. Site Area &
\end{tabular}

9. Objective/Purpose

The Advanced Test Reactor (ATR) Fresh Fuel Shipping Container (FFSC) is a rectangular stainlesssteel- container used for shipping radioactive material. The container is described in the ATR FFSC Safety Analysis Report (SAR). Per the ATR FFSC SAR, the ATR FFSC is designated a Type AF-96 packaging per the definition of $10 \mathrm{CFR} \S 71.4$ and was originally designed to transport highly enriched uranium (HEU) reactor fuel elements for the ATR, the Advanced Test Reactor Critical (ATRC) Facility, the Massachusetts Institute of Technology Reactor (MITR), and the University of Missouri Research Reactor (MURR). The Department of Energy, National Nuclear Security Administration's (NNSA), Office of Material Management and Minimization (M3) is working with Idaho National Laboratory (INL) to develop and qualify new low-enriched uranium (LEU) fuels and technologies for use in the ATR, ATRC, MITR, and MURR reactors. The LEU fuel elements will weigh significantly more than the current HEU designs and, combined with their associated fuel-handling enclosures for packaging, some configurations will exceed the $50 \mathrm{lbf}$ used in the ATR FFSC qualifying drop tests. There are LEU versions of MITR, MURR, and ATR fuel elements. However, for this evaluation, drop analysis of the ATR FFSC with only the heavier ATR low enrichment (LOWE) fuel element is considered in this evaluation because the LOWE fuel element is the heaviest of the considered LEU fuel elements.

The ATR HEU fuel element and the ATR LOWE fuel element are identical in every design aspect except for the fuel meat inside the 19 fuel plates. The LEU fuel meats are made using a U-10Mo highdensity foil rather than uranium dispersed in aluminum in the HEU fuel elements. The high density of the uranium in the LEU fuel meat increases the LOWE fuel element weight to just under $44 \mathrm{lbf}$ (versus the $22.1 \mathrm{lbf}$ weight of the tested ATR HEU fuel element). ATR fuel elements are placed in a thingauge aluminum weldment called a "fuel-handling enclosure" during packaging. The fuel-handling enclosure is used to cover and protect the element during loading and unloading operations. The ATR fuel-handling enclosure weighs about $15 \mathrm{lbf}$ per the drawings in the ATR FFSC SAR, and the weight is accounted for in this evaluation. 
Transporting the heavier LEU fuel elements require evaluation of two issues. The first is the effect of the increased mass of the LEU fuel elements on the survivability of the ATR FFSC package following the requisite drop qualifications. The second is the effect of the increased mass of the fuel plates on the fuel element during the same drops.

The ATR FFSC containing an ATR HEU fuel element in an ATR fuel-handling enclosure was physically dropped multiple times to qualify the container as a Type AF-96 package. The ATR FFSC SAR describes the drop tests performed with an actual ATR HEU fuel element weighing $22.1 \mathrm{lbf}$ contained in a $14.3 \mathrm{lbf}$ fuel-handling enclosure for a total payload of $36.4 \mathrm{lbf}$. Those drop tests showed that the ATR FFSC maintained containment of the ATR HEU fuel element and the fuel element was not significantly damaged. (Containment herein is not defined as leak tight, but as retention of the radioactive contents.)

The purpose of the evaluation is to show analytically that, for a similar set of tests, the ATR FFSC maintains containment of the heavier ATR LOWE fuel element and to assess the damage to the fuel element during the drops. The approach was to create finite element analysis (FEA) models that produce the same results as the physical drops. Those models were then used as the benchmarks for the follow-on analyses using the heavier contents. FEA models of the drops of ATR FFSC using up to a $115 \mathrm{lbf}$ fuel element were run and evaluated. Likewise, drops of a LOWE fuel element weighing $44 \mathrm{lbf}$ in the ATR FFSC were run and evaluated.

It is important to note that this report was done at the quality level necessary to be included in a nuclear-facility safety basis. However, it is not the intent of this report to conclude the suitability of the ATR FFSC for transporting the heavier payloads. This report only describes the results of the FEA as related to the required drop scenarios. Incorporation of the FEA into the safety basis will be evaluated by the ATR FFSC design authority.

The physical drop tests of the HEU fuel element and FEA drops for the LOWE fuel element showed noteworthy damage to the fuel plates. An aluminum protective block was conceived to mitigate the damage. The concept requires the blocks to be placed in the fuel element between the end boxes and fuel plates. Additional FEA drops were performed using the protective block. The addition of the blocks is primarily intended to mitigate the damage to the LOWE fuel-plates in the fuel element. However, FEA drops of the ATR HEU fuel element with the blocks were also performed and included for information.

FEA drops for the ATR FFSC were performed with nonlinear elastic/plastic evaluation. Suitability of the FEA drops for establishing a safety basis for the ATR FFSC were based on material rupture (i.e., through-thickness failure), gross deformation, and the ability of the ATR FFSC to retain the materials after the drops. Below is a list of failures that were considered not acceptable for the evaluation of the ATR FFSC and the LOWE fuel element:

1. Rupture causing loss of the bayonet-style lid lugs that represent the main structural attachment between the closure assembly and ATR FFSC body

2. Rupture of the locking pins in the closure assembly which could allow the closure assembly to rotate and disengage the bayonet-style lid lugs 


\section{Rupture of the closure assembly itself}

4. Rupture of the ATR FFSC body cavity wall or bottom

5. Damage to the fuel plates that results in exposure of the fuel meat. ${ }^{1}$

Two further studies were performed to improve confidence of the results. First, to establish some measure of containment safety factor of the ATR FFSC, the drop scenarios were performed with a stiff ATR fuel element weighing a little more than five times that of the physical test (115 lbf). Second, the ATR FFSC SAR identified a rupture of one of the two locking pins in the closure assembly. Scoping analysis tended to indicate that this occurred as a result of multiple physical drops that caused repeated rotation of the ATR FFSC body relative to the closure assembly. The second study explored multiple impact orientations like those that induced failure in the locking pin during the physical drops. The objective of this study was to show that locking-pin failure was unlikely in a single impact.

10. If revision, please state the reason and list sections and/or page being affected.

$\mathrm{N} / \mathrm{A}$-this is the original release of this report.

11. Conclusion/Recommendations

The ATR FFSC FEA model provided results that were reasonable and/or conservative when compared with the physical drops documented in the ATR FFSC SAR. Even with the conservatism, the ATR FFSC FEA model showed acceptable results for the FEA drop scenarios. The same FEA model was then used to provide results for drop scenarios with a stiff ATR fuel element weighing $115 \mathrm{lbf}$ which is a little more than five times that of the actual test fuel element. This model easily enveloped the results for the LOWE fuel element (44 lbf). The ATR FFSC results with a $115 \mathrm{lbf}$ fuel element demonstrated that no model showed unacceptable results for the ATR FFSC.

FEA models intended to mimic the physical drops were also run for the multiple impact orientations like those that failed the locking pin in the closure assembly for the physical drops. These results demonstrated significant locking pin plasticity but no locking pin failure. This supports the idea that multiple impacts were necessary to cause locking pin failure in the physical drops. Though, given the ATR FFSC SAR discussion, it is difficult to be sure of the failure mechanism in the physical drops. Considering all the evaluated drop scenarios, the locking pins were the FFSC component closest to having an unacceptable rupture. It must be noted that both locking pins must fail, and the closure assembly must have a rotational force such that the bayonet-style lid lugs become disengaged, in order for the closure assembly to open.

1 SAR-153, Chapter 4, Table 4.2-2 states that the fuel plates are 49.5 inches long and the fueled region is 48 inches. Consequently, end rupture to 0.75 inches will be considered acceptable. 
The FEA models used to benchmark the physical HEU fuel-element drops provided reasonable and conservative results compared with the physical-drop damage documented in the ATR FFSC SAR. The conservatism in the ATR HEU fuel element FEA model did, however, show damage into the fuelmeat region of the fuel plates. The same ATR fuel element FEA model was then used for the LOWE fuel element (44 lbf) drops. Not surprisingly, the FEA model showed significant damage into the fuel zone of the plates. These models were then run with the new aluminum blocks inserted in the end boxes. With the blocks in place, no penetration into the fuel zone occurred in any of the FEA drop scenarios.

In summary, the FEA analysis demonstrated that the ATR FFSC could accommodate fuel-element weights up to $115 \mathrm{lbf}$ for the postulated drop scenarios. Additionally, it showed acceptable results for the postulated drop scenarios of a LOWE fuel element (44 lbf) using the new block design. While the ATR FFSC SAR showed the damage to ATR HEU fuel element to be acceptable without the new block design, having the new block design could provide defense in depth if warranted.

The $115 \mathrm{lbf}$ fuel element evaluation was performed using the physical test component weights (other than for the fuel element). Consequently, the component weights included an FFSC body and closure assembly weighing $234 \mathrm{lbf}$ (225.0 lbf and $9.0 \mathrm{lbf}$, respectively), a fuel-handling enclosure weighing $14.3 \mathrm{lbf}$, and a fuel element weighing $115 \mathrm{lbf}$. This produced a package weight of about $363 \mathrm{lbf}$. The estimated weight of the FFSC body and closure assembly was about $240 \mathrm{lbf}$ per the drawings in the ATR FFSC SAR. Considering a $240 \mathrm{lbf}$ weight for the FFSC and a $363 \mathrm{lbf}$ evaluated package weight, the maximum evaluated weight carried by the FFSC was about $123 \mathrm{lbf}$. The $363 \mathrm{lbf}$ (package weight) or $123 \mathrm{lbf}$ (total payload) were the limits for this evaluation. Further evaluation may demonstrate higher weights are acceptable. 


\section{CONTENTS}

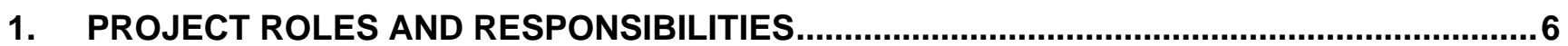

2. SCOPE AND BRIEF DESCRIPTION ................................................................................

3. DESIGN OR TECHNICAL PARAMETER INPUT AND SOURCES ........................................12

4. RESULTS OF LITERATURE SEARCHES AND OTHER BACKGROUND DATA....................13

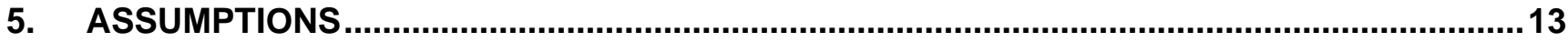

6. COMPUTER CODE VALIDATION-MATHCAD .............................................................13

7. COMPUTER CODE VALLIDATION_ABAQUS ................................................................... 14

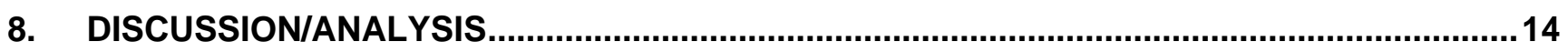

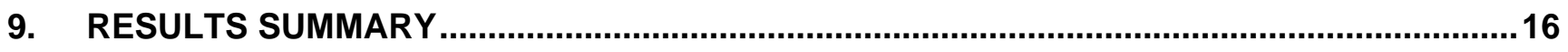

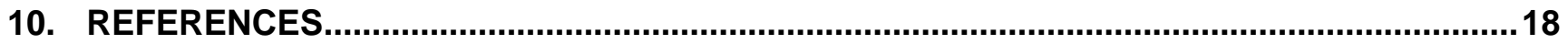

\section{APPENDIXES}

Appendix A-Engineering Inputs

Appendix B-Drop Analyses Model Development

Appendix C-ATR FFSC Evaluation Results

Appendix D-Fuel Element Evaluation Results 
Drop Analysis of the Advanced Test Reactor Fresh Fuel Shipping Container with Heavier Low-Enriched Uranium Fuel Contents

\section{PROJECT ROLES AND RESPONSIBILITIES}

\begin{tabular}{|c|c|c|c|}
\hline Project Role & Name & Organization & Pages Covered (if applicable) \\
\hline Performer & R. E. Spears & $\mathrm{J} 212$ & See eCR: 682141 \\
\hline Checkera & S. D. Snow & $\mathrm{J} 212$ & See eCR: 682141 \\
\hline Independent Reviewer ${ }^{b}$ & K. D Ellis & $\mathrm{J} 212$ & See eCR: 682141 \\
\hline CUI Reviewer ${ }^{c}$ & R. Harwell & J212 & See eCR: 682141 \\
\hline Manager ${ }^{d}$ & R. Harwell & $\mathrm{J} 212$ & See eCR: 682141 \\
\hline Requestoref & E. C. Woolstenhulme & D230 & See eCR: 682141 \\
\hline Nuclear Safety ${ }^{\dagger}$ & A. L. Tam & U740 & See eCR: 682141 \\
\hline Document Owner ${ }^{f}$ & E. C. Woolstenhulme & $\mathrm{D} 230$ & See eCR: 682141 \\
\hline Reviewer ${ }^{f}$ & & & \\
\hline
\end{tabular}

Responsibilities:

a. Confirmation of completeness, mathematical accuracy, and correctness of data and appropriateness of assumptions.

b. Concurrence of method or approach. See definition, LWP-10106.

c. Concurrence with the document's markings in accordance with LWP-11202.

d. Concurrence of procedure compliance. Concurrence with method/approach and conclusion.

e. Authorizes the commencement of work of the engineering deliverable. See Appendix A.

f. Concurrence with the document's assumptions and input information. See definition of Acceptance, LWP10200. 
Drop Analysis of the Advanced Test Reactor Fresh Fuel Shipping Container with Heavier Low-Enriched Uranium Fuel Contents

\section{SCOPE AND BRIEF DESCRIPTION}

Figure 1 shows the evaluated ATR FFSC package (per the ATR FFSC SAR (2017), Figure 1.2-1). As an extra level of protection, Figure 2 and Figure 3 show an aluminum 6061-T6 block design which can be placed between the fuel-element end boxes and fuel plates. This is to give additional protection to the fuel plates from pieces of a ruptured end box that could otherwise cut into the fuel plates.

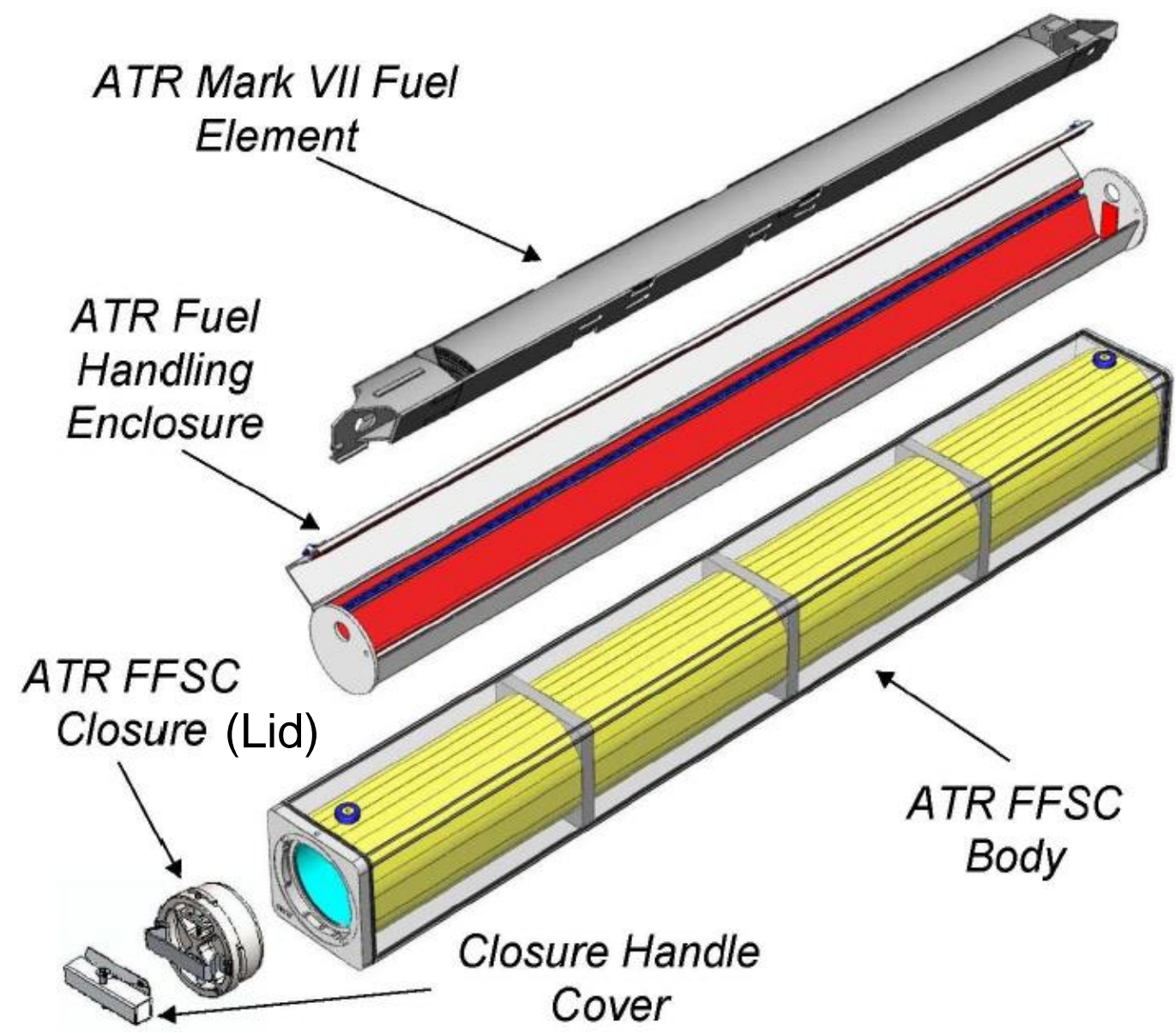

Figure 1. ATR FFSC package (per the ATR FFSC SAR (2017), Figure 1.2-1).

NOTE: The closure-handle cover is used for application of a tamper indicating device and does not have a safety function for the container. It does not appear in the ATR FFSC SAR (2017) photographs of the physical drops. Consequently, it is not considered in this evaluation. 
Drop Analysis of the Advanced Test Reactor Fresh Fuel Shipping Container with Heavier Low-Enriched Uranium Fuel Contents

Figure 2. Block design.

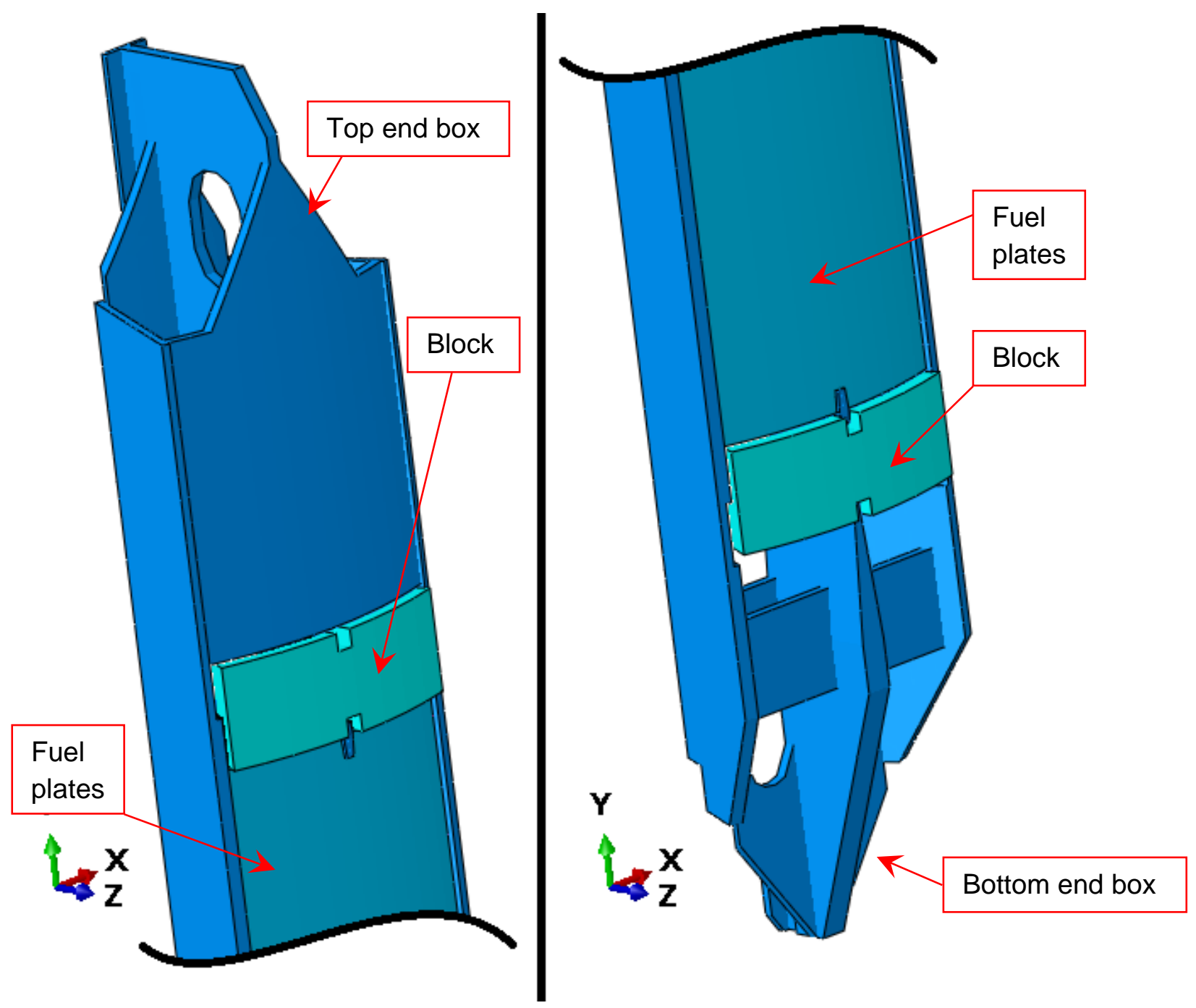

Figure 3. Block design installed at either end of the fuel element. 
Per Table 2.12.1.3 of the ATR FFSC SAR (2017), eleven consecutive drop tests were performed with an ATR FFSC containing an actual ATR HEU fuel element. These drop scenarios are shown in Table 1. Table 2 lists the FEA modeled scenarios for this evaluation. Three of the drops from Table 1 were not evaluated with the model, given that they were a repeat of a drop already considered or they were an unscheduled drop intended for a specific check, given the damage from the previous tests (as listed in Table 2). Three additional drop scenarios, typically addressed in package analyses, were evaluated. For the slap-down model, scoping evaluation was performed at impact angles of 10 and 20 degrees off horizontal. The 20 degree off horizontal slap-down models produced higher damage, so those results were documented.

Table 1. List of physical drop tests.

\begin{tabular}{|c|c|c|}
\hline Test No. & $\begin{array}{l}\text { Drop } \\
\text { Height }\end{array}$ & Impact Orientation \\
\hline 1. CN1-1 & $4 \mathrm{ft}$ & Center of gravity over the top corner. \\
\hline 2. CD1-1 & $30 \mathrm{ft}$ & Flat-side drop with the pocket side down. \\
\hline 3. CD2.A-1 & $30 \mathrm{ft}$ & Flat-side drop with the index lugs facing down. \\
\hline 4. CD2.B-1 & $30 \mathrm{ft}$ & Flat-side drop with the index lugs facing down. \\
\hline 5. CD3-1 & $30 \mathrm{ft}$ & $\begin{array}{l}\text { Flat-side drop with pockets and index lugs on the sides (surface temperature } \\
\text { approximately } 13^{\circ} \mathrm{F} \text { ) }\end{array}$ \\
\hline 6. CD4-1 & $30 \mathrm{ft}$ & Vertical bottom drop (surface temperature approximately $\left.41^{\circ} \mathrm{F}\right)^{*}$ \\
\hline 7. CP3-1 & $40 \mathrm{in.}$ & $\begin{array}{l}\text { Closure assembly (referred to as the lid from this point further) over a } 6 \text {-inch } \\
\text { diameter puncture bar (attempting to cause rotation of the lid) }\end{array}$ \\
\hline 8. CD5-1 & $30 \mathrm{ft}$ & Center of gravity over the top corner. \\
\hline 9. CD2.C-1 & $30 \mathrm{ft}$ & Flat-side drop with the index lugs facing down. \\
\hline 10. CP2-1 & $40 \mathrm{in.}$ & $\begin{array}{l}\text { Center-of-gravity over side and } 30 \text { degrees off horizontal over a } 6 \text {-inch } \\
\text { diameter puncture bar }\end{array}$ \\
\hline 11. CP1-1 & $40 \mathrm{in.}$ & Vertical top drop with the lid centered over a 6 -inch diameter puncture bar \\
\hline
\end{tabular}

As shown in Table 1, there is a temperature range that must be considered for the evaluated drops. Per ATR FFSC SAR (2017), Section 3.3.1.1, the maximum ambient air temperature that must be considered is $100^{\circ} \mathrm{F}$, per $10 \mathrm{CFR} \S 71.71$ (c)(1). The ATR FFSC SAR (2017), Section 2.6.1 notes that the maximum ATR FFSC package temperature under conditions of $100^{\circ} \mathrm{F}$ ambient temperature and full insolation is $186^{\circ} \mathrm{F}$ on the outer shell. Per ATR FFSC SAR (2017), Section 3.3.1.2, the minimum ambient air temperature that must be considered is $-40^{\circ} \mathrm{F}$, per $10 \mathrm{CFR} \S 71.71$ (c)(2). The ATR FFSC SAR (2017), Section 2.6.2, notes that a minimum ambient temperature of $-40^{\circ} \mathrm{F}$ can produce a minimum average package temperature of $-40^{\circ} \mathrm{F}$. Discussion relative to material properties for this temperature range is given in Appendix B, Section B2.1.

Table 2 lists the drop scenarios considered in the scope of this evaluation. The ATR FFSC SAR (2017), Section 2.6.1 notes that a potential maximum pressure rise of less than 4 psi is possible within the sealed cavity. This is not considered to be significant enough for inclusion in the drop scenarios. 

with Heavier Low-Enriched Uranium Fuel Contents

Table 2. List of FEA model-simulated drop tests.

\begin{tabular}{|c|c|c|}
\hline Test No. & $\begin{array}{l}\text { Drop } \\
\text { Height }\end{array}$ & Impact Orientation \\
\hline 1. $\mathrm{CN} 1-1$ & $4 \mathrm{ft}$ & Center of gravity over the top corner \\
\hline 2. CD1-1 & $30 \mathrm{ft}$ & Flat-side drop with the pocket side down \\
\hline 3. CD2.A-1 & $30 \mathrm{ft}$ & $\begin{array}{l}\text { Side drop with the index lugs facing downward and the edge impacting } \\
\text { slightly before the index lugs }{ }^{\star 2}\end{array}$ \\
\hline 4. CD2.B-1 & $30 \mathrm{ft}$ & Not evaluated due to its similarity with Test No. 3.) \\
\hline 5. CD3-1 & $30 \mathrm{ft}$ & Flat-side drop with pockets and index lugs on the sides \\
\hline 6. CD4-1 & $30 \mathrm{ft}$ & Vertical bottom drop \\
\hline 7. CP3-1 & $40 \mathrm{in.}$ & $\begin{array}{l}\text { Not evaluated due to its being an unscheduled drop intended to see if } \\
\text { the lid would rotate given the damage from the previous tests }\end{array}$ \\
\hline 8. CD5-1 & $30 \mathrm{ft}$ & Center of gravity over the top corner \\
\hline 9. CD2.C-1 & $30 \mathrm{ft}$ & Not evaluated due to its similarity with Test No. 3.) \\
\hline 10. CP2-1 & $40 \mathrm{in.}$ & $\begin{array}{l}\text { Center-of-gravity over side and } 30 \text { degrees off horizontal over a } 6 \text {-inch } \\
\text { diameter puncture bar }\end{array}$ \\
\hline 11. CP1-1 & $40 \mathrm{in.}$ & Vertical top drop with the lid centered over a 6-inch diameter puncture bar \\
\hline 12. & $30 \mathrm{ft}$ & Added vertical top drop \\
\hline 13. & $30 \mathrm{ft}$ & Added flat-side drop on an edge \\
\hline 14. & $30 \mathrm{ft}$ & $\begin{array}{l}\text { Added } 20 \text { degrees off horizontal slap-down side drop with pockets and index } \\
\text { lugs on the sides }\end{array}$ \\
\hline
\end{tabular}

Table 3 provides a summary of the scope. The first part of the scope includes performing the Table 2 drop scenarios with FEA models best suited to represent them. The fuel element to be used is an ATR HEU fuel element weighing 22.1 lbf per Table 2.12.1-1 of the ATR FFSC SAR (2017). For reasons listed in the DISCUSSION/ANALYSIS section, an exact match is not expected between the physicaldrop scenarios and the FEA simulations of the drop scenarios. However, a reasonable match can be expected. The basic strategy of this evaluation is to produce accurate or relatively conservative results (i.e., more damage than the physical-drop scenario). With this approach, the expectation is that if the same modeling strategy is used on drop scenarios not physically tested, the damage shown by the FEA model should be conservatively high. Therefore, if an FEA model shows acceptable results, a physical drop of the same scenario should show acceptable results with margin. With this in mind, the ATR FFSC and the fueled region of the fuel plates are always modeled with minimum-strength material properties because their damage is of primary concern. Damage to the ATR fuel-handling enclosure (referred to the enclosure from here forward) and end boxes are not a concern unless that damage affects the response of the fuel-element fuel plates. Therefore, two versions of the enclosure and end-

2 Upon impact, the physical drop test spun about the lengthwise axis of the package. The scuff marks in Figures 2.12.1-15 and 2.12.1-16 of the ATR FFSC SAR (2017) make it appear that impact first occurred near the edge. To accommodate the description of the physical drop, an initial angle $\left(9.75^{\circ}\right.$ about the lengthwise axis of the package) is defined to make the edge impact slightly before the index lugs in the FEA model. 
box materials are considered. First, they are modeled with minimum material properties. This causes them to fail with minimal energy absorption, thereby causing more energy to be absorbed by the fuel plates. Second, they are modeled with typical or conservatively high (i.e., relatively tough) material properties. This causes them not to fail as quickly and gives them more potential for producing local damage in the fuel plates (such as cutting the fuel plates with sharp edges). To help ensure conservative damage, a finer fuel-plate mesh is used at the ends of the fuel plates in drop scenarios where the fuel-plate ends are damaged. Additionally, for information, these models are rerun with blocks included.

The second part of the scope is to run the Table 2 model-simulated drop tests with a LOWE fuel element. Per Quirl (2019), the bounding weight for a LOWE fuel element is $44 \mathrm{lbf}$. Consequently, the models are modified such that the fuel-plate density provides a fuel-element mass equivalent to that of the LOWE fuel element. For this scope part, a similar modeling strategy is used as that used in the first part of the scope, and the blocks are included out of necessity (as discussed in Appendix D).

As a measure of how robust the ATR FFSC is for the Table 2 drop scenarios, a third part of the scope includes having a fuel element a little more than five times the weight of the standard ATR HEU fuel element (115 lbf). To cause conservative damage to the ATR FFSC, the relatively tough enclosure material properties are used without failure defined (see Section B2.1 for further discussion). Additionally, a coarse-meshed version of the fuel element is used (without individual fuel plates). For additional conservatism, the fuel element uses 6061-T6 material properties throughout without failure. For this set of drop scenarios, Test 1 (from Table 2) is not included because it is enveloped by Test 8 (from Table 2).

Considering the physical drop tests, one of the two locking pins in the closure assembly (referred to as lid pins from this point further) lid pins had a shear failure in the fifth drop test. The purpose of the lid pins is to prevent rotation of the lid in a drop accident. If the lid pins prevent rotation of the lid, the primary load path keeping the lid in place is through the bayonet-style lid lugs (referred to as bayonets from this point further). The descriptions for most of the physical side drops indicated that the ATR FFSC spun about its length upon rebound. This indicates that, rather than being a flat-side impact, the ATR FFSC was rotated about the axis along its length at impact. Scoping analysis based on these descriptions indicated that the physical-impact orientations cause greater plasticity in the lid pins than when the impact occurs in a perfectly flat orientation. As evidence that the lid-pin failure occurred as a result of accumulated damage (from multiple drop tests) rather than being something that can be expected from a single impact, a fourth part to the scope is performed. For the fourth part to the scope, the fifth drop test (flat side drop with pockets and index lugs on the sides, surface temperature approximately $13^{\circ} \mathrm{F}$ ) of the first part of the scope is considered for multiple impact orientations about the axis along the length of the ATR FFSC. The first part of the scope provides the flat (i.e., 0 degree) impact. The fourth part of the scope adds impact angles at 5-degree intervals from 5 to 30 degrees. 
Table 3. Scope summary.

Fuel

Scope Element

Part Weight

Discussion

1. $22.1 \mathrm{lbf} \quad$ Table 2 drop scenarios with consideration to:

a. The whole model using minimum material properties.

b. The whole model using minimum material properties except the enclosure and end boxes which will use relatively tough material properties.

c. Repeating a to include blocks between the fuel plates and end boxes.

d. Repeating $b$ to include blocks between the fuel plates and end boxes.

2. $44 \mathrm{lbf} \quad$ Table 2 drop scenarios with consideration to:

a. The whole model using minimum material properties.

b. The whole model using minimum material properties except the enclosure and end boxes which will use relatively tough material properties.

c. Repeating a to include blocks between the fuel plates and end boxes.

d. Repeating $b$ to include blocks between the fuel plates and end boxes.

3. $115 \mathrm{lbf} \quad$ Table 2 drop scenarios (excluding Test 1 which is enveloped by Test 8 ) where the ATR FFSC has minimum material properties and the enclosure and fuel element have relatively tough material properties with no failure

4. $\quad 22.1 \mathrm{lbf} \quad$ Similar to the Scope Parts 1 and 3, Test 5, except impact angles at 5 degree and intervals from 5 to 30 degrees off horizontal and about the axis along the length $115 \mathrm{lbf}$ of the ATR FFSC

\section{DESIGN OR TECHNICAL PARAMETER INPUT AND SOURCES}

This is a drop-accident evaluation. Therefore, natural-phenomena hazard does not apply. The load scenarios are based on physical drop tests described in the ATR FFSC SAR (2017) and are defined in the SCOPE AND BRIEF DESCRIPTION section of this ECAR.

The acceptance criteria are based on the ATR FFSC SAR (2017). Each drop accident could have material rupture and/or gross deformation that is acceptable. However, overall acceptance for this evaluation is primarily based on the ability of the ATR FFSC to maintain containment of the payload. (Containment herein is not defined as leak tight, but as retention of the radioactive contents.) However, a rupture that might expose the fueled region of the fuel-element plates is also considered for acceptance. Table 4 gives a list of failures that are considered not acceptable for this evaluation. 
Table 4. Failures that are considered not acceptable for this evaluation.

No.

Failure

1. Rupture causing loss of the bayonets that represent the main structural attachment between the lid and body

2. Rupture of the lid pins which could allow the lid to rotate and disengage the bayonets

3. Rupture of the lid itself

4. Rupture of the body cavity wall or bottom

5. Damage to the fuel plates that results in exposure of the fuel meat ${ }^{3}$

This work is performed in accordance with the applicable requirements of LWP-10000, "Engineering Evaluation" (2020), LWP-10106, "Engineering Verification" (2018), and LWP-10200, "Engineering Calculations and Analysis Report" (2018).

\section{RESULTS OF LITERATURE SEARCHES AND OTHER BACKGROUND DATA}

For this evaluation, many documents are referenced for specific information, but the fundamental technical document used for this evaluation is the ATR FFSC SAR (2017). The ATR FFSC SAR (2017) also provides the necessary drawings used for modeling.

\section{ASSUMPTIONS}

Bounding or simplifying assumptions used in this evaluation are stated and justified when employed. No assumptions were made needing post-analysis verification.

\section{COMPUTER CODE VALIDATION-MATHCAD}

A. Computer type: Latitude 7490 laptop

B. Operating System and Version: Windows10 Enterprise (INL610883)

C. Computer program name and revision: Mathcad (2015)

D. Evidence of, or reference to, computer program validation: Mathcad does not have a formal validation. However, the Mathcad calculations are validated by the technical checker in the review process, as permitted by Appendix E of LWP-10200 (2018).

E. Bases supporting application of the computer program to the specific physical problem: Mathcad was specifically written to perform the types of calculations employed herein.

3 SAR-153 (2019), Table 4.2-2 states that the fuel plates are 49.5 inches long and the fueled region is 48 inches. Consequently, end rupture to 0.75 inches will be considered acceptable. 


\section{COMPUTER CODE VALLIDATION-ABAQUS}

For the Abaqus (2018) FEA software:

Abaqus Standard and Explicit Version 2018.HF3 Validation on Compute Server Sawtooth:

On July 30, 2020, the validation script approved in ECAR-3845 Rev. 0 was run on Sawtooth. The results of the validation script agreed with the results discussed in ECAR-3845 Rev. 0. Therefore, Abaqus Standard and Explicit Version 2018.HF3 are considered validated for structural analysis use running on the following configuration:

- "Sawtooth," which is an HPE SGI 8600 system (maintained by the High Performance Computing group) with 2,079 compute nodes (48 cores per node, Intel 8268 CPUs), CentOS 7.7.1908 operating system (kernel release: 3.10.0-1062.9.1.e17.x86_64 \#1 SMP Fri Dec 6 15:49:49 UTC 2019).

Technical Checker: Spencer Snow, 07/30/2020.

\section{DISCUSSION/ANALYSIS}

The ATR FFSC SAR (2017) describes a series of physical drop tests and evaluations to show the acceptability of an ATR FFSC loaded with a standard ATR HEU fuel element. The purpose of this present evaluation is to check the acceptability of an ATR FFSC loaded with a LOWE fuel element. To accomplish this, FEA models are developed to mimic the physical drop tests. Subsequently, the FEA models are modified to evaluate the acceptability of an ATR FFSC loaded with a LOWE fuel element.

While physical drop test data provided in ATR FFSC SAR (2017) are used for calibration of the FEA models in this evaluation, there are limitations to an exact comparison as listed below:

1. Actual material properties (yield stress, ultimate stress, ultimate elongation, etc.) are not available for the components of the dropped package. Consequently, material properties are based on minimums provided in the ATR FFSC SAR (2017), ASTM A240 (2019), ASTM A269 (2019), ASTM A276 (2017), ASTM A312 (2019), ASTM A479 (2019), ASTM A554 (2016), ASTM B209 (2019), ASTM F835 (2018), and Snow (2013). To reduce potentially unconservative behavior (where failure in noncritical components might reduce loading on critical components) relatively tough material properties are used in noncritical components for some drop scenarios (see the SCOPE AND BRIEF DESCRIPTION section of this ECAR).

2. Exact impact orientations for the physical drops (listed in Table 1) are not known. Though the ATR FFSC SAR (2017) discussion gives some idea of how the physical impact orientation differed from that listed in Table 1, the exact physical impact orientations are not documented. This likely has a small effect for some impact orientations (such as the center of gravity over the top corner). However, it does seem to be important for side drops (as discussed in the SCOPE AND BRIEF DESCRIPTION section of this ECAR). For the orientations in this evaluation, ideal orientations are run for most drop scenarios. However, some attempt is made at mimicking physical-impact orientations for a side drop. 
3. The physical drops were performed consecutively with the same package. This is possible, but difficult, with FEA modeling. For actual use, the loaded ATR FFSC must survive only one accidental drop. Considering this and the limitations already listed, no attempt was made to do successive FEA model drops.

4. Exact package geometry is not known for the dropped package. This is not considered a significant problem, and nominal dimensions are used for the FEA model. Page 2-27 of the ATR FFSC SAR (2017) states that the ATR HEU fuel element used was a rejected production fuel element. However, the defects were considered cosmetic, not structurally significant for purposes of the certification tests. Page 2.12.1-2 of the ATR FFSC SAR (2017) says that the discrepancies between the tested ATR FFSC and the ATR FFSC drawings were minor and would not significantly affect the ATR FFSC during testing.

Considering the limitations, there is no expectation of exactly matching the FEA models with physical tests. However, reasonable comparison is still expected.

When setting up the FEA model for the loaded ATR FFSC, the structural components were included. Notable items that were not included were neoprene in the enclosure. Also not included were the insulation and 0.015-in. thick sheet that contains the insulation in the ATR FFSC. This, along with possible effects due to the limitations listed above, resulted in small discrepancies in the modeled weight versus actual measured weight. Table 2.12.1-1 of the ATR FFSC SAR (2017) lists the actual component weights. These include a body-assembly weighing $225.0 \mathrm{lbf}$, a closure assembly (lid) weighing $9.0 \mathrm{lbf}$, a fuel-handling enclosure (enclosure) weighing $14.3 \mathrm{lbf}$, and an ATR HEU fuel element weighing $22.1 \mathrm{lbf}$. To match the actual component weights, the component densities were adjusted in the FEA model.

In an actual ATR HEU fuel element, the fuel plates are attached to the side plates with a swaged joint. Section 4.2.1.3.2 of SAR 153 (2012) states that the point of swage joint release is required to be greater than $150 \mathrm{lbf}$ per linear inch of joint. For the ATR HEU fuel-element model and the LOWE fuelelement model, swaging is performed as part of the model runs. A detailed discussion of how the swage joints are modeled and calibrated can be found in Section B2.2.

Appendixes A-D provide the details of this evaluation. Appendix A provides engineering inputs, including the work request and attached references. Appendix $B$ provides the model development for all models needed for the drop analyses listed in Table 3. Model development includes defining material properties (see Section B2.1), calibrating the swaged connection in the fuel element (see Section B-B2.2), defining initial conditions (see Section B2.3), defining the FEA models (see Section B3), and providing abbreviated input files (see Section B4). Using Appendix B data, along with the referenced documents, generation of a similar complete set of FEA models should be possible. Using the models developed in Appendix $B$, a complete set of model runs were performed per Table 3.

Appendix C provides ATR FFSC evaluation results. Initially, it shows that the ATR FFSC FEA model provides results that are reasonable and/or conservative when compared with the physical drops (see Section C2). Showing that the model can reasonably and/or conservatively predict the ATR FFSC damage in the physical-drop events validates the use of the model for increased fuel-element weights as well. Consequently, further evaluation is performed to show that the same ATR FFSC FEA model 
can accommodate much higher fuel-element weights, including a $115 \mathrm{lbf}$ fuel-element weight (see Section C3). This fuel-element weight is more than five times the ATR HEU fuel-element weight and more than 2.5 times the LOWE fuel-element weight 44 lbf per Quirl (2019). Additional ATR FFSC evaluation related to lid-pin failure is provided in Section C4. As described in Section C2.4.1, one of the lid pins sheared off between the lid and body in the physical drop for scope Part 1 (Table 3), Test 5 (Table 2). Section C4 documents two sets of models to study this. First, models similar to the physical drops are performed at multiple impact angles about the length of the ATR FFSC. This causes relative rotation between the FFSC body and lid that the lid pins must resist. The motivation is to check whether it is likely that a single drop could fail a lid pin. If lid-pin failure is not demonstrated, then the results help support the idea that multiple drops are necessary to produce lid-pin failure. Second, high weight models (115 lbf fuel element) are performed. The motivation is to check whether higher fuel-element weight drops make lid-pin failure more likely.

Appendix D provides fuel-element results. Initially, it shows that the model for the ATR HEU fuel element provides results that are reasonable and/or conservative when compared with the physical drops documented in the ATR FFSC SAR (2017). These results, along with results in which blocks are included (for information) are given in Section D2. Showing that the model can reasonably and/or conservatively predict the ATR HEU fuel-element damage in the physical-drop events validates the use of the model for increased fuel-element weights as well. Considering this, the same mesh with increased fuel-plate density is used to evaluated drop scenarios with the LOWE fuel element. Per the ATR FFSC SAR (2017), the physically dropped ATR HEU fuel element weighed 22.1 lbf. Per Quirl (2019), the bounding weight for a LOWE fuel element is $44 \mathrm{lbf}$. Because of the greatly increased fuelelement weight for the LOWE fuel element, the block design is included more out of necessity. LOWE fuel-element results, without and with blocks, are given in Section D3.

\section{RESULTS SUMMARY}

Appendix C, Section C2 shows that the ATR FFSC FEA model provides results that are reasonable and/or conservative when compared with the physical drops documented in the ATR FFSC SAR (2017). This can be expected given that the ATR FFSC is modeled with minimum material properties. Even with the conservative damage, the FEA models showed acceptable results for the ATR FFSC (considering Numbers 1-4 from Table 4).

Appendix C, Sections C3 and C4 provide results for Scope Parts 3 and 4 (Table 3). These drop scenarios are the most challenging to the ATR FFSC and include all of the results with a $115 \mathrm{lbf}$ fuel element. This set of model runs is intended to easily envelope the planned fuel-element weight that may be carried by the ATR FFSC, including the $44 \mathrm{lbf}$ weight of the LOWE fuel element, per Quirl (2019). The FEA model showed acceptable results for the ATR FFSC (considering Numbers 1-4 of Table 4). Appendix C, Section C-4.0, also provided a study with multiple impact orientations intended to challenge the lid pin and having the ATR HEU fuel-element weight of the physical drops (22.1 lbf). These drop scenarios studied the possibility of a lid-pin failure from a single drop scenario. While the drop scenarios produced significant plasticity whereby multiple impacts could produce lid-pin failure, no single impact caused such a failure. While not conclusive, this lends credibility that the lid-pin failure in the physical drops occurred as a result of multiple impacts and is not likely in a single impact. 
Considering Number 1 of Table 4 (Rupture causing loss of the bayonets that represent the main structural attachment between the lid and body), the damage shown in Figure C-144 and Figure C-168 are the closest to having an unacceptable failure in the bayonets. These are Scope Part 3 of Table 3, Tests 8 and 12 (Table 2) top-impact models. No model shows failure in the bayonets, and the worstcase damage involves a shearing load on one or more bayonets. Consequently, there is still significant margin before complete failure could be expected.

Considering Number 2 of Table 4 (Rupture of the lid pins which could allow the lid to rotate and disengage the bayonets), the damage shown in Figure C-185 and Figure C-233 are the closest to having an unacceptable failure. No model showed failure in the lid pins. Though these two models showed local strains above failure, likely because of extrapolation for results display (as integration point strains are the important strains for failure). In both cases, the high strains only existed on one of the two lid pins. If the high strained elements were considered as having failed (which represents less than $20 \%$ of the lid-pin cross section), there is still significant margin before complete failure could be expected. Lid-pin failure is likely the limiting factor to an ATR FFSC carrying weight significantly greater than that evaluated.

Considering Number 3 of Table 4 (Rupture of the lid itself), no element failure contributed to rupture of the lid itself for any drop scenario. Consequently, there is significant margin before complete failure could be expected.

Considering Number 4 of Table 4 (Rupture of the body cavity wall or bottom), no element failure contributed to rupture of the body cavity wall or bottom for any drop scenario. Consequently, there is significant margin before complete failure could be expected.

Appendix D, Section D2 provides results for Scope Part 1 (Table 3) relative to fuel-element damage. These results show that the ATR HEU fuel-element model provides reasonable and/or conservative damage when compared with physical drops documented in the ATR FFSC SAR (2017). With the conservative damage, the FEA models did show unacceptable results for the ATR HEU fuel element (considering Number 5 of Table 4). However, the inclusion of blocks produced acceptable results for all drop scenarios.

Appendix D, Section D3 provides results for Scope Part 2 (Table 3) relative to fuel-element damage. These drop scenarios are for a LOWE fuel element in the ATR FFSC. For a fuel element, fuel-plate damage is of most concern, and these drop scenarios produce the most significant fuel-plate damage. The FEA model showed unacceptable results for the LOWE fuel element (considering Number 5 of Table 4). However, the inclusion of blocks produced acceptable results for all the drop scenarios.

Considering Number 5 of Table 4 (Damage to the fuel plates that results in exposure of the fuel meat), the damage shown in Figure D-244 and Figure D-304 is the closest to having an unacceptable failure. These are the Scope Part 2 (Table 3) models, impacting as flat bottom and flat top impacts with conservatively fine fuel-plate meshes. The damage included compressive failure up to the edge of the fuel meat. As noted in Section D2.11, compressive failure in the fuel plates is predicted with significant conservatism because the defined failure parameters are based only on tensile failure (which represents the available data for the materials in the evaluation). Consequently, this amount of failure is considered as acceptable in not exposing the fuel meat in the LOWE fuel plates. 


\section{REFERENCES}

1. Abaqus (2018). Abaqus Version 2018.HF3, Dassault Systèmes Simulia Corp., 2018.

2. ASME (2019). "ASME Boiler \& Pressure Vessel Code, Section II, Materials, Part D, Properties (Customary)", 2019 Edition, The American Society of Mechanical Engineers, Two Park Avenue, New York, NY 10016 USA, July 2019.

3. ASTM A240 (2019). ASTM A240/A240M-19, "Standard Specification for Chromium and Chromium-Nickel Stainless Steel Plate, Sheet, and Strip for Pressure Vessels and for General Applications," ASTM International, 100 Barr Harbor Drive, PO Box C700, West Conshohocken, PA 19428-2959, 2019.

4. ASTM A269 (2019). ASTM A269/A269M-15a (Reapproved 2019), "Standard Specification for Seamless and Welded Austenitic Stainless Steel Tubing for General Service," ASTM International, 100 Barr Harbor Drive, PO Box C700, West Conshohocken, PA 19428-2959, 2019.

5. ASTM A276 (2017). ASTM A276/A276M-17, "Standard Specification for Stainless Steel Bars and Shapes," ASTM International, 100 Barr Harbor Drive, PO Box C700, West Conshohocken, PA 19428-2959, 2017.

6. ASTM A312 (2019). ASTM A312/A312M-19, "Standard Specification for Seamless, Welded, and Heavily Cold Worked Austenitic Stainless Steel Pipes," ASTM International, 100 Barr Harbor Drive, PO Box C700, West Conshohocken, PA 19428-2959, 2019.

7. ASTM A479 (2019). ASTM A479/A479M-19, "Standard Specification for Stainless Steel Bars and Shapes for Use in Boilers and Other Pressure Vessels," ASTM International, 100 Barr Harbor Drive, PO Box C700, West Conshohocken, PA 19428-2959, 2019.

8. ASTM A554 (2016). ASTM A554-16, "Standard Specification for Welded Stainless Steel Mechanical Tubing," ASTM International, 100 Barr Harbor Drive, PO Box C700, West Conshohocken, PA 19428-2959, 2016.

9. ASTM B209 (2014). ASTM B209-14, "Standard Specification for Aluminum and Aluminum-Alloy Sheet and Plate," ASTM International, 100 Barr Harbor Drive, PO Box C700, West Conshohocken, PA 19428-2959, 2019.

10. ASTM F835 (2018). ASTM F835-18, "Standard Specification for Alloy Steel Socket Button and Flat Countersunk Head Cap Screws," ASTM International, 100 Barr Harbor Drive, PO Box C700, West Conshohocken, PA 19428-2959, 2018.

11. ATR FFSC SAR (2017). "Advanced Test Reactor Fresh Fuel Shipping Container (ATR FFSC), Safety Analysis Report (SAR)," Docket 71-9330, Revision 14, AREVA Federal Services LLC, May 2017. 
12. Kaufman, J. G., (2019). "Properties and Selection of Cast Aluminum Alloys," ASM Handbook, Volume 2B, Properties and Selection of Aluminum Alloys, ASM International, 2019.

13. LWP-10000 (2020). "Engineering Initiation," Revision 12, Laboratory-wide Procedure, August 2020.

14. LWP-10106 (2018). "Engineering Verification," Revision 10, Laboratory-wide Procedure, November 2018.

15. LWP-10200 (2018). "Engineering Calculations and Analysis Report," Revision 11, Laboratorywide Procedure, February 2018.

16. LWP-10010 (2019). "Use of Registered Professional Engineers," Revision 3, Laboratory-wide Procedure, November 2019.

17. Mathcad (2015). Version 15.0 M040, Needham, MA: Parametric Technology Corporation, 2015.

18. SAR-153 (2019), "Upgraded Final Safety Analysis Report for the Advanced Test Reactor, Chapter 4, Reactor," SAR-153, Revision 24, Idaho National Laboratory, October 2019.

19. Snow, S. D., (2013). "RERTR Full-Size Element Assembly Structural Evaluation for ATR Vessel Loadings," ECAR-1482, Revision 1, Project File No.: 25228, June 2013.

20. Snow, S. D., (2019). "Software Validation Report for Abaqus Standard and Explicit Version 2018.HF3 for Structural Analyses," ECAR-3845, Revision 0, April 2019.

21. Quirl, S. K., (2019). "Weight of ATR Low Enriched (LOWE) Fuel Elements," TEV-3383, Revision 0, June 2019. 


\section{Appendix A:}

\section{Engineering Inputs}

\section{A1 ANALYSIS PLAN}

\section{A1.1 Scope}

The Advanced Test Reactor Fresh Fuel Shipping Container (ATR FFSC) is a rectangular stainless-steel container described in the ATR FFSC Safety Analysis Report (SAR). Per the ATR FFSC SAR, the ATR FFSC is designated a Type AF-96 packaging per the definition of $10 \mathrm{CFR} \S 71.4$, and has been designed to transport a single, unirradiated research-reactor fuel element or the associated loose plates.

The ATR FFSC SAR showed acceptance of the loaded ATR FFSC with physical drop tests. The scope of this ECAR is initially to show that finite element analysis (FEA) can be used to accurately represent the damage in the physical drop tests. If the physical drop damage can be accurately represented with FEA, drop analysis of the ATR FFSC with heavier low-enriched uranium (LEU) fuel contents will be considered. If unacceptable damage results with the heavier-payload contents, then one of three options will be considered. First, design modifications will be considered for the current ATR FFSC. Second, an impact limiter or overpack design will be considered for the current ATR FFSC. Third, a new ATR FFSC design will be considered. If the current ATR FFSC design provides acceptable results with the heavier LEU fuel contents, then heavier fuel elements will be considered to provide a measure of the ATR FFSC capability.

\section{A1.2 Deliverables}

The deliverable is an ECAR that can be reviewed by other labs and, potentially, the NRC.

\section{A1.3 Schedule}

Dependent on the success of the modeling progression.

\section{A1.4 Assumptions}

Bounding or simplifying assumptions to be used in this evaluation will be stated and justified when employed. Assumptions needing post-analysis verification, if any, will be identified.

\section{A1.5 Safety/Non-Safety SSC}

This ECAR involves a safety structure, system, or component (SSC).

Safety SSC Determination Document ID: STC-000160

SSC ID: USA/9330/AF-96

Project No.: Docket No. 71-9330

\section{A1.6 Natural phenomena hazards criteria (if applicable)}

This is a drop accident evaluation. Therefore, natural phenomena hazard does not apply. 


\section{A1.7 Load scenarios and acceptance criteria (if applicable)}

The load scenarios are based on physical drop tests described in the ATR FFSC SAR and extra drop scenarios that are often included in a drop evaluation.

The acceptance criteria are based on the ATR FFSC SAR. Each drop accident could have material rupture and/or gross deformation that is acceptable. However, overall acceptance for this evaluation is primarily based on the ability of the ATR FFSC to maintain containment of the payload. (Containment herein is not defined as leak tight, but as retention of the radioactive contents.) However, rupture that might expose the fueled region of the fuel element plates is also considered for acceptance. Below is a list of failures that are considered not acceptable for this evaluation.

1. Rupture causing loss of the bayonet-style lid lugs that represent the main structural attachment between the closure assembly and ATR FFSC body

2. Rupture of the locking pins in the lid, which could allow the lid to rotate and disengage the bayonets

3. Rupture of the lid itself

4. Rupture of the ATR FFSC body cavity wall or bottom

5. Damage to the fuel plates that results in exposure of the fuel meat.

\section{A1.8 Verification/validation of calculation and analysis software (if applicable)} The Abaqus Version 2018.HF3 software used in the ECAR is validated with Snow, S. D., "Software Validation Report for Abaqus Standard and Explicit Version 2018.HF3 for Structural Analyses," ECAR-3845, Revision 0, April 2019.

\section{A2 ATTACHED REFERENCES}

Below is the aluminum $5052-\mathrm{H} 32$ data sheet downloaded from https://www.protolabs.com/media/1016196/datasheet-sm-aluminum5052-h32.pdf: 


\begin{tabular}{|lcr|}
\hline $\begin{array}{l}\text { TEM-10200-1, Rev. } 11 \\
11 / 20 / 2019\end{array}$ & ENGINEERING CALCULATIONS AND ANALYSIS & Page A3 of A5 \\
& $\begin{array}{c}\text { Drop Analysis of the Advanced Test Reactor Fresh Fuel Shipping Container } \\
\text { with Heavier Low-Enriched Uranium Fuel Contents }\end{array}$ & \\
\hline
\end{tabular}

\section{Aluminum 5052-H32}

Categories: Metal; Nonferrous Metal; Aluminum Allov; 5000 Series Aluminum Allov

Material This alloy has good workability, very good corrosion resistance, high fatigue strength, weldability, and

Notes: moderate strength. This leads to its use in aircraft fuel/oil lines, fuel tanks, other transportation areas, sheet metal work, appliances and lighting, wire, and rivets.

Data points with the AA note have been provided by the Aluminum Association, Inc. and are NOT FOR DESIGN.

Composition Notes:

Composition information provided by the Aluminum Association and is not for design.

Key Words: UNS A95052; ISO AlMg2.5; Aluminium 5052-H32; AA5052-H32

\begin{tabular}{|c|c|c|c|}
\hline $\begin{array}{l}\text { Physical } \\
\text { Properties }\end{array}$ & Metric & English & Comments \\
\hline Density & $\underline{2.68 \mathrm{~g} / \mathrm{cc}}$ & $\underline{0.0968 \mathrm{lb} / \mathrm{in}^{3}}$ & AA; Typical \\
\hline $\begin{array}{l}\text { Mechanical } \\
\text { Properties }\end{array}$ & Metric & English & Comments \\
\hline $\begin{array}{l}\text { Hardness, } \\
\text { Brinell }\end{array}$ & 60 & 60 & AA; Typical; $500 \mathrm{~g}$ load; $10 \mathrm{~mm}$ ball \\
\hline $\begin{array}{l}\text { Hardness, } \\
\text { Knoop }\end{array}$ & 83 & 83 & Converted from Brinell Hardness Value \\
\hline $\begin{array}{l}\text { Hardness, } \\
\text { Vickers }\end{array}$ & 68 & 68 & Converted from Brinell Hardness Value \\
\hline $\begin{array}{l}\text { Tensile } \\
\text { Strength, } \\
\text { Ultimate }\end{array}$ & $\underline{228} \mathrm{MPa}$ & $\underline{33000} \mathrm{psi}$ & AA; Typical \\
\hline $\begin{array}{l}\text { Tensile } \\
\text { Strength, } \\
\text { Yield }\end{array}$ & $193 \mathrm{MPa}$ & $\underline{28000}$ psi & AA; Typical \\
\hline $\begin{array}{l}\text { Elongation at } \\
\text { Break }\end{array}$ & $\begin{array}{r}12.0 \% \\
\text { @Thickness } 1.59 \mathrm{~mm}\end{array}$ & $\begin{array}{r}12.0 \% \\
\text { @Thickness } 0.0625 \text { in }\end{array}$ & AA; Typical \\
\hline & $\begin{array}{r}18.0 \% \\
\text { @Diameter } 12.7 \mathrm{~mm}\end{array}$ & $\begin{array}{r}18.0 \% \\
\text { @Diameter } 0.500 \text { in }\end{array}$ & 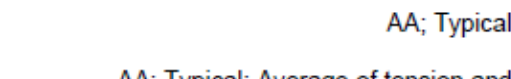 \\
\hline $\begin{array}{l}\text { Modulus of } \\
\text { Elasticity }\end{array}$ & $\underline{70.3} \mathrm{GPa}$ & $10200 \mathrm{ksi}$ & $\begin{array}{r}\text { AA; Typical; Average of tension and } \\
\text { compression. Compression modulus is about } \\
2 \% \text { greater than tensile modulus. }\end{array}$ \\
\hline $\begin{array}{l}\text { Poissons } \\
\text { Ratio }\end{array}$ & 0.330 & 0.330 & \\
\hline Fatigue & $117 \mathrm{MPa}$ & $\underline{17000}$ psi & completely reversed stress; RR Moore \\
\hline $\begin{array}{l}\text { Strength } \\
\text { Shear }\end{array}$ & $\begin{array}{r}\text { @ \# of Cycles } 5.00 \mathrm{e}+8 \\
\underline{\mathbf{2 5 . 9}} \mathrm{GPa}\end{array}$ & $\begin{array}{r}@ \# \text { of Cycles } 5.00 \mathrm{e}+8 \\
\underline{3760} \mathrm{ksi}\end{array}$ & machine/specimen \\
\hline $\begin{array}{l}\text { Modulus } \\
\text { Shear } \\
\text { Strength }\end{array}$ & $138 \mathrm{MPa}$ & $\underline{20000} \mathrm{psi}$ & AA; Typical \\
\hline $\begin{array}{l}\text { Electrical } \\
\text { Properties }\end{array}$ & Metric & English & Comments \\
\hline $\begin{array}{l}\text { Electrical } \\
\text { Resistivity }\end{array}$ & @ $\frac{0.00000499}{\text { Temperature }} 20.0^{\circ} \mathrm{C}$ & $\begin{array}{l}0.00000499 \text { ohm-cm } \\
@ \text { Temperature } 68.0^{\circ} \mathrm{F}\end{array}$ & AA; Typical \\
\hline $\begin{array}{l}\text { Thermal } \\
\text { Properties }\end{array}$ & Metric & English & Comments \\
\hline \multirow[t]{2}{*}{$\begin{array}{l}\text { CTE, linear } \\
\text { Wl }\end{array}$} & @Temperature $-\frac{22.1}{-50.0}-20 . \mathrm{m}^{\circ} \mathrm{m}-{ }^{\circ} \mathrm{C}$ & QTemperature $\begin{array}{r}12.3 \\
-58.0\end{array}$ & \\
\hline & $\begin{array}{r}\quad \underline{23.8} \mu \mathrm{m} / \mathrm{m}-{ }^{\circ} \mathrm{C} \\
\text { @Temperature } 20.0-100^{\circ} \mathrm{C} \\
23.8 \mu \mathrm{m} / \mathrm{m}-{ }^{\circ} \mathrm{C} \\
\text { @Temperature } 20.0-100^{\circ} \mathrm{C} \\
\underline{24.8} \mu \mathrm{m} / \mathrm{m}-{ }^{\circ} \mathrm{C} \\
\text { @Temperature } 20.0-200^{\circ} \mathrm{C} \\
\underline{25.7} \mu \mathrm{m} / \mathrm{m}-{ }^{\circ} \mathrm{C} \\
\text { @Temperature } 20.0-300^{\circ} \mathrm{C} \\
\text { @Temperature } 25.7 \mu \mathrm{m} / \mathrm{m}-{ }^{\circ} \mathrm{C}\end{array}$ & 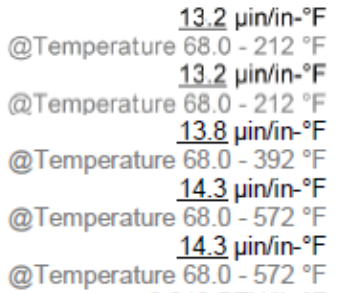 & AA; Typical; average over range \\
\hline $\begin{array}{l}\text { Specific Heat } \\
\text { Capacity }\end{array}$ & $\underline{0.880} \mathrm{~J} / \mathrm{g}-{ }^{\circ} \mathrm{C}$ & $\underline{0.210} \mathrm{BTU} / \mathrm{b}-{ }^{\circ} \mathrm{F}$ & Estimated from trends in similar Al alloys. \\
\hline $\begin{array}{l}\text { Thermal } \\
\text { Conductivity }\end{array}$ & $138 \mathrm{~W} / \mathrm{m}-\mathrm{K}$ & $\underline{960} \mathrm{BTU}$-in $/ \mathrm{hr}^{-\mathrm{ft}^{2}-{ }^{\circ} \mathrm{F}}$ & AA; Typical at $77^{\circ} \mathrm{F}$ \\
\hline
\end{tabular}




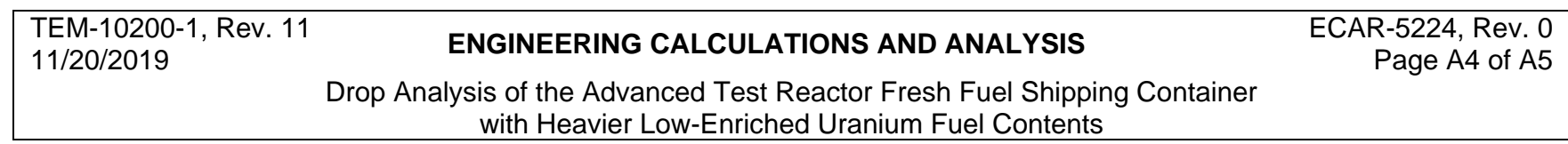

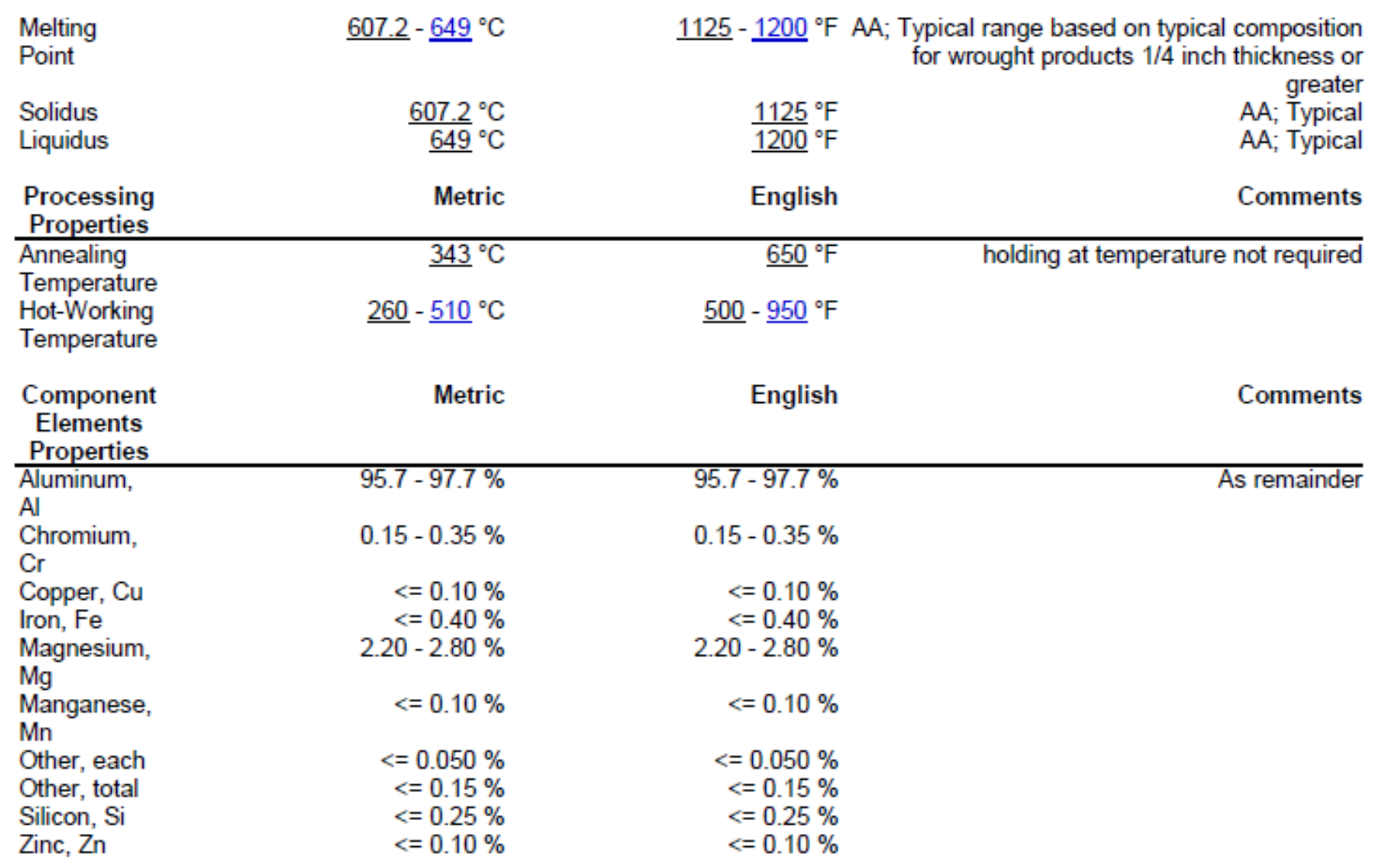

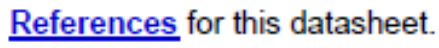

This data is for reference only and is not intended for engineer or design. Please consult a Clinton aluminum authorized representative. 
Drop Analysis of the Advanced Test Reactor Fresh Fuel Shipping Container with Heavier Low-Enriched Uranium Fuel Contents

Aluminum-Aluminum friction: https://www.engineeringtoolbox.com/friction-coefficients-d 778.html:

\section{Friction Coefficients for some Common Materials and Materials} Combinations

\begin{tabular}{|c|c|c|c|c|}
\hline \multirow{2}{*}{\multicolumn{2}{|c|}{ Materials and Material Combinations }} & \multirow{3}{*}{$\begin{array}{c}\text { Surface Conditions } \\
\text { Clean and Dry }\end{array}$} & \multicolumn{2}{|c|}{ Frictional Coefficient } \\
\hline & & & $\begin{array}{l}\text { Static } \\
-\mu_{\text {static }}-\end{array}$ & $\begin{array}{c}\text { Kinetic (sliding) } \\
-\mu_{\text {sliding }}\end{array}$ \\
\hline Aluminum & Aluminum & & $1.05-1.35$ & 1.4 \\
\hline
\end{tabular}

Stress versus strain plots:

http://rheneas.eng.buffalo.edu/wiki/MaterialFracture:Background:Material Fracture Stress versus Stra in

\begin{tabular}{|l|l|l|}
\hline page discussion & view source history \\
\hline
\end{tabular}

\section{MaterialFracture:Background:Material Fracture Stress versus Strain}

Stress-Strain Curve

The stress-strain curve is produced from the tensile test.

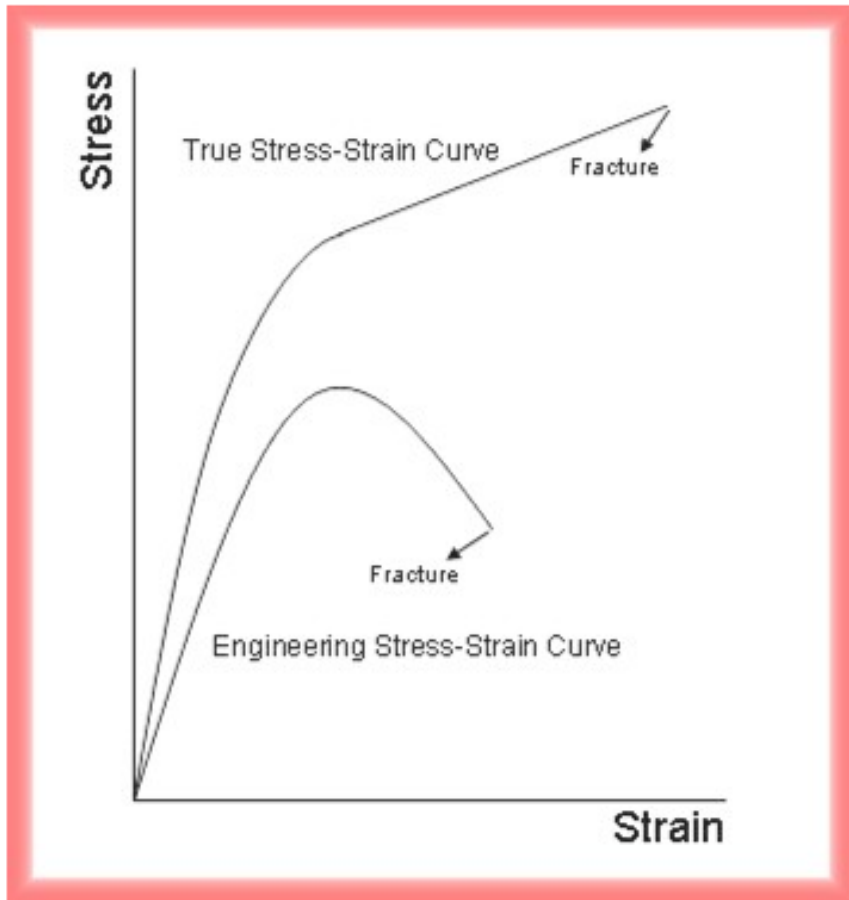




\section{Appendix B}

\section{Drop Analyses Model Development}

\section{CONTENTS}

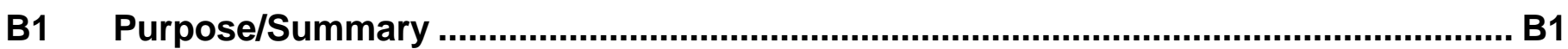

B2 Material Properties, Swage Calibration, and Initial Velocities ................................... B1

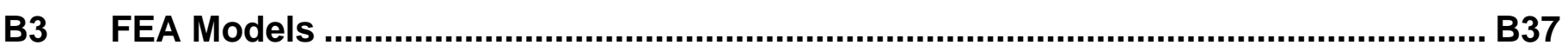

B4 Drop Analysis Models Abbreviated Input Files ....................................................... B62

NOTE: References identified in this appendix can be found at the end of the main body.

\section{B1 PURPOSE/SUMMARY}

The purpose of this appendix is to develop the drop analyses models for the loaded Advanced Test Reactor (ATR) Fresh Fuel Shipping Container (FFSC). The modeled drop accidents are per Table 3 in the SCOPE AND BRIEF DESCRIPTION section of the main body.

\section{B2 MATERIAL PROPERTIES, SWAGE CALIBRATION, AND INITIAL VELOCITIES}

Material properties are given in Section B2.1. Swage calibration is defined in Section B2.2. Initial conditions are defined in Section B2.3.

\section{B2.1 Material Properties}

The materials used in this evaluation are summarized in Table B-1 to Table B-5. These material properties are defined relative to the scope summary given in Table 3 (see the SCOPE AND BRIEF DESCRIPTION section of the main body). Material-property evaluation is performed in Sections B2.1.1 to B2.1.14.

Material property input in Abaqus (2018) is defined with true stress and true plastic strain for materials exhibiting plastic behavior in this evaluation. The true stress versus true plastic strain values shown in Table B-1 to Table B-5 are bilinear curves based on yield and ultimate stress and elongation strain values from the applicable references. Figure B-1 is per http://rheneas.eng.buffalo.edu/wiki/MaterialFracture:Background:Material Fracture Stress versus Strain (see attachment in Appendix A) and shows a typical true-stress versus true-strain plot. (For information, true plastic strain is simply the [total] true strain minus the elastic true strain.) Figure B-1 also shows a true-stress versus true-strain bilinear curve that could result from data that are available for this evaluation. 


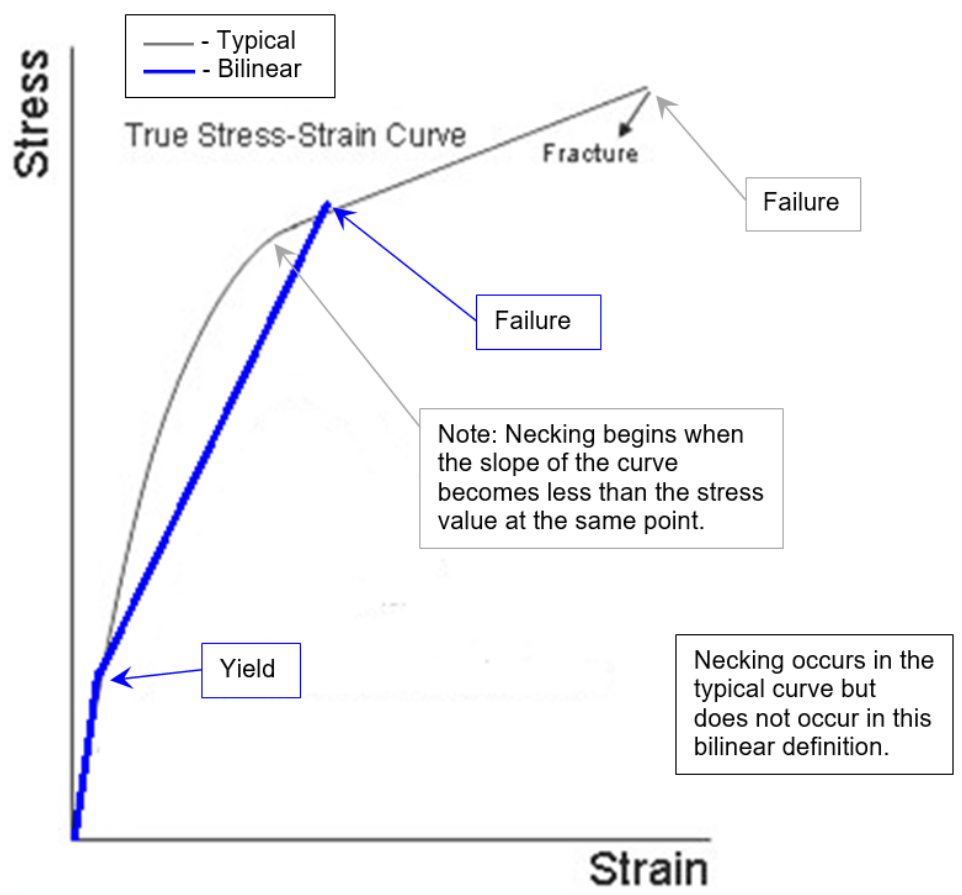

Figure B-1. Typical and bilinear true-stress versus true-strain plot.

To help explain how the referenced data are used in this evaluation, scoping-analysis results are provided in Figure B-2 to Figure B-4. The material properties used for Figure B-2 to Figure B-4 are reasonable for typical 304 stainless steel. However, these material properties are only used as demonstration and are not used in the actual evaluation. 

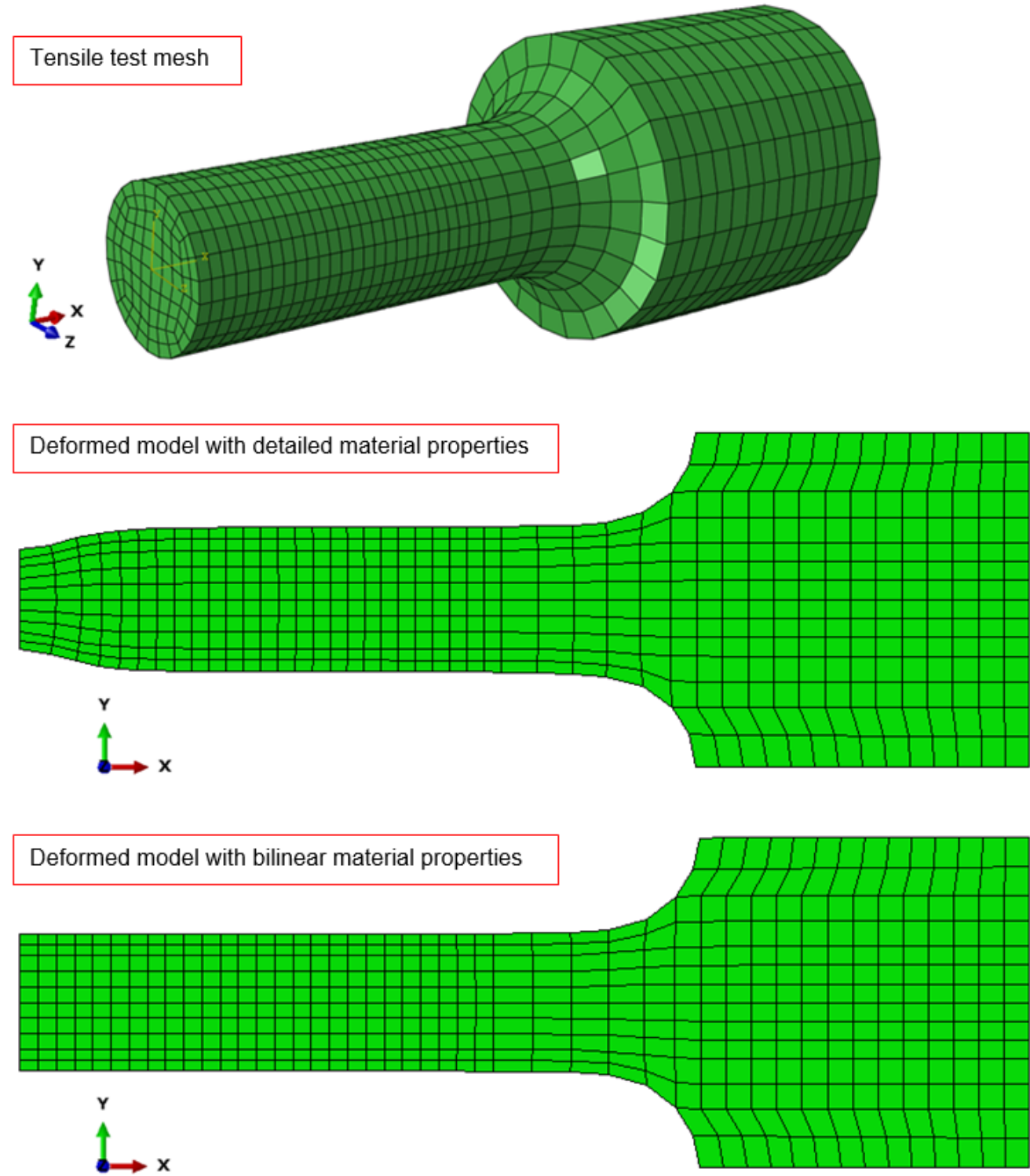

Figure B-2. Tensile-test model for detailed and bilinear material properties. 


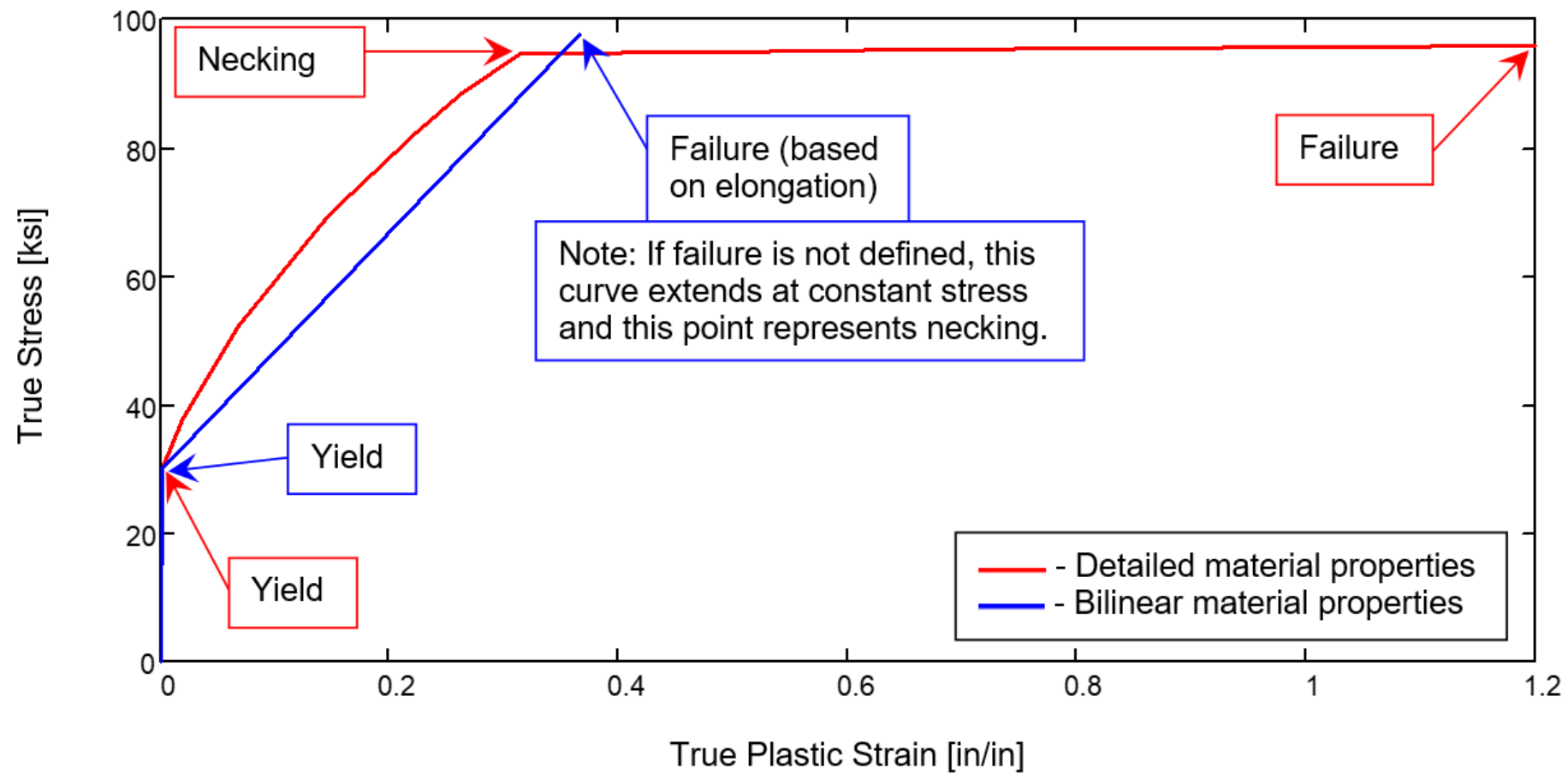

Figure B-3. Abaqus input true stress versus true plastic strain for detailed and bilinear material properties.

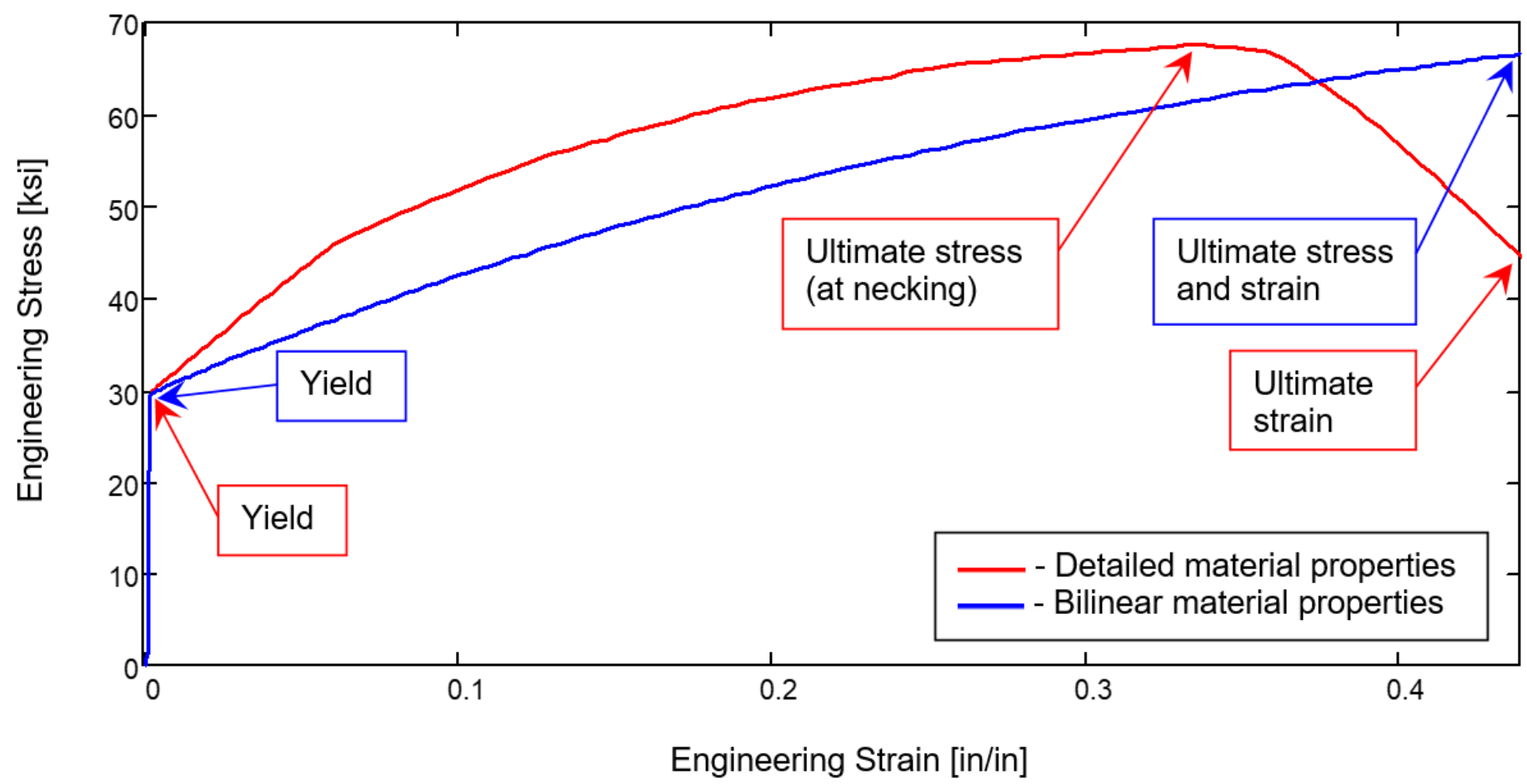

Figure B-4. Engineering stress versus engineering strain output for detailed and bilinear material properties. 
To perform the scoping analysis, a detailed material-properties model is first set up to demonstrate that a very accurate deformed shape can be achieved in Abaqus (2018) with detailed material properties. To develop the model, an engineering stress-versus-strain curve is selected (similar to the detailed material-properties curve in Figure B-4). The uniform strain portion of the curve is next converted to true stress and true plastic strain with equations from Abaqus (2018), Analysis User's Guide, Section 23.1.1. The post necking values are then established iteratively. For each iteration, post-necking values are selected, a model run is performed, and the resulting engineering stress versus strain is compared with the desired curve. With several iterations, the detailed material-properties curve in Figure B-3 is selected.

NOTE: $\quad$ Due to the sharp downturn after necking in Figure B-4, the post-necking curve in Figure B-2 has a flatter slope than that shown in Figure B-1.

The deformed model with detailed material properties (see Figure B-2) and detailed material-properties curve (see Figure B-4) are then the model-run results for the detailed material-properties curve (see Figure B-3). As can be seen in Figure B-2, the detailed material properties produce a deformed model with necking completely reasonable for a physical test.

Detailed material properties (as discussed for the detailed material-properties model) are not available for the physical drops. Consequently, a reasonable material-property strategy must be selected. Actual tensile tests can be expected to produce a shape like that of the detailed material properties curve in Figure B-4. Typically, the available ASTM data are in engineering terms and include minimum yield stress, minimum ultimate stress, and minimum ultimate elongation strain. For the scoping analysis, the engineering yield and ultimate stresses and engineering ultimate strain are taken from the detailed material properties in Figure B-4. They are then converted to true stress and true plastic strain with equations from Abaqus (2018), Analysis User's Guide, Section 23.1.1. This is performed as though the engineering ultimate stress and ultimate strain occur at the same point (which they typically do not as shown for the detailed materialproperties curve in Figure B-4). However, this approach is considered reasonably accurate. The resulting true stress versus true plastic strain bilinear curve is shown in Figure B-3. Running the scoping analysis for the bilinear-curve model produces the deformed model with bilinear material properties (see Figure B-2) and bilinear material-properties curve (see Figure B-4).

Comparing the detailed and bilinear model results, both models produce the same values for engineering yield, ultimate stresses, and engineering ultimate strain (as defined by ASTM data). Of course, the curve shapes are not the same. As can be seen in the engineering-stress versus engineering-strain curves (in Figure B-4), the bilinear material-properties curve produces conservatively low stresses over most of the tensile test. It becomes unconservative near the end of the tensile test. However, the total strain energy absorbed using the bilinear material properties is conservatively $90 \%$ of that for the detailed material properties (considering this example). With this approach, conservatism for total strain energy is not guaranteed for all materials, but it is likely for a tensile test like that performed for the ASTM data. However though not a common stress state for a drop scenario, if the item for a tensile test becomes relatively long compared to the cross section, this approach can lose its conservatism and become unconservative. This is due to the post-necking strain energy becoming much less significant compared to the pre-necking strain energy. (This is limited to a maximum of $17 \%$ unconservative for the example, as the post-necking strain energy goes to zero percent of the total.) This potentially unconservative situation is not apparent in any of the drop scenarios. Also, FEA model results will be compared to physical drop tests results lending credibility to the approach. Another consideration is different failure stress states, such as bending and compression, which are common in drop scenarios. Much higher strains may be possible before failure 
occurs in these stress states. This could make the defined bilinear-curve ultimate strain very conservative (which is why there is not strong motivation to reduce the total strain energy to accommodate potentially unconservative tensile failure). Overall, given that the actual material properties are not available, the bilinear curves based on minimum specified material properties are considered valid and conservative (i.e., they produce a reasonable response with conservatively less strain energy absorption than the actual materials).

Abaqus (2018) has triaxiality capability to address failure in different stress states, but sufficient data are not currently available for the materials in this evaluation. Triaxiality is the hydrostatic stress divided by the von Mises stress. Different failure strains can be assigned to different triaxiality values to accommodate failure in different stress states. Given that the capability is in Abaqus (2018), an effort is being made at Idaho National Laboratory to provide more-accurate data for failure prediction in different stress states. This could be used to address both the potentially unconservative tensile failure and the potentially overly conservative compressive and bending failure.

While Abaqus (2018) provides ways to include strain rate effects, they are not considered for this evaluation. This should be conservative because strain-rate effects give an apparent strengthening of the metals. If included, care would need to be used because the inertial aspect of the strain-rate strengthening is approximated already in the explicit solver.

As shown in Figure B-2, a typical bilinear curve (generated as discussed with failure) for a metal will not neck in a model run (because the stress value never exceeds the slope of the curve that is necessary for necking on a true stress versus true strain plot). To accurately capture necking, a relatively fine mesh is required. Whereas, if no necking is possible, a much coarser mesh can produce accurate results. This makes the lack of necking a positive feature relative to producing an accurate mesh with minimal elements.

For an element having material properties with failure defined, the element will only provide stress and strain results when its strains are less than the failure strain. When failure strain is reached, the element is removed from the mesh display and ceases to resist deformation.

The fuel element and enclosure do not have failure defined for the material properties in Table B-5. Having no failure defined, plastic strains that exceed the ultimate strain occur at a constant stress equal to the true ultimate stress. This produces a conservatively stiff response and a potential for necking with strains greater than ultimate strain. However, components without failure defined are only meant to apply a conservatively high load to components of concern (that do have failure defined). Consequently, accurate stress and strain are not expected or needed for components without failure defined.

The temperature range considered for the ATR FFSC package in the evaluated drops is -40 to $186^{\circ} \mathrm{F}$. The ATR FFSC SAR (2017), Section 2.6.2, notes that a minimum ambient temperature of -40 \% $F$ can produce a minimum average package temperature of $-40^{\circ} \mathrm{F}$. The ATR FFSC SAR (2017), Section 2.6.1, notes that the maximum ATR FFSC package temperature under conditions of $100^{\circ} \mathrm{F}$ ambient temperature and full insolation is $186^{\circ} \mathrm{F}$ on the outer shell. For this temperature range, the important material properties (i.e., modulus of elasticity, Poisson's ratio, density, yield stress, ultimate stress, and ultimate strain) do not change substantially. Additionally, ATR FFSC SAR (2017), Section 2.1.2.1.1, states that "brittle fracture is not a concern for the ATR FFSC packaging." The ATR FFSC SAR (2017), Section 2.1.2.1.1, also states "the performance of both the payload and packaging, including the reduced temperature tests, was satisfactory." Consequently, ambient-temperature material properties are used for drop scenarios of the full temperature range. 
Table B-1. Material properties used at impact for Table 3, Scope Parts 1a and 4 (see the main body).

\begin{tabular}{|c|c|c|c|c|c|c|c|}
\hline Name & Section & 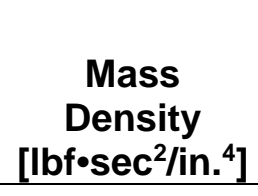 & $\begin{array}{c}\text { Modulus } \\
\text { of } \\
\text { Elasticity } \\
{\left[10^{6} \cdot p s i\right]}\end{array}$ & $\begin{array}{c}\text { Poisson's } \\
\text { Ratio } \\
\end{array}$ & $\begin{array}{c}\text { True } \\
\text { Yield } \\
\text { Stress } \\
\text { [ksi] }\end{array}$ & $\begin{array}{c}\text { True } \\
\text { Ultimate } \\
\text { Stress } \\
\text { [ksi] }\end{array}$ & $\begin{array}{c}\text { Ultimate } \\
\text { Plastic } \\
\text { Strain } \\
\text { [in./in.] }\end{array}$ \\
\hline SST304BODY & B-2.1.1 & $0.0007817^{(1)}$ & 28.3 & 0.31 & 30.03 & 97.50 & 0.259 \\
\hline F835 & B-2.1.10 & 0.0007511 & 28.3 & 0.31 & 116.5 & 156.6 & 0.071 \\
\hline SST304LID & B-2.1.1 & $0.0007511^{(2)}$ & 28.3 & 0.31 & 30.03 & 97.50 & 0.259 \\
\hline NITRONIC_60 & B-2.1.2 & 0.0007511 & 25.8 & 0.31 & 50.10 & 128.25 & 0.295 \\
\hline UALX_FUEL ${ }^{(3)}$ & B-2.1.4 & $0.0002585^{(4)}$ & 10.0 & 0.33 & 8.006 & 24.11 & 0.205 \\
\hline AL6061T6 & B-2.1.3 & 0.0002538 & 10.0 & 0.33 & 35.12 & 52.65 & 0.152 \\
\hline AL6061W & B-2.1.4 & 0.0002538 & 10.0 & 0.33 & 8.006 & 24.11 & 0.205 \\
\hline AL356 & B-2.1.5 & 0.0002538 & 10.3 & 0.33 & 18.03 & 25.75 & 0.027 \\
\hline AL356W & B-2.1.6 & 0.0002538 & 10.3 & 0.33 & 9.509 & 22.77 & 0.032 \\
\hline AL5052 & B-2.1.8 & $0.000331^{(5)}$ & 10.3 & 0.33 & 23.05 & 34.41 & 0.101 \\
\hline AL5052THN & B-2.1.7 & $0.000331^{(5)}$ & 10.3 & 0.33 & 23.05 & 33.17 & 0.064 \\
\hline AL5052W & B-2.1.9 & $0.000331^{(5)}$ & 10.3 & 0.33 & 9.509 & 29.50 & 0.163 \\
\hline STEEL ${ }^{(6)}$ & B-2.1.1 & 0.0007511 & 28.3 & 0.31 & 30.03 & 97.50 & 0.259 \\
\hline POST_STEEL & B-2.1.11 & 0.000733 & 30.0 & 0.30 & $\mathrm{~N} / \mathrm{A}$ & $\mathrm{N} / \mathrm{A}$ & $\mathrm{N} / \mathrm{A}$ \\
\hline
\end{tabular}

1. This density is modified to cause the ATR FFSC body to weight $225 \mathrm{lbf}$ as defined in Table 2.12.1-1 in the ATR FFSC SAR (2017).

2. This density is not modified because the ATR FFSC lid (closure assembly) weighs 9 lbf as defined in Table 2.12.1-1 in the ATR FFSC SAR (2017).

3. Material properties representing the ATR fuel plates from the ATR FFSC SAR (2017).

4. The fuel-plate density is modified to cause the fuel element to weight $22.1 \mathrm{lbf}$, as defined in Table 2.12.1-1 in the ATR FFSC SAR (2017).

5. The enclosure density is modified to cause it to weight $14.3 \mathrm{lbf}$, as defined in Table 2.12.1-1 in the ATR FFSC SAR (2017).

6. The material data for the spring plunger in the enclosure says only, "steel corrosion resisting body." Given that its failure is not important, its material will be approximated as 304 stainless steel. 
Table B-2. Material properties used at impact for Table 3, Scope Part 1b (see the main body).

\begin{tabular}{|l|l|l|l|l|l|l|l|}
\hline \multicolumn{1}{|c|}{ Name } & \multicolumn{1}{|c|}{$\begin{array}{c}\text { Mass } \\
\text { Density } \\
\text { [lbf•sec }{ }^{2} \text { in. }{ }^{4} \text { ] }\end{array}$} & $\begin{array}{c}\text { Modulus } \\
\text { of } \\
\text { Elasticity } \\
{\left[\mathbf{1 0}^{6} \cdot \text { psi] }\right.}\end{array}$ & $\begin{array}{c}\text { Poisson's } \\
\text { Ratio }\end{array}$ & $\begin{array}{c}\text { True } \\
\text { Yield } \\
\text { Stress } \\
\text { [ksi] }\end{array}$ & $\begin{array}{c}\text { True } \\
\text { Ultimate } \\
\text { Stress } \\
\text { [ksi] }\end{array}$ & $\begin{array}{c}\text { Ultimate } \\
\text { Plastic } \\
\text { Strain } \\
\text { [in./in.] }\end{array}$ \\
\hline SST304BODY & B-2.1.1 & $0.0007817^{(1)}$ & 28.3 & 0.31 & 30.03 & 97.50 & 0.259 \\
\hline F835 & B-2.1.10 & 0.0007511 & 28.3 & 0.31 & 116.5 & 156.6 & 0.071 \\
\hline SST304LID & B-2.1.1 & $0.0007511^{(2)}$ & 28.3 & 0.31 & 30.03 & 97.50 & 0.259 \\
\hline NITRONIC_60 & B-2.1.2 & 0.0007511 & 25.8 & 0.31 & 50.10 & 128.25 & 0.295 \\
\hline UALX_FUEL(3) & B-2.1.4 & $0.0002585^{(4)}$ & 10.0 & 0.33 & 8.006 & 24.11 & 0.205 \\
\hline AL6061T6 & B-2.1.3 & 0.0002538 & 10.0 & 0.33 & 35.12 & 52.65 & 0.152 \\
\hline AL6061W & B-2.1.4 & 0.0002538 & 10.0 & 0.33 & 8.006 & 24.11 & 0.205 \\
\hline AL356 & B-2.1.12 & 0.0002538 & 10.3 & 0.33 & $30.29^{(7)}$ & $45.26^{(7)}$ & $0.08^{(7)}$ \\
\hline AL356W & B-2.1.13 & 0.0002538 & 10.3 & 0.33 & $9.509^{(7)}$ & $32.40^{(7)}$ & $0.115^{(7)}$ \\
\hline AL5052 & B-2.1.14 & $0.000331^{(5)}$ & 10.3 & 0.33 & $28.08^{(7)}$ & $38.94^{(7)}$ & $0.162^{(7)}$ \\
\hline AL5052THN & B-2.1.14 & $0.000331^{(5)}$ & 10.3 & 0.33 & $28.08^{(7)}$ & $38.94^{(7)}$ & $0.162^{(7)}$ \\
\hline AL5052W & B-2.1.14 & $0.000331^{(5)}$ & 10.3 & 0.33 & $28.08^{(7)}$ & $38.94^{(7)}$ & $0.162^{(7)}$ \\
\hline STEEL(6) & B-2.1.1 & 0.0007511 & 28.3 & 0.31 & 30.03 & 97.50 & 0.259 \\
\hline POST_STEEL & B-2.1.11 & 0.000733 & 30.0 & 0.30 & N/A & N/A & N/A \\
\hline
\end{tabular}

1. This density is modified to cause the ATR FFSC body to weight $225 \mathrm{lbf}$, as defined in Table 2.12.1-1 in the ATR FFSC SAR (2017).

2. This density is not modified because the ATR FFSC lid (closure assembly) weighs 9 lbf, as defined in Table 2.12.1-1 in the ATR FFSC SAR (2017).

3. Material properties representing the ATR fuel plates from the ATR FFSC SAR (2017).

4. The fuel plate density is modified to cause the fuel element to weight $22.1 \mathrm{lbf}$, as defined in Table 2.12.1-1 in the ATR FFSC SAR (2017).

5. The enclosure density is modified to cause it to weight $14.3 \mathrm{lbf}$ as defined in Table 2.12.1-1 in the ATR FFSC SAR (2017).

6. The material data for the spring plunger in the enclosure says only, "steel corrosion resisting body." Given that its failure is not important, its material will be approximated as 304 stainless steel.

7. These are the values the are modified from Table B-1 to Table B-2. 
Table B-3. Material properties used at impact for Table 3, Scope Parts 1c and 1d (see the main body).

\begin{tabular}{|c|l|l|l|l|l|l|c|}
\hline & & $\begin{array}{c}\text { Mass } \\
\text { Density } \\
\text { Name }^{(1)}\end{array}$ & $\begin{array}{c}\text { Modulus } \\
\text { of } \\
\text { Elasticity } \\
{\left[\mathbf{1 0}^{6} \cdot \mathbf{p s i}\right]}\end{array}$ & $\begin{array}{c}\text { Poisson's } \\
\text { Ratio }\end{array}$ & $\begin{array}{c}\text { True } \\
\text { Yield } \\
\text { Stress } \\
\text { [ksi] }\end{array}$ & $\begin{array}{c}\text { True } \\
\text { Ultimate } \\
\text { Stress } \\
\text { [ksi] }\end{array}$ & $\begin{array}{c}\text { Ultimate } \\
\text { Plastic } \\
\text { Strain } \\
\text { [in./in.] }\end{array}$ \\
\hline AL6061T6_BLC & B-2.1.3 & 0.0002538 & 10.0 & 0.33 & 35.12 & 52.65 & 0.152 \\
\hline
\end{tabular}

1. The material properties for Table 3, Scope Part 1c are the same as in Table B-1 and Table 3, Scope Part $1 \mathrm{~d}$ are the same as in Table B-2 except for the added block material properties

(AL6061T6_BLC).

Table B-4. Material properties used at impact for Table 3, Scope Parts 2 (see the main body).

\begin{tabular}{|c|c|c|c|c|c|c|c|}
\hline Name $^{(1)}$ & Section & 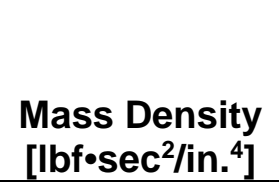 & $\begin{array}{c}\text { Modulus } \\
\text { of } \\
\text { Elasticity } \\
{\left[10^{6} \cdot p s i\right]}\end{array}$ & $\begin{array}{l}\text { Poisson's } \\
\text { Ratio }\end{array}$ & $\begin{array}{c}\text { True } \\
\text { Yield } \\
\text { Stress } \\
\text { [ksi] }\end{array}$ & $\begin{array}{c}\text { True } \\
\text { Ultimate } \\
\text { Stress } \\
\text { [ksi] }\end{array}$ & $\begin{array}{c}\text { Ultimate } \\
\text { Plastic } \\
\text { Strain } \\
\text { [in./in.] }\end{array}$ \\
\hline LOWE_FUEL (2) & B-2.1.4 & $0.0006239^{(3)}$ & 10.0 & 0.33 & 8.006 & 24.11 & 0.205 \\
\hline
\end{tabular}

1. The material properties for Table 3 Scope Parts $2 a, 2 b, 2 c$, and $2 d$ are the same as those in Table B-1, Table B-2, and Table B-3, except for the fuel plate material properties.

2. Material properties representing LOWE fuel plates are taken as the same as UALX_FUEL plates (except for density). The structural response of the LOWE fuel plates in compression, bending, and buckling under impact loads will be dominated by the thick aluminum covers and not the thin U-10Mo fuel layer. Therefore, using the UALX_FUEL properties is justified.

3. The fuel plate density is modified to cause the fuel element to weight $44 \mathrm{lbf}$, as defined in Quirl (2019).

Table B-5. Material properties used at impact for Table 3, Scope Part 3 (see the main body).

\begin{tabular}{|c|c|c|c|c|c|c|c|}
\hline Name & Section & $\begin{array}{l}\text { Mass Density } \\
\text { [lbf•sec2/in.4] }\end{array}$ & $\begin{array}{l}\text { Modulus } \\
\text { of } \\
\text { Elasticity } \\
\text { [106•psi] }\end{array}$ & $\begin{array}{c}\text { Poisson's } \\
\text { Ratio }\end{array}$ & $\begin{array}{c}\text { True } \\
\text { Yield } \\
\text { Stress } \\
\text { [ksi] }\end{array}$ & $\begin{array}{c}\text { True } \\
\text { Ultimate } \\
\text { Stress } \\
\text { [ksi] }\end{array}$ & $\begin{array}{c}\text { Ultimate } \\
\text { Plastic } \\
\text { Strain } \\
\text { [in./in.] }\end{array}$ \\
\hline SST304BODY & B-2.1.1 & $0.0007817(1)$ & 28.3 & 0.31 & 30.03 & 97.50 & 0.259 \\
\hline F835 & B-2.1.10 & 0.0007511 & 28.3 & 0.31 & 116.5 & 156.6 & 0.071 \\
\hline SST304LID & B-2.1.1 & $0.0007511(2)$ & 28.3 & 0.31 & 30.03 & 97.50 & 0.259 \\
\hline NITRONIC_60 & B-2.1.2 & 0.0007511 & 25.8 & 0.31 & 50.10 & 128.25 & 0.295 \\
\hline UALX_FUEL(3) & B-2.1.3 & $0.001843(4)$ & $10.0(4)$ & $0.33(4)$ & $35.12(4$ & $52.65(4)$ & $0.152(4)$ \\
\hline AL6061W & B-2.1.3 & $0.001843(4)$ & $10.0(4)$ & $0.33(4)$ & $\begin{array}{l}35.12(4 \\
)\end{array}$ & $52.65(4)$ & $0.152(4)$ \\
\hline AL356 & B-2.1.3 & $0.001843(4)$ & $10.0(4)$ & $0.33(4)$ & $35.12(4$ & $52.65(4)$ & $0.152(4)$ \\
\hline
\end{tabular}




\begin{tabular}{|c|c|c|c|c|c|c|c|}
\hline Name & Section & $\begin{array}{l}\text { Mass Density } \\
\text { [lbf•sec2/in.4] }\end{array}$ & $\begin{array}{c}\text { Modulus } \\
\text { of } \\
\text { Elasticity } \\
\text { [106•psi] }\end{array}$ & $\begin{array}{c}\text { Poisson's } \\
\text { Ratio }\end{array}$ & $\begin{array}{c}\text { True } \\
\text { Yield } \\
\text { Stress } \\
\text { [ksi] }\end{array}$ & $\begin{array}{c}\text { True } \\
\text { Ultimate } \\
\text { Stress } \\
\text { [ksi] }\end{array}$ & $\begin{array}{c}\text { Ultimate } \\
\text { Plastic } \\
\text { Strain } \\
\text { [in./in.] }\end{array}$ \\
\hline AL356W & B-2.1.3 & $0.001843(4)$ & $10.0(4)$ & $0.33(4)$ & $35.12(4$ & $52.65(4)$ & $0.152(4)$ \\
\hline AL5052 & B-2.1.14 & $0.000331(5)$ & 10.3 & 0.33 & 28.08 & 38.94 & 0.162 \\
\hline AL5052THN & B-2.1.14 & $0.000331(5)$ & 10.3 & 0.33 & 28.08 & 38.94 & 0.162 \\
\hline AL5052W & B-2.1.14 & $0.000331(5)$ & 10.3 & 0.33 & 28.08 & 38.94 & 0.162 \\
\hline STEEL(6) & B-2.1.1 & 0.0007511 & 28.3 & 0.31 & 30.03 & 97.50 & 0.259 \\
\hline POST_STEEL & B-2.1.11 & 0.000733 & 30.0 & 0.30 & $\mathrm{~N} / \mathrm{A}$ & $\mathrm{N} / \mathrm{A}$ & $\mathrm{N} / \mathrm{A}$ \\
\hline
\end{tabular}

1. This density is modified to cause the ATR FFSC body to weight $225 \mathrm{lbf}$, as defined in Table 2.12.1-1 in the ATR FFSC SAR (2017).

2. This density is not modified because the ATR FFSC lid (closure assembly) weighs 9 lbf, as defined in Table 2.12.1-1 in the ATR FFSC SAR (2017).

3. Material properties for the coarse mesh representing the fuel element.

4. The fuel element density is modified to cause the fuel element to weight $115 \mathrm{lbf}$, as defined in Table 3 (see the main body). Also, all fuel element material properties are defined as 6061-T6 aluminum with no failure.

5. The enclosure density is modified to cause it to weight $14.3 \mathrm{lbf}$, as defined in Table 2.12.1-1 in the ATR FFSC SAR (2017). Also, all 5052 aluminum is defined with no failure.

6. The material data for the spring plunger in the enclosure says only, "steel corrosion resisting body." Given that its failure is not important, its material will be approximated as 304 stainless steel. Also, it is defined with no failure.

\section{B2.1.1 Stainless Steel (304) Material Properties}

The modulus of elasticity, Poisson's ratio, and mass density in this section are based on the ASME (2019). The modulus of elasticity is from Material Group G values in Table TM-1. The Poisson's ratio and mass density are from the 300 series values in Table PRD. The yield and ultimate stress values are from the ATR FFSC SAR (2017), Table 2.2-1. The ultimate strain is representative of values for ASTM A240 (2019), ASTM A269 (2019), ASTM A479 (2019), and ASTM A554 (2016) Grade MT. The conversion to true stress and true strain are done with equations from Abaqus (2018), Analysis User's Guide, Section 23.1.1. 


$$
\begin{aligned}
& \mathrm{E}_{304}:=28 \cdot 3 \cdot 10^{6} \cdot \mathrm{psi} \quad \text { Modulus of elasticity. } \\
& \nu_{304}:=0.31 \quad \text { Poisson's ratio. } \\
& \rho_{304}=0.290 \frac{\mathrm{lb}}{\mathrm{in}^{3}} \quad \text { Mass density. } \\
& \rho_{304}=7.511 \times 10^{-4} \cdot \frac{\mathrm{lbf} \cdot \mathrm{sec}^{2}}{\mathrm{in}^{4}} \\
& \sigma_{\mathrm{y} 304}:=30 \cdot \mathrm{ksi} \quad \text { Engineering yield stress. } \\
& \sigma_{\mathrm{u} 304}:=75 \cdot \mathrm{ksi} \quad \text { Engineering ultimate stress that is } \\
& \varepsilon_{\mathrm{y} 304}:=\frac{\sigma_{\mathrm{y} 304}}{\mathrm{E}_{304}} \\
& \varepsilon_{\mathrm{y} 304}=0.00106 \cdot \frac{\text { in }}{\text { in }} \\
& \varepsilon_{\mathrm{u} 304}=0.30 \cdot \frac{\text { in }}{\text { in }} \quad \text { Minimum engineering ultimate strain. } \\
& \text { conservatively tough. } \\
& \text { Engineering yield strain }(0.2 \% \text { offset is not } \\
& \text { considered). }
\end{aligned}
$$

NOTE: $\quad$ The minimum engineering ultimate strain value is the minimum specified elongation for a two-inch specimen from the ASTM specifications referenced above.

$$
\begin{aligned}
& \sigma_{\mathrm{Ty} 304}:=\sigma_{\mathrm{y} 304} \cdot\left(1+\varepsilon_{\mathrm{y} 304}\right) \\
& \text { True yield stress. } \\
& \sigma_{\mathrm{Ty} 304}=30031.8 \cdot \mathrm{psi} \\
& \sigma_{\mathrm{Tu} 304}:=\sigma_{\mathrm{u} 304} \cdot\left(1+\varepsilon_{\mathrm{u} 304}\right) \quad \text { True ultimate stress. } \\
& \sigma_{\mathrm{Tu} 304}=97500 \cdot 0 \cdot \mathrm{psi} \\
& \varepsilon_{\text {Ty304 }}:=\ln \left(1+\varepsilon_{\mathrm{y} 304}\right) \quad \text { True yield strain. } \\
& \varepsilon_{\mathrm{Ty} 304}=0.0010595 \cdot \frac{\text { in }}{\text { in }} \\
& \varepsilon_{\mathrm{Tu} 304}:=\ln \left(1+\varepsilon_{\mathrm{u} 304}\right) \\
& \text { True ultimate strain. } \\
& \varepsilon_{\mathrm{Tu} 304}=0.262 \cdot \frac{\text { in }}{\text { in }} \\
& \varepsilon_{\mathrm{Tp} 304}:=\varepsilon_{\mathrm{Tu} 304}-\frac{\sigma_{\mathrm{Tu} 304}}{\mathrm{E}_{304}} \quad \text { True plastic strain. } \\
& \varepsilon_{\mathrm{Tp} 304}=0.259 \cdot \frac{\text { in }}{\text { in }}
\end{aligned}
$$




\section{B2.1.2 Stainless Steel Nitronic 60 (UNS S21800) Material Properties}

The modulus of elasticity, Poisson's ratio, and mass density in this section are based on the ASME (2019). The modulus of elasticity is from Material Group I values in Table TM-1. The Poisson's ratio and mass density are from the 300 Series values in Table PRD. The yield and ultimate stress values are from the ATR FFSC SAR (2017), Table 2.2-1. The ultimate strain is representative of values for ASTM A276 (2017). The conversion to true stress and true strain are done with equations from Abaqus (2018), Analysis User's Guide, Section 23.1.1.

$$
\begin{array}{rlrl}
\mathrm{E}_{\mathrm{N} 60} & :=25.8 \cdot 10^{6} \cdot \mathrm{psi} & & \text { Modulus of elasticity. } \\
\nu_{\mathrm{N} 60} & =0.31 & & \text { Poisson's ratio. } \\
\rho_{\mathrm{N} 60} & =0.290 \frac{\mathrm{lb}}{\mathrm{in}^{3}} & & \text { Mass density. } \\
\rho_{\mathrm{N} 60} & =7.511 \times 10^{-4} \cdot \frac{\mathrm{lbf} \cdot \mathrm{sec}^{2}}{\mathrm{in}^{4}} & & \text { Engineering yield stress. } \\
\sigma_{\mathrm{yN} 60}:=50 \cdot \mathrm{ksi} & & \text { Engineering ultimate stress that is } \\
\sigma_{\mathrm{UN} 60}:=95 \cdot \mathrm{ksi} & & \begin{array}{l}
\text { Engineering yield strain }(0.2 \% \text { offset is not } \\
\text { considered). }
\end{array} \\
\varepsilon_{\mathrm{yN} 60}:=\frac{\sigma_{\mathrm{yN} 60}}{\mathrm{E}_{\mathrm{N} 60}} & & \\
\varepsilon_{\mathrm{yN} 60}=0.001938 \cdot \frac{\mathrm{in}}{\mathrm{in}} & & \text { Minimum engineering ultimate strain. } \\
\varepsilon_{\mathrm{UN} 60}:=0.35 \cdot \frac{\mathrm{in}}{\mathrm{in}} & &
\end{array}
$$




$$
\begin{aligned}
& \sigma_{\mathrm{TyN} 60}:=\sigma_{\mathrm{yN} 60} \cdot\left(1+\varepsilon_{\mathrm{yN} 60}\right) \quad \text { True yield stress. } \\
& \sigma_{\mathrm{TyN} 60}=50096 \cdot 9 \cdot \mathrm{psi} \\
& \sigma_{\mathrm{TuN} 60}:=\sigma_{\mathrm{UN} 60} \cdot\left(1+\varepsilon_{\mathrm{UN} 60}\right) \quad \text { True ultimate stress. } \\
& \sigma_{\mathrm{TuN60}}=128250.0 \cdot \mathrm{psi} \\
& \varepsilon_{\text {TyN60 }}:=\ln \left(1+\varepsilon_{\mathrm{yN} 60}\right) \quad \text { True yield strain. } \\
& \varepsilon_{\mathrm{TyN} 60}=0.0019361 \cdot \frac{\mathrm{in}}{\mathrm{in}} \\
& \varepsilon_{\text {TuN60 }}:=\ln \left(1+\varepsilon_{\mathrm{uN} 60}\right) \quad \text { True ultimate strain. } \\
& \varepsilon_{\text {TuN60 }}=0.3 \cdot \frac{\text { in }}{\text { in }} \\
& \varepsilon_{\mathrm{TpN60}}:=\varepsilon_{\mathrm{TuN} 60}-\frac{\sigma_{\mathrm{TuN60}}}{\mathrm{E}_{\mathrm{N} 60}} \quad \text { True plastic strain. } \\
& \varepsilon_{\mathrm{TpN} 60}=0.295 \cdot \frac{\text { in }}{\text { in }}
\end{aligned}
$$

\section{B2.1.3 Aluminum (6061-T6 and -T651) Material Properties}

The material properties in this section are based on material-property definitions from Appendix A of Snow (2013). The conversion to true stress and true strain are done with equations from Abaqus (2018), Analysis User's Guide, Section 23.1.1.

$$
\begin{array}{ll}
\mathrm{E}_{\mathrm{T} 6}:=10 \cdot 10^{6} \cdot \mathrm{psi} & \text { Modulus of elasticity. } \\
\nu_{\mathrm{T} 6}:=0.33 & \text { Poisson's ratio. } \\
\rho_{\mathrm{T} 6}:=0.098 \frac{\mathrm{lb}}{\mathrm{in}^{3}} & \text { Mass density. } \\
\rho_{\mathrm{T} 6}=2.538 \times 10^{-4} \cdot \frac{\mathrm{lbf} \cdot \mathrm{sec}^{2}}{\mathrm{in}^{4}} &
\end{array}
$$




$$
\begin{aligned}
& \sigma_{\mathrm{yT} 6}:=35 \cdot \mathrm{ksi} \\
& \text { Engineering yield stress. } \\
& \sigma_{\mathrm{UT} 6}:=45 \cdot \mathrm{ksi} \\
& \text { Engineering ultimate stress that is } \\
& \varepsilon_{\mathrm{yT} 6}:=\frac{\sigma_{\mathrm{yT} 6}}{\mathrm{E}_{\mathrm{T} 6}} \\
& \varepsilon_{\mathrm{yT} 6}=0.0035 \cdot \frac{\text { in }}{\text { in }} \\
& \varepsilon_{\mathrm{UT} 6}:=0.17 \cdot \frac{\text { in }}{\text { in }} \\
& \sigma_{\text {TyT6 }}:=\sigma_{\mathrm{yT} 6} \cdot\left(1+\varepsilon_{\mathrm{yT} 6}\right) \\
& \text { True yield stress. } \\
& \sigma_{\text {TyT6 }}=35122.5 \cdot p s i \\
& \sigma_{\text {TuT6 }}:=\sigma_{\mathrm{UT} 6} \cdot\left(1+\varepsilon_{\mathrm{UT} 6}\right) \\
& \text { True ultimate stress. } \\
& \sigma_{\text {TuT6 }}=52650.0 \cdot p s i \\
& \varepsilon_{\text {TyT6 }}:=\ln \left(1+\varepsilon_{\text {yT } 6}\right) \\
& \varepsilon_{\text {TyT6 }}=0.0034939 \cdot \frac{\text { in }}{\text { in }} \\
& \varepsilon_{\text {TuT6 }}:=\ln \left(1+\varepsilon_{\mathrm{uT} 6}\right) \\
& \varepsilon_{\text {TuT } 6}=0.157 \cdot \frac{\text { in }}{\text { in }} \\
& \varepsilon_{\text {TpT6 }}:=\varepsilon_{\text {TuT6 }}-\frac{\sigma_{\text {TuT6 }}}{E_{\text {T6 }}} \\
& \varepsilon_{\text {TpT } 6}=0.152 \cdot \frac{\text { in }}{\text { in }}
\end{aligned}
$$

Minimum engineering ultimate strain.

\section{B2.1.4 Aluminum (6061-T0 and 6061-T6 weld) Material Properties}

The material properties in this section are based on material-property definitions from Appendix A of Snow (2013). The conversion to true stress and true strain are done with equations from Abaqus (2018), Analysis User's Guide, Section 23.1.1. 


$$
\begin{aligned}
& \mathrm{E}_{\mathrm{T} 0}:=10 \cdot 10^{6} \cdot \mathrm{psi} \quad \text { Modulus of elasticity. } \\
& \nu_{\mathrm{TO}}:=0.33 \quad \text { Poisson's ratio. } \\
& \text { คт0 }:=0.098 \frac{\mathrm{lb}}{\mathrm{in}^{3}} \quad \text { Mass density. } \\
& \text { От0 }=2.538 \times 10^{-4} \cdot \frac{\mathrm{lbf} \cdot \mathrm{sec}^{2}}{\mathrm{in}^{4}} \\
& \sigma_{\text {ут0 }}:=8.0 \cdot \mathrm{ksi} \\
& \text { Engineering yield stress. } \\
& \sigma_{\mathrm{UTO}}:=19.6 \cdot \mathrm{ksi} \\
& \varepsilon_{\mathrm{yT} 0}:=\frac{\sigma_{\mathrm{yT} 0}}{\mathrm{E}_{\mathrm{T} 0}} \\
& \varepsilon_{\mathrm{yT} 0}=0.0008 \cdot \frac{\text { in }}{\text { in }} \\
& \varepsilon_{\mathrm{UT} 0}:=0.23 \cdot \frac{\text { in }}{\text { in }} \\
& \sigma_{\text {Тут0 }}:=\sigma_{\text {уто }} \cdot\left(1+\varepsilon_{\text {ут0 }}\right) \\
& \text { Engineering ultimate stress that is } \\
& \text { conservatively tough. } \\
& \text { Engineering yield strain ( } 0.2 \% \text { offset is not } \\
& \text { considered). } \\
& \sigma_{\text {Тут0 }}=8006.4 \cdot p s i \\
& \sigma_{\text {TUTO }}:=\sigma_{\text {UTO }} \cdot\left(1+\varepsilon_{\mathrm{UTO}}\right) \\
& \text { True ultimate stress. } \\
& \sigma_{\text {TuTo }}=24108.0 \cdot \text { psi } \\
& \varepsilon_{\text {Тут0 }}:=\ln \left(1+\varepsilon_{\text {yTo }}\right) \\
& \varepsilon_{\text {TyT0 }}=0.0007997 \cdot \frac{\text { in }}{\text { in }} \\
& \varepsilon_{\text {TUTO }}:=\ln \left(1+\varepsilon_{\mathrm{UTO}}\right) \\
& \text { True ultimate strain. } \\
& \varepsilon_{\text {TuT0 }}=0.207 \cdot \frac{\text { in }}{\text { in }} \\
& \varepsilon_{\text {TpT0 }}=\varepsilon_{\text {TuT0 }}-\frac{\sigma_{\text {TuT0 }}}{\mathrm{E}_{\text {T0 }}} \quad \text { True plastic strain. } \\
& \varepsilon_{\text {TpT0 }}=0.205 \cdot \frac{\text { in }}{\text { in }}
\end{aligned}
$$




\section{B2.1.5 Cast Aluminum (A356.0-T71 or A356.0-T6) Material Properties}

The material properties in this section are based on material-property definitions from Appendix A of Snow (2013). The conversion to true stress and true strain are done with equations from Abaqus (2018), Analysis User's Guide, Section 23.1.1.

$$
\begin{array}{rlrl}
\mathrm{E}_{356} & =10.3 \cdot 10^{6} \cdot \mathrm{psi} & & \text { Modulus of elasticity. } \\
\nu_{356} & =0.33 & & \text { Poisson's ratio. } \\
\rho_{356}:=0.098 \frac{\mathrm{lb}}{\mathrm{in}^{3}} & & \text { Mass density. } \\
\rho_{356}=2.538 \times 10^{-4} \cdot \frac{\mathrm{lbf} \cdot \mathrm{sec}^{2}}{\mathrm{in}^{4}} & & \text { Engineering yield stress. } \\
\sigma_{\mathrm{y} 356}:=18 \cdot \mathrm{ksi} & & \begin{array}{l}
\text { Engineering ultimate stress that is } \\
\text { conservatively tough. }
\end{array} \\
\sigma_{\mathrm{u} 356}:=25 \cdot \mathrm{ksi} & & \begin{array}{l}
\text { Engineering yield strain }(0.2 \% \text { offset is not } \\
\text { considered). }
\end{array} \\
\varepsilon_{\mathrm{y} 356}:=\frac{\sigma_{\mathrm{y} 356}}{\mathrm{E}_{356}} & & \\
\varepsilon_{\mathrm{y} 356}=0.001748 \cdot \frac{\text { in }}{\text { in }} & \text { in } & \text { Minimum engineering ultimate strain. } \\
\varepsilon_{\mathrm{u} 356}:=0.03 \cdot \frac{\mathrm{in}}{\mathrm{in}} &
\end{array}
$$




$$
\begin{aligned}
& \sigma_{\mathrm{Ty} 356}:=\sigma_{\mathrm{y} 356} \cdot\left(1+\varepsilon_{\mathrm{y} 356}\right) \quad \text { True yield stress. } \\
& \sigma_{\mathrm{Ty} 356}=18031.5 \cdot \mathrm{psi} \\
& \sigma_{\mathrm{Tu} 356}:=\sigma_{\mathrm{u} 356} \cdot\left(1+\varepsilon_{\mathrm{u} 356}\right) \quad \text { True ultimate stress. } \\
& \sigma_{\text {Tu356 }}=25750.0 \cdot p s i \\
& \varepsilon_{\mathrm{Ty} 356}:=\ln \left(1+\varepsilon_{\mathrm{y} 356}\right) \quad \text { True yield strain. } \\
& \varepsilon_{\text {Ty356 }}=0.001746 \cdot \frac{\text { in }}{\text { in }} \\
& \varepsilon_{\text {Tu356 }}:=\ln \left(1+\varepsilon_{\mathrm{u} 356}\right) \quad \text { True ultimate strain. } \\
& \varepsilon_{\mathrm{Tu} 356}=0.03 \cdot \frac{\text { in }}{\text { in }} \\
& \varepsilon_{\mathrm{Tp} 356}:=\varepsilon_{\mathrm{Tu} 356}-\frac{\sigma_{\mathrm{Tu} 356}}{\mathrm{E}_{356}} \quad \text { True plastic strain. } \\
& \varepsilon_{\mathrm{Tp} 356}=0.027 \cdot \frac{\text { in }}{\text { in }}
\end{aligned}
$$

\section{B2.1.6 Cast Aluminum (356 weld) Material Properties}

The material properties in this section are based on material-property definitions from of Snow (2013), Appendix A, Table A9. While all the data below did not appear to be available from Appendix A of Snow (2013), reasonable values are used to produce similar Abaqus material properties. (However, the 0.032 in/in true plastic strain is erroneously $6.7 \%$ higher than the 0.03 in/in value in Snow [2013]. This difference was noticed after all the model runs were performed. Given the low yield and ultimate stress values and the relatively low volume of material, this difference does not represent a sufficiently significant change in the energy to cause fuel element damage. Also, the endbox and endbox welds model still appear to absorb significantly less energy than those in the physical drops. Consequently, this difference is not considered significant.)

The conversion to true stress and true strain are done with equations from Abaqus (2018), Analysis User's Guide, Section 23.1.1.

$$
\begin{aligned}
& E_{356 w}:=10.3 \cdot 10^{6} \cdot \mathrm{psi} \quad \text { Modulus of elasticity. } \\
& \nu_{356 \mathrm{w}}=0.33 \quad \text { Poisson's ratio. } \\
& \rho_{356 \mathrm{w}}:=0.098 \frac{\mathrm{lb}}{\mathrm{in}^{3}} \quad \text { Mass density. } \\
& \rho_{356 \mathrm{w}}=2.538 \times 10^{-4} \cdot \frac{\mathrm{lbf} \cdot \mathrm{sec}^{2}}{\text { in }^{4}}
\end{aligned}
$$




$$
\begin{aligned}
& \sigma_{\mathrm{y} 356 \mathrm{w}}:=9.5 \cdot \mathrm{ksi} \\
& \text { Engineering yield stress. } \\
& \sigma_{\mathrm{u} 356 \mathrm{w}}:=22 \cdot \mathrm{ksi} \\
& \text { Engineering ultimate stress that is } \\
& \varepsilon_{\mathrm{y} 356 \mathrm{w}}:=\frac{\sigma_{\mathrm{y} 356 \mathrm{w}}}{\mathrm{E}_{356 \mathrm{w}}} \\
& \text { conservatively tough. } \\
& \varepsilon_{y 356 w}=0.000922 \cdot \frac{\text { in }}{\text { in }} \\
& \varepsilon_{\mathrm{u} 356 \mathrm{w}}:=0.035 \cdot \frac{\text { in }}{\text { in }} \\
& \sigma_{\mathrm{Ty} 356 \mathrm{w}}:=\sigma_{\mathrm{y} 356 \mathrm{w}} \cdot\left(1+\varepsilon_{\mathrm{y} 356 \mathrm{w}}\right) \\
& \text { considered). } \\
& \text { Minimum engineering ultimate strain. } \\
& \sigma_{\mathrm{Ty} 356 \mathrm{w}}=9508.8 \cdot \mathrm{psi} \\
& \sigma_{\mathrm{Tu} 356 \mathrm{w}}:=\sigma_{\mathrm{u} 356 \mathrm{w}} \cdot\left(1+\varepsilon_{\mathrm{u} 356 \mathrm{w}}\right) \\
& \text { True ultimate stress. } \\
& \sigma_{\mathrm{Tu} 356 \mathrm{w}}=22770.0 \cdot \mathrm{psi} \\
& \varepsilon_{\text {Ty356w }}:=\ln \left(1+\varepsilon_{\mathrm{y} 356 \mathrm{w}}\right) \\
& \text { True yield strain } \\
& \varepsilon_{\mathrm{Ty} 356 \mathrm{w}}=0.0009219 \cdot \frac{\text { in }}{\text { in }} \\
& \varepsilon_{\mathrm{Tu} 356 \mathrm{w}}:=\ln \left(1+\varepsilon_{\mathrm{u} 356 \mathrm{w}}\right) \\
& \text { True ultimate strain. } \\
& \varepsilon_{\mathrm{Tu} 356 \mathrm{~W}}=0.034 \cdot \frac{\text { in }}{\text { in }} \\
& \varepsilon_{\mathrm{Tp} 356 \mathrm{w}}:=\varepsilon_{\mathrm{Tu} 356 \mathrm{w}}-\frac{\sigma_{\mathrm{Tu} 356 \mathrm{w}}}{\mathrm{E}_{356 \mathrm{w}}} \quad \text { True plastic strain. } \\
& \varepsilon_{\mathrm{Tp} 356 \mathrm{w}}=0.032 \cdot \frac{\text { in }}{\text { in }}
\end{aligned}
$$$$
\text { Engineering yield strain }(0.2 \% \text { offset is not }
$$

\section{B2.1.7 Aluminum (5052-H32 Sheet) Material Properties}

The modulus of elasticity, Poisson's ratio, and mass density in this section are based on Appendix A of Snow (2013) as being similar to 356 aluminum. The yield and ultimate stress values are from the ATR FFSC SAR (2017), Table 2.2-2. The ultimate strain is from ASTM B209 (2014) for specified thicknesses of $0.051-0.113 \mathrm{in}$. The conversion to true stress and true strain are done with equations from Abaqus (2018), Analysis User's Guide, Section 23.1.1. 


$$
\begin{aligned}
& E_{5052 \mathrm{~s}}:=10.3 \cdot 10^{6} \cdot \mathrm{psi} \quad \text { Modulus of elasticity. } \\
& \nu_{5052 s}:=0.33 \quad \text { Poisson's ratio. } \\
& \rho_{5052 \mathrm{~s}}=0.098 \frac{\mathrm{lb}}{\mathrm{in}^{3}} \quad \text { Mass density. } \\
& \rho_{5052 \mathrm{~s}}=2.538 \times 10^{-4} \cdot \frac{\mathrm{lbf} \cdot \mathrm{sec}^{2}}{\mathrm{in}^{4}} \\
& \sigma_{\mathrm{y} 5052 \mathrm{~s}}:=23 \cdot \mathrm{ksi} \\
& \sigma_{\mathrm{u} 5052 \mathrm{~s}}:=31 \cdot \mathrm{ksi} \\
& \varepsilon_{\mathrm{y} 5052 \mathrm{~s}}:=\frac{\sigma_{\mathrm{y} 5052 \mathrm{~s}}}{\mathrm{E}_{5052 \mathrm{~s}}} \\
& \varepsilon_{y 5052 s}=0.002233 \cdot \frac{\text { in }}{\text { in }} \\
& \varepsilon_{\mathrm{u} 5052 \mathrm{~s}}:=0.07 \cdot \frac{\mathrm{in}}{\mathrm{in}} \\
& \sigma_{\mathrm{Ty} 5052 \mathrm{~s}}:=\sigma_{\mathrm{y} 5052 \mathrm{~s}} \cdot\left(1+\varepsilon_{\mathrm{y} 5052 \mathrm{~s}}\right) \\
& \sigma_{\mathrm{Ty} 5052 \mathrm{~s}}=23051.4 \cdot \mathrm{psi} \\
& \sigma_{\text {Tu5052s }}:=\sigma_{\mathrm{u} 5052 \mathrm{~s}} \cdot\left(1+\varepsilon_{\mathrm{u} 5052 \mathrm{~s}}\right) \\
& \sigma_{\text {Tu5052s }}=33170.0 \cdot \mathrm{psi} \\
& \varepsilon_{\text {Ty5052s }}:=\ln \left(1+\varepsilon_{y 5052 s}\right) \\
& \varepsilon_{\text {Ty5052s }}=0.0022305 \cdot \frac{\text { in }}{\text { in }} \\
& \varepsilon_{\text {Tu5052s }}:=\ln \left(1+\varepsilon_{\mathrm{u} 5052 \mathrm{~s}}\right) \\
& \varepsilon_{\text {Tu5052s }}=0.068 \cdot \frac{\text { in }}{\text { in }} \\
& \varepsilon_{\text {Tp5052s }}:=\varepsilon_{\text {Tu5052s }}-\frac{\sigma_{\text {Tu5052s }}}{\mathrm{E}_{5052 \mathrm{~s}}} \quad \text { True plastic strain. } \\
& \varepsilon_{\mathrm{Tp} 5052 \mathrm{~s}}=0.064 \cdot \frac{\text { in }}{\text { in }}
\end{aligned}
$$




\section{B2.1.8 Aluminum (5052-H32 Plate) Material Properties}

The modulus of elasticity, Poisson's ratio, and mass density in this section are based on Appendix A of Snow (2013) as being similar to 356 aluminum. The yield and ultimate stress values are from the ATR FFSC SAR (2017), Table 2.2-2. The ultimate strain is from ASTM B209 (2014) for specified thicknesses of 0.250-0.499 in. The conversion to true stress and true strain are done with equations from Abaqus (2018), Analysis User's Guide, Section 23.1.1.

$$
\begin{array}{rlrl}
\mathrm{E}_{5052 \mathrm{p}}:=10.3 \cdot 10^{6} \cdot \mathrm{psi} & & \text { Modulus of elasticity. } \\
\nu_{5052 \mathrm{p}}:=0.33 & & \text { Poisson's ratio. } \\
\rho_{5052 \mathrm{p}}:=0.098 \frac{\mathrm{lb}}{\mathrm{in}^{3}} & & \text { Mass density. } \\
\rho_{5052 \mathrm{p}}=2.538 \times 10^{-4} \cdot \frac{\mathrm{lbf} \cdot \mathrm{sec}^{2}}{\mathrm{in}^{4}} & & \text { Engineering yield stress. } \\
\sigma_{\mathrm{y} 5052 \mathrm{p}}:=23 \cdot \mathrm{ksi} & & \begin{array}{l}
\text { Engineering ultimate stress that is } \\
\text { conservatively tough. }
\end{array} \\
\sigma_{\mathrm{u} 5052 \mathrm{p}}:=31 \cdot \mathrm{ksi} & & \begin{array}{l}
\text { Engineering yield strain }(0.2 \% \text { offset is not } \\
\text { considered). }
\end{array} \\
\varepsilon_{\mathrm{y} 5052 \mathrm{p}}:=\frac{\sigma_{\mathrm{y} 5052 \mathrm{p}}}{\mathrm{E}_{5052 \mathrm{p}}} & & \\
\varepsilon_{\mathrm{y} 5052 \mathrm{p}}=0.002233 \cdot \frac{\text { in }}{\mathrm{in}} & \text { Minimum engineering ultimate strain. } \\
\varepsilon_{\mathrm{u} 5052 \mathrm{p}}:=0.11 \cdot \frac{\mathrm{in}}{\mathrm{in}} & &
\end{array}
$$




$$
\begin{array}{ll}
\sigma_{\text {Ty5052p }}:=\sigma_{y 5052 p} \cdot\left(1+\varepsilon_{\mathrm{y} 5052 \mathrm{p}}\right) & \text { True yield stress. } \\
\sigma_{\text {Ty5052p }}=23051.4 \cdot \mathrm{psi} & \\
\sigma_{\text {Tu5052p }}=\sigma_{\mathrm{U} 5052 \mathrm{p}} \cdot\left(1+\varepsilon_{\mathrm{u} 5052 \mathrm{p}}\right) & \text { True ultimate stress. } \\
\sigma_{\text {Tu5052p }}=34410.0 \cdot \mathrm{psi} & \text { True yield strain. } \\
\varepsilon_{\text {Ty5052p }}:=\ln \left(1+\varepsilon_{\mathrm{y} 5052 \mathrm{p}}\right) & \\
\varepsilon_{\text {Ty5052p }}=0.0022305 \cdot \frac{\text { in }}{\text { in }} & \text { True ultimate strain. } \\
\varepsilon_{\text {Tu5052p }}:=\ln \left(1+\varepsilon_{\mathrm{u} 5052 \mathrm{p}}\right) & \\
\varepsilon_{\text {Tu5052p }}=0.104 \cdot \frac{\text { in }}{\text { in }} & \\
\varepsilon_{\text {Tp5052p }}:=\varepsilon_{\text {Tu5052p }}-\frac{\sigma_{\text {Tu5052p }}}{E_{5052 p}} & \text { True plastic strain. } \\
\varepsilon_{\text {Tp5052p }}=0.101 \cdot \frac{\text { in }}{\text { in }} &
\end{array}
$$

\section{B2.1.9 Aluminum (5052-O for Weld) Material Properties}

The modulus of elasticity, Poisson's ratio, and mass density in this section are based on Appendix A of Snow (2013) as being similar to 356 aluminum. The yield and ultimate stress values and ultimate strain value are minimum values from ASTM B209 (2014) for specified thicknesses of 0.051-0.113 in. or 0.250-3.000 in. The conversion to true stress and true strain are done with equations from Abaqus (2018), Analysis User's Guide, Section 23.1.1.

$$
\begin{array}{ll}
\mathrm{E}_{5052 \mathrm{w}}:=10.3 \cdot 10^{6} \cdot \mathrm{psi} & \text { Modulus of elasticity. } \\
\nu_{5052 \mathrm{w}}:=0.33 & \text { Poisson's ratio. } \\
\rho_{5052 \mathrm{w}}:=0.098 \frac{\mathrm{lb}}{\mathrm{in}^{3}} & \text { Mass density. } \\
\rho_{5052 \mathrm{w}}=2.538 \times 10^{-4} \cdot \frac{\mathrm{lbf} \cdot \mathrm{sec}^{2}}{\mathrm{in}^{4}} &
\end{array}
$$




$$
\begin{aligned}
& \sigma_{\mathrm{y} 5052 \mathrm{w}}:=9.5 \cdot \mathrm{ksi} \\
& \text { Engineering yield stress. } \\
& \sigma_{\mathrm{u} 5052 \mathrm{w}}:=25 \cdot \mathrm{ksi} \\
& \varepsilon_{y 5052 w}:=\frac{\sigma_{y 5052 w}}{E_{5052 w}} \\
& \text { Engineering ultimate stress that is } \\
& \text { conservatively tough. } \\
& \varepsilon_{y 5052 w}=0.000922 \cdot \frac{\text { in }}{\text { in }} \\
& \varepsilon_{\mathrm{u} 5052 \mathrm{w}}=0.18 \cdot \frac{\text { in }}{\text { in }} \\
& \sigma_{\text {Ty5052w }}:=\sigma_{y 5052 \mathrm{w}} \cdot\left(1+\varepsilon_{\mathrm{y} 5052 \mathrm{w}}\right) \quad \text { True yield stress. } \\
& \sigma_{T y 5052 \mathrm{w}}=9508.8 \cdot \mathrm{psi} \\
& \sigma_{\mathrm{Tu} 5052 \mathrm{w}}:=\sigma_{\mathrm{u} 5052 \mathrm{w}} \cdot\left(1+\varepsilon_{\mathrm{u} 5052 \mathrm{w}}\right) \quad \text { True ultimate stress. } \\
& \sigma_{\mathrm{Tu} 5052 \mathrm{w}}=29500.0 \cdot \mathrm{psi} \\
& \varepsilon_{\mathrm{Ty} 5052 \mathrm{w}}:=\ln \left(1+\varepsilon_{\mathrm{y} 5052 \mathrm{w}}\right) \\
& \text { considered). } \\
& \text { Minimum engineering ultimate strain. } \\
& \varepsilon_{\text {Ty5052w }}=0.0009219 \cdot \frac{\text { in }}{\text { in }} \\
& \varepsilon_{\text {Tu5052w }}:=\ln \left(1+\varepsilon_{\mathrm{u} 5052 \mathrm{w}}\right) \quad \text { True ultimate strain. } \\
& \varepsilon_{\mathrm{Tu} 5052 \mathrm{~W}}=0.166 \cdot \frac{\text { in }}{\text { in }} \\
& \varepsilon_{\mathrm{Tp5052w}}:=\varepsilon_{\mathrm{Tu} 5052 \mathrm{w}}-\frac{\sigma_{\mathrm{Tu}} \text { 5052w }}{\mathrm{E}_{5052 \mathrm{w}}} \quad \text { True plastic strain. } \\
& \varepsilon_{\mathrm{Tp} 5052 \mathrm{w}}=0.163 \cdot \frac{\text { in }}{\text { in }}
\end{aligned}
$$$$
\text { Engineering yield strain }(0.2 \% \text { offset is not }
$$

\section{B2.1.10 Enclosure 3/8-16UNC Screw Material Properties}

The tensile stress area for the screw is from ASTM F835 (2018). The modulus of elasticity, Poisson's ratio, and mass density in this section are approximated as being similar to the 304 stainless steel properties, already defined. The yield and ultimate stress values are from the ATR FFSC SAR (2017), Section 2.5.2.3. The ultimate strain is representative of values for ASTM F835 (2018). The conversion to true stress and true strain are done with equations from Abaqus (2018), Analysis User's Guide, Section 23.1.1. 


$$
\begin{aligned}
& \mathrm{A}_{\mathrm{t} 1}:=0.0775 \cdot \mathrm{in}^{2} \\
& \mathrm{~d}_{\mathrm{e} 1}:=\sqrt{\frac{4}{\pi} \cdot \mathrm{A}_{\mathrm{t} 1}} \\
& \mathrm{~d}_{\mathrm{e} 1}=0.314 \cdot \mathrm{in} \\
& \mathrm{E}_{\mathrm{F} 835}:=28.3 \cdot 10^{6} \cdot \mathrm{psi} \\
& \nu_{\mathrm{F} 835}:=0.31 \\
& \rho_{\mathrm{F} 835}:=0.290 \frac{\mathrm{lb}}{\mathrm{in}^{3}} \\
& \rho_{\mathrm{F} 835}=7.511 \times 10^{-4} \cdot \frac{\mathrm{lbf} \cdot \mathrm{sec}^{2}}{\mathrm{in}^{4}} \\
& \sigma_{\mathrm{yF} 835}:=116 \cdot \mathrm{ksi} \\
& \sigma_{\mathrm{UF} 835}:=145 \cdot \mathrm{ksi} \\
& \varepsilon_{\mathrm{yF} 835}:=\frac{\sigma_{\mathrm{yF} 835}}{\mathrm{E}_{\mathrm{F} 835}} \\
& \varepsilon_{\mathrm{yF} 835}=0.004099 \cdot \frac{\mathrm{in}_{\mathrm{in}}}{\mathrm{in}} \\
& \mathrm{in}
\end{aligned}
$$$$
\text { Modulus of elasticity. }
$$$$
\text { Tensile stress area }
$$

Effective diameter (for the finite element model)

Mass density.

\section{Engineering yield stress. \\ Engineering ultimate stress that is conservatively tough.}

Engineering yield strain $(0.2 \%$ offset is not considered).

Minimum engineering ultimate strain. 


$$
\begin{aligned}
& \sigma_{\text {TyF835 }}:=\sigma_{\mathrm{yF} 835} \cdot\left(1+\varepsilon_{\mathrm{yF} 835}\right) \quad \text { True yield stress. } \\
& \sigma_{\mathrm{TyF} 835}=116475.5 \cdot \mathrm{psi} \\
& \sigma_{\mathrm{TuF835}}:=\sigma_{\mathrm{uF} 835} \cdot\left(1+\varepsilon_{\mathrm{uF} 835}\right) \quad \text { True ultimate stress. } \\
& \sigma_{\text {TuF835 }}=156600.0 \cdot p s i \\
& \varepsilon_{\text {TyF835 }}:=\ln \left(1+\varepsilon_{\mathrm{yF} 835}\right) \quad \text { True yield strain. } \\
& \varepsilon_{\text {TyF835 }}=0.0040906 \cdot \frac{\text { in }}{\text { in }} \\
& \varepsilon_{\text {TuF835 }}:=\ln \left(1+\varepsilon_{\mathrm{uF} 835}\right) \quad \text { True ultimate strain. } \\
& \varepsilon_{\text {TuF835 }}=0.077 \cdot \frac{\text { in }}{\text { in }} \\
& \varepsilon_{\text {TpF835 }}=\varepsilon_{\text {TuF835 }}-\frac{\sigma_{\text {TuF835 }}}{\mathrm{E}_{\mathrm{F} 835}} \quad \text { True plastic strain. } \\
& \varepsilon \mathrm{TpF835}=0.071 \cdot \frac{\text { in }}{\text { in }}
\end{aligned}
$$

\section{B2.1.11 Steel Post Material Properties}

The steel post is simply modeled as being elastic with reasonable values for carbon steel. These values are approximately equal to those listed in the ASME (2019), Tables TM-1 and PRD. The conversion to true stress and true strain are done with equations from Abaqus (2018), Analysis User's Guide, Section 23.1.1.

$$
\begin{array}{ll}
\mathrm{E}_{\mathrm{st}}:=30.0 \cdot 10^{6} \cdot \mathrm{psi} & \text { Modulus of elasticity. } \\
\nu_{\mathrm{st}}:=0.30 & \text { Poisson's ratio. } \\
\rho_{\text {st }}:=0.283 \frac{\mathrm{lb}}{\mathrm{in}^{3}} & \text { Mass density. } \\
\rho_{\text {st }}=7.330 \times 10^{-4} \cdot \frac{\mathrm{lbf} \cdot \mathrm{sec}^{2}}{\mathrm{in}^{4}} &
\end{array}
$$

\section{B2.1.12 Tough Cast Aluminum (A356.0-T71 or A356.0-T6) Material Properties}

Components of concern are the ATR FFSC body and lid and the fueled region of the fuel element.

Consequently, failure of the end boxes and enclosure does not ensure a conservative amount of damage to the components of concern. To address this, typical or conservatively tough values are used in the end boxes and enclosure for some drop scenarios. 
The modulus of elasticity, Poisson's ratio, and mass density in this section are from Section B-2.1.5 of this calculation. The yield, ultimate stress, and elongation are from Table 24, Premium engineered castings, 356.0-T6 in Kaufman (2019). The conversion to true stress and true strain are done with equations from Abaqus (2018), Analysis User's Guide, Section 23.1.1.

$$
\begin{aligned}
& \mathrm{E}_{356}=1.03 \times 10^{7} \cdot \mathrm{psi} \quad \text { Modulus of elasticity. } \\
& \nu_{356}=0.33 \quad \text { Poisson's ratio. } \\
& \rho_{356}=2.538 \times 10^{-4} \cdot \frac{\mathrm{lbf} \cdot \mathrm{sec}^{2}}{\text { in }^{4}} \quad \text { Mass density. } \\
& \sigma_{\mathrm{y} 356 \mathrm{~m}}:=30.2 \cdot \mathrm{ksi} \quad \text { Engineering yield stress. } \\
& \sigma_{\mathrm{u} 356 \mathrm{~m}}:=41.6 \cdot \mathrm{ksi} \quad \text { Engineering ultimate stress that is } \\
& \varepsilon_{\mathrm{y} 356 \mathrm{~m}}:=\frac{\sigma_{\mathrm{y} 356 \mathrm{~m}}}{\mathrm{E}_{356}} \quad \begin{array}{l}
\text { Conservatively tough. } \\
\text { Engineering yield strain }(0.2 \% \text { offset is not }
\end{array} \\
& \varepsilon_{\mathrm{y} 356 \mathrm{~m}}=0.002932 \cdot \frac{\mathrm{in}}{\mathrm{in}} \\
& \varepsilon_{\mathrm{u} 356 \mathrm{~m}}:=0.088 \cdot \frac{\text { in }}{\text { in }} \quad \text { Minimum engineering ultimate strain. } \\
& \sigma_{\text {Ty } 356 \mathrm{~m}}:=\sigma_{\mathrm{y} 356 \mathrm{~m}} \cdot\left(1+\varepsilon_{\mathrm{y} 356 \mathrm{~m}}\right) \quad \text { True yield stress. } \\
& \sigma_{\mathrm{Ty} 356 \mathrm{~m}}=30288.5 \cdot \mathrm{psi} \\
& \sigma_{\mathrm{Tu} 356 \mathrm{~m}}:=\sigma_{\mathrm{u} 356 \mathrm{~m}} \cdot\left(1+\varepsilon_{\mathrm{u} 356 \mathrm{~m}}\right) \quad \text { True ultimate stress. } \\
& \sigma_{\mathrm{Tu} 356 \mathrm{~m}}=45260.8 \cdot \mathrm{psi}
\end{aligned}
$$

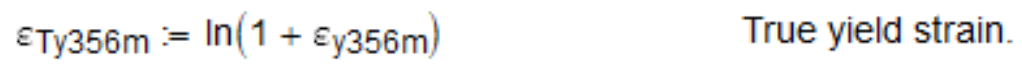

$$
\begin{aligned}
& \varepsilon_{\mathrm{Ty} 356 \mathrm{~m}}=0.0029277 \cdot \frac{\text { in }}{\text { in }} \\
& \varepsilon_{\mathrm{Tu} 356 \mathrm{~m}}:=\ln \left(1+\varepsilon_{\mathrm{u} 356 \mathrm{~m}}\right) \quad \text { True ultimate strain. } \\
& \varepsilon_{\mathrm{Tu} 356 \mathrm{~m}}=0.084 \cdot \frac{\text { in }}{\text { in }} \\
& \varepsilon_{\mathrm{Tp} 356 \mathrm{~m}}:=\varepsilon_{\mathrm{Tu} 356 \mathrm{~m}}-\frac{\sigma_{\mathrm{Tu} 356 \mathrm{~m}}}{\mathrm{E}_{356}} \quad \text { True plastic strain. } \\
& \varepsilon_{\mathrm{Tp} 356 \mathrm{~m}}=0.08 \cdot \frac{\text { in }}{\text { in }}
\end{aligned}
$$




\section{B2.1.13 Tough Cast Aluminum (356 weld) Material Properties}

Components of concern are the ATR FFSC body and lid and the fueled region of the fuel element.

Consequently, failure of the end boxes and enclosure does not ensure a conservative amount of damage to the components of concern. To address this, typical or conservatively tough values are used in the end boxes and enclosure for some drop scenarios.

The modulus of elasticity, Poisson's ratio, and mass density in this section are from Section B-2.1.6 of this calculation. The ultimate stress and elongation are from Table 25, Permanent mold casting, 356.0-T6 to 6061-T6, 4043 weld (free bend elongation treated as equivalent to tensile elongation) in Kaufman (2019). The conversion to true stress and true strain are done with equations from Abaqus (2018), Analysis User's Guide, Section 23.1.1.

$$
\begin{aligned}
& E_{356 w}=1.03 \times 10^{7} \cdot \mathrm{psi} \quad \text { Modulus of elasticity. } \\
& \nu_{356 \mathrm{w}}=0.33 \quad \text { Poisson's ratio. } \\
& \rho_{356 \mathrm{w}}=2.538 \times 10^{-4} \cdot \frac{\mathrm{lbf} \cdot \mathrm{sec}^{2}}{\text { in }^{4}} \quad \text { Mass density. } \\
& \sigma_{\mathrm{y} 356 \mathrm{w}}=9.5 \cdot \mathrm{ksi} \quad \text { Engineering yield stress } \text {. } \\
& \sigma_{\mathrm{u} 356 \mathrm{mw}}:=28.8 \cdot \mathrm{ksi} \quad \text { Engineering ultimate stress that is } \\
& \text { conservatively tough. } \\
& \varepsilon_{\mathrm{y} 356 \mathrm{w}}=0.000922 \cdot \frac{\text { in }}{\text { in }} \quad \text { Engineering yield strain }(0.2 \% \text { offset is not } \\
& \varepsilon_{\mathrm{u} 356 \mathrm{mw}}:=0.125 \cdot \frac{\text { in }}{\text { in }} \quad \text { Minimum engineering ultimate strain. } \\
& \sigma_{\text {Ty356w }}=9508.8 \cdot \mathrm{psi} \quad \text { True yield stress. } \\
& \sigma_{\mathrm{Tu} 356 \mathrm{mw}}:=\sigma_{\mathrm{u} 356 \mathrm{mw}} \cdot\left(1+\varepsilon_{\mathrm{u} 356 \mathrm{mw}}\right) \quad \text { True ultimate stress. } \\
& \sigma_{\mathrm{Tu} 356 \mathrm{mw}}=32400.0 \cdot \mathrm{psi} \\
& \varepsilon_{\text {Ty356w }}=0.0009219 \cdot \frac{\text { in }}{\text { in }} \quad \text { True yield strain. } \\
& \varepsilon_{\mathrm{Tu} 356 \mathrm{mw}}:=\ln \left(1+\varepsilon_{\mathrm{u} 356 \mathrm{mw}}\right) \quad \text { True ultimate strain. } \\
& \varepsilon_{\mathrm{Tu} 356 \mathrm{mw}}=0.118 \cdot \frac{\mathrm{in}}{\mathrm{in}} \\
& \varepsilon_{\mathrm{Tp} 356 \mathrm{mw}}:=\varepsilon_{\mathrm{Tu} 356 \mathrm{mw}}-\frac{\sigma_{\mathrm{Tu} 356 \mathrm{mw}}}{\mathrm{E}_{356 \mathrm{w}}} \quad \text { True plastic strain. } \\
& \varepsilon_{\mathrm{Tp} 356 \mathrm{mw}}=0.115 \cdot \frac{\text { in }}{\text { in }}
\end{aligned}
$$




\section{B2.1.14 Tough Aluminum (5052-H32) Material Properties}

Components of concern are the ATR FFSC body and lid and the fueled region of the fuel element.

Consequently, failure of the end boxes and enclosure does not ensure a conservative amount of damage to the components of concern. To address this, typical or conservatively tough values are used in the end boxes and enclosure for some drop scenarios. The material properties below represent tough values and will be used for plate, sheet, and welds in the enclosure.

The modulus of elasticity, Poisson's ratio, and mass density in this section are from Section B-2.1.7 of this calculation. The ultimate stress and elongation are from Clinton Aluminum \& Stainless Steel (see data sheet attached in Appendix A). The conversion to true stress and true strain are done with equations from Abaqus (2018), Analysis User's Guide, Section 23.1.1.

$$
\begin{aligned}
& E_{5052 p}=1.03 \times 10^{7} \cdot p s i \quad \text { Modulus of elasticity. } \\
& \nu_{5052 p}=0.33 \quad \text { Poisson's ratio. }
\end{aligned}
$$

$\rho_{5052 p}=2.538 \times 10^{-4} \cdot \frac{\mathrm{lbf} \cdot \mathrm{sec}^{2}}{\text { in }^{4}} \quad$ Mass density

$$
\begin{array}{ll}
\sigma_{\mathrm{y} 5052 \mathrm{~m}}:=28 \cdot \mathrm{ksi} & \text { Engineering yield stress. } \\
\sigma_{\mathrm{u} 5052 \mathrm{~m}}:=33 \cdot \mathrm{ksi} & \begin{array}{l}
\text { Engineering ultimate stress that is } \\
\text { conservatively tough. }
\end{array} \\
\varepsilon_{\mathrm{y} 5052 \mathrm{~m}}:=\frac{\sigma_{\mathrm{y} 5052 \mathrm{~m}}}{\mathrm{E}_{5052 \mathrm{p}}} & \begin{array}{l}
\text { Engineering yield strain }(0.2 \% \text { offset is not } \\
\text { Considered }) \text {. }
\end{array}
\end{array}
$$$$
\text { considered). }
$$$$
\varepsilon_{y 5052 m}=0.002718 \cdot \frac{\text { in }}{\text { in }}
$$$$
\varepsilon_{\mathrm{u} 5052 \mathrm{~m}}=0.18 \cdot \frac{\text { in }}{\text { in }} \quad \text { Minimum engineering ultimate strain. }
$$ 


$$
\begin{aligned}
& \sigma_{\text {Ty5052m }}:=\sigma_{\mathrm{y} 5052 \mathrm{~m}} \cdot\left(1+\varepsilon_{\mathrm{y} 5052 \mathrm{~m}}\right) \quad \text { True yield stress. } \\
& \sigma_{\text {Ty5052m }}=28076.1 \cdot \mathrm{psi} \\
& \sigma_{\text {Tu5052m }}:=\sigma_{\mathrm{u} 5052 \mathrm{~m}} \cdot\left(1+\varepsilon_{\mathrm{u} 5052 \mathrm{~m}}\right) \quad \text { True ultimate stress. } \\
& \sigma_{\text {Tu5052m }}=38940.0 \cdot p s i \\
& \varepsilon_{\mathrm{Ty} 5052 \mathrm{~m}}:=\ln \left(1+\varepsilon_{\mathrm{y} 5052 \mathrm{~m}}\right) \\
& \text { True yield strain. } \\
& \varepsilon_{\text {Ty5052m }}=0.0027148 \cdot \frac{\text { in }}{\text { in }} \\
& \varepsilon_{\mathrm{Tu} 5052 \mathrm{~m}}:=\ln \left(1+\varepsilon_{\mathrm{u} 5052 \mathrm{~m}}\right) \\
& \text { True ultimate strain. } \\
& \varepsilon_{\mathrm{Tu} 5052 \mathrm{~m}}=0.166 \cdot \frac{\mathrm{in}}{\text { in }} \\
& \varepsilon_{\text {Tp5052m }}:=\varepsilon_{\text {Tu5052m }}-\frac{\sigma_{\text {Tu5052m }}}{E_{5052 p}} \quad \text { True plastic strain. } \\
& \varepsilon_{\mathrm{Tp} 5052 \mathrm{~m}}=0.162 \cdot \frac{\mathrm{in}}{\mathrm{in}}
\end{aligned}
$$

\section{B2.2 Swage Calibration}

In an actual ATR HEU fuel element, the fuel plates are attached to the side plates with a swaged joint. Section 4.2.1.3.2 of SAR-153 (2019) states that the point of swage joint release is required to be greater than $150 \mathrm{lbf}$ per linear inch of joint. For the ATR HEU fuel element model and the LOWE fuel element model, the swage is approximated in the model. Figure B-5 shows the calibration model used to generate the swage parameters.

To model the swage, the initial geometry of the fuel element is defined so that the fuel plates are in (initially touching) frictional contact with the side plates. Next, swaging beams are added to the comb portions of the side plates (see Figure B-6 to Figure B-7). In the model run time before impact occurs, a rapidly ramped (over 0.01 second) temperature drop of $7000^{\circ} \mathrm{F}$ for the end-plate swaging beams and $5000^{\circ} \mathrm{F}$ for the interior-plate swaging beams is applied. This causes the swage beams to plasticly compress the comb portions of the side plates to produce swaging. Each swage beam cross-section matches the cross-section being compressed and the aluminum-to-aluminum coefficient of friction between the fuel plate and side plate is approximated as $1.2 \mathrm{per}$ https://www.engineeringtoolbox.com/friction-coefficients-d 778.html (see attached table in Appendix A).

NOTE: $\quad$ The coefficient of friction is one of multiple calibration factors, so its exact value is not of high importance. 
The swage beam material properties are defined with failure and the amplitude of the temperature is set high enough to fail the swage beams after they have produced the swage. Once failed, the swage beams play no further role in the stress and strain of the fuel element. The swage beams do have a small amount of mass (less than one pound), and this is considered in the fuel-element mass. Considering this modeling approach, the swage-beam material properties were iteratively modified to produce a reasonable swage (see Table B-6 for final material-property values).

The partial model shown in Figure B-5 is generated with one side plate and the fuel plate ends that interact with it. Swaging is performed on all 19 of the fuel plates. Once swaging is complete, Plates 1, 5, 10, 15, and 19 are pulled to produce pull-out loads for a representative sample of all 19 plates. The process is only repeated until the pull-out loads for all five fuel plates are between $100 \mathrm{lbf} / \mathrm{in}$. and $150 \mathrm{lbf} / \mathrm{in}$. (as shown in Figure B-8). Once achieve, the expectation is that all plates will produce similar pull-out loads. This produces a model where the fuel plates can be pulled out at a conservatively low load where the alternative of connecting the fuel plates to the side plate would have been overly strong. The plate pull-out did not turn out to be a significant factor in this evaluation. However, by including it, its contribution has been considered.

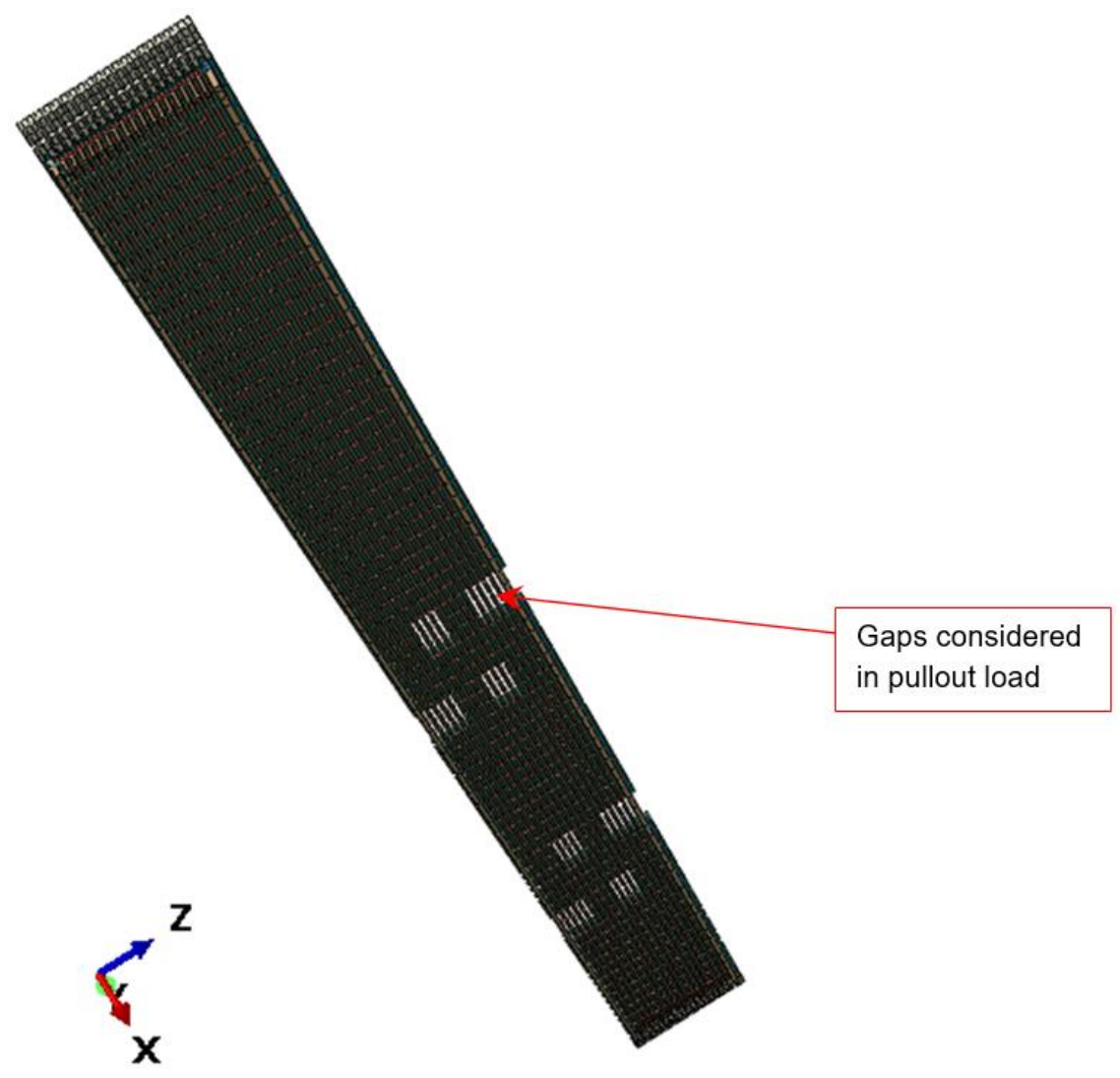

Figure B-5. Swage calibration mesh.

When establishing pullout load, the total load is gathered from the model results for each plate that is pulled out. To establish pullout load per inch, the total load is divided by the total plate length minus the length of the two gaps (where there is no swaging support). 
The swage calibration mesh is generated with (C3D8I) linear brick elements and (B31) linear beam elements.

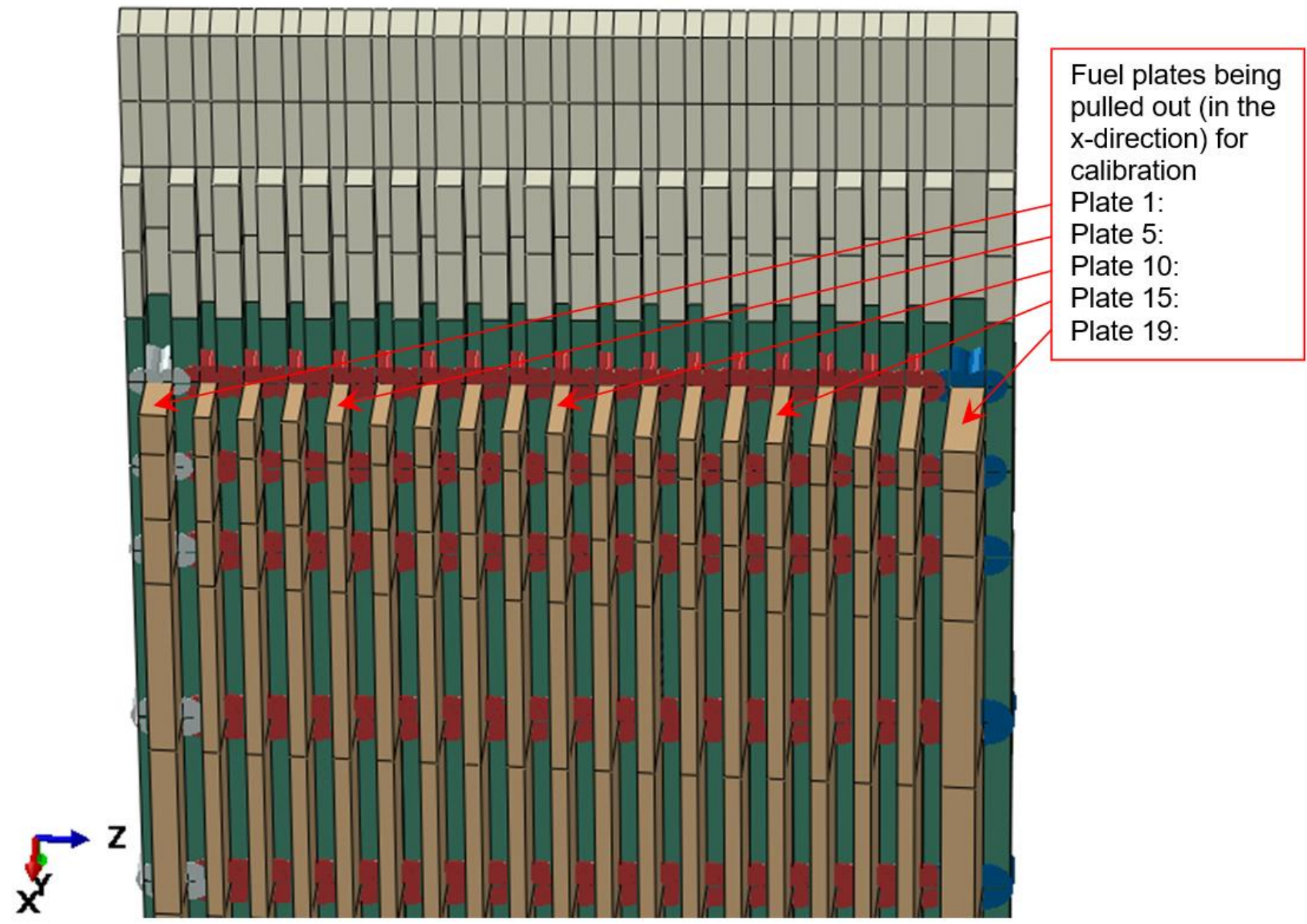

Figure B-6. Zoomed view of the negative y-direction portion of the swage calibration mesh.

Considering Figure B-6, there are several defined boundary conditions for the swage calibration mesh. First, $\mathrm{x}$-direction translation is restrained for all the nodes on the negative $\mathrm{x}$-direction (back) surface of the side plate. Second, y-direction translation is restrained for all the nodes on the negative $y$-direction surface (shown at the top of Figure B-6). Third, z-direction translation is restrained for all the nodes on the shared negative $x$-direction and negative z-direction edge. Finally, all the nodes at the free ends (positive $x$-direction) of the fuel plates being pulled are pinned. These nodes on the fuel plates are not allowed to translate while the swaging is applied. Once all of the swaging beams (identified in Figure B-7) have failed, the pinned nodes are displaced horizontally to pull the fuel plate out of the side plate. The pull direction is mostly in the x-direction. However, there is a slight $y$-direction component to pull parallel to the swaging slot. Due to the arc of the fuel plates, some binding can occur as they are pulled completely from the swaging slots. Consequently, Figure B-8 shows only the initial pull that breaks them free. Additionally, the swaging process causes the pinned nodes to carry some compressive loading. It would be preferable for this to not occur. However, it is not considered to have a significant effect on the tensile pullout loads. Figure B-9 
shows the swaged plastic strains in the side plate for the calibration mesh and the swage plastic strains for an unrestrained fuel element (with a mesh described in Section B3).

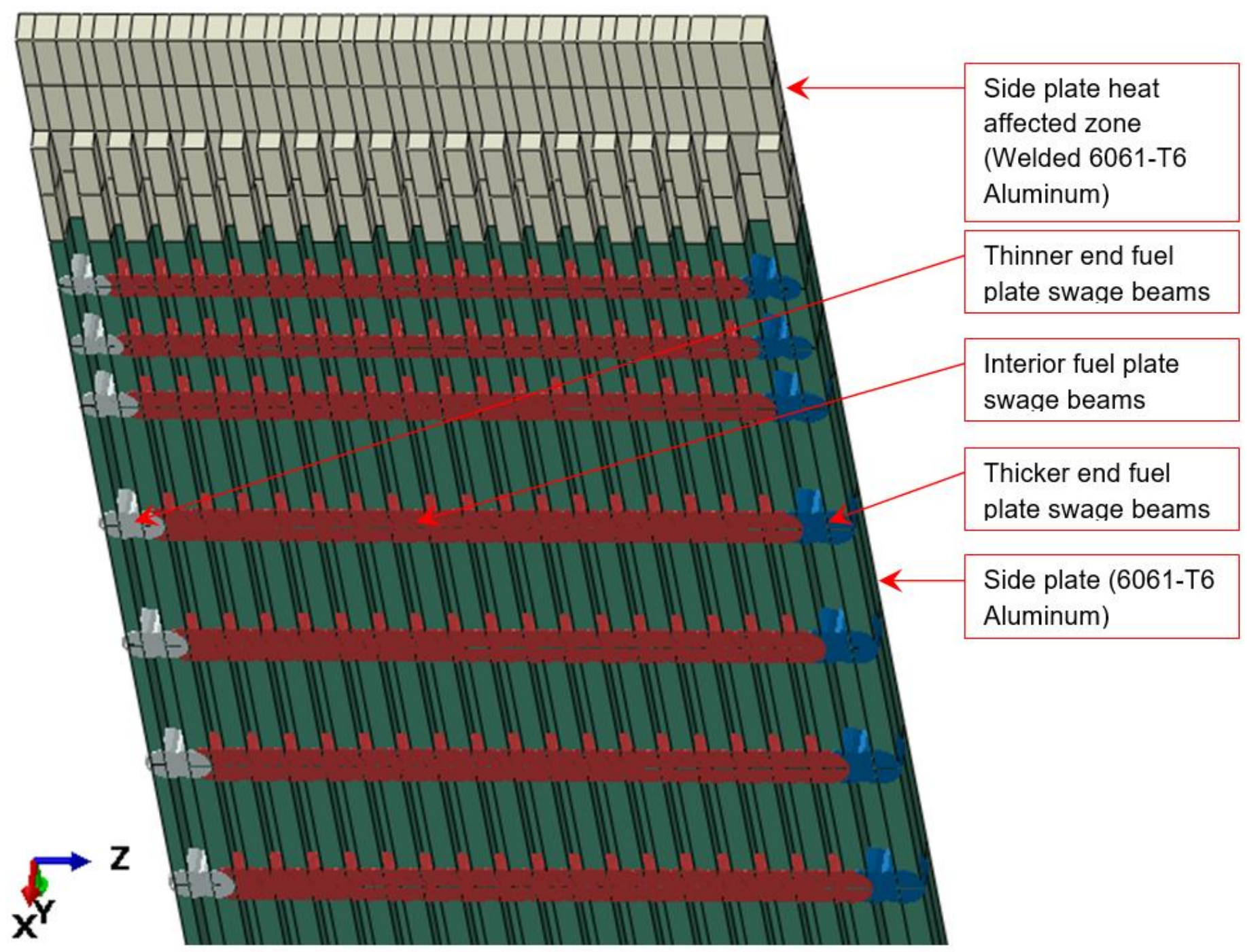

Figure B-7. Swage calibration mesh materials.

The heat affected zone for aluminum welds in this evaluation is considered to occur within approximately one inch of a weld. The ATR FFSC SAR (2017) does not appear to consider heat-affected zones. However, physical drops are performed in the ATR FFSC SAR (2017), so heat-affected zones have an influence even if they are not specifically recognized. 
ENGINEERING CALCULATIONS AND ANALYSIS

Drop Analysis of the Advanced Test Reactor Fresh Fuel Shipping Container with Heavier Low-Enriched Uranium Fuel Contents
ECAR-5224, Rev. 0

Page B32 of B100

Table B-6. Material properties for swage beams.

\begin{tabular}{|c|c|c|c|c|c|c|c|}
\hline Name & $\begin{array}{c}\text { Thermal } \\
\text { Expansion } \\
\left.\left[\text { in./(in. }{ }^{\circ} \mathrm{F}\right)\right]\end{array}$ & $\begin{array}{c}\text { Mass } \\
\text { Density } \\
{\left[\text { lbf·sec } / \text { in. }{ }^{4}\right]}\end{array}$ & $\begin{array}{c}\text { Modulus } \\
\text { of } \\
\text { Elasticity } \\
{\left[10^{6} \cdot \text { psi] }\right.}\end{array}$ & $\begin{array}{c}\text { Poisson's } \\
\text { Ratio }\end{array}$ & $\begin{array}{c}\text { True } \\
\text { Yield } \\
\text { Stress } \\
\text { [psi] }\end{array}$ & $\begin{array}{c}\text { True } \\
\text { Ultimate } \\
\text { Stress } \\
\text { [psi] }\end{array}$ & $\begin{array}{c}\text { Ultimate } \\
\text { Plastic } \\
\text { Strain } \\
\text { [in./in.] }\end{array}$ \\
\hline FUSE $^{(1)}$ & 0.00001 & 0.0002538 & 10.0 & 0.33 & 37120. & 37121. & 0.001 \\
\hline FUSE_THIN(2) & 0.00001 & 0.0002538 & 10.0 & 0.33 & 51480. & 51481. & 0.001 \\
\hline FUSE_END ${ }^{(3)}$ & 0.00001 & 0.0002538 & 10.0 & 0.33 & 41900. & 41901. & 0.001 \\
\hline
\end{tabular}

1. Material properties for Fuel plates 2-8 swage beams.

2. Material properties for Fuel Plate 1 swage beams.

3. Material properties for Fuel Plate 19 swage beams.

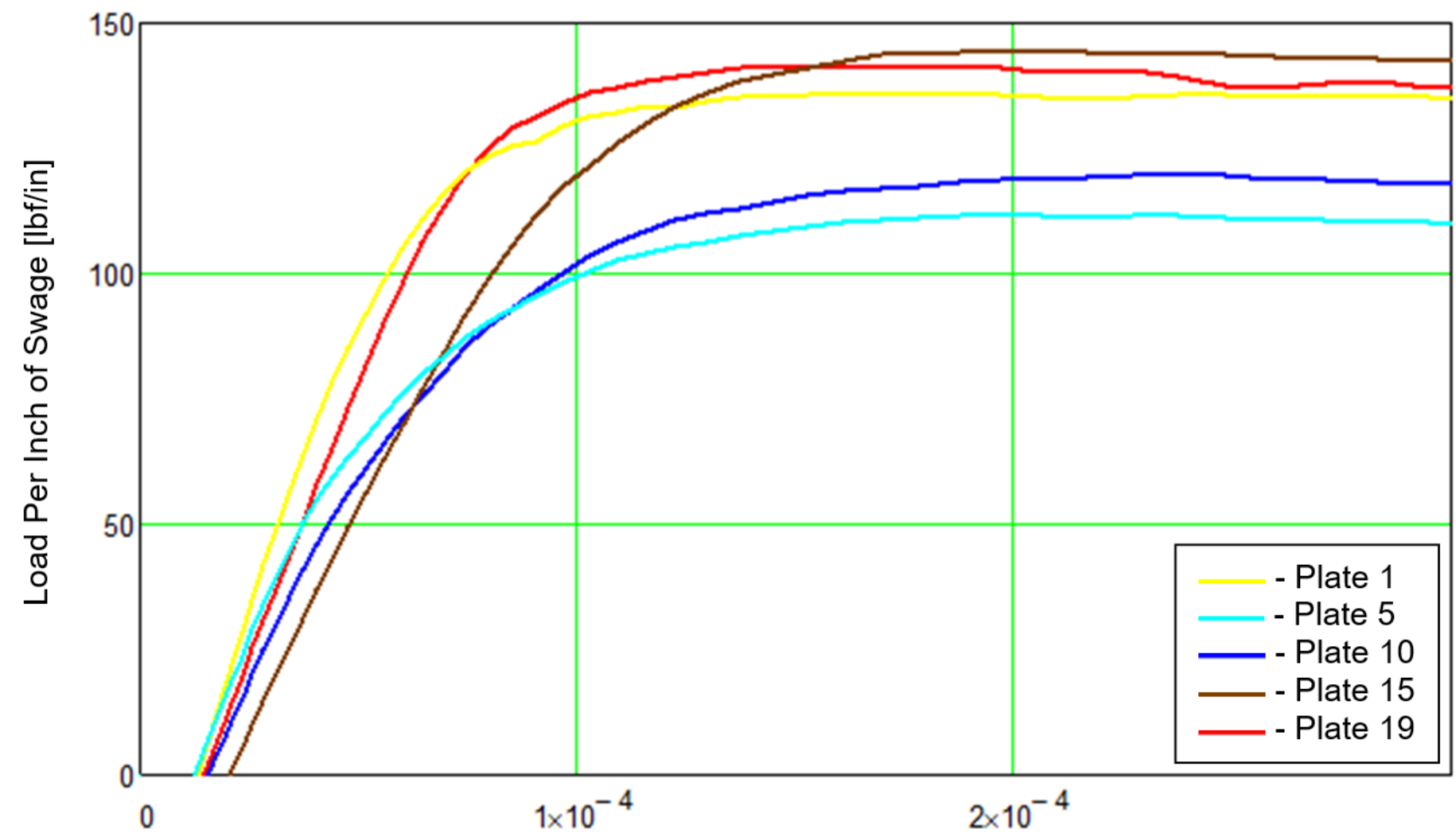

Displacement [in]

Figure B-8. Swage pullout loads (for fuel-element plates listed in Figure B-6). 


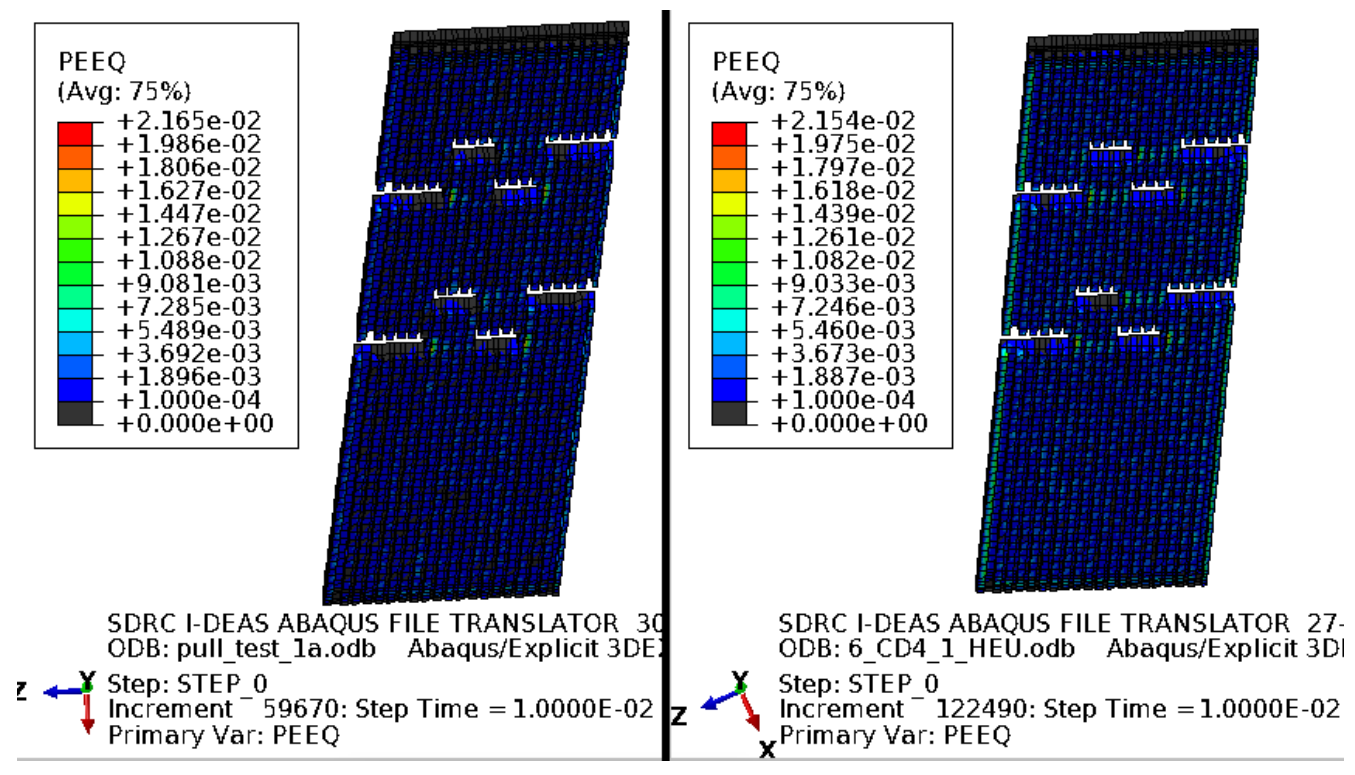

Figure B-9. Plastic equivalent strain in the side plates from the calibration mesh and from a mesh used for evaluation.

Figure B-9 shows the plastic equivalent strain in the side plates from the calibration mesh and from a mesh used for Test 6 (Table 2) for Scope Part 1a (Table 3) of the scope. The plastic strains are similar between the models with the calibration mesh showing a slightly higher maximum plastic equivalent strain. Given the similarity in the plastic equivalent strains in Figure B-9 and the room for error shown in Figure B-8, this approach is considered adequate to model swaging in the models used for evaluation.

\section{B2.3 Initial Conditions}

The initial conditions for the evaluation include initial velocity for the loaded ATR FFSC and temperature on the swaging beams (in models where swaging beams are used). The initial temperature for all models where it is applicable, is $0^{\circ} \mathrm{F}$. This has no relevance for material properties, and temperature is only used to strain the swaging beams. Initial velocity, however, is not constant for all models. All of the models are run in a single step, and some require swaging prior to impact. Consequently, time required for potential swaging is accommodated by providing a gap (prior to impact) for the loaded ATR FFSC. Table 2 in the SCOPE AND BRIEF DESCRIPTION section gives three different drop heights. To include drop scenarios with and without swaging, six initial conditions must be defined including initial velocities and initial gap (where applicable). When swaging is not performed, an initial gap of $0.1 \mathrm{in}$. is defined just to help ensure that there is no initial interference. Sections B2.3.1 to B2.3.6 define these initial conditions.

The drop scenarios are all in air and gravitational acceleration is applied to all elements. Consequently, the following simple derivation is used for calculating initial conditions for the drop scenarios with swaging.

$$
\begin{aligned}
& \mathrm{u}=\frac{1}{2} \cdot \mathrm{a} \cdot \mathrm{t}^{2}+\mathrm{v}_{0} \cdot \mathrm{t}+\mathrm{u}_{0} \quad \text { For: } \quad \mathrm{a}=-\mathrm{g}, \mathrm{v}_{0}=0 \text { and } \mathrm{u}_{0}=\mathrm{h} \\
& \mathrm{u}=\mathrm{h}-\frac{1}{2} \cdot \mathrm{g} \cdot \mathrm{t}^{2} \quad \text { and } \quad \mathrm{v}=\frac{\mathrm{d}}{\mathrm{dt}}\left(\mathrm{h}-\frac{1}{2} \cdot \mathrm{g} \cdot \mathrm{t}^{2}\right)=-\mathrm{g} \cdot \mathrm{t}
\end{aligned}
$$


Calculations for the drop scenarios without swaging can be more simply performed using the energy calculation below.

$$
\text { Energy }=\frac{1}{2} \cdot \mathrm{m} \cdot \mathrm{v}^{2}=\mathrm{m} \cdot \mathrm{g} \cdot \mathrm{h} \quad=\mathrm{v}=\sqrt{2 \cdot \mathrm{g} \cdot \mathrm{h}} \quad \text { Velocity }
$$

\section{B2.3.1 Initial Conditions for a $4 \mathrm{ft}$ Drop with Swaging}

The following derivation finds the initial velocity and initial gap for a drop scenario from $4 \mathrm{ft}$ that includes time for swaging. The calibration model (see Section B2.2) used a swaging time of 0.01 second. To provide extra time to settle any local motion due to swaging, the time prior to impact (for swaging) is set to 0.015 second.

$$
\begin{aligned}
& \mathrm{h}_{4}:=4.0 \cdot \mathrm{ft} \quad \text { Drop height } \\
& \mathrm{t}_{4}:=\sqrt{\frac{2 \cdot \mathrm{h}_{4}}{\mathrm{~g}}} \quad \text { Time to impact (for } \mathrm{u}=0 \mathrm{ft} \text { ) } \\
& \mathrm{t}_{4}=0.499 \cdot \mathrm{sec} \\
& t_{\mathrm{sW}}:=0.015 \cdot \mathrm{sec} \quad \text { Time used to swage the fuel plates in position } \\
& \text { plus } 0.005 \mathrm{sec} \text { for separation between the } \\
& \text { swage and the impact. } \\
& \mathrm{u}_{4}:=\mathrm{h}_{4}-\frac{1}{2} \cdot \mathrm{g} \cdot\left(\mathrm{t}_{4}-\mathrm{t}_{\mathrm{sw}}\right)^{2} \quad \text { Initial gap above the impacted surface } \\
& \mathrm{u}_{4}=2.844 \cdot \mathrm{in} \\
& v_{4}:=-g \cdot\left(t_{4}-t_{s w}\right) \quad \text { Initial velocity } \\
& \mathrm{v}_{4}=-186.73 \cdot \frac{\text { in }}{\mathrm{sec}}
\end{aligned}
$$

\section{B2.3.2 Initial Conditions for a $\mathbf{3 0} \mathrm{ft}$ Drop with Swaging}

The following derivation finds the initial velocity and initial gap for a drop scenario from thirty feet that includes time for swaging. The calibration model (see Section B2.2) used a swaging time of 0.01 second. To provide extra time to settle any local motion due to swaging, the time prior to impact (for swaging) is set to 0.015 second.

$$
\begin{aligned}
& \mathrm{h}_{30}:=30.0 \cdot \mathrm{ft} \quad \text { Drop height } \\
& \mathrm{t}_{30}=\sqrt{\frac{2 \cdot \mathrm{h}_{30}}{\mathrm{~g}}} \quad \text { Time to impact (for } \mathrm{u}=0 \mathrm{ft} \text { ) } \\
& t_{30}=1.366 \cdot \sec
\end{aligned}
$$




$$
\begin{array}{ll}
\mathrm{u}_{30}:=\mathrm{h}_{30}-\frac{1}{2} \cdot \mathrm{g} \cdot\left(\mathrm{t}_{30}-\mathrm{t}_{\mathrm{sw}}\right)^{2} & \text { Initial gap above the impacted surface } \\
\mathrm{u}_{30}=7.865 \cdot \text { in } & \text { Initial velocity } \\
\mathrm{v}_{30}:=-\mathrm{g} \cdot\left(\mathrm{t}_{30}-\mathrm{t}_{\mathrm{sw}}\right) & \\
\mathrm{v}_{30}=-521.45 \cdot \frac{\mathrm{in}}{\mathrm{sec}} &
\end{array}
$$

\section{B2.3.3 Initial Conditions for a $\mathbf{4 0}$ in. Drop with Swaging}

The following derivation finds the initial velocity and initial gap for a drop scenario from 40 in. that includes time for swaging. The calibration model (see Section B2.2) used a swaging time of 0.01 second. To provide extra time to settle any local motion due to swaging, the time prior to impact (for swaging) is set to 0.015 second.

$$
\begin{aligned}
& \mathrm{h}_{3 \_}:=40 \cdot \text { in } \\
& \text { Drop height } \\
& t_{3 \_3}=\sqrt{\frac{2 \cdot h_{3} \_}{g}} \\
& \text { Time to impact (for } \mathrm{u}=0 \mathrm{ft} \text { ) } \\
& t_{3 \_3}=0.455 \cdot \sec \\
& \mathrm{u}_{3 \_} 3:=\mathrm{h}_{3 \_}-\frac{1}{2} \cdot \mathrm{g} \cdot\left(\mathrm{t}_{3}{ }_{3}-\mathrm{t}_{\mathrm{sw}}\right)^{2} \quad \text { Initial gap above the impacted surface } \\
& \mathrm{u}_{3 \_}{ }_{3}=2.593 \cdot \mathrm{in} \\
& v_{3 \_}:=-g \cdot\left(t_{3} \_3-t_{s w}\right) \quad \text { Initial velocity } \\
& v_{3 \_3}=-169.96 \cdot \frac{\text { in }}{\mathrm{sec}}
\end{aligned}
$$

\section{B2.3.4 Initial Conditions for a $4 \mathrm{ft}$ Drop without Swaging}

The following derivation finds the initial velocity for a drop scenario from $4 \mathrm{ft}$. The evaluation is performed as though there is no initial gap. However, to ensure no initial interference, an initial gap of 0.1 in. is defined for the actual model run. An additional conservatism for the actual model run is an added $5 \%$ impact energy to the drop scenarios. This is added where no comparison to a physical drop is available and helps account for potential model error. 


$$
\begin{array}{ll}
\mathrm{h}_{4}=4 \cdot \mathrm{ft} & \text { Drop height } \\
\mathrm{v}_{4 \mathrm{~m}}:=\sqrt{2 \cdot \mathrm{g} \cdot \mathrm{h}_{4}} & \text { Impact velocity } \\
\mathrm{v}_{4 \mathrm{~m}}=192.521 \cdot \frac{\mathrm{in}}{\mathrm{sec}} & \text { Adjusted velocity for a } 5 \% \text { energy increase } \\
\mathrm{v}_{4 \mathrm{~m}_{-} 5}:=\sqrt{1+5 \% \cdot \mathrm{v}_{4 \mathrm{~m}}} & \\
\mathrm{~V}_{4 \mathrm{~m}_{-} 5}=197 \cdot \frac{\mathrm{in}}{\mathrm{sec}} &
\end{array}
$$

\section{B2.3.5 Initial Conditions for a $\mathbf{3 0} \mathrm{ft}$ Drop without Swaging}

The following derivation finds the initial velocity for a drop scenario from $30 \mathrm{ft}$. The evaluation is performed as though there is no initial gap. However, to ensure no initial interference an initial gap of 0.1 in. is defined for the actual model run. An additional conservatism for the actual model run is an added $5 \%$ impact energy to the drop scenarios. This is added where no comparison to a physical drop is available and helps account for potential model error.

$$
\begin{array}{ll}
\mathrm{h}_{30}=30 \cdot \mathrm{ft} & \text { Drop height } \\
\mathrm{v}_{30 \mathrm{~m}}:=\sqrt{2 \cdot \mathrm{g} \cdot \mathrm{h}_{30}} & \text { Impact velocity } \\
\mathrm{v}_{30 \mathrm{~m}}=527.242 \cdot \frac{\mathrm{in}}{\mathrm{sec}} & \text { Adjusted velocity for a } 5 \% \text { energy increase } \\
\mathrm{v}_{30 \mathrm{~m} \_}:=\sqrt{1+5 \% \cdot \mathrm{v}_{30 \mathrm{~m}}} & \\
\mathrm{v}_{30 \mathrm{~m}} 5=540 \cdot \frac{\text { in }}{\mathrm{sec}} &
\end{array}
$$

\section{B2.3.6 Initial Conditions for a $\mathbf{4 0}$ in. Drop without Swaging}

The following derivation finds the initial velocity for a drop scenario from $40 \mathrm{in}$. The evaluation is performed as though there is no initial gap. However, to ensure no initial interference an initial gap of 0.1 in. is defined for the actual model run. An additional conservatism for the actual model run is an added $5 \%$ impact energy to the drop scenarios. This is added where no comparison to a physical drop is available and helps account for potential model error. 


$$
\begin{aligned}
& \mathrm{h}_{3 \_3}=40 \cdot \text { in } \quad \text { Drop height } \\
& v_{3 \_3 m}:=\sqrt{2 \cdot g \cdot h_{3 \_}} \quad \text { Impact velocity } \\
& \mathrm{v}_{3} \_3 \mathrm{~m}=175.747 \cdot \frac{\text { in }}{\mathrm{sec}} \\
& v_{3 \_3 m \_5}:=\sqrt{1+5 \%} \cdot v_{3} \_3 m \\
& \text { Adjusted velocity for a } 5 \% \text { energy increase } \\
& V_{3} \_3 m_{-} 5=180 \cdot \frac{\text { in }}{\mathrm{sec}}
\end{aligned}
$$

\section{B3 FEA MODELS}

The FEA model meshes for this evaluation are shown in Figure B-10 to Figure B-41. These meshes accommodate the list of FEA modeled tests (Table 2 of the SCOPE AND BRIEF DESCRIPTION section) and are sufficient for the model runs required for the scope of this evaluation (Table 3 of the SCOPE AND BRIEF DESCRIPTION section).

The ATR FFSC body and lid are meshed continuously without special consideration of welding. This is due to the discussion in ATR FFSC SAR (2017), Section 1.2.1.1 shown below.

With the exception of several minor components, all steel used in the ATR FFSC packaging is of a Type 304 stainless steel. Components are joined using full-thickness fillet welds (i.e., fillet welds the leg size of which are nominally equal to the lesser thickness of the parts joined) and full- and partial-penetration groove welds.

The enclosure and fuel element are modeled with consideration to welds. These components are mostly aluminum and elements within approximately an inch of a weld (i.e., the heat-affected zone) are meshed with welded material properties. For the enclosure, the end plates are only connected to the wall and door where skip welds are identified on the drawings.

For all models, general contact is defined with a friction coefficient of 0.1 . The expectation is that friction does not play a large role in the impacts and frictional-energy dissipation tends to reduce the required energy absorbed in deformation, which could be unconservative. A friction coefficient of 0.1 is selected as a reasonable, yet relatively low value. For models where swaging is performed to secure the fuel plates, additional frictional contact is defined per the swaging calibration (see Section B2.2).

The boundary conditions for the models include having the rigid-surface reference node being fixed in all translation and rotation or, for models with the puncture bar instead of a rigid surface, having the nodes at the base of the puncture bar fixed in translation. (The puncture bar is a brick element, so no rotation degrees of freedom exist on the nodes).

As an extra level of protection, Figure B-26 and Figure B-27 show a block mesh that can be placed between the end boxes and fuel plates. This is to give additional protection to the fuel plates from failed pieces of end box that could otherwise cut into the fuel plates. 
To help ensure that the FEA models show conservative damage in the fuel plates, a refined mesh (as shown in Figure B-28 and Figure B-29) is also included at the end of the fuel plates for models where the damage gets near the fuel meat. Considering the potentially added block design and potentially refined fuelplate mesh, three model runs may be performed for a given drop scenario to provide necessary data. An example of this: three models are run for Test 6 (Table 2) for Scope Part 1 (Table 3). In this case, the initial drop includes the initial fuel-element mesh with no blocks. Using this mesh, a reasonable comparison can be made with the physical test. Next, a refined fuel-plate mesh is run with no blocks to demonstrate that it produces a conservative amount of damage. Finally, the refined fuel-plate mesh is run with the blocks to demonstrate that the blocks provide fuel-plate protection with margin.

To help ensure that the FEA models show conservative damage in the lid pins, a refined mesh (as shown in Figure B-30) is included in the ATR FFSC for all drop scenarios with a fuel element weighing 115 lbf. These models are the most challenging to the ATR FFSC.

The Abaqus (2018) solver used for all of the model runs is Abaqus/Explicit. This is an appropriate solver for impact analysis. The deformable elements for all of models in this evaluation include (C3D8I) linear brick elements, (S4R) linear shell elements, and (B31) linear beam elements. The rigid surface used in many models is a single (R3D4) rigid element. Each (B31) beam element is a simple beam element that is valid for Abaqus/Explicit model runs. The (S4R) shell elements are reduced integration shell elements that are recommended for Abaqus/Explicit model runs. The (C3D8I) brick elements are incompatible-mode elements. Per the Abaqus (2018), Analysis User's Guide, incompatible mode elements are first-order elements that are enhanced by incompatible modes to improve their bending behavior. With the improved bending behavior noted by the Abaqus (2018), Analysis User's Guide, only one element through the thickness of a component is necessary to produce accurate bending behavior.

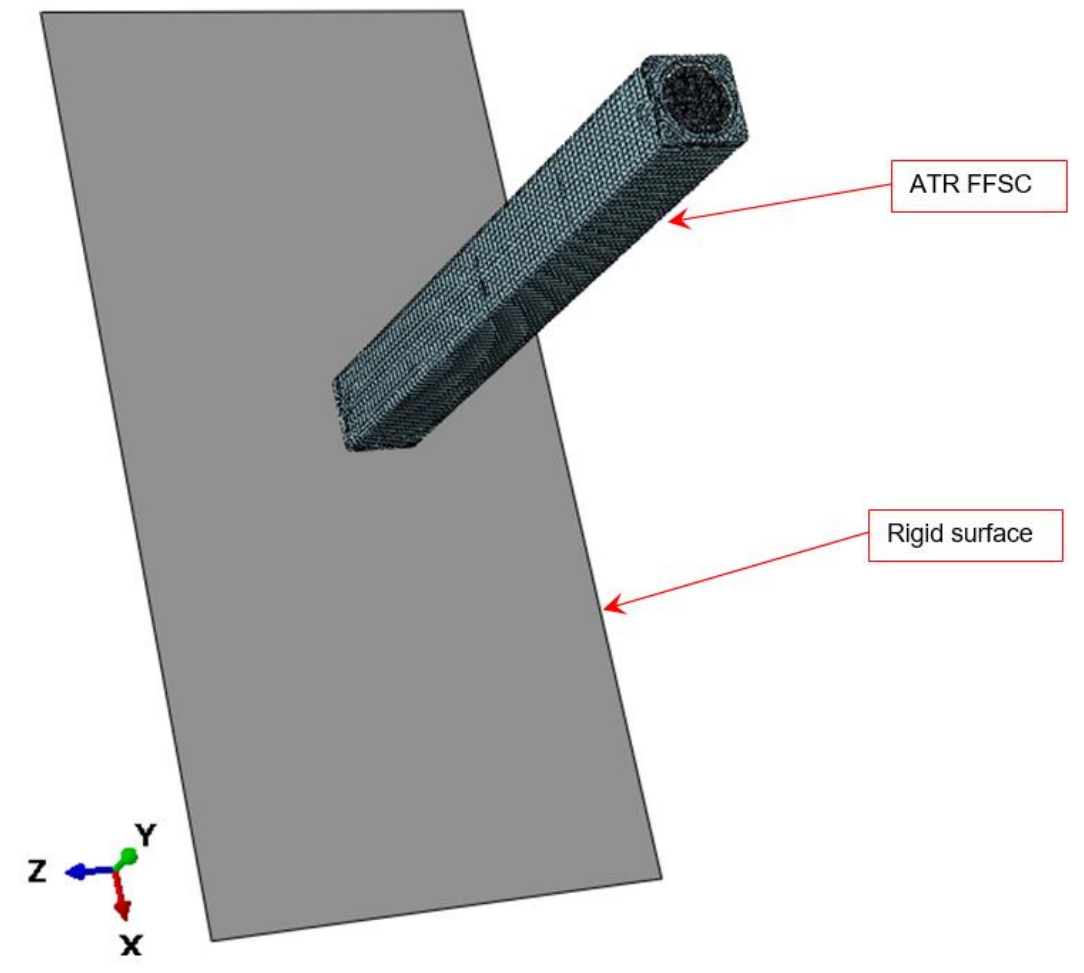

Figure B-10. ATR FFSC and rigid-surface mesh. 
ENGINEERING CALCULATIONS AND ANALYSIS

Drop Analysis of the Advanced Test Reactor Fresh Fuel Shipping Container with Heavier Low-Enriched Uranium Fuel Contents

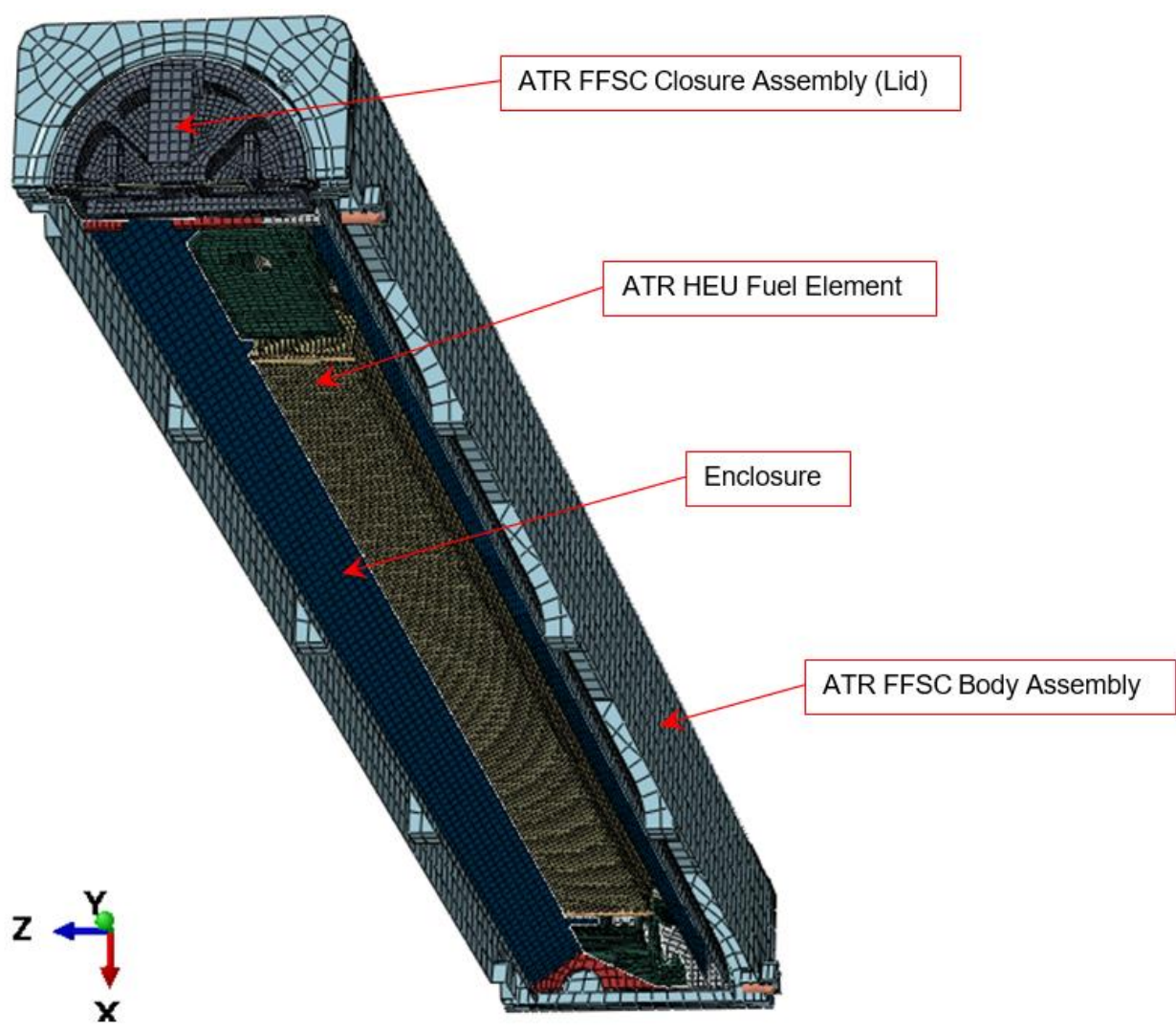

Figure B-11. Cut-away of the ATR FFSC mesh.

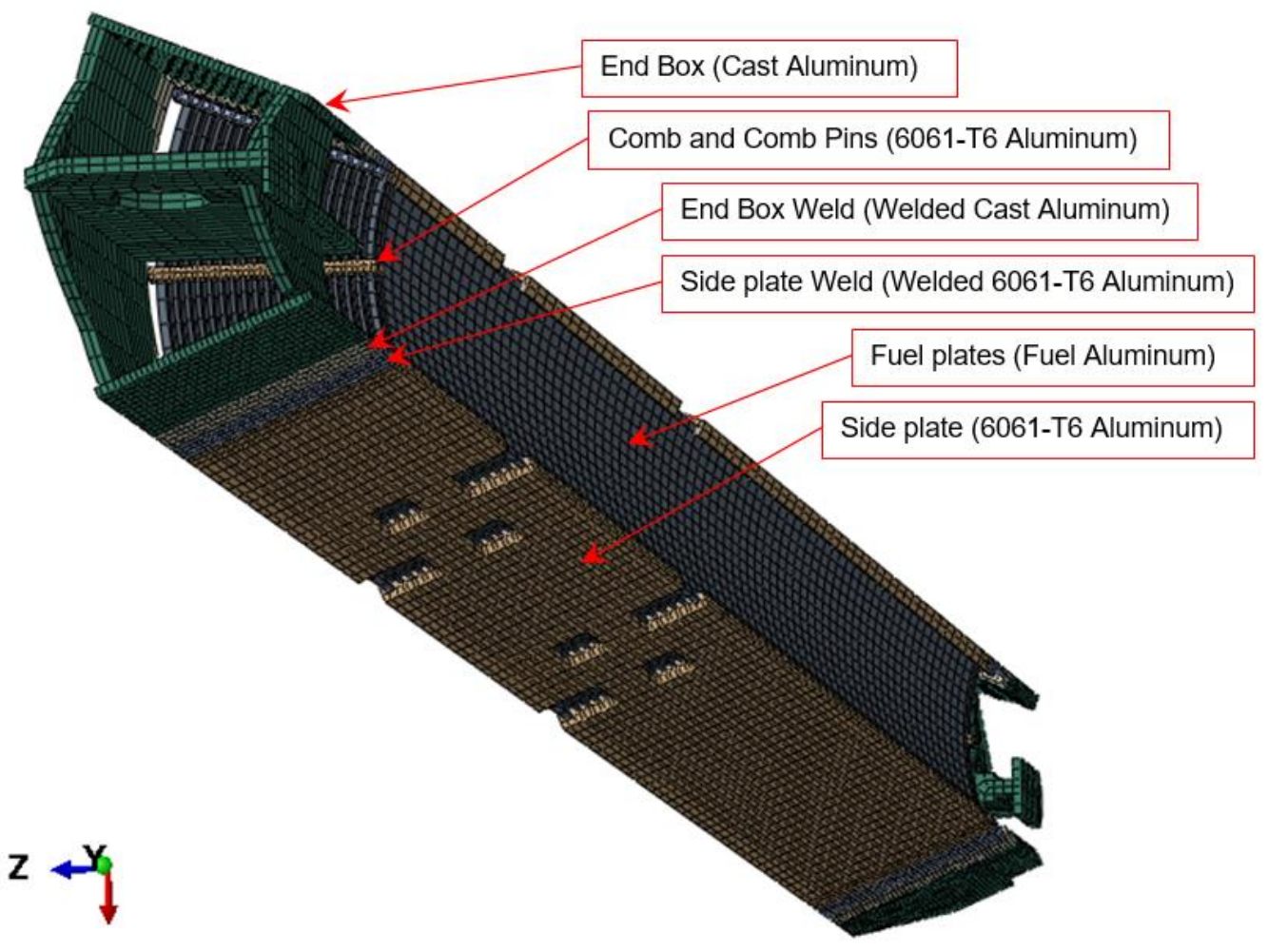

Figure B-12. Fuel-element mesh. 
The fuel-element mesh is continuously meshed through the end boxes, end-box welds, side-plate welds, and side plates. The fuel plates are swaged into the side plates (as defined in Section B2.2). The combs are in contact with the fuel plates, and the comb pins provide continuous attachment between the combs and fuel plates (as shown in Figure B-13 and Figure B-14).

When defining element material properties for all aluminum items, welded properties were assigned to elements within approximately an inch of a weld location.

Side plate, side plate heat affected zone, swage beams, and portion of fuel plates described in Section B2.2 are meshed the same here.

The comb pins share nodes with the comb and, to help produce an efficient mesh, additional beams are used to attach and share nodes with a single layer of fuel plate nodes (as shown in Figure B 14).
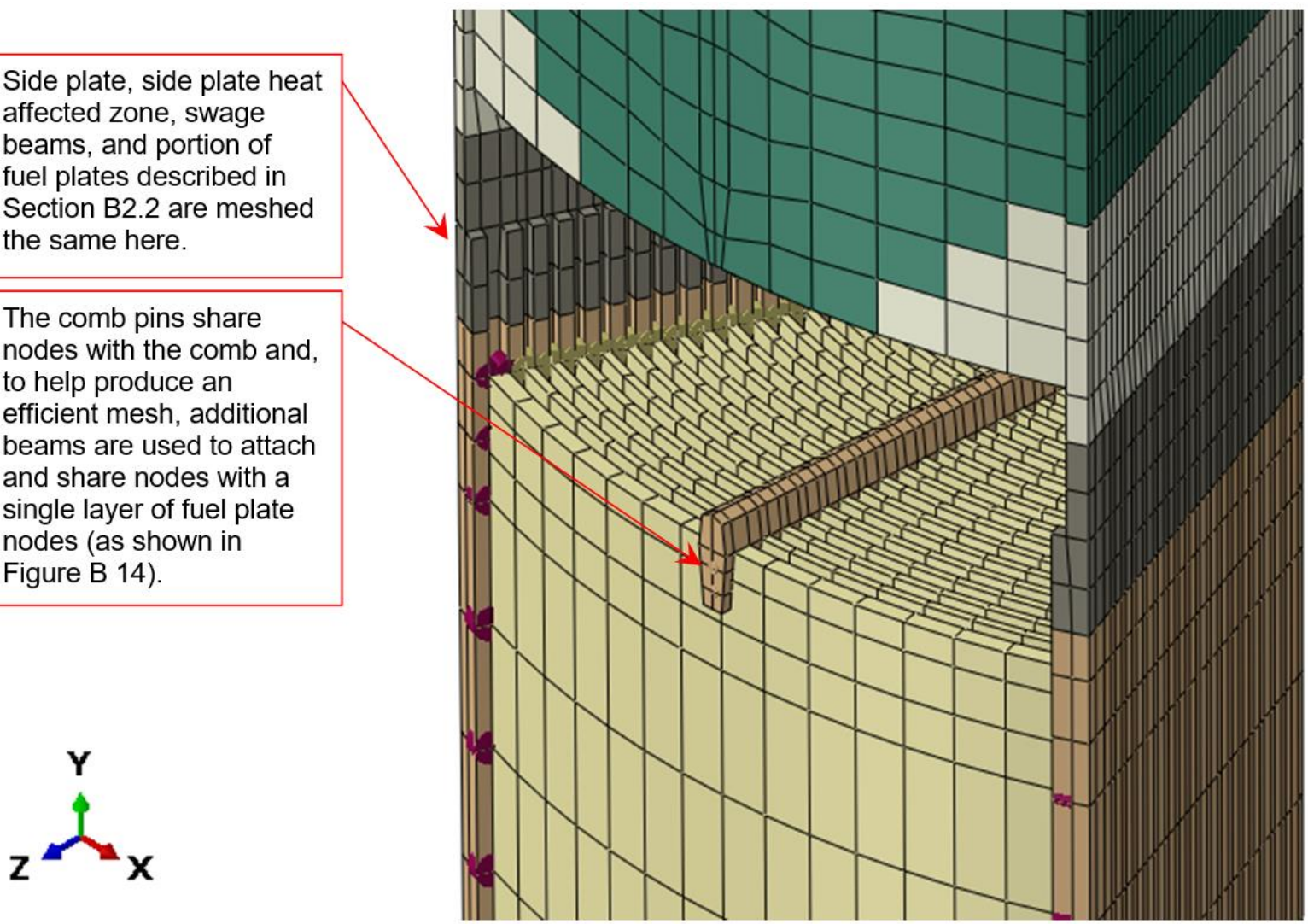

Figure B-13. Zoomed view of the fuel element. 


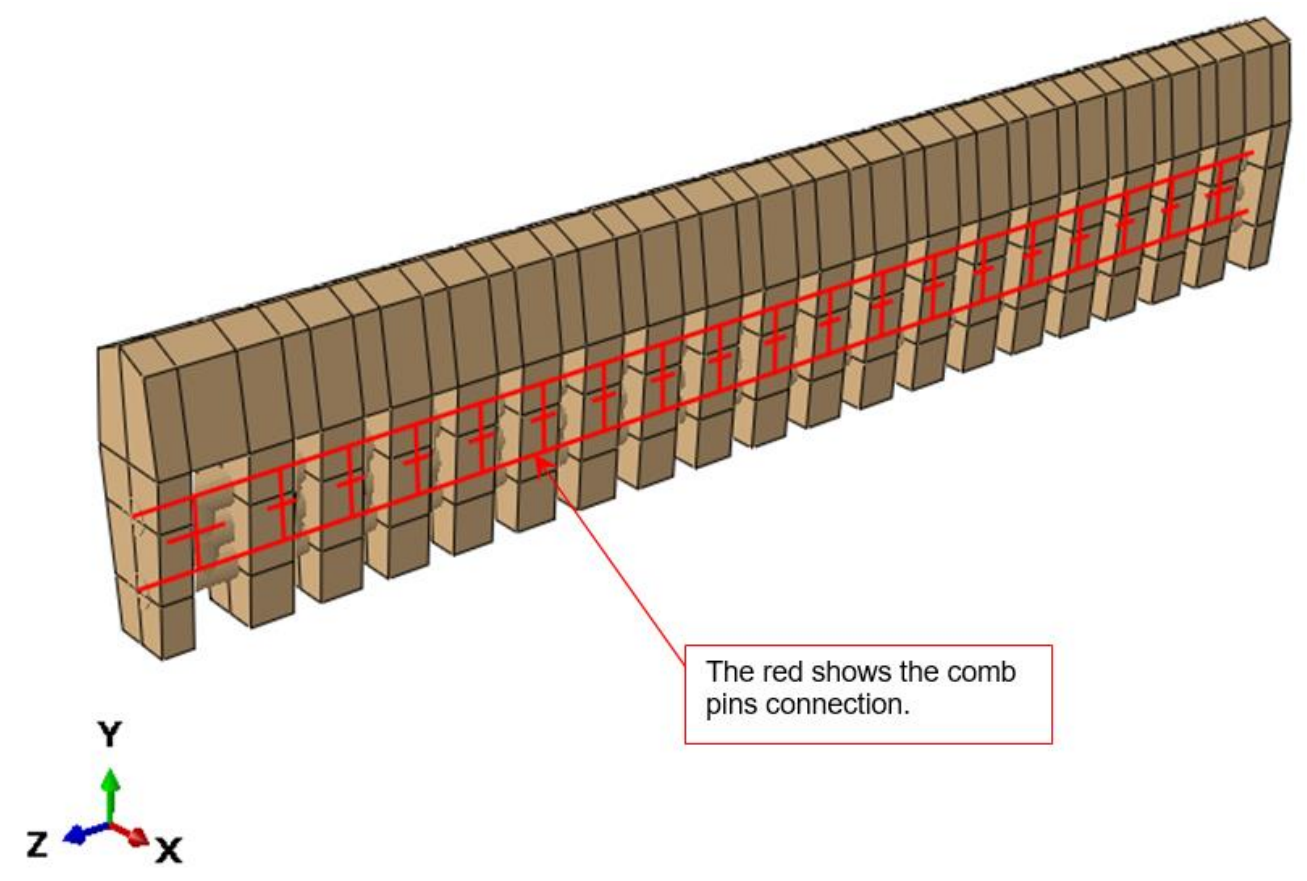

Figure B-14. Comb and comb pins mesh.

(Figure B-15 shows two elements that were erroneously defined with welded material properties. Many of the model runs were performed with these two elements having welded material properties. This, in general, is not considered a significant problem. However, all Table 2, Test 8 and 12 models were rerun with corrected material properties to dispel any doubt.) 


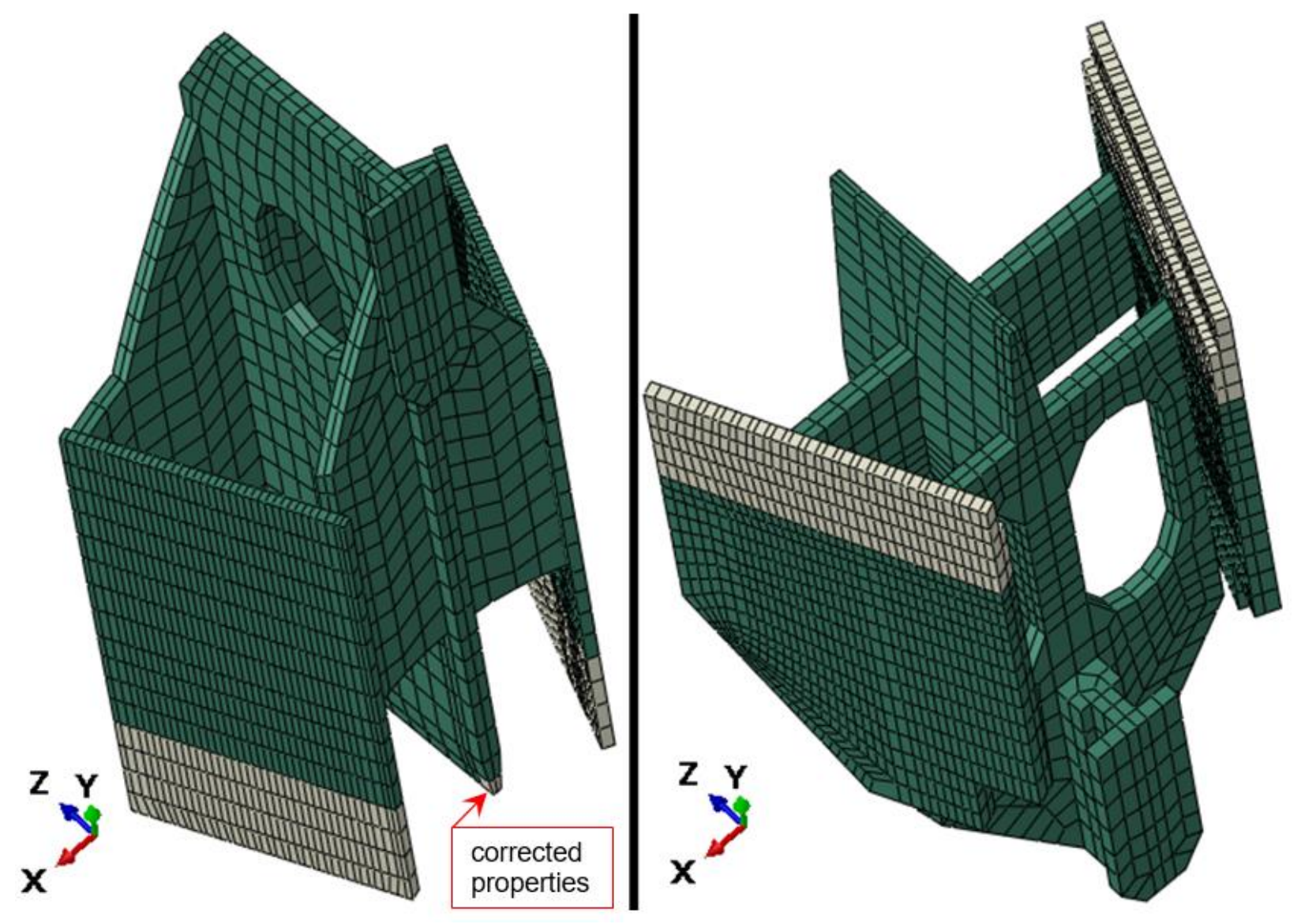

Figure B-15. Top and bottom end boxes. 


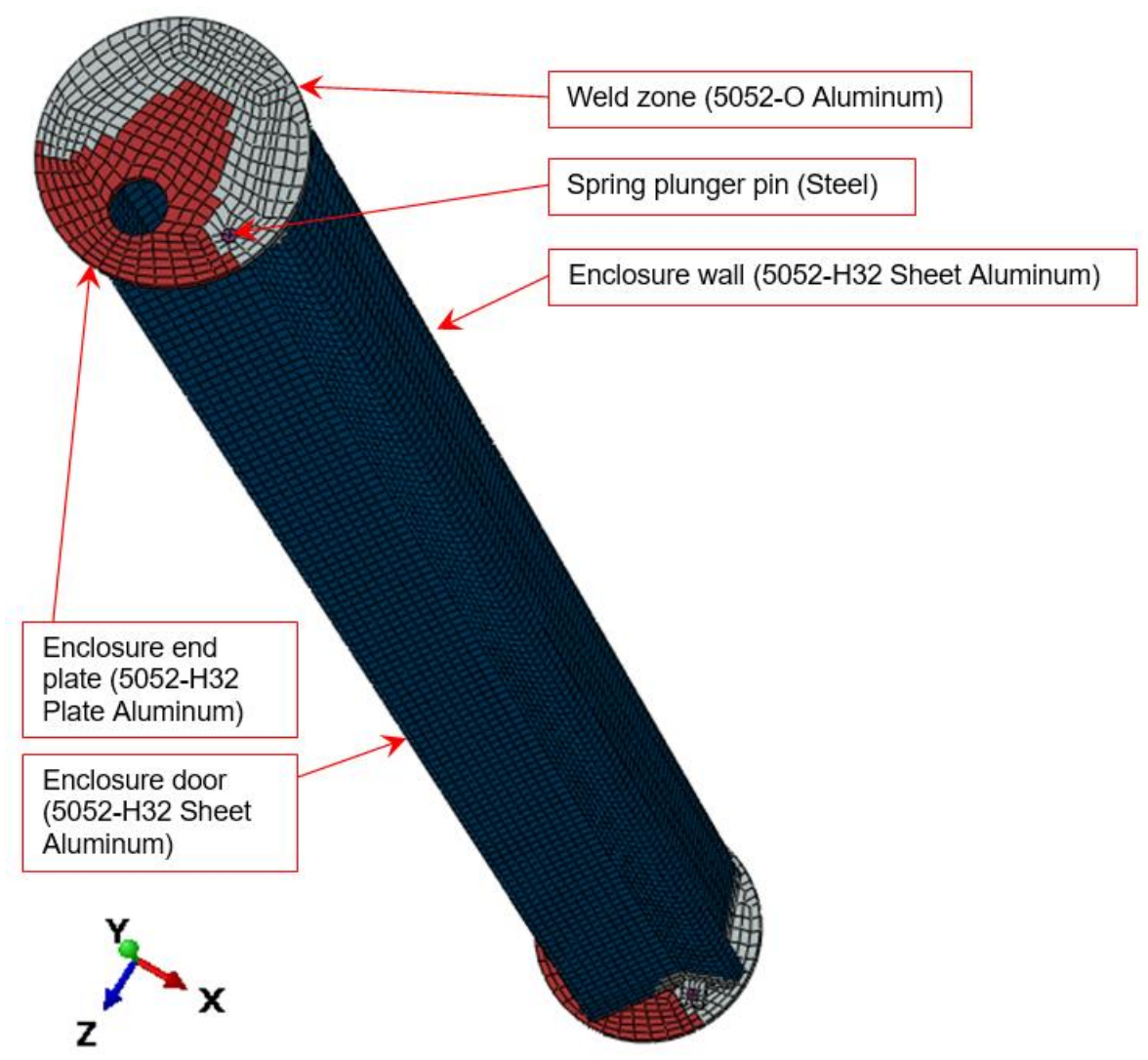

Figure B-16. Enclosure mesh.

The enclosure is mostly made up of shell elements. In general (for all components in the loaded ATR FFSC), the shell meshes are modeled on the center plane of the plate or sheet thickness, and contact is considered based on the thickness of the shell. Also, for all components in the loaded ATR FFSC, continuous attachment between shell and solid elements is achieved by extending the shells one layer into (or next to) the solid-element mesh, thereby producing moment-bearing attachment.

Figure B-17 shows the enclosure end with the end plate removed. In meshing the enclosure, the spring plunger pin is continuously attached to the enclosure door. The spring-plunger pin fits through a hole in the enclosure end plate (see Figure B-16) and is in contact with it. The enclosure door hinge is meshed with brick elements. These brick elements are continuously attached to the door-shell elements (that extend across the back of the brick elements in the figure). Then the nodes in one edge are shared with the enclosure wall-shell elements. Because the nodes in the brick elements only have the three translational degrees of freedom, this attachment behaves as a hinge. The mesh at the opposing end of the enclosure is a mirror image to that shown in Figure B-17. 


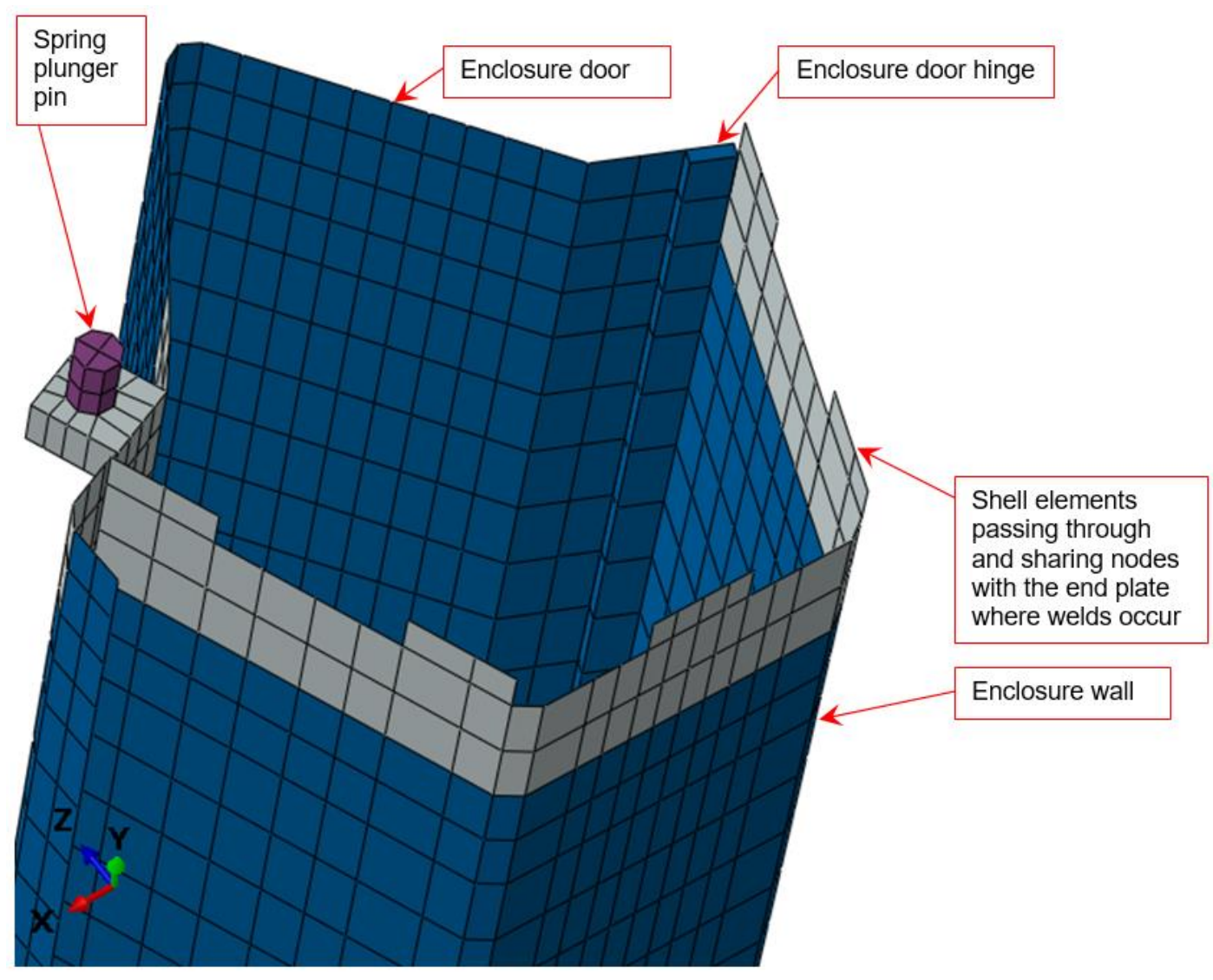

Figure B-17. Enclosure end with the end plate removed.

The ATR FFSC body assembly (see Figure B-18) is entirely 304 stainless steel, except for the two screws that hold the index lugs in place. These screws are ASTM F835 (2018), 3/8-16UNC screws.

The ATR FFSC body assembly is modeled as a continuous mesh throughout. The outer wall is continuously attached to the top on bottom plates. The ribs are continuously attached to the inner pipe but not the outer wall. 


\section{ENGINEERING CALCULATIONS AND ANALYSIS}

Drop Analysis of the Advanced Test Reactor Fresh Fuel Shipping Container

with Heavier Low-Enriched Uranium Fuel Contents

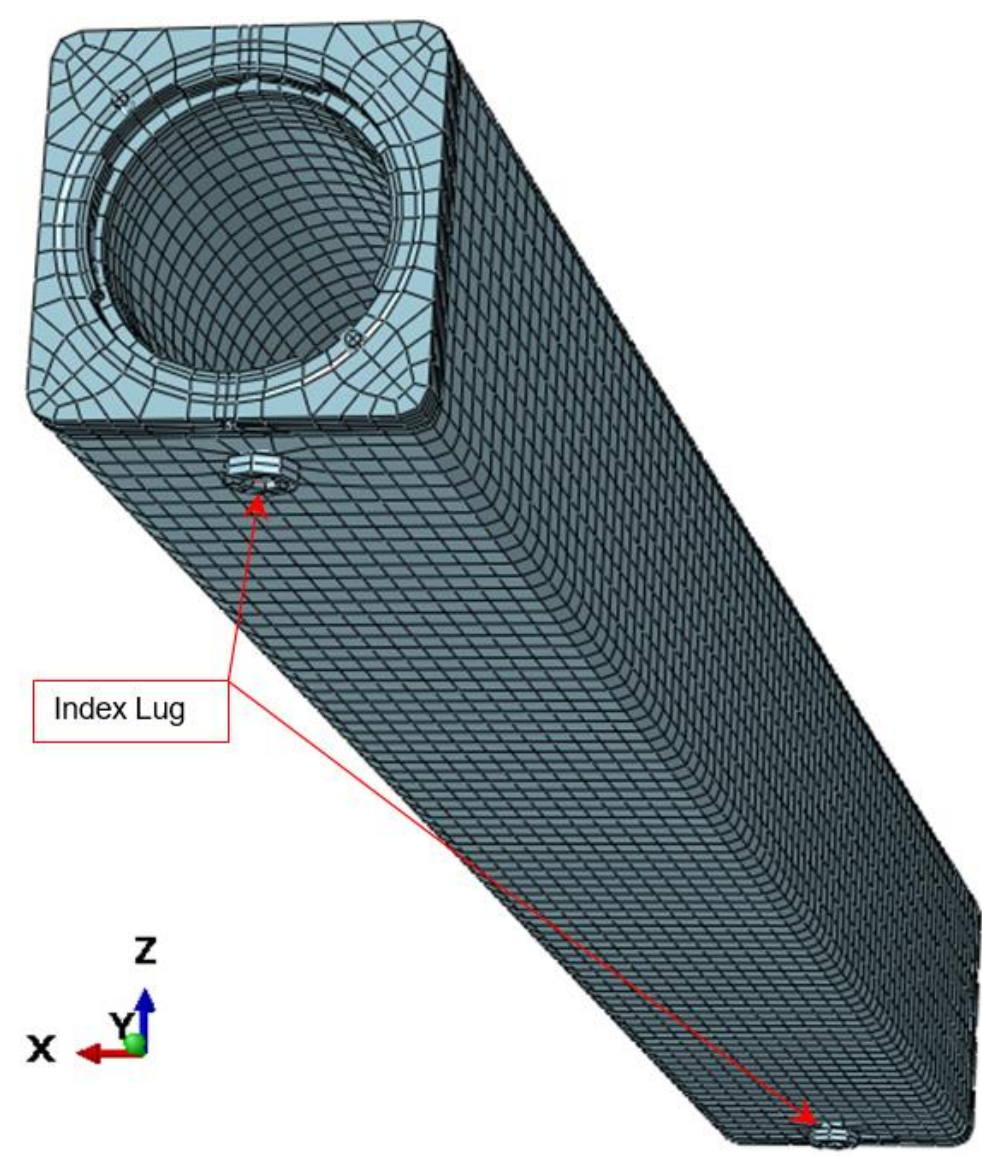

ECAR-5224, Rev. 0

Page B45 of B100

Figure B-18. ATR FFSC body assembly. 
Drop Analysis of the Advanced Test Reactor Fresh Fuel Shipping Container with Heavier Low-Enriched Uranium Fuel Contents

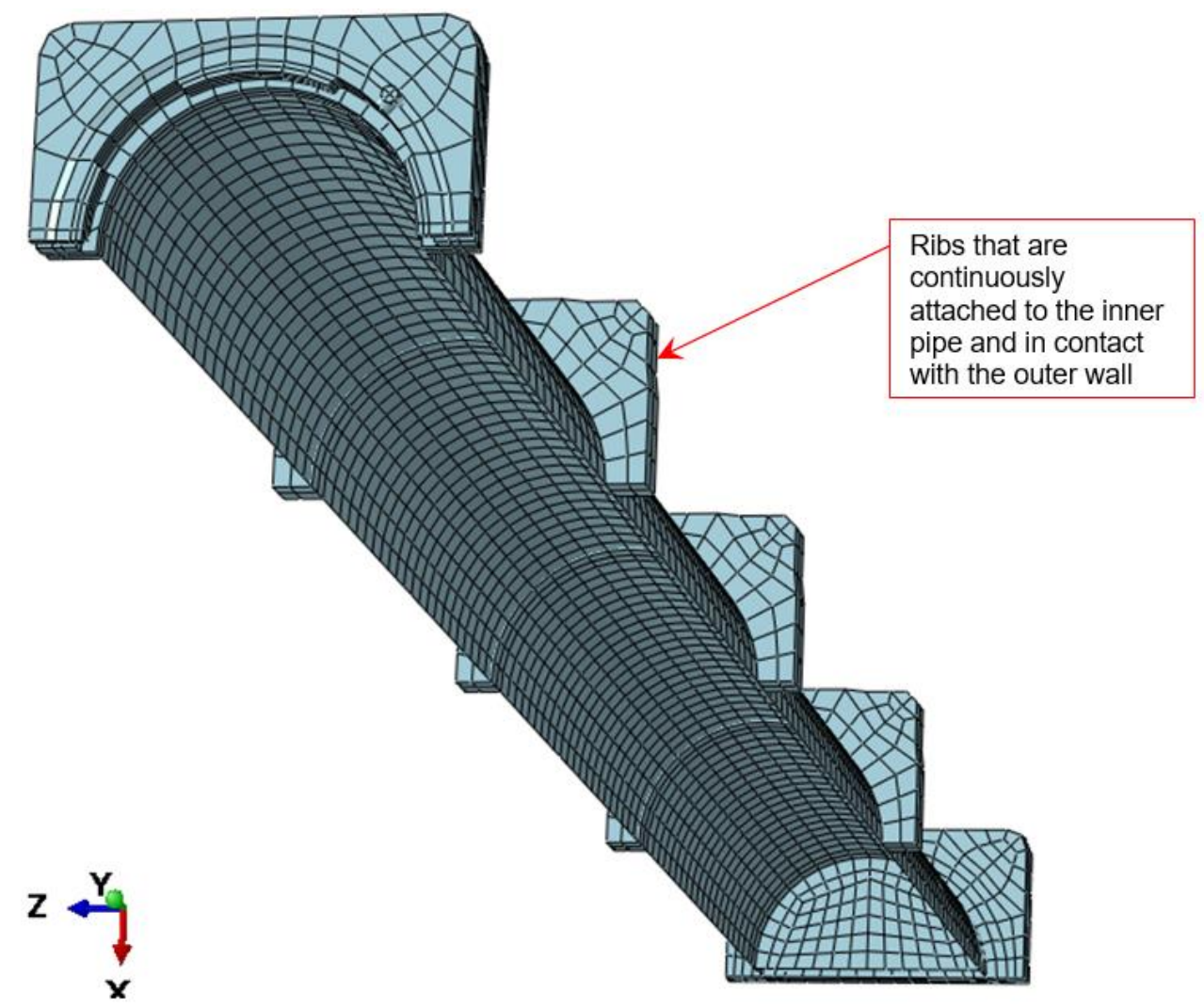

Figure B-19. Cut-away of the ATR FFSC body assembly with the outer wall removed.

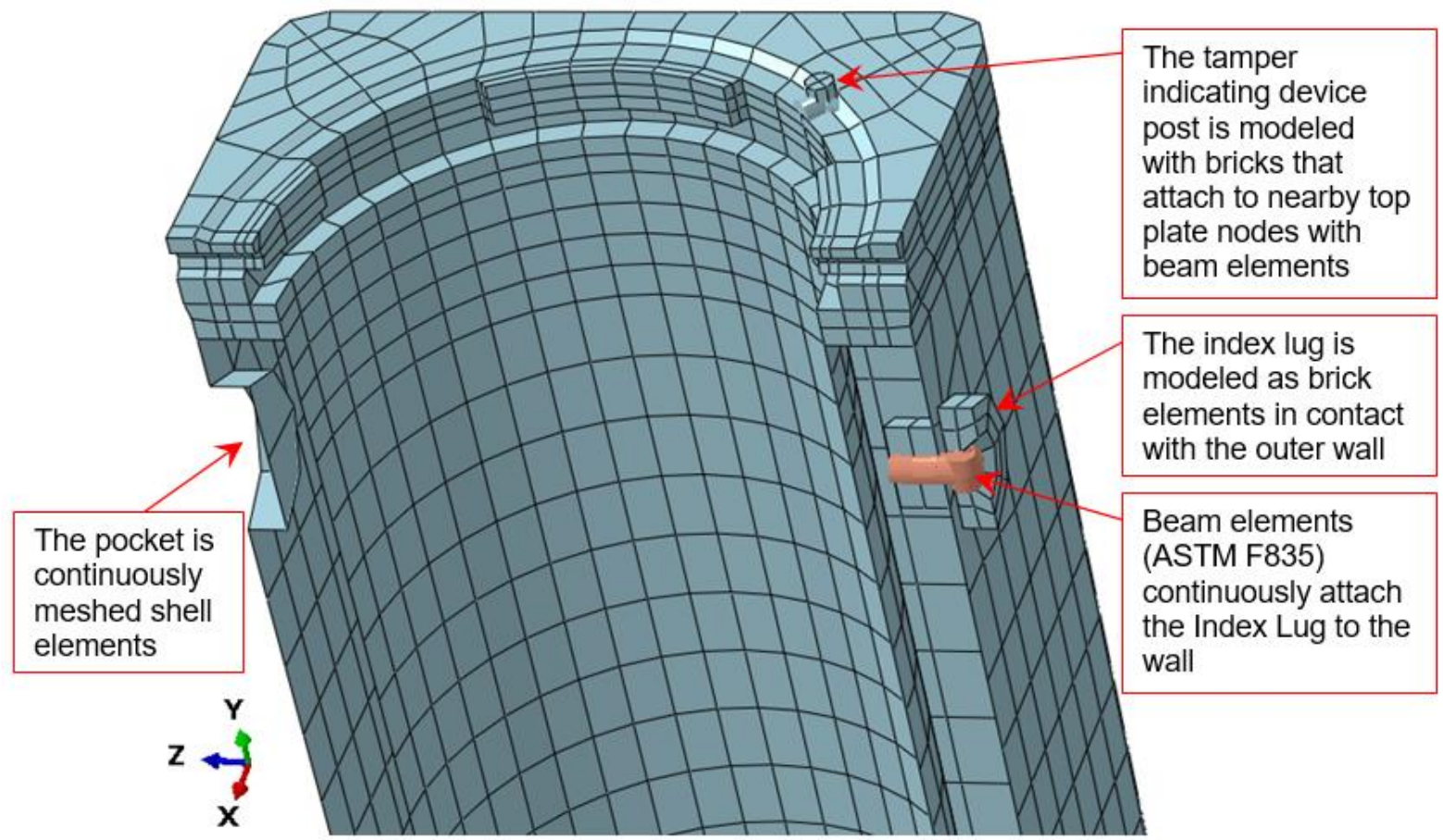

Figure B-20. Cut-away of the ATR FFSC body assembly top. 
Drop Analysis of the Advanced Test Reactor Fresh Fuel Shipping Container with Heavier Low-Enriched Uranium Fuel Contents

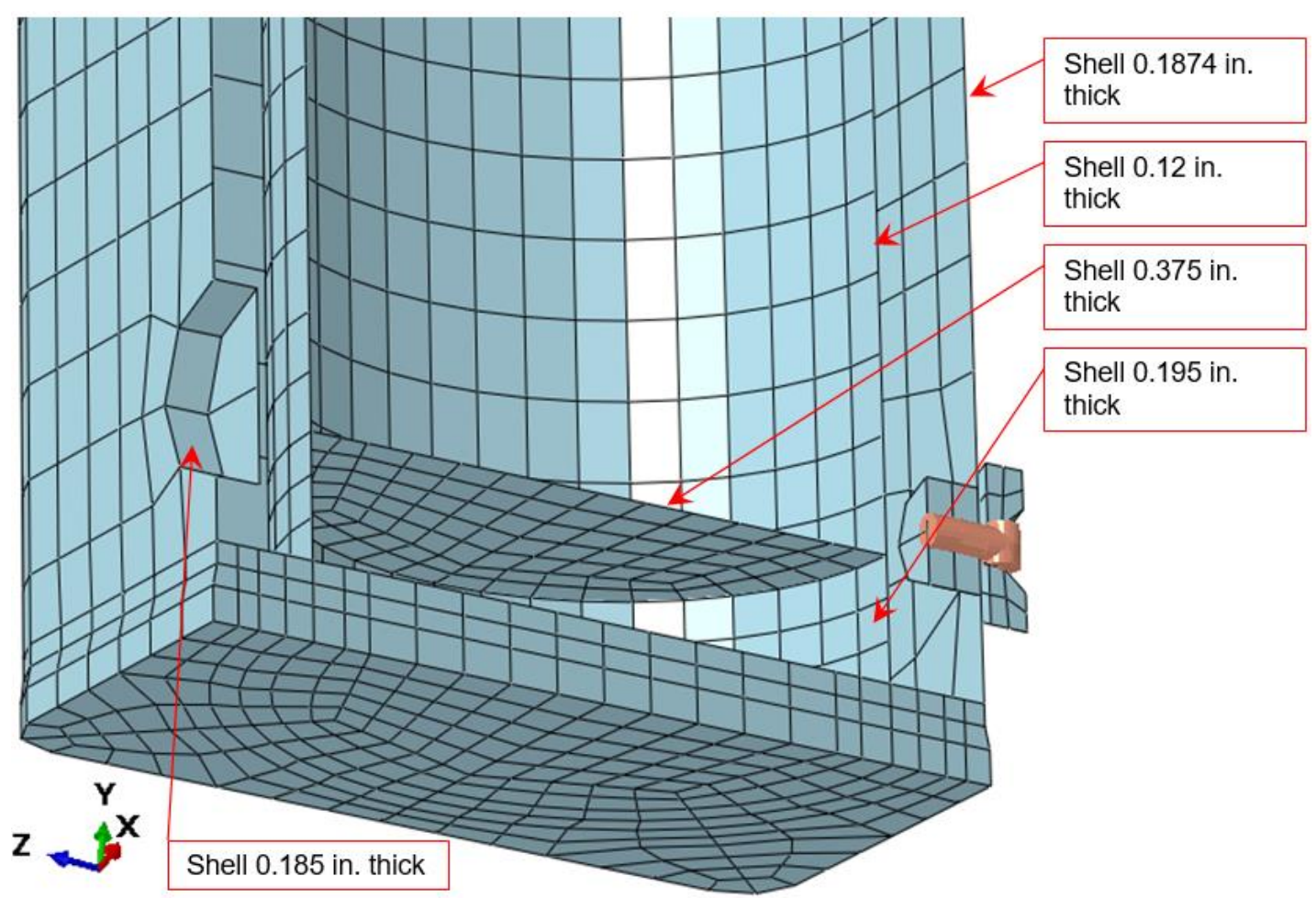

Figure B-21. Cut-away of the ATR FFSC body assembly bottom.

Figure B-22 shows how the lid interacts with the ATR FFSC body assembly. This shows that the bayonets are of primary importance for maintaining lid attachment. The lid pins are also important as lid-pin failure could allow the lid to rotate and disengage without loading the bayonets. 


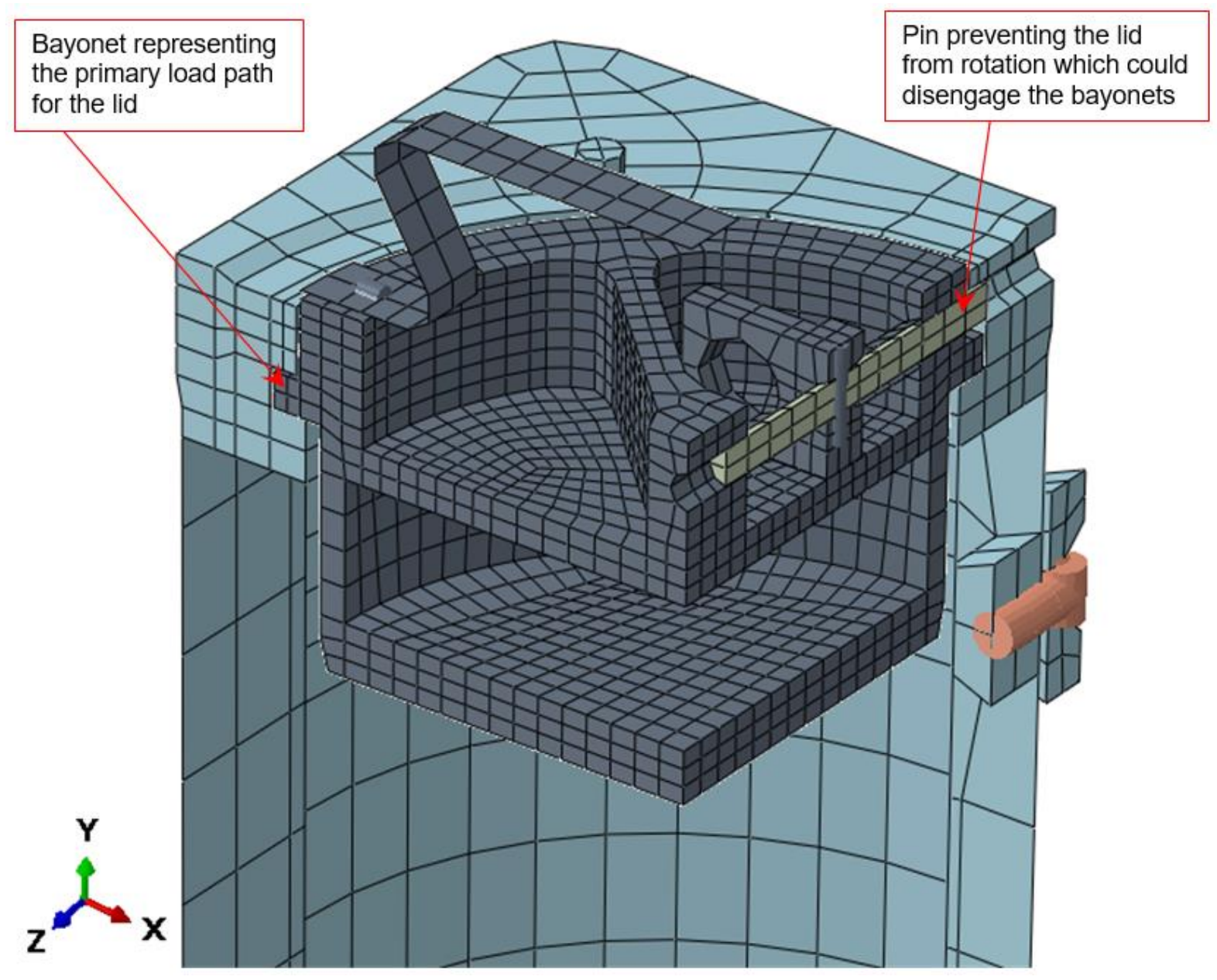

Figure B-22. Cut-away of the ATR FFSC body assembly and lid.

Figure B-23 shows the full lid mesh. The closure handle is in contact with the body of the lid and is also continuously connected to the lid body through the closure-handle screws. Considering Figure B-24, the lid pin and lid-pin handle are in contact and are also continuously connected through the roll pin. The lid pin and lid-pin handle are in contact with the lid body. The pin associated with the tamper-indicating device is continuously meshed with the lid body.

The lid is entirely 304 stainless steel except for the two Nitronic 60 pins (which prevent lid rotation).

Figure B-30 shows a fine-meshed version of the lid pin that is used to show conservative damage for all of the model runs with the $115 \mathrm{lbf}$ fuel-element weight. Its connection to the roll pin and interaction with the pin handle and lid are the same as that for the pin mesh shown in Figure B-23 and Figure B-24. 
Drop Analysis of the Advanced Test Reactor Fresh Fuel Shipping Container with Heavier Low-Enriched Uranium Fuel Contents

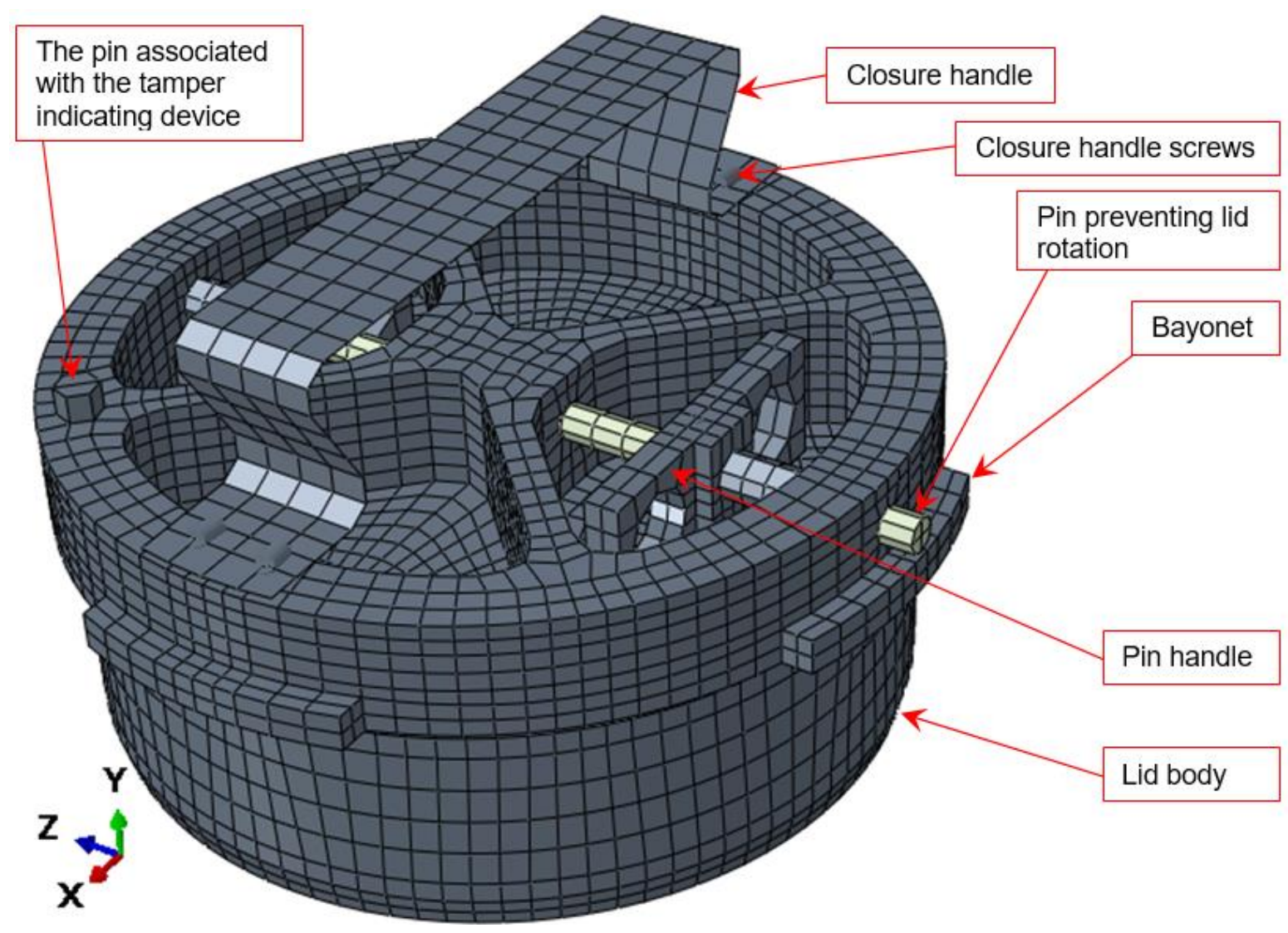

Figure B-23. Lid mesh. 


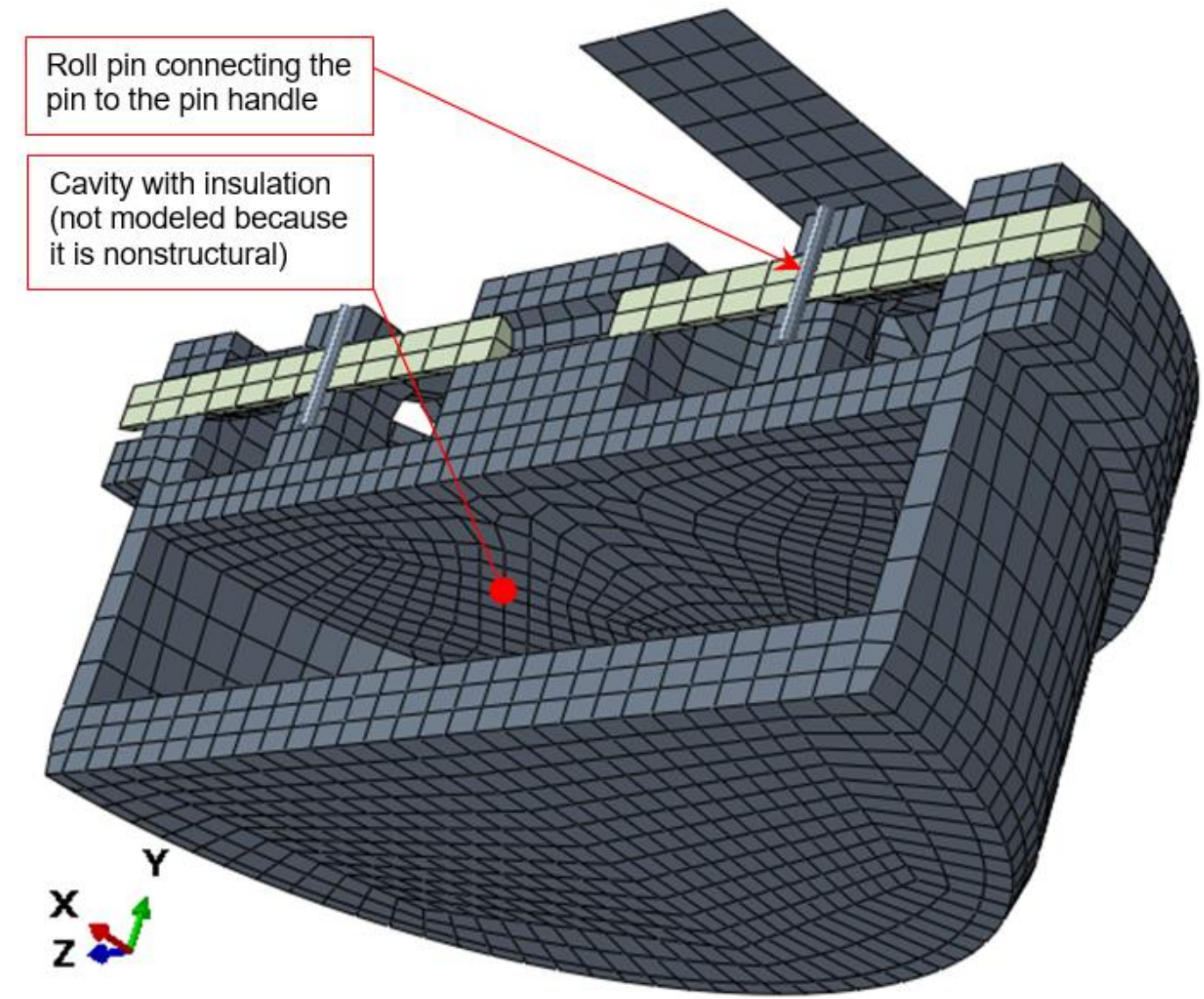

Figure B-24. Cut-away of the lid mesh.

Per the ATR FFSC SAR (2017), Section 2.6.10, the puncture-bar drops are based on the "puncture bar described in $\S 71.73(\mathrm{c})(3)$." Per the ATR FFSC SAR (2017), Section 2.12.1.2.2, the puncture bar that they used measured 6 in. in diameter and was 36 in. above the drop pad. The puncture bar (see Figure B-25) is meshed 6 in. high with a 6 in. diameter, and it has material properties of elastic steel. The short height and elastic material properties cause modeled puncture bar to be conservatively stiff relative to the actual puncture bar. However, the actual puncture bar is very stiff relative to the ATR FFSC package making this conservatism less significant.

The block (Figure B-26) is solid 6061-T6 aluminum and is added for fuel-plate protection. The block design is sized so that the same block fits in both top- and bottom-end boxes (as shown in Figure B-27). Also, with symmetric (top and bottom) comb slots, there is no up or down, which simplifies block insertion. 
ENGINEERING CALCULATIONS AND ANALYSIS

Drop Analysis of the Advanced Test Reactor Fresh Fuel Shipping Container with Heavier Low-Enriched Uranium Fuel Contents

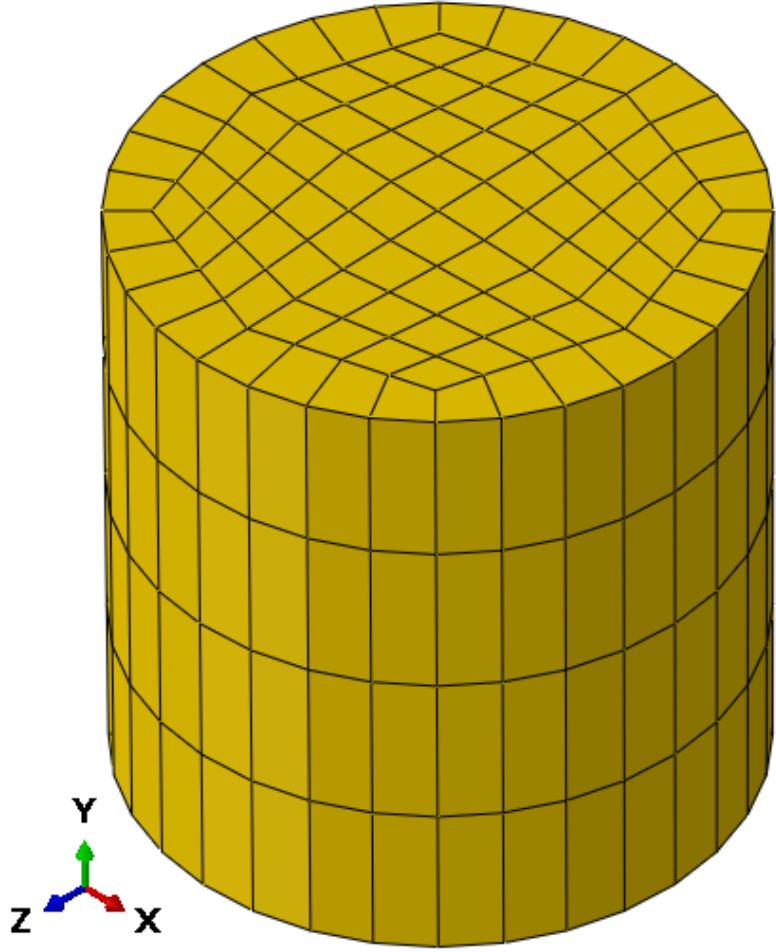

Figure B-25. Puncture bar mesh.

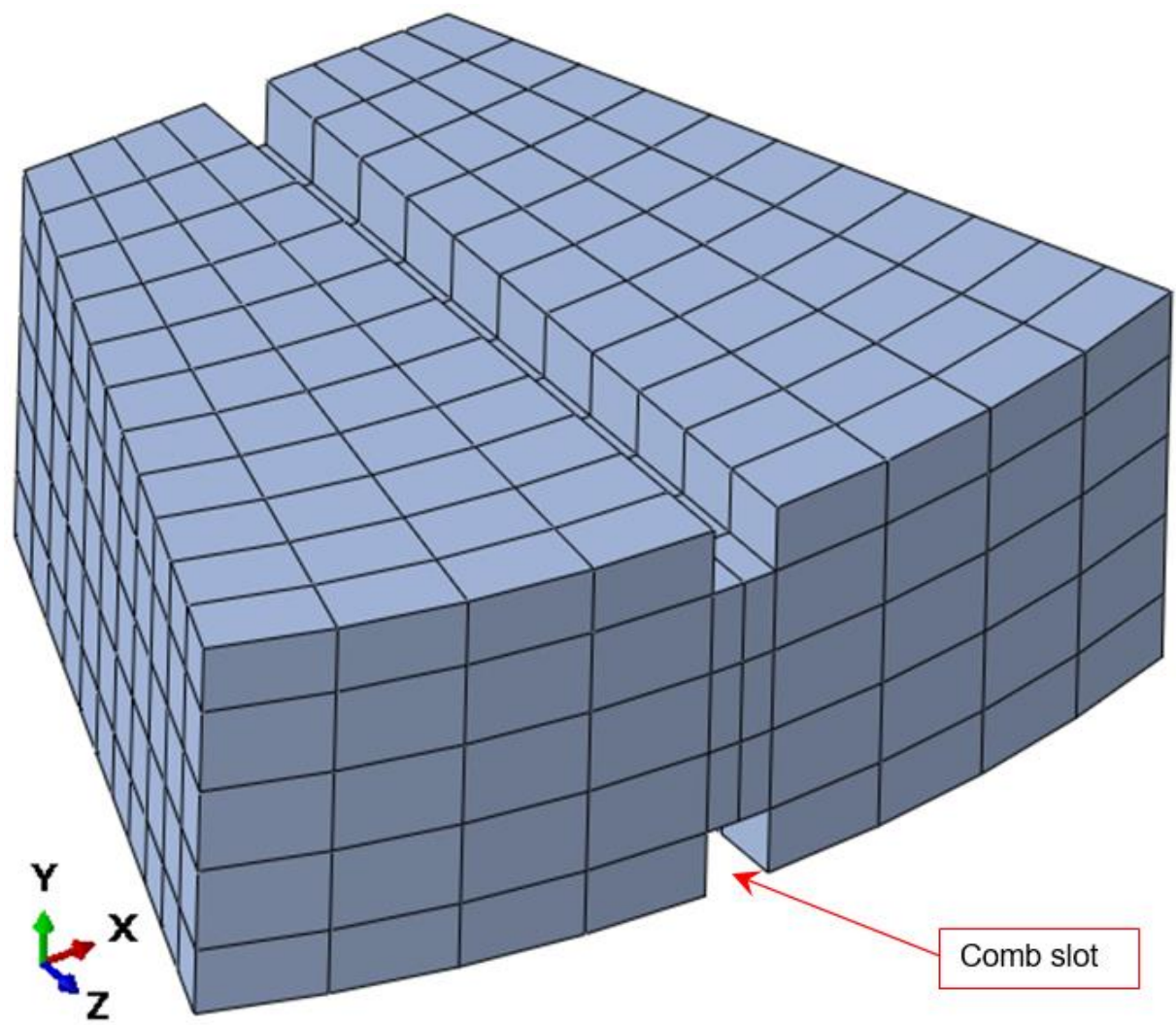

Figure B-26. Block mesh. 


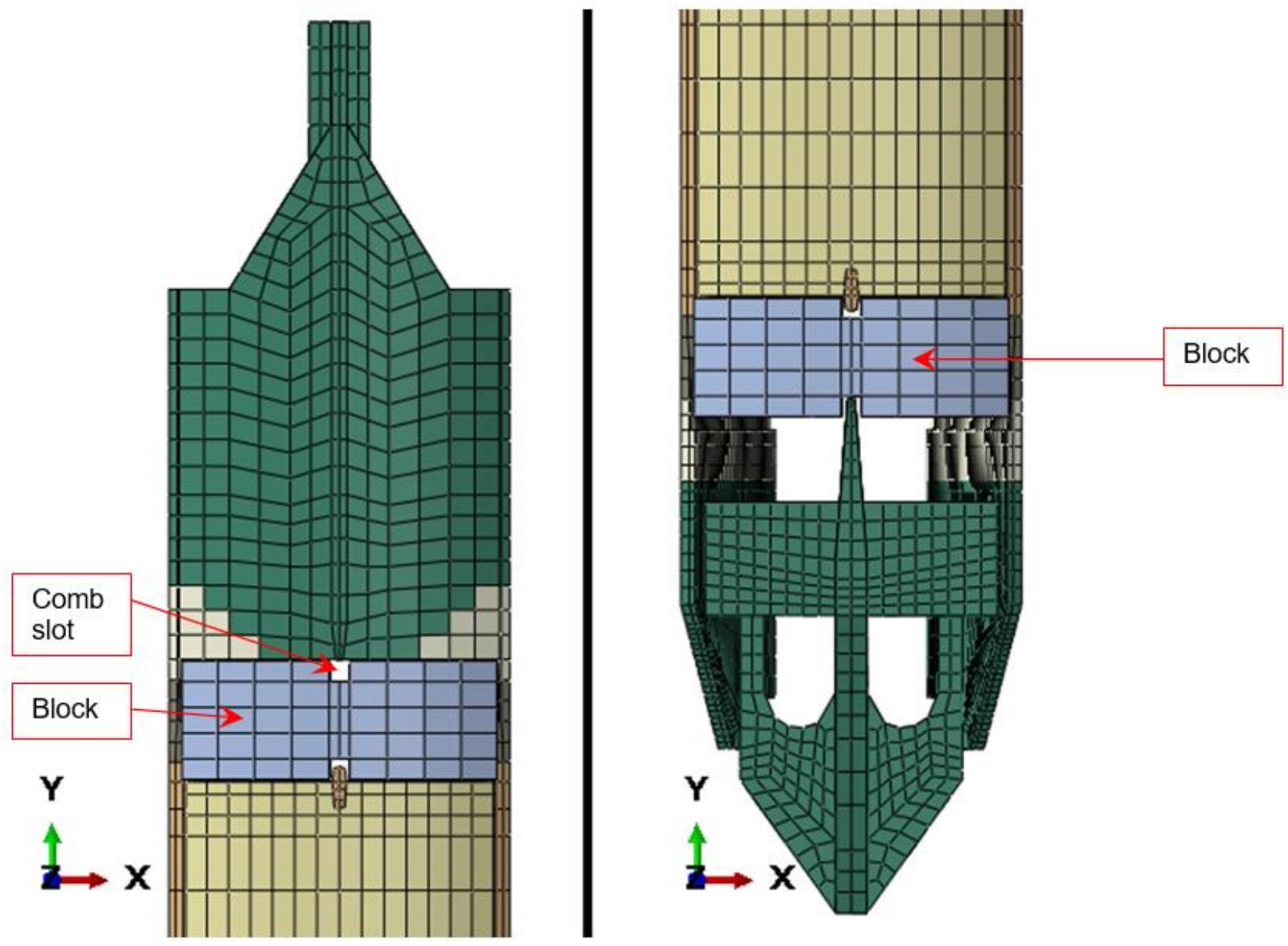

Figure B-27. Top and bottom regions of the fuel element with protective blocks inserted.

Figure B-28 shows a fine-meshed version of the fuel-plate ends and comb-pins connection. This is generated for additional study of vertical (and near-vertical) impacts from $30 \mathrm{ft}$ This version of the mesh is added to help ensure that a conservative amount of fuel-plate damage occurs in the simulation. 

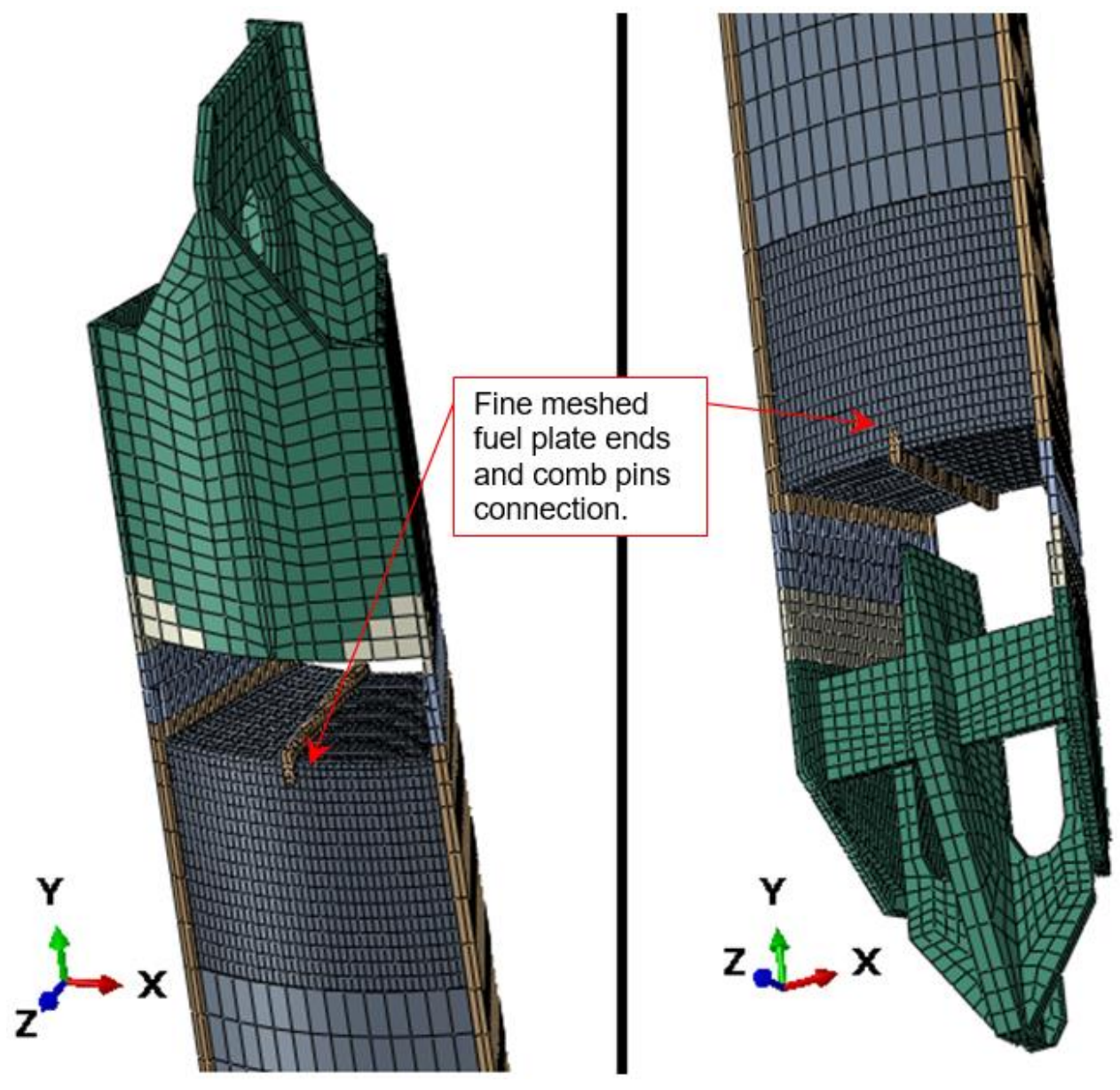

Figure B-28. Top and bottom regions of the fuel element, showing a fine-meshed version.

Figure B-29 shows the fine-meshed region of the fuel plates and comb-pins connection. The comb-pin beam elements pass through all the comb nodes on their linear paths. In the comb-pin beam mesh, a node is added at the center of the gap between each pair of comb teeth. Additional comb-pin beam elements connect between these nodes and the adjacent fuel-plate element nodes. This makes the combs continuously connected to the fuel plates (and contact is also defined between the combs and fuel plates).

The fine-meshed portion of the fuel plates is made continuous with the rest of the fuel plate mesh using tied contact. The portion of the fuel plate mesh that is "pinched" during swage calibration (see Section B2.2) is left unchanged. 


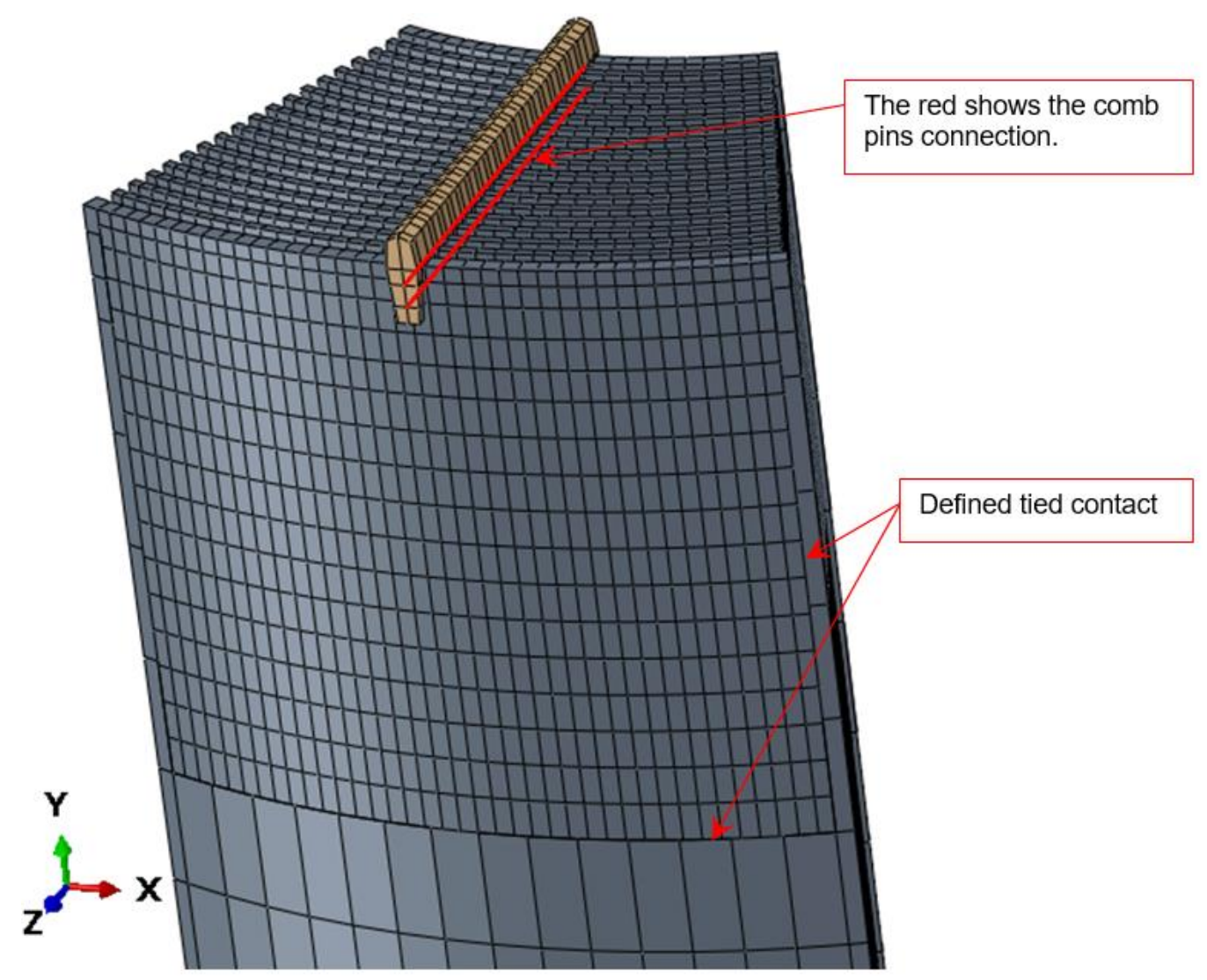

Figure B-29. Fine-meshed region of the fuel plates and comb-pins connection.

Figure B-30 shows the fine-meshed version of the lid pin. This version is used for all of the model runs with the $115 \mathrm{lbf}$ fuel-element weight. This provides the most conservative results for the models most damaging to the lid pins.

Figure B-31 to Figure B-41 shows the models where swaging is applied (so there is a significant gap before impact). The similar impacts without swaging look the same except that the loaded ATR FFSC is only $0.1 \mathrm{in}$. from the impacted surface. 

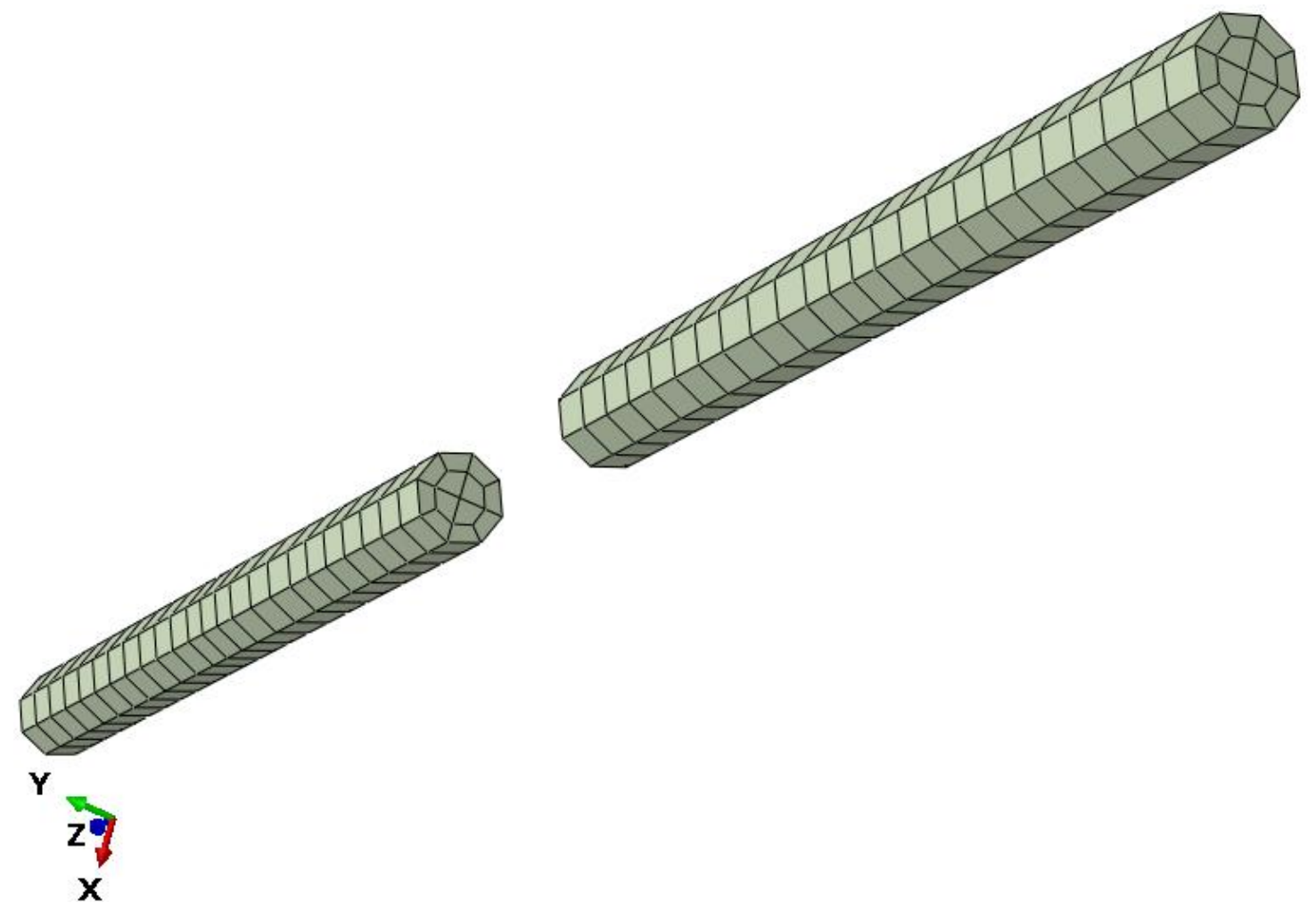

Figure B-30. Fine-meshed representation of the lid pin.

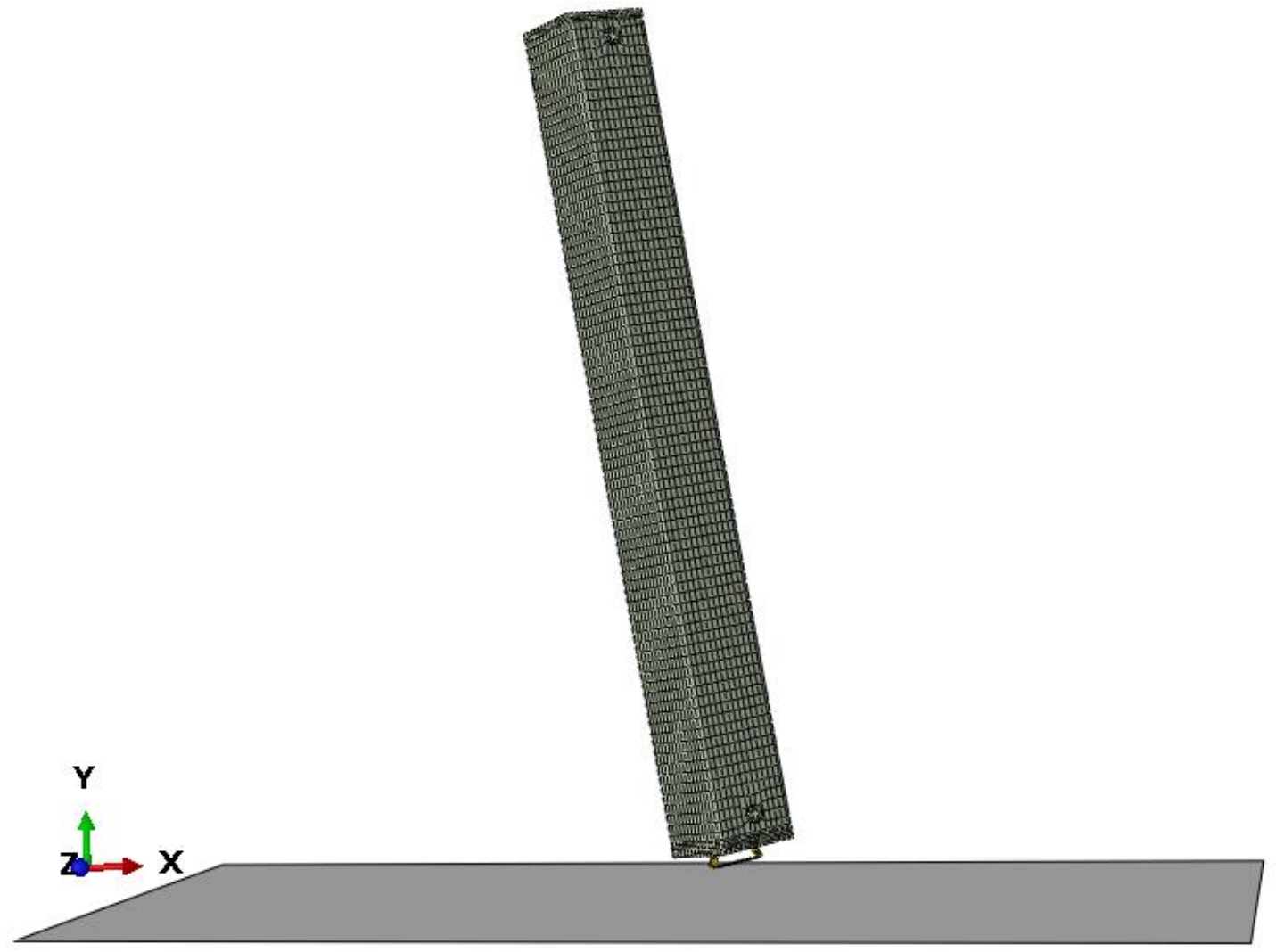

Figure B-31. Mesh for Test 1 (Table 2). 


\section{ENGINEERING CALCULATIONS AND ANALYSIS}

Drop Analysis of the Advanced Test Reactor Fresh Fuel Shipping Container with Heavier Low-Enriched Uranium Fuel Contents

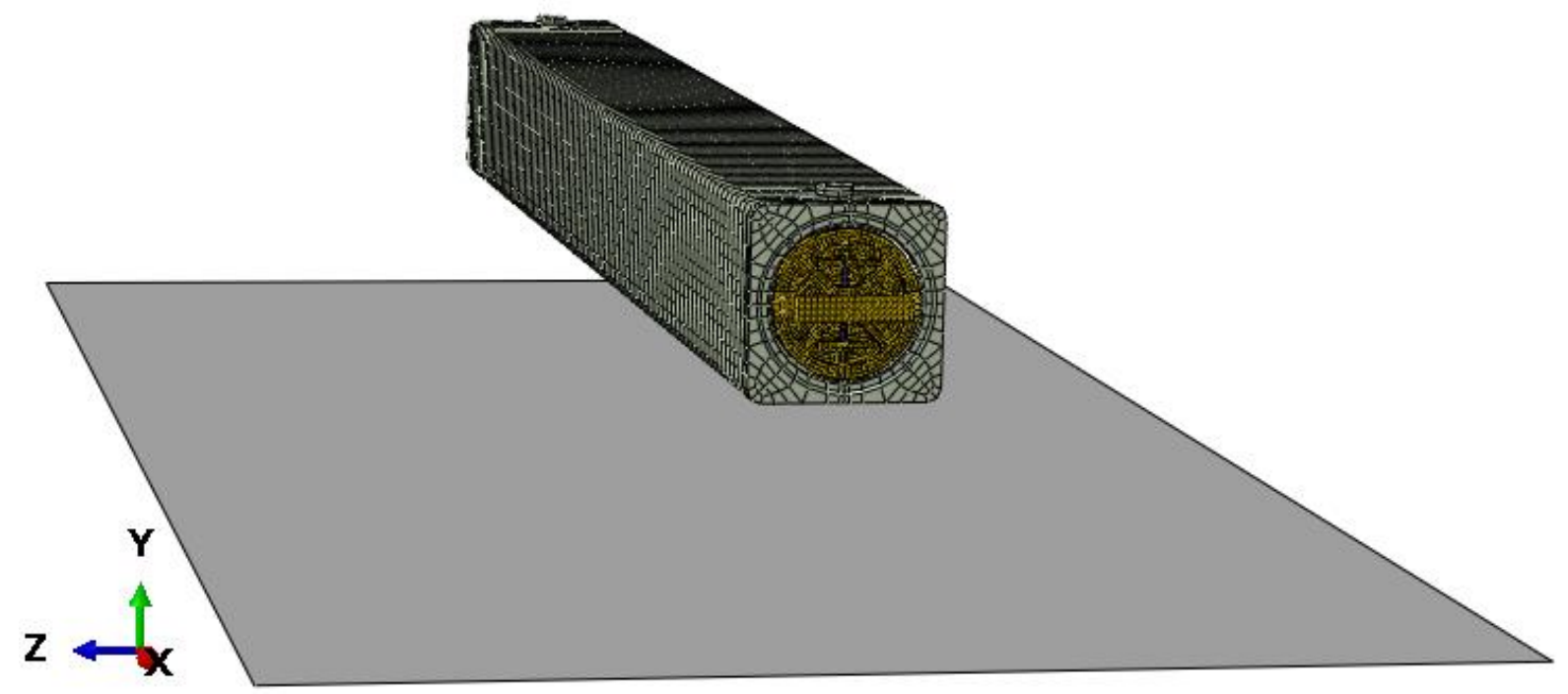

Figure B-32. Mesh for Test 2 (Table 2).

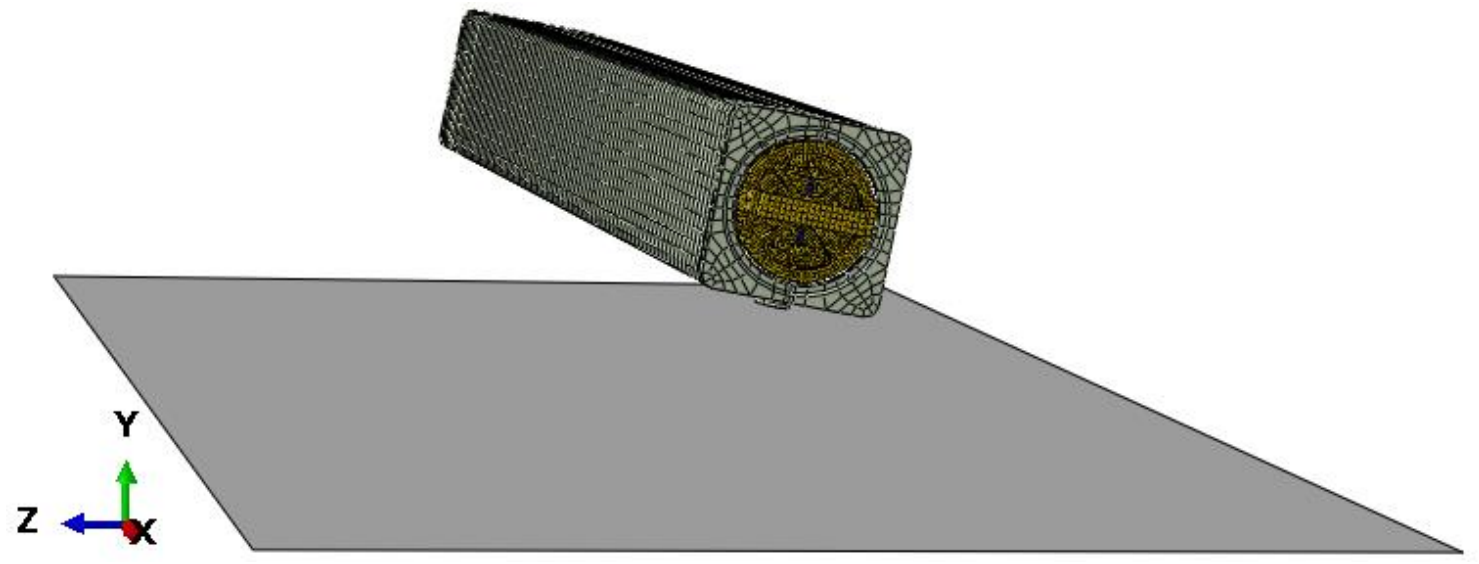

Figure B-33. Mesh for Test 3 (Table 2).

NOTE: $\quad$ As discussed in Table 2, Tests 4, 7, and 9 are not performed with an FEA model. 


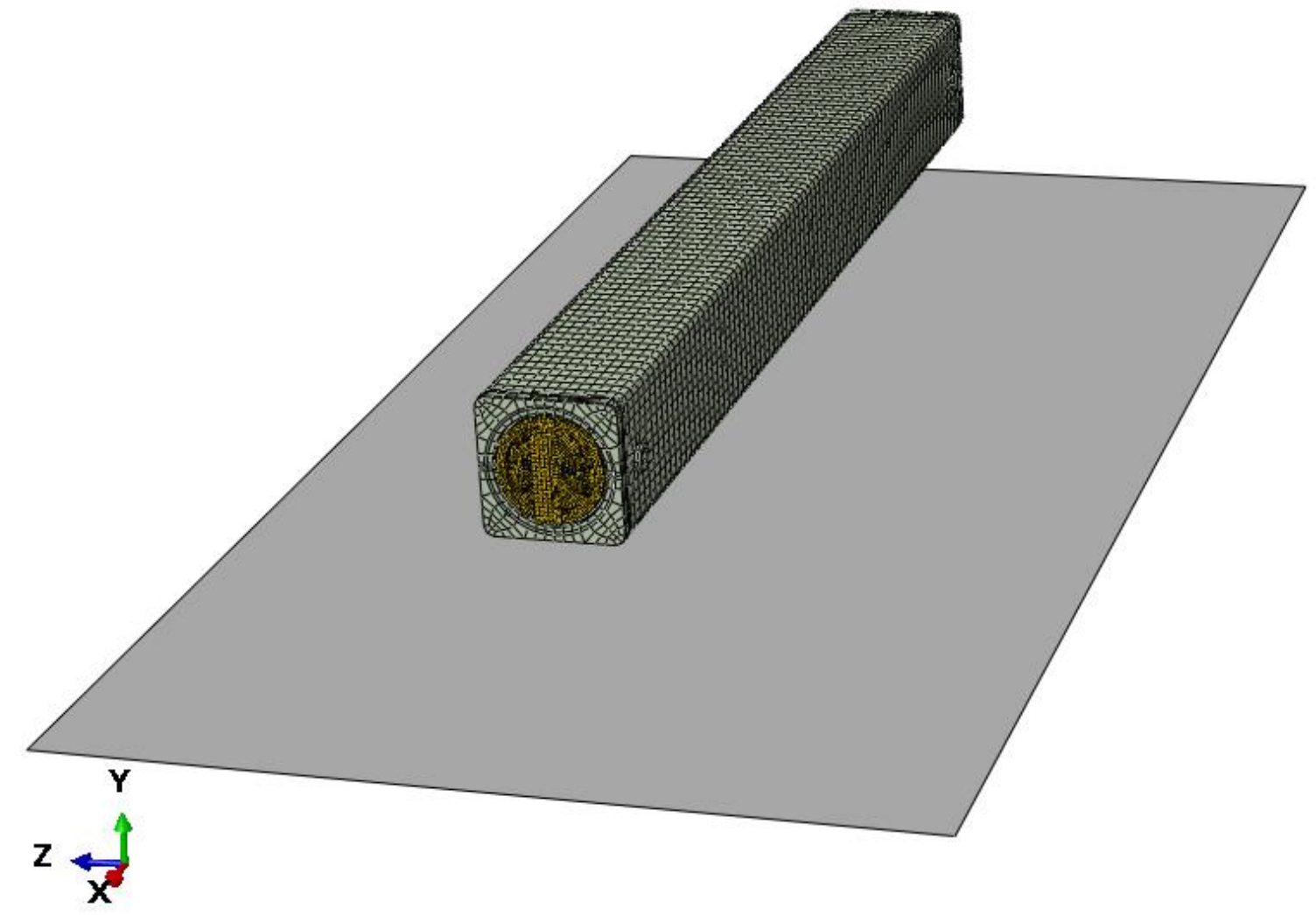

Figure B-34. Mesh for Test 5 (Table 2). 


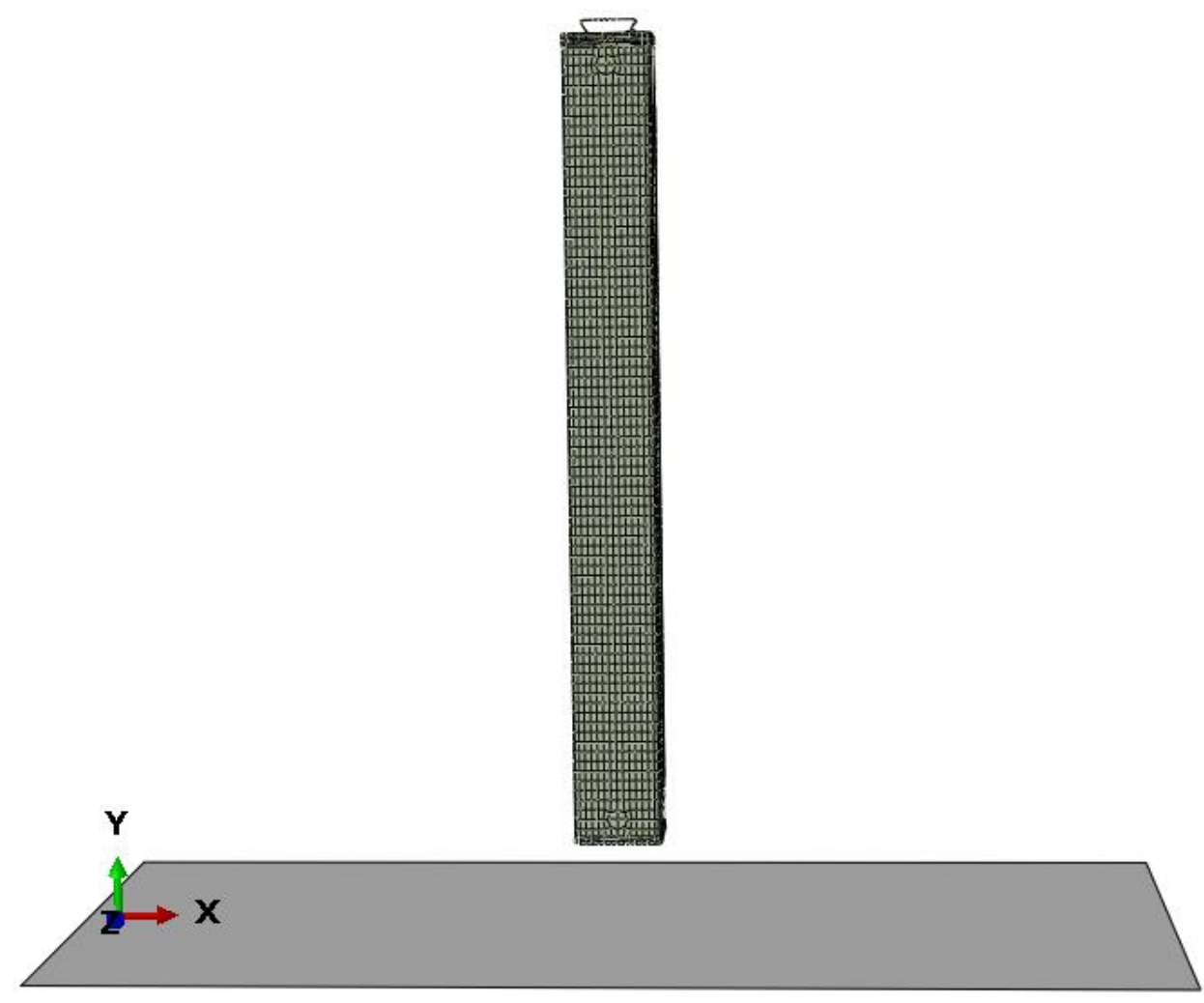

Figure B-35. Mesh for Test 6 (Table 2). 


\section{ENGINEERING CALCULATIONS AND ANALYSIS}

Drop Analysis of the Advanced Test Reactor Fresh Fuel Shipping Container with Heavier Low-Enriched Uranium Fuel Contents
ECAR-5224, Rev. 0

Page B59 of B100

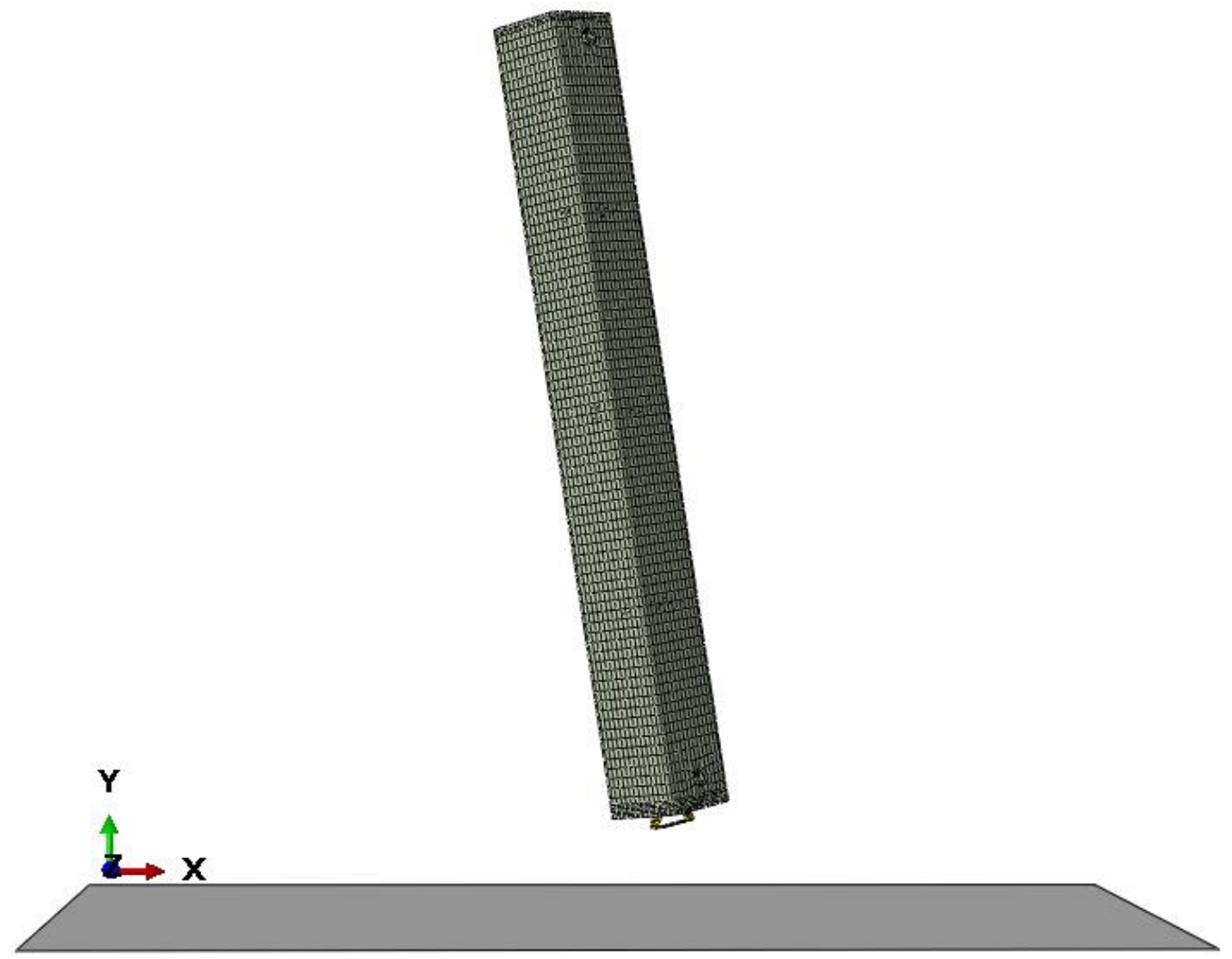

Figure B-36. Mesh for Test 8 (Table 2).

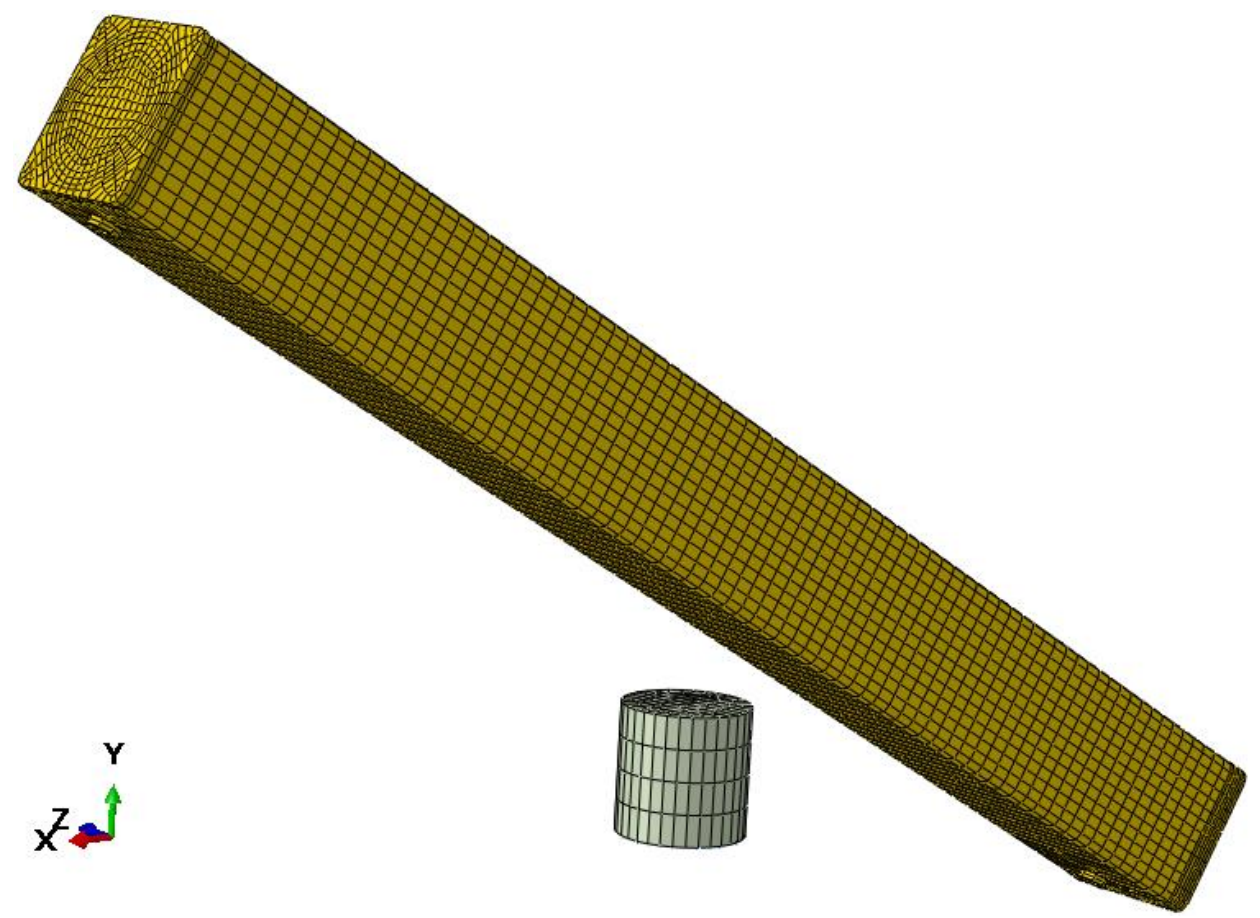

Figure B-37. Mesh for Test 10 (Table 2). 
ENGINEERING CALCULATIONS AND ANALYSIS

Drop Analysis of the Advanced Test Reactor Fresh Fuel Shipping Container with Heavier Low-Enriched Uranium Fuel Contents
ECAR-5224, Rev. 0

Page $\mathrm{B} 60$ of $\mathrm{B} 100$

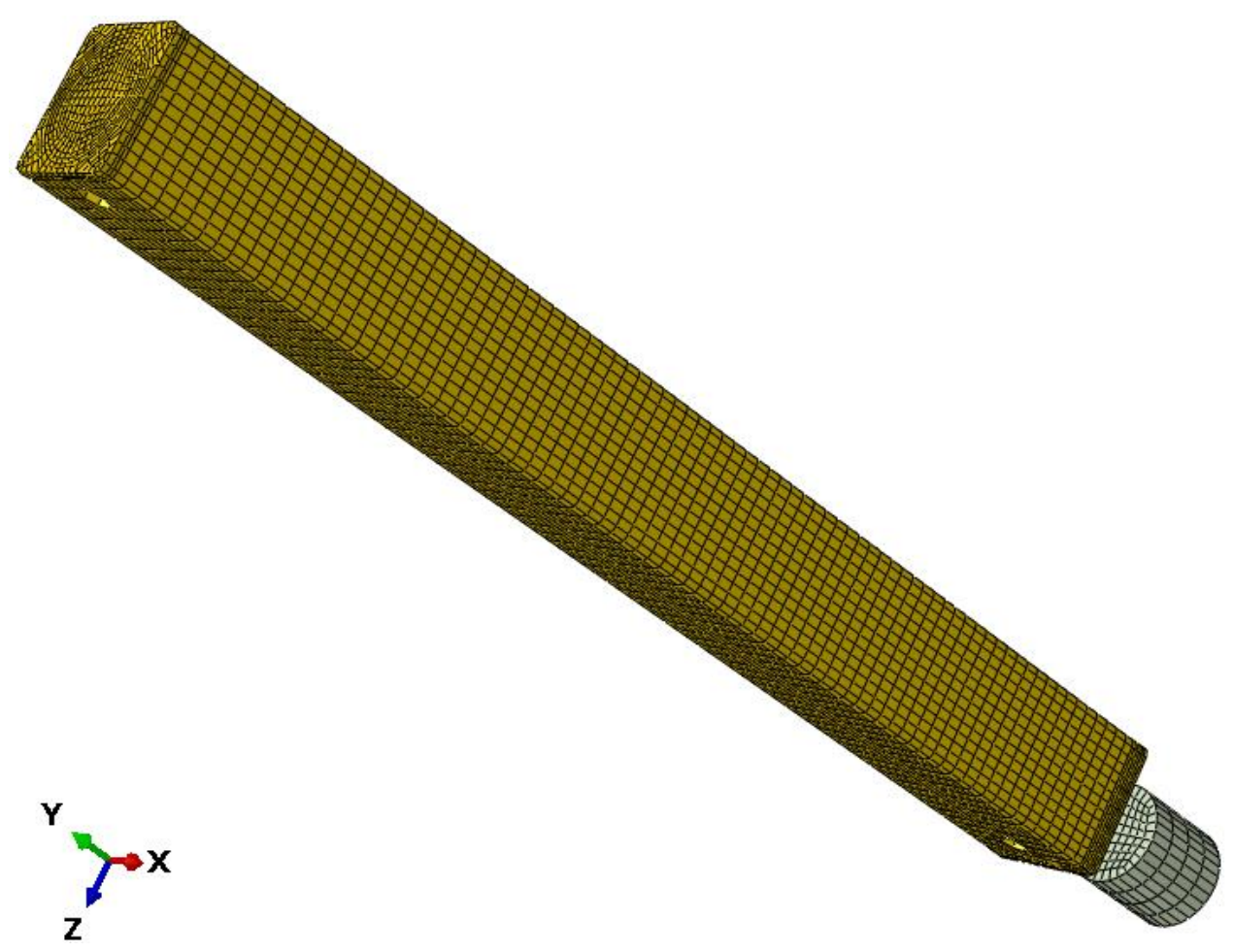

Figure B-38. Mesh for Test 11 (Table 2).

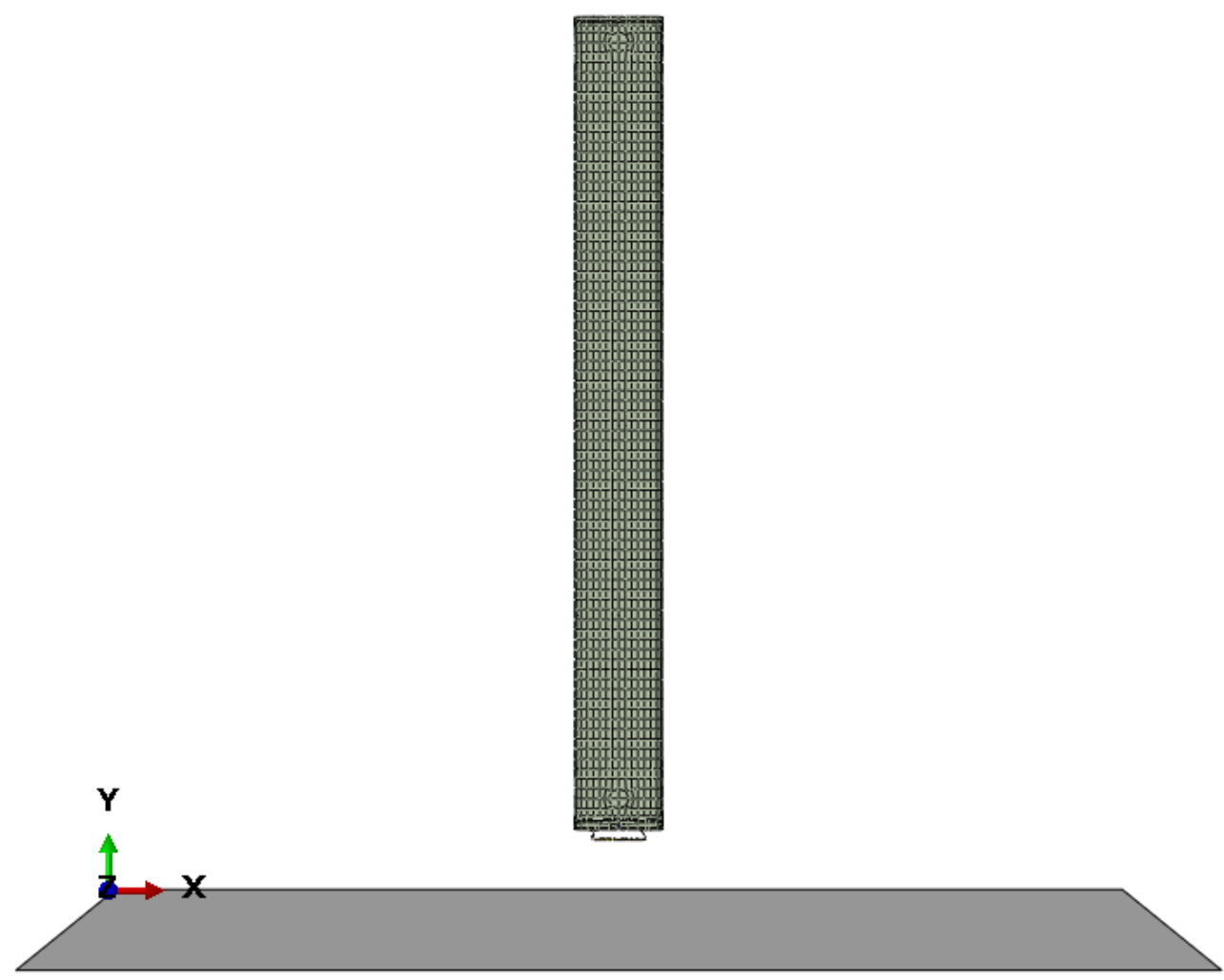

Figure B-39. Mesh for Test 12 (Table 2). 


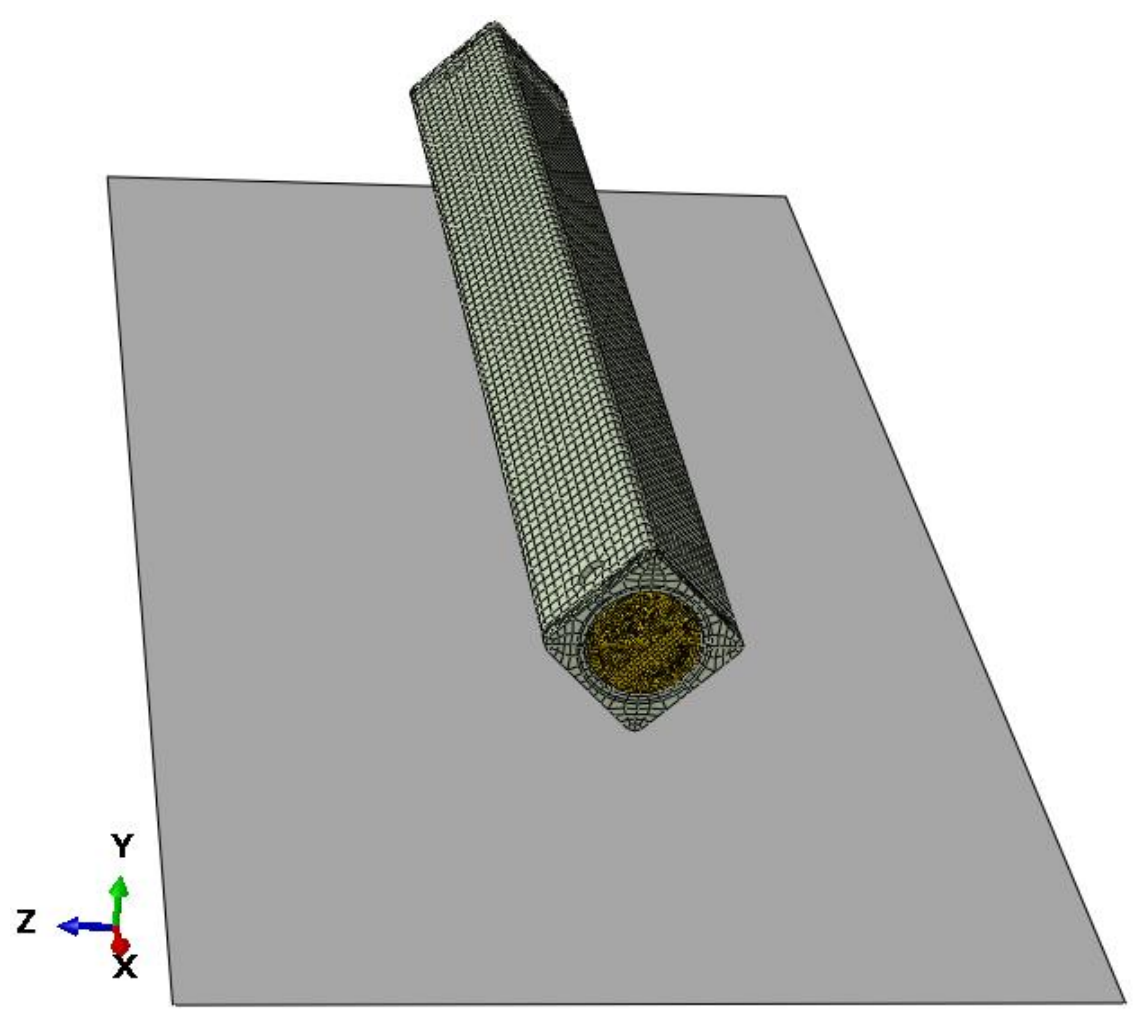

Figure B-40. Mesh for Test 13 (Table 2).
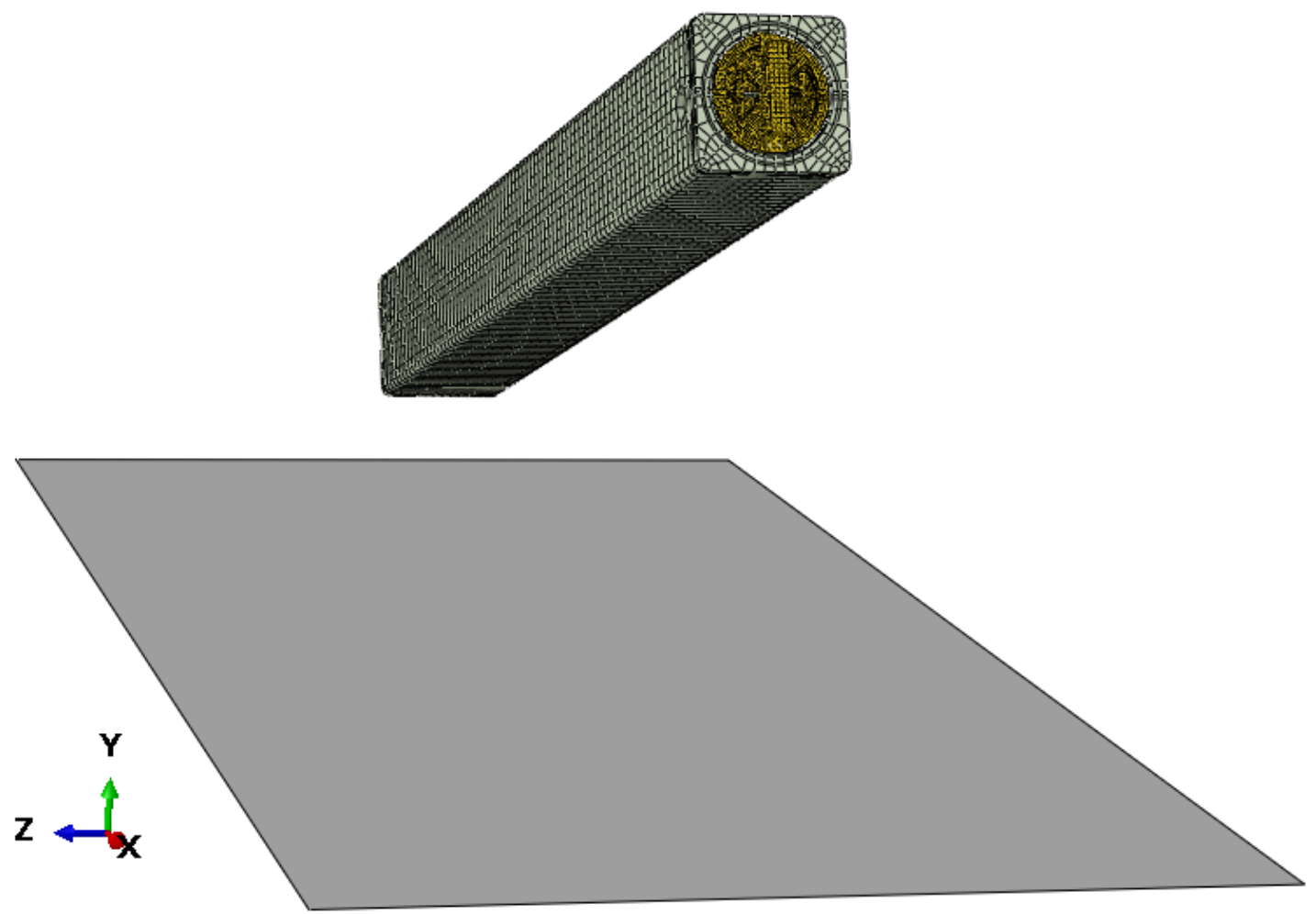

Figure B-41. Mesh for Test 14 (Table 2). 


\section{B4 DROP ANALYSIS MODELS ABBREVIATED INPUT FILES}

The input files below are representative of the model-run input files. They are reduced primarily to just card definitions. Element and node data represent the biggest portion removed from the file. Using this input file data, referenced documents, and the mesh descriptions in Section B3, generation of a similar complete set of input files should be possible.

In general, short input files were written for individual drop scenarios. These input files used *INCLUDE commands to read in included files (ending in ."i") that contained model data shared by multiple drop scenarios. To reduce voluminous data with limited added benefit, reduced input files will be provided for only a few drop scenarios. These provide examples of how the included files are used. For simplicity of model-run automation, some input-file names were repeated. However, they exist in different directories, so the directories are listed with the names below (e.g. Directory "FFSC_1a" contains drop scenarios using minimum material properties, so if the file is "6_CD4_1_HEU.inp" is in that directory, the model is for Scope Part 1a [Table 3]; Test 6 [Table 2]).

Below are data for the Scope Part 1a (Table 3); Test 6 (Table 2) input file.

FFSC_1a/6_CD4_1_HEU.inp:

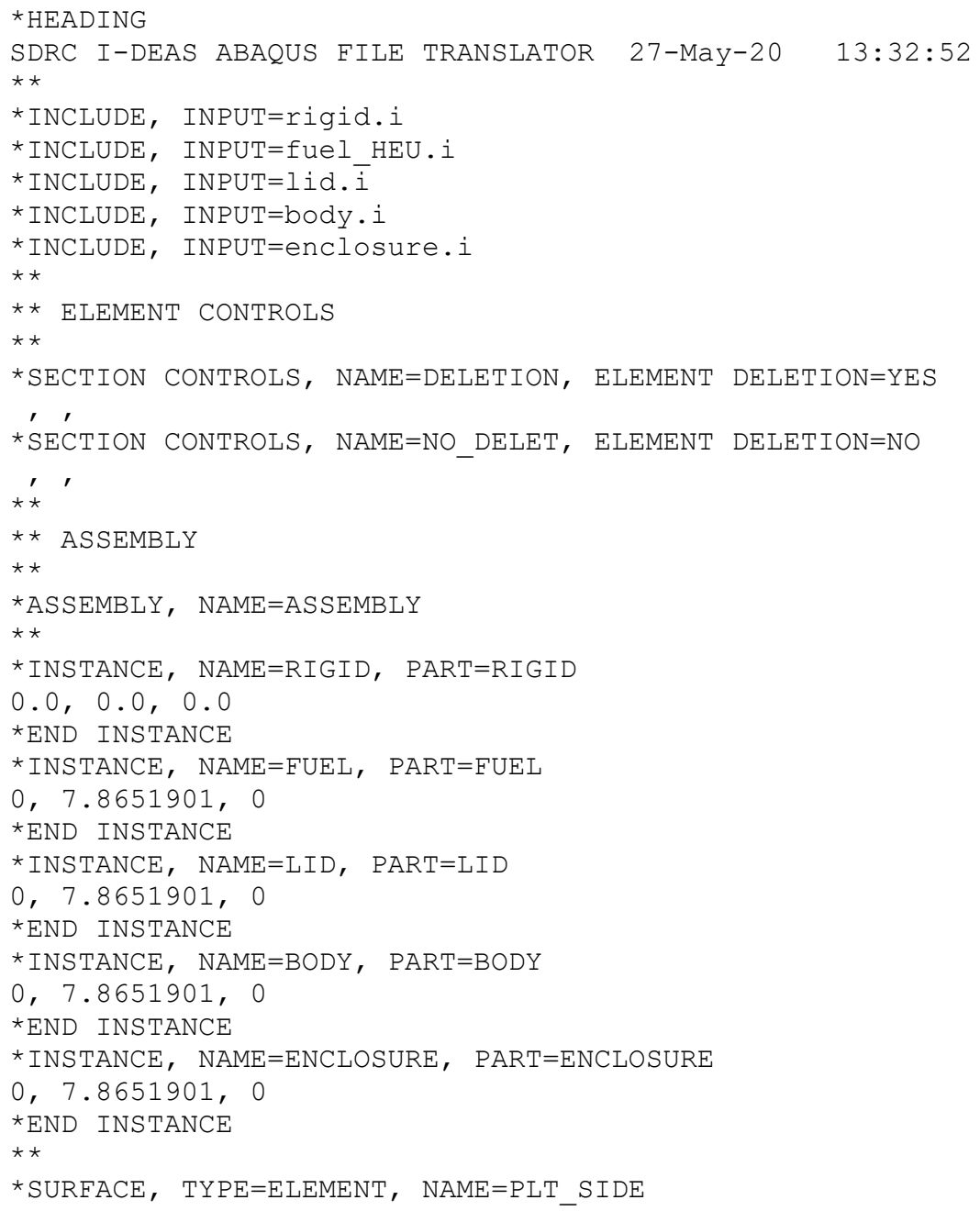




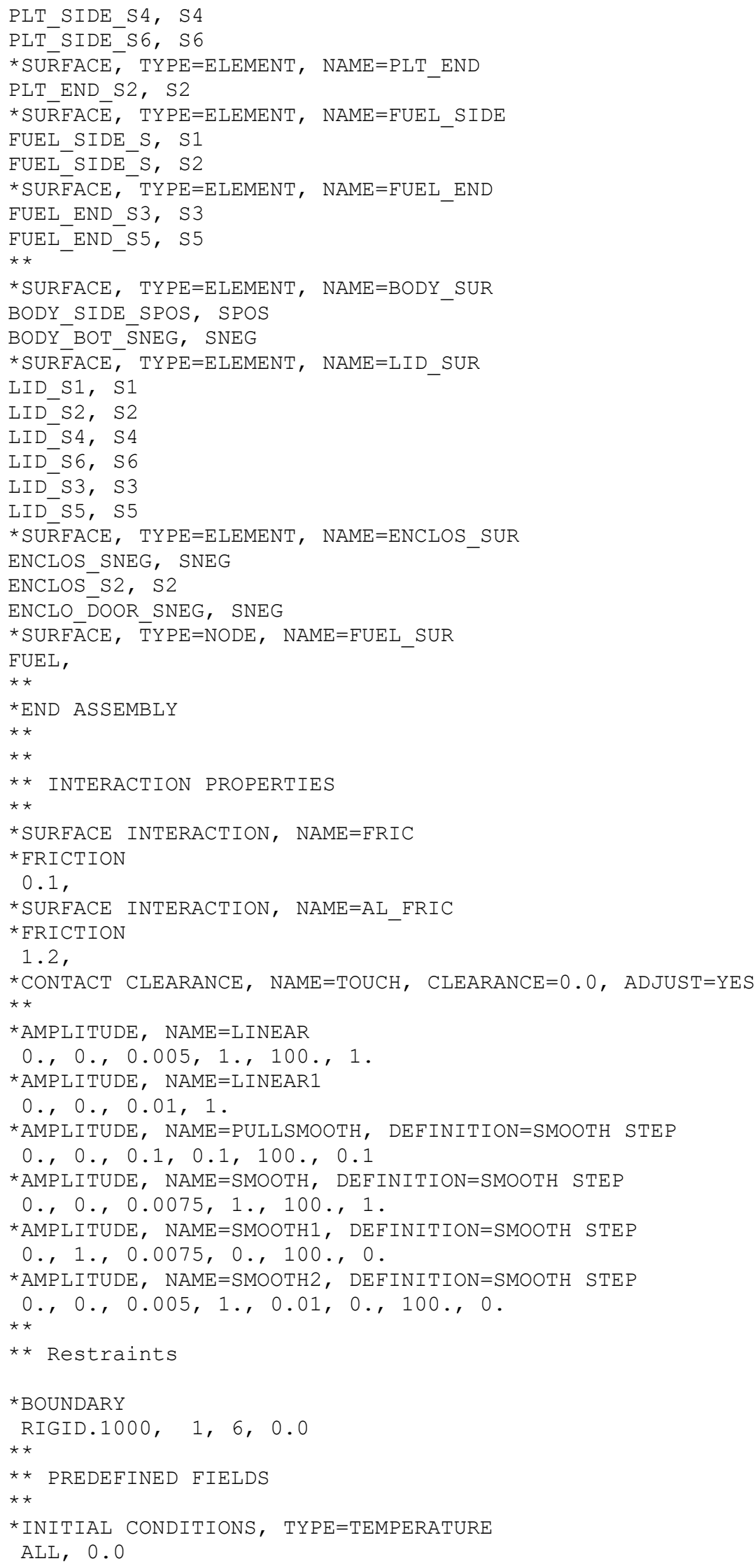




\begin{tabular}{|lcr|}
\hline TEM-10200-1, Rev. 11 & ENGINEERING CALCULATIONS AND ANALYSIS & ECAR-5224, Rev. 0 \\
$11 / 20 / 2019$ & $\begin{array}{c}\text { Drop Analysis of the Advanced Test Reactor Fresh Fuel Shipping Container } \\
\text { with Heavier Low-Enriched Uranium Fuel Contents }\end{array}$ & of B100 \\
\hline
\end{tabular}

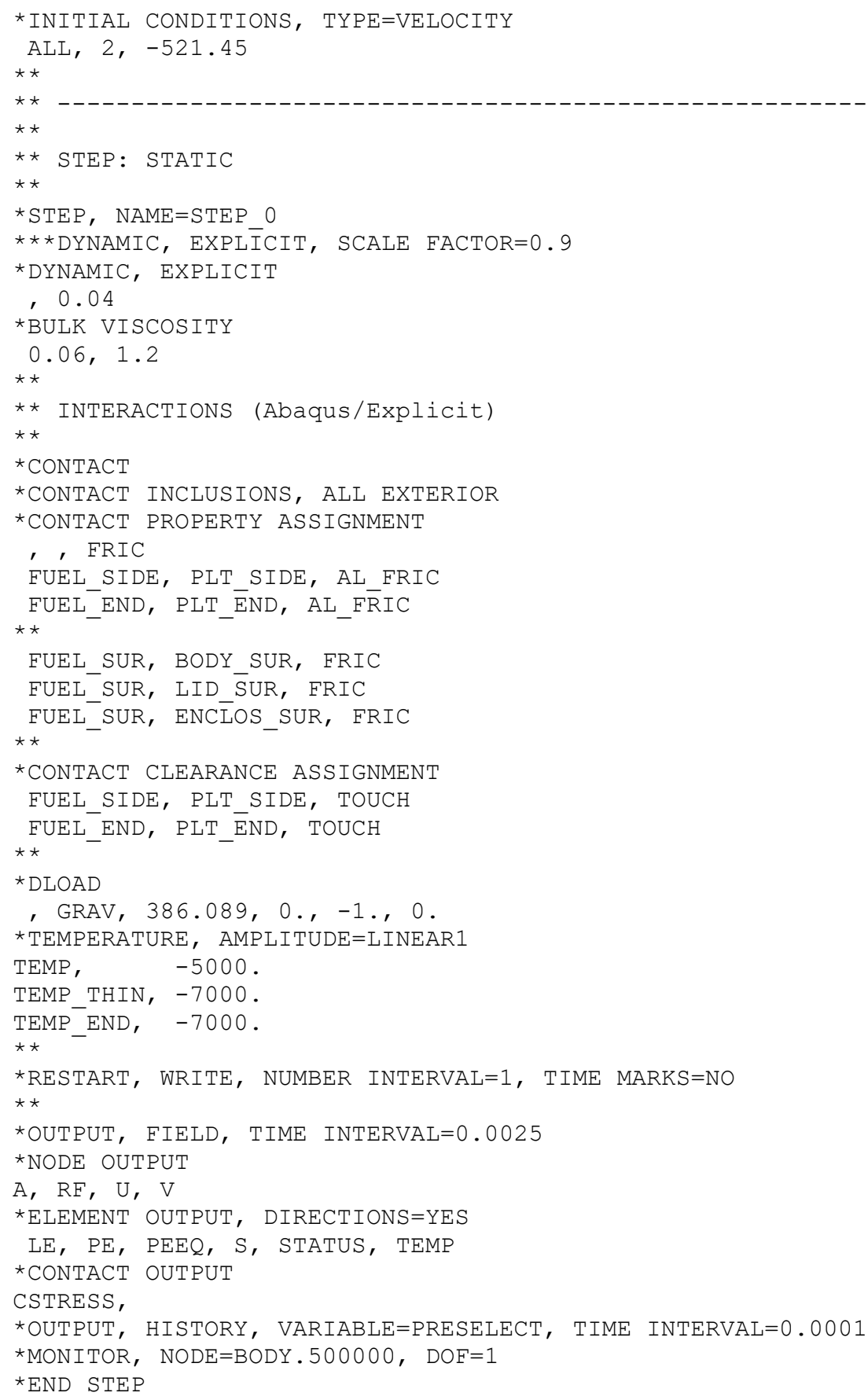

Below are data for the Scope Part 1a (Table 3); Test 6 (Table 2) input file with the finer meshed fuel plate ends.

\section{FFSC_1a/6_CD4_1_HEU_med_plt.inp:}

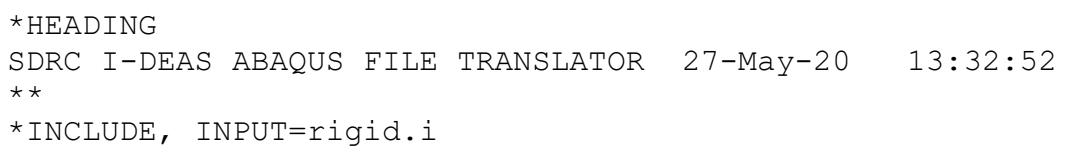




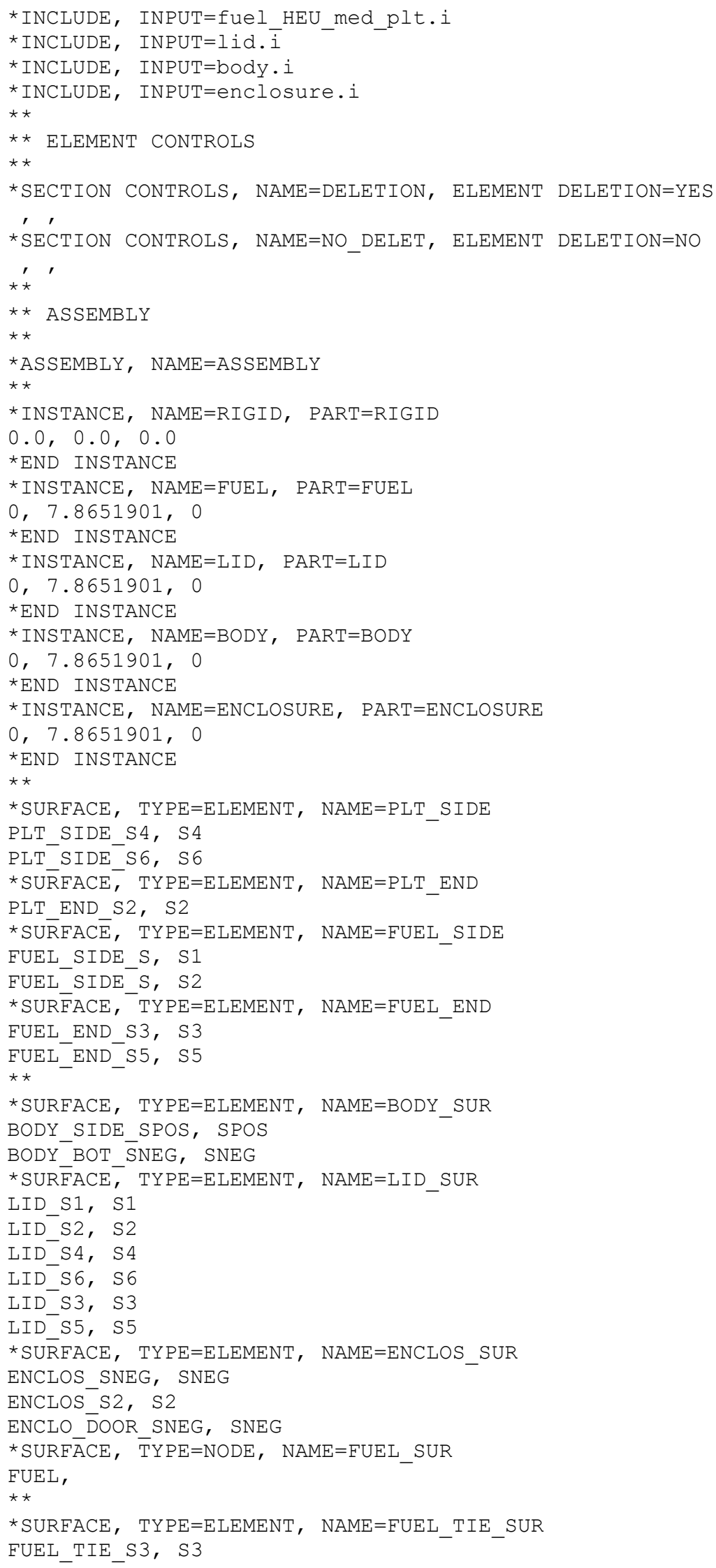




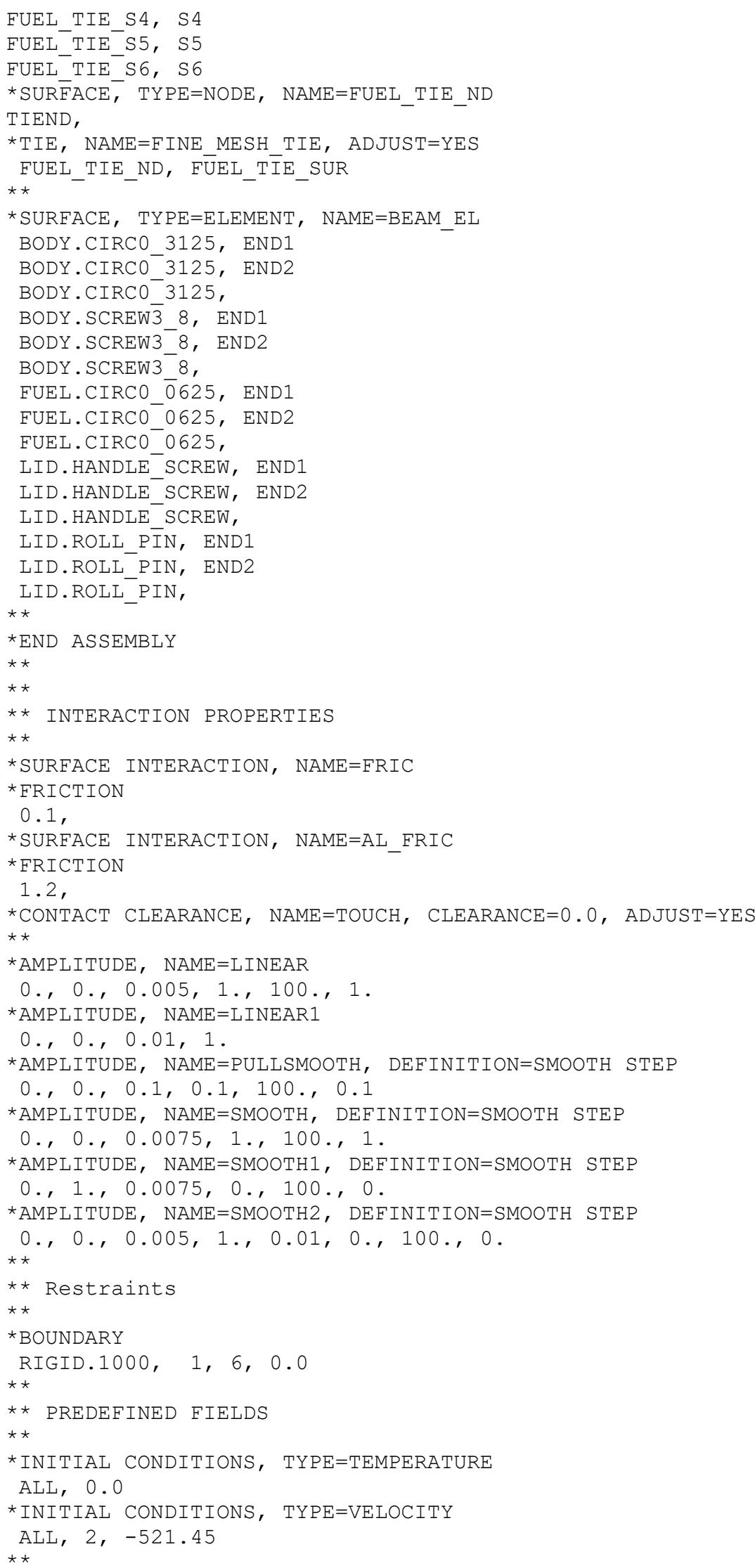


$\star \star$

* STEP: STATIC

$\star \star$

* STEP, NAME $=$ STEP_O

$\star \star \star D Y N A M I C$, EXPLĪCIT, SCALE FACTOR $=0.9$

*DYNAMIC, EXPLICIT

, 0.04

*BULK VISCOSITY

$0.06,1.2$

$\star \star$

** INTERACTIONS (Abaqus/Explicit)

$\star \star$

* CONTACT

*CONTACT INCLUSIONS, ALL EXTERIOR

*CONTACT EXCLUSIONS

, BEAM EL

*CONTACT PROPERTY ASSIGNMENT

, , FRIC

FUEL SIDE, PLT SIDE, AL FRIC

FUEL_END, PLT_END, AL_FRIC

FUEL_SUR, BODY_SUR, FRIC

FUEL_SUR, LID_SUR, FRIC

FUEL SUR, ENCĒOS SUR, FRIC

$\star \star$

*CONTACT CLEARANCE ASSIGNMENT

FUEL SIDE, PLT SIDE, TOUCH

FUEL_END, PLT_END, TOUCH

* DLOAD

, GRAV, 386.089, 0., -1., 0.

*TEMPERATURE, AMPLITUDE=LINEAR1

TEMP, $\quad-5000$.

TEMP_THIN, -7000 .

TEMP_END, $\quad-7000$.

$\star \star$

$\star \star$

*RESTART, WRITE, NUMBER INTERVAL=1, TIME MARKS=NO

$\star \star$

*OUTPUT, FIELD, TIME INTERVAL=0.0025

*NODE OUTPUT

A, RE, U, V

*ELEMENT OUTPUT, DIRECTIONS=YES

LE, PE, PEEQ, S, STATUS, TEMP

*CONTACT OUTPUT

CSTRESS,

$\star \star$

*OUTPUT, HISTORY, VARIABLE=PRESELECT, TIME INTERVAL=0.0001

*MONITOR, NODE=BODY.500000, DOF=1

*END STEP

Below are data for the Scope Part 1a (Table 3); Test 10 (Table 2) input file.

FFSC_1a/10_CP2_1_HEU.inp:

*HEADING

SDRC I-DEAS ABAQUS FILE TRANSLATOR 27-May-20 13:32:52

$\star \star$

*INCLUDE, INPUT=post.i 


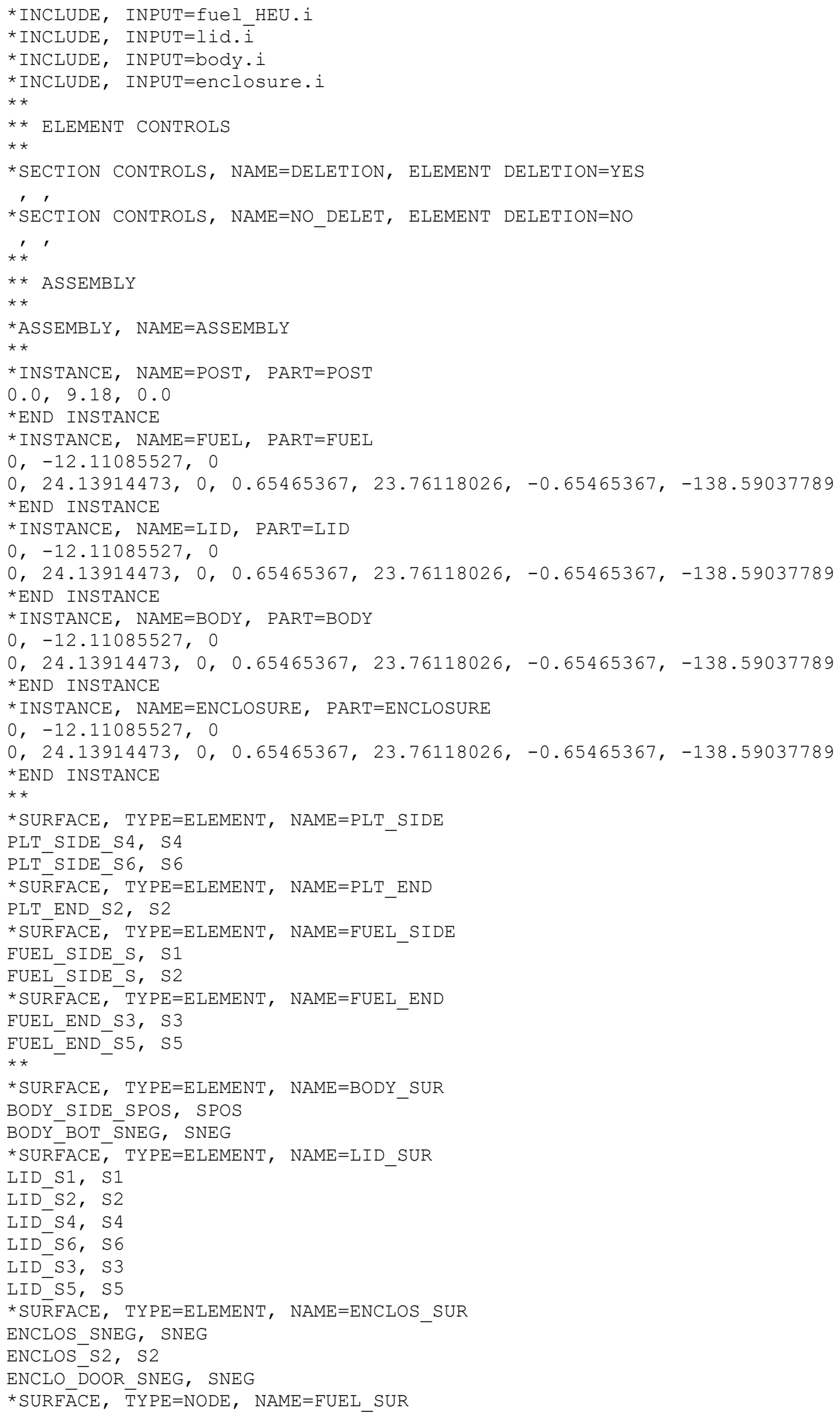




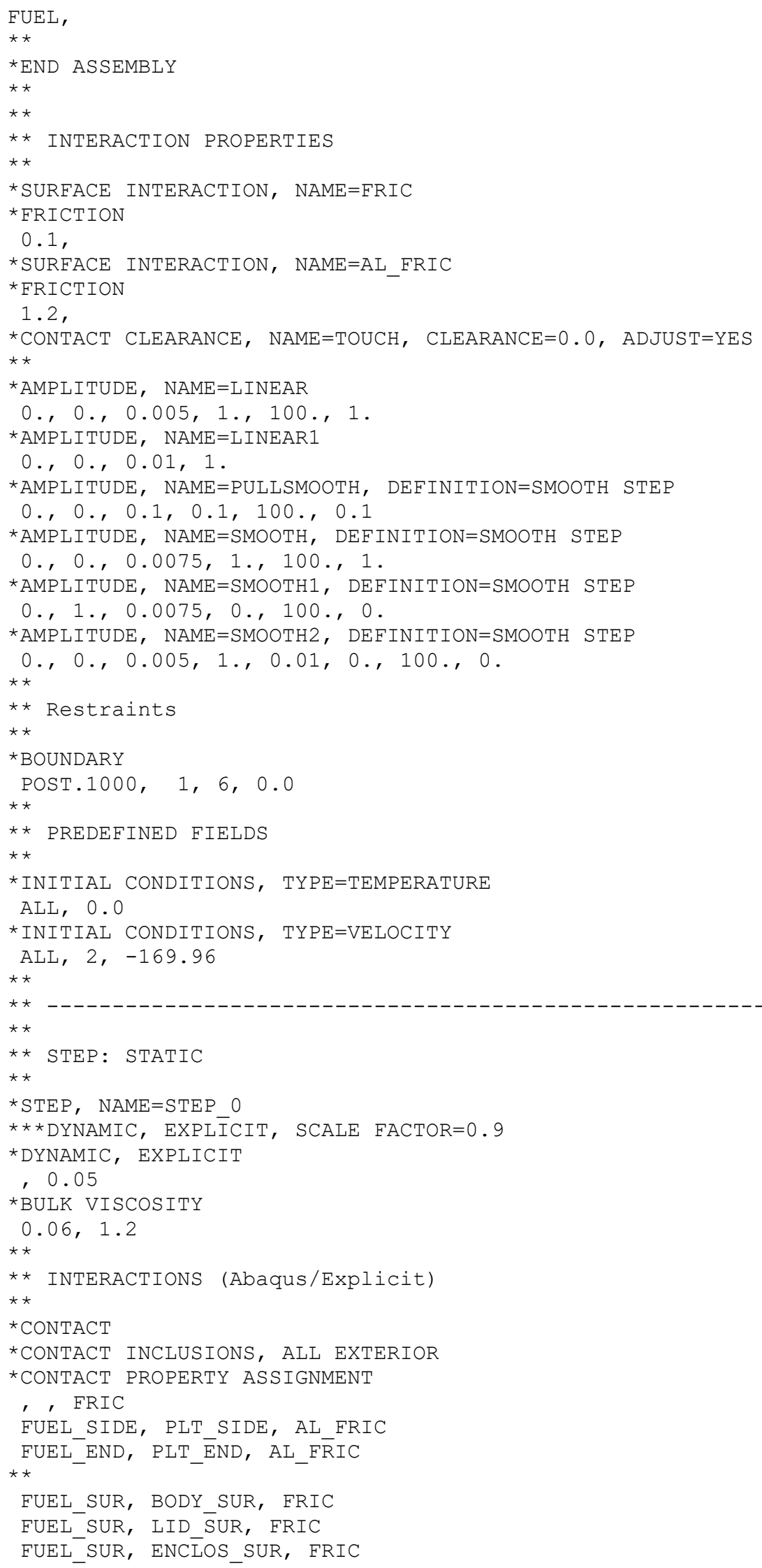


$\star \star$

*CONTACT CLEARANCE ASSIGNMENT

FUEL_SIDE, PLT_SIDE, TOUCH

FUEL END, PLT END, TOUCH

$\star *$

$\star \mathrm{DLOAD}$

, GRAV, 386.089, 0., -1., 0 .

*TEMPERATURE, AMPLITUDE=LINEAR1

TEMP, $\quad-5000$.

TEMP THIN, -7000 .

TEMP_END, -7000 .

$\star \star$

$\star \star$

*RESTART, WRITE, NUMBER INTERVAL=1, TIME MARKS=NO

$\star \star$

*OUTPUT, FIELD, TIME INTERVAL $=0.0025$

*NODE OUTPUT

$A, R F, U, V$

*ELEMENT OUTPUT, DIRECTIONS=YES

LE, PE, PEEQ, S, STATUS, TEMP

*CONTACT OUTPUT

CSTRESS,

$\star \star$

*OUTPUT, HISTORY, VARIABLE=PRESELECT, TIME INTERVAL=0.0001

*MONITOR, NODE=BODY. $500000, \mathrm{DOF}=1$

*END STEP

Below are data for the Scope Part 1b (Table 3); Test 6 (Table 2) input file. The data shown is how this file below differs from that of the similar Scope Part 1a (Table 3); Test 6 (Table 2) input file (shown previously).

FFSC_1a_tough_end_box_and_enclosure/6_CD4_1_HEU.inp:

*INCLUDE, INPUT=rigid.i

*INCLUDE, INPUT=fuel_HEU_tough_end_box.i

*INCLUDE, INPUT=lid. $\bar{i}$

*INCLUDE, INPUT=body.i

*INCLUDE, INPUT=enclosure_tough.i

Below are data for the Scope Part $1 \mathrm{~b}$ (Table 3); Test 10 (Table 2) input file. The data shown is how this file below differs from that of the similar Scope Part 1a (Table 3); Test 6 (Table 2) input file (shown previously). FFSC_1a_tough_end_box_and_enclosure/10_CP2_1_HEU.inp:

*INCLUDE, INPUT=post.i

*INCLUDE, INPUT=fuel HEU tough end box.i

*INCLUDE, INPUT=lid. $\bar{i}$

*INCLUDE, INPUT=body.i 
*INCLUDE, INPUT=enclosure tough.i

Below are data for the Scope Part 2c (Table 3); Test 6 (Table 2) input file. FFSC_1a/6_CD4_1_LOWE_block.inp:

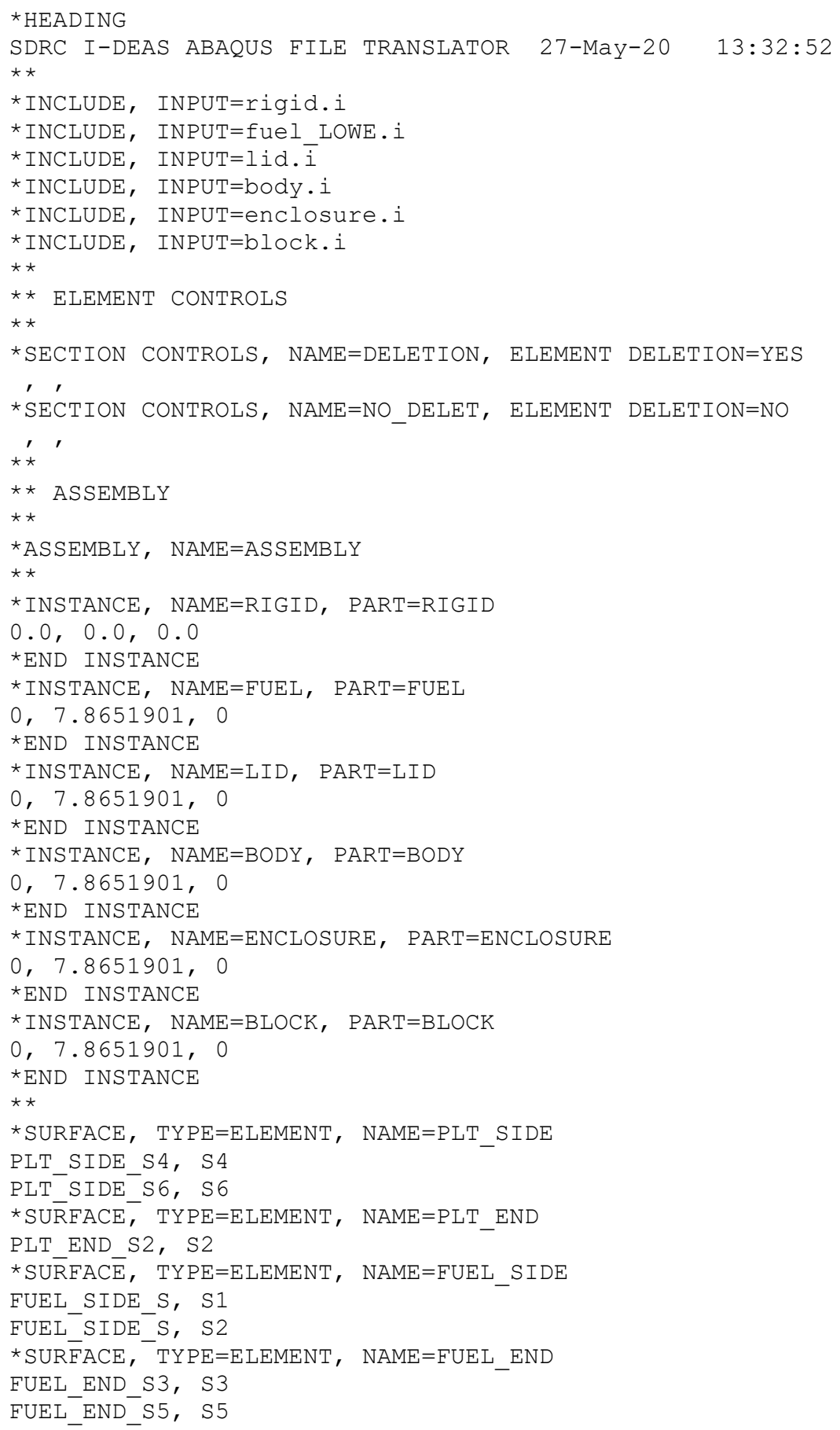




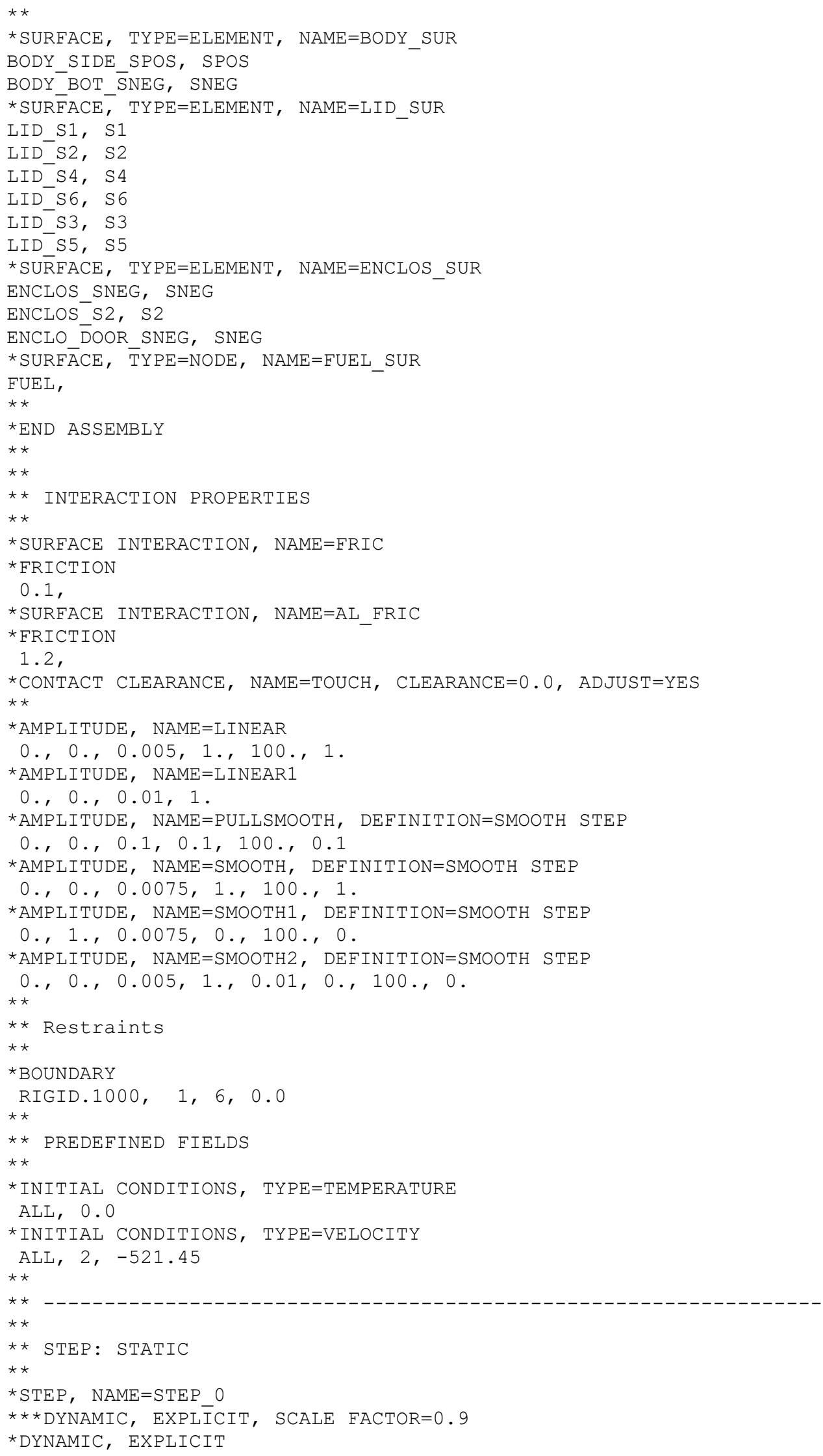




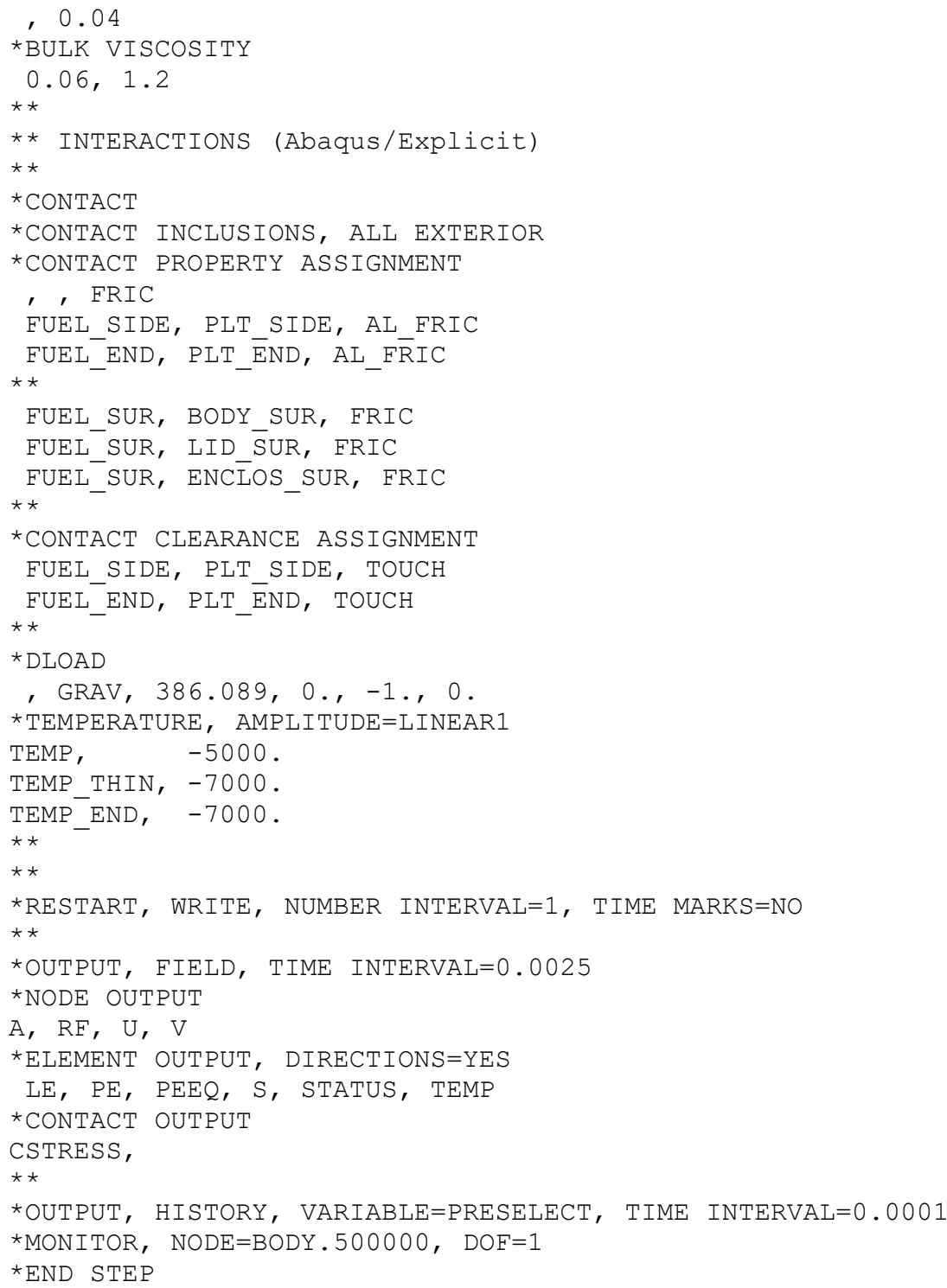

Below are data for the Scope Part 2d (Table 3); Test 6 (Table 2) input file. The data shown is how this file below differs from that of the similar Scope Part 2c (Table 3); Test 6 (Table 2) input file (shown previously). FFSC_1a_tough_end_box_and_enclosure/6_CD4_1_LOWE_block.inp:

*INCLUDE, INPUT=rigid.i

*INCLUDE, INPUT=fuel_LOWE_tough_end_box.i

*INCLUDE, INPUT=lid. $\bar{i}$

*INCLUDE, INPUT=body.i

*INCLUDE, INPUT=enclosure_tough.i

*INCLUDE, INPUT=block.i 
Below are data for the Scope Part 3 (Table 3); Test 6 (Table 2) input file.

\section{FFSCa_1_5xmass_no_fail_contents/6_CD4_1_5x.inp:}

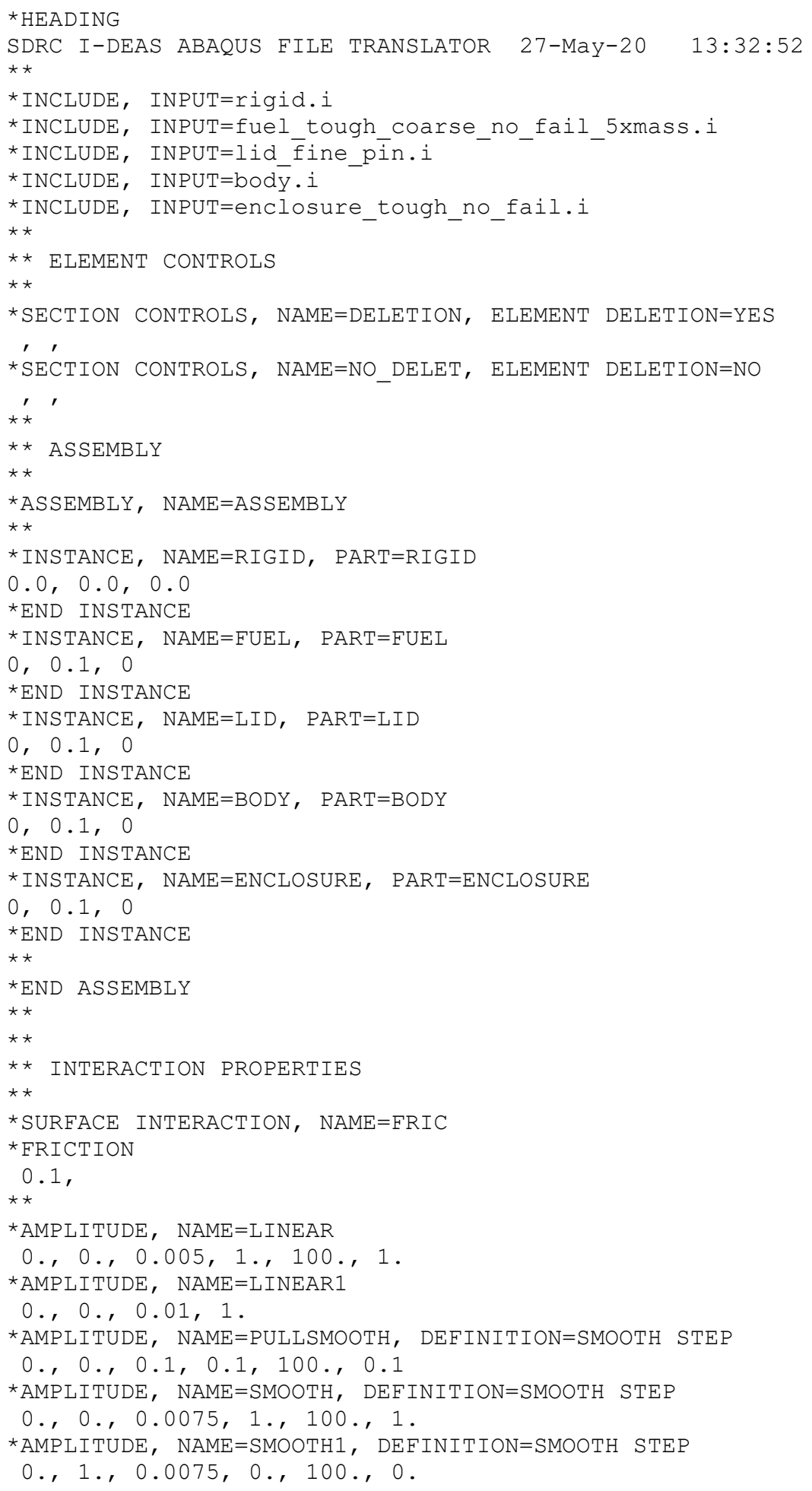




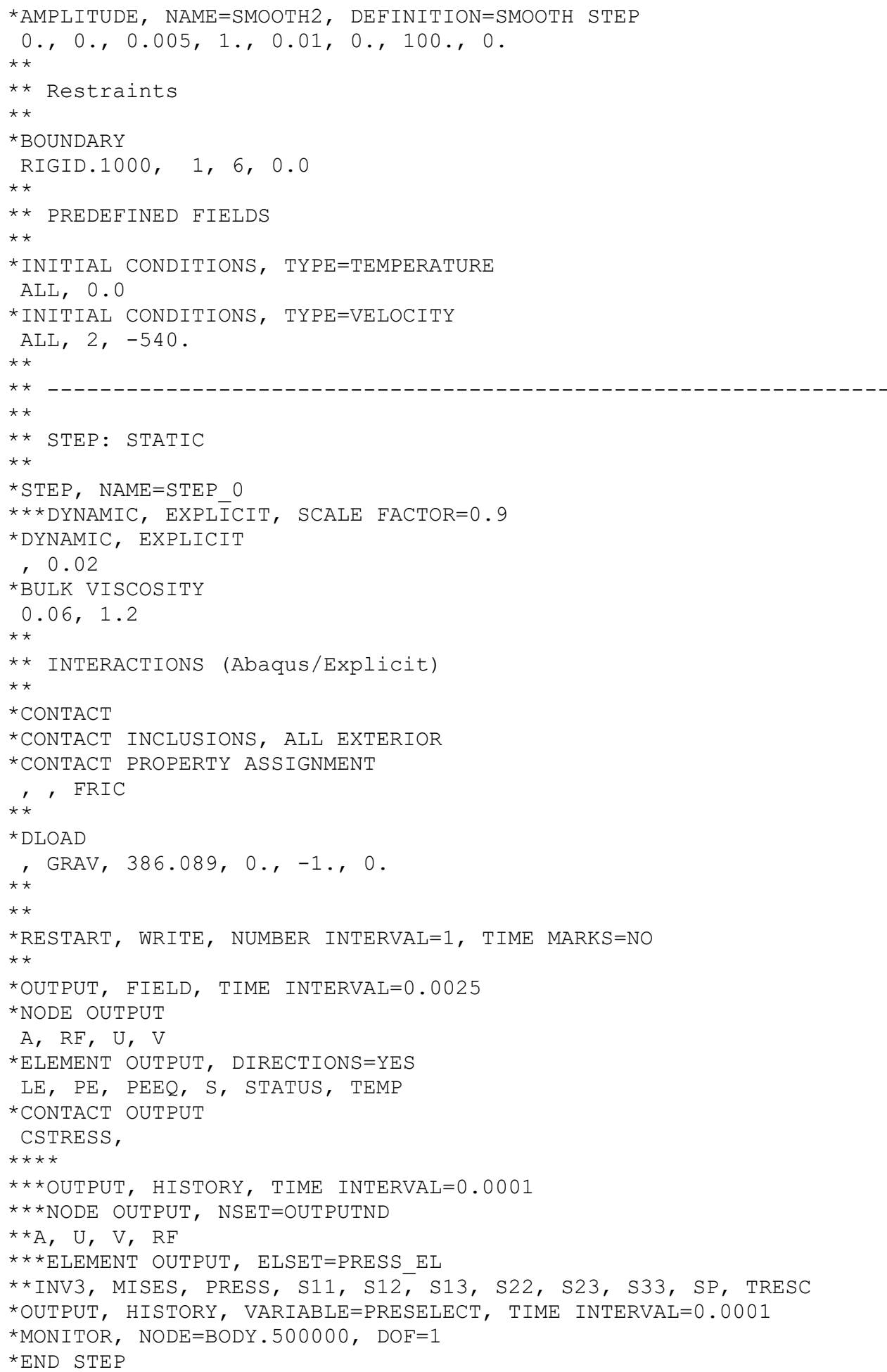


Below are data for the Scope Part 3 (Table 3); Test 10 (Table 2) input file.

\section{FFSC_1a/10_CP2_1_5x.inp:}

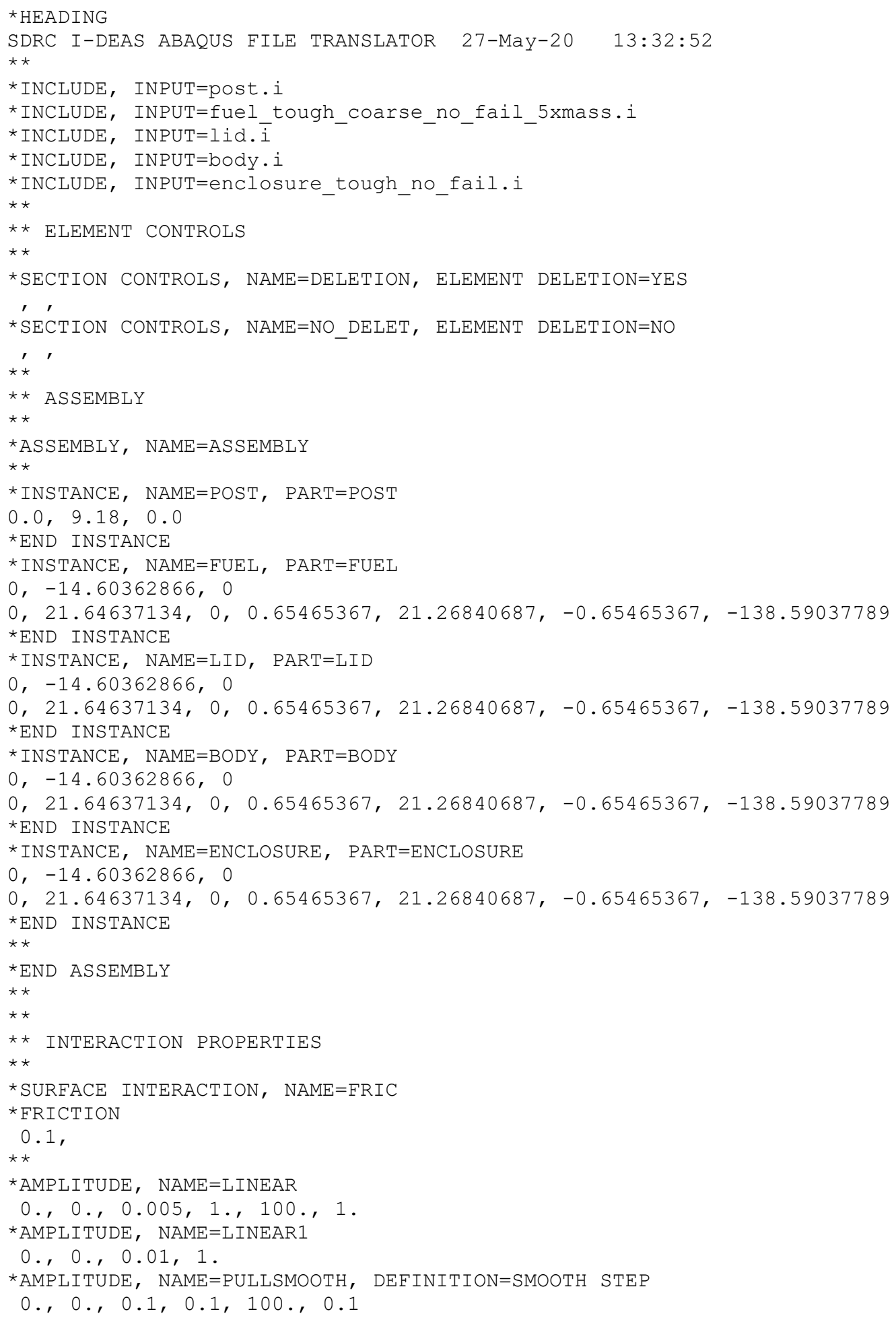




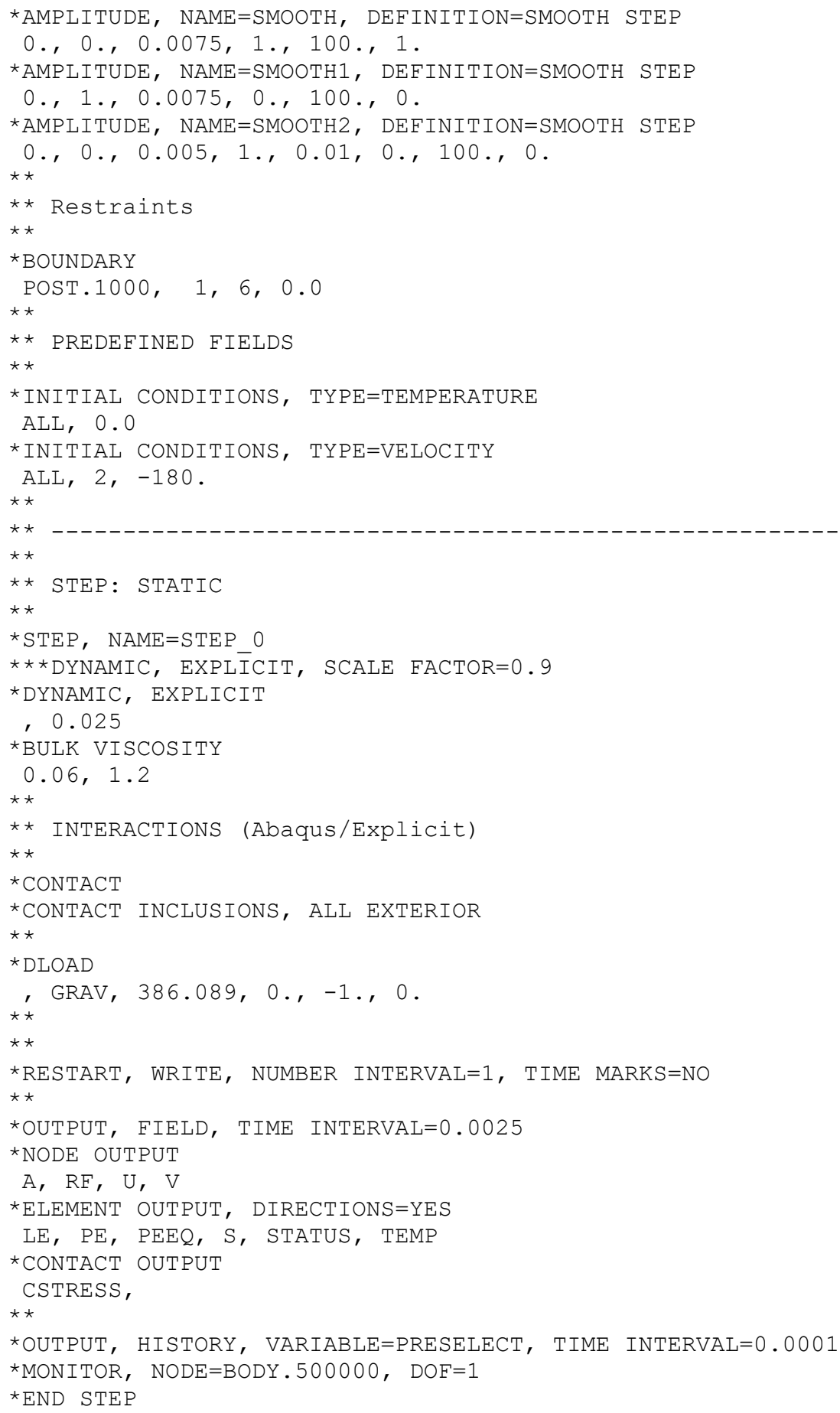




\section{Below are the files that are included into the input files:}

Below are data for the rigid surface.

rigid.i:

*PART, NAME $=$ RIGID

*NODE

$1000,0.0000000 \mathrm{E}+00,-1.0000000 \mathrm{E}+00,0.0000000 \mathrm{E}+00$

$1001,5.0000000 \mathrm{E}+01,0.0000000 \mathrm{E}+00,2.5000000 \mathrm{E}+01$

$1002, \quad 5.0000000 \mathrm{E}+01, \quad 0.0000000 \mathrm{E}+00,-2.5000000 \mathrm{E}+01$

$1003,-5.0000000 \mathrm{E}+01,0.0000000 \mathrm{E}+00,-2.5000000 \mathrm{E}+01$

$1004,-5.0000000 \mathrm{E}+01,0.0000000 \mathrm{E}+00, \quad 2.5000000 \mathrm{E}+01$

*ELEMENT, TYPE=R3D4 , ELSET=RIGID

1000, 1001, 1002, 1003, 1004

*RIGID BODY, ELSET=RIGID, REF NODE $=1000$

0.0 ,

*END PART

Below are data for the 6-inch diameter puncture bar.

post.i:

$\star$ PART, $\quad \mathrm{NAME}=\mathrm{POST}$

${ }^{\star} \mathrm{NODE}$

$1000,6.3828622 \mathrm{E}-07,3.0733291 \mathrm{E}-16,0.0000000 \mathrm{E}+00$

*ELEMENT, TYPE $=$ C3D8I, ELSET=POST

1000, 1001, 1002, 1007, 1006, 1046, 1047, 1052, 1051

$\star \mathrm{MPC}$

BEAM, $1001, \quad 1000$

$\dot{*} *$

*SOLID SECTION, ELSET=POST, MATERIAL=POST STEEL

$\star \star \star \circ$

$\star$ END PART

$\star \star \star \circ$

*MATERIAL, NAME=POST_STEEL

*ELASTIC, TYPE=ISOTRŌPIC

$30.0 E+06,0.30$

*DENSITY

7.330E-04, 


\section{Below are data for the ATR FFSC body.}

body.i:

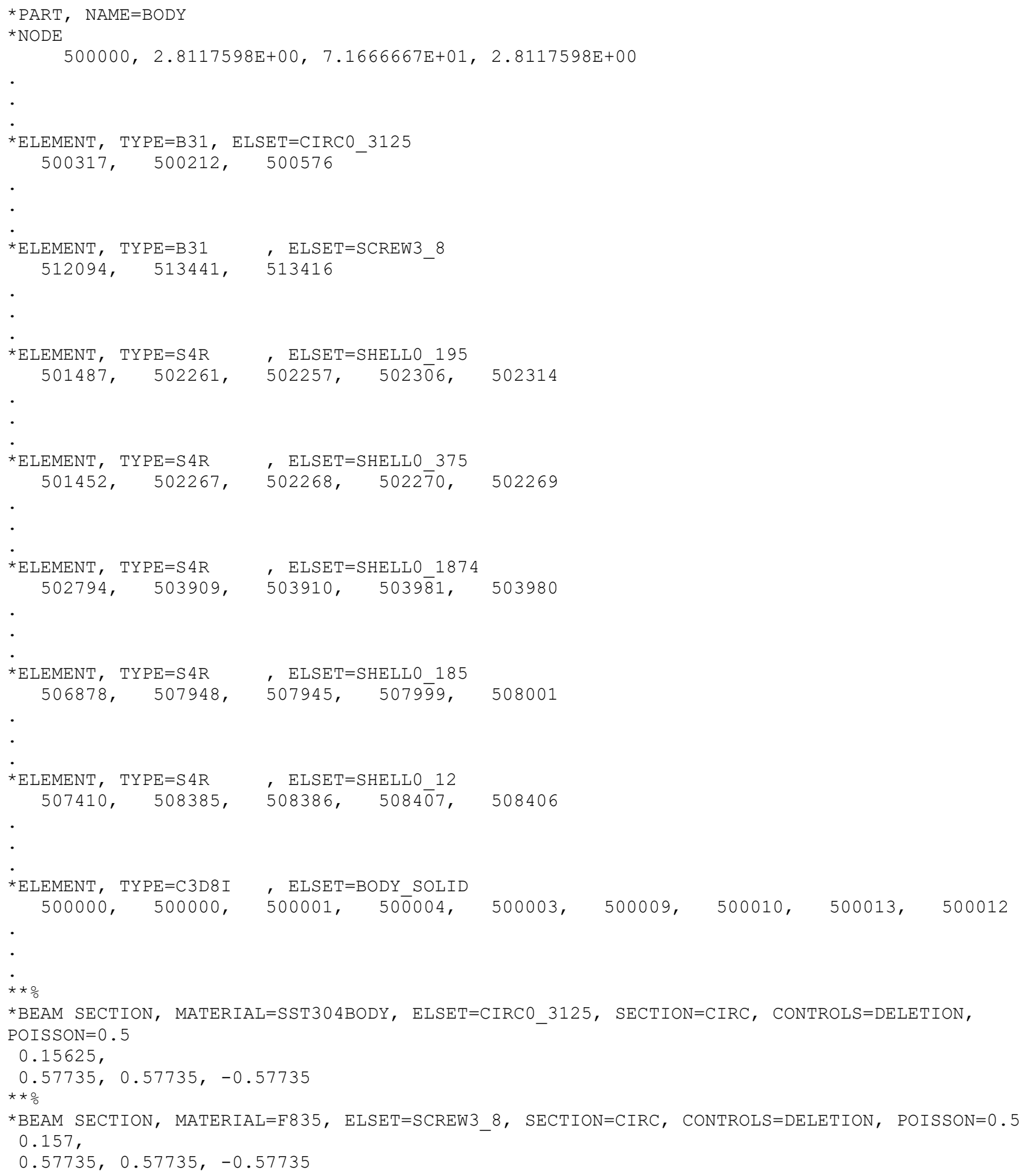


$\star \star$ 응

*SHELL SECTION, ELSET=SHELLO_195, SECTION INTEGRATION=SIMPSON, MATERIAL=SST304BODY, CONTROLS=DELETION 0.195 ,

*SHELL SECTION, ELSET=SHELLO_375, SECTION INTEGRATION=SIMPSON, MATERIAL=SST304BODY, CONTROLS=DELETION

0.375 ,

*SHELL SECTION, ELSET=SHELLO_1874, SECTION INTEGRATION=SIMPSON, MATERIAL=SST304BODY, CONTROLS=DELETION

0.1874 ,

*SHELL SECTION, ELSET=SHELLO_185, SECTION INTEGRATION=SIMPSON, MATERIAL=SST304BODY, CONTROLS=DELETION

0.185 ,

*SHELL SECTION, ELSET=SHELLO_12, SECTION INTEGRATION=SIMPSON, MATERIAL=SST304BODY, CONTROLS=DELETION

0.12 ,

$\star \star \circ \%$

*SOLID SECTION, ELSET=BODY_SOLID, MATERIAL=SST304BODY, CONTROLS=DELETION

$\star \star \circ \%$

*END PART

$\star \star \circ \frac{\circ}{0}$

*MATERIAL, NAME $=$ SST304BODY

*ELASTIC, TYPE=ISOTROPIC

$28.3 E+06,0.31$

*DENSITY

$7.817 \mathrm{E}-04$

* $7.511 \mathrm{E}-04$,

**Density is changed to accommodate actual mass

*PLASTIC

$30031.8,0$.

$97500.0,0.259$

*DAMAGE INITIATION, CRITERION=DUCTILE

0.259 ,

*DAMAGE EVOLUTION, TYPE=DISPLACEMENT, SOFTENING=LINEAR

0.0 ,

$\star \star \star \circ \%$

*MATERIAL, NAME $=$ F835

*ELASTIC, TYPE=ISOTROPIC

$28.3 E+06,0.31$

*DENSITY

$7.511 \mathrm{E}-04$,

*PLASTIC

$116475.5,0$.

$156600.0,0.071$

*DAMAGE INITIATION, CRITERION=DUCTILE

0.071 ,

*DAMAGE EVOLUTION, TYPE=DISPLACEMENT, SOFTENING=LINEAR

0.0 ,

$\star \star \circ \%$

*NSET, NSET=ALL, GENERATE, INSTANCE=BODY $500000,513514, \quad 1$

*NSET, NSET=BODY, GENERATE, INSTANCE=BODY $500000, \quad 513514, \quad 1$

*ELSET, ELSET=ALL, GENERATE, INSTANCE=BODY $500000,512143, \quad 1$

*ELSET, ELSET=BODY, GENERATE, INSTANCE=BODY $500000, \quad 512143, \quad 1$

*ELSET, ELSET=HALF YZ, GENERATE, INSTANCE=BODY $500633, \quad 501 \overline{2} 65, \quad 1$

*ELSET, ELSET=CAVITY, INSTANCE=BODY 


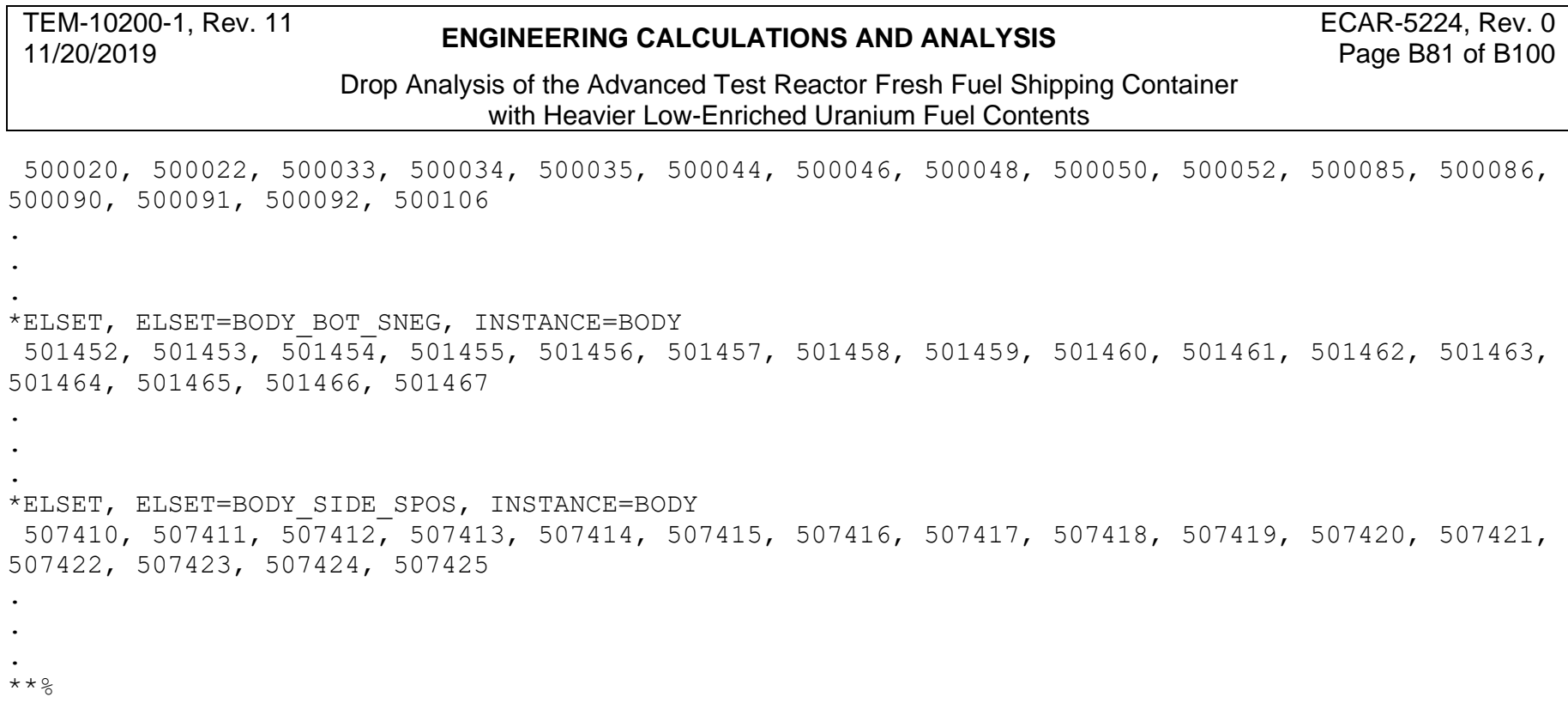

$500020,500022,500033,500034,500035,500044,500046,500048,500050,500052,500085,500086$, $500090,500091,500092,500106$

-

*ELSET, ELSET=BODY BOT SNEG, INSTANCE=BODY

$501452,501453,5 \overline{0} 145 \overline{4}, 501455,501456,501457,501458,501459,501460,501461,501462,501463$, $501464,501465,501466,501467$

•

*ELSET, ELSET=BODY SIDE SPOS, INSTANCE=BODY

$507410,507411,507412,507413,507414,507415,507416,507417,507418,507419,507420,507421$, $507422,507423,507424,507425$

$\star \star \circ \frac{0}{0}$

Below are data for the ATR FFSC lid. (Note: The file "lid_fine_pin.i" differs only in the lid pin being meshed as shown in Figure B-30.)

lid.:

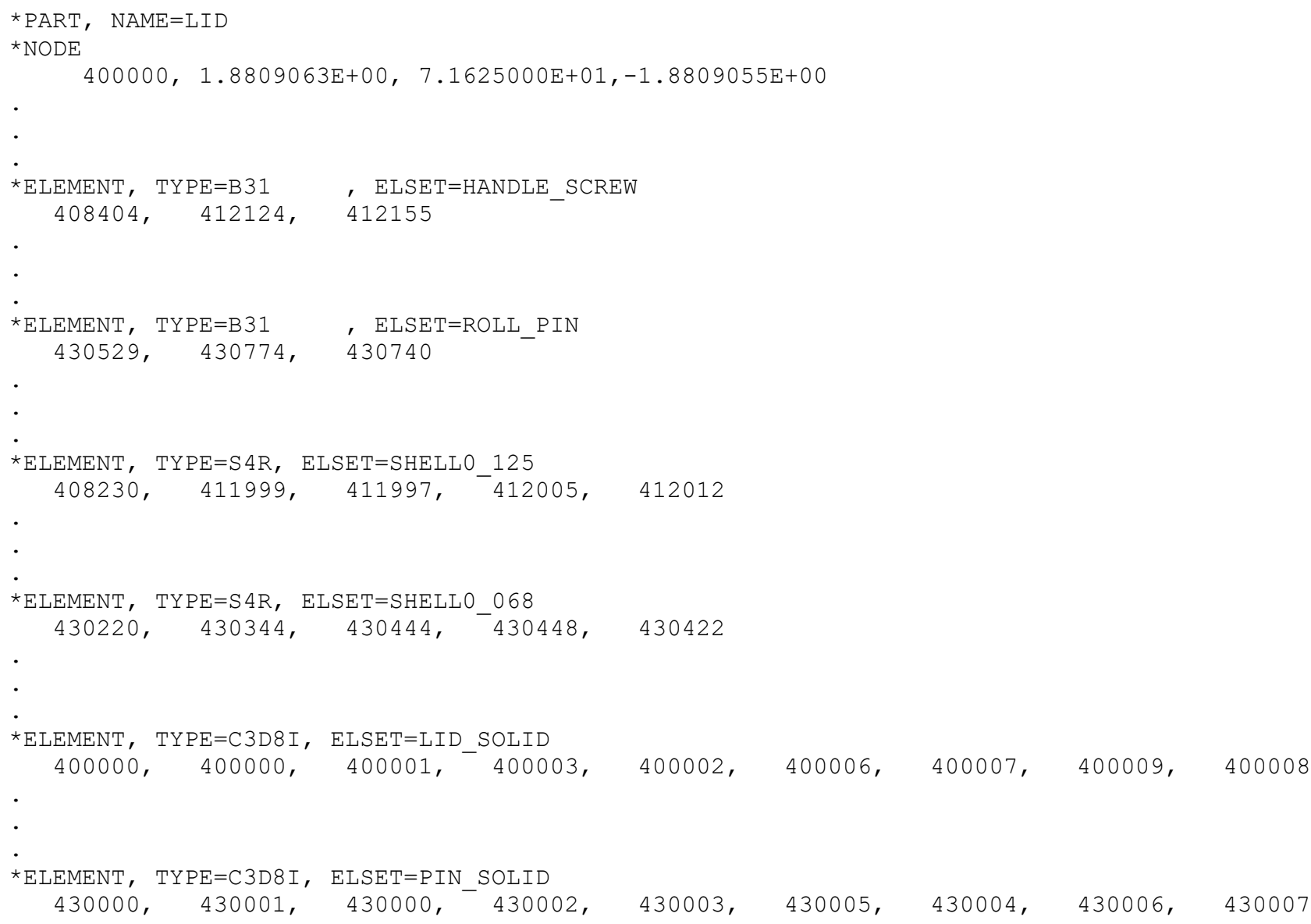




\section{$\star \star \circ \%$}

*BEAM SECTION, MATERIAL=SST304LID, ELSET=HANDLE_SCREW, SECTION=CIRC, CONTROLS=DELETION, $\mathrm{POISSON}=0.5$

0.0745 ,

$0.0,0.0,1.0$

$\star \star \circ \%$

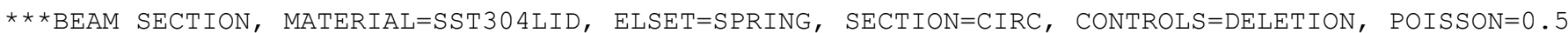

$\star \star 0.014$,

$\star * 0.0,0.0,1.0$

$\star \star \circ \frac{\circ}{0}$

*BEAM SECTION, MATERIAL=SST304LID, ELSET=ROLL_PIN, SECTION=PIPE, CONTROLS=DELETION, POISSON=0.5

$0.046875,0.20000 E-01$

$0.0,0.0,1.0$

$\star \star \circ \%$

*SHELL SECTION, ELSET=SHELLO_125, SECTION INTEGRATION=SIMPSON, MATERIAL=SST304LID,

CONTROLS=DELETION

$$
0.125 \text {, }
$$

*SHELL SECTION, ELSET=SHELLO_068, SECTION INTEGRATION=SIMPSON, MATERIAL=SST304LID, CONTROLS $=$ DELETION

$$
0.068 \text {, }
$$

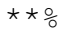

*SOLID SECTION, ELSET=LID_SOLID, MATERIAL=SST304LID, CONTROLS=DELETION

$\star \star \circ \%$

*SOLID SECTION, ELSET=PIN_SOLID, MATERIAL=NITRONIC_60, CONTROLS=DELETION

$\star \star \circ \frac{0}{0}$

*END PART

$\star \star \circ \%$

*MATERIAL, NAME $=$ SST304LID

*ELASTIC, TYPE=ISOTROPIC

28.3E+06, 0.31

*DENSITY

7.511E-04,

*PLASTIC

$30031.8,0$.

$97500.0,0.259$

*DAMAGE INITIATION, CRITERION=DUCTILE

0.259 ,

*DAMAGE EVOLUTION, TYPE=DISPLACEMENT, SOFTENING=LINEAR

0.0 ,

$\star \star \circ \circ$

*MATERIAL, NAME $=$ NITRONIC 60

*ELASTIC, TYPE=ISOTROPIC

$25.8 \mathrm{E}+06,0.31$

*DENSITY

7. 511E-04,

* PLASTIC

$50096.9,0$.

$128250.0,0.295$

*DAMAGE INITIATION, CRITERION=DUCTILE

0.295 ,

*DAMAGE EVOLUTION, TYPE=DISPLACEMENT, SOFTENING=LINEAR

0.0 ,

$\star \star \circ \%$

*NSET, NSET=ALL, GENERATE, INSTANCE=LID

$400000,412207, \quad 1$

$430000,430955, \quad 1$

*NSET, NSET=LID, GENERATE, INSTANCE=LID

$400000,412207, \quad 1$

$430000,430955, \quad 1$

*ELSET, ELSET=LID_SST, GENERATE, INSTANCE=LID $400000,40 \overline{8} 229, \quad 1$

*ELSET, ELSET=PINS, GENERATE, INSTANCE=LID

$408410,408417, \quad 1$ 


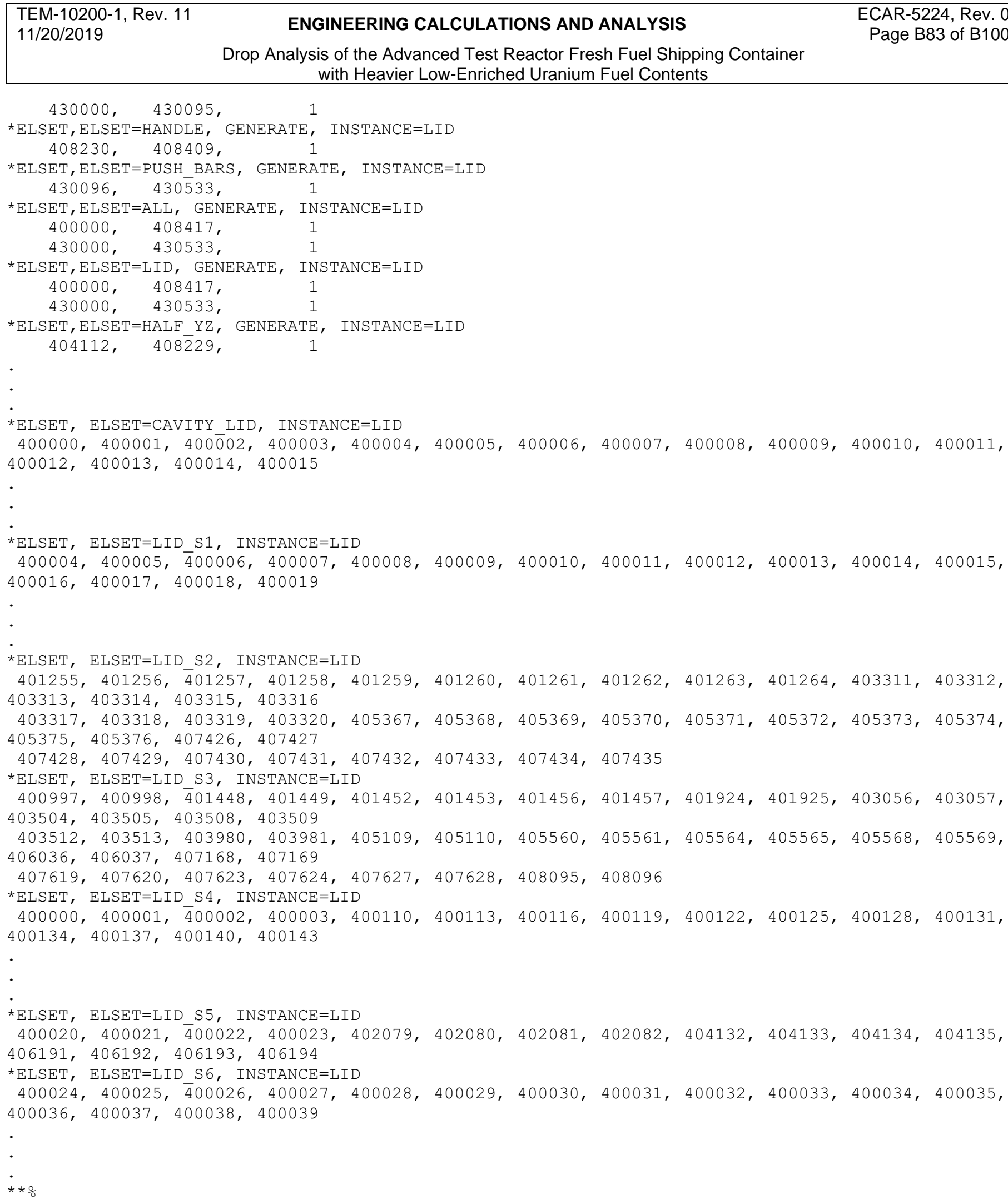


Below are data for the new block design added to help protect the fuel plates from potential failed pieces of the end boxes.

block.i:

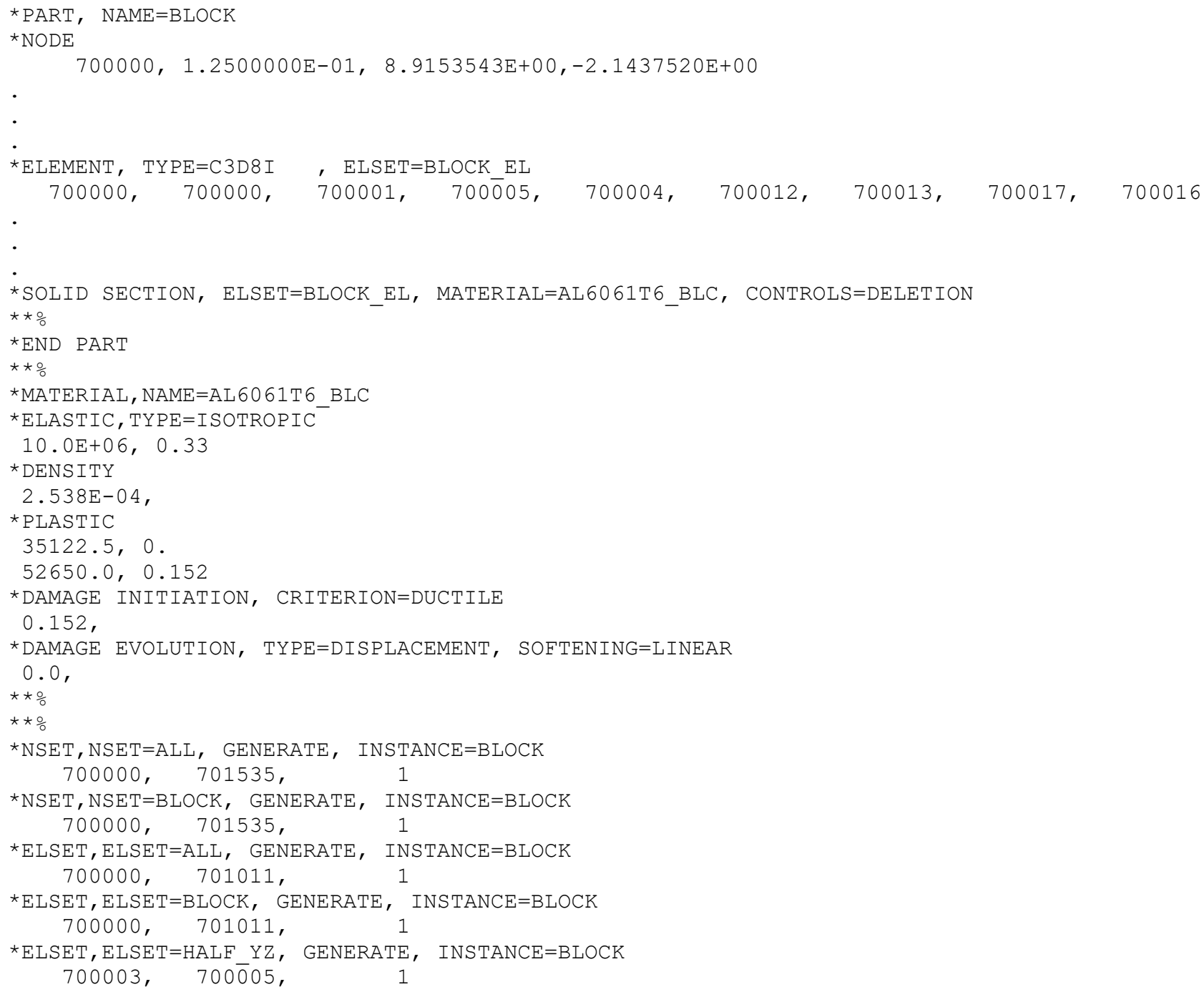

Below are data for the Scope Part 1 (Table 3) enclosure.

enclosure.i:

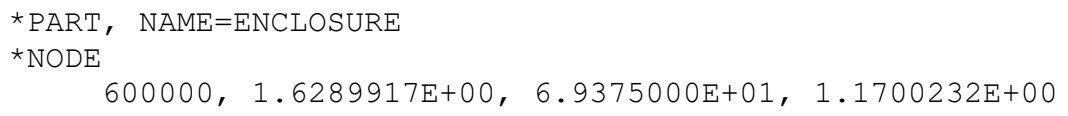




\begin{tabular}{|lcr|}
\hline TEM-10200-1, Rev. 11 & ENGINEERING CALCULATIONS AND ANALYSIS & ECAR-5224, Rev. 0 \\
$11 / 20 / 2019$ & $\begin{array}{c}\text { Drop Analysis of the Advanced Test Reactor Fresh Fuel Shipping Container } \\
\text { with Heavier Low-Enriched Uranium Fuel Contents }\end{array}$ & of B100 \\
\hline
\end{tabular}

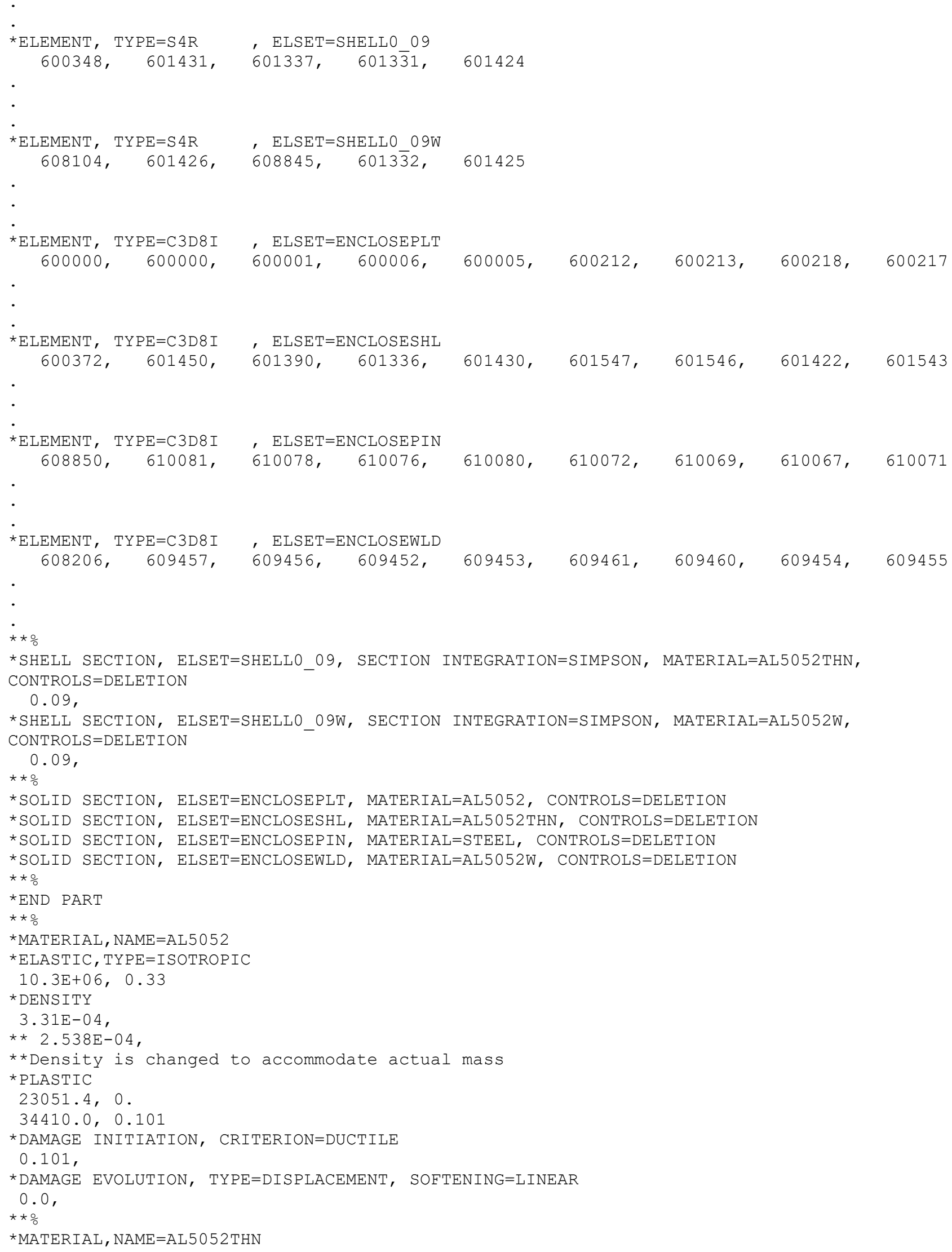




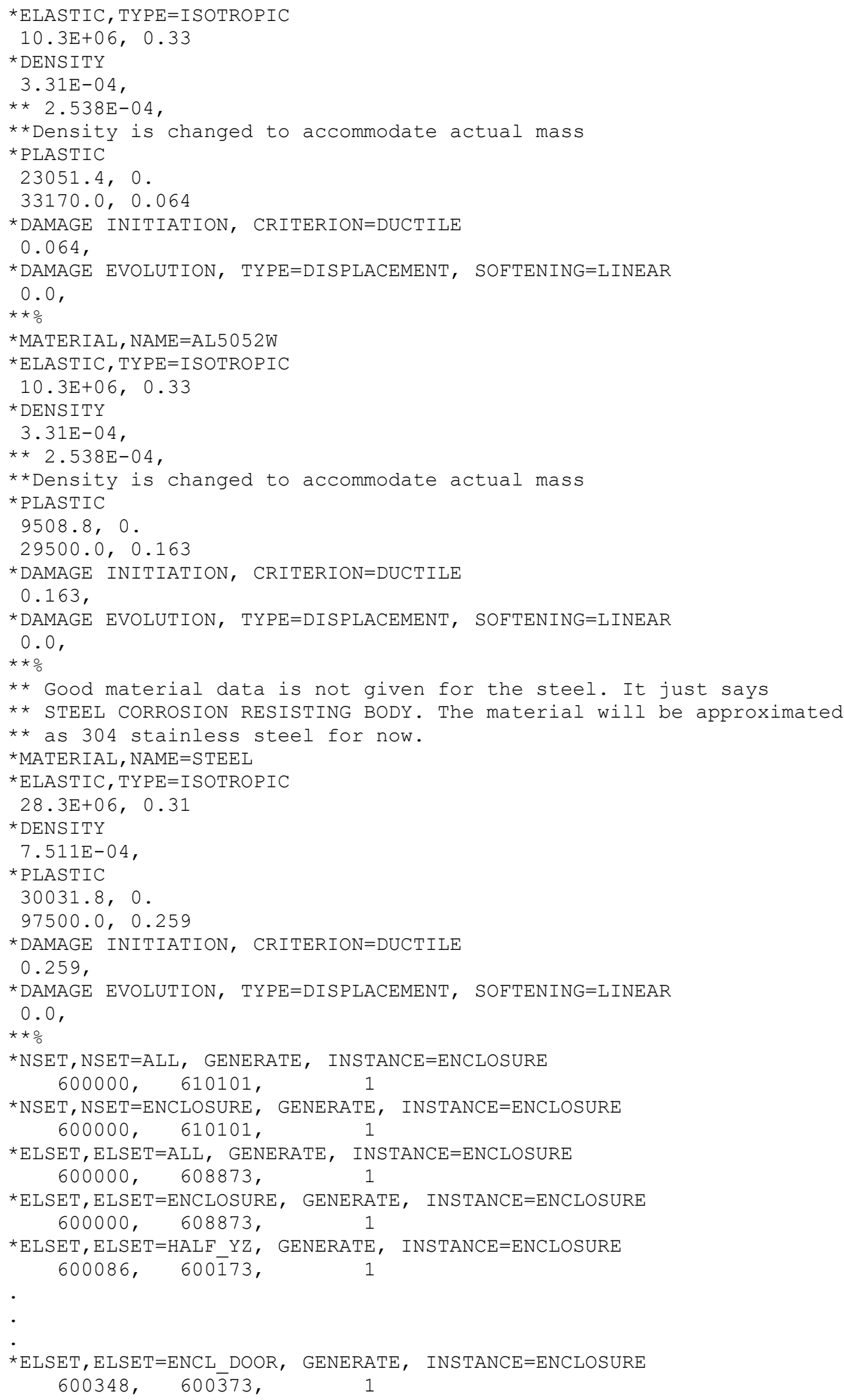




\begin{tabular}{|lcr|}
\hline $\begin{array}{l}\text { TEM-10200-1, Rev. 11 } \\
11 / 20 / 2019\end{array}$ & ENGINEERING CALCULATIONS AND ANALYSIS \\
& $\begin{array}{c}\text { Drop Analysis of the Advanced Test Reactor Fresh Fuel Shipping Container } \\
\text { with Heavier Low-Enriched Uranium Fuel Contents }\end{array}$ & Page B87 of B100 0 \\
\hline
\end{tabular}

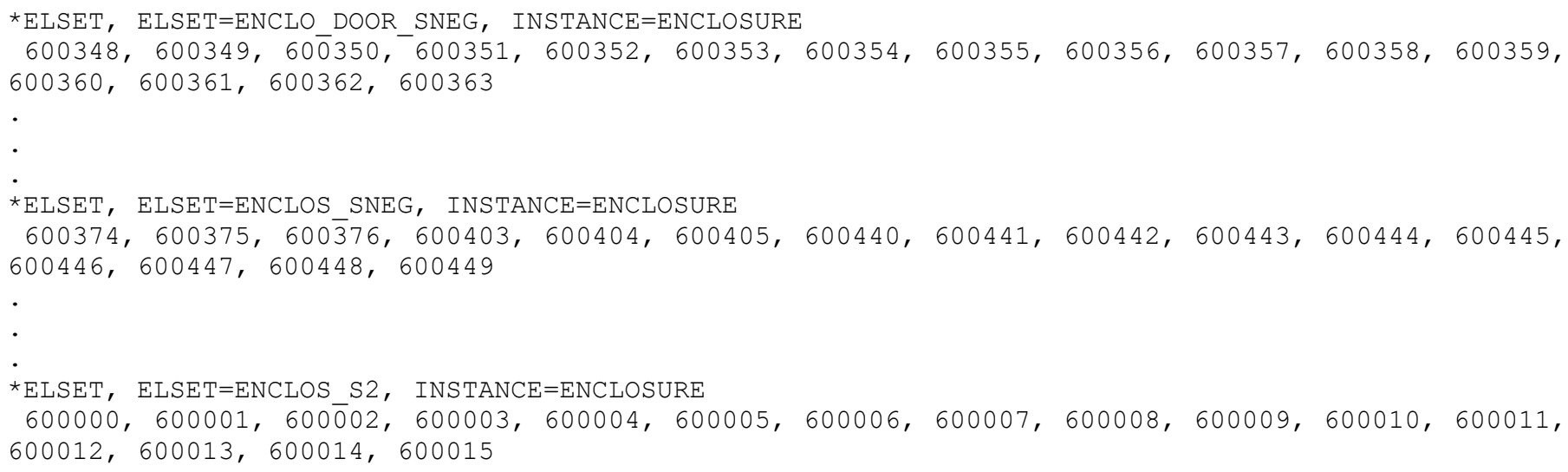

Below are data for the Scope Part 2 (Table 3) enclosure. This file is a modified version of "enclosure.i" where only the material properties have been modified. Consequently, only the material properties are shown.

\section{enclosure_tough.i:}

*MATERIAL, NAME=AL5052

*ELASTIC, TYPE=ISOTROPIC

$10.3 E+06,0.33$

*DENSITY

3. 31E-04,

* $2.538 \mathrm{E}-04$,

**Density is changed to accommodate actual mass

$\star$ PLASTIC

$\star \star 23051.4,0$.

$\star * 34410.0,0.162$

**Plastic and damage values modified to be relatively tough $28076.1,0$.

$38940.0,0.162$

*DAMAGE INITIATION, CRITERION=DUCTILE

0.162 ,

*DAMAGE EVOLUTION, TYPE=DISPLACEMENT, SOFTENING=LINEAR

0.0 ,

$\star \star * \circ$

*MATERIAL, NAME=AL5052THN

*ELASTIC, TYPE=ISOTROPIC

$10.3 \mathrm{E}+06,0.33$

*DENSITY

3. 31E-04,

* $2.538 \mathrm{E}-04$,

**Density is changed to accommodate actual mass

*PLASTIC

$\star * 23051.4,0$.

** 33170.0, 0.064

**Plastic and damage values modified to be relatively tough 


\begin{tabular}{|lcr|}
\hline $\begin{array}{l}\text { TEM-10200-1, Rev. 11 } \\
11 / 20 / 2019\end{array}$ & ENGINEERING CALCULATIONS AND ANALYSIS \\
& $\begin{array}{c}\text { Drop Analysis of the Advanced Test Reactor Fresh Fuel Shipping Container } \\
\text { with Heavier Low-Enriched Uranium Fuel Contents }\end{array}$ & Page B88 of B100 \\
\hline
\end{tabular}

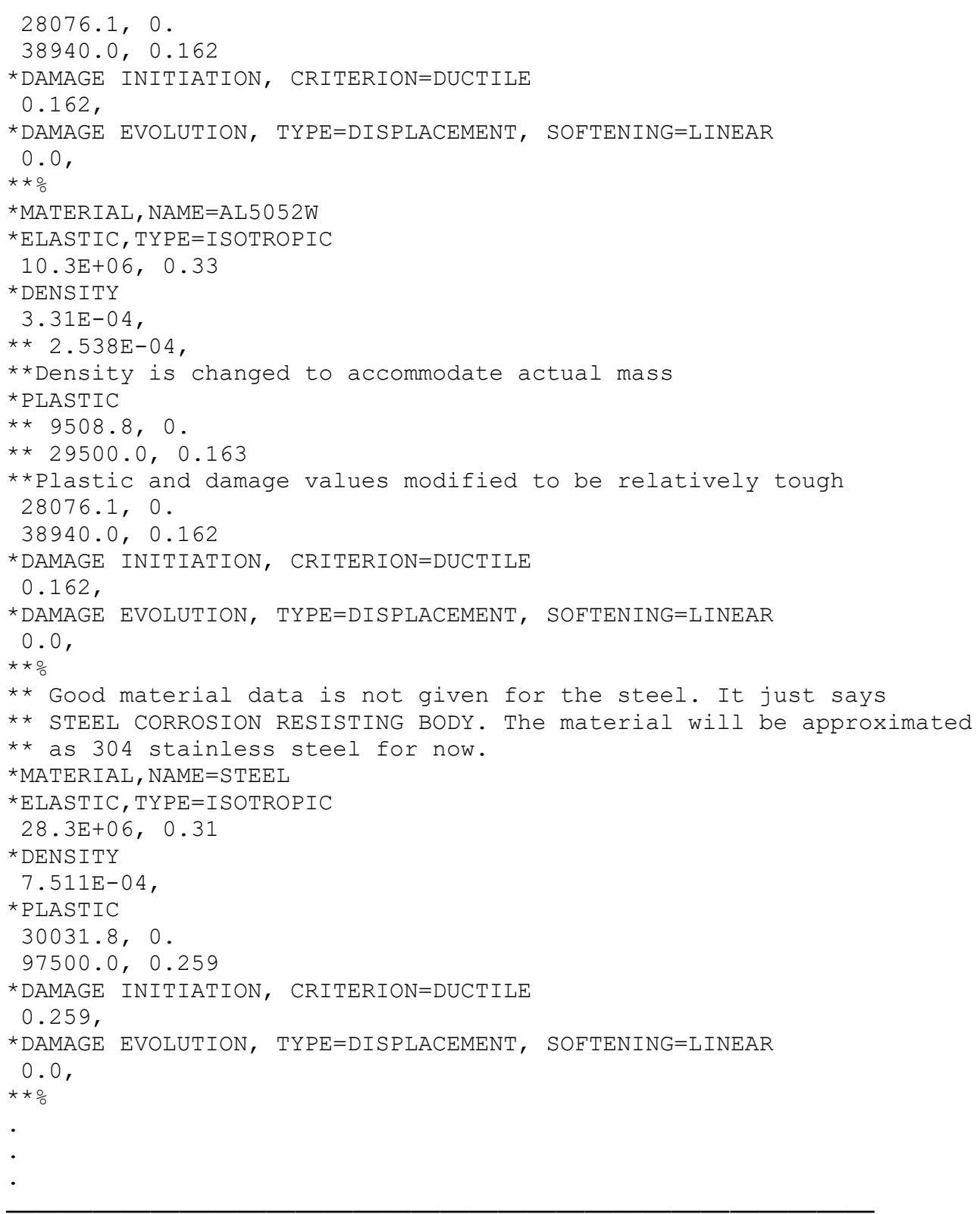

Below are data for the Scope Part 3 (Table 3) enclosure. This file is a modified version of "enclosure.i" where only the material properties have been modified. Consequently, only the material properties are shown.

enclosure_tough_no_fail.i:

*MATERIAL, NAME=AL5052

*ELASTIC, TYPE=ISOTROPIC

10.3E+06, 0.33

*DENSITY

3. 31E-04, 


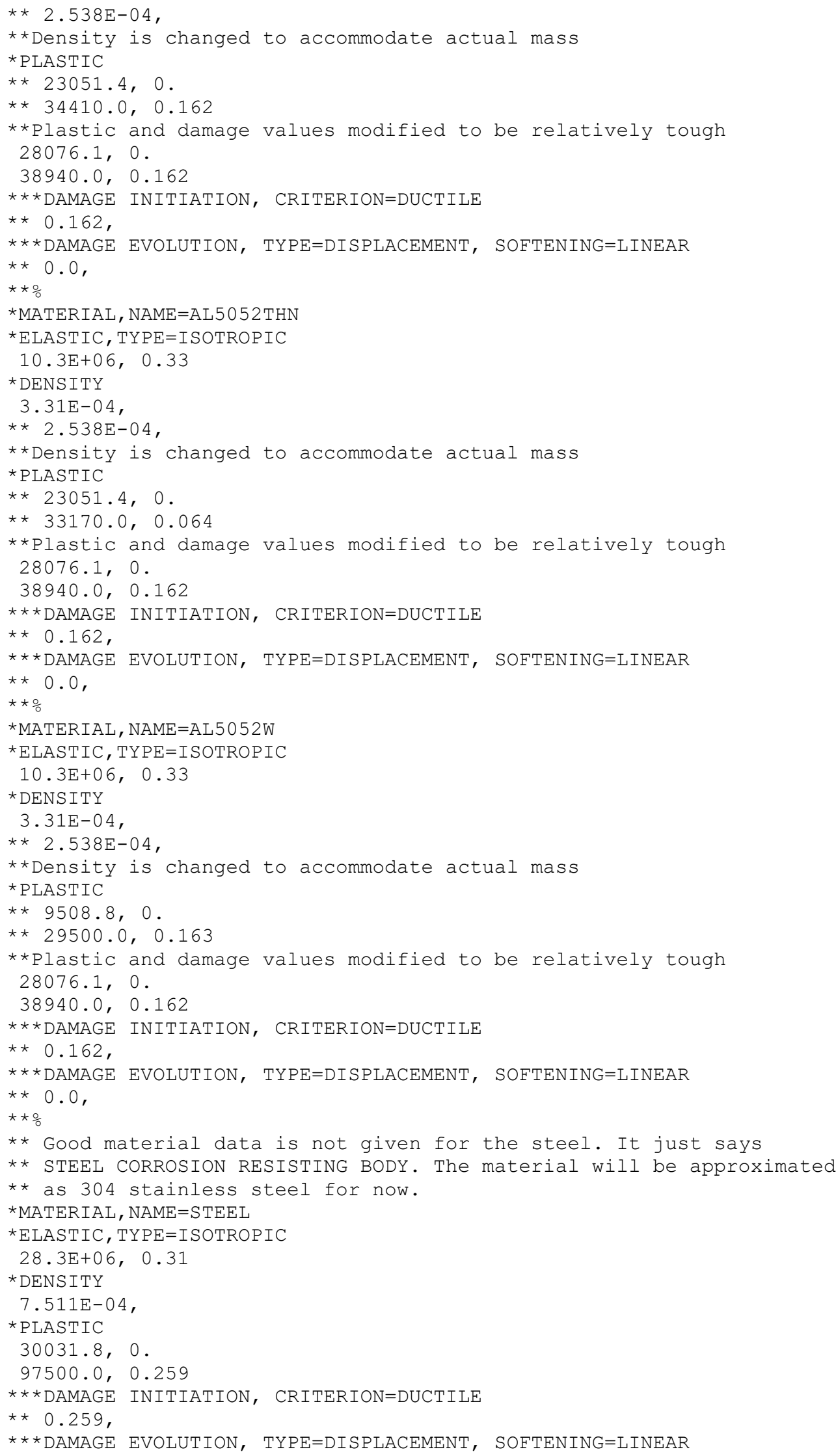


Below are data for the Scope Part 1a (Table 3) fuel element.

fuel_HEU.i:

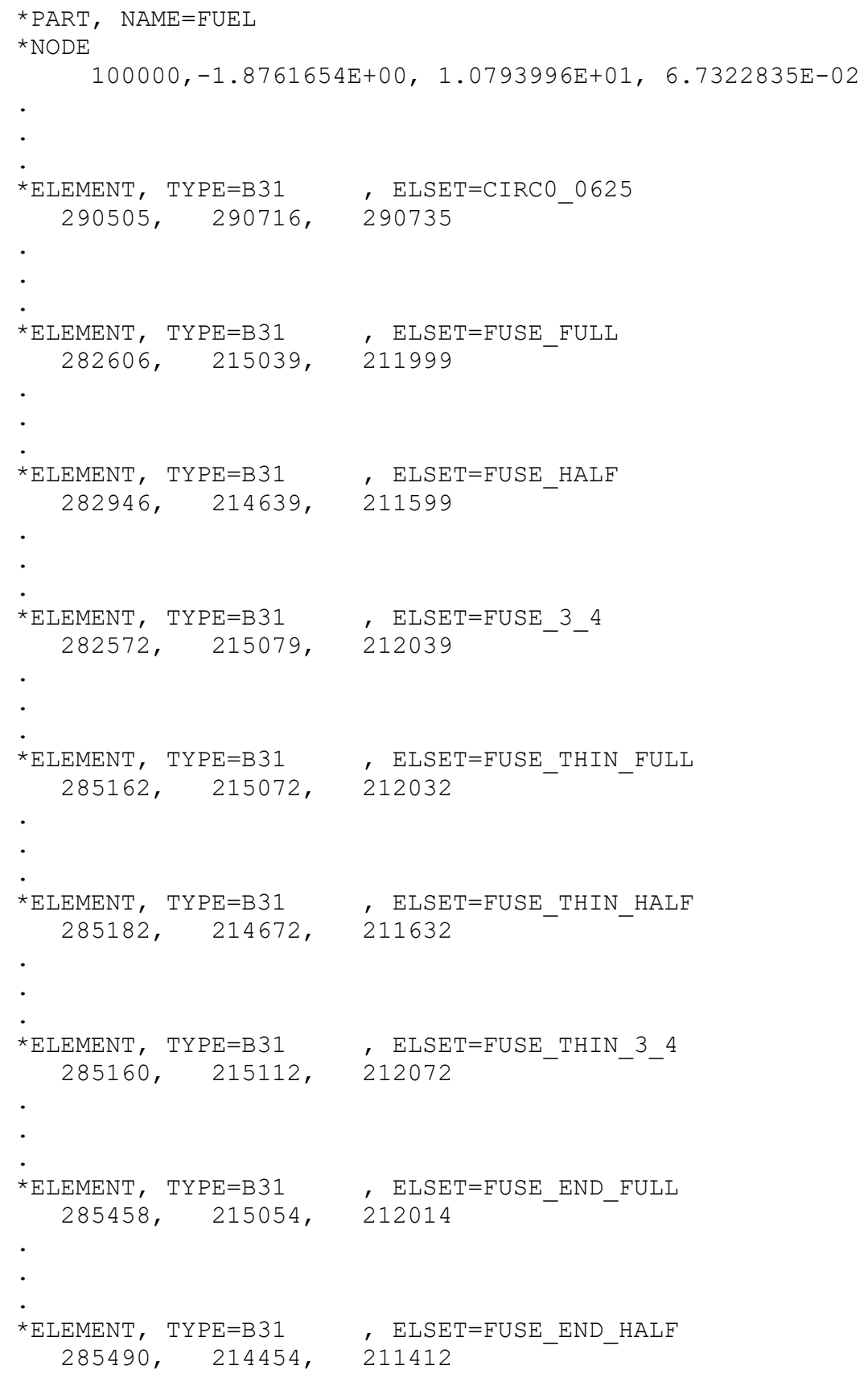




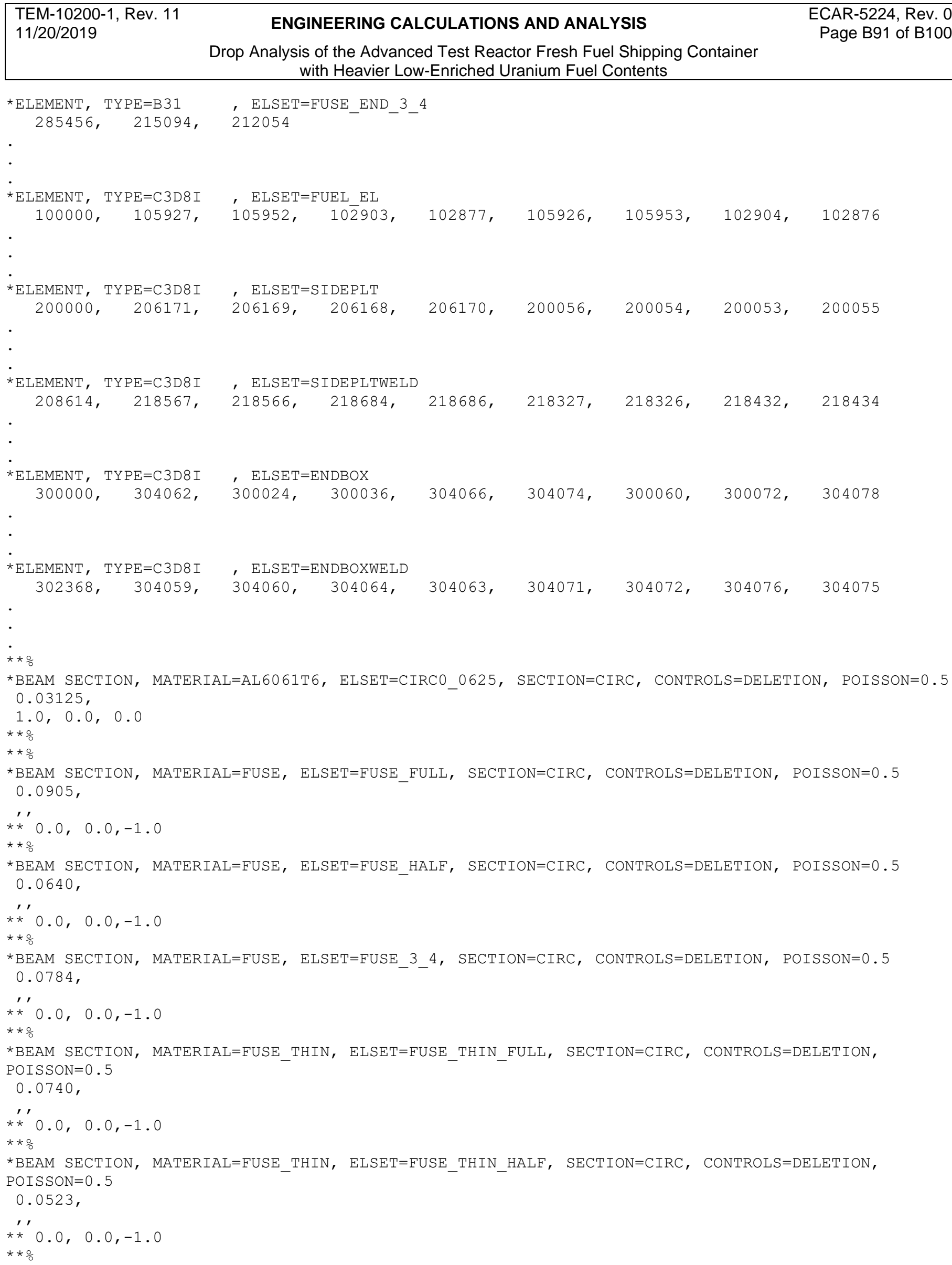




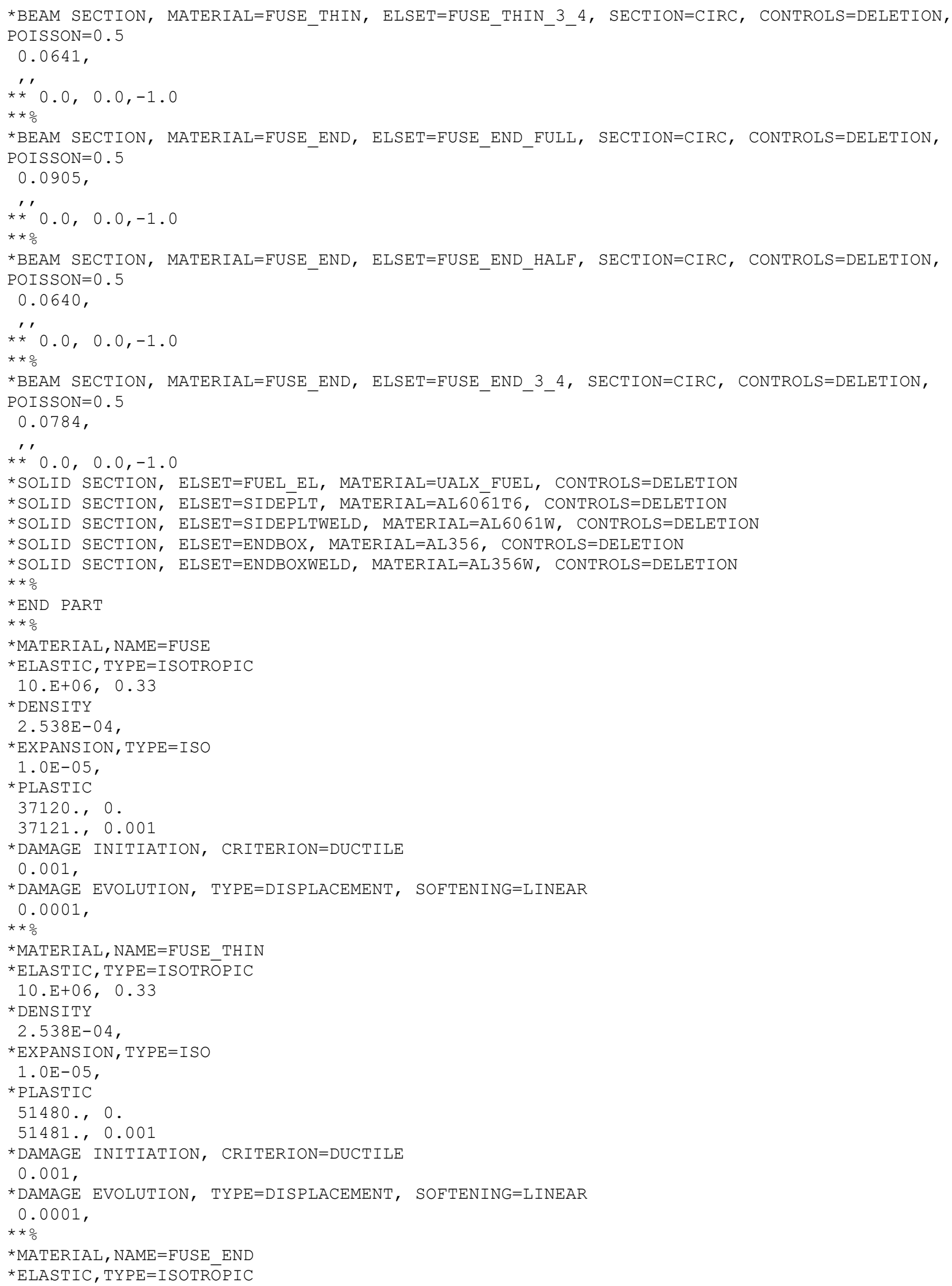




\begin{tabular}{|lcr|}
\hline $\begin{array}{l}\text { TEM-10200-1, Rev. 11 } \\
11 / 20 / 2019\end{array}$ & ENGINEERING CALCULATIONS AND ANALYSIS & ECAR-5224, Rev. 0 \\
& $\begin{array}{c}\text { Drop Analysis of the Advanced Test Reactor Fresh Fuel Shipping Container } \\
\text { with Heavier Low-Enriched Uranium Fuel Contents }\end{array}$ & \\
\hline
\end{tabular}

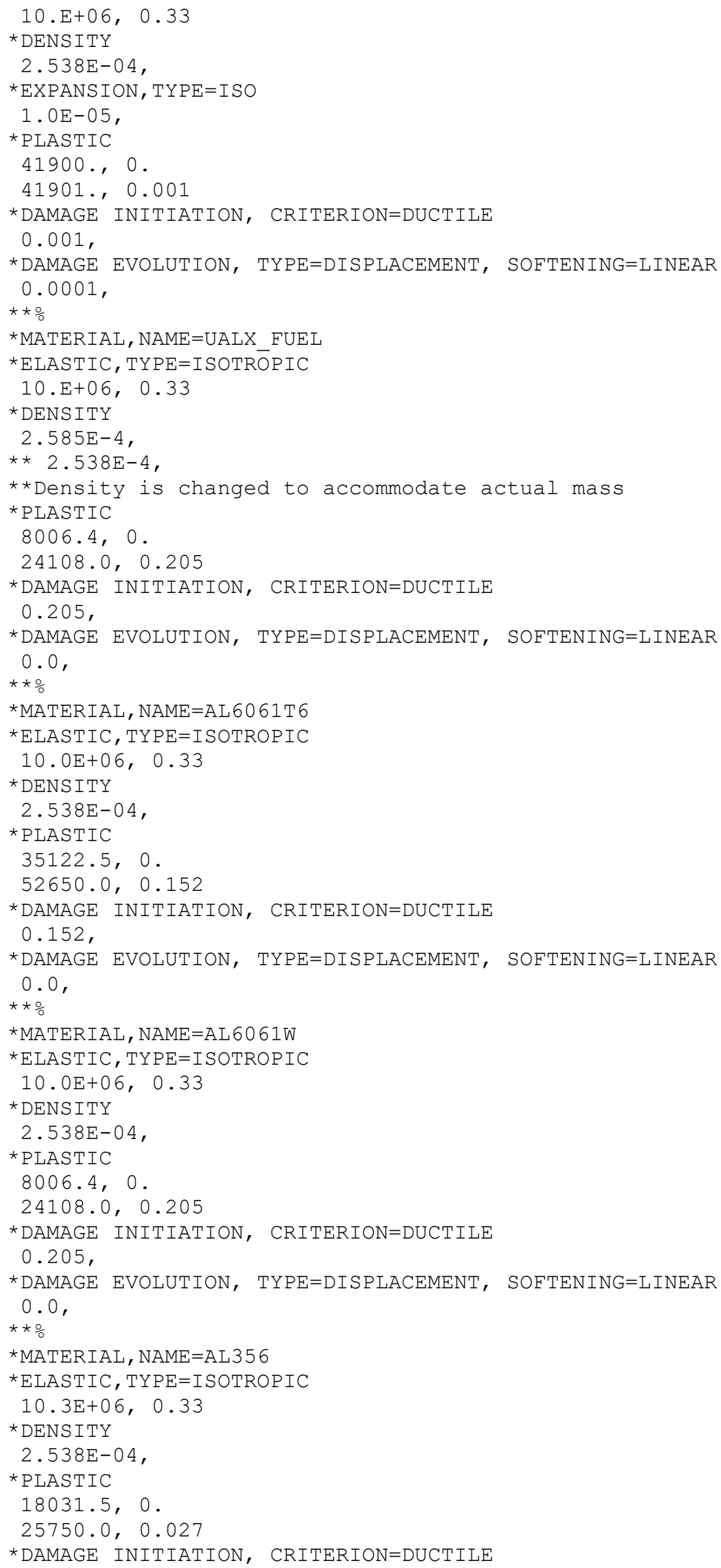




\begin{tabular}{|lcr|}
\hline $\begin{array}{l}\text { TEM-10200-1, Rev. 11 } \\
11 / 20 / 2019\end{array}$ & $\begin{array}{c}\text { ENGINEERING CALCULATIONS AND ANALYSIS } \\
\text { Drop Analysis of the Advanced Test Reactor Fresh Fuel Shipping Container } \\
\text { with Heavier Low-Enriched Uranium Fuel Contents }\end{array}$ & Page B94 of B100 \\
\hline
\end{tabular}

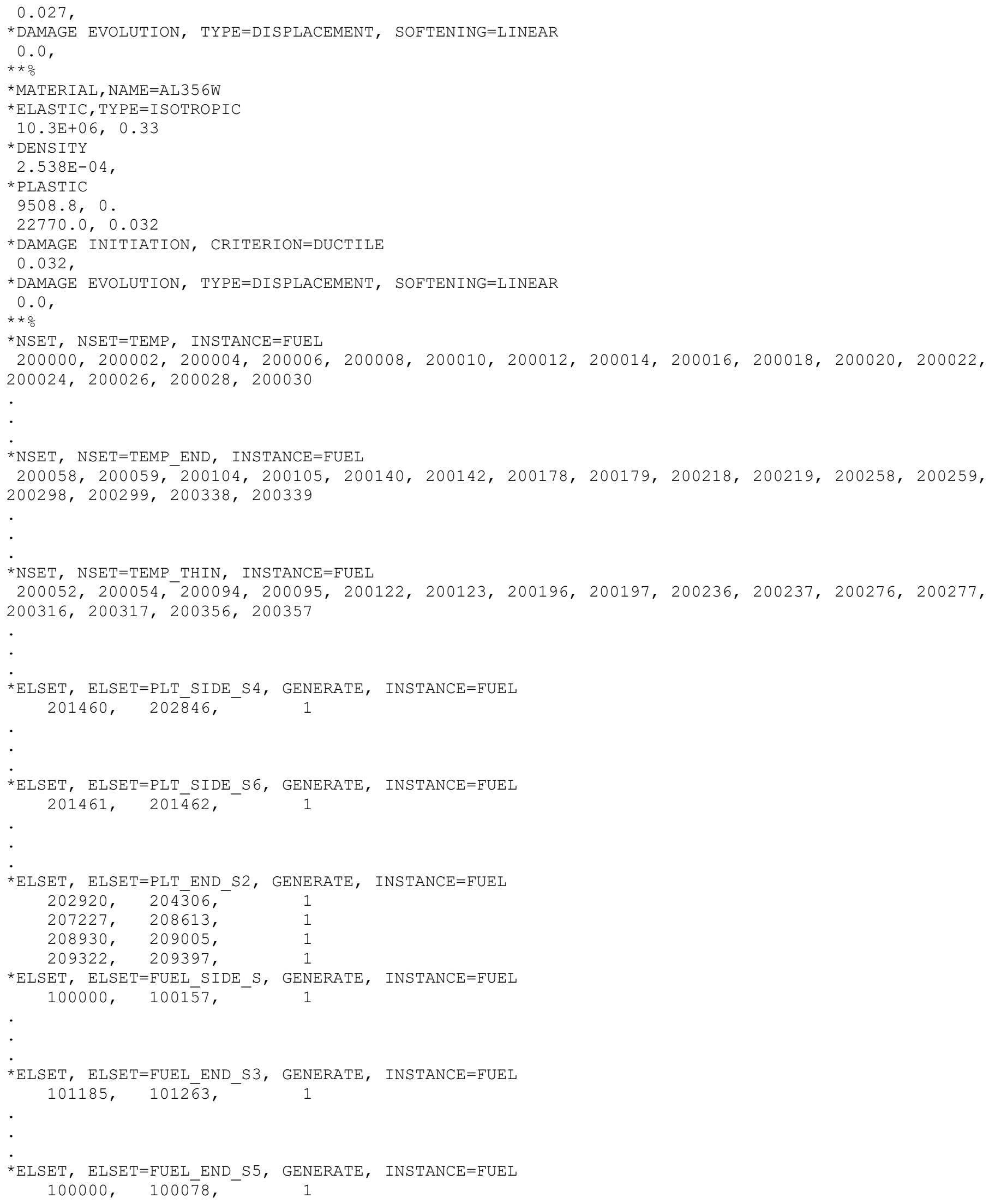




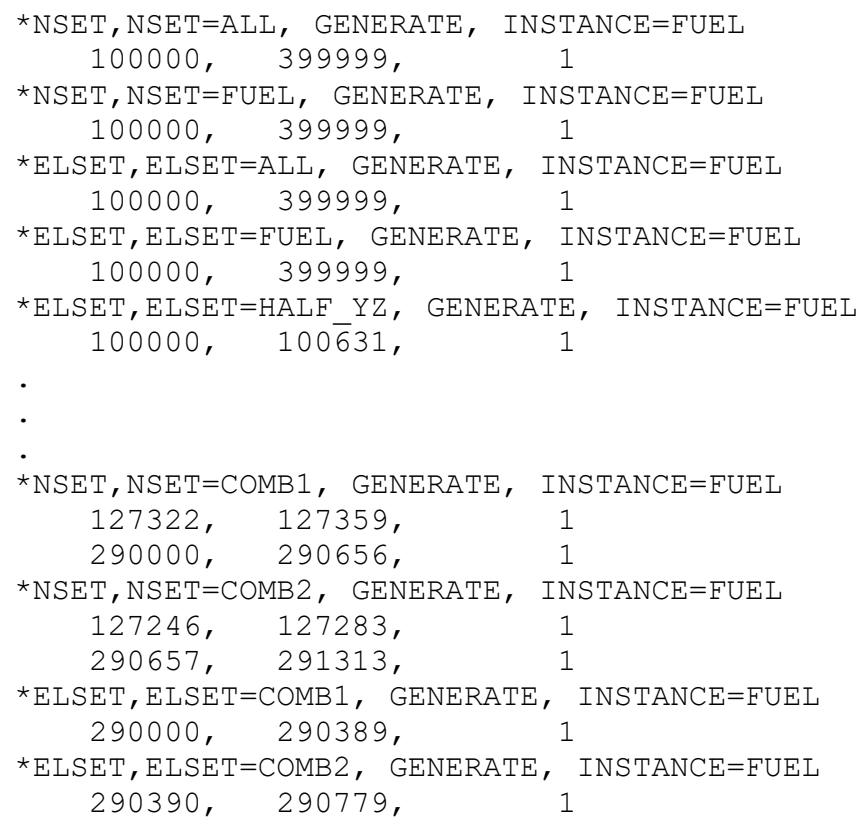

Below are data for the with the Scope Part 1a (Table 3) fuel element finer meshed fuel plate ends. This file is a modified version of "fuel_HEU.i" where coarse meshed elements and nodes are deleted and replaced with fine meshed elements and nodes. Additionally, sets are added for tying the fine meshed portion in place. Consequently, only the important set changes from "fuel_HEU.i" are shown.

fuel_HEU_med_plt.i:

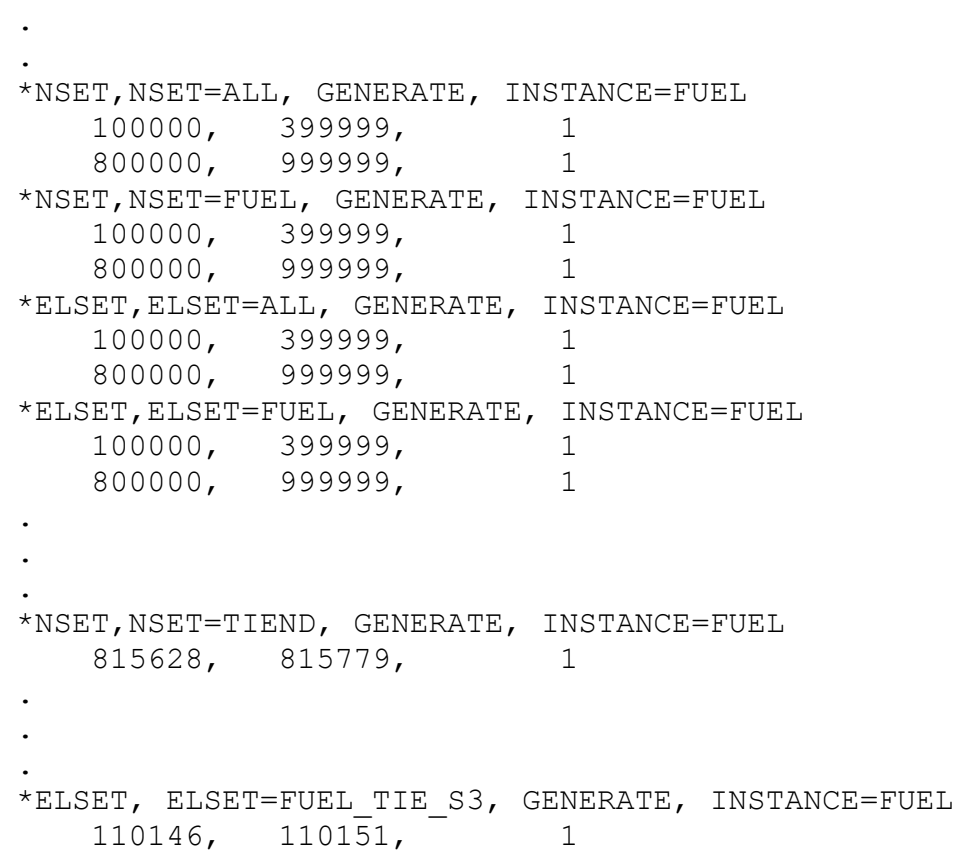




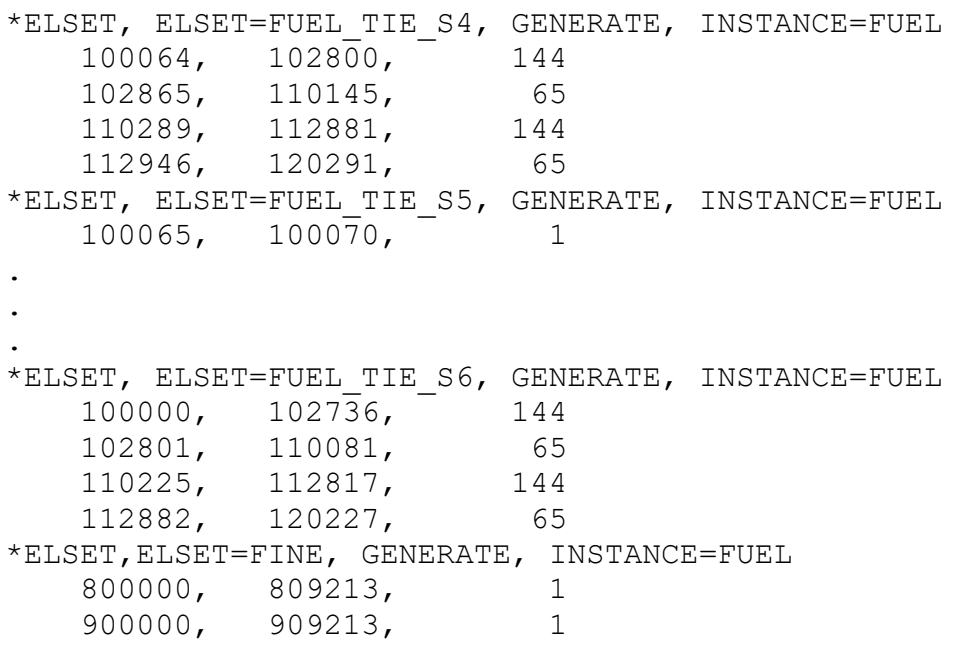

Below are data for the Scope Part 1b (Table 3) fuel element. This file is a modified version of "fuel_HEU.i" where only the material properties have been modified. Consequently, only the material properties are shown.

fuel_HEU_tough_end_box.i:

*MATERIAL, NAME $=$ FUSE

*ELASTIC, TYPE=ISOTROPIC

10.E+06, 0.33

*DENSITY

2.538E-04,

$\star$ EXPANSION, TYPE $=$ ISO

1. OE-05,

*PLASTIC

$37120 ., 0$.

$37121 ., 0.001$

*DAMAGE INITIATION, CRITERION=DUCTILE

0.001 ,

*DAMAGE EVOLUTION, TYPE=DISPLACEMENT, SOFTENING=LINEAR

0.0001 ,

$\star * \frac{\circ}{\circ}$

*MATERIAL, NAME $=$ FUSE THIN

*ELASTIC, TYPE=ISOTROPIC

$10 . E+06,0.33$

*DENSITY

2.538E-04,

$\star$ EXPANSION, TYPE $=$ ISO

1. OE-05,

*PLASTIC

$51480 ., 0$.

51481., 0.001

*DAMAGE INITIATION, CRITERION=DUCTILE

0.001 ,

*DAMAGE EVOLUTION, TYPE=DISPLACEMENT, SOFTENING=LINEAR

0.0001 , 


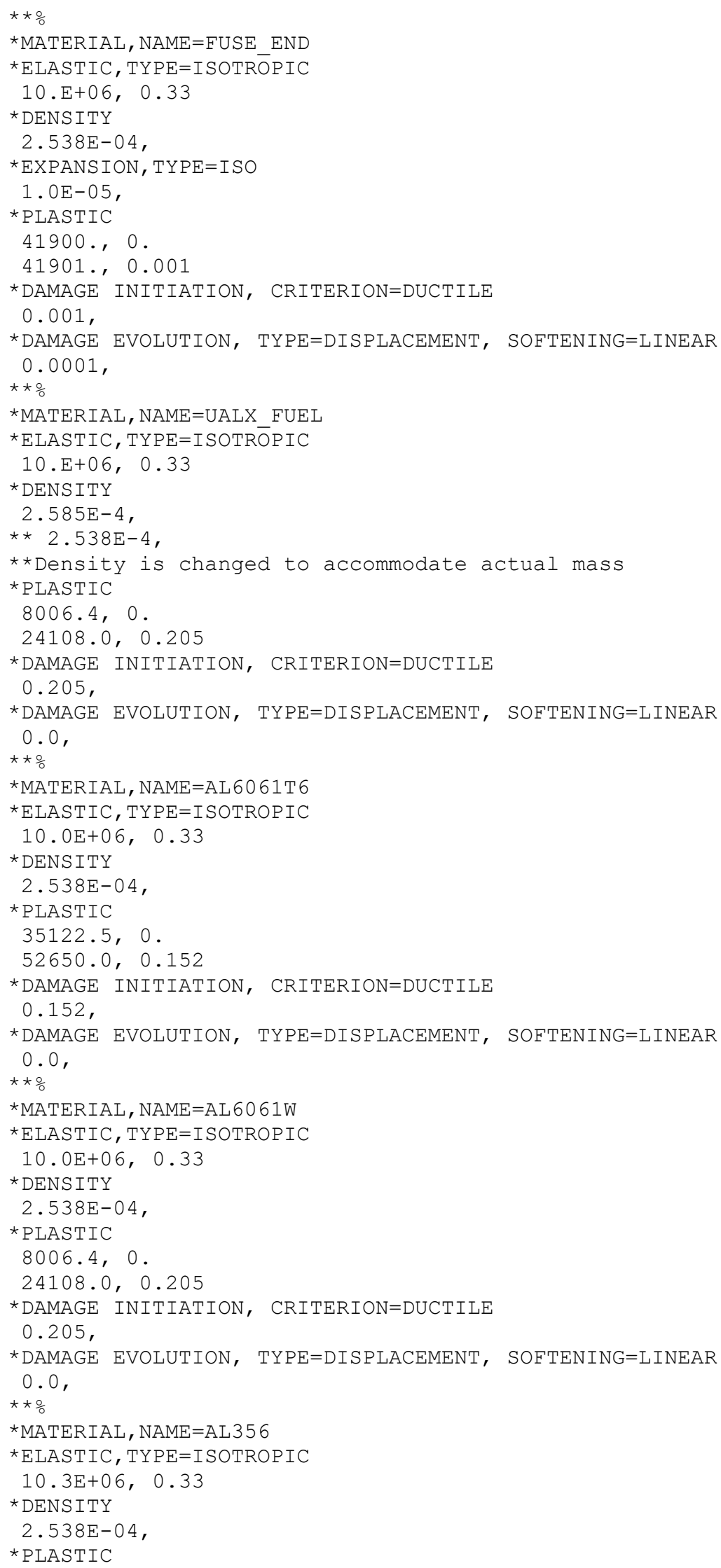




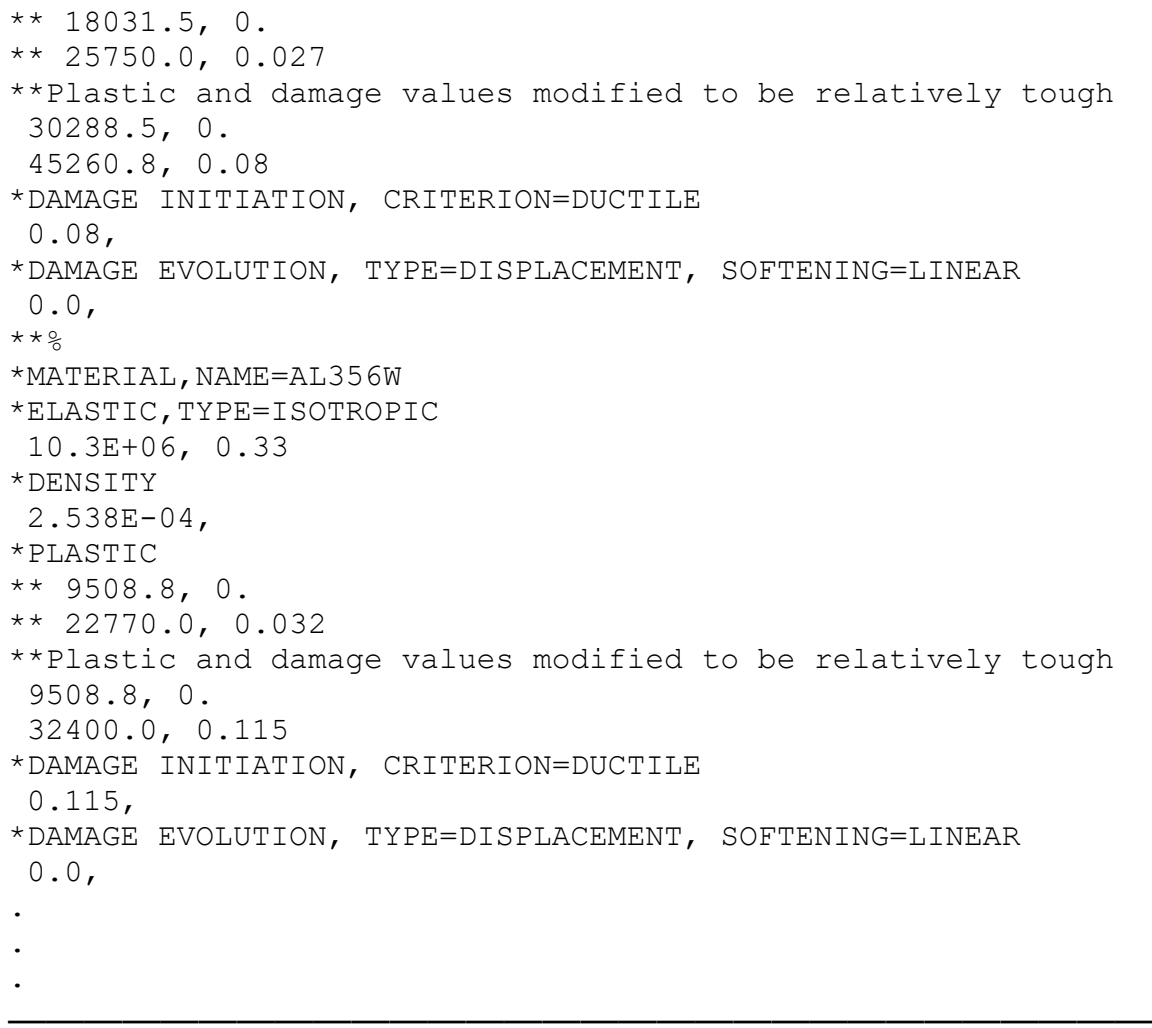

Below are data for the Scope Part 2a (Table 3) fuel element. This file is a modified version of "fuel_HEU.i" where only the fuel plate material properties have been modified. Consequently, only the fuel plate material properties are shown.

fuel_LOWE.i:

*MATERIAL, NAME = LOWE_FUEL

*ELASTIC, TYPE $=$ ISOTRO $\overline{\mathrm{P}} I \mathrm{C}$

10. E+06, 0.33

*DENSITY

$6.239 \mathrm{E}-4$,

$\star * 2.538 \mathrm{E}-4$,

**Density is changed to accommodate actual mass

*PLASTIC

$8006.4,0$.

$24108.0,0.205$

*DAMAGE INITIATION, CRITERION=DUCTILE

0.205 ,

*DAMAGE EVOLUTION, TYPE=DISPLACEMENT, SOFTENING=LINEAR

0.0 , 
Below are data for the Scope Part $2 b$ (Table 3) fuel element. This file is the same as the file "fuel_HEU_tough_end_box.i" except fuel plate material properties have been modified to accommodate the LOWE fuel element. Consequently, only the fuel plate material properties are shown.

fuel_LOWE_tough_end_box.i:

*MATERIAL, NAME=LOWE FUEL

*ELASTIC, TYPE=ISOTRŌPIC

10. $\mathrm{E}+06,0.33$

*DENSITY

$6.239 \mathrm{E}-4$,

** $2.538 \mathrm{E}-4$,

**Density is changed to accommodate actual mass

*PLASTIC

$8006.4,0$

$24108.0,0.205$

*DAMAGE INITIATION, CRITERION=DUCTILE

0.205 ,

*DAMAGE EVOLUTION, TYPE=DISPLACEMENT, SOFTENING=LINEAR

0.0 ,

Below are data for the Scope Part 3 (Table 3) fuel element.

fuel_tough_coarse_no_fail_5xmass.i:

*PART, NAME $=$ FUEL

*NODE

$100000,9.3685906 \mathrm{E}-01,6.9968622 \mathrm{E}+00,-9.9880669 \mathrm{E}-01$

*ELEMENT, TYPE=C3D8I , ELSET $=E N D B O X$

100000, 100024, 100025, 100028, 100027, 100039, 100040, 100043, 100042

*ELEMENT, TYPE=C3D8I , ELSET=SIDEPLTWELD

102245, 102239, 102241, 102242, 102240, 104299, 104301, 104302, 104300

.

*ELEMENT, TYPE=C3D8I , ELSET=FUEL_EL

101095, 102268, 102267, 102269, 102270, 102274, 102275, 102320, 102311

.

*ELEMENT, TYPE=C3D8I , ELSET=ENDBOXWELD

100100, 100271, 100272, 100275, 100274, 100423, 100425, 100431, 100429 
ENGINEERING CALCULATIONS AND ANALYSIS

Drop Analysis of the Advanced Test Reactor Fresh Fuel Shipping Container with Heavier Low-Enriched Uranium Fuel Contents

$\star \star \circ \%$

*SOLID SECTION, ELSET=ENDBOX, MATERIAL=AL356, CONTROLS=DELETION

*SOLID SECTION, ELSET=SIDEPLTWELD, MATERIAL=AL6061W, CONTROLS=DELETION

*SOLID SECTION, ELSET=FUEL EL, MATERIAL=UALX FUEL, CONTROLS=DELETION

*SOLID SECTION, ELSET=ENDBŌXWELD, MATERIAL=Ā $356 \mathrm{~W}$, CONTROLS=DELETION

$\star \star \circ \frac{0}{0}$

*END PART

$\star \star \circ \div$

* Note: All material properties are defined as AL6061T6 without failure

$\star \star \circ \%$

*MATERIAL, NAME $=$ UALX FUEL

*ELASTIC, TYPE=ISOTRŌPIC

$10.0 \mathrm{E}+06,0.33$

*DENSITY

1.843E-03,

** 2.538E-04,

* PLASTIC

$35122.5,0$.

$52650.0,0.152$

$\star \star * \circ$

*MATERIAL, NAME=AL $6061 \mathrm{~W}$

*ELASTIC, TYPE=ISOTROPIC

10.0E+06, 0.33

*DENSITY

1. $843 \mathrm{E}-03$,

* 2.538E-04,

*PLASTIC

$35122.5,0$.

$52650.0,0.152$

$\star \star * \circ$

*MATER IAL, NAME=AL356

*ELASTIC, TYPE=ISOTROPIC

10.0E+06, 0.33

*DENSITY

1.843E-03,

** 2.538E-04,

*PLASTIC

$35122.5,0$.

$52650.0,0.152$

$\star \star \circ \circ$

*MATERIAL, NAME $=$ AL3 $56 \mathrm{~W}$

*ELASTIC, TYPE=ISOTROPIC

10.0E+06, 0.33

*DENSITY

1. $843 \mathrm{E}-03$,

** 2.538E-04,

*PLASTIC

$35122.5,0$.

$52650.0,0.152$

$\star \star \circ \%$

*NSET, NSET=ALL, GENERATE, INSTANCE=FUEL $100000, \quad 108179,1$

*NSET, NSET=FUEL, GENERATE, INSTANCE=FUEL 100000, 108179, 1

*ELSET, ELSET=ALL, GENERATE, INSTANCE=FUEL 100000, 104669, 1

*ELSET, ELSET=FUEL, GENERATE, INSTANCE=FUEL $100000,104669,1$ 


\section{Appendix C}

\section{ATR FFSC Evaluation Results}

\section{CONTENTS}

C1 PURPOSE/SUMMARY.

C2 PHYSICAL AND MODELED ATR FFSC RESULTS COMPARISON (SCOPE PART 1, TABLE 3)C2

C3 HIGH FUEL ELEMENT WEIGHT ATR FFSC RESULTS (SCOPE PART 3, TABLE 3) C76

C4 ATR FFSC LID PIN STUDY RESULTS (SCOPE PART 4, TABLE 3)

NOTE: References identified in this appendix can be found at the end of the main body.)

\section{C1 PURPOSE/SUMMARY}

This appendix documents the drop scenario results for the Advanced Test Reactor (ATR) Fresh Fuel Shipping Container (FFSC). Appendix B provides the model development for the loaded ATR FFSC drop scenarios used for evaluation. While each of the drop scenarios include a fuel element, the fuel element drop scenario results are documented in Appendix D. Though, some fuel element results are provided for information in this appendix for models where fuel element results are otherwise not given.

The purpose of this appendix is to provide ATR FFSC evaluation results. Important results include showing that the ATR FFSC model is reasonable and/or conservative when compared with the physical drops documented in the ATR FFSC Safety Analysis Report (SAR) (2017). In these drop scenarios, the ATR highly enriched uranium fuel element weight is $22.1 \mathrm{lbf}$. It is also important to show that the same ATR FFSC model can accommodate much higher fuel element weights. The minimum fuel element weight that the ATR FFSC must accommodate is the LOWE fuel element weight. Per Quirl (2019), the bounding weight for a LOWE fuel element is $44 \mathrm{lbf}$.

Results showing that the ATR FFSC model is reasonable and/or conservative when compared with the physical drops are documented in Section C2. The ATR FFSC mesh and material properties are the same for all the FEA models in this evaluation. For the drop scenarios in Scope Part 1 (Table 3), a minimum of four model runs are performed per drop scenario (i.e., Scope Parts 1a-1d). (There is a minimum of four model runs because there could be two model runs for a given Scope Part for mesh refinement.) Scope Parts 1a and $1 \mathrm{~b}$ (Table 3) are relevant for comparison with physical drops (where Scope Parts 1c and 1d included blocks). The reason for multiple model runs is to better understand the fuel element damage. The ATR FFSC results for the multiple model runs are very similar. Consequently, to reduce voluminous results description, only Scope Part 1a (Table 3) or Scope Part 1b (Table 3) needs to be documented. Scope Part $1 \mathrm{~b}$ (Table 3 ) is selected as the documented results because the relatively tough material properties for the end boxes and enclosure could cause slightly higher strains in the ATR FFSC. Showing that the model can reasonably and/or conservatively predict the ATR FFSC damage in the physical drop events validates the use of the model for increased fuel element weights as well. 
NOTE: $\quad$ The results in Section C2.9.2 are Part 1a, Table 3 results with discussion of how Part 1b, Table 3 results differ. This is because the fuel element damage caused instability in the Part 1b, Table 3 results. The ATR FFSC did not show any stability issues in either model run and similar damage occurred.

Results showing that the ATR FFSC model can accommodate much higher fuel element weights are documented in Section C3. Scope Part 2 (Table 3) provides results for drop scenarios with the 44-lbf LOWE fuel element and Scope Part 3 (Table 3) provides results for drop scenarios with a 115-lbf fuel element. Given that the Scope Part 3 (Table 3) fuel element weight easily encompasses the Scope Part 2 (Table 3) weight, the Scope Part 3 (Table 3) damage should easily encompass the Scope Part 3 (Table 3) damage. Consequently, to reduce voluminous results description, only Scope Part 3 (Table 3 ) is documented for the ATR FFSC.

Scope Part 4 (Table 3) is an additional study specific to the ATR FFSC damage and is documented in Section C4. As described in Section C2.4.1, one of the lid pins sheared off between the lid and body in the physical drop for Scope Part 1 (Table 3), Test 5 (Table 2). Section C4 documents two sets of models to study this. First, models similar to the physical drops are evaluated. The motivation is to check if it is likely that a single drop could fail a lid pin and that models similar to the Scope Part 1b (Table 3), Test 5 (Table 2) are used. If lid pin failure is not demonstrated, then the results help support the idea that multiple drops are necessary to produce lid pin failure. Second, high weight models (115-lbf fuel element) are performed. The motivation is to check if the more massive drop makes lid pin failure more likely.

Energy curves are provided for all of the presented drop scenarios. The energy units are "in॰lbf" and the time is in "second."

\section{C2 PHYSICAL AND MODELED ATR FFSC RESULTS COMPARISON (SCOPE PART 1, TABLE 3)}

Sections C2.1-C2.11 show the physical and FEA model results for the Scope Part 1 (Table 3) drop scenarios (with a fuel element weight of $22.1 \mathrm{lbf}$ ). Section C2.12 provides a brief summary of the results for the Scope Part 1 (Table 3) drop scenarios.

NOTE: $\quad$ As discussed in Table 2 of the main body, Tests 4, 7, and 9 are not performed with a FEA model.

Figure C-1 shows the ATR Package Orientation Markings defined in the ATR FFSC SAR (2017). ATR FFSC SAR (2017), Figure 2.12.1-4, is referenced numerous times in the descriptions of the physical drop results and shown here for reference. 


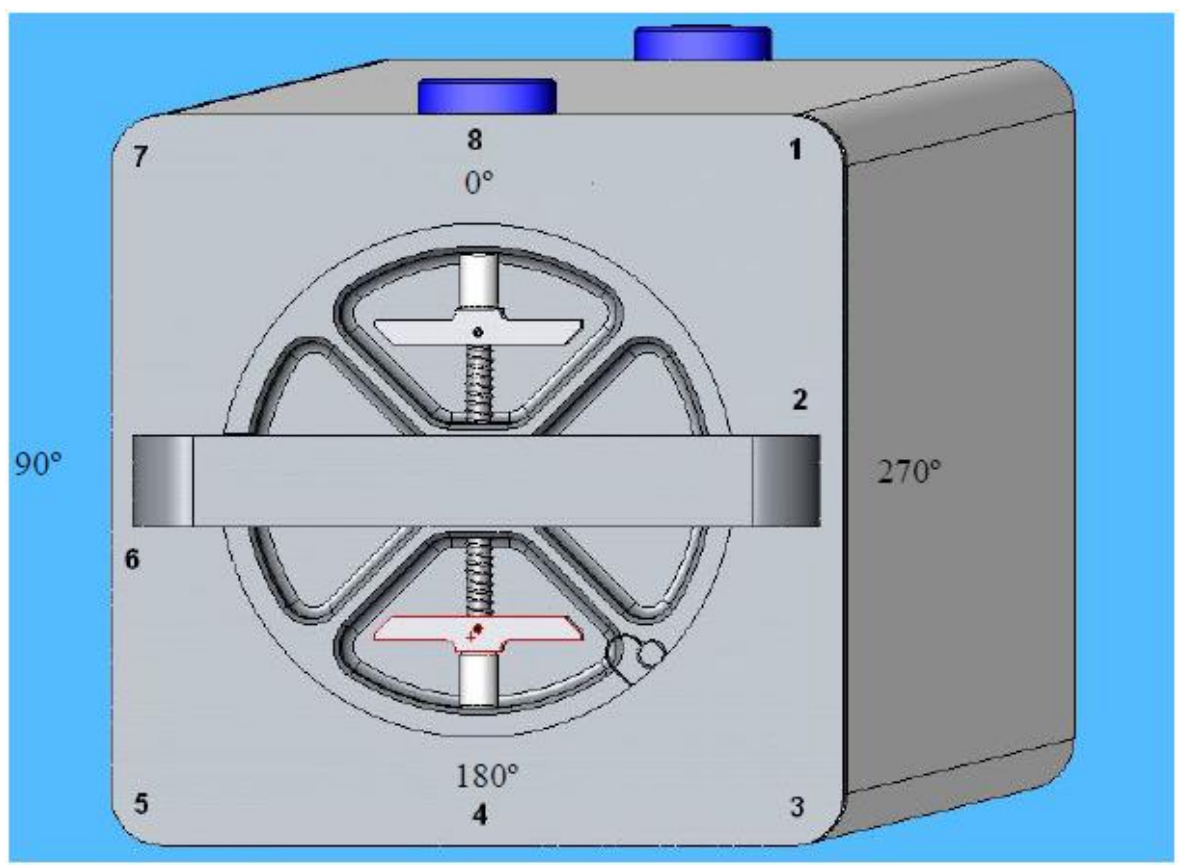

Figure C-1. ATR package orientation markings [ATR FFSC SAR (2017), Figure 2.12.1-4].

\section{C2.1 Results for Scope Part 1 (Table 3), Test 1 (Table 2)}

The drop scenario considered in this section is a 4-ft drop where the loaded ATR FFSC impacts with its center of gravity over the top corner. It is identified as CN1-1 in the ATR FFSC SAR (2017).

\section{C2.1.1 Results from the Physical Drop Scenario}

A summary of the physical drop scenario results for Scope Part 1 (Table 3), Test 1 (Table 2) is provided in the ATR FFSC SAR (2017), Section 2.12.1.4.1.1 (shown below for reference). Figure C-1 along with Figure C-2 and Figure C-3 provide the supporting ATR FFSC SAR (2017) figures for reference.

The impact location was at Corner 5 identified in Figure 2.12.1-4. Following the impact, the CTU bounced slightly and tipped over onto its side. There was minor visible exterior damage at the impact corner. The maximum deformation at the corner was approximately 1/8 in. The closure handle was also deformed as a result of the drop. The overall length of the package did not change other than the 1/8 in. at the impact corner and compression of the closure handle of approximately $1 / 2 \mathrm{in.} \mathrm{on} \mathrm{one} \mathrm{side.} \mathrm{There} \mathrm{was} \mathrm{also} \mathrm{a} \mathrm{1/8} \mathrm{in.}$ deformation on the side corner approximately $11 / 4 \mathrm{in}$. from the impact corner. There was no visible deformation or rotation of the closure, other than the handle. Figure 2.12.1-6 and Figure 2.12.1-7 show the CTU following the NCT drop. 
ENGINEERING CALCULATIONS AND ANALYSIS

Drop Analysis of the Advanced Test Reactor Fresh Fuel Shipping Container with Heavier Low-Enriched Uranium Fuel Contents
ECAR-5224, Rev. 0

Page C4 of C190

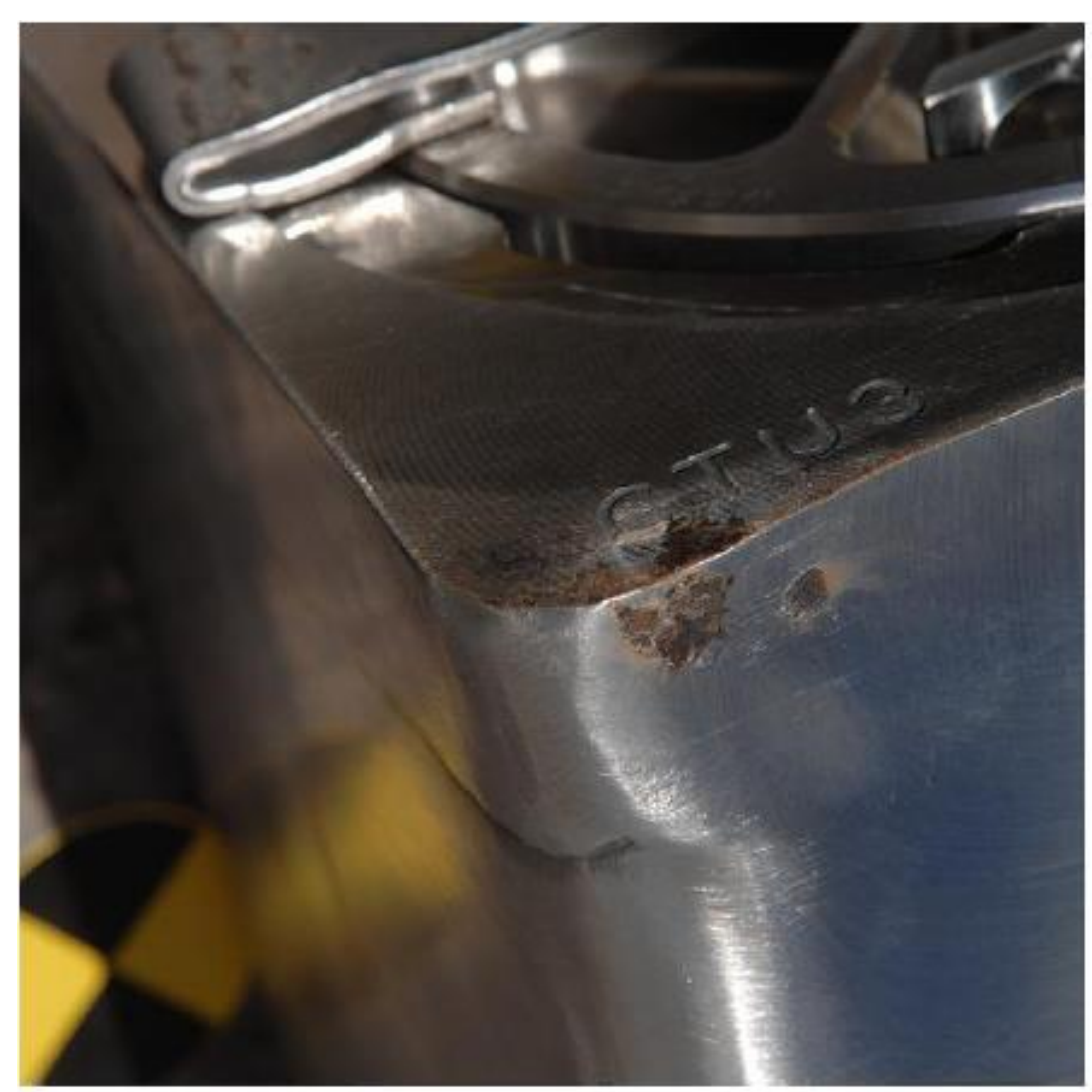

Figure C-2. CN1-1 impact damage [ATR FFSC SAR (2017), Figure 2.12.1-6].

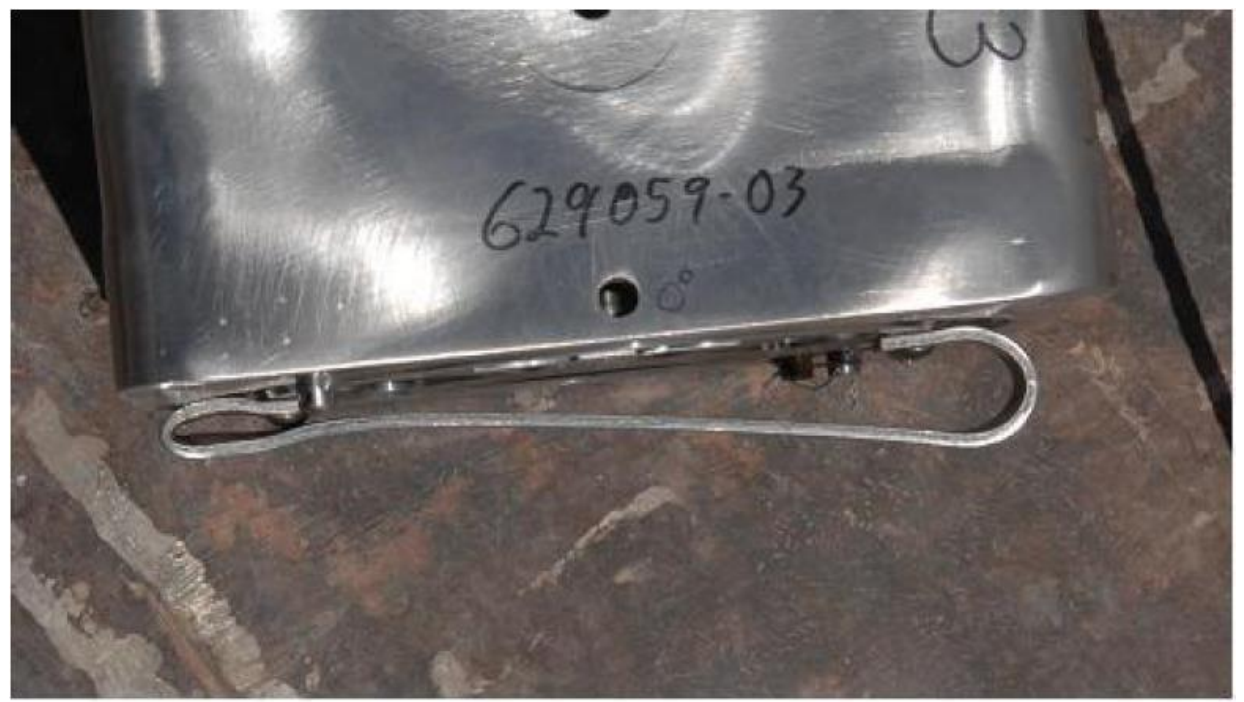

Figure C-3. CN1-1 impact on closure handle [ATR FFSC SAR (2017), Figure 2.12.1-7]. 


\section{C2.1.2 Results for Scope Part $1 \mathrm{~b}$ (Table 3), Test 1 (Table 2)}

The FEA model results for the Scope Part 1b (Table 3), Test 1 (Table 2) model are shown below in

Figure C-4 to Figure C-10. This drop scenario is a 4-ft drop where the loaded ATR FFSC impacts with its center of gravity over the top corner. The fuel element weights $22.1 \mathrm{lbf}$ and the drop scenario is modeled with minimum material properties except the enclosure and end boxes, which are modeled with relatively tough material properties.

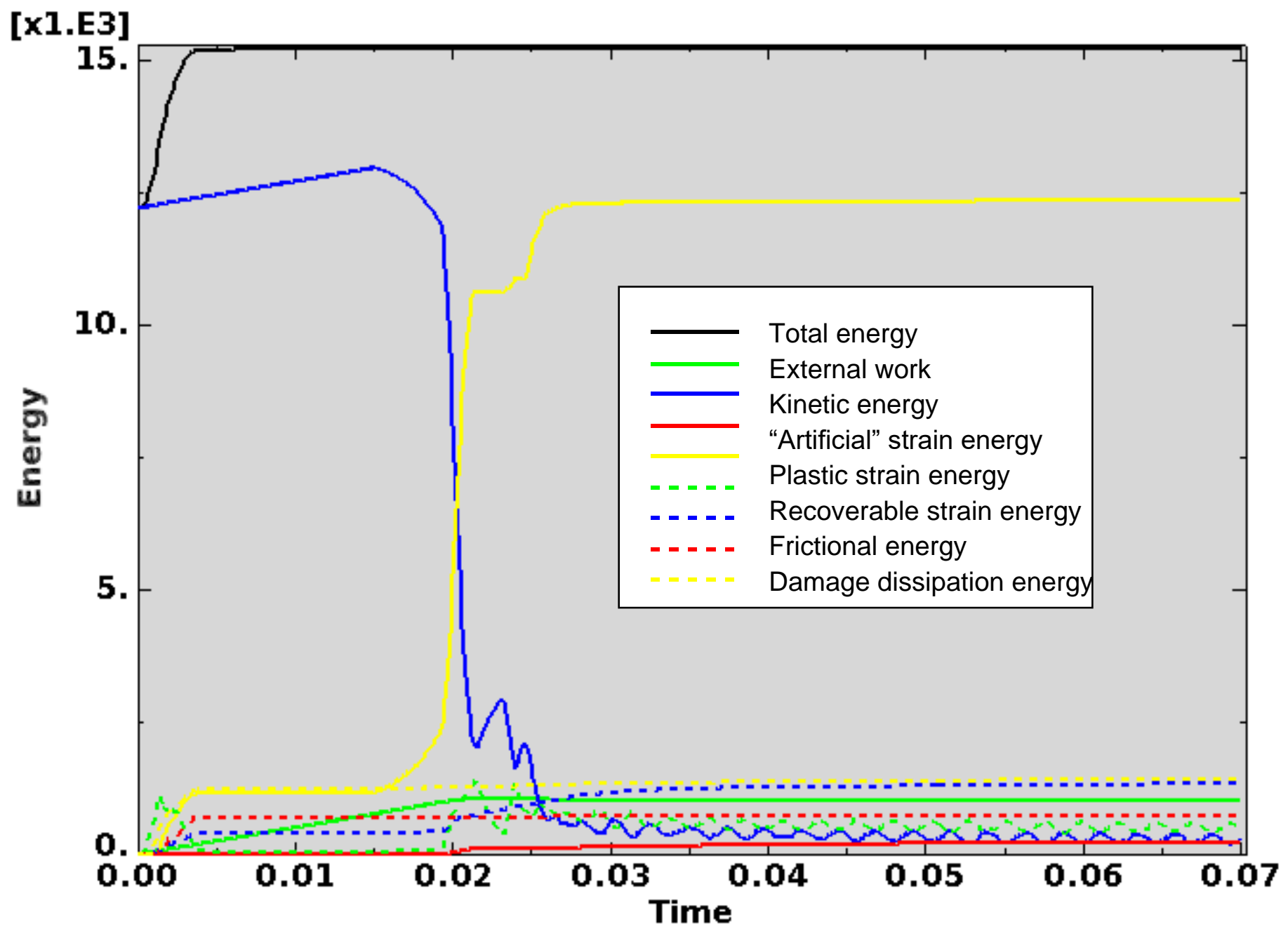

Figure C-4. Scope Part 1b (Table 3), Test 1 (Table 2) energy curves.

Figure C-4 shows the energy curves for Scope Part 1b (Table 3), Test 1 (Table 2) drop scenario. These curves exhibit a stable shape. Artificial strain energy represents the energy required to keep reduced integration elements from taking on a zero-energy hourglass shape. As shown in Figure C-4, the artificial energy at the end of the model run is $1.5 \%$ of the total energy. Therefore, the potential error associated with artificial energy is not considered to be significant. 


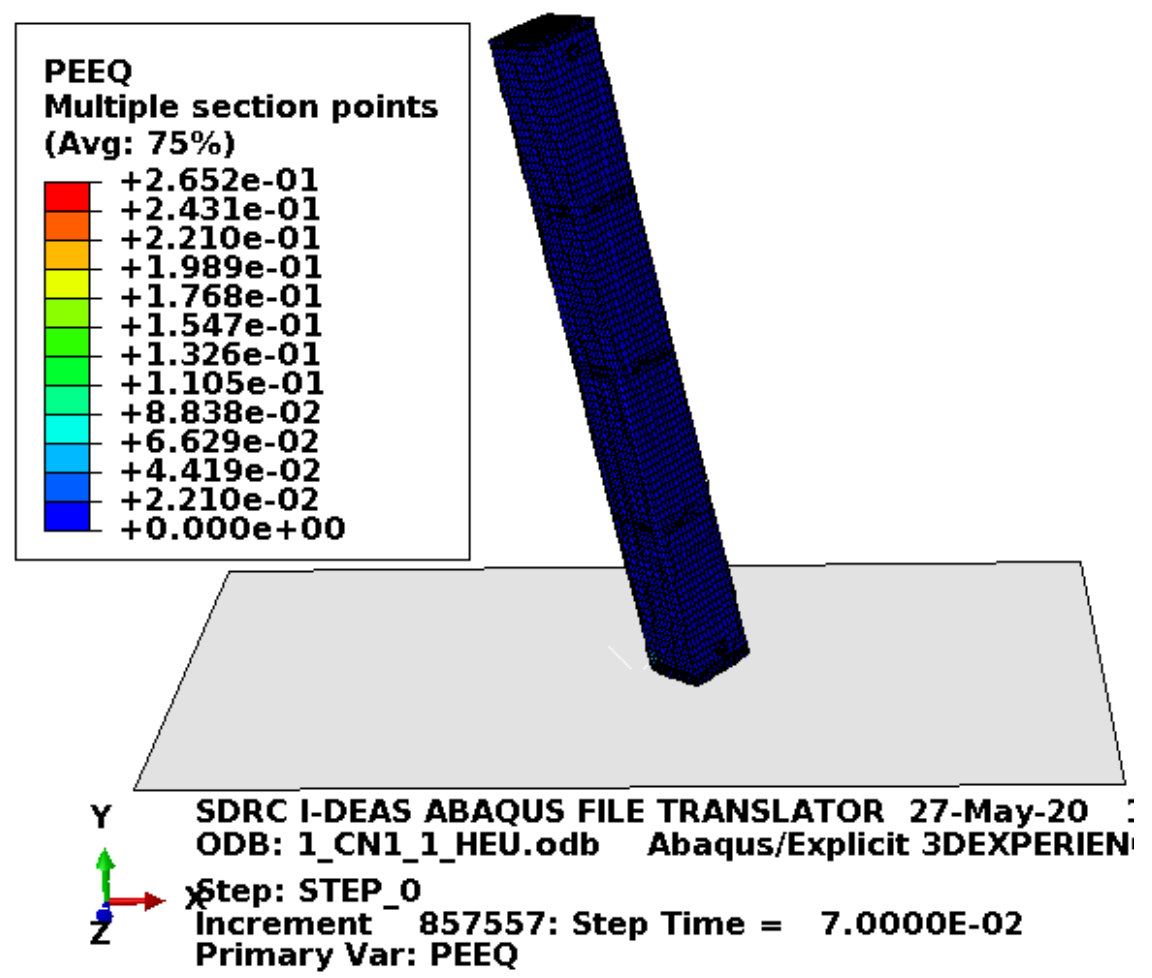

Figure C-5. Scope Part 1b (Table 3), Test 1 (Table 2) full-model plastic-equivalent strain.

Figure C-6 shows the equivalent plastic strain in the lid. The most deformation is in the closure handle, which is not a concern.

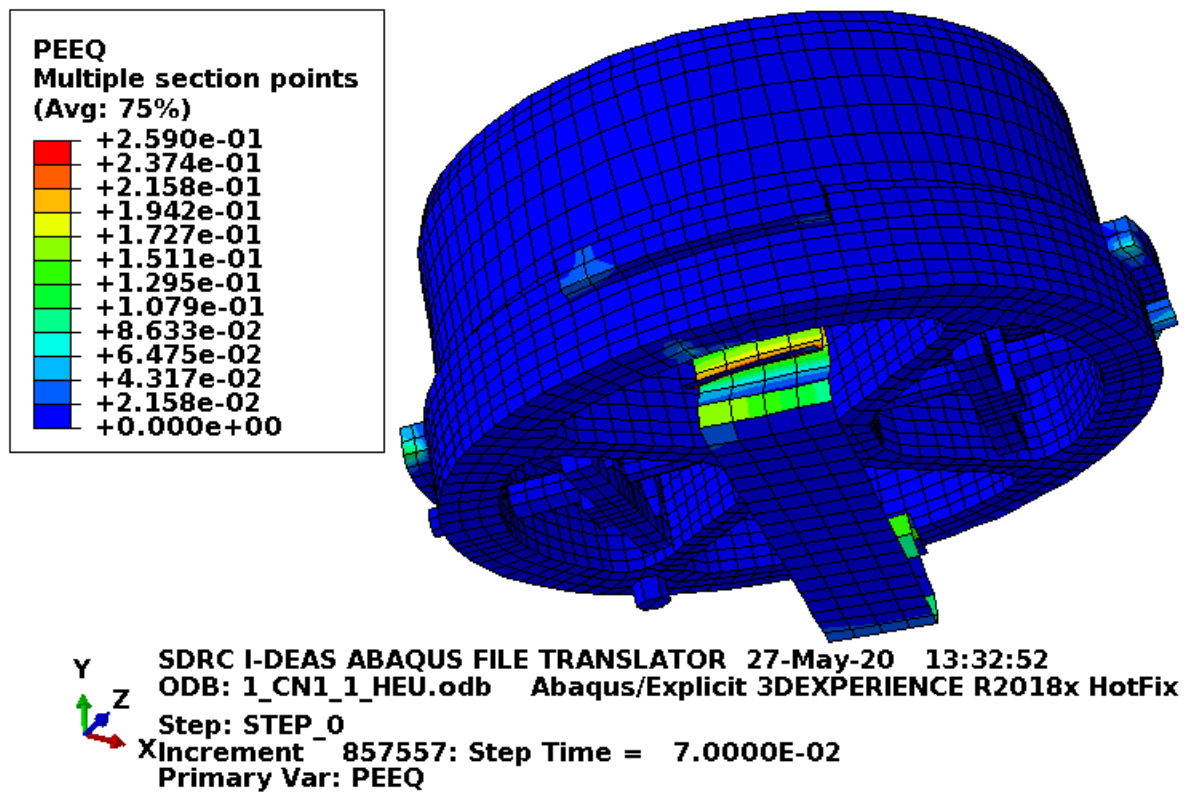

Figure C-6. Scope Part 1b (Table 3), Test 1 (Table 2) lid plastic-equivalent strain. 
ENGINEERING CALCULATIONS AND ANALYSIS

Drop Analysis of the Advanced Test Reactor Fresh Fuel Shipping Container with Heavier Low-Enriched Uranium Fuel Contents

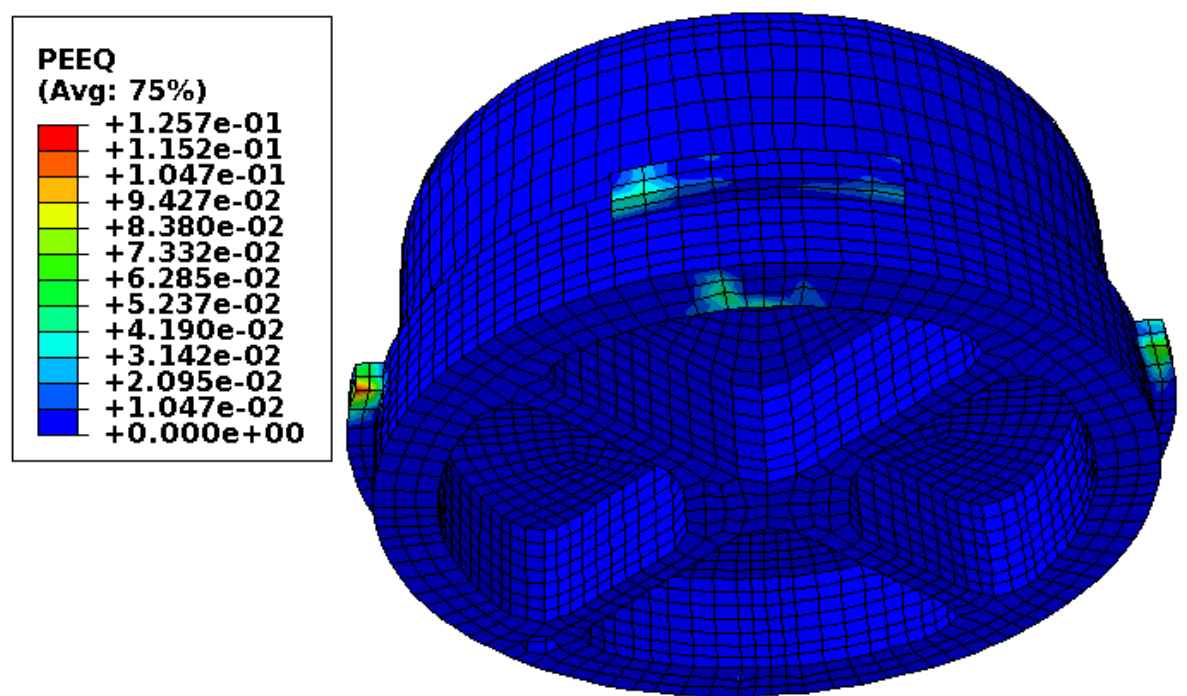

SDRC I-DEAS ABAQUS FILE TRANSLATOR 27-May-20 13:32:52

$Y$ z ODB: 1_CN1_1_HEU.odb Abaqus/Explicit 3DEXPERIENCE R2018 $\mathrm{H}$

Step: STEP 0

Increment ${ }^{-}$857557: Step Time $=$7.0000E-02

$X$ Primary Var: PEEQ

Figure C-7. Scope Part 1b (Table 3), Test 1 (Table 2) lid structure plastic-equivalent strain.

Figure C-7 shows the equivalent plastic strain in the structurally significant portion of the lid. Failure in these elements occurs at an equivalent plastic strain of $0.259 \mathrm{in}$./in. If element failure were to occur, the element would be deleted and removed from the model (thereby making its equivalent plastic strain not included in the maximum equivalent plastic strain for the plot). However, the missing element would be visible in the plot. Figure C-7 shows no element failure with margin.

Figure $\mathrm{C}-8$ shows the equivalent plastic strain in the lid pins. Failure in these elements occurs at an equivalent plastic strain of $0.295 \mathrm{in}$./in. If element failure were to occur, the element would be deleted and removed from the model (thereby making its equivalent plastic strain not included in the maximum equivalent plastic strain for the plot). However, the missing element would be visible in the plot. Figure C-8 shows no element failure with margin. 


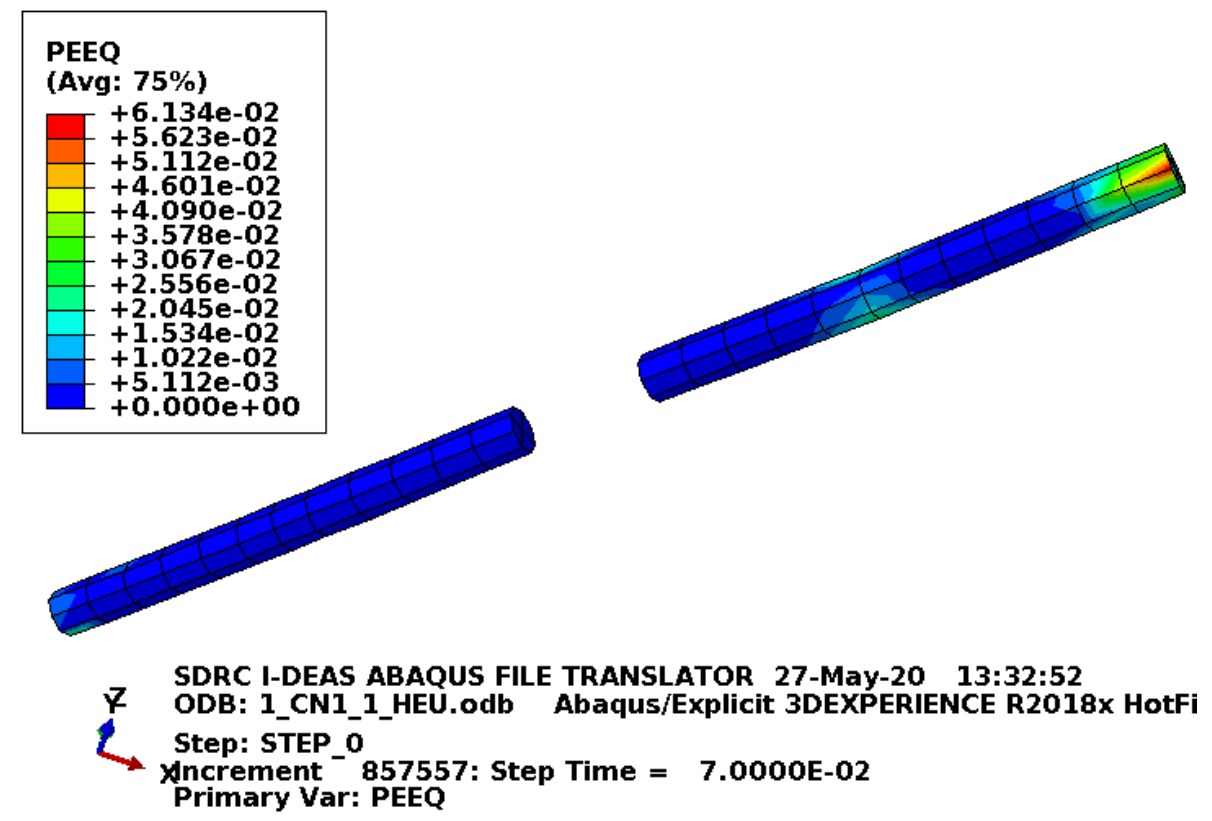

Figure C-8. Scope Part 1b (Table 3), Test 1 (Table 2) lid pins plastic-equivalent strain.

Figure C-9 shows the equivalent plastic strain in the body. Failure in these elements occurs at an equivalent plastic strain of $0.259 \mathrm{in}$./in. If element failure were to occur, the element would be deleted and removed from the model (thereby making its equivalent plastic strain not included in the maximum equivalent plastic strain for the plot). However, the missing element would be visible in the plot. Figure C-9 shows no element failure with margin.

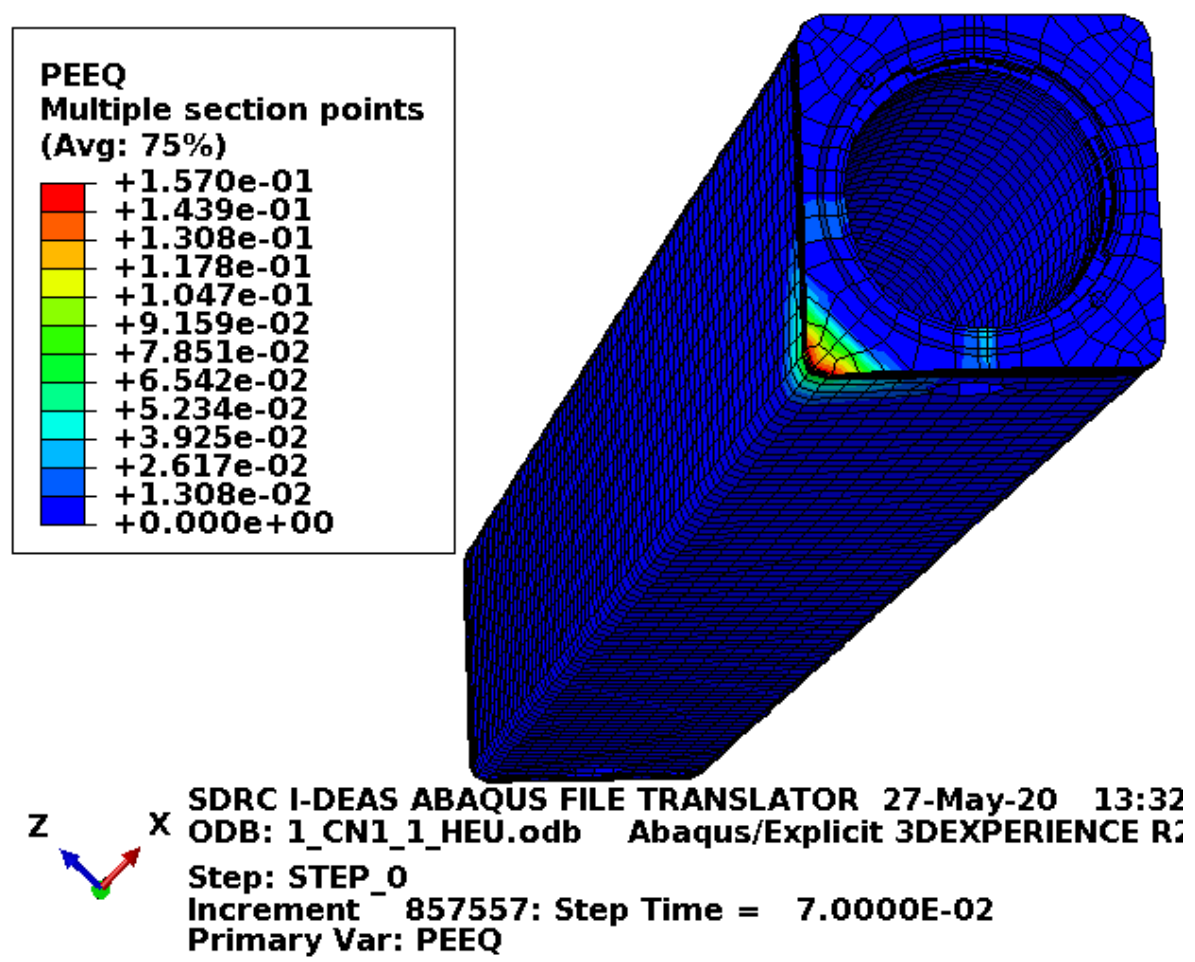

Figure C-9. Scope Part 1b (Table 3), Test 1 (Table 2) body plastic-equivalent strain. 
The maximum change in length of the body at the impacted corner is $0.24 \mathrm{in}$. This is comparable to the approximately 1/8-in. measured deformation in the physical drop (see Section C2.1.1). The conservatively high value in the FEA model can be somewhat attributed to using minimum material properties. This is a desirable result because when the FEA model is performed on similar drop scenarios where physical drops have not been performed, the FEA model should still produce conservative results.

Figure $\mathrm{C}-10$ shows the equivalent plastic strain in the enclosure. This is just for information as damage to the enclosure is acceptable.
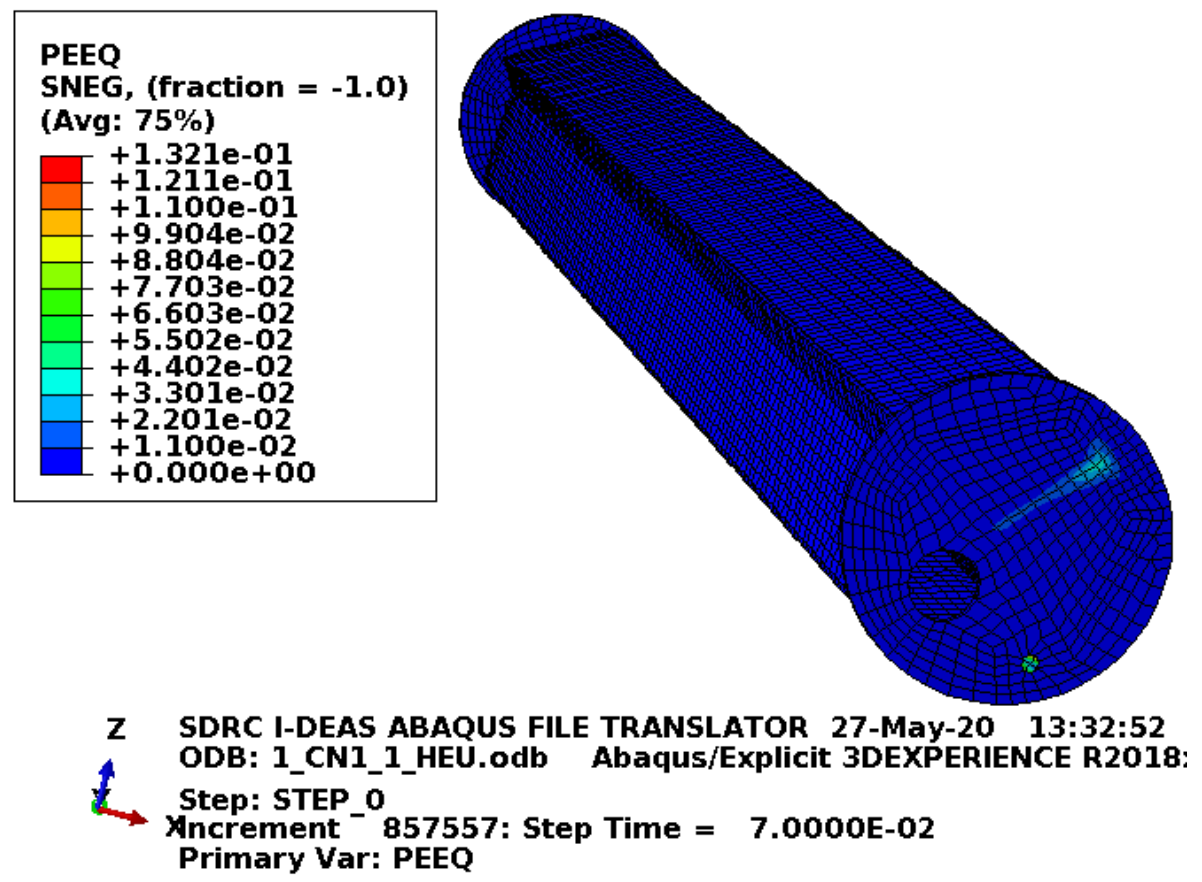

Figure C-10. Scope Part 1b (Table 3), Test 1 (Table 2) enclosure plastic-equivalent strain.

\section{C2.2 Results for Scope Part 1 (Table 3), Test 2 (Table 2)}

The drop scenario considered in this section is a 30-ft drop where the loaded ATR FFSC impacts flat on its side drop with the pocket-side down. It is identified as CD1-1 in the ATR FFSC SAR (2017).

\section{C2.2.1 Results from the Physical Drop Scenario}

A summary of the physical drop scenario results for Scope Part 1 (Table 3), Test 2 (Table 2) is provided in the ATR FFSC SAR (2017), Section 2.12.1.4.1.2 (shown below for reference). Figure C-1 along with Figure C-11 and Figure C-15 provide the supporting ATR FFSC SAR (2017) figures for reference.

Following impact, the CTU bounced and rotated slightly in the air. The high-speed video was reviewed and the impact was determined to be sufficiently flat. The justification for the determination was the large number of drops planned for the CTU, and that there were two more similar flat-side drops. Also, data gathered during engineering test were consistent with the deformation exhibited from the CD1-1 drop.

There were minor visible exterior scratches resulting from the drop. The areas showing the greatest impact marks are at each end plate and near the three internal stiffening ribs. There was no significant bowing or other visible deformation. There was no visible deformation or rotation of the closure and the locking pins remained in the locked position. Figure 2.12.1-9 shows the CTU following the drop. 
Upon inspection of the CTU the closure assembly was fully functional and able to be opened, as illustrated in Figure 2.12.1-10. The FHE was removed and visually inspected, as illustrated in Figure 2.12.1-11. There were no major deformations or cracked welds noticed. One of the spring plungers on the FHE lid was bent slightly but still functional.

As illustrated in Figure 2.12.1-12, there was no visible damage to the fuel element. The fuel element was not removed from the FHE but both end boxes were clearly visible and fully intact.

With the closure assembly removed from the body of the CTU, the locking pin was noticeably bent approximately 1/32 in. as illustrated in Figure 2.12.1-13. This locking pin was located near Position 8 identified in Figure 2.12.1-4. The other locking pin was not deformed and there was no other visible deformation of the closure assembly. It was noticed that the bent locking pin tended to bind when compressed to the open position.

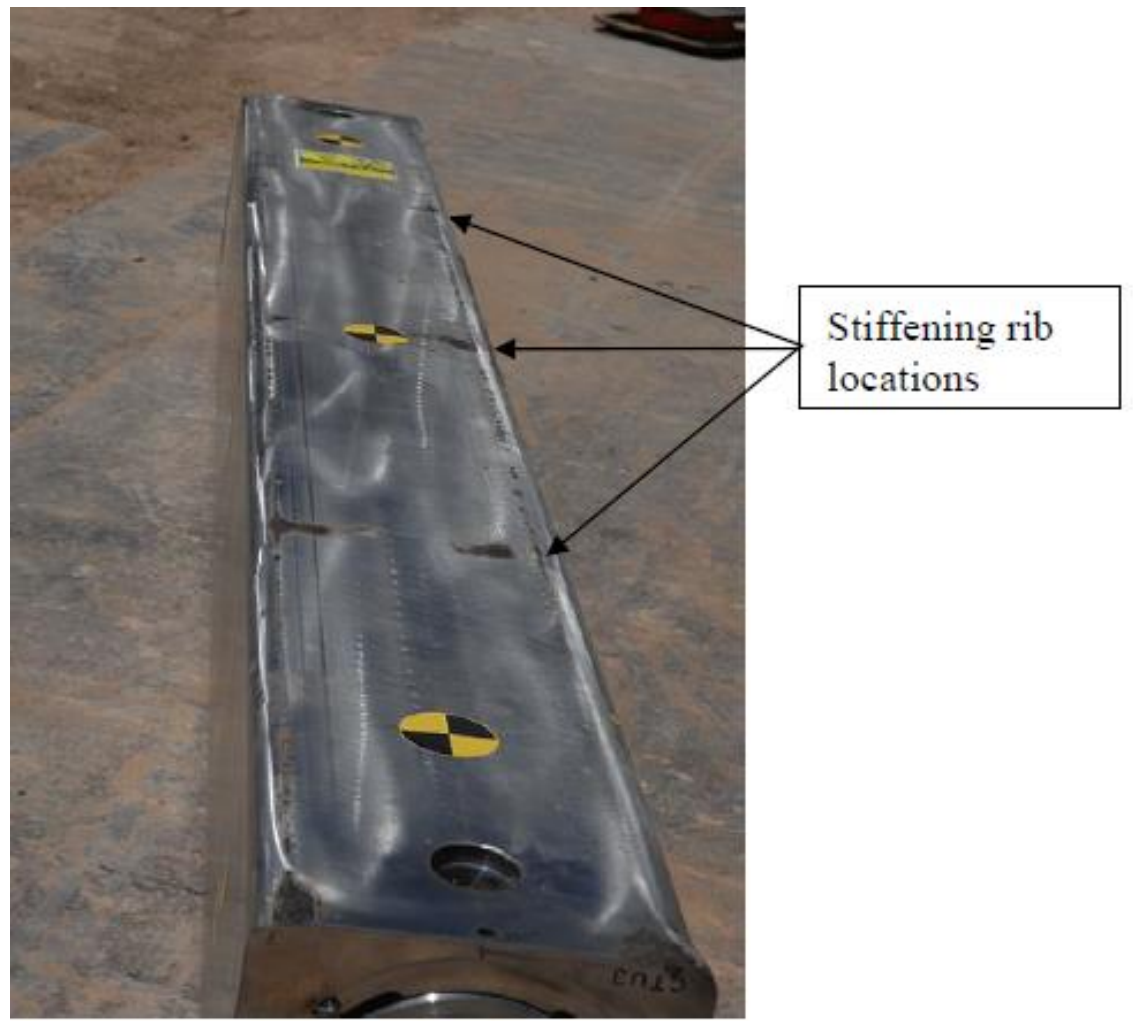

Figure C-11. CD1-1 impact side [ATR FFSC SAR (2017), Figure 2.12.1-9]. 

with Heavier Low-Enriched Uranium Fuel Contents

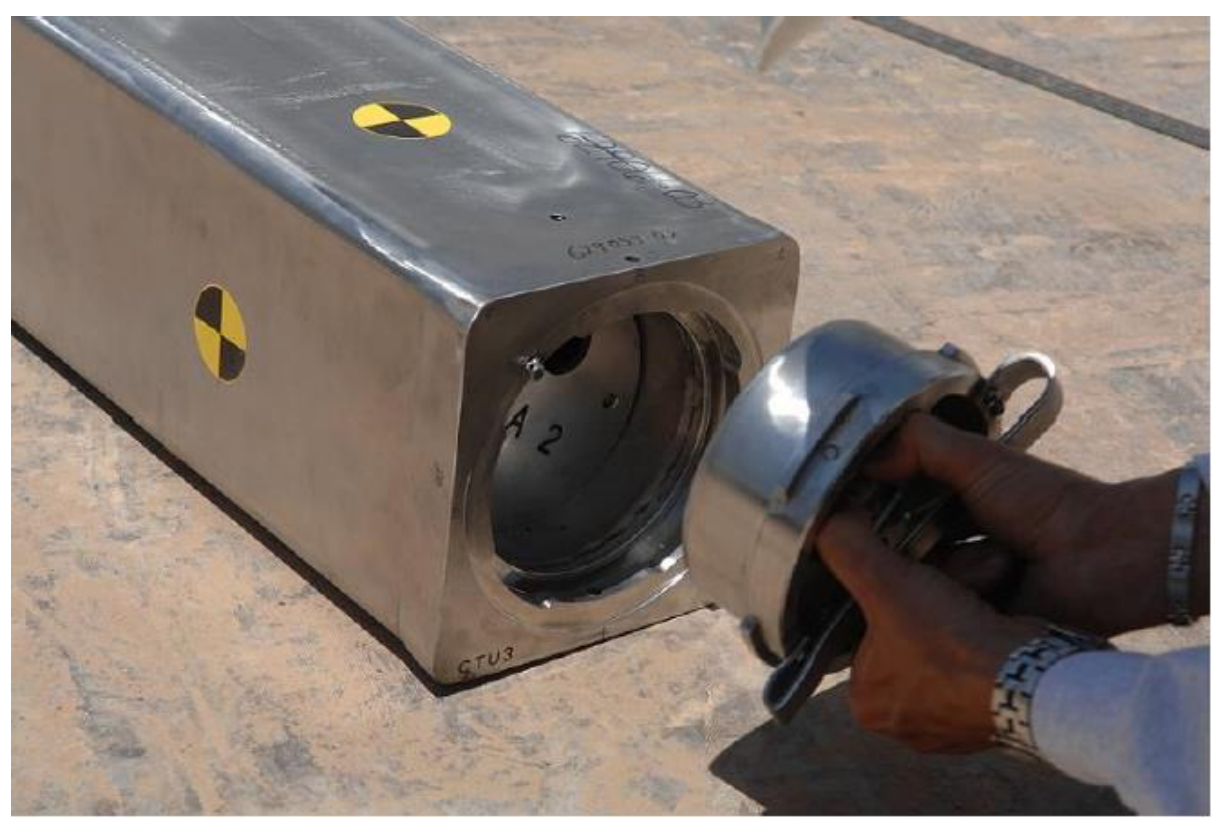

Figure C-12. Opening of CTU following CD1-1 [ATR FFSC SAR (2017), Figure 2.12.1-10].

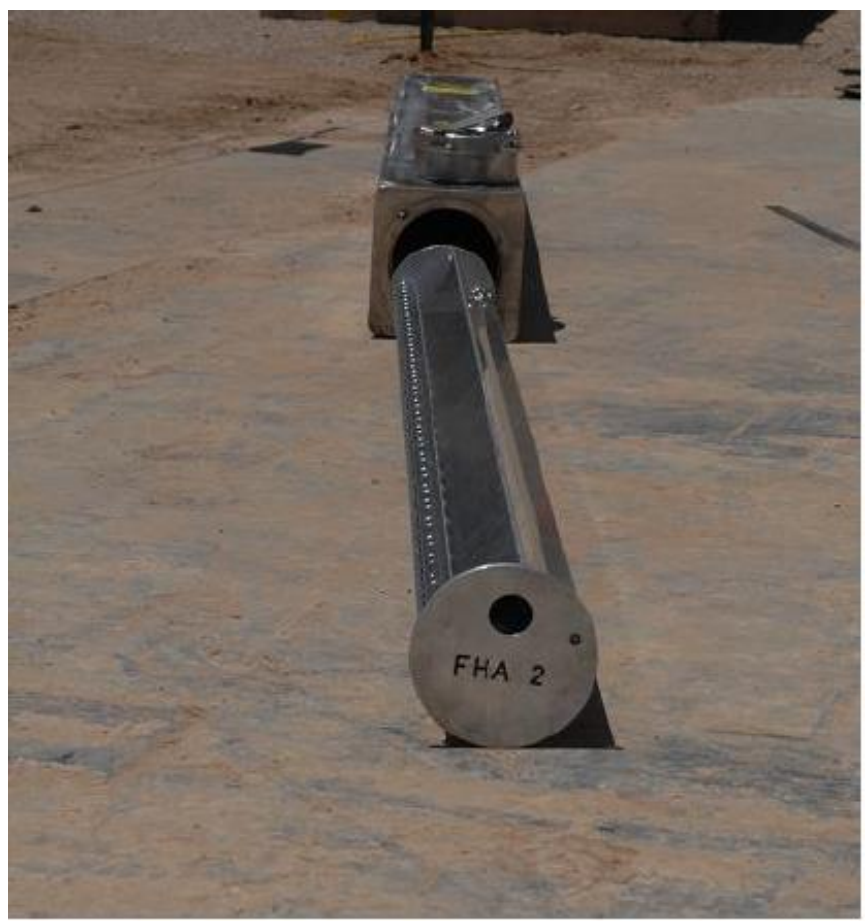

Figure C-13. Inspection of payload following CD1-1 [ATR FFSC SAR (2017), Figure 2.12.1-11]. 
Figure C-14. Inspection of fuel element following CD1-1 [ATR FFSC SAR (2017), Figure 2.12.1-12].

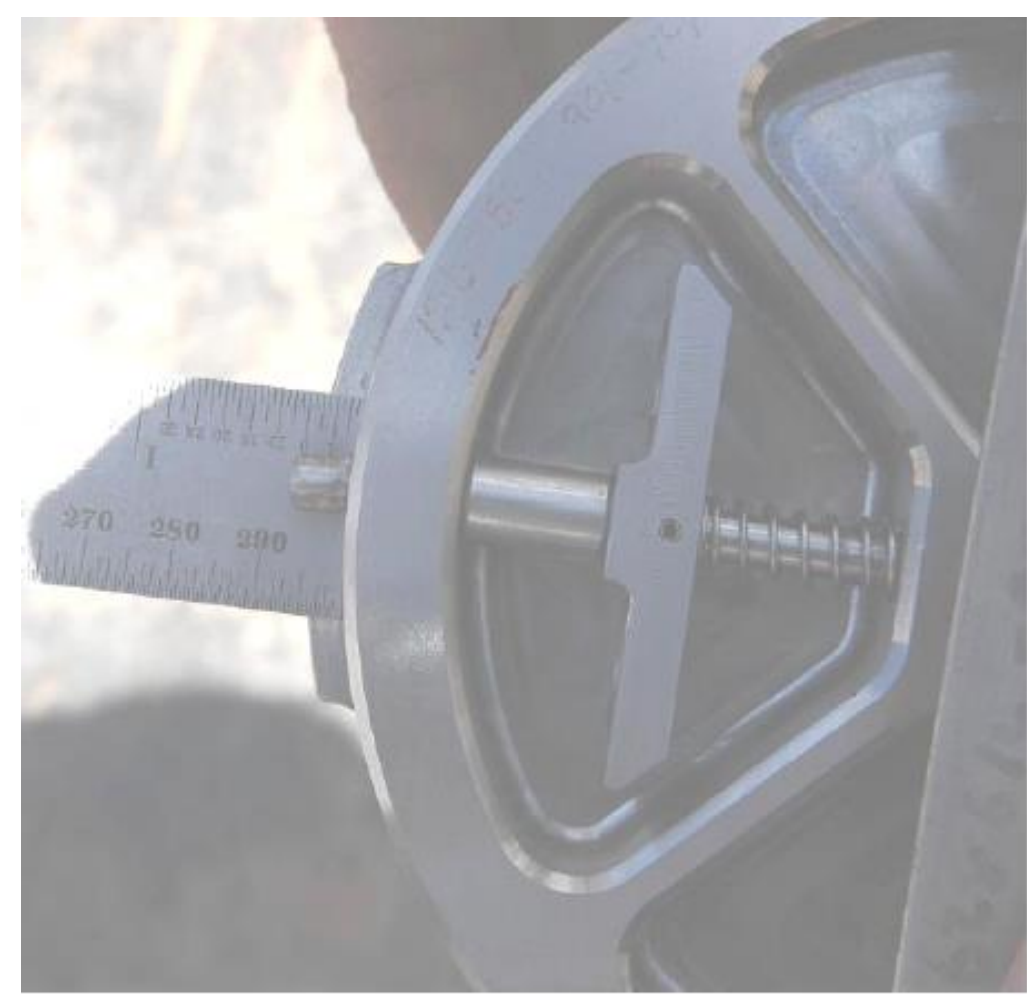

Figure C-15. Inspection of closure assembly following CD1-1 [ATR FFSC SAR (2017), Figure 2.12.1-13]. 


\section{C2.2.2 Results for Scope Part 1 b (Table 3), Test 2 (Table 2)}

The FEA model results for the Scope Part 1b (Table 3), Test 2 (Table 2) model are shown below in

Figure C-16 to Figure C-22. This drop scenario is a 30-ft drop where the loaded ATR FFSC impacts flat on its side drop with the pocket-side down. The fuel element weights $22.1 \mathrm{lbf}$ and the drop scenario is modeled with minimum material properties except the enclosure and end boxes, which are modeled with relatively tough material properties.

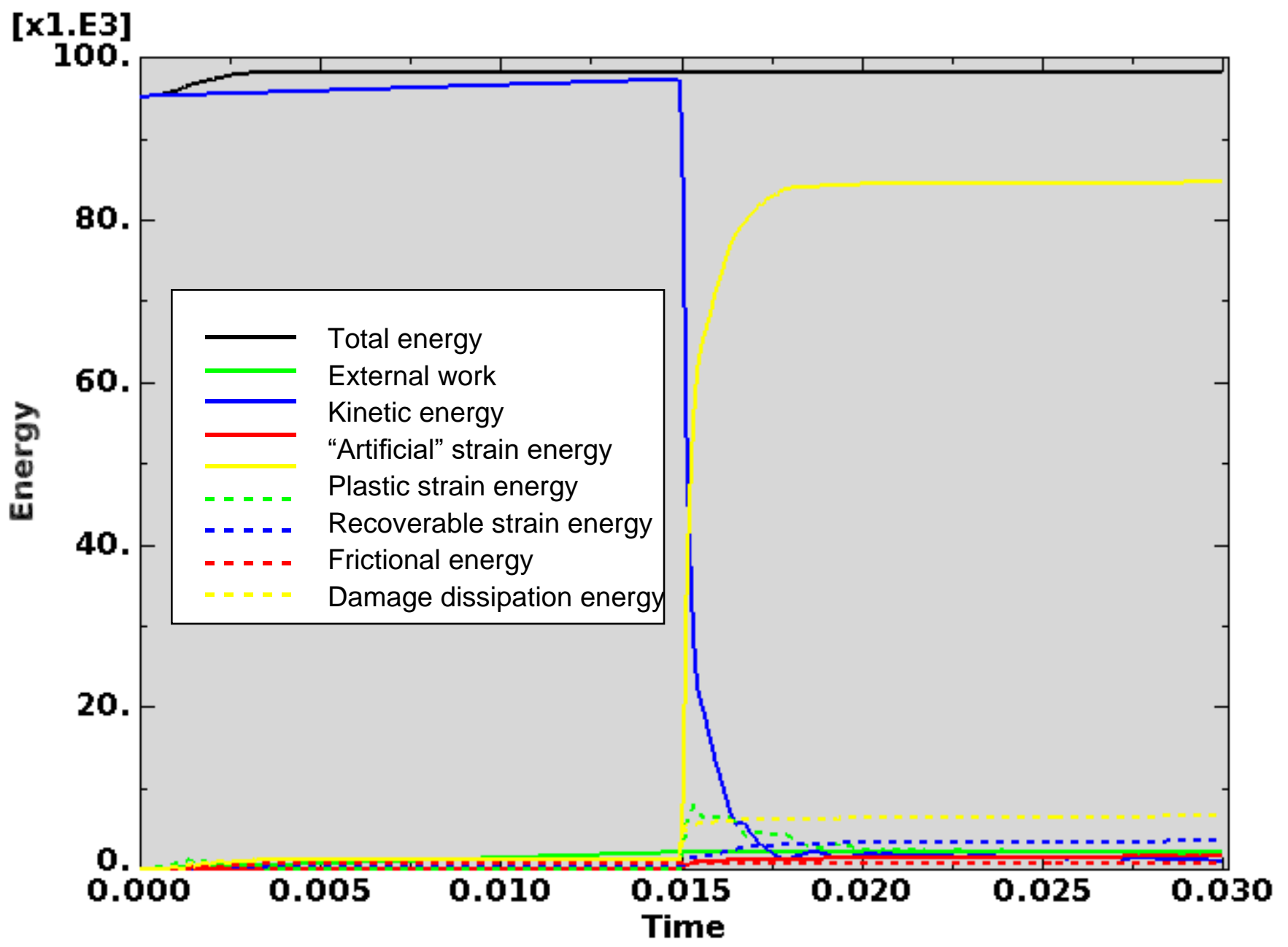

Figure C-16. Scope Part 1b (Table 3), Test 2 (Table 2) energy curves.

Figure C-16 shows the energy curves for Scope Part 1b (Table 3), Test 2 (Table 2) drop scenario. These curves exhibit a stable shape. Artificial strain energy represents the energy required to keep reduced integration elements from taking on a zero-energy hourglass shape. As shown in Figure C-16, the artificial energy at the end of the model run is $1.7 \%$ of the total energy. Therefore, the potential error associated with artificial energy is not considered to be significant. 

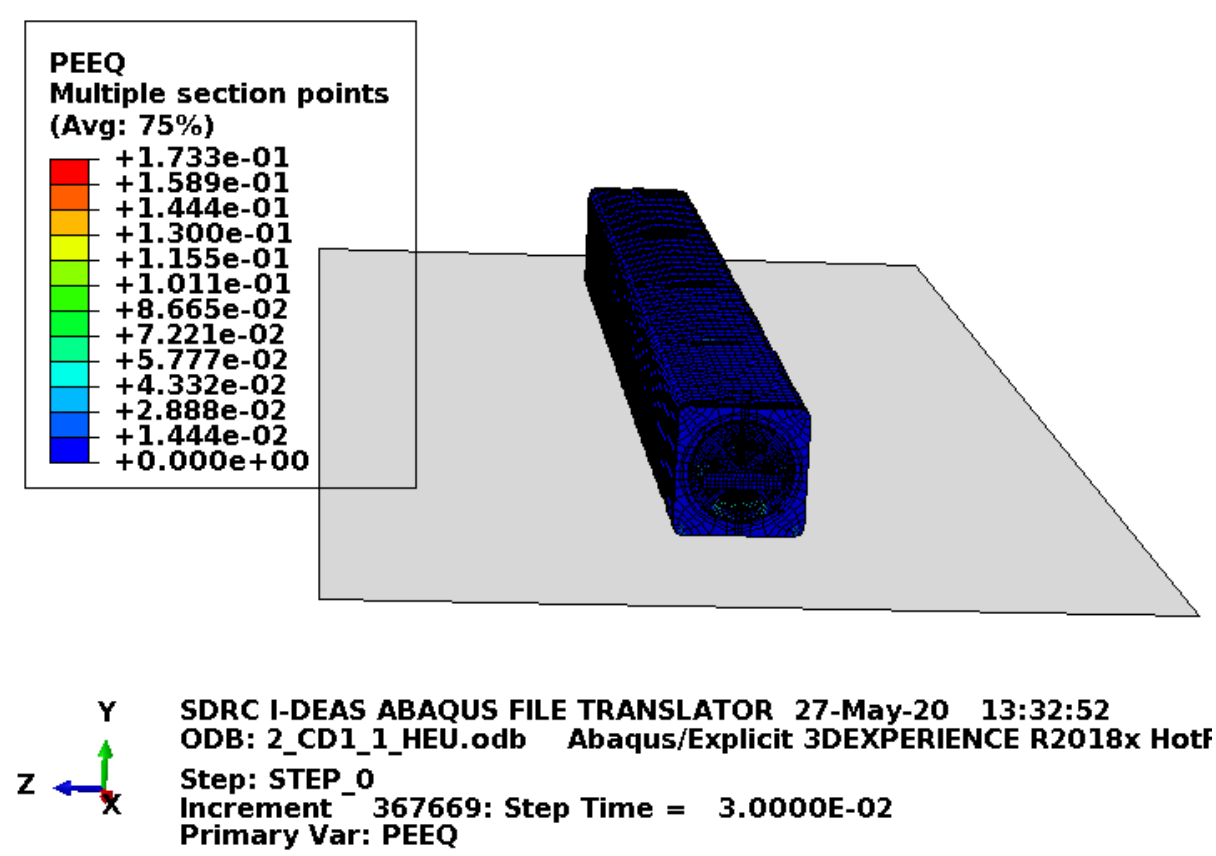

Figure C-17. Scope Part 1b (Table 3), Test 2 (Table 2) full-model plastic-equivalent strain.

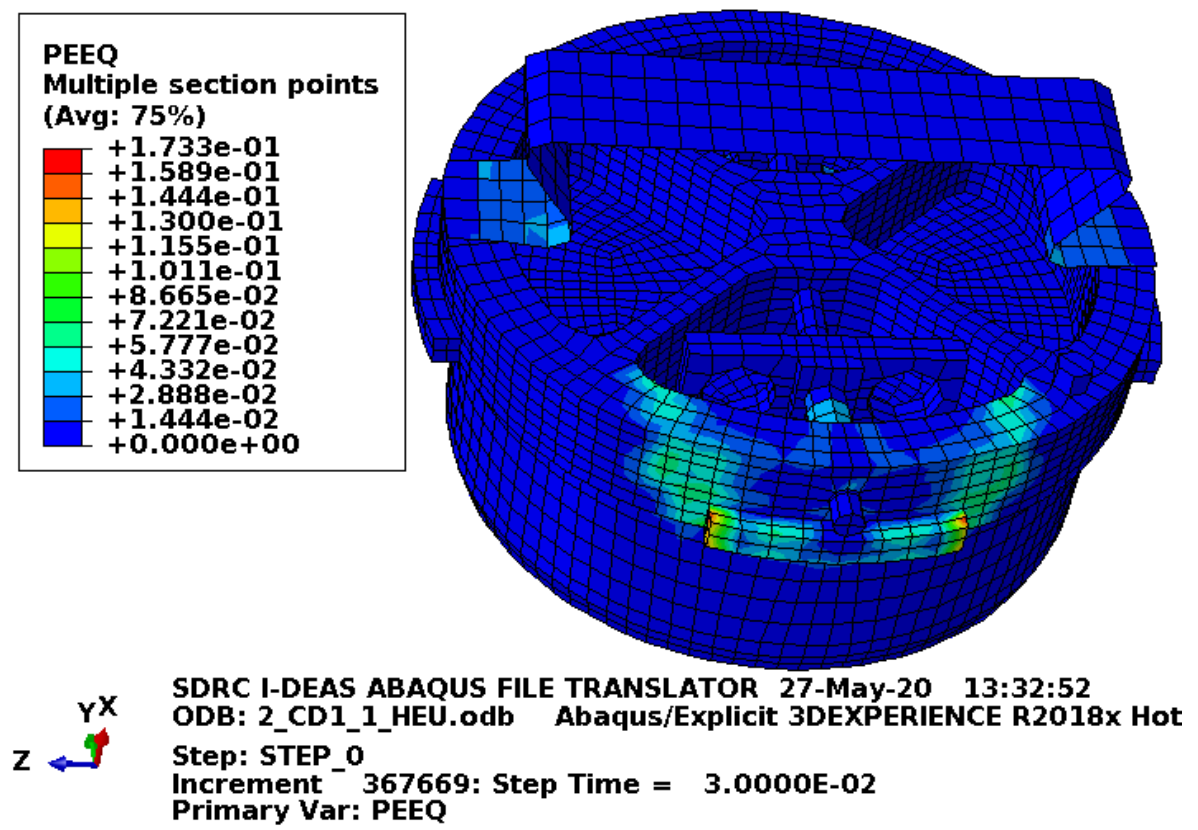

Figure C-18. Scope Part 1b (Table 3), Test 2 (Table 2) lid plastic-equivalent strain.

Figure $\mathrm{C}-19$ shows the equivalent plastic strain in the structurally significant portion of the lid. Failure in these elements occurs at an equivalent plastic strain of $0.259 \mathrm{in}$./in. If element failure were to occur, the element would be deleted and removed from the model (thereby making its equivalent plastic strain not included in the maximum equivalent plastic strain for the plot). However, the missing element would be visible in the plot. Figure $\mathrm{C}-19$ shows no element failure with margin. 
ENGINEERING CALCULATIONS AND ANALYSIS

Drop Analysis of the Advanced Test Reactor Fresh Fuel Shipping Container with Heavier Low-Enriched Uranium Fuel Contents
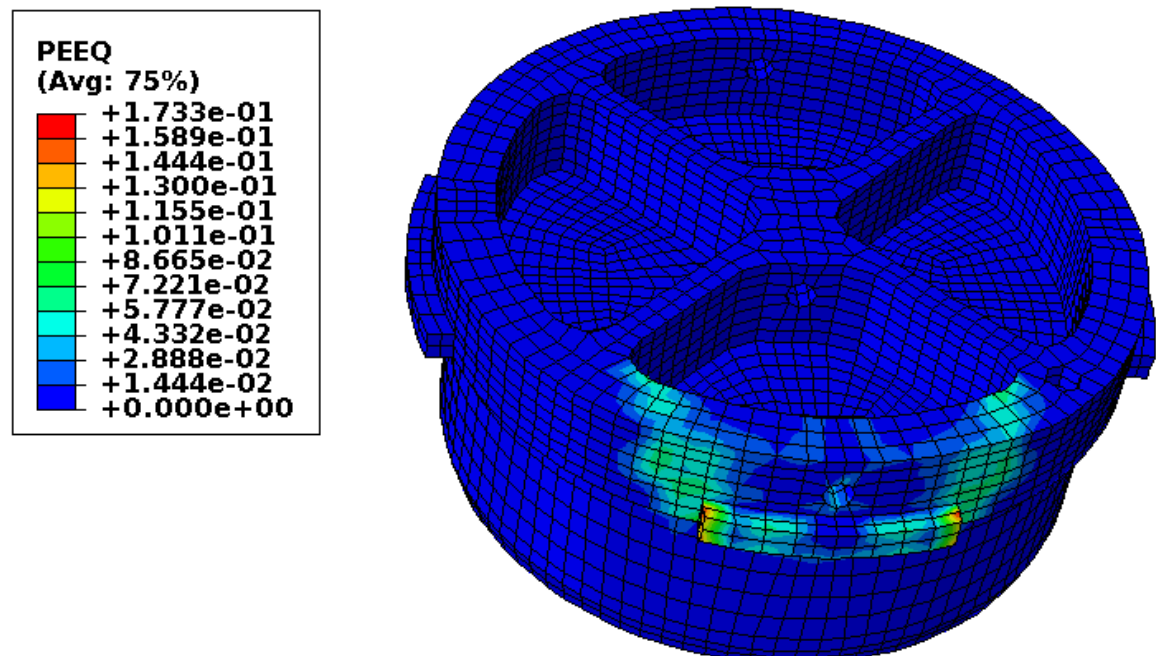

SDRC I-DEAS ABAQUS FILE TRANSLATOR 27-May-20 13:32:52

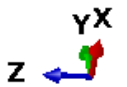

ODB: 2_CD1_1_HEU.odb Abaqus/Explicit 3DEXPERIENCE R2018x Hot

Step: STEP_o

Increment 367669 : Step Time $=3.0000 E-02$

Primary Var: PEEQ

Figure C-19. Scope Part 1b (Table 3), Test 2 (Table 2) lid structure plastic-equivalent strain.

Figure C-20 shows the equivalent plastic strain in the lid pins. Failure in these elements occurs at an equivalent plastic strain of $0.295 \mathrm{in}$./in. If element failure were to occur, the element would be deleted and removed from the model (thereby making its equivalent plastic strain not included in the maximum equivalent plastic strain for the plot). However, the missing element would be visible in the plot. Figure C-20 shows no element failure.

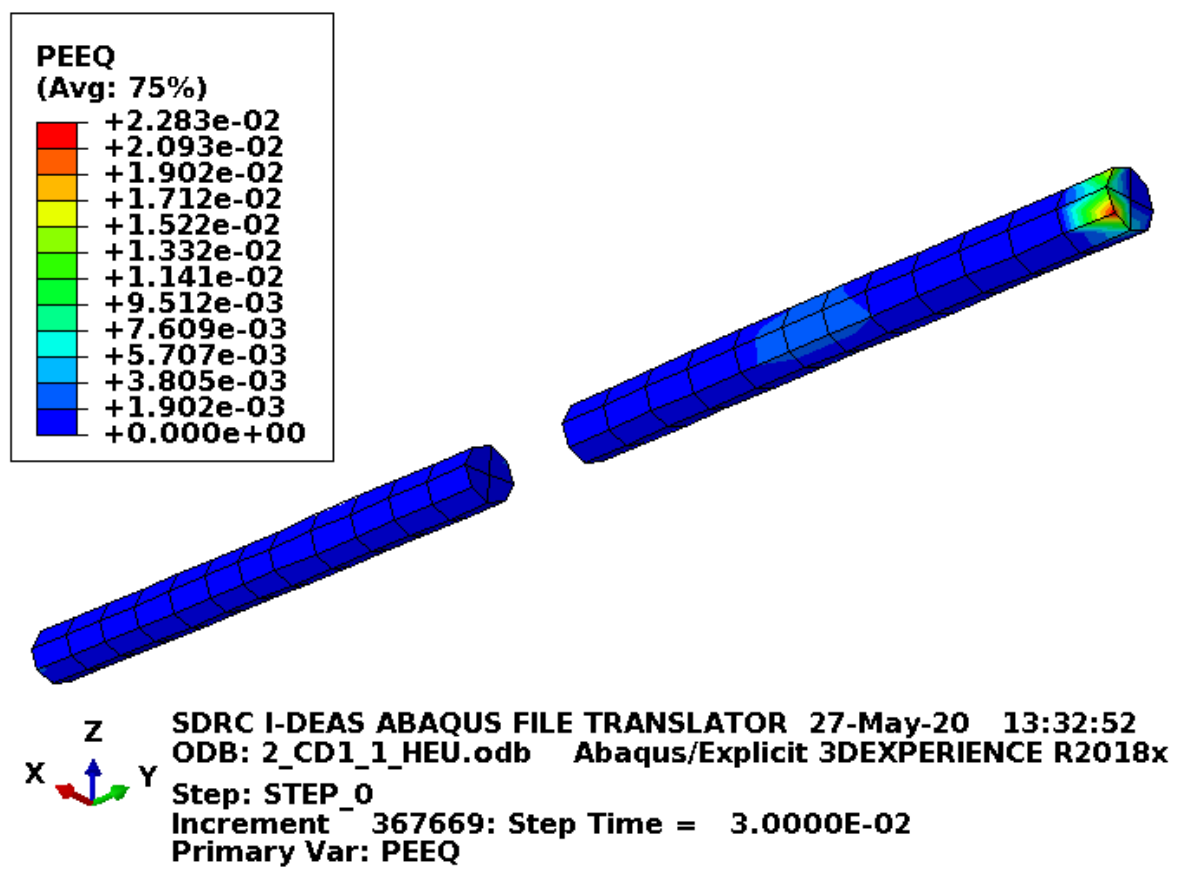

Figure C-20. Scope Part 1b (Table 3), Test 2 (Table 2) lid pins plastic-equivalent strain. 
As noted in the physical drop (see Section C2.2.1), the lid pin was noticeably bent approximately $1 / 32$ in. This did not occur in this FEA model. It was also noted in the physical drop (see Section C2.2.1) that the loaded ATR FFSC rotated on rebound. The FEA model impacted flat resulting in no rotation upon rebound. Scoping FEA models indicated that plasticity did occur in the lid pins similar to that described in the physical drop if the impact resulted in a rotation about the length of the ATR FFSC. However, the scoping FEA models resulting in rotation showed reduced damage in the rest of the model. Consequently, for this drop scenario, the orientation is performed flat. Rotating rebound is studied further in Sections C2.3 and C4 of this study.

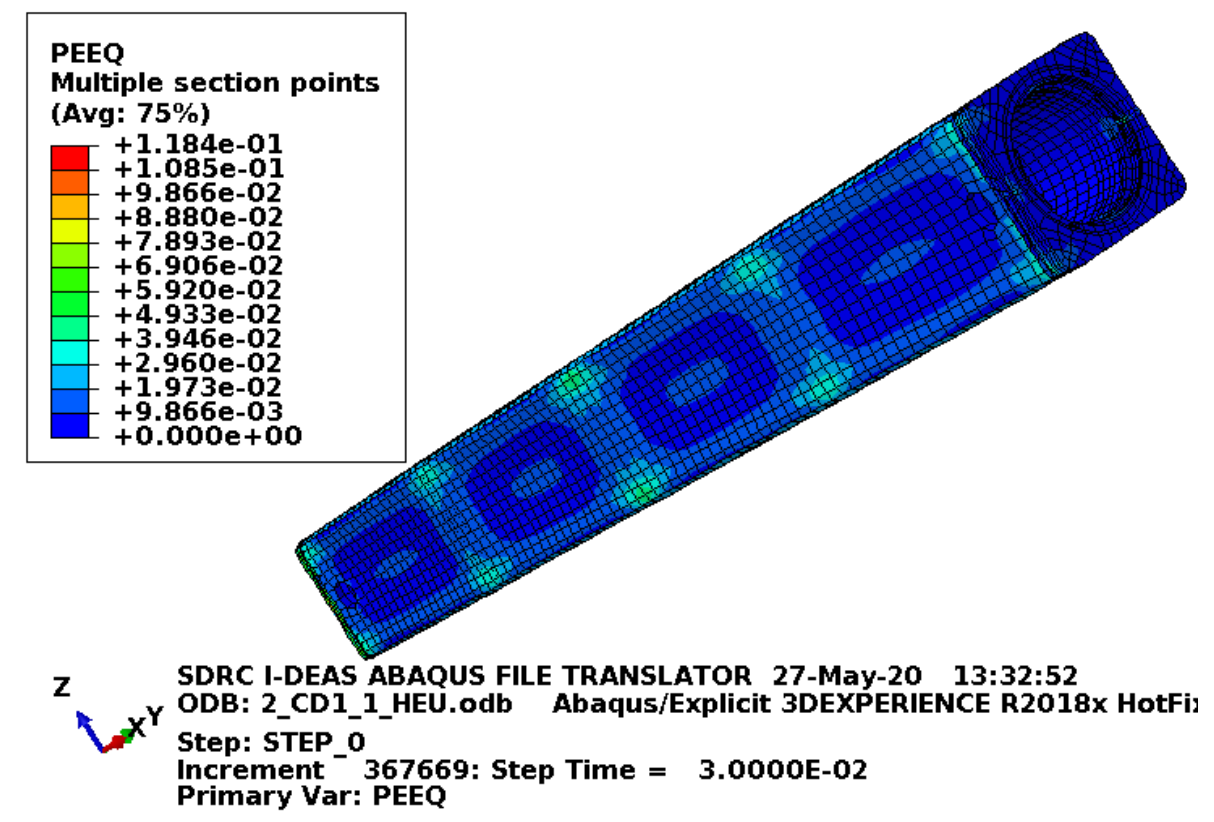

Figure C-21. Scope Part 1b (Table 3), Test 2 (Table 2) body plastic-equivalent strain.

Figure C-21 shows the equivalent plastic strain in the body. Failure in these elements occurs at an equivalent plastic strain of $0.259 \mathrm{in}$./in. If element failure were to occur, the element would be deleted and removed from the model (thereby making its equivalent plastic strain not included in the maximum equivalent plastic strain for the plot). However, the missing element would be visible in the plot. Figure C-21 shows no element failure with margin.

As noted in the physical drop (see Section C2.2.1), the areas of the FEA model showing the greatest plasticity are at each end plate and near the three internal stiffening ribs. Also, the FEA model showed no significant bowing or other visible deformation. Additionally, the lid opening plastically deformed. The plastic deformation made the opening diameter in the direction of the impact reduce by a little less than 0.06 in. and, in the perpendicular direction, it expanded by a little more than $0.05 \mathrm{in}$.

Figure C-22 shows the equivalent plastic strain in the enclosure. This is just for information as damage to the enclosure is acceptable. 


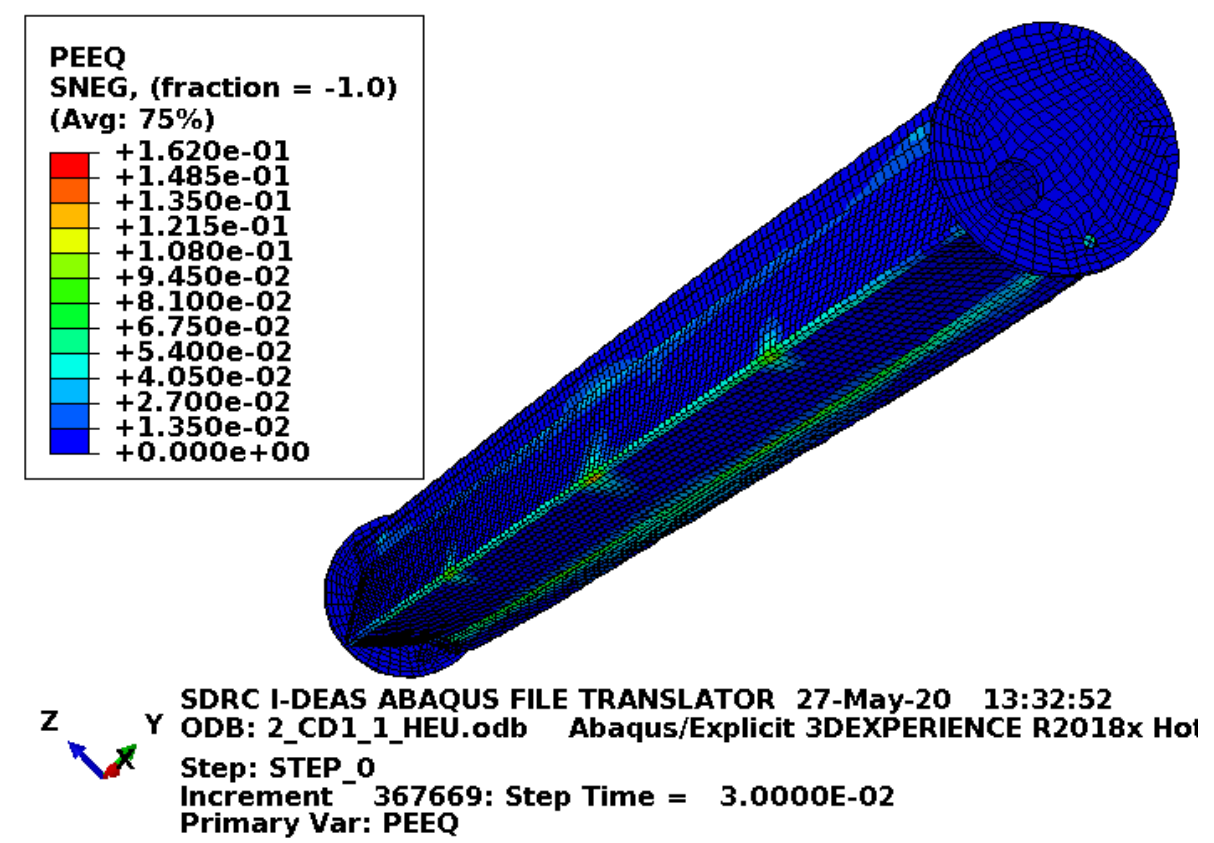

Figure C-22. Scope Part 1b (Table 3), Test 2 (Table 2) enclosure plastic-equivalent strain.

\section{C2.3 Results for Scope Part 1 (Table 3), Test 3 (Table 2)}

The drop scenario considered in this section is a 30 -ft drop modeled as a side drop with the index lugs facing downward and the edge impacting slightly before the index lugs. It is identified as CD2.A-1 in the ATR FFSC SAR (2017). Though physical drops CD2.B-1 and CD2.C-1 in the ATR FFSC SAR (2017) are similar. All three drops had rotation and the first two had a lot of rotation, so unlike Section C2.2, the FEA model was adjusted to try to reasonably capture the rotation.

\section{C2.3.1 Results from the Physical Drop Scenario}

Three physical drops were performed similar to Test 3 (Table 2) test. These include Tests 3,4 , and 9 (Table 2). A summary of the physical drop scenario results for Scope Part 1 (Table 3), Test 3 (Table 2) is provided in the ATR FFSC SAR (2017), Sections 2.12.1.4.1.3, 2.12.1.4.2, and 2.12.1.4.7 (shown below for reference). Figure C-1 along with Figure C-23 and Figure C-30 provide the supporting ATR FFSC SAR (2017) figures for reference.

Text from ATR FFSC SAR (2017), Section 2.12.1.4.1.3:

Following impact, the CTU bounced and spun in the air about its longitudinal axis. After viewing the highspeed video, it was confirmed that the CTU impacted the drop pad at a slight angle on the longitudinal axis, which caused the CTU to spin during the rebound. The index lugs did receive much of the impact, but due to the angle it may not have been the worst-case impact to the index lugs. There was visible exterior damage resulting from the drop at the index lugs. The index lugs were both pressed inward approximately 1/8 in. There were no visible signs of broken welds. 
The center of the package had an inward bow of about 1/16 in. There was no other significant visible deformation. There was no visible rotation of the closure. Figure 2.12.1-15 and Figure 2.12.1-16 show the CTU following the drop. Following CD2.A-1 the closure could no longer be opened due to the body opening becoming slightly out-of-round. As illustrated in Figure 2.12.1-17, the body and closure assembly pinched in two locations.

The locking pin on the left side (near 8) of Figure 2.12.1-17 is shown stuck in the open-unlocked position. This happened during the inspection and not because of the drop. As the locking pins and closure assembly were inspected functionally by the test engineer, the one locking pin would bind in the open position and require a light tap from a hammer to become unstuck. However, the photo was taken before the locking pin was returned to the locked position.

Text from ATR FFSC SAR (2017), Section 2.12.1.4.2:

During the drop the high-speed video showed that the CTU rotated past the horizontal position in the air and impacted at an incline again. Furthermore, the rigging caught a gust of wind and blew to the side and caught the north stadia board. Following impact, the CTU bounced and spun in the air about the longitudinal axis indicating a non-flat impact. The index lugs were both pressed inward approximately 3/16 in., at the greatest point, from the original surface of the tube. There were no visible signs of broken welds. The handle of the closure assembly broke loose at Point 6, shown in Figure 2.12.1-4. The two screws both sheared off and the opposite side remained attached. No other significant deformation was visible. No deformation or rotation of the closure was visible and the locking pins remained in the locked position following the drop. During a functional test of the closure assembly the locking pins functioned well (with the locking pin near 8 binding in the open position) and the closure could rotate approximately $1 / 4$ in. Figure 2.12.1-19 and Figure 2.12.1-20 show the CTU following the drop.

Text from ATR FFSC SAR (2017), Section 2.12.1.4.1.7:

The third try produced a satisfactory drop orientation. Following impact, the CTU bounced and spun just slightly indicating the impact was directly on the index lugs. The index lugs were both pressed inward. The index lug at the closure end was flush with the general surface. The index lug at the bottom end was pushed in to approximately 1/8 in. from the general surface. Figure 2.12.1-38 and Figure 2.12.1-39 show the index lugs following the drop. The index lugs were removed and a cracked weld was revealed under the index lug near the closure end as shown in Figure 2.12.1-40. The length of the cracked weld was approximately 1/2 in. No other significant deformation was visible. No deformation or rotation of the closure visible as a result of the drop. 


\section{ENGINEERING CALCULATIONS AND ANALYSIS}

Drop Analysis of the Advanced Test Reactor Fresh Fuel Shipping Container with Heavier Low-Enriched Uranium Fuel Contents
ECAR-5224, Rev. 0

Page $\mathrm{C} 19$ of $\mathrm{C} 190$

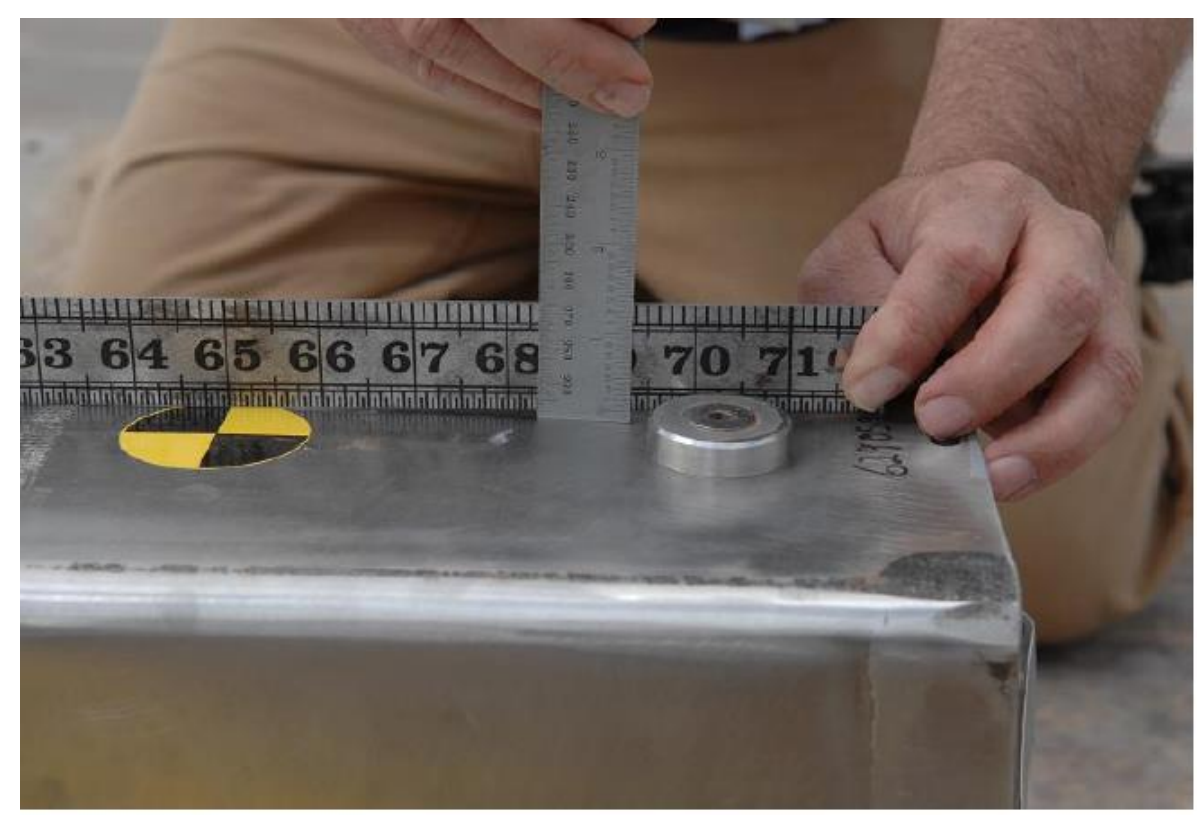

Figure C-23. Index lug near closure end, CD2.A-1 [ATR FFSC SAR (2017), Figure 2.12.1-15].

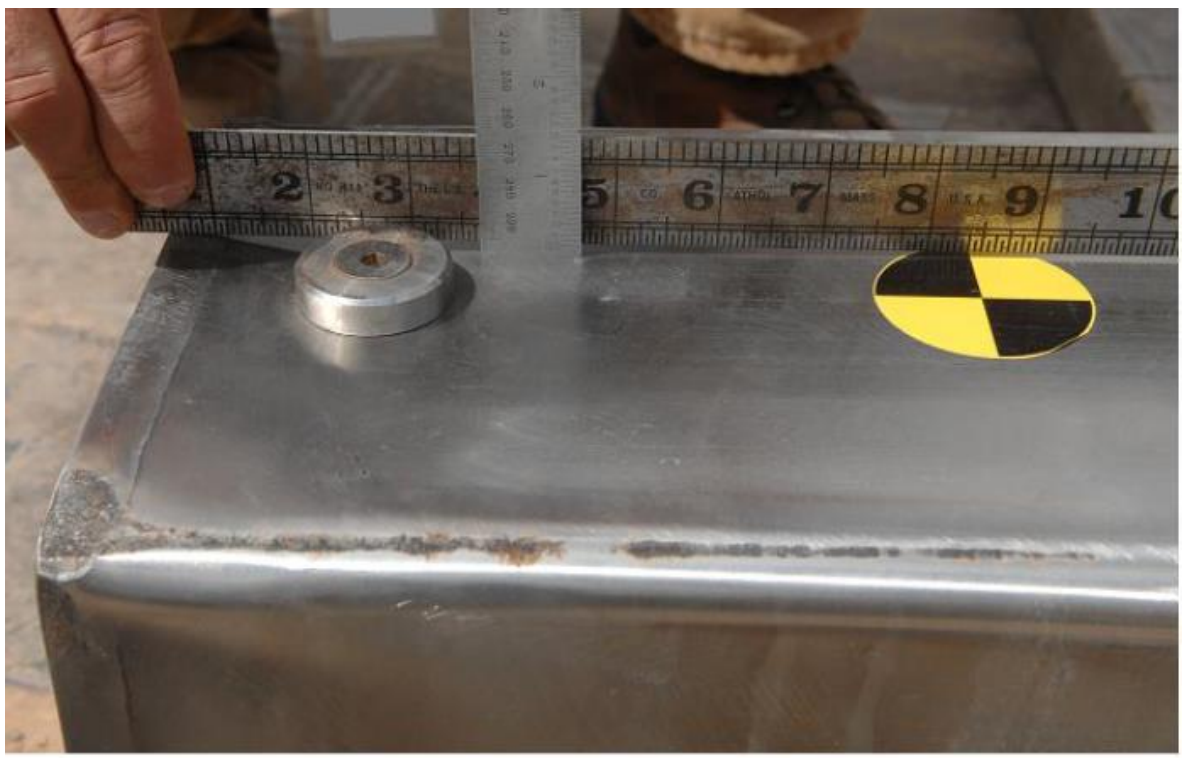

Figure C-24. Index lug near bottom end, CD2.A-1 [ATR FFSC SAR (2017), Figure 2.12.1-16]. 
Drop Analysis of the Advanced Test Reactor Fresh Fuel Shipping Container with Heavier Low-Enriched Uranium Fuel Contents

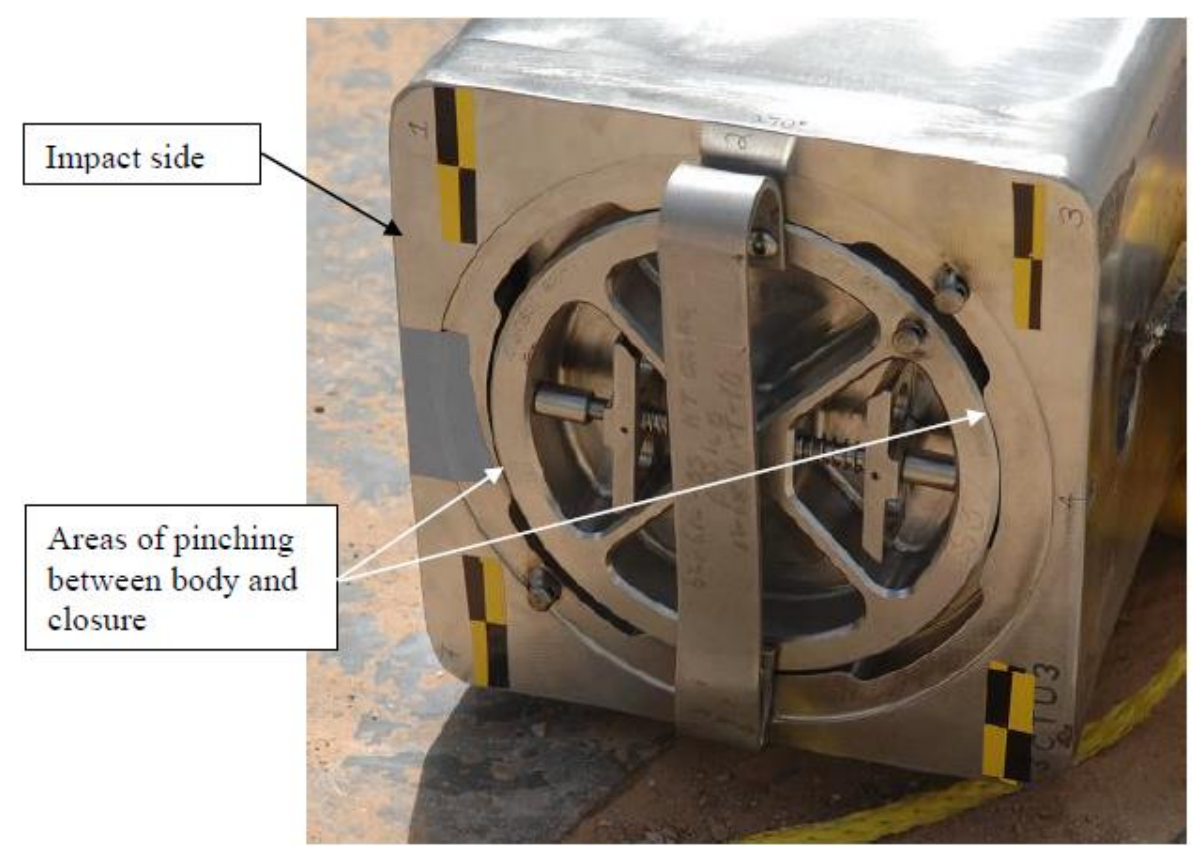

Figure C-25. View of closure following CD2.A-1 [ATR FFSC SAR (2017), Figure 2.12.1-17].

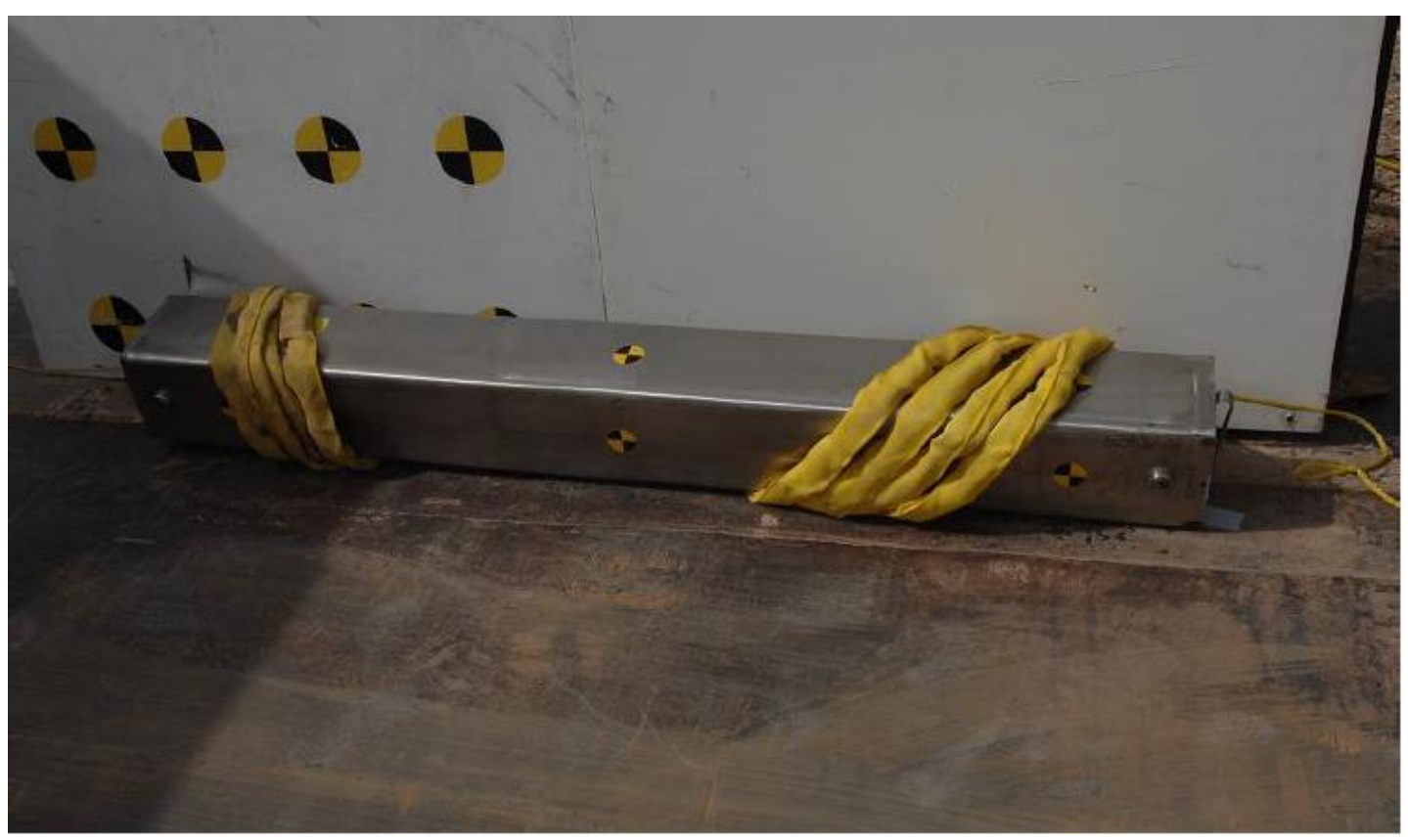

Figure C-26. CTU position following CD2.B-1 drop [ATR FFSC SAR (2017), Figure 2.12.1-19]. 
Drop Analysis of the Advanced Test Reactor Fresh Fuel Shipping Container with Heavier Low-Enriched Uranium Fuel Contents

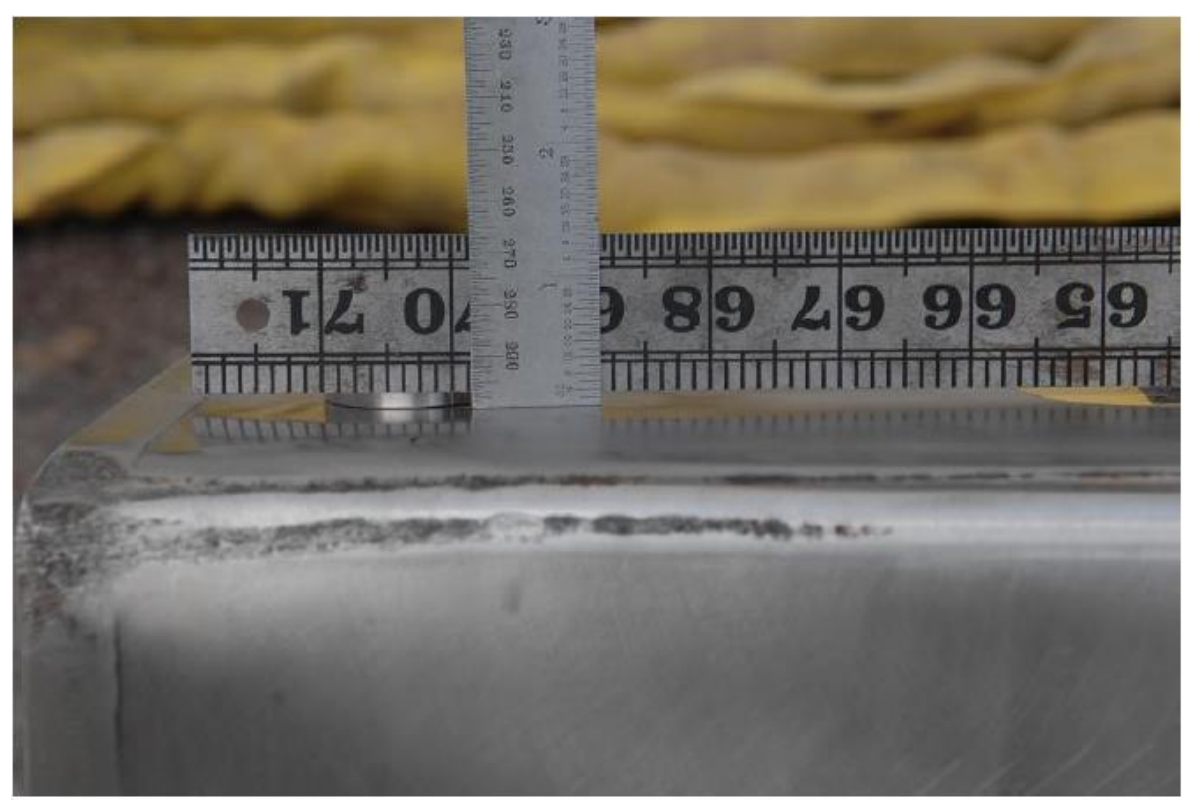

Figure C-27. Index lug near bottom end, CD2.B-1 [ATR FFSC SAR (2017), Figure 2.12.1-20].

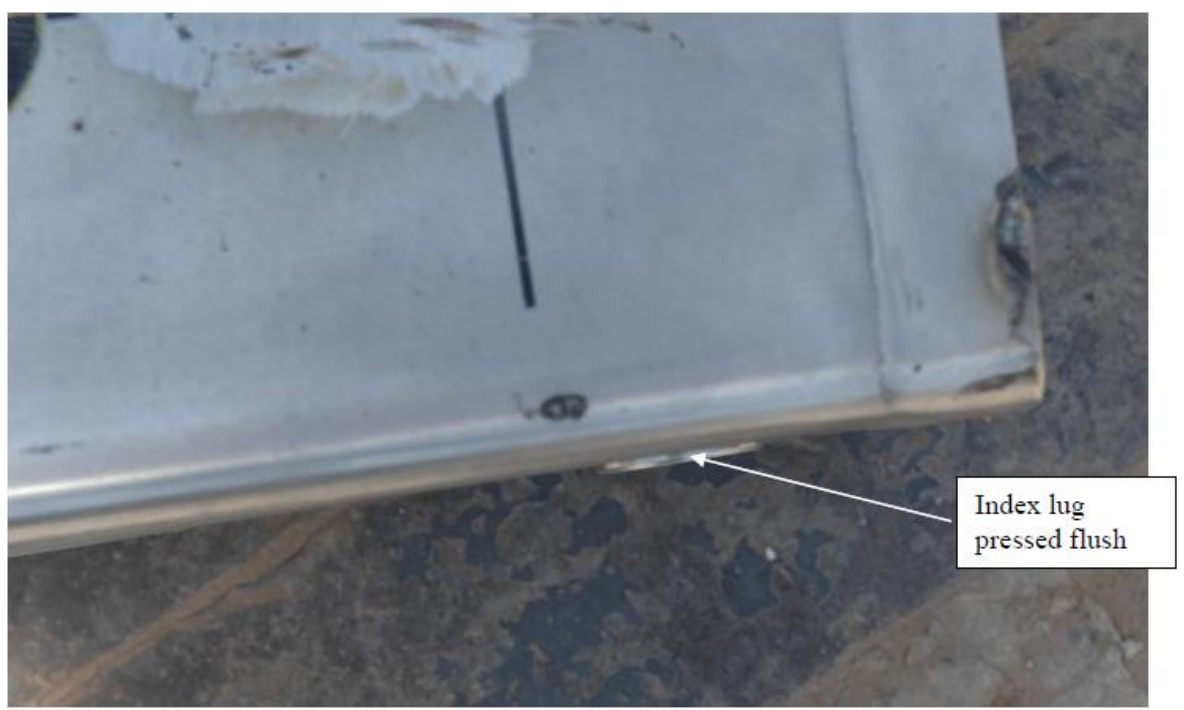

Figure C-28. Side view of CTU following CD2.C-1 drop [ATR FFSC SAR (2017), Figure 2.12.1-38]. 


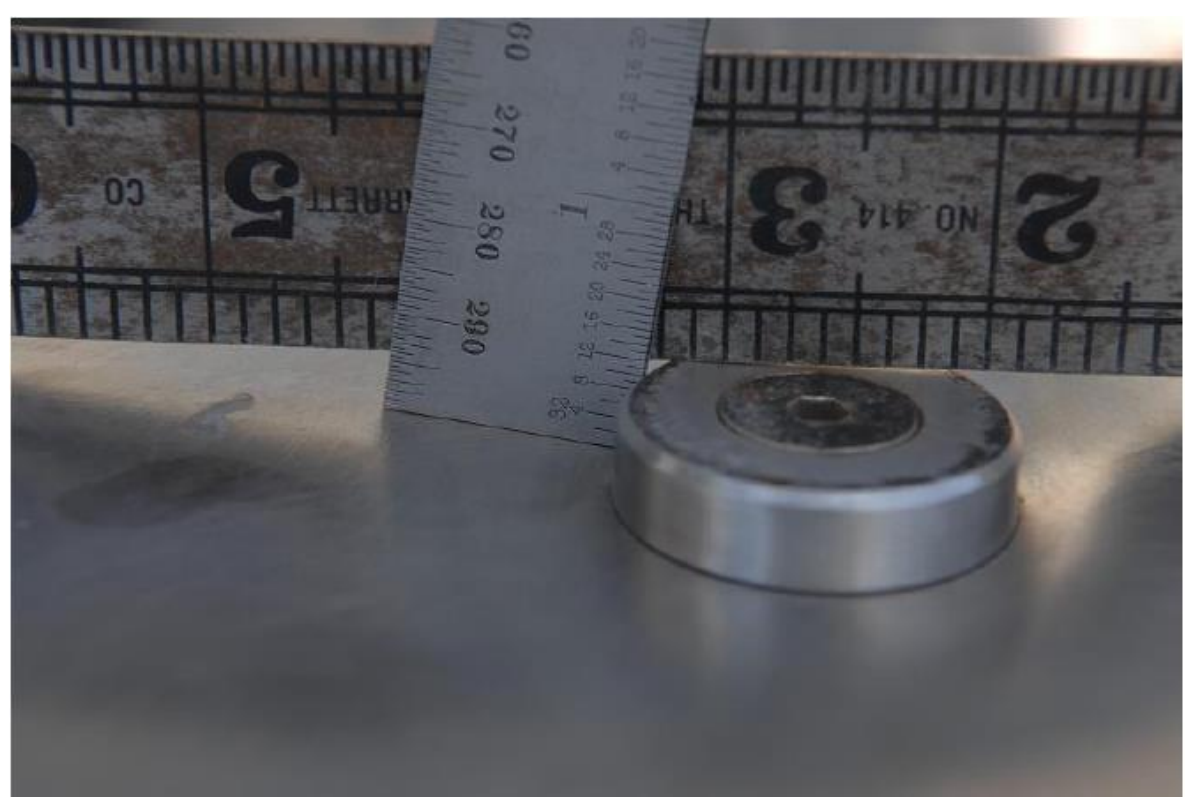

Figure C-29. Index lug near closure end, CD2.C-1 [ATR FFSC SAR (2017), Figure 2.12.1-39].

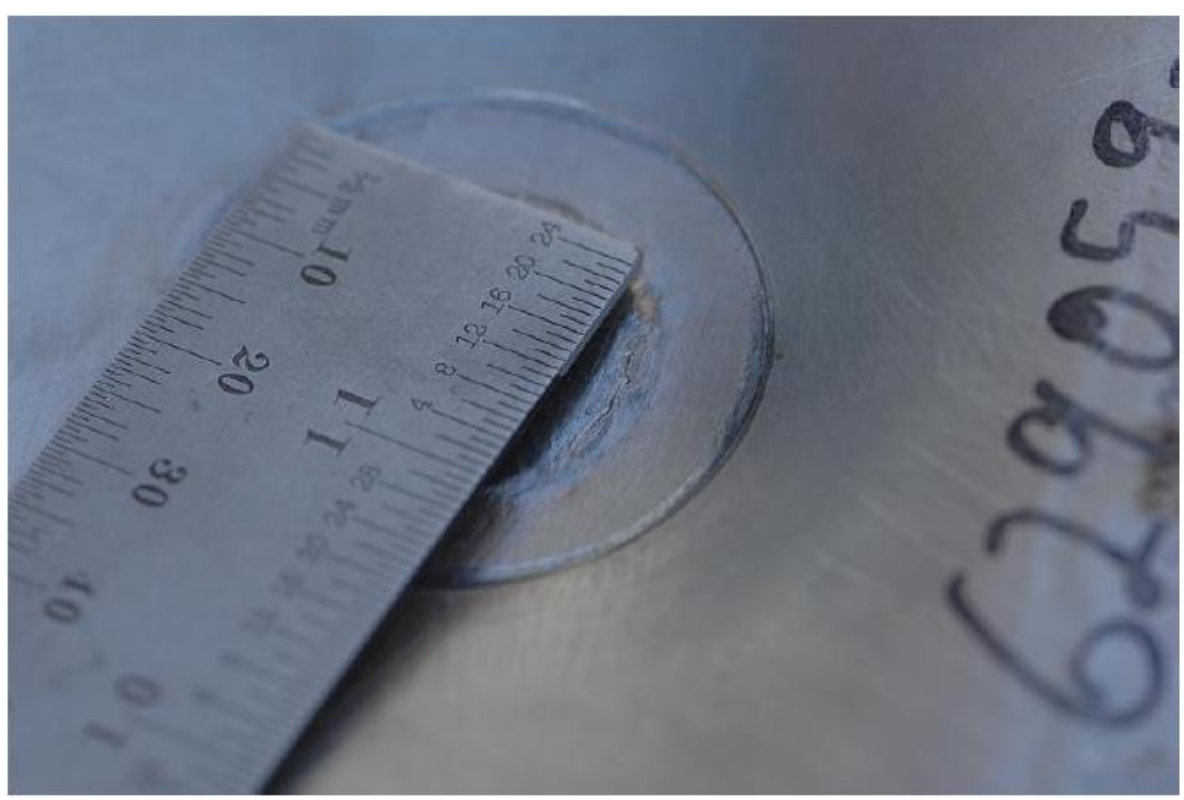

Figure C-30. Cracked weld under index lug, CD2.C-1 [ATR FFSC SAR (2017), Figure 2.12.1-40].

\section{C2.3.2 Results for Scope Part 1b (Table 3), Test 3 (Table 2)}

The FEA model results for the Scope Part $1 \mathrm{~b}$ (Table 3), Test 3 (Table 2) model are shown below in

Figure C-31 to Figure C-37. This drop scenario is a 30-ft drop modeled as a side drop with the index lugs facing downward and the edge impacting slightly before the index lugs. The fuel element weights $22.1 \mathrm{lbf}$ and the drop scenario is modeled with minimum material properties except the enclosure and end boxes, which are modeled with relatively tough material properties. 


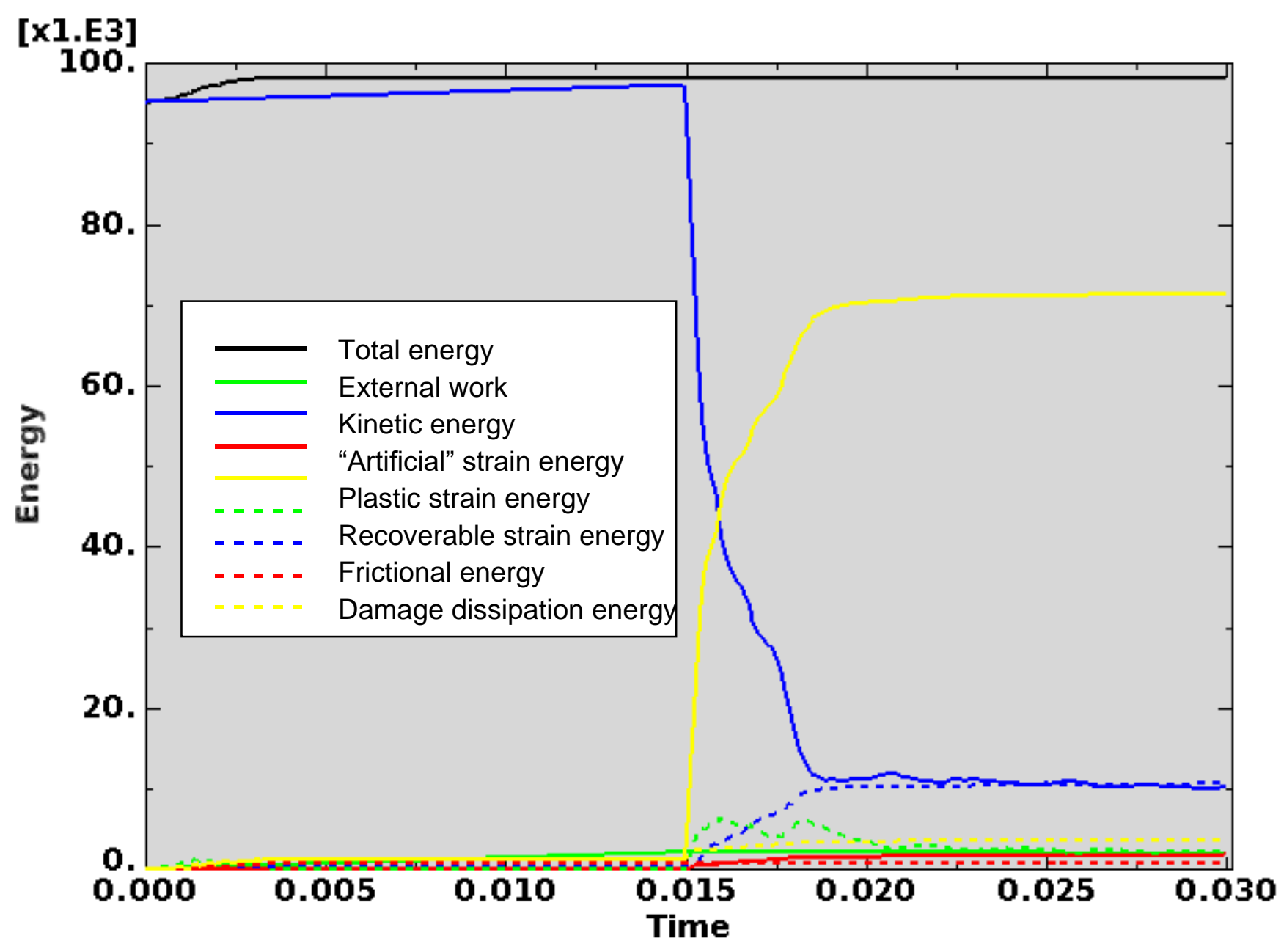

Figure C-31. Scope Part 1b (Table 3), Test 3 (Table 2) energy curves.

Figure C-31 shows the energy curves for Scope Part 1b (Table 3), Test 3 (Table 2) drop scenario. These curves exhibit a stable shape. Artificial strain energy represents the energy required to keep reduced integration elements from taking on a zero-energy hourglass shape. As shown in Figure C-31, the artificial energy at the end of the model run is $1.8 \%$ of the total energy. Therefore, the potential error associated with artificial energy is not considered to be significant. 


\section{ENGINEERING CALCULATIONS AND ANALYSIS}

Drop Analysis of the Advanced Test Reactor Fresh Fuel Shipping Container with Heavier Low-Enriched Uranium Fuel Contents
ECAR-5224, Rev. 0

Page C24 of C190
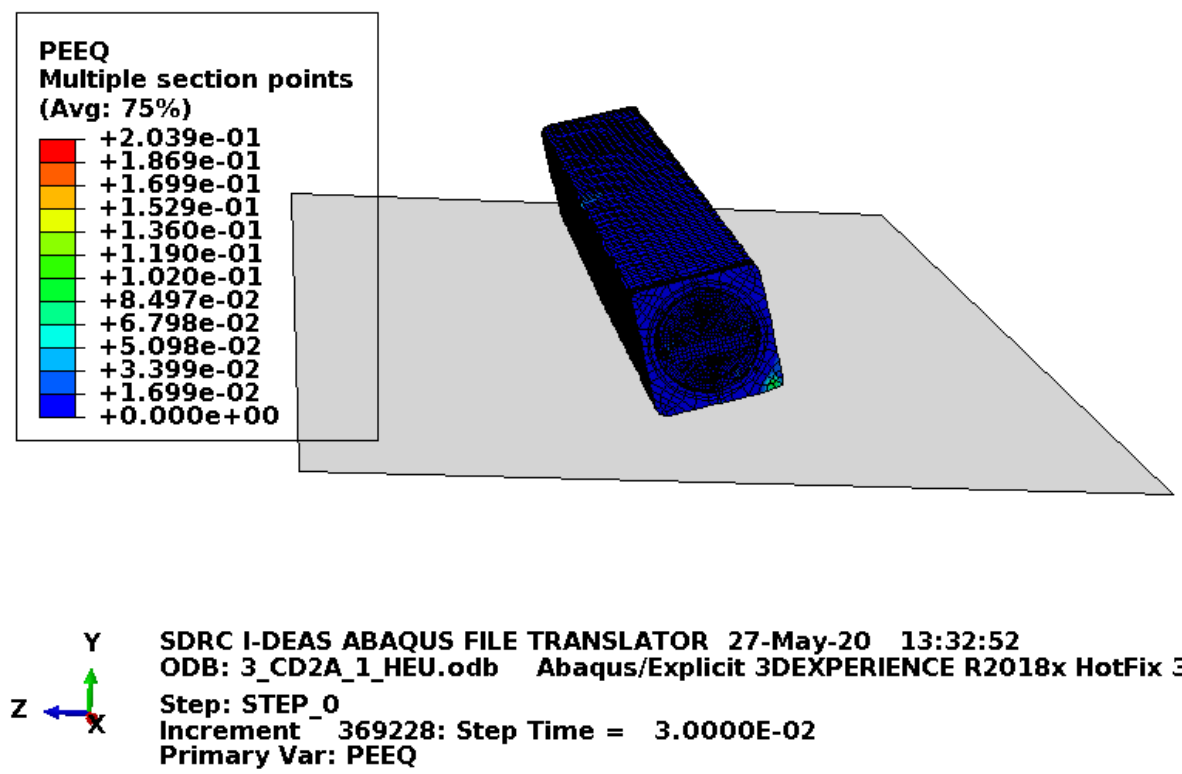

Figure C-32. Scope Part 1b (Table 3), Test 3 (Table 2) full-model plastic-equivalent strain.
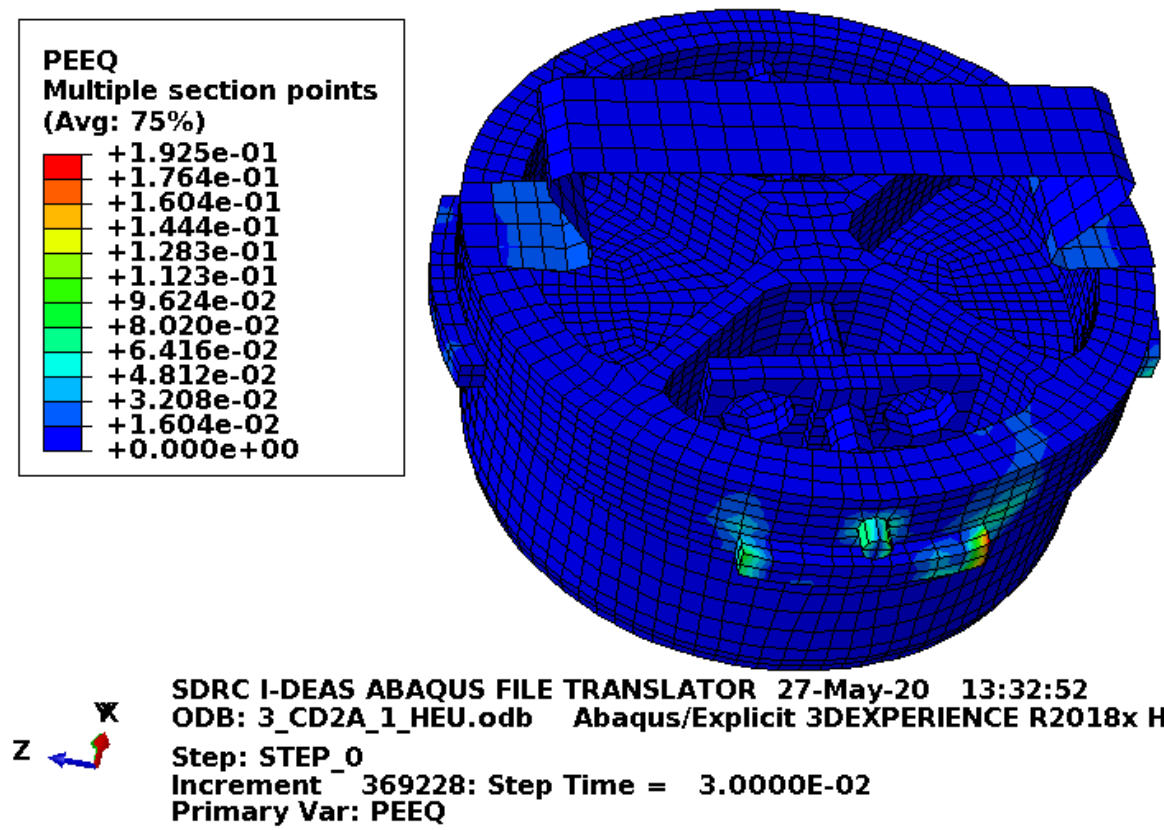

Figure C-33. Scope Part 1b (Table 3), Test 3 (Table 2) lid plastic-equivalent strain. 
ENGINEERING CALCULATIONS AND ANALYSIS

Drop Analysis of the Advanced Test Reactor Fresh Fuel Shipping Container with Heavier Low-Enriched Uranium Fuel Contents
ECAR-5224, Rev. 0

Page C25 of C190
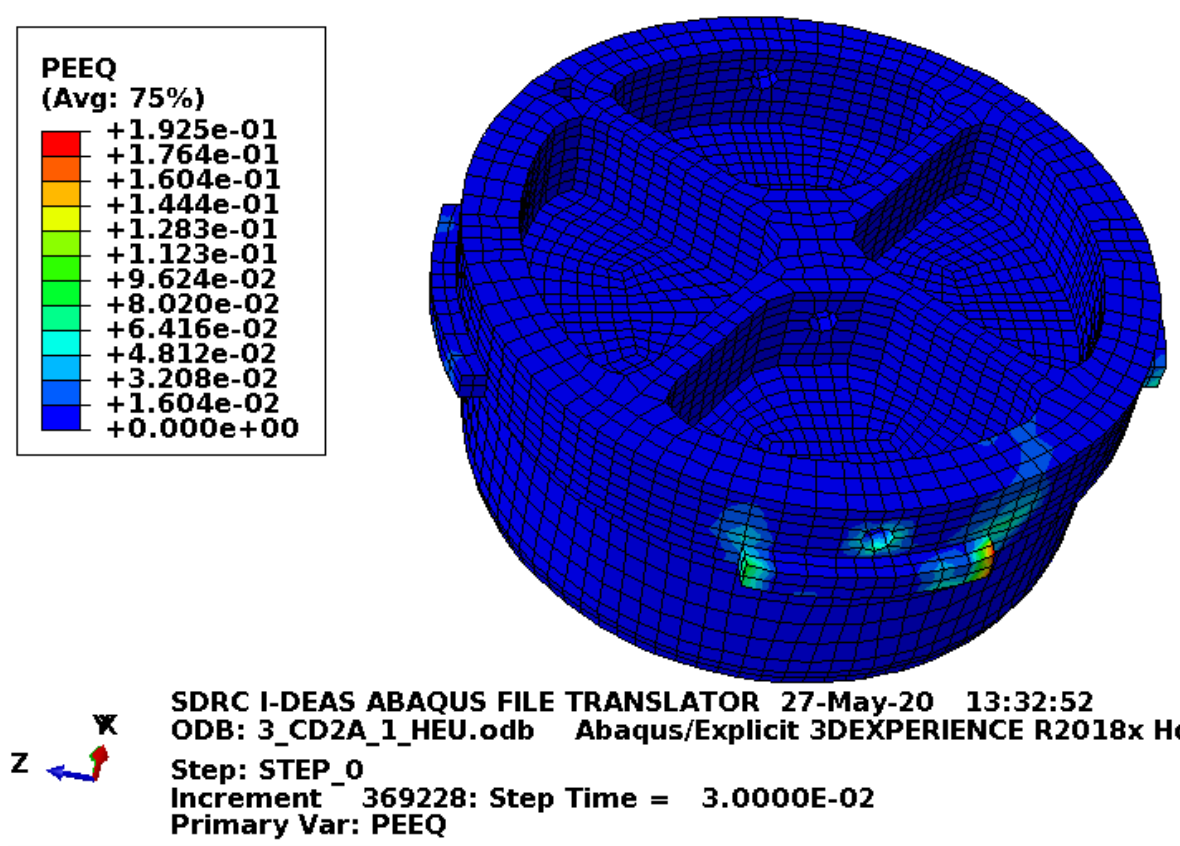

Figure C-34. Scope Part 1b (Table 3), Test 3 (Table 2) lid structure plastic-equivalent strain.

Figure C-34 shows the equivalent plastic strain in the structurally significant portion of the lid. Failure in these elements occurs at an equivalent plastic strain of $0.259 \mathrm{in}$./in. If element failure were to occur, the element would be deleted and removed from the model (thereby making its equivalent plastic strain not included in the maximum equivalent plastic strain for the plot). However, the missing element would be visible in the plot. Figure C-34 shows no element failure with margin.

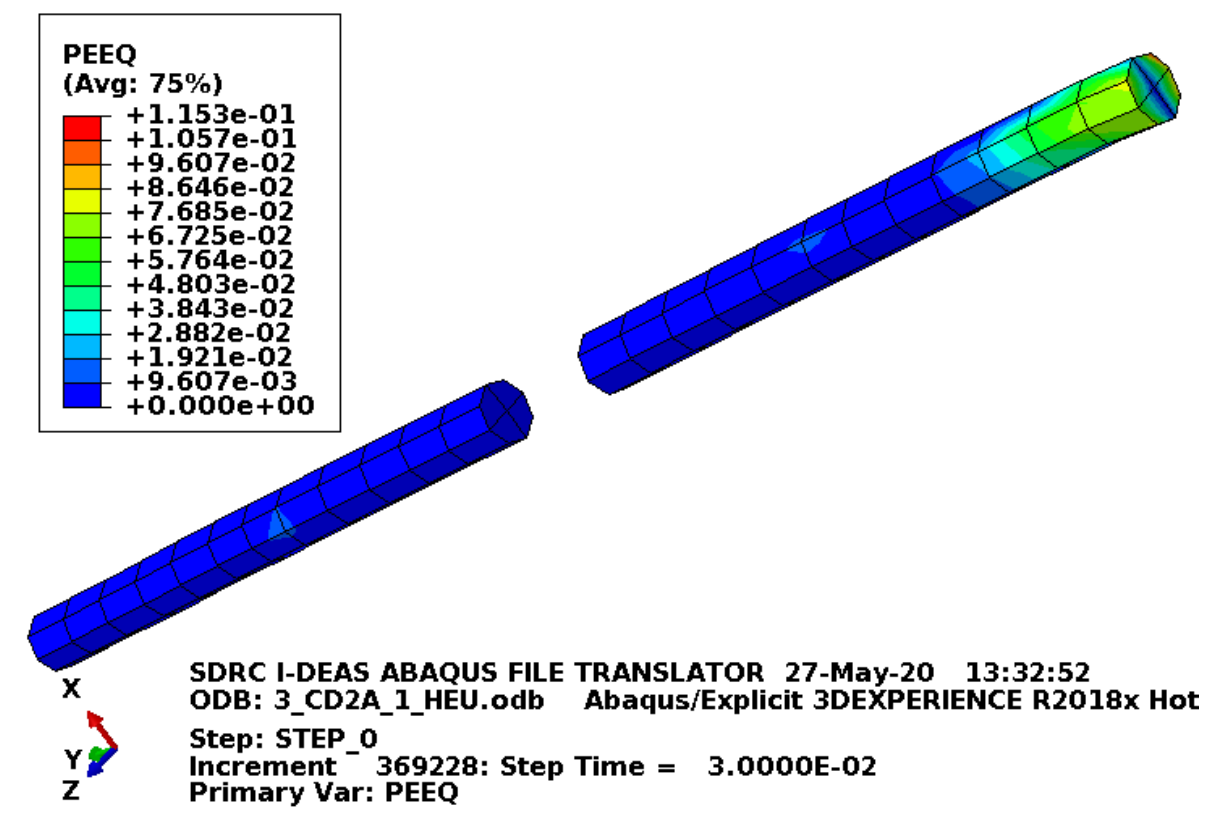

Figure C-35. Scope Part 1b (Table 3), Test 3 (Table 2) lid pins plastic-equivalent strain. 
Figure C-35 shows the equivalent plastic strain in the lid pins. Failure in these elements occurs at an equivalent plastic strain of $0.295 \mathrm{in}$./in. If element failure were to occur, the element would be deleted and removed from the model (thereby making its equivalent plastic strain not included in the maximum equivalent plastic strain for the plot). However, the missing element would be visible in the plot. Figure C-35 shows no element failure.

As noted in the description of all three physical drops (see Section C2.3.1), the ATR FFSC rotated on rebound. The FEA model in this section attempts to capture the rotation approximately with an off-flat impact (acknowledging that the three models had different rotations on rebound and this FEA model only attempts to capture a reasonable rotation considering the observed damage in the physical drop, CD2.A-1.) With the model exhibiting rotation upon rebound, the lid pin in Figure C-35 is bent about 0.027 in. This result contrasts with the lid pin in a flat impact (as shown in Figure C-20) where no lid pin bending is observed in the FEA model. The 0.027 -in. deformation corresponds quite well with the approximately 1/32-in. deformation noted in Section C2.2.1 (where the first plastic deformation of the lid pin is noted.) Rotating rebound is studied further in Section C4 of this study.
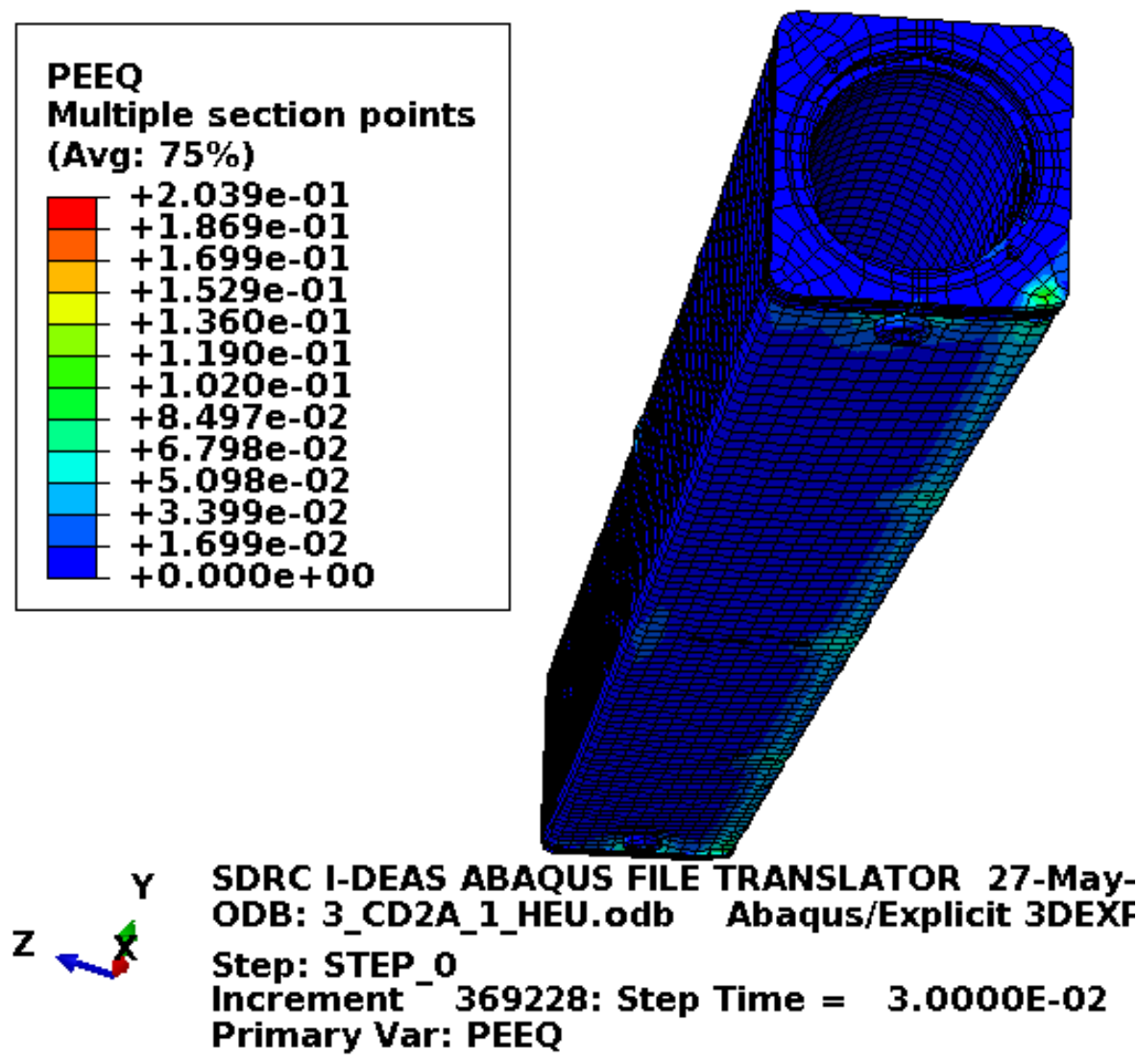

Figure C-36. Scope Part 1b (Table 3), Test 3 (Table 2) body plastic-equivalent strain.

Figure C-36 shows the equivalent plastic strain in the body. Failure in these elements occurs at an equivalent plastic strain of $0.259 \mathrm{in}$./in. If element failure were to occur, the element would be deleted and removed from the model (thereby making its equivalent plastic strain not included in the maximum equivalent plastic strain for the plot). However, the missing element would be visible in the plot. Figure C-36 shows no element failure with margin. 
The three physical drops produced a variety of index lug deformation (see Section C2.3.1) that grew in magnitude consecutively. These ranged from a 1/8-in. deformation to Figure C-28 stating that the index lug was pressed flat. The index lug is 3/8-in.-thick and the FEA model showed an index lug deformation of about 0.36 in. Consequently, the FEA model produced reasonably conservative results considering that significant rotation was captured while deforming the index lug nearly as much as was achieved on the third of three similar physical drops.

Figure C-25 shows the lid being pinched by plastic deformation of the body at the lid opening. In the Figure C-21 discussion, the lid opening plastically deformed with a maximum in the direction of the impact reduce by a little less than 0.06 in. In the Figure C-36 drop, the impact reduced the opening by a maximum of a little more than 0.05 in. on the diagonal (from the impacted corner to the opposite corner). Considering this and the physical drop represented by Figure C-21 was not perfectly flat; the physical drop maximum deformation could be expected to be offset from being perfectly in line with the impact direction. The initial nominal lid to body gap on diameter is $1 / 16$ in. Therefore, putting the Section C2.2 and Section C2.3 drops in sequence, produces a pinch very much like that shown in Figure C-25.

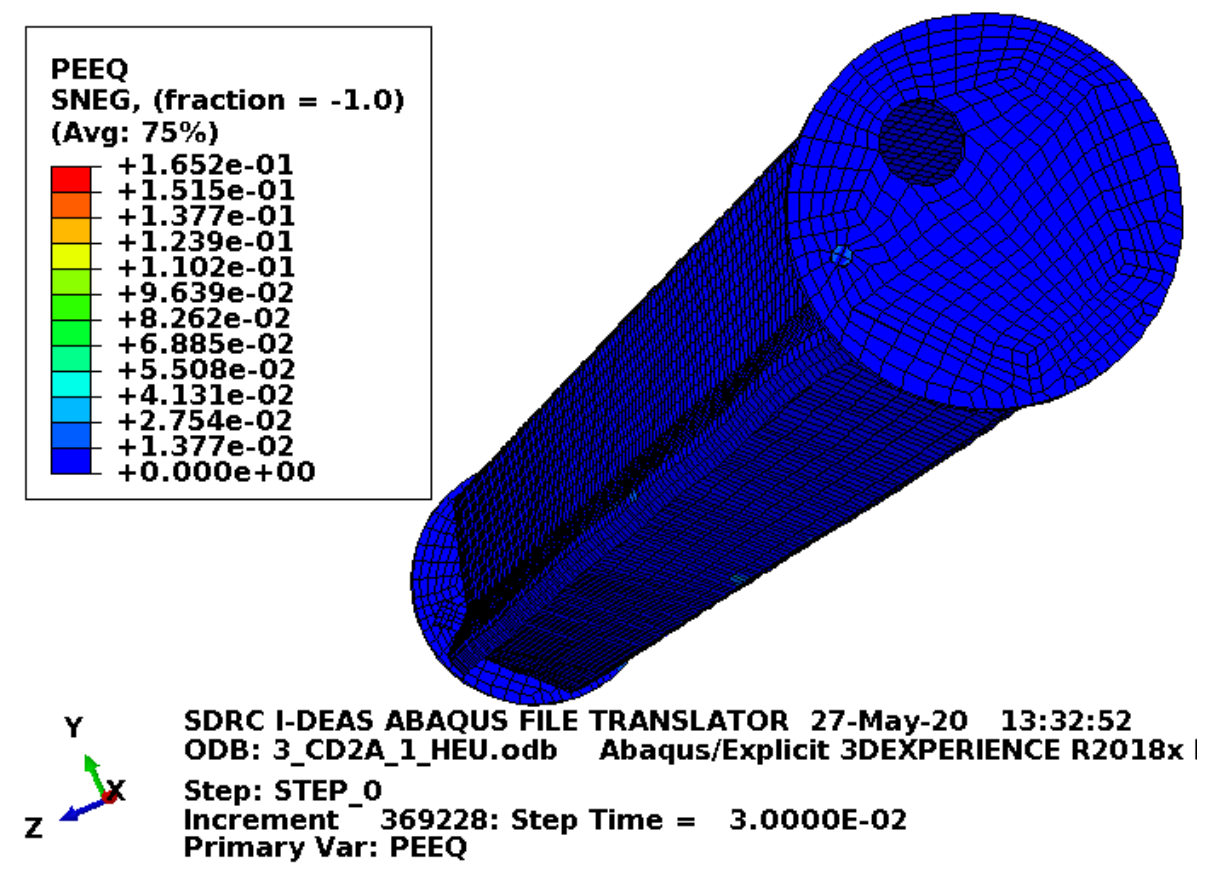

Figure C-37, Scope Part 1b (Table 3), Test 3 (Table 2) enclosure plastic-equivalent strain.

Figure C-37 shows the equivalent plastic strain in the enclosure. This is just for information as damage to the enclosure is acceptable.

\section{C2.4 Results for Scope Part 1 (Table 3), Test 5 (Table 2)}

The drop scenario considered in this section is a 30 -ft drop modeled as a flat-side drop with the pockets and index lugs on the sides. It is identified as CD3-1 in the ATR FFSC SAR (2017). 


\section{C2.4.1 Results from the Physical Drop Scenario}

A summary of the physical drop scenario results for Scope Part 1 (Table 3), Test 5 (Table 2) is provided in the ATR FFSC SAR (2017), Section 2.12.1.4.3 (shown below for reference). Figure C-1 along with Figure C-11 and Figure C-13 provide the supporting ATR FFSC SAR (2017) figures for reference.

Following impact, the CTU bounced slightly and came to rest in its standard position with the index lugs facing up. The impact side showed just minor scratches and impact marks from the drop. Figure 2.12.1-23 and Figure 2.12.1-24 show the CTU following the drop. The impact side showed a slight bowing of the ends. Using a straight edge, the maximum gap at each end was approximately $1 / 8$ in. There was no visible rotation of the closure and the locking pins remained in the locked position following the CD3-1 drop.

As illustrated in Figure 2.12.1-25, the closure assembly was functionally tested and upon close inspection it was found that the locking pin near point 4 (bottom of picture) had sheared off between the closure assembly and body preventing the locking pin from engaging in the body. The locking pin near point 8 was engaged following the drop but continued to bind in the open-unlocked position when depressed by hand. Figure 2.12.1-25 shows this locking pin in the open position following the attempt to open the closure. The closure assembly could partially rotate approximately 1/4 in. but was unable to fully rotate to the open position. The locking pin near Point 8 was returned to the locked position following the inspection. The dull gray color seen on the photographs is frost.

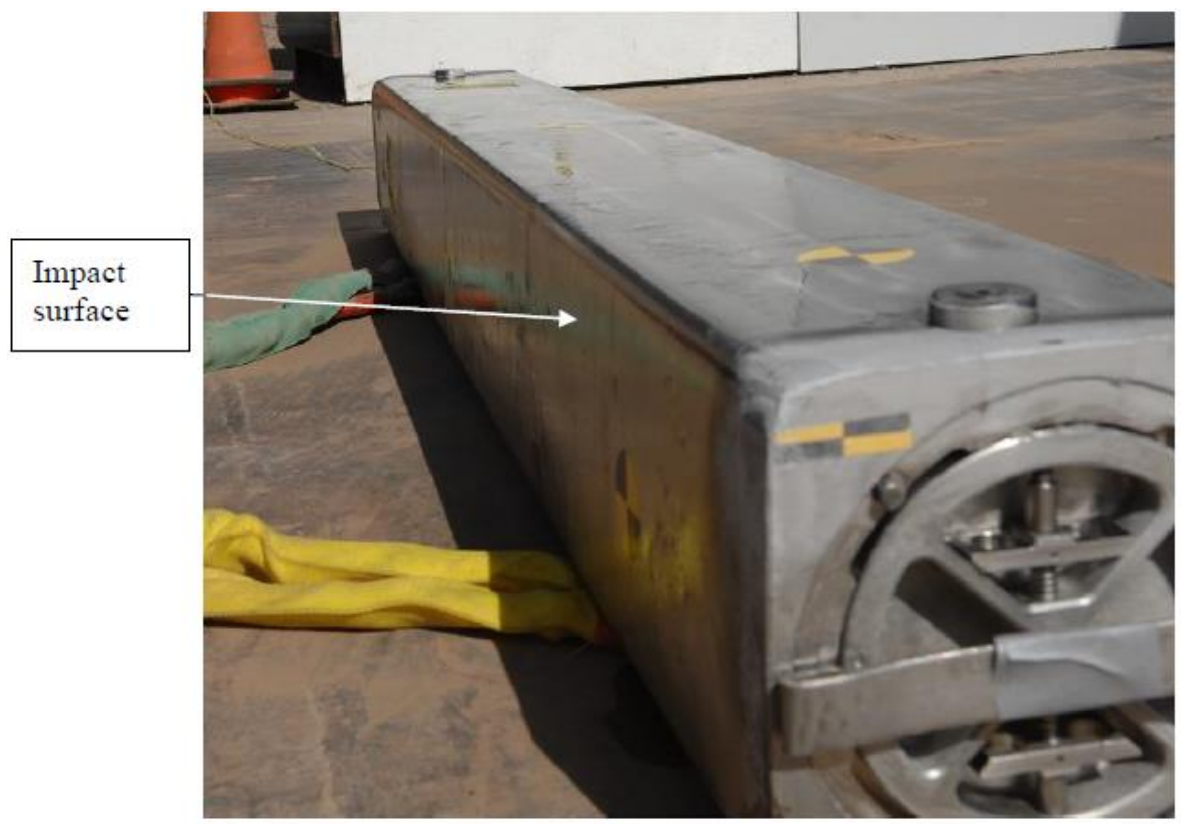

Figure C-38. CTU following CD3-1 impact [ATR FFSC SAR (2017), Figure 2.12.1-23]. 
Drop Analysis of the Advanced Test Reactor Fresh Fuel Shipping Container with Heavier Low-Enriched Uranium Fuel Contents

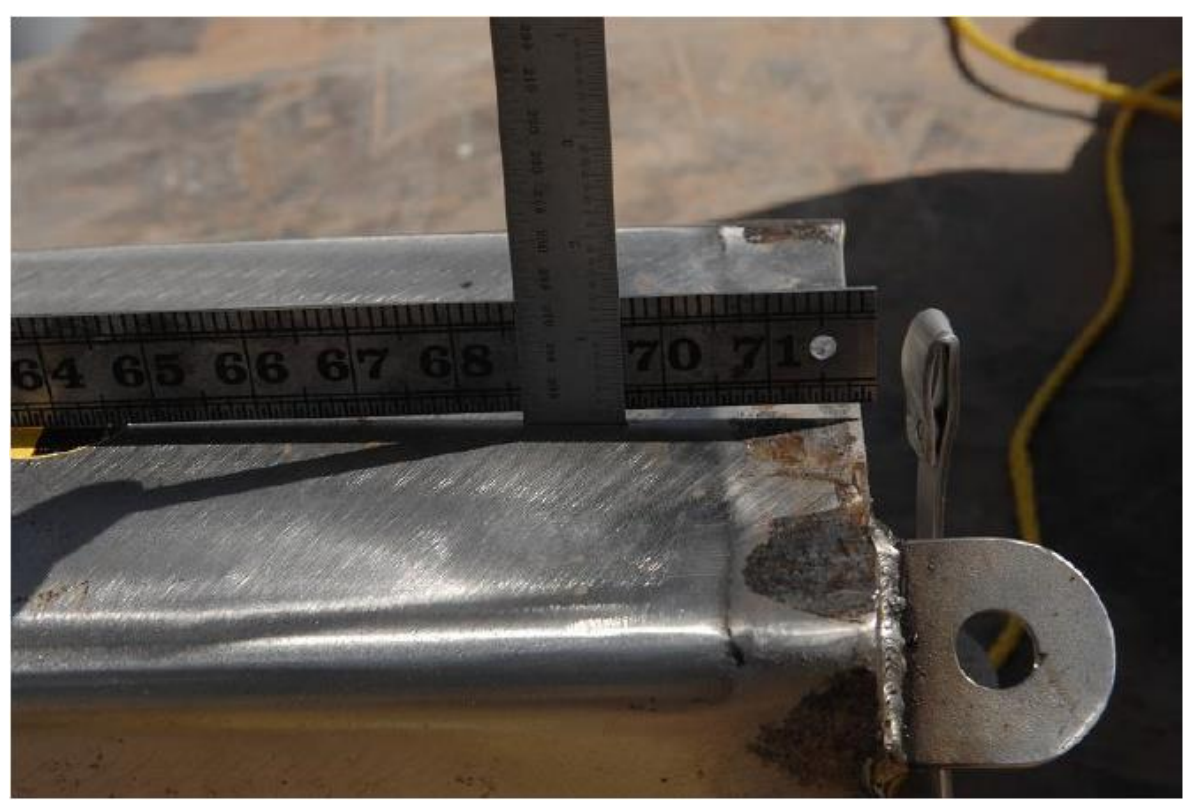

Figure C-39. Deformation near closure end following CD3-1 [ATR FFSC SAR (2017), Figure 2.12.1-24].

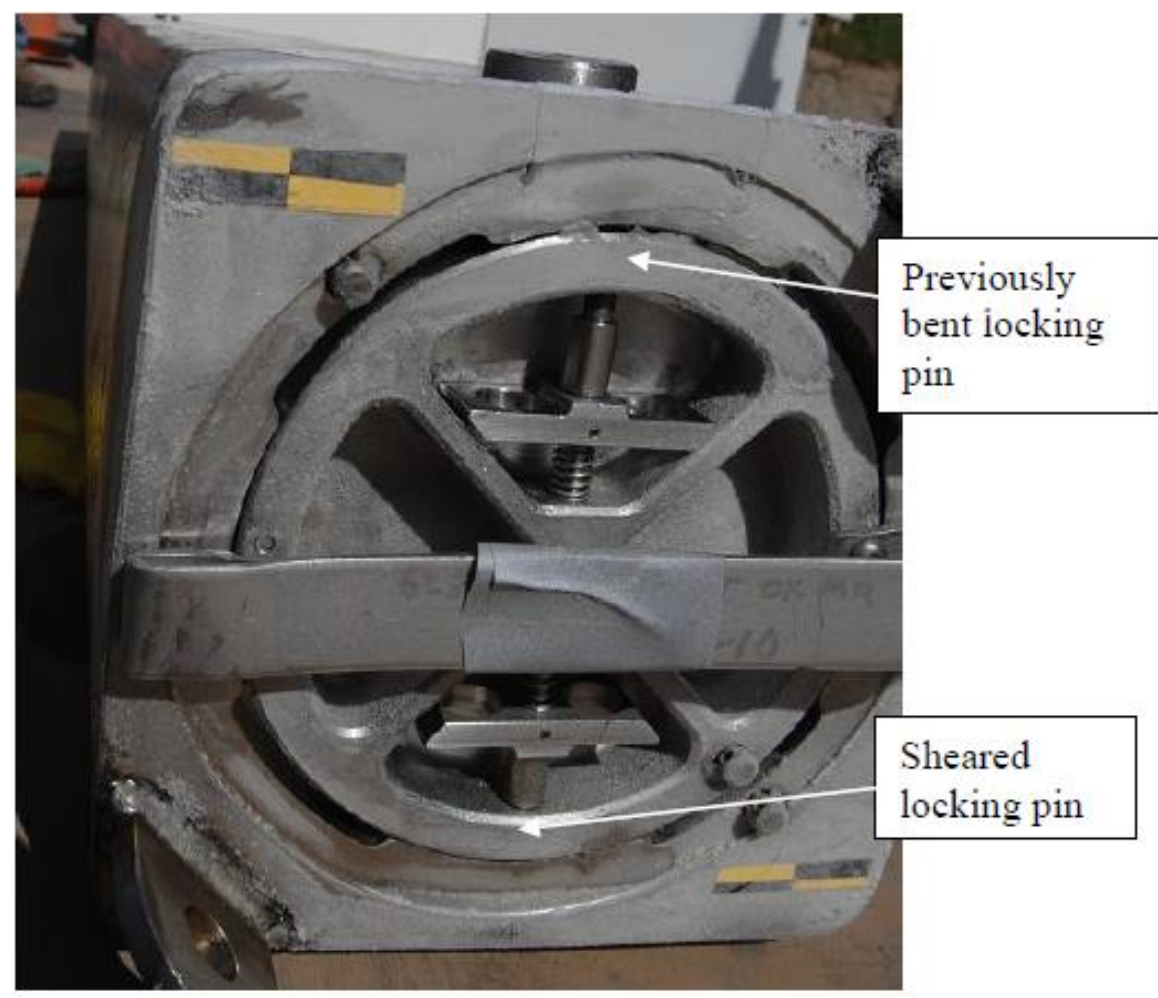

Figure C-40. View of closure following CD3-1 [ATR FFSC SAR (2017), Figure 2.12.1-25]. 


\section{C2.4.2 Results for Scope Part $1 \mathrm{~b}$ (Table 3), Test 5 (Table 2)}

The FEA model results for the Scope Part 1b (Table 3), Test 5 (Table 2) model are shown below in

Figure C-41 to Figure C-47. This drop scenario is a 30-ft drop modeled as a flat-side drop with the pockets and index lugs on the sides. The fuel element weights $22.1 \mathrm{lbf}$ and the drop scenario is modeled with minimum material properties except the enclosure and end boxes, which are modeled with relatively tough material properties.

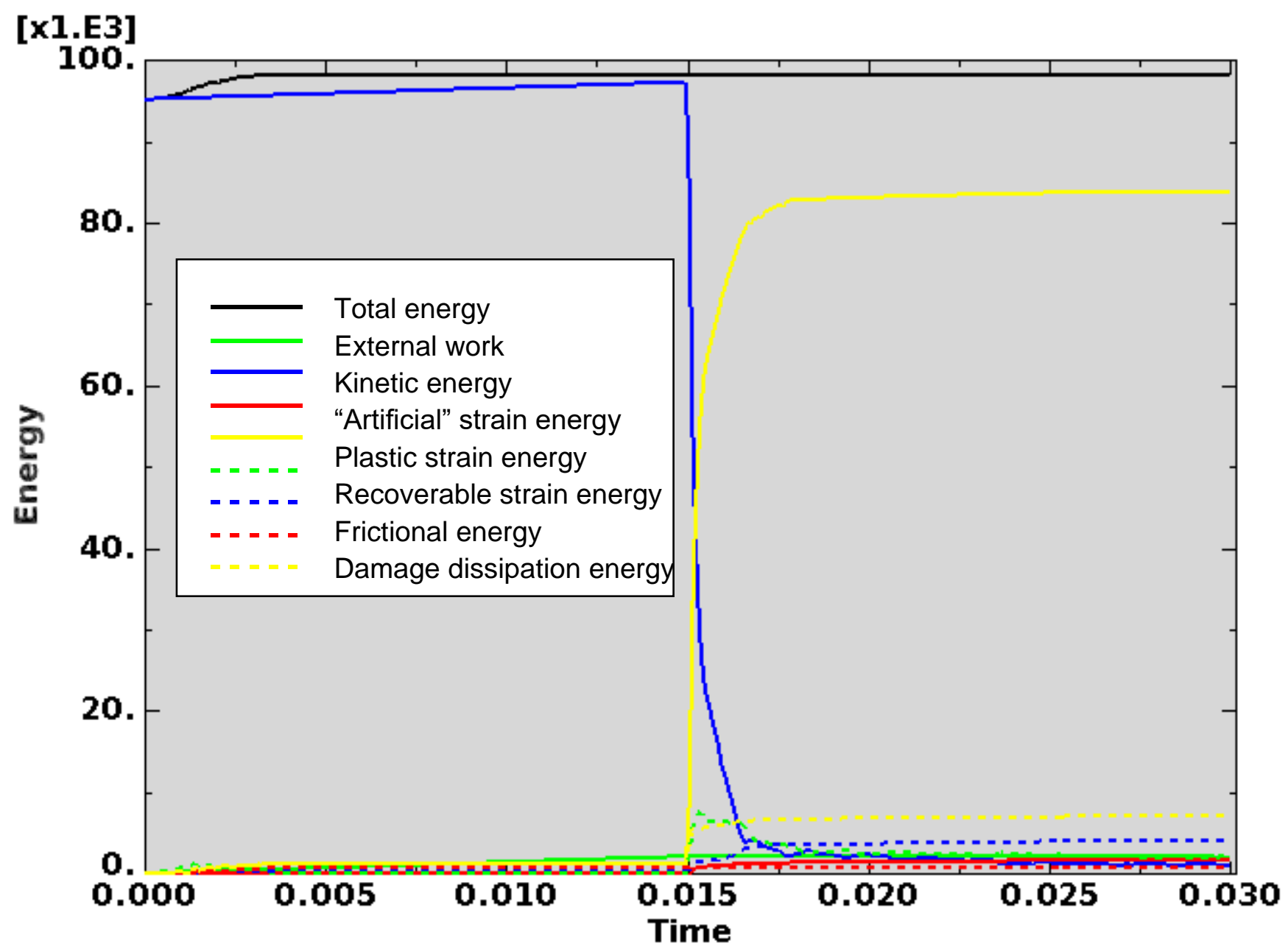

Figure C-41. Scope Part 1b (Table 3), Test 5 (Table 2) energy curves.

Figure C-41 shows the energy curves for Scope Part 1b (Table 3), Test 5 (Table 2) drop scenario. These curves exhibit a stable shape. Artificial strain energy represents the energy required to keep reduced integration elements from taking on a zero-energy hourglass shape. As shown in Figure C-41, the artificial energy at the end of the model run is $1.7 \%$ of the total energy. Therefore, the potential error associated with artificial energy is not considered to be significant. 


\section{ENGINEERING CALCULATIONS AND ANALYSIS}

Drop Analysis of the Advanced Test Reactor Fresh Fuel Shipping Container with Heavier Low-Enriched Uranium Fuel Contents
ECAR-5224, Rev. 0

Page C31 of C190
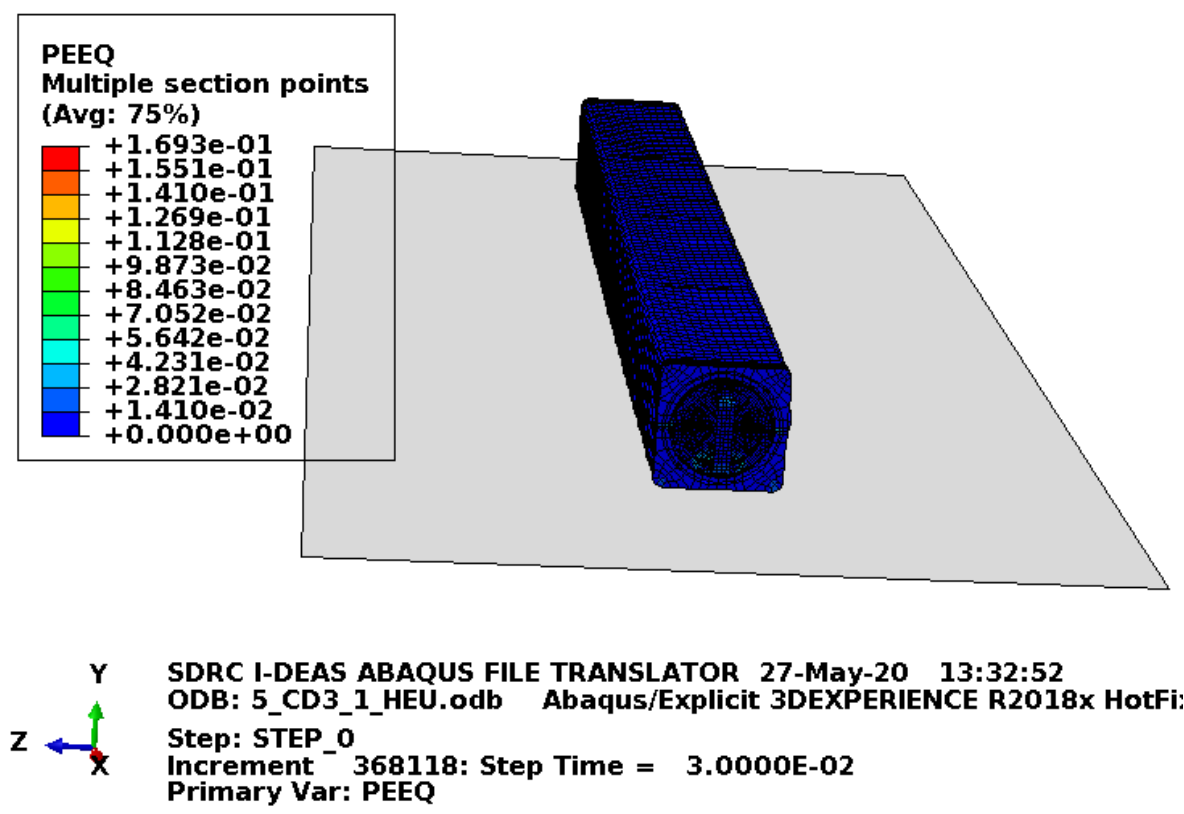

Figure C-42. Scope Part 1b (Table 3), Test 5 (Table 2) full-model plastic-equivalent strain.
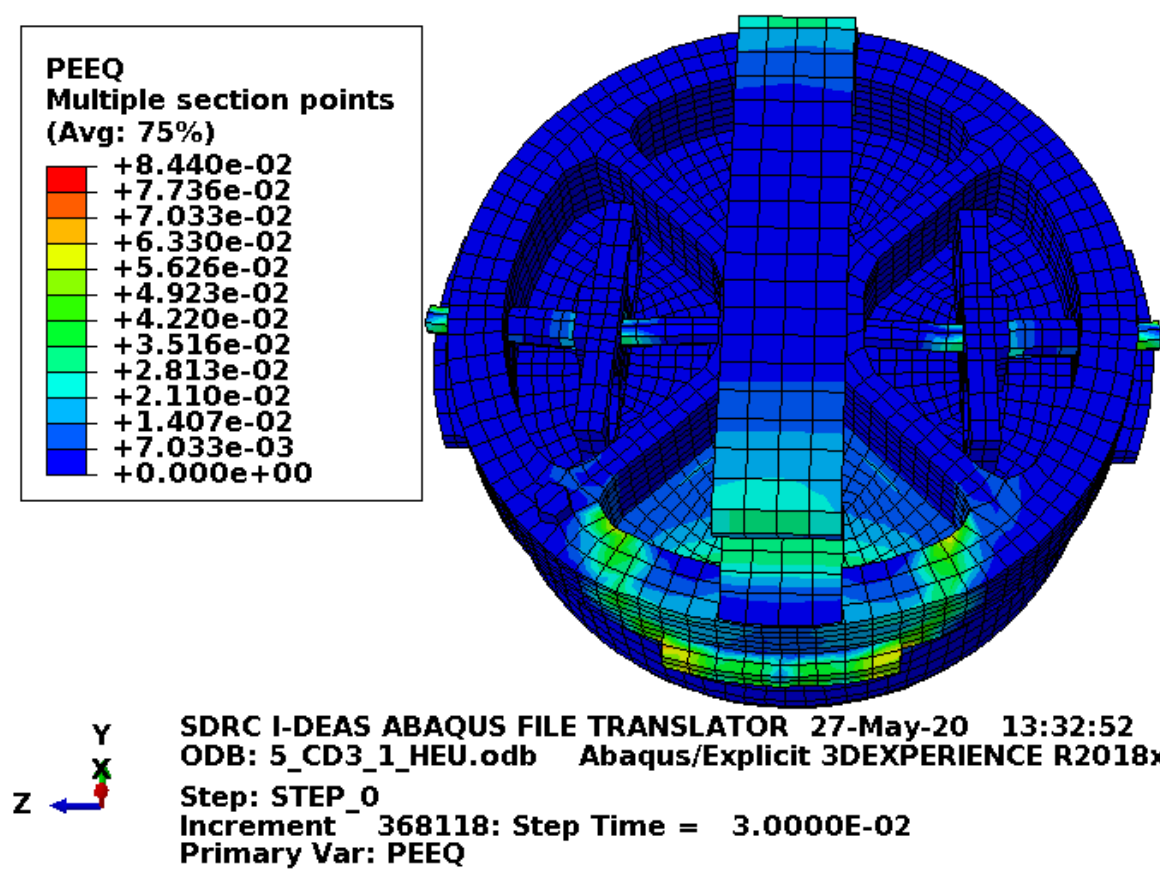

Figure C-43. Scope Part 1b (Table 3), Test 5 (Table 2) lid plastic-equivalent strain. 
ENGINEERING CALCULATIONS AND ANALYSIS

Drop Analysis of the Advanced Test Reactor Fresh Fuel Shipping Container with Heavier Low-Enriched Uranium Fuel Contents
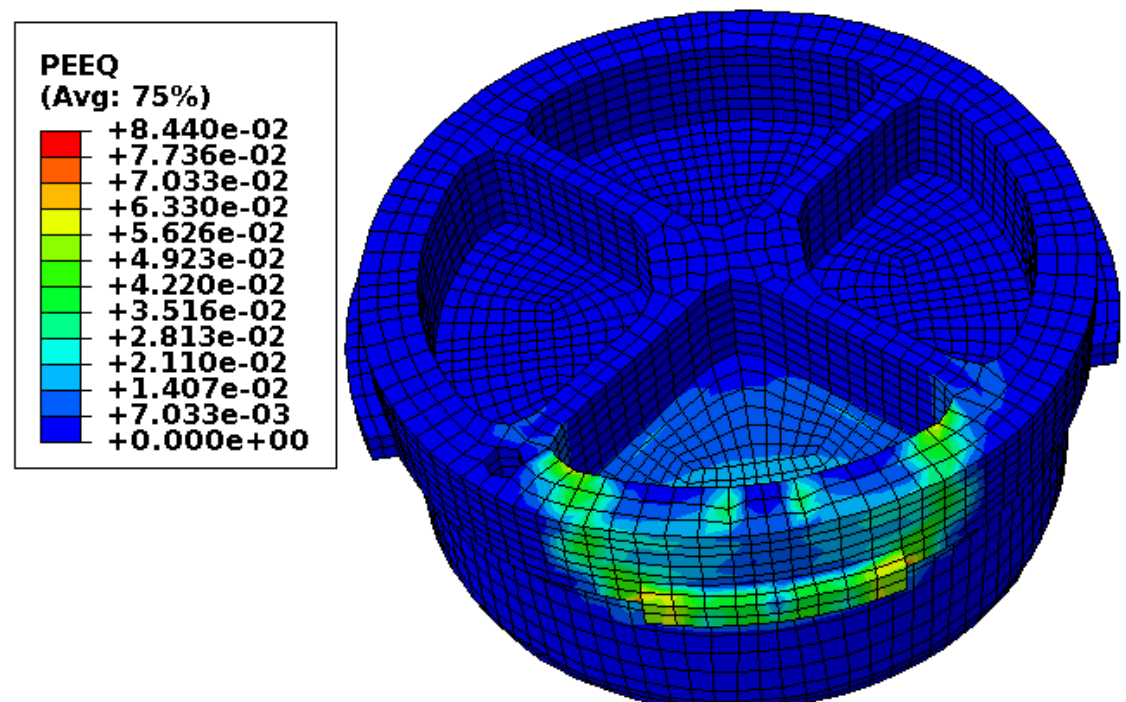

SDRC I-DEAS ABAQUS FILE TRANSLATOR 27-May-20 13:32:52

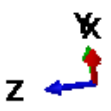

ODB: 5_CD3_1_HEU.odb Abaqus/Explicit 3DEXPERIENCE R2018x

Step: STEP 0

Increment ${ }^{-}$368118: Step Time $=3.0000 E-02$

Primary Var: PEEQ

Figure C-44. Scope Part 1b (Table 3), Test 5 (Table 2) lid structure plastic-equivalent strain.

Figure C-44 shows the equivalent plastic strain in the structurally significant portion of the lid. Failure in these elements occurs at an equivalent plastic strain of $0.259 \mathrm{in}$./in. If element failure were to occur, the element would be deleted and removed from the model (thereby making its equivalent plastic strain not included in the maximum equivalent plastic strain for the plot). However, the missing element would be visible in the plot. Figure $\mathrm{C}-44$ shows no element failure with margin.

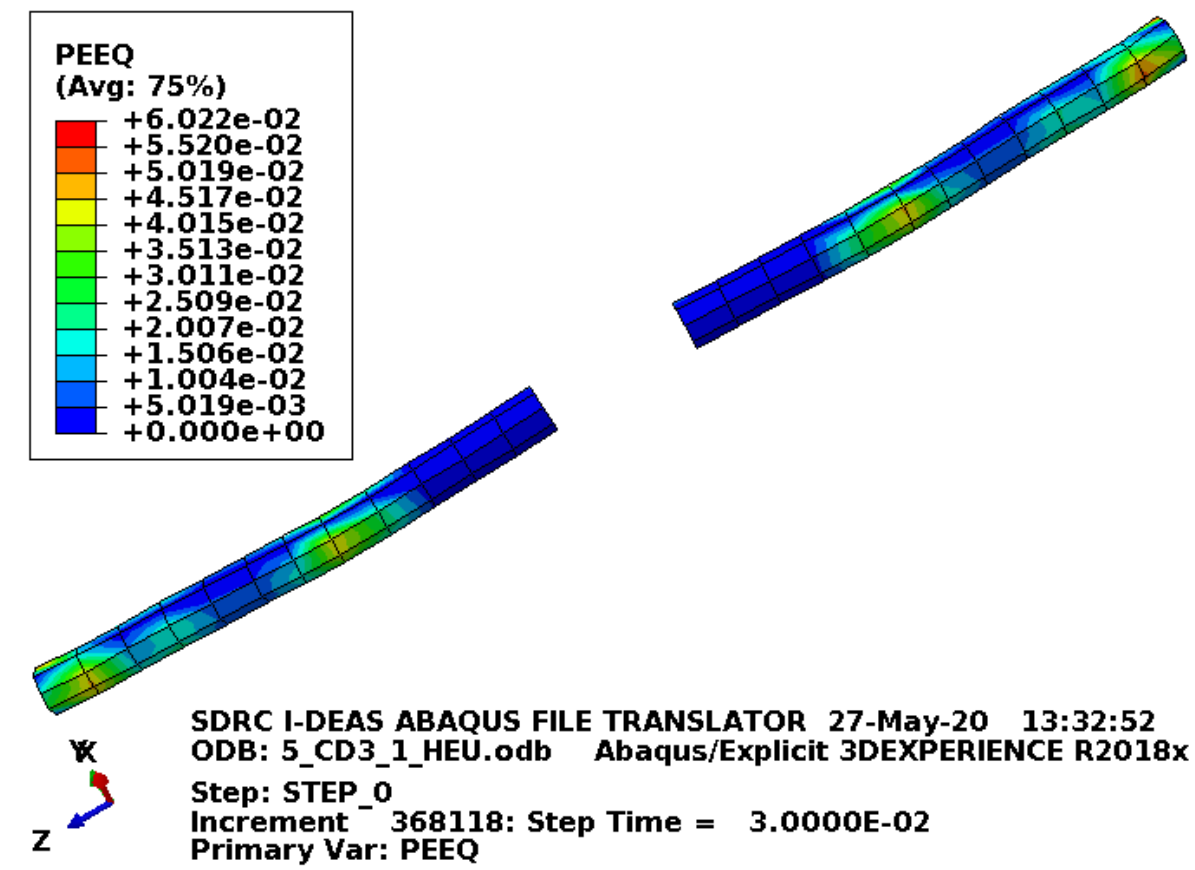

Figure C-45. Scope Part 1b (Table 3), Test 5 (Table 2) lid pins plastic-equivalent strain. 
Figure C-45 shows the equivalent plastic strain in the lid pins. Failure in these elements occurs at an equivalent plastic strain of $0.295 \mathrm{in}$./in. If element failure were to occur, the element would be deleted and removed from the model (thereby making its equivalent plastic strain not included in the maximum equivalent plastic strain for the plot). However, the missing element would be visible in the plot. Figure C-45 shows no element failure.

In this physical drop, one lid pin was sheared between the lid and body. It is difficult to make a solid case for why the lid pin sheared given the description in Section C2.4.1. In the first paragraph, it is noted that there was no visible rotation of the lid relative to the body. This physical drop occurred with an average FFSC surface temperature of $13^{\circ} \mathrm{F}$. However, brittle fracture should not be an issue given that the ASME (2015) lists the yield and ultimate values for the structural materials of the ATR FFSC body and lid as being constant for temperatures from $-20^{\circ} \mathrm{F}$ to $100^{\circ} \mathrm{F}$. Figure $\mathrm{C}-40$ notes that the sheared lid pin (at Position 4 in Figure C-1) was not the one that was bent (at Position 8 in Figure C-1) in the physical drop CD1-1. Also, the description for CD1-1 commented that this lid pin was not damaged. Finally, there is no evidence of the lid translating out of the body in Figure C-40 (and this path is well supported by the bayonets if no rotation has occurred). Considering these observations, there would seem to be no reason for the lid pin to shear between the lid and body.

This physical drop is the fourth side drop performed on the loaded ATR FFSC. Physical drops CD2.A-1 and CD2.B-1 were noted as having a lot of rebound rotation and the lid pin (at position 4 in Figure C-1) was not mentioned. Given the scoping model evidence, lid pin damage occurring from rebound rotation is studied as the primary load path for shearing the lid pins. The FEA model in this section does not attempt to capture the rotation. Though, the model from this section is used for the rotating rebound study in Section C4.

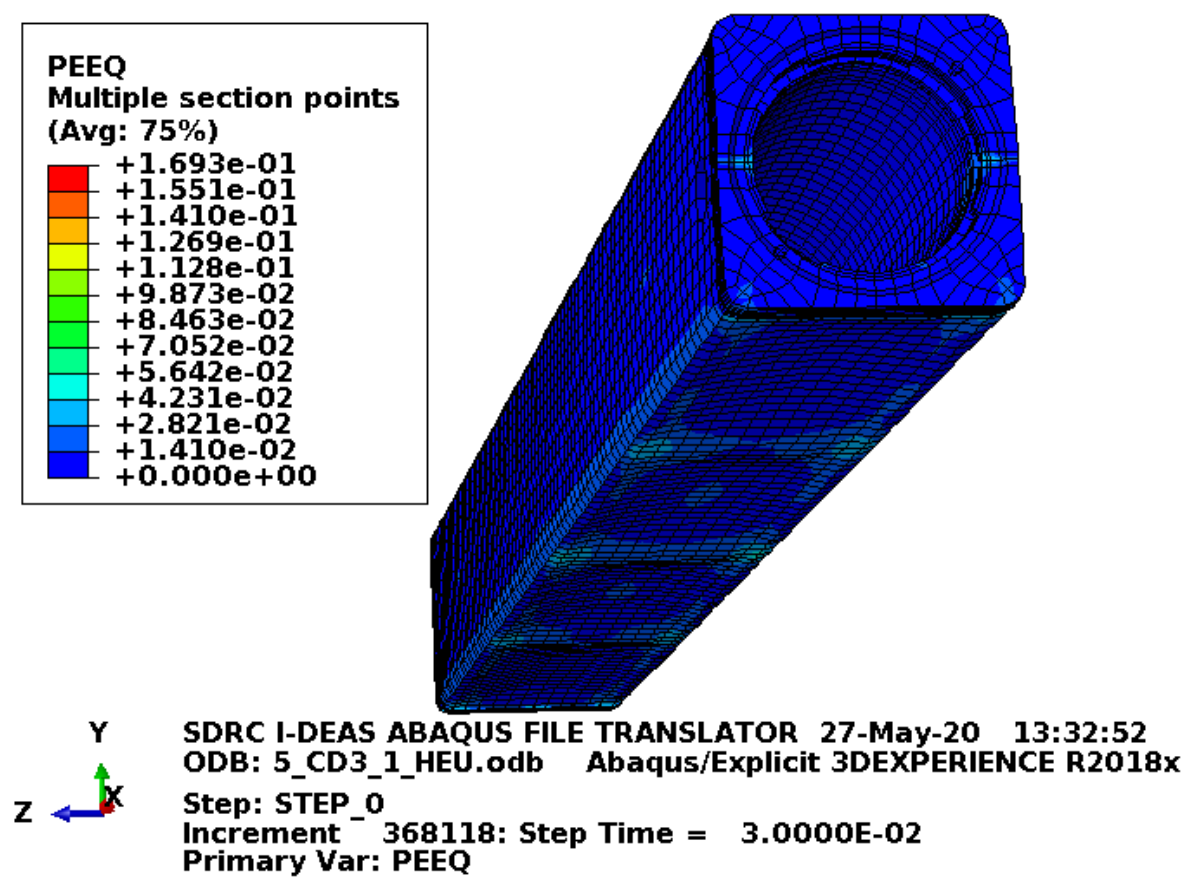

Figure C-46. Scope Part 1b (Table 3), Test 5 (Table 2) body plastic-equivalent strain. 
Figure C-46 shows the equivalent plastic strain in the body. Failure in these elements occurs at an equivalent plastic strain of $0.259 \mathrm{in}$./in. If element failure were to occur, the element would be deleted and removed from the model (thereby making its equivalent plastic strain not included in the maximum equivalent plastic strain for the plot). However, the missing element would be visible in the plot. Figure C-46 shows no element failure with margin.

The physical drop description (see Section C2.4.1) notes that the ATR FFSC showed slight bowing. The FEA model produced similar deformation to the flat-side drop in Section C2.2.

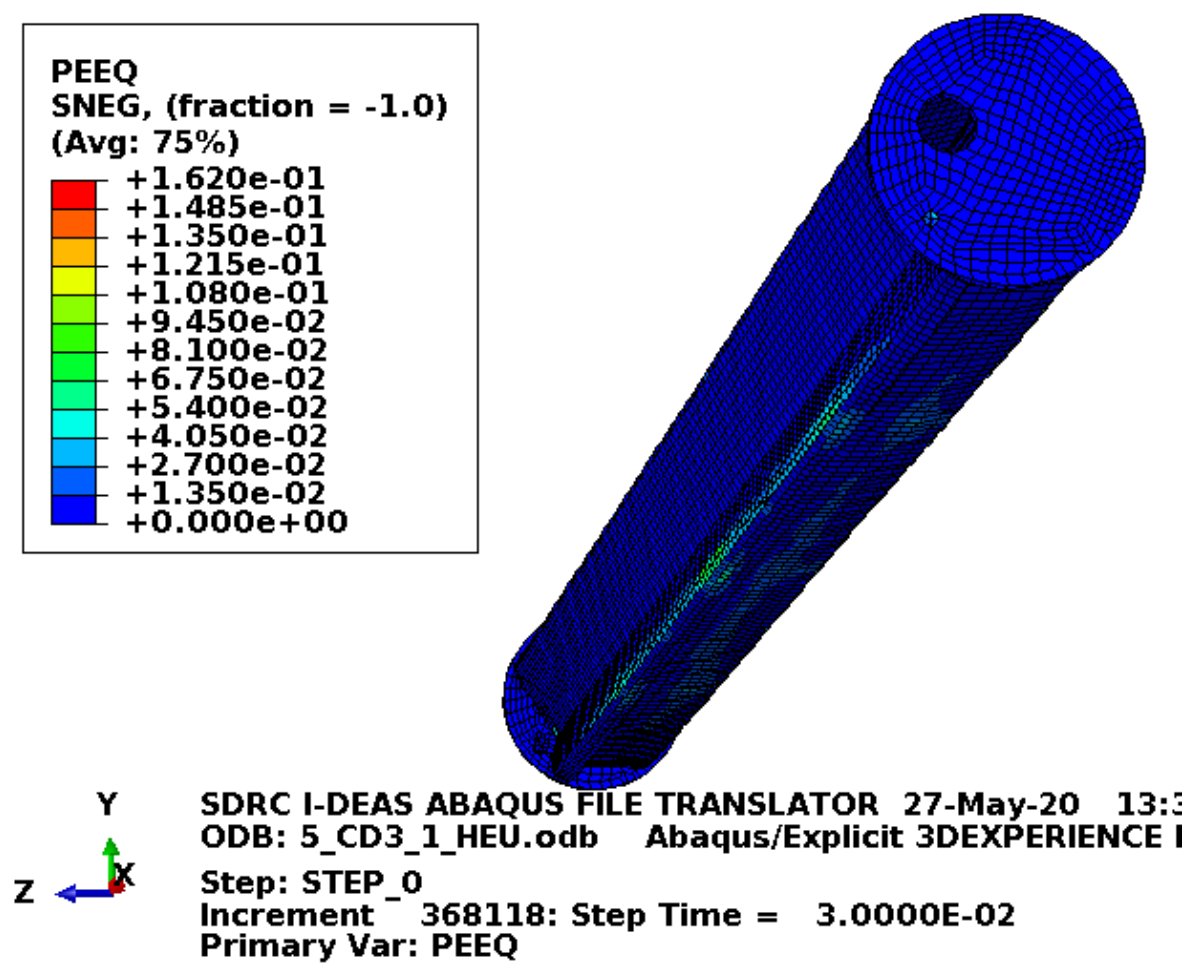

Figure C-47. Scope Part 1b (Table 3), Test 5 (Table 2) enclosure plastic-equivalent strain.

Figure C-47 shows the equivalent plastic strain in the enclosure. This is just for information as damage to the enclosure is acceptable.

\section{C2.5 Results for Scope Part 1 (Table 3), Test 6 (Table 2)}

The drop scenario considered in this section is a 30-ft drop modeled as a vertical bottom impact. It is identified as CD4-1 in the ATR FFSC SAR (2017).

\section{C2.5.1 Results from the Physical Drop Scenario}

A summary of the physical drop scenario results for Scope Part 1 (Table 3), Test 6 (Table 2) is provided in the ATR FFSC SAR (2017), Section 2.12.1.4.4 (shown below for reference). Figure C-1 along with Figure C-11 and Figure C-12 provide the supporting ATR FFSC SAR (2017) figures for reference. 
Following the impact, the outer shell of the CTU exhibited minor bowing near the impact end with the greatest deformation measuring approximately 1/8 in. on the 90-degree side per Figure 2.12.1-4. The overall length of the package body was compared with the initial measurements at the eight locations and found to have compressed a maximum of approximately $1 / 8$ in. There was no visible deformation or rotation of the closure following the drop and the functionality of the closure assembly did not change.

Figure 2.12.1-27 and Figure 2.12.1-28 show the CTU following the drop.

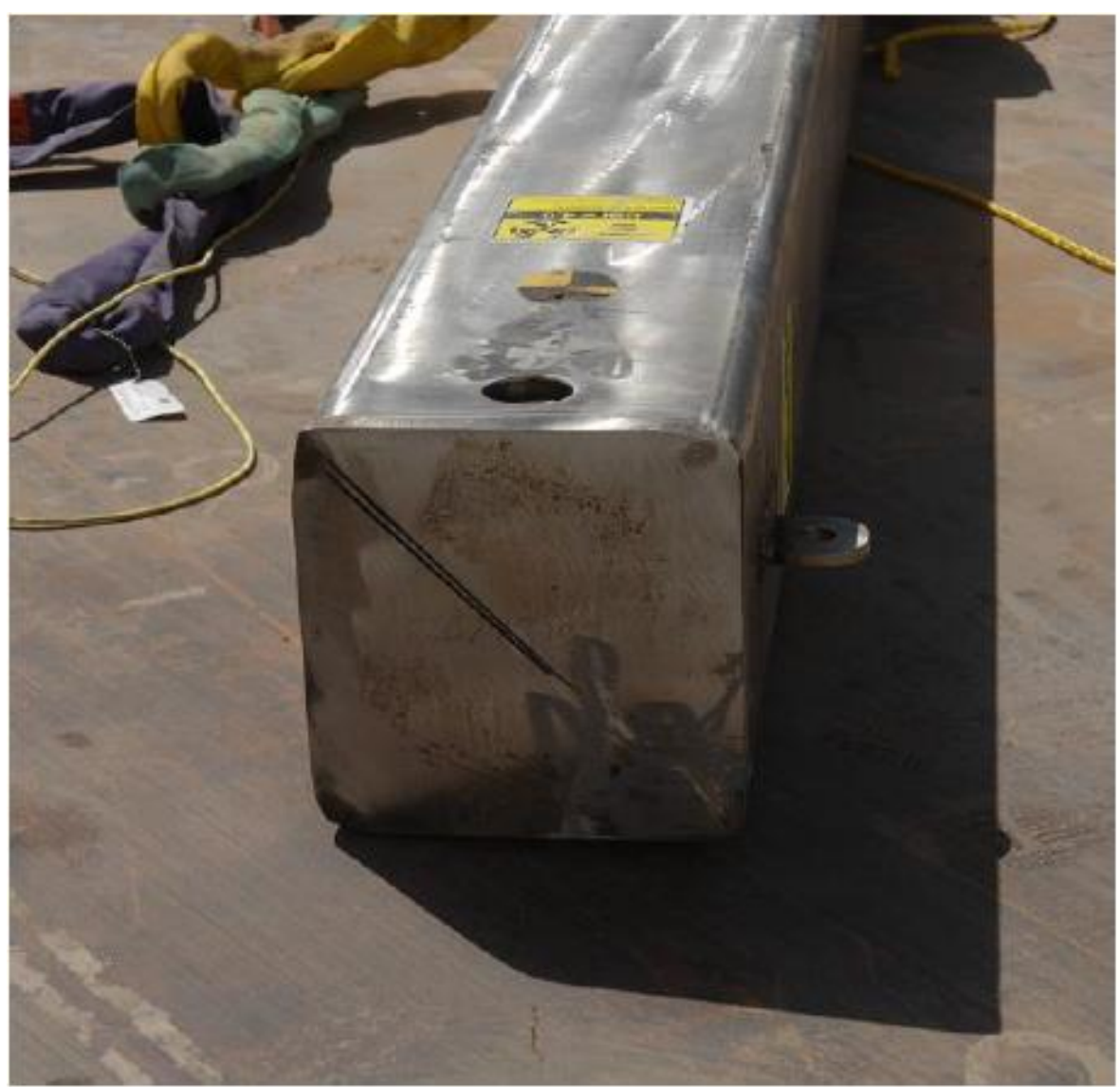

Figure C-48. View of impact end following CD4-1 [ATR FFSC SAR (2017), Figure 2.12.1-27]. 


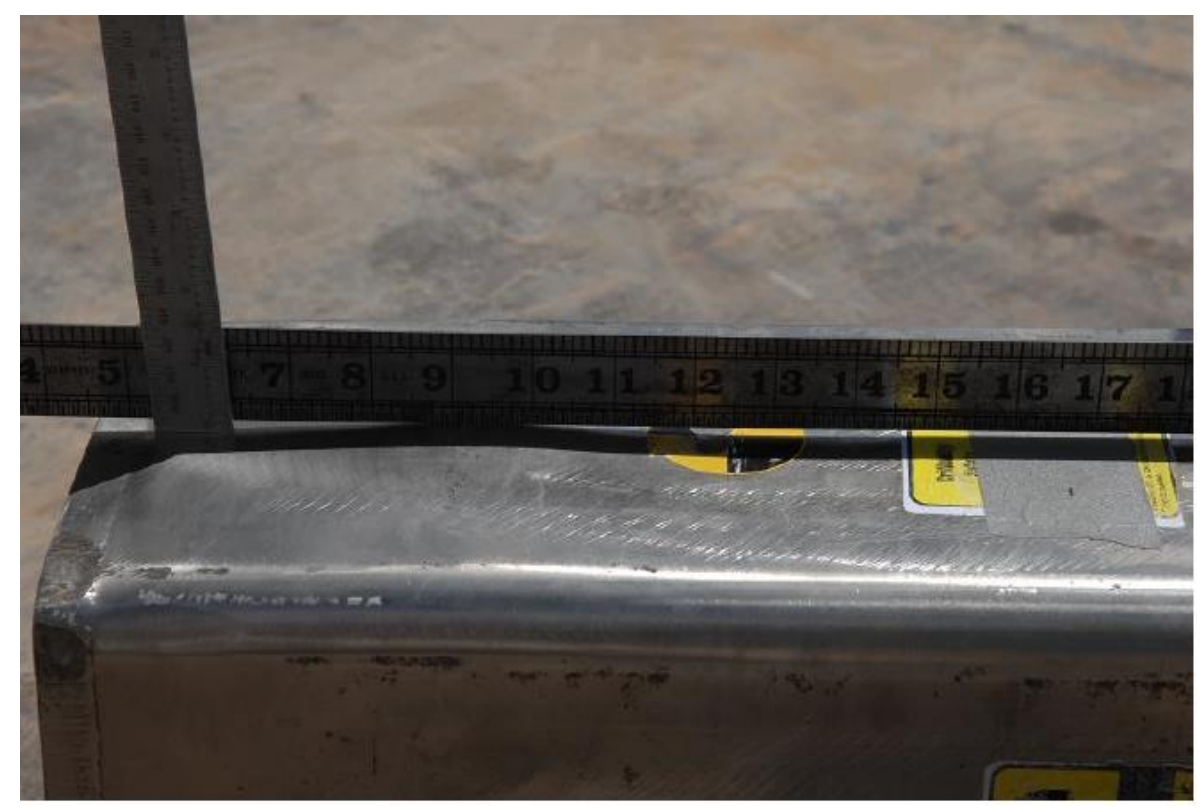

Figure C-49. View of side bowing following CD4-1 [ATR FFSC SAR (2017), Figure 2.12.1-28].

\section{C2.5.2 Results for Scope Part 1b (Table 3), Test 6 (Table 2)}

The FEA model results for the Scope Part $1 \mathrm{~b}$ (Table 3), Test 6 (Table 2) model are shown below in Figure C-50 to Figure C-57. This drop scenario is a $30-\mathrm{ft}$ drop modeled as a vertical bottom impact. The fuel element weights $22.1 \mathrm{lbf}$ and the drop scenario is modeled with minimum material properties except the enclosure and end boxes, which are modeled with relatively tough material properties. 


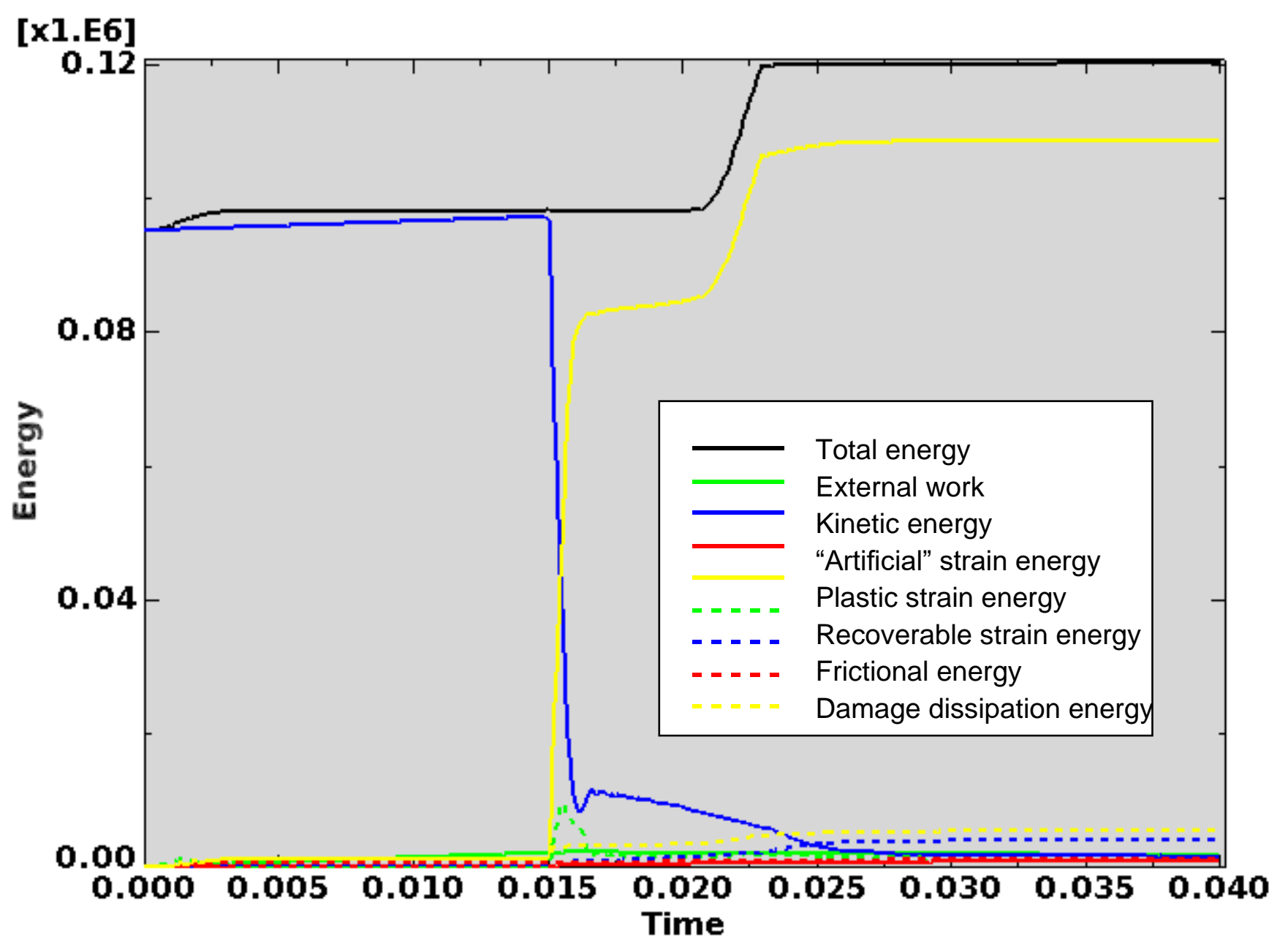

Figure C-50. Scope Part 1b (Table 3), Test 6 (Table 2) energy curves.

Figure C-50 shows the energy curves for Scope Part 1b (Table 3), Test 6 (Table 2) drop scenario. These curves exhibit a somewhat stable shape. The ATR FFSC impacts the rigid surface at around 0.015 second and the curve shape is stable for the initial impact. Later, the fuel element impacts the ATR FFSC and failure associated with the end boxes allows interaction between the end boxes and fuel plates. This interaction is complex with failure and Abaqus (2018) seems to have some trouble with it. The fuel element response is compared with physical drop test results (see Appendix D) to establish that the results are sufficiently accurate. The ATR FFSC results are compared to physical drop results for acceptability in this section.

Artificial strain energy represents the energy required to keep reduced integration elements from taking on a zero-energy hourglass shape. As shown in Figure C-50, the artificial energy at the end of the model run is $0.7 \%$ of the total energy. Therefore, the potential error associated with artificial energy is not considered to be significant. 


\section{ENGINEERING CALCULATIONS AND ANALYSIS}

Drop Analysis of the Advanced Test Reactor Fresh Fuel Shipping Container with Heavier Low-Enriched Uranium Fuel Contents
ECAR-5224, Rev. 0

Page C38 of C190
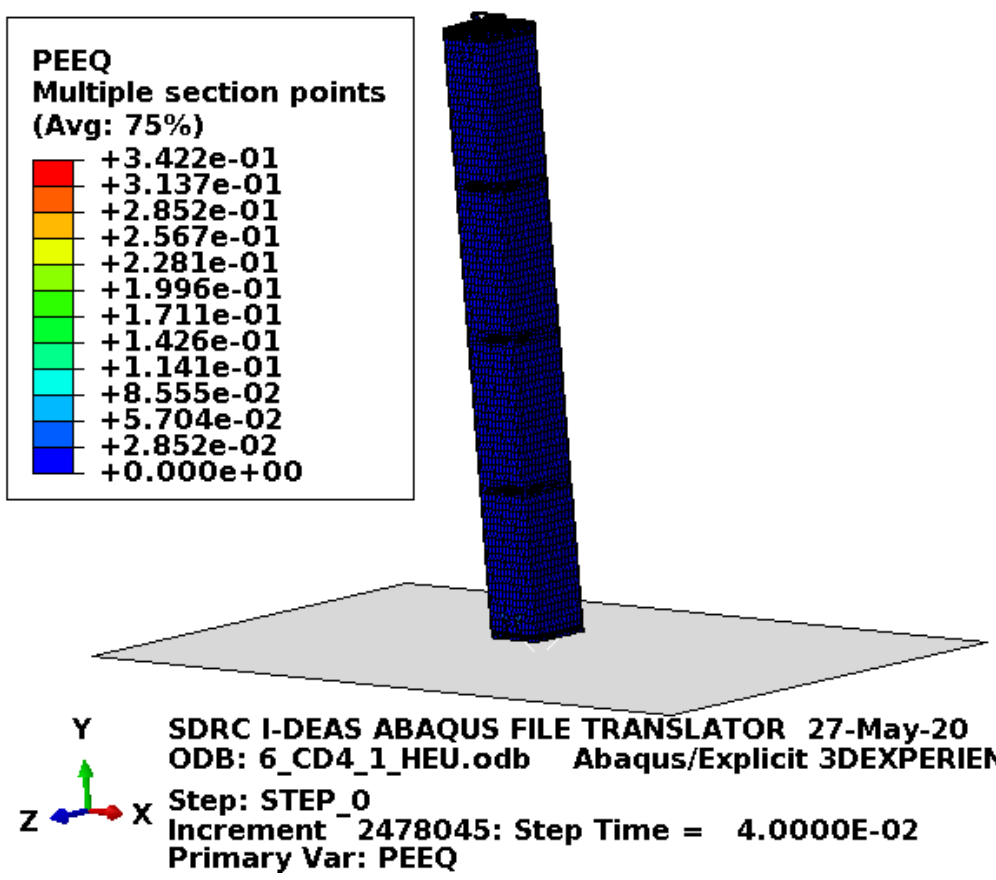

Figure C-51. Scope Part 1b (Table 3), Test 6 (Table 2) full-model plastic-equivalent strain.

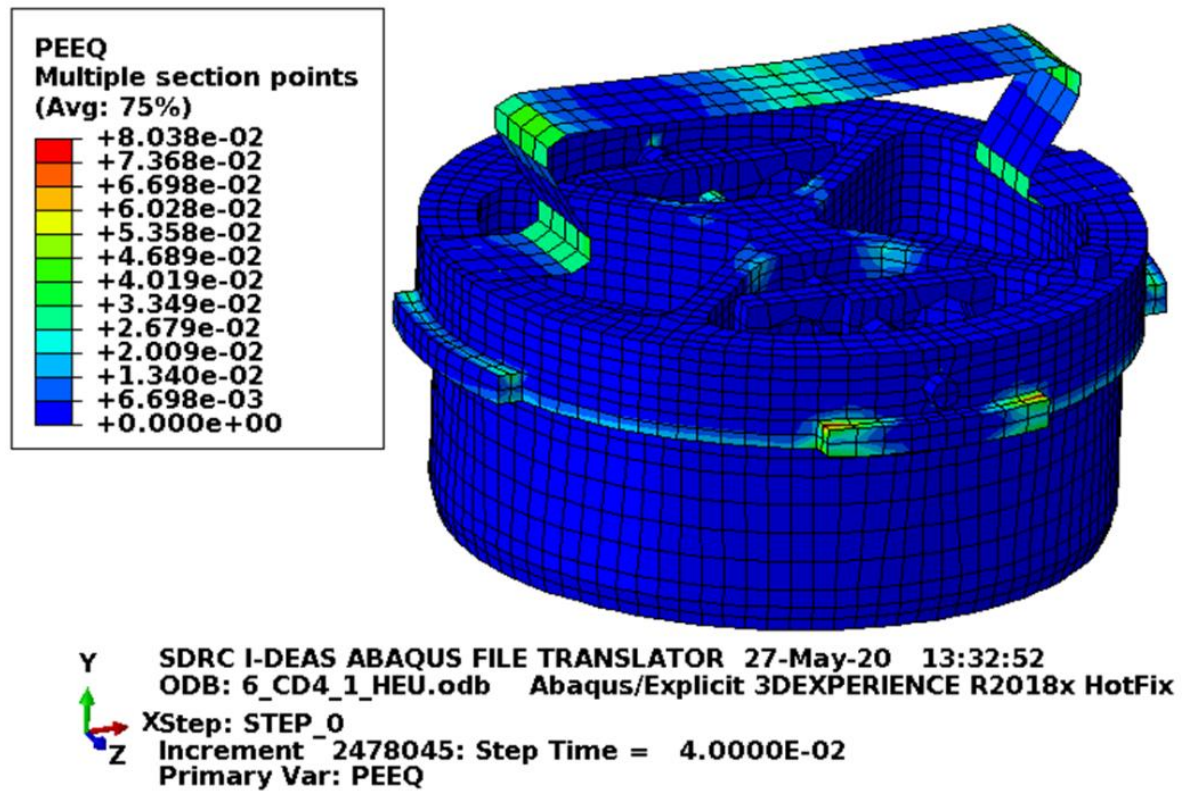

Figure C-52. Scope Part 1b (Table 3), Test 6 (Table 2) lid plastic-equivalent strain. 
ENGINEERING CALCULATIONS AND ANALYSIS

Drop Analysis of the Advanced Test Reactor Fresh Fuel Shipping Container with Heavier Low-Enriched Uranium Fuel Contents

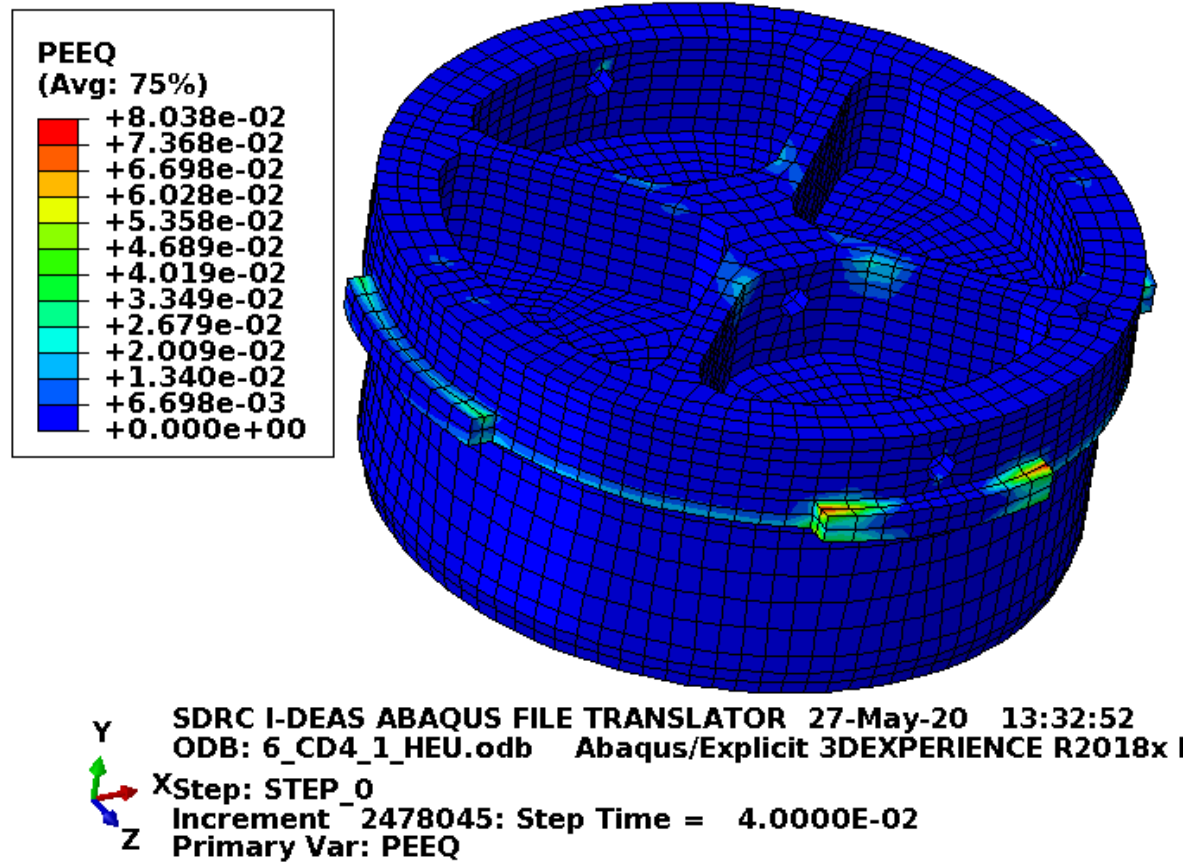

Figure C-53. Scope Part 1b (Table 3), Test 6 (Table 2) lid structure plastic-equivalent strain.

Figure C-53 shows the equivalent plastic strain in the structurally significant portion of the lid. Failure in these elements occurs at an equivalent plastic strain of $0.259 \mathrm{in}$./in. If element failure were to occur, the element would be deleted and removed from the model (thereby making its equivalent plastic strain not included in the maximum equivalent plastic strain for the plot). However, the missing element would be visible in the plot. Figure $\mathrm{C}-53$ shows no element failure with margin.

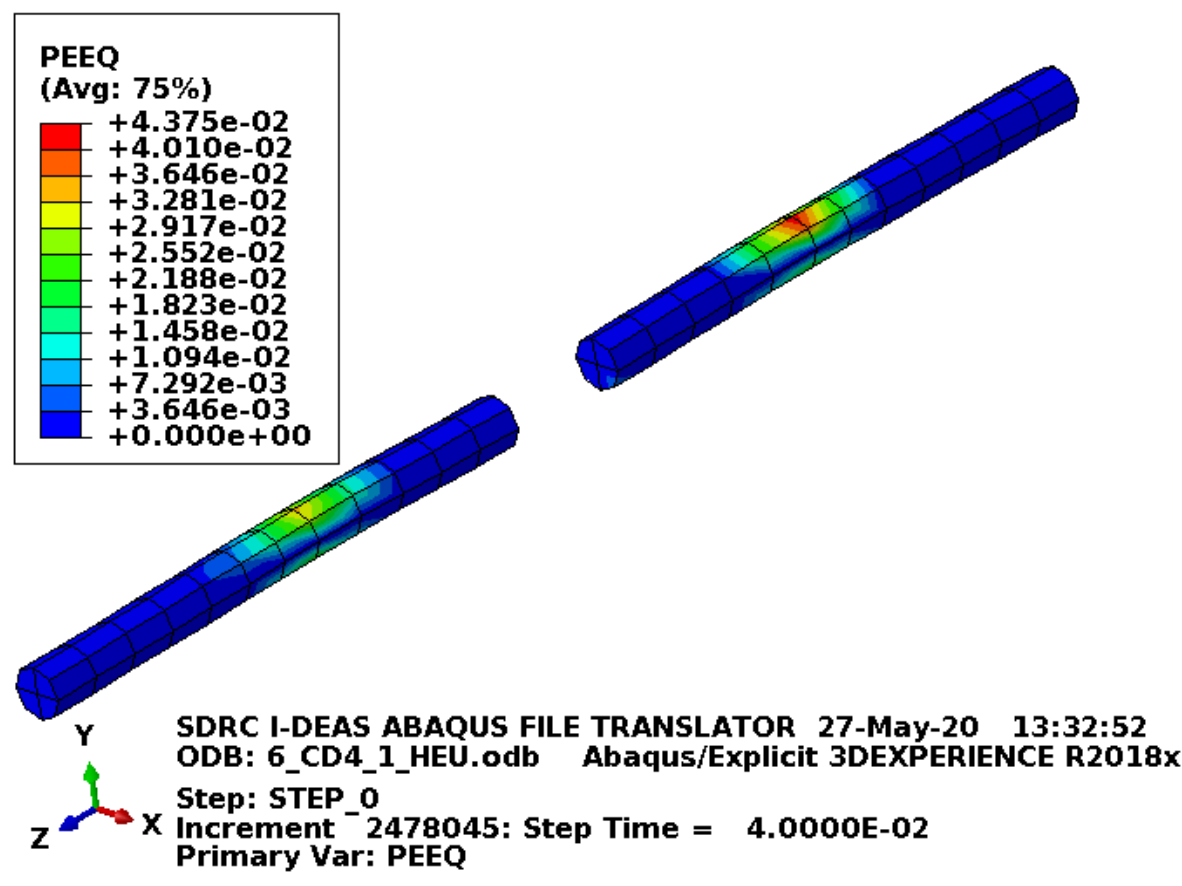

Figure C-54. Scope Part 1b (Table 3), Test 6 (Table 2) lid pins plastic-equivalent strain. 
Figure C-54 shows the equivalent plastic strain in the lid pins. Failure in these elements occurs at an equivalent plastic strain of $0.295 \mathrm{in}$./in. If element failure were to occur, the element would be deleted and removed from the model (thereby making its equivalent plastic strain not included in the maximum equivalent plastic strain for the plot). However, the missing element would be visible in the plot. Figure C-54 shows no element failure.
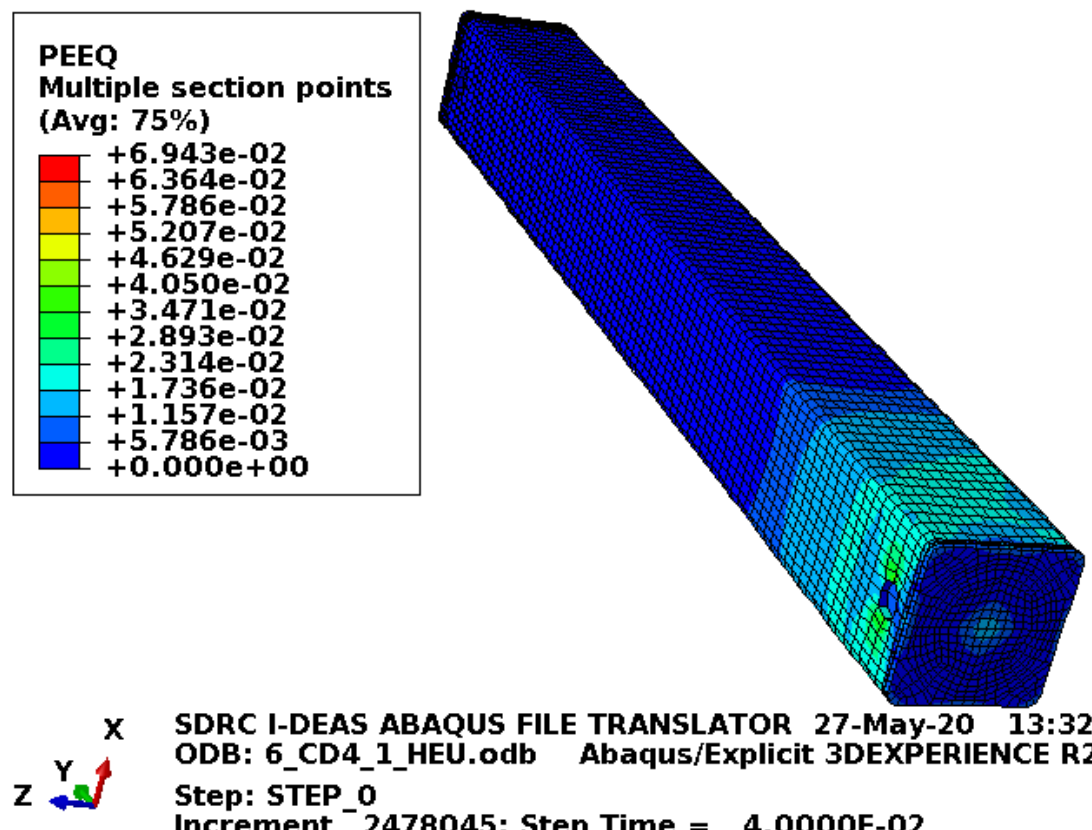

SDRC I-DEAS ABAQUS FILE TRANSLATOR 27-May-20 $\quad 13: 32: 52$

ODB: 6_CD4_1_HEU.odb Abaqus/Explicit 3DEXPERIENCE R2018x

Step: STEP_o

Increment 2478045: Step Time =

Primary Var: PEEQ

\subsection{E-02}

Figure C-55. Scope Part 1b (Table 3), Test 6 (Table 2) body plastic-equivalent strain.

Figure C-55 shows the equivalent plastic strain in the body. Failure in these elements occurs at an equivalent plastic strain of $0.259 \mathrm{in}$./in. If element failure were to occur, the element would be deleted and removed from the model (thereby making its equivalent plastic strain not included in the maximum equivalent plastic strain for the plot). However, the missing element would be visible in the plot. Figure C-55 shows no element failure with margin. 

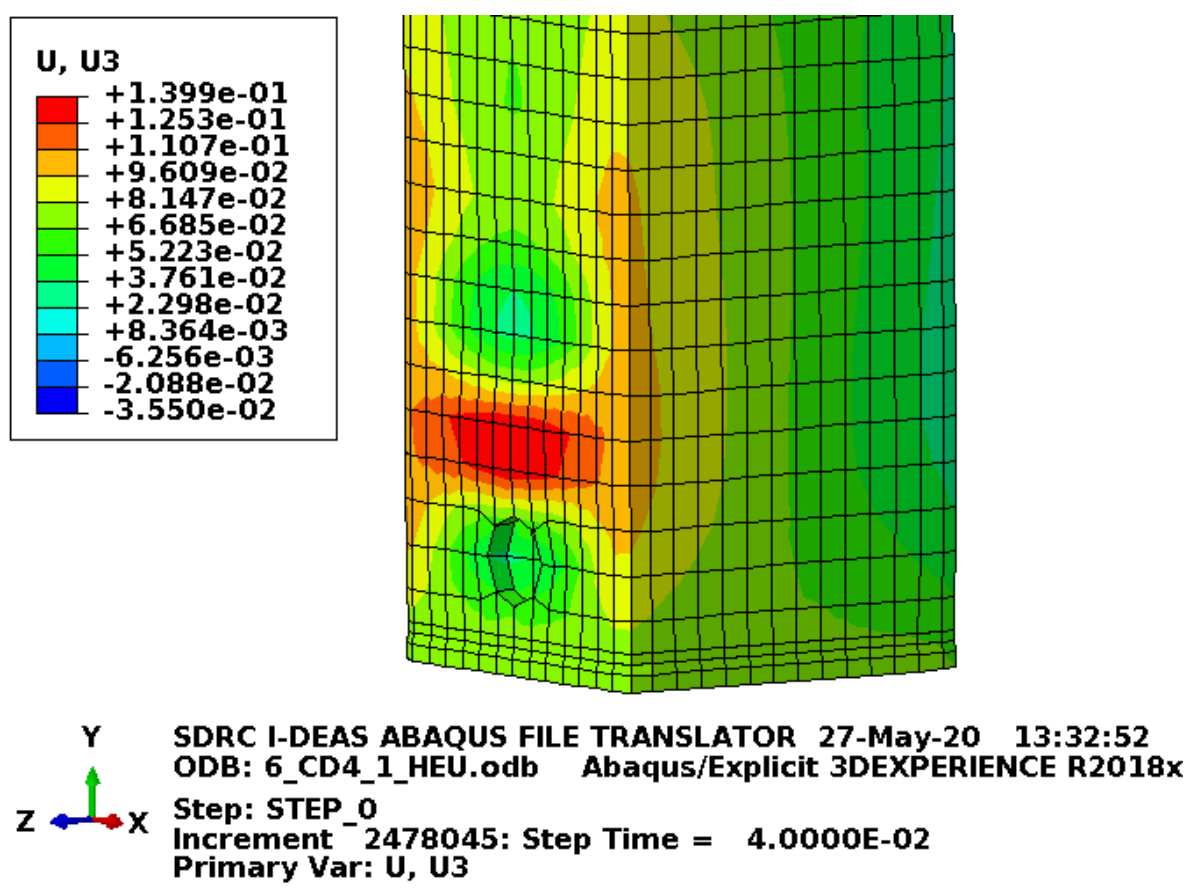

Figure C-56. Scope Part 1b (Table 3), Test 6 (Table 2) body z-direction displacement.

The physical drop description (see Section C2.5.1) notes that the ATR FFSC showed minor bowing with a greatest deformation of approximately $1 / 8$ in. on the 90 -degree side (see Figure C-1). The FEA model produced bowing but on the 180-degree side (see Figure C-1) and a magnitude of about 0.13 in. (per Figure C-56). Considering that the orientation of the physical drop may have favored the 90-degree side, this result is considered accurate and conservative.
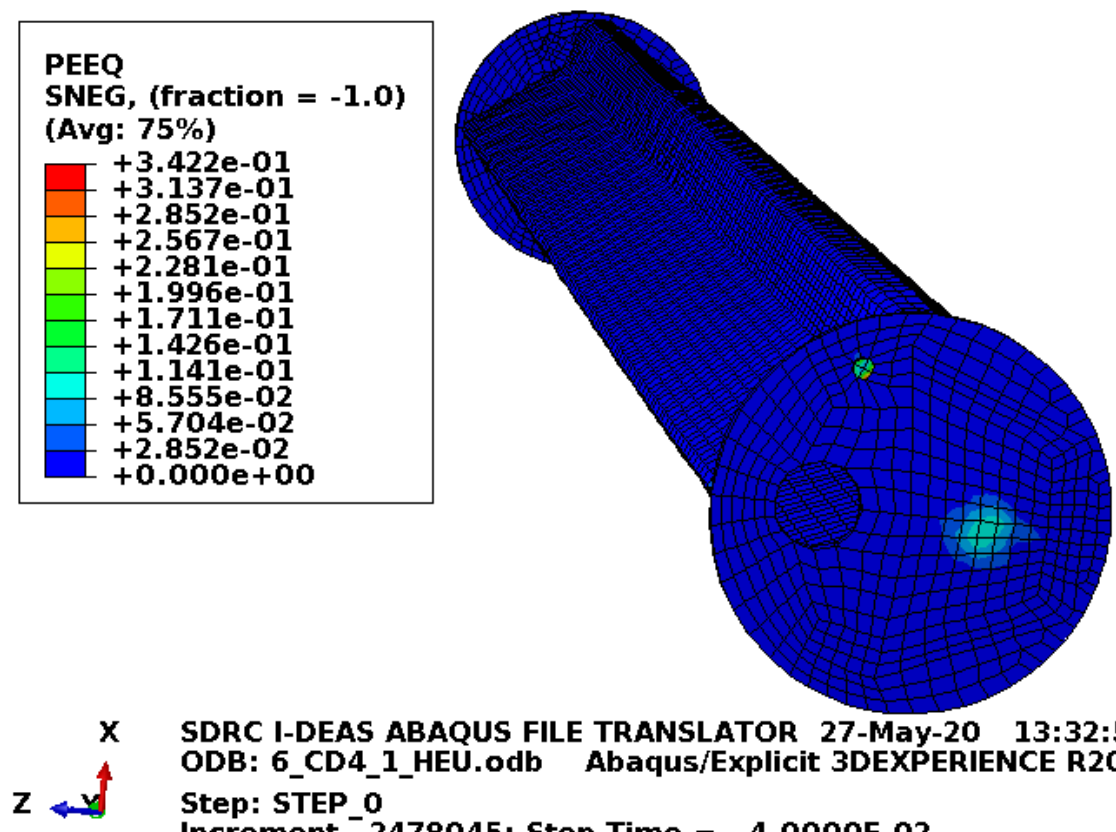

SDRC I-DEAS ABAQUS FILE TRANSLATOR 27-May-20 13:32:52 ODB: 6_CD4_1_HEU.odb Abaqus/Explicit 3DEXPERIENCE R2018x Step: STEP_0 Increment $2478045:$ Step Time $=$ 4.0000E-02 Primary Var: PEEQ

Figure C-57. Scope Part 1b (Table 3), Test 6 (Table 2) enclosure plastic-equivalent strain. 
Figure $\mathrm{C}-57$ shows the equivalent plastic strain in the enclosure. This is just for information as damage to the enclosure is acceptable.

\section{C2.6 Results for Scope Part 1 (Table 3), Test 8 (Table 2)}

The drop scenario considered in this section is a 30-ft drop modeled as a center of gravity over the topcorner impact. It is identified as CD5-1 in the ATR FFSC SAR (2017).

\section{C2.6.1 Results from the Physical Drop Scenario}

A summary of the physical drop scenario results for Scope Part 1 (Table 3), Test 8 (Table 2) is provided in the ATR FFSC SAR (2017), Section 2.12.1.4.6 (shown below for reference). Figure C-1 along with Figure C-11 and Figure C-14 provide the supporting ATR FFSC SAR (2017) figures for reference.

Following impact, the CTU bounced slightly and tipped over onto its side. The impact corner was deformed in approximately 5/8 in. There was modest deformation on the sides of the package near the impact location bulging in approximately 1/2 in. near the index lug pocket and bulged out approximately 5/8 in. on the adjoining side. The impacted corner deformed in approximately 5/8 in. and the opposite corner, 1, had no change in length. Figure 2.12.1-33 through Figure 2.12.1-36 show the CTU following CD5-1.

Following the drop, the closure assembly exhibited deformation with the end of the package and was unable to be rotated more than 1/8 in. in either direction. The locking pins showed no visible signs of deformation and the pin by 8 remained in the locked position. Both locking pins were functioning and able to be moved and compressed against the spring when tested by hand.

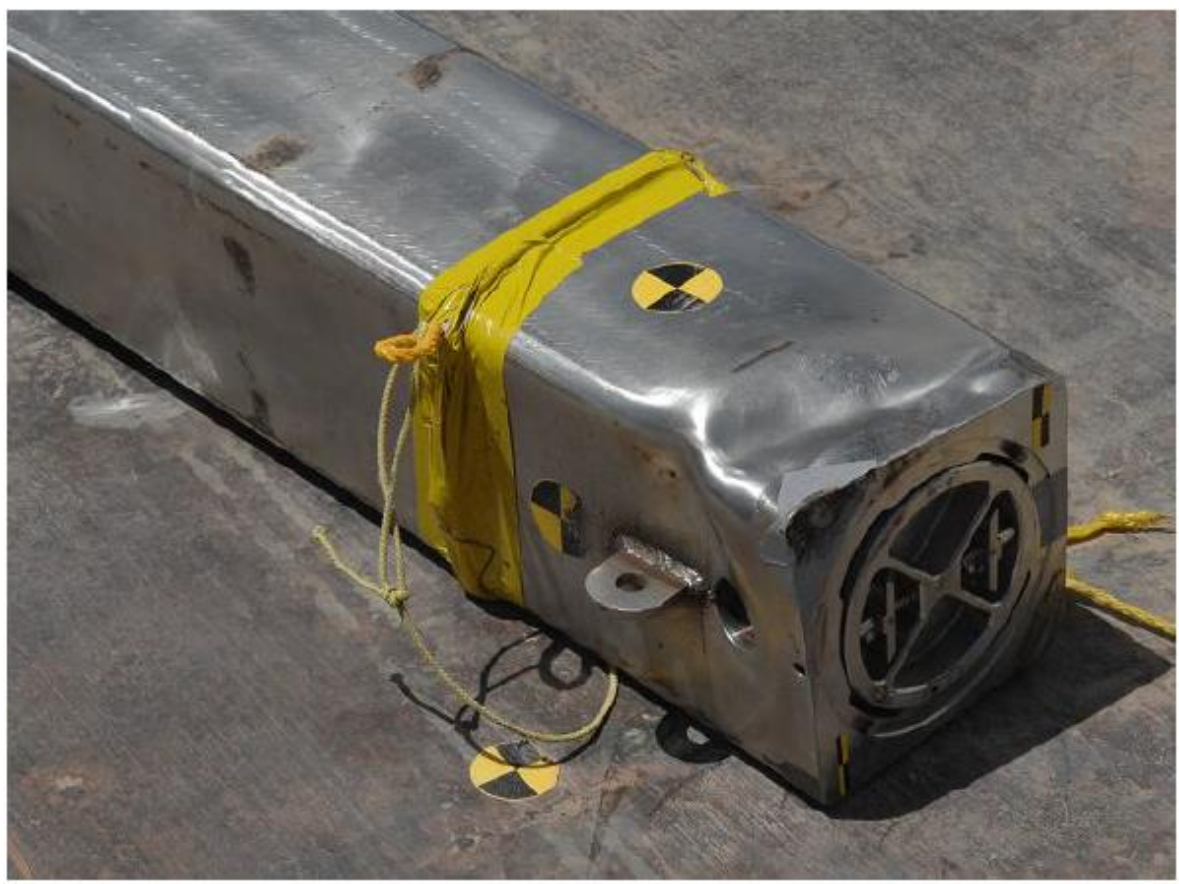

Figure C-58. CTU following CD5-1 impact [ATR FFSC SAR (2017), Figure 2.12.1-33]. 
ENGINEERING CALCULATIONS AND ANALYSIS

Drop Analysis of the Advanced Test Reactor Fresh Fuel Shipping Container with Heavier Low-Enriched Uranium Fuel Contents
ECAR-5224, Rev. 0

Page $\mathrm{C} 43$ of $\mathrm{C} 190$

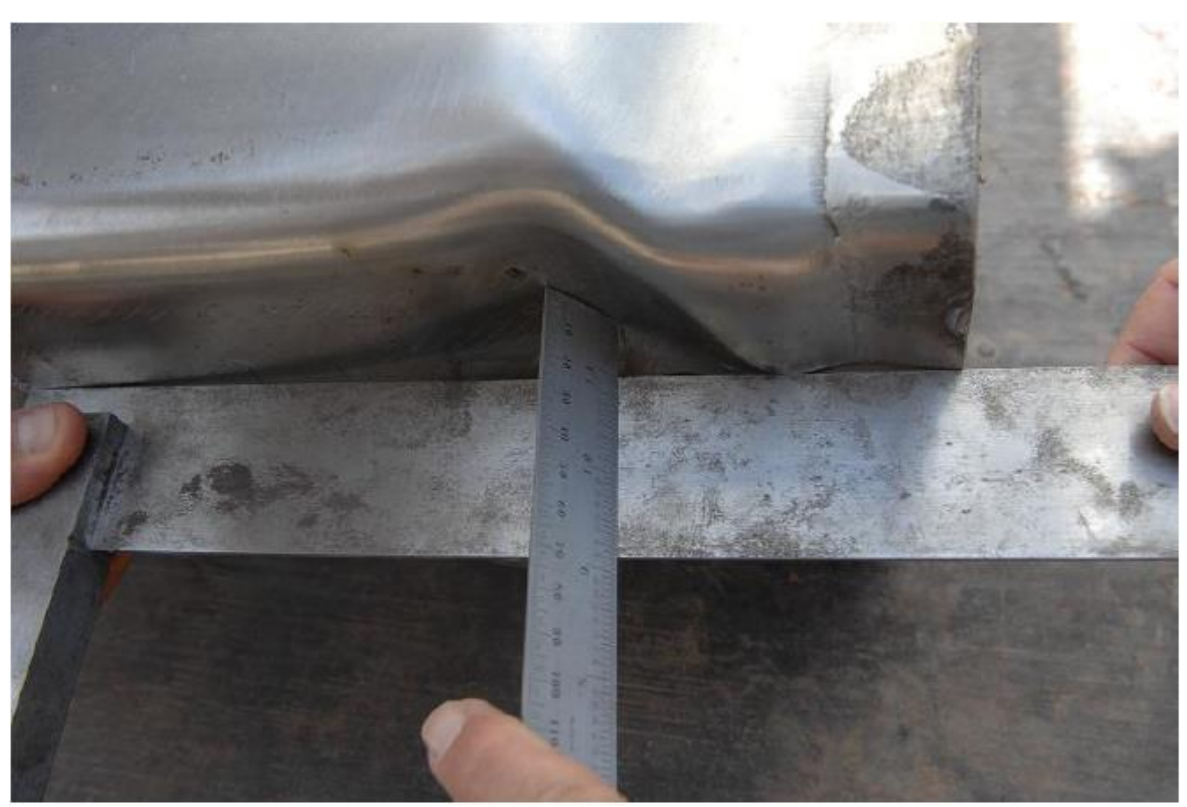

Figure C-59. CD5-1 impact damage on bottom 180-degree side [ATR FFSC SAR (2017), Figure 2.12.1-34].

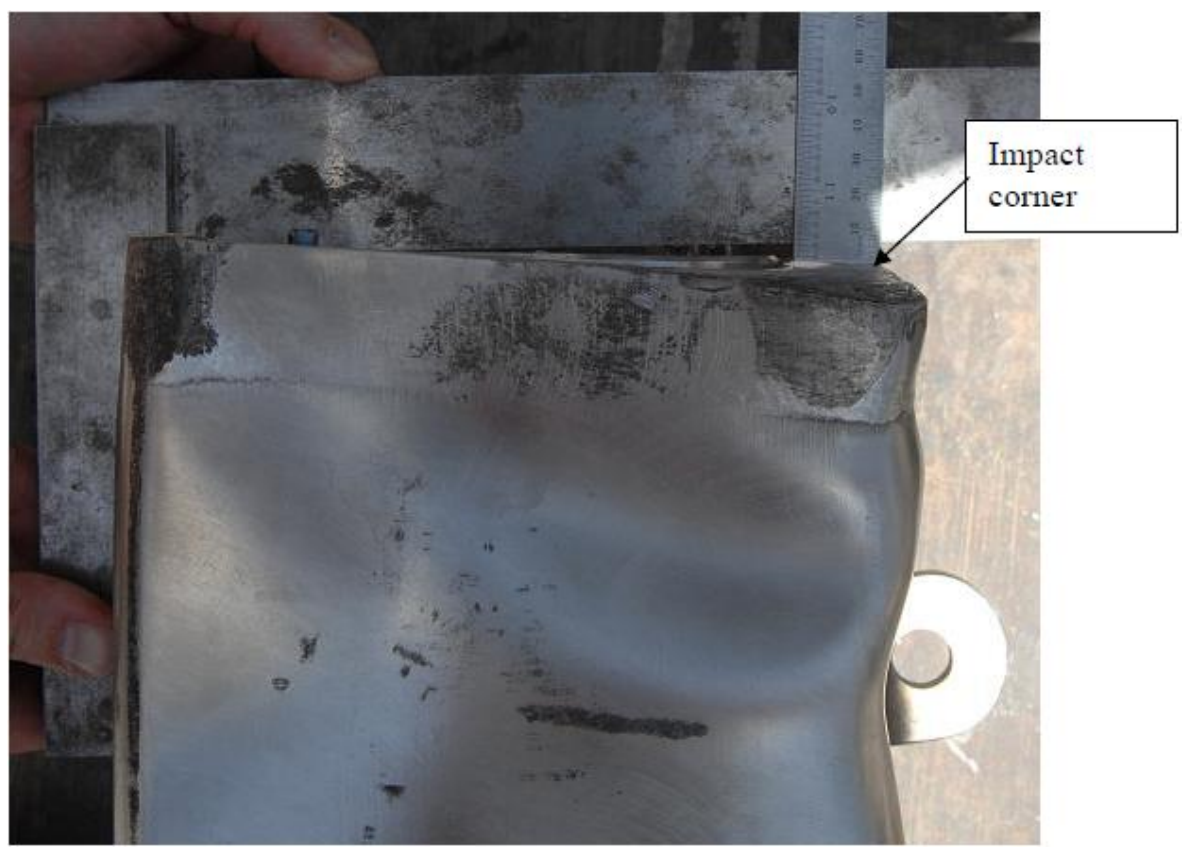

Figure C-60. CD5-1 impact damage on closure end [ATR FFSC SAR (2017), Figure 2.12.1-35]. 


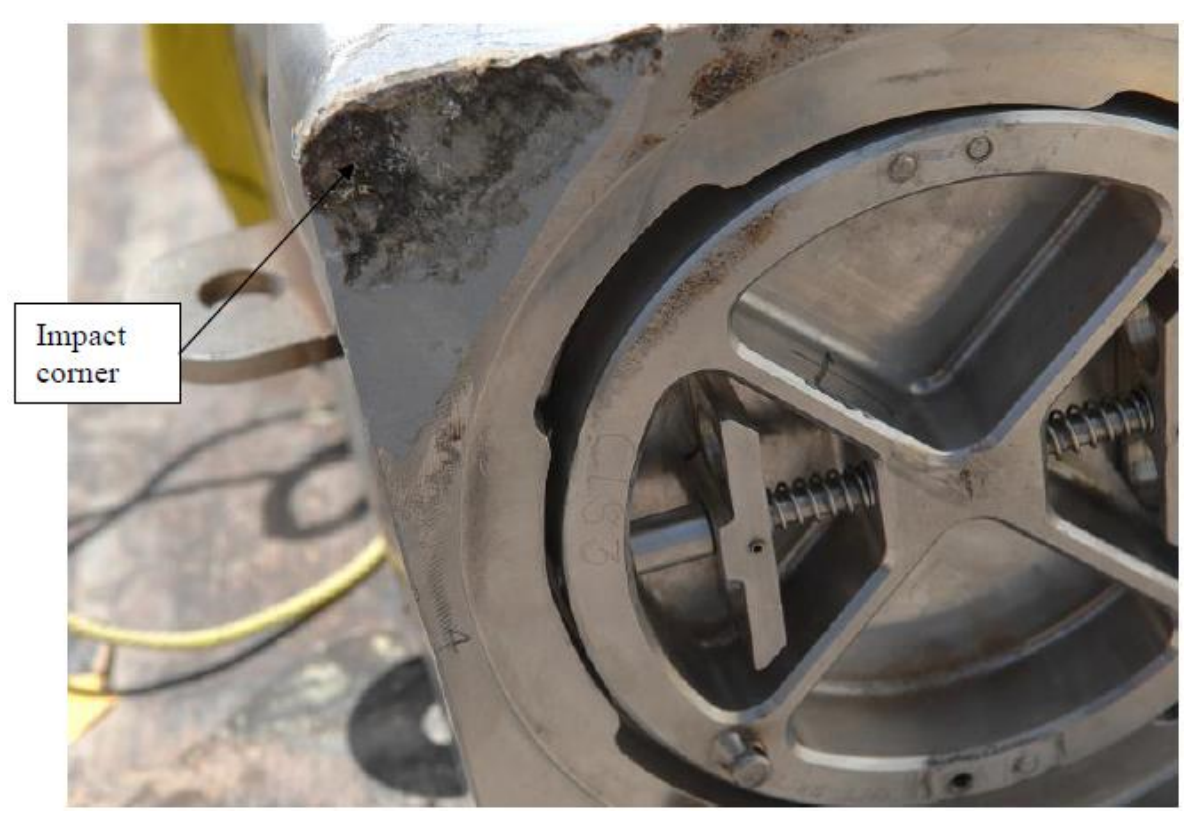

Figure C-61. CD5-1 impact damage on closure area [ATR FFSC SAR (2017), Figure 2.12.1-36].

\section{C2.6.2 Results for Scope Part 1b (Table 3), Test 8 (Table 2)}

The FEA model results for the Scope Part $1 \mathrm{~b}$ (Table 3), Test 8 (Table 2) model are shown below in Figure C-62 to Figure C-68. This drop scenario is a 30 -ft drop modeled as a center of gravity over the topcorner impact. The fuel element weights $22.1 \mathrm{lbf}$ and the drop scenario is modeled with minimum material properties except the enclosure and end boxes, which are modeled with relatively tough material properties. 


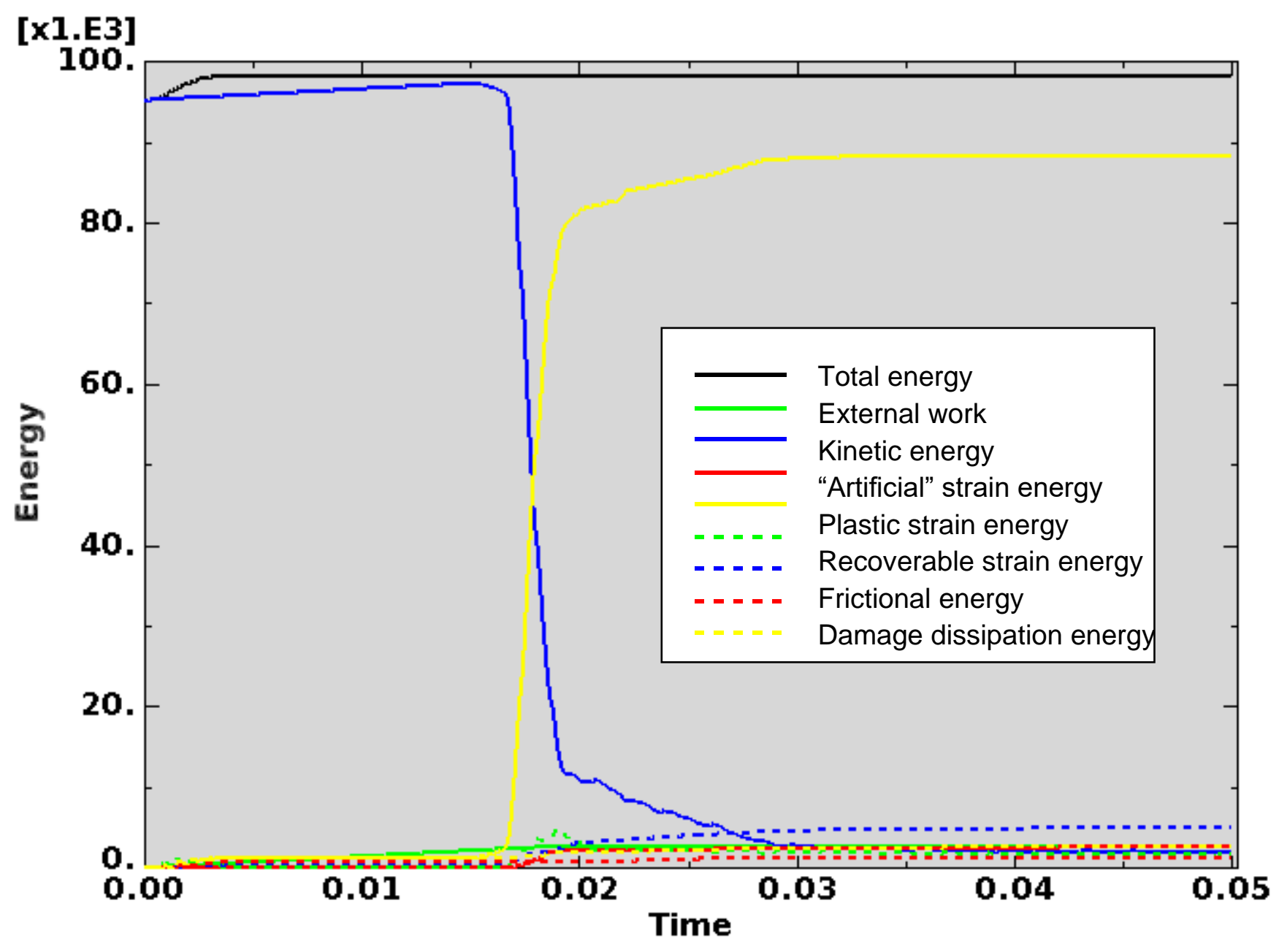

Figure C-62. Scope Part 1b (Table 3), Test 8 (Table 2) energy curves.

Figure C-62 shows the energy curves for Scope Part 1b (Table 3), Test 8 (Table 2) drop scenario. These curves exhibit a stable shape. Artificial strain energy represents the energy required to keep reduced integration elements from taking on a zero-energy hourglass shape. As shown in Figure C-62, the artificial energy at the end of the model run is $2.6 \%$ of the total energy. Therefore, the potential error associated with artificial energy is not considered to be significant. 
Drop Analysis of the Advanced Test Reactor Fresh Fuel Shipping Container with Heavier Low-Enriched Uranium Fuel Contents
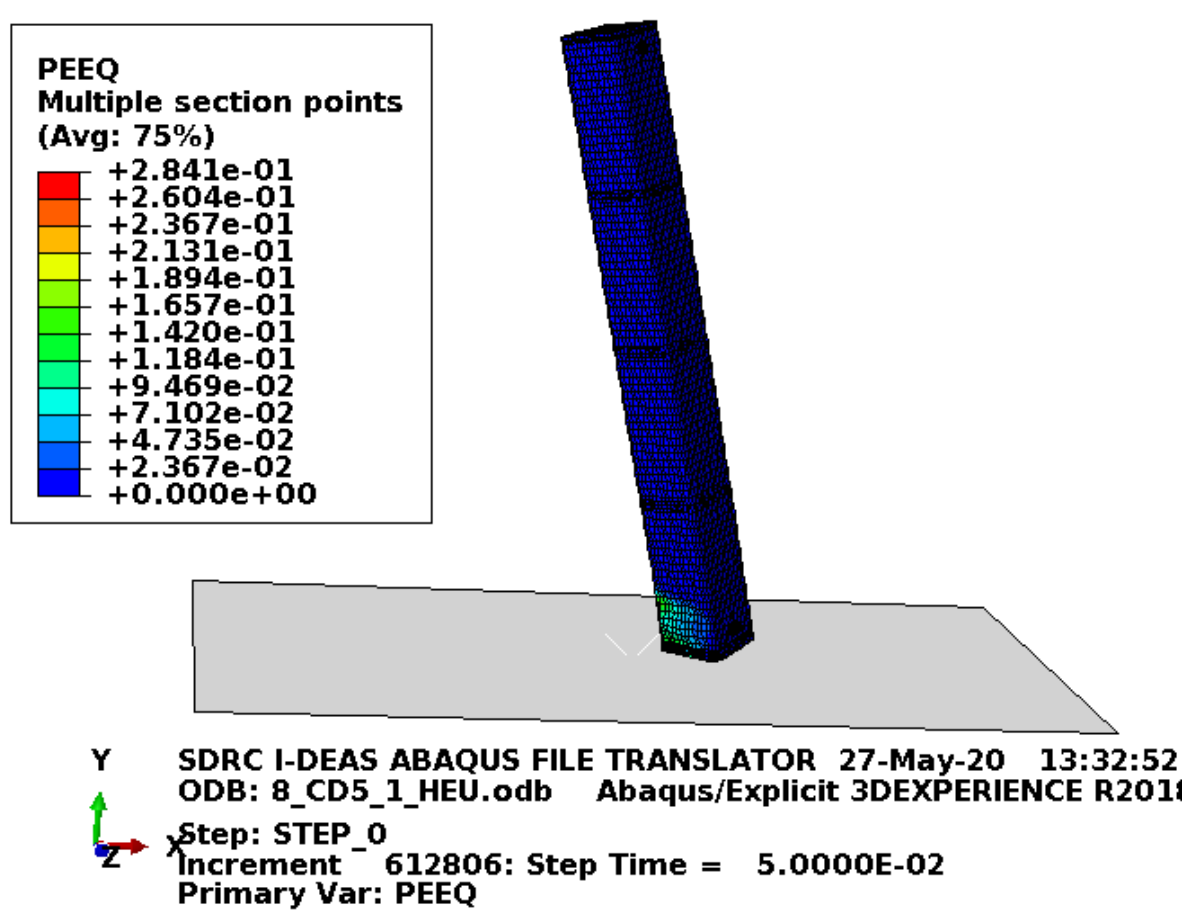

Figure C-63. Scope Part 1b (Table 3), Test 8 (Table 2) full-model plastic-equivalent strain.

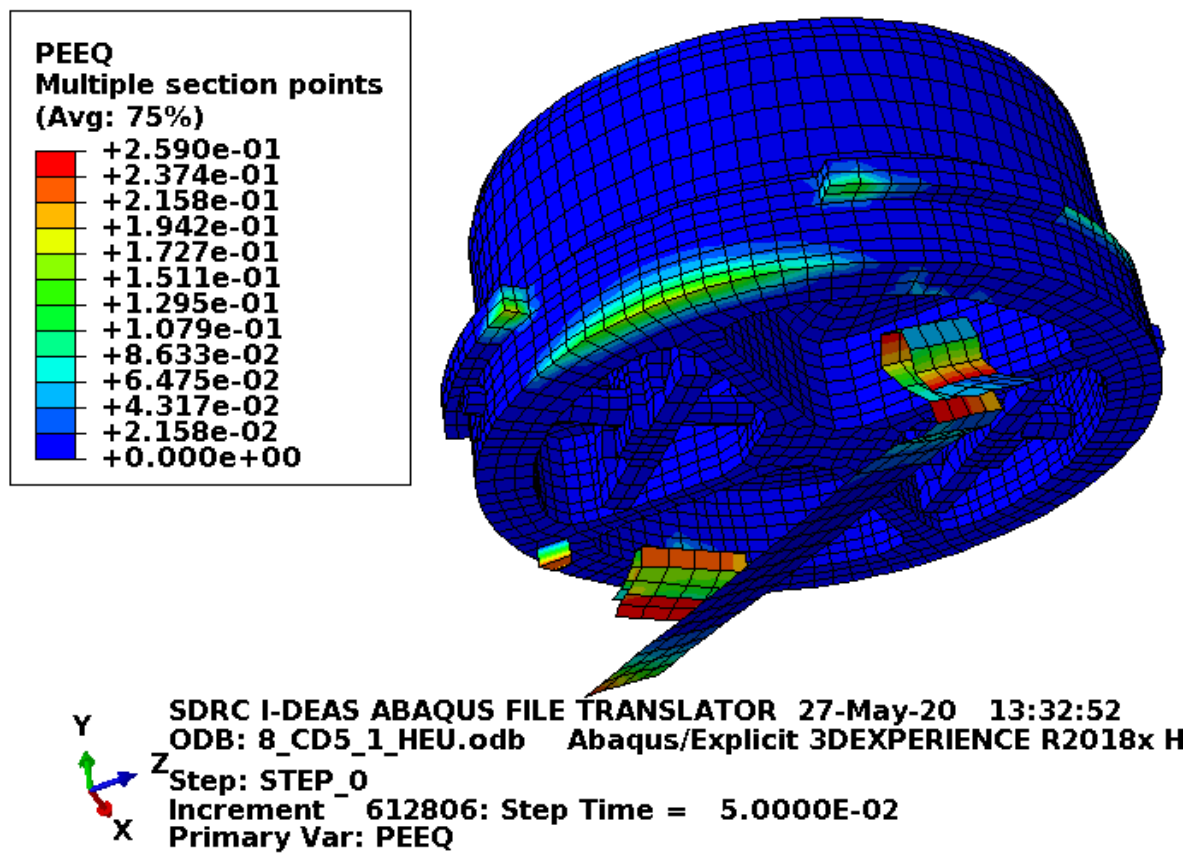

Figure C-64. Scope Part 1b (Table 3), Test 8 (Table 2) lid plastic-equivalent strain.

Figure C-64 shows the equivalent plastic strain in the lid. The most deformation is in the closure handle, which is not of concern. 
ENGINEERING CALCULATIONS AND ANALYSIS

Drop Analysis of the Advanced Test Reactor Fresh Fuel Shipping Container with Heavier Low-Enriched Uranium Fuel Contents
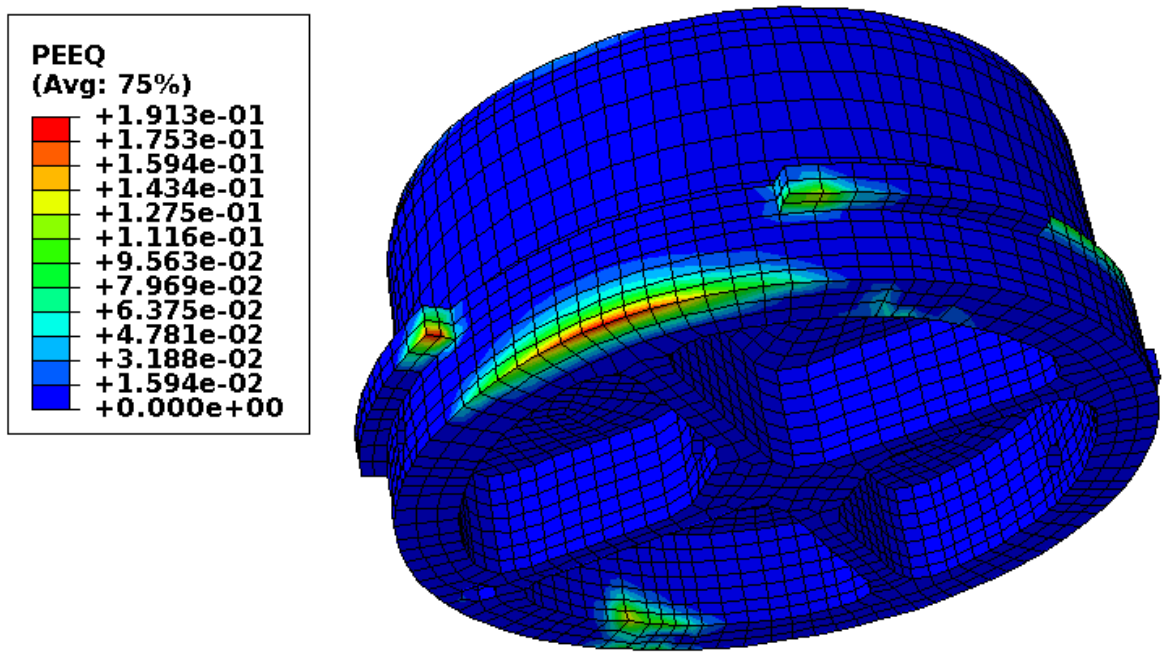

SDRC I-DEAS ABAQUS FILE TRANSLATOR 27-May-20 13:32:52

ODB: 8_CD5_1_HEU.odb Abaqus/Explicit 3DEXPERIENCE R2018x HotFi

ZStep: STEP_o

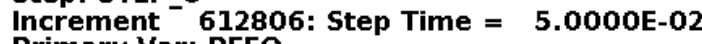

Primary Var: PEEQ

Figure C-65. Scope Part 1b (Table 3), Test 8 (Table 2) lid structure plastic-equivalent strain.

Figure C-65 shows the equivalent plastic strain in the structurally significant portion of the lid. Failure in these elements occurs at an equivalent plastic strain of $0.259 \mathrm{in}$./in. If element failure were to occur, the element would be deleted and removed from the model (thereby making its equivalent plastic strain not included in the maximum equivalent plastic strain for the plot). However, the missing element would be visible in the plot. Figure C-65 shows no element failure with margin.

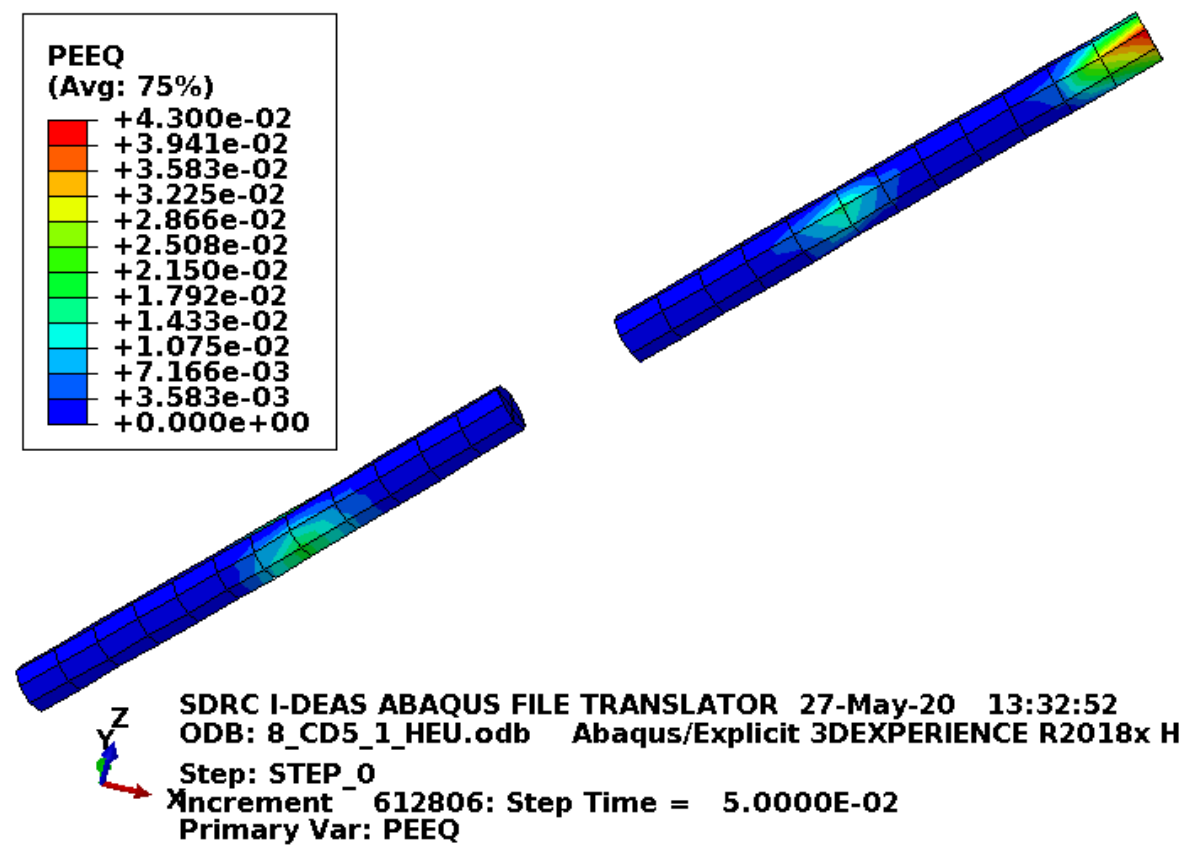

Figure C-66. Scope Part 1b (Table 3), Test 8 (Table 2) lid pins plastic-equivalent strain. 
Figure C-66 shows the equivalent plastic strain in the lid pins. Failure in these elements occurs at an equivalent plastic strain of $0.295 \mathrm{in}$./in. If element failure were to occur, the element would be deleted and removed from the model (thereby making its equivalent plastic strain not included in the maximum equivalent plastic strain for the plot). However, the missing element would be visible in the plot. Figure C-66 shows no element failure.
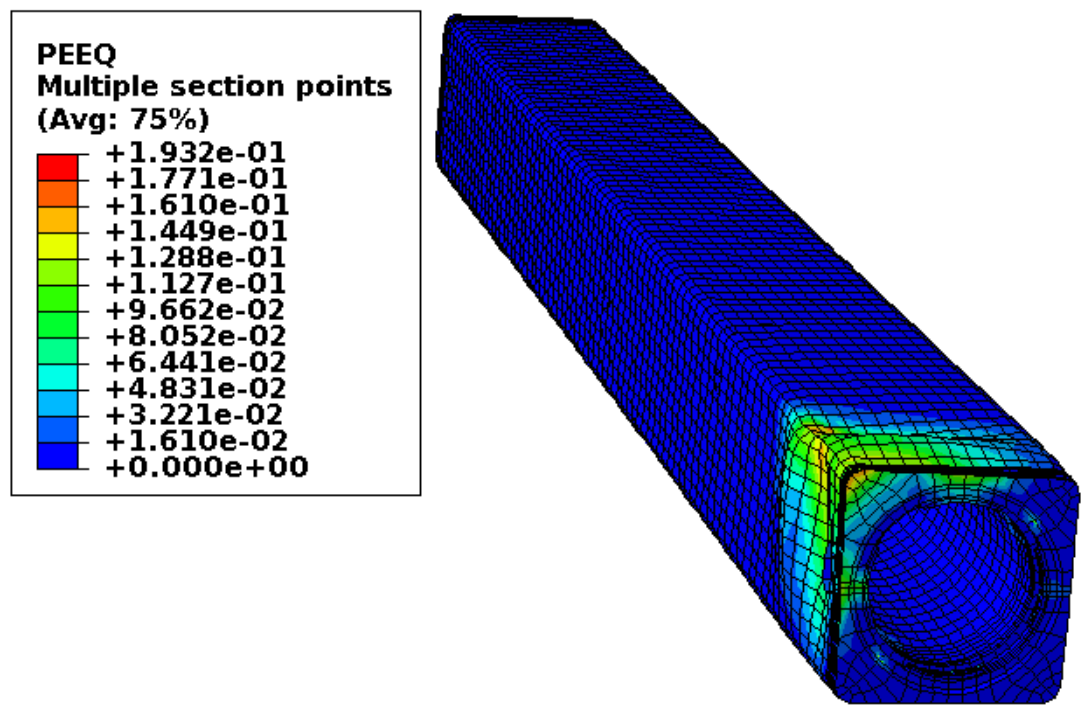

SDRC I-DEAS ABAQUS FILE TRANSLATOR 27-May-20 13:32:52

Z ODB: 8_CD5_1_HEU.odb Abaqus/Explicit 3DEXPERIENCE R2018x

Step: STEP 0

Increment ${ }^{-612806:}$ Step Time $=$ 5.0000E-02

$\mathrm{X}$ Primary Var: PEEQ

Figure C-67. Scope Part 1b (Table 3), Test 8 (Table 2) body plastic-equivalent strain.

Figure C-67 shows the equivalent plastic strain in the body. Failure in these elements occurs at an equivalent plastic strain of $0.259 \mathrm{in}$./in. If element failure were to occur, the element would be deleted and removed from the model (thereby making its equivalent plastic strain not included in the maximum equivalent plastic strain for the plot). However, the missing element would be visible in the plot. Figure C-67 shows no element failure with margin.

The physical drop description (see Section C2.6.1) notes that the ATR FFSC showed slight bowing. The FEA model produced similar deformation to the flat-side drop in Section C2.2.

The maximum change in length of the body at the impacted corner is $0.95 \mathrm{in}$. This is conservative and comparable to the approximately 5/8-in. measured deformation in the physical drop (see Section C2.1.1). Section C2.1.1 also provides dimensions for the observed buckling. However, the physical drop buckling pattern cannot be expected to be accurate given the drop testing lifting eye that is welded in the buckled region. The FEA model buckling in Figure $\mathrm{C}-67$ is considered reasonable. 


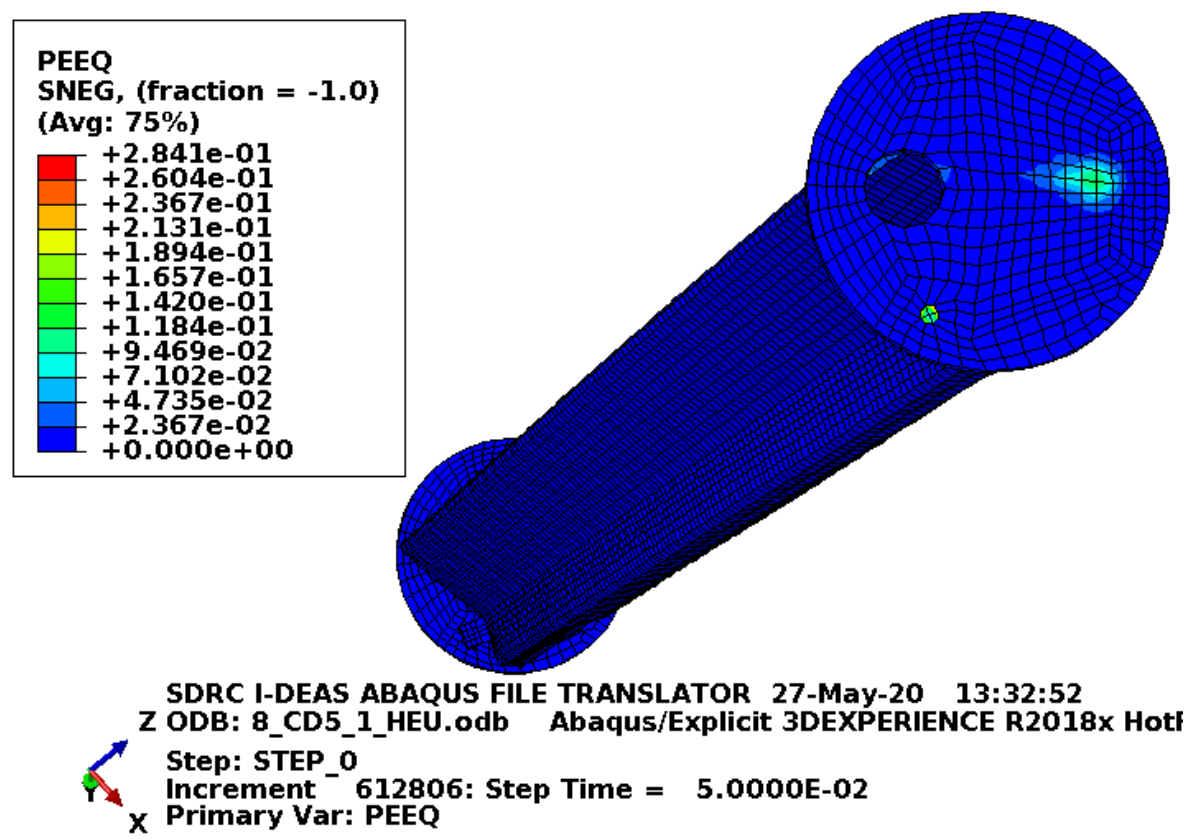

Figure C-68. Scope Part 1b (Table 3), Test 8 (Table 2) enclosure plastic-equivalent strain.

Figure C-68 shows the equivalent plastic strain in the enclosure. This is just for information as damage to the enclosure is acceptable.

\section{C2.7 Results for Scope Part 1 (Table 3), Test 10 (Table 2)}

The drop scenario considered in this section is a 40 -in. drop modeled as 30 degrees off horizontal, center of gravity over a 6-in.-diameter puncture bar. It is identified as CP2-1 in the ATR FFSC SAR (2017).

\section{C2.7.1 Results from the Physical Drop Scenario}

A summary of the physical drop scenario results for Scope Part 1 (Table 3), Test 10 (Table 2) is provided in the ATR FFSC SAR (2017), Section 2.12.1.4.8 (shown below for reference). Figure C-11 and Figure C-12 provide the supporting ATR FFSC SAR (2017) figures for reference.

As the CTU impacted the puncture bar, there was no tearing of severe deformation. The initial impact caused a deformation of approximately 1/2 in. deep by $5 \mathrm{in}$. across with a radius the same as the puncture bar. There was no fracture of the outer shell. Figure 2.12.1-42 and Figure 2.12.1-43 show the CTU following the CP2-1 drop. 


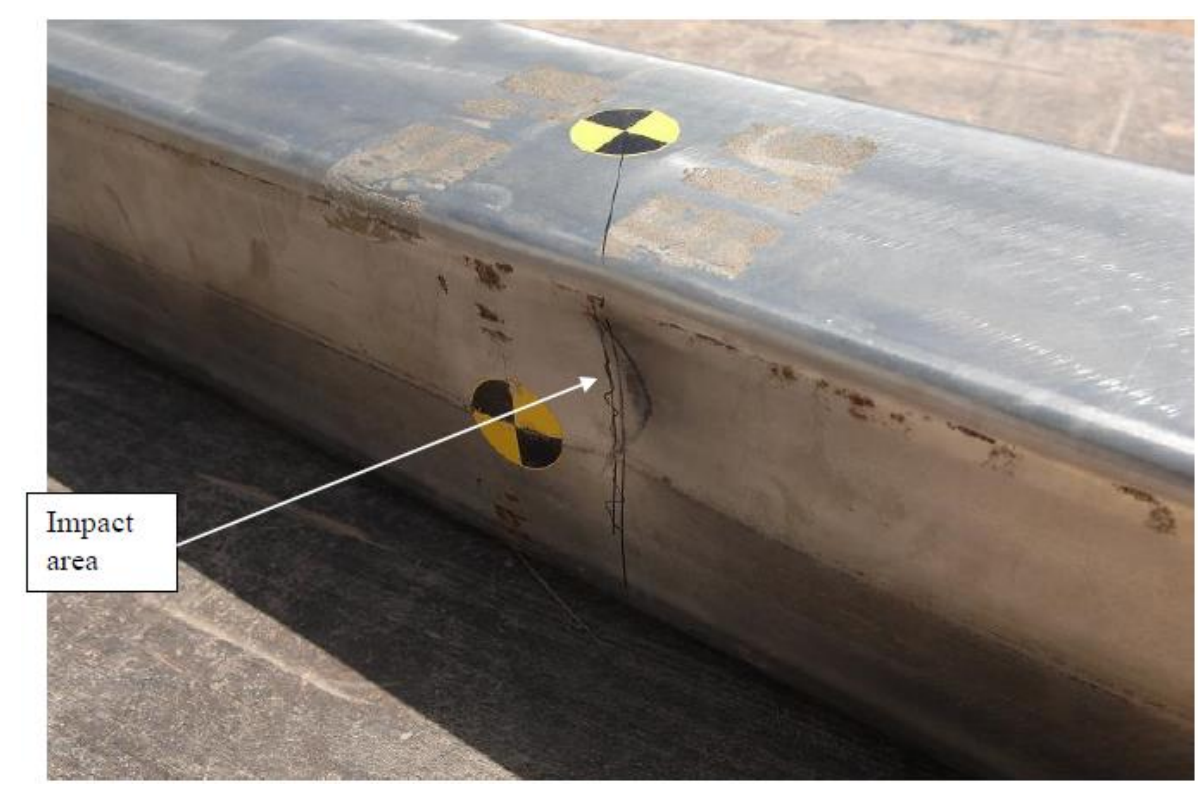

Figure C-69. CTU following CP2-1 impact [ATR FFSC SAR (2017), Figure 2.12.1-42].

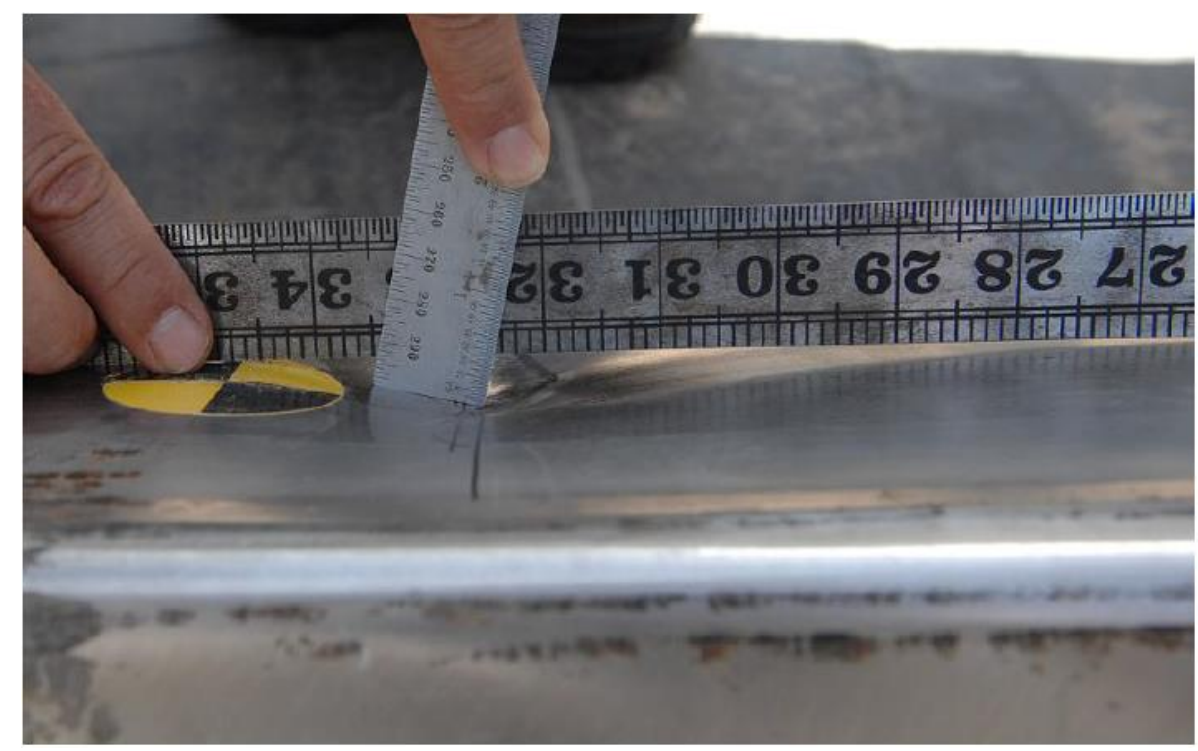

Figure C-70. CP2-1 impact damage [ATR FFSC SAR (2017), Figure 2.12.1-43].

\section{C2.7.2 Results for Scope Part 1b (Table 3), Test 10 (Table 2)}

The FEA model results for the Scope Part $1 \mathrm{~b}$ (Table 3), Test 10 (Table 2) model are shown below in Figure C-71 to Figure C-77. This drop scenario is a 40-in. drop modeled as 30-degree off horizontal, center of gravity over a 6-in.-diameter puncture bar. The fuel element weights $22.1 \mathrm{lbf}$ and the drop scenario is modeled with minimum material properties except the enclosure and end boxes, which are modeled with relatively tough material properties. 


\section{[x1.E3]}

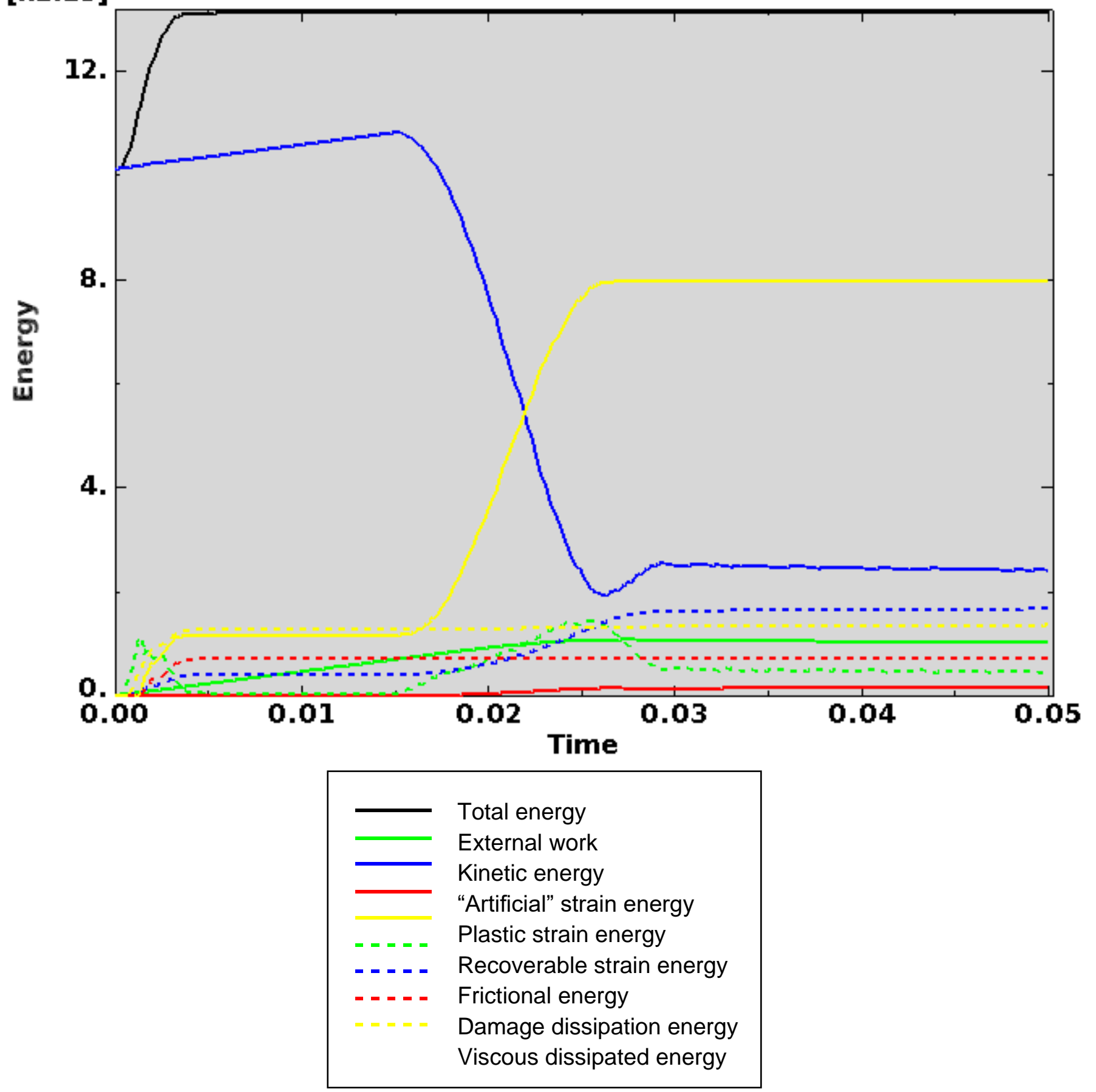

Figure C-71. Scope Part 1b (Table 3), Test 10 (Table 2) energy curves.

Figure C-71 shows the energy curves for Scope Part 1b (Table 3), Test 10 (Table 2) drop scenario. These curves exhibit a stable shape. Artificial strain energy represents the energy required to keep reduced integration elements from taking on a zero-energy hourglass shape. As shown in Figure C-71, the artificial energy at the end of the model run is $1.3 \%$ of the total energy. Therefore, the potential error associated with artificial energy is not considered to be significant. 


\section{ENGINEERING CALCULATIONS AND ANALYSIS}

Drop Analysis of the Advanced Test Reactor Fresh Fuel Shipping Container with Heavier Low-Enriched Uranium Fuel Contents

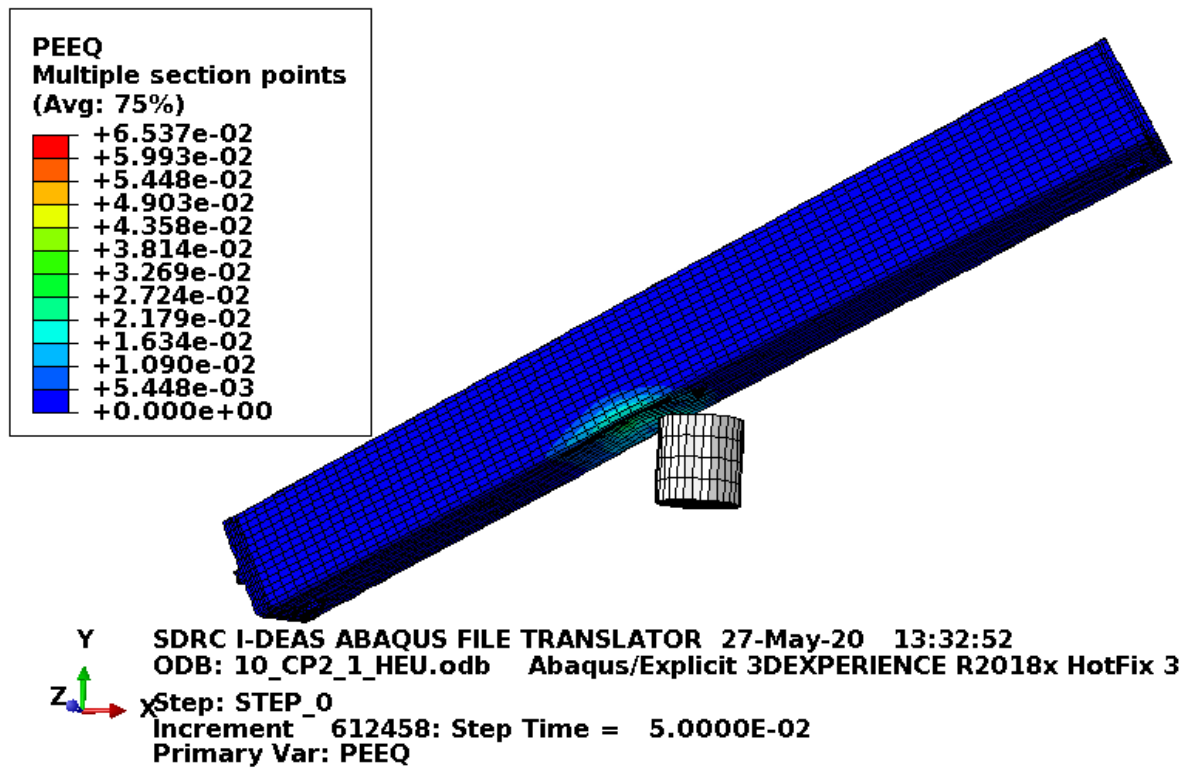

Figure C-72. Scope Part 1b (Table 3), Test 10 (Table 2) full-model plastic-equivalent strain.

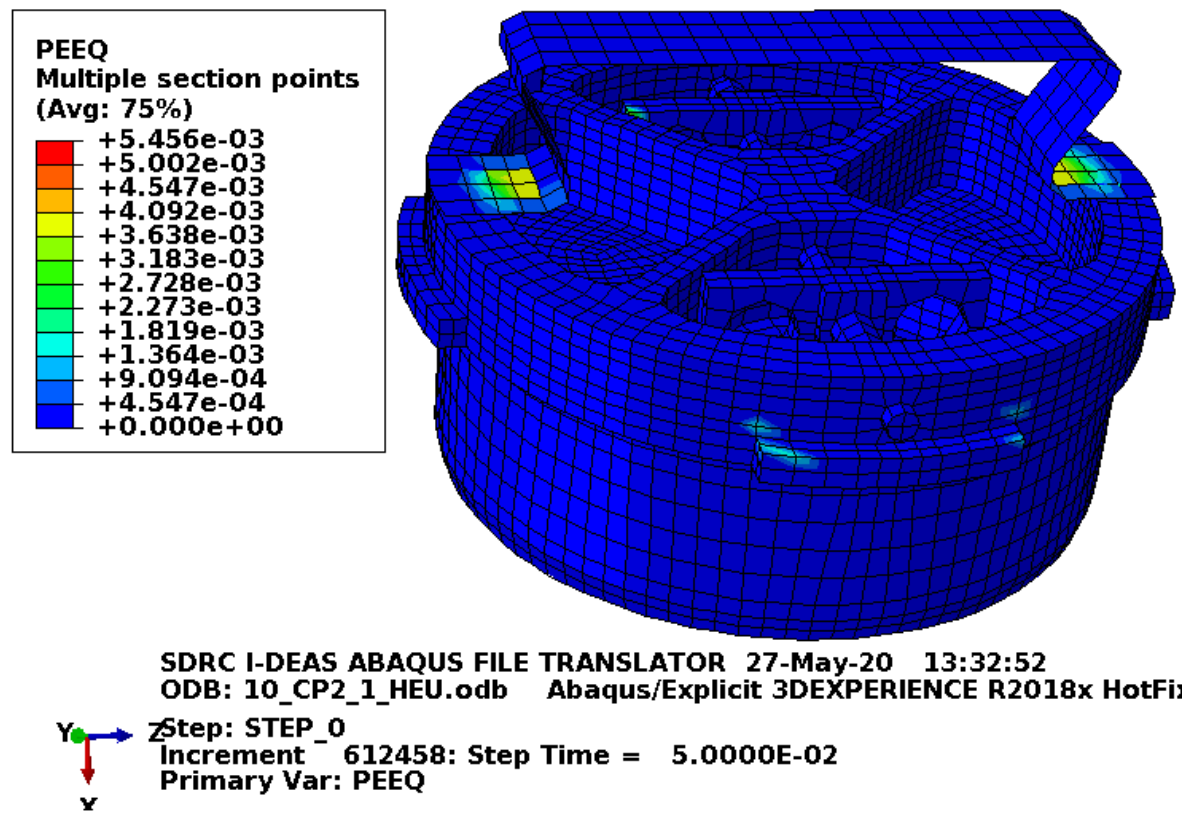

Figure C-73. Scope Part 1b (Table 3), Test 10 (Table 2) lid plastic-equivalent strain. 
ENGINEERING CALCULATIONS AND ANALYSIS

Drop Analysis of the Advanced Test Reactor Fresh Fuel Shipping Container with Heavier Low-Enriched Uranium Fuel Contents

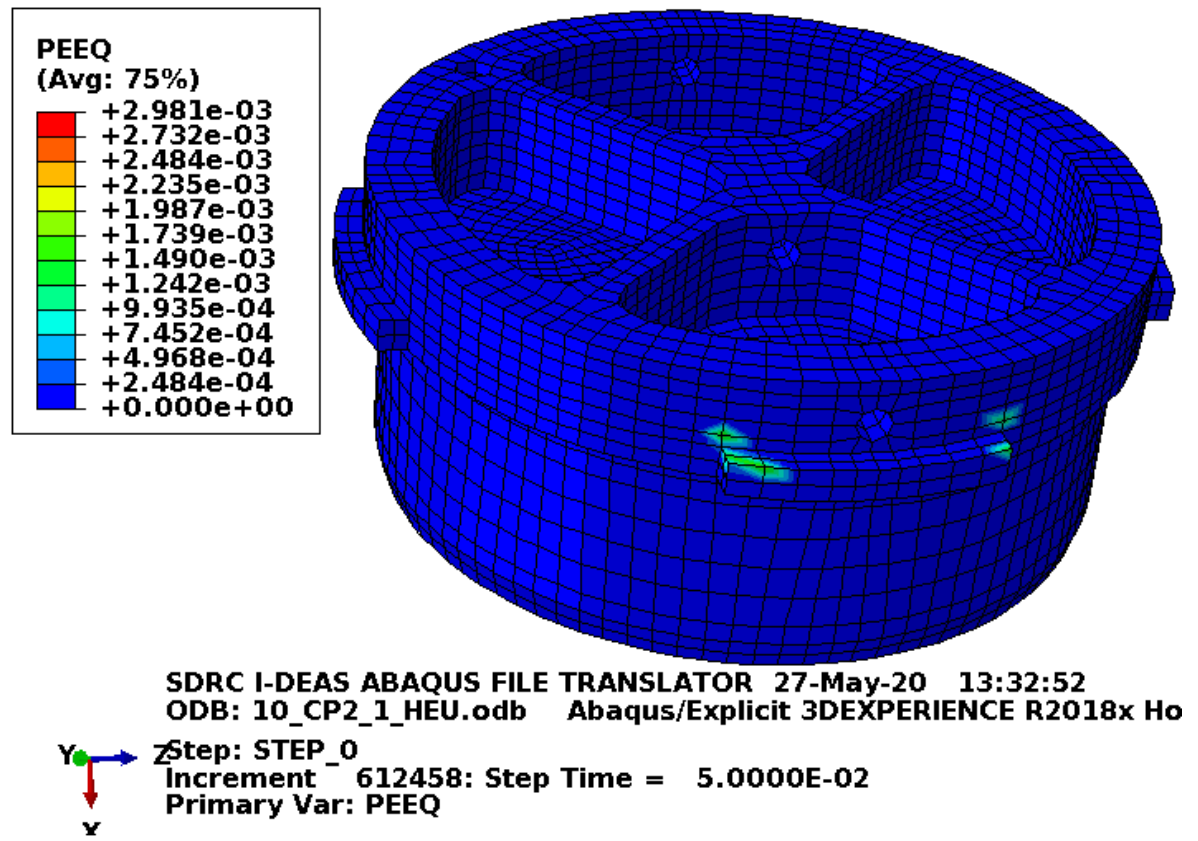

Figure C-74. Scope Part 1b (Table 3), Test 10 (Table 2) lid structure plastic-equivalent strain.

Figure C-74 shows the equivalent plastic strain in the structurally significant portion of the lid. Failure in these elements occurs at an equivalent plastic strain of $0.259 \mathrm{in}$./in. If element failure were to occur, the element would be deleted and removed from the model (thereby making its equivalent plastic strain not included in the maximum equivalent plastic strain for the plot). However, the missing element would be visible in the plot. Figure C-74 shows no element failure with margin.

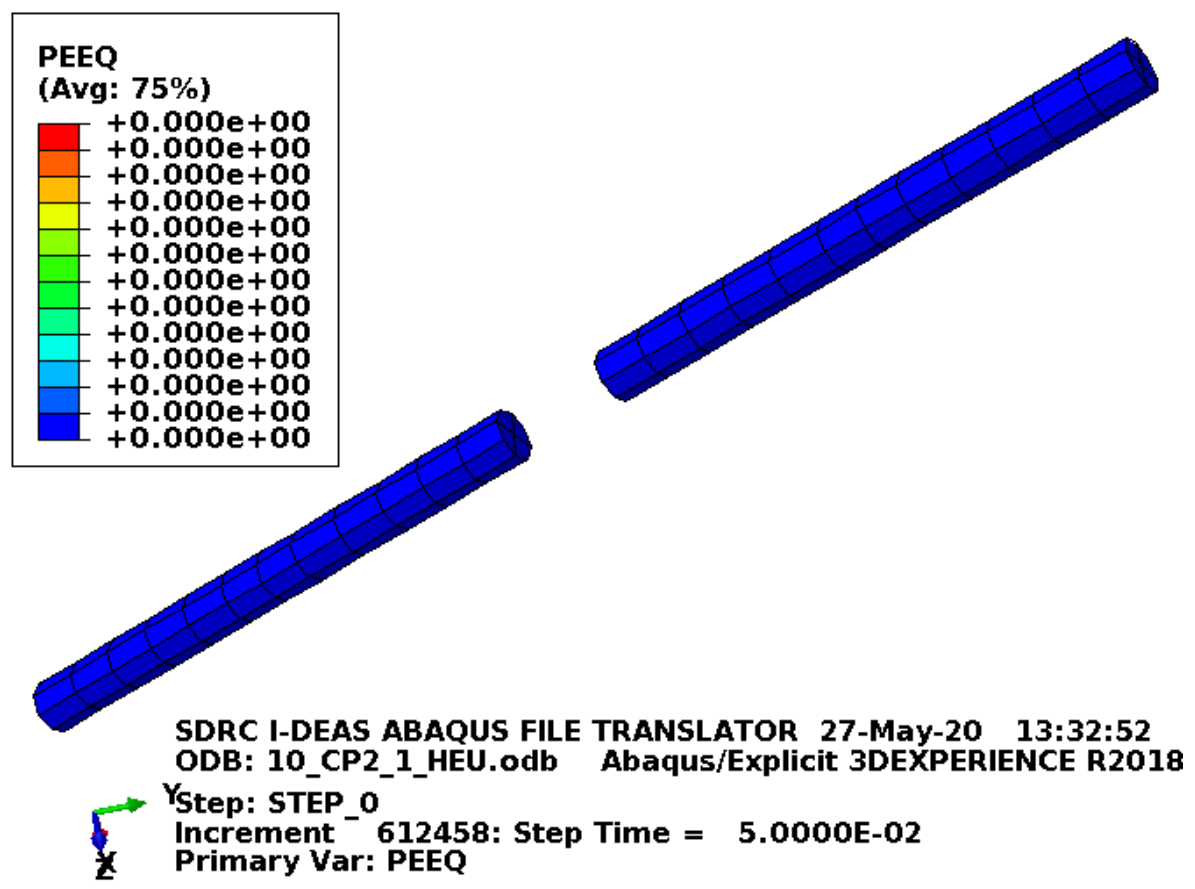

Figure C-75. Scope Part 1b (Table 3), Test 10 (Table 2) lid pins plastic-equivalent strain.

Figure C-75 shows that there is no plasticity in the lid pins for this drop scenario. 

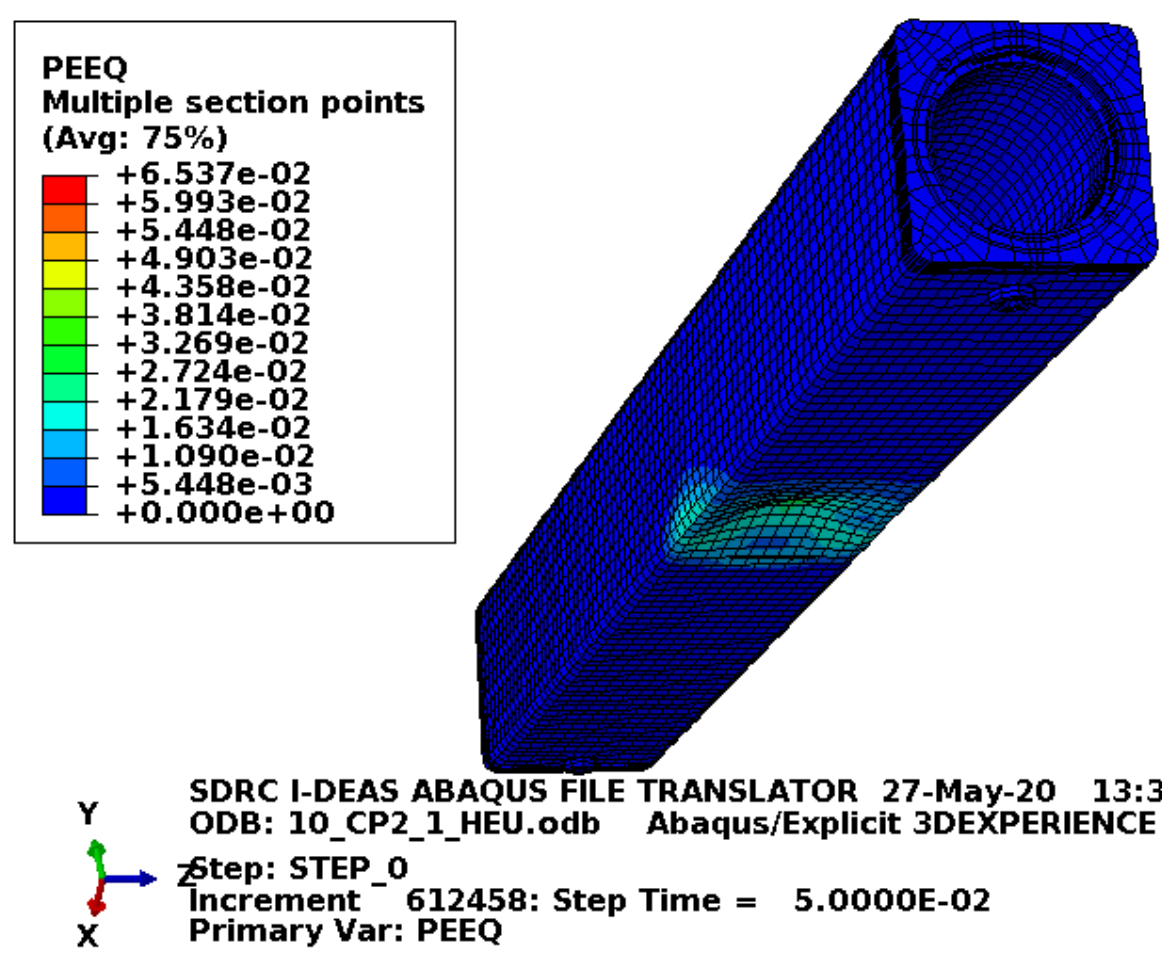

SDRC I-DEAS ABAQUS FILE TRANSLATOR 27-May-20 13:32

ODB: 10_CP2_1_HEU.odb Abaqus/Explicit 3DEXPERIENCE R

Etep: STEP_o

Increment ${ }^{-612458: \text { Step Time }=5.0000 \mathrm{E}-02}$

Primary Var: PEEQ

Figure C-76. Scope Part 1b (Table 3), Test 10 (Table 2) body plastic-equivalent strain.

Figure C-76 shows the equivalent plastic strain in the body. Failure in these elements occurs at an equivalent plastic strain of $0.259 \mathrm{in}$./in. If element failure were to occur, the element would be deleted and removed from the model (thereby making its equivalent plastic strain not included in the maximum equivalent plastic strain for the plot). However, the missing element would be visible in the plot. Figure C-76 shows no element failure with margin.

The physical drop description (see Section C2.7.1) notes that the impact caused a deformation (dent) of approximately $1 / 2 \mathrm{in}$. deep. The comparable deformation in the FEA model is approximately $0.93 \mathrm{in}$. deep. This again demonstrates conservatism with the FEA model. Though, Figure C-69 tends to indicate that the physical drop did not occur with the ATR FFSC perfectly centered over the puncture bar. Therefore, the dent depth of the physical drop would likely increase some if it were perfectly centered. 


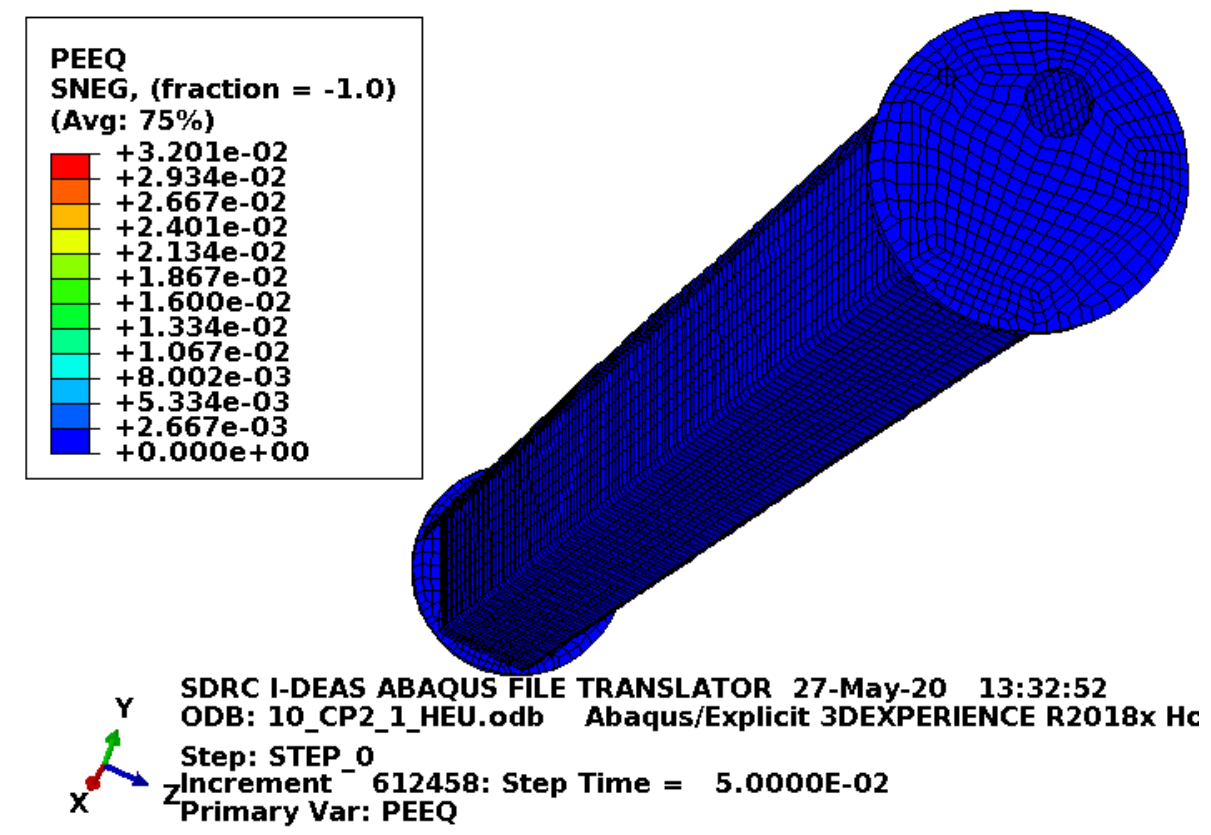

Figure C-77. Scope Part 1b (Table 3), Test 10 (Table 2) enclosure plastic-equivalent strain.

Figure C-77 shows the equivalent plastic strain in the enclosure. This is just for information as damage to the enclosure is acceptable.

\section{C2.8 Results for Scope Part 1 (Table 3), Test 11 (Table 2)}

The drop scenario considered in this section is a 40 -in. drop modeled as a vertical top drop with the lid centered over a 6-in.-diameter puncture bar. It is identified as CP1-1 in the ATR FFSC SAR (2017).

\section{C2.8.1 Results from the Physical Drop Scenario}

A summary of the physical drop scenario results for Scope Part 1 (Table 3), Test 11 (Table 2) is provided in the ATR FFSC SAR (2017), Section 2.12.1.4.9 (shown below for reference). Figure C-1 along with Figure C-11 and Figure C-12 provide the supporting ATR FFSC SAR (2017) figures for reference.

Following impact, the CTU bounced slightly on the puncture bar, as verified by high-speed video, and came to rest in the vertical position on top of the puncture bar as seen in Figure 2.12.1-45. Following the drop, the tamper-indicating device (TID) post was deformed into the closure. The closure assembly exhibited minor scratches from the puncture bar. The locking pins showed no visible signs of deformation and the remaining locking pin by 8 remained in the locked position. Both locking pins were functioning and able to be moved and compressed against the spring when tested by hand. Figure 2.12.1-46 shows the CTU in the up-sidedown position following CP1-1. Note that both locking pins were binding somewhat following testing and shown in the photographs in the open-unlocked position following the functional tests. 
ENGINEERING CALCULATIONS AND ANALYSIS

Drop Analysis of the Advanced Test Reactor Fresh Fuel Shipping Container with Heavier Low-Enriched Uranium Fuel Contents

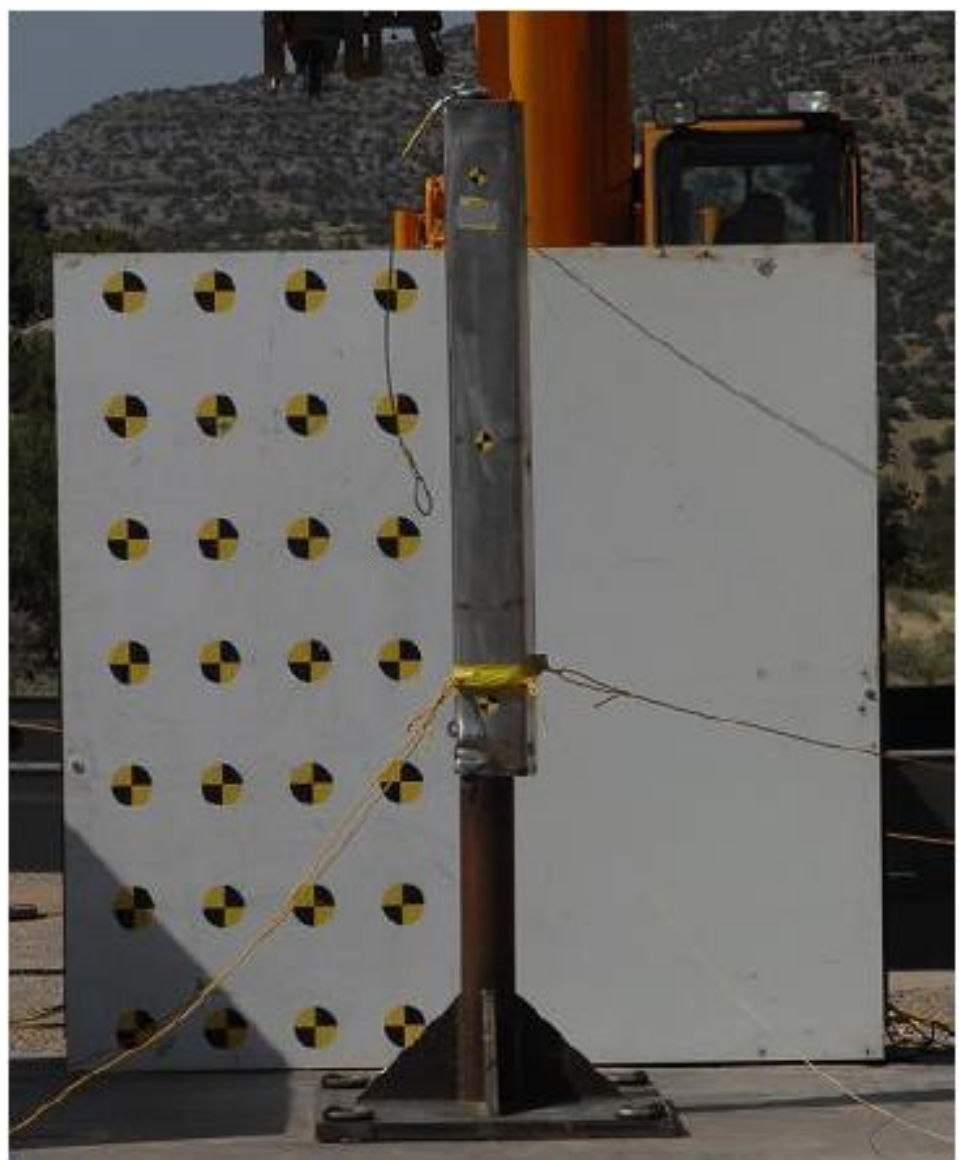

Figure C-78. CTU following CP1-1 impact [ATR FFSC SAR (2017), Figure 2.12.1-45].

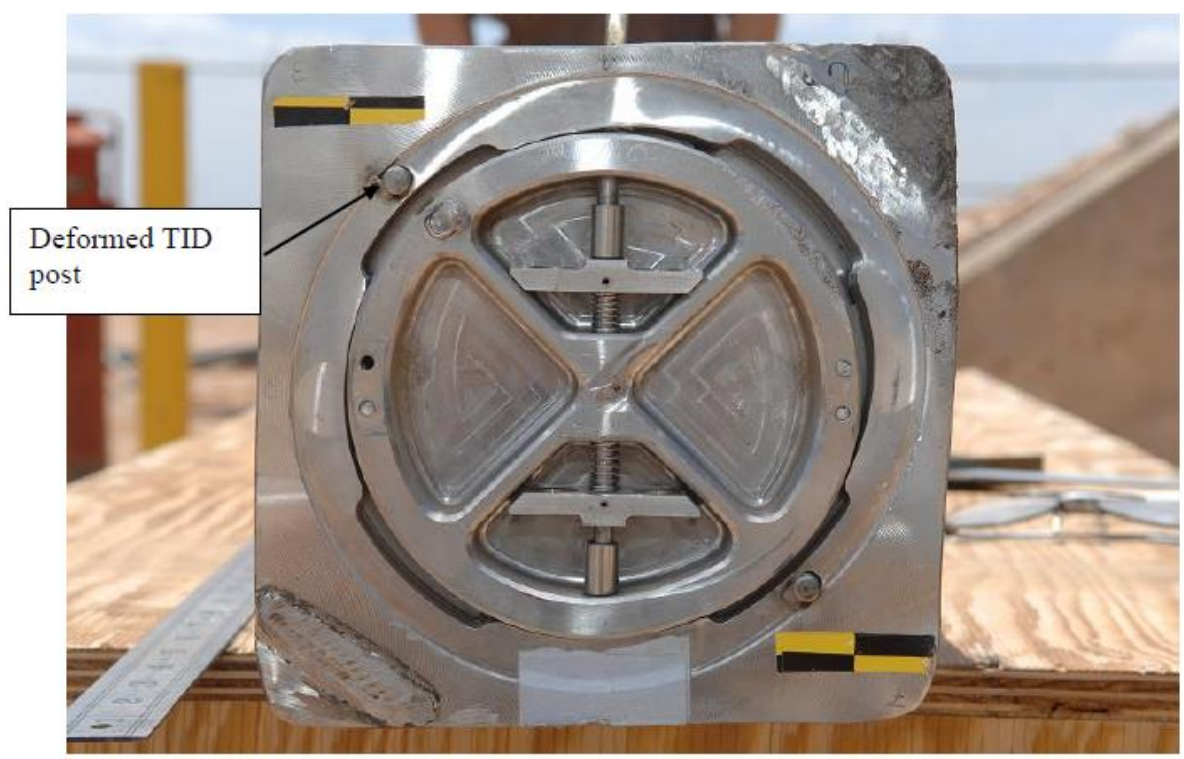

Figure C-79. CP1-1 impact damage (Shown Index Lugs Down) [ATR FFSC SAR (2017), Figure 2.12.1-46]. 


\section{C2.8.2 Results for Scope Part 1b (Table 3), Test 11 (Table 2)}

The FEA model results for the Scope Part $1 \mathrm{~b}$ (Table 3), Test 11 (Table 2) model are shown below in Figure C-80 to Figure C-86. This drop scenario is a 40-in. drop modeled as a vertical top drop with the lid centered over a 6-in.-diameter puncture bar. The fuel element weights $22.1 \mathrm{lbf}$ and the drop scenario is modeled with minimum material properties except the enclosure and end boxes, which are modeled with relatively tough material properties.

[X1.E3]

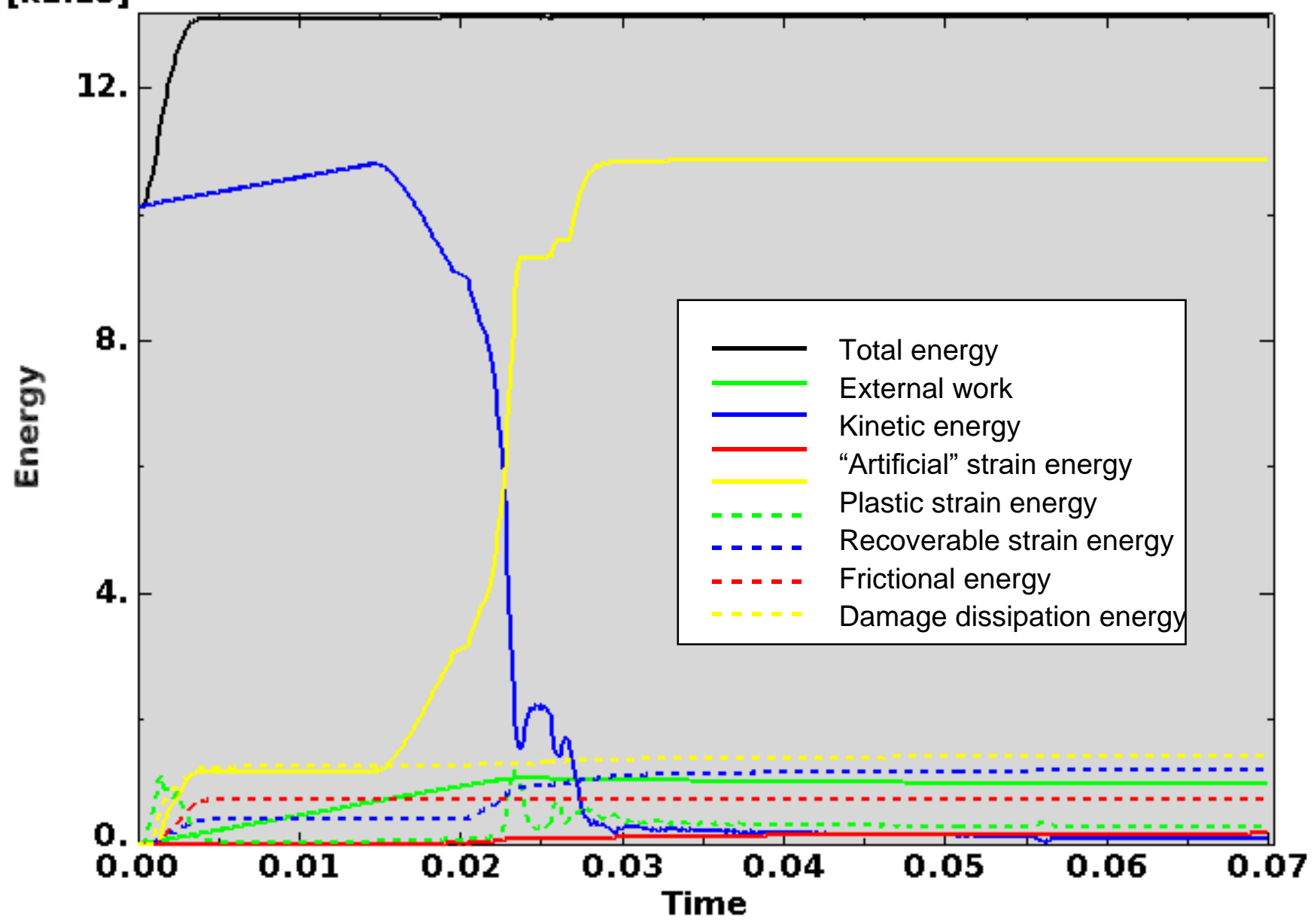

Figure C-80. Scope Part 1b (Table 3), Test 11 (Table 2) energy curves.

Figure C-80 shows the energy curves for Scope Part $1 \mathrm{~b}$ (Table 3), Test 11 (Table 2) drop scenario. These curves exhibit a stable shape. Artificial strain energy represents the energy required to keep reduced integration elements from taking on a zero-energy hourglass shape. As shown in Figure C-80, the artificial energy at the end of the model run is $1.3 \%$ of the total energy. Therefore, the potential error associated with artificial energy is not considered to be significant. 


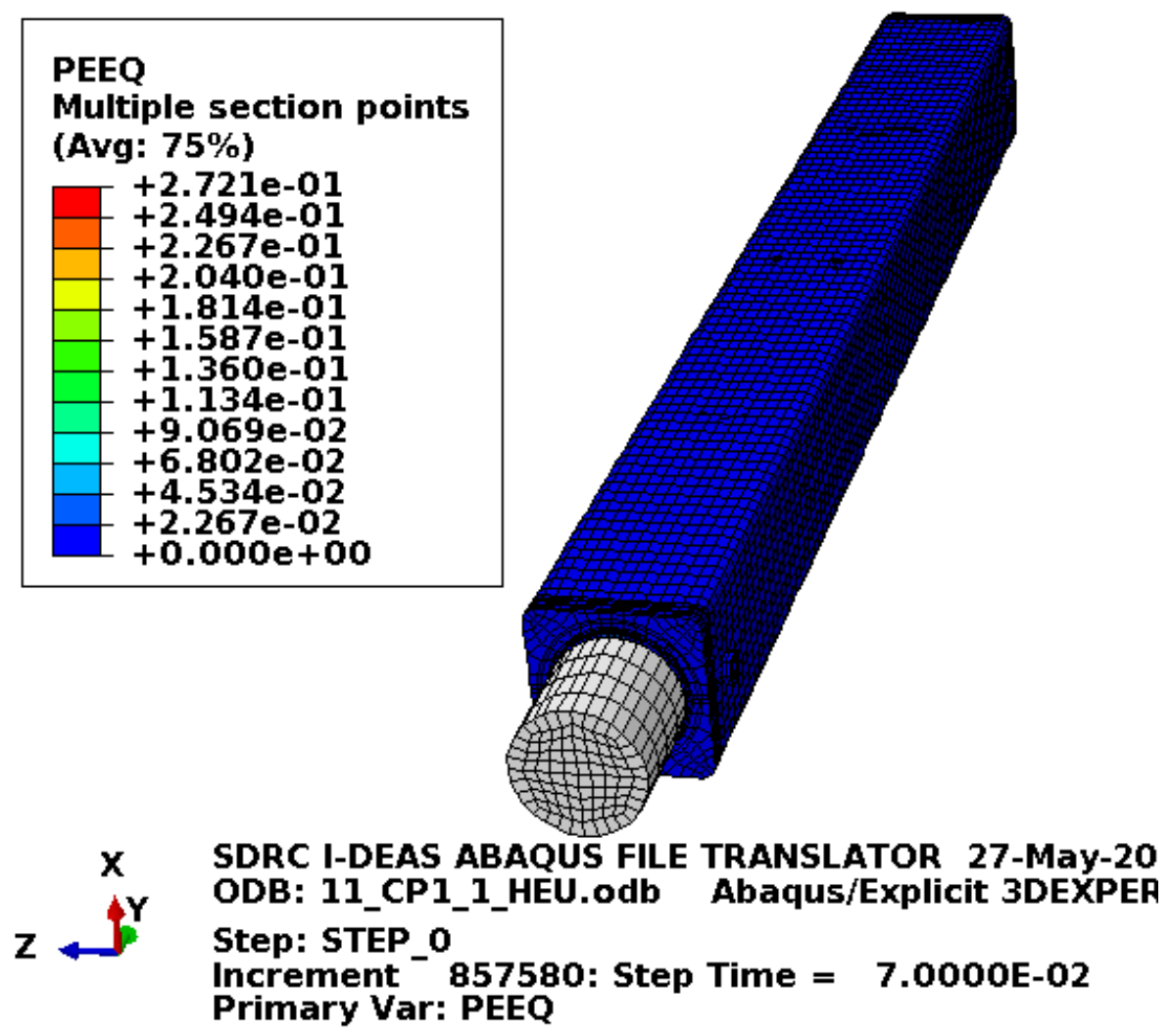

Figure C-81. Scope Part 1b (Table 3), Test 11 (Table 2) full-model plastic-equivalent strain.

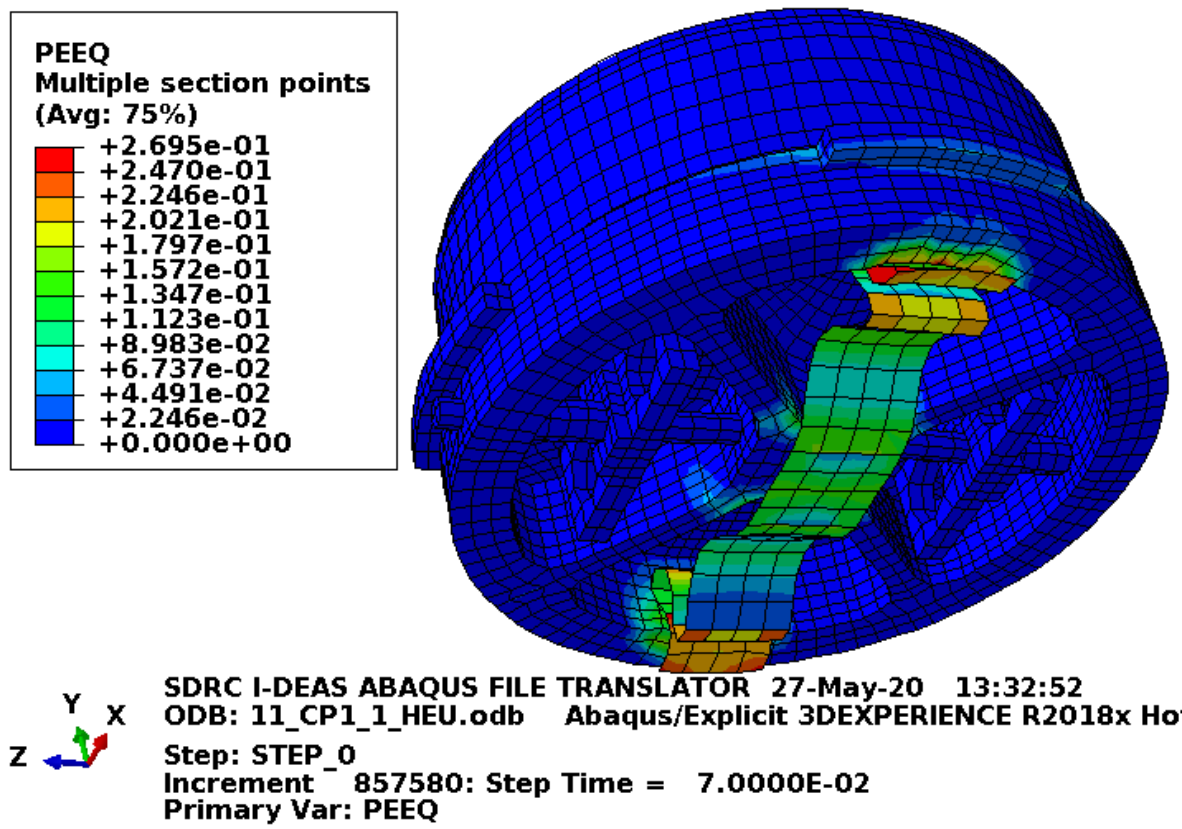

Figure C-82. Scope Part 1b (Table 3), Test 11 (Table 2) lid plastic-equivalent strain.

Figure C-82 shows the equivalent plastic strain in the lid. The most deformation is in the closure handle, which is not a concern. 
Drop Analysis of the Advanced Test Reactor Fresh Fuel Shipping Container with Heavier Low-Enriched Uranium Fuel Contents
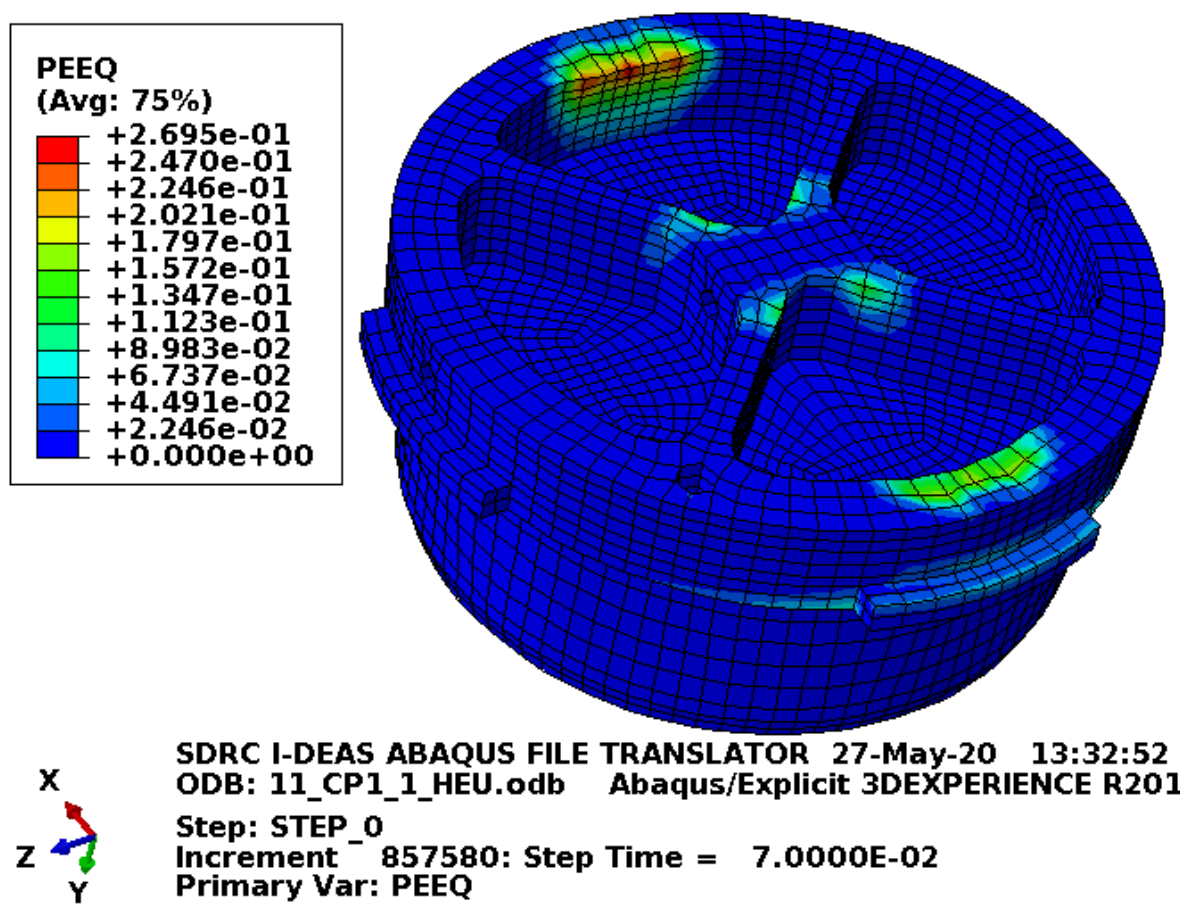

SDRC I-DEAS ABAQUS FILE TRANSLATOR 27-May-20 13:32:52 ODB: 11_CP1_1_HEU.odb Abaqus/Explicit 3DEXPERIENCE R201 Step: STEP_o

Increment ${ }^{-}$857580: Step Time $=$7.0000E-02 Primary Var: PEEQ

Figure C-83. Scope Part 1b (Table 3), Test 11 (Table 2) lid structure plastic-equivalent strain.

Figure $\mathrm{C}-83$ shows the equivalent plastic strain in the structurally significant portion of the lid. Failure in these elements occurs at an equivalent plastic strain of $0.259 \mathrm{in}$./in. If element failure were to occur, the element would be deleted and removed from the model (thereby making its equivalent plastic strain not included in the maximum equivalent plastic strain for the plot). However, the missing element would be visible in the plot. Figure C-83 shows no element failure though a few elements show strains above failure. The strains shown above the failure strain likely result from extrapolation (as integration point strains are the important strains for failure). Even if the elements with high strain were removed as being failed, the lid would still be capable of performing its function. 


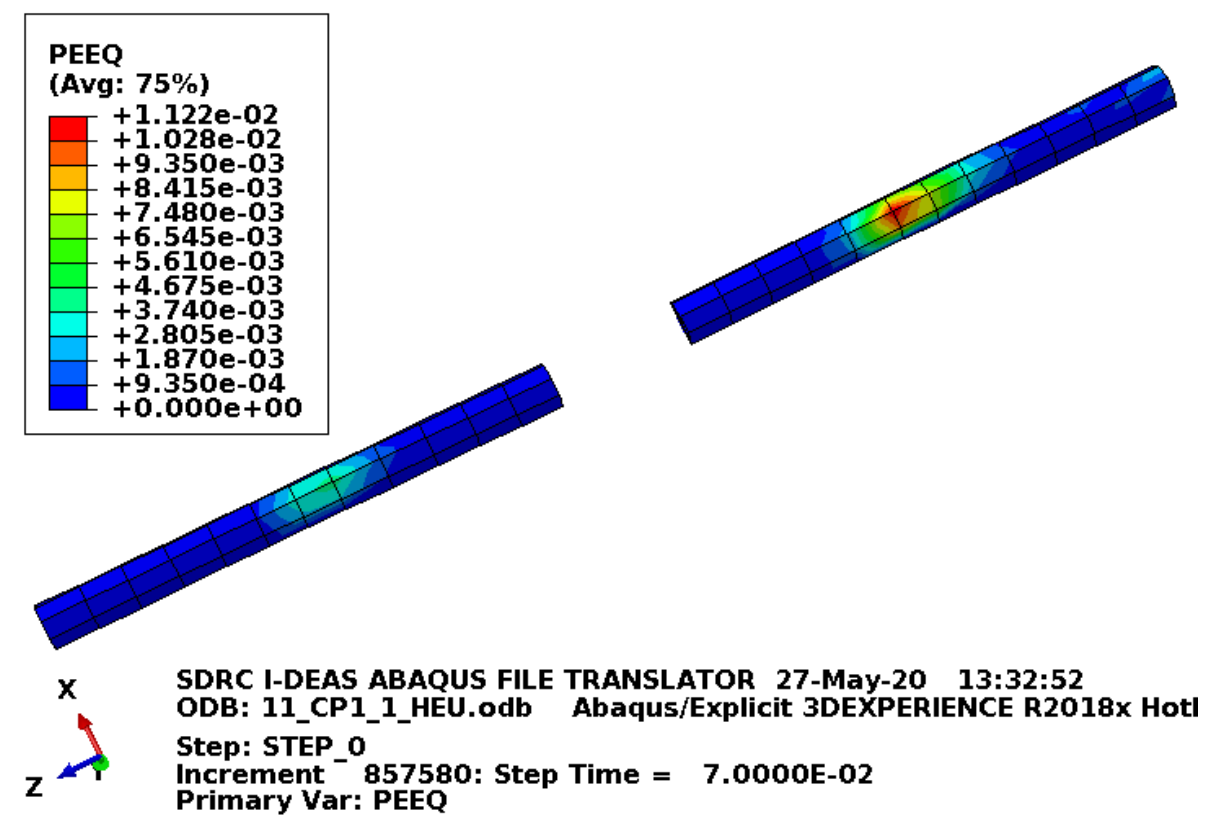

Figure C-84. Scope Part 1b (Table 3), Test 11 (Table 2) lid pins plastic-equivalent strain.

Figure C-84 shows the equivalent plastic strain in the lid pins. Failure in these elements occurs at an equivalent plastic strain of $0.295 \mathrm{in}$./in. If element failure were to occur, the element would be deleted and removed from the model (thereby making its equivalent plastic strain not included in the maximum equivalent plastic strain for the plot). However, the missing element would be visible in the plot. Figure C-84 shows no element failure with margin.

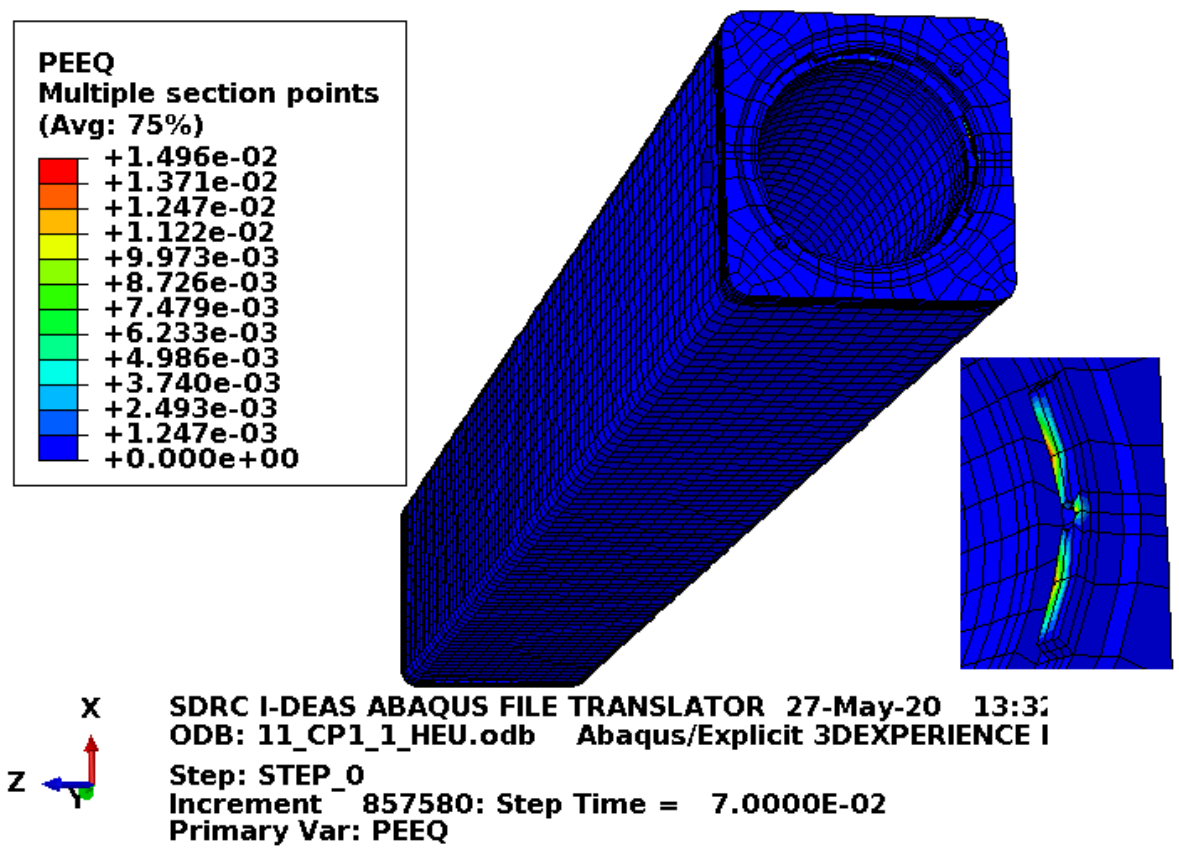

Figure C-85. Scope Part 1b (Table 3), Test 11 (Table 2) body plastic-equivalent strain. 
Figure C-85 shows the equivalent plastic strain in the body. Failure in these elements occurs at an equivalent plastic strain of $0.259 \mathrm{in}$./in. If element failure were to occur, the element would be deleted and removed from the model (thereby making its equivalent plastic strain not included in the maximum equivalent plastic strain for the plot). However, the missing element would be visible in the plot. Figure C-85 shows no element failure with margin.

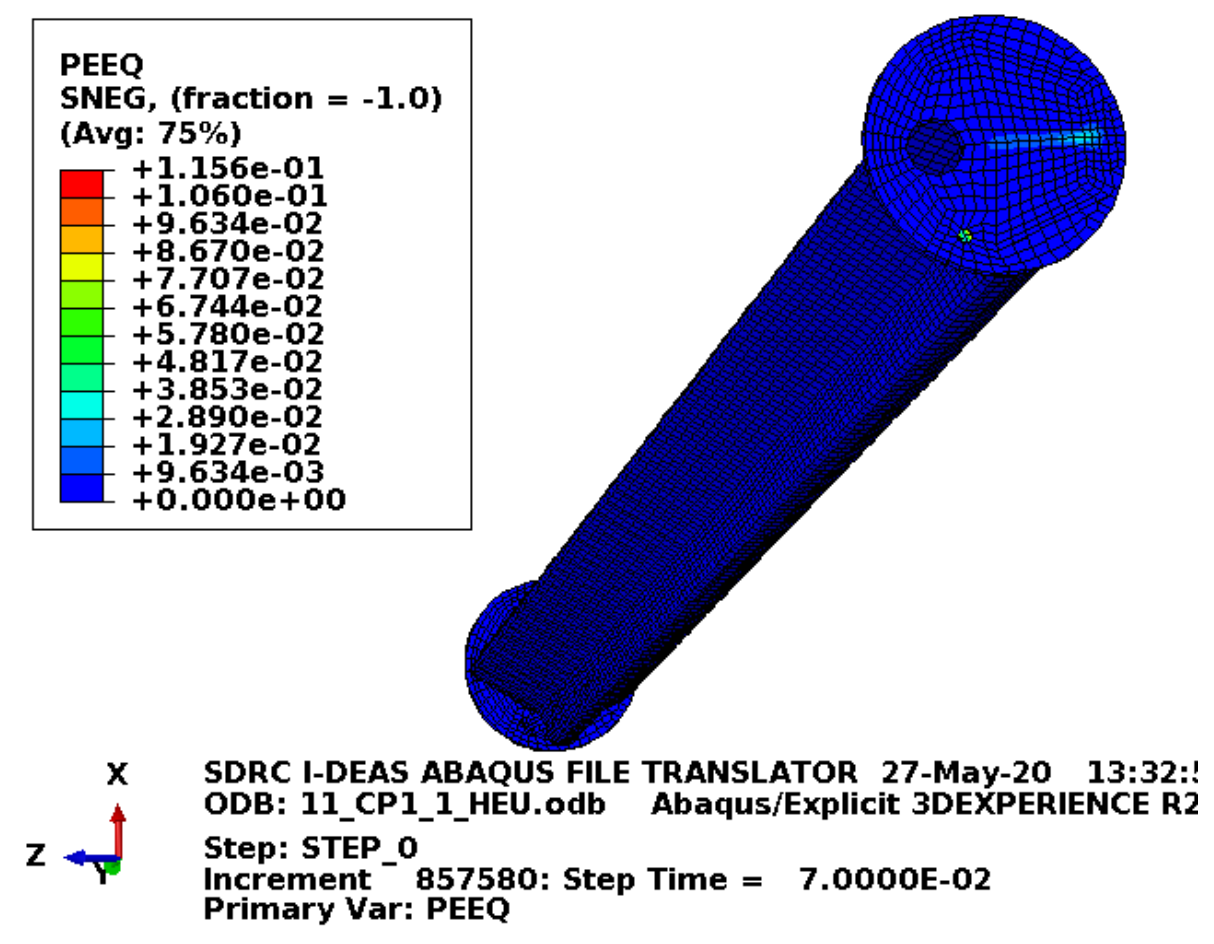

Figure C-86. Scope Part 1b (Table 3), Test 11 (Table 2) enclosure plastic-equivalent strain.

Figure C-86 shows the equivalent plastic strain in the enclosure. This is just for information as damage to the enclosure is acceptable.

\section{C2.9 Results for Scope Part 1 (Table 3), Test 12 (Table 2)}

The drop scenario considered in this section is a $30-\mathrm{ft}$ drop modeled as a vertical top impact.

\section{C2.9.1 Results from the Physical Drop Scenario}

No physical drop was performed for this drop scenario. Instead, it is performed for information as a drop scenario of interest.

\section{C2.9.2 Results for Scope Part 1a (Table 3), Test 12 (Table 2)}

The FEA model results for the Scope Part $1 \mathrm{~b}$ (Table 3), Test 12 (Table 2) model became unstable due to the fuel element response (as discussed in Section D2.9.2) while Scope Part 1a (Table 3), Test 12 (Table 2) results remained mostly stable. The ATR FFSC did not show any stability issues in either model run and similar damage occurred. Consequently, the Scope Part 1a (Table 3), Test 12 (Table 2) are given for this drop scenario. For information, the Scope Part $1 \mathrm{~b}$ (Table 3), Test 12 (Table 2) model results are described for the important structural components in this section. 
Scope Part 1a (Table 3), Test 12 (Table 2) results are shown below in Figure C-87 to Figure C-93. This drop scenario is a $30-\mathrm{ft}$ drop modeled as a vertical top impact. The fuel element weights $22.1 \mathrm{lbf}$ and the drop scenario is modeled with all minimum material properties.

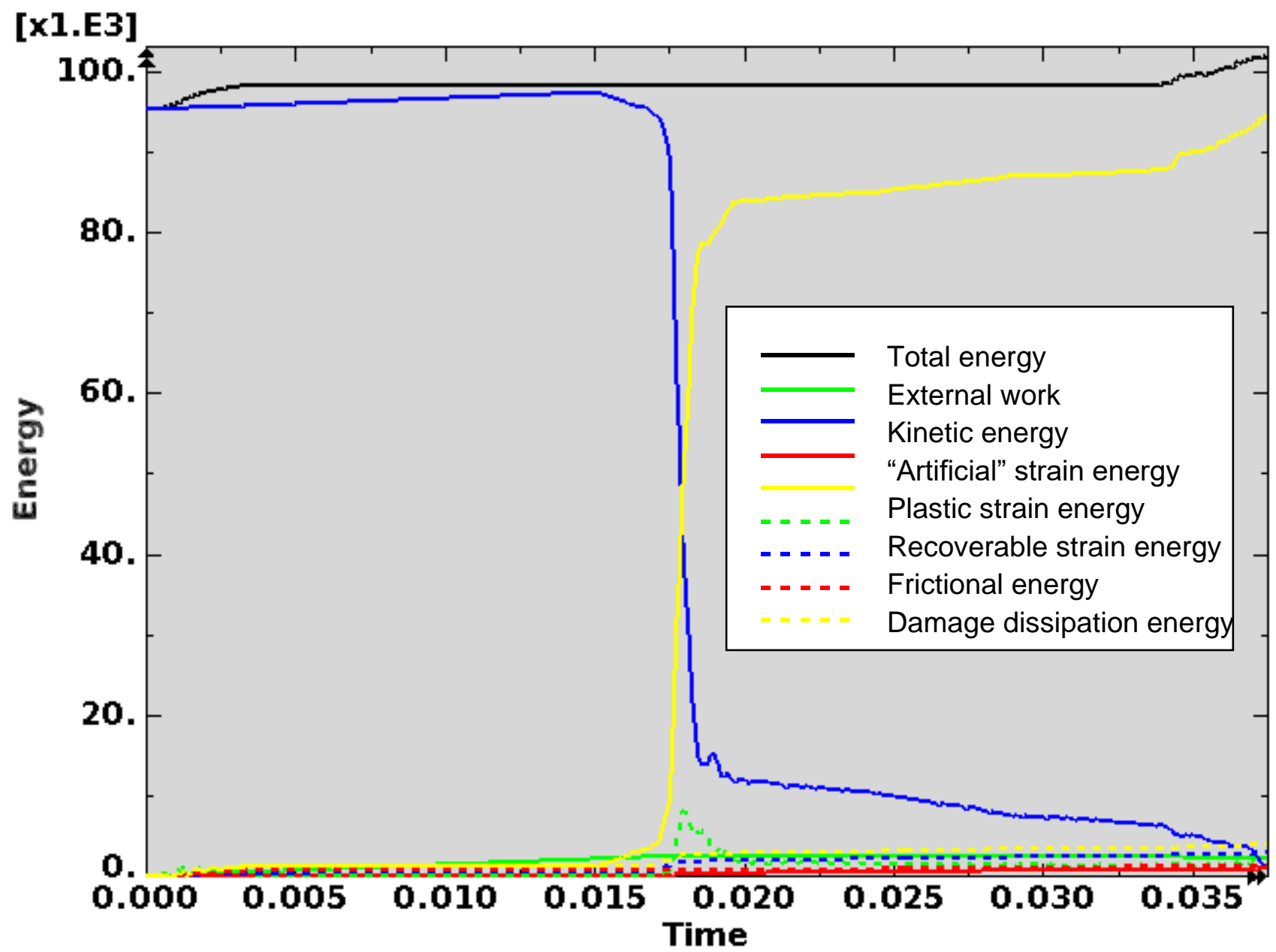

Figure C-87. Scope Part 1a (Table 3), Test 12 (Table 2) energy curves.

Figure C-87 shows the energy curves for Scope Part 1a (Table 3), Test 12 (Table 2) drop scenario. These curves exhibit mostly stable behavior. Near the end of the model run, the total energy and plastic strain energy start to show undesirable behavior. As discussed in Section D2.5 this appears to result from contact difficultly between failed portions of the fuel element. Consequently, output is shown at the first output frame after fuel element rebound ( 0.0375 second) to try to minimize potential error associated with this.

Artificial strain energy represents the energy required to keep reduced integration elements from taking on a zero-energy hourglass shape. As shown in Figure C-50, the artificial energy at the end of the model run is $0.3 \%$ of the total energy. Therefore, the potential error associated with artificial energy is not considered to be significant. 
ENGINEERING CALCULATIONS AND ANALYSIS

Drop Analysis of the Advanced Test Reactor Fresh Fuel Shipping Container with Heavier Low-Enriched Uranium Fuel Contents
ECAR-5224, Rev. 0

Page $\mathrm{C} 63$ of $\mathrm{C} 190$

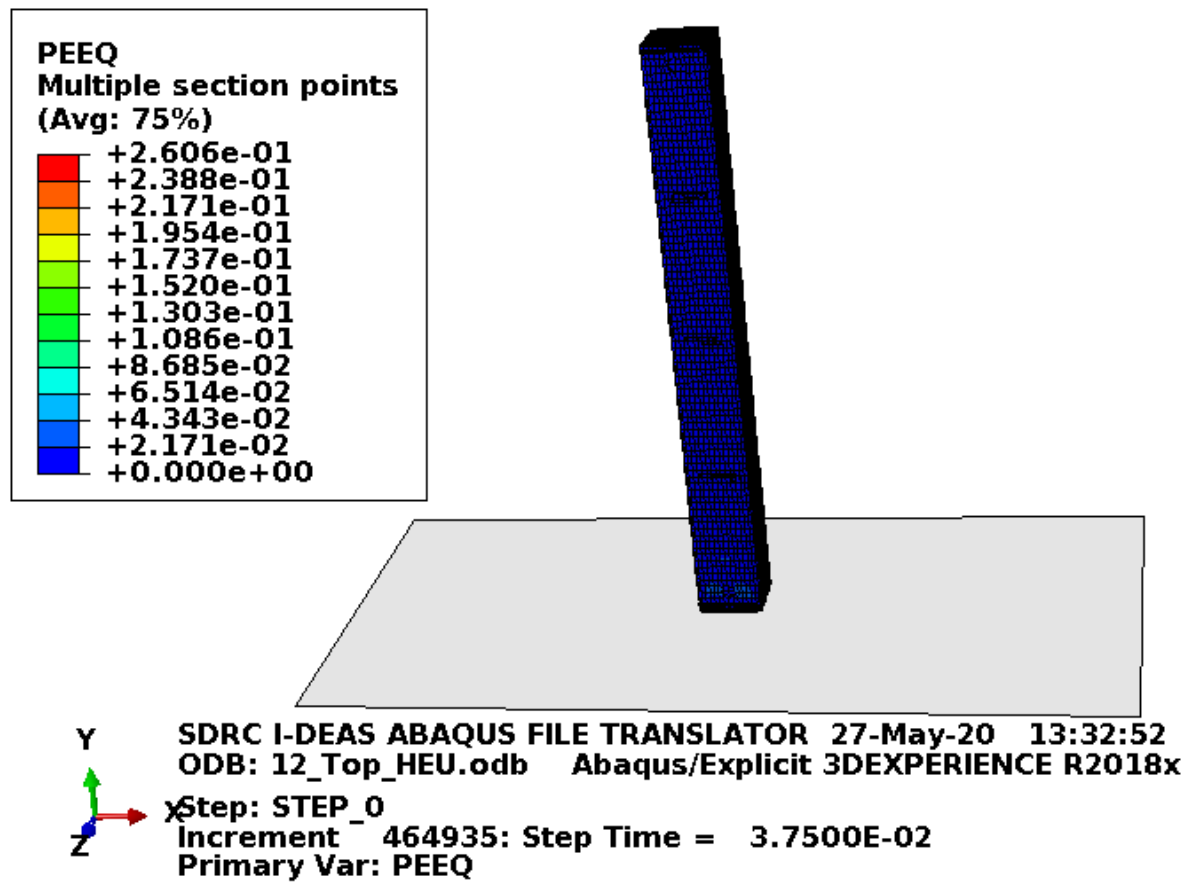

Figure C-88. Scope Part 1a (Table 3), Test 12 (Table 2) full-model plastic-equivalent strain.

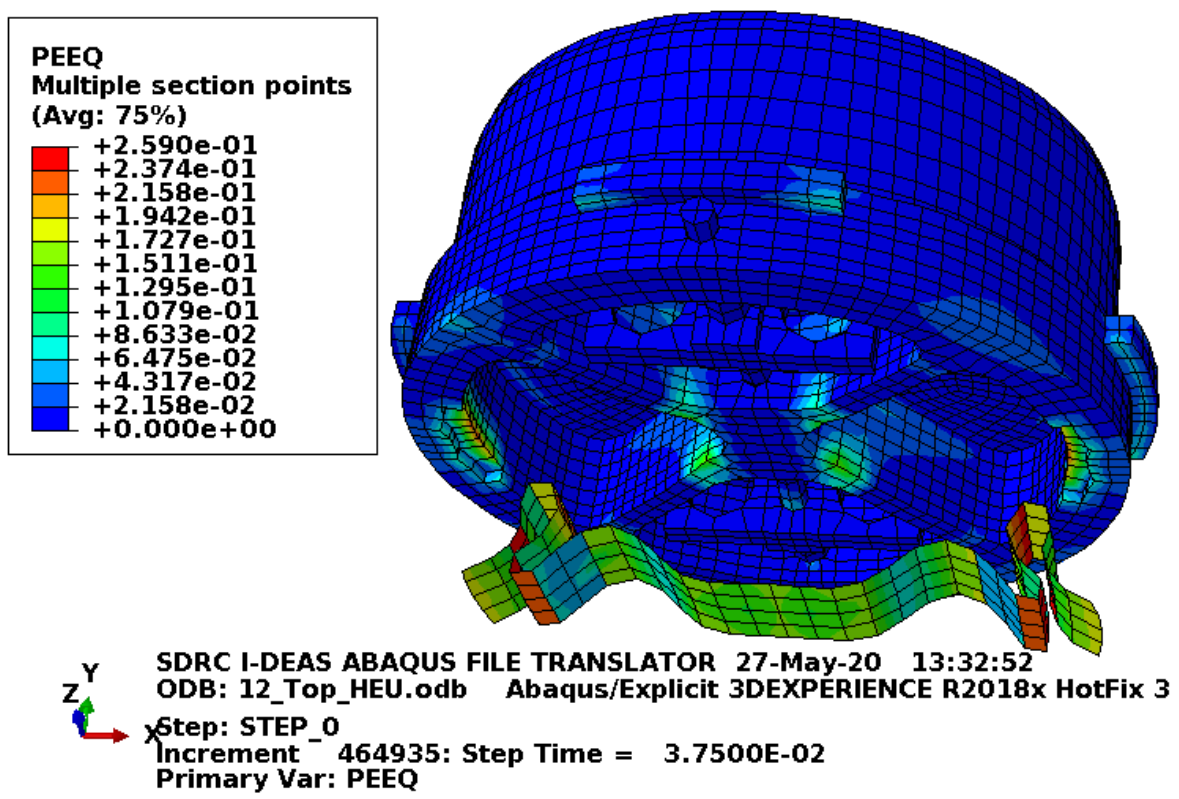

Figure C-89. Scope Part 1a (Table 3), Test 12 (Table 2) lid plastic-equivalent strain.

Figure C-89 shows the equivalent plastic strain in the lid. The most deformation is in the closure handle, which is not a concern. 
ENGINEERING CALCULATIONS AND ANALYSIS

Drop Analysis of the Advanced Test Reactor Fresh Fuel Shipping Container with Heavier Low-Enriched Uranium Fuel Contents

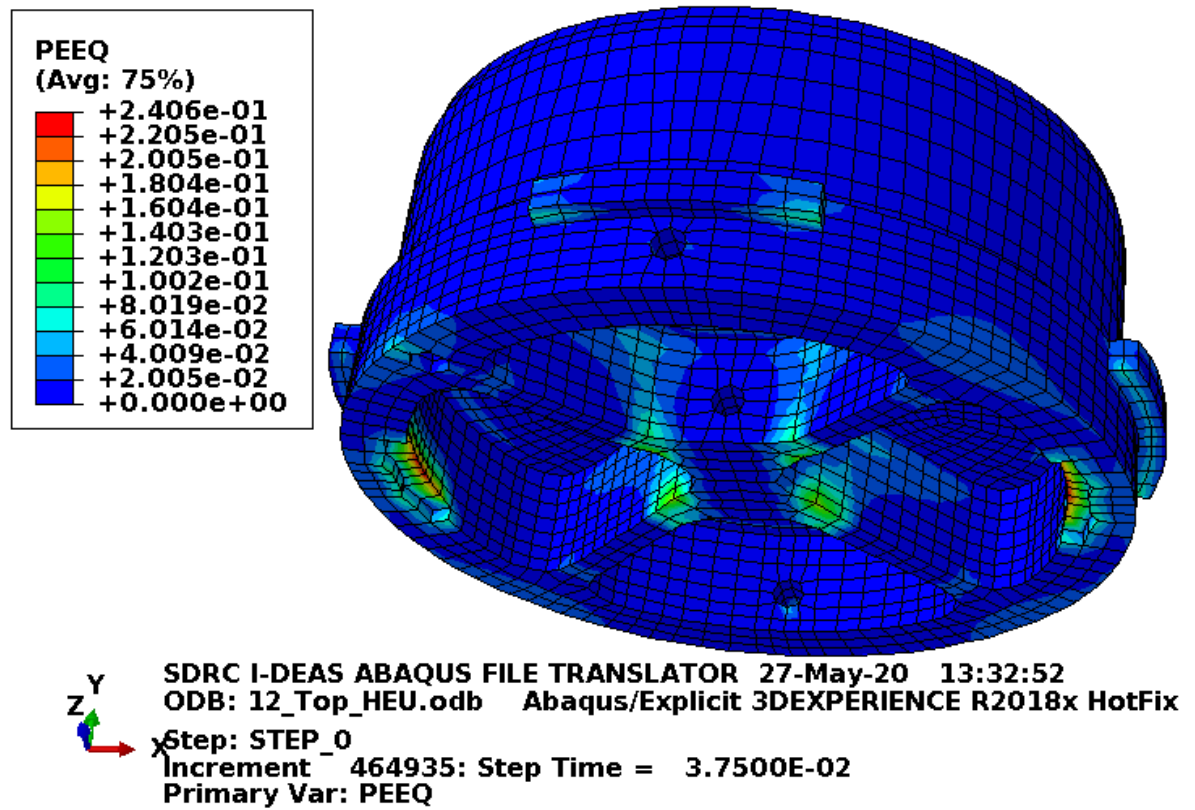

Figure C-90. Scope Part 1a (Table 3), Test 12 (Table 2) lid structure plastic-equivalent strain.

Figure C-90 shows the equivalent plastic strain in the structurally significant portion of the lid. Failure in these elements occurs at an equivalent plastic strain of $0.259 \mathrm{in}$./in. and some elements near the closure handle have failed. Since the failed elements are deleted and removed from the model, the equivalent plastic strain does not include the maximum equivalent plastic strain in the plot. The failure shown in Figure C-90 is acceptable as it does not prevent the lid from providing fuel element containment.

For information, the Scope Part 1b (Table 3), Test 12 (Table 2) model showed the same failure pattern in the structural portion of the lid.

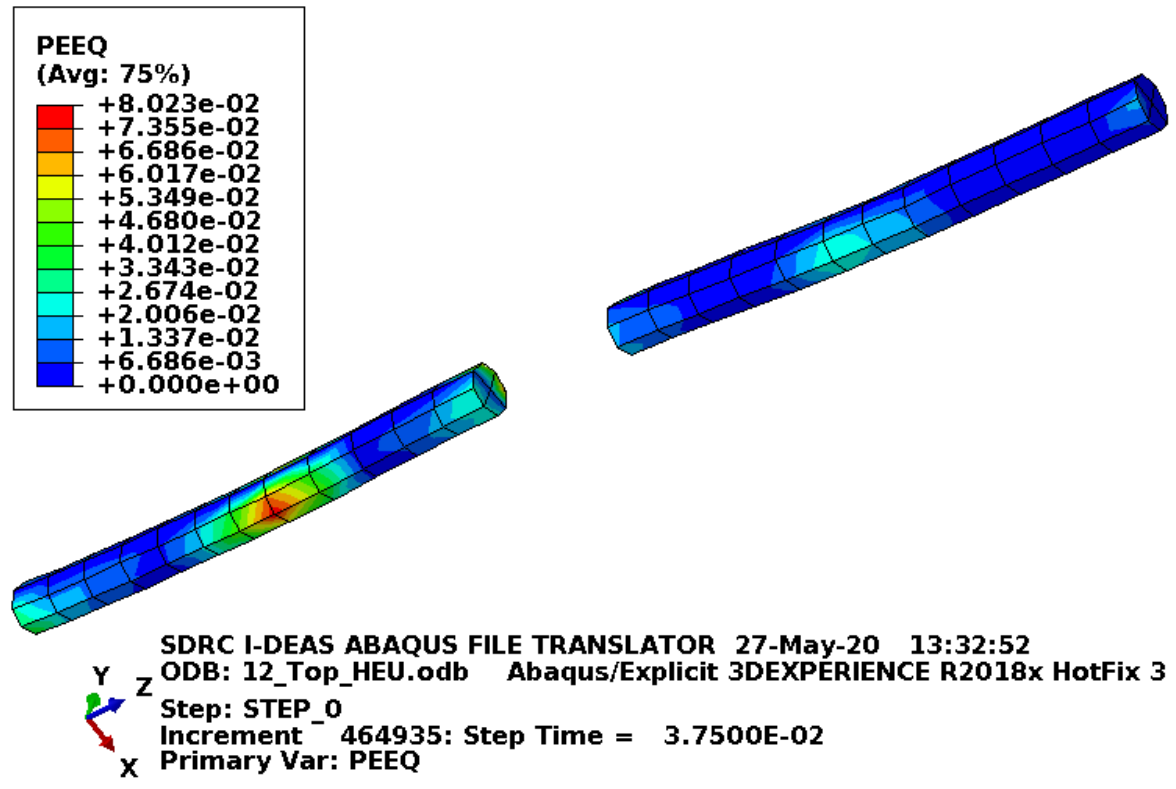

Figure C-91. Scope Part 1a (Table 3), Test 12 (Table 2) lid pins plastic-equivalent strain. 
Figure C-91 shows the equivalent plastic strain in the lid pins. Failure in these elements occurs at an equivalent plastic strain of $0.295 \mathrm{in}$./in. If element failure were to occur, the element would be deleted and removed from the model (thereby making its equivalent plastic strain not included in the maximum equivalent plastic strain for the plot). However, the missing element would be visible in the plot. Figure C-91 shows no element failure.

For information, the Scope Part 1b (Table 3), Test 12 (Table 2) model showed a similar plastic-equivalent strain pattern in the lid pin. In the Scope Part 1b (Table 3), Test 12 (Table 2) model, the highest strain (0.051 in./in) was in the end of a lid pin and the strain in the middle of the pin was not as dominant as that shown in Figure C-91.

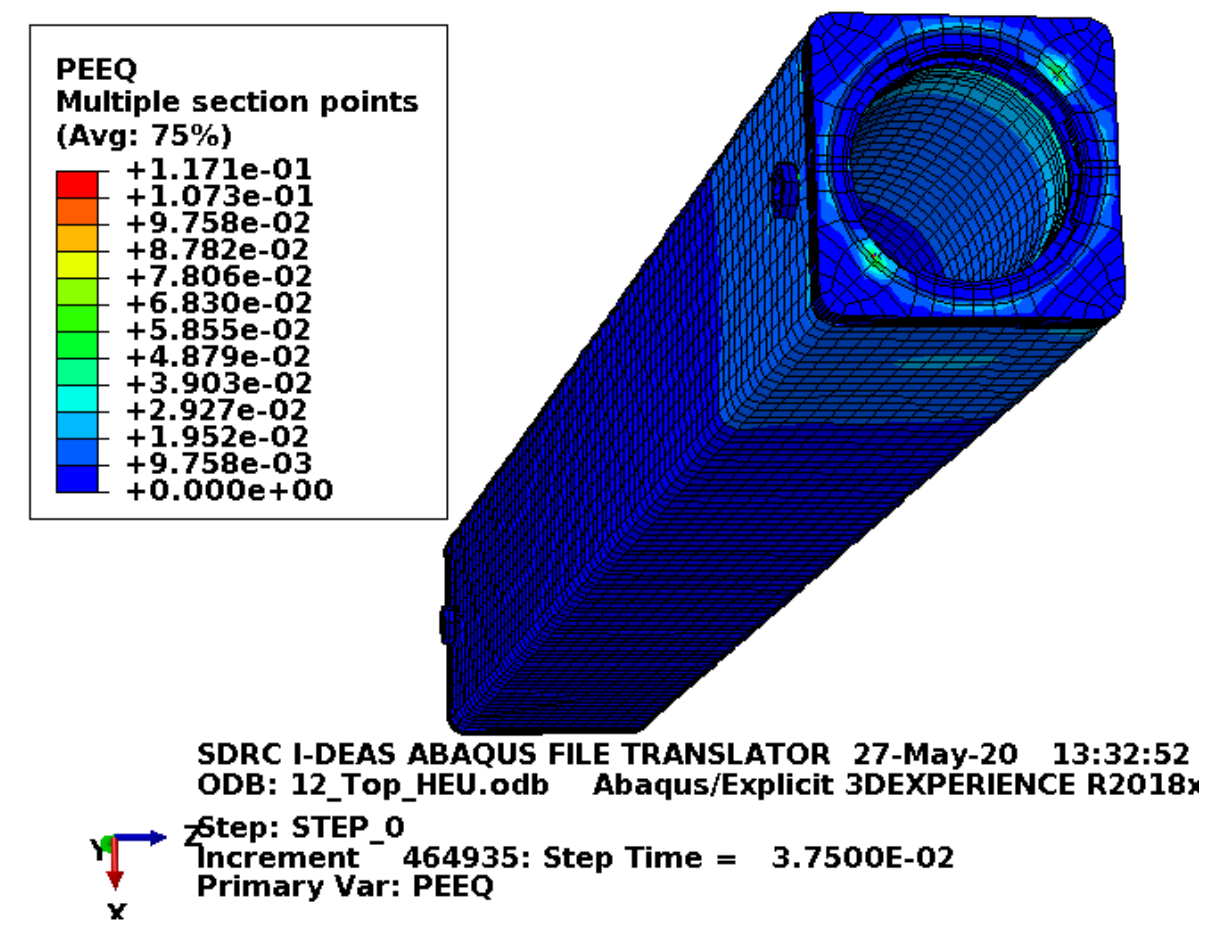

Figure C-92. Scope Part 1a (Table 3), Test 12 (Table 2) body plastic-equivalent strain.

Figure C-92 shows the equivalent plastic strain in the body. Failure in these elements occurs at an equivalent plastic strain of 0.259 in./in. and the TID posts have failed. Since the failed elements are deleted and removed from the model, the equivalent plastic strain does not include the maximum equivalent plastic strain in the plot. The tamper indicating device post failure shown in Figure C-90 is acceptable. Additionally, the body has no other failure, so it remains functional.

For information, the Scope Part 1b (Table 3), Test 12 (Table 2) model showed a similar plastic-equivalent strain pattern in the body. Though, in the Scope Part $1 \mathrm{~b}$ (Table 3), Test 12 (Table 2) model, the highest strain (0.149 in./in.) was a little higher than that shown in Figure C-92. 


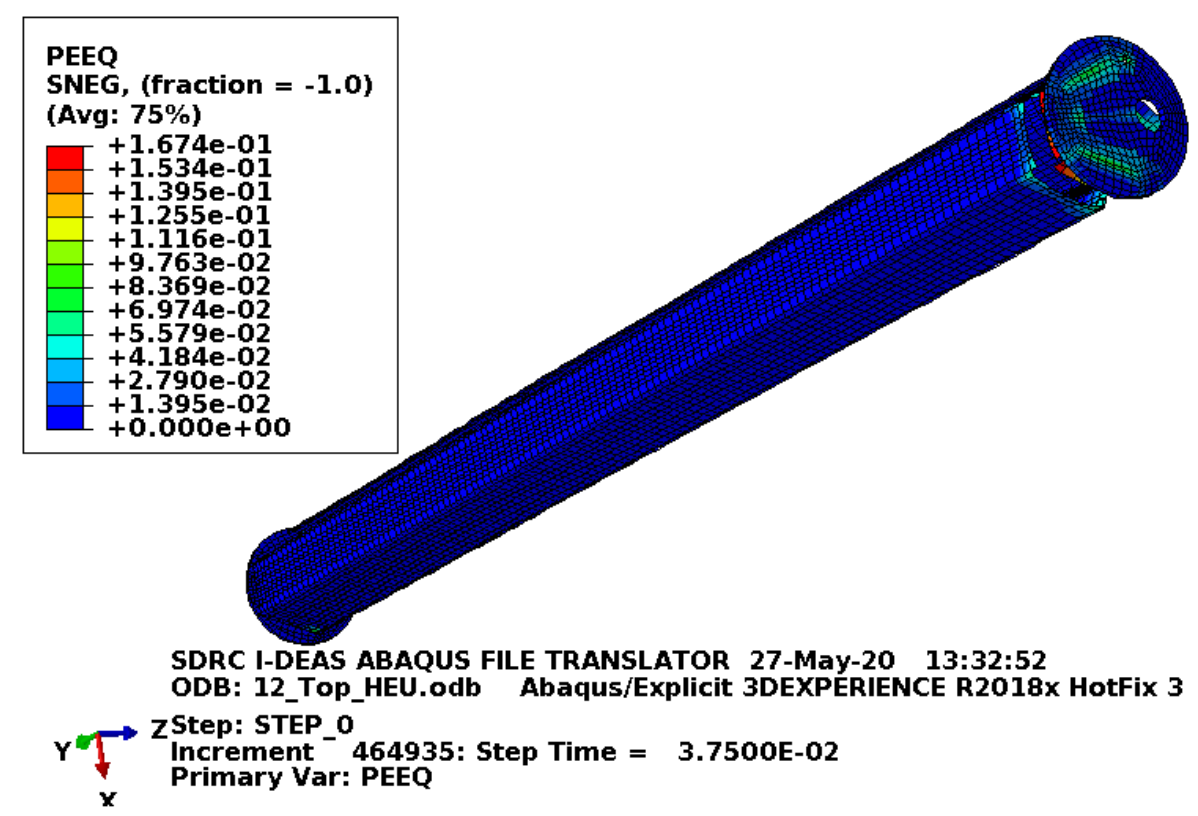

Figure C-93. Scope Part 1a (Table 3), Test 12 (Table 2) enclosure plastic-equivalent strain.

Figure C-93 shows the equivalent plastic strain in the enclosure. This is just for information as damage to the enclosure is acceptable.

For information, the Scope Part 1b (Table 3), Test 12 (Table 2) model showed higher strains in the enclosure (maximum of 0.272 in./in.) because relatively tougher material properties were used.

\section{C2.10 Results for Scope Part 1 (Table 3), Test 13 (Table 2)}

The drop scenario considered in this section is a 30 -ft drop modeled as a flat-side drop on an edge.

\section{C2.10.1 Results from the Physical Drop Scenario}

No physical drop was performed for this drop scenario. Instead, it is performed for information as a drop scenario of interest.

\section{C2.10.2 Results for Scope Part 1b (Table 3), Test 13 (Table 2)}

The FEA model results for the Scope Part 1b (Table 3), Test 13 (Table 2) model are shown below in Figure C-94 to Figure C-100. This drop scenario is a 30 -ft drop modeled as a flat-side drop on an edge. The fuel element weights $22.1 \mathrm{lbf}$ and the drop scenario is modeled with minimum material properties except the enclosure and end boxes, which are modeled with relatively tough material properties. 


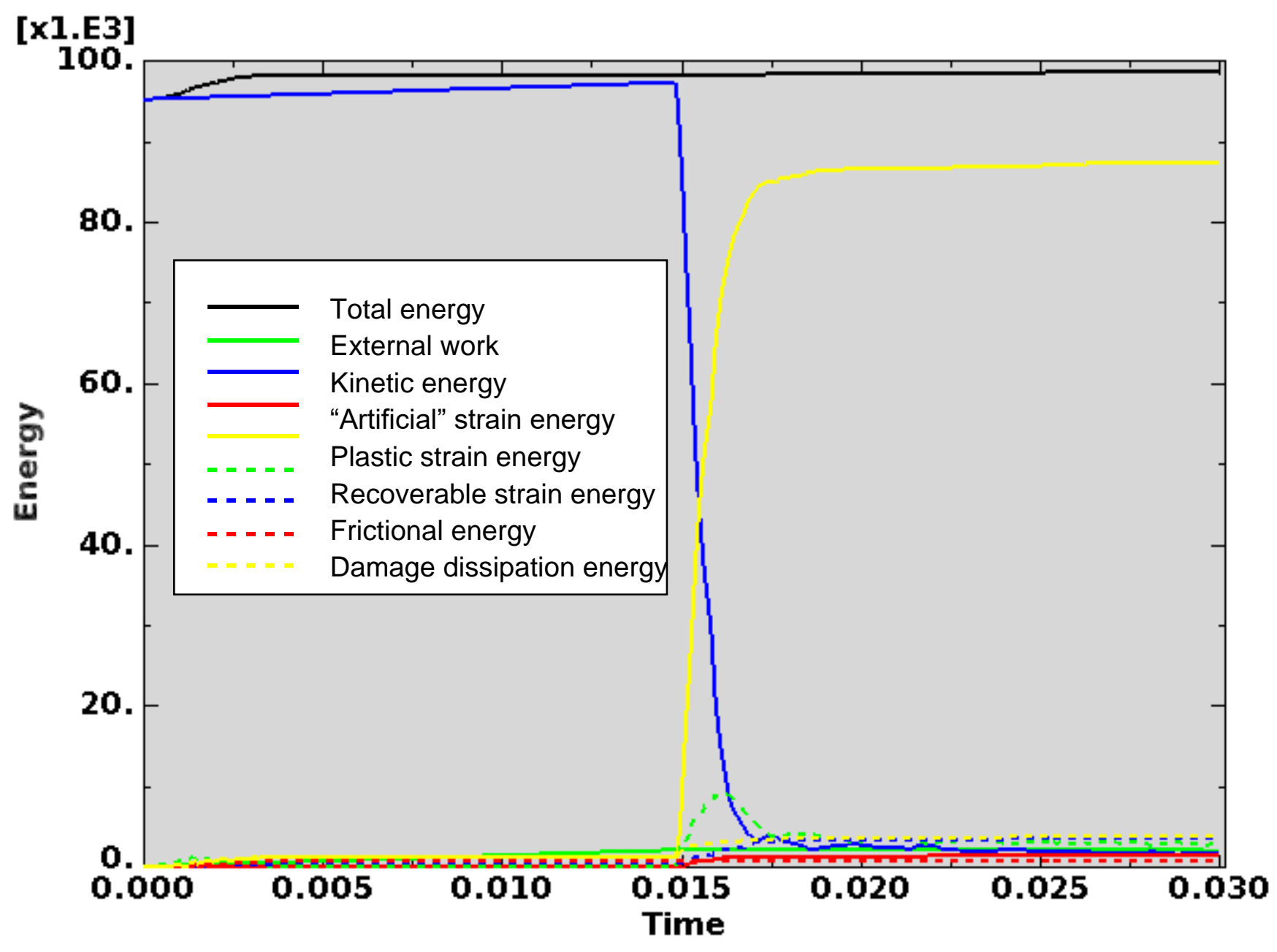

Figure C-94. Scope Part 1b (Table 3), Test 13 (Table 2) energy curves.

Figure C-94 shows the energy curves for Scope Part 1b (Table 3), Test 13 (Table 2) drop scenario. These curves exhibit a stable shape. Artificial strain energy represents the energy required to keep reduced integration elements from taking on a zero-energy hourglass shape. As shown in Figure C-94, the artificial energy at the end of the model run is $1.5 \%$ of the total energy. Therefore, the potential error associated with artificial energy is not considered to be significant. 


\section{ENGINEERING CALCULATIONS AND ANALYSIS}

Drop Analysis of the Advanced Test Reactor Fresh Fuel Shipping Container with Heavier Low-Enriched Uranium Fuel Contents
ECAR-5224, Rev. 0

Page $\mathrm{C} 68$ of C190

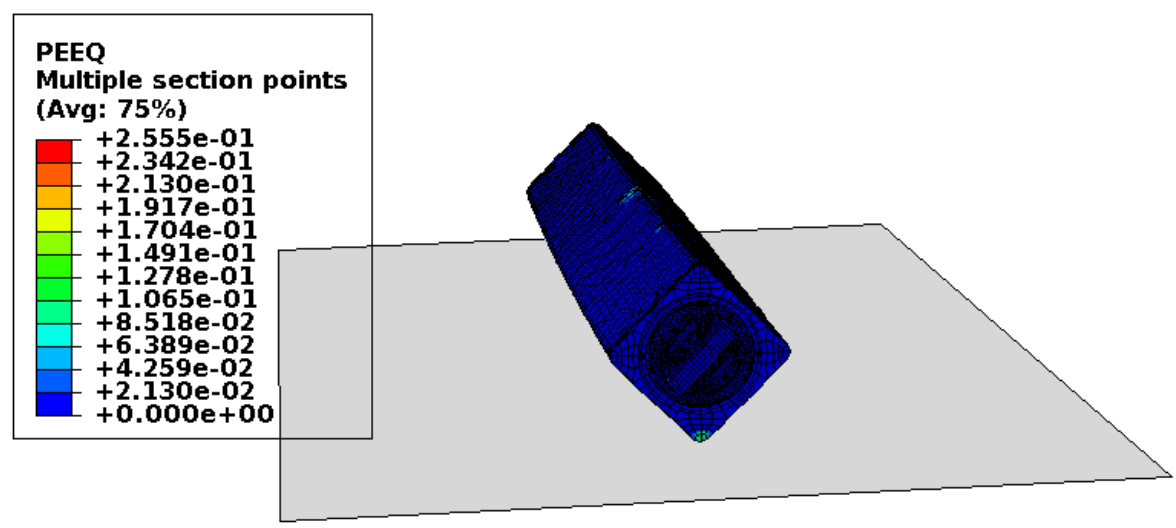 Y SDRC I-DEAS ABAQUS FILE TRANSLATOR 27-May-20 13:32:52
ODB: 13_Side_Edge_HEU.odb Abaqus/Explicit 3DEXPERIENCE R2018x HotF
Increment -375406 : Step Time $=3.0000 E-02$ Primary Var: PEEQ

Figure C-95. Scope Part 1b (Table 3), Test 13 (Table 2) full-model plastic-equivalent strain.
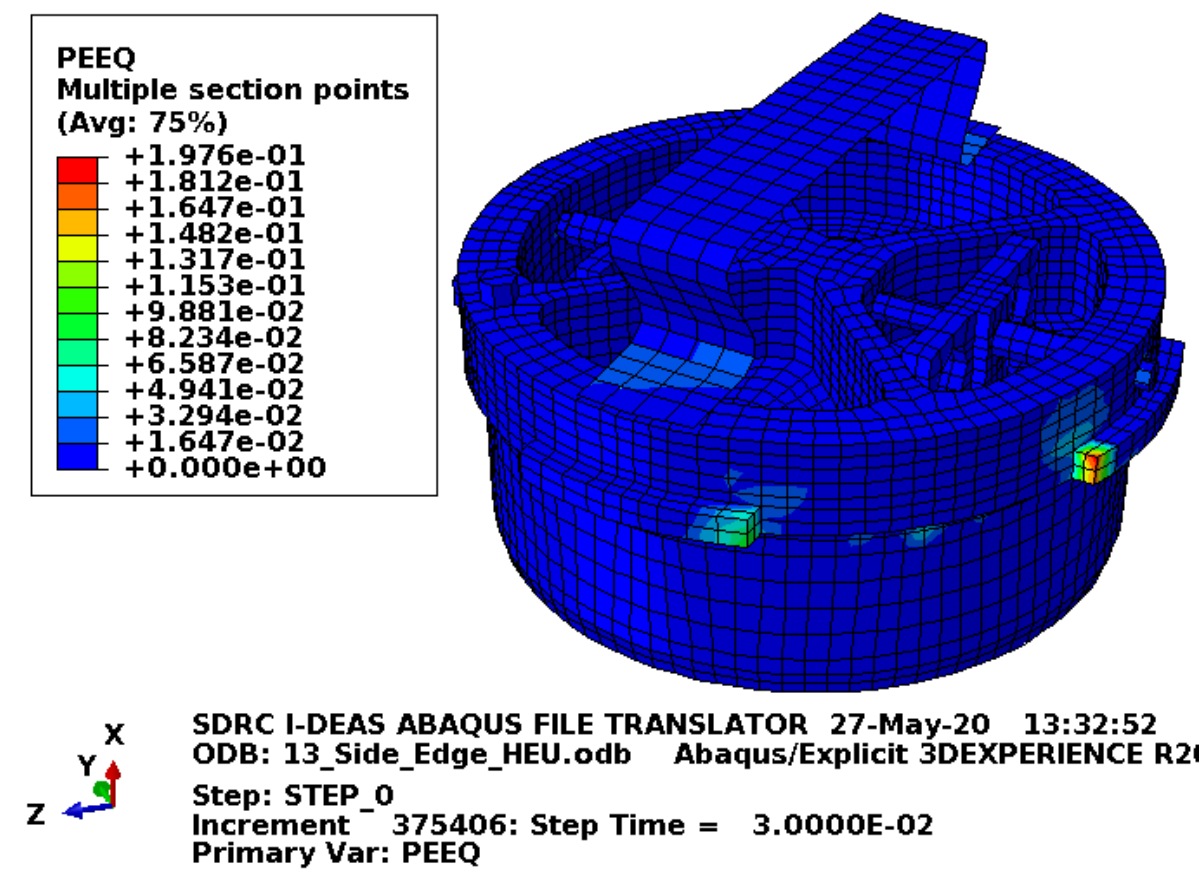

Figure C-96. Scope Part 1b (Table 3), Test 13 (Table 2) lid plastic-equivalent strain. 
ENGINEERING CALCULATIONS AND ANALYSIS

Drop Analysis of the Advanced Test Reactor Fresh Fuel Shipping Container with Heavier Low-Enriched Uranium Fuel Contents
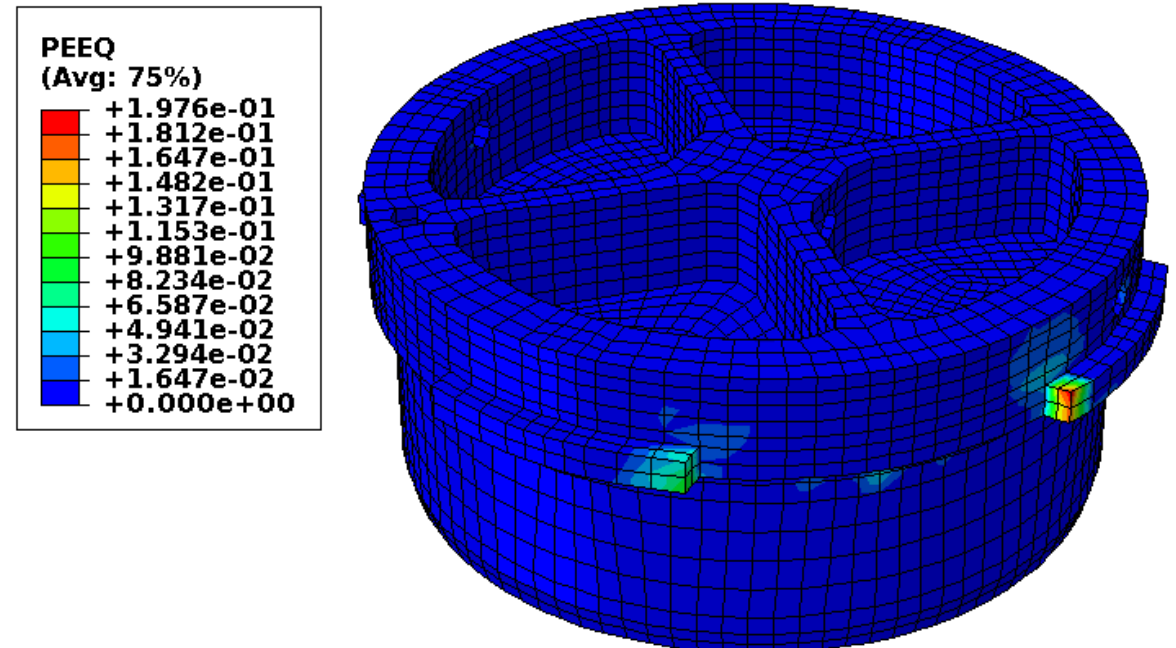

SDRC I-DEAS ABAQUS FILE TRANSLATOR 27-May-20 13:32:52

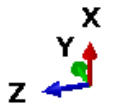
ODB: 13_Side_Edge_HEU.odb

Abaqus/Explicit 3DEXPERIENCE R2018x

Step: STEP_0

Increment ${ }^{-375406: \text { Step Time }=3.0000 \mathrm{E}-02}$

Primary Var: PEEQ

Figure C-97. Scope Part 1b (Table 3), Test 13 (Table 2) lid structure plastic-equivalent strain.

Figure C-97 shows the equivalent plastic strain in the structurally significant portion of the lid. Failure in these elements occurs at an equivalent plastic strain of $0.259 \mathrm{in}$./in. If element failure were to occur, the element would be deleted and removed from the model (thereby making its equivalent plastic strain not included in the maximum equivalent plastic strain for the plot). However, the missing element would be visible in the plot. Figure C-97 shows no element failure with margin.

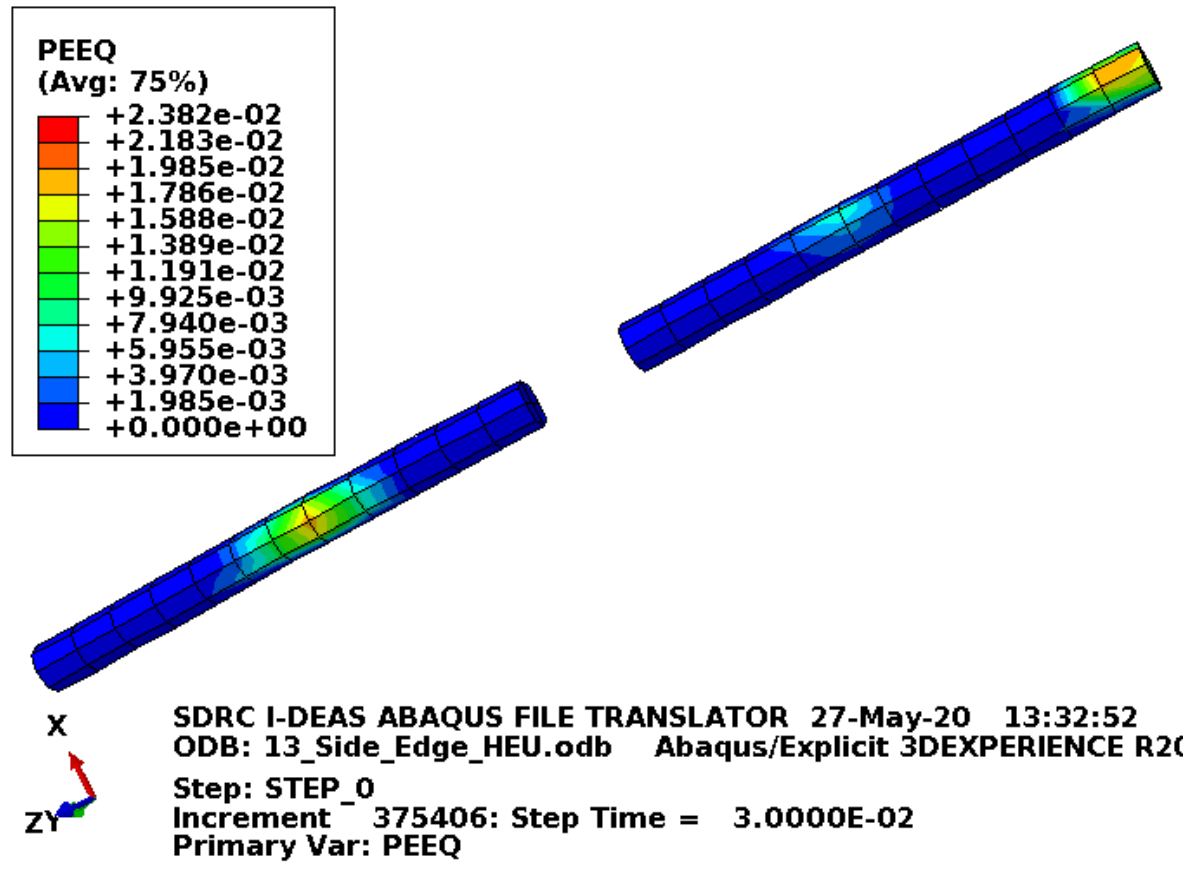

Figure C-98. Scope Part 1b (Table 3), Test 13 (Table 2) lid pins plastic-equivalent strain. 
Figure C-98 shows the equivalent plastic strain in the lid pins. Failure in these elements occurs at an equivalent plastic strain of $0.295 \mathrm{in}$./in. If element failure were to occur, the element would be deleted and removed from the model (thereby making its equivalent plastic strain not included in the maximum equivalent plastic strain for the plot). However, the missing element would be visible in the plot. Figure C-98 shows no element failure.
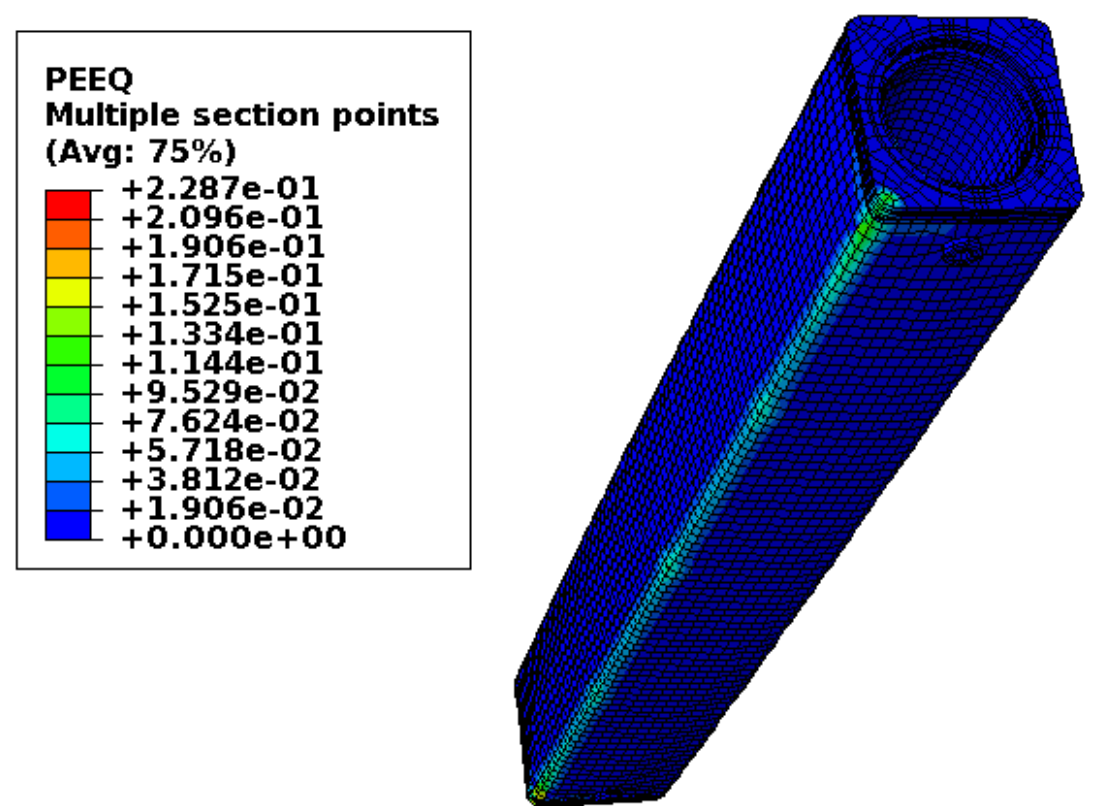

SDRC I-DEAS ABAQUS FILE TRANSLATOR 27-May-20 13:'

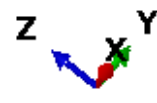

\section{ODB: 13_Side_Edge_HEU.odb Abaqus/Explicit 3DEXPERIE \\ Step: STEP_o}

Increment ${ }^{-}$375406: Step Time $=$3.0000E-02

Primary Var: PEEQ

Figure C-99. Scope Part 1b (Table 3), Test 13 (Table 2) body plastic-equivalent strain.

Figure C-99 shows the equivalent plastic strain in the body. Failure in these elements occurs at an equivalent plastic strain of $0.259 \mathrm{in}$./in. If element failure were to occur, the element would be deleted and removed from the model (thereby making its equivalent plastic strain not included in the maximum equivalent plastic strain for the plot). However, the missing element would be visible in the plot. Figure C-99 shows no element failure with margin. 


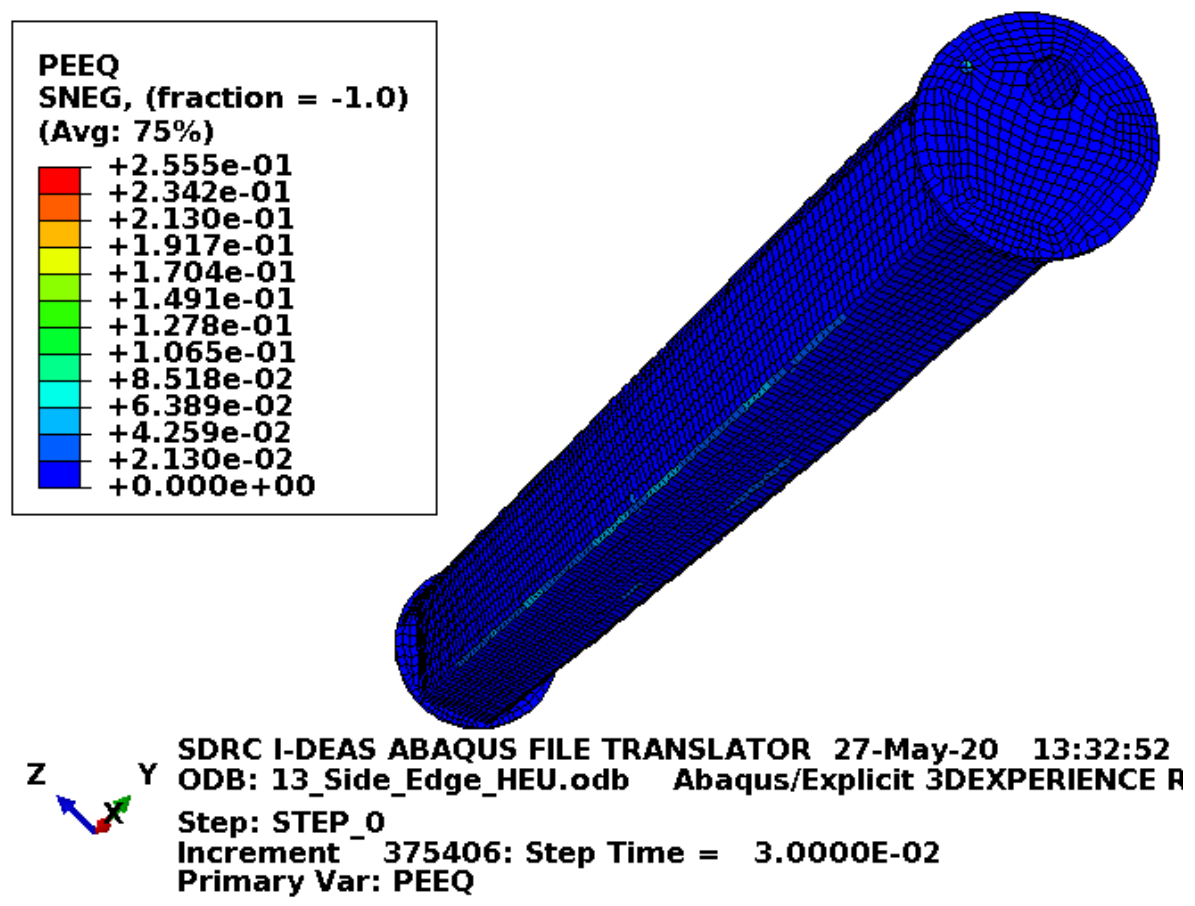

Figure C-100. Scope Part 1b (Table 3), Test 13 (Table 2) enclosure plastic-equivalent strain.

Figure $\mathrm{C}-100$ shows the equivalent plastic strain in the enclosure. This is just for information as damage to the enclosure is acceptable.

\section{C2.11 Results for Scope Part 1 (Table 3), Test 14 (Table 2)}

The drop scenario considered in this section is a 30-ft slap-down drop with pockets and index lugs on the sides. The impact orientation is 20 -degree off horizontal with the ATR FFSC bottom hitting first.

\section{C2.11.1 Results from the Physical Drop Scenario}

No physical drop was performed for this drop scenario. Instead, it is performed for information as a drop scenario of interest.

\section{C2.11.2 Results for Scope Part 1b (Table 3), Test 14 (Table 2)}

The FEA model results for the Scope Part $1 b$ (Table 3), Test 14 (Table 2) model are shown below in Figure C-101 to Figure C-107. This drop scenario is a 30-ft drop modeled as 20-degree off horizontal slapdown. The fuel element weights $22.1 \mathrm{lbf}$ and the drop scenario is modeled with minimum material properties except the enclosure and end boxes, which are modeled with relatively tough material properties. 
Drop Analysis of the Advanced Test Reactor Fresh Fuel Shipping Container with Heavier Low-Enriched Uranium Fuel Contents

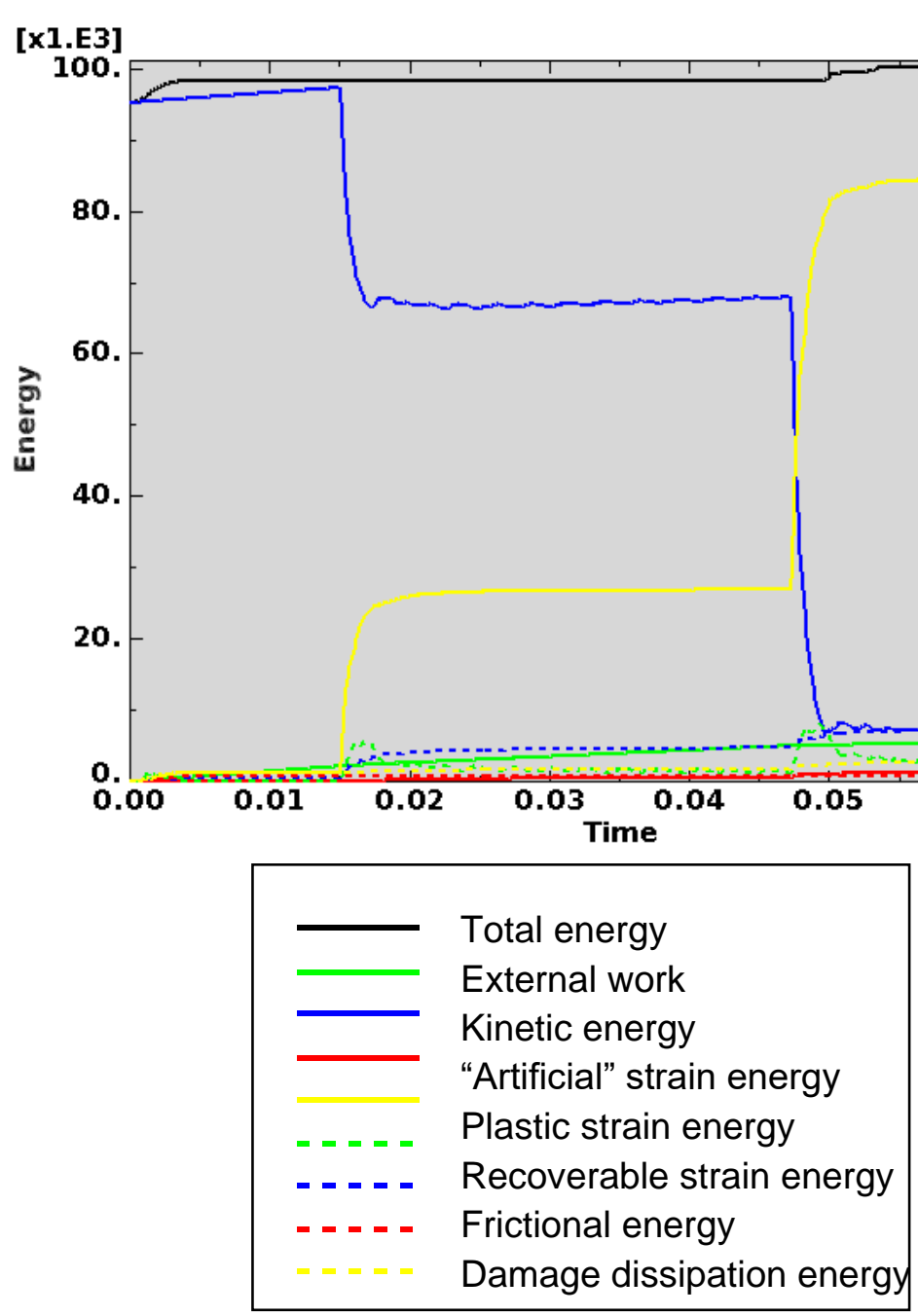

Figure C-101. Scope Part 1b (Table 3), Test 14 (Table 2) energy curves.

Figure C-101 shows the energy curves for Scope Part 1b (Table 3), Test 14 (Table 2) drop scenario. These curves exhibit a somewhat stable shape. There is a small amount of undesirable increase in total and plastic strain energy, but it is not considered significantly detrimental to the validity of the results. Artificial strain energy represents the energy required to keep reduced integration elements from taking on a zeroenergy hourglass shape. As shown in Figure C-101, the artificial energy at the end of the model run is $1.7 \%$ of the total energy. Therefore, the potential error associated with artificial energy is not considered to be significant. 


\section{ENGINEERING CALCULATIONS AND ANALYSIS}

Drop Analysis of the Advanced Test Reactor Fresh Fuel Shipping Container with Heavier Low-Enriched Uranium Fuel Contents
ECAR-5224, Rev. 0

Page $\mathrm{C} 73$ of $\mathrm{C} 190$

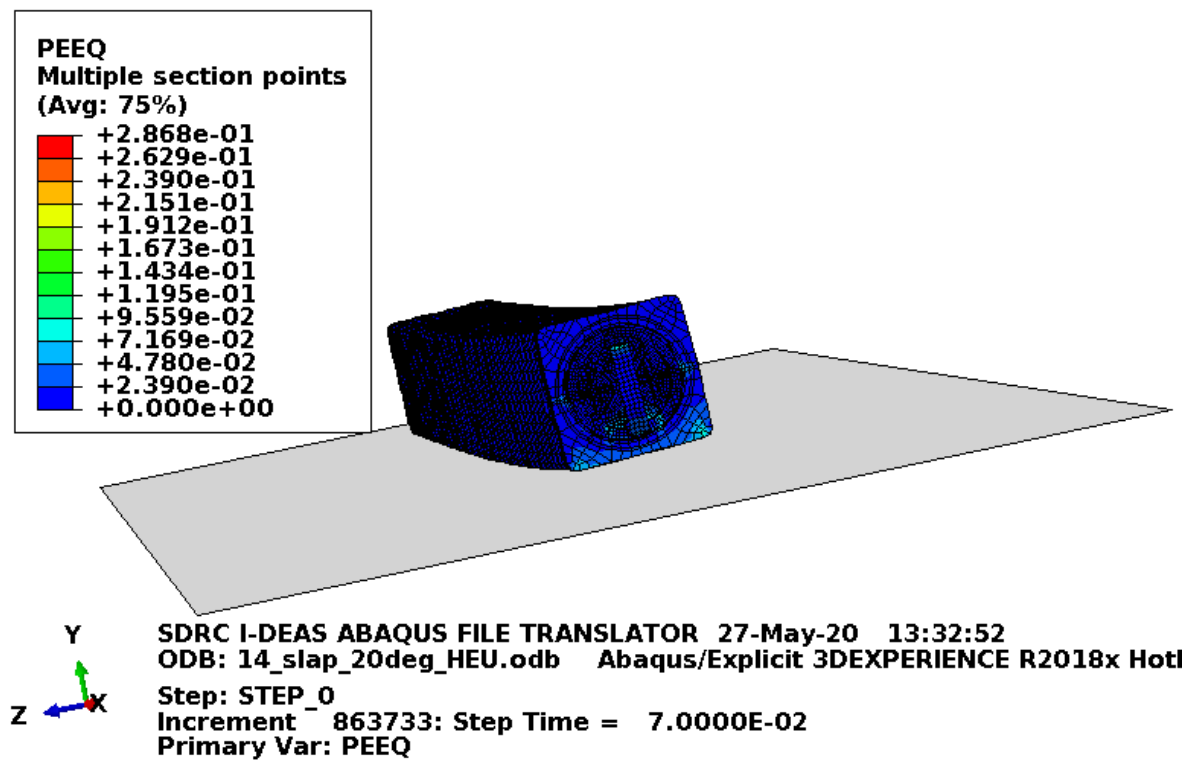

Figure C-102. Scope Part 1b (Table 3), Test 14 (Table 2) full-model plastic-equivalent strain.
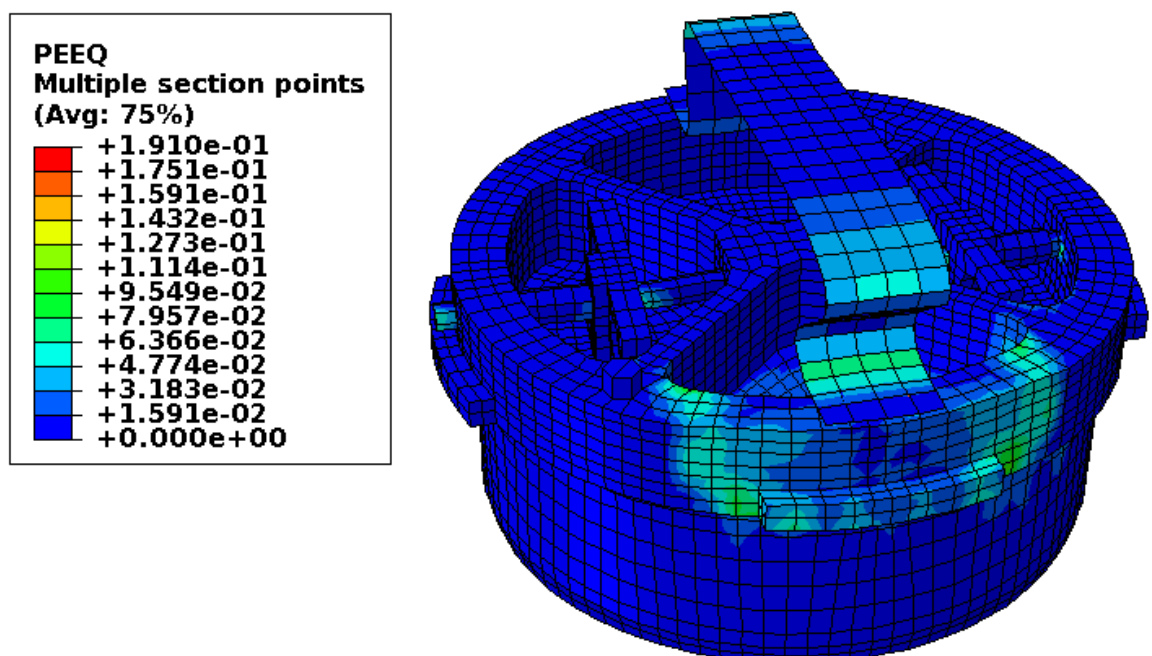

$z$

SDRC I-DEAS ABAQUS FILE TRANSLATOR 27-May-20 13:32:52

ODB: 14_slap_20deg_HEU.odb Abaqus/Explicit 3DEXPERIENCE R2018

Step: STEP 0

Increment ${ }^{-}$863733: Step Time $=$7.0000E-02

Primary Var: PEEQ

Figure C-103. Scope Part 1b (Table 3), Test 14 (Table 2) lid plastic-equivalent strain. 
ENGINEERING CALCULATIONS AND ANALYSIS

Drop Analysis of the Advanced Test Reactor Fresh Fuel Shipping Container with Heavier Low-Enriched Uranium Fuel Contents
ECAR-5224, Rev. 0

Page C74 of C190
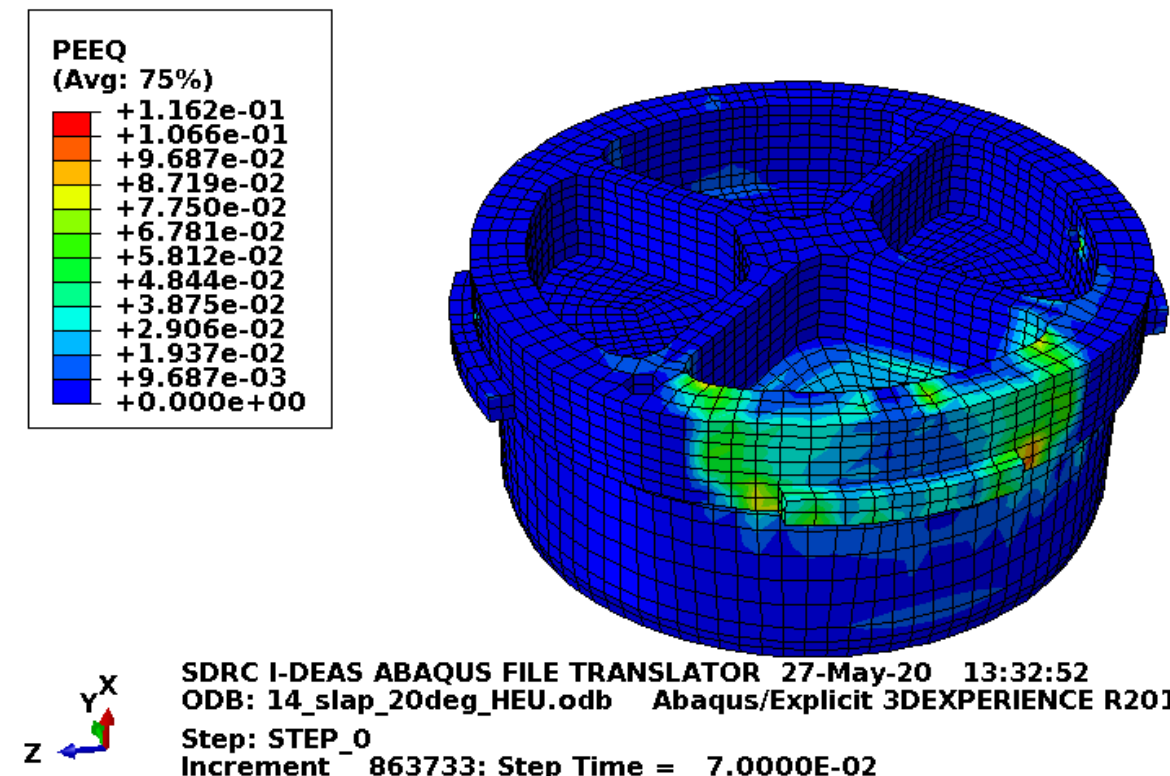

SDRC I-DEAS ABAQUS FILE TRANSLATOR 27-May-20 13:32:52

ODB: 14_slap_20deg_HEU.odb Abaqus/Explicit 3DEXPERIENCE R2018

Step: STEP_0

Increment 863733: Step Time $=$ 7.0000E-02

Primary Var: PEEQ

Figure C-104. Scope Part 1b (Table 3), Test 14 (Table 2) lid structure plastic-equivalent strain.

Figure C-104 shows the equivalent plastic strain in the structurally significant portion of the lid. Failure in these elements occurs at an equivalent plastic strain of $0.259 \mathrm{in}$./in. If element failure were to occur, the element would be deleted and removed from the model (thereby making its equivalent plastic strain not included in the maximum equivalent plastic strain for the plot). However, the missing element would be visible in the plot. Figure C-104 shows no element failure with margin.

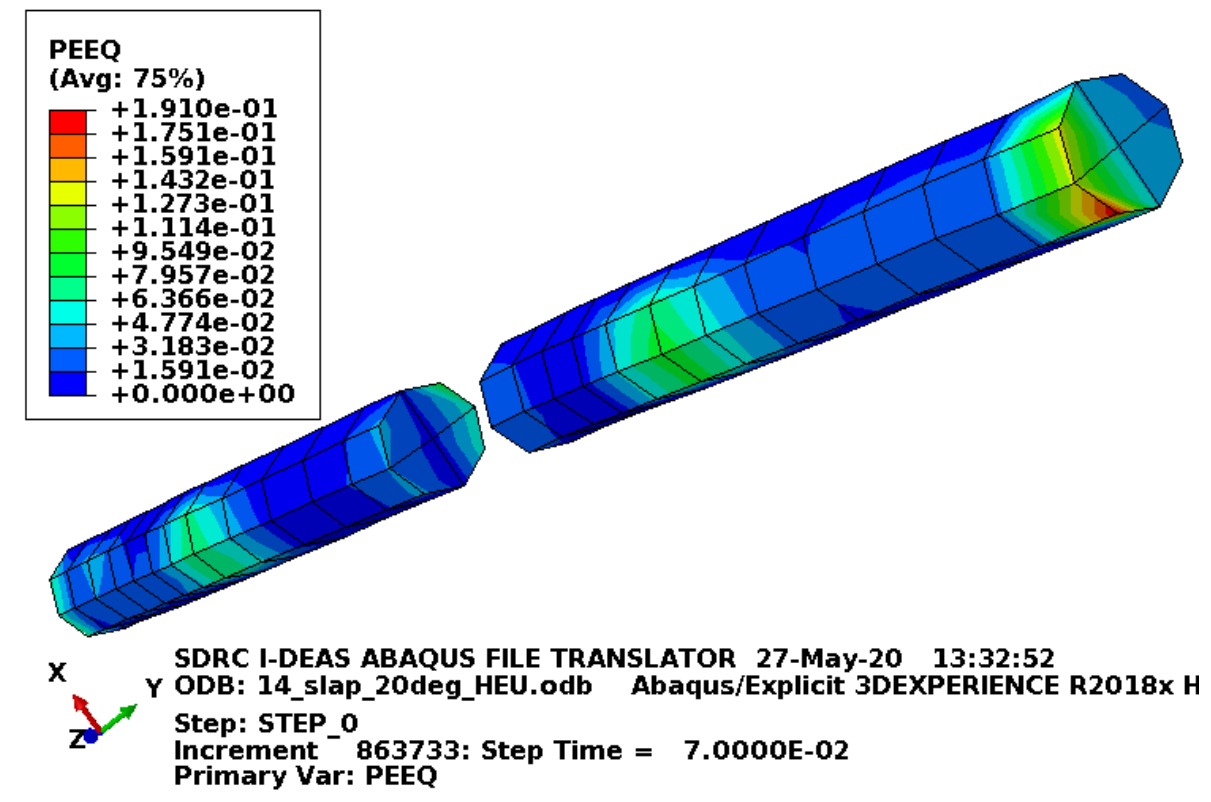

Figure C-105. Scope Part 1b (Table 3), Test 14 (Table 2) lid pins plastic-equivalent strain. 
Figure C-105 shows the equivalent plastic strain in the lid pins. Failure in these elements occurs at an equivalent plastic strain of $0.295 \mathrm{in}$./in. If element failure were to occur, the element would be deleted and removed from the model (thereby making its equivalent plastic strain not included in the maximum equivalent plastic strain for the plot). However, the missing element would be visible in the plot. Figure C-105 shows no element failure with margin.

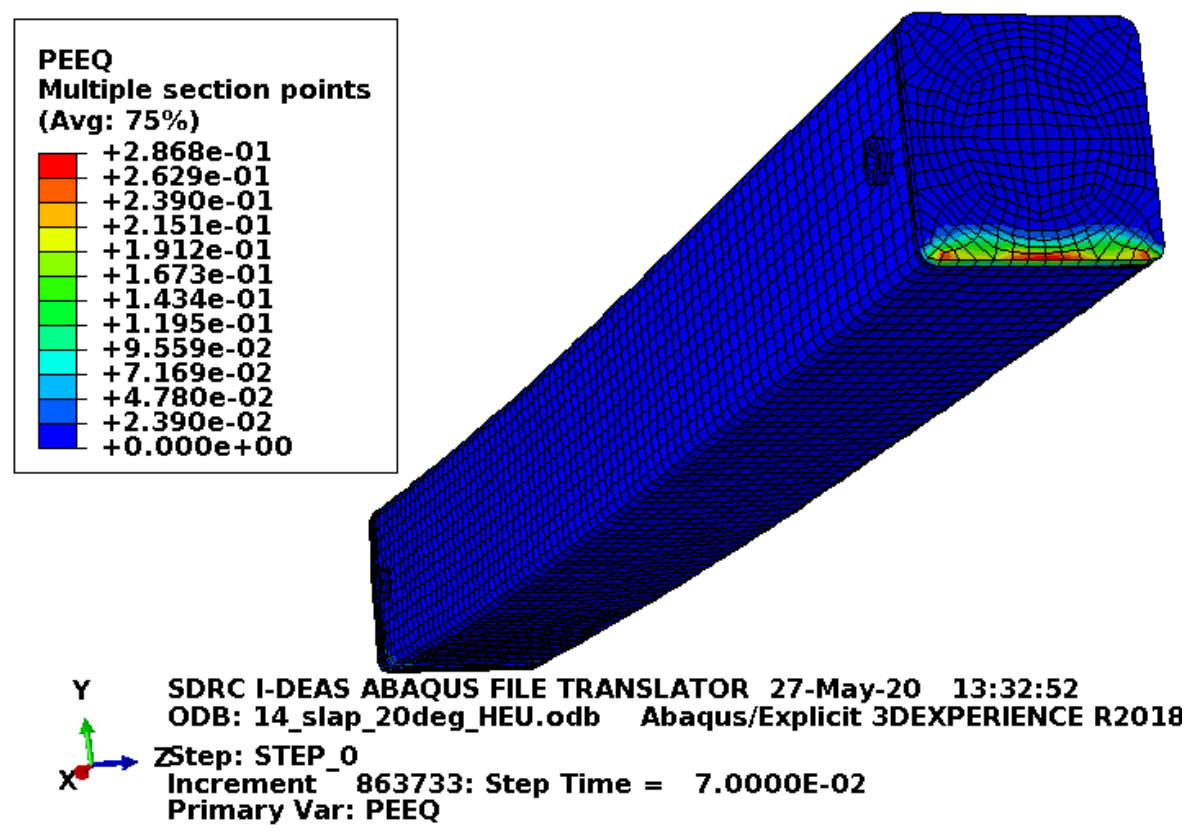

Figure C-106. Scope Part 1b (Table 3), Test 14 (Table 2) body plastic-equivalent strain.

Figure C-106 shows the equivalent plastic strain in the body. Failure in these elements occurs at an equivalent plastic strain of $0.259 \mathrm{in}$./in. If element failure were to occur, the element would be deleted and removed from the model (thereby making its equivalent plastic strain not included in the maximum equivalent plastic strain for the plot). However, the missing element would be visible in the plot.

Figure C-106 shows no element failure, but above failure strain values are shown in the base plate of the ATR FFSC. These are very local strains from the initial impact. The strains shown above the failure strain likely result from extrapolation (as integration point strains are the important strains for failure). It is still acceptable if these elements were considered as being failed. 


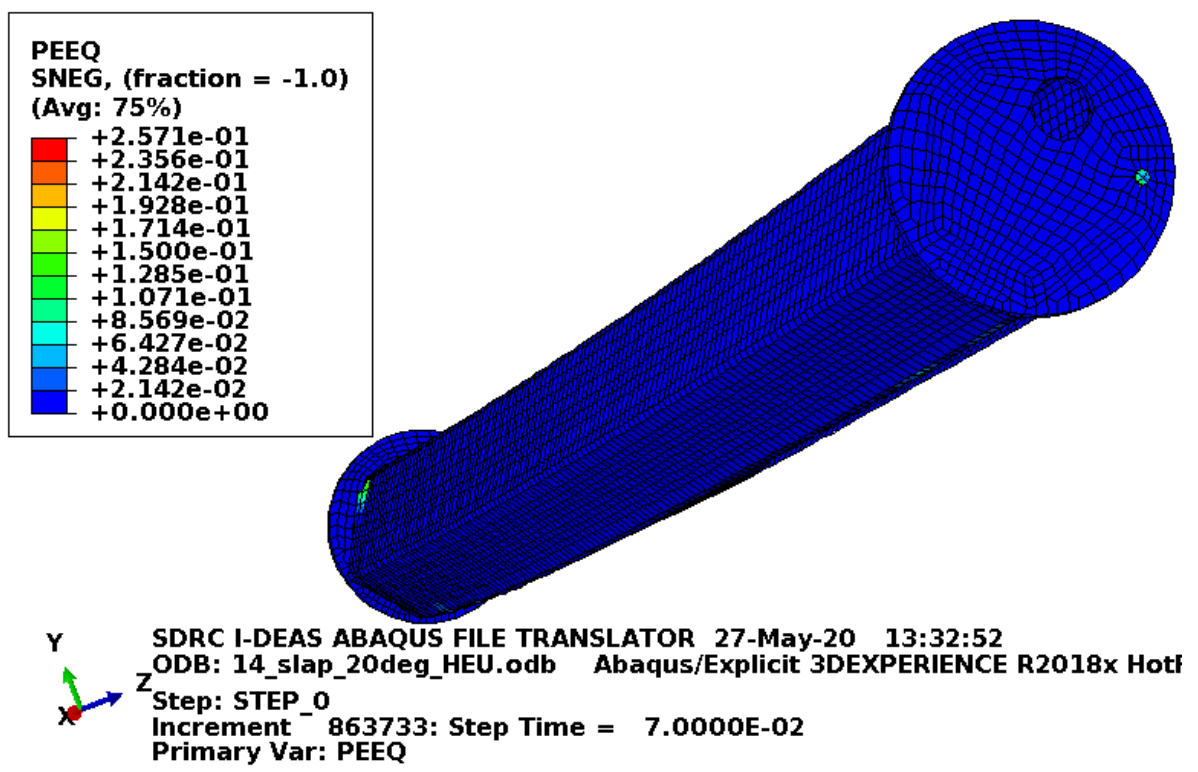

Figure C-107. Scope Part 1b (Table 3), Test 14 (Table 2) enclosure plastic-equivalent strain.

Figure $\mathrm{C}-107$ shows the equivalent plastic strain in the enclosure. This is just for information as damage to the enclosure is acceptable.

\section{C2.12 Summary of Results for Scope Part 1 (Table 3)}

The Scope Part 1a (Table 3) results demonstrate that the FEA models produce reasonable results with conservatively more damage than the equivalent physical drops. This can be expected given that the ATR FFSC is modeled with minimum material properties. Even with the conservative damage, no FEA model showed results that were not acceptable for the ATR FFSC (considering Tests 1 to 4, Table 4 in the main body of this report).

\section{C3 HIGH FUEL ELEMENT WEIGHT ATR FFSC RESULTS (SCOPE PART 3, TABLE 3)}

Section C2 showed that the ATR FFSC model produced reasonable results with conservatively more damage than the equivalent physical drops. This section shows results with the same ATR FFSC model and a fuel element weight of $115 \mathrm{lbf}$ (which is five times the fuel element weight of the physical drops rounded up to the nearest 5-lbf interval). For additional conservatism, the enclosure and fuel element are conservatively stiff and not allowed to fail. Also, a 5\% impact energy increase is added to conservatively compensate for possible error. This set of model runs is intended to easily envelope the planned fuel element weight, which may be carried by the ATR FFSC including the 44-lbf weight of the LOWE fuel element Per Quirl (2019).

Sections C3.1-C3.10 show the FEA model results for the Scope Part 3 (Table 3) drop scenarios and Section C3.11 provides a summary of the results.

NOTE: $\quad$ As discussed in Table 2 of the main body, Tests 4, 7, and 9 are not performed with a FEA model. As discussed in Table 3 of the main body, Test 1 is not performed in this section as its damage is enveloped by Test 8. 


\section{C3.1 Results for Scope Part 3 (Table 3), Test 2 (Table 2)}

The FEA model results are shown below in Figure C-108 to Figure C-115. This drop scenario is a 30-ft drop where the loaded ATR FFSC impacts flat on its side drop with the pocket-side down. The fuel element weights $115 \mathrm{lbf}$ and the drop scenario is modeled with the ATR FFSC having minimum material properties and the enclosure and fuel element having relatively tough material properties with no failure.

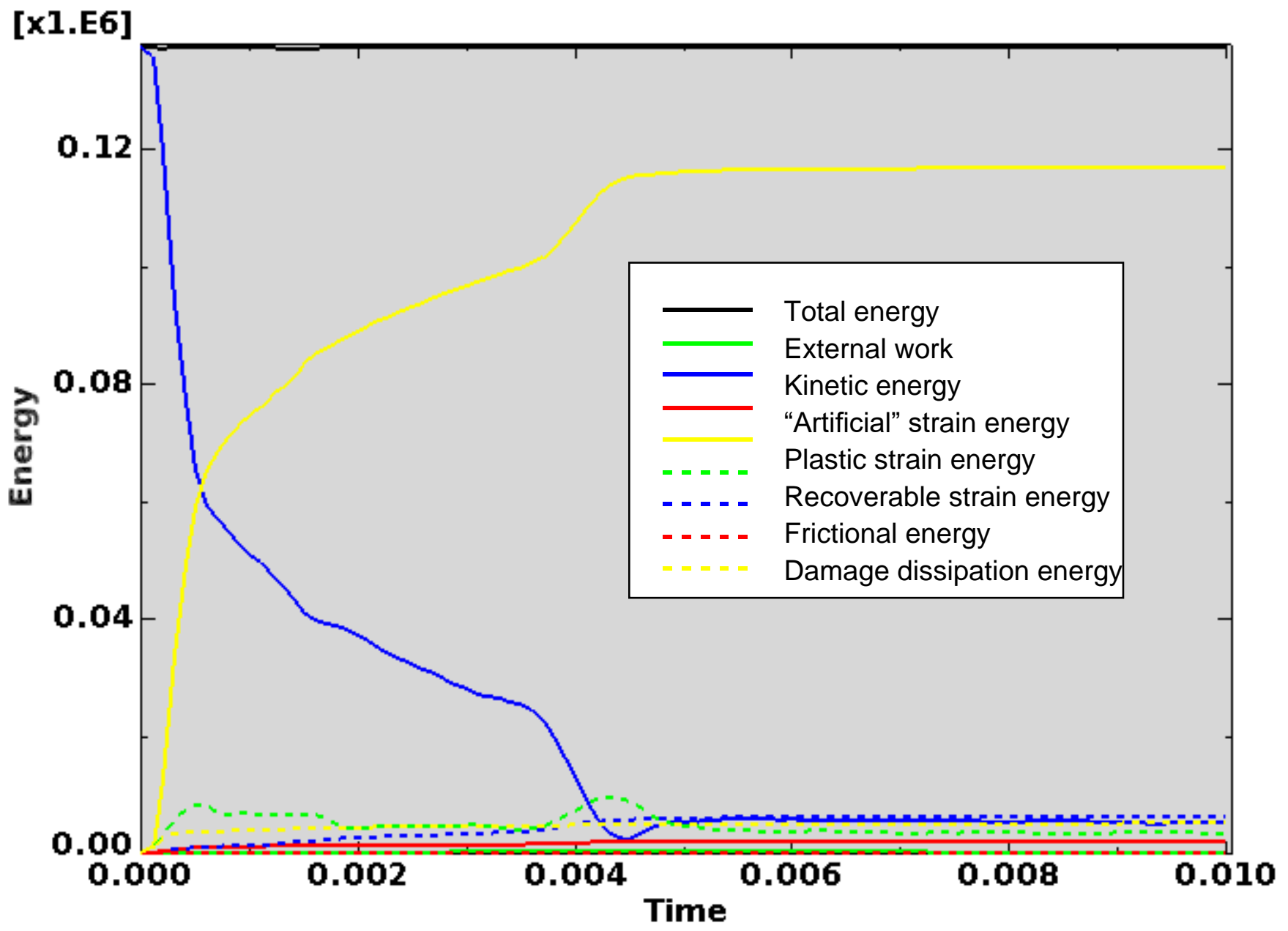

Figure C-108. Scope Part 3 (Table 3), Test 2 (Table 2) energy curves.

Figure C-108 shows the energy curves for Scope Part 3 (Table 3), Test 2 (Table 2) drop scenario. These curves exhibit a stable shape. Artificial energy represents the energy required to keep reduced integration elements from taking on a zero-energy hourglass shape. As shown in Figure C-108, the artificial energy at the end of the model run is $1.5 \%$ of the total energy. Therefore, the potential error associated with artificial energy is not considered to be significant. 


\section{ENGINEERING CALCULATIONS AND ANALYSIS}

Drop Analysis of the Advanced Test Reactor Fresh Fuel Shipping Container with Heavier Low-Enriched Uranium Fuel Contents
ECAR-5224, Rev. 0

Page $\mathrm{C} 78$ of $\mathrm{C} 190$

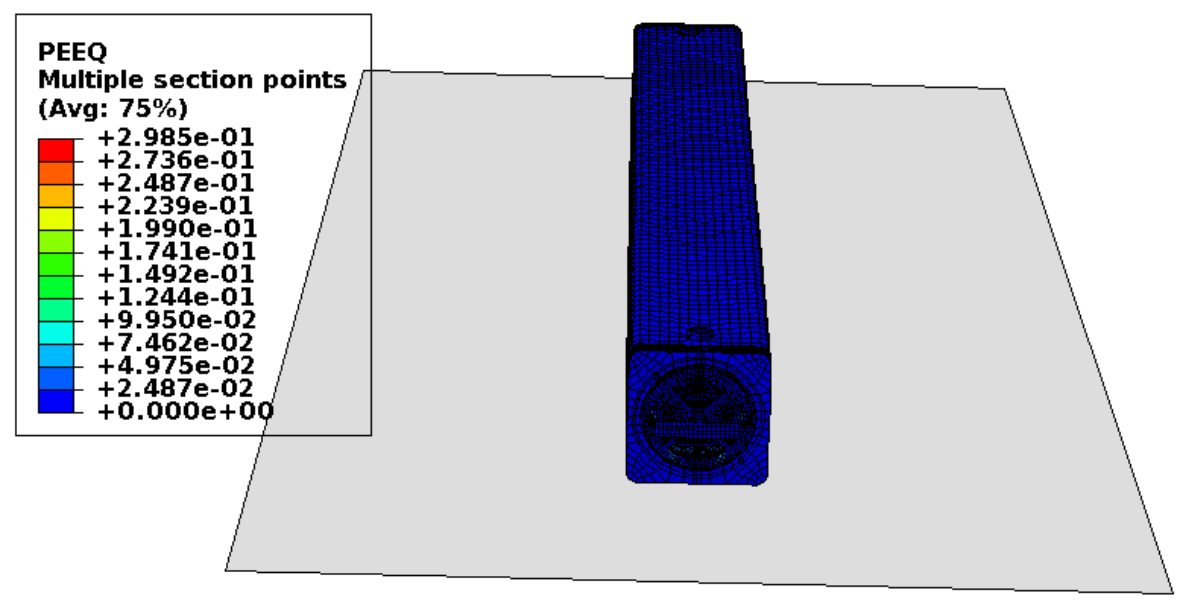

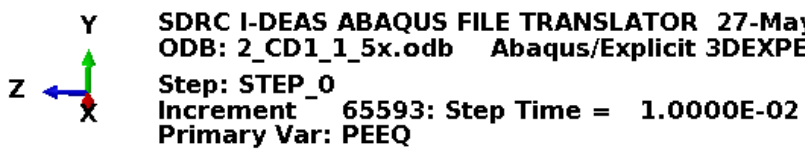

Figure C-109. Scope Part 3 (Table 3), Test 2 (Table 2) full-model plastic-equivalent strain.
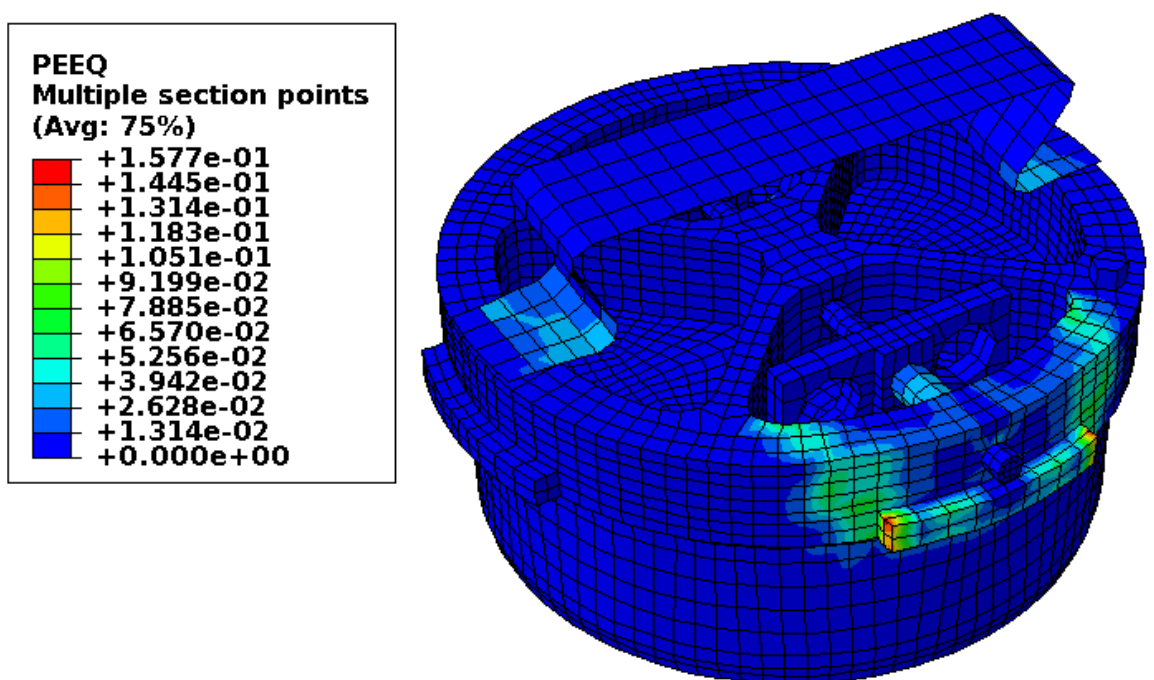

SDRC I-DEAS ABAQUS FILE TRANSLATOR 27-May-20 13:32:52

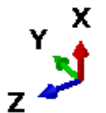

ODB: 2_CD1_1_5x.odb Abaqus/Explicit 3DEXPERIENCE R2018x HotFi

Step: STEP_0

Increment ${ }^{-65593: \text { Step Time }=1.0000 E-02}$

Primary Var: PEEQ

Figure C-110. Scope Part 3 (Table 3), Test 2 (Table 2) lid plastic-equivalent strain. 
ENGINEERING CALCULATIONS AND ANALYSIS

Drop Analysis of the Advanced Test Reactor Fresh Fuel Shipping Container with Heavier Low-Enriched Uranium Fuel Contents
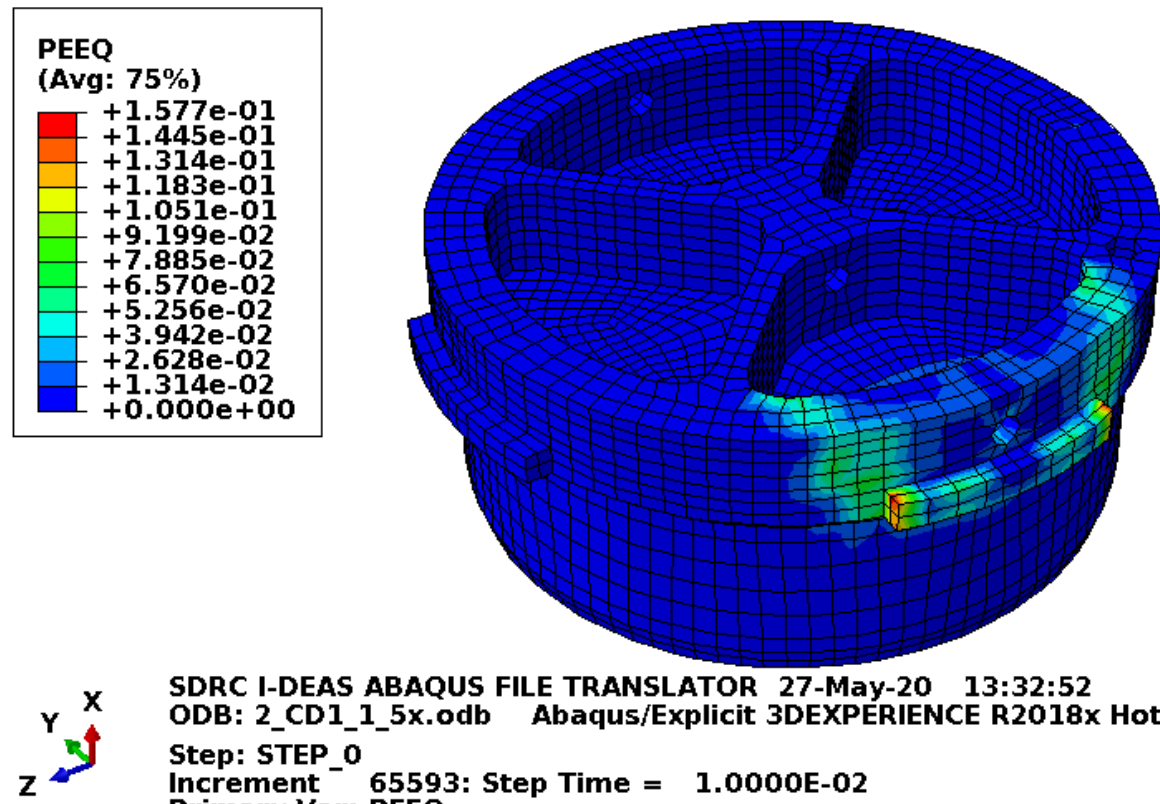

SDRC I-DEAS ABAQUS FILE TRANSLATOR 27-May-20 13:32:52

ODB: 2_CD1_1_5x.odb Abaqus/Explicit 3DEXPERIENCE R2018x HotFi

Step: STEP_o

Increment ${ }^{-}$65593: Step Time $=$1.0000E-02

Primary Var: PEEQ

Figure C-111. Scope Part 3 (Table 3), Test 2 (Table 2) lid structure plastic-equivalent strain.

Figure C-111 shows the equivalent plastic strain in the structurally significant portion of the lid. Failure in these elements occurs at an equivalent plastic strain of $0.259 \mathrm{in}$./in. If element failure were to occur, the element would be deleted and removed from the model (thereby making its equivalent plastic strain not included in the maximum equivalent plastic strain for the plot). However, the missing element would be visible in the plot. Figure C-111 shows no element failure with margin.

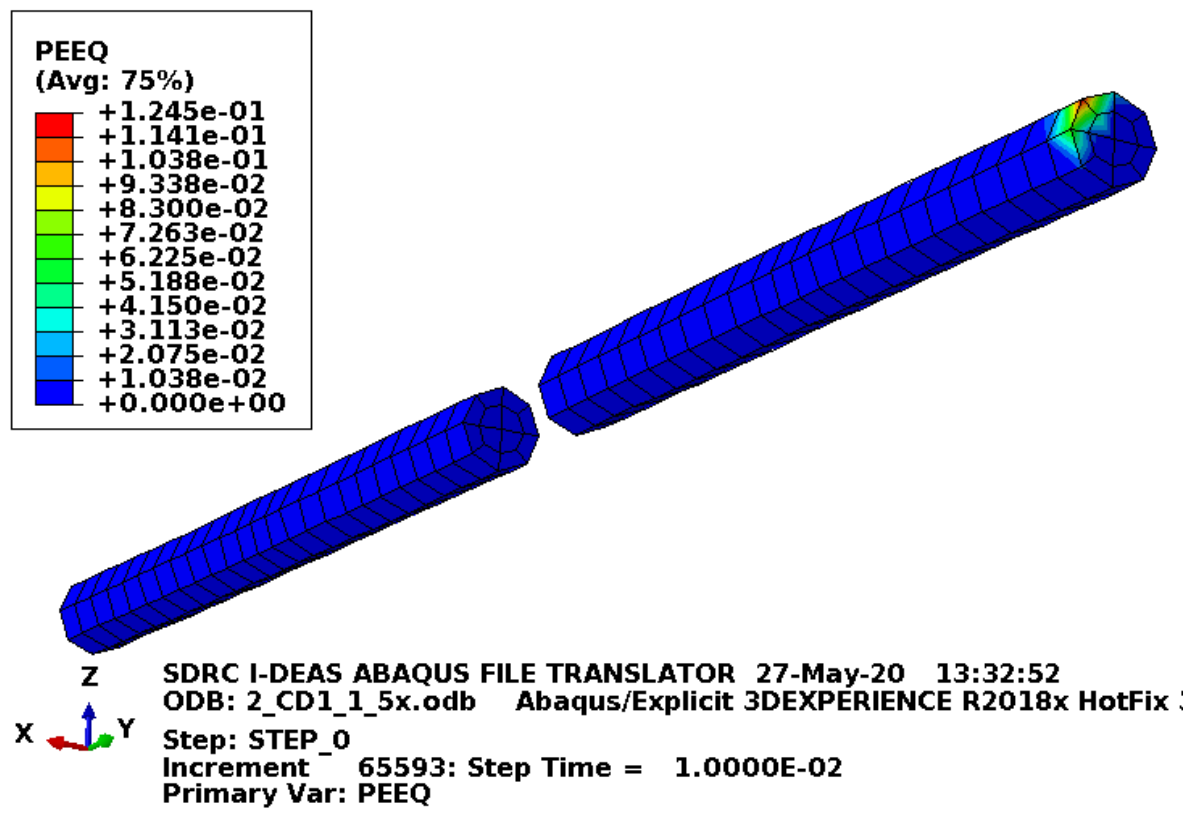

Figure C-112. Scope Part 3 (Table 3), Test 2 (Table 2) lid pins plastic-equivalent strain. 
Figure C-112 shows the equivalent plastic strain in the lid pins. Failure in these elements occurs at an equivalent plastic strain of $0.295 \mathrm{in}$./in. If element failure were to occur, the element would be deleted and removed from the model (thereby making its equivalent plastic strain not included in the maximum equivalent plastic strain for the plot). However, the missing element would be visible in the plot. Figure C-112 shows no element failure.

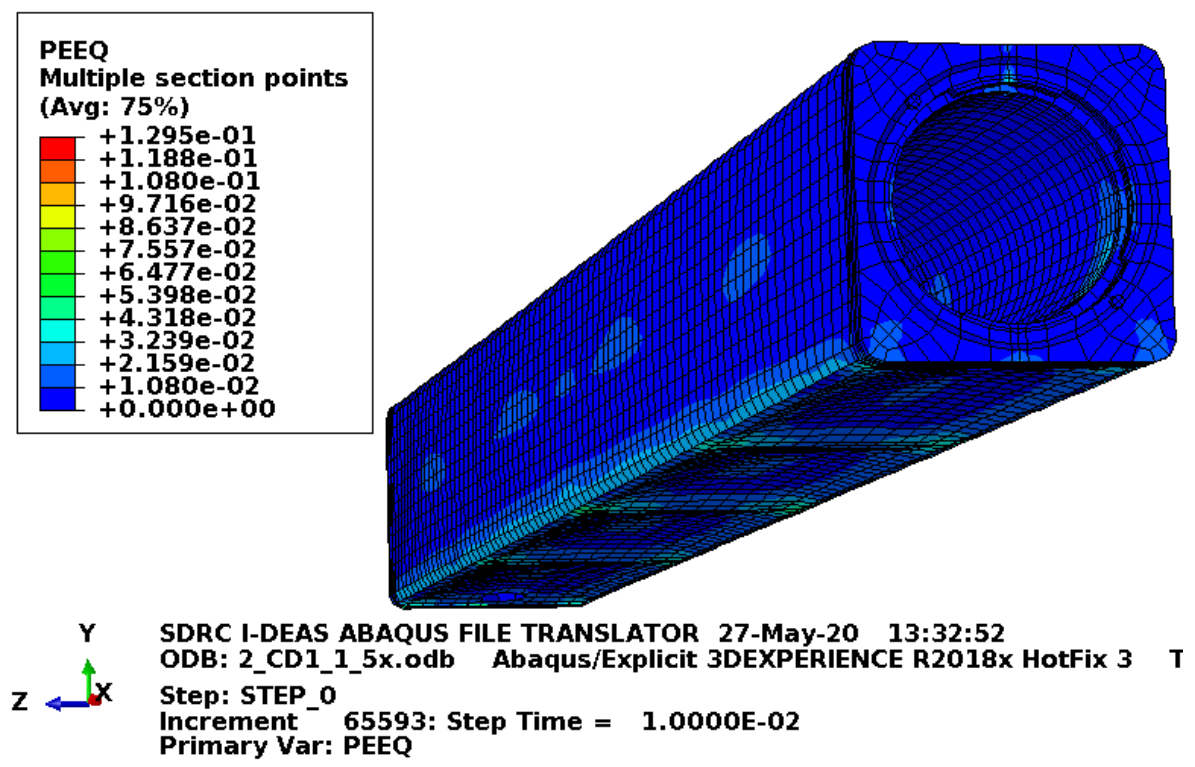

Figure C-113. Scope Part 3 (Table 3), Test 2 (Table 2) body plastic-equivalent strain.

Figure C-113 shows the equivalent plastic strain in the body. Failure in these elements occurs at an equivalent plastic strain of $0.259 \mathrm{in}$./in. If element failure were to occur, the element would be deleted and removed from the model (thereby making its equivalent plastic strain not included in the maximum equivalent plastic strain for the plot). However, the missing element would be visible in the plot. Figure C-113 shows no element failure with margin. 
ENGINEERING CALCULATIONS AND ANALYSIS

Drop Analysis of the Advanced Test Reactor Fresh Fuel Shipping Container with Heavier Low-Enriched Uranium Fuel Contents

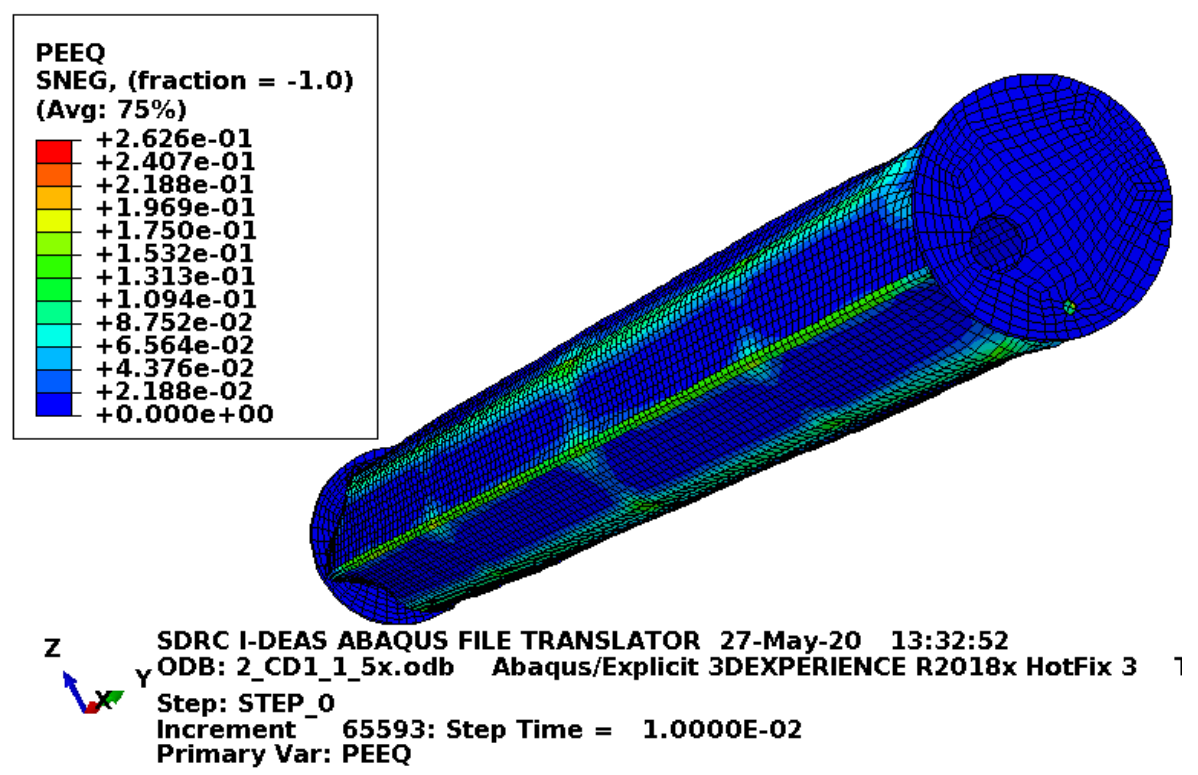

Figure C-114. Scope Part 3 (Table 3), Test 2 (Table 2) enclosure plastic-equivalent strain.

Figure $\mathrm{C}-114$ shows the equivalent plastic strain in the enclosure. This is just for information as damage to the enclosure is acceptable.

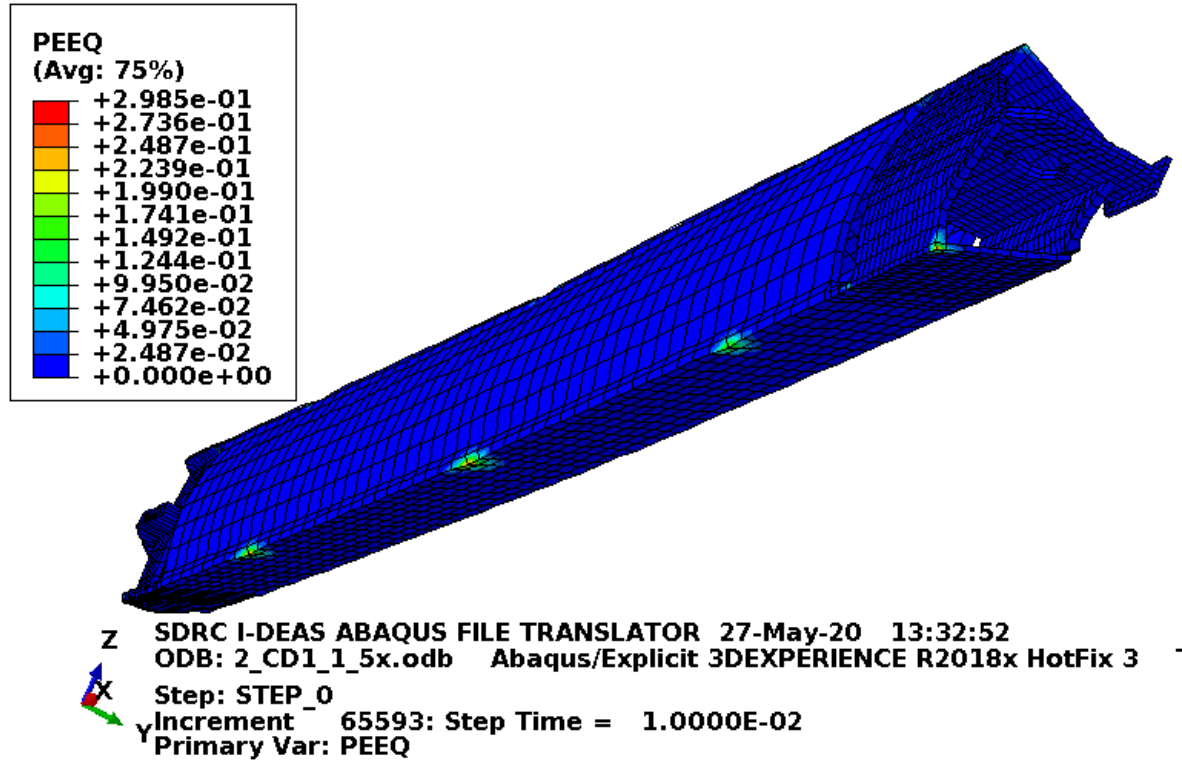

Figure C-115. Scope Part 3 (Table 3), Test 2 (Table 2) fuel element plastic-equivalent strain.

Figure $\mathrm{C}-115$ shows the equivalent plastic strain in the fuel element. For this model, the fuel element is coarse meshed, massive, and has no failure defined. Consequently, this is just shown for information and is not relevant to the acceptability of the fuel element. 


\section{C3.2 Results for Scope Part 3 (Table 3), Test 3 (Table 2)}

The FEA model results are shown below in Figure C-116 to Figure C-123. This drop scenario is a $30-\mathrm{ft}$ drop modeled as a side drop with the index lugs facing downward and the edge impacting slightly before the index lugs. The fuel element weights $115 \mathrm{lbf}$ and the drop scenario is modeled with the ATR FFSC having minimum material properties and the enclosure and fuel element having relatively tough material properties with no failure.

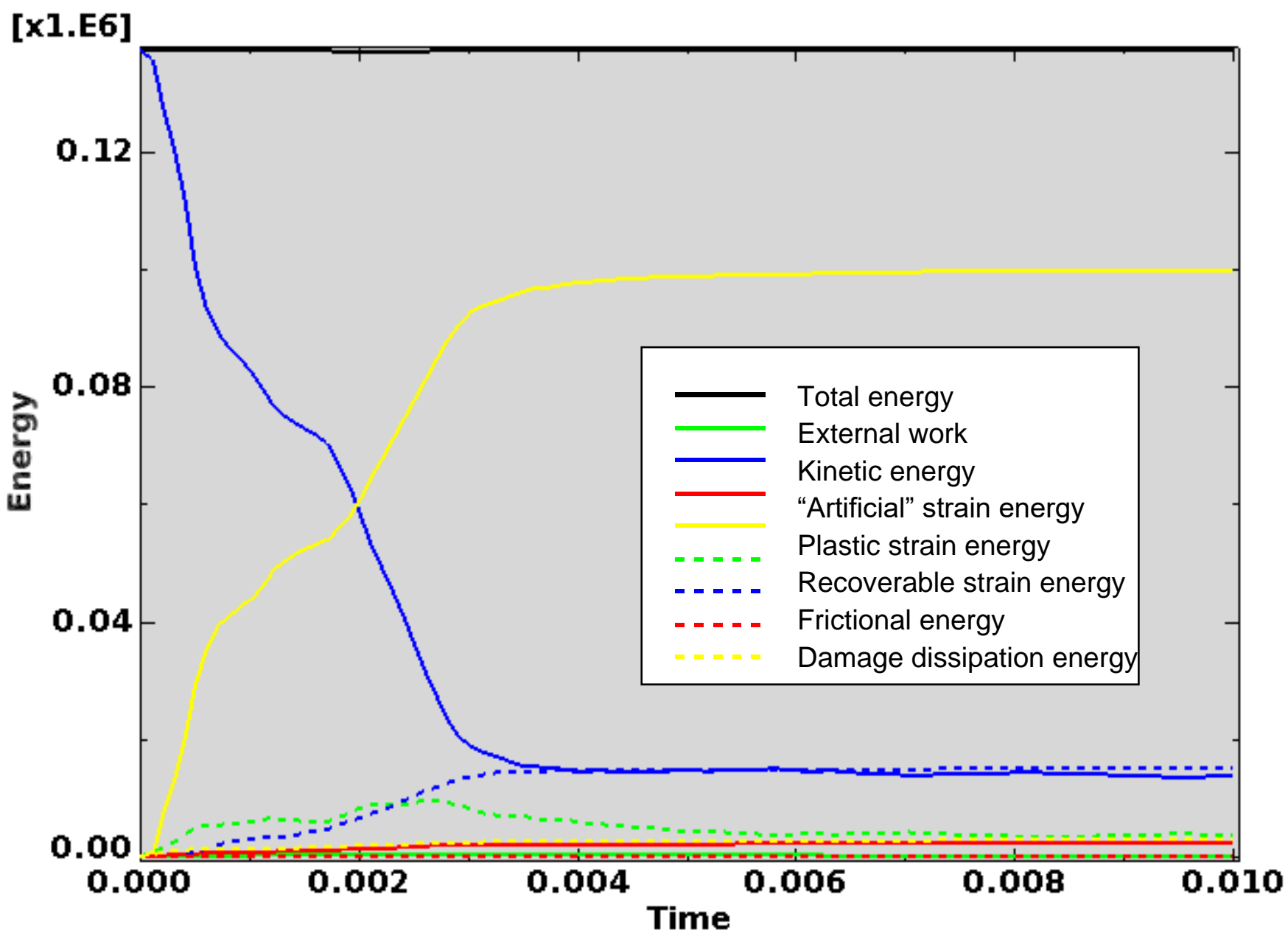

Figure C-116. Scope Part 3 (Table 3), Test 3 (Table 2) energy curves.

Figure C-116 shows the energy curves for Scope Part 3 (Table 3), Test 3 (Table 2) drop scenario. These curves exhibit a stable shape. Artificial energy represents the energy required to keep reduced integration elements from taking on a zero-energy hourglass shape. As shown in Figure C-116, the artificial energy at the end of the model run is $1.6 \%$ of the total energy. Therefore, the potential error associated with artificial energy is not considered to be significant. 
ENGINEERING CALCULATIONS AND ANALYSIS

Drop Analysis of the Advanced Test Reactor Fresh Fuel Shipping Container with Heavier Low-Enriched Uranium Fuel Contents
ECAR-5224, Rev. 0

Page C83 of C190

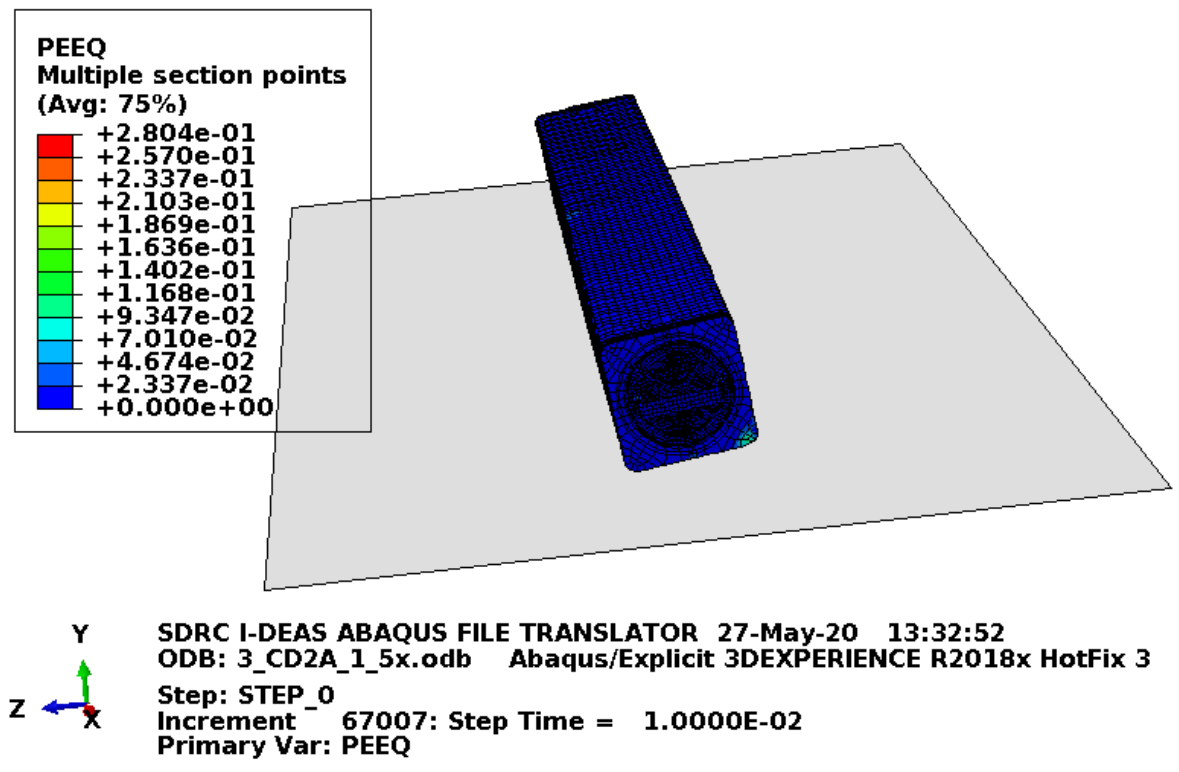

Figure C-117. Scope Part 3 (Table 3), Test 3 (Table 2) full-model plastic-equivalent strain.
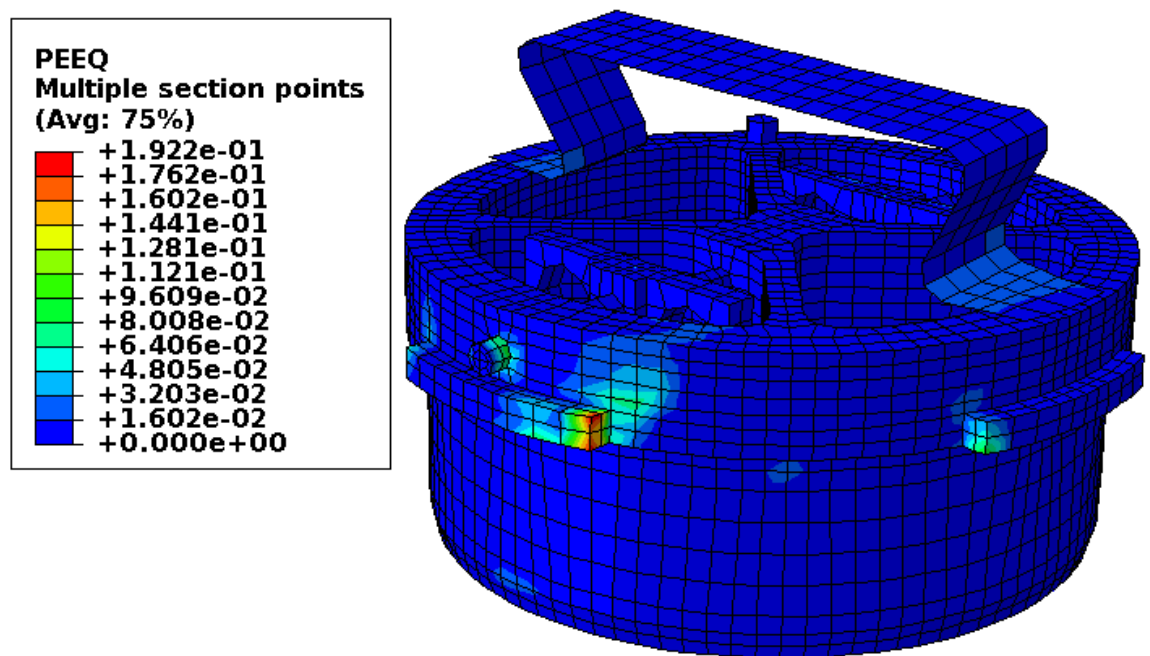

$X$ SDRC I-DEAS ABAQUS FILE TRANSLATOR 27-May-20 13:32:52 ODB: 3_CD2A_1_5x.odb Abaqus/Explicit 3DEXPERIENCE R2018x HotFi

$Z=$ Y Step: STEP_o

Increment ${ }^{-}$67007: Step Time $=1.0000 E-02$

Primary Var: PEEQ

Figure C-118. Scope Part 3 (Table 3), Test 3 (Table 2) lid plastic-equivalent strain. 
ENGINEERING CALCULATIONS AND ANALYSIS

Drop Analysis of the Advanced Test Reactor Fresh Fuel Shipping Container with Heavier Low-Enriched Uranium Fuel Contents

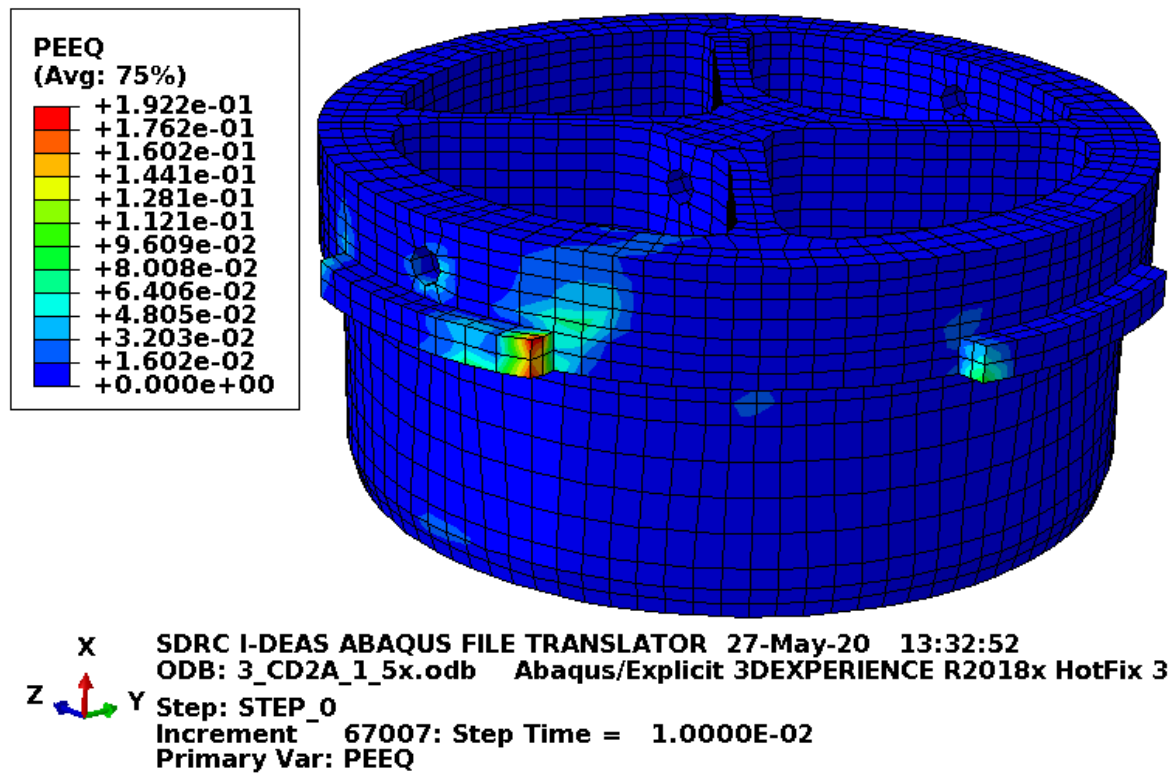

Figure C-119. Scope Part 3 (Table 3), Test 3 (Table 2) lid structure plastic-equivalent strain.

Figure C-119 shows the equivalent plastic strain in the structurally significant portion of the lid. Failure in these elements occurs at an equivalent plastic strain of $0.259 \mathrm{in}$./in. If element failure were to occur, the element would be deleted and removed from the model (thereby making its equivalent plastic strain not included in the maximum equivalent plastic strain for the plot). However, the missing element would be visible in the plot. Figure $\mathrm{C}-119$ shows no element failure.

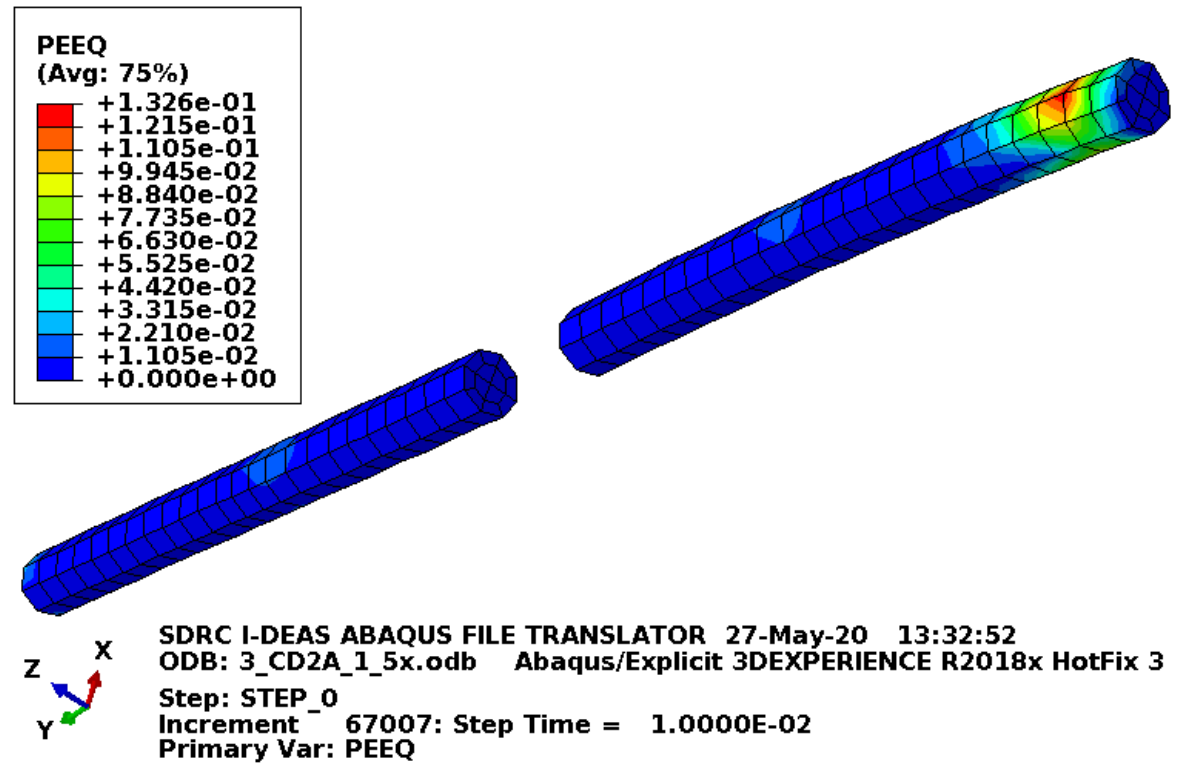

Figure C-120. Scope Part 3 (Table 3), Test 3 (Table 2) lid pins plastic-equivalent strain. 
Figure C-120 shows the equivalent plastic strain in the lid pins. Failure in these elements occurs at an equivalent plastic strain of $0.295 \mathrm{in}$./in. If element failure were to occur, the element would be deleted and removed from the model (thereby making its equivalent plastic strain not included in the maximum equivalent plastic strain for the plot). However, the missing element would be visible in the plot. Figure C-120 shows no element failure.

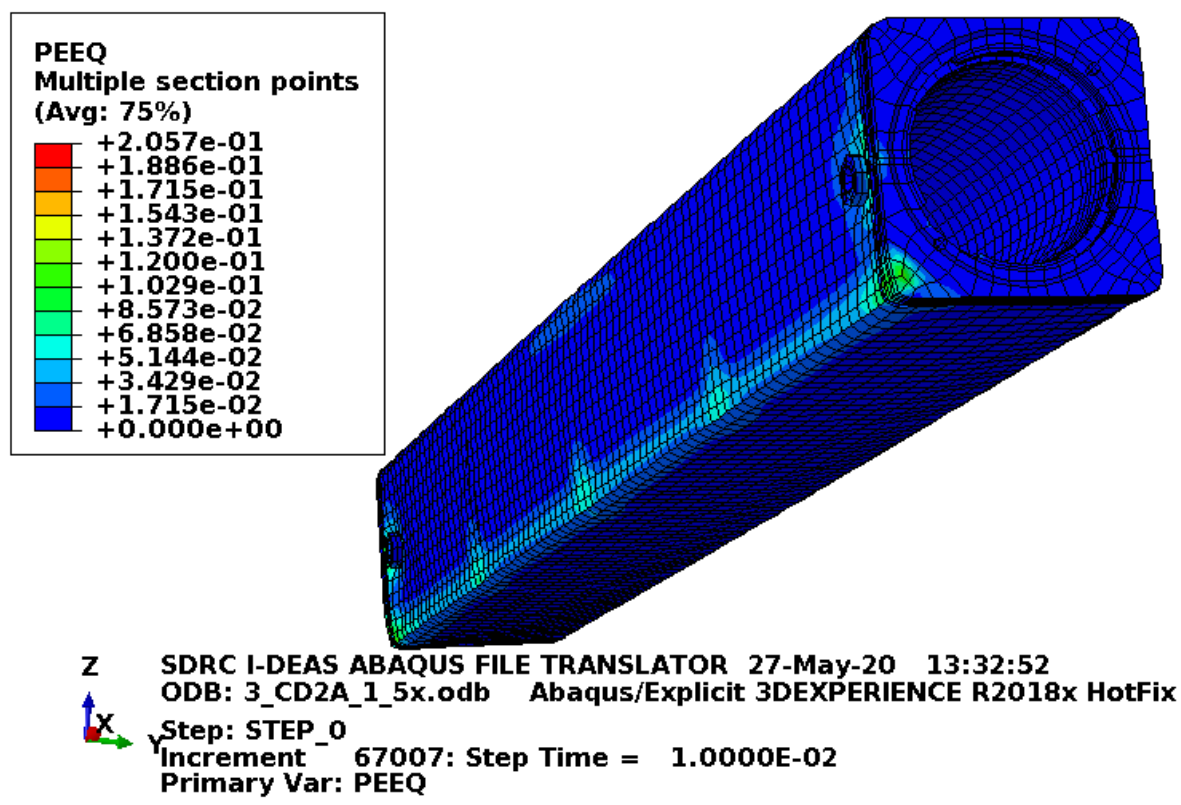

Figure C-121. Scope Part 3 (Table 3), Test 3 (Table 2) body plastic-equivalent strain.

Figure C-121 shows the equivalent plastic strain in the body. Failure in these elements occurs at an equivalent plastic strain of $0.259 \mathrm{in}$./in. If element failure were to occur, the element would be deleted and removed from the model (thereby making its equivalent plastic strain not included in the maximum equivalent plastic strain for the plot). However, the missing element would be visible in the plot. Figure C-121 shows no element failure. 
ENGINEERING CALCULATIONS AND ANALYSIS

Drop Analysis of the Advanced Test Reactor Fresh Fuel Shipping Container with Heavier Low-Enriched Uranium Fuel Contents

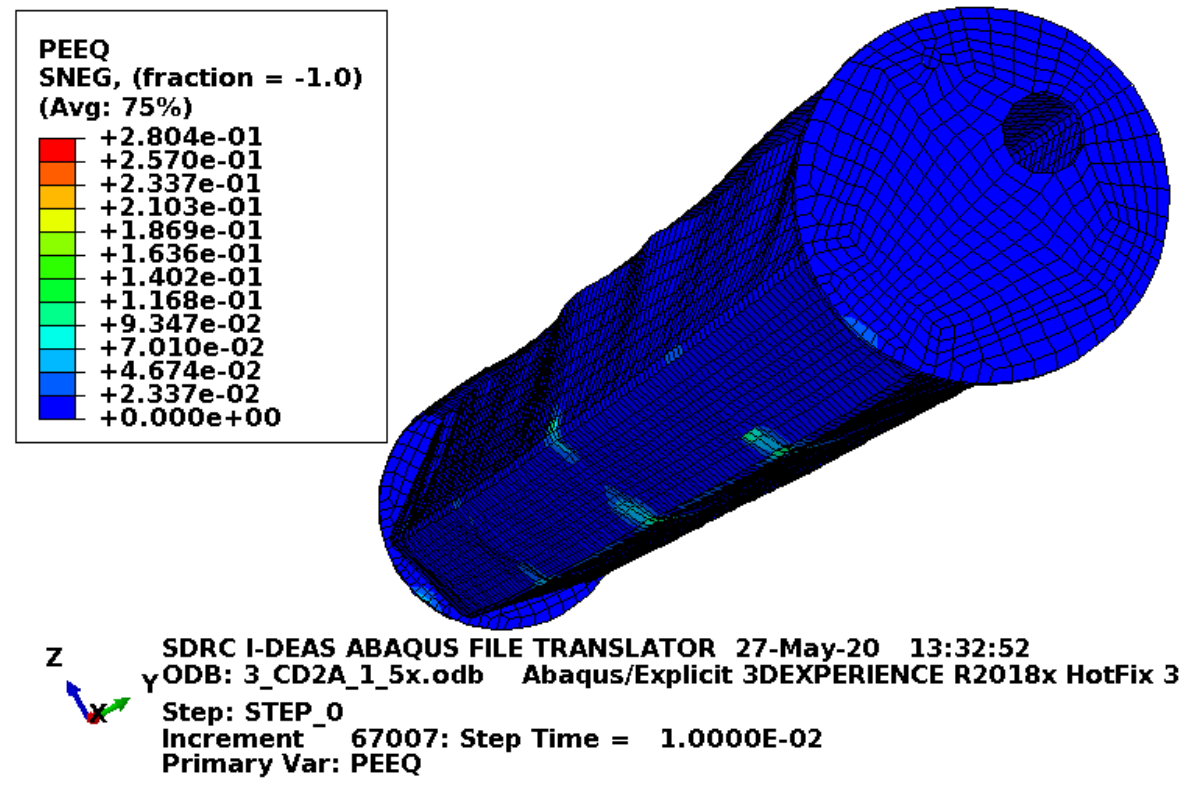

Figure C-122. Scope Part 3 (Table 3), Test 3 (Table 2) enclosure plastic-equivalent strain.

Figure $\mathrm{C}-122$ shows the equivalent plastic strain in the enclosure. This is just for information as damage to the enclosure is acceptable.

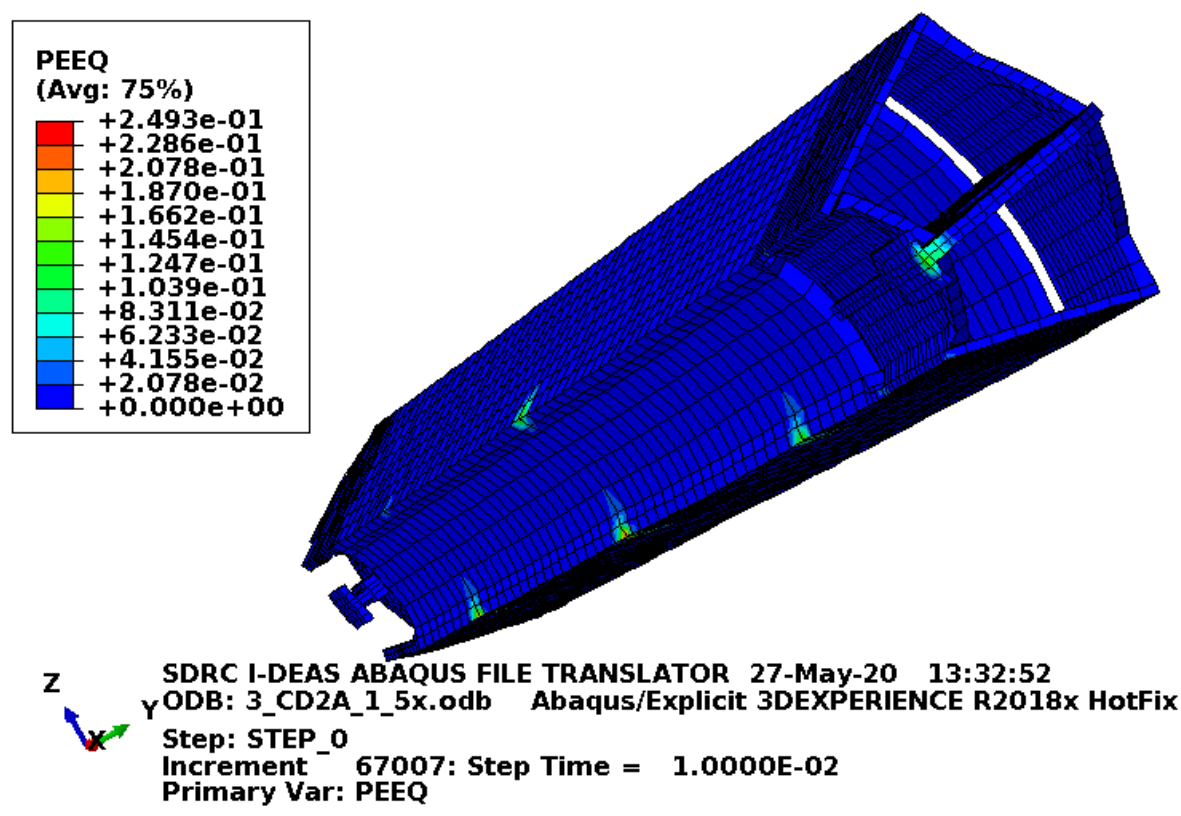

Figure C-123. Scope Part 3 (Table 3), Test 3 (Table 2) fuel element plastic-equivalent strain.

Figure C-123 shows the equivalent plastic strain in the fuel element. For this model, the fuel element is coarse meshed, massive, and has no failure defined. Consequently, this is just shown for information and is not relevant to the acceptability of the fuel element. 


\section{C3.3 Results for Scope Part 3 (Table 3), Test 5 (Table 2)}

The FEA model results are shown below in Figure C-124 to Figure C-131. This drop scenario is a 30-ft drop modeled as a flat-side drop with the pockets and index lugs on the sides. The fuel element weighs $115 \mathrm{lbf}$ and the drop scenario is modeled with the ATR FFSC having minimum material properties and the enclosure and fuel element having relatively tough material properties with no failure.

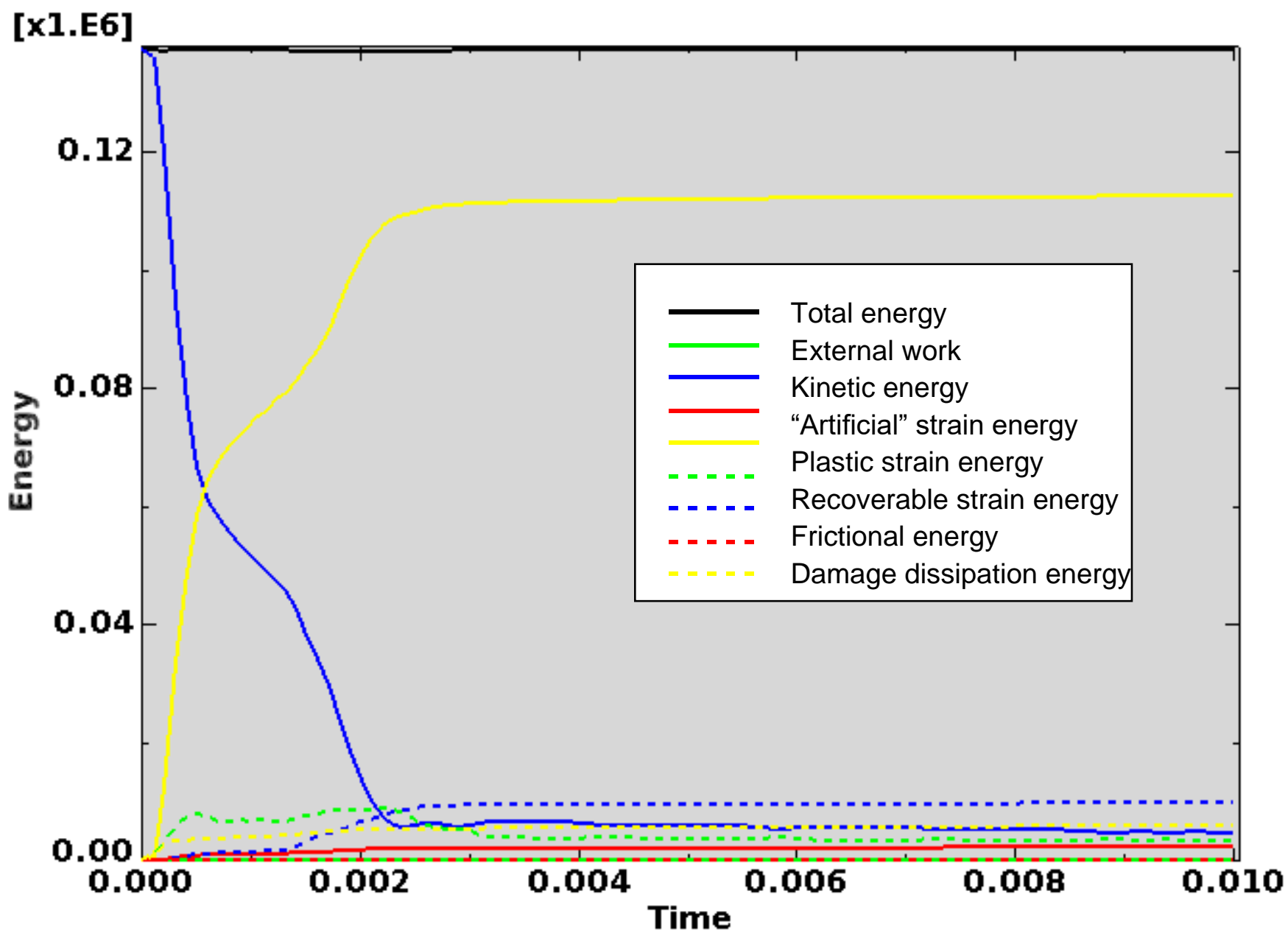

Figure C-124. Scope Part 3 (Table 3), Test 5 (Table 2) energy curves.

Figure C-124 shows the energy curves for Scope Part 3 (Table 3), Test 5 (Table 2) drop scenario. These curves exhibit a stable shape. Artificial energy represents the energy required to keep reduced integration elements from taking on a zero-energy hourglass shape. As shown in Figure C-124, the artificial energy at the end of the model run is $1.7 \%$ of the total energy. Therefore, the potential error associated with artificial energy is not considered to be significant. 
ENGINEERING CALCULATIONS AND ANALYSIS

Drop Analysis of the Advanced Test Reactor Fresh Fuel Shipping Container with Heavier Low-Enriched Uranium Fuel Contents
ECAR-5224, Rev. 0

Page C88 of C190

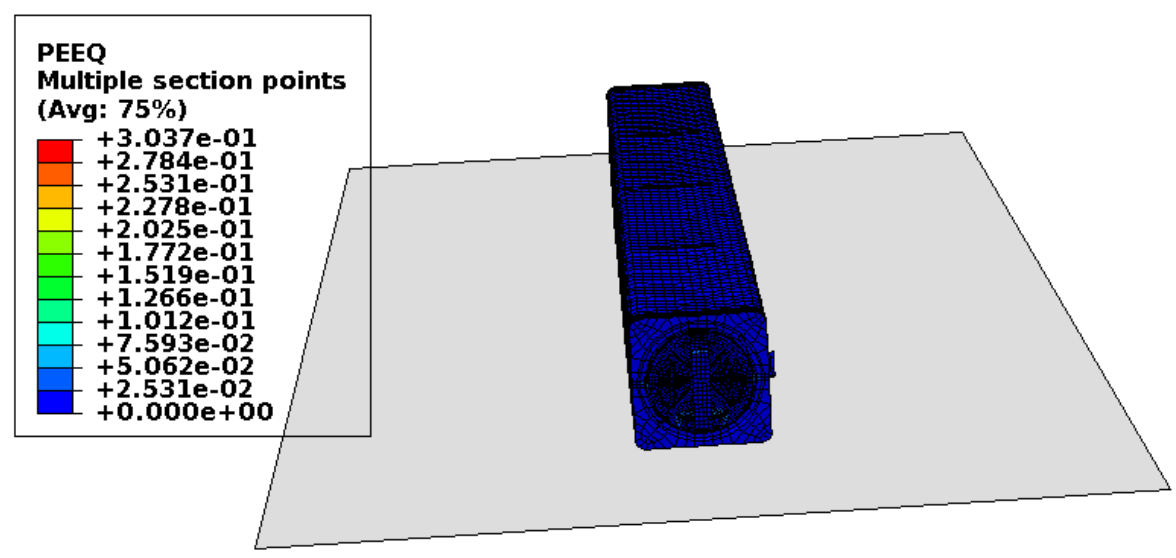

Y
$\mathrm{Z} \leftarrow \mathrm{ODRC}$ I-DEAS ABAQUS FILE TRANSLATOR 27-May
ODB: 5_CD3_1_5x.odb Abaqus/Explicit 3DEXPER
Step: STEP_o
$\begin{aligned} & \text { Increment } \\ & \text { Primary Var: PEEQ }\end{aligned}$

Figure C-125. Scope Part 3 (Table 3), Test 5 (Table 2) full-model plastic-equivalent strain.
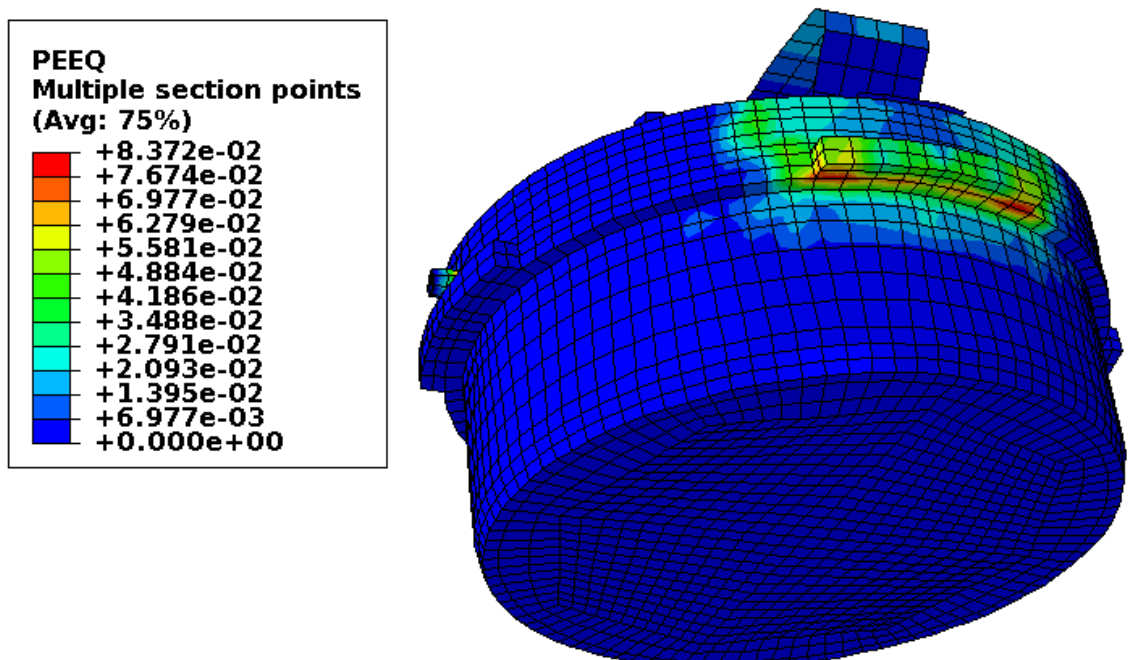

$z$

SDRC I-DEAS ABAQUS FILE TRANSLATOR 27-May-20 13:32:52

ODB: 5_CD3_1_5x.odb Abaqus/Explicit 3DEXPERIENCE R2018x HotFix

Step: STEP_0

Increment ${ }^{-}$65617: Step Time $=1.0000 \mathrm{E}-02$

Primary Var: PEEQ

Figure C-126. Scope Part 3 (Table 3), Test 5 (Table 2) lid plastic-equivalent strain. 
ENGINEERING CALCULATIONS AND ANALYSIS

Drop Analysis of the Advanced Test Reactor Fresh Fuel Shipping Container with Heavier Low-Enriched Uranium Fuel Contents
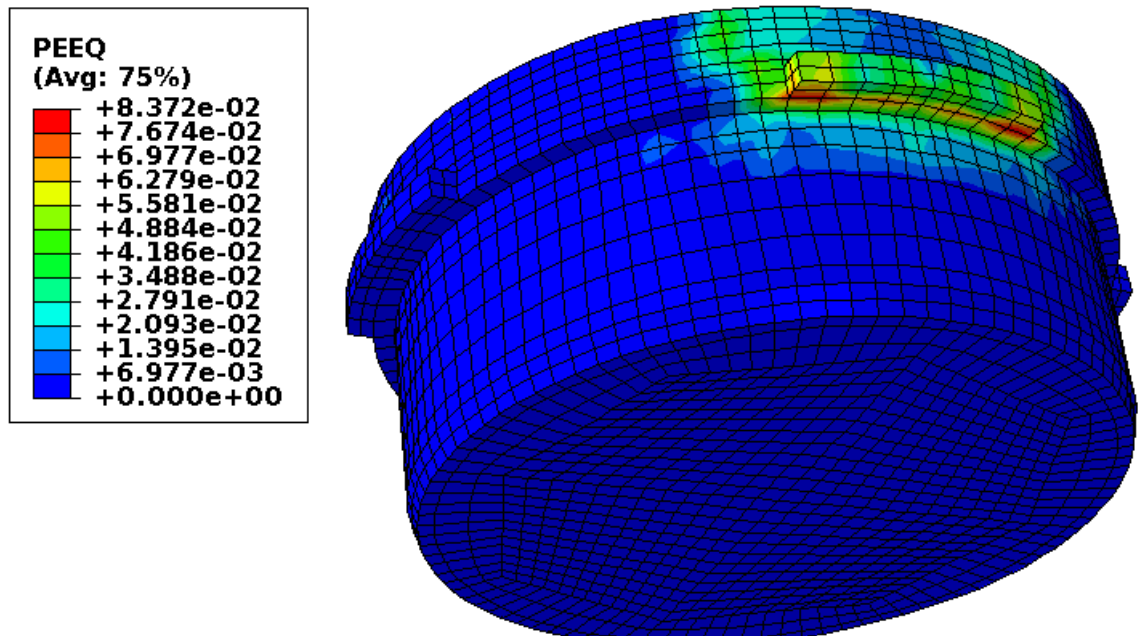

SDRC I-DEAS ABAQUS FILE TRANSLATOR 27-May-20 13:32:52

$z+\frac{1}{Y}$

ODB: 5_CD3_1_5x.odb Abaqus/Explicit 3DEXPERIENCE R2018x HotFix :

Step: STEP_o

Increment ${ }^{-65617: \text { Step Time }=1.0000 E-02}$

Primary Var: PEEQ

Figure C-127. Scope Part 3 (Table 3), Test 5 (Table 2) lid structure plastic-equivalent strain.

Figure C-127 shows the equivalent plastic strain in the structurally significant portion of the lid. Failure in these elements occurs at an equivalent plastic strain of $0.259 \mathrm{in}$./in. If element failure were to occur, the element would be deleted and removed from the model (thereby making its equivalent plastic strain not included in the maximum equivalent plastic strain for the plot). However, the missing element would be visible in the plot. Figure $\mathrm{C}-127$ shows no element failure with margin.

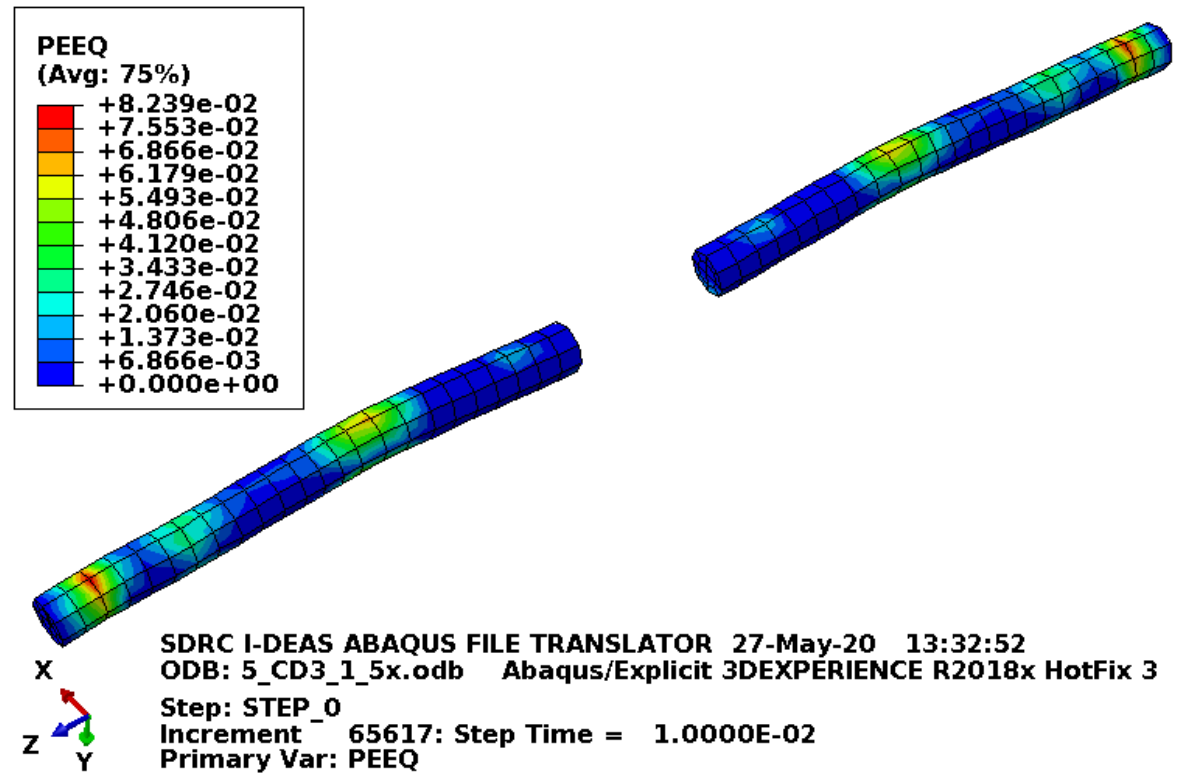

Figure C-128. Scope Part 3 (Table 3), Test 5 (Table 2) lid pins plastic-equivalent strain. 
Figure C-128 shows the equivalent plastic strain in the lid pins. Failure in these elements occurs at an equivalent plastic strain of $0.295 \mathrm{in}$./in. If element failure were to occur, the element would be deleted and removed from the model (thereby making its equivalent plastic strain not included in the maximum equivalent plastic strain for the plot). However, the missing element would be visible in the plot. Figure C-128 shows no element failure with margin.

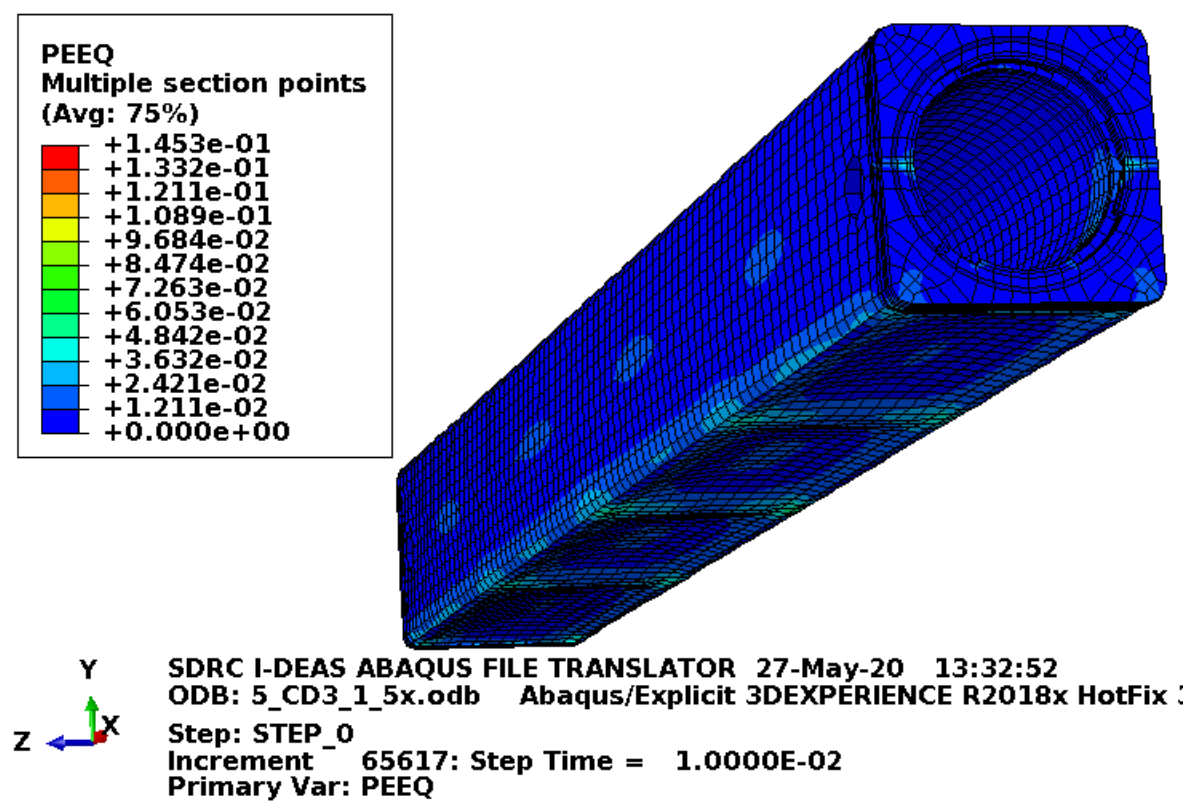

Figure C-129. Scope Part 3 (Table 3), Test 5 (Table 2) body plastic-equivalent strain.

Figure C-129 shows the equivalent plastic strain in the body. Failure in these elements occurs at an equivalent plastic strain of $0.259 \mathrm{in}$./in. If element failure were to occur, the element would be deleted and removed from the model (thereby making its equivalent plastic strain not included in the maximum equivalent plastic strain for the plot). However, the missing element would be visible in the plot. Figure C-129 shows no element failure. 
Drop Analysis of the Advanced Test Reactor Fresh Fuel Shipping Container with Heavier Low-Enriched Uranium Fuel Contents

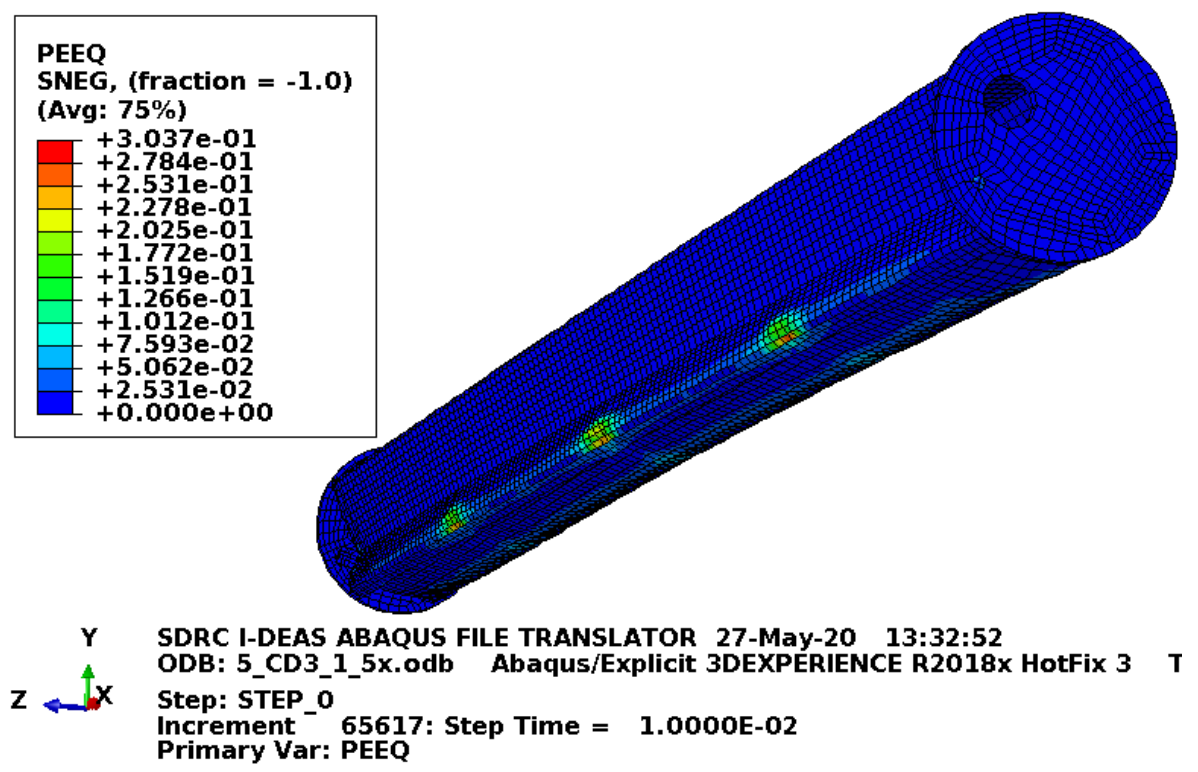

Figure C-130. Scope Part 3 (Table 3), Test 5 (Table 2) enclosure plastic-equivalent strain.

Figure $\mathrm{C}-130$ shows the equivalent plastic strain in the enclosure. This is just for information as damage to the enclosure is acceptable.

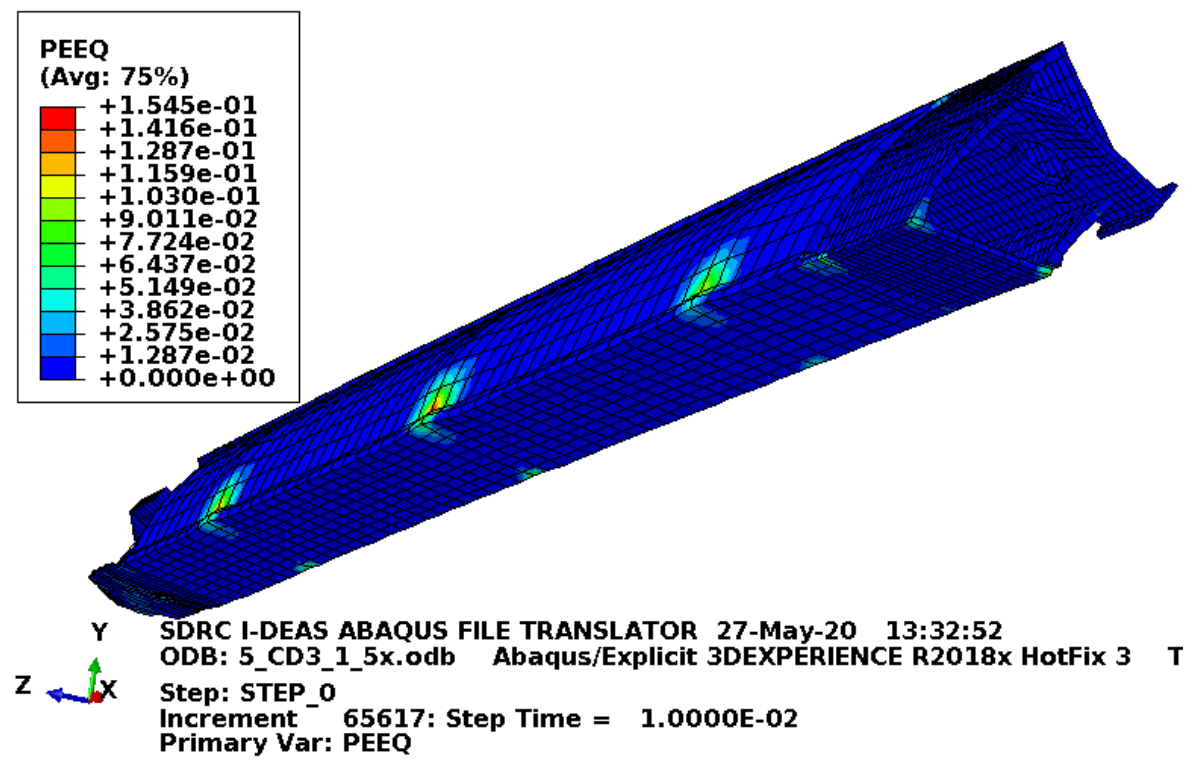

Figure C-131. Scope Part 3 (Table 3), Test 5 (Table 2) fuel element plastic-equivalent strain.

Figure C-131 shows the equivalent plastic strain in the fuel element. For this model, the fuel element is coarse meshed, massive, and has no failure defined. Consequently, this is just shown for information and is not relevant to the acceptability of the fuel element. 


\section{C3.4 Results for Scope Part 3 (Table 3), Test 6 (Table 2)}

The FEA model results are shown below in Figure C-132 to Figure C-140. This drop scenario is a 30-ft drop modeled as a vertical bottom impact. The fuel element weighs $115 \mathrm{lbf}$ and the drop scenario is modeled with the ATR FFSC having minimum material properties and the enclosure and fuel element having relatively tough material properties with no failure.

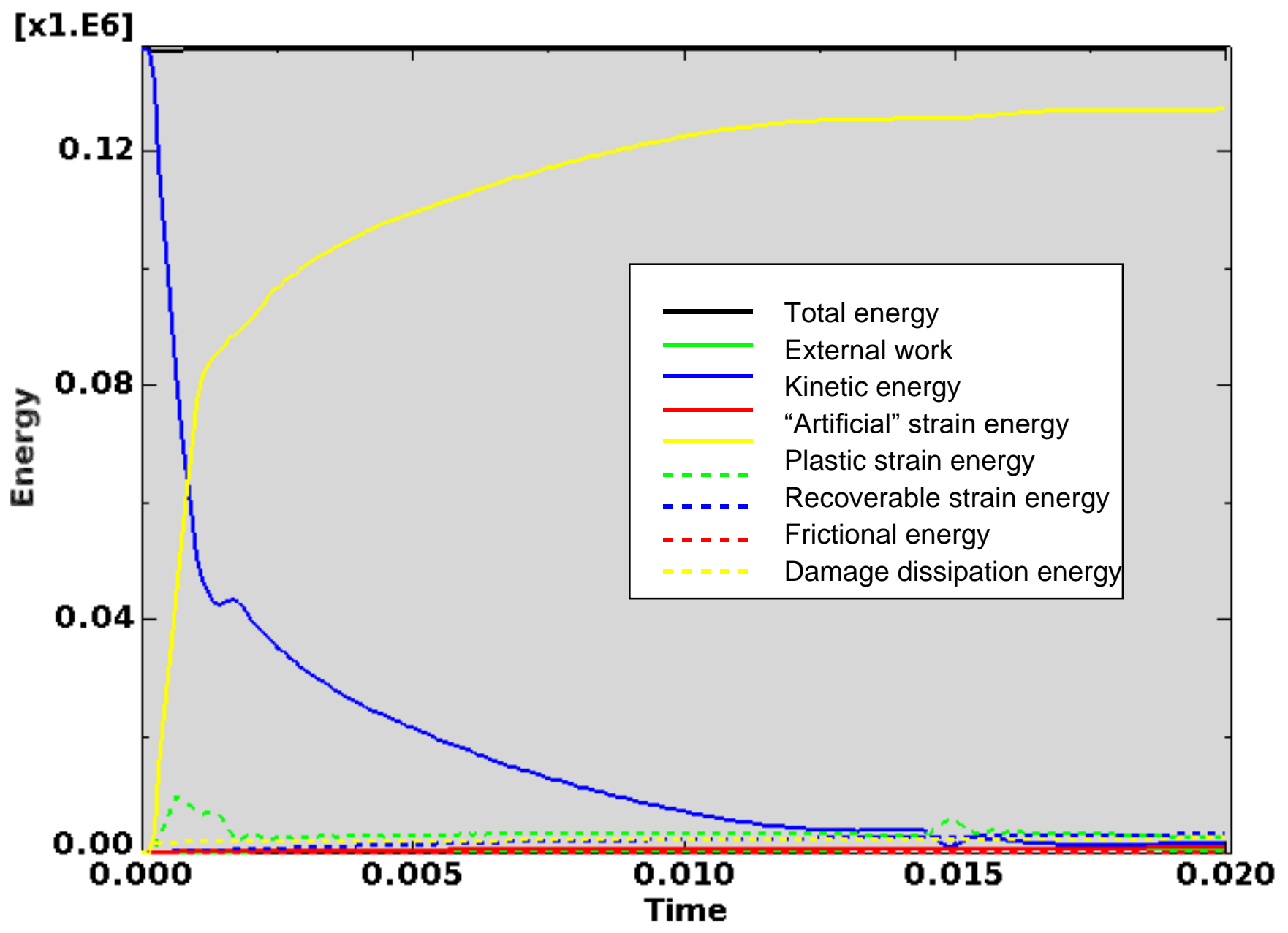

Figure C-132. Scope Part 3 (Table 3), Test 6 (Table 2) energy curves.

Figure C-132 shows the energy curves for Scope Part 3 (Table 3), Test 6 (Table 2) drop scenario. These curves exhibit a stable shape. Artificial energy represents the energy required to keep reduced integration elements from taking on a zero-energy hourglass shape. As shown in Figure C-132, the artificial energy at the end of the model run is $0.6 \%$ of the total energy. Therefore, the potential error associated with artificial energy is not considered to be significant. 


\section{ENGINEERING CALCULATIONS AND ANALYSIS}

Drop Analysis of the Advanced Test Reactor Fresh Fuel Shipping Container with Heavier Low-Enriched Uranium Fuel Contents
ECAR-5224, Rev. 0

Page C93 of C190

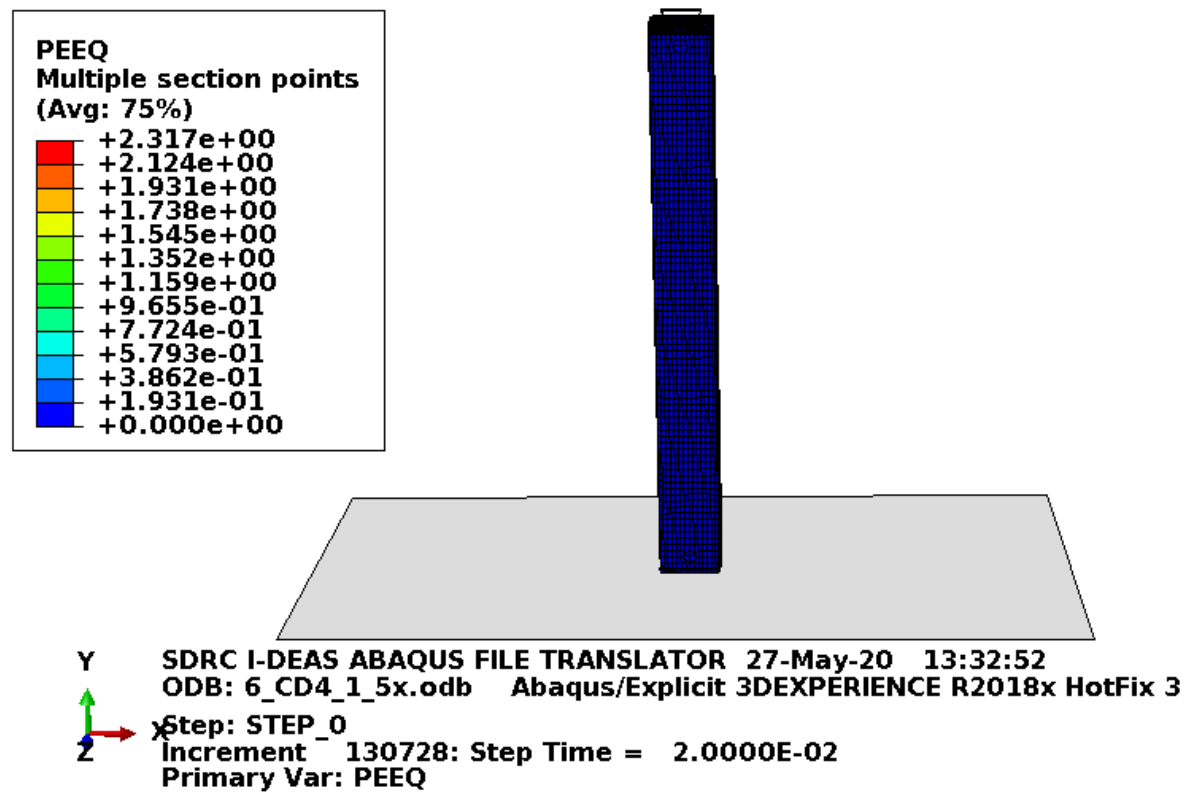

Figure C-133. Scope Part 3 (Table 3), Test 6 (Table 2) full-model plastic-equivalent strain.
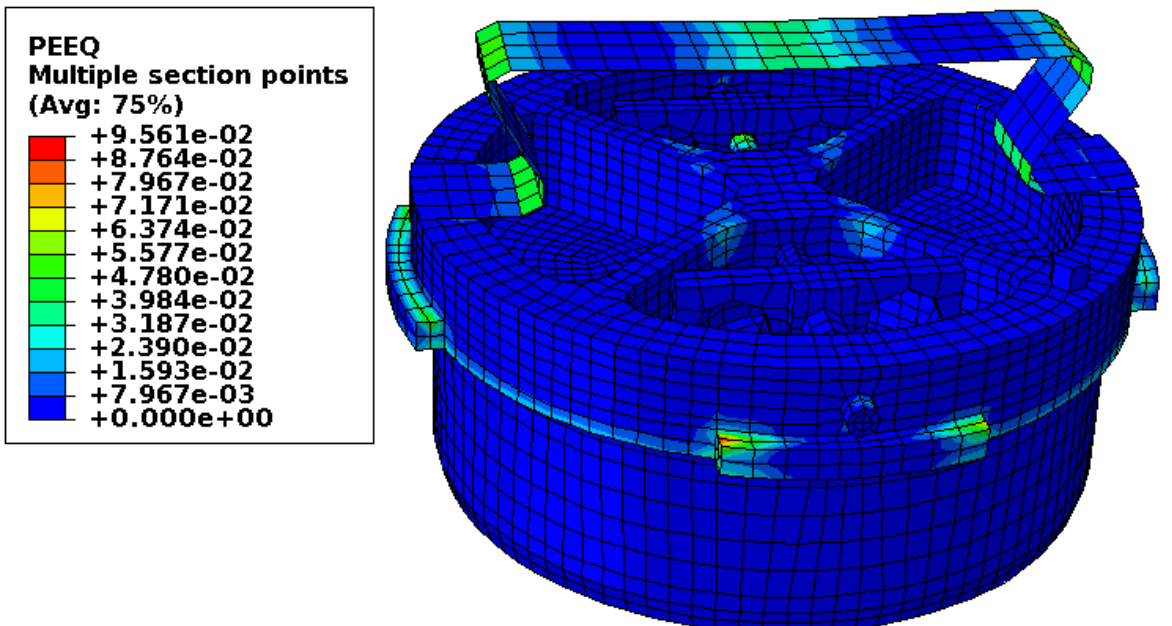

Y SDRC I-DEAS ABAQUS FILE TRANSLATOR 27-May-20 13:32:52

ODB: 6_CD4_1_5x.odb Abaqus/Explicit 3DEXPERIENCE R2018x HotFix 3

$\rightarrow$ Xtep: STEP_o

Z Increment 130728: Step Time = 2.0000E-02

Primary Var: PEEQ

Figure C-134. Scope Part 3 (Table 3), Test 6 (Table 2) lid plastic-equivalent strain. 
ENGINEERING CALCULATIONS AND ANALYSIS

Drop Analysis of the Advanced Test Reactor Fresh Fuel Shipping Container with Heavier Low-Enriched Uranium Fuel Contents
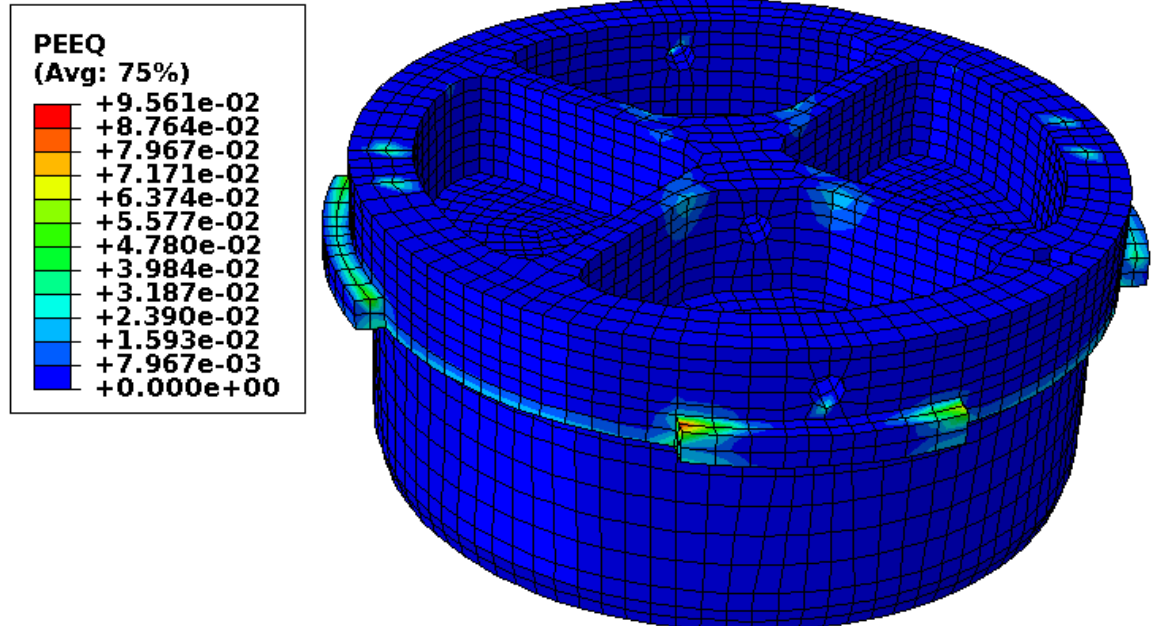

Y SDRC I-DEAS ABAQUS FILE TRANSLATOR 27-May-20 13:32:52

ODB: 6_CD4_1_5x.odb Abaqus/Explicit 3DEXPERIENCE R2018x HotFix 3

ODB: 6_CD4_1_5x.odb Abaqus/Explic
Xtep: STEP_o
Increment ${ }_{\text {130728: }}$ Step Time $=2.0000 E-02$

Figure C-135. Scope Part 3 (Table 3), Test 6 (Table 2) lid structure plastic-equivalent strain.

Figure C-135 shows the equivalent plastic strain in the structurally significant portion of the lid. Failure in these elements occurs at an equivalent plastic strain of $0.259 \mathrm{in}$./in. If element failure were to occur, the element would be deleted and removed from the model (thereby making its equivalent plastic strain not included in the maximum equivalent plastic strain for the plot). However, the missing element would be visible in the plot. Figure $\mathrm{C}-135$ shows no element failure with margin.

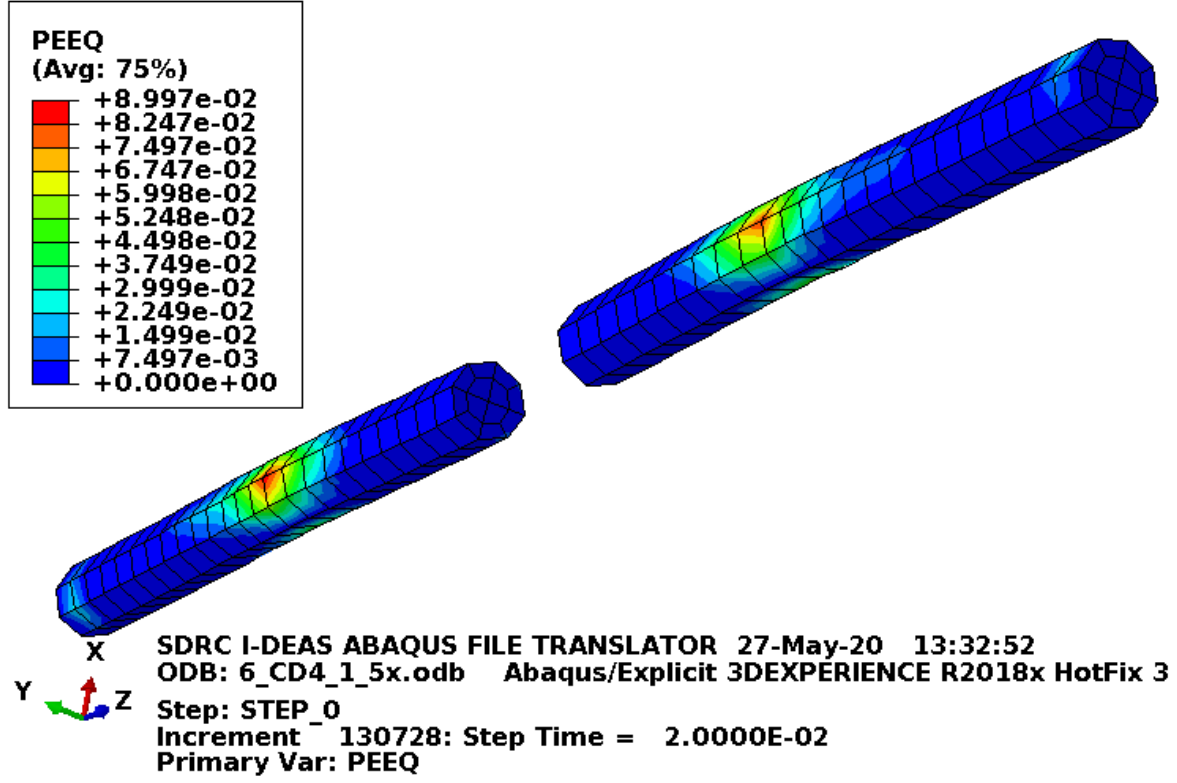

Figure C-136. Scope Part 3 (Table 3), Test 6 (Table 2) lid pins plastic-equivalent strain. 
Figure C-136 shows the equivalent plastic strain in the lid pins. Failure in these elements occurs at an equivalent plastic strain of $0.295 \mathrm{in}$./in. If element failure were to occur, the element would be deleted and removed from the model (thereby making its equivalent plastic strain not included in the maximum equivalent plastic strain for the plot). However, the missing element would be visible in the plot. Figure C-136 shows no element failure with margin.

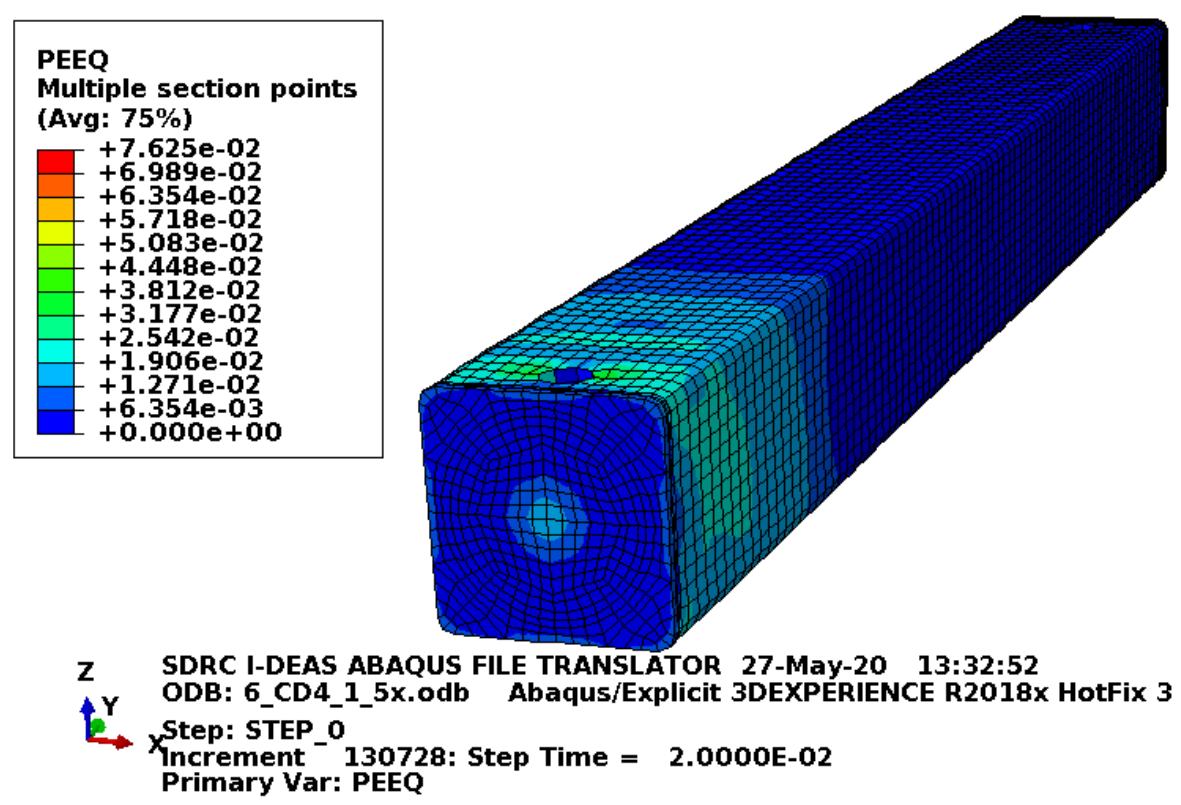

Figure C-137. Scope Part 3 (Table 3), Test 6 (Table 2) body plastic-equivalent strain.

Figure C-137 shows the equivalent plastic strain in the body. Failure in these elements occurs at an equivalent plastic strain of $0.259 \mathrm{in}$./in. If element failure were to occur, the element would be deleted and removed from the model (thereby making its equivalent plastic strain not included in the maximum equivalent plastic strain for the plot). However, the missing element would be visible in the plot. Figure C-137 shows no element failure. 
ENGINEERING CALCULATIONS AND ANALYSIS

Drop Analysis of the Advanced Test Reactor Fresh Fuel Shipping Container with Heavier Low-Enriched Uranium Fuel Contents
ECAR-5224, Rev. 0 Page C96 of C190
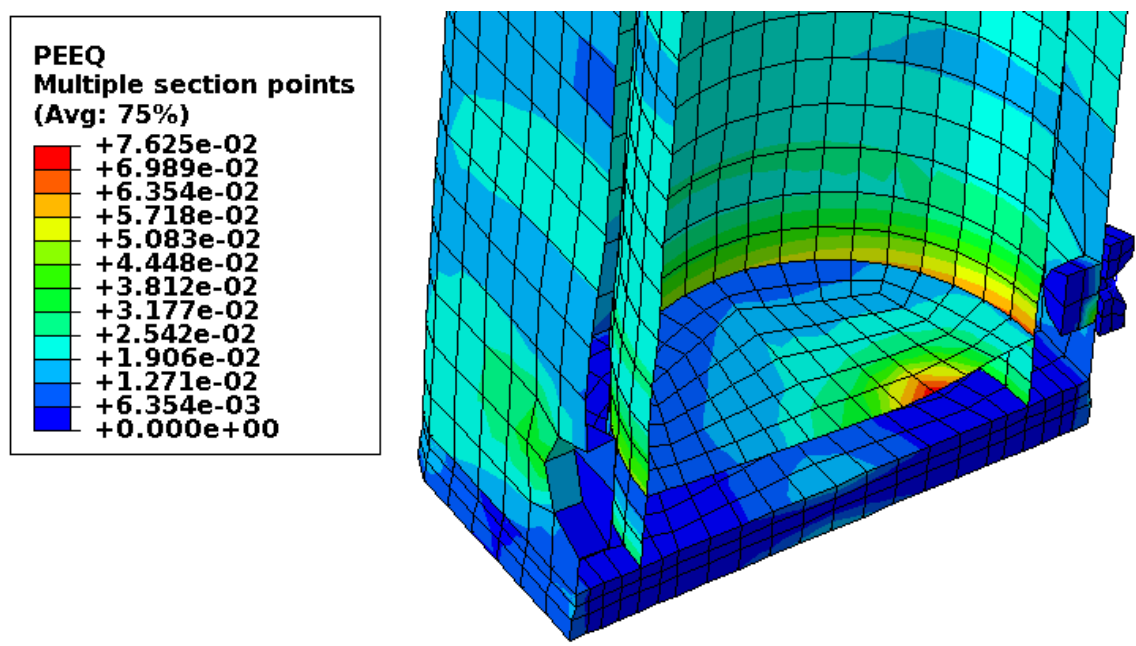

SDRC I-DEAS ABAQUS FILE TRANSLATOR 27-May-20 13:32:52

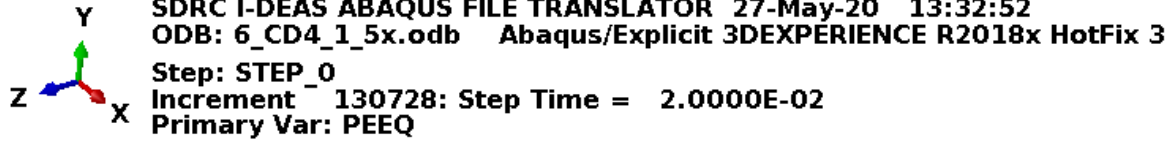

Figure C-138. Scope Part 3 (Table 3), Test 6 (Table 2) cut-away body plastic-equivalent strain.

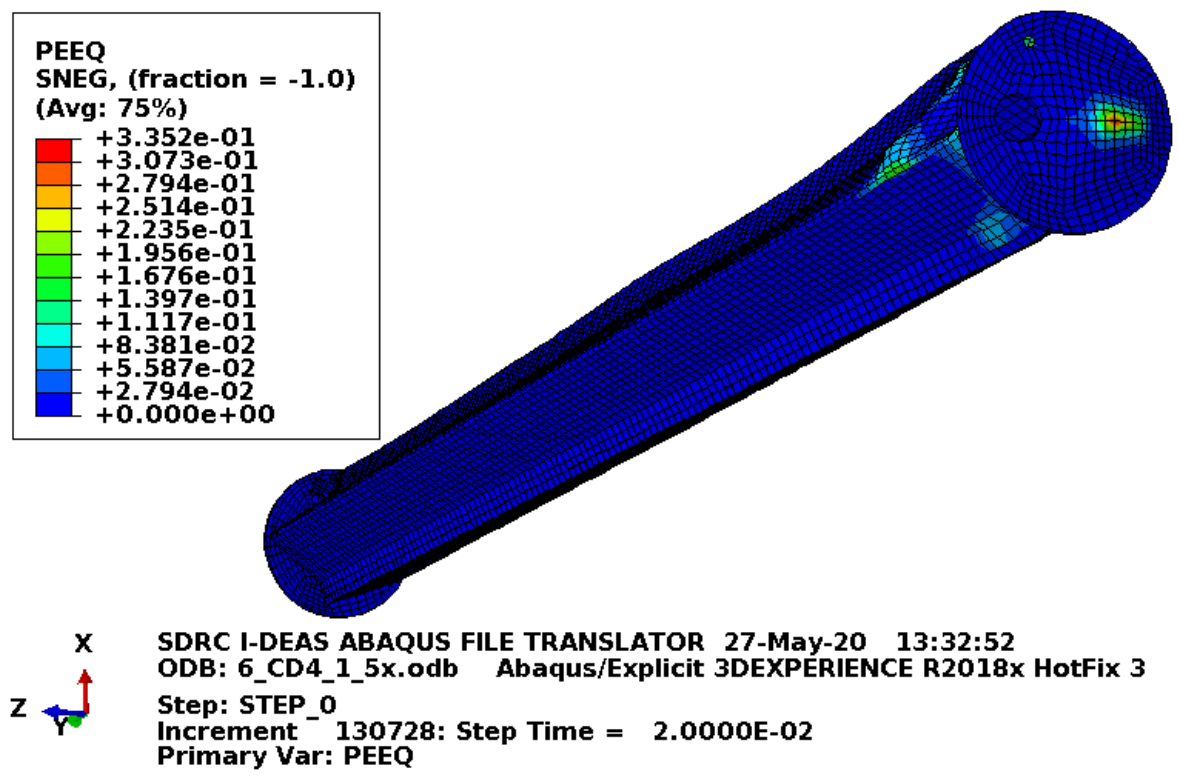

Figure C-139. Scope Part 3 (Table 3), Test 6 (Table 2) enclosure plastic-equivalent strain.

Figure C-139 shows the equivalent plastic strain in the enclosure. This is just for information as damage to the enclosure is acceptable. 


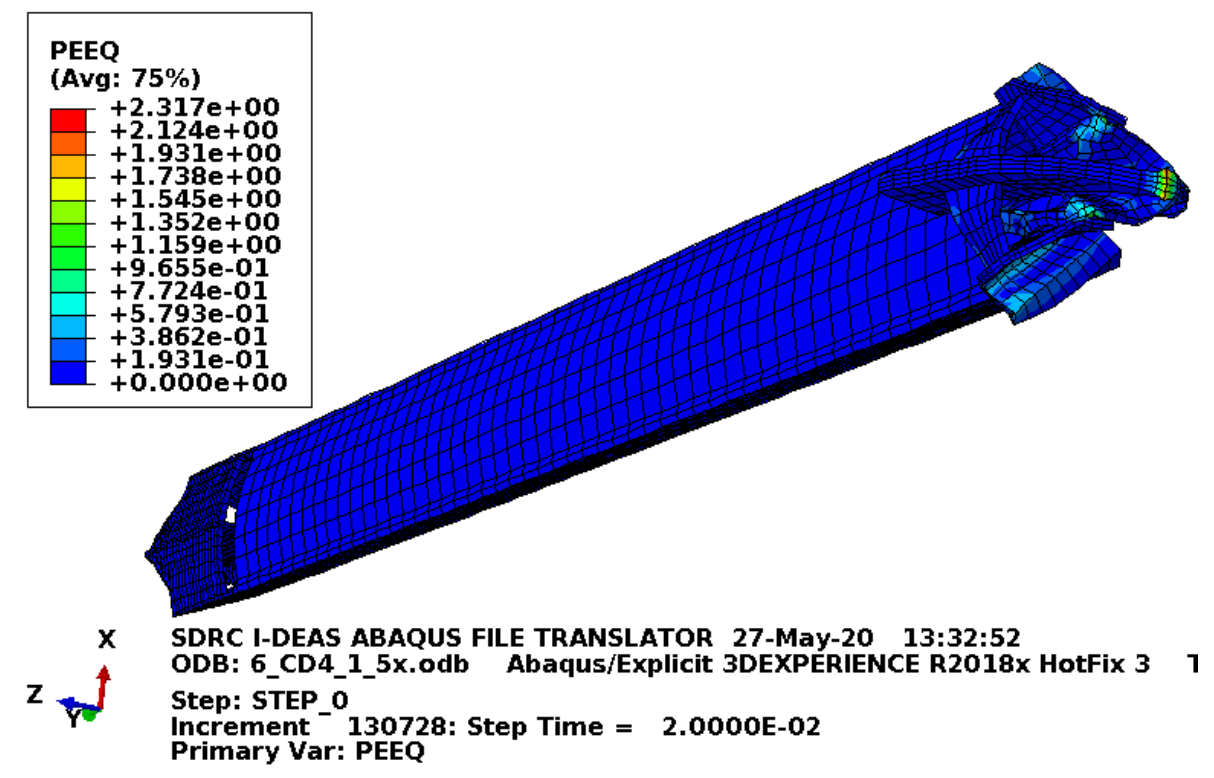

Figure C-140. Scope Part 3 (Table 3), Test 6 (Table 2) fuel element plastic-equivalent strain.

Figure C-140 shows the equivalent plastic strain in the fuel element. For this model, the fuel element is coarse meshed, massive, and has no failure defined. Consequently, this is just shown for information and is not relevant to the acceptability of the fuel element.

\section{C3.5 Results for Scope Part 3 (Table 3), Test 8 (Table 2)}

The FEA model results are shown below in Figure C-141 to Figure C-148. This drop scenario is a 30-ft drop modeled as a center of gravity over the top-corner impact. The fuel element weights $115 \mathrm{lbf}$ and the drop scenario is modeled with the ATR FFSC having minimum material properties and the enclosure and fuel element having relatively tough material properties with no failure. 


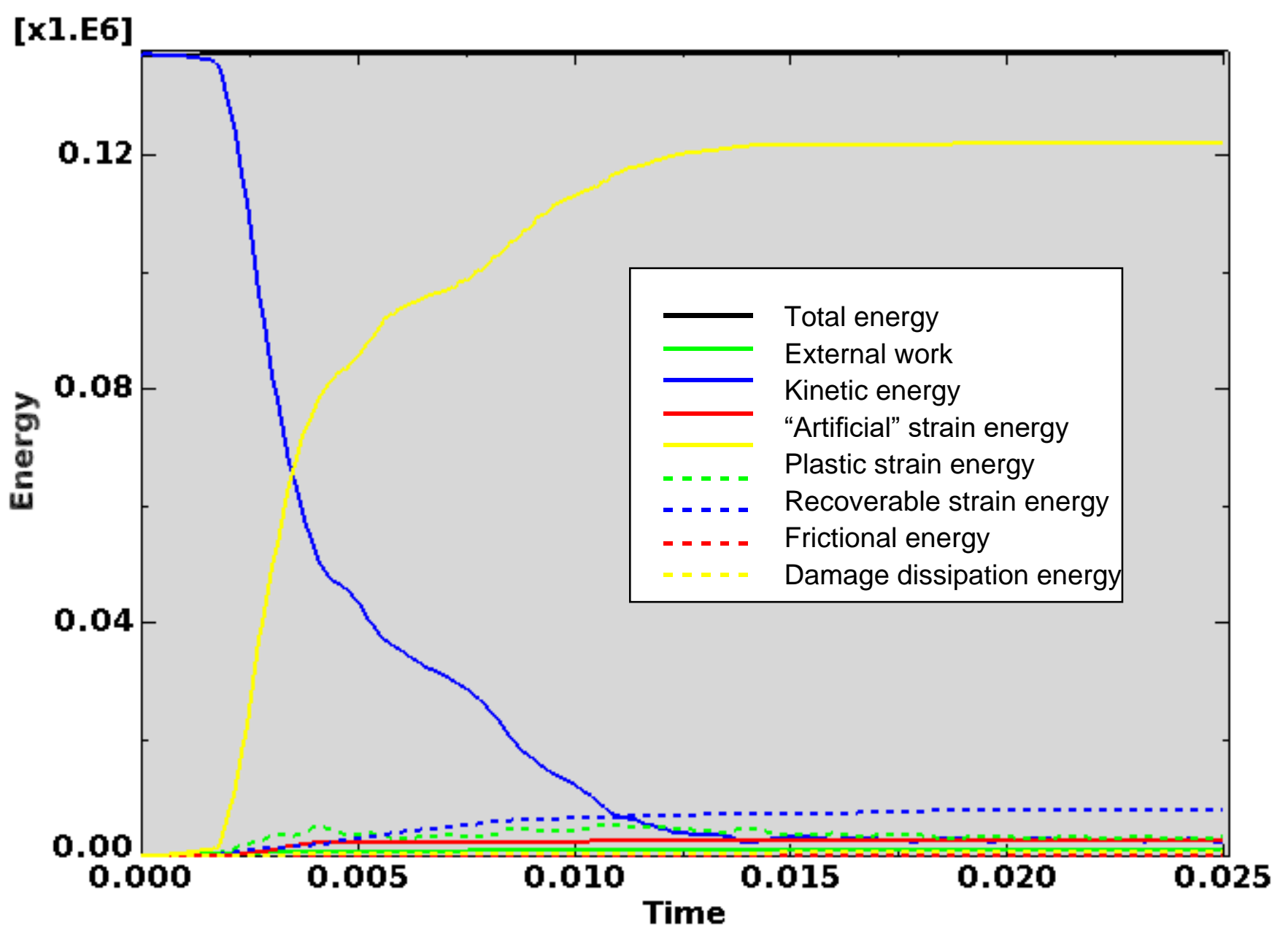

Figure C-141. Scope Part 3 (Table 3), Test 8 (Table 2) energy curves.

Figure C-141 shows the energy curves for Scope Part 3 (Table 3), Test 8 (Table 2) drop scenario. These curves exhibit a stable shape. Artificial energy represents the energy required to keep reduced integration elements from taking on a zero-energy hourglass shape. As shown in Figure C-141, the artificial energy at the end of the model run is $1.9 \%$ of the total energy. Therefore, the potential error associated with artificial energy is not considered to be significant. 


\section{ENGINEERING CALCULATIONS AND ANALYSIS}

Drop Analysis of the Advanced Test Reactor Fresh Fuel Shipping Container with Heavier Low-Enriched Uranium Fuel Contents
ECAR-5224, Rev. 0

Page C99 of C190

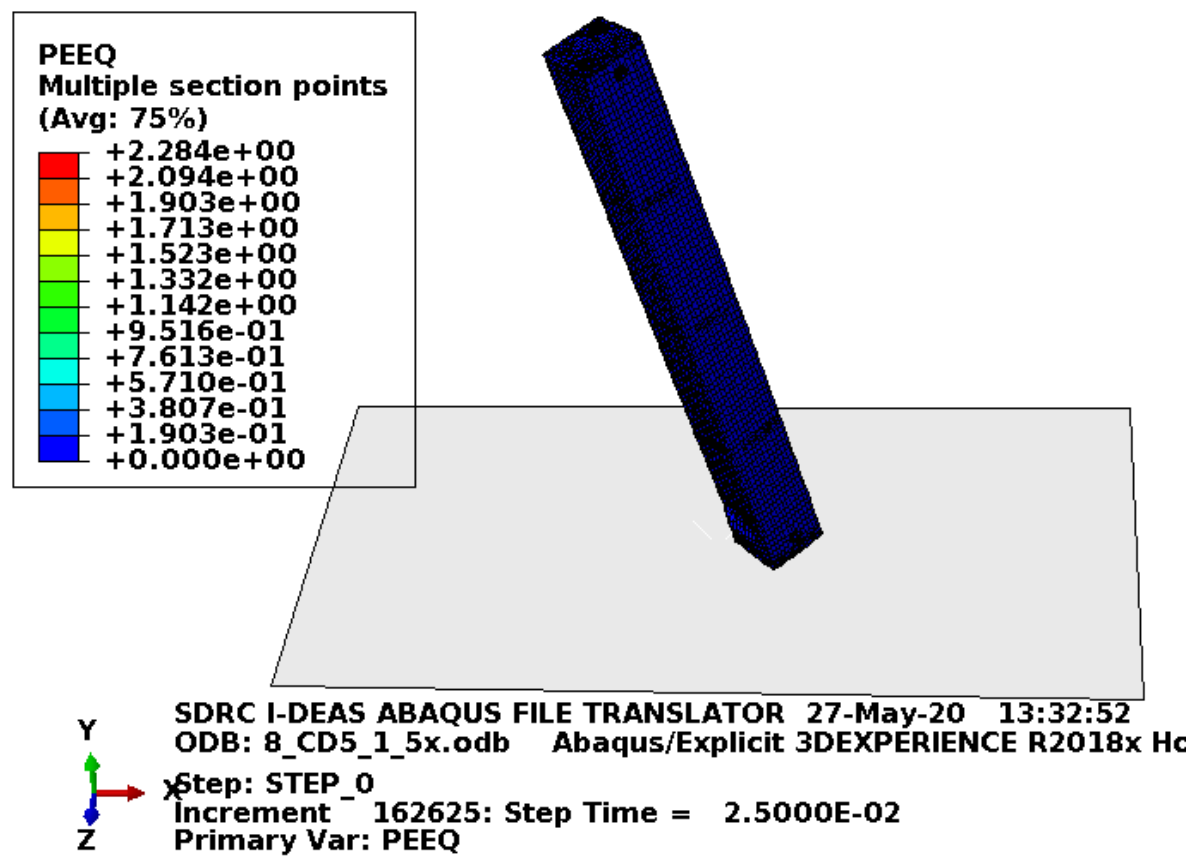

Figure C-142. Scope Part 3 (Table 3), Test 8 (Table 2) full-model plastic-equivalent strain.
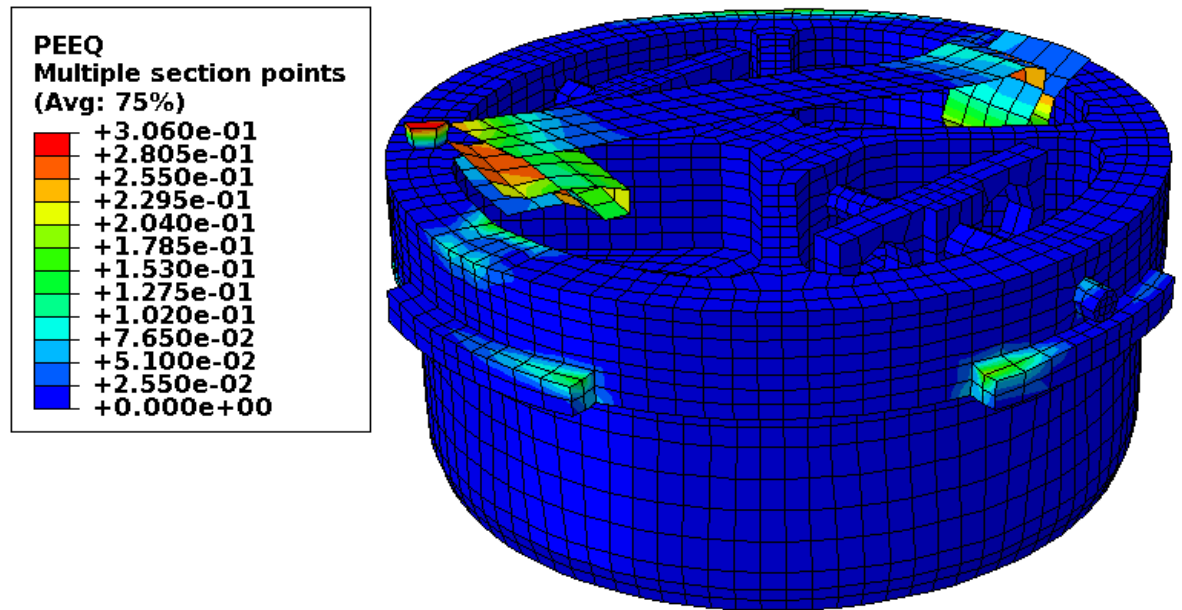

SDRC I-DEAS ABAQUS FILE TRANSLATOR 27-May-20 13:32:52 ODB: 8_CD5_1_5x.odb Abaqus/Explicit 3DEXPERIENCE R2018x HotFix 3 Btep: STEP_o Increment 162625: Step Time $=2.5000 \mathrm{E}-02$ Primary Var: PEEQ

Figure C-143. Scope Part 3 (Table 3), Test 8 (Table 2) lid plastic-equivalent strain. 
ENGINEERING CALCULATIONS AND ANALYSIS

Drop Analysis of the Advanced Test Reactor Fresh Fuel Shipping Container with Heavier Low-Enriched Uranium Fuel Contents
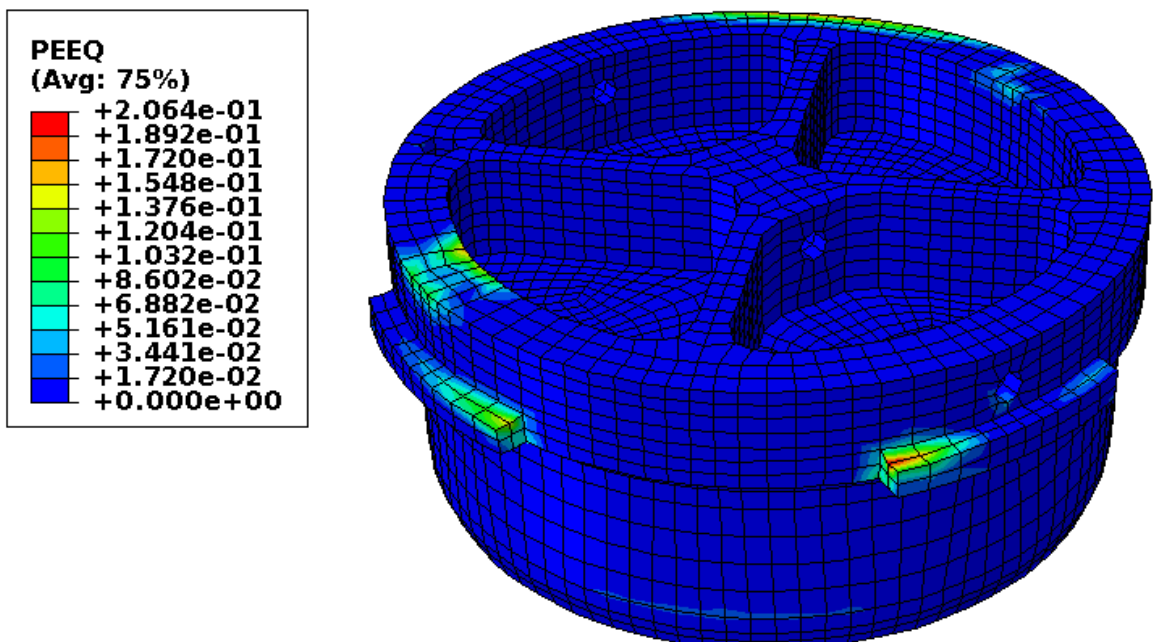

SDRC I-DEAS ABAQUS FILE TRANSLATOR 27-May-20 13:32:52

ODB: 8_CD5_1_5x.odb Abaqus/Explicit 3DEXPERIENCE R2018x HotFix

Step: STEP_o

Increment 162625: Step Time $=2.5000 \mathrm{E}-02$

Primary Var: PEEQ

Figure C-144. Scope Part 3 (Table 3), Test 8 (Table 2) lid structure plastic-equivalent strain.

Figure C-144 shows the equivalent plastic strain in the structurally significant portion of the lid. Failure in these elements occurs at an equivalent plastic strain of 0.259 in./in. Figure C-144 shows no element failure.

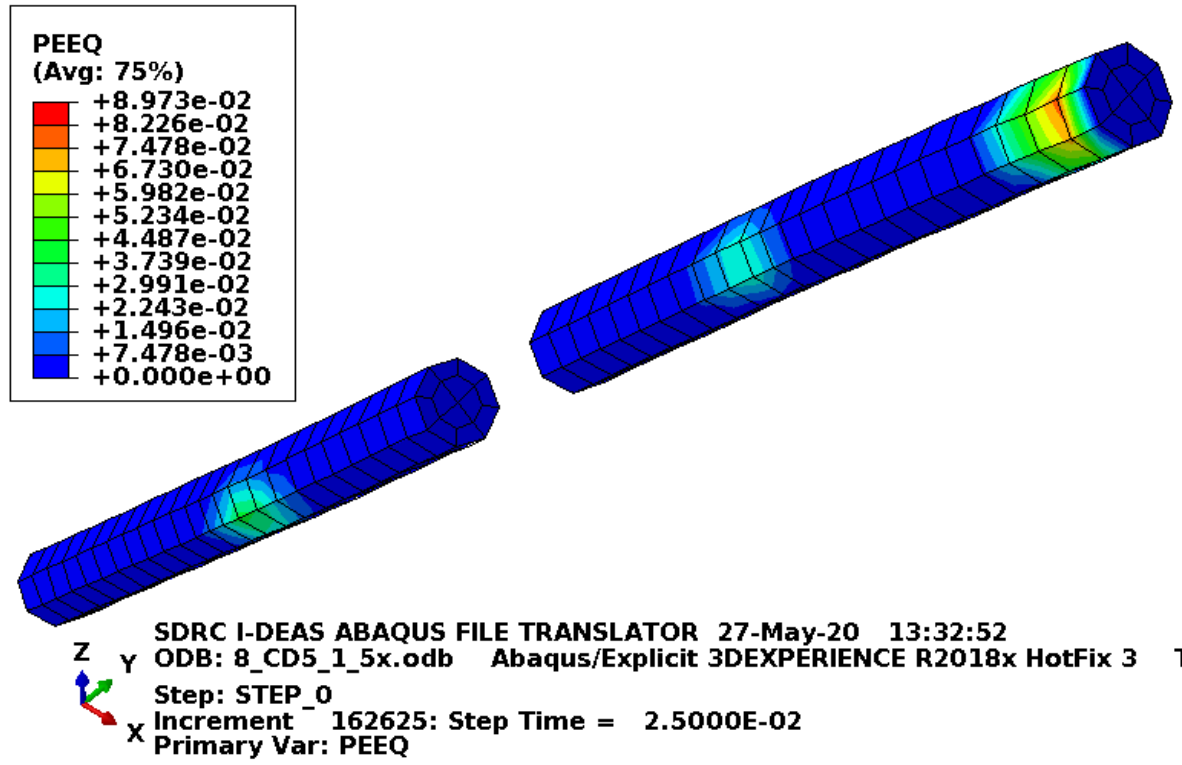

Figure C-145. Scope Part 3 (Table 3), Test 8 (Table 2) lid pins plastic-equivalent strain.

Figure C-145 shows the equivalent plastic strain in the lid pins. Failure in these elements occurs at an equivalent plastic strain of $0.295 \mathrm{in}$./in. If element failure were to occur, the element would be deleted and removed from the model (thereby making its equivalent plastic strain not included in the maximum equivalent plastic strain for the plot). However, the missing element would be visible in the plot. Figure C-145 shows no element failure. 
ENGINEERING CALCULATIONS AND ANALYSIS

Drop Analysis of the Advanced Test Reactor Fresh Fuel Shipping Container with Heavier Low-Enriched Uranium Fuel Contents
ECAR-5224, Rev. 0

Page C101 of C190

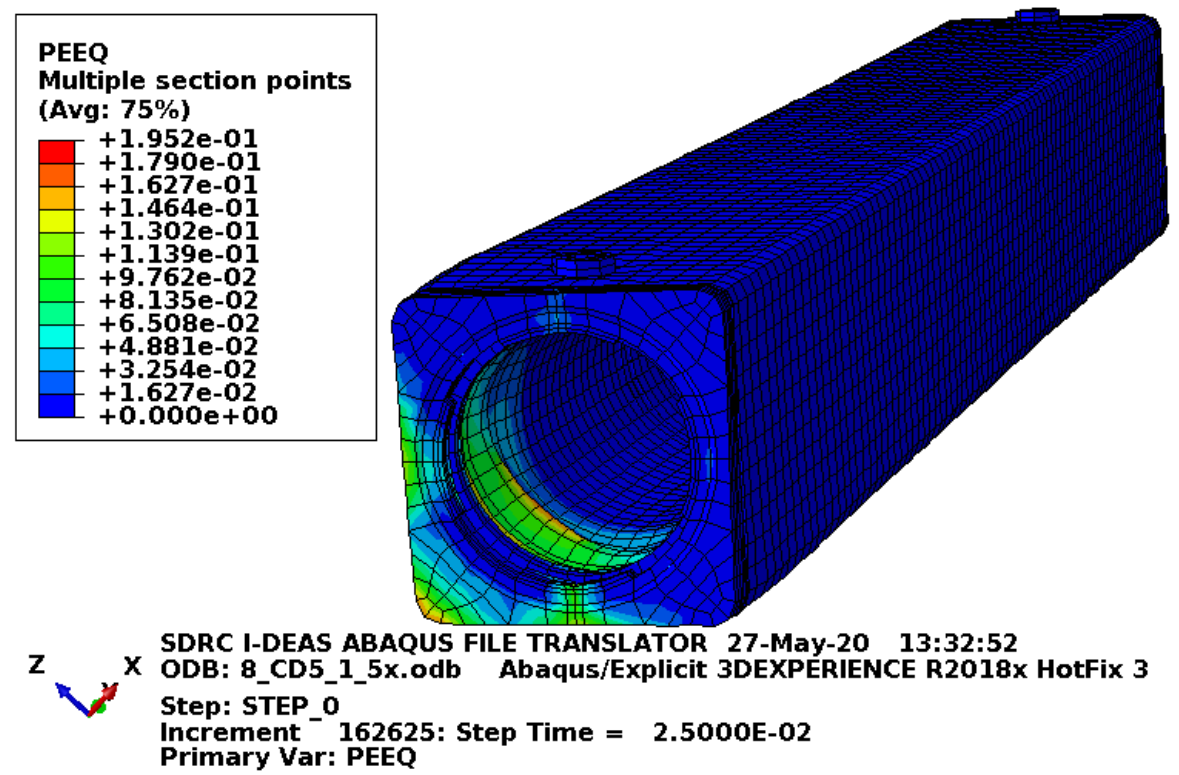

Figure C-146. Scope Part 3 (Table 3), Test 8 (Table 2) body plastic-equivalent strain.

Figure C-146 shows the equivalent plastic strain in the body. Failure in these elements occurs at an equivalent plastic strain of $0.259 \mathrm{in}$./in. and the TID posts have failed. Since the failed elements are deleted and removed from the model, the equivalent plastic strain does not include the maximum equivalent plastic strain in the plot. Figure C-146 shows failure in the TID post, which is acceptable. The body has no other failure, so it remains functional.

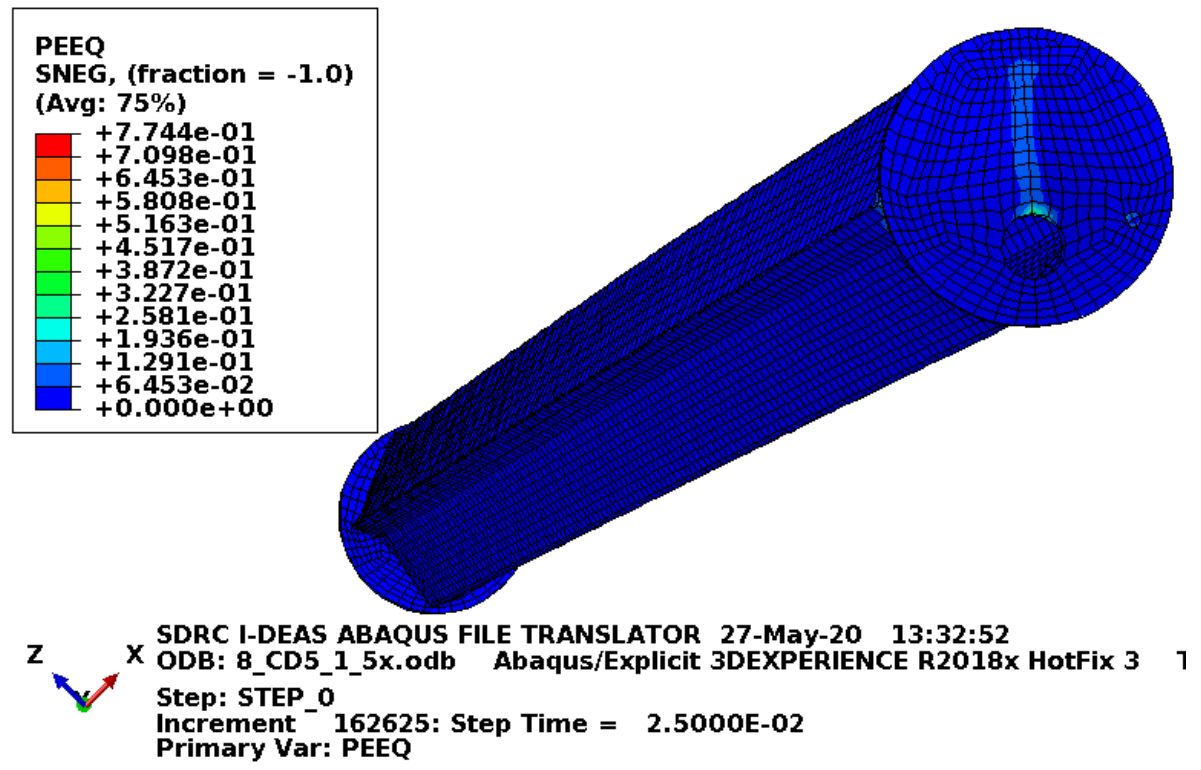

Figure C-147. Scope Part 3 (Table 3), Test 8 (Table 2) enclosure plastic-equivalent strain.

Figure $\mathrm{C}-147$ shows the equivalent plastic strain in the enclosure. This is just for information as damage to the enclosure is acceptable. 


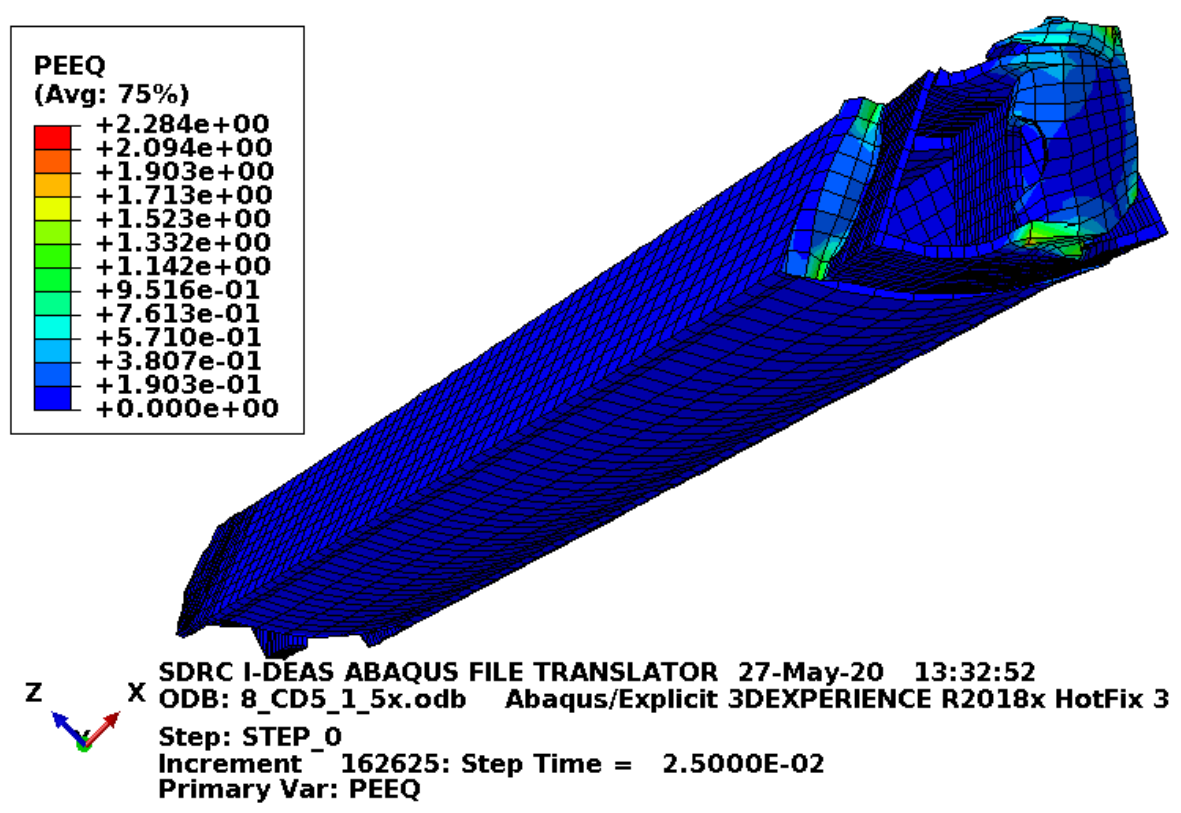

Figure C-148. Scope Part 3 (Table 3), Test 8 (Table 2) fuel element plastic-equivalent strain.

Figure C-148 shows the equivalent plastic strain in the fuel element. For this model, the fuel element is coarse meshed, massive, and has no failure defined. Consequently, this is just shown for information and is not relevant to the acceptability of the fuel element.

\section{C3.6 Results for Scope Part 3 (Table 3), Test 10 (Table 2)}

The FEA model results are shown below in Figure C-149 to Figure C-156. This drop scenario is a 40-in. drop modeled as 30 degrees off horizontal, center of gravity over a 6 -in.-diameter puncture bar. The fuel element weights $115 \mathrm{lbf}$ and the drop scenario is modeled with the ATR FFSC having minimum material properties and the enclosure and fuel element having relatively tough material properties with no failure. 
Drop Analysis of the Advanced Test Reactor Fresh Fuel Shipping Container with Heavier Low-Enriched Uranium Fuel Contents
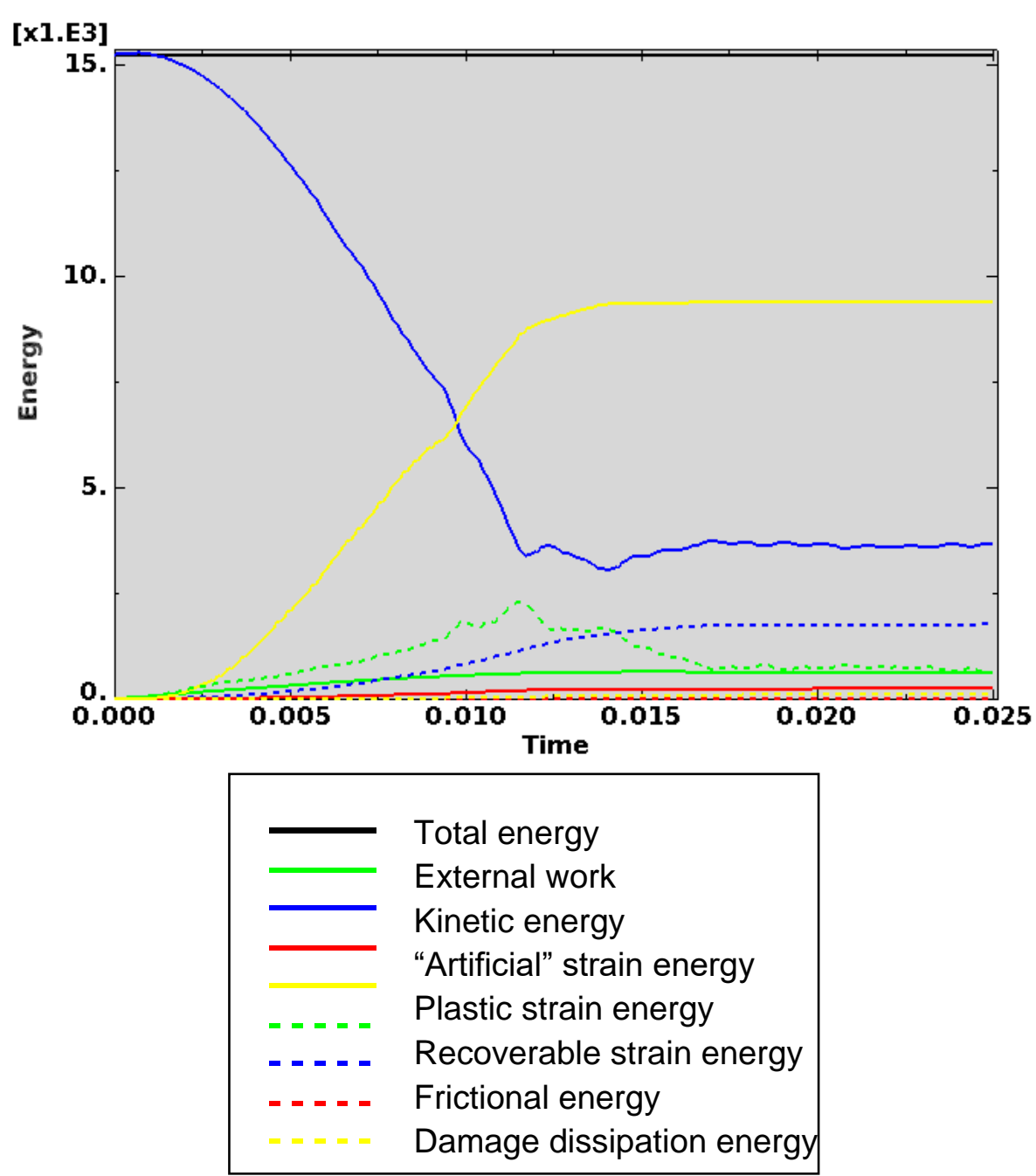

Figure C-149. Scope Part 3 (Table 3), Test 10 (Table 2) energy curves.

Figure C-149 shows the energy curves for Scope Part 3 (Table 3), Test 10 (Table 2) drop scenario. These curves exhibit a stable shape. Artificial energy represents the energy required to keep reduced integration elements from taking on a zero-energy hourglass shape. As shown in Figure C-149, the artificial energy at the end of the model run is $1.7 \%$ of the total energy. Therefore, the potential error associated with artificial energy is not considered to be significant. 


\section{ENGINEERING CALCULATIONS AND ANALYSIS}

Drop Analysis of the Advanced Test Reactor Fresh Fuel Shipping Container with Heavier Low-Enriched Uranium Fuel Contents

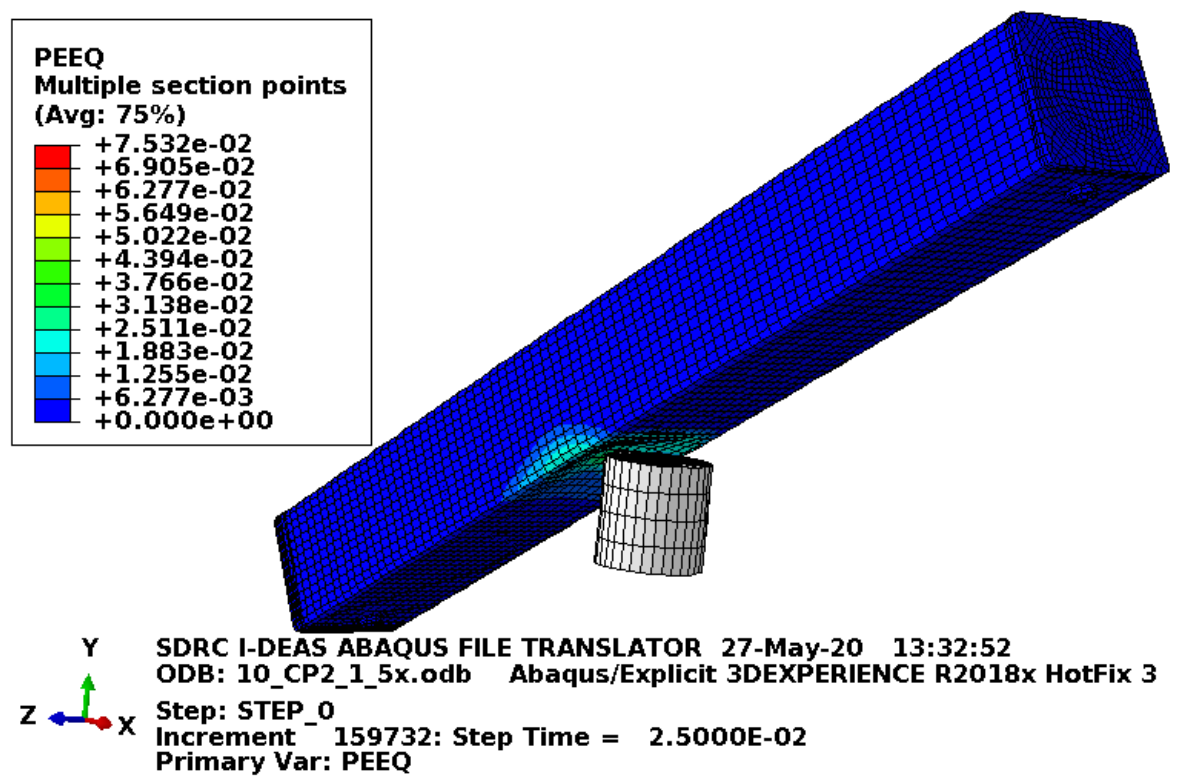

Figure C-150. Scope Part 3 (Table 3), Test 10 (Table 2) full-model plastic-equivalent strain.
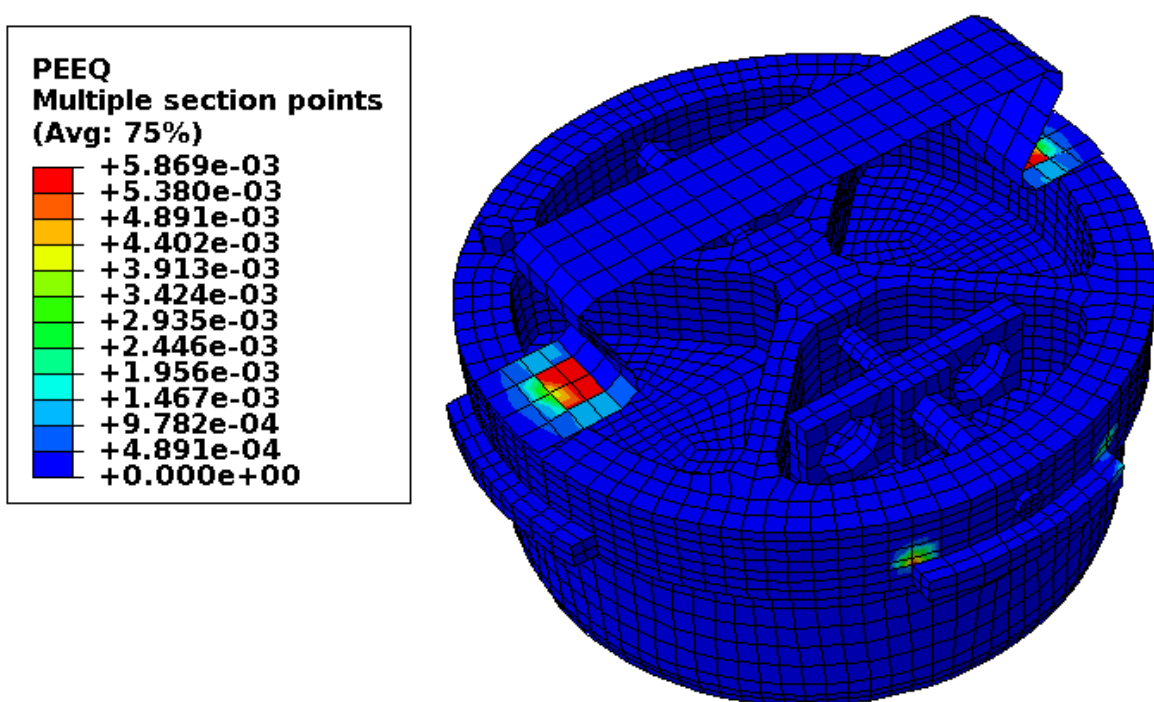

SDRC I-DEAS ABAQUS FILE TRANSLATOR 27-May-20 13:32:52 z ODB: 10_CP2_1_5x.odb Abaqus/Explicit 3DEXPERIENCE R2018x r<smiles>[Y]C([Y])[3H]</smiles>
Step: STEP

Increment 159732: Step Time $=2.5000 \mathrm{E}-02$

$\mathrm{X}$ 
ENGINEERING CALCULATIONS AND ANALYSIS

Drop Analysis of the Advanced Test Reactor Fresh Fuel Shipping Container with Heavier Low-Enriched Uranium Fuel Contents

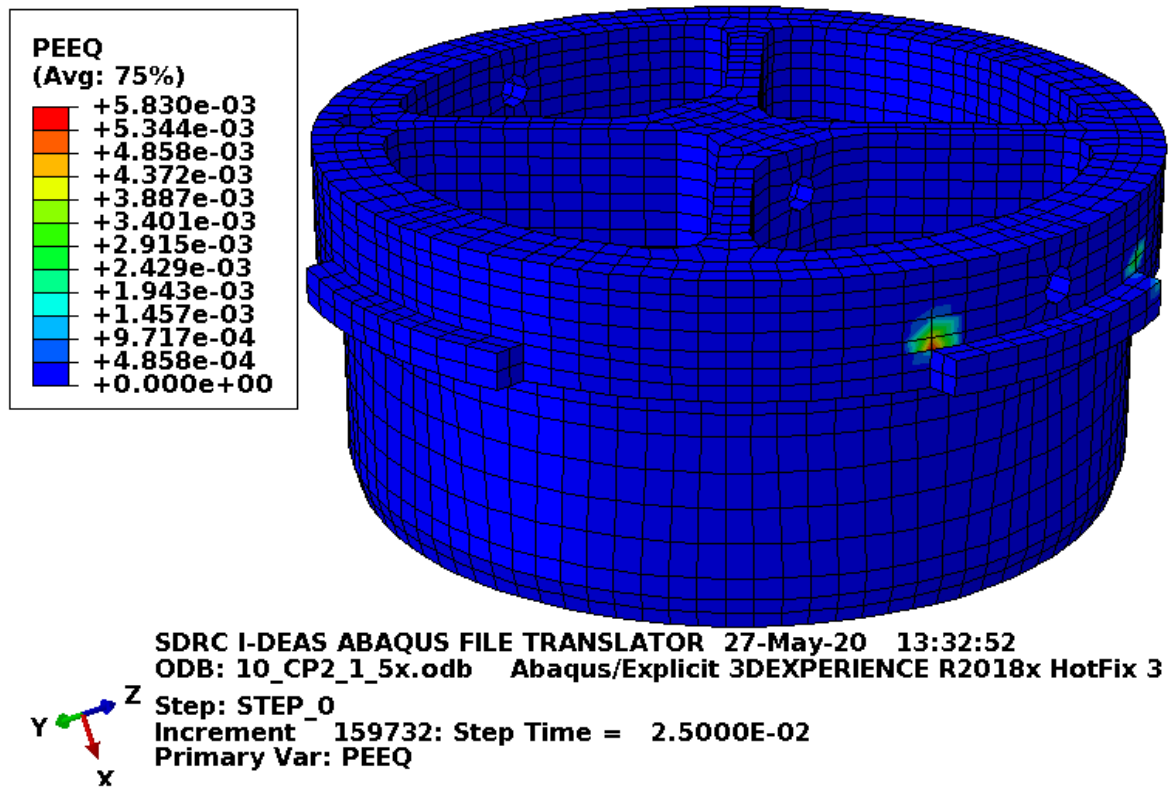

Figure C-152. Scope Part 3 (Table 3), Test 10 (Table 2) lid structure plastic-equivalent strain.

Figure C-152 shows the equivalent plastic strain in the structurally significant portion of the lid. Failure in these elements occurs at an equivalent plastic strain of $0.259 \mathrm{in}$./in. If element failure were to occur, the element would be deleted and removed from the model (thereby making its equivalent plastic strain not included in the maximum equivalent plastic strain for the plot). However, the missing element would be visible in the plot. Figure $\mathrm{C}-152$ shows no element failure with margin.

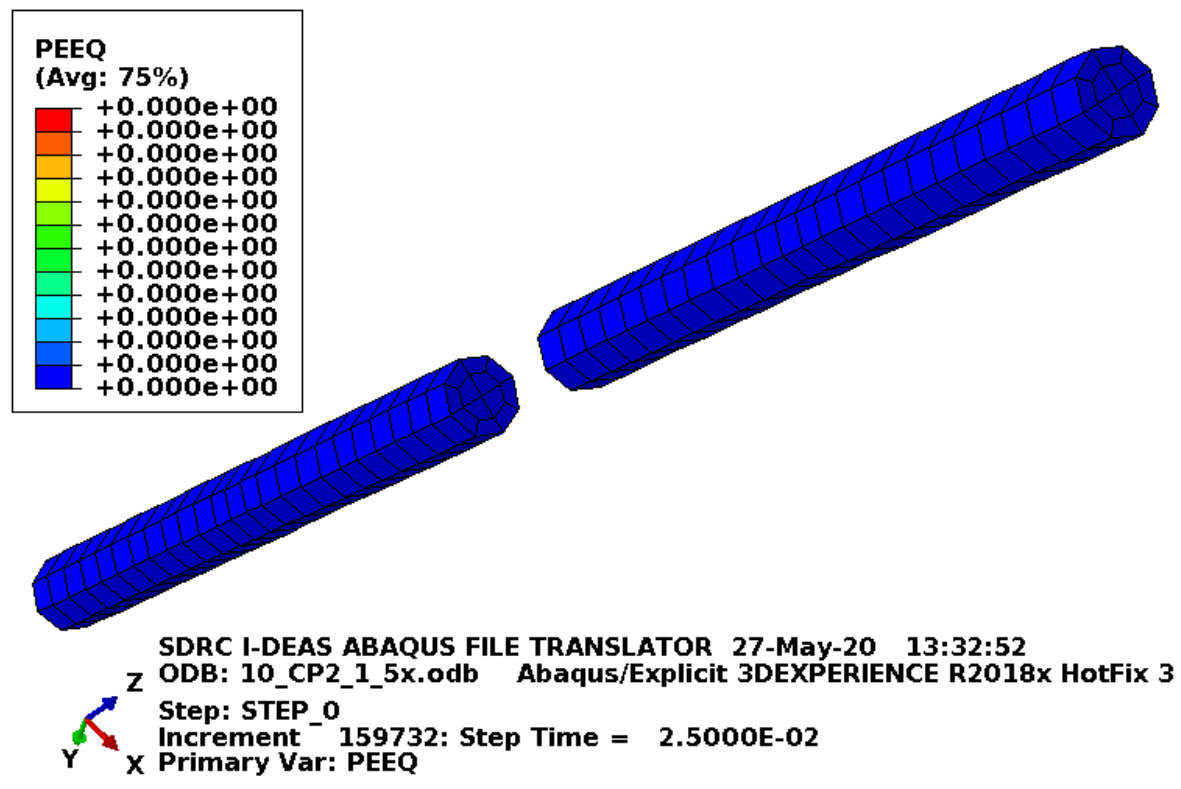

Figure C-153. Scope Part 3 (Table 3), Test 10 (Table 2) lid pins plastic-equivalent strain.

Figure $\mathrm{C}-153$ shows no plastic strains in the pins. 
ENGINEERING CALCULATIONS AND ANALYSIS

Drop Analysis of the Advanced Test Reactor Fresh Fuel Shipping Container with Heavier Low-Enriched Uranium Fuel Contents

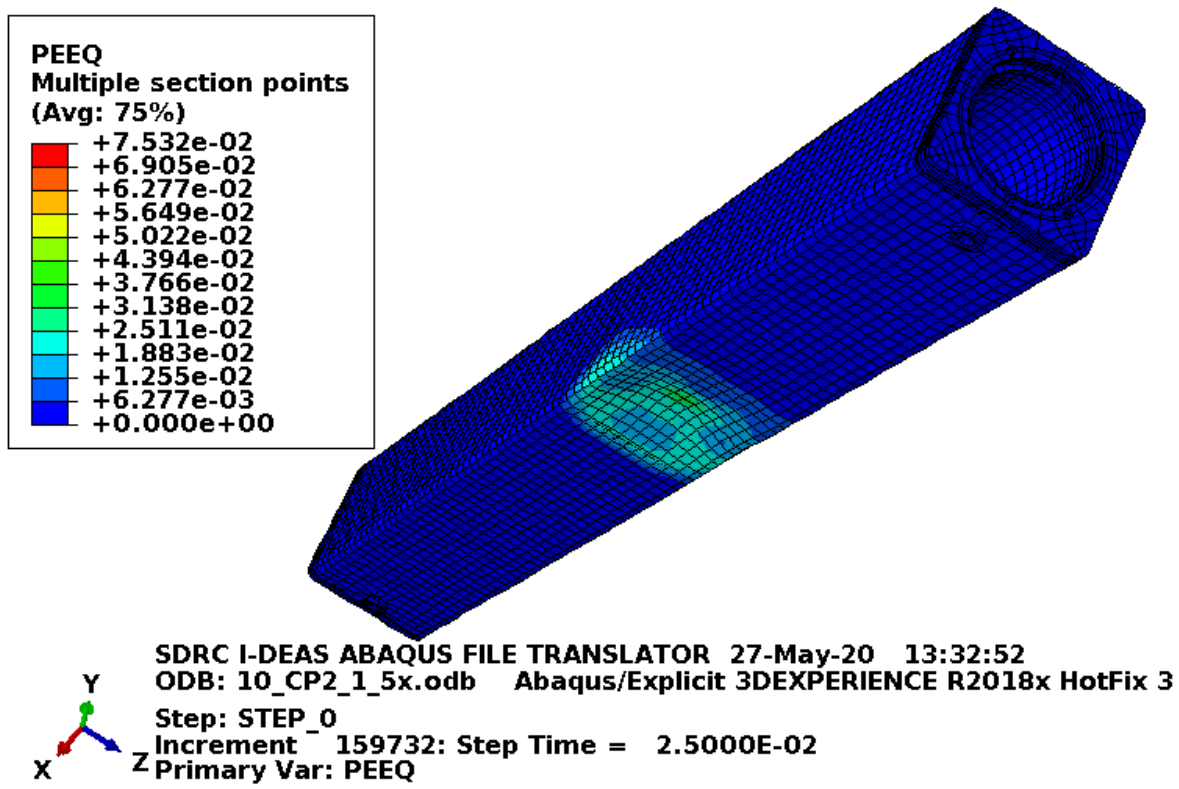

Figure C-154. Scope Part 3 (Table 3), Test 10 (Table 2) body plastic-equivalent strain.

Figure C-154 shows the equivalent plastic strain in the body. Failure in these elements occurs at an equivalent plastic strain of $0.259 \mathrm{in}$./in. If element failure were to occur, the element would be deleted and removed from the model (thereby making its equivalent plastic strain not included in the maximum equivalent plastic strain for the plot). However, the missing element would be visible in the plot.

Figure C-154 shows no element failure with margin.

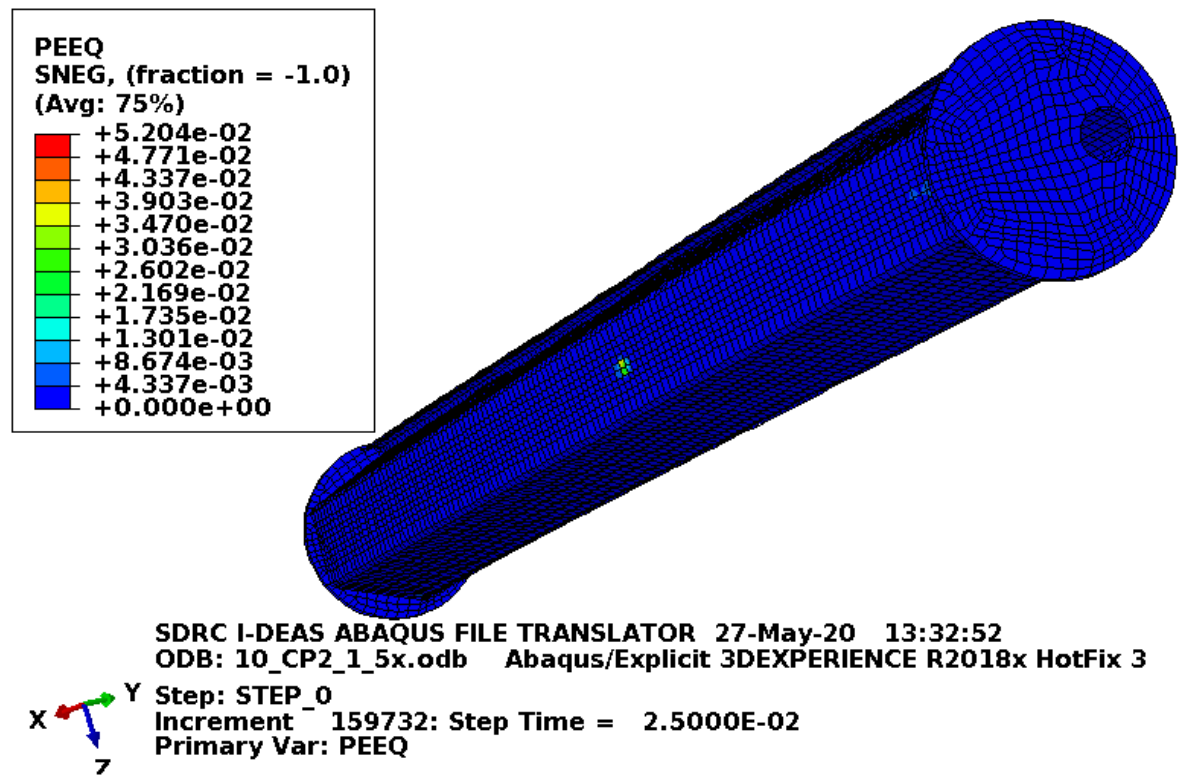

Figure C-155. Scope Part 3 (Table 3), Test 10 (Table 2) enclosure plastic-equivalent strain.

Figure $\mathrm{C}-155$ shows the equivalent plastic strain in the enclosure. This is just for information as damage to the enclosure is acceptable. 


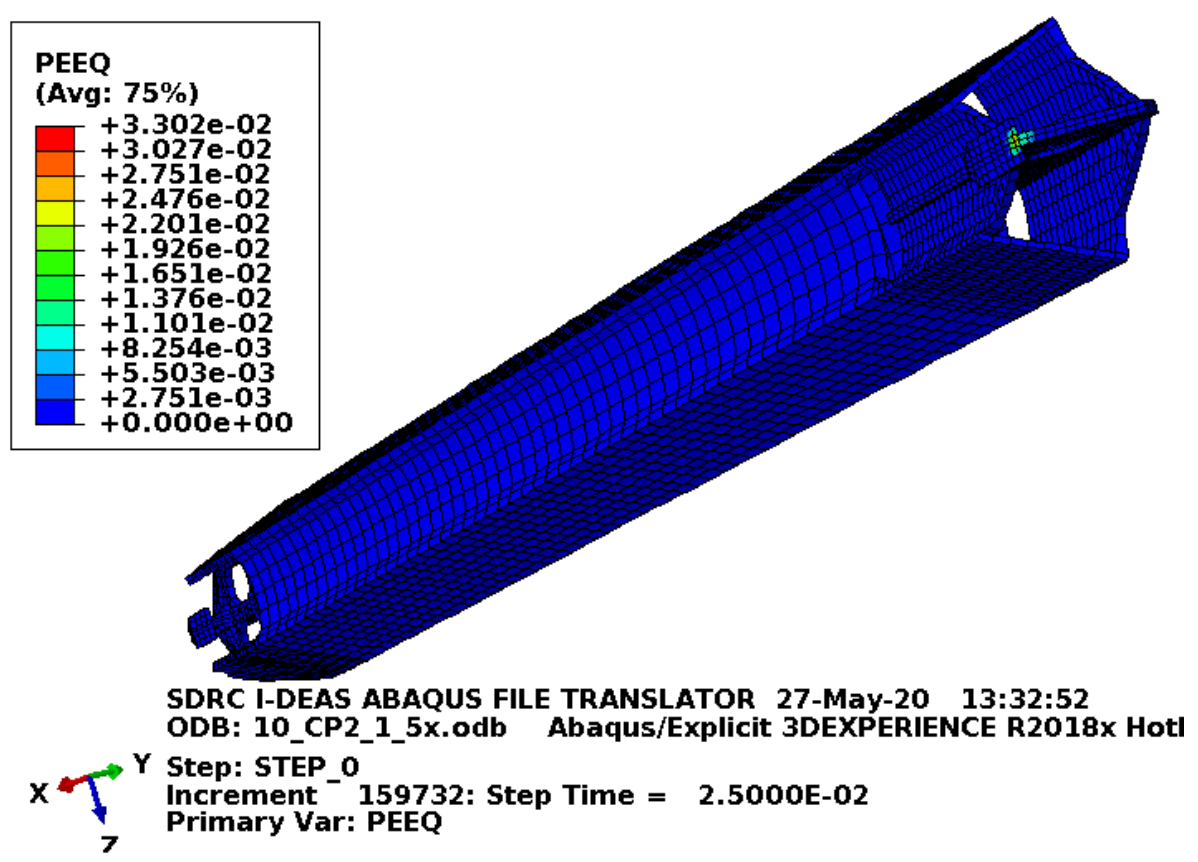

Figure C-156. Scope Part 3 (Table 3), Test 10 (Table 2) fuel element plastic-equivalent strain.

Figure C-156 shows the equivalent plastic strain in the fuel element. For this model, the fuel element is coarse meshed, massive, and has no failure defined. Consequently, this is just shown for information and is not relevant to the acceptability of the fuel element.

\section{C3.7 Results for Scope Part 3 (Table 3), Test 11 (Table 2)}

The FEA model results are shown below in Figure C-157 to Figure C-164. This drop scenario is a 40-in. drop modeled as a vertical top drop with the lid centered over a 6 -in.-diameter puncture bar. The fuel element weights $115 \mathrm{lbf}$ and the drop scenario is modeled with the ATR FFSC having minimum material properties and the enclosure and fuel element having relatively tough material properties with no failure. 
Drop Analysis of the Advanced Test Reactor Fresh Fuel Shipping Container with Heavier Low-Enriched Uranium Fuel Contents

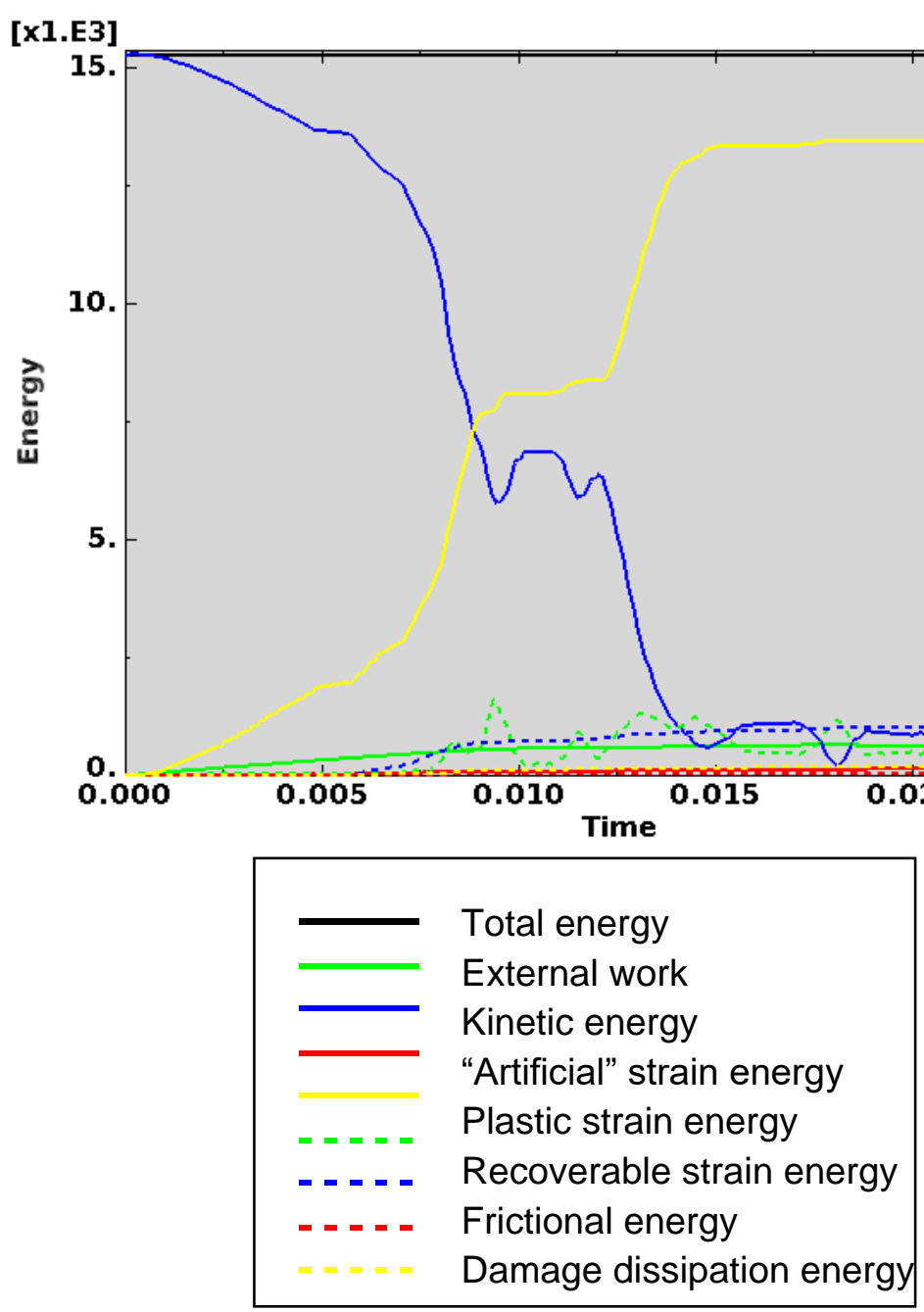

Figure C-157. Scope Part 3 (Table 3), Test 11 (Table 2) energy curves.

Figure C-157 shows the energy curves for Scope Part 3 (Table 3), Test 11 (Table 2) drop scenario. These curves exhibit a stable shape. Artificial energy represents the energy required to keep reduced integration elements from taking on a zero-energy hourglass shape. As shown in Figure C-157, the artificial energy at the end of the model run is $1.0 \%$ of the total energy. Therefore, the potential error associated with artificial energy is not considered to be significant. 
ENGINEERING CALCULATIONS AND ANALYSIS

Drop Analysis of the Advanced Test Reactor Fresh Fuel Shipping Container with Heavier Low-Enriched Uranium Fuel Contents

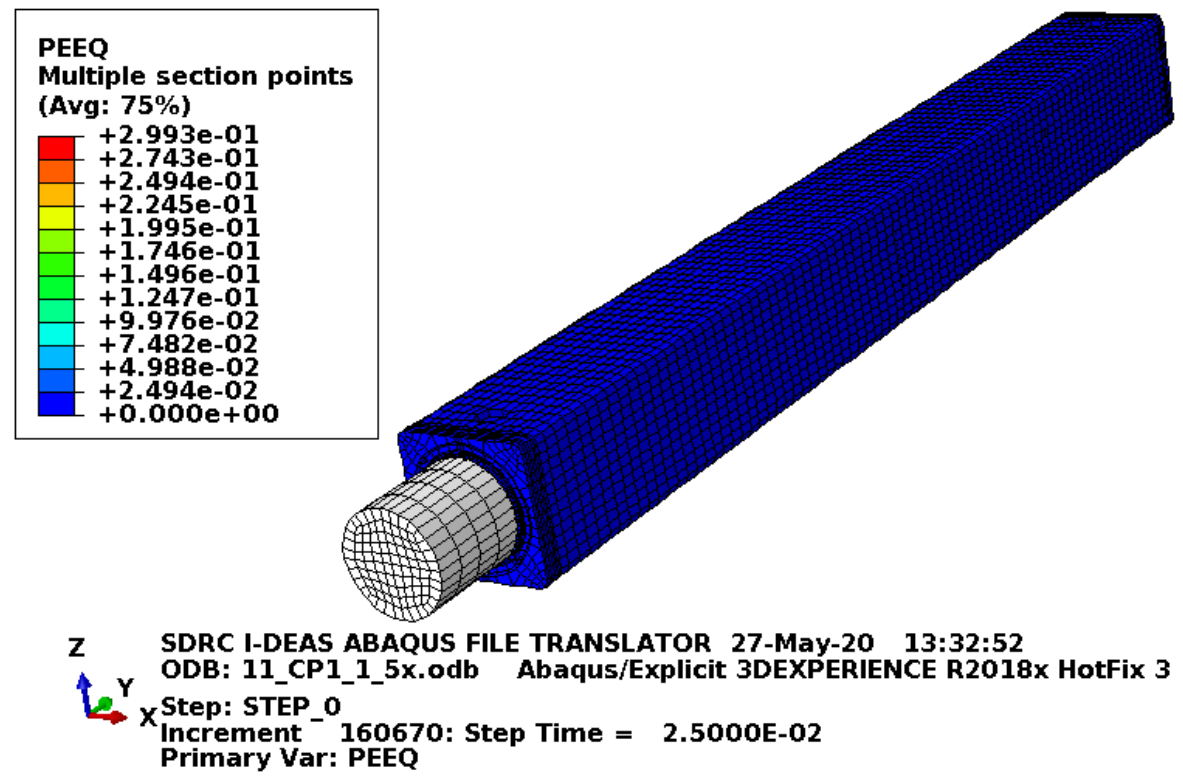

Figure C-158. Scope Part 3 (Table 3), Test 11 (Table 2) full-model plastic-equivalent strain.
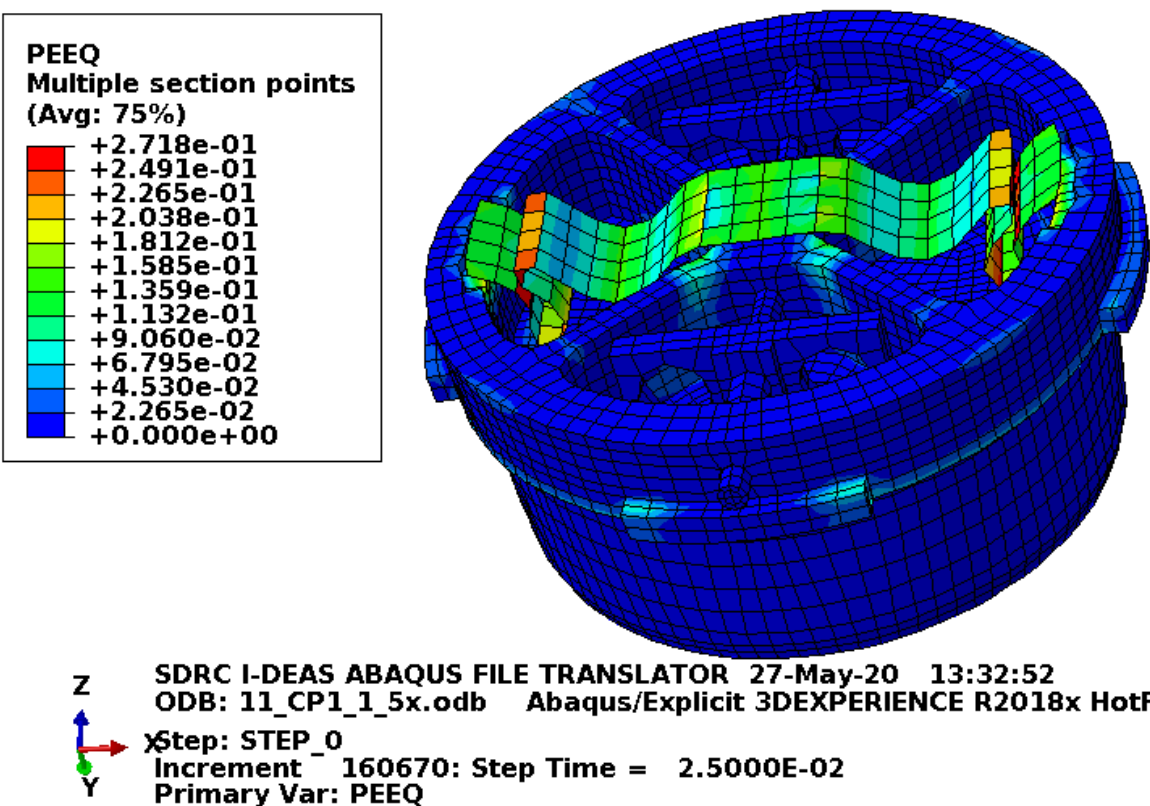

SDRC I-DEAS ABAQUS FILE TRANSLATOR 27-May-20 13:32:52

ODB: 11_CP1_1_5x.odb Abaqus/Explicit 3DEXPERIENCE R2018x HotFix

Xtep: STEP 0

Increment 160670: Step Time $=$ 2.5000E-02

Primary Var: PEEQ

Figure C-159. Scope Part 3 (Table 3), Test 11 (Table 2) lid plastic-equivalent strain.

Figure C-159 shows the equivalent plastic strain in the lid. The most deformation is in the closure handle which, is not a concern. 
ENGINEERING CALCULATIONS AND ANALYSIS

Drop Analysis of the Advanced Test Reactor Fresh Fuel Shipping Container with Heavier Low-Enriched Uranium Fuel Contents

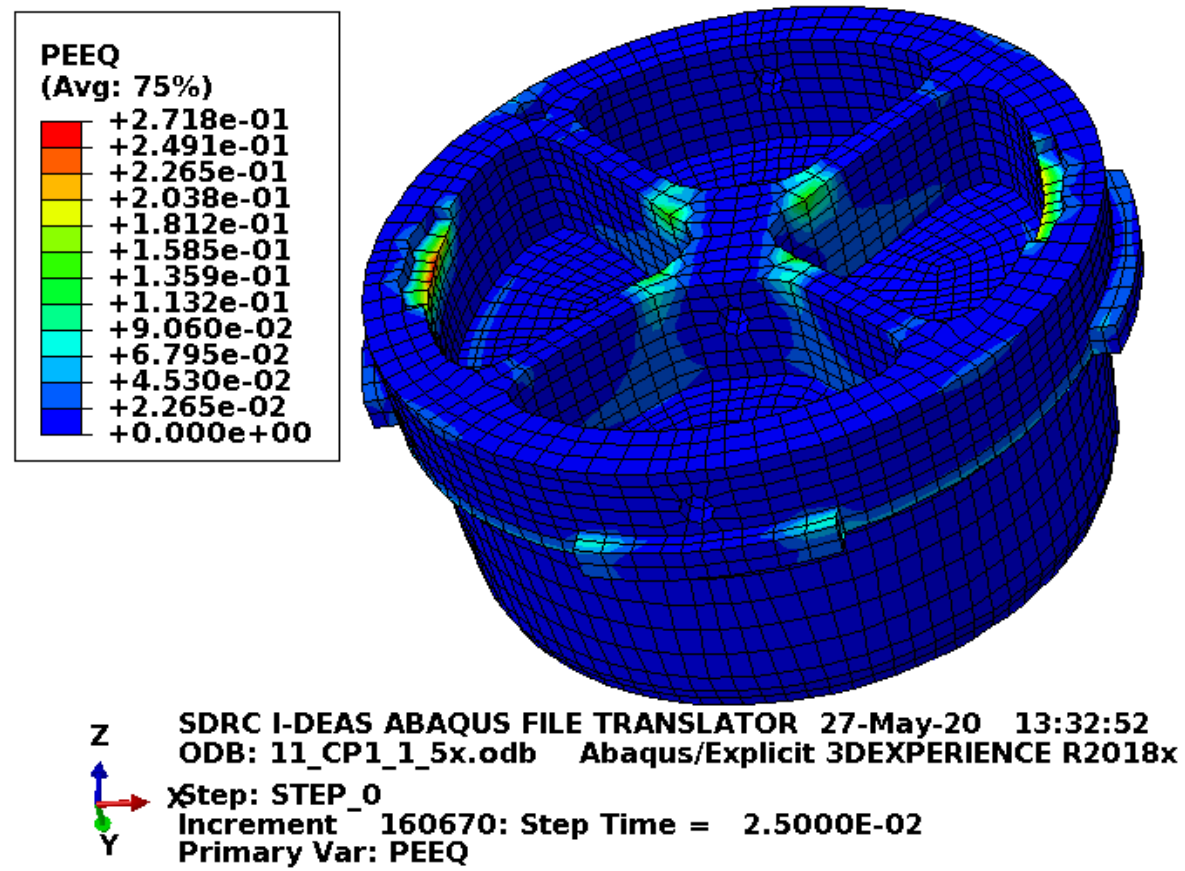

Figure C-160. Scope Part 3 (Table 3), Test 11 (Table 2) lid structure plastic-equivalent strain.

Figure C-160 shows the equivalent plastic strain in the structurally significant portion of the lid. Failure in these elements occurs at an equivalent plastic strain of $0.259 \mathrm{in}$./in. If element failure were to occur, the element would be deleted and removed from the model (thereby making its equivalent plastic strain not included in the maximum equivalent plastic strain for the plot). However, the missing element would be visible in the plot. Figure C-160 shows some element failure. Also, above failure strain values are shown in a few elements. The strains shown above the failure strain likely result from extrapolation (as integration point strains are the important strains for failure). It is acceptable with the failed elements and if the high strained elements are considered as being failed because the lid can still perform its function. 


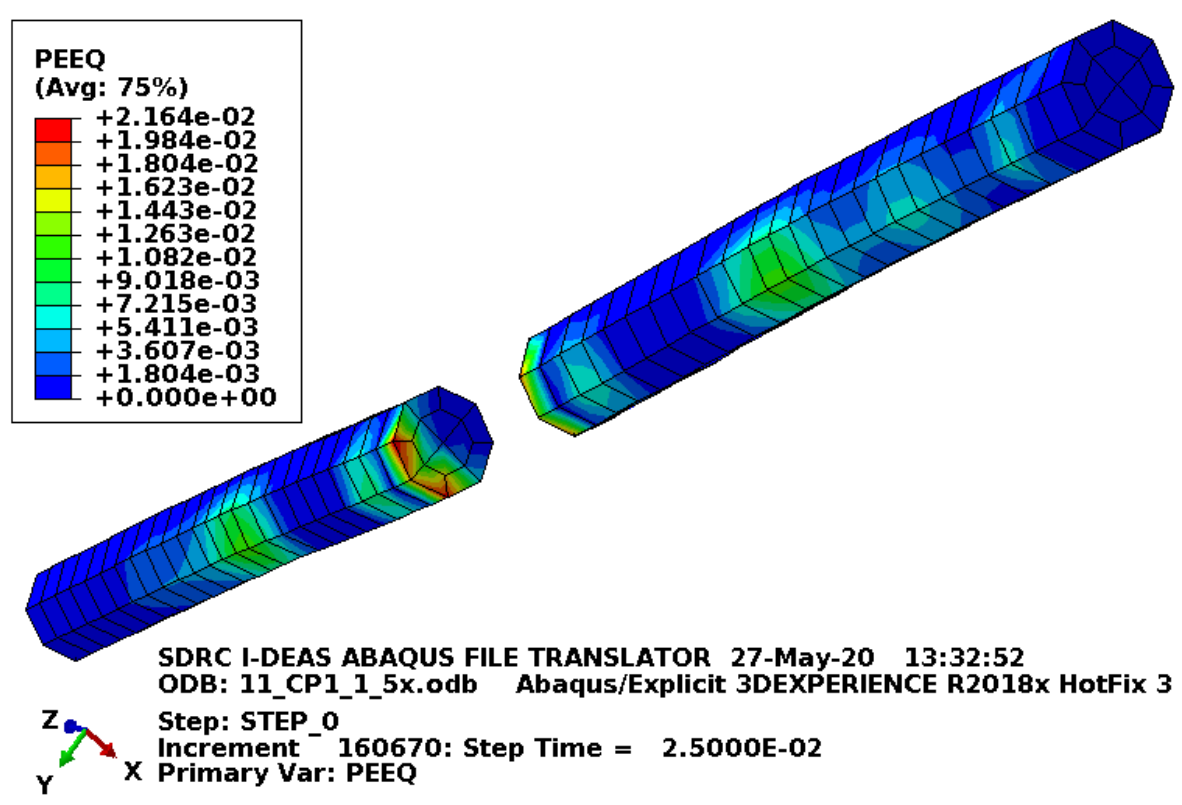

Figure C-161. Scope Part 3 (Table 3), Test 11 (Table 2) lid pins plastic-equivalent strain.

Figure C-161 shows the equivalent plastic strain in the lid pins. Failure in these elements occurs at an equivalent plastic strain of $0.295 \mathrm{in}$./in. If element failure were to occur, the element would be deleted and removed from the model (thereby making its equivalent plastic strain not included in the maximum equivalent plastic strain for the plot). However, the missing element would be visible in the plot. Figure C-161 shows no element failure with margin.

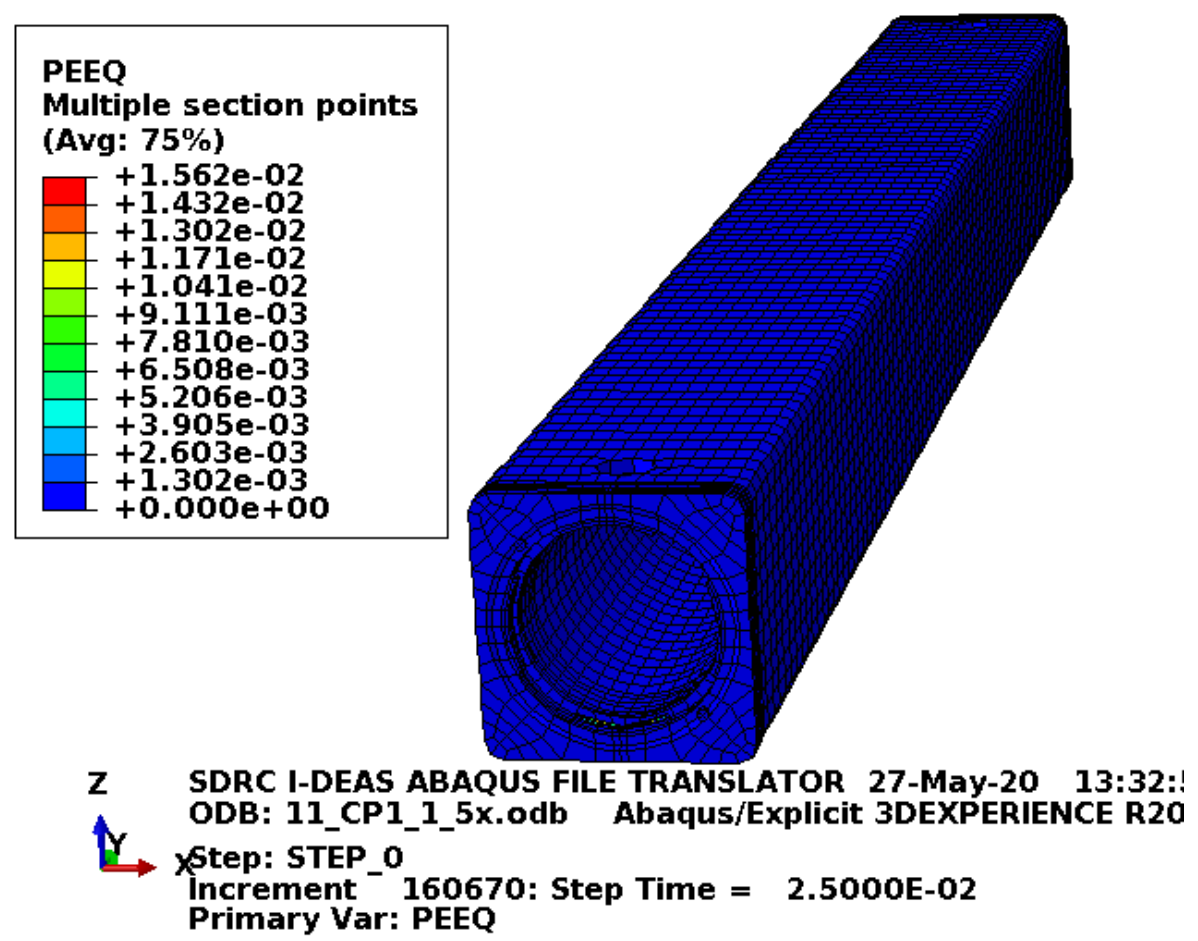

Figure C-162. Scope Part 3 (Table 3), Test 11 (Table 2) body plastic-equivalent strain. 
Figure C-162 shows the equivalent plastic strain in the body. Failure in these elements occurs at an equivalent plastic strain of $0.259 \mathrm{in}$./in. If element failure were to occur, the element would be deleted and removed from the model (thereby making its equivalent plastic strain not included in the maximum equivalent plastic strain for the plot). However, the missing element would be visible in the plot. Figure C-162 shows no element failure with margin.

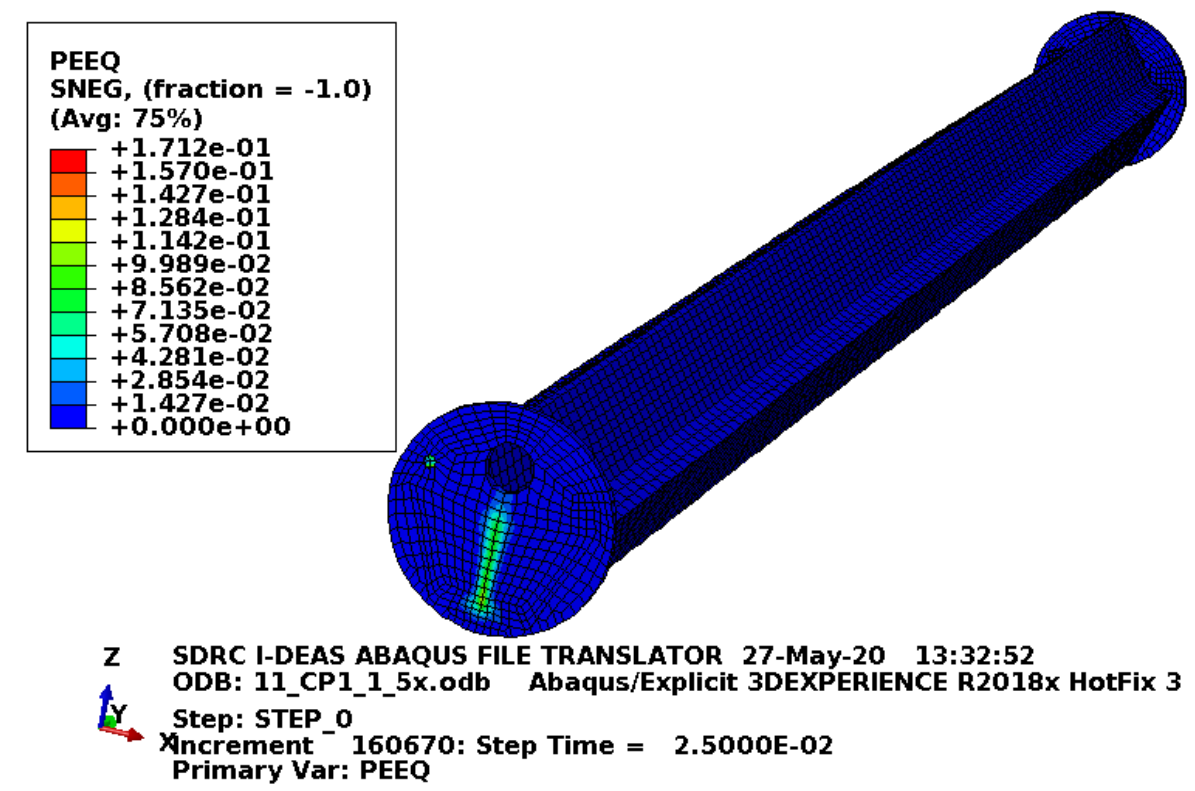

Figure C-163. Scope Part 3 (Table 3), Test 11 (Table 2) enclosure plastic-equivalent strain.

Figure $\mathrm{C}-163$ shows the equivalent plastic strain in the enclosure. This is just for information as damage to the enclosure is acceptable.

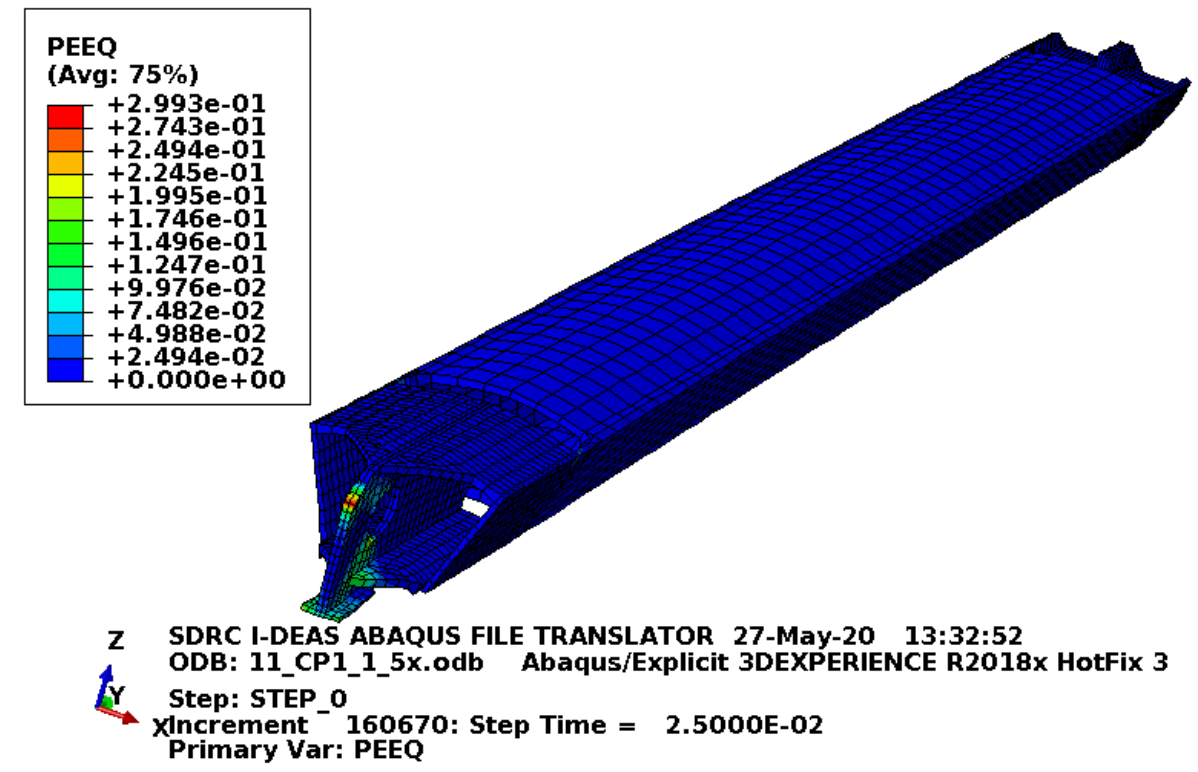

Figure C-164. Scope Part 3 (Table 3), Test 11 (Table 2) fuel element plastic-equivalent strain. 
Figure C-164 shows the equivalent plastic strain in the fuel element. For this model, the fuel element is coarse meshed, massive, and has no failure defined. Consequently, this is just shown for information and is not relevant to the acceptability of the fuel element.

\section{C3.8 Results for Scope Part 3 (Table 3), Test 12 (Table 2)}

The FEA model results are shown below in Figure C-165 to Figure C-172. This drop scenario is a 30-ft drop modeled as a vertical top impact. The fuel element weights $115 \mathrm{lbf}$ and the drop scenario is modeled with the ATR FFSC having minimum material properties and the enclosure and fuel element having relatively tough material properties with no failure.

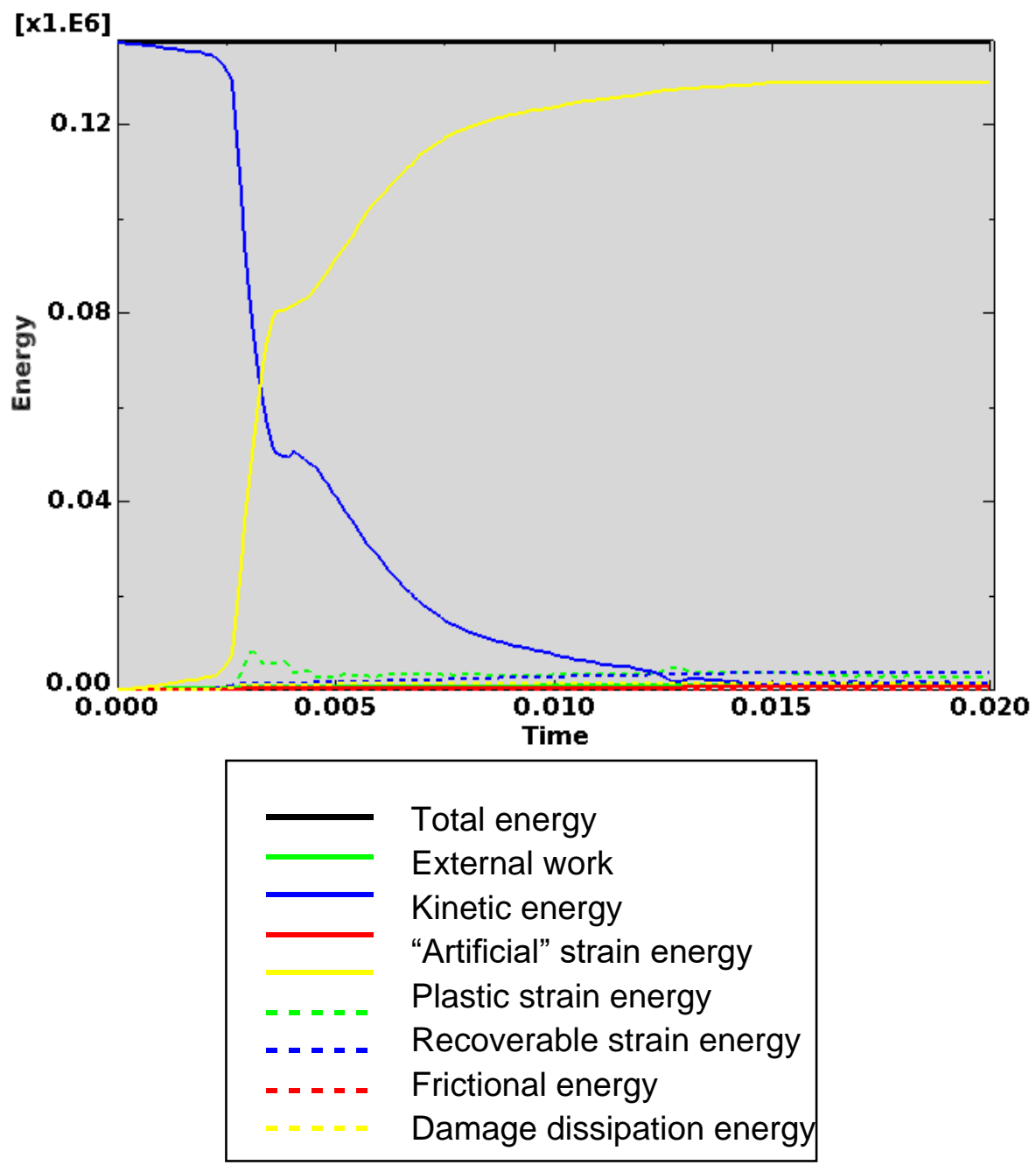

Figure C-165. Scope Part 3 (Table 3), Test 12 (Table 2) energy curves.

Figure C-165 shows the energy curves for Scope Part 3 (Table 3), Test 12 (Table 2) drop scenario. These curves exhibit a stable shape. Artificial energy represents the energy required to keep reduced integration elements from taking on a zero-energy hourglass shape. As shown in Figure C-165, the artificial energy at the end of the model run is $0.5 \%$ of the total energy. Therefore, the potential error associated with artificial energy is not considered to be significant. 


\section{ENGINEERING CALCULATIONS AND ANALYSIS}

Drop Analysis of the Advanced Test Reactor Fresh Fuel Shipping Container with Heavier Low-Enriched Uranium Fuel Contents
ECAR-5224, Rev. 0

Page C114 of C190

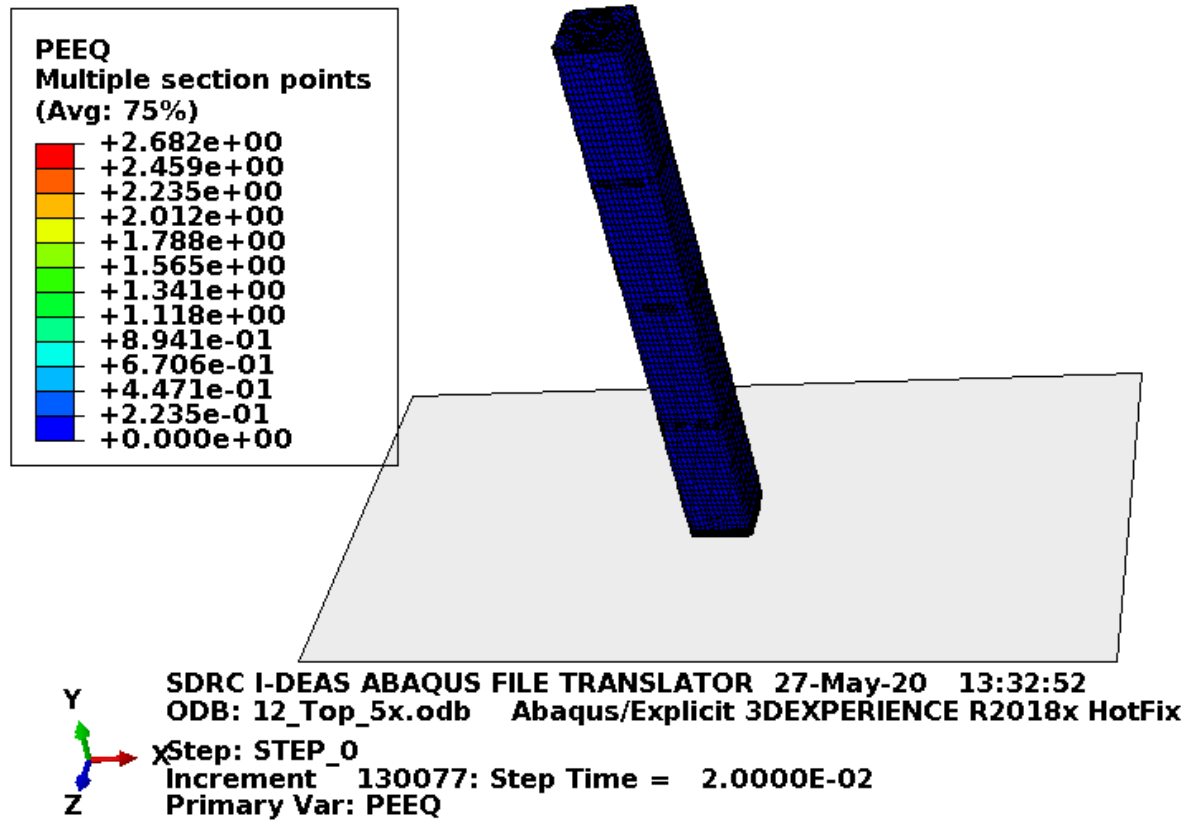

Figure C-166. Scope Part 3 (Table 3), Test 12 (Table 2) full-model plastic-equivalent strain.
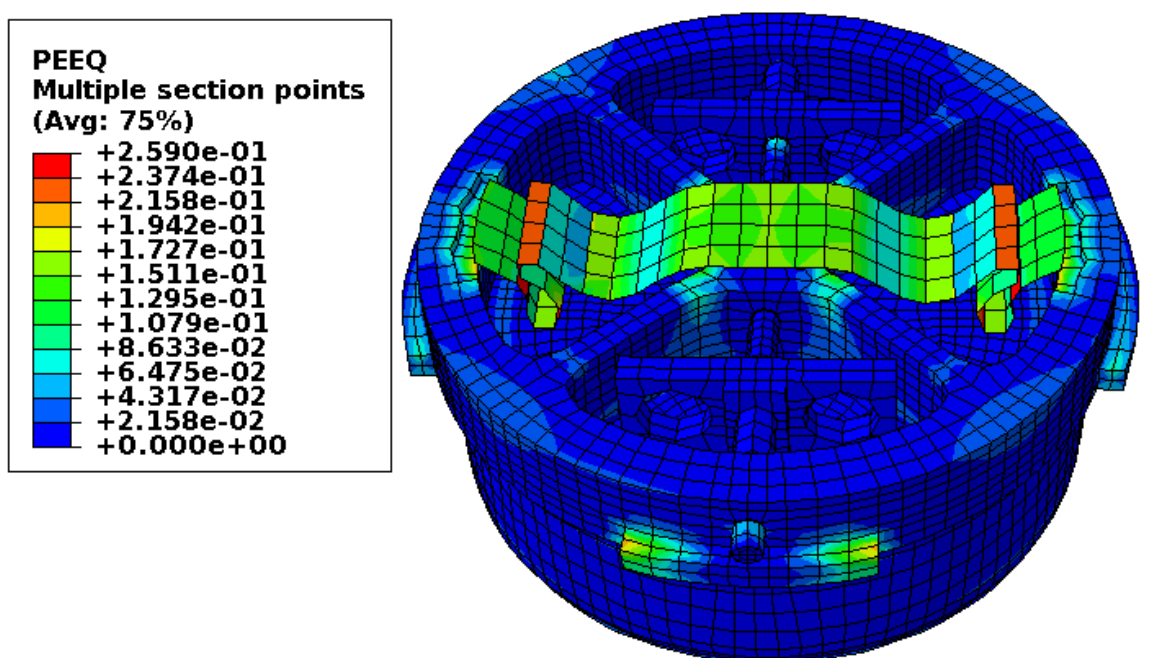

SDRC I-DEAS ABAQUS FILE TRANSLATOR 27-May-20 13:32:52

$Z$ ODB: 12_Top_5x.odb Abaqus/Explicit 3DEXPERIENCE R2018x HotFix

$\longrightarrow$ Step: STEP_o

Increment 130077: Step Time $=$ 2.0000E-02

Primary Var: PEEQ

Figure C-167. Scope Part 3 (Table 3), Test 12 (Table 2) lid plastic-equivalent strain.

Figure C-167 shows the equivalent plastic strain in the lid. The most deformation is in the closure handle, which is not a concern. 

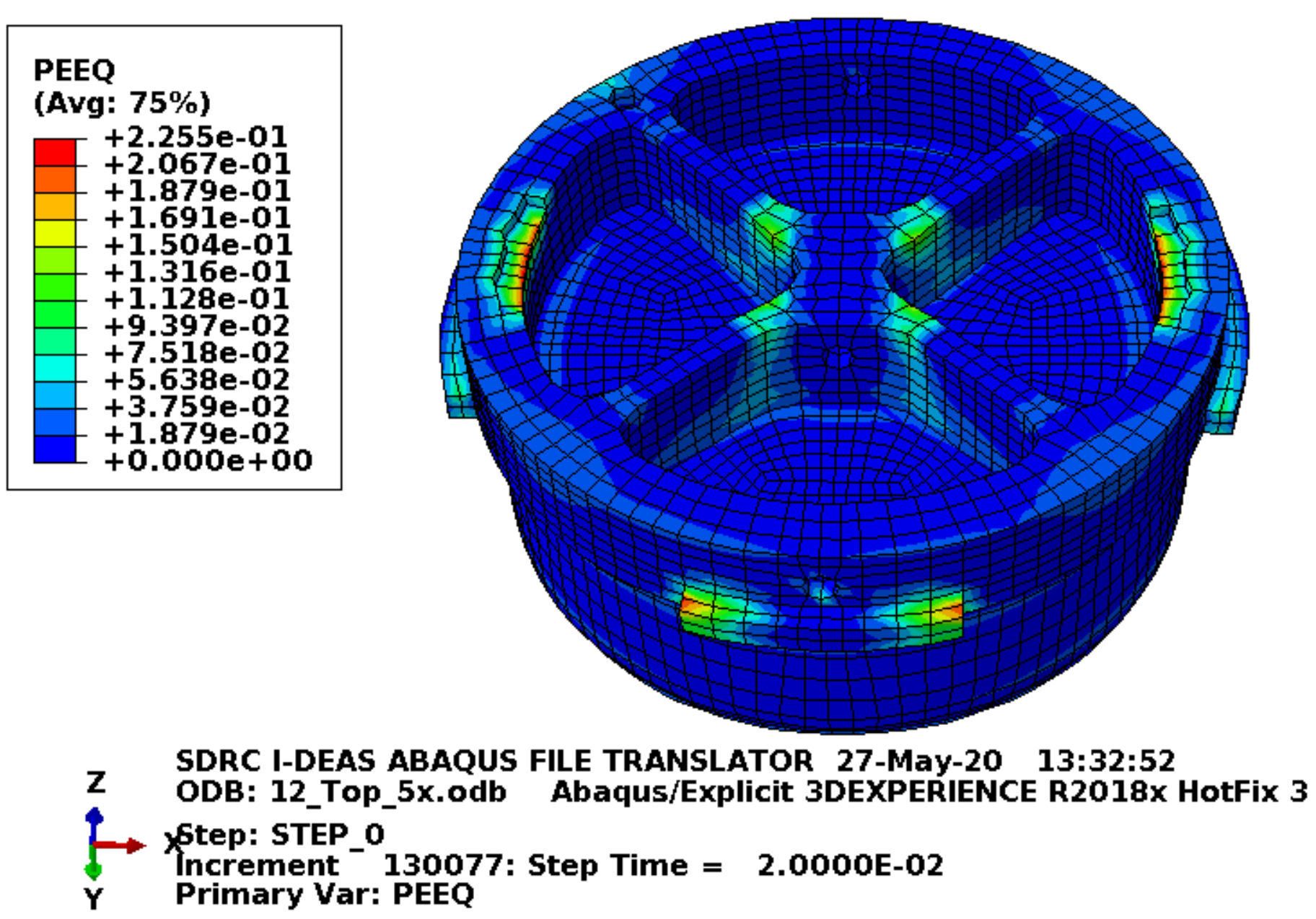

Figure C-168. Scope Part 3 (Table 3), Test 12 (Table 2) lid structure plastic-equivalent strain.

Figure C-168 shows the equivalent plastic strain in the structurally significant portion of the lid. Failure in these elements occurs at an equivalent plastic strain of $0.259 \mathrm{in}$./in. and one element in one bayonet has failed. Since the failed element is deleted and removed from the model, the equivalent plastic strain does not include the maximum equivalent plastic strain in the plot. Figure C-168 shows some failure. However, the failure is acceptable as it does not prevent the lid from providing fuel element containment. 


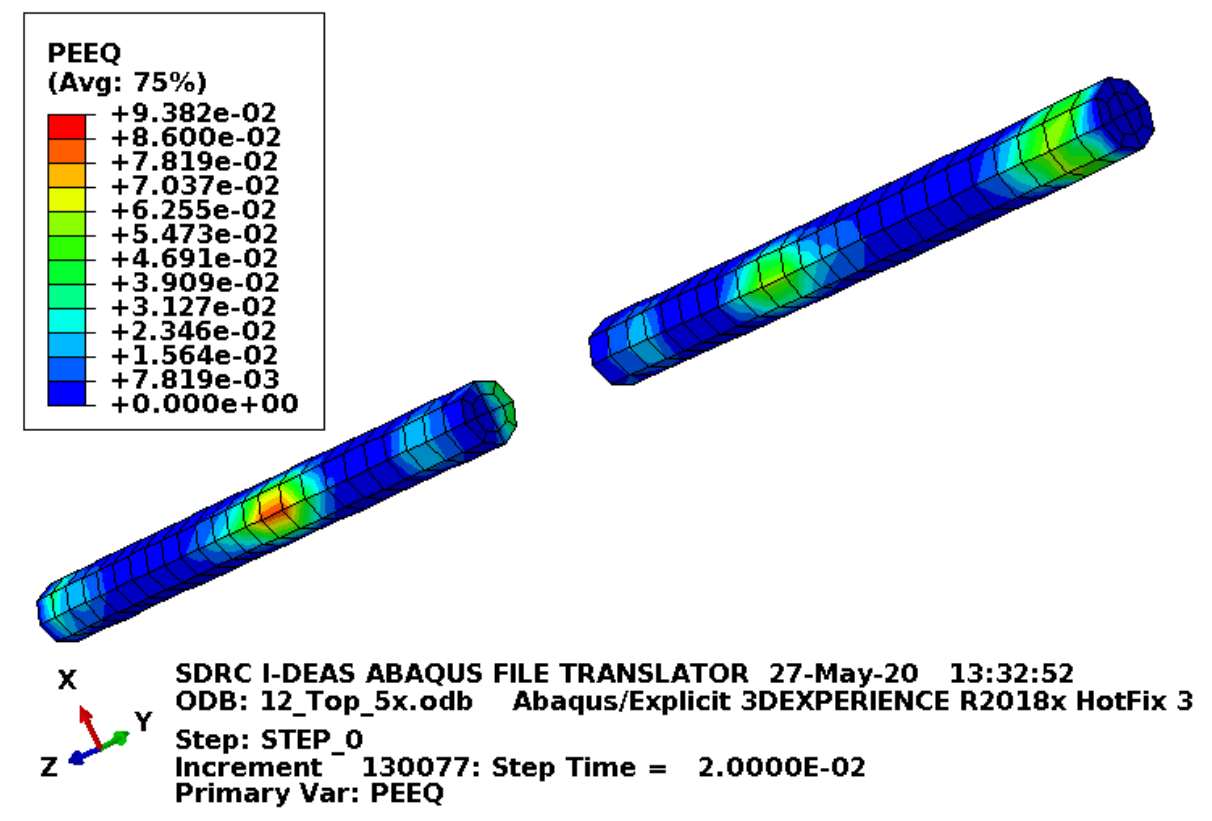

Figure C-169. Scope Part 3 (Table 3), Test 12 (Table 2) lid pins plastic-equivalent strain.

Figure C-169 shows the equivalent plastic strain in the lid pins. Failure in these elements occurs at an equivalent plastic strain of $0.295 \mathrm{in}$./in. If element failure were to occur, the element would be deleted and removed from the model (thereby making its equivalent plastic strain not included in the maximum equivalent plastic strain for the plot). However, the missing element would be visible in the plot.

Figure C-169 shows no element failure with margin.

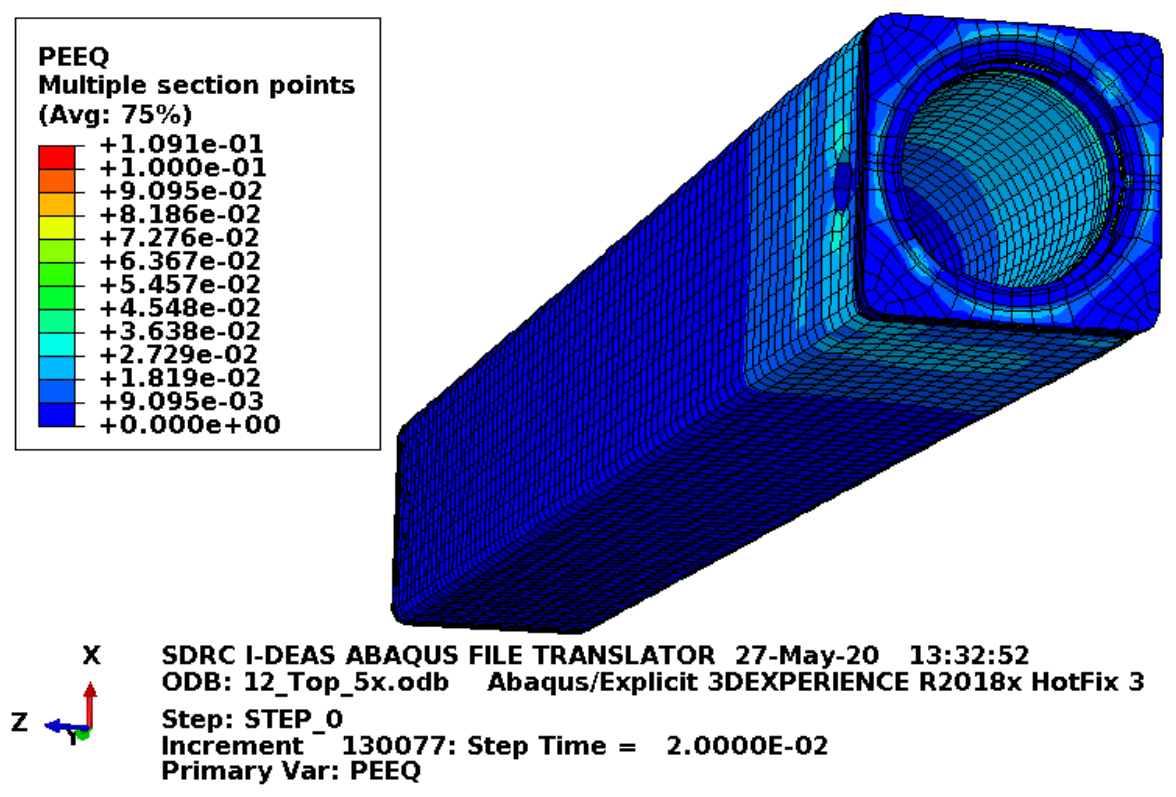

Figure C-170. Scope Part 3 (Table 3), Test 12 (Table 2) body plastic-equivalent strain. 
Figure C-170 shows the equivalent plastic strain in the body. Failure in these elements occurs at an equivalent plastic strain of $0.259 \mathrm{in}$./in. If element failure were to occur, the element would be deleted and removed from the model (thereby making its equivalent plastic strain not included in the maximum equivalent plastic strain for the plot). However, the missing element would be visible in the plot. Figure C-170 shows only failure of the TID posts. The body has no other failure, so it remains functional.

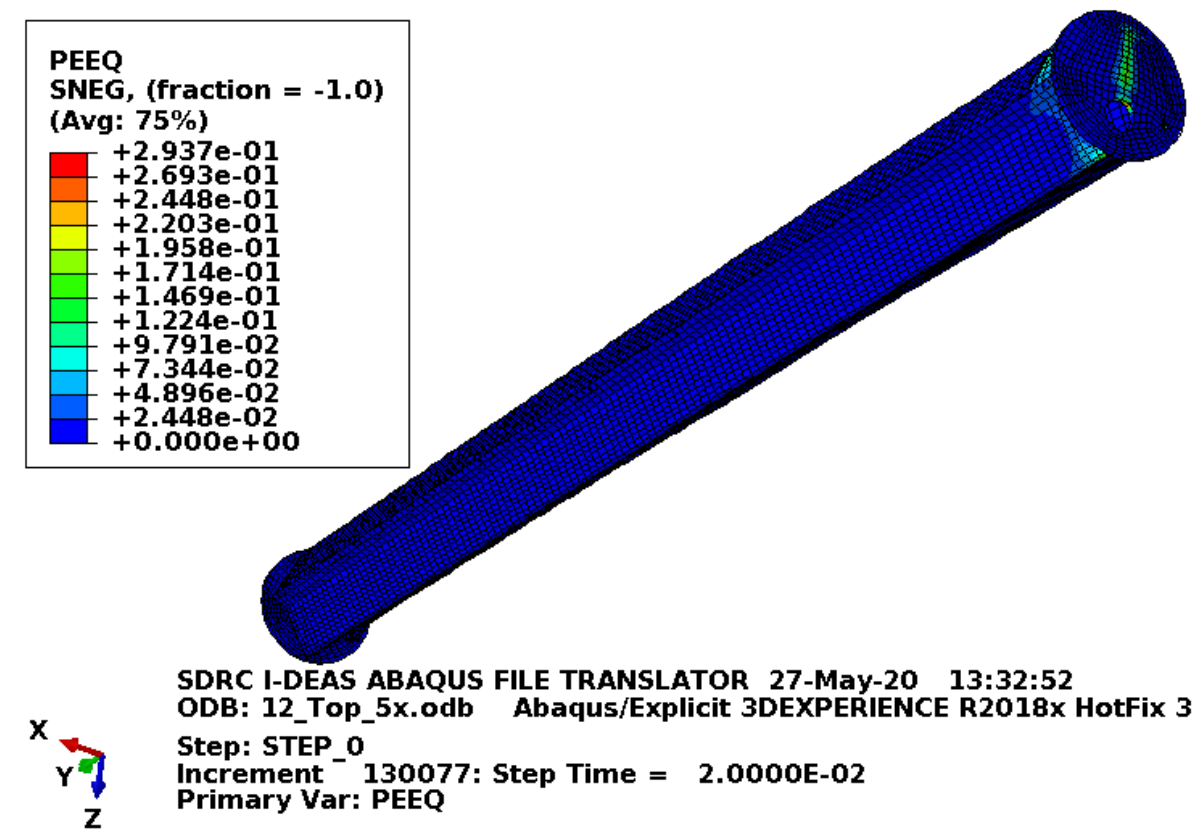

Figure C-171. Scope Part 3 (Table 3), Test 12 (Table 2) enclosure plastic-equivalent strain.

Figure C-171 shows the equivalent plastic strain in the enclosure. This is just for information as damage to the enclosure is acceptable.

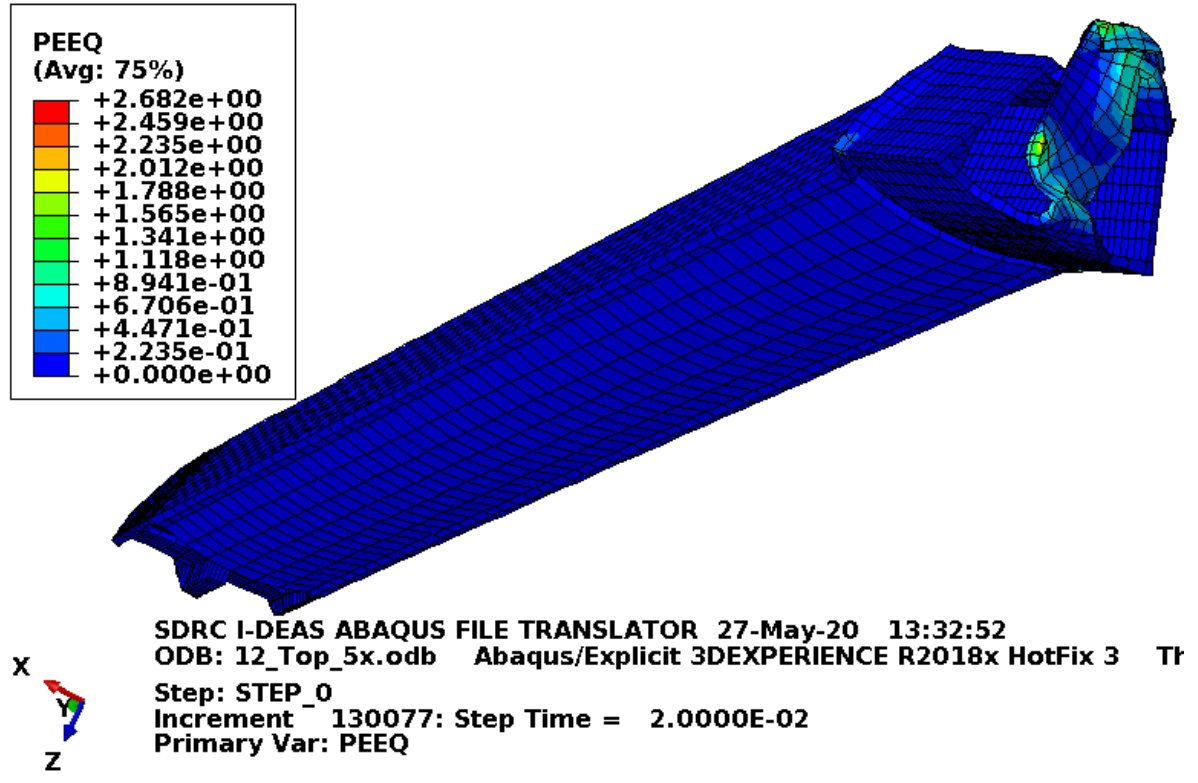

Figure C-172. Scope Part 3 (Table 3), Test 12 (Table 2) fuel element plastic-equivalent strain. 
Figure C-172 shows the equivalent plastic strain in the fuel element. For this model, the fuel element is coarse meshed, massive, and has no failure defined. Consequently, this is just shown for information and is not relevant to the acceptability of the fuel element.

\section{C3.9 Results for Scope Part 3 (Table 3), Test 13 (Table 2)}

The FEA model results are shown below in Figure C-173 to Figure C-180. This drop scenario is a 30-ft drop modeled as a flat-side drop on an edge. The fuel element weights $115 \mathrm{lbf}$ and the drop scenario is modeled with the ATR FFSC having minimum material properties and the enclosure and fuel element having relatively tough material properties with no failure.

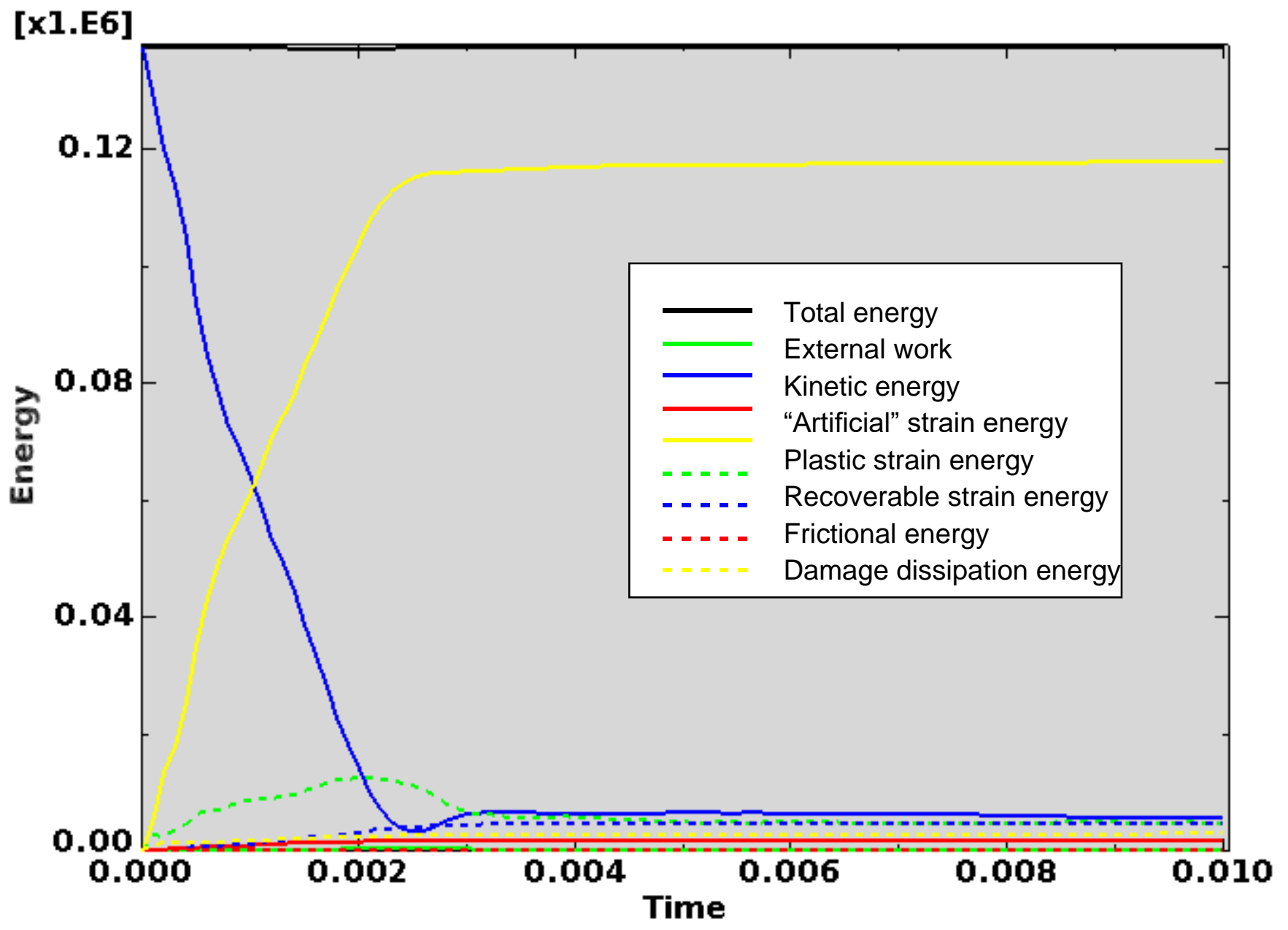

Figure C-173. Scope Part 3 (Table 3), Test 13 (Table 2) energy curves.

Figure C-173 shows the energy curves for Scope Part 3 (Table 3), Test 13 (Table 2) drop scenario. These curves exhibit a stable shape. Artificial energy represents the energy required to keep reduced integration elements from taking on a zero-energy hourglass shape. As shown in Figure C-173, the artificial energy at the end of the model run is $1.3 \%$ of the total energy. Therefore, the potential error associated with artificial energy is not considered to be significant. 
ENGINEERING CALCULATIONS AND ANALYSIS

Drop Analysis of the Advanced Test Reactor Fresh Fuel Shipping Container with Heavier Low-Enriched Uranium Fuel Contents
ECAR-5224, Rev. 0

Page C119 of C190

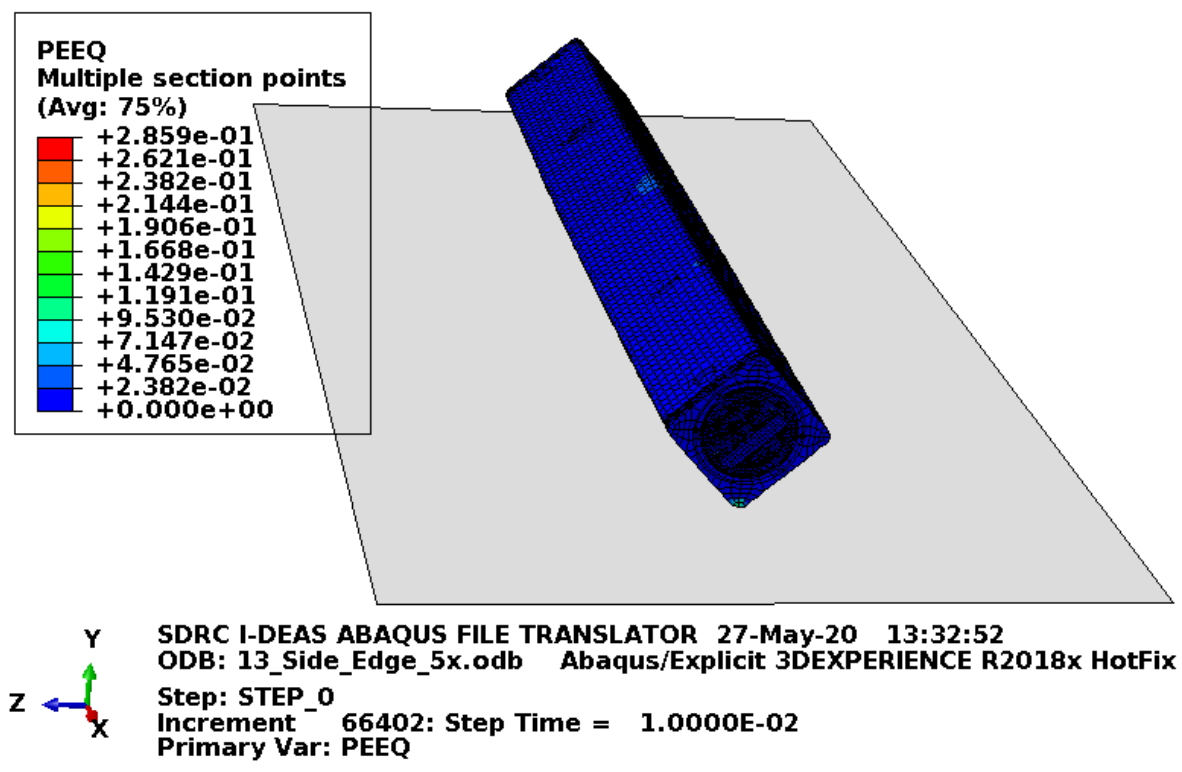

Figure C-174. Scope Part 3 (Table 3), Test 13 (Table 2) full-model plastic-equivalent strain.
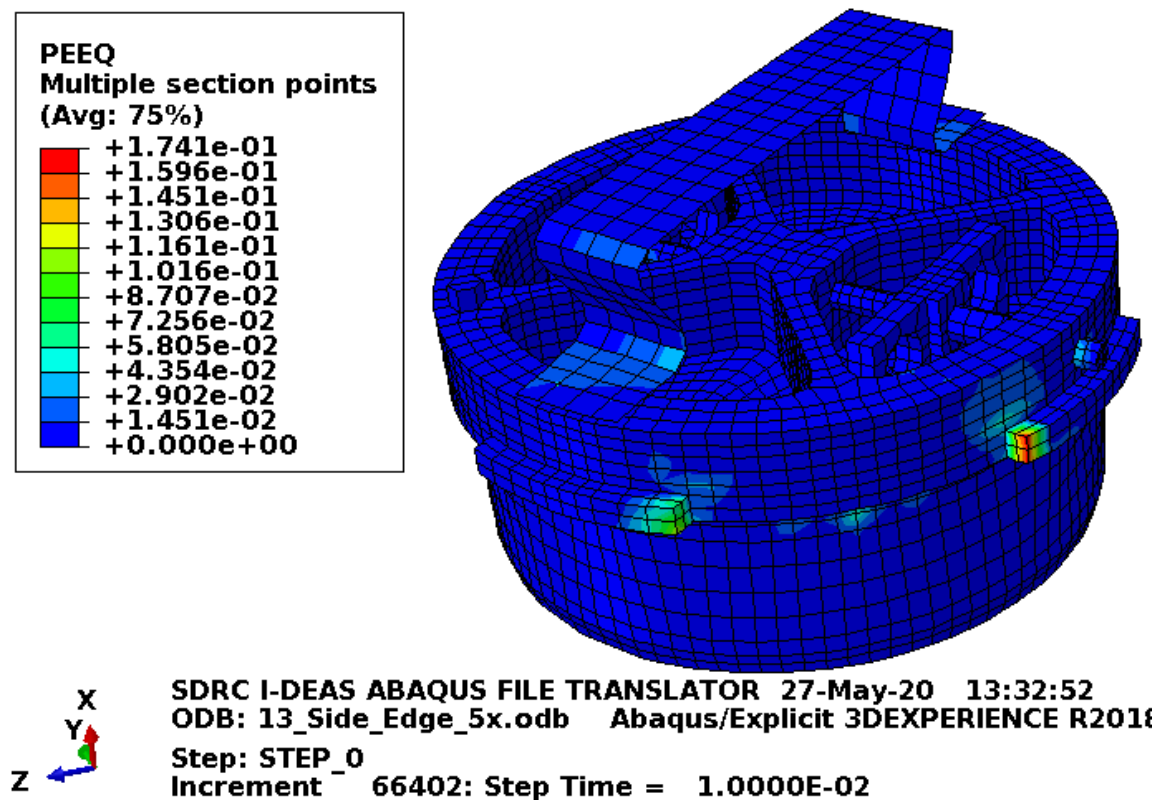

SDRC I-DEAS ABAQUS FILE TRANSLATOR 27-May-20 13:32:52

ODB: 13_Side_Edge_5x.odb Abaqus/Explicit 3DEXPERIENCE R2018x

Step: STEP 0

Increment ${ }^{-}$66402: Step Time $=1.0000 \mathrm{E}-02$

Primary Var: PEEQ

Figure C-175. Scope Part 3 (Table 3), Test 13 (Table 2) lid plastic-equivalent strain. 
ENGINEERING CALCULATIONS AND ANALYSIS

Drop Analysis of the Advanced Test Reactor Fresh Fuel Shipping Container with Heavier Low-Enriched Uranium Fuel Contents
ECAR-5224, Rev. 0

Page $\mathrm{C} 120$ of $\mathrm{C} 190$
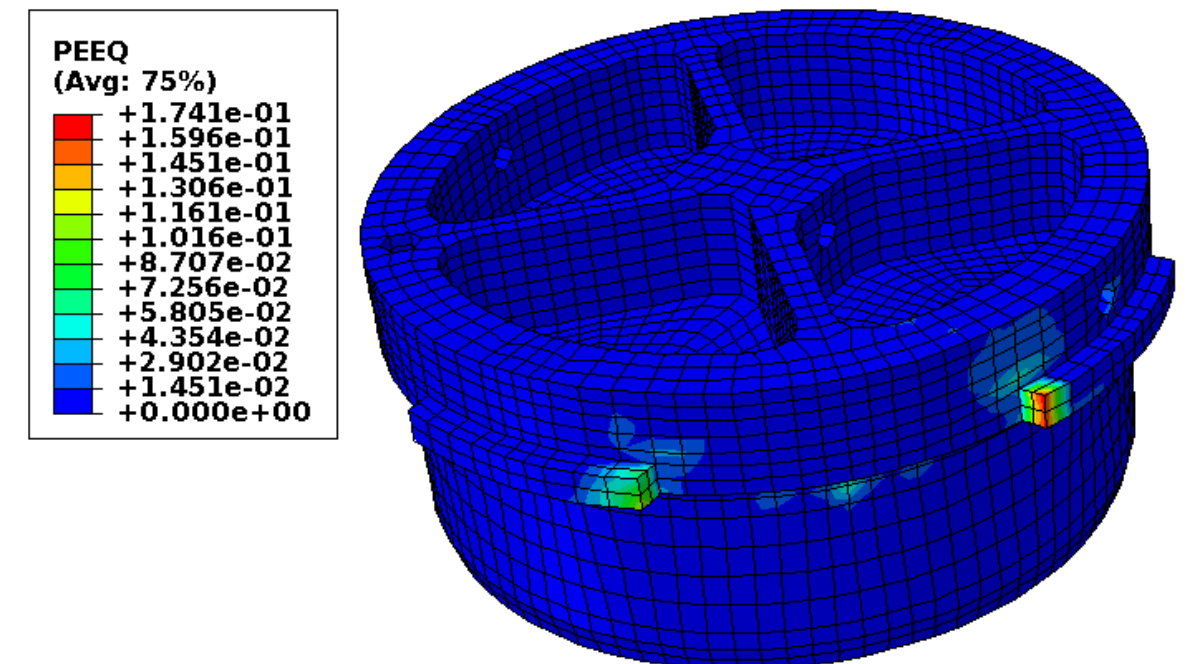

$$
z
$$

SDRC I-DEAS ABAQUS FILE TRANSLATOR 27-May-20 13:32:52

ODB: 13_Side_Edge_5x.odb Abaqus/Explicit 3DEXPERIENCE R2018x

Step: STEP_o

Increment ${ }^{-}$66402: Step Time $=1.0000 \mathrm{E}-02$

Primary Var: PEEQ

Figure C-176. Scope Part 3 (Table 3), Test 13 (Table 2) lid structure plastic-equivalent strain.

Figure C-176 shows the equivalent plastic strain in the structurally significant portion of the lid. Failure in these elements occurs at an equivalent plastic strain of $0.259 \mathrm{in}$./in. If element failure were to occur, the element would be deleted and removed from the model (thereby making its equivalent plastic strain not included in the maximum equivalent plastic strain for the plot). However, the missing element would be visible in the plot. Figure $\mathrm{C}-176$ shows no element failure.

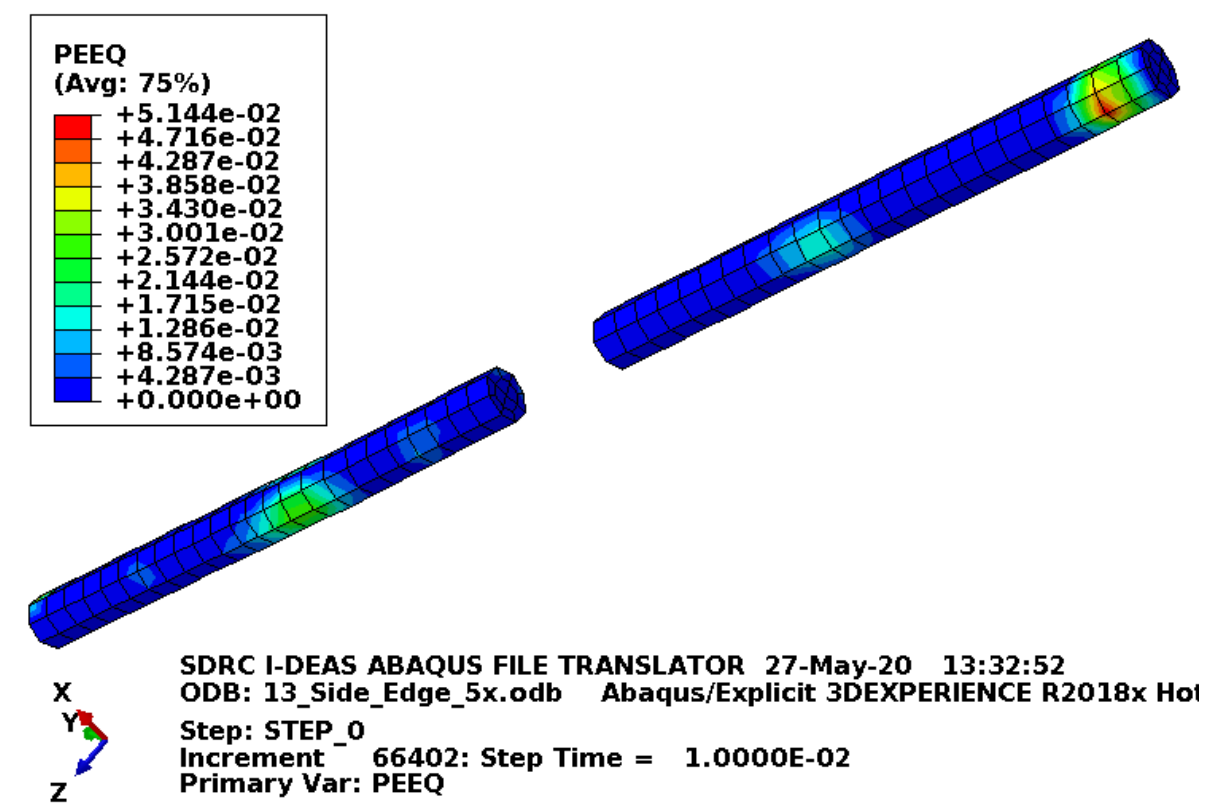

Figure C-177. Scope Part 3 (Table 3), Test 13 (Table 2) lid pins plastic-equivalent strain. 
Figure C-177 shows the equivalent plastic strain in the lid pins. Failure in these elements occurs at an equivalent plastic strain of $0.295 \mathrm{in}$./in. If element failure were to occur, the element would be deleted and removed from the model (thereby making its equivalent plastic strain not included in the maximum equivalent plastic strain for the plot). However, the missing element would be visible in the plot. Figure C-177 shows no element failure with margin.

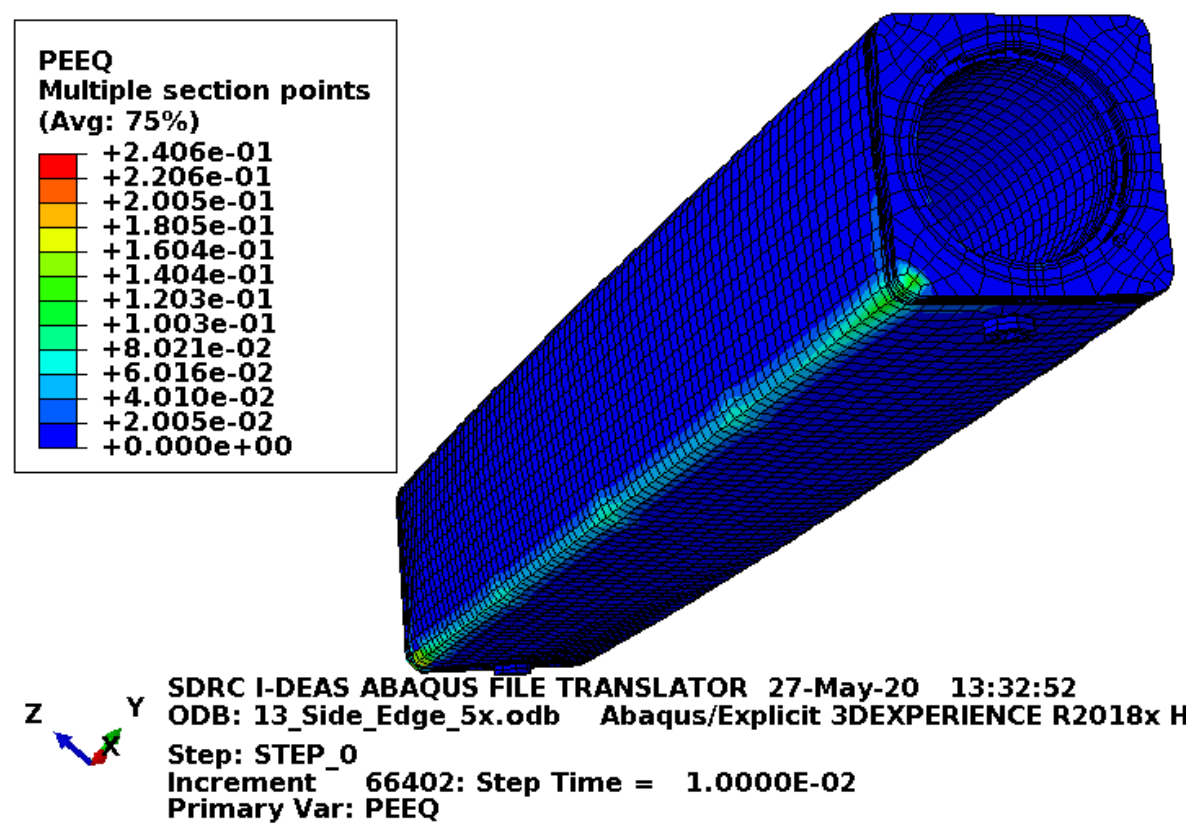

Figure C-178. Scope Part 3 (Table 3), Test 13 (Table 2) body plastic-equivalent strain.

Figure C-178 shows the equivalent plastic strain in the body. Failure in these elements occurs at an equivalent plastic strain of 0.259 in./in. If element failure were to occur, the element would be deleted and removed from the model (thereby making its equivalent plastic strain not included in the maximum equivalent plastic strain for the plot). However, the missing element would be visible in the plot. Figure C-178 shows no element failure. 
ENGINEERING CALCULATIONS AND ANALYSIS

Drop Analysis of the Advanced Test Reactor Fresh Fuel Shipping Container with Heavier Low-Enriched Uranium Fuel Contents

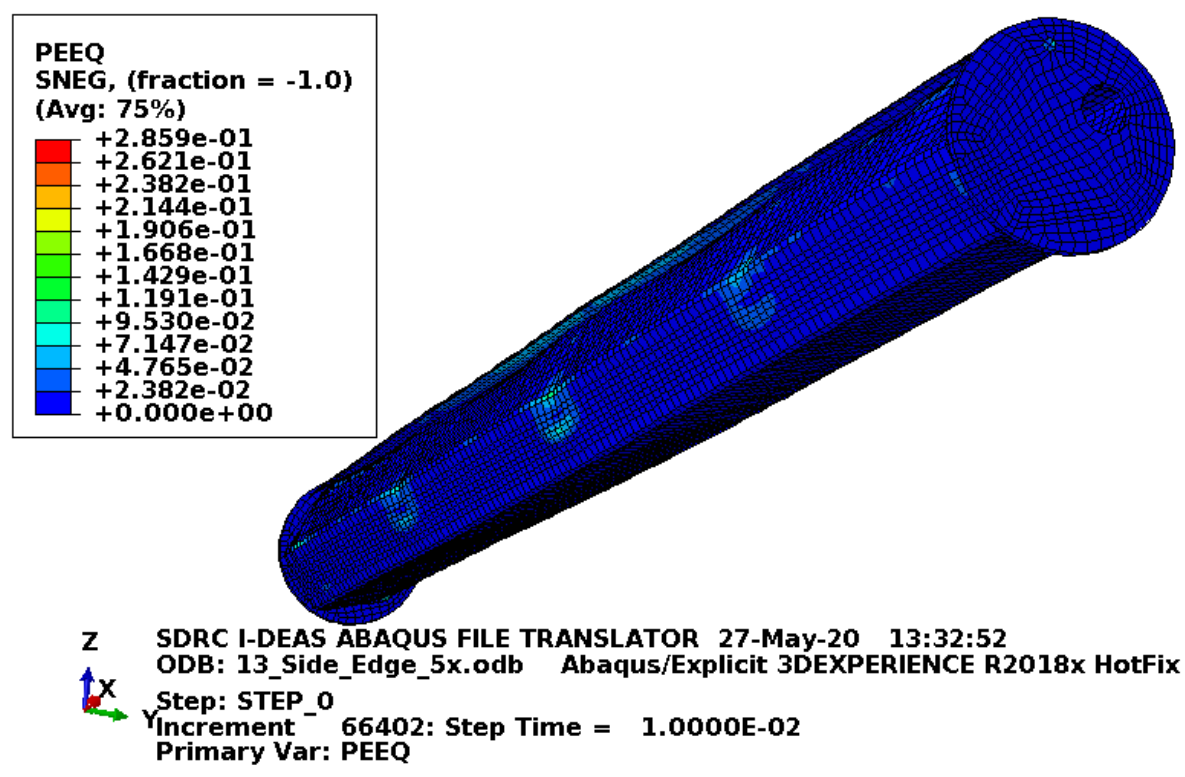

Figure C-179. Scope Part 3 (Table 3), Test 13 (Table 2) enclosure plastic-equivalent strain.

Figure $\mathrm{C}-179$ shows the equivalent plastic strain in the enclosure. This is just for information as damage to the enclosure is acceptable.

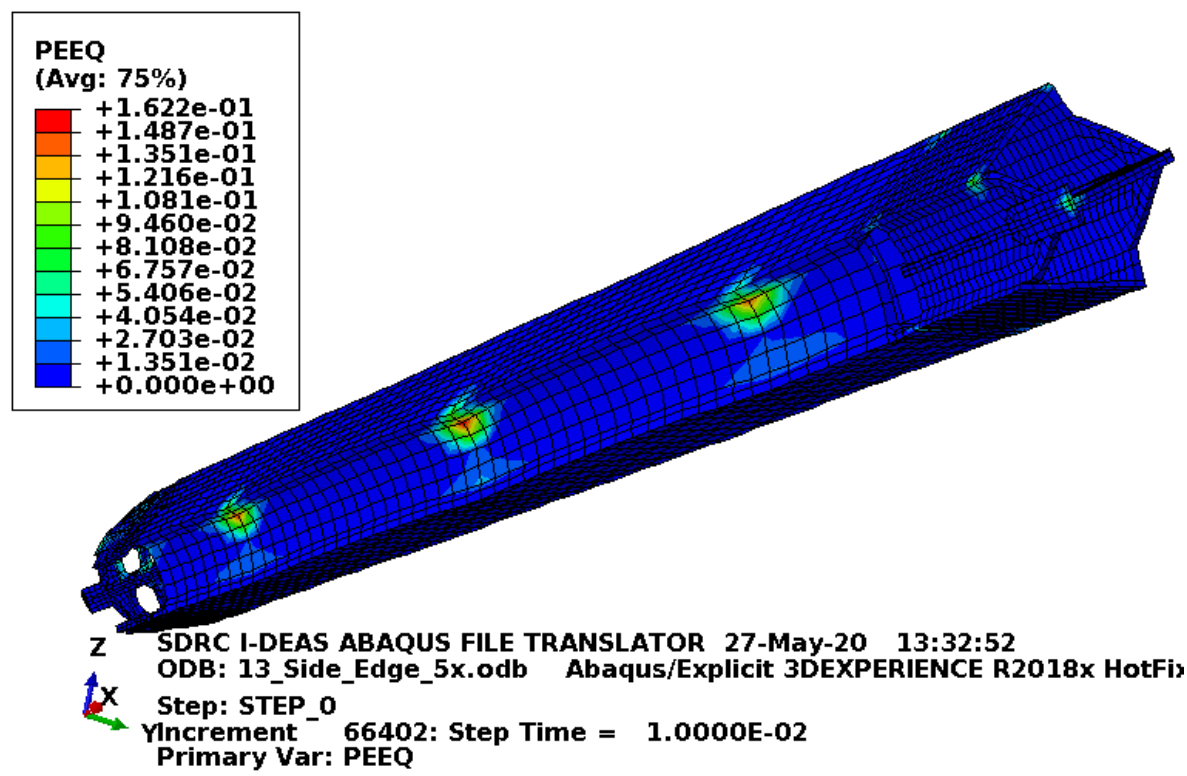

Figure C-180. Scope Part 3 (Table 3), Test 13 (Table 2) fuel element plastic-equivalent strain.

Figure C-180 shows the equivalent plastic strain in the fuel element. For this model, the fuel element is coarse meshed, massive, and has no failure defined. Consequently, this is just shown for information and is not relevant to the acceptability of the fuel element. 


\section{C3.10 Results for Scope Part 3 (Table 3), Test 14 (Table 2)}

The FEA model results are shown below in Figure C-181 to Figure C-188. This drop scenario is a $30-\mathrm{ft}$ slap--own drop with pockets and index lugs on the sides. The impact orientation is 20 degrees off horizontal with the ATR FFSC bottom hitting first. The fuel element weights $115 \mathrm{lbf}$ and the drop scenario is modeled with the ATR FFSC having minimum material properties and the enclosure and fuel element having relatively tough material properties with no failure.

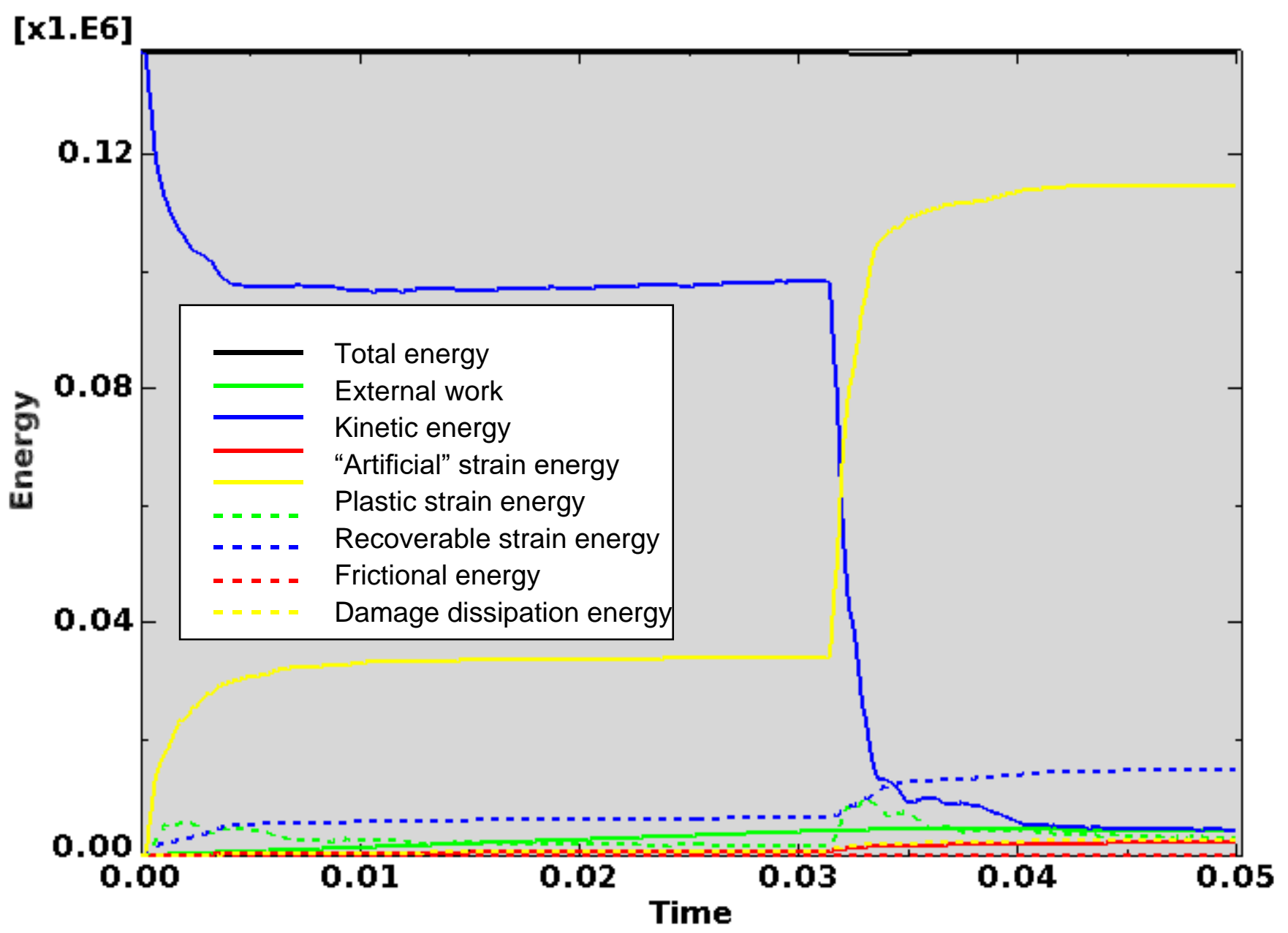

Figure C-181. Scope Part 3 (Table 3), Test 14 (Table 2) energy curves.

Figure C-181 shows the energy curves for Scope Part 3 (Table 3), Test 14 (Table 2) drop scenario. These curves exhibit a stable shape. Artificial energy represents the energy required to keep reduced integration elements from taking on a zero-energy hourglass shape. As shown in Figure C-181, the artificial energy at the end of the model run is $1.7 \%$ of the total energy. Therefore, the potential error associated with artificial energy is not considered to be significant. 
ENGINEERING CALCULATIONS AND ANALYSIS

Drop Analysis of the Advanced Test Reactor Fresh Fuel Shipping Container with Heavier Low-Enriched Uranium Fuel Contents
ECAR-5224, Rev. 0

Page C124 of C190

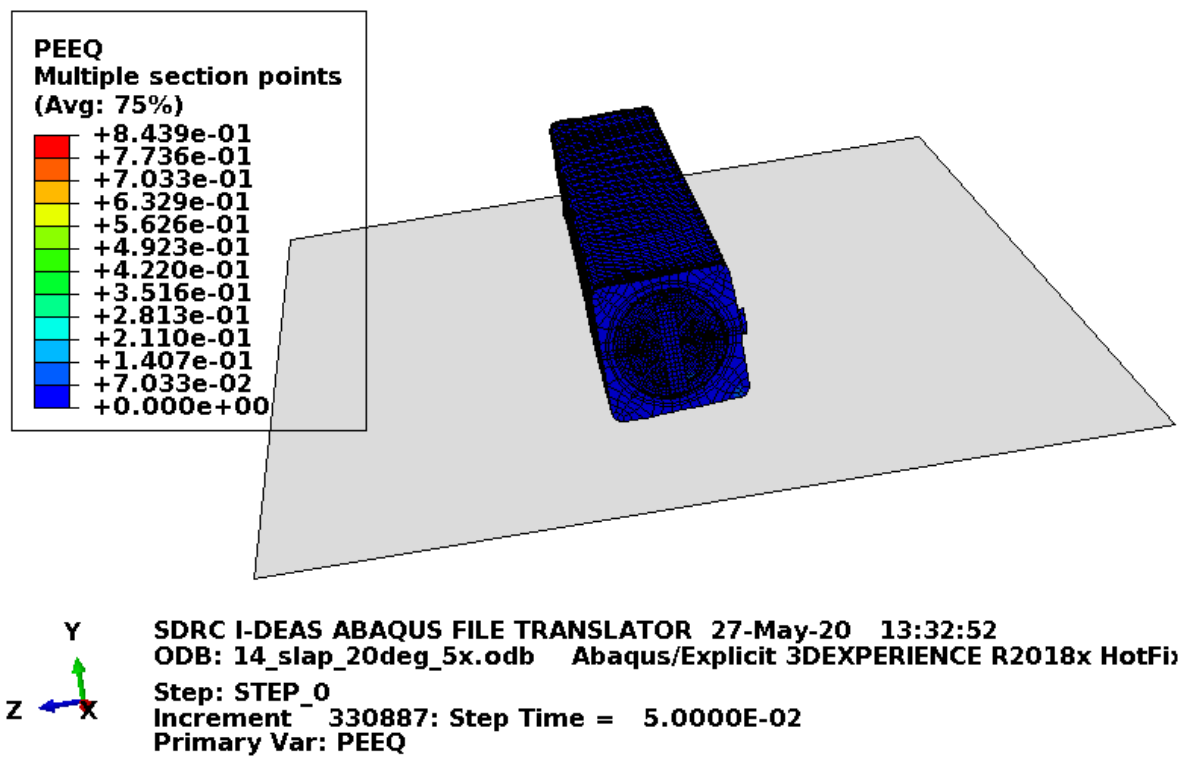

Figure C-182. Scope Part 3 (Table 3), Test 14 (Table 2) full-model plastic-equivalent strain.
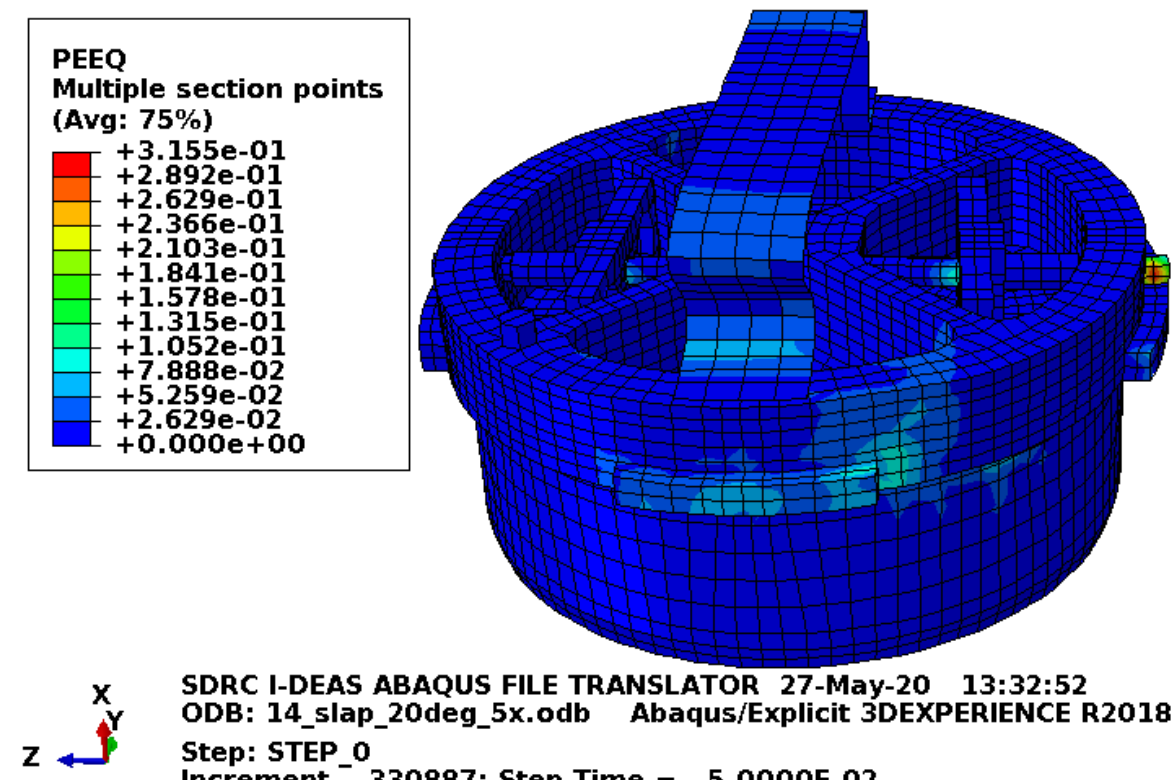

SDRC I-DEAS ABAQUS FILE TRANSLATOR 27-May-20 13:32:52 ODB: 14_slap_20deg_5x.odb Abaqus/Explicit 3DEXPERIENCE R2018x Step: STEP_o

Increment 330887 : Step Time $=$ 5.0000E-02

Primary Var: PEEQ

Figure C-183. Scope Part 3 (Table 3), Test 14 (Table 2) lid plastic-equivalent strain. 
ENGINEERING CALCULATIONS AND ANALYSIS

Drop Analysis of the Advanced Test Reactor Fresh Fuel Shipping Container with Heavier Low-Enriched Uranium Fuel Contents

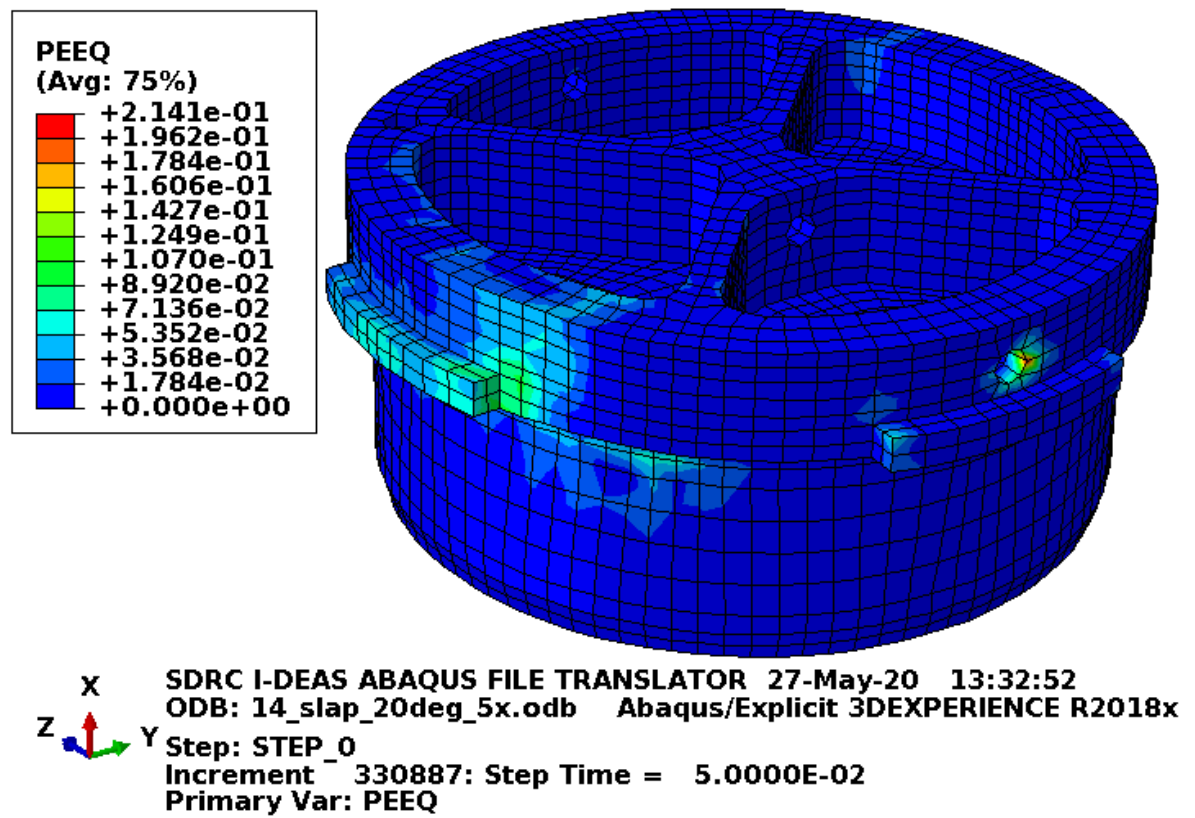

Figure C-184. Scope Part 3 (Table 3), Test 14 (Table 2) lid structure plastic-equivalent strain.

Figure C-184 shows the equivalent plastic strain in the structurally significant portion of the lid. Failure in these elements occurs at an equivalent plastic strain of $0.259 \mathrm{in}$./in. If element failure were to occur, the element would be deleted and removed from the model (thereby making its equivalent plastic strain not included in the maximum equivalent plastic strain for the plot). However, the missing element would be visible in the plot. Figure C-184 shows no element failure.

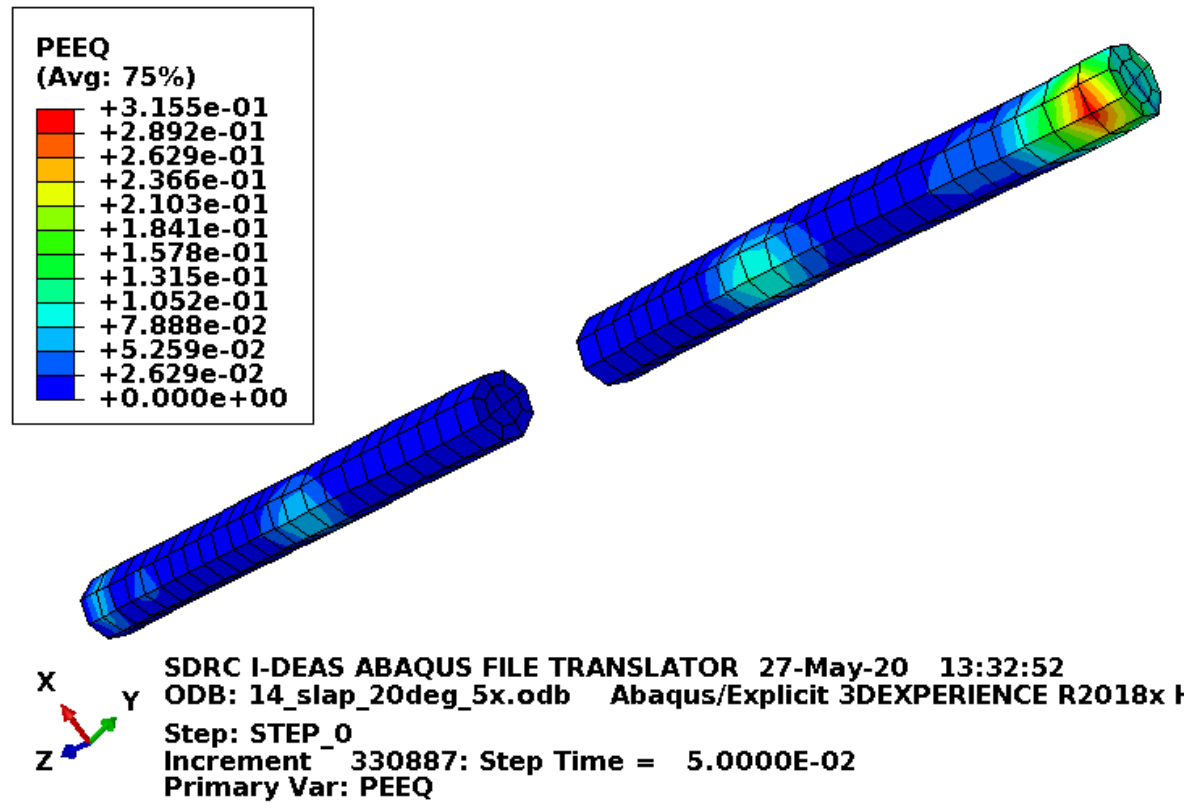

Figure C-185. Scope Part 3 (Table 3), Test 14 (Table 2) lid pins plastic-equivalent strain. 
Figure C-185 shows the equivalent plastic strain in the lid pins. Failure in these elements occurs at an equivalent plastic strain of $0.295 \mathrm{in}$./in. If element failure were to occur, the element would be deleted and removed from the model (thereby making its equivalent plastic strain not included in the maximum equivalent plastic strain for the plot). However, the missing element would be visible in the plot.

Figure C-185 shows no element failure, but above failure strain values are shown in one lid pin. The strains shown above the failure strain likely result from extrapolation (as integration point strains are the important strains for failure). If these elements were considered as having failed (which represents less than $20 \%$ of the lid pin cross section), it would still be acceptable.

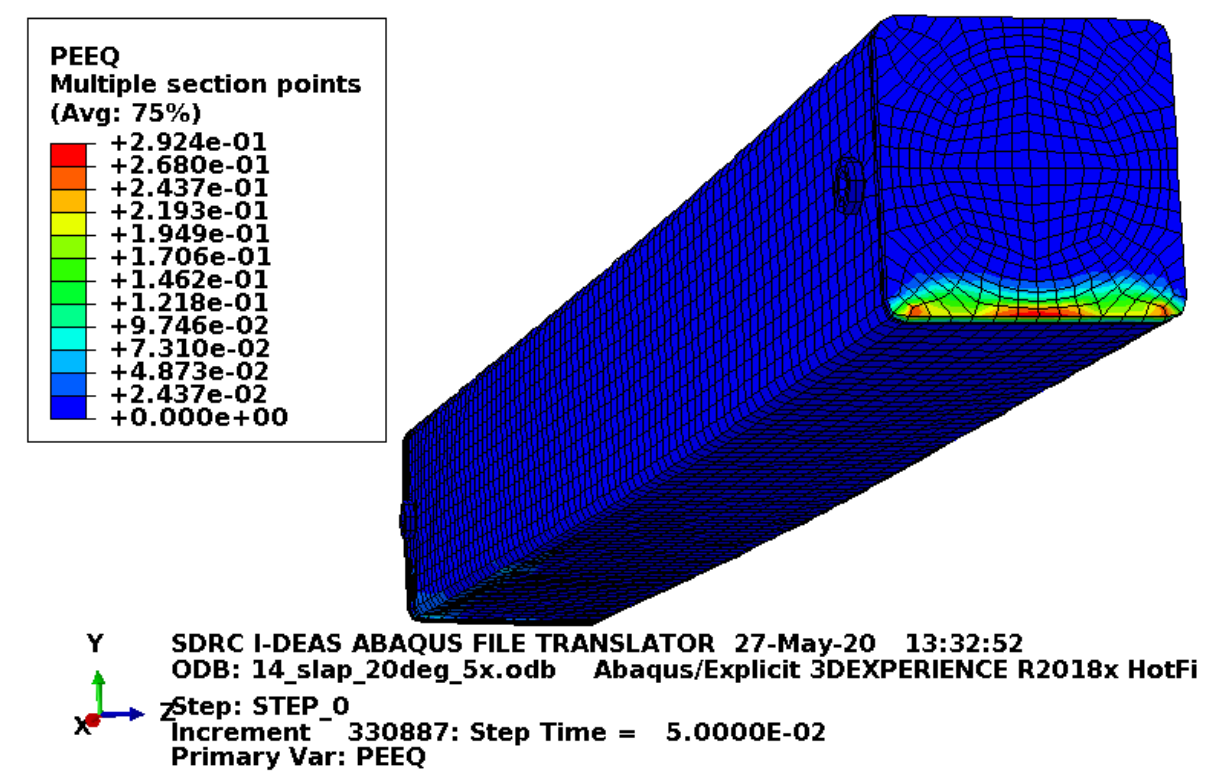

Figure C-186. Scope Part 3 (Table 3), Test 14 (Table 2) body plastic-equivalent strain.

Figure C-186 shows the equivalent plastic strain in the body. Failure in these elements occurs at an equivalent plastic strain of $0.259 \mathrm{in}$./in. If element failure were to occur, the element would be deleted and removed from the model (thereby making its equivalent plastic strain not included in the maximum equivalent plastic strain for the plot). However, the missing element would be visible in the plot. above shows no element failure, but above failure strain values are shown in the base plate of the ATR FFSC. These are very local strains from the initial impact. The strains shown above the failure strain likely result from extrapolation (as integration point strains are the important strains for failure). It is acceptable if these elements were considered as having failed. 
ENGINEERING CALCULATIONS AND ANALYSIS

Drop Analysis of the Advanced Test Reactor Fresh Fuel Shipping Container with Heavier Low-Enriched Uranium Fuel Contents

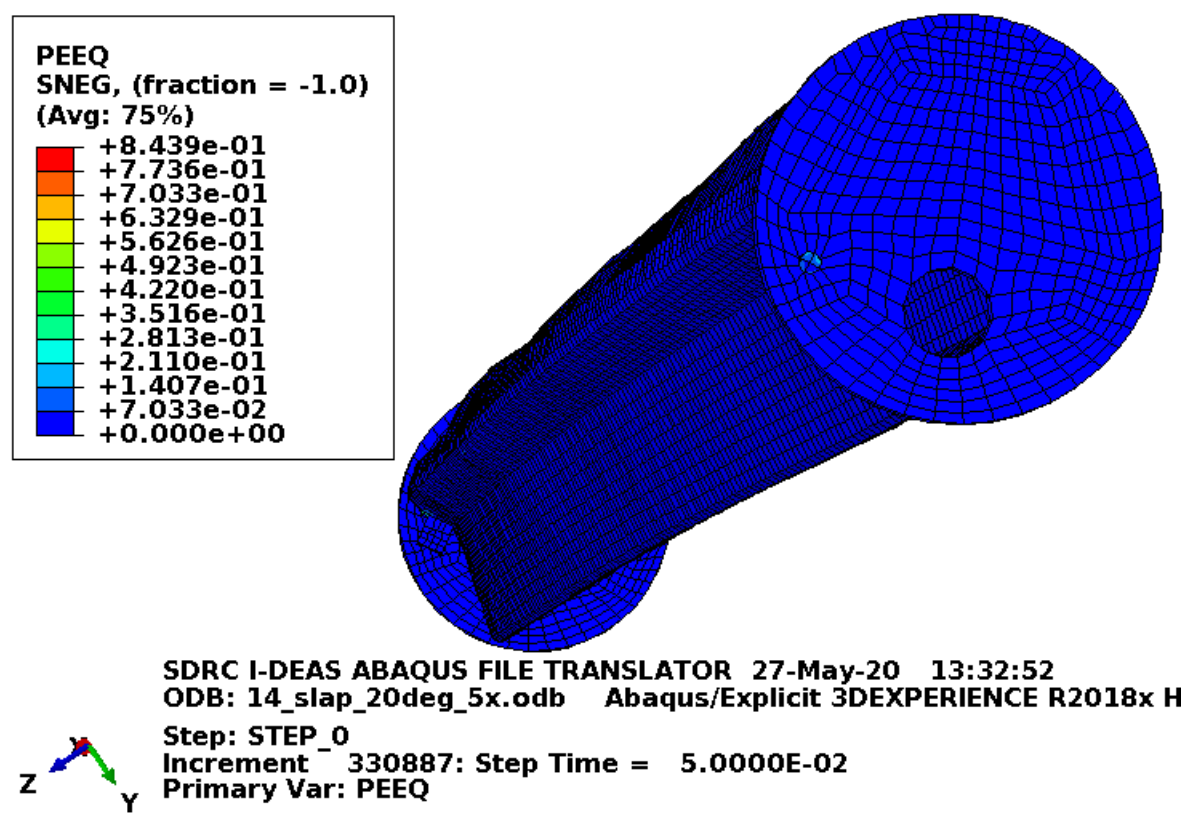

Figure C-187. Scope Part 3 (Table 3), Test 14 (Table 2) enclosure plastic-equivalent strain.

Figure $\mathrm{C}-187$ shows the equivalent plastic strain in the enclosure. This is just for information as damage to the enclosure is acceptable.

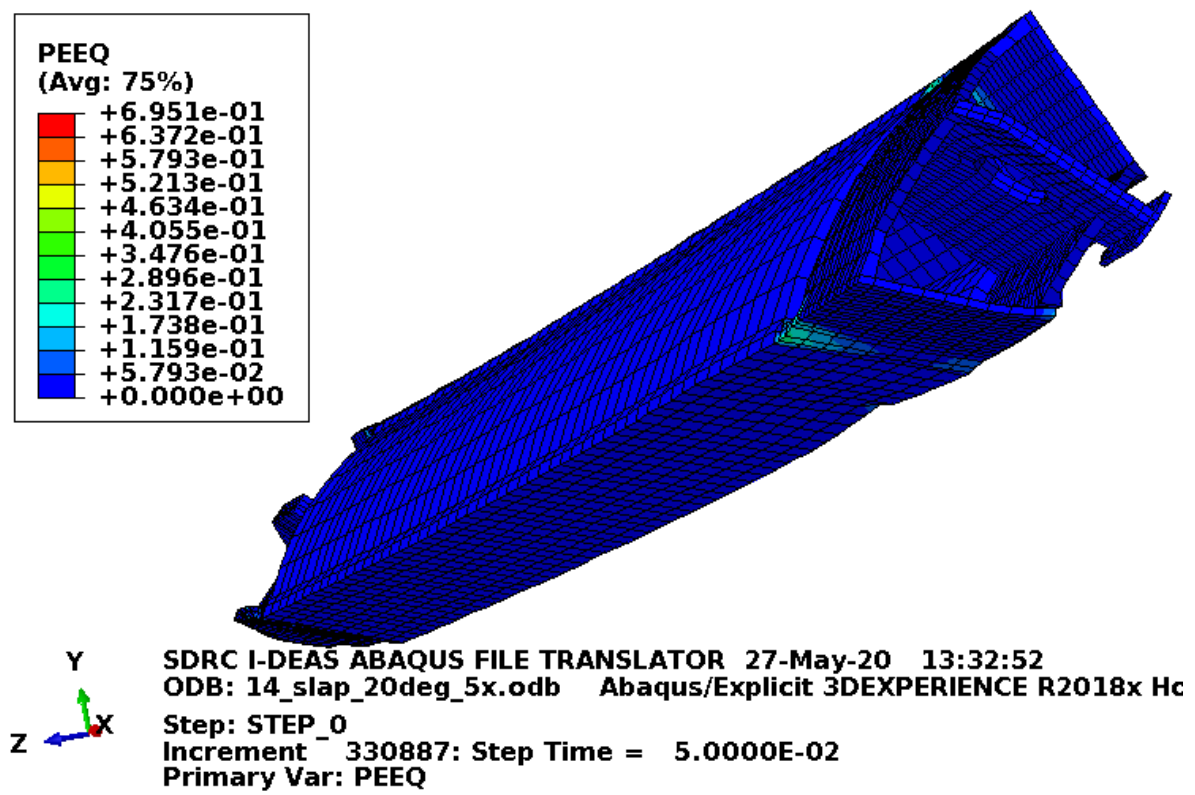

Figure C-188. Scope Part 3 (Table 3), Test 14 (Table 2) fuel element plastic-equivalent strain.

Figure C-188 shows the equivalent plastic strain in the fuel element. For this model, the fuel element is coarse meshed, massive, and has no failure defined. Consequently, this is just shown for information and is not relevant to the acceptability of the fuel element. 


\section{C3.11 Summary of Results for Scope Part 1 (Table 3)}

The Scope Part 1 (Table 3) results (see Section C2) demonstrated that the FEA models produce reasonable results with conservatively more damage than the equivalent physical drops. The Scope Part 3 (Table 3) results given in this section use the same ATR FFSC model and a fuel element weight of $115 \mathrm{lbf}$ (which is five times the fuel element weight of the physical drops rounded up to the nearest 5-lbf interval). For additional conservatism, the enclosure and fuel element are conservatively stiff and not allowed to fail. Also, a $5 \%$ impact energy increase is added to conservatively compensate for possible error associated with energy. This set of model runs is intended to easily envelope the planned fuel element weight, which may be carried by the ATR FFSC including the 44-lbf weight of the LOWE fuel element Per Quirl (2019). Even with the added conservatism in this section, all the FEA models showed acceptable results for the ATR FFSC (considering Tests 1 to 4 , Table 4 in the main body of this report).

\section{C4 ATR FFSC LID PIN STUDY RESULTS (SCOPE PART 4, TABLE 3)}

As described in Section C2.4.1, one of the lid pins in lid sheared off between the lid and body in the physical drop for Scope Part 1 (Table 3), Test 5 (Table 2). Considering the discussion with Figure C-45, it's difficult to make a solid case for why the lid pin sheared given the description in Section C2.4.1. However, the lid pin shear occurred in the fourth consecutive side drop from 30 feet and they all rotated upon rebound. Given this information along with the scoping model evidence, lid pin damage occurring from rebound rotation is studied as the primary load path for shearing the lid pins. The FEA models in this section attempt to capture worst-case lid pin damage from rotation about an axis along the length of the ATR FFSC.

Two sets of models are considered in this section. First, models similar to the physical drops (22.1-lbf fuel element) are performed. The motivation is to check if it is likely that a single drop could fail a lid pin. If lid pin failure is not demonstrated, then the results help support the idea that multiple drops are necessary to produce lid pin failure. Second, high weight models (115-lbf fuel element) are performed. The motivation is to check if the more massive drop makes lid pin failure more likely.

Sections C4.1-C4.6 show the FEA model results for the Scope Part 3 (Table 3) drop scenarios and Section $\mathrm{C} 4.7$ provides a summary of the results.

\section{C4.1 Results for Scope Part 4 (Table 3), Impacting 5 Degrees Off Horizontal}

The drop scenario considered in this section is a 30-ft drop modeled as a side drop with the pockets and index lugs on the sides. It is oriented 5 degrees off horizontal about an axis along the length of the ATR FFSC.

\section{C4.1.1 Results for Scope Part 4 (Table 3) with 22.1-Ibf Fuel Element and Impacting 5 Degrees Off Horizontal}

The FEA model results for the Scope Part 4 (Table 3) with 22.1-lbf fuel element weight and impacting 5 degrees off horizontal model are shown below in Figure C-189 to Figure C-196. This drop scenario is a 30-ft drop modeled as a side drop with the pockets and index lugs on the sides. The 5 degrees off horizontal angle is a rotation about an axis along the length of the ATR FFSC. The drop scenario is modeled with minimum material properties except the enclosure and end boxes, which are modeled with relatively tough material properties. 


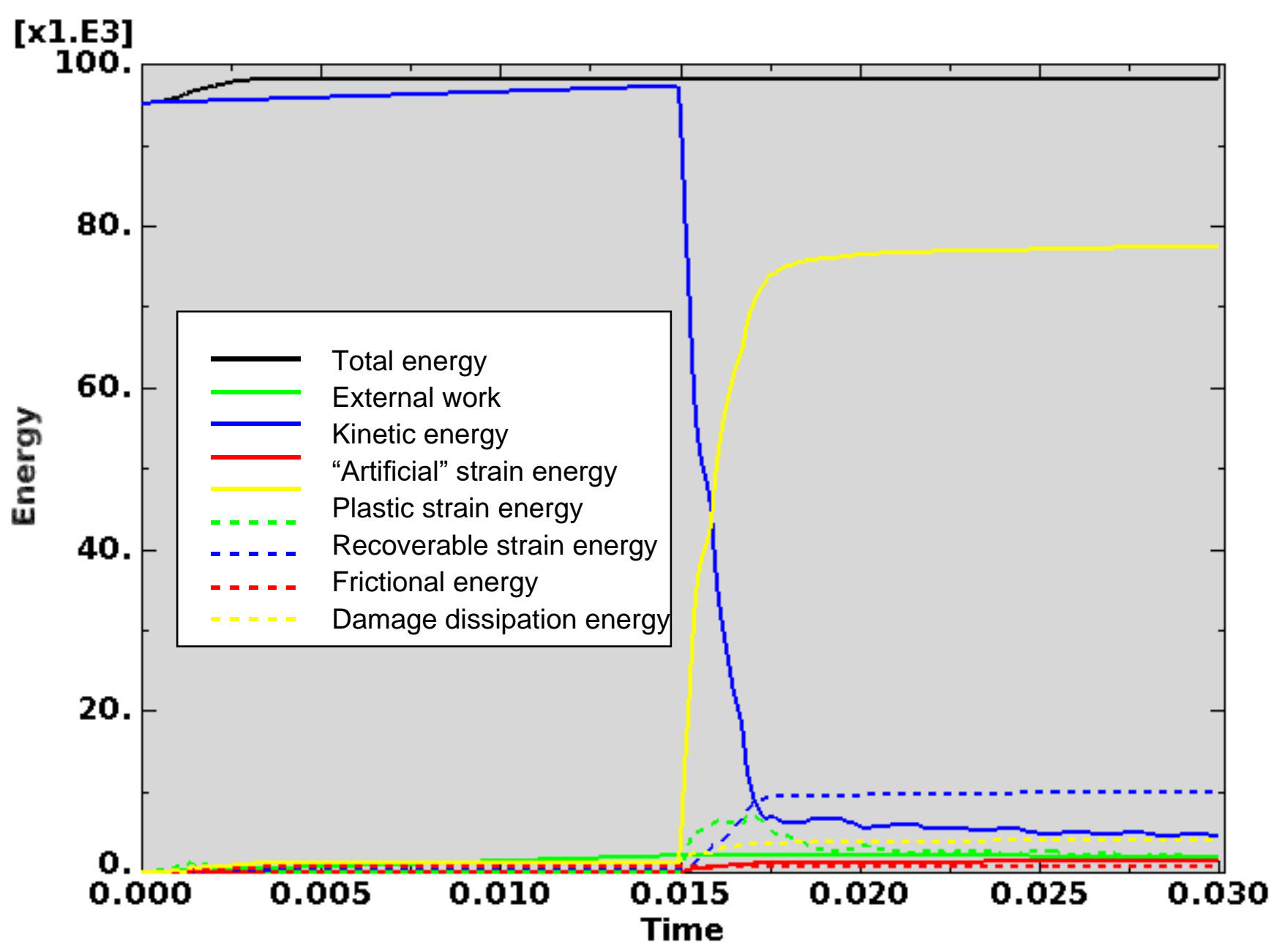

Figure C-189. Scope Part 4 (Table 3), 22.1-Ibf fuel element, and 5 degrees angle energy curves.

Figure C-189 shows the energy curves for Scope Part 4 (Table 3) with 22.1-lbf fuel element weight and impacting 5 degrees off horizontal drop scenario. These curves exhibit a stable shape. Artificial strain energy represents the energy required to keep reduced integration elements from taking on a zero-energy hourglass shape. As shown in Figure C-189, the artificial energy at the end of the model run is $1.5 \%$ of the total energy. Therefore, the potential error associated with artificial energy is not considered to be significant. 


\section{ENGINEERING CALCULATIONS AND ANALYSIS}

Drop Analysis of the Advanced Test Reactor Fresh Fuel Shipping Container with Heavier Low-Enriched Uranium Fuel Contents
ECAR-5224, Rev. 0

Page $\mathrm{C} 130$ of $\mathrm{C} 190$

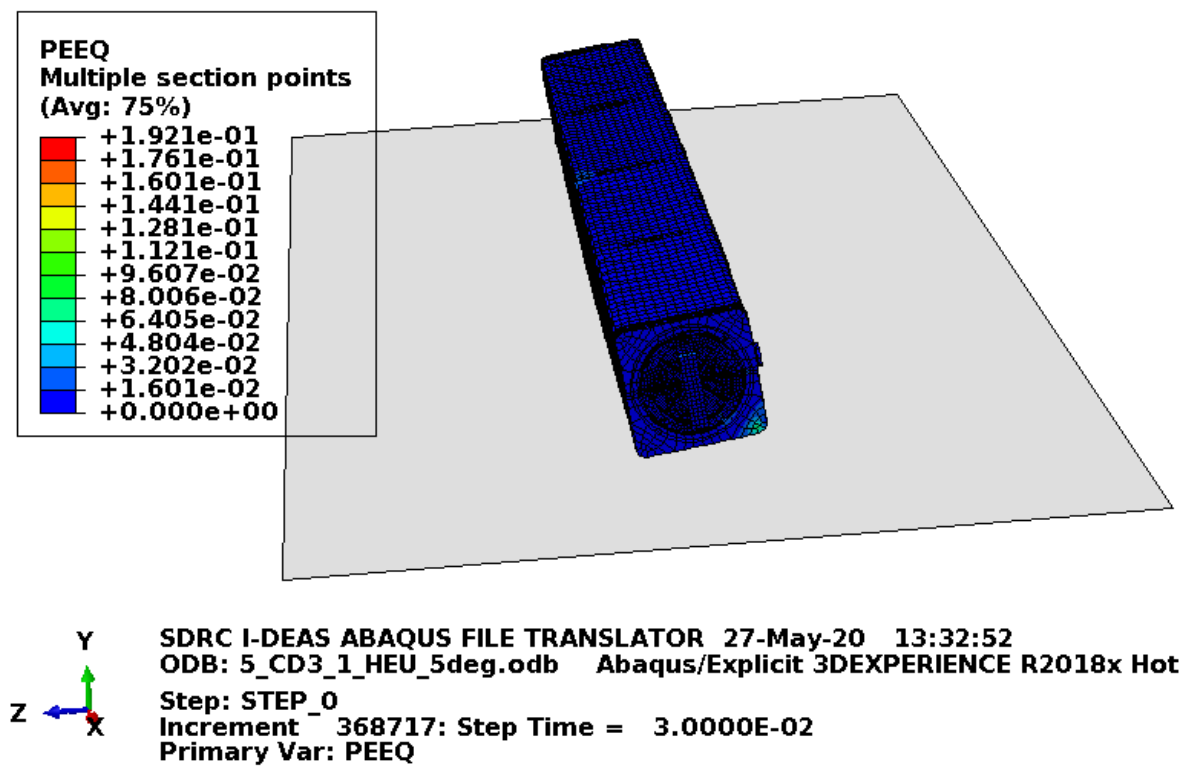

Figure C-190. Scope Part 4 (Table 3), 22.1-lbf fuel element, and 5 degrees angle full-model plasticequivalent strain.
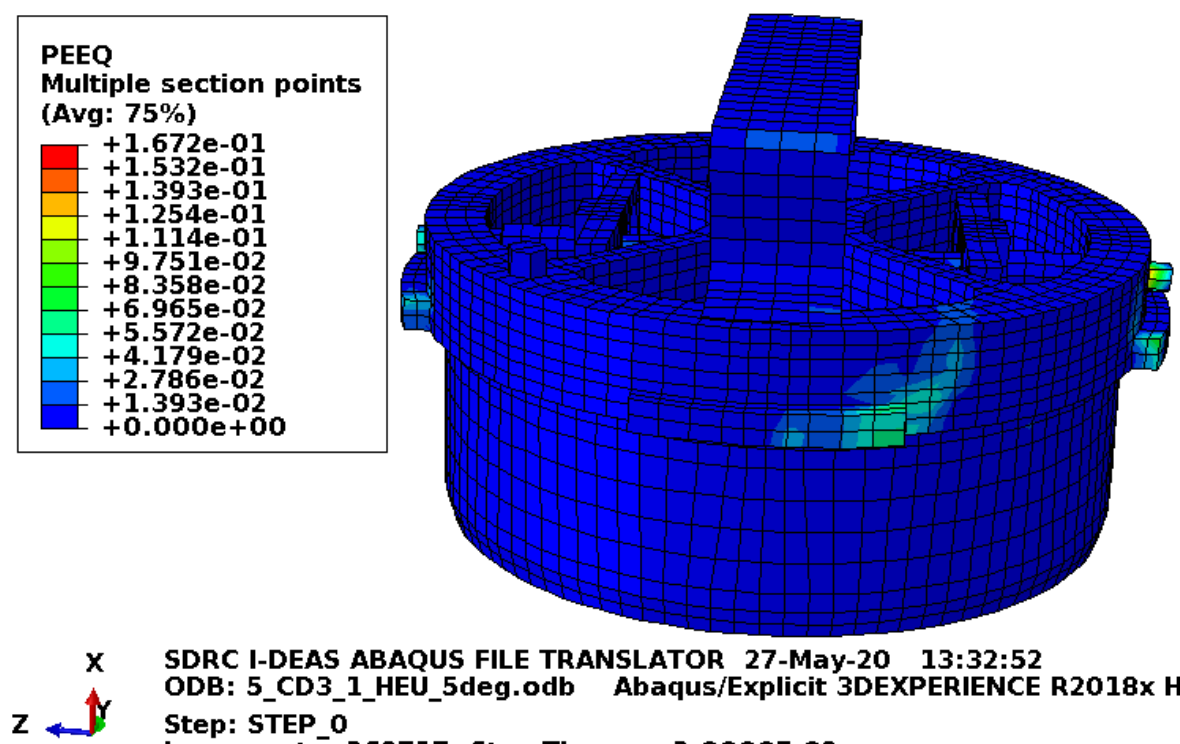

SDRC I-DEAS ABAOUS FILE TRANSLATOR 27-May-20 13:32:52

ODB: 5_CD3_1_HEU_5deg.odb Abaqus/Explicit 3DEXPERIENCE R2018x H Step: STEP 0

Increment ${ }^{-}$368717: Step Time $=3.0000 \mathrm{E}-02$ Primary Var: PEEQ

Figure C-191. Scope Part 4 (Table 3), 22.1-lbf fuel element, and 5-degree angle lid plastic-equivalent strain. 
ENGINEERING CALCULATIONS AND ANALYSIS

Drop Analysis of the Advanced Test Reactor Fresh Fuel Shipping Container with Heavier Low-Enriched Uranium Fuel Contents
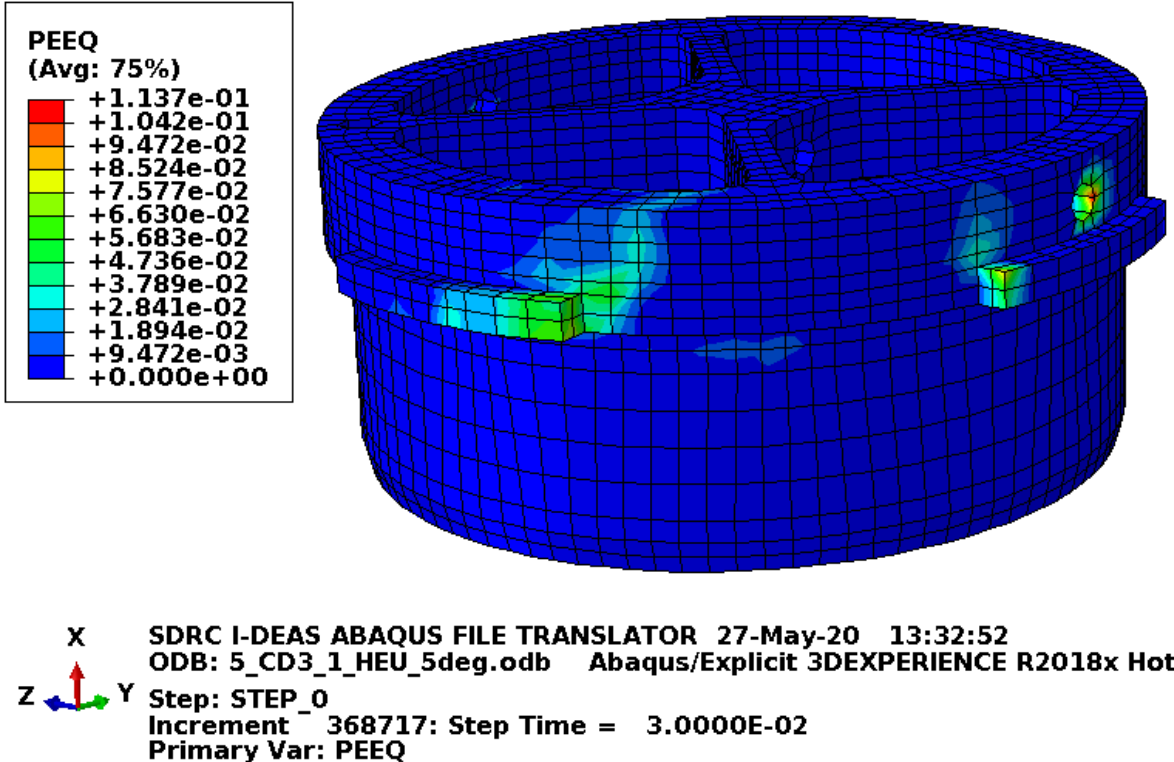

Figure C-192. Scope Part 4 (Table 3), 22.1-Ibf fuel element, and 5 degrees angle lid structure plasticequivalent strain.

Figure C-192 shows the equivalent plastic strain in the structurally significant portion of the lid. Failure in these elements occurs at an equivalent plastic strain of $0.259 \mathrm{in}$./in. If element failure were to occur, the element would be deleted and removed from the model (thereby making its equivalent plastic strain not included in the maximum equivalent plastic strain for the plot). However, the missing element would be visible in the plot. Figure C-192 shows no element failure with margin.

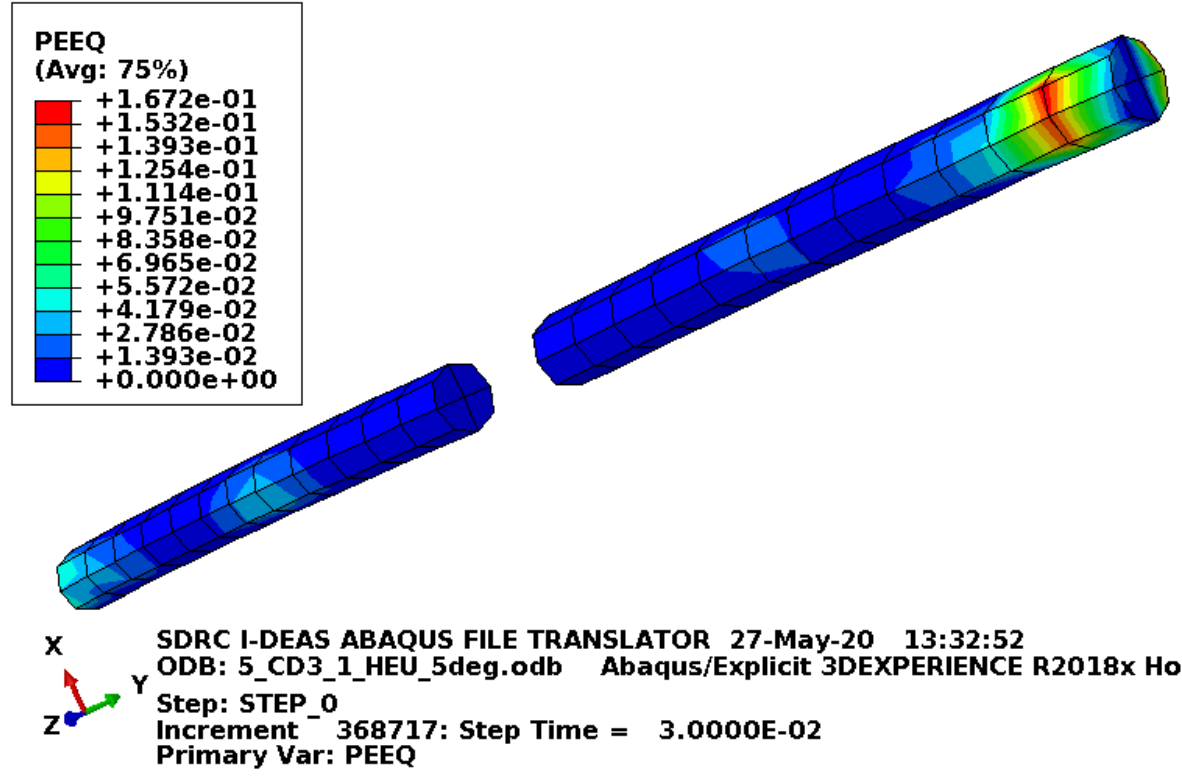

Figure C-193. Scope Part 4 (Table 3), 22.1-lbf fuel element, and 5-degree angle lid pins plastic-equivalent strain. 
Figure C-193 shows the equivalent plastic strain in the lid pins. Failure in these elements occurs at an equivalent plastic strain of $0.295 \mathrm{in}$./in. If element failure were to occur, the element would be deleted and removed from the model (thereby making its equivalent plastic strain not included in the maximum equivalent plastic strain for the plot). However, the missing element would be visible in the plot. Figure C-193 shows no element failure with margin.

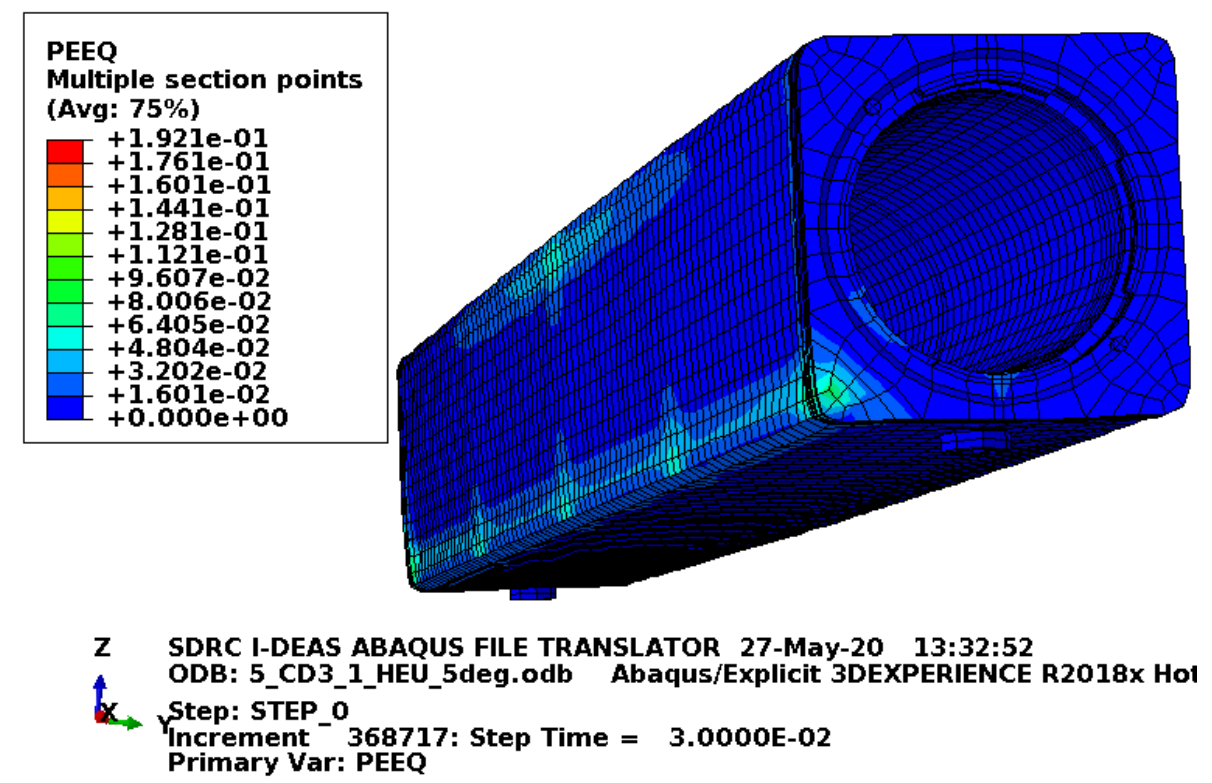

Figure C-194. Scope Part 4 (Table 3), 22.1-lbf fuel element, and 5-degree angle body plastic-equivalent strain.

Figure C-194 shows the equivalent plastic strain in the body. Failure in these elements occurs at an equivalent plastic strain of $0.259 \mathrm{in}$./in. If element failure were to occur, the element would be deleted and removed from the model (thereby making its equivalent plastic strain not included in the maximum equivalent plastic strain for the plot). However, the missing element would be visible in the plot. Figure C-194 shows no element failure with margin. 
ENGINEERING CALCULATIONS AND ANALYSIS

Drop Analysis of the Advanced Test Reactor Fresh Fuel Shipping Container with Heavier Low-Enriched Uranium Fuel Contents
ECAR-5224, Rev. 0

Page $\mathrm{C} 133$ of $\mathrm{C} 190$

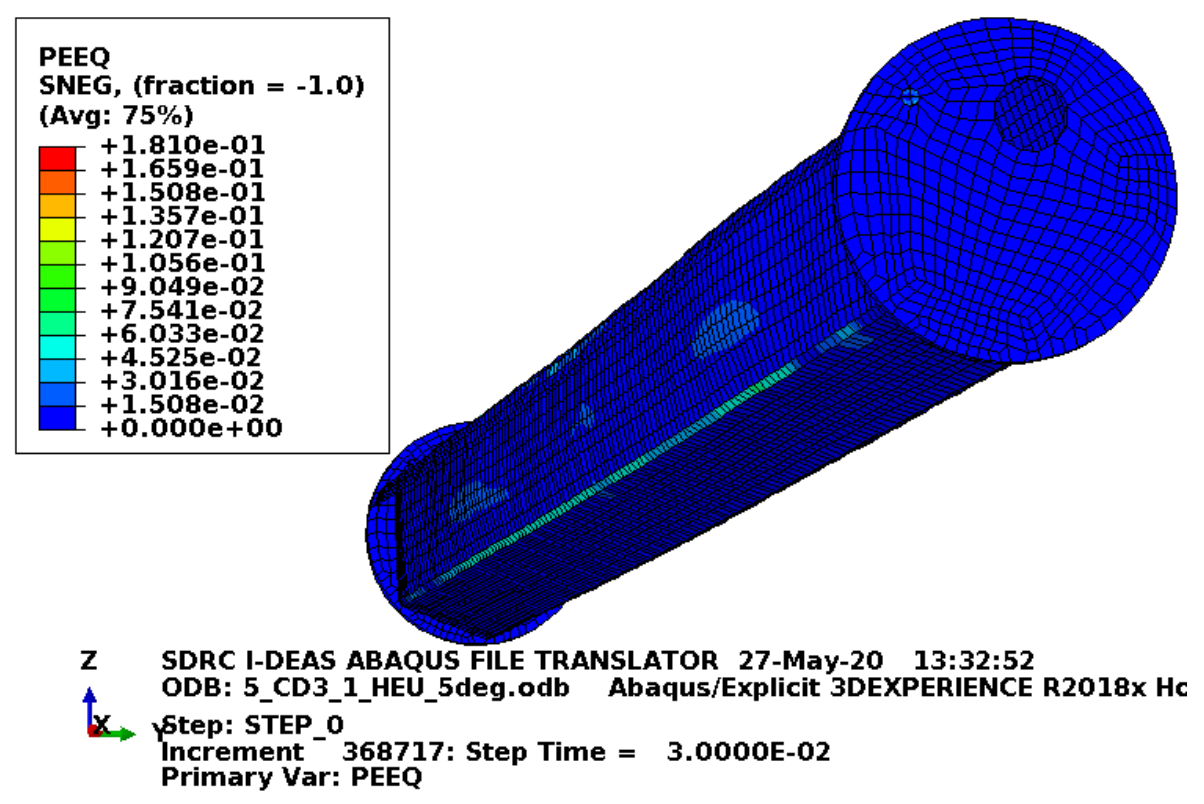

Figure C-195. Scope Part 4 (Table 3), 22.1-Ibf fuel element, and 5 degrees angle enclosure plasticequivalent strain.

Figure C-195 shows the equivalent plastic strain in the enclosure. This is just for information as damage to the enclosure is acceptable.

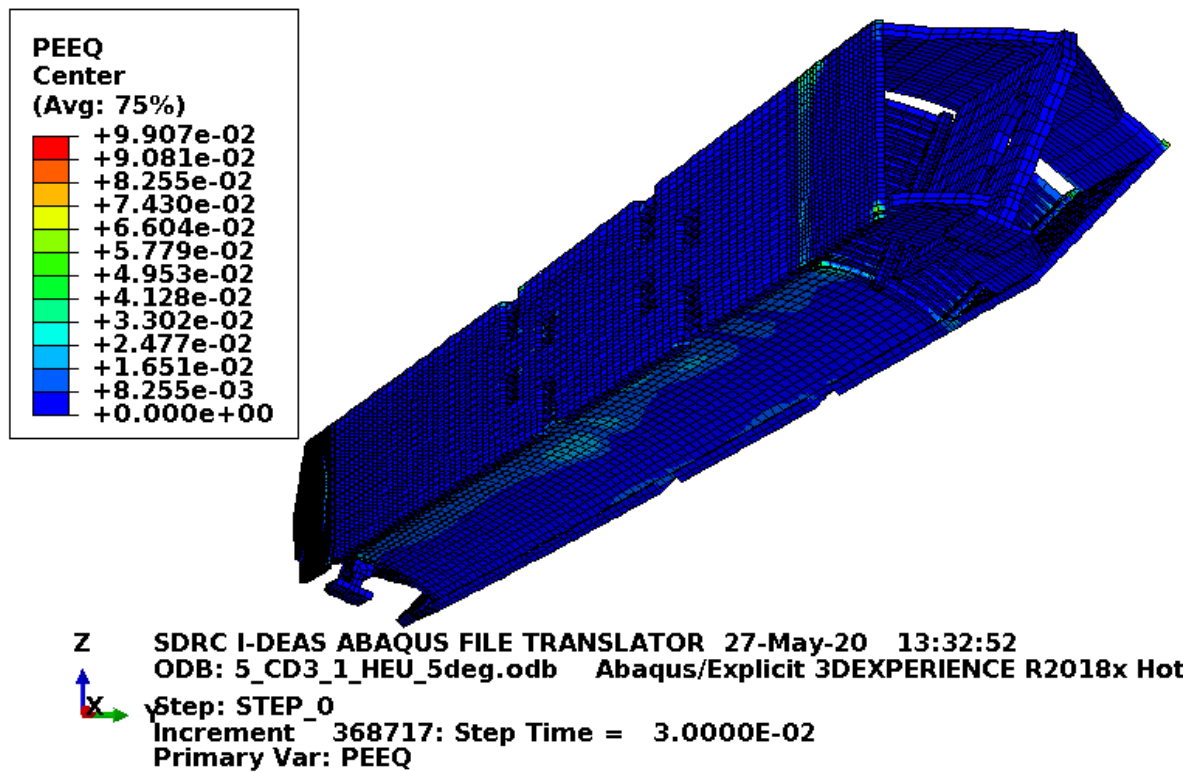

Figure C-196. Scope Part 4 (Table 3), 22.1-lbf fuel element, and 5-degree angle fuel element plasticequivalent strain.

Figure C-196 shows the equivalent plastic strain in the fuel element. For this model, the fuel element is modeled with minimum material properties except the end boxes, which are modeled with relatively tough material properties. While this model is appropriate for fuel element damage consideration, it is only shown here as it is not significantly damaged and other similar drop scenarios are documented in more detail. 


\section{C4.1.2 Results for Scope Part 4 (Table 3) with 115-Ibf Fuel Element and Impacting 5 Degrees Off Horizontal}

The FEA model results for the Scope Part 4 (Table 3) with 115-lbf fuel element weight and impacting 5 degrees off horizontal model are shown below in Figure C-197 to Figure C-204. This drop scenario is a 30-ft drop modeled as a side drop with the pockets and index lugs on the sides. The 5 degrees off horizontal angle is a rotation about an axis along the length of the ATR FFSC. The drop scenario is modeled with the ATR FFSC having minimum material properties and the enclosure and fuel element having relatively tough material properties with no failure.

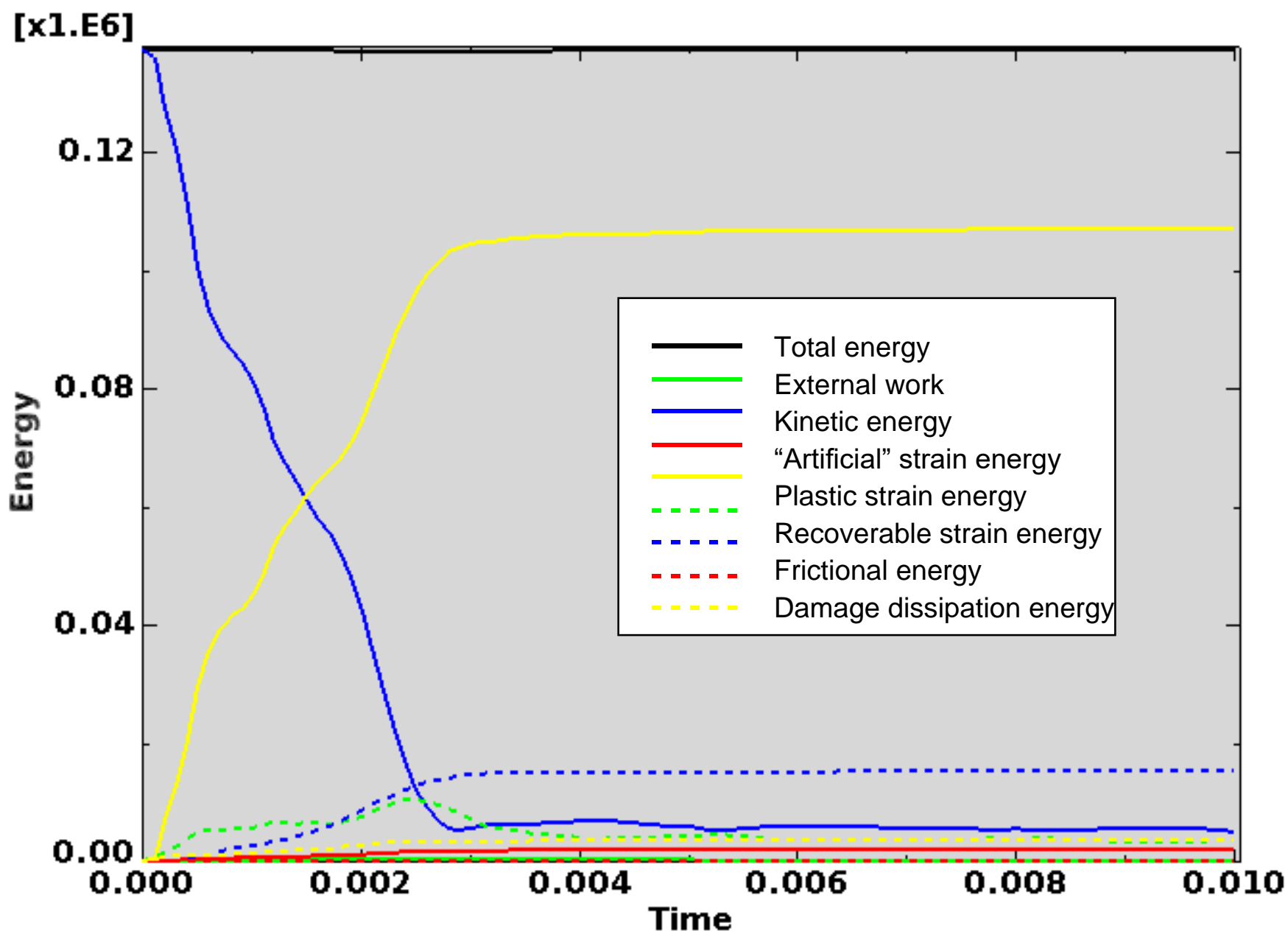

Figure C-197. Scope Part 4 (Table 3), 115-lbf fuel element, and 5 degrees angle energy curves.

Figure C-197 shows the energy curves for Scope Part 4 (Table 3) with 115-lbf fuel element weight and impacting 5 degrees off horizontal drop scenario. These curves exhibit a stable shape. Artificial energy represents the energy required to keep reduced integration elements from taking on a zero-energy hourglass shape. As shown in Figure C-197, the artificial energy at the end of the model run is $1.5 \%$ of the total energy. Therefore, the potential error associated with artificial energy is not considered to be significant. 
ENGINEERING CALCULATIONS AND ANALYSIS

Drop Analysis of the Advanced Test Reactor Fresh Fuel Shipping Container with Heavier Low-Enriched Uranium Fuel Contents
ECAR-5224, Rev. 0

Page $\mathrm{C} 135$ of $\mathrm{C} 190$

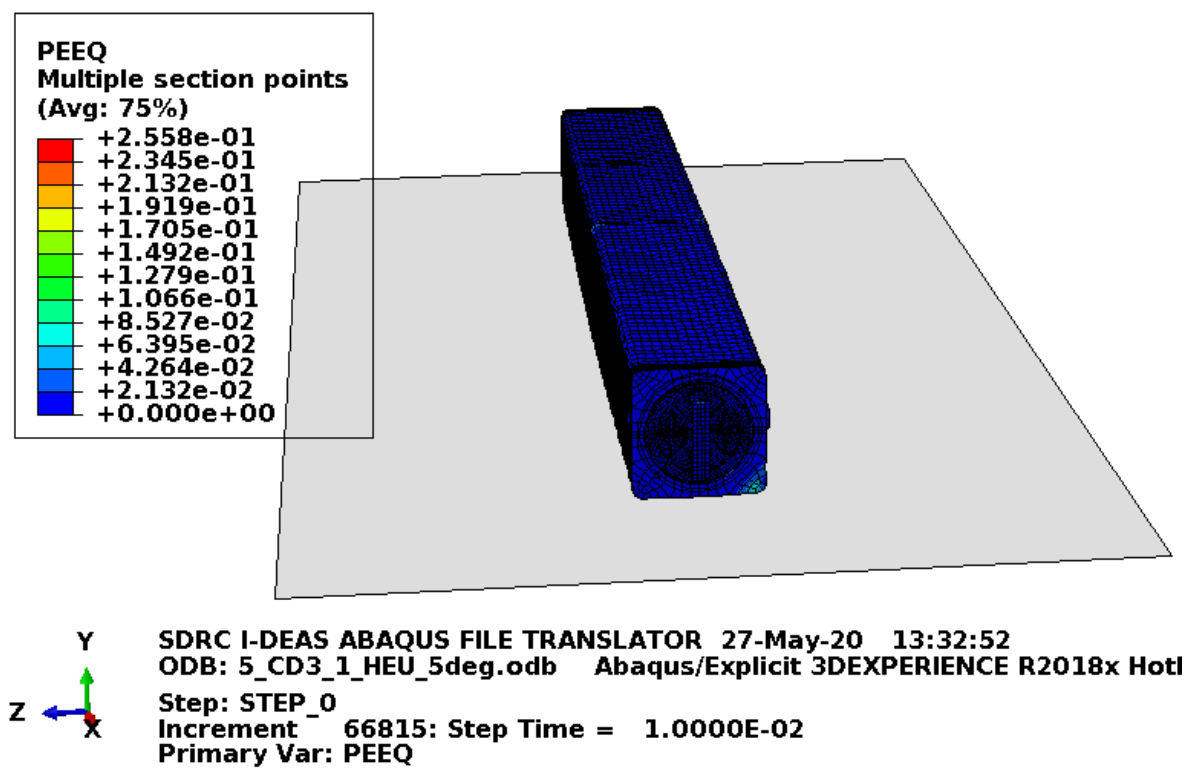

Figure C-198. Scope Part 4 (Table 3), 115-lbf fuel element, and 5-degree angle full-model plastic-equivalent strain.

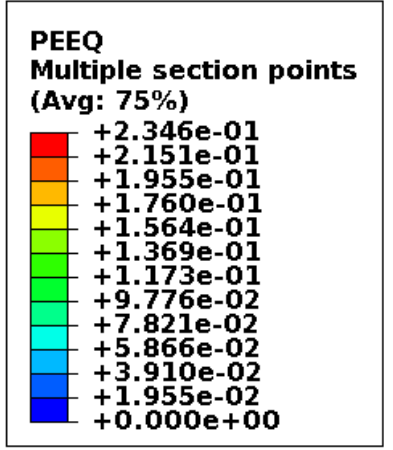

Multiple section points

(Avg: 75\%)

$2.346 \mathrm{e}-01$

$+2.1515 \mathrm{e}-01$

$+1.760 \mathrm{e}-01$

$1.564 \mathrm{e}-01$

$1.369 \mathrm{e}-01$

$7.821 \mathrm{e}-02$

$5.866 \mathrm{e}-02$

$+1.955 \mathrm{e}-02$

$+0.000 \mathrm{e}+00$

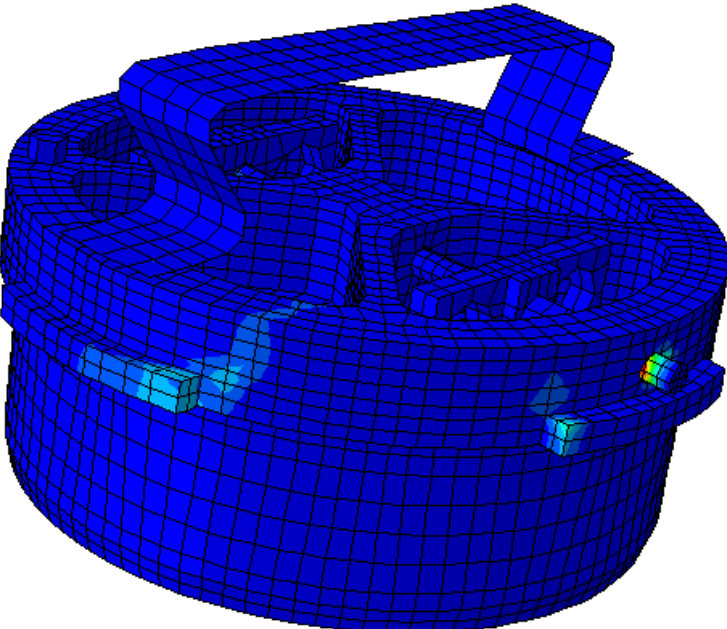

$X \quad$ SDRC I-DEAS ABAQUS FILE TRANSLATOR 27-May-20 13:32:52

ODB: 5_CD3_1_HEU_5deg.odb Abaqus/Explicit 3DEXPERIENCE R2018x

$Z=1$ Y Step: STEP 0

Increment 66815: Step Time $=1.0000 E-02$

Primary Var: PEEQ

Figure C-199. Scope Part 4 (Table 3), 115-lbf fuel element, and 5-degree angle lid plastic-equivalent strain. 
ENGINEERING CALCULATIONS AND ANALYSIS

Drop Analysis of the Advanced Test Reactor Fresh Fuel Shipping Container with Heavier Low-Enriched Uranium Fuel Contents
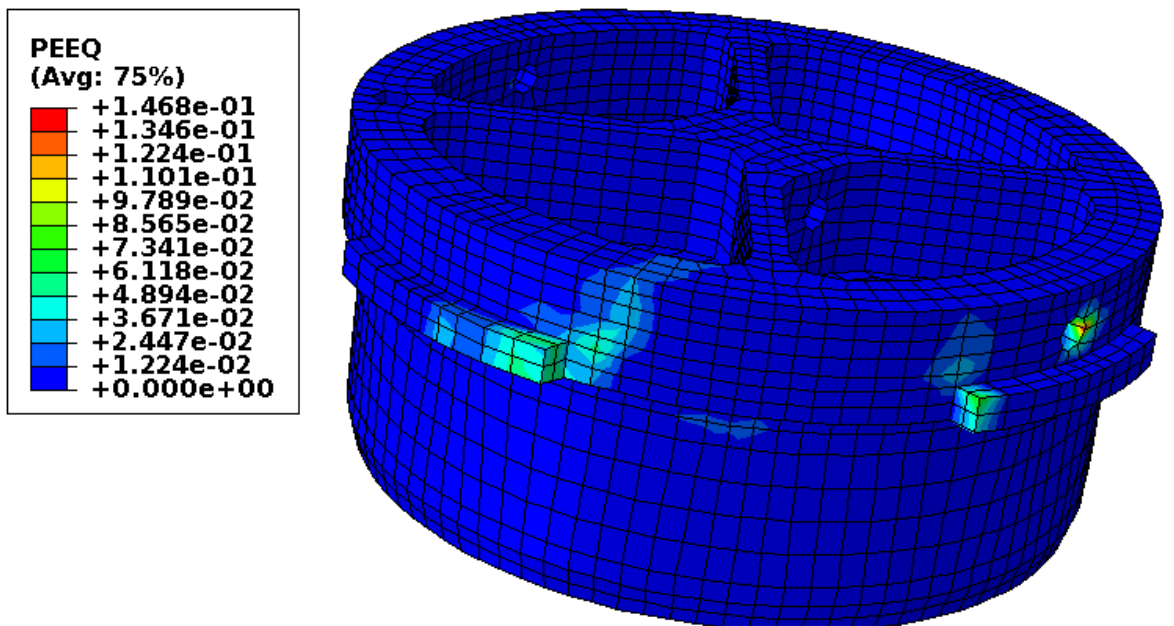

SDRC I-DEAS ABAQUS FILE TRANSLATOR 27-May-20 13:32:52

ODB: 5_CD3_1_HEU_5deg.odb Abaqus/Explicit 3DEXPERIENCE R2018x Hc

$Z$ Y Y Step: STEP_o

Increment 66815: Step Time $=1.0000 E-02$

Primary Var: PEEQ

Figure C-200. Scope Part 4 (Table 3), 115-lbf fuel element, and 5-degree angle lid structure plasticequivalent strain.

Figure C-200 shows the equivalent plastic strain in the structurally significant portion of the lid. Failure in these elements occurs at an equivalent plastic strain of $0.259 \mathrm{in}$./in. If element failure were to occur, the element would be deleted and removed from the model (thereby making its equivalent plastic strain not included in the maximum equivalent plastic strain for the plot). However, the missing element would be visible in the plot. Figure C-200 shows no element failure.

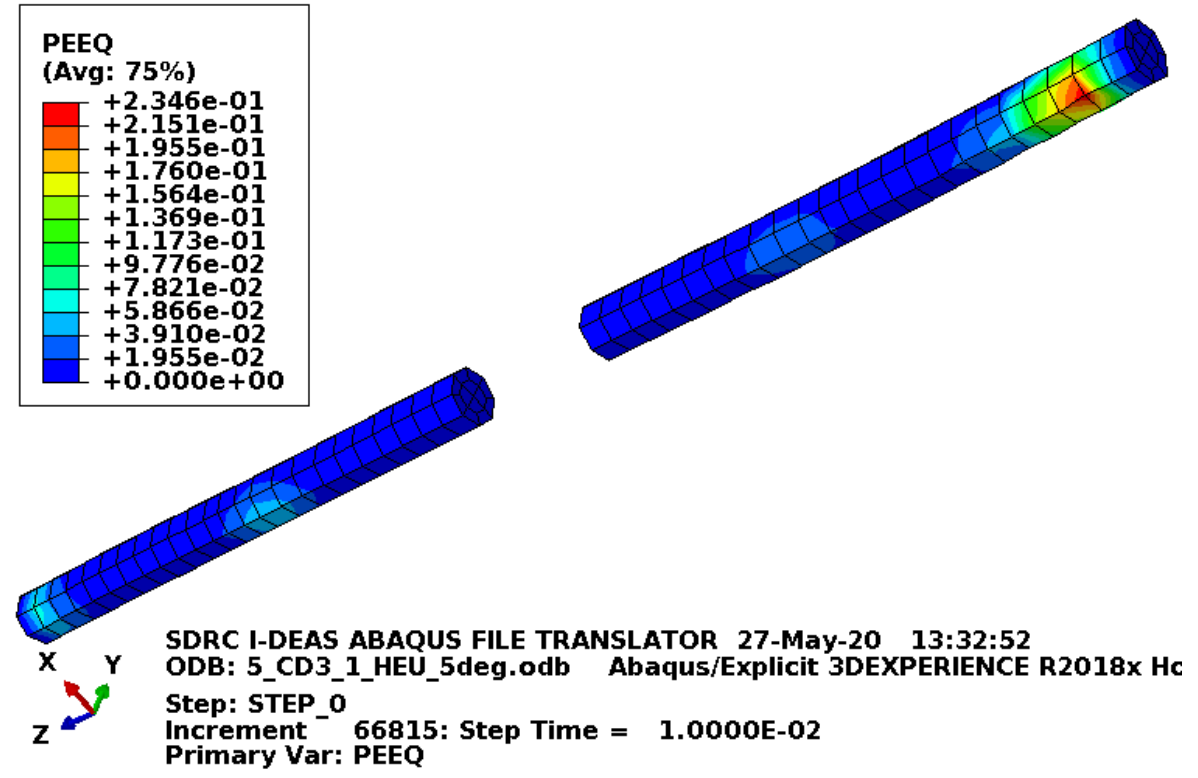

Figure C-201. Scope Part 4 (Table 3), 115-lbf fuel element, and 5 degrees angle lid pins plastic-equivalent strain. 
Figure C-201 shows the equivalent plastic strain in the lid pins. Failure in these elements occurs at an equivalent plastic strain of $0.295 \mathrm{in}$./in. If element failure were to occur, the element would be deleted and removed from the model (thereby making its equivalent plastic strain not included in the maximum equivalent plastic strain for the plot). However, the missing element would be visible in the plot. Figure C-201 shows no element failure.

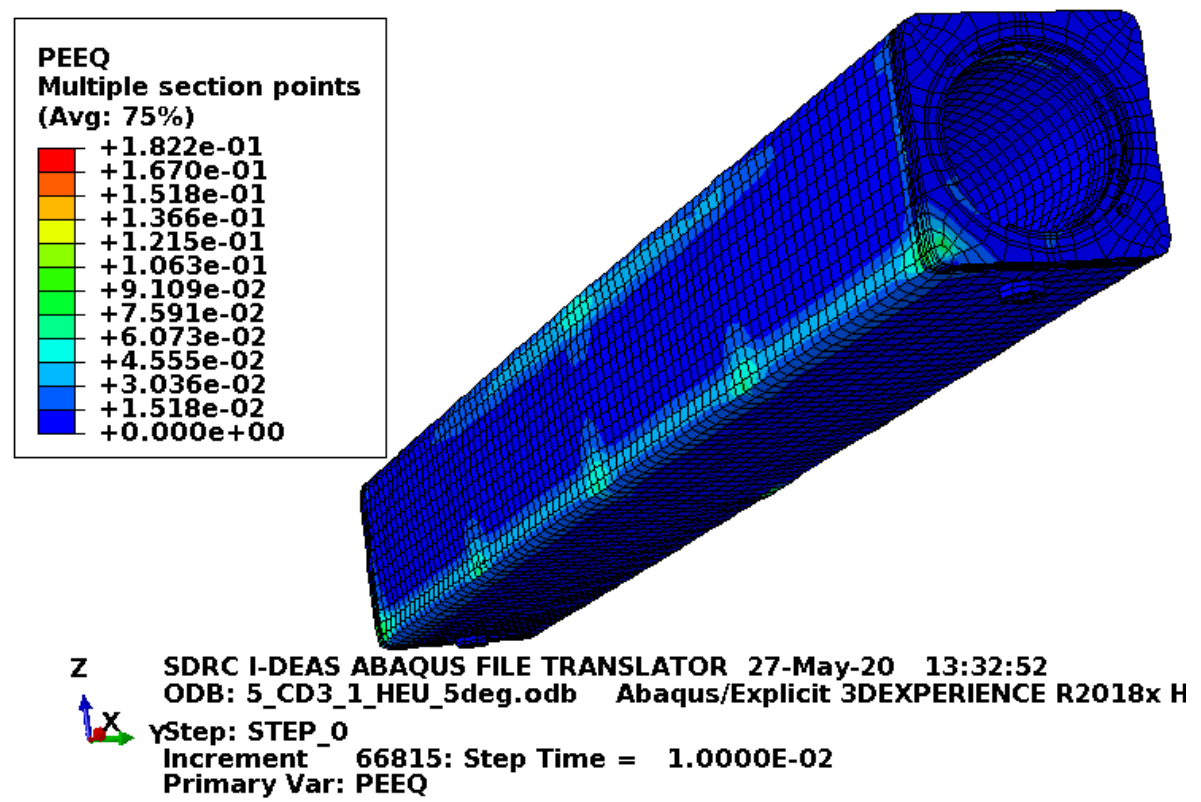

Figure C-202. Scope Part 4 (Table 3), 115-lbf fuel element, and 5 degrees angle body plastic-equivalent strain.

Figure C-202 shows the equivalent plastic strain in the body. Failure in these elements occurs at an equivalent plastic strain of $0.259 \mathrm{in}$./in. If element failure were to occur, the element would be deleted and removed from the model (thereby making its equivalent plastic strain not included in the maximum equivalent plastic strain for the plot). However, the missing element would be visible in the plot. Figure C-202 shows no element failure. 
ENGINEERING CALCULATIONS AND ANALYSIS

Drop Analysis of the Advanced Test Reactor Fresh Fuel Shipping Container with Heavier Low-Enriched Uranium Fuel Contents

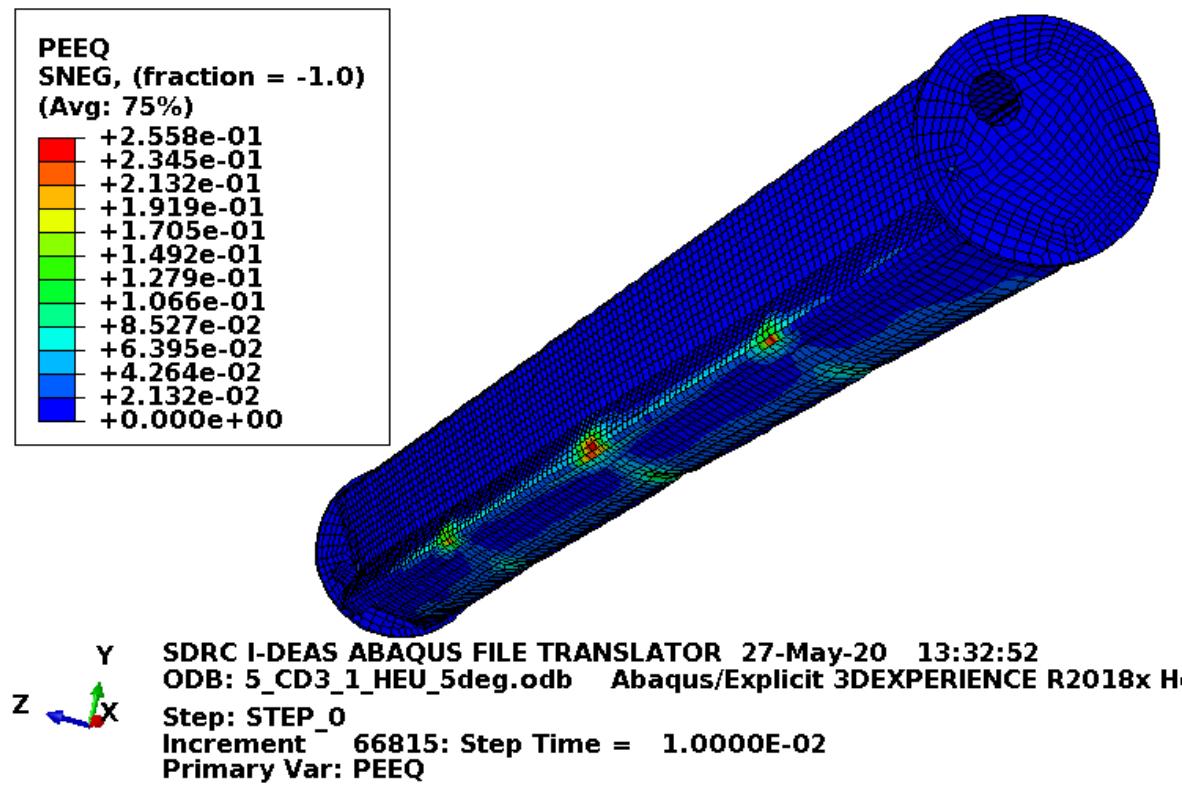

Figure C-203. Scope Part 4 (Table 3), 115-lbf fuel element, and 5-degree angle enclosure plastic-equivalent strain.

Figure C-203 shows the equivalent plastic strain in the enclosure. This is just for information as damage to the enclosure is acceptable.

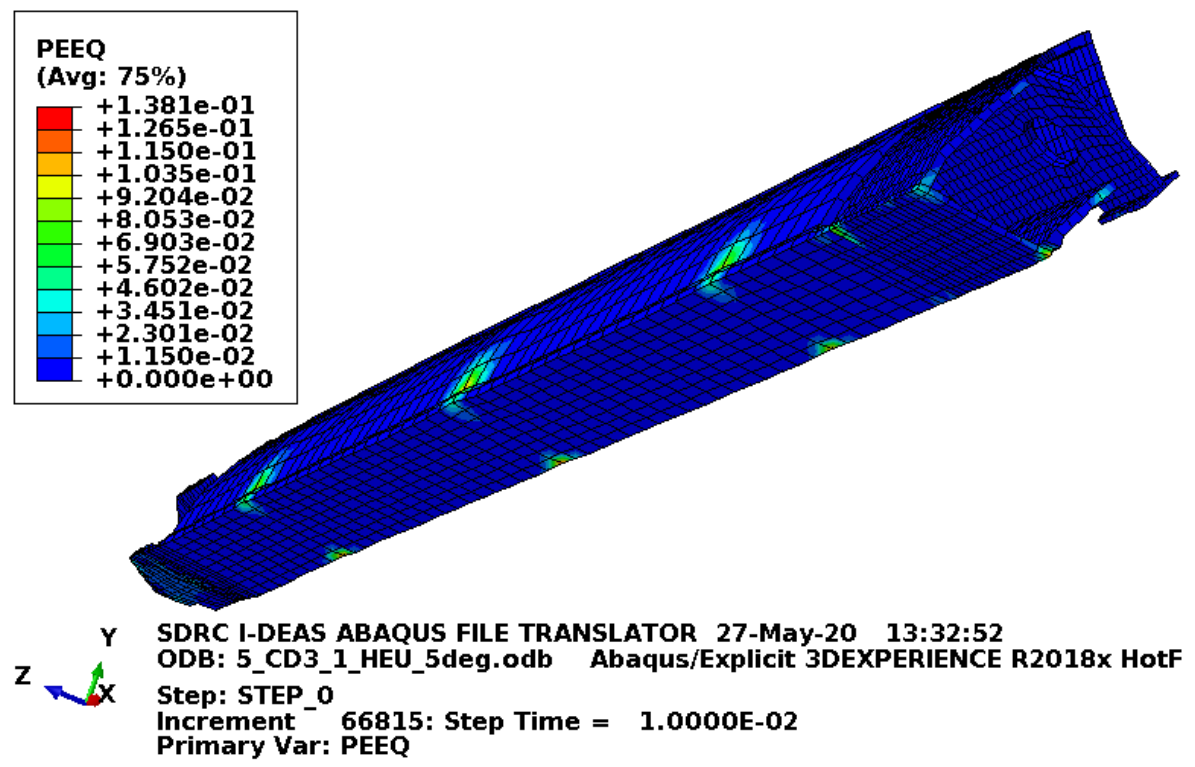

Figure C-204. Scope Part 4 (Table 3), 115-lbf fuel element, and 5 degrees angle fuel element plasticequivalent strain.

Figure C-204 shows the equivalent plastic strain in the fuel element. For this model, the fuel element is coarse meshed, massive, and has no failure defined. Consequently, this is just shown for information and is not relevant to the acceptability of the fuel element. 
ENGINEERING CALCULATIONS AND ANALYSIS

Drop Analysis of the Advanced Test Reactor Fresh Fuel Shipping Container with Heavier Low-Enriched Uranium Fuel Contents

\section{C4.2 Results for Scope Part 4 (Table 3), Impacting 10 Degrees Off Horizontal}

The drop scenario considered in this section is a 30 -ft drop modeled as a side drop with the pockets and index lugs on the sides. It is oriented 10 degrees off horizontal about an axis along the length of the ATR FFSC.

\section{C4.2.1 Results for Scope Part 4 (Table 3) with 22.1-Ibf Fuel Element and Impacting 10 Degrees Off Horizontal}

The FEA model results for the Scope Part 4 (Table 3) with 22.1-lbf fuel element weight and impacting 10 degrees off horizontal model are shown below in Figure C-205 to Figure C-212. This drop scenario is a $30-\mathrm{ft}$ drop modeled as a side drop with the pockets and index lugs on the sides. The 10 degrees off horizontal angle is a rotation about an axis along the length of the ATR FFSC. The drop scenario is modeled with minimum material properties except the enclosure and end boxes, which are modeled with relatively tough material properties.

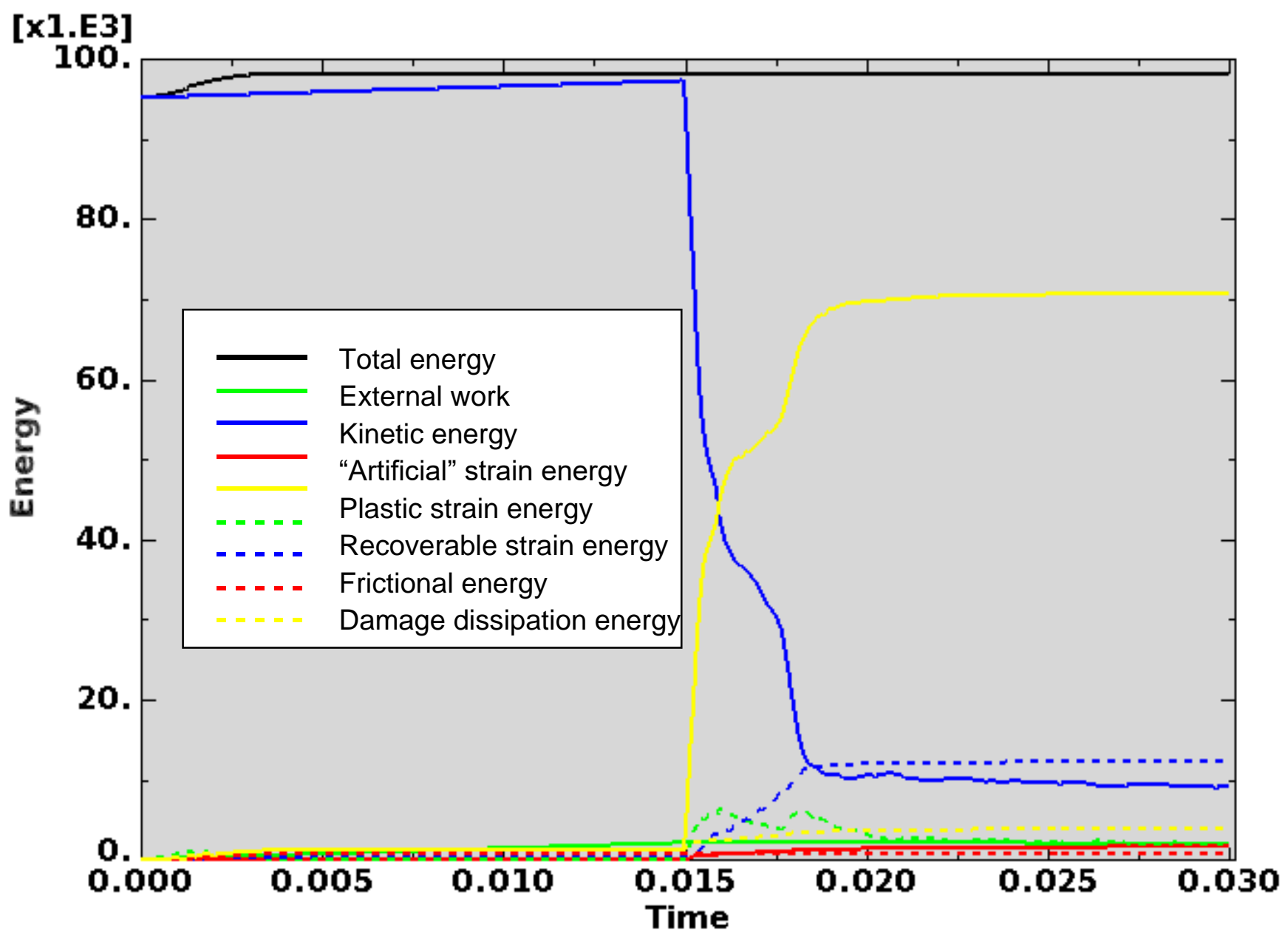

Figure C-205. Scope Part 4 (Table 3), 22.1-lbf fuel element, and 10-degree angle energy curves. 
Figure C-205 shows the energy curves for Scope Part 4 (Table 3) with 22.1-lbf fuel element weight and impacting 10 degrees off horizontal drop scenario. These curves exhibit a stable shape. Artificial strain energy represents the energy required to keep reduced integration elements from taking on a zero-energy hourglass shape. As shown in Figure C-205, the artificial energy at the end of the model run is $1.7 \%$ of the total energy. Therefore, the potential error associated with artificial energy is not considered to be significant.

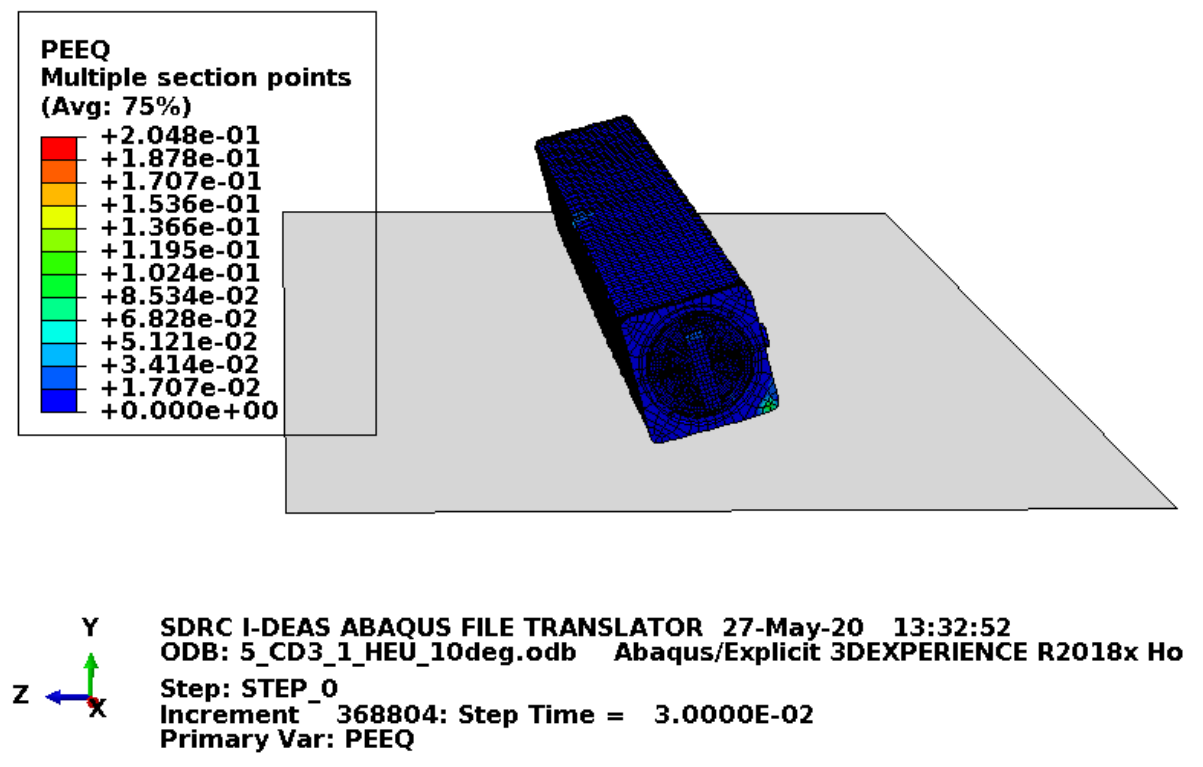

Figure C-206. Scope Part 4 (Table 3), 22.1-lbf fuel element, and 10-degree angle full-model plasticequivalent strain.
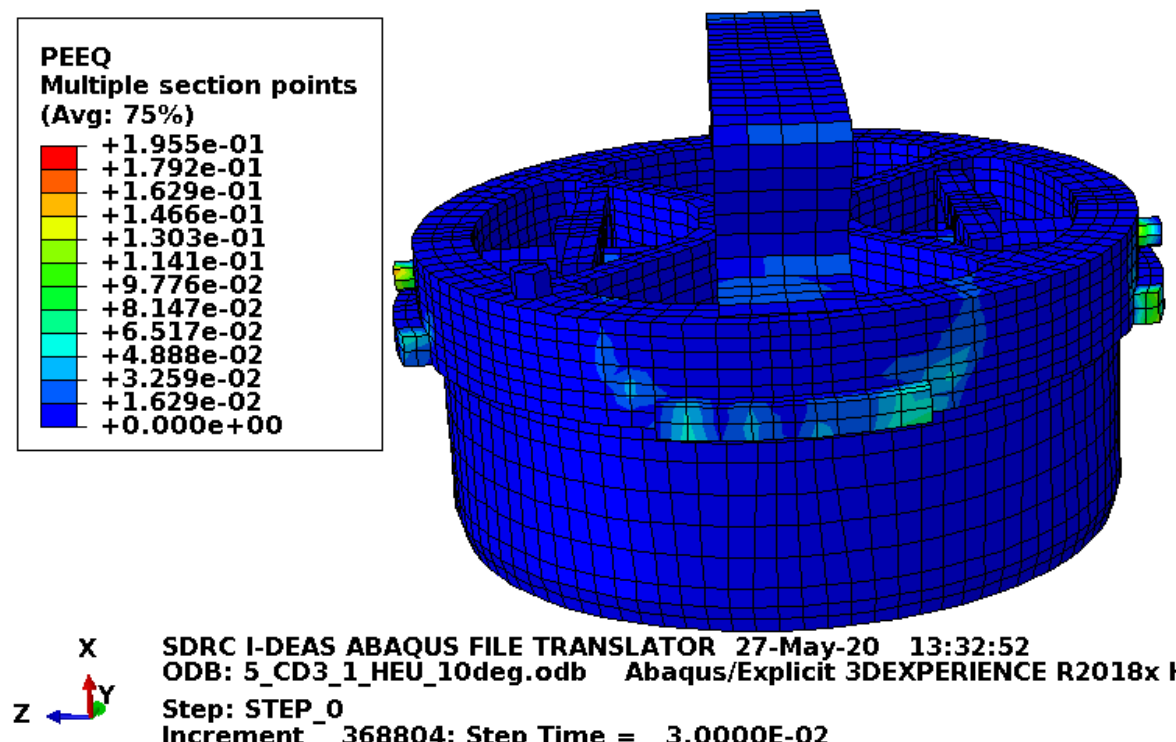

SDRC I-DEAS ABAQUS FILE TRANSLATOR 27-May-20 13:32:52

ODB: 5_CD3_1_HEU_10deg.odb Abaqus/Explicit 3DEXPERIENCE R2018x +

Step: STEP_o

Increment ${ }^{-}$368804: Step Time $=3.0000 \mathrm{E}-02$

Primary Var: PEEQ

Figure C-207. Scope Part 4 (Table 3), 22.1-lbf fuel element, and 10-degree angle lid plastic-equivalent strain. 
ENGINEERING CALCULATIONS AND ANALYSIS

Drop Analysis of the Advanced Test Reactor Fresh Fuel Shipping Container with Heavier Low-Enriched Uranium Fuel Contents
ECAR-5224, Rev. 0

Page C141 of C190

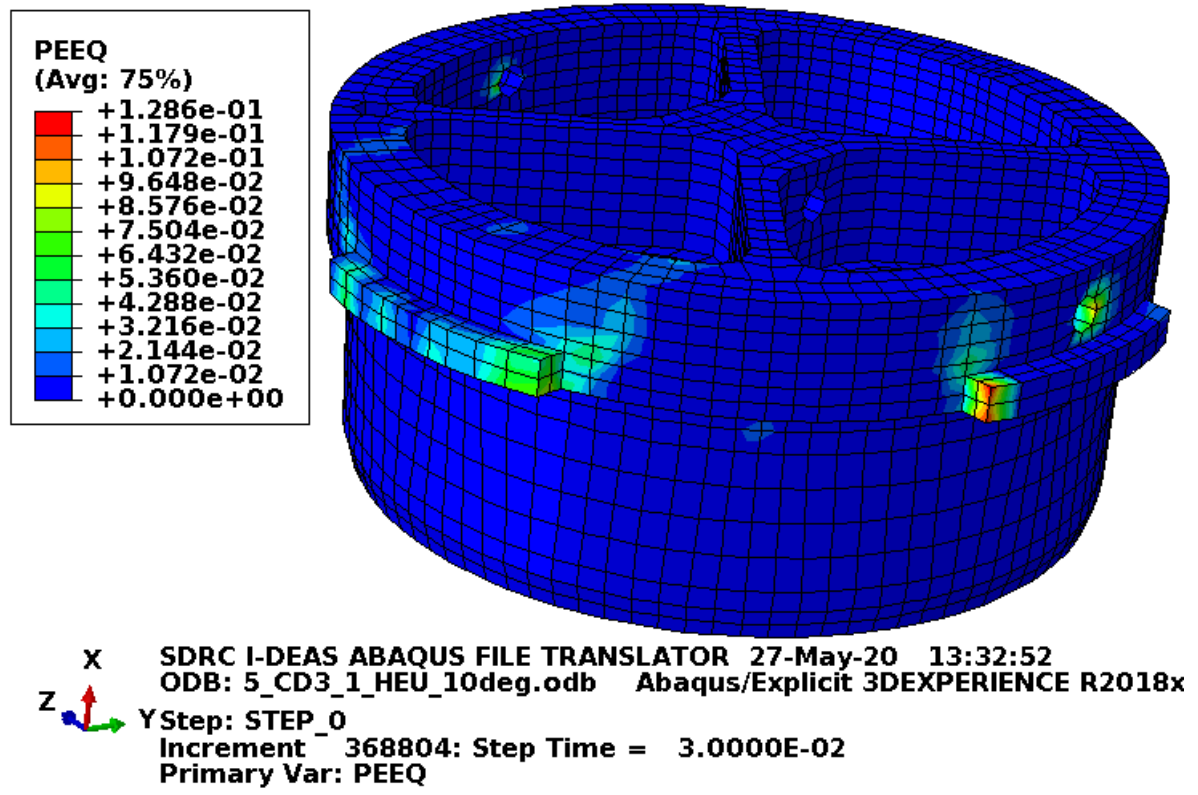

Figure C-208. Scope Part 4 (Table 3), 22.1-lbf fuel element, and 10-degree angle lid structure plasticequivalent strain.

Figure C-208 shows the equivalent plastic strain in the structurally significant portion of the lid. Failure in these elements occurs at an equivalent plastic strain of $0.259 \mathrm{in}$./in. If element failure were to occur, the element would be deleted and removed from the model (thereby making its equivalent plastic strain not included in the maximum equivalent plastic strain for the plot). However, the missing element would be visible in the plot. Figure C-208 shows no element failure with margin.

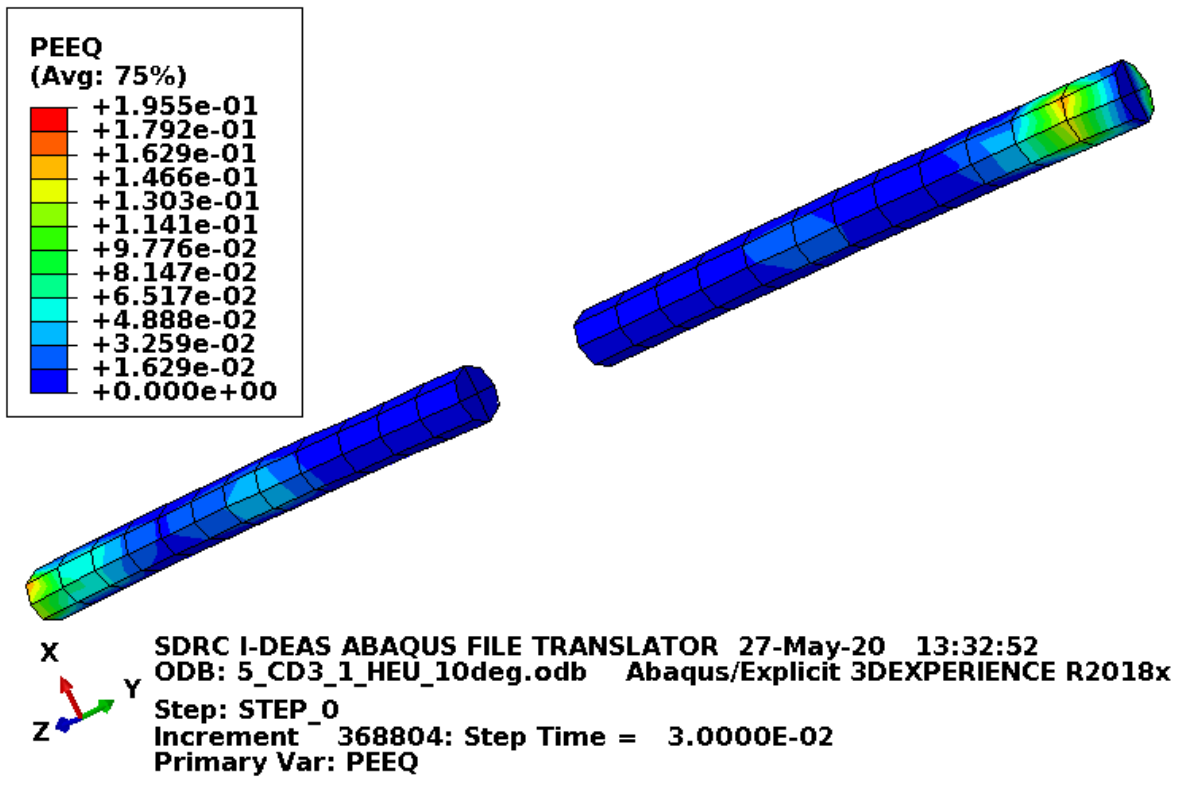

Figure C-209. Scope Part 4 (Table 3), 22.1-lbf fuel element, and 10-degree angle lid pins plastic-equivalent strain. 
Figure C-209 shows the equivalent plastic strain in the lid pins. Failure in these elements occurs at an equivalent plastic strain of $0.295 \mathrm{in}$./in. If element failure were to occur, the element would be deleted and removed from the model (thereby making its equivalent plastic strain not included in the maximum equivalent plastic strain for the plot). However, the missing element would be visible in the plot. Figure C-209 shows no element failure with margin.
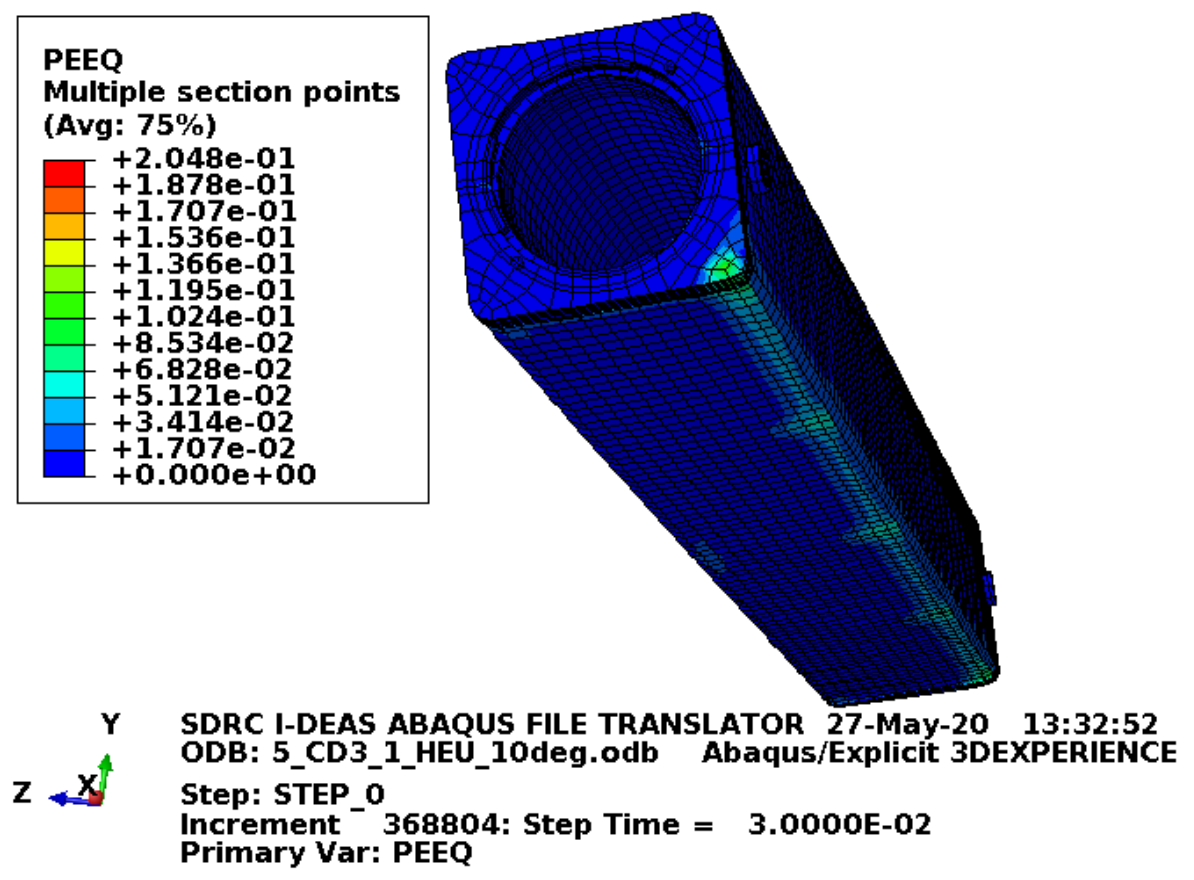

Figure C-210. Scope Part 4 (Table 3), 22.1-lbf fuel element, and 10-degree angle body plastic-equivalent strain.

Figure C-210 shows the equivalent plastic strain in the body. Failure in these elements occurs at an equivalent plastic strain of $0.259 \mathrm{in}$./in. If element failure were to occur, the element would be deleted and removed from the model (thereby making its equivalent plastic strain not included in the maximum equivalent plastic strain for the plot). However, the missing element would be visible in the plot. Figure C-210 shows no element failure. 

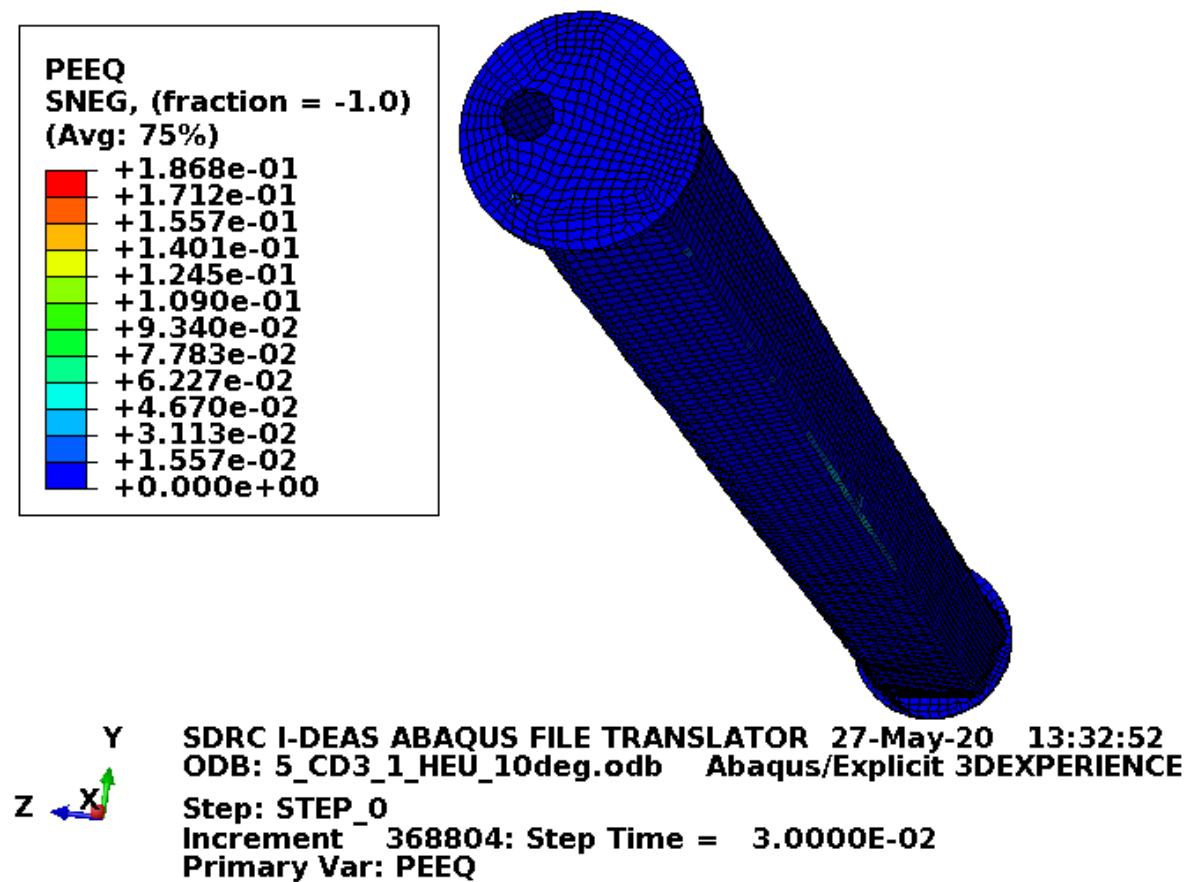

Figure C-211. Scope Part 4 (Table 3), 22.1-lbf fuel element, and 10-degree angle enclosure plasticequivalent strain.

Figure C-211 shows the equivalent plastic strain in the enclosure. This is just for information as damage to the enclosure is acceptable.

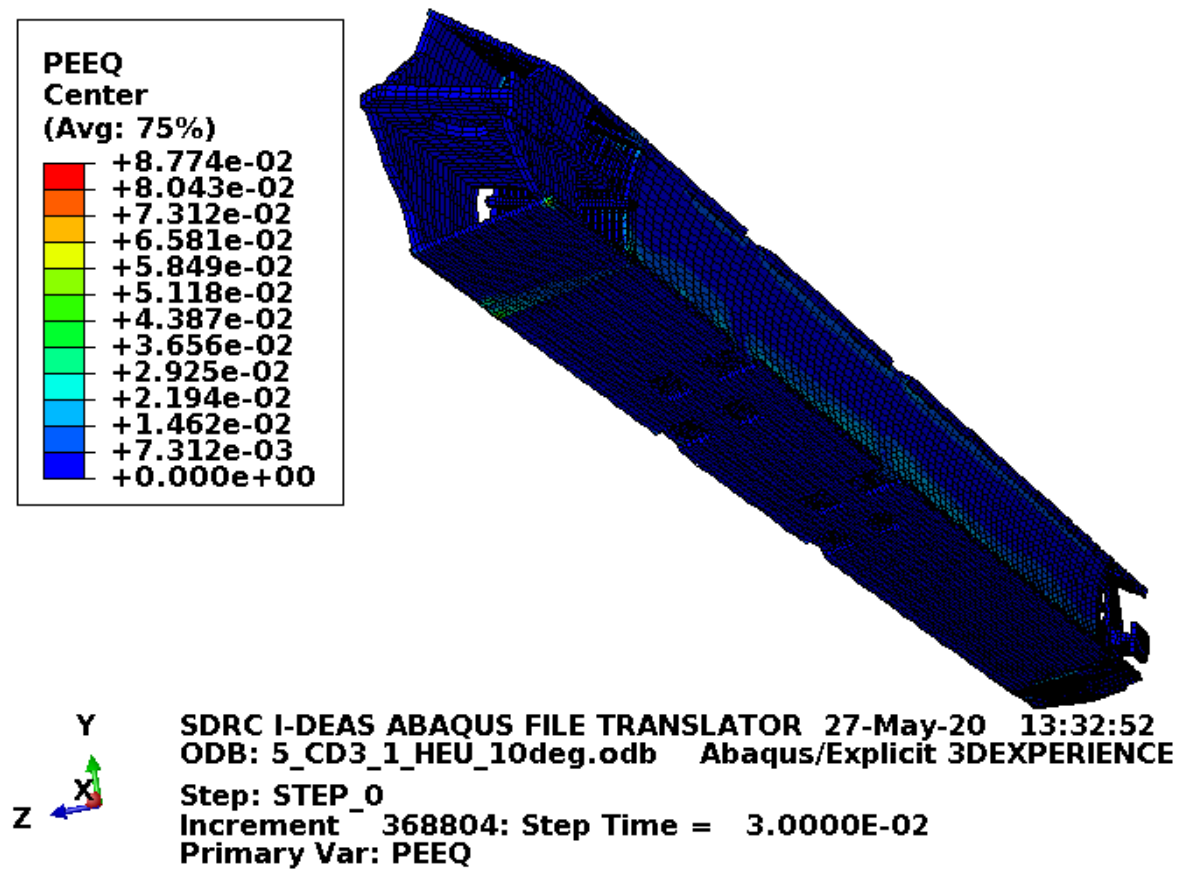

Figure C-212. Scope Part 4 (Table 3), 22.1-lbf fuel element, and 10-degree angle fuel element plastic-equivalent strain. 
Figure C-212 shows the equivalent plastic strain in the fuel element. For this model, the fuel element is modeled with minimum material properties except the end boxes, which are modeled with relatively tough material properties. While this model is appropriate for fuel element damage consideration, it is only shown here as it is not significantly damaged and other similar drop scenarios are documented in more detail.

\section{C4.2.2 Results for Scope Part 4 (Table 3) with 115-Ibf Fuel Element and Impacting 10 Degrees Off Horizontal}

The FEA model results for the Scope Part 4 (Table 3) with 115-lbf fuel element weight and impacting 10 degrees off horizontal model are shown below in Figure C-213 to Figure C-220. This drop scenario is a $30-\mathrm{ft}$ drop modeled as a side drop with the pockets and index lugs on the sides. The 10-degree off horizontal angle is a rotation about an axis along the length of the ATR FFSC. The drop scenario is modeled with the ATR FFSC having minimum material properties and the enclosure and fuel element having relatively tough material properties with no failure.

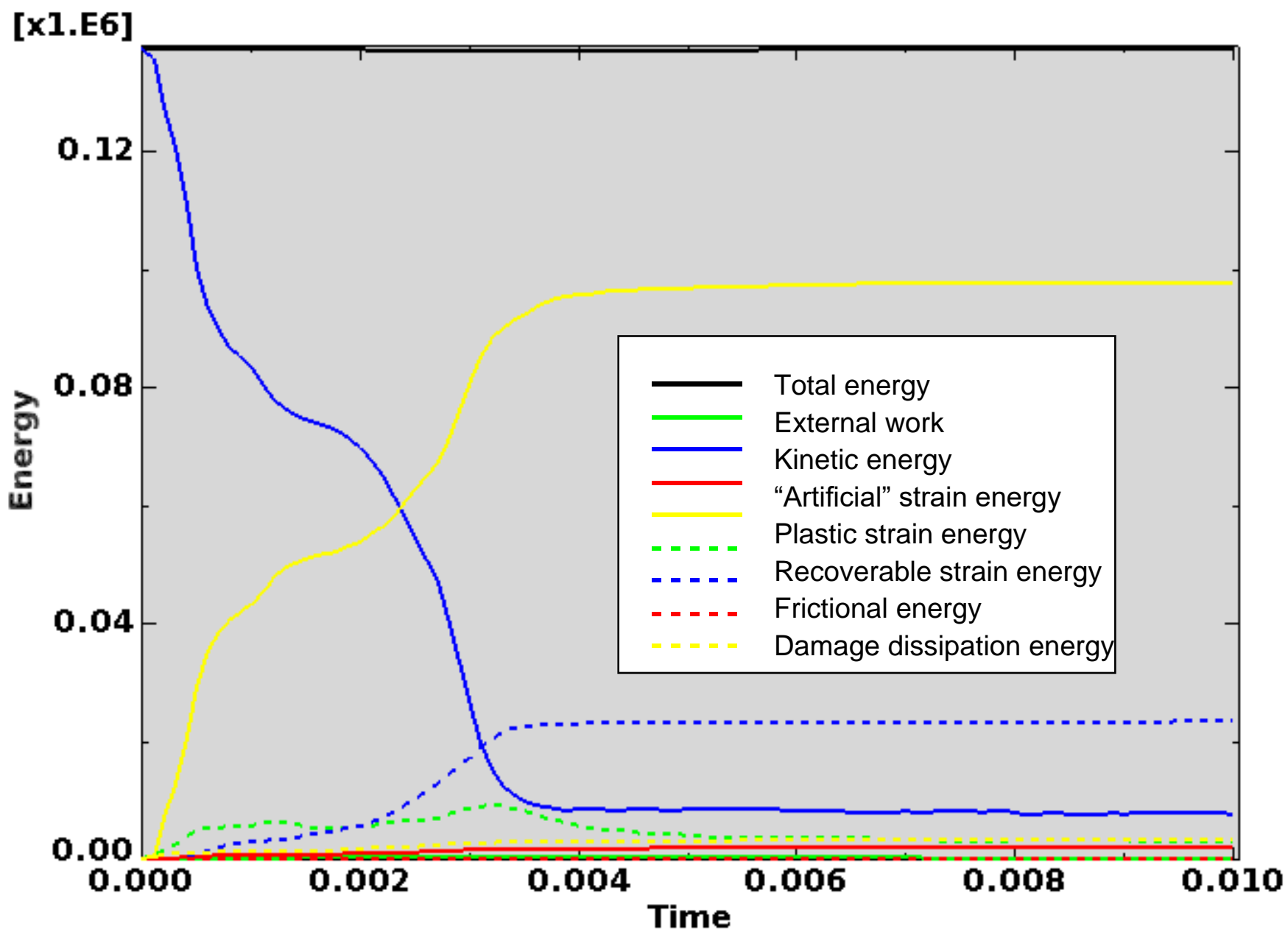

Figure C-213. Scope Part 4 (Table 3), 115-lbf fuel element, and 10-degree angle energy curves. 
Figure C-213 shows the energy curves for Scope Part 4 (Table 3) with 115-lbf fuel element weight and impacting 10 degrees off horizontal drop scenario. These curves exhibit a stable shape. Artificial energy represents the energy required to keep reduced integration elements from taking on a zero-energy hourglass shape. As shown in Figure C-213 the artificial energy at the end of the model run is $1.5 \%$ of the total energy. Therefore, the potential error associated with artificial energy is not considered to be significant.

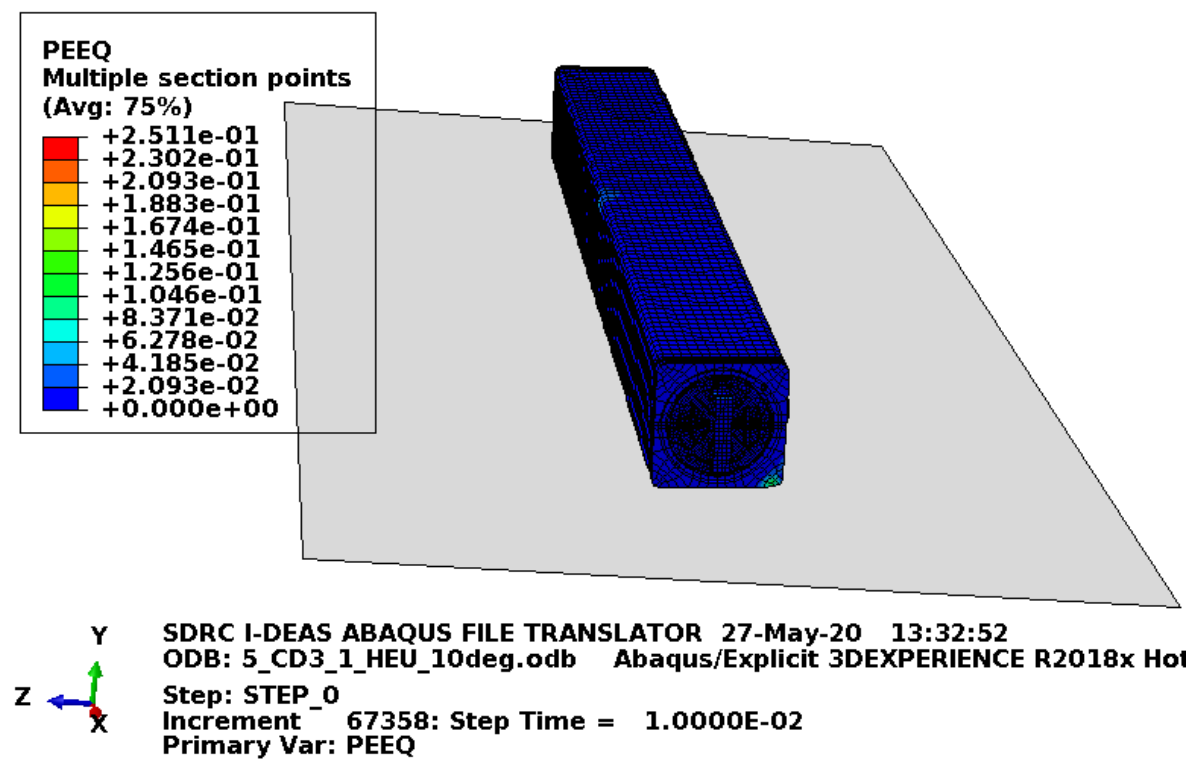

Figure C-214. Scope Part 4 (Table 3), 115-lbf fuel element, and 10-degree angle full-model plasticequivalent strain.
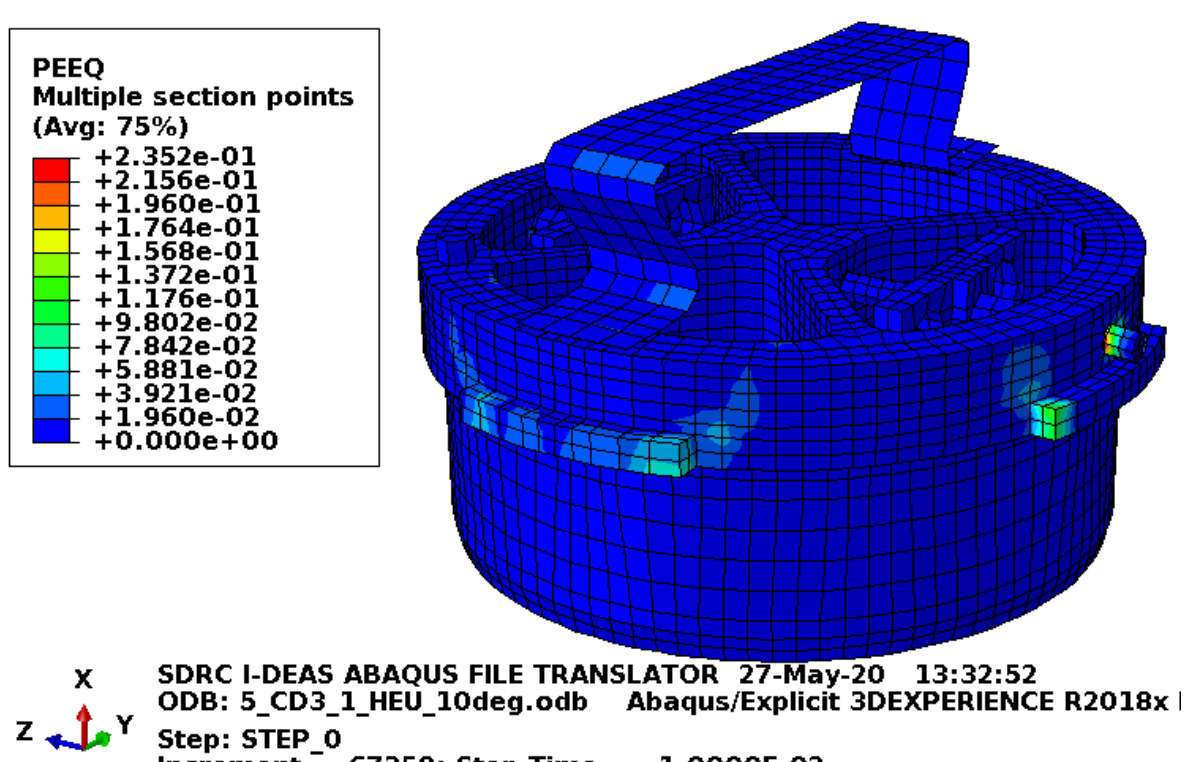

SDRC I-DEAS ABAQUS FILE TRANSLATOR 27-May-20 13:32:52

ODB: 5_CD3_1_HEU_10deg.odb Abaqus/Explicit 3DEXPERIENCE R2018x

Step: STEP 0

Increment ${ }^{-}$67358: Step Time $=1.0000 E-02$

Primary Var: PEEQ

Figure C-215. Scope Part 4 (Table 3), 115-lbf fuel element, and 10-degree angle lid plastic-equivalent strain. 
ENGINEERING CALCULATIONS AND ANALYSIS

Drop Analysis of the Advanced Test Reactor Fresh Fuel Shipping Container with Heavier Low-Enriched Uranium Fuel Contents
ECAR-5224, Rev. 0

Page C146 of C190
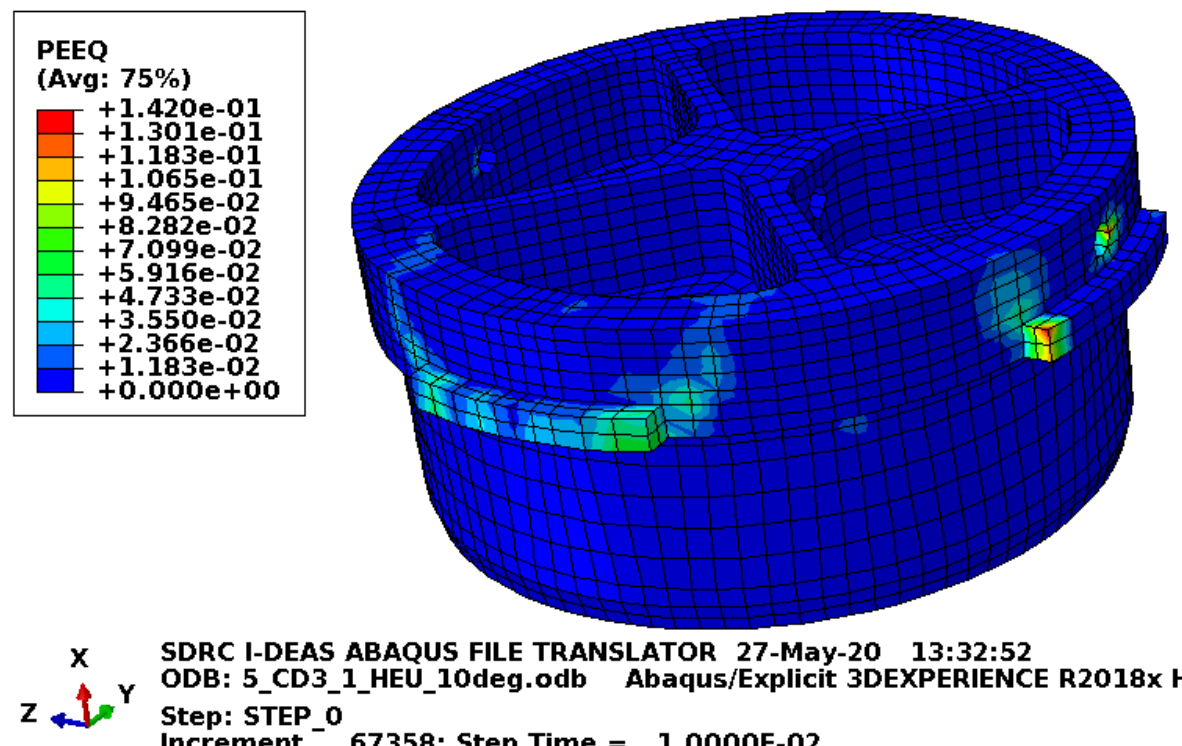

SDRC I-DEAS ABAQUS FILE TRANSLATOR 27-May-20 13:32:52

ODB: 5_CD3_1_HEU_10deg.odb Abaqus/Explicit 3DEXPERIENCE R2018x H

Step: STEP o

Increment ${ }^{-}$67358: Step Time $=1.0000 \mathrm{E}-02$

Primary Var: PEEQ

Figure C-216. Scope Part 4 (Table 3), 115-lbf fuel element, and 10-degree angle lid structure plasticequivalent strain.

Figure C-216 shows the equivalent plastic strain in the structurally significant portion of the lid. Failure in these elements occurs at an equivalent plastic strain of $0.259 \mathrm{in}$./in. If element failure were to occur, the element would be deleted and removed from the model (thereby making its equivalent plastic strain not included in the maximum equivalent plastic strain for the plot). However, the missing element would be visible in the plot. Figure C-216 shows no element failure.

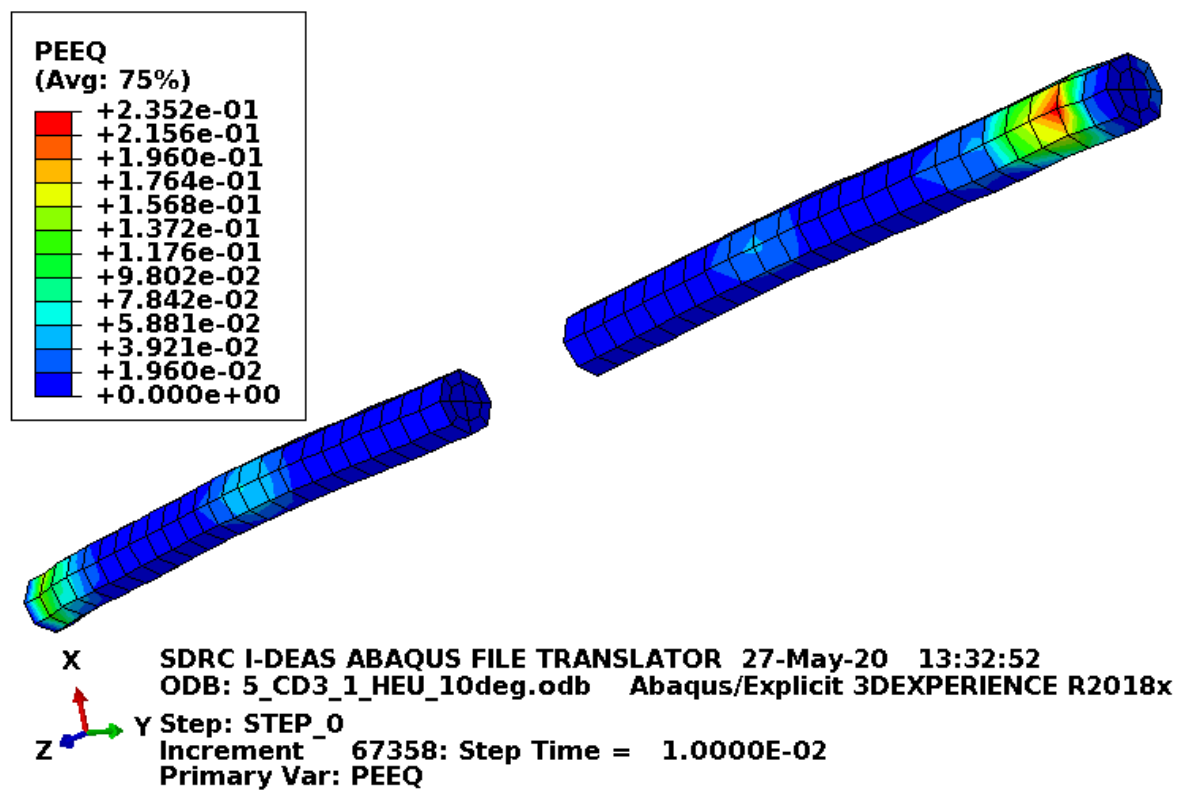

Figure C-217. Scope Part 4 (Table 3), 115-lbf fuel element, and 10-degree angle lid pins plastic-equivalent strain. 
Figure C-217 shows the equivalent plastic strain in the lid pins. Failure in these elements occurs at an equivalent plastic strain of $0.295 \mathrm{in}$./in. If element failure were to occur, the element would be deleted and removed from the model (thereby making its equivalent plastic strain not included in the maximum equivalent plastic strain for the plot). However, the missing element would be visible in the plot. Figure C-217 shows no failed elements.

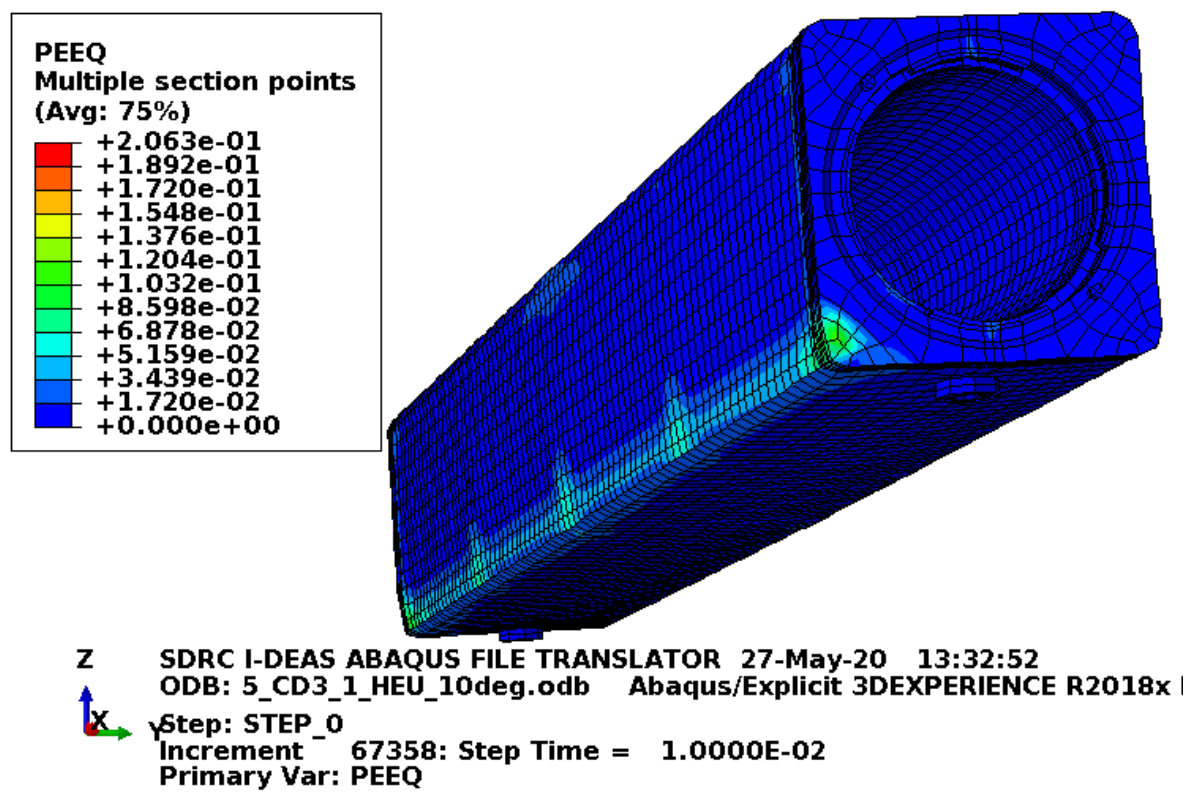

Figure C-218. Scope Part 4 (Table 3), 115-lbf fuel element, and 10-degree angle body plastic-equivalent strain.

Figure C-217 shows the equivalent plastic strain in the body. Failure in these elements occurs at an equivalent plastic strain of $0.259 \mathrm{in}$./in. If element failure were to occur, the element would be deleted and removed from the model (thereby making its equivalent plastic strain not included in the maximum equivalent plastic strain for the plot). However, the missing element would be visible in the plot.

Figure C-217 shows no element failure. 
Drop Analysis of the Advanced Test Reactor Fresh Fuel Shipping Container with Heavier Low-Enriched Uranium Fuel Contents

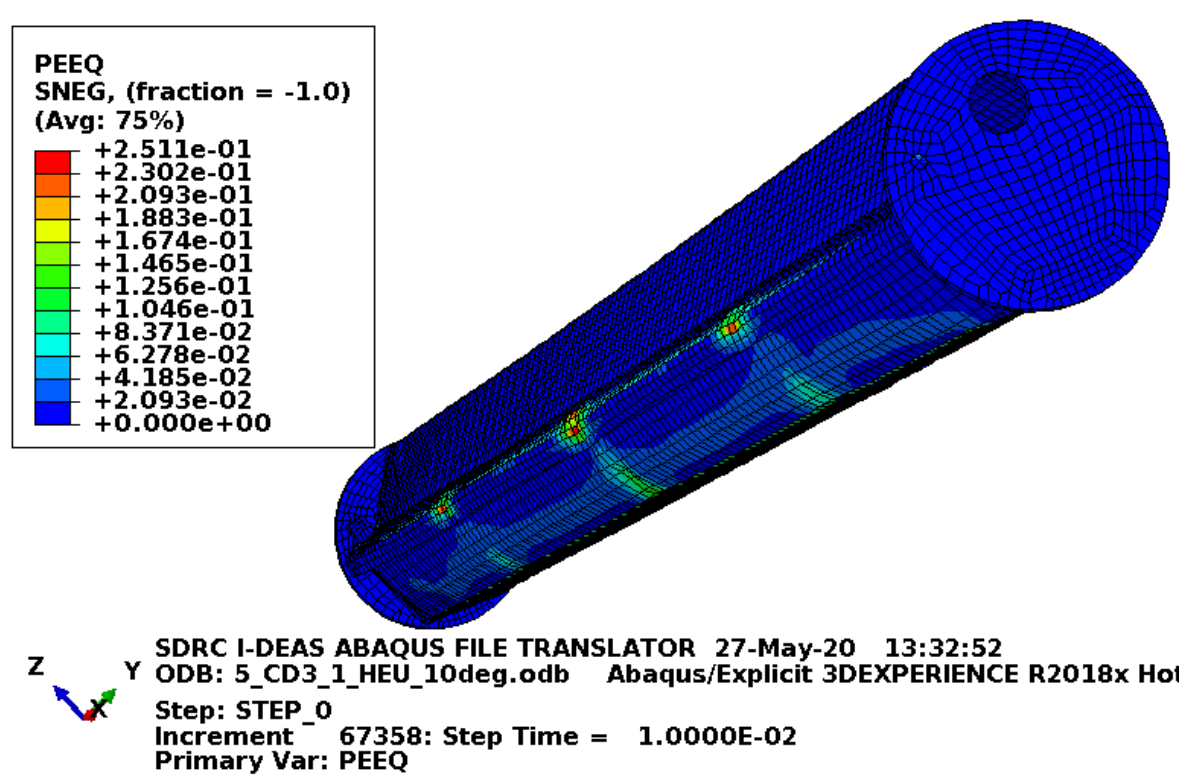

Figure C-219. Scope Part 4 (Table 3), 115-lbf fuel element, and 10-degree angle enclosure plasticequivalent strain.

Figure C-219 shows the equivalent plastic strain in the enclosure. This is just for information as damage to the enclosure is acceptable.

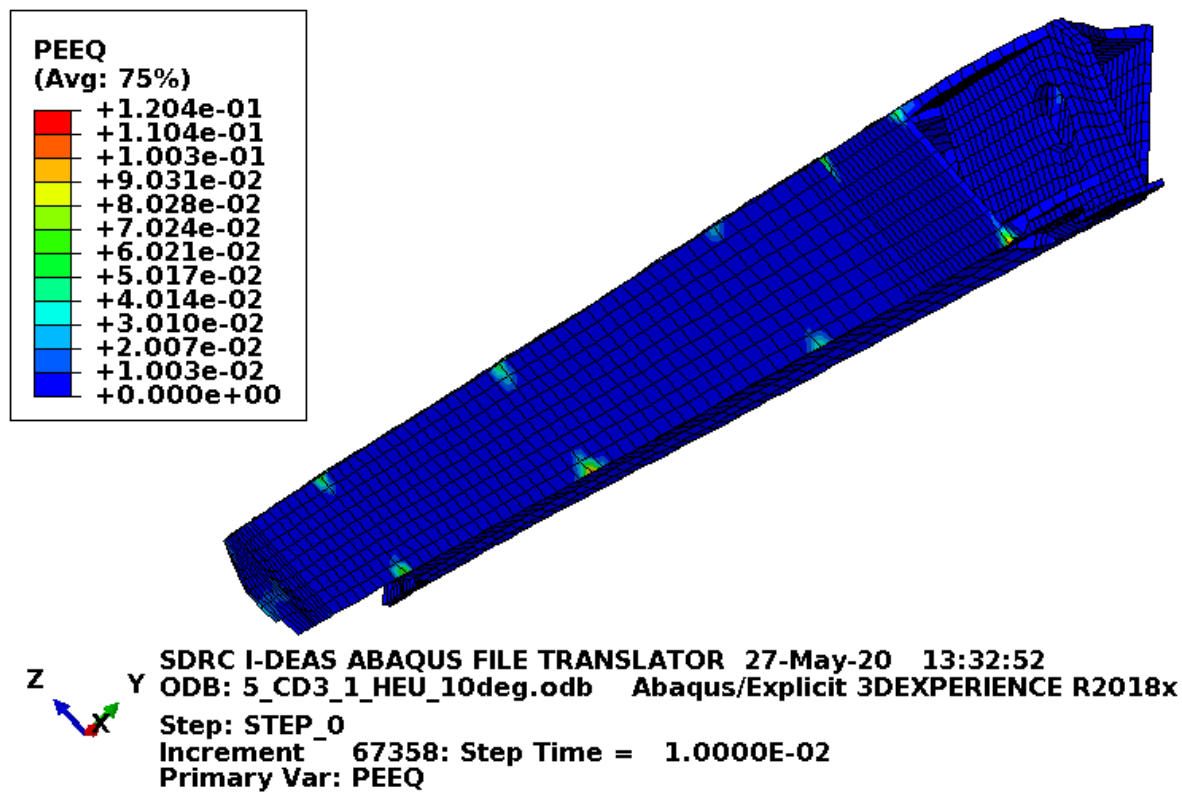

Figure C-220. Scope Part 4 (Table 3), 115-lbf fuel element, and 10-degree angle fuel element plasticequivalent strain.

Figure C-220 shows the equivalent plastic strain in the fuel element. For this model, the fuel element is coarse meshed, massive, and has no failure defined. Consequently, this is just shown for information and is not relevant to the acceptability of the fuel element. 
ENGINEERING CALCULATIONS AND ANALYSIS

Drop Analysis of the Advanced Test Reactor Fresh Fuel Shipping Container with Heavier Low-Enriched Uranium Fuel Contents

\section{C4.3 Results for Scope Part 4 (Table 3), Impacting 15 Degrees Off Horizontal}

The drop scenario considered in this section is a 30 -ft drop modeled as a side drop with the pockets and index lugs on the sides. It is oriented 15 degrees off horizontal about an axis along the length of the ATR FFSC.

\section{C4.3.1 Results for Scope Part 4 (Table 3) with 22.1-Ibf Fuel Element and Impacting 15 Degrees Off Horizontal}

The FEA model results for the Scope Part 4 (Table 3) with 22.1-lbf fuel element weight and impacting 15 degrees off horizontal model are shown below in Figure C-221 to Figure C-238. This drop scenario is a $30-\mathrm{ft}$ drop modeled as a side drop with the pockets and index lugs on the sides. The 15 degrees off horizontal angle is a rotation about an axis along the length of the ATR FFSC. The drop scenario is modeled with minimum material properties except the enclosure and end boxes, which are modeled with relatively tough material properties.

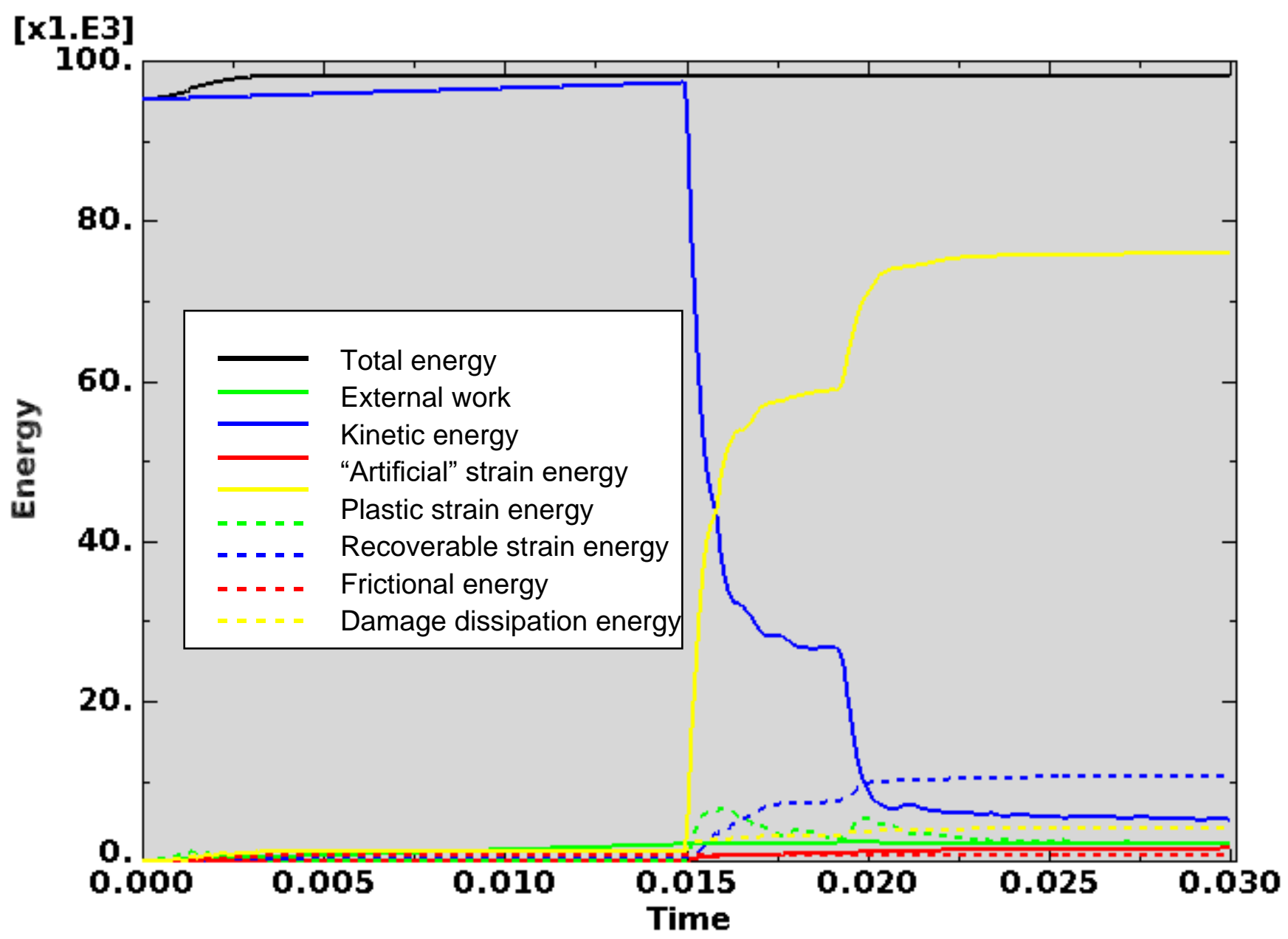

Figure C-221. Scope Part 4 (Table 3), 22.1-Ibf fuel element, and 15-degree angle energy curves. 
Figure C-221 shows the energy curves for Scope Part 4 (Table 3) with 22.1-lbf fuel element weight and impacting 15 degrees off horizontal drop scenario. These curves exhibit a stable shape. Artificial strain energy represents the energy required to keep reduced integration elements from taking on a zero-energy hourglass shape. As shown in Figure C-221, the artificial energy at the end of the model run is $1.6 \%$ of the total energy. Therefore, the potential error associated with artificial energy is not considered to be significant.
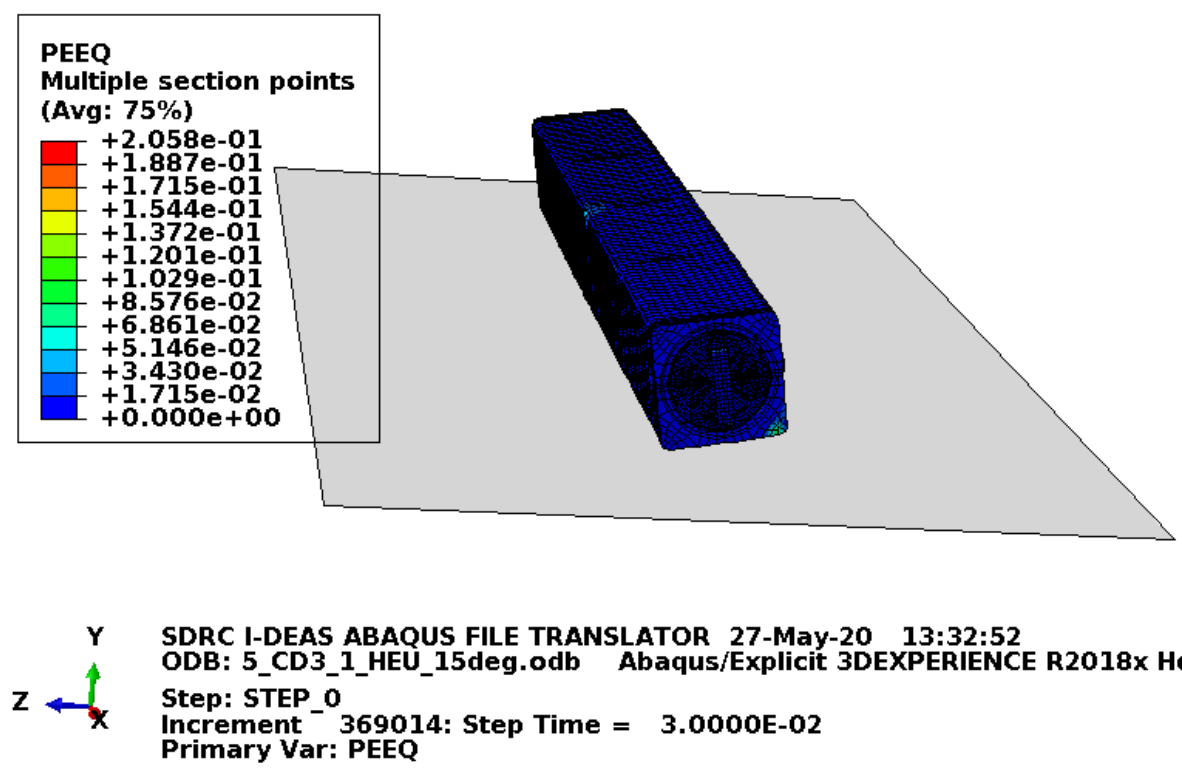

Figure C-222. Scope Part 4 (Table 3), 22.1-Ibf fuel element, and 15-degree angle full-model plasticequivalent strain.
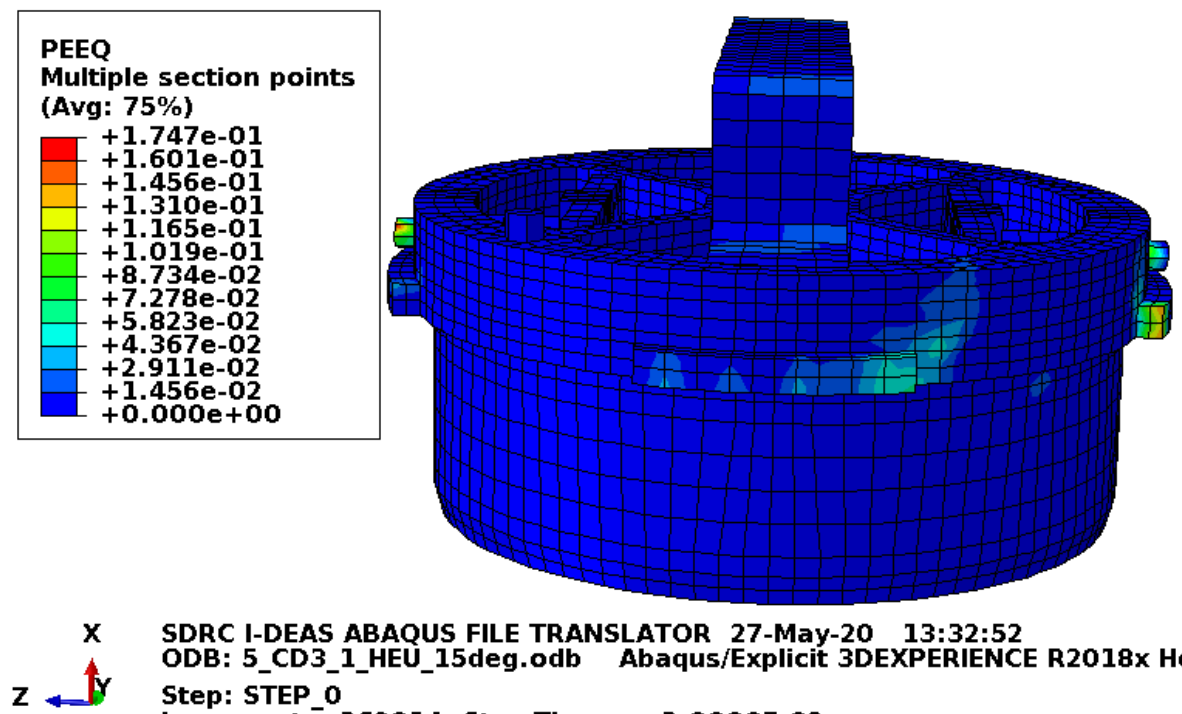

SDRC I-DEAS ABAQUS FILE TRANSLATOR 27-May-20 13:32:52

ODB: 5_CD3_1_HEU_15deg.odb Abaqus/Explicit 3DEXPERIENCE R2018x Hr

Step: STEP 0

Increment ${ }^{-}$369014: Step Time $=3.0000 \mathrm{E}-02$

Primary Var: PEEQ

Figure C-223. Scope Part 4 (Table 3), 22.1-lbf fuel element, and 15-degree angle lid plastic-equivalent strain. 
ENGINEERING CALCULATIONS AND ANALYSIS

Drop Analysis of the Advanced Test Reactor Fresh Fuel Shipping Container with Heavier Low-Enriched Uranium Fuel Contents

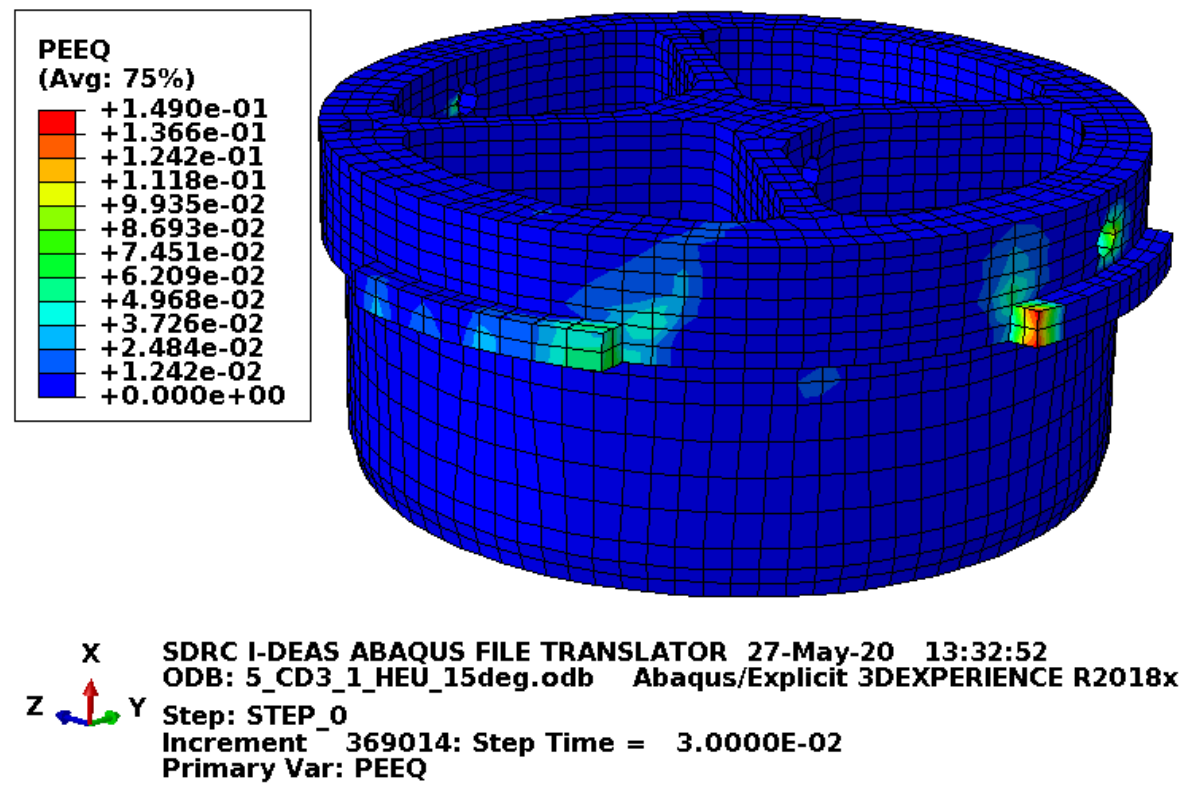

Figure C-224. Scope Part 4 (Table 3), 22.1-lbf fuel element, and 15-degree angle lid structure plasticequivalent strain.

Figure C-224 shows the equivalent plastic strain in the structurally significant portion of the lid. Failure in these elements occurs at an equivalent plastic strain of $0.259 \mathrm{in}$./in. If element failure were to occur, the element would be deleted and removed from the model (thereby making its equivalent plastic strain not included in the maximum equivalent plastic strain for the plot). However, the missing element would be visible in the plot. Figure C-224 shows no element failure with margin.

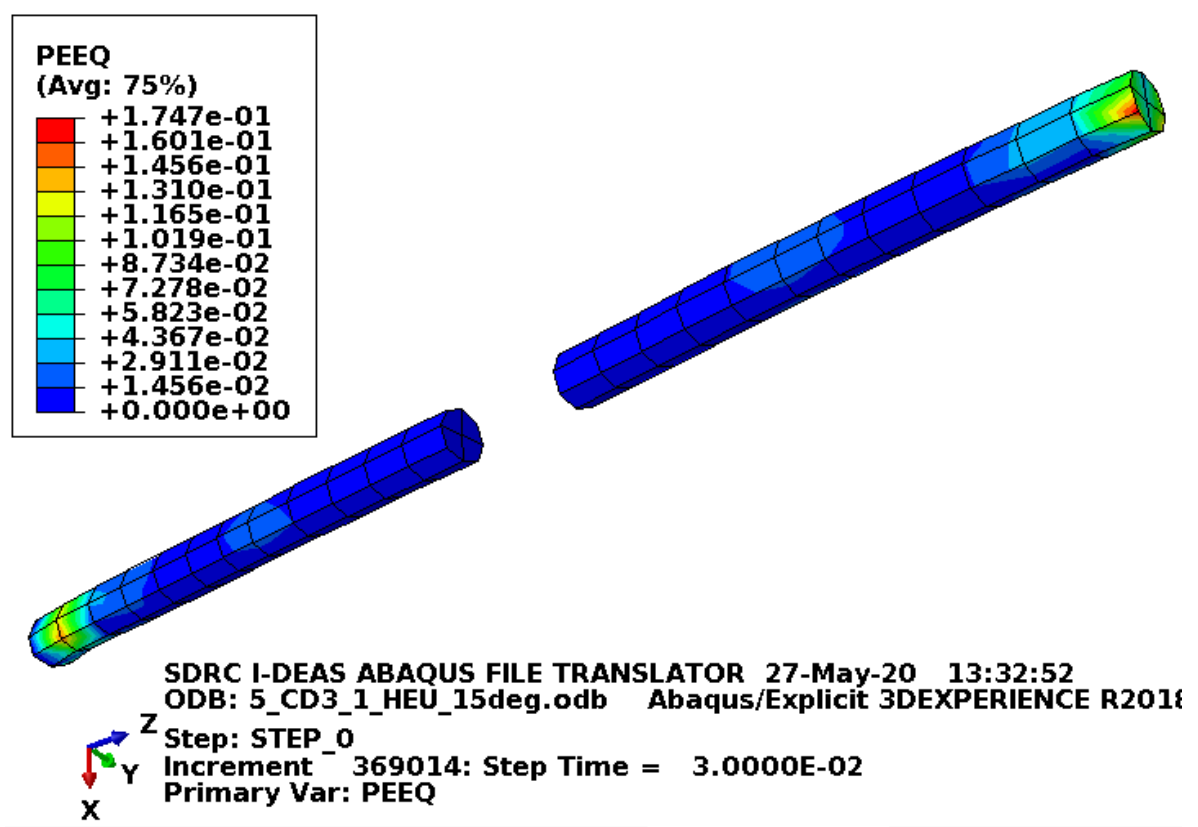

Figure C-225. Scope Part 4 (Table 3), 22.1-lbf fuel element, and 15-degree angle lid pins plastic-equivalent strain. 
Figure C-225 shows the equivalent plastic strain in the lid pins. Failure in these elements occurs at an equivalent plastic strain of $0.295 \mathrm{in}$./in. If element failure were to occur, the element would be deleted and removed from the model (thereby making its equivalent plastic strain not included in the maximum equivalent plastic strain for the plot). However, the missing element would be visible in the plot. Figure C-225 shows no element failure with margin.
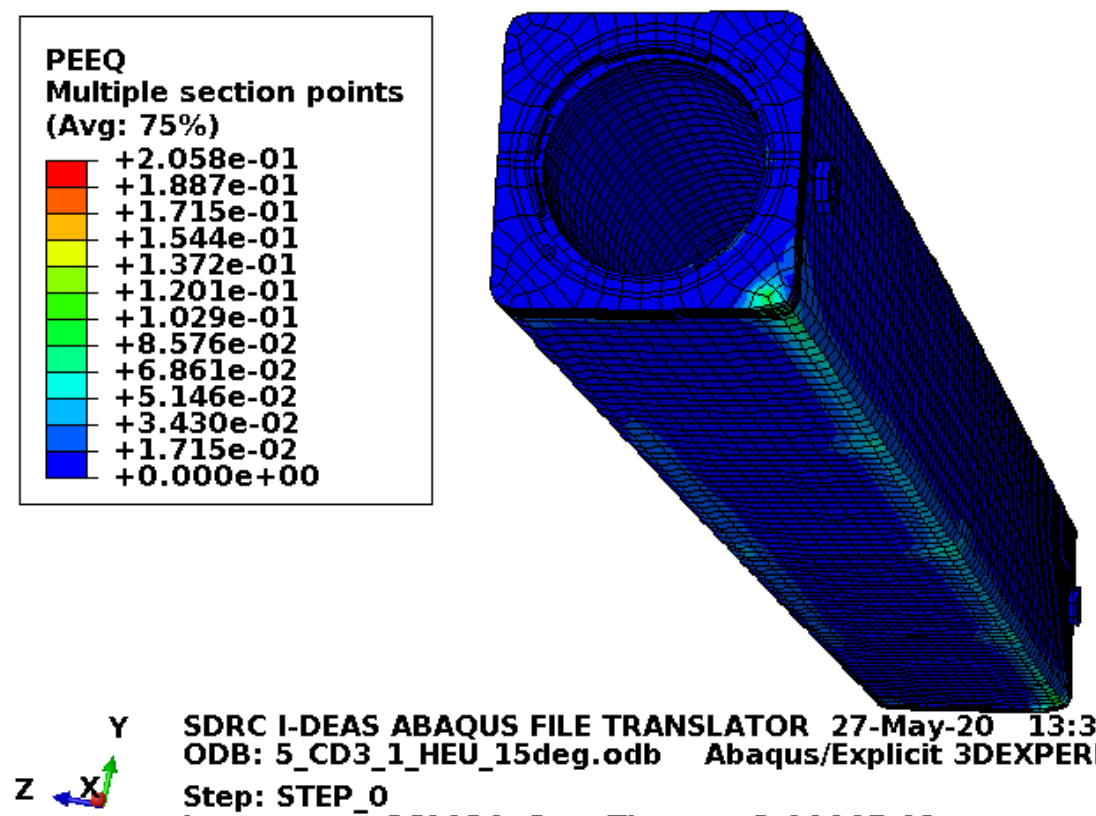

SDRC I-DEAS ABAQUS FILE TRANSLATOR 27-May-20 $\quad 13: 32: 52$

ODB: 5_CD3_1_HEU_15deg.odb Abaqus/Explicit 3DEXPERIENCE

Step: STEP 0

Increment ${ }^{-}$369014: Step Time $=3.0000 E-02$

Primary Var: PEEQ

Figure C-226. Scope Part 4 (Table 3), 22.1-lbf fuel element, and 15-degree angle body plastic-equivalent strain.

Figure C-226 shows the equivalent plastic strain in the body. Failure in these elements occurs at an equivalent plastic strain of $0.259 \mathrm{in}$./in. If element failure were to occur, the element would be deleted and removed from the model (thereby making its equivalent plastic strain not included in the maximum equivalent plastic strain for the plot). However, the missing element would be visible in the plot. Figure C-226 shows no element failure with margin. 
ENGINEERING CALCULATIONS AND ANALYSIS

Drop Analysis of the Advanced Test Reactor Fresh Fuel Shipping Container with Heavier Low-Enriched Uranium Fuel Contents
ECAR-5224, Rev. 0

Page $\mathrm{C} 153$ of $\mathrm{C} 190$
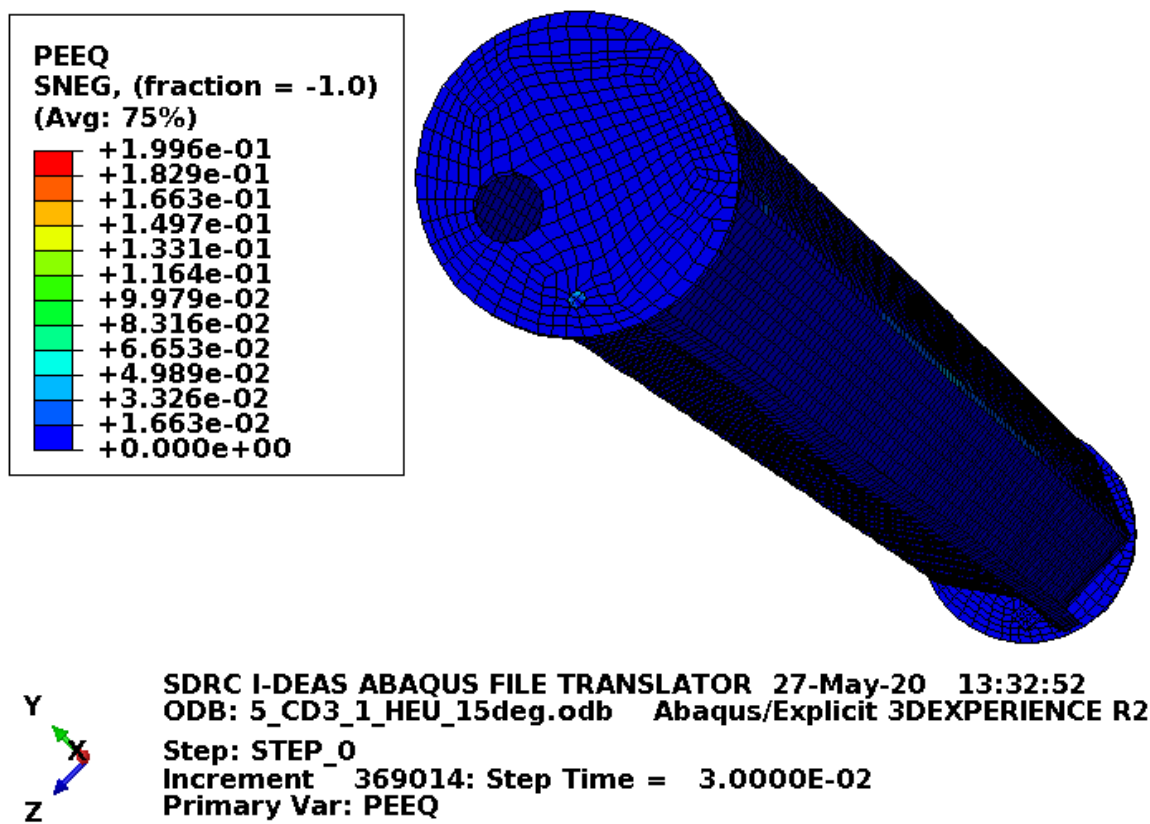

SDRC I-DEAS ABAQUS FILE TRANSLATOR 27-May-20 13:32:52

ODB: 5_CD3_1_HEU_15deg.odb Abaqus/Explicit 3DEXPERIENCE R20:

Step: STEP_0

Increment ${ }^{-}$369014: Step Time = 3.0000E-02

$\mathbf{Z}$

Primary Var: PEEQ

Figure C-227. Scope Part 4 (Table 3), 22.1-lbf fuel element, and 15-degree angle enclosure plasticequivalent strain.

Figure $\mathrm{C}-127$ shows the equivalent plastic strain in the enclosure. This is just for information as damage to the enclosure is acceptable.
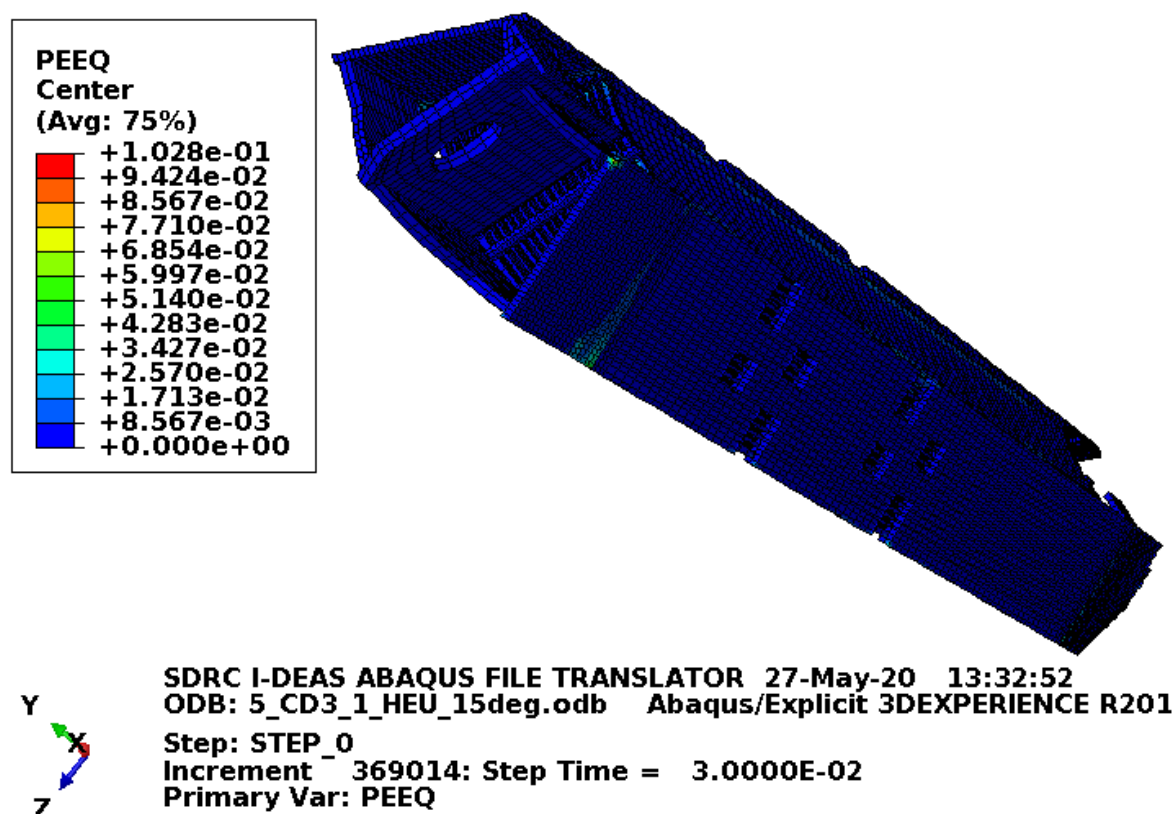

SDRC I-DEAS ABAOUS FILE TRANSLATOR 27-May-20 13:32:52

ODB: 5_CD3_1_HEU_15deg.odb Abaqus/Explicit 3DEXPERIENCE R201:

Step: STEP 0

Increment 369014: Step Time $=$ 3.0000E-02

$\mathbf{Z}$

Primary Var: PEEQ

Figure C-228. Scope Part 4 (Table 3), 22.1-lbf fuel element, and 15-degree angle fuel element plasticequivalent strain. 
Figure C-228 shows the equivalent plastic strain in the fuel element. For this model, the fuel element is modeled with minimum material properties except the end boxes, which are modeled with relatively tough material properties. While this model is appropriate for fuel element damage consideration, it is only shown here as it is not significantly damaged and other similar drop scenarios are documented in more detail.

\section{C4.3.2 Results for Scope Part 4 (Table 3) with 115-Ibf Fuel Element and Impacting 15 Degree Off Horizontal}

The FEA model results for the Scope Part 4 (Table 3) with 115-lbf fuel element weight and impacting 15 degrees off horizontal model are shown below in Figure C-229 to Figure C-236. This drop scenario is a 30-ft drop modeled as a side drop with the pockets and index lugs on the sides. The 15 degrees off horizontal angle is a rotation about an axis along the length of the ATR FFSC. The drop scenario is modeled with the ATR FFSC having minimum material properties and the enclosure and fuel element having relatively tough material properties with no failure.

\section{[x1.E6]}

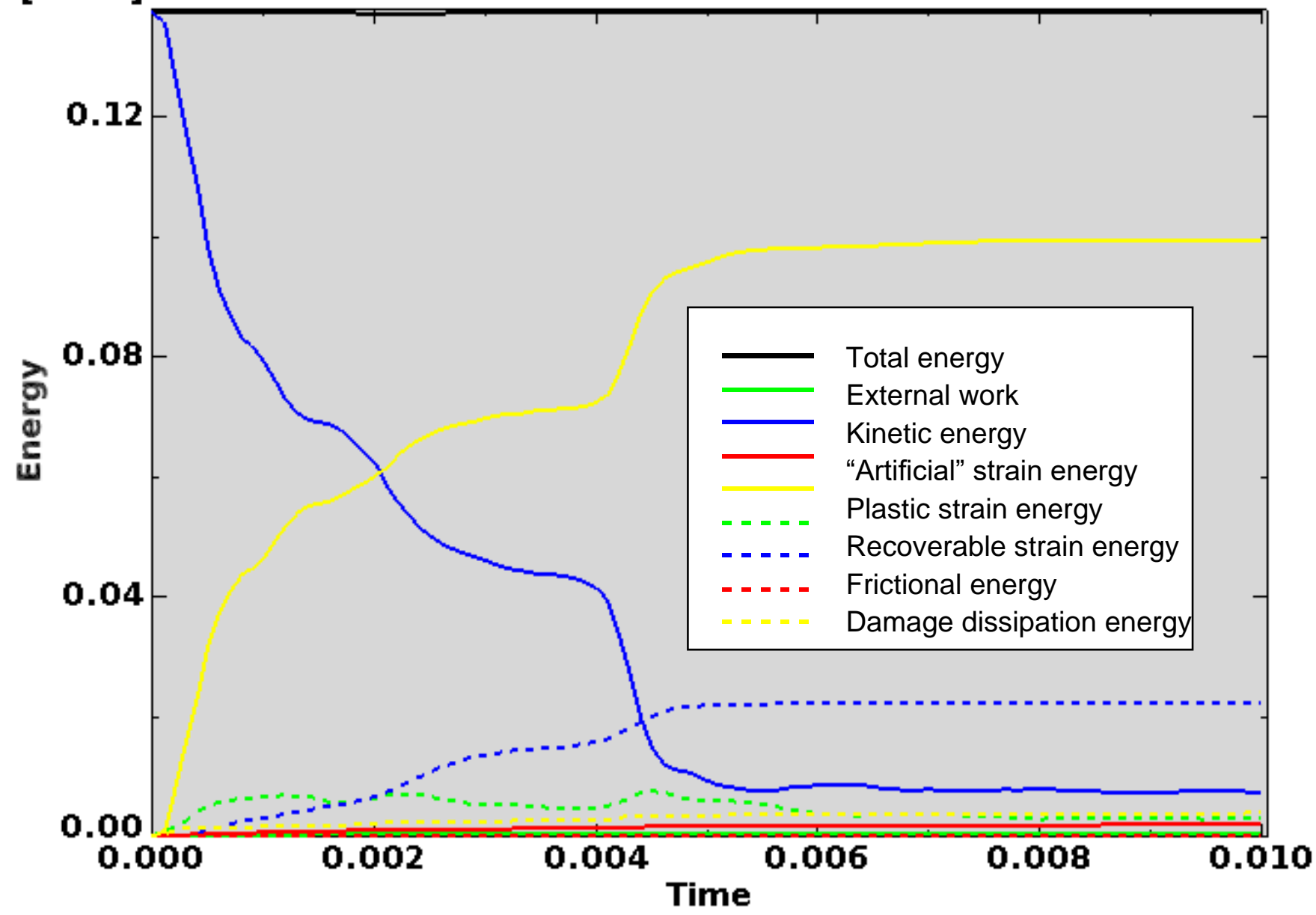

Figure C-229. Scope Part 4 (Table 3), 115-lbf fuel element, and 15-degree angle energy curves. 
Figure C-229 shows the energy curves for Scope Part 4 (Table 3) with 115-lbf fuel element weight and impacting 15 degrees off horizontal drop scenario. These curves exhibit a stable shape. Artificial energy represents the energy required to keep reduced integration elements from taking on a zero-energy hourglass shape. As shown in Figure C-229, the artificial energy at the end of the model run is $1.4 \%$ of the total energy. Therefore, the potential error associated with artificial energy is not considered to be significant.

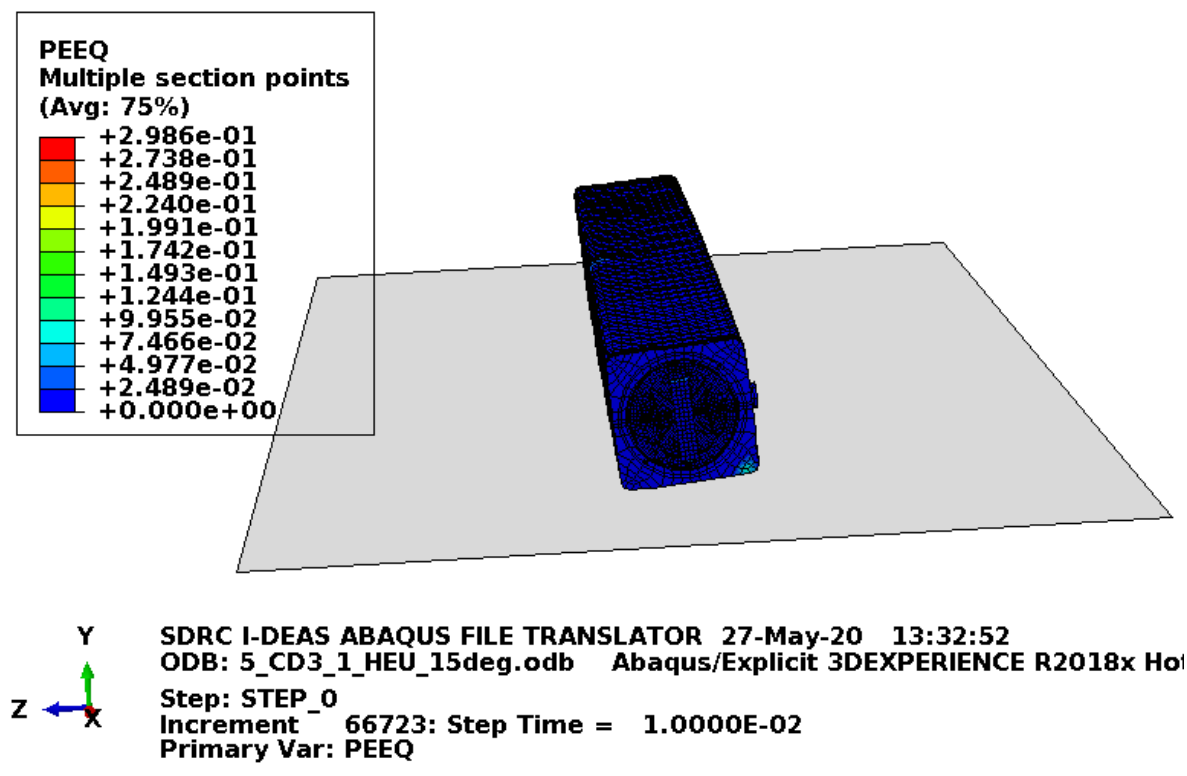

Figure C-230. Scope Part 4 (Table 3), 115-lbf fuel element, and 15-degree angle full-model plasticequivalent strain.

\begin{tabular}{|l|}
\hline PEEQ \\
Multiple section points \\
(Avg: $75 \%$ ) \\
\begin{tabular}{|c|}
$+2.986 \mathrm{e}-01$ \\
$+2.738 \mathrm{e}-01$ \\
$+2.489 \mathrm{e}-01$ \\
$+2.240 \mathrm{e}-01$ \\
$+1.991 \mathrm{e}-01$ \\
$+1.742 \mathrm{e}-01$ \\
$+1.493 \mathrm{e}-01$ \\
$+1.244 \mathrm{e}-01$ \\
$+9.955 \mathrm{e}-02$ \\
$+7.466 \mathrm{e}-02$ \\
$+4.977 \mathrm{e}-02$ \\
$+2.489 \mathrm{e}-02$ \\
$+0.000 \mathrm{e}+00$ \\
\hline
\end{tabular} \\
\hline
\end{tabular}
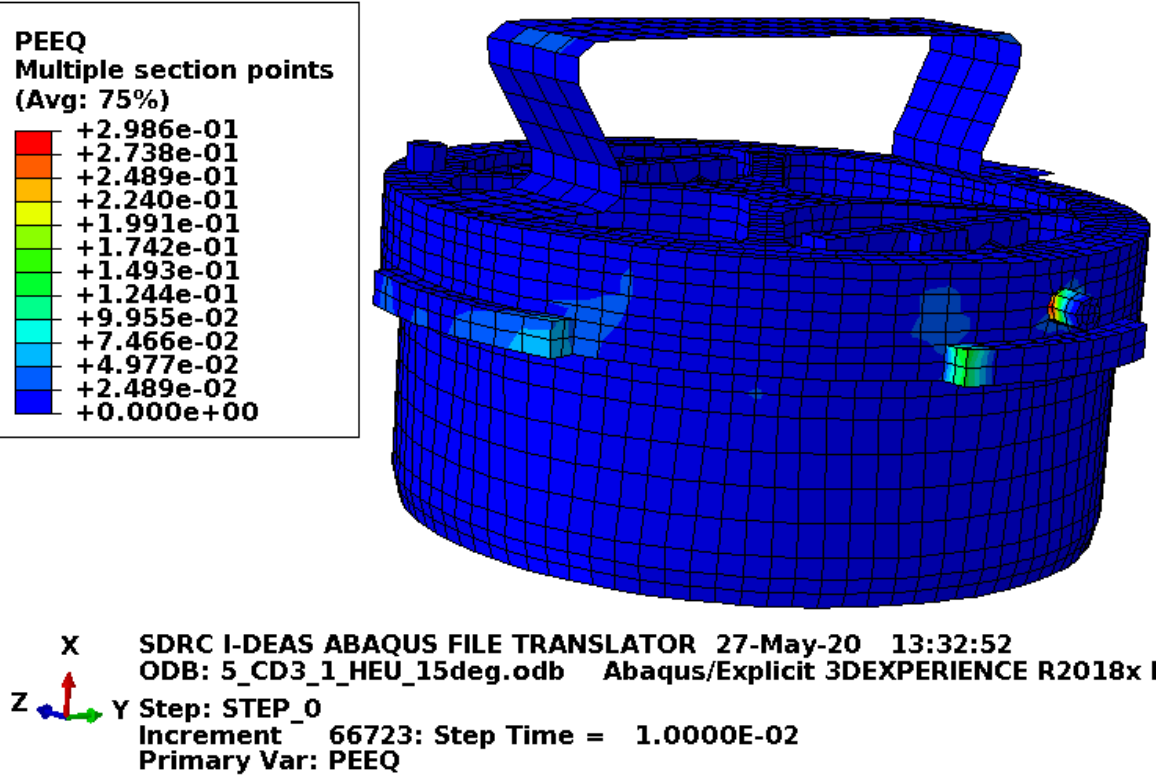

Figure C-231. Scope Part 4 (Table 3), 115-lbf fuel element, and 15-degree angle lid plastic-equivalent strain. 
ENGINEERING CALCULATIONS AND ANALYSIS

Drop Analysis of the Advanced Test Reactor Fresh Fuel Shipping Container with Heavier Low-Enriched Uranium Fuel Contents
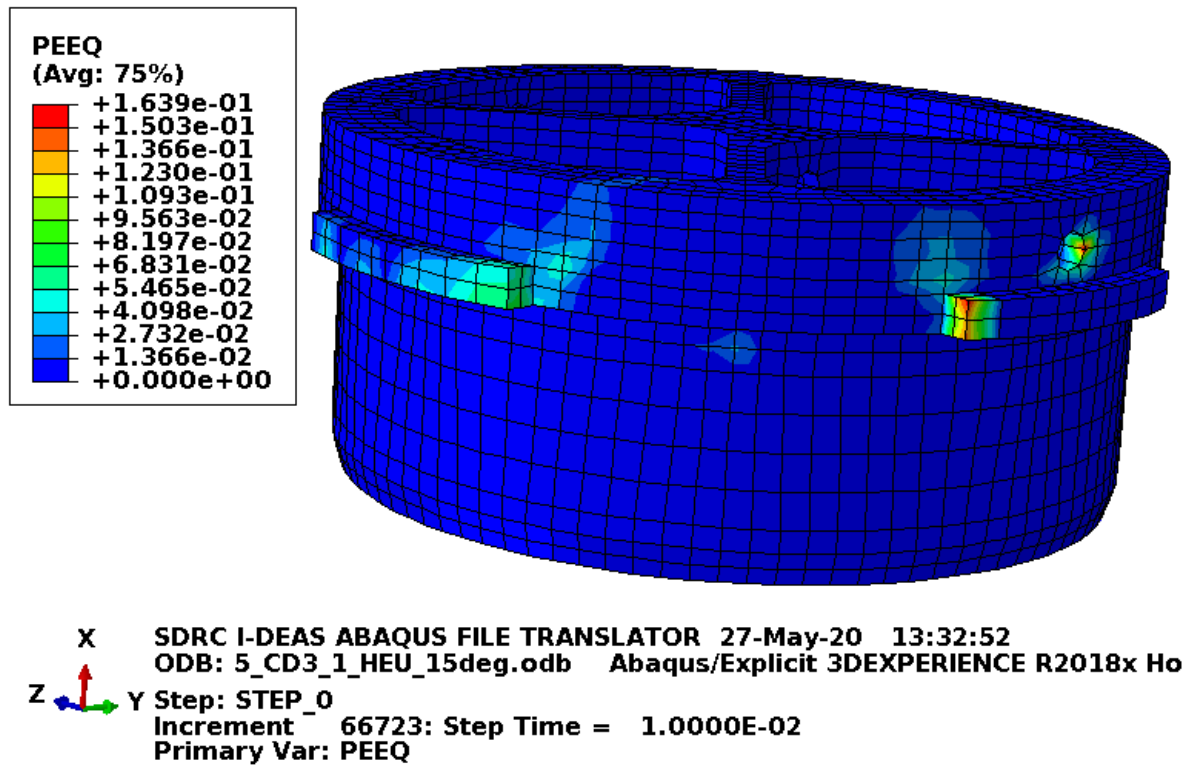

Figure C-232. Scope Part 4 (Table 3), 115-lbf fuel element, and 15-degree angle lid structure plasticequivalent strain.

Figure C-232 shows the equivalent plastic strain in the structurally significant portion of the lid. Failure in these elements occurs at an equivalent plastic strain of $0.259 \mathrm{in}$./in. If element failure were to occur, the element would be deleted and removed from the model (thereby making its equivalent plastic strain not included in the maximum equivalent plastic strain for the plot). However, the missing element would be visible in the plot. Figure C-232 shows no element failure.

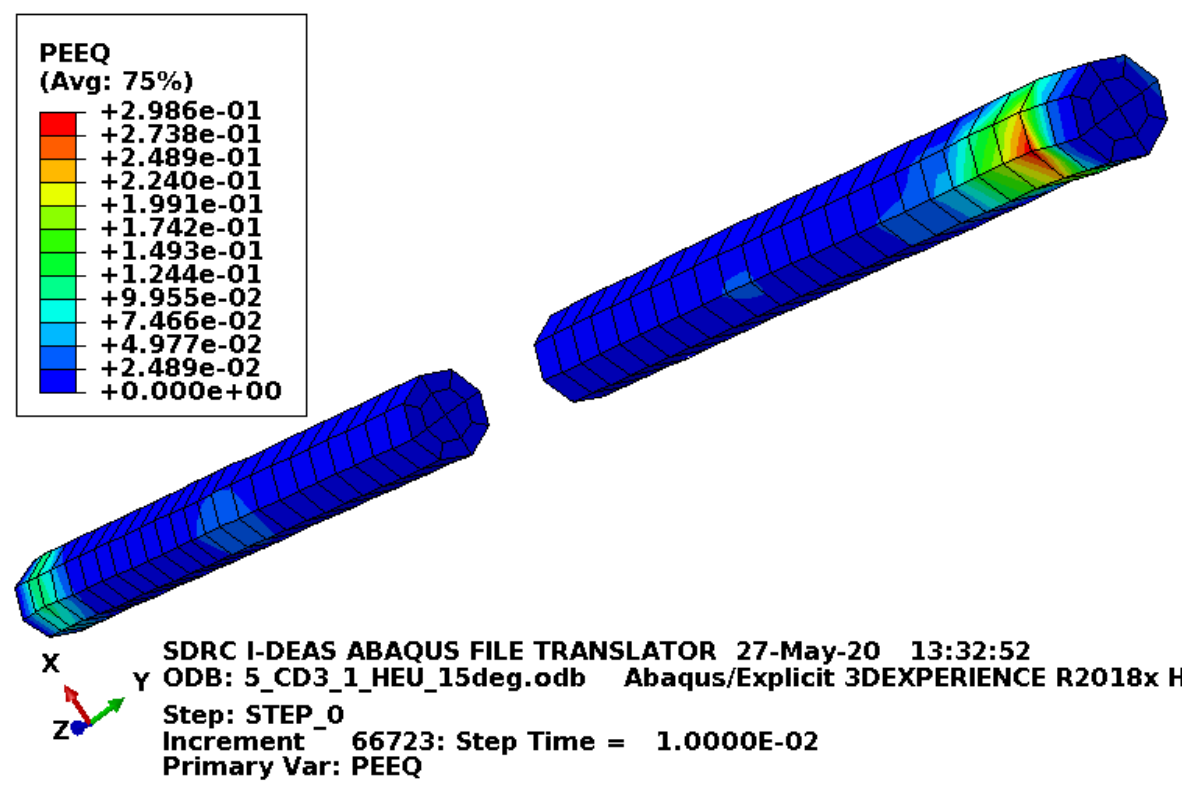

Figure C-233. Scope Part 4 (Table 3), 115-lbf fuel element, and 15-degree angle lid pins plastic-equivalent strain. 
Figure C-233 shows the equivalent plastic strain in the lid pins. Failure in these elements occurs at an equivalent plastic strain of $0.295 \mathrm{in}$./in. If element failure were to occur, the element would be deleted and removed from the model (thereby making its equivalent plastic strain not included in the maximum equivalent plastic strain for the plot). However, the missing element would be visible in the plot.

Figure C-233 shows no element failure though the plot shows local strains slightly above failure. The strains shown above the failure strain likely result from extrapolation (as integration point strains are the important strains for failure). Even if the elements with high strain were removed as being failed, the lid pin would still be capable of performing its function. The failure would be through less than $20 \%$ of the lid pin cross section leaving it still functional and the lid pin on the other side has no failure or high strains.

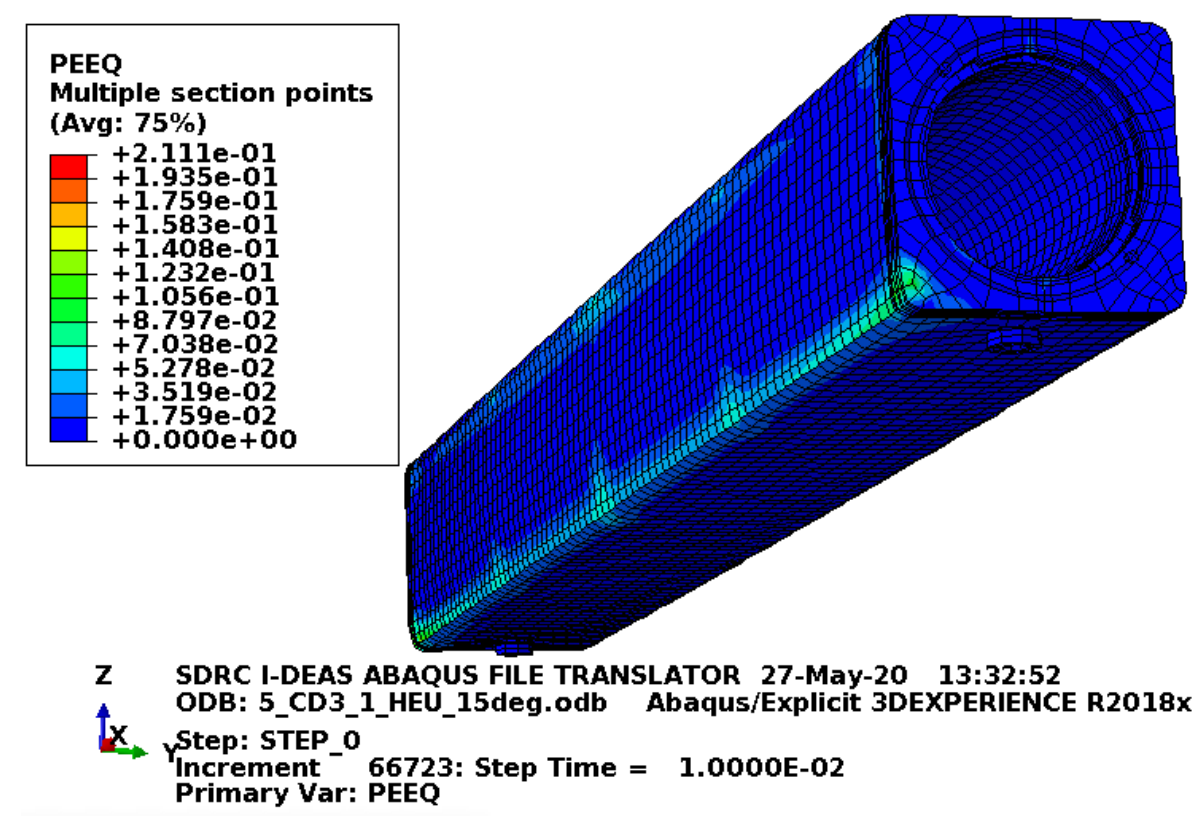

Figure C-234. Scope Part 4 (Table 3), 115-lbf fuel element, and 15-degree angle body plastic-equivalent strain.

Figure C-234 shows the equivalent plastic strain in the body. Failure in these elements occurs at an equivalent plastic strain of 0.259 in./in. If element failure were to occur, the element would be deleted and removed from the model (thereby making its equivalent plastic strain not included in the maximum equivalent plastic strain for the plot). However, the missing element would be visible in the plot. Figure C-234 shows no element failure. 
ENGINEERING CALCULATIONS AND ANALYSIS

Drop Analysis of the Advanced Test Reactor Fresh Fuel Shipping Container with Heavier Low-Enriched Uranium Fuel Contents

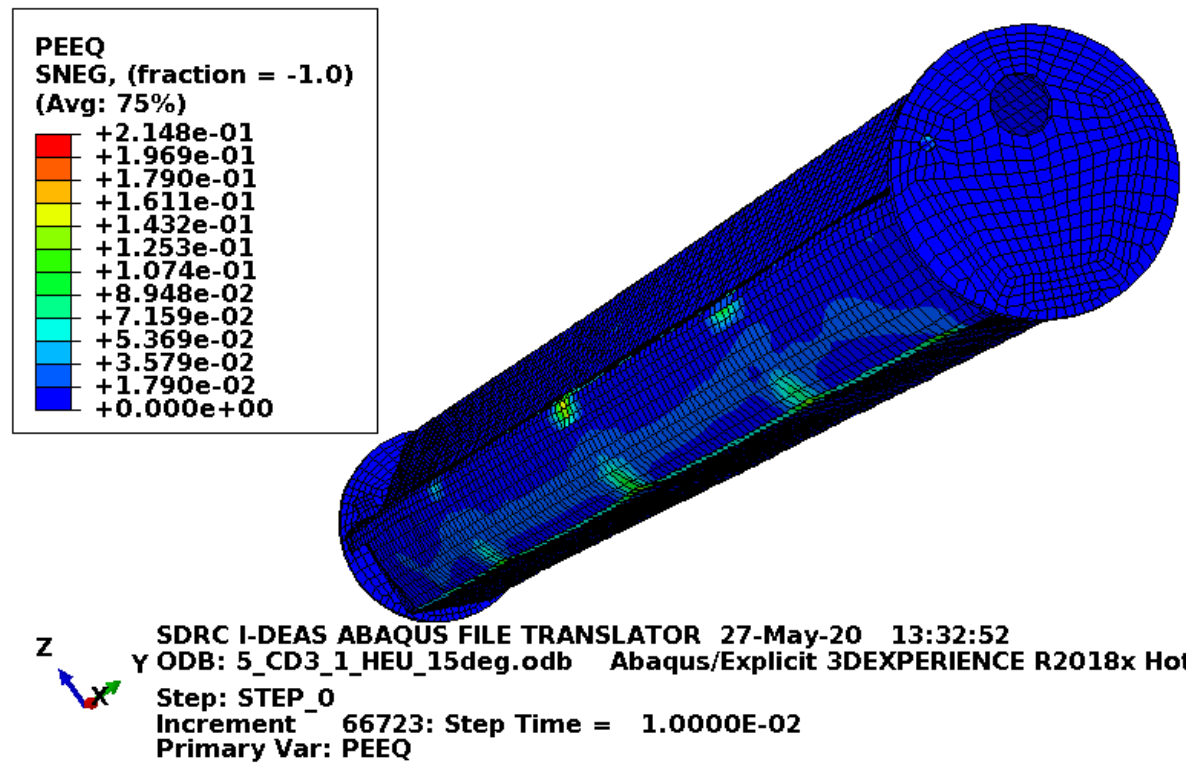

Figure C-235. Scope Part 4 (Table 3), 115-lbf fuel element, and 15-degree angle enclosure plasticequivalent strain.

Figure C-235 shows the equivalent plastic strain in the enclosure. This is just for information as damage to the enclosure is acceptable.

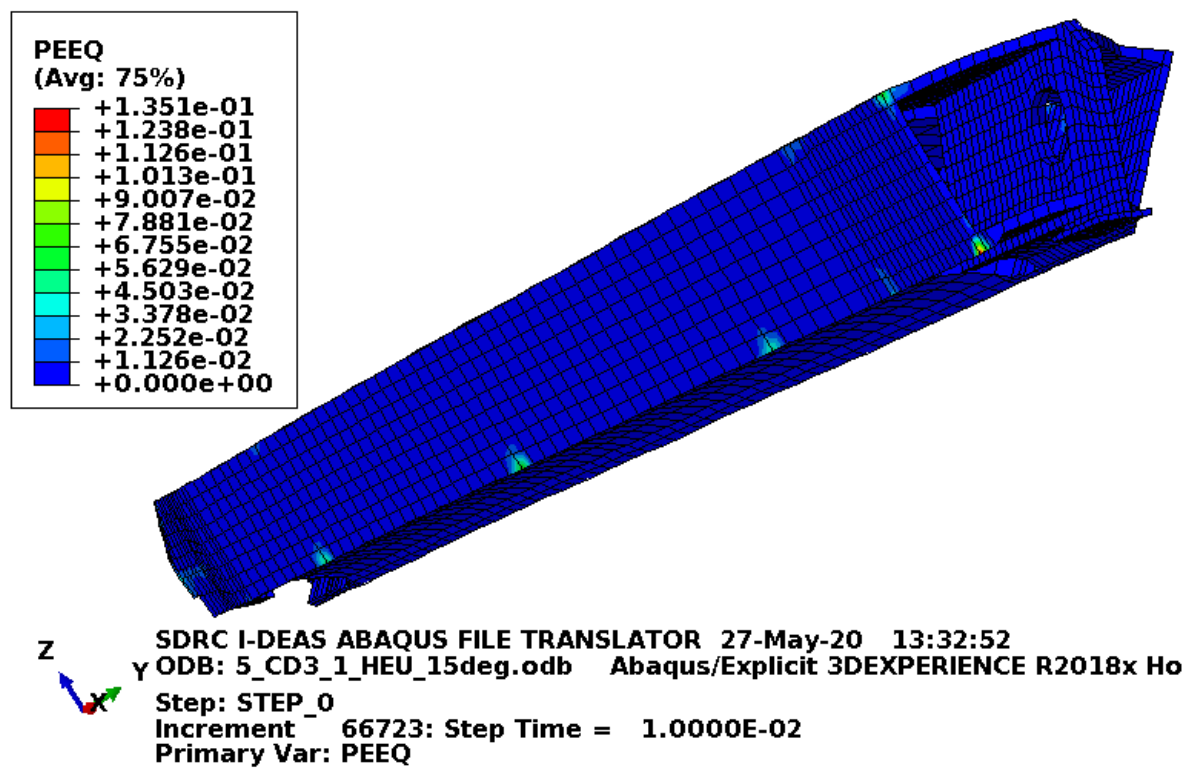

Figure C-236. Scope Part 4 (Table 3), 115-lbf fuel element, and 15-degree angle fuel element plasticequivalent strain.

Figure C-236 shows the equivalent plastic strain in the fuel element. For this model, the fuel element is coarse meshed, massive, and has no failure defined. Consequently, this is just shown for information and is not relevant to the acceptability of the fuel element. 
ENGINEERING CALCULATIONS AND ANALYSIS

Drop Analysis of the Advanced Test Reactor Fresh Fuel Shipping Container with Heavier Low-Enriched Uranium Fuel Contents

\section{C4.4 Results for Scope Part 4 (Table 3), Impacting 20 Degrees Off Horizontal}

The drop scenario considered in this section is a 30 -ft drop modeled as a side drop with the pockets and index lugs on the sides. It is oriented 20 degrees off horizontal about an axis along the length of the ATR FFSC.

\section{C4.4.1 Results for Scope Part 4 (Table 3) with 22.1-Ibf Fuel Element and Impacting 20 Degrees Off Horizontal}

The FEA model results for the Scope Part 4 (Table 3) with 22.1-lbf fuel element weight and impacting 20-degree off horizontal model are shown below in Figure C-237 to Figure C-244. This drop scenario is a $30-\mathrm{ft}$ drop modeled as a side drop with the pockets and index lugs on the sides. The 20 degrees off horizontal angle is a rotation about an axis along the length of the ATR FFSC. The drop scenario is modeled with minimum material properties except the enclosure and end boxes, which are modeled with relatively tough material properties.

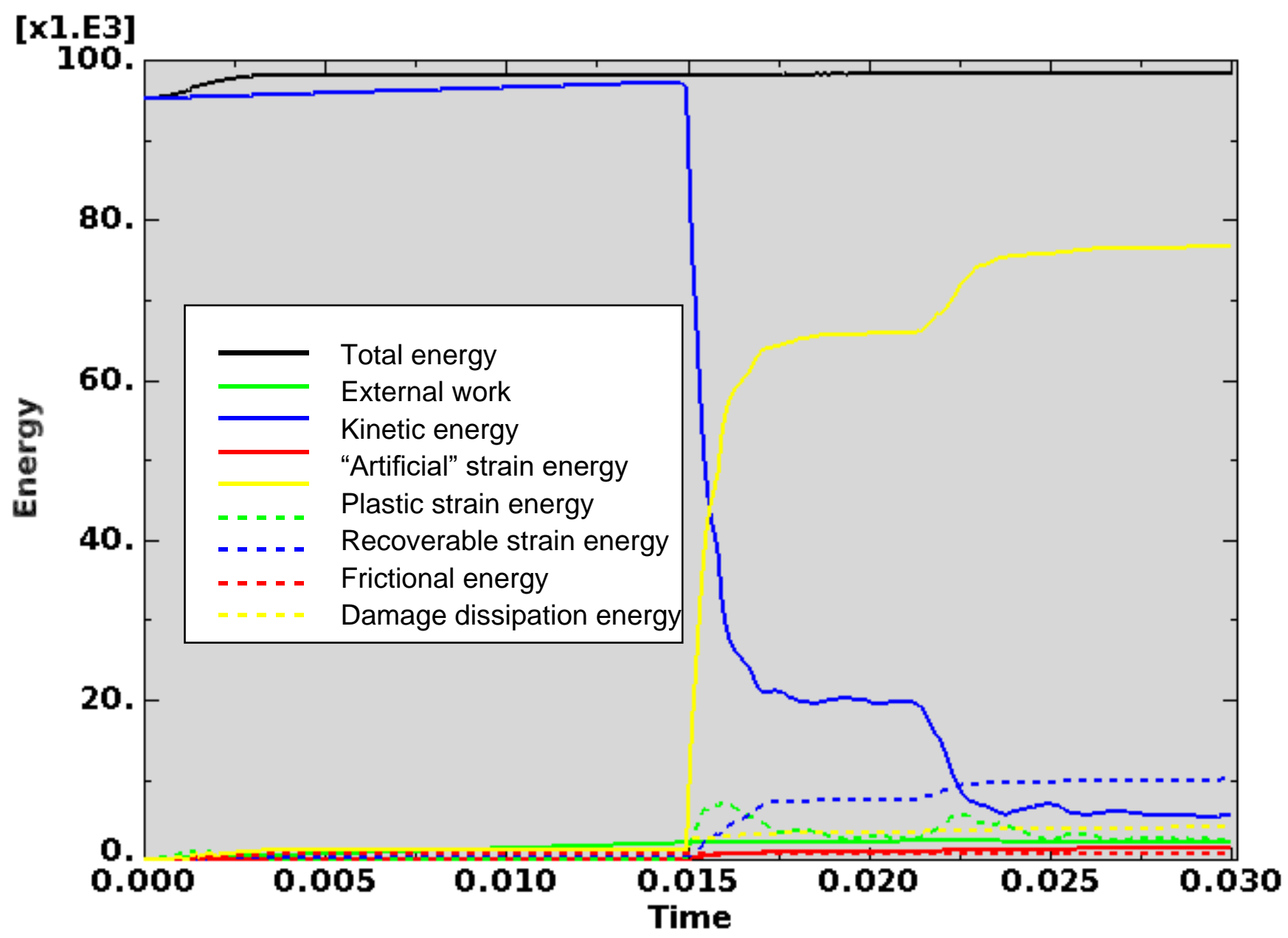

Figure C-237. Scope Part 4 (Table 3), 22.1-Ibf fuel element, and 20-degree angle energy curves. 
Figure C-237 shows the energy curves for Scope Part 4 (Table 3) with 22.1-lbf fuel element weight and impacting 20 degrees off horizontal drop scenario. These curves exhibit a stable shape. Artificial strain energy represents the energy required to keep reduced integration elements from taking on a zero-energy hourglass shape. As shown in Figure C-237, the artificial energy at the end of the model run is $1.5 \%$ of the total energy. Therefore, the potential error associated with artificial energy is not considered to be significant.
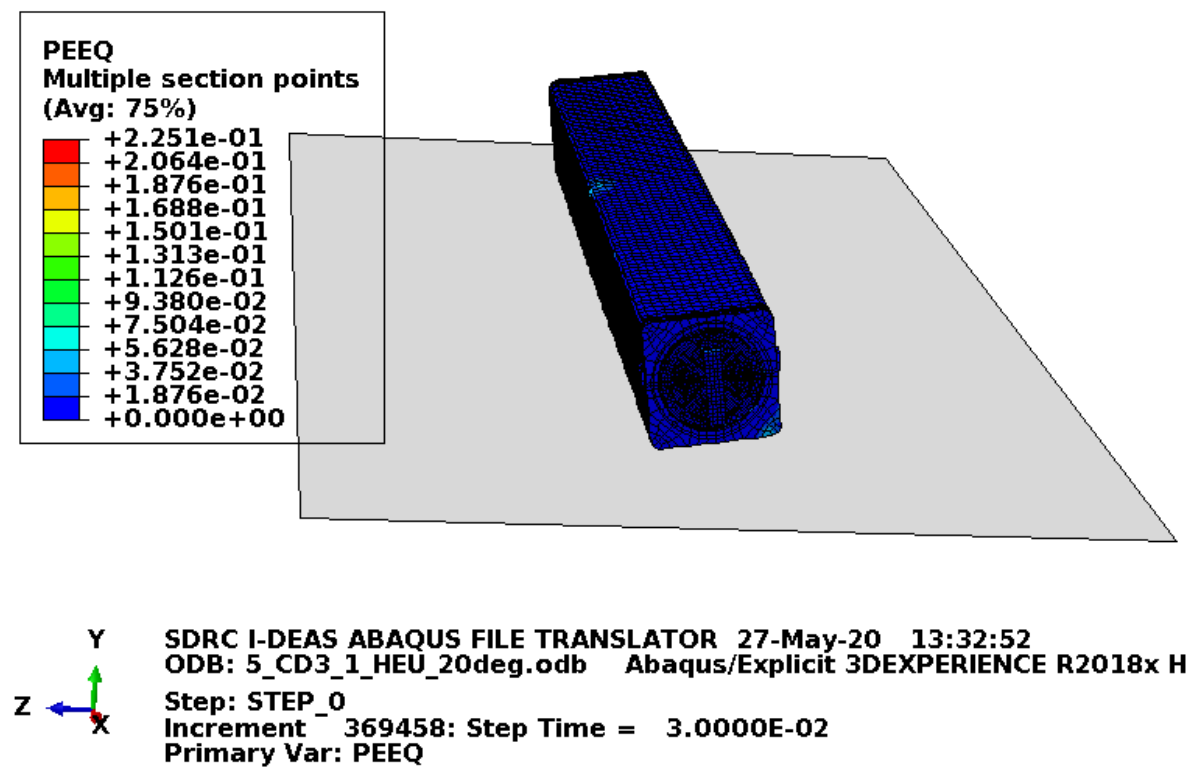

Figure C-238. Scope Part 4 (Table 3), 22.1-lbf fuel element, and 20-degree angle full-model plasticequivalent strain.
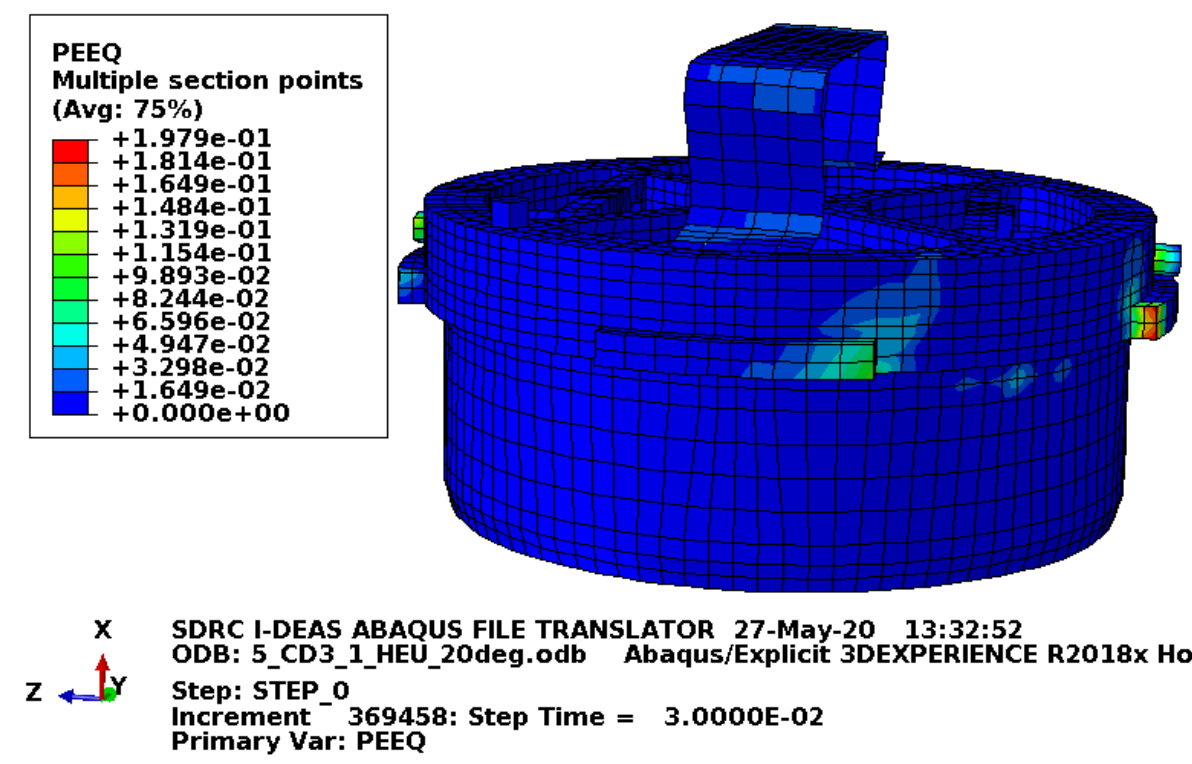

Figure C-239. Scope Part 4 (Table 3), 22.1-lbf fuel element, and 20-degree angle lid plastic-equivalent strain. 
ENGINEERING CALCULATIONS AND ANALYSIS

Drop Analysis of the Advanced Test Reactor Fresh Fuel Shipping Container with Heavier Low-Enriched Uranium Fuel Contents

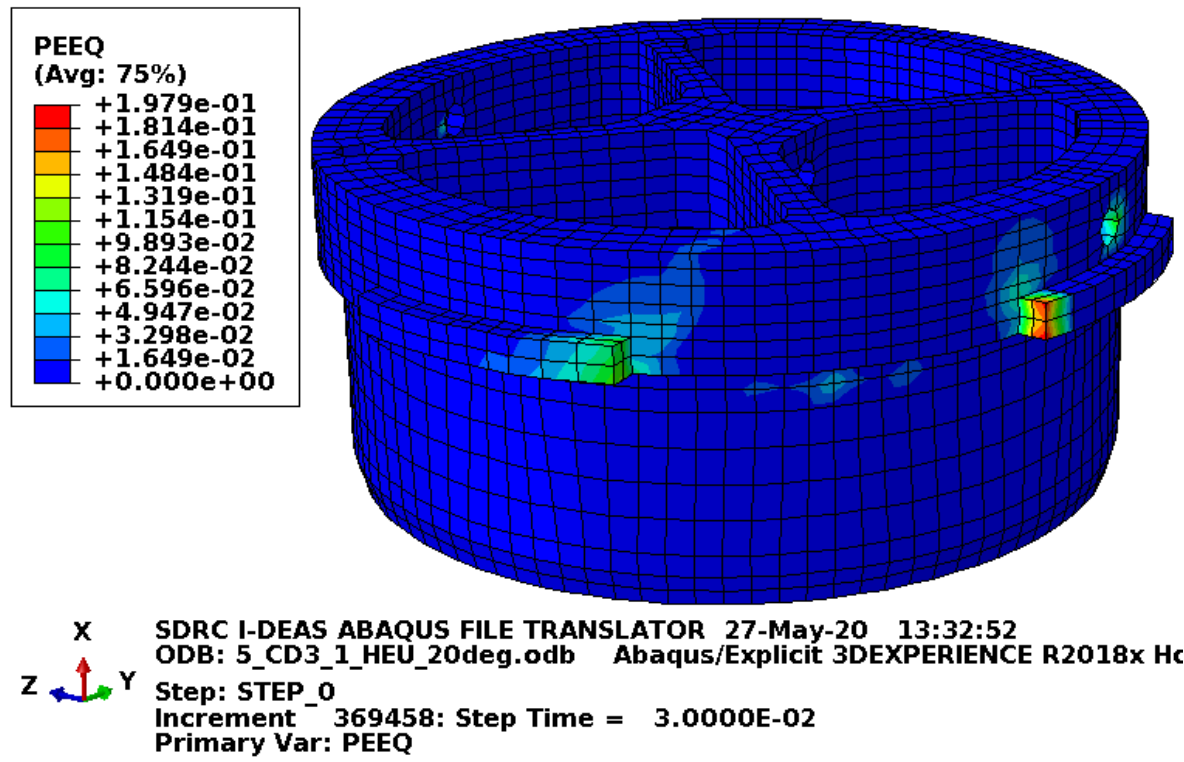

Figure C-240. Scope Part 4 (Table 3), 22.1-lbf fuel element, and 20-degree angle lid structure plasticequivalent strain.

Figure C-240 shows the equivalent plastic strain in the structurally significant portion of the lid. Failure in these elements occurs at an equivalent plastic strain of $0.259 \mathrm{in}$./in. If element failure were to occur, the element would be deleted and removed from the model (thereby making its equivalent plastic strain not included in the maximum equivalent plastic strain for the plot). However, the missing element would be visible in the plot. Figure C-240 shows no element failure with margin.

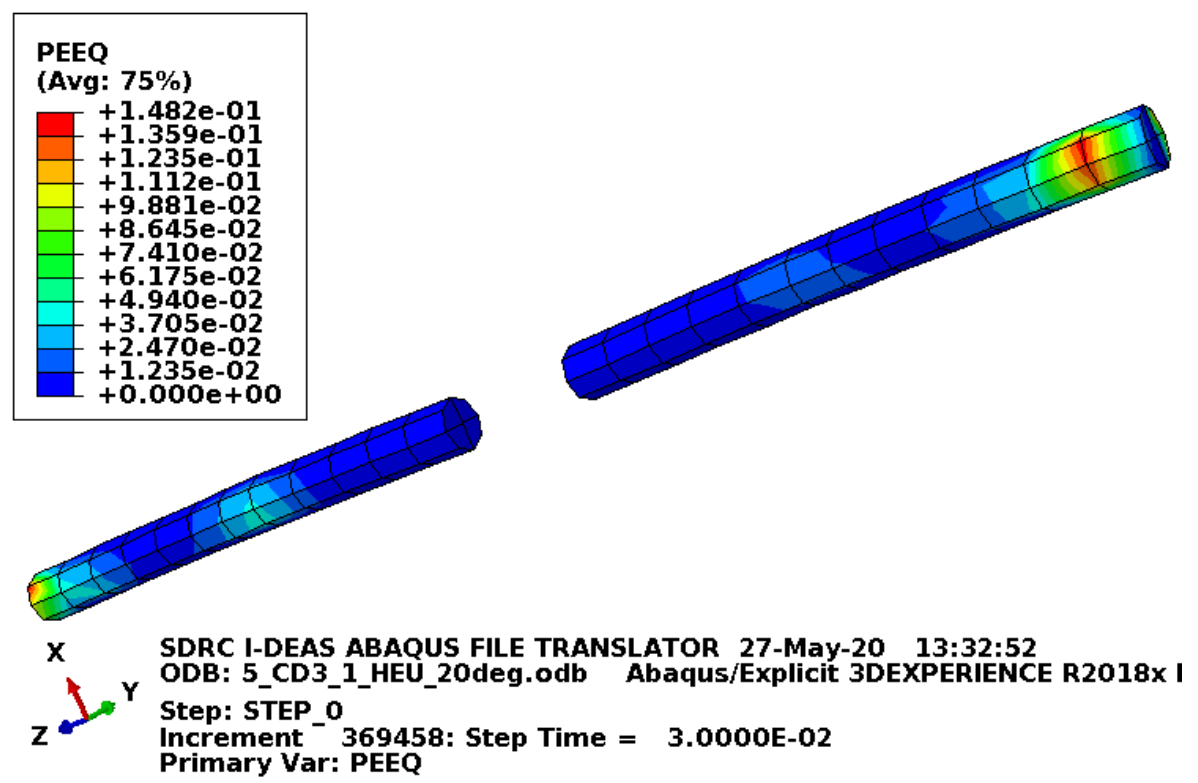

Figure C-241. Scope Part 4 (Table 3), 22.1-lbf fuel element, and 20-degree angle lid pins plastic-equivalent strain. 
Figure C-241 shows the equivalent plastic strain in the lid pins. Failure in these elements occurs at an equivalent plastic strain of $0.295 \mathrm{in}$./in. If element failure were to occur, the element would be deleted and removed from the model (thereby making its equivalent plastic strain not included in the maximum equivalent plastic strain for the plot). However, the missing element would be visible in the plot. Figure C-241 shows no element failure with margin.
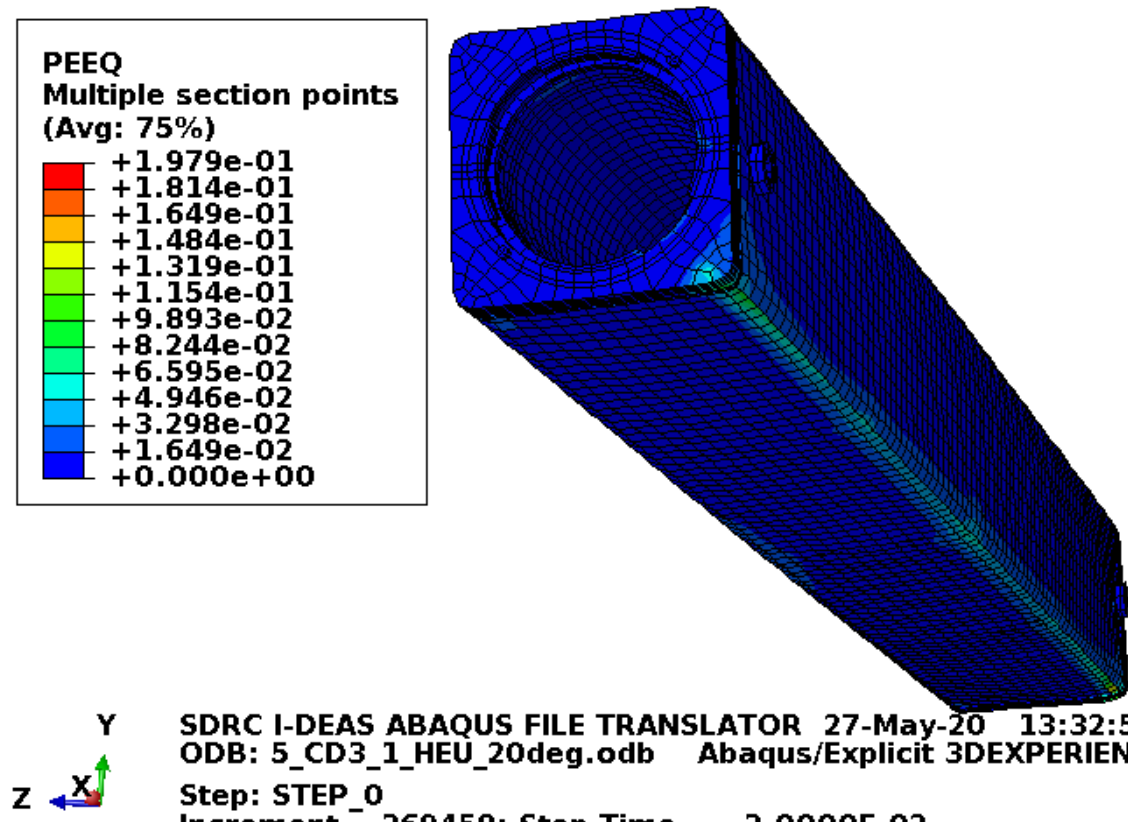

SDRC I-DEAS ABAQUS FILE TRANSLATOR 27-May-20 13:32:52 ODB: 5_CD3_1_HEU_20deg.odb Abaqus/Explicit 3DEXPERIENCE Step: STEP_0 Increment ${ }^{-}$369458: Step Time $=3.0000 E-02$ Primary Var: PEEQ

Figure C-242. Scope Part 4 (Table 3), 22.1-lbf fuel element, and 20-degree angle body plastic-equivalent strain.

Figure C-242 shows the equivalent plastic strain in the body. Failure in these elements occurs at an equivalent plastic strain of $0.259 \mathrm{in}$./in. If element failure were to occur, the element would be deleted and removed from the model (thereby making its equivalent plastic strain not included in the maximum equivalent plastic strain for the plot). However, the missing element would be visible in the plot. Figure C-242 shows no element failure with margin. 
ENGINEERING CALCULATIONS AND ANALYSIS

Drop Analysis of the Advanced Test Reactor Fresh Fuel Shipping Container with Heavier Low-Enriched Uranium Fuel Contents
ECAR-5224, Rev. 0

Page $\mathrm{C} 163$ of $\mathrm{C} 190$
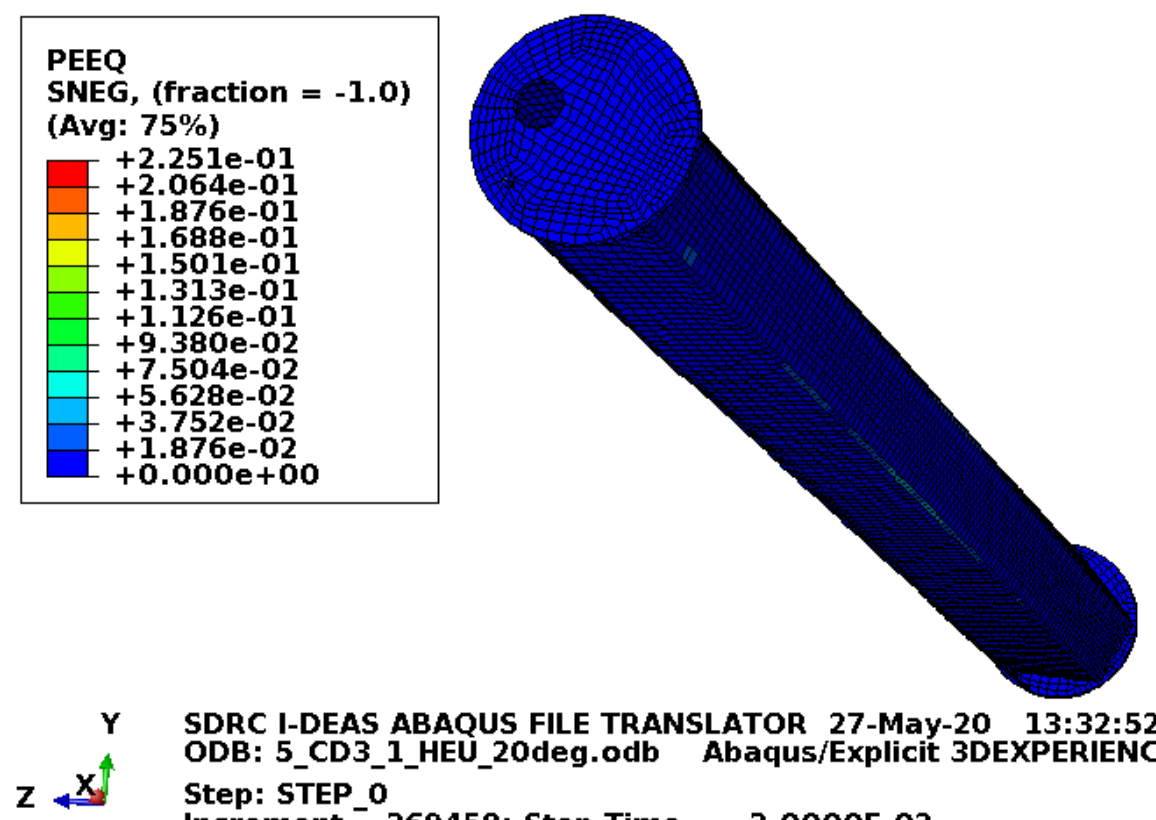

SDRC I-DEAS ABAQUS FILE TRANSLATOR 27-May-20 13:32:52

ODB: 5_CD3_1_HEU_20deg.odb Abaqus/Explicit 3DEXPERIENCE

Step: STEP_0

Increment ${ }^{-}$369458: Step Time $=3.0000 E-02$

Primary Var: PEEQ

Figure C-243. Scope Part 4 (Table 3), 22.1-lbf fuel element, and 20-degree angle enclosure plasticequivalent strain.

Figure C-243 shows the equivalent plastic strain in the enclosure. This is just for information as damage to the enclosure is acceptable.
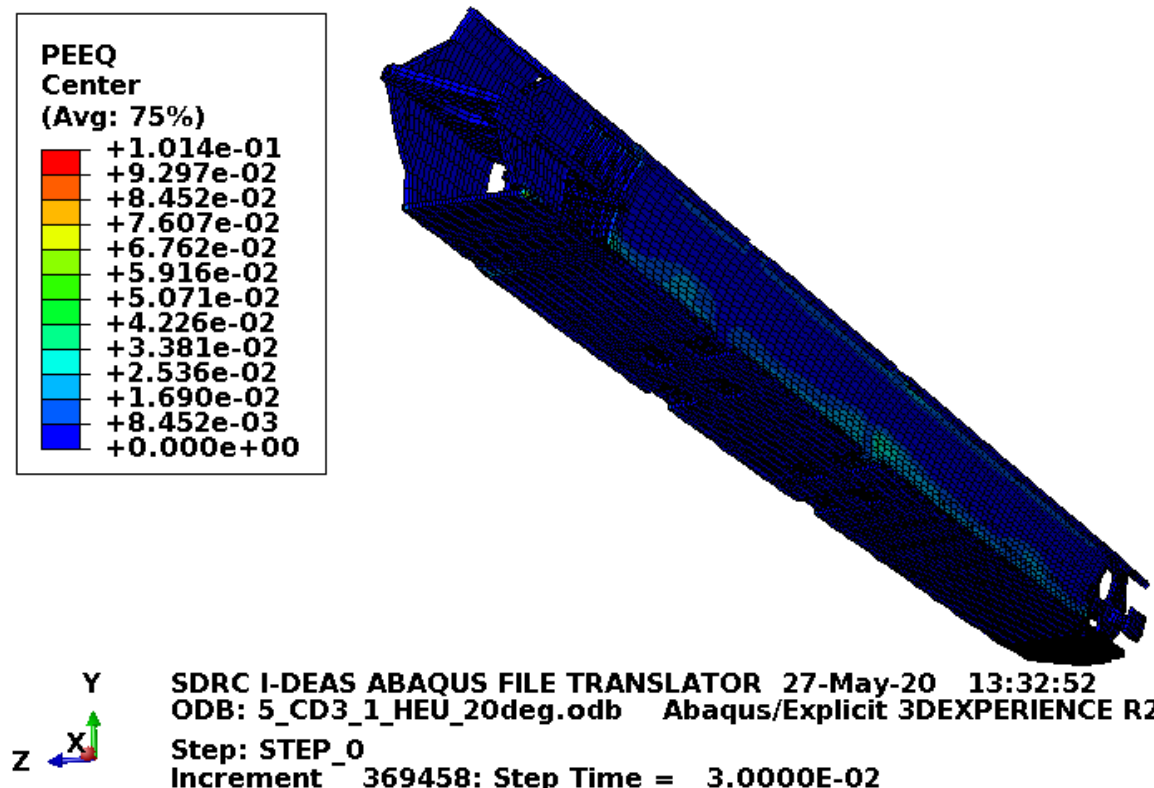

SDRC I-DEAS ABAOUS FILE TRANSLATOR 27-May-20 13:32:52

ODB: 5_CD3_1_HEU_20deg.odb Abaqus/Explicit 3DEXPERIENCE R20

Step: STEP o

Increment ${ }^{-}$369458: Step Time $=$3.0000E-02

Primary Var: PEEQ

Figure C-244. Scope Part 4 (Table 3), 22.1-lbf fuel element, and 20-degree angle fuel element plasticequivalent strain. 
Figure C-244 shows the equivalent plastic strain in the fuel element. For this model, the fuel element is modeled with minimum material properties except the end boxes, which are modeled with relatively tough material properties. While this model is appropriate for fuel element damage consideration, it is only shown here as it is not significantly damaged and other similar drop scenarios are documented in more detail.

\section{C4.4.2 Results for Scope Part 4 (Table 3) with 115-Ibf Fuel Element and Impacting 20 Degrees Off Horizontal}

The FEA model results for the Scope Part 4 (Table 3) with 115-lbf fuel element weight and impacting 20 degrees off horizontal model are shown below in Figure C-237 to Figure C-244. This drop scenario is a 30 -ft drop modeled as a side drop with the pockets and index lugs on the sides. The 20 degrees off horizontal angle is a rotation about an axis along the length of the ATR FFSC. The drop scenario is modeled with the ATR FFSC having minimum material properties and the enclosure and fuel element having relatively tough material properties with no failure. 


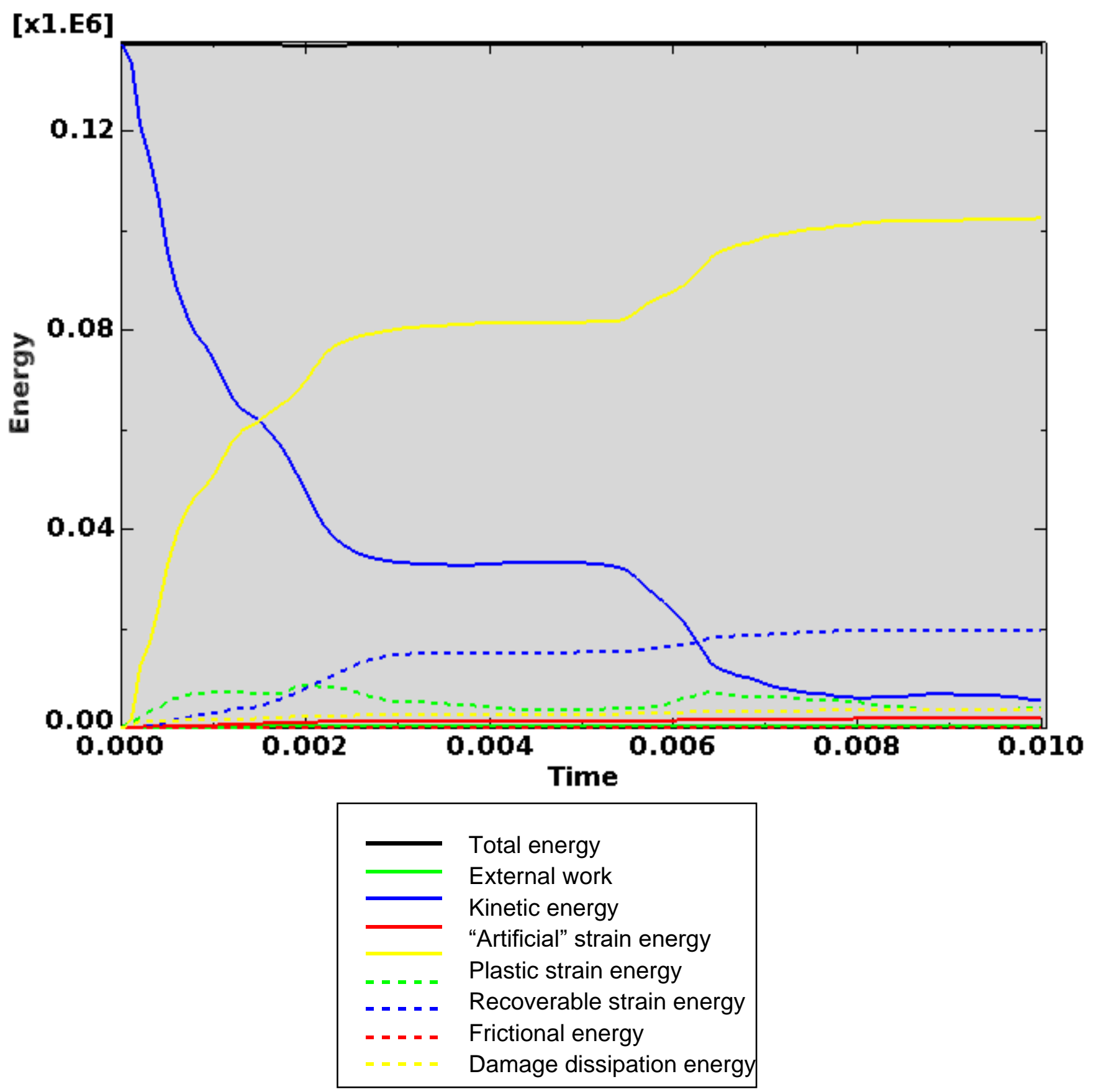

Figure C-245. Scope Part 4 (Table 3), 115-lbf fuel element, and 20-degree angle energy curves.

Figure C-245 shows the energy curves for Scope Part 4 (Table 3) with 115-lbf fuel element weight and impacting 20 degrees off horizontal drop scenario. These curves exhibit a stable shape. Artificial energy represents the energy required to keep reduced integration elements from taking on a zero-energy hourglass shape. As shown in Figure C-245, the artificial energy at the end of the model run is $1.4 \%$ of the total energy. Therefore, the potential error associated with artificial energy is not considered to be significant. 
ENGINEERING CALCULATIONS AND ANALYSIS

Drop Analysis of the Advanced Test Reactor Fresh Fuel Shipping Container with Heavier Low-Enriched Uranium Fuel Contents

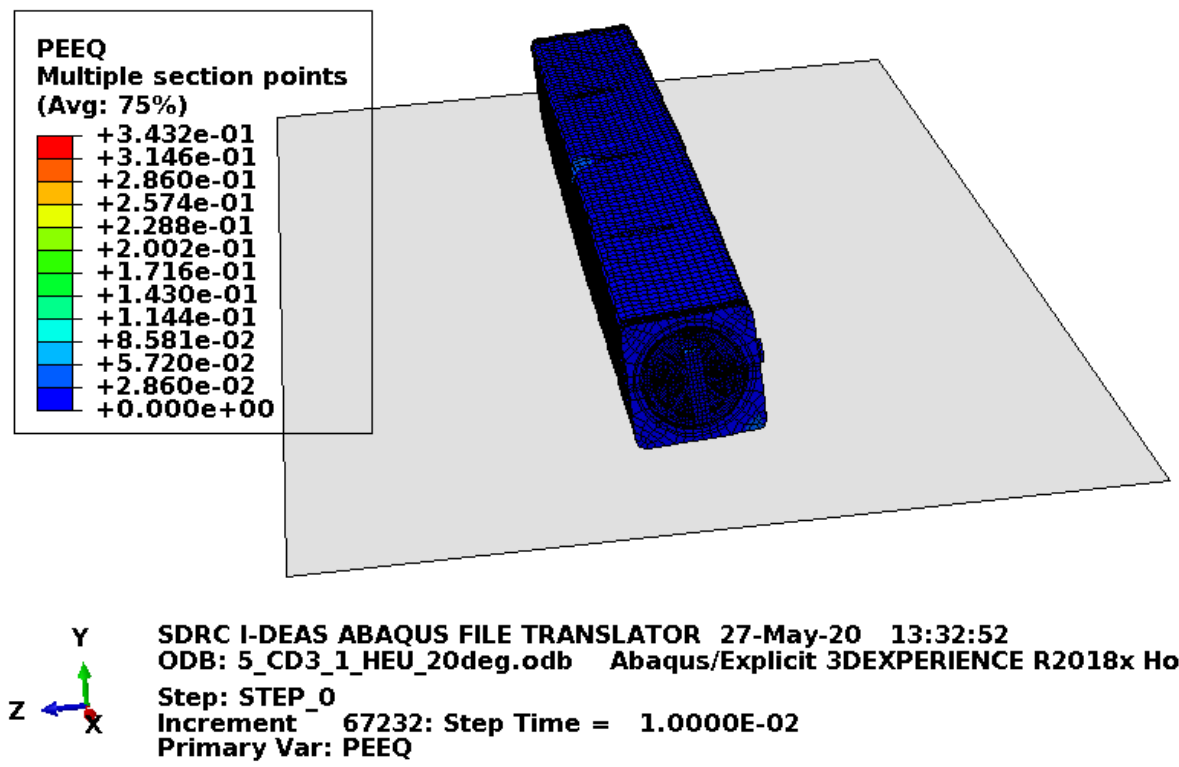

Figure C-246. Scope Part 4 (Table 3), 115-Ibf fuel element, and 20-degree angle full-model plasticequivalent strain.
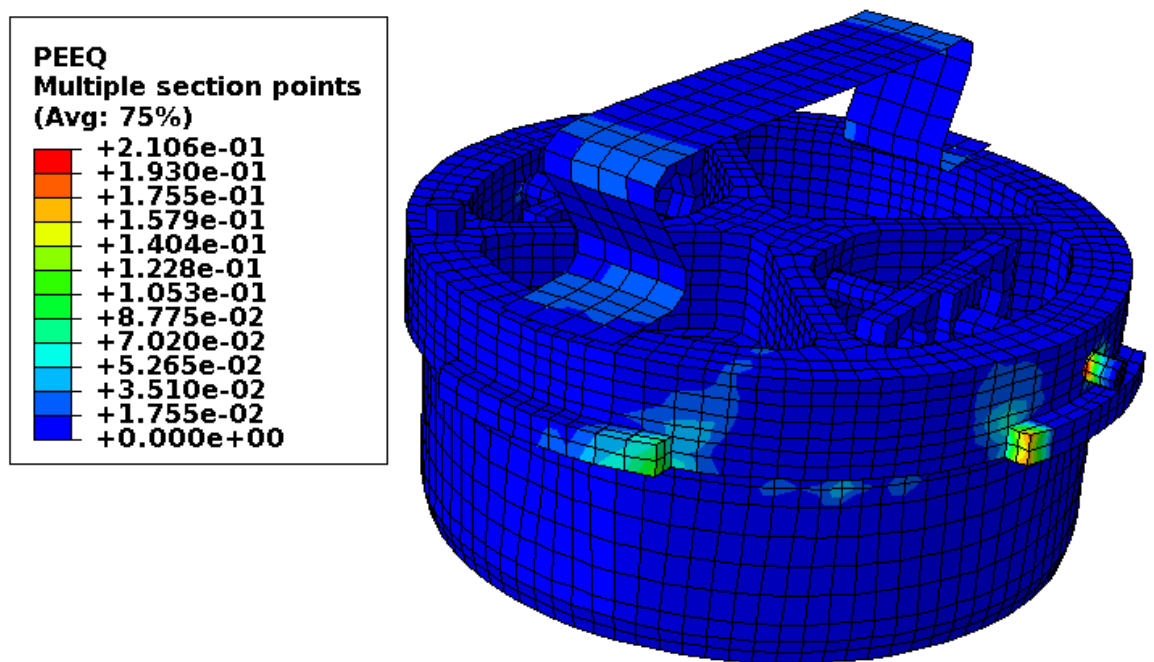

$\mathbf{x}$

SDRC I-DEAS ABAQUS FILE TRANSLATOR 27-May-20 13:32:52

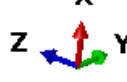

ODB: 5_CD3_1_HEU_20deg.odb Abaqus/Explicit 3DEXPERIENCE R2018,

Step: STEP_o

Increment ${ }^{-}$67232: Step Time $=1.0000 E-02$

Primary Var: PEEQ

Figure C-247. Scope Part 4 (Table 3), 115-Ibf fuel element, and 20-degree angle lid plastic-equivalent strain. 
ENGINEERING CALCULATIONS AND ANALYSIS

Drop Analysis of the Advanced Test Reactor Fresh Fuel Shipping Container with Heavier Low-Enriched Uranium Fuel Contents
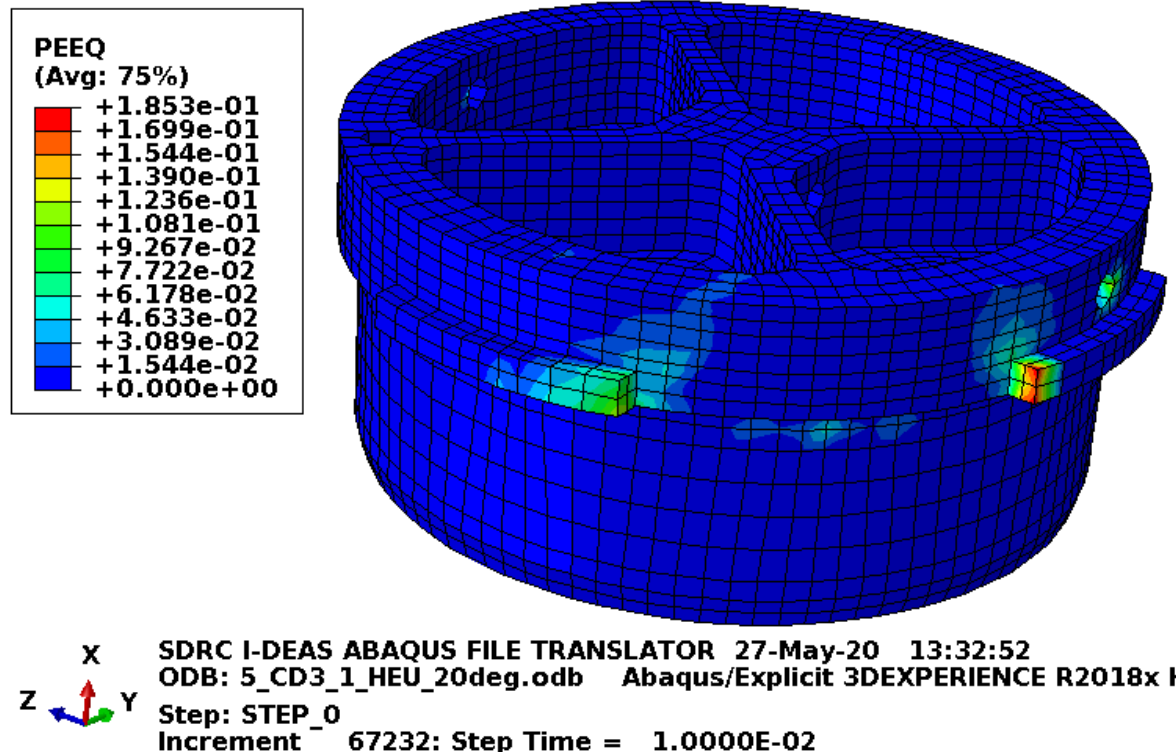

SDRC I-DEAS ABAQUS FILE TRANSLATOR 27-May-20 13:32:52

ODB: 5_CD3_1_HEU_20deg.odb Abaqus/Explicit 3DEXPERIENCE R2018x r

Step: STEP_o

Increment ${ }^{-}$67232: Step Time $=1.0000 \mathrm{E}-02$

Primary Var: PEEQ

Figure C-248. Scope Part 4 (Table 3), 115-lbf fuel element, and 20-degree angle lid structure plastic-equivalent strain.

Figure C-248 shows the equivalent plastic strain in the structurally significant portion of the lid. Failure in these elements occurs at an equivalent plastic strain of $0.259 \mathrm{in}$./in. If element failure were to occur, the element would be deleted and removed from the model (thereby making its equivalent plastic strain not included in the maximum equivalent plastic strain for the plot). However, the missing element would be visible in the plot. Figure C-248 shows no element failure.

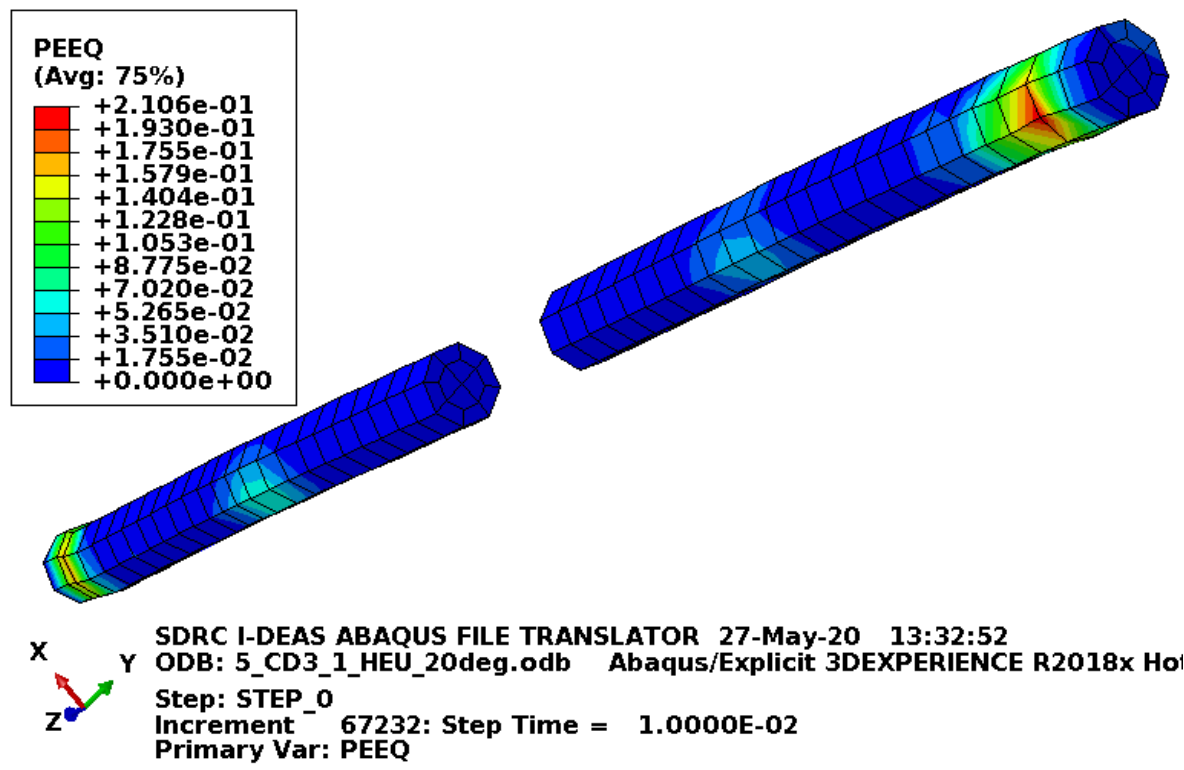

Figure C-249. Scope Part 4 (Table 3), 115-lbf fuel element, and 20-degree angle lid pins plastic-equivalent strain. 
Figure C-249 shows the equivalent plastic strain in the lid pins. Failure in these elements occurs at an equivalent plastic strain of $0.295 \mathrm{in}$./in. If element failure were to occur, the element would be deleted and removed from the model (thereby making its equivalent plastic strain not included in the maximum equivalent plastic strain for the plot). However, the missing element would be visible in the plot. Figure C-249 shows no failure.

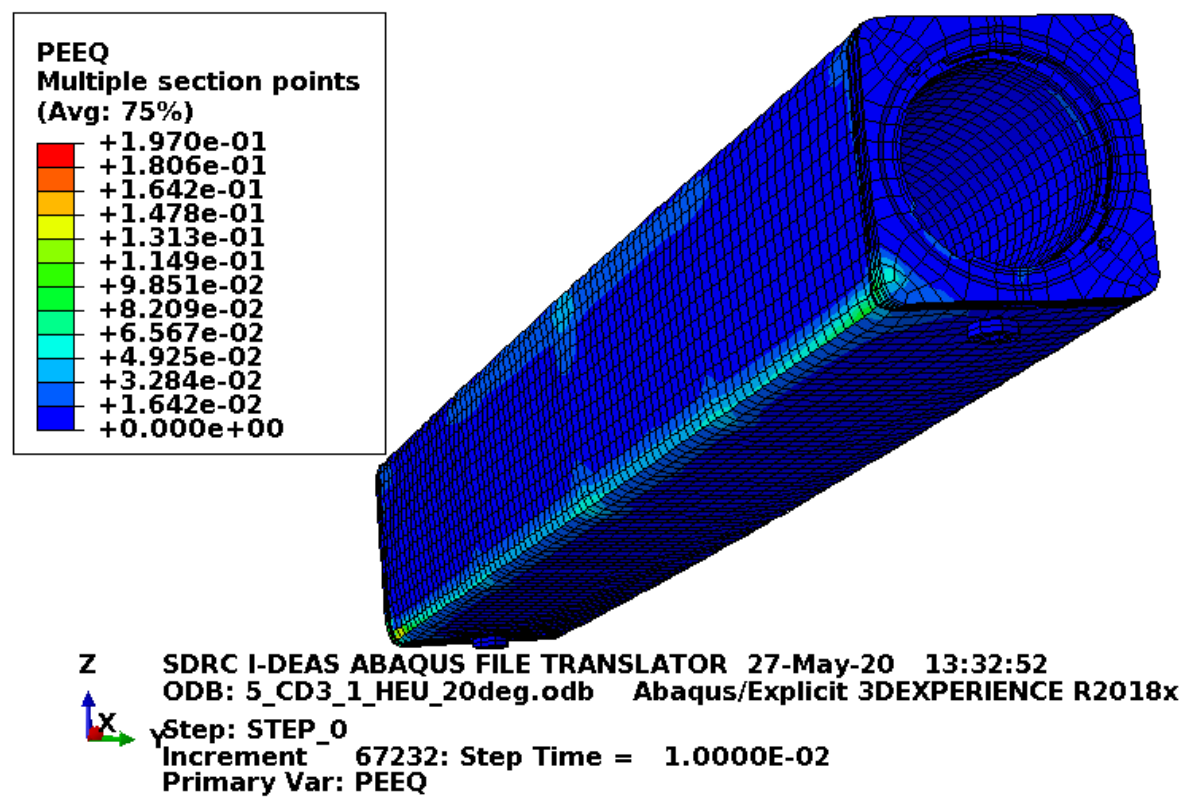

Figure C-250. Scope Part 4 (Table 3), 115-lbf fuel element, and 20-degree angle body plastic-equivalent strain.

Figure C-250 shows the equivalent plastic strain in the body. Failure in these elements occurs at an equivalent plastic strain of $0.259 \mathrm{in}$./in. If element failure were to occur, the element would be deleted and removed from the model (thereby making its equivalent plastic strain not included in the maximum equivalent plastic strain for the plot). However, the missing element would be visible in the plot.

Figure C-250 shows no element failure. 
ENGINEERING CALCULATIONS AND ANALYSIS

Drop Analysis of the Advanced Test Reactor Fresh Fuel Shipping Container with Heavier Low-Enriched Uranium Fuel Contents

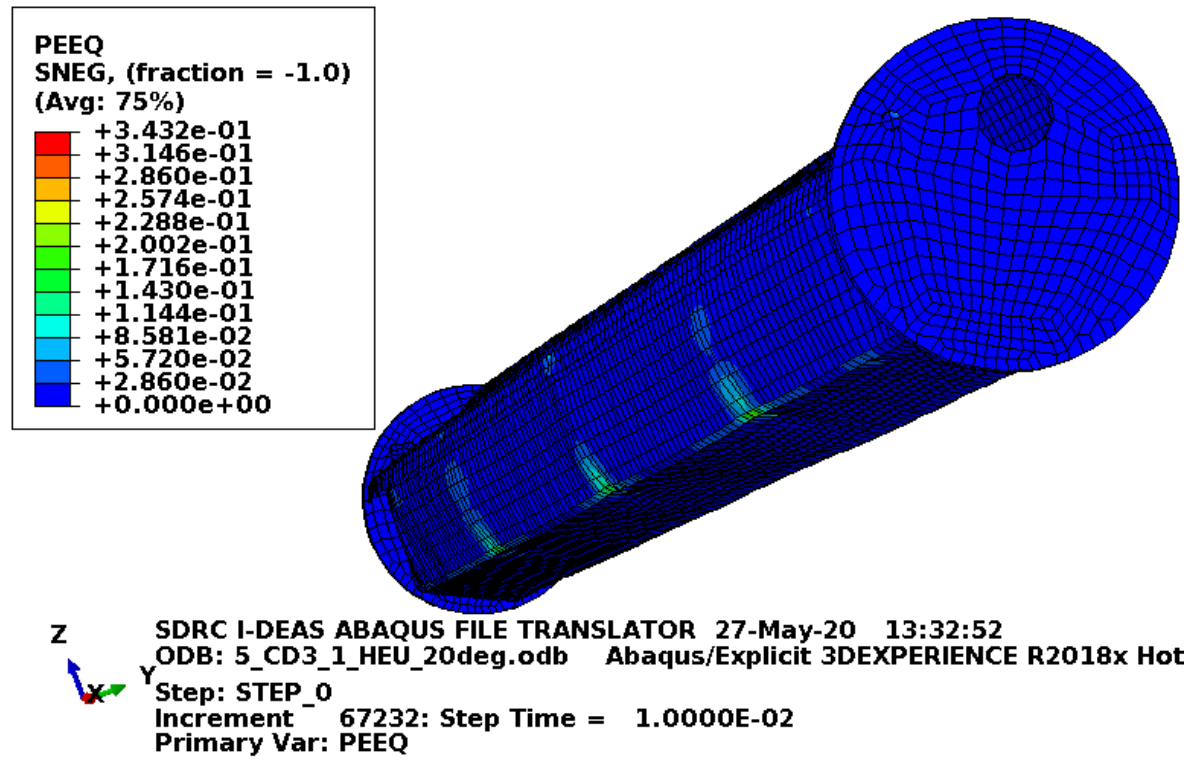

Figure C-251. Scope Part 4 (Table 3), 115-lbf fuel element, and 20-degree angle enclosure plasticequivalent strain.

Figure C-251 shows the equivalent plastic strain in the enclosure. This is just for information as damage to the enclosure is acceptable.

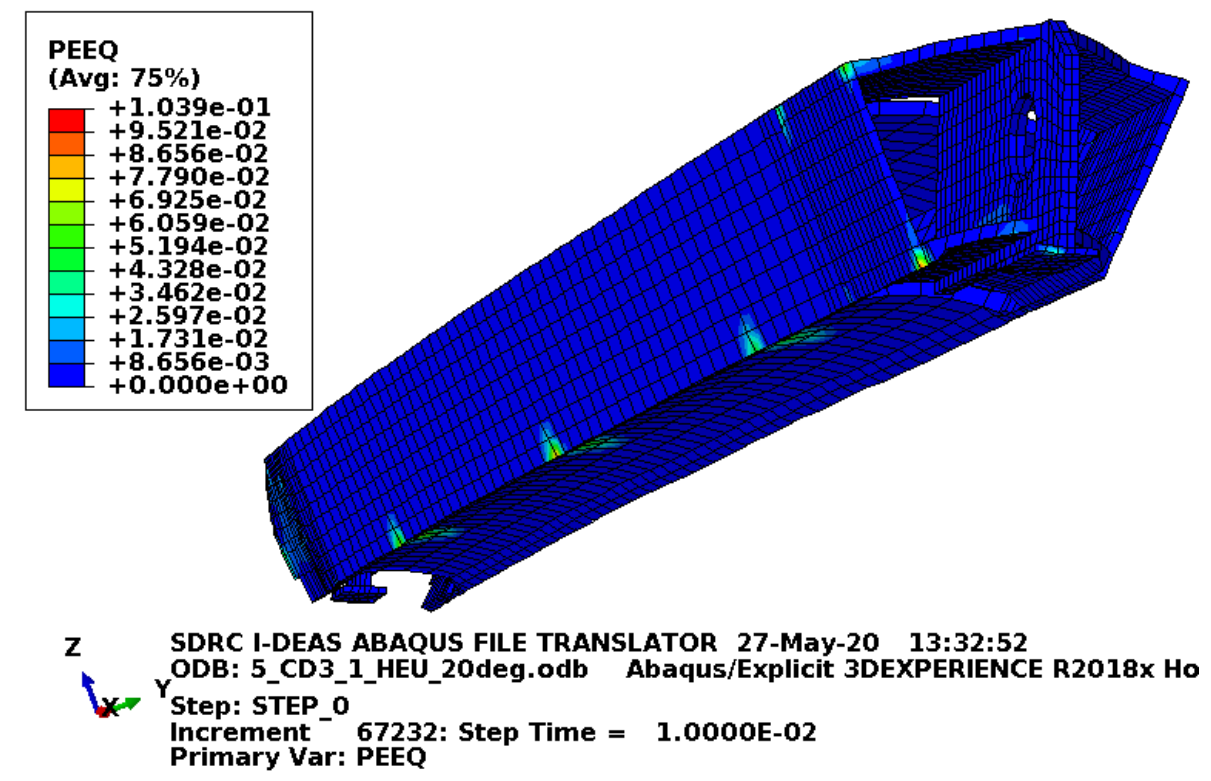

Figure C-252. Scope Part 4 (Table 3), 115-lbf fuel element, and 20-degree angle fuel element plasticequivalent strain.

Figure C-252 shows the equivalent plastic strain in the fuel element. For this model, the fuel element is coarse meshed, massive, and has no failure defined. Consequently, this is just shown for information and is not relevant to the acceptability of the fuel element. 
ENGINEERING CALCULATIONS AND ANALYSIS

Drop Analysis of the Advanced Test Reactor Fresh Fuel Shipping Container with Heavier Low-Enriched Uranium Fuel Contents

\section{C4.5 Results for Scope Part 4 (Table 3), Impacting 25 Degrees Off Horizontal}

The drop scenario considered in this section is a 30 -ft drop modeled as a side drop with the pockets and index lugs on the sides. It is oriented 25 degrees off horizontal about an axis along the length of the ATR FFSC.

\section{C4.5.1 Results for Scope Part 4 (Table 3) with 22.1-Ibf Fuel Element and Impacting 25-Degree Off Horizontal}

The FEA model results for the Scope Part 4 (Table 3) with 22.1-lbf fuel element weight and impacting 25 degrees off horizontal model are shown below in Figure C-253 to Figure C-268. This drop scenario is a $30-\mathrm{ft}$ drop modeled as a side drop with the pockets and index lugs on the sides. The 25 degrees off horizontal angle is a rotation about an axis along the length of the ATR FFSC. The drop scenario is modeled with minimum material properties except the enclosure and end boxes, which are modeled with relatively tough material properties.

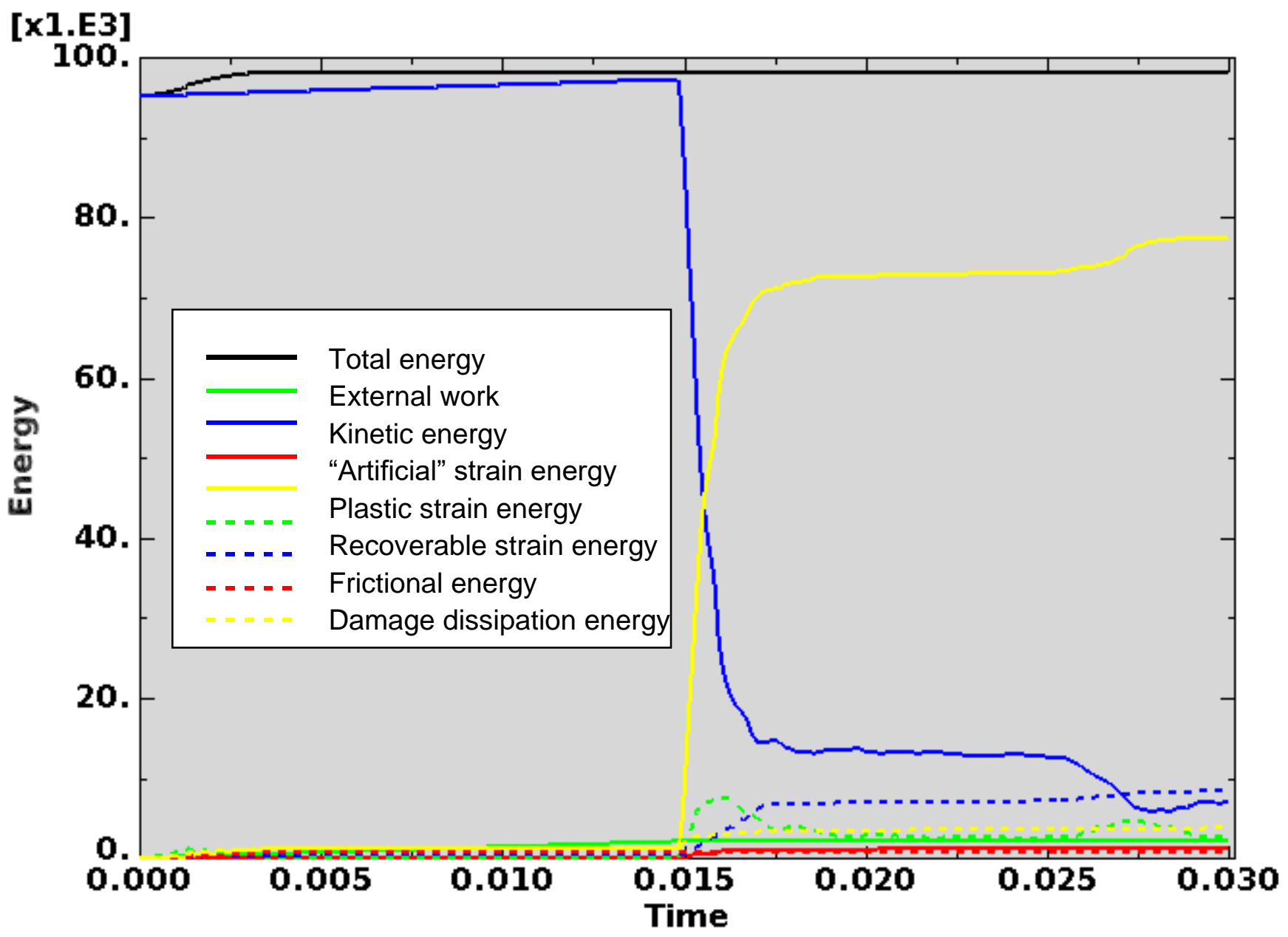

Figure C-253. Scope Part 4 (Table 3), 22.1-lbf fuel element, and 25-degree angle energy curves. 
Figure C-253 shows the energy curves for Scope Part 4 (Table 3) with 22.1-lbf fuel element weight and impacting 25 degrees off horizontal drop scenario. These curves exhibit a stable shape. Artificial strain energy represents the energy required to keep reduced integration elements from taking on a zero-energy hourglass shape. As shown in Figure C-253, the artificial energy at the end of the model run is $1.4 \%$ of the total energy. Therefore, the potential error associated with artificial energy is not considered to be significant.
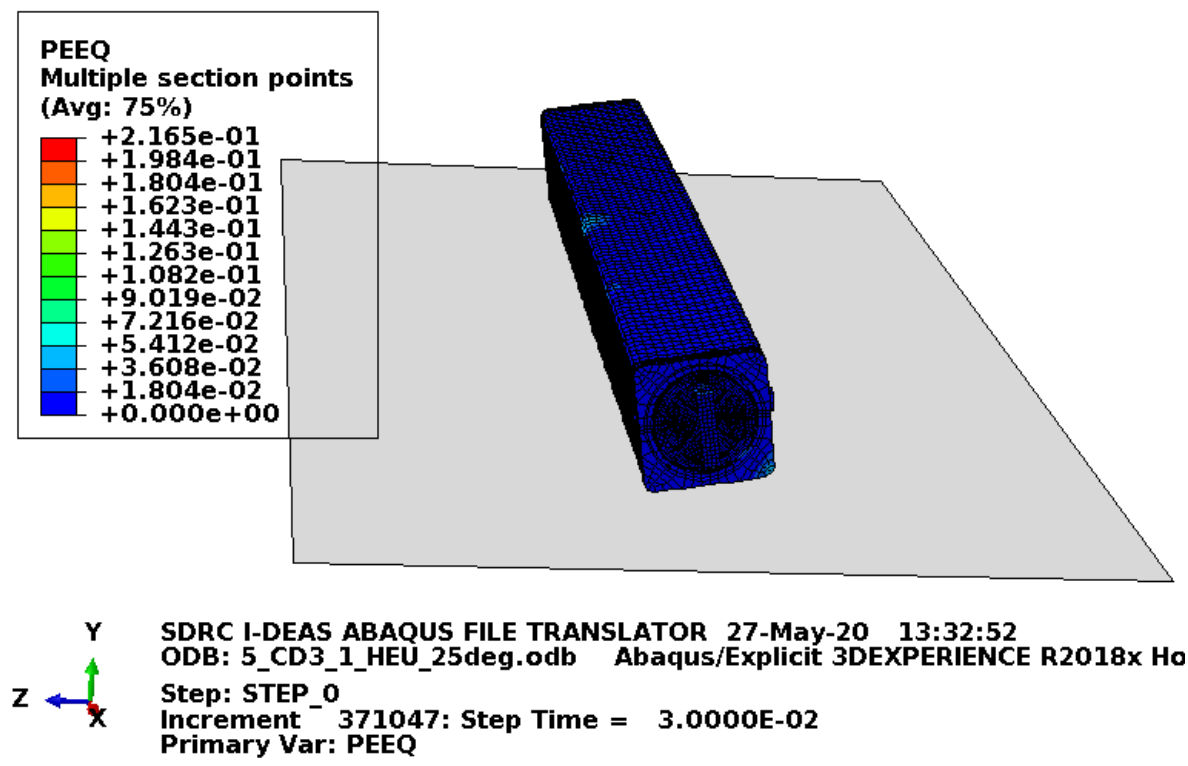

Figure C-254. Scope Part 4 (Table 3), 22.1-lbf fuel element, and 25-degree angle full-model plasticequivalent strain.
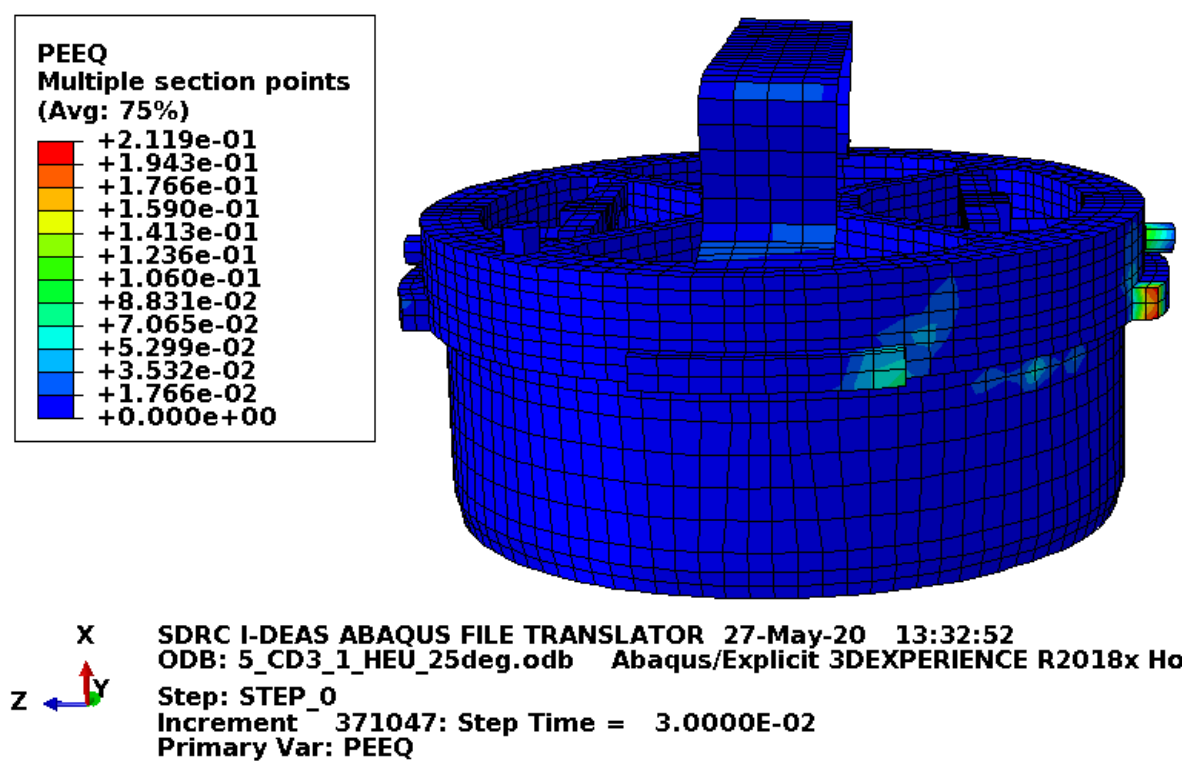

Figure C-255. Scope Part 4 (Table 3), 22.1-lbf fuel element, and 25-degree angle lid plastic-equivalent strain. 
ENGINEERING CALCULATIONS AND ANALYSIS

Drop Analysis of the Advanced Test Reactor Fresh Fuel Shipping Container with Heavier Low-Enriched Uranium Fuel Contents
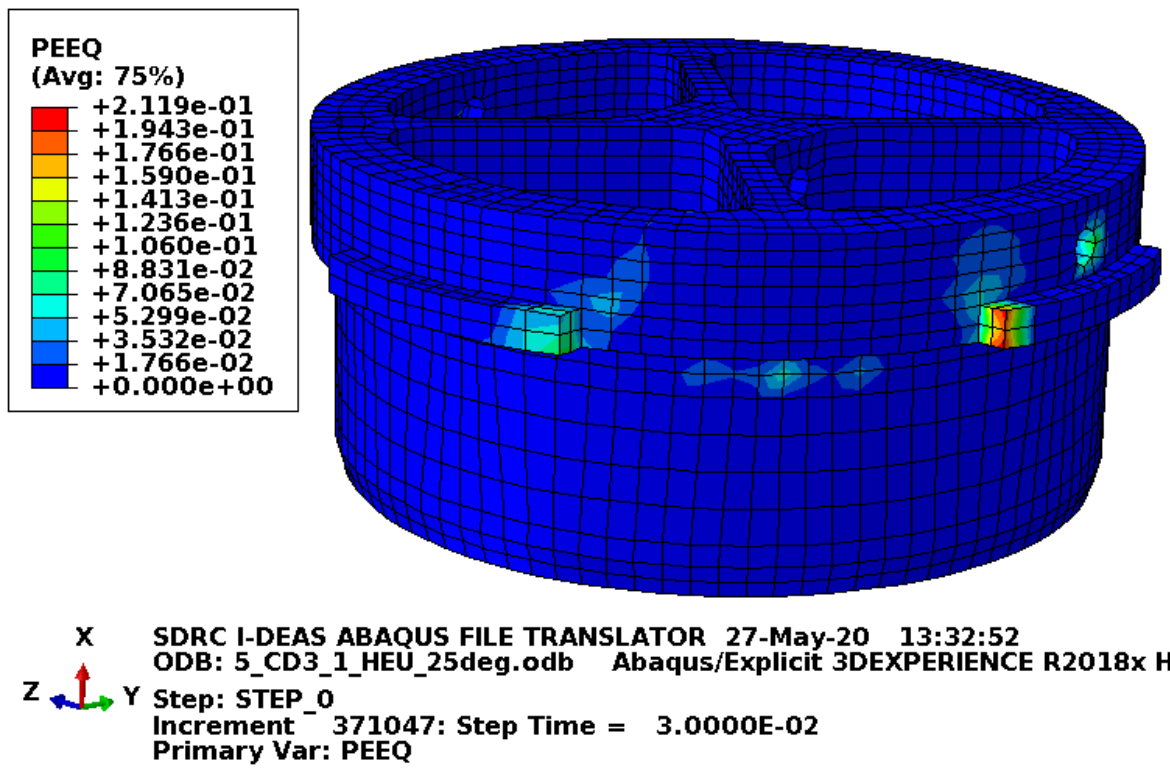

Figure C-256. Scope Part 4 (Table 3), 22.1-lbf fuel element, and 25-degree angle lid structure plasticequivalent strain.

Figure C-156 shows the equivalent plastic strain in the structurally significant portion of the lid. Failure in these elements occurs at an equivalent plastic strain of $0.259 \mathrm{in}$./in. If element failure were to occur, the element would be deleted and removed from the model (thereby making its equivalent plastic strain not included in the maximum equivalent plastic strain for the plot). However, the missing element would be visible in the plot. Figure C-156 shows no element failure with margin.

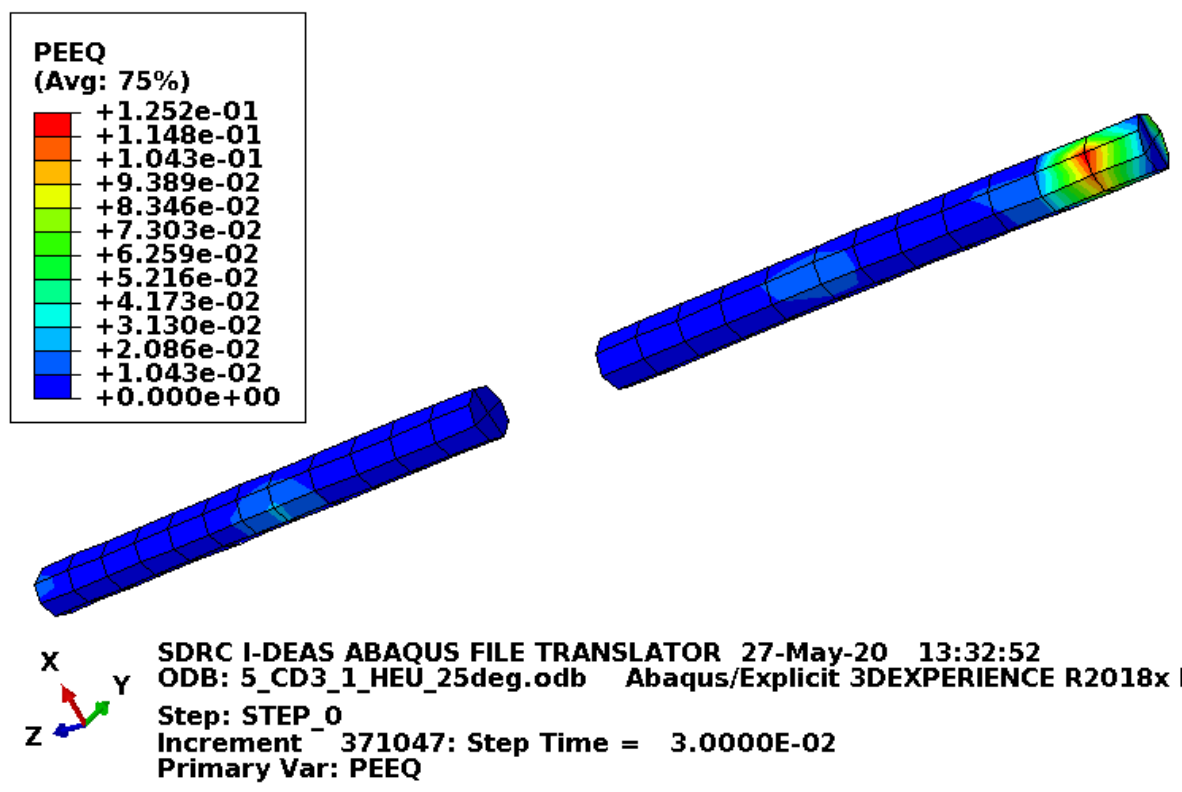

Figure C-257. Scope Part 4 (Table 3), 22.1-Ibf fuel element, and 25-degree angle lid pins plastic-equivalent strain. 
Figure C-157 shows the equivalent plastic strain in the lid pins. Failure in these elements occurs at an equivalent plastic strain of $0.295 \mathrm{in}$./in. If element failure were to occur, the element would be deleted and removed from the model (thereby making its equivalent plastic strain not included in the maximum equivalent plastic strain for the plot). However, the missing element would be visible in the plot. Figure C-157 shows no element failure with margin.
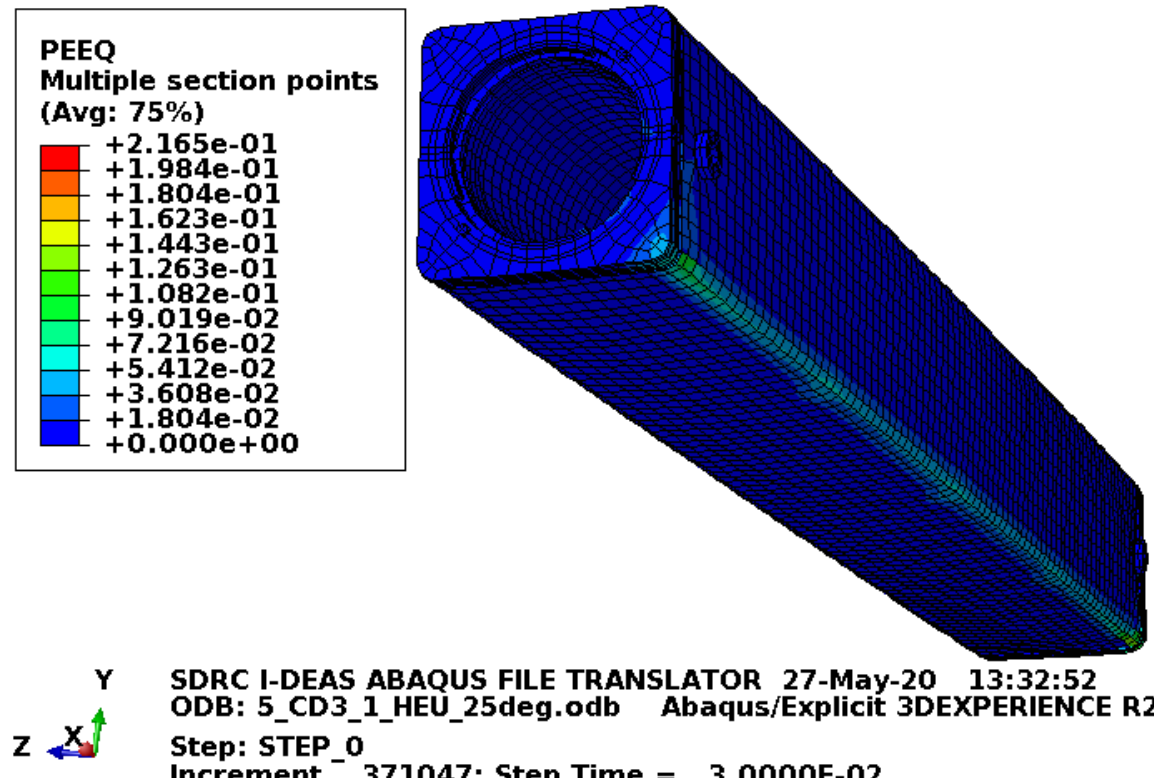

SDRC I-DEAS ABAQUS FILE TRANSLATOR 27-May-20 13:32:52

ODB: 5_CD3_1_HEU_25deg.odb Abaqus/Explicit 3DEXPERIENCE R20

Step: STEP_o

Increment ${ }^{-}$371047: Step Time $=3.0000 E-02$

Primary Var: PEEQ

Figure C-258. Scope Part 4 (Table 3), 22.1-lbf fuel element, and 25-degree angle body plastic-equivalent strain.

Figure C-258 shows the equivalent plastic strain in the body. Failure in these elements occurs at an equivalent plastic strain of $0.259 \mathrm{in}$./in. If element failure were to occur, the element would be deleted and removed from the model (thereby making its equivalent plastic strain not included in the maximum equivalent plastic strain for the plot). However, the missing element would be visible in the plot. Figure C-258 shows no element failure with margin. 


\section{ENGINEERING CALCULATIONS AND ANALYSIS}

Drop Analysis of the Advanced Test Reactor Fresh Fuel Shipping Container with Heavier Low-Enriched Uranium Fuel Contents
ECAR-5224, Rev. 0

Page C174 of C190
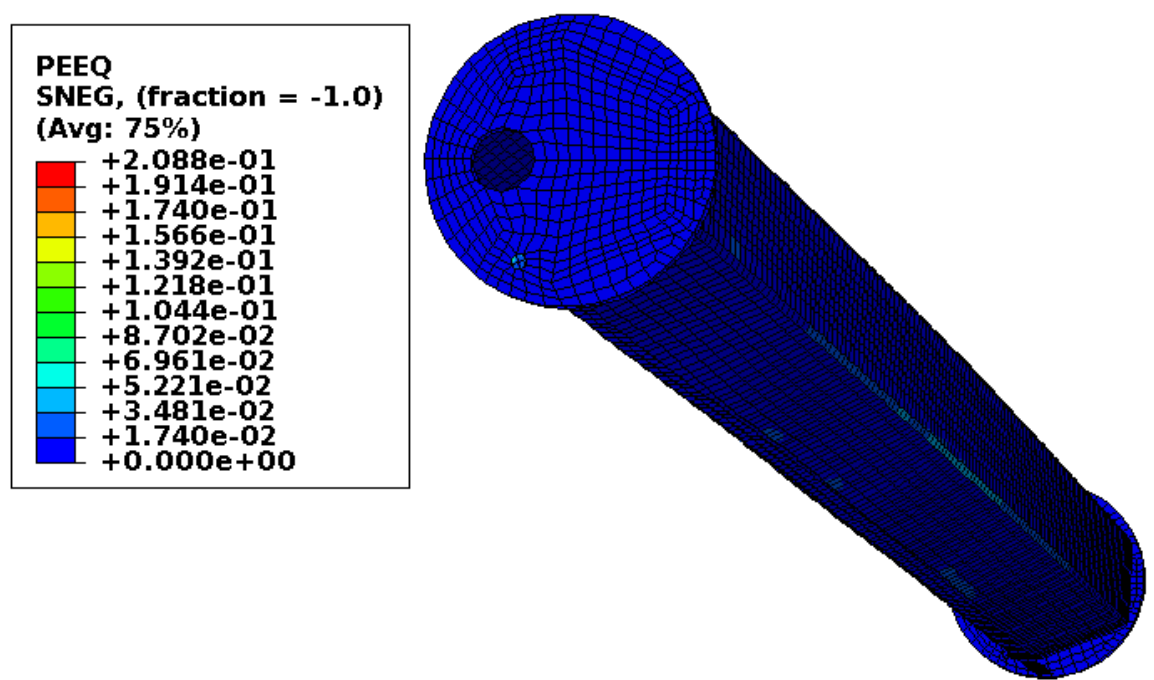

SDRC I-DEAS ABAQUS FILE TRANSLATOR 27-May-
ODB: 5_CD3_1_HEU_25deg.odb Abaqus/Explicit
Z
$\begin{aligned} & \text { Step: STEP_0 } \\ & \text { Increment } \\ & \text { Primary Var: PEEQ }\end{aligned}$

Figure C-259. Scope Part 4 (Table 3), 22.1-lbf fuel element, and 25-degree angle enclosure plasticequivalent strain.

Figure C-259 shows the equivalent plastic strain in the enclosure. This is just for information as damage to the enclosure is acceptable.
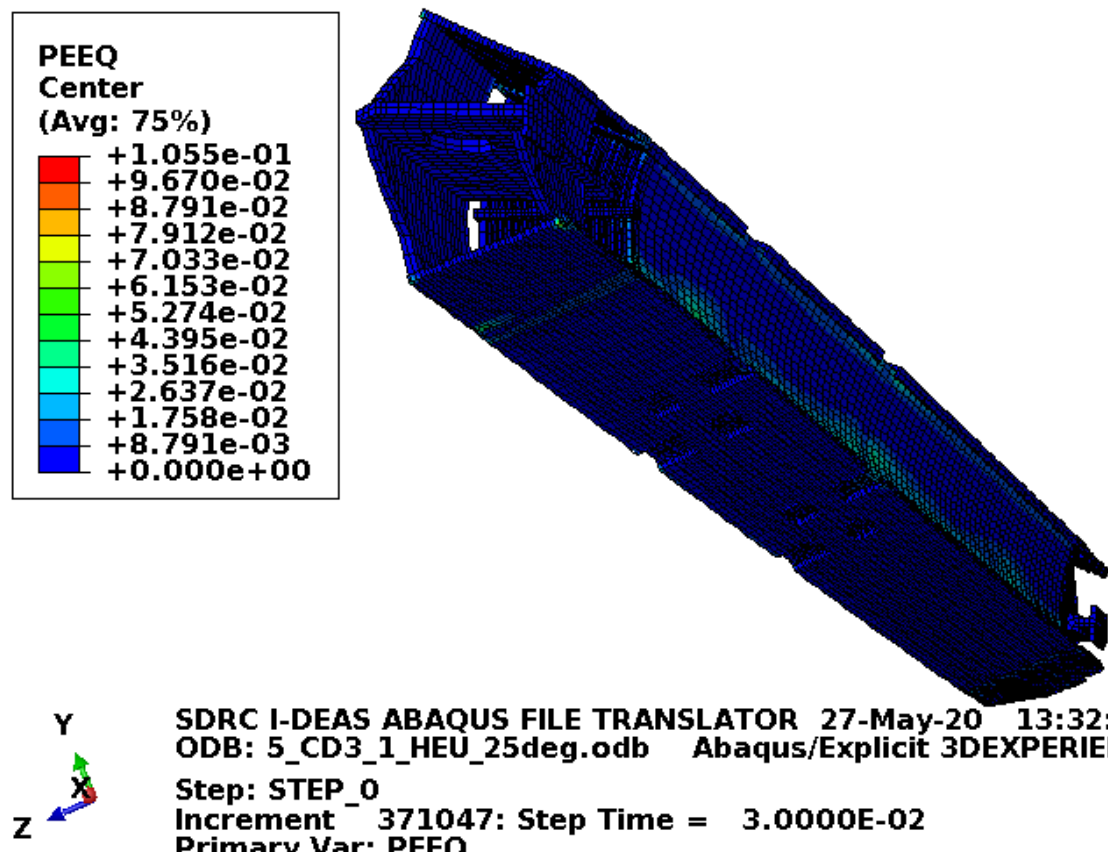

SDRC I-DEAS ABAQUS FILE TRANSLATOR 27-May-20 13:32:52

ODB: 5_CD3_1_HEU_25deg.odb Abaqus/Explicit 3DEXPERIENCE

Step: STEP_0

Increment ${ }^{-371047: \text { Step Time }=3.0000 E-02}$

Primary Var: PEEQ

Figure C-260. Scope Part 4 (Table 3), 22.1-Ibf fuel element, and 25-degree angle fuel element plasticequivalent strain. 
Figure C-260 shows the equivalent plastic strain in the fuel element. For this model, the fuel element is modeled with minimum material properties except the end boxes, which are modeled with relatively tough material properties. While this model is appropriate for fuel element damage consideration, it is only shown here as it is not significantly damaged and other similar drop scenarios are documented in more detail.

\section{C4.5.2 Results for Scope Part 4 (Table 3) with 115-Ibf Fuel Element and Impacting 25 Degrees Off Horizontal}

The FEA model results for the Scope Part 4 (Table 3) with 115-lbf fuel element weight and impacting 25 degrees off horizontal model are shown below in Figure C-261 to Figure C-268. This drop scenario is a 30 -ft drop modeled as a side drop with the pockets and index lugs on the sides. The 25 degrees off horizontal angle is a rotation about an axis along the length of the ATR FFSC. The drop scenario is modeled with the ATR FFSC having minimum material properties and the enclosure and fuel element having relatively tough material properties with no failure.

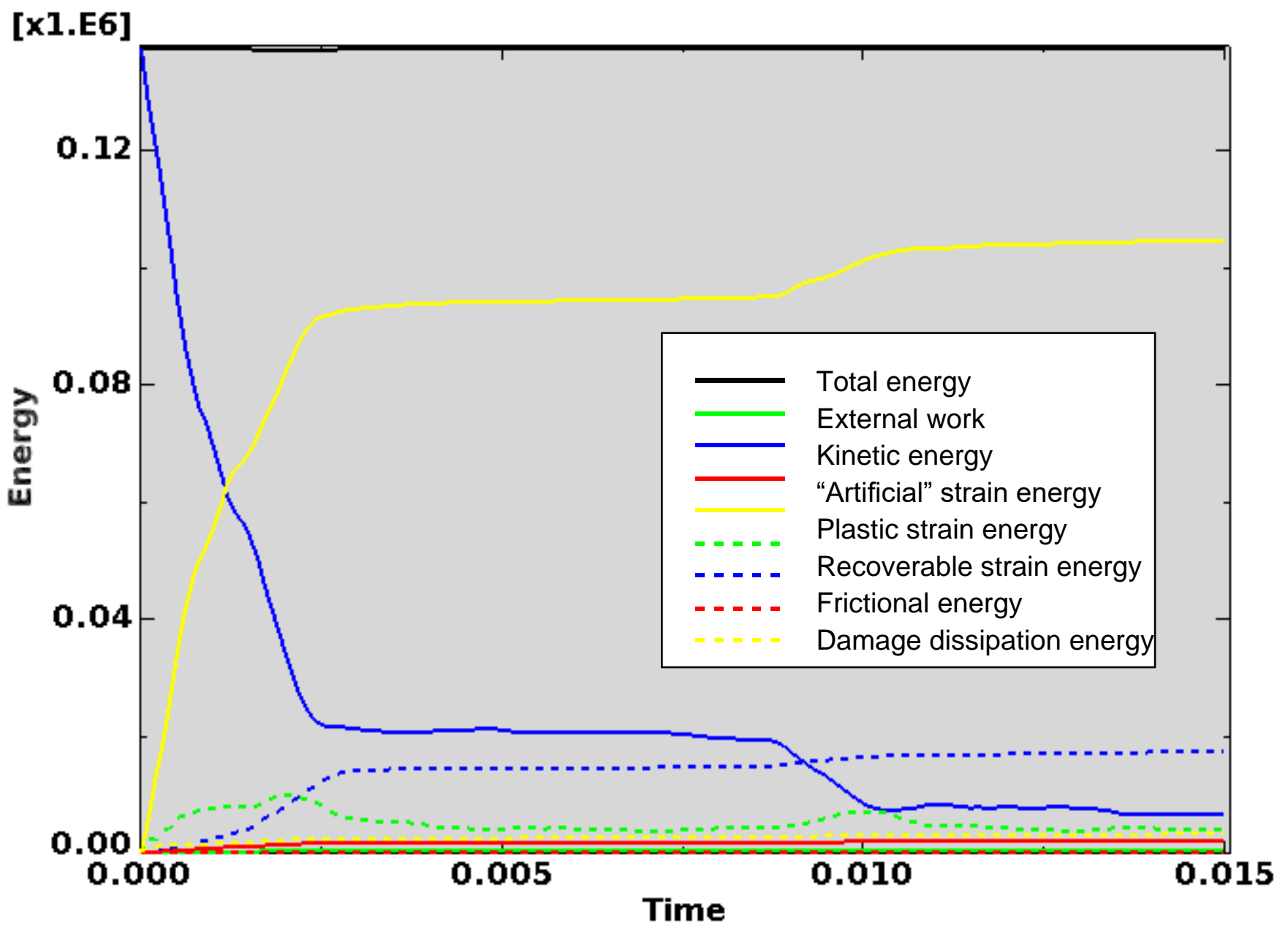

Figure C-261. Scope Part 4 (Table 3), 115-lbf fuel element, and 25-degree angle energy curves. 
Figure C-261 shows the energy curves for Scope Part 4 (Table 3) with 115-lbf fuel element weight and impacting 25 degrees off horizontal drop scenario. These curves exhibit a stable shape. Artificial energy represents the energy required to keep reduced integration elements from taking on a zero-energy hourglass shape. As shown in Figure C-261, the artificial energy at the end of the model run is $1.5 \%$ of the total energy. Therefore, the potential error associated with artificial energy is not considered to be significant.

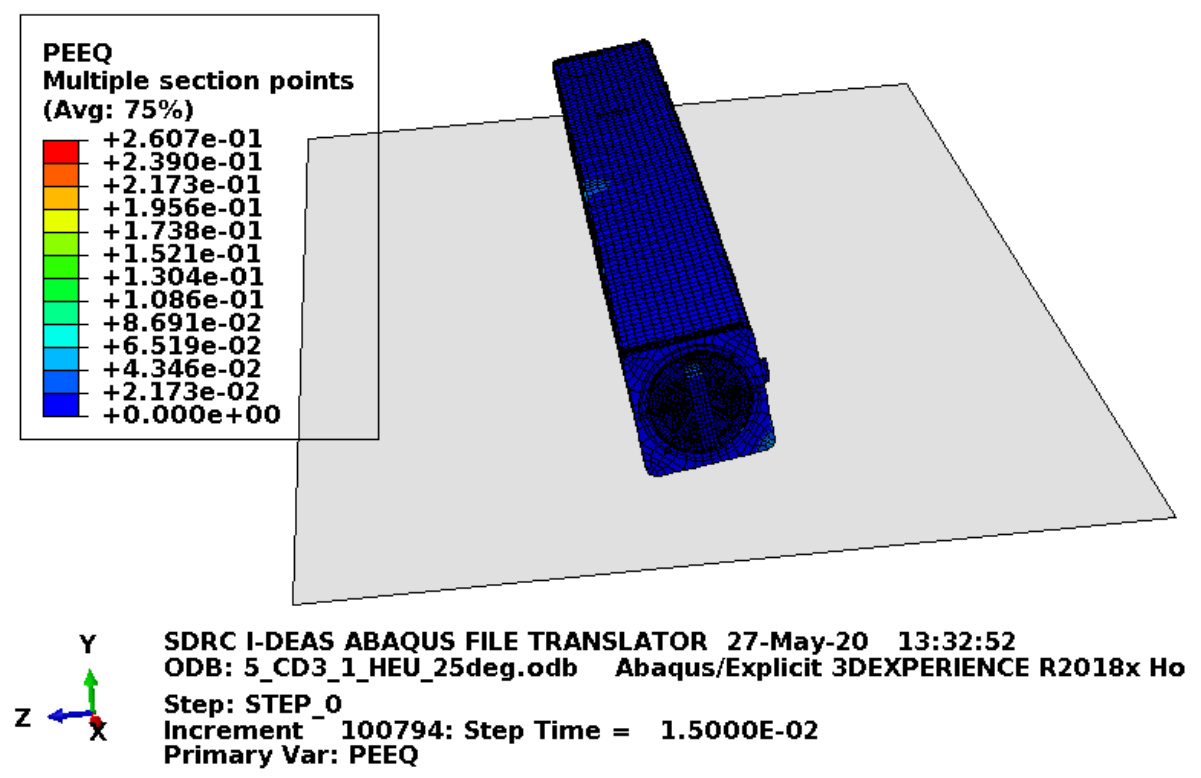

Figure C-262. Scope Part 4 (Table 3), 115-lbf fuel element, and 25-degree angle full-model plasticequivalent strain.
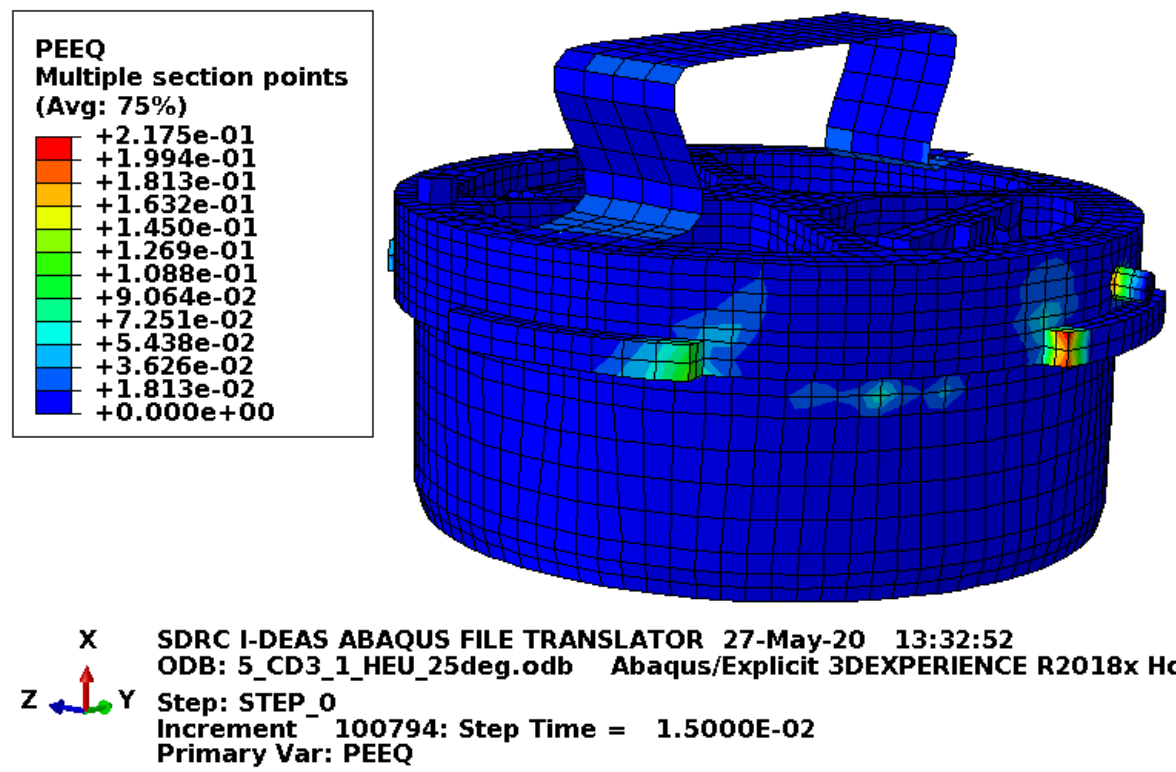

Figure C-263. Scope Part 4 (Table 3), 115-lbf fuel element, and 25-degree angle lid plastic-equivalent strain. 
ENGINEERING CALCULATIONS AND ANALYSIS

Drop Analysis of the Advanced Test Reactor Fresh Fuel Shipping Container with Heavier Low-Enriched Uranium Fuel Contents
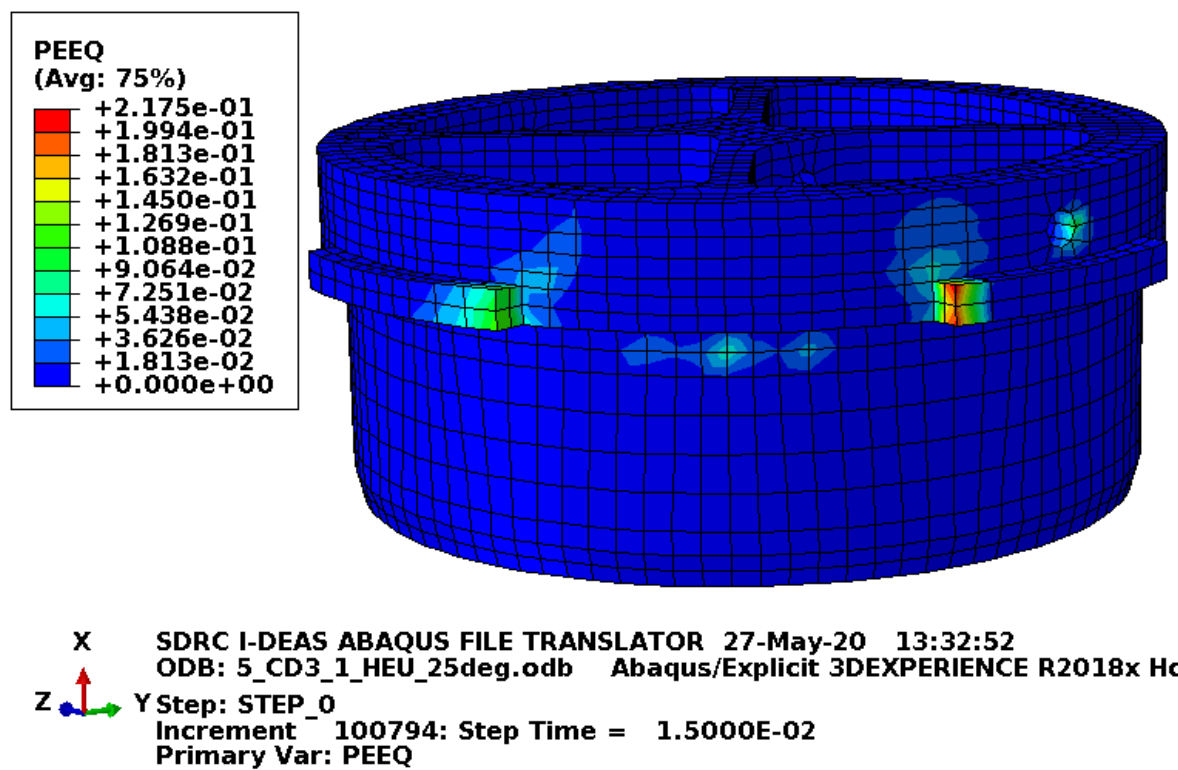

Figure C-264. Scope Part 4 (Table 3), 115-lbf fuel element, and 25-degree angle lid structure plasticequivalent strain.

Figure C-264 shows the equivalent plastic strain in the structurally significant portion of the lid. Failure in these elements occurs at an equivalent plastic strain of $0.259 \mathrm{in}$./in. If element failure were to occur, the element would be deleted and removed from the model (thereby making its equivalent plastic strain not included in the maximum equivalent plastic strain for the plot). However, the missing element would be visible in the plot. Figure C-264 shows no element failure.

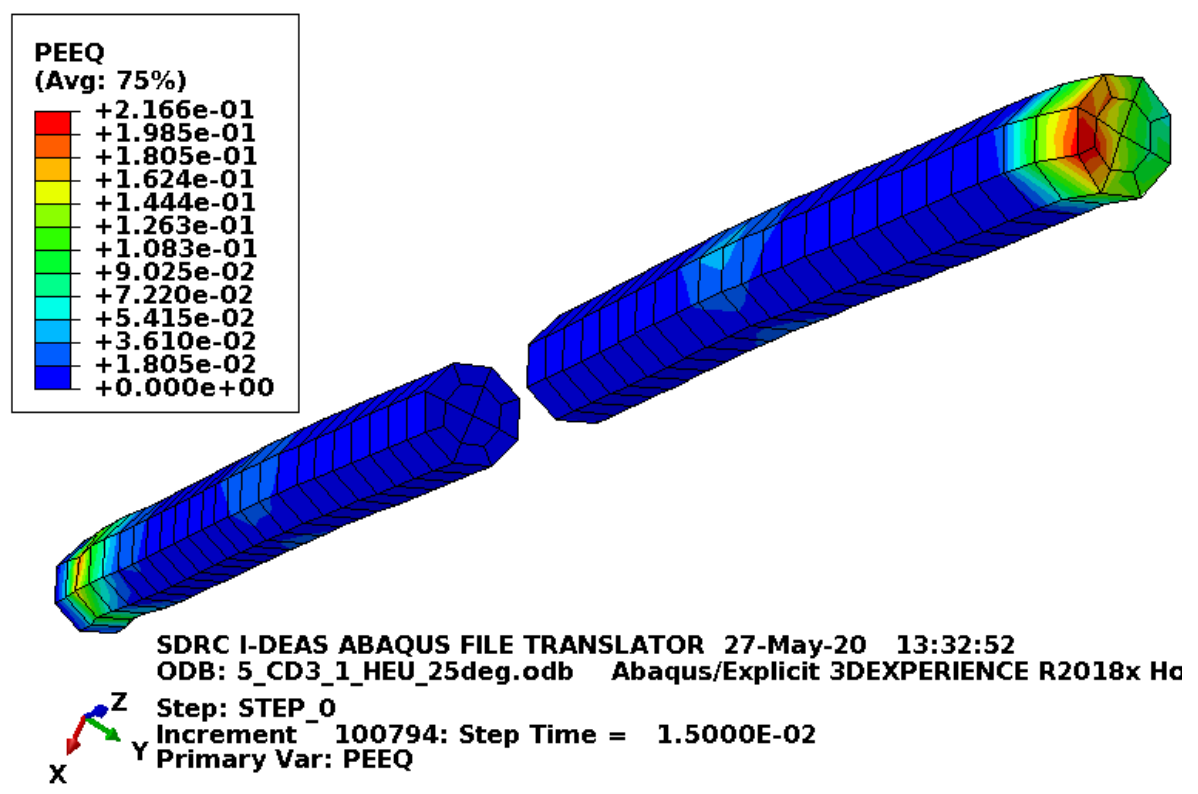

Figure C-265. Scope Part 4 (Table 3), 115-lbf fuel element, and 25-degree angle lid pins plastic-equivalent strain. 
Figure C-265 shows the equivalent plastic strain in the lid pins. Failure in these elements occurs at an equivalent plastic strain of $0.295 \mathrm{in}$./in. If element failure were to occur, the element would be deleted and removed from the model (thereby making its equivalent plastic strain not included in the maximum equivalent plastic strain for the plot). However, the missing element would be visible in the plot. Figure C-265 shows no element failure.

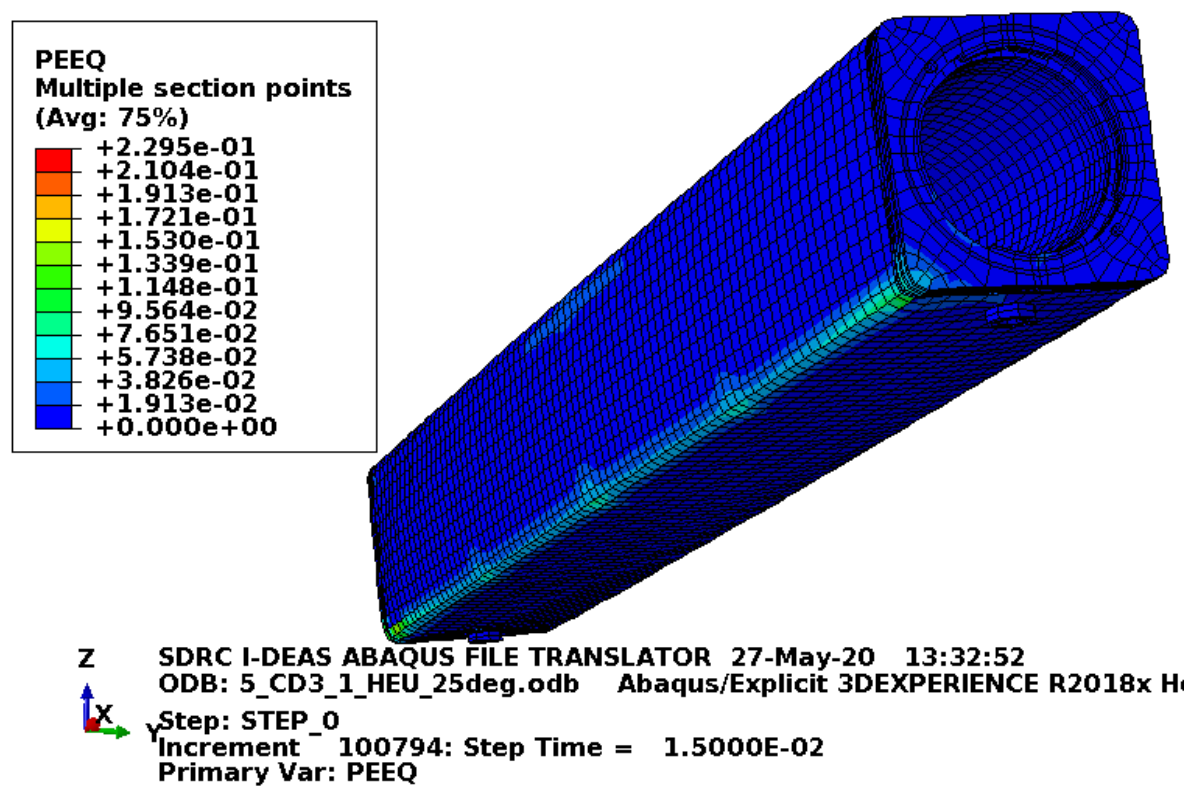

Figure C-266. Scope Part 4 (Table 3), 115-lbf fuel element, and 25-degree angle body plastic-equivalent strain.

Figure C-266 shows the equivalent plastic strain in the body. Failure in these elements occurs at an equivalent plastic strain of $0.259 \mathrm{in}$./in. If element failure were to occur, the element would be deleted and removed from the model (thereby making its equivalent plastic strain not included in the maximum equivalent plastic strain for the plot). However, the missing element would be visible in the plot. Figure C-266 shows no element failure. 
ENGINEERING CALCULATIONS AND ANALYSIS

Drop Analysis of the Advanced Test Reactor Fresh Fuel Shipping Container with Heavier Low-Enriched Uranium Fuel Contents

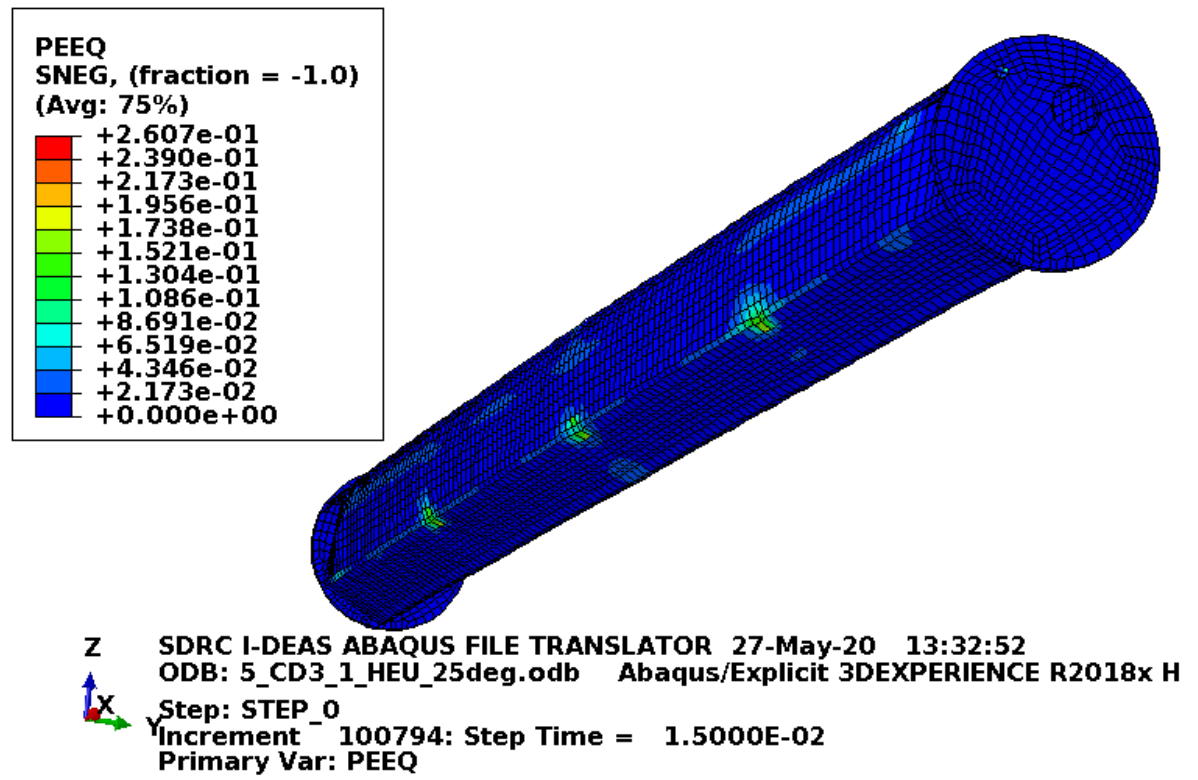

Figure C-267. Scope Part 4 (Table 3), 115-Ibf fuel element, and 25-degree angle enclosure plasticequivalent strain.

Figure C-267 shows the equivalent plastic strain in the enclosure. This is just for information as damage to the enclosure is acceptable.

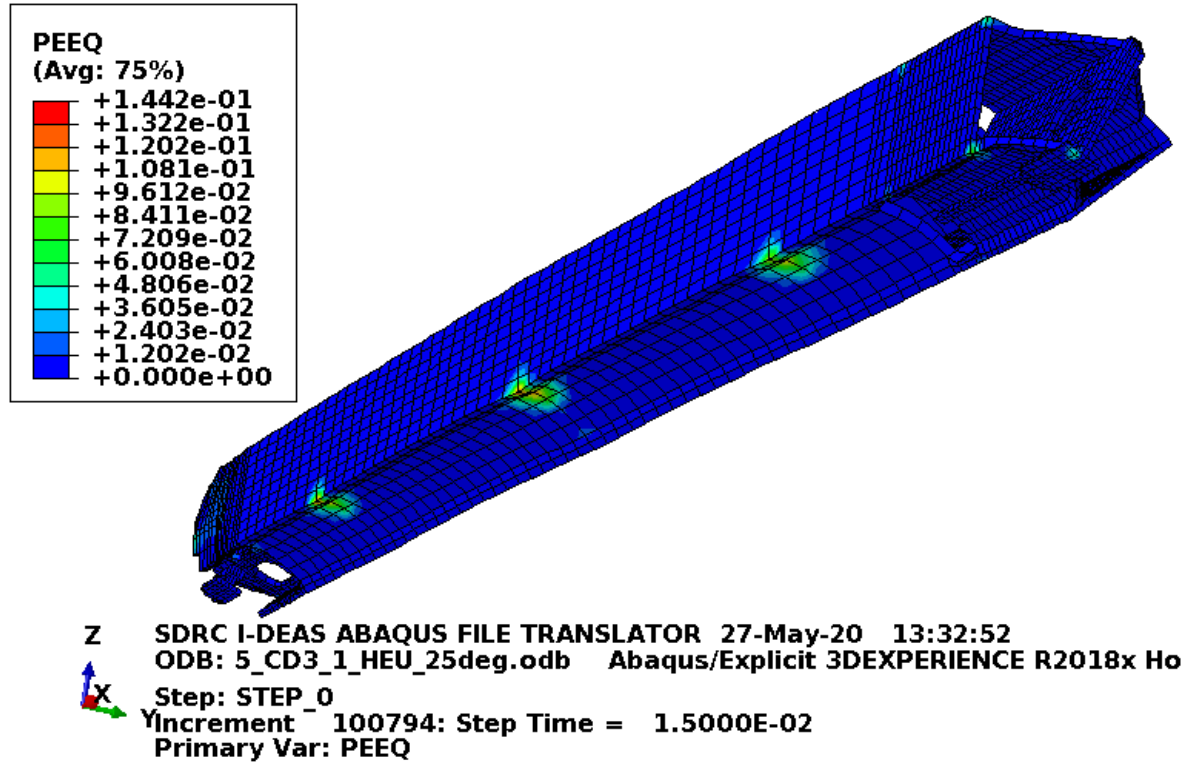

Figure C-268. Scope Part 4 (Table 3), 115-lbf fuel element, and 25-degree angle fuel element plasticequivalent strain.

Figure C-268 shows the equivalent plastic strain in the fuel element. For this model, the fuel element is coarse meshed, massive, and has no failure defined. Consequently, this is just shown for information and is not relevant to the acceptability of the fuel element. 
ENGINEERING CALCULATIONS AND ANALYSIS

Drop Analysis of the Advanced Test Reactor Fresh Fuel Shipping Container with Heavier Low-Enriched Uranium Fuel Contents

\section{C4.6 Results for Scope Part 4 (Table 3), Impacting 30 Degrees Off Horizontal}

The drop scenario considered in this section is a 30 -ft drop modeled as a side drop with the pockets and index lugs on the sides. It is oriented 30 degrees off horizontal about an axis along the length of the ATR FFSC.

\section{C4.6.1 Results for Scope Part 4 (Table 3) with 22.1-Ibf Fuel Element and Impacting 30 Degrees Off Horizontal}

The FEA model results for the Scope Part 4 (Table 3) with 22.1-lbf fuel element weight and impacting 30 degrees off horizontal model are shown below in Figure C-269 to Figure C-276. This drop scenario is a $30-\mathrm{ft}$ drop modeled as a side drop with the pockets and index lugs on the sides. The 30 degrees off horizontal angle is a rotation about an axis along the length of the ATR FFSC. The drop scenario is modeled with minimum material properties except the enclosure and end boxes, which are modeled with relatively tough material properties.

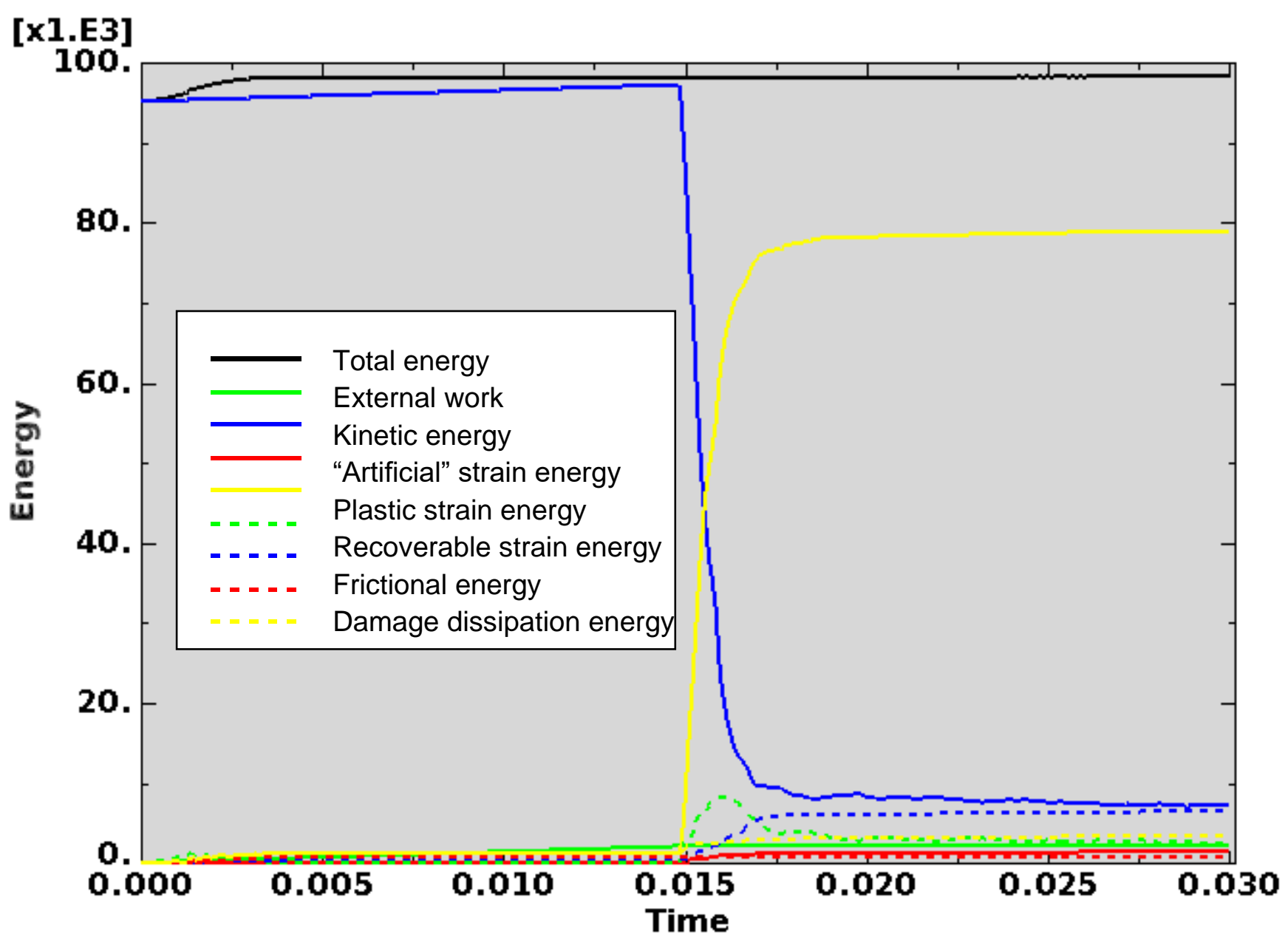

Figure C-269. Scope Part 4 (Table 3), 22.1-Ibf fuel element, and 30-degree angle energy curves. 
Figure C-269 shows the energy curves for Scope Part 4 (Table 3) with 22.1-lbf fuel element weight and impacting 30 degrees off horizontal drop scenario. These curves exhibit a stable shape. Artificial strain energy represents the energy required to keep reduced integration elements from taking on a zero-energy hourglass shape. As shown in Figure C-269, the artificial energy at the end of the model run is $1.5 \%$ of the total energy. Therefore, the potential error associated with artificial energy is not considered to be significant.

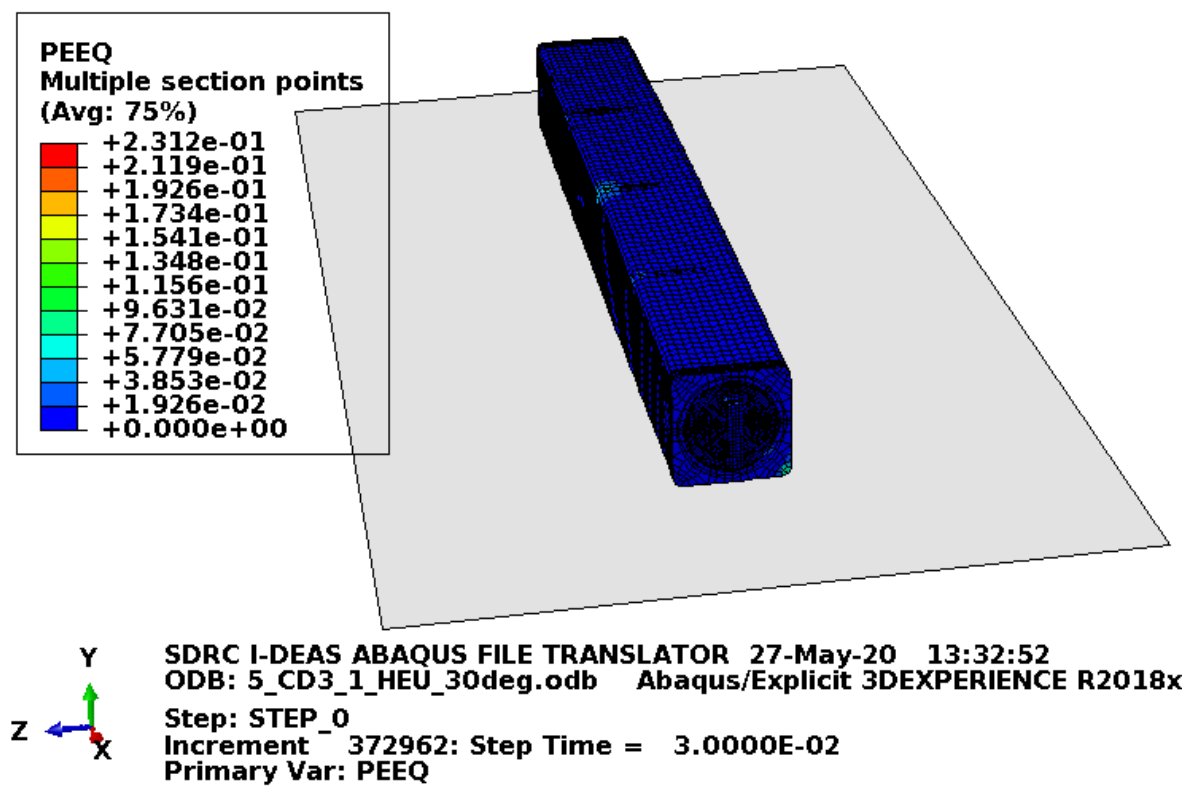

Figure C-270. Scope Part 4 (Table 3), 22.1-lbf fuel element, and 30-degree angle full-model plasticequivalent strain.

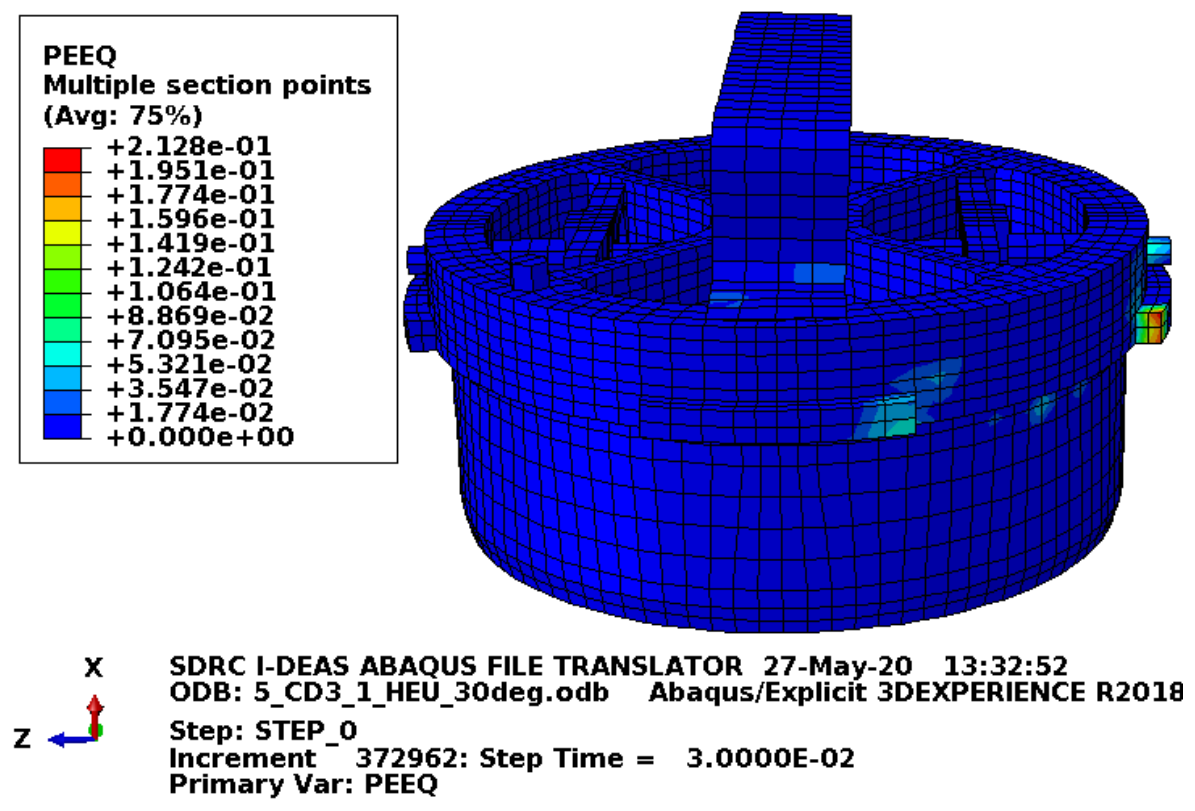

Figure C-271. Scope Part 4 (Table 3), 22.1-lbf fuel element, and 30-degree angle lid plastic-equivalent strain. 
ENGINEERING CALCULATIONS AND ANALYSIS

Drop Analysis of the Advanced Test Reactor Fresh Fuel Shipping Container with Heavier Low-Enriched Uranium Fuel Contents
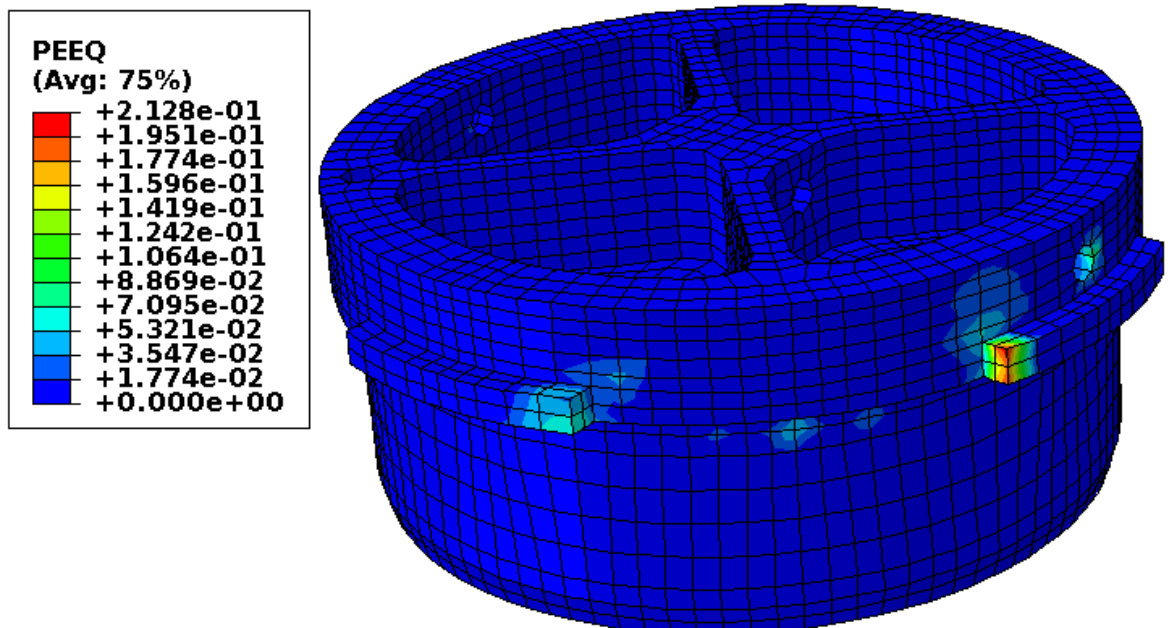

$\mathbf{X}$

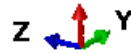

SDRC I-DEAS ABAQUS FILE TRANSLATOR 27-May-20 13:32:52

ODB: 5_CD3_1_HEU_30deg.odb Abaqus/Explicit 3DEXPERIENCE R2018

Step: STEP o

Increment ${ }^{-}$372962: Step Time $=3.0000 \mathrm{E}-02$

Primary Var: PEEQ

Figure C-272. Scope Part 4 (Table 3), 22.1-lbf fuel element, and 30-degree angle lid structure plasticequivalent strain.

Figure C-272 shows the equivalent plastic strain in the structurally significant portion of the lid. Failure in these elements occurs at an equivalent plastic strain of $0.259 \mathrm{in}$./in. If element failure were to occur, the element would be deleted and removed from the model (thereby making its equivalent plastic strain not included in the maximum equivalent plastic strain for the plot). However, the missing element would be visible in the plot. Figure C-272 shows no element failure with margin.

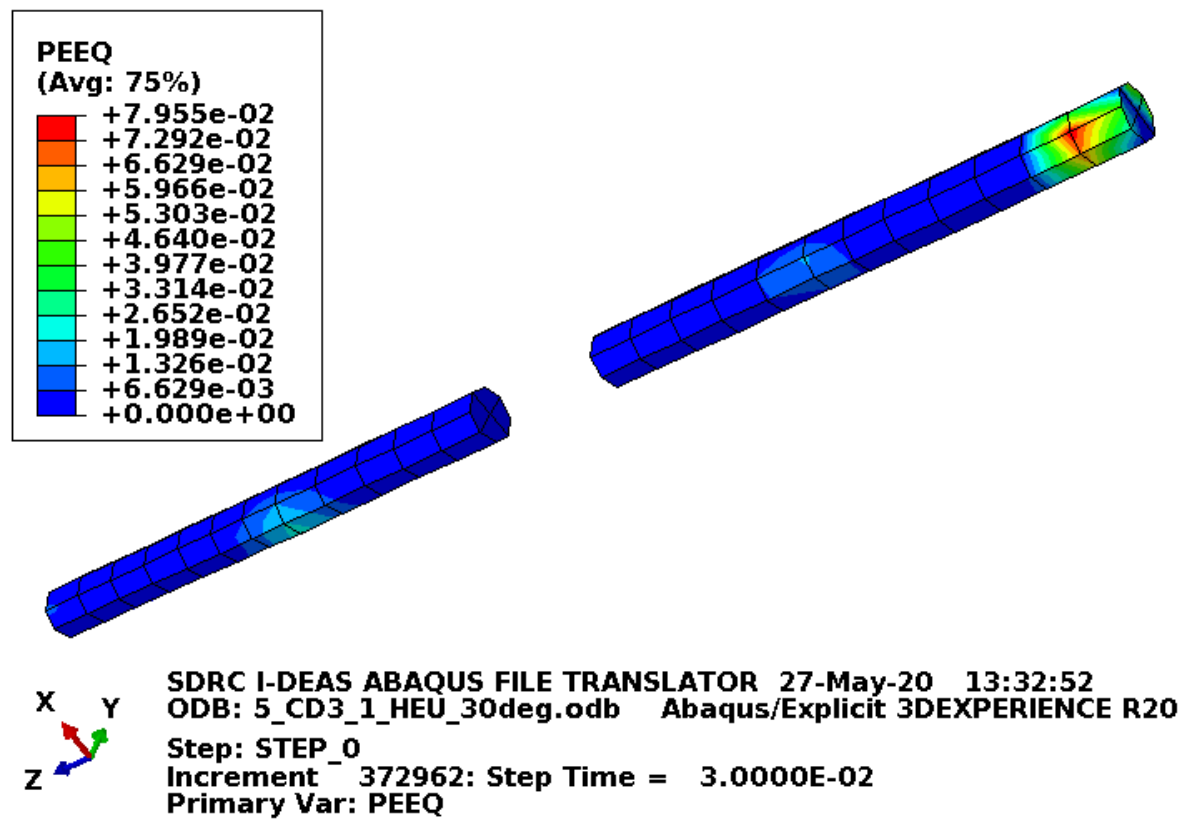

Figure C-273. Scope Part 4 (Table 3), 22.1-lbf fuel element, and 30-degree angle lid pins plastic-equivalent strain. 
Figure C-273 shows the equivalent plastic strain in the lid pins. Failure in these elements occurs at an equivalent plastic strain of $0.295 \mathrm{in}$./in. If element failure were to occur, the element would be deleted and removed from the model (thereby making its equivalent plastic strain not included in the maximum equivalent plastic strain for the plot). However, the missing element would be visible in the plot. Figure C-273 shows no element failure with margin.
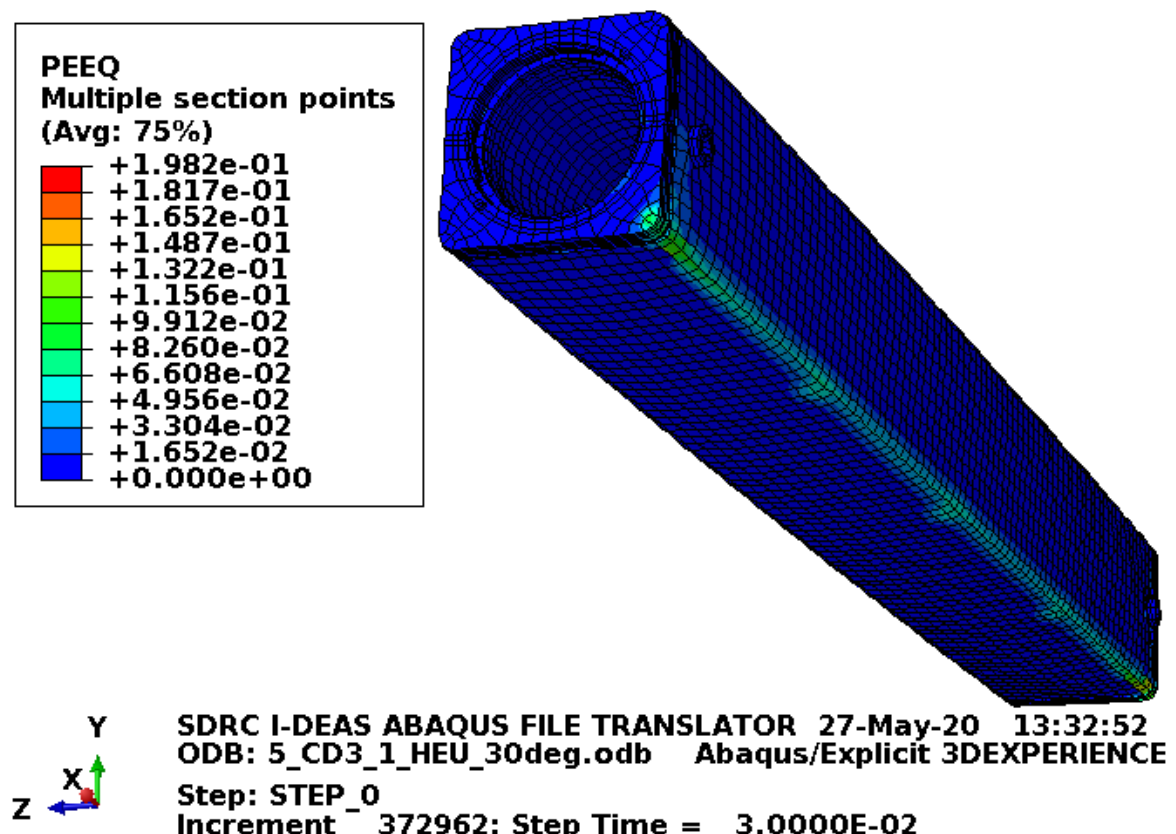

SDRC I-DEAS ABAQUS FILE TRANSLATOR 27-May-20 13:32:52

ODB: 5_CD3_1_HEU_30deg.odb Abaqus/Explicit 3DEXPERIENCE ।

Step: STEP_o

Increment ${ }^{-372962: \text { Step Time }=3.0000 \mathrm{E}-02}$

Primary Var: PEEQ

Figure C-274. Scope Part 4 (Table 3), 22.1-lbf fuel element, and 30-degree angle body plastic-equivalent strain.

Figure C-274 shows the equivalent plastic strain in the body. Failure in these elements occurs at an equivalent plastic strain of $0.259 \mathrm{in}$./in. If element failure were to occur, the element would be deleted and removed from the model (thereby making its equivalent plastic strain not included in the maximum equivalent plastic strain for the plot). However, the missing element would be visible in the plot. Figure C-274 shows no element failure with margin. 

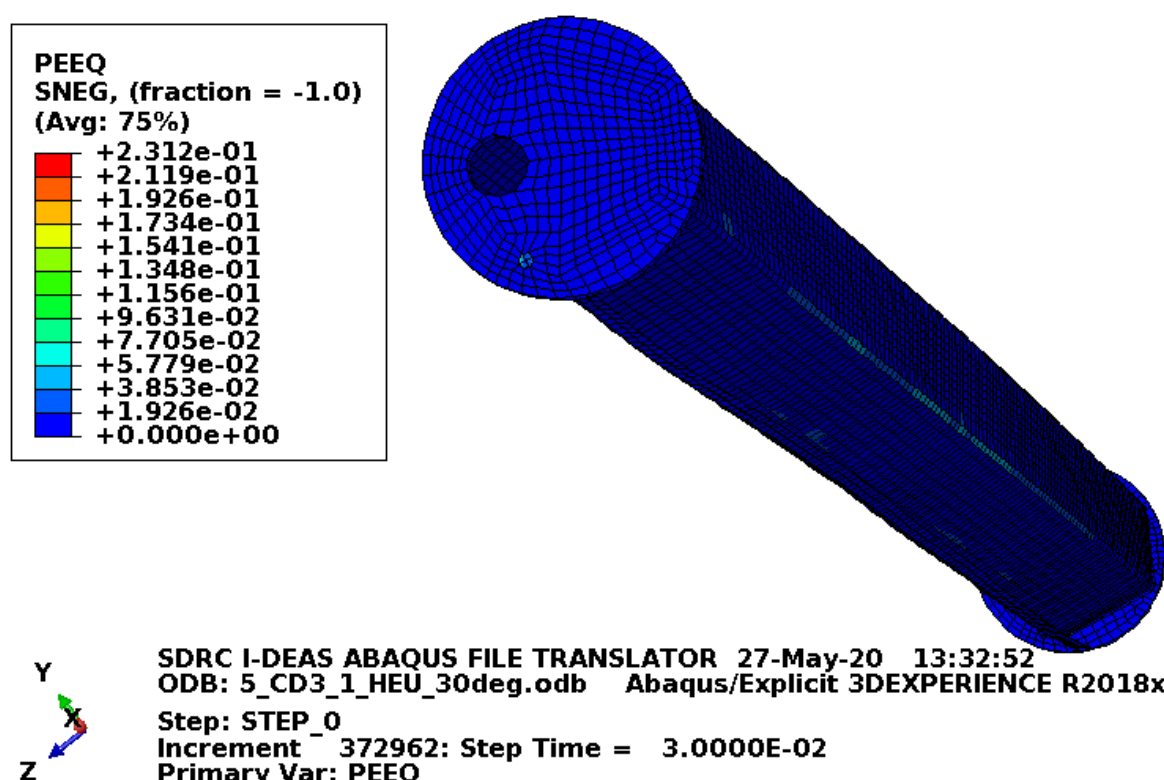

SDRC I-DEAS ABAQUS FILE TRANSLATOR 27-May-20 13:32:52

ODB: 5_CD3_1_HEU_30deg.odb Abaqus/Explicit 3DEXPERIENCE R2018x

$\mathbf{Z}$

Step: STEP_0

Increment ${ }^{-}$372962: Step Time $=3.0000 \mathrm{E}-02$

Primary var: PEEQ

Figure C-275. Scope Part 4 (Table 3), 22.1-lbf fuel element, and 30-degree angle enclosure plasticequivalent strain.

Figure $\mathrm{C}-275$ shows the equivalent plastic strain in the enclosure. This is just for information as damage to the enclosure is acceptable.
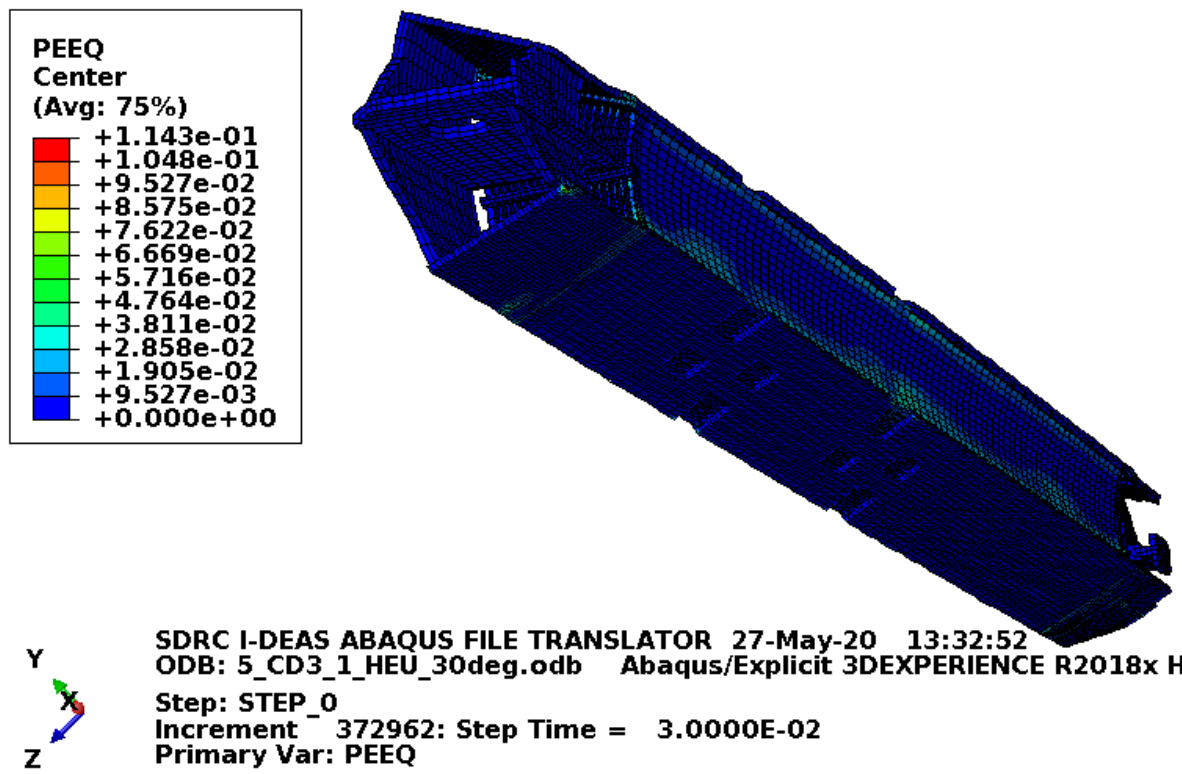

SDRC I-DEAS ABAQUS FILE TRANSLATOR 27-May-20 13:32:52
ODB: 5_CD3_1_HEU_30deg.odb Abaqus/Explicit 3DEXPERIENCE R2018x H

Step: STEP 0

Increment ${ }^{-372962: \text { Step Time }=3.0000 E-02}$

Primary Var: PEEQ

Figure C-276. Scope Part 4 (Table 3), 22.1-lbf fuel element, and 30-degree angle fuel element plasticequivalent strain.

Figure C-276 shows the equivalent plastic strain in the fuel element. For this model, the fuel element is modeled with minimum material properties except the end boxes, which are modeled with relatively tough material properties. While this model is appropriate for fuel element damage consideration, it is only shown here as it is not significantly damaged and other similar drop scenarios are documented in more detail. 


\section{C4.6.2 Results for Scope Part 4 (Table 3) with 115-Ibf Fuel Element and Impacting 30 Degrees Off Horizontal}

The FEA model results for the Scope Part 4 (Table 3) with 115-lbf fuel element weight and impacting 30 degrees off horizontal model are shown below in Figure C-277 to Figure C-284. This drop scenario is a 30-ft drop modeled as a side drop with the pockets and index lugs on the sides. The 30 degrees off horizontal angle is a rotation about an axis along the length of the ATR FFSC. The drop scenario is modeled with the ATR FFSC having minimum material properties and the enclosure and fuel element having relatively tough material properties with no failure.

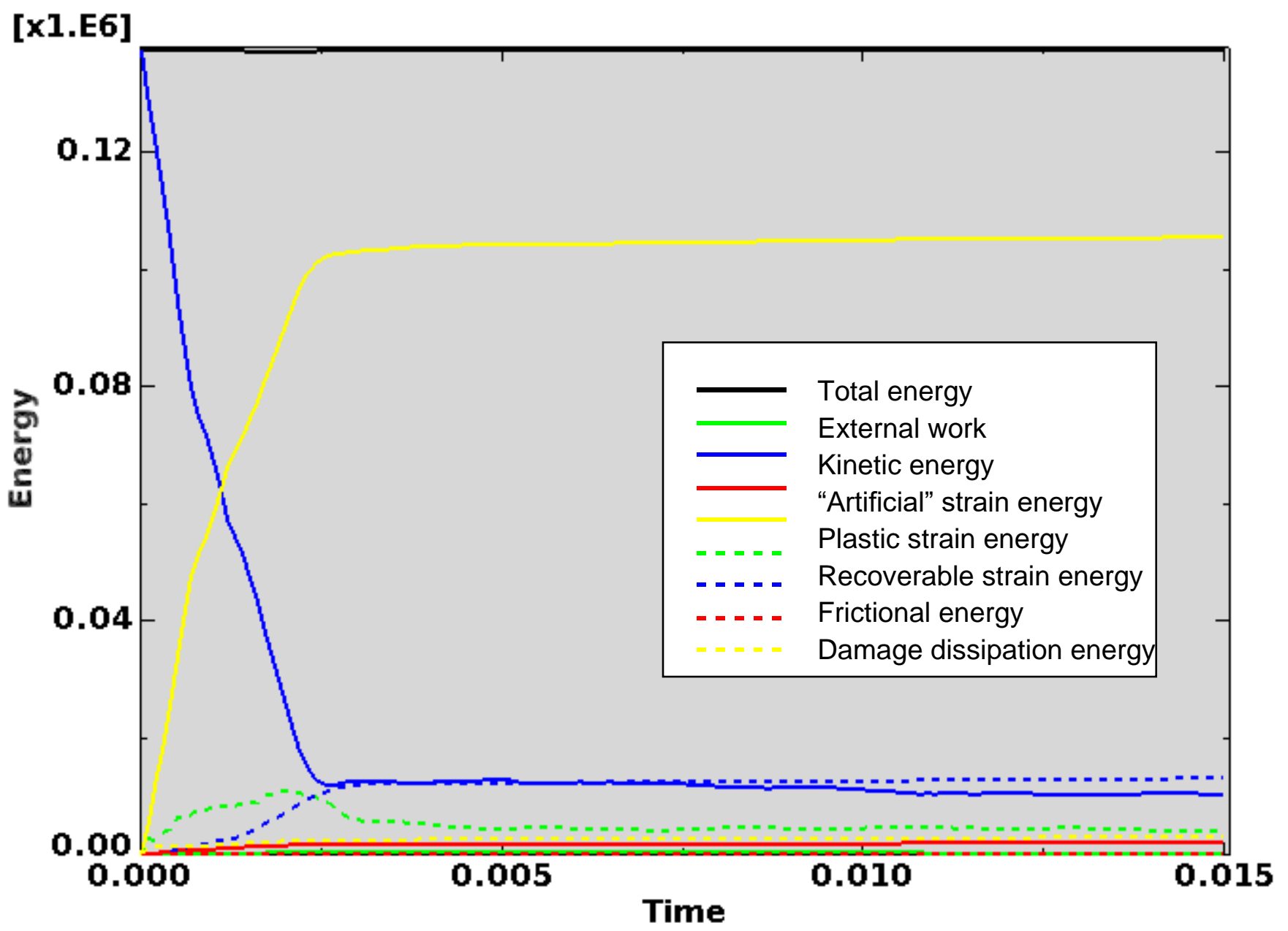

Figure C-277. Scope Part 4 (Table 3), 115-lbf fuel element, and 30-degree angle energy curves.

Figure C-277 shows the energy curves for Scope Part 4 (Table 3) with 115-Ibf fuel element weight and impacting 30 degrees off horizontal drop scenario. These curves exhibit a stable shape. Artificial energy represents the energy required to keep reduced integration elements from taking on a zero-energy hourglass shape. As shown in Figure C-277, the artificial energy at the end of the model run is $1.4 \%$ of the total energy. Therefore, the potential error associated with artificial energy is not considered to be significant. 
ENGINEERING CALCULATIONS AND ANALYSIS

Drop Analysis of the Advanced Test Reactor Fresh Fuel Shipping Container with Heavier Low-Enriched Uranium Fuel Contents

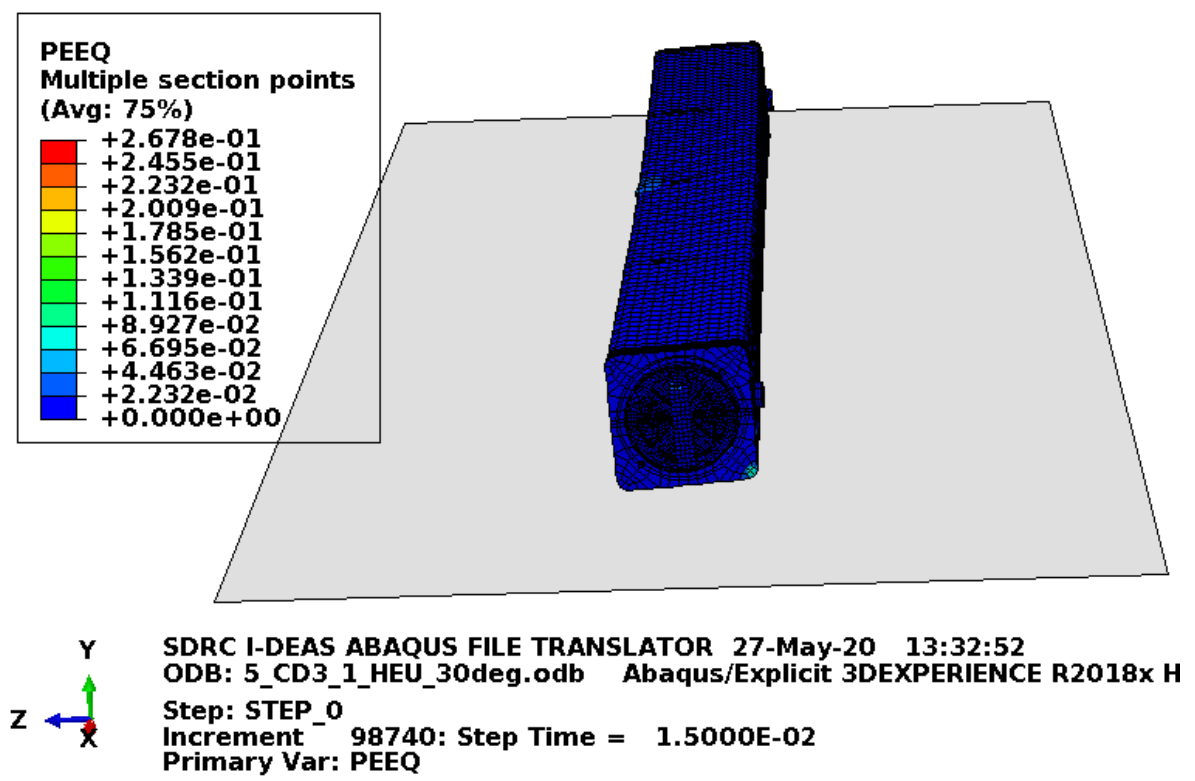

Figure C-278. Scope Part 4 (Table 3), 115-Ibf fuel element, and 30-degree angle full-model plasticequivalent strain.
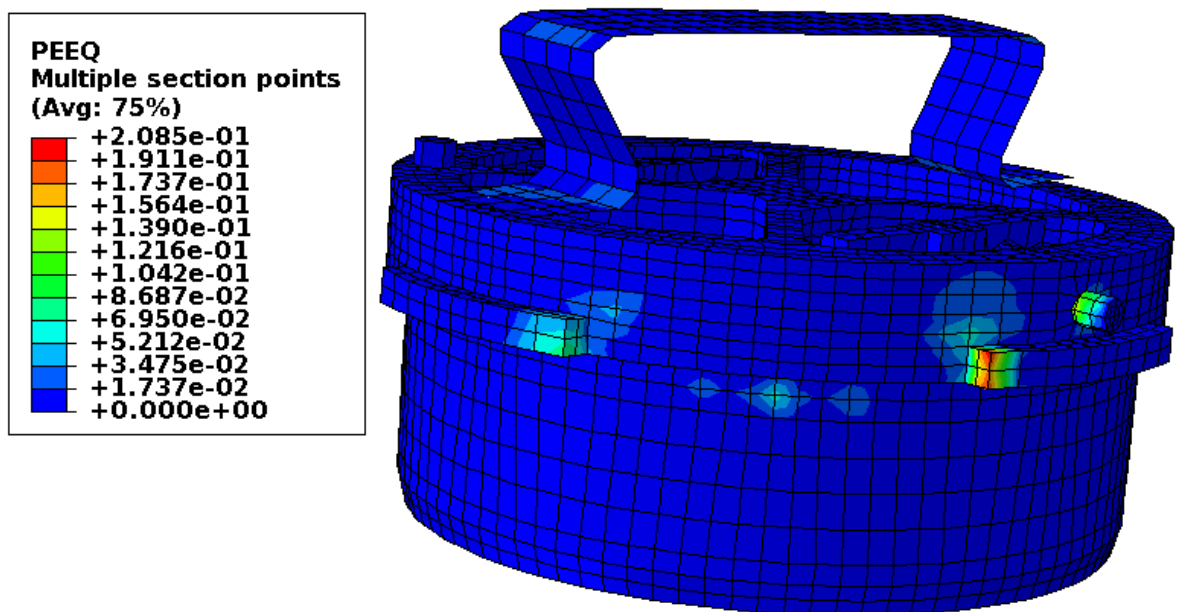

$X \quad$ SDRC I-DEAS ABAQUS FILE TRANSLATOR 27-May-20 13:32:52

ODB: 5_CD3_1_HEU_30deg.odb Abaqus/Explicit 3DEXPERIENCE R2018x Hot

$Z \leadsto$ Y Step: STEP_o

Increment ${ }^{-18740:}$ Step Time $=$ 1.5000E-02

Primary Var: PEEQ

Figure C-279. Scope Part 4 (Table 3), 115-Ibf fuel element, and 30-degree angle lid plastic-equivalent strain. 
ENGINEERING CALCULATIONS AND ANALYSIS

Drop Analysis of the Advanced Test Reactor Fresh Fuel Shipping Container with Heavier Low-Enriched Uranium Fuel Contents
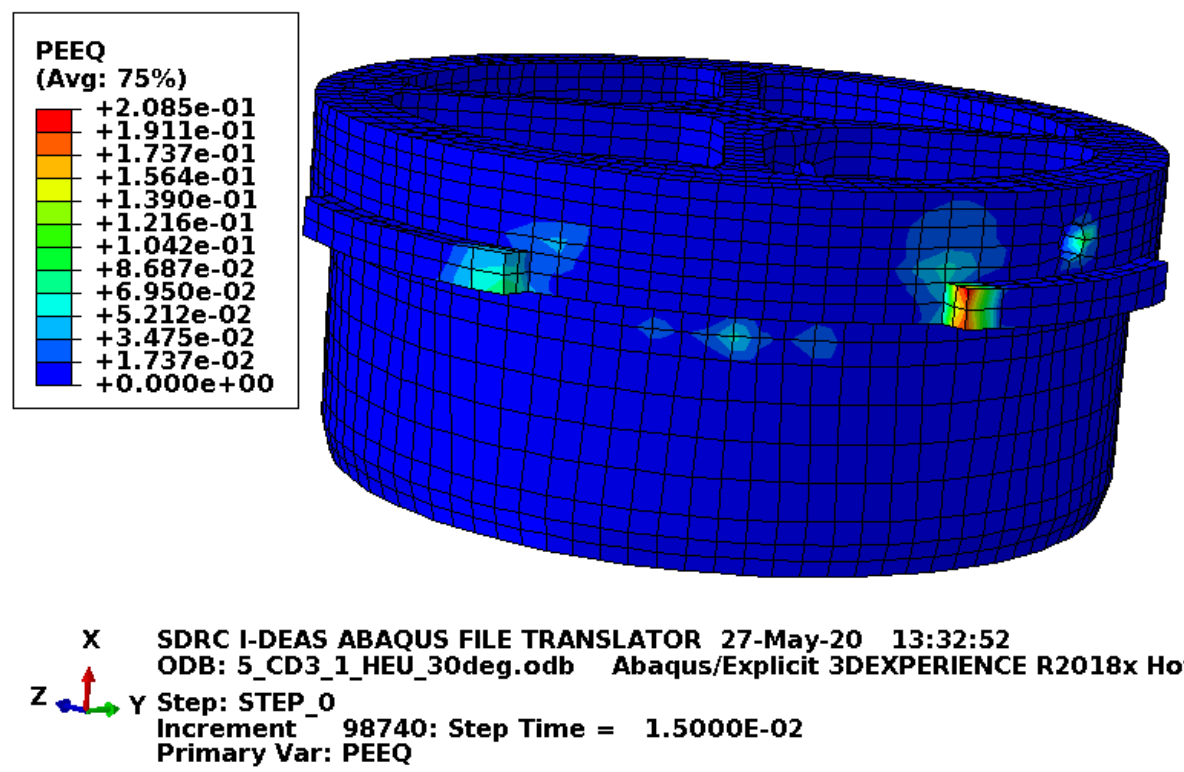

Figure C-280. Scope Part 4 (Table 3), 115-lbf fuel element, and 30-degree angle lid structure plasticequivalent strain.

Figure C-280 shows the equivalent plastic strain in the structurally significant portion of the lid. Failure in these elements occurs at an equivalent plastic strain of $0.259 \mathrm{in}$./in. If element failure were to occur, the element would be deleted and removed from the model (thereby making its equivalent plastic strain not included in the maximum equivalent plastic strain for the plot). However, the missing element would be visible in the plot. Figure C-280 shows no element failure.

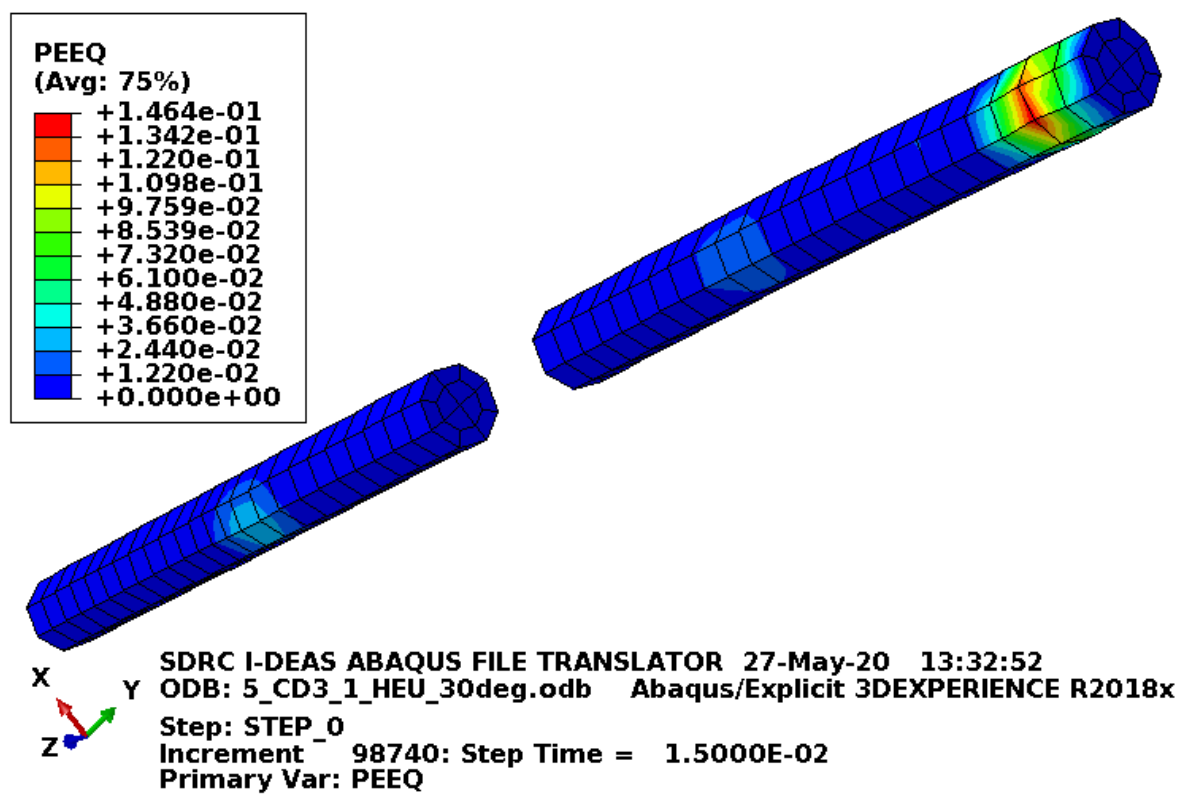

Figure C-281. Scope Part 4 (Table 3), 115-lbf fuel element, and 30-degree angle lid pins plastic-equivalent strain. 
Figure C-281 shows the equivalent plastic strain in the lid pins. Failure in these elements occurs at an equivalent plastic strain of $0.295 \mathrm{in}$./in. If element failure were to occur, the element would be deleted and removed from the model (thereby making its equivalent plastic strain not included in the maximum equivalent plastic strain for the plot). However, the missing element would be visible in the plot. Figure C-281 shows no element failure.

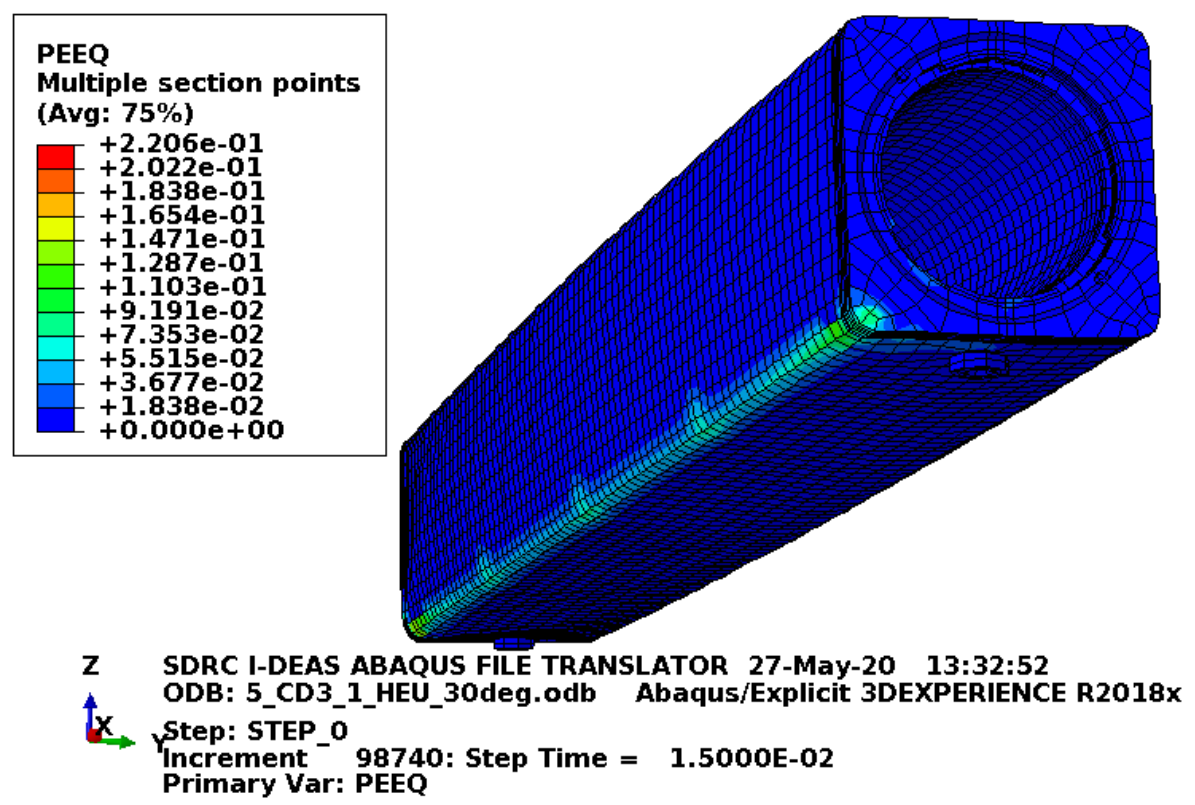

Figure C-282. Scope Part 4 (Table 3), 115-Ibf fuel element, and 30-degree angle body plastic-equivalent strain.

Figure C-282 shows the equivalent plastic strain in the body. Failure in these elements occurs at an equivalent plastic strain of $0.259 \mathrm{in}$./in. If element failure were to occur, the element would be deleted and removed from the model (thereby making its equivalent plastic strain not included in the maximum equivalent plastic strain for the plot). However, the missing element would be visible in the plot.

Figure C-282 shows no element failure. 
ENGINEERING CALCULATIONS AND ANALYSIS

Drop Analysis of the Advanced Test Reactor Fresh Fuel Shipping Container with Heavier Low-Enriched Uranium Fuel Contents

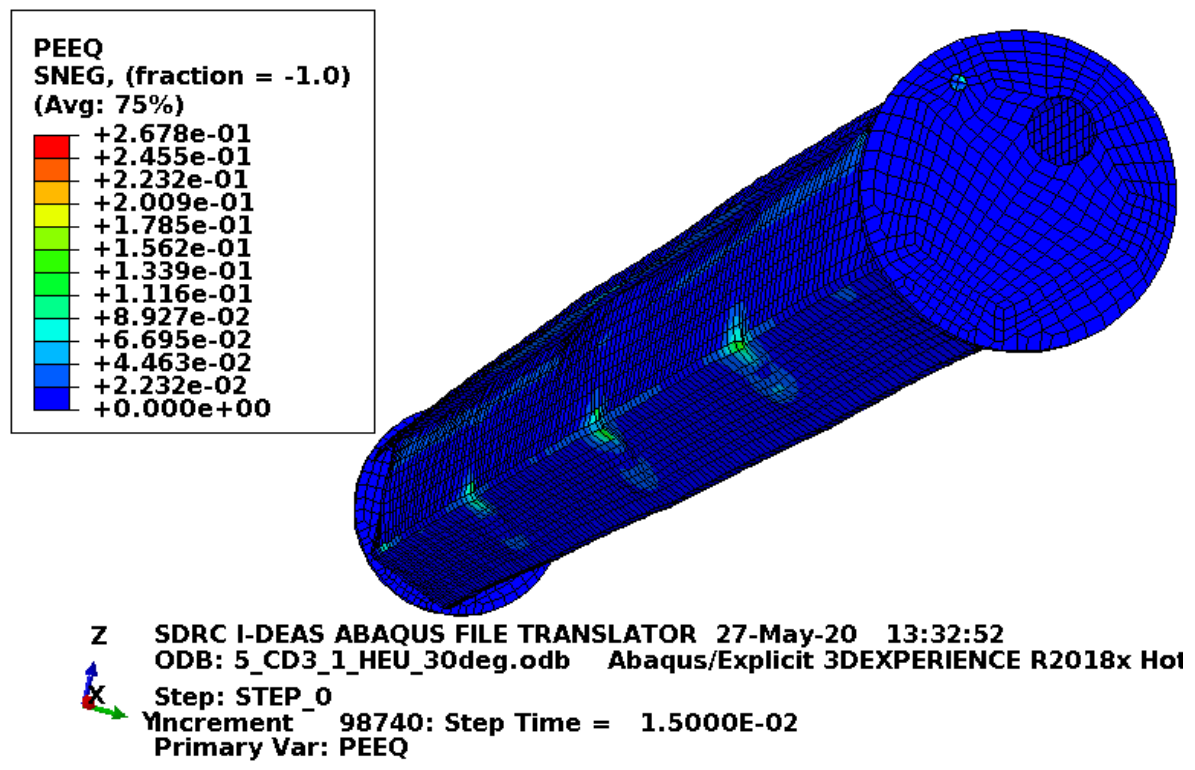

Figure C-283. Scope Part 4 (Table 3), 115-lbf fuel element, and 30-degree angle enclosure plasticequivalent strain.

Figure C-283 shows the equivalent plastic strain in the enclosure. This is just for information as damage to the enclosure is acceptable.

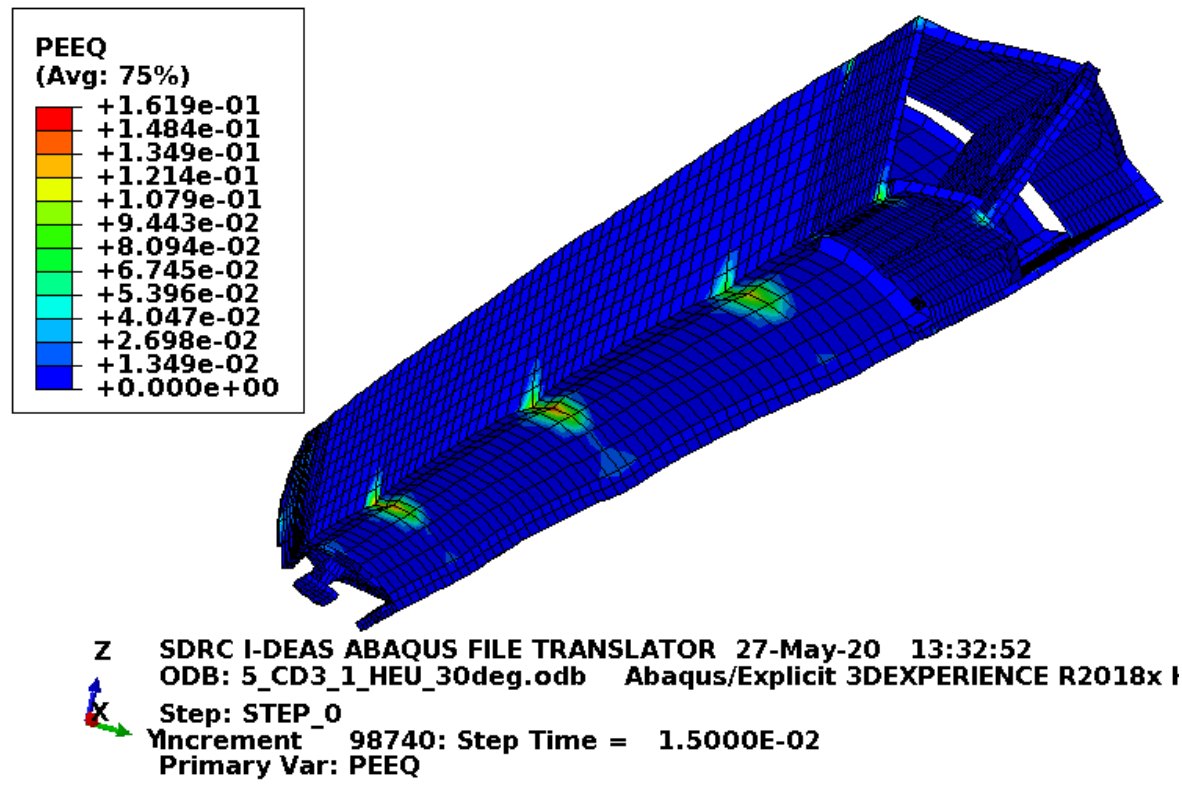

Figure C-284. Scope Part 4 (Table 3), 115-lbf fuel element, and 30-degree angle fuel element plasticequivalent strain.

Figure C-284 shows the equivalent plastic strain in the fuel element. For this model, the fuel element is coarse meshed, massive, and has no failure defined. Consequently, this is just shown for information and is not relevant to the acceptability of the fuel element. 


\section{C4.7 Summary of Results for Scope Part 1 (Table 3)}

As described in Section C2.4.1, one of the lid pins in lid sheared off between the lid and body in the physical drop for Scope Part 1 (Table 3), Test 5 (Table 2). Considering the discussion with Figure C-45, it's difficult to make a solid case for why the lid pin sheared given the description in Section C2.4.1. However, the lid pin shear occurred in the fourth consecutive side drop from 30 feet and they all rotated upon rebound. Given this information along with the scoping model evidence, lid pin damage occurring from rebound rotation is studied as the primary load path for shearing the lid pins. The FEA models in this section showed that significant lid pin strain could occur as a result of rotation on rebound. However, no lid pin failure was shown for a single drop accident.

Two sets of models are considered in this section. First, models similar to the physical drops (22.1-lbf fuel element) are performed. For these models, the worst-case lid pin damage is shown in Figure C-209 where the loaded ATR FFSC impacted 10-degree off horizontal. There is no failure in the lid pins. However, the maximum strain is about $0.196 \mathrm{in}$./in. (with failure occurring at $0.295 \mathrm{in}$./in). This data supports the idea that multiple drops are necessary to produce lid pin failure for drop scenarios like the physical drop scenarios. Second, high weight models (115-lbf fuel element) are performed. For these models, the worst-case lid pin damage is shown in Figure C-233 where the loaded ATR FFSC impacted 15-degree off horizontal. There is no failure in the lid pins. However, a maximum strain of about $0.299 \mathrm{in}$./in. was shown, which is above the failure strain of $0.295 \mathrm{in}$./in. This is the only model for Scope Part 4 (Table 3) where this occurred and the strains shown above the failure strain likely result from extrapolation (as integration point strains are the important strains for failure). Even if the elements with high strain were removed as being failed, the lid pin would still be capable of performing its function. The failure would be through less than $20 \%$ of the lid pin cross section leaving it still functional and the lid pin on the other side has no failure or high strains. 


\section{Appendix D}

\section{ATR FFSC Evaluation Results}

\section{Table of Contents}

D1 PURPOSE/SUMMARY .

D2 PHYSICAL AND MODELED ATR HEU FUEL ELEMENT RESULTS COMPARISON (SCOPE PART 1, TABLE 3)

D3 LOWE FUEL ELEMENT RESULTS (SCOPE PART 2, TABLE 3) D164

NOTE: References identified in this appendix can be found at the end of the main body.

\section{D1 PURPOSE/SUMMARY}

This appendix documents the drop scenario results for the tested Advanced Test Reactor (ATR) highly enriched uranium (HEU) fuel element and the LOWE fuel element. Appendix B provides the model development for the loaded ATR Fresh Fuel Shipping Container (FFSC) drop scenarios used for evaluation. Appendix $\mathrm{C}$ documents the important results for the ATR FFSC (which contains the fuel elements in the drop scenarios). While all of the drop scenarios include a fuel element, Scope Parts 1 and 2 (Table 3) are the portion of the scope intended to capture fuel element damage. Consequently, the fuel element results for Scope Parts 1 and 2 (Table 3) are documented in this appendix.

The purpose of this appendix includes showing that the model representing the tested ATR HEU fuel element provides results that are reasonable and conservative when compared with the physical drops documented in the ATR FFSC safety analysis and review (SAR) (2017). These results along with results where blocks are included for information are given in Section D2. Showing that the model can reasonably and conservatively predict the ATR HEU fuel element damage in the physical drop events validates the use of the model for increased fuel element weights as well. Considering this, the purpose also includes showing LOWE fuel element results using the same mesh and increased fuel plate density. Per the ATR FFSC SAR (2017), the physical dropped ATR HEU fuel element weighed 22.1 lbf. Per Quirl (2019), the bounding weight for a LOWE fuel element is $44 \mathrm{lbf}$. Because of the greatly increased fuel element weight for the LOWE fuel element, the block design is included more out of necessity. LOWE fuel element results with and without blocks are given in Section D3.

Energy curves are provided for the presented drop scenarios. The energy units are "in॰lbf" and the time is in "sec".

\section{D2 PHYSICAL AND MODELED ATR HEU FUEL ELEMENT RESULTS COMPARISON (SCOPE PART 1, TABLE 3)}

Sections D2.1-D2.11 show the finite element analysis (FEA) model results for the Scope Part 1 (Table 3) drop scenarios (with a fuel element weight of $22.1 \mathrm{lbf}$ ). Section D2.12 provides a summary of the results for the Scope Part 1 (Table 3) drop scenarios.

NOTE: $\quad$ As discussed in Table 2 of the main body, Test 4, 7, and 9 are not performed with an FEA model. 
Unlike the ATR FFSC discussion of physical drops (provided in Appendix C), fuel element damage was only discussed after the physical drop scenario for Scope Part 1 (Table 3), Test 2 (Table 2) and after all the drops were performed. The fuel element damage discussion for Scope Part 1 (Table 3), Test 2 (Table 2) is provided in the ATR FFSC SAR (2017), Section 2.12.1.4.1.2 (shown below for reference). The drop test was identified as CD1-1 and Figure D-1 provides the supporting ATR FFSC SAR (2017) figure for reference. The discussion on fuel element damage after all the drops were performed is provided in the ATR FFSC SAR (2017), Sections 2.12.1.5.1 and 2.12.1.5.2 (shown below for reference). Figure D-2 to Figure D-10 provides the supporting ATR FFSC SAR (2017) figures and table for reference.

Text from ATR FFSC SAR (2017), Section 2.12.1.4.1.2:

As illustrated in Figure 2.12.1-12, there was no visible damage to the fuel element. The fuel element was not removed from the fuel-handling equipment (FHE), but both end boxes were clearly visible and fully intact.

Text from ATR FFSC SAR (2017), Section 2.12.1.5.1:

Figure 2.12.1-54 illustrates the relatively unchanged position of the FHE and fuel element within the CTU. Also seen in this figure are pieces of the broken end box at the bottom end and also pieces of neoprene padding from the FHE during removal. The FHE was somewhat difficult to remove and the aluminum end plate had broken off, so the ATR fuel element was carefully pulled from the bottom end of the package as illustrated in Figure 2.12.1-55. Both end boxes of the fuel element had shattered into several pieces. These pieces were collected and kept with the fuel element. There were no pieces of the fuel element end boxes found outside the FHE. Once the fuel element was removed, the FHE was pulled from the inner tube. The welds securing each FHE end plate to the body were completely broken and both the end plates were loose. Figure 2.12.1-56 illustrates the area of greatest deformation to the FHE which was at the closure end.

Text from ATR FFSC SAR (2017), Section 2.12.1.5.2:

The ATR fuel element was placed on an inspection table and compared against the same pre-test measurements for the fuel plates. Because the fuel element end boxes had shattered and bent the ends of the side plates, some of the fuel plate measurements taken from the side plates could be slightly exaggerated. The measurements included side plate flatness, in plane bending of the side plates, side plate spacing, overall fuel plate spacing, and fuel plate to fuel plate spacing. Table D-1 provides the general change in dimensions to the fuel plates. Measurements were generally taken at five locations along the length of the fuel element. The five locations include 1 in from the end of the fuel plate (neglecting the end boxes), 12 in from each end of the fuel plate, and at the center of the fuel plate.

Figure 2.12.1-57 through Figure 2.12.1-62 illustrate the condition of the ATR fuel element. As shown in Figure 2.12.1-58 and Figure 2.12.1-59, fragments from the fuel element end boxes deformed and cut into the ends of the fuel plates during testing. At no point did the fuel meat, the embedded uranium within the aluminum cladding, become exposed.

In conclusion, the CTU satisfied the acceptance criteria of preventing loss or dispersal of the contents, the outer shell remained intact, the insulation remained within the assumptions of the thermal analysis, and the package and fuel geometry remained greatly unchanged. The deformations of the package and condition of the ATR fuel element were evaluated against the criticality and thermal evaluations and determined to be within the bounds of the assumptions and conditions used to ensure safety. 


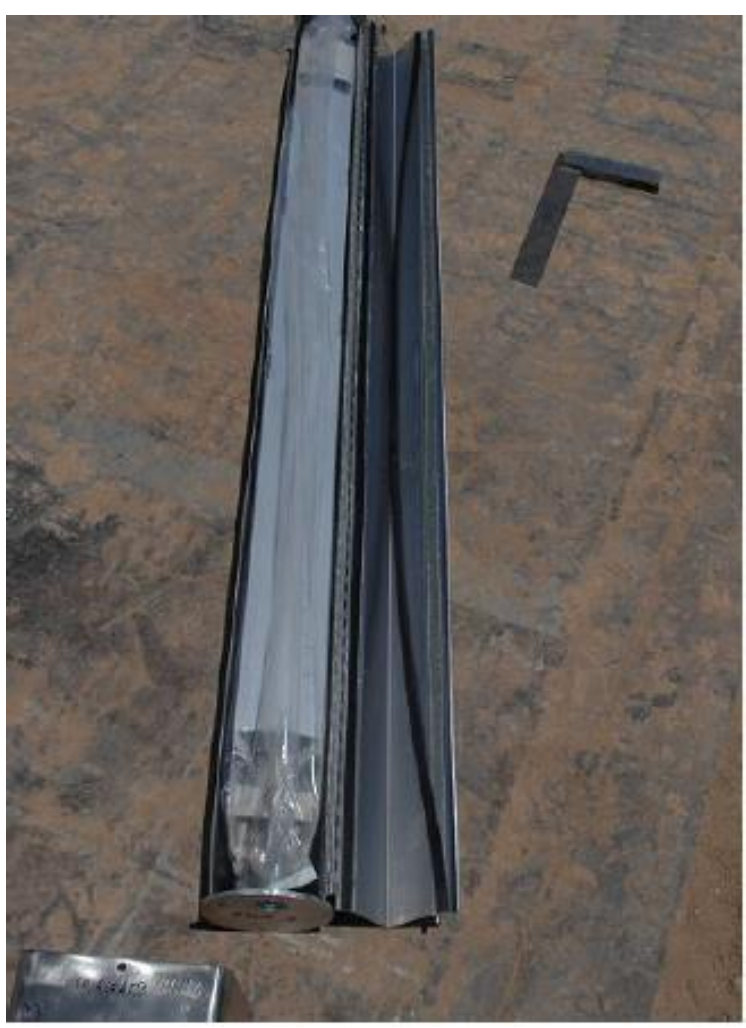

Figure D-1. Inspection of Fuel Element Following CD1-1 [ATR FFSC SAR (2017), Figure 2.12.1-12].

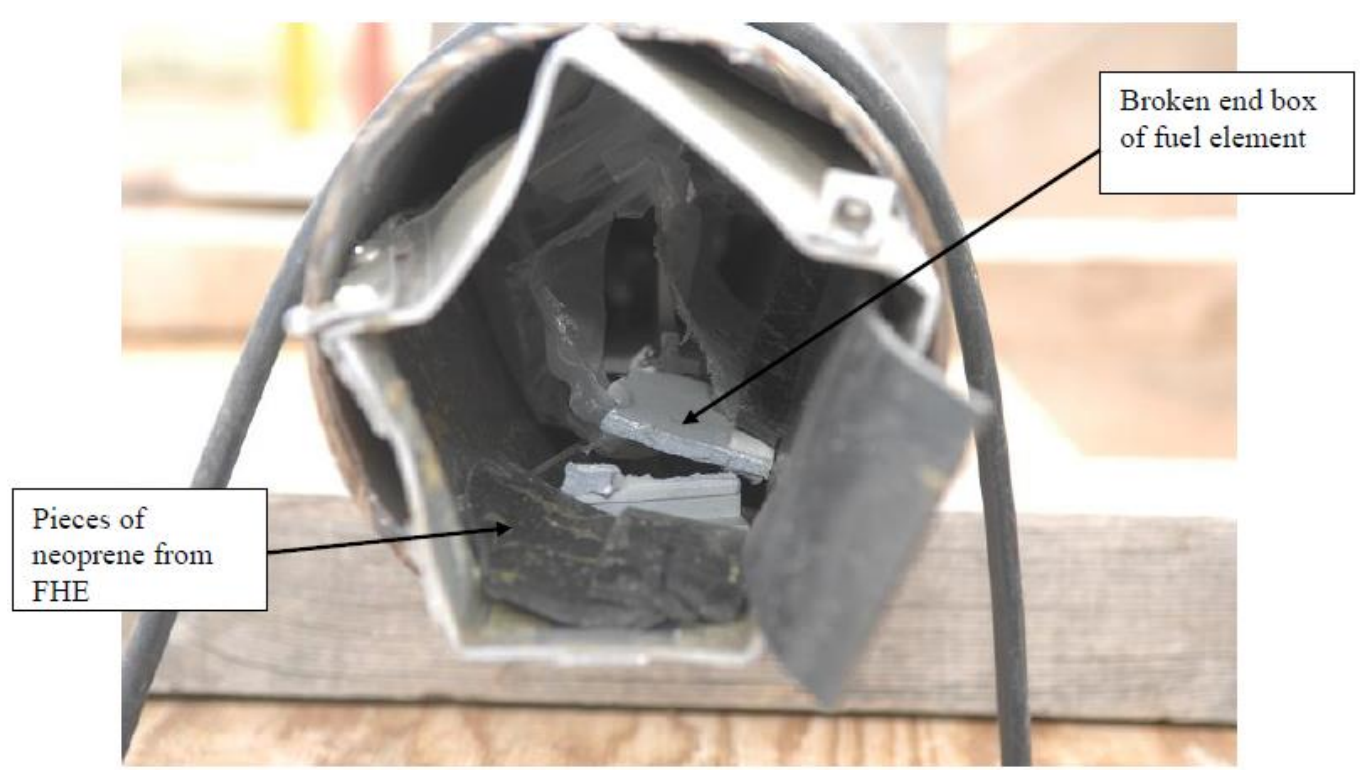

Figure D-2. End View (Bottom) of Opened CTU [ATR FFSC SAR (2017), Figure 2.12.1-54]. 


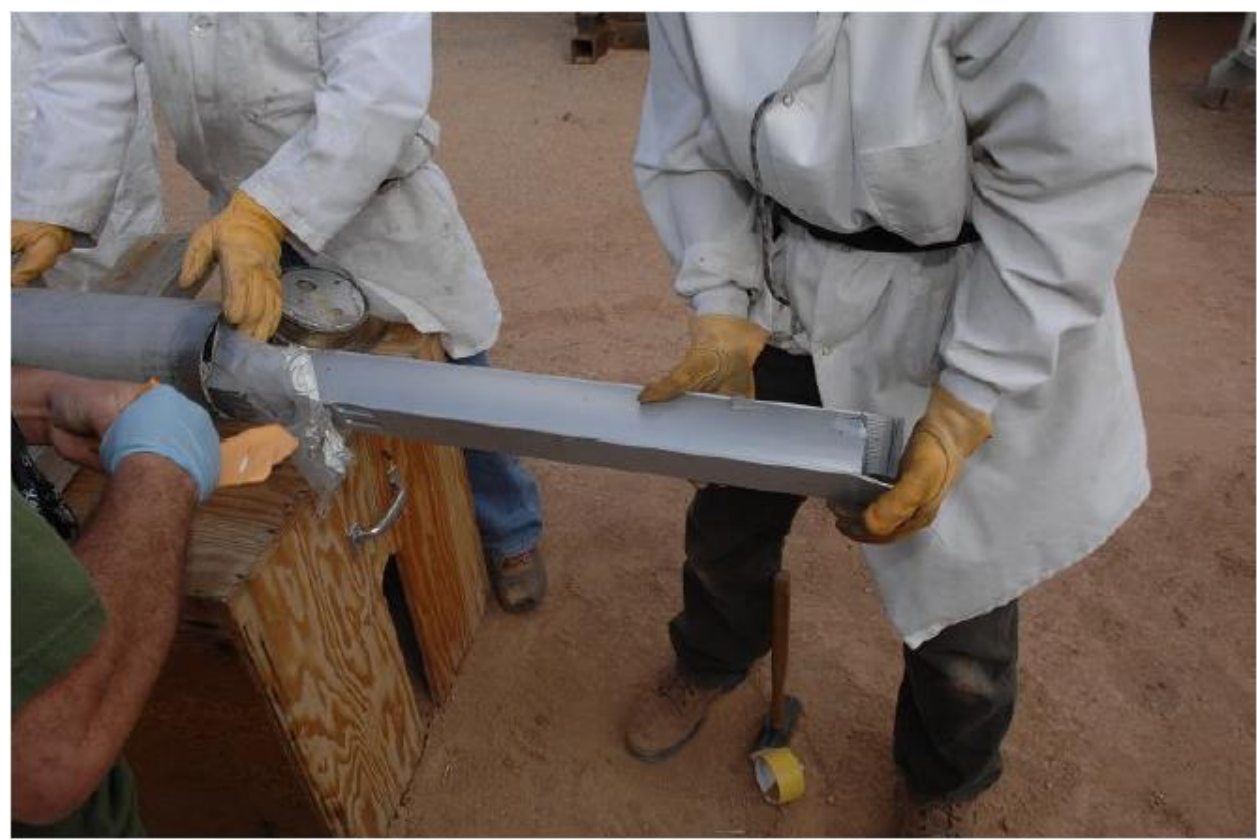

Figure D-3. Removal of ATR HEU fuel element [ATR FFSC SAR (2017), Figure 2.12.1-55].

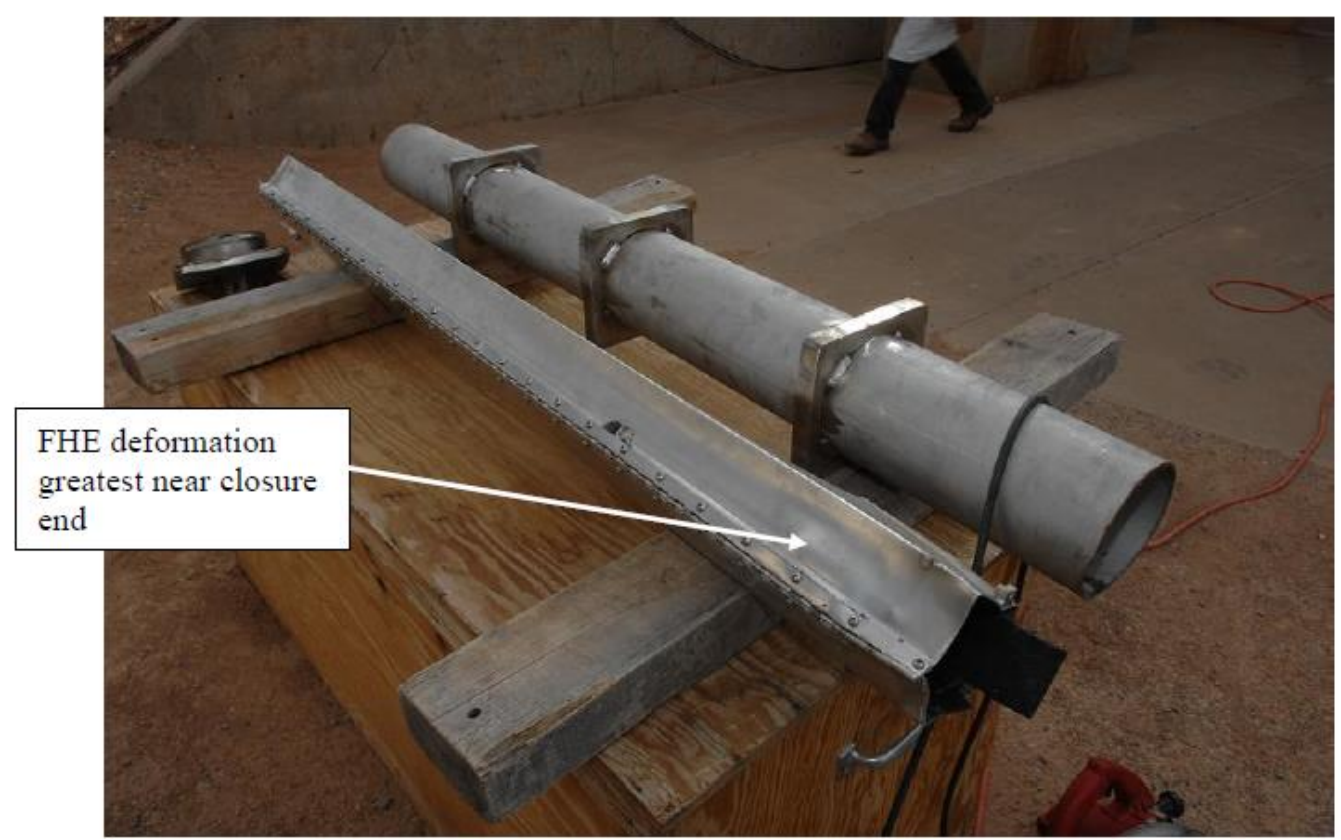

Figure D-4. Fuel Handling Enclosure Deformation [ATR FFSC SAR (2017), Figure 2.12.1-56]. 


\section{ENGINEERING CALCULATIONS AND ANALYSIS}

Drop Analysis of the Advanced Test Reactor Fresh Fuel Shipping Container with Heavier Low-Enriched Uranium Fuel Contents
ECAR-5224, Rev. 0

Page D5 of D293

Table D-1. ATR Fuel Element Measurements

\begin{tabular}{|l|c|c|}
\hline \multicolumn{1}{|c|}{ Measurement Area } & \multicolumn{1}{|c|}{$\begin{array}{c}\text { Pre-Test Rang } \\
\text { (in) }\end{array}$} & $\begin{array}{c}\text { Post-Test Range } \\
\text { (in) }\end{array}$ \\
\hline Side Plate Flatness & \pm 0.010 & \pm 0.075 \\
\hline In-Plane Bending of Side Plates & \pm 0.011 & \pm 0.025 \\
\hline Side Plate Spacing-Top & $4.113-4.130$ & $4.015-4.131$ \\
\hline Side Plate Spacing-Bottom & $1.840-1.845$ & $1.937-1.845$ \\
\hline $\begin{array}{l}\text { Height of Top Fuel Plate from } \\
\text { Table (top side up) }\end{array}$ & $2.675-2.691$ & $2.655-2.785$ \\
\hline $\begin{array}{l}\text { Height of Bottom Fuel Plate from } \\
\text { Table (bottom side down) }\end{array}$ & $2.500-2.540$ & $2.415-2.508$ \\
\hline Fuel Plate to Fuel Plate Spacing & 0.075 to 0.080 & 0.023 to $0.098^{*}$ \\
\hline
\end{tabular}

${ }^{*}$ The minimum and maximum fuel plate spacing were in localized areas near the side vents and not representative of the general spacing.

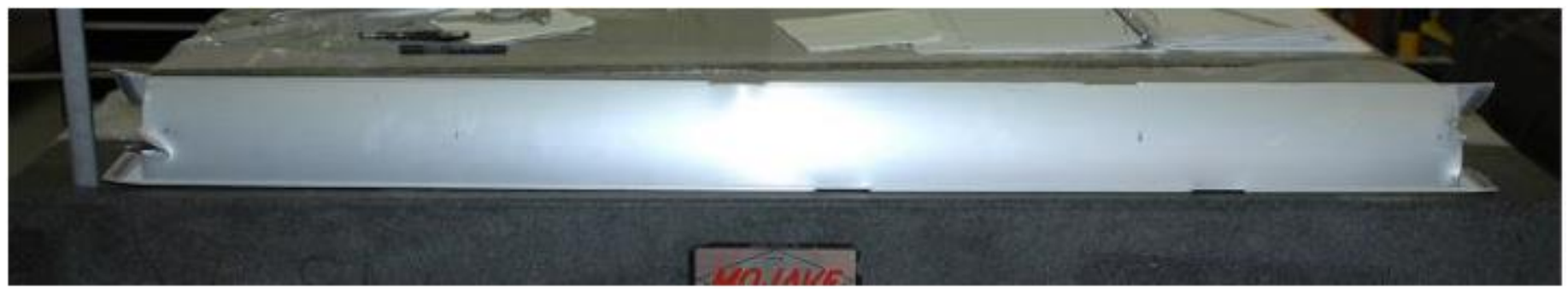

Figure D-5. ATR HEU fuel element Inspection [ATR FFSC SAR (2017), Figure 2.12.1-57].

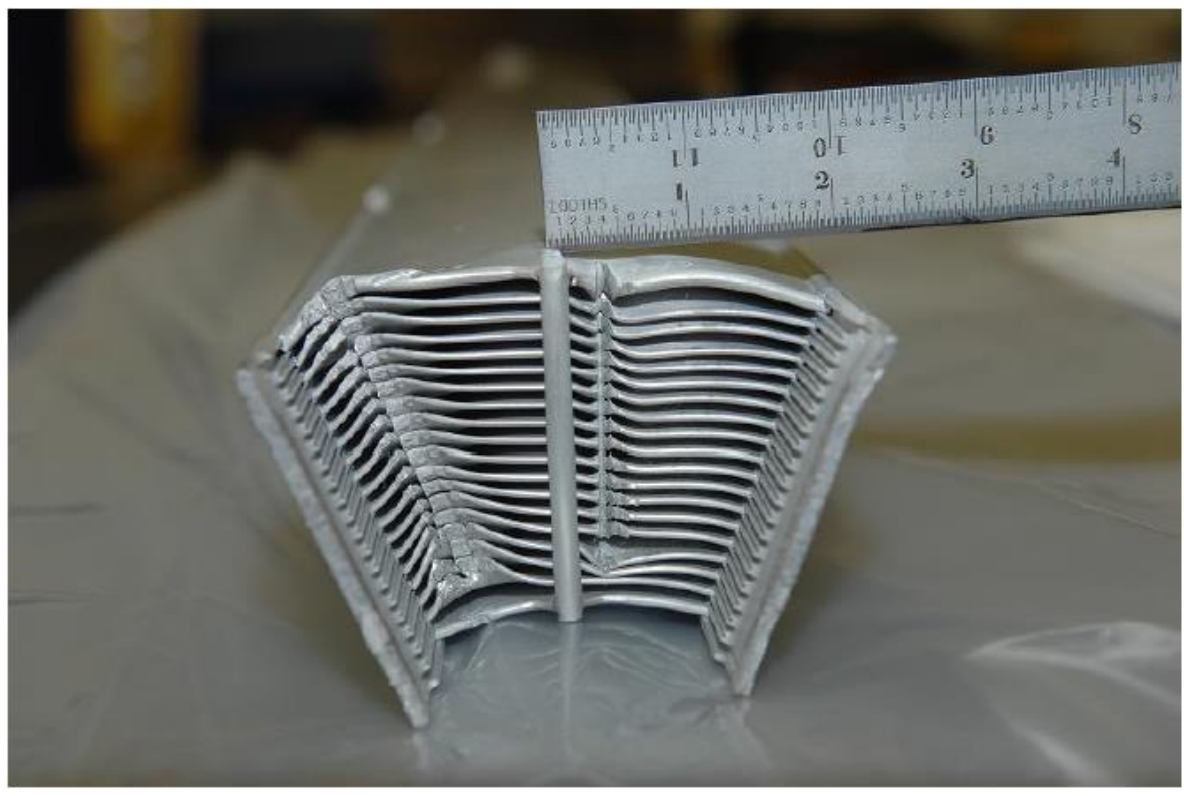

Figure D-6. ATR HEU fuel element at Head End [ATR FFSC SAR (2017), Figure 2.12.1-58]. 
Drop Analysis of the Advanced Test Reactor Fresh Fuel Shipping Container with Heavier Low-Enriched Uranium Fuel Contents

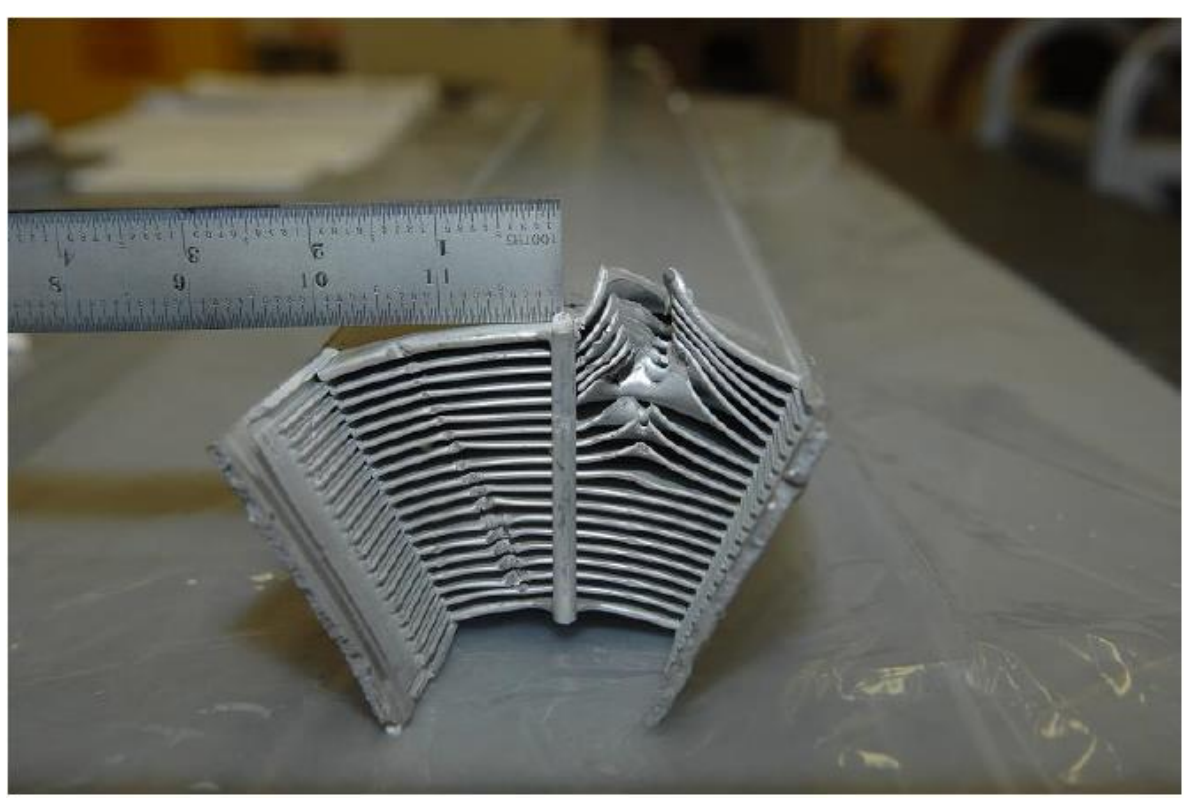

Figure D-7. ATR HEU fuel element Damage at Bottom End [ATR FFSC SAR (2017), Figure 2.12.1-59].

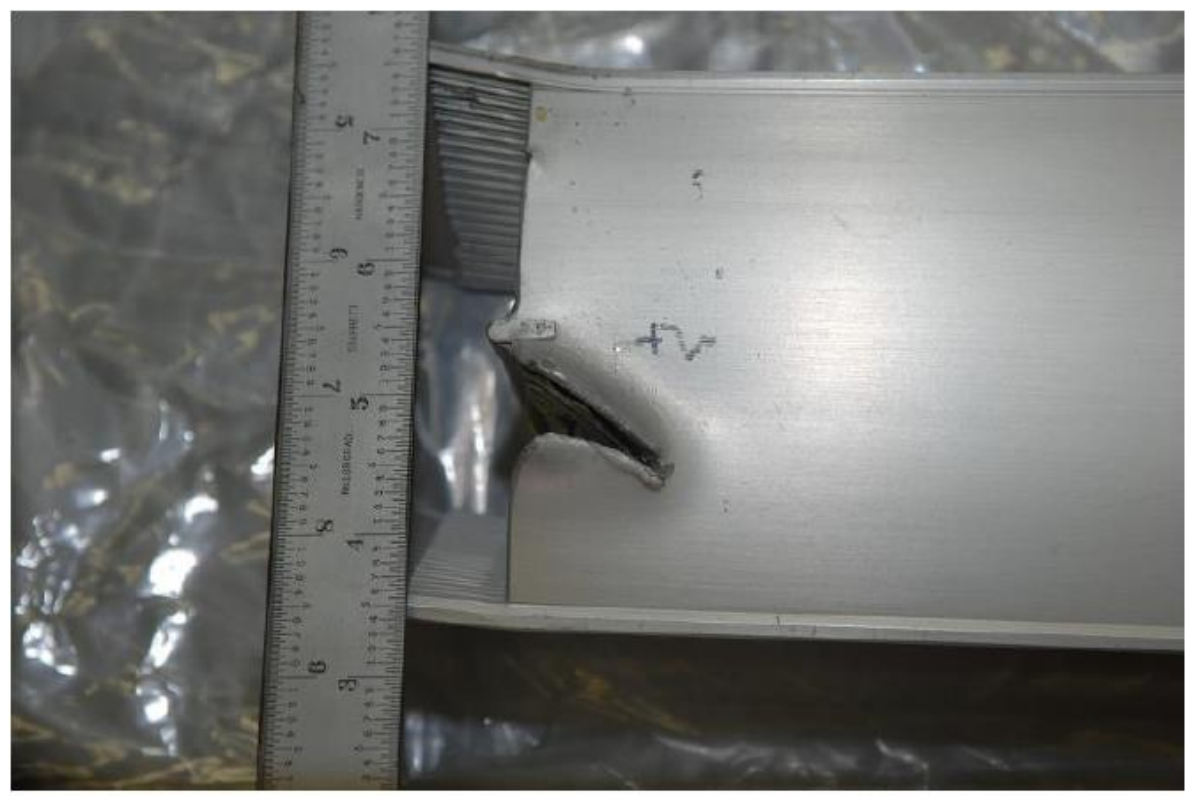

Figure D-8. Top View ATR HEU fuel element at Bottom End [ATR FFSC SAR (2017), Figure 2.12.1-60]. 
Drop Analysis of the Advanced Test Reactor Fresh Fuel Shipping Container with Heavier Low-Enriched Uranium Fuel Contents

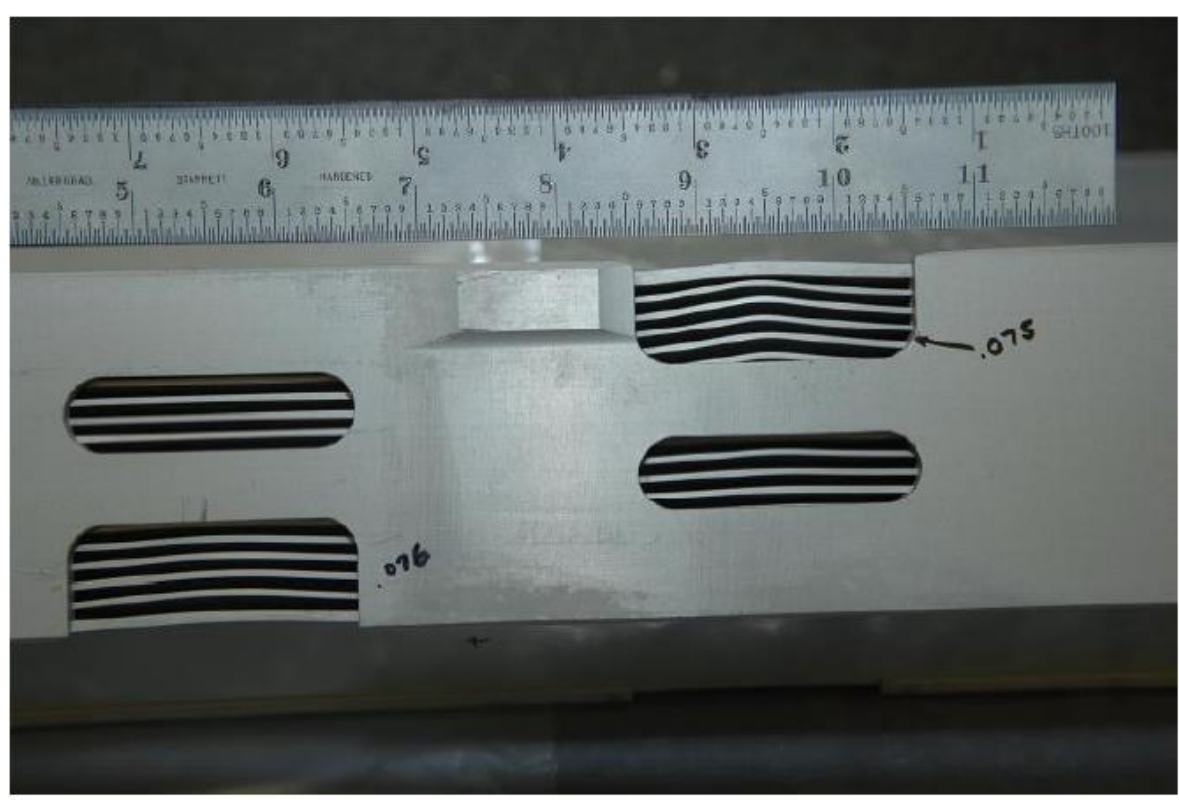

Figure D-9. ATR HEU fuel element Fuel Plates Left Side [ATR FFSC SAR (2017), Figure 2.12.1-61].

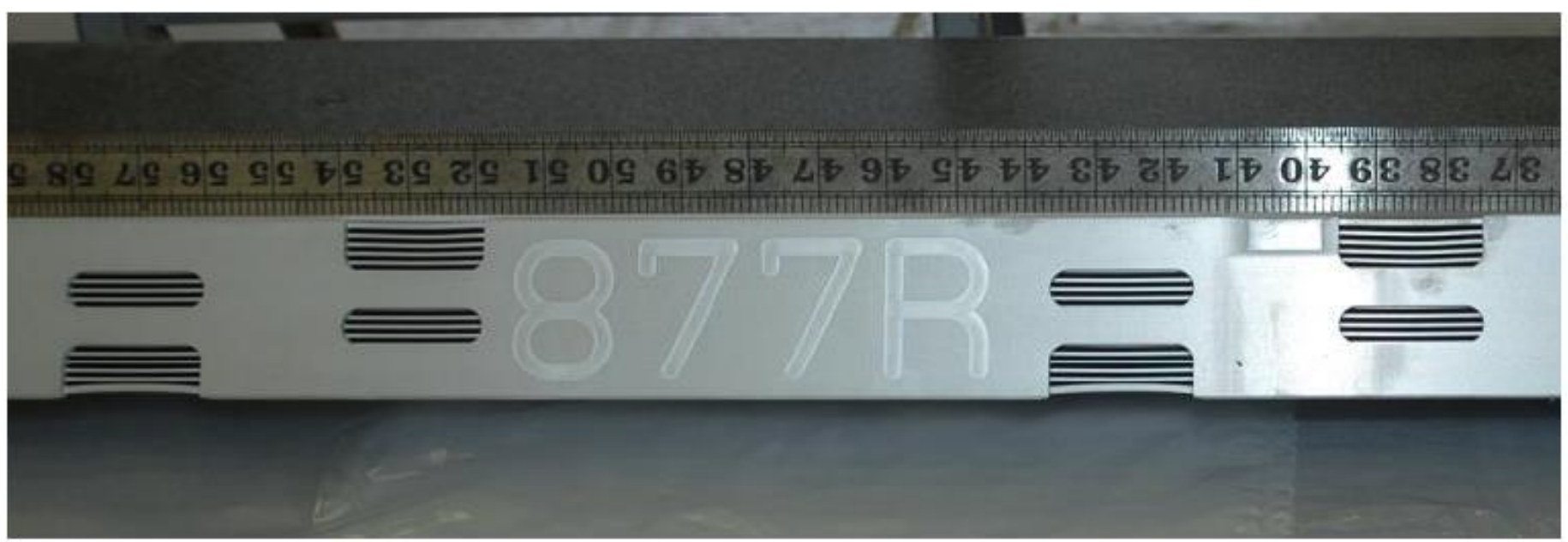

Figure D-10. ATR HEU fuel element Fuel Plates Right Side [ATR FFSC SAR (2017), Figure 2.12.1-62].

\section{D2.1 Results for Scope Part 1 (Table 3), Test 1 (Table 2)}

The drop scenario considered in this section is a $4 \mathrm{ft}$ drop where the loaded ATR FFSC impacts with its center of gravity over the top corner. It is identified as CN1-1 in the ATR FFSC SAR (2017).

\section{D2.1.1 Results for Scope Part 1a (Table 3), Test 1 (Table 2)}

The FEA model results for the Scope Part 1a (Table 3), Test 1 (Table 2) model are shown below in Figure D-11 to Figure D-13. The fuel element weighs $22.1 \mathrm{lbf}$ and the whole model is modeled with minimum material properties. 


\section{[X1.E3]}

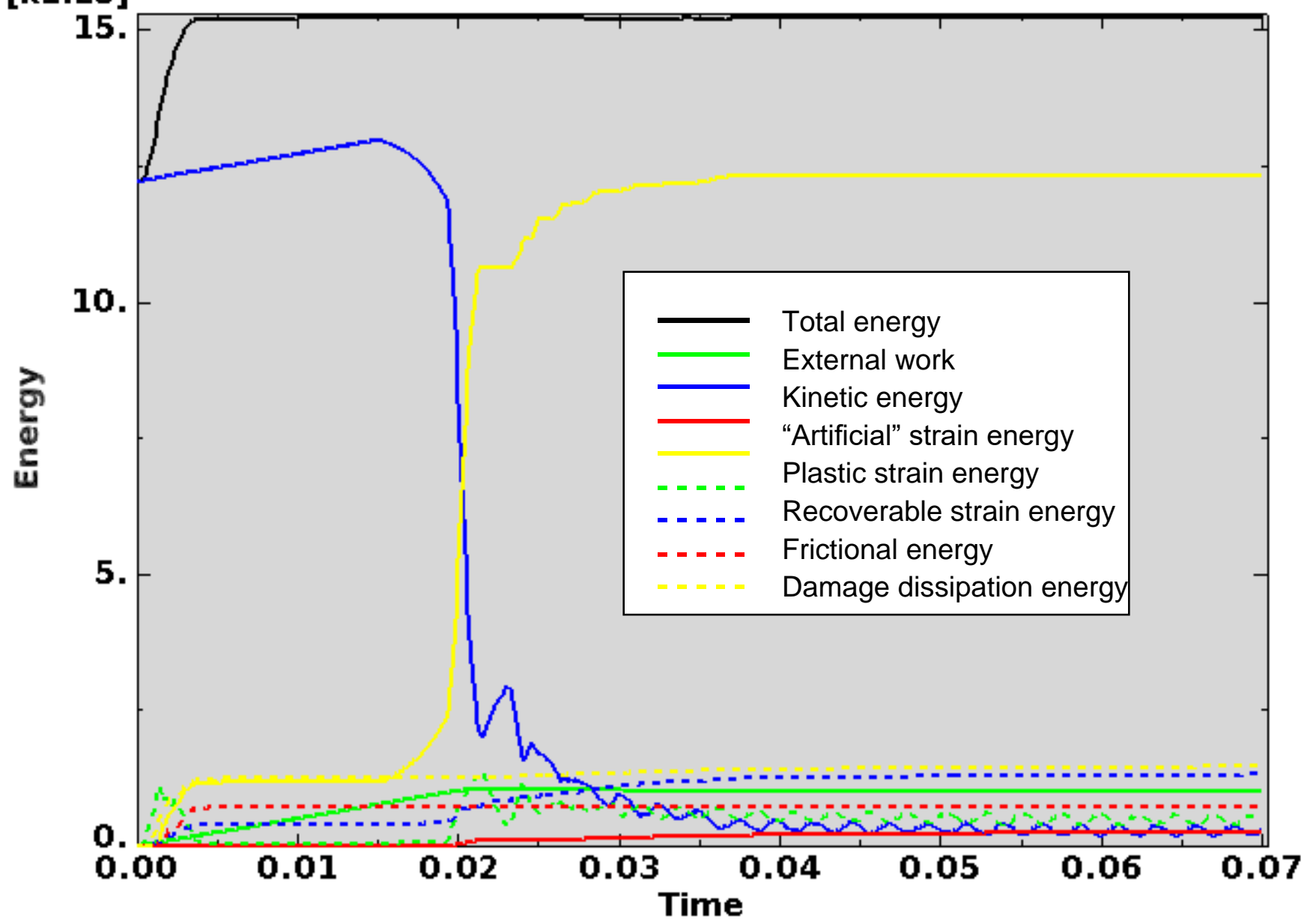

Figure D-11. Scope Part 1a (Table 3), Test 1 (Table 2) energy curves.

Figure D-11 shows the energy curves for Scope Part 1a (Table 3), Test 1 (Table 2) drop scenario. These curves exhibit a stable shape. Artificial strain energy represents the energy required to keep reduced integration elements from taking on a zero-energy hourglass shape. As shown in Figure D-11, the artificial energy at the end of the model run is $1.7 \%$ of the total energy. Therefore, the potential error associated with artificial energy is not considered to be significant. 
ENGINEERING CALCULATIONS AND ANALYSIS

Drop Analysis of the Advanced Test Reactor Fresh Fuel Shipping Container with Heavier Low-Enriched Uranium Fuel Contents

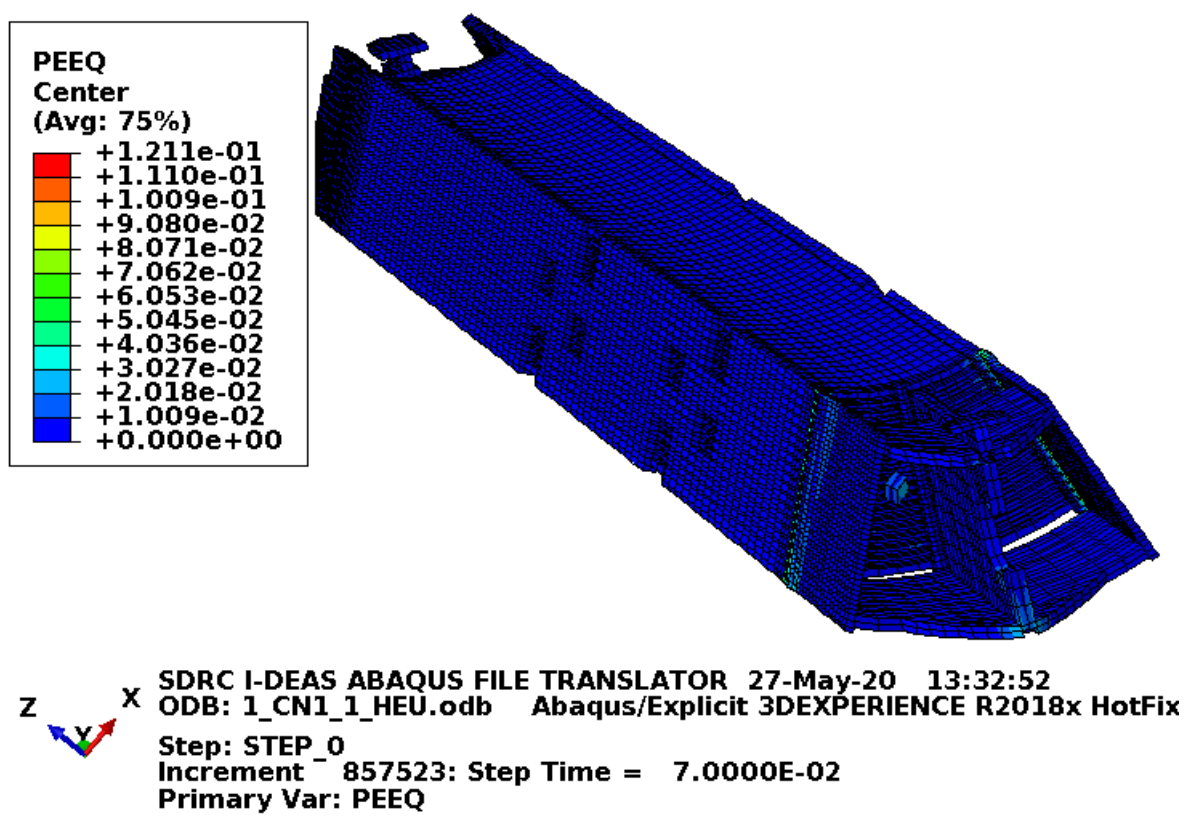

Figure D-12. Scope Part 1 a (Table 3), Test 1 (Table 2) fuel element plastic equivalent strain.

Figure D-12 shows the equivalent plastic strain in the fuel element. Failure in the end box elements occurs at an equivalent plastic strain of $0.027 \mathrm{in}$./in. Failure in the end box weld elements occurs at an equivalent plastic strain of $0.032 \mathrm{in}$./in. Failure in the side plate and comb elements occurs at an equivalent plastic strain of $0.152 \mathrm{in./in.} \mathrm{Failure} \mathrm{in} \mathrm{the} \mathrm{side} \mathrm{plate} \mathrm{weld} \mathrm{elements} \mathrm{occurs} \mathrm{at} \mathrm{an} \mathrm{equivalent} \mathrm{plastic} \mathrm{strain} \mathrm{of}$ $0.205 \mathrm{in}$./in. If element failure were to occur, the element would be removed from the model (thereby excluding its equivalent plastic strain from the maximum equivalent plastic strain for the plot). However, the missing element would be visible in the plot. Figure D-12 shows failure in the end box nearest the impact. Considering the discussion of physical drop results (see Section D2), there was no visible damage in the fuel element after the consecutive Tests 1 and 2 (Table 2) physical drops. Consequently, end box damage shown in Figure D-12 is conservatively high. 
ENGINEERING CALCULATIONS AND ANALYSIS

Drop Analysis of the Advanced Test Reactor Fresh Fuel Shipping Container with Heavier Low-Enriched Uranium Fuel Contents
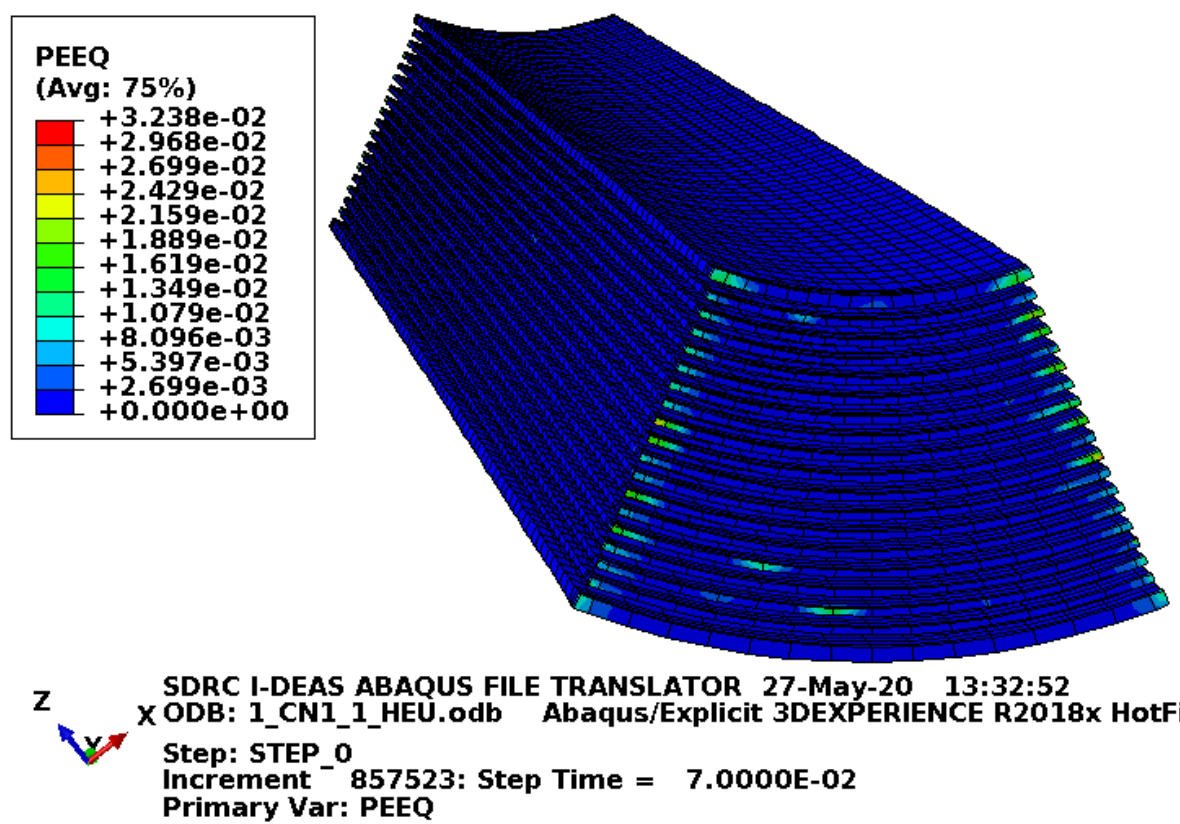

Figure D-13. Scope Part 1a (Table 3), Test 1 (Table 2) fuel plate equivalent strain.

Figure D-13 shows the equivalent plastic strain in the fuel plates. Failure in these elements occurs at an equivalent plastic strain of $0.205 \mathrm{in}$./in. If element failure were to occur, the element would be removed from the model (thereby excluding its equivalent plastic strain not included in the maximum equivalent plastic strain for the plot). However, the missing element would be visible in the plot. Figure D-13 shows no failure in the fuel plates with margin.

\section{D2.1.2 Results for Scope Part 1b (Table 3), Test 1 (Table 2)}

The FEA model results for the Scope Part $1 \mathrm{~b}$ (Table 3), Test 1 (Table 2) model are shown below in Figure D-14 to Figure D-16. The fuel element weighs $22.1 \mathrm{lbf}$ and the drop scenario is modeled with minimum material properties except the enclosure and end boxes, which are modeled with relatively tough material properties. 


\section{[X1.E3]}

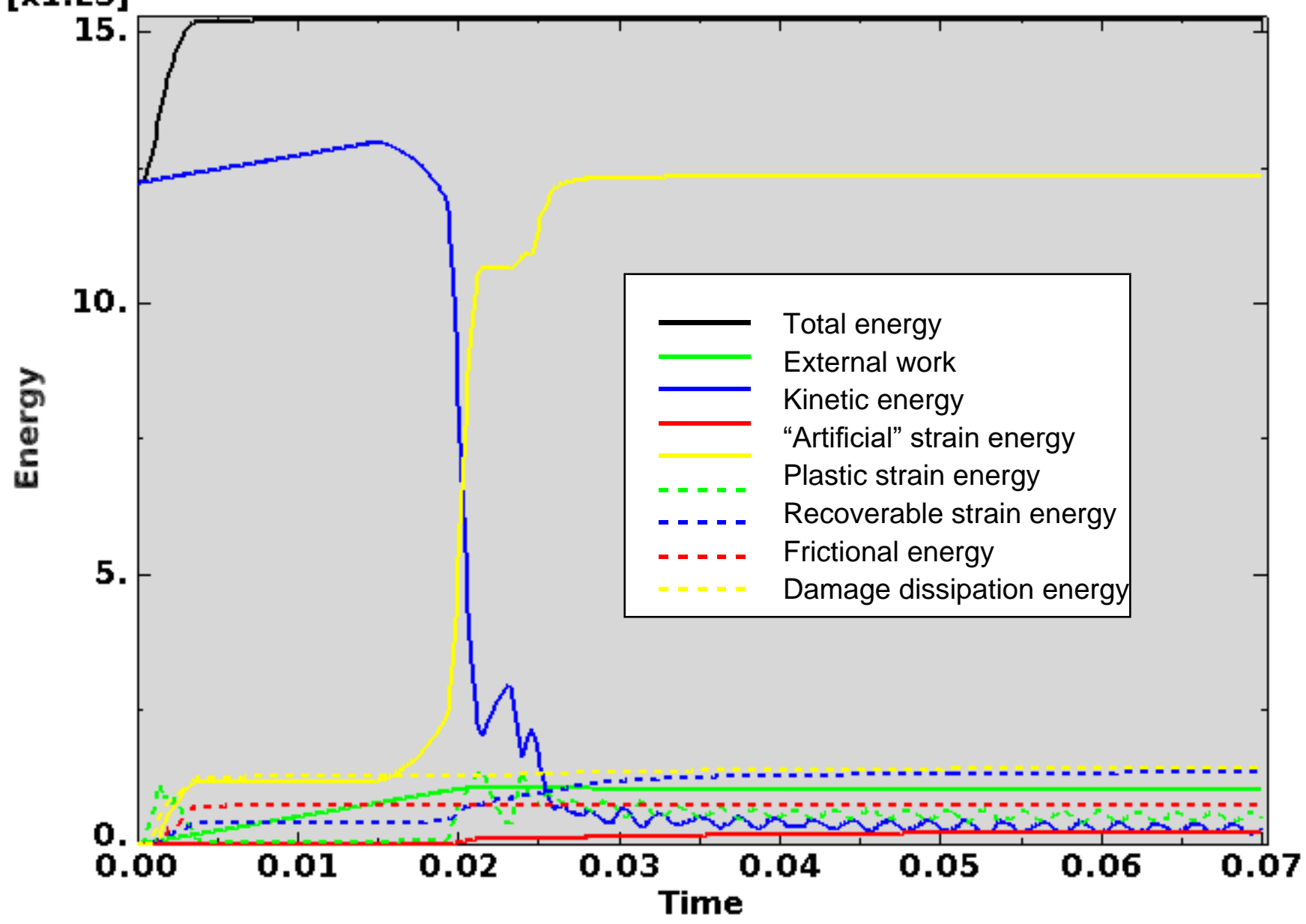

Figure D-14. Scope Part 1b (Table 3), Test 1 (Table 2) energy curves.

Figure D-14 shows the energy curves for Scope Part 1b (Table 3), Test 1 (Table 2) drop scenario. These curves exhibit a stable shape. Artificial strain energy represents the energy required to keep reduced integration elements from taking on a zero-energy hourglass shape. As shown in Figure D-14, the artificial energy at the end of the model run is $1.5 \%$ of the total energy. Therefore, the potential error associated with artificial energy is not considered to be significant. 
ENGINEERING CALCULATIONS AND ANALYSIS

Drop Analysis of the Advanced Test Reactor Fresh Fuel Shipping Container with Heavier Low-Enriched Uranium Fuel Contents

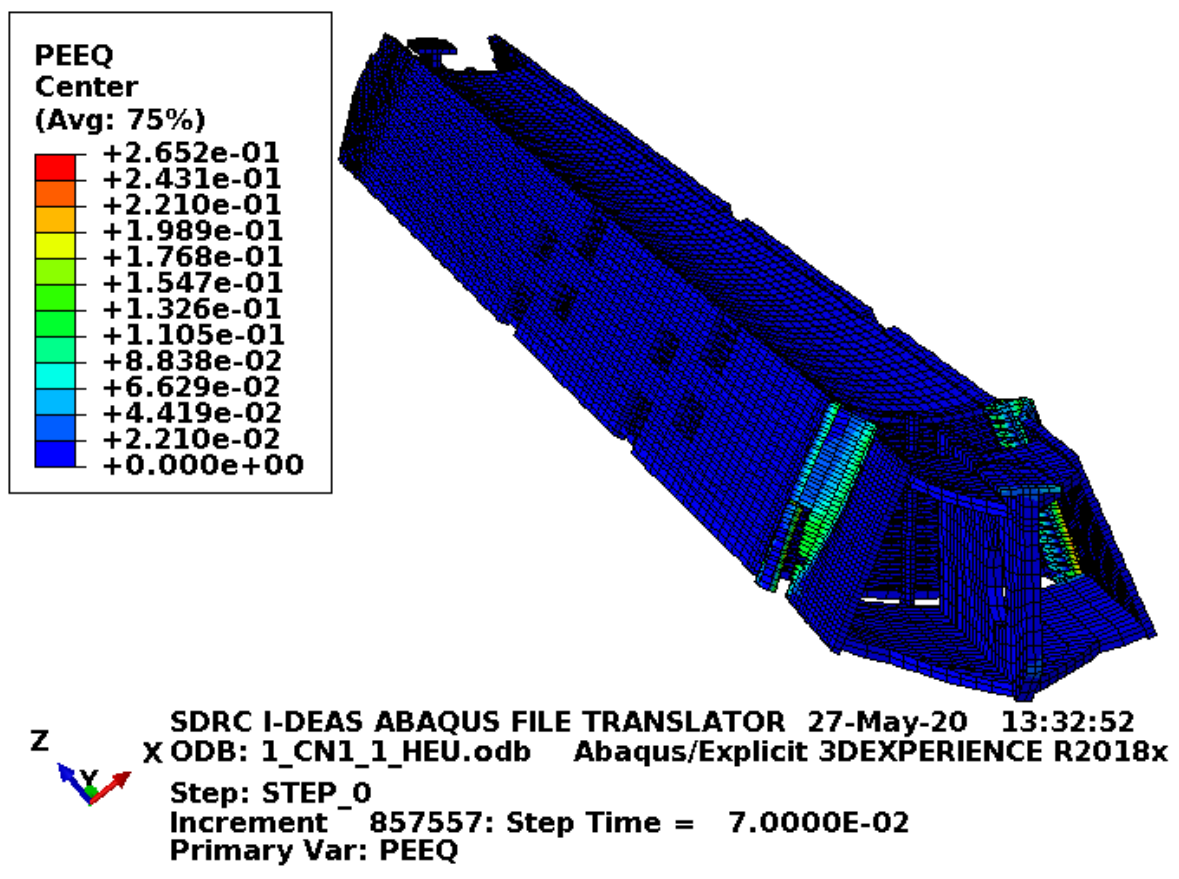

Figure D-15. Scope Part 1b (Table 3), Test 1 (Table 2) fuel element plastic equivalent strain.

Figure D-15 shows the equivalent plastic strain in the fuel element. Failure in the end box elements occurs at an equivalent plastic strain of $0.08 \mathrm{in./in.} \mathrm{(for} \mathrm{the} \mathrm{relatively} \mathrm{tough} \mathrm{material} \mathrm{properties).} \mathrm{Failure} \mathrm{in} \mathrm{the} \mathrm{end}$ box weld elements occurs at an equivalent plastic strain of $0.115 \mathrm{in}$./in. (for the relatively tough material properties). Failure in the side plate and comb elements occurs at an equivalent plastic strain of $0.152 \mathrm{in}$./in. Failure in the side plate weld elements occurs at an equivalent plastic strain of $0.205 \mathrm{in}$./in. If element failure were to occur, the element would be removed from the model (thereby excluding its equivalent plastic strain from the maximum equivalent plastic strain for the plot). However, the missing element would be visible in the plot. Figure D-15 shows failure in the welds attaching the end box nearest the impact. Considering the discussion of physical drop results (see Section D2), there was no visible damage in the fuel element after consecutive Tests 1 and 2 (Table 2) physical drops. Consequently, end box damage shown in Figure D-15 is conservatively high. 
ENGINEERING CALCULATIONS AND ANALYSIS

Drop Analysis of the Advanced Test Reactor Fresh Fuel Shipping Container with Heavier Low-Enriched Uranium Fuel Contents

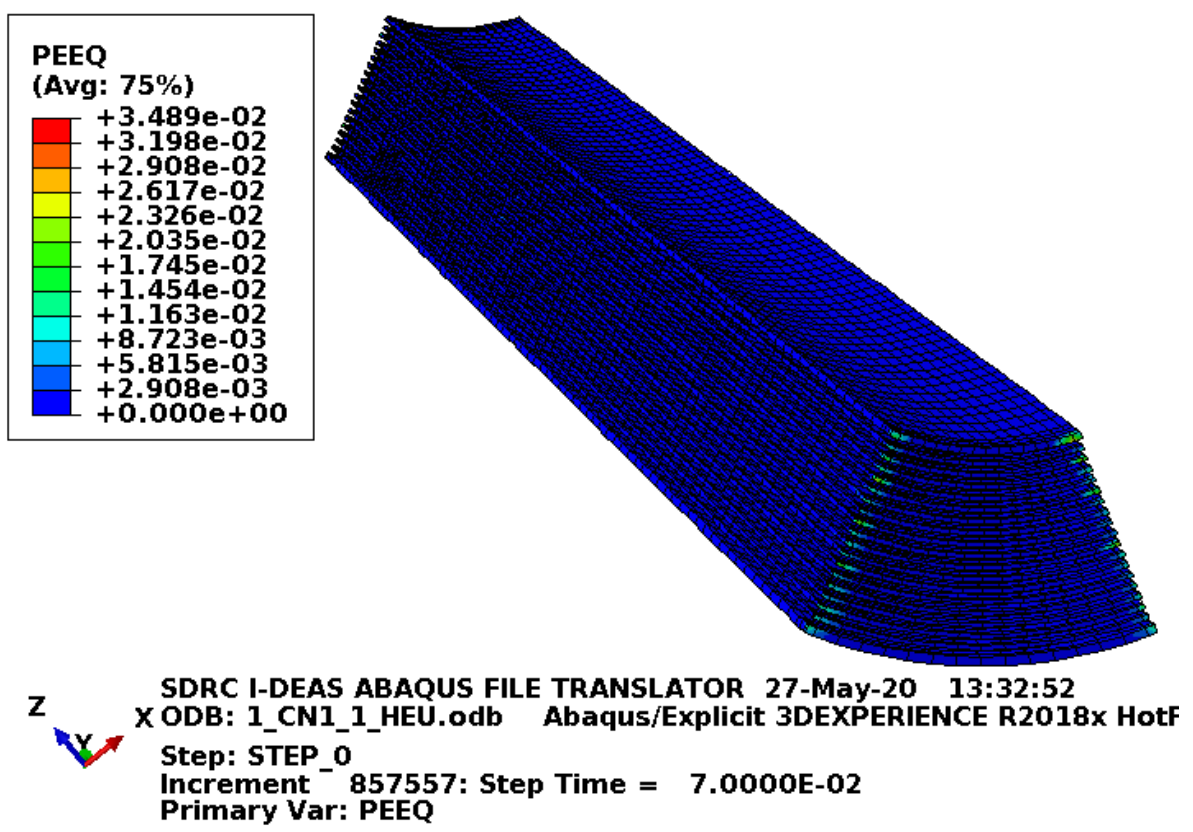

Figure D-16. Scope Part 1b (Table 3), Test 1 (Table 2) fuel plate equivalent strain.

Figure D-16 shows the equivalent plastic strain in the fuel plates. Failure in these elements occurs at an equivalent plastic strain of 0.205 in./in. If element failure were to occur, the element would be removed from the model (thereby excluding its equivalent plastic strain from the maximum equivalent plastic strain for the plot). However, the missing element would be visible in the plot. Figure D-16 shows no failure in the fuel plates with margin.

\section{D2.1.3 Results for Scope Part 1c (Table 3), Test 1 (Table 2)}

The FEA model results for the Scope Part 1c (Table 3), Test 1 (Table 2) model are shown below in Figure D-17 to Figure D-19. The fuel element weighs $22.1 \mathrm{lbf}$ and the whole model is modeled with minimum material properties. Though ATR FFSC SAR (2017) shows the Scope Part 1 (Table 3) drop scenarios to be acceptable, the results shown (for information) in this section include the blocks as added fuel plate protection. 


\section{[x1.E3]}

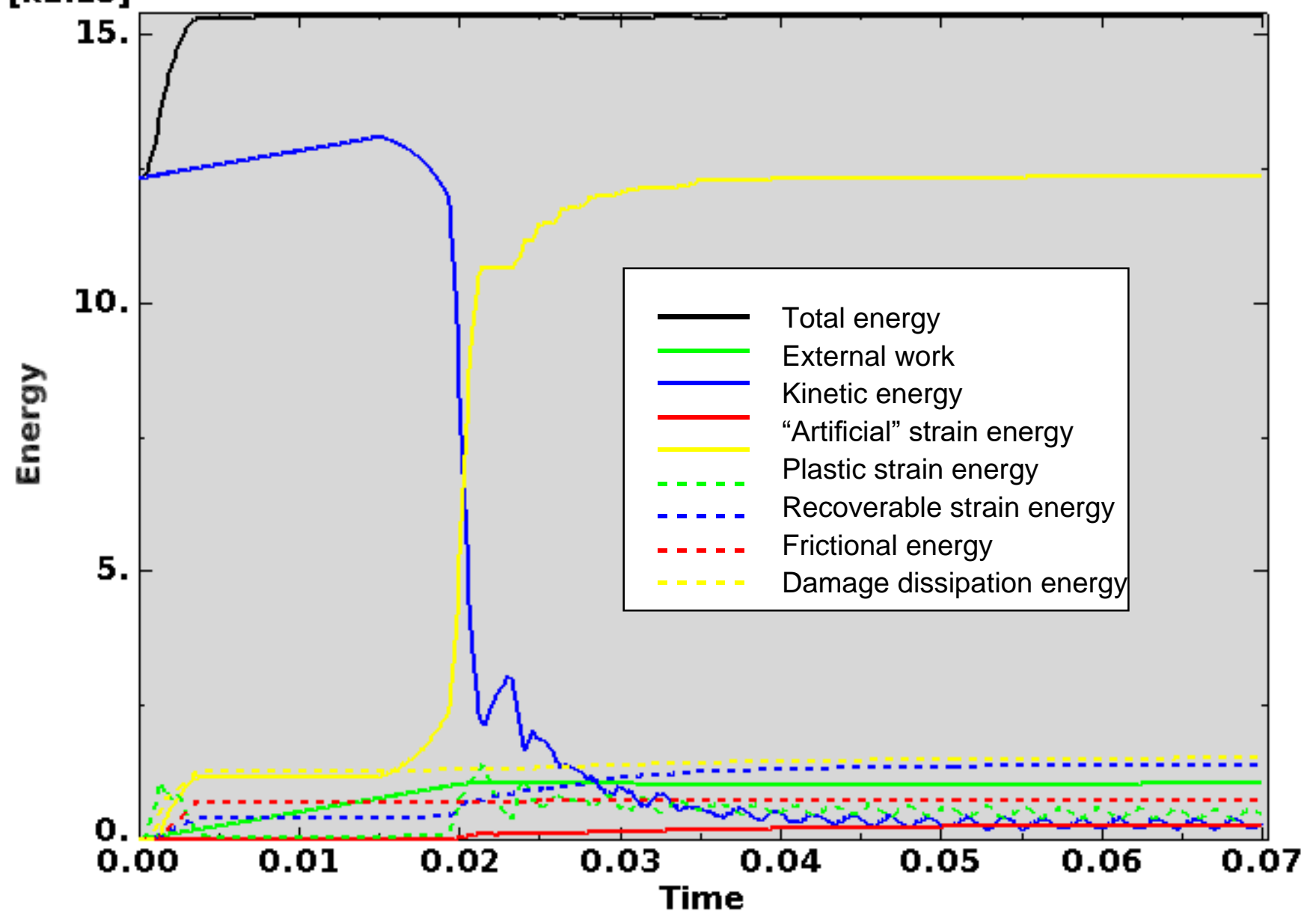

Figure D-17. Scope Part 1c (Table 3), Test 1 (Table 2) energy curves.

Figure D-17 shows the energy curves for Scope Part 1c (Table 3), Test 1 (Table 2) drop scenario. These curves exhibit a stable shape. Artificial strain energy represents the energy required to keep reduced integration elements from taking on a zero-energy hourglass shape. As shown in Figure D-17, the artificial energy at the end of the model run is $1.8 \%$ of the total energy. Therefore, the potential error associated with artificial energy is not considered to be significant. 
ENGINEERING CALCULATIONS AND ANALYSIS

Drop Analysis of the Advanced Test Reactor Fresh Fuel Shipping Container with Heavier Low-Enriched Uranium Fuel Contents

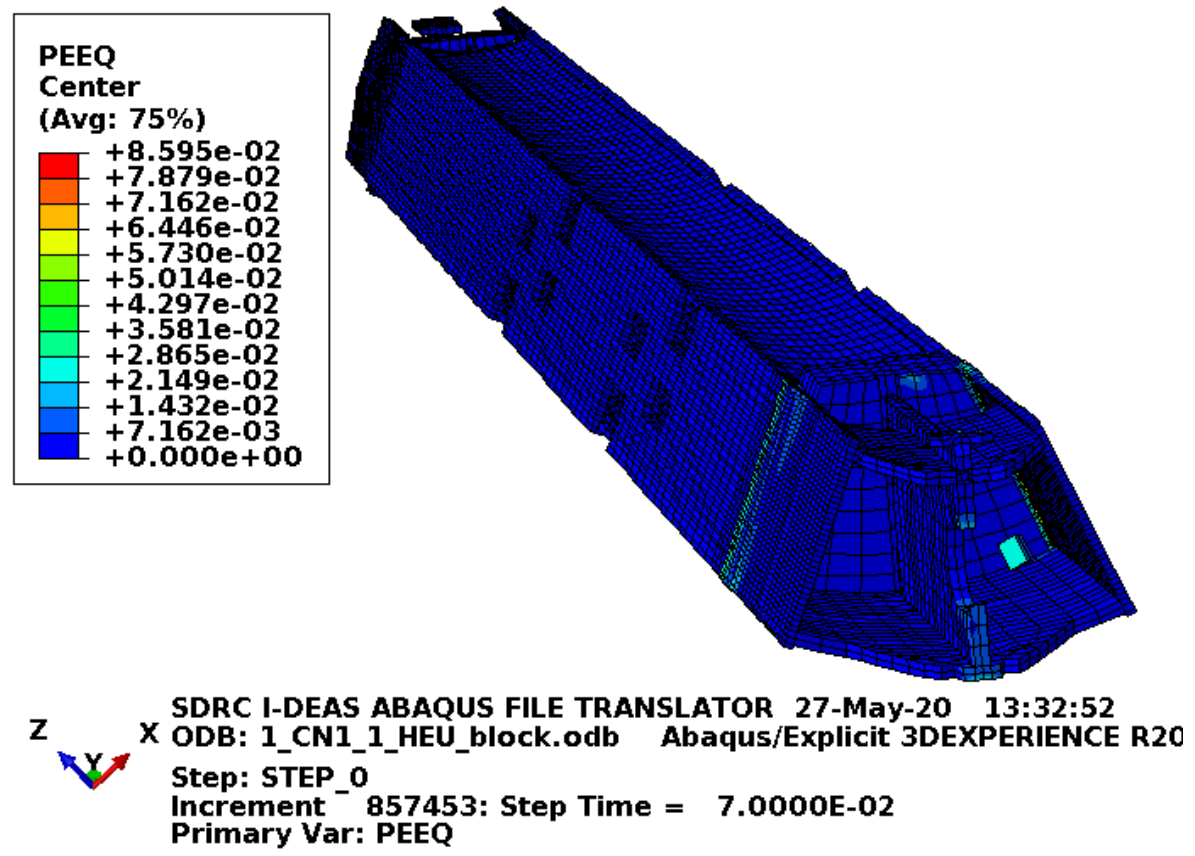

Figure D-18. Scope Part 1c (Table 3), Test 1 (Table 2) fuel element plastic equivalent strain.

Figure D-18 shows the equivalent plastic strain in the fuel element. Failure in the end box elements occurs at an equivalent plastic strain of $0.027 \mathrm{in}$./in. Failure in the end box weld elements occurs at an equivalent plastic strain of $0.032 \mathrm{in}$./in. Failure in the side plate and comb elements occurs at an equivalent plastic strain of $0.152 \mathrm{in./in.} \mathrm{Failure} \mathrm{in} \mathrm{the} \mathrm{side} \mathrm{plate} \mathrm{weld} \mathrm{elements} \mathrm{occurs} \mathrm{at} \mathrm{an} \mathrm{equivalent} \mathrm{plastic} \mathrm{strain} \mathrm{of}$ $0.205 \mathrm{in}$./in. If element failure were to occur, the element would be removed from the model (thereby excluding its equivalent plastic strain from the maximum equivalent plastic strain for the plot). However, the missing element would be visible in the plot. Figure D-18 shows failure in the end box nearest the impact.
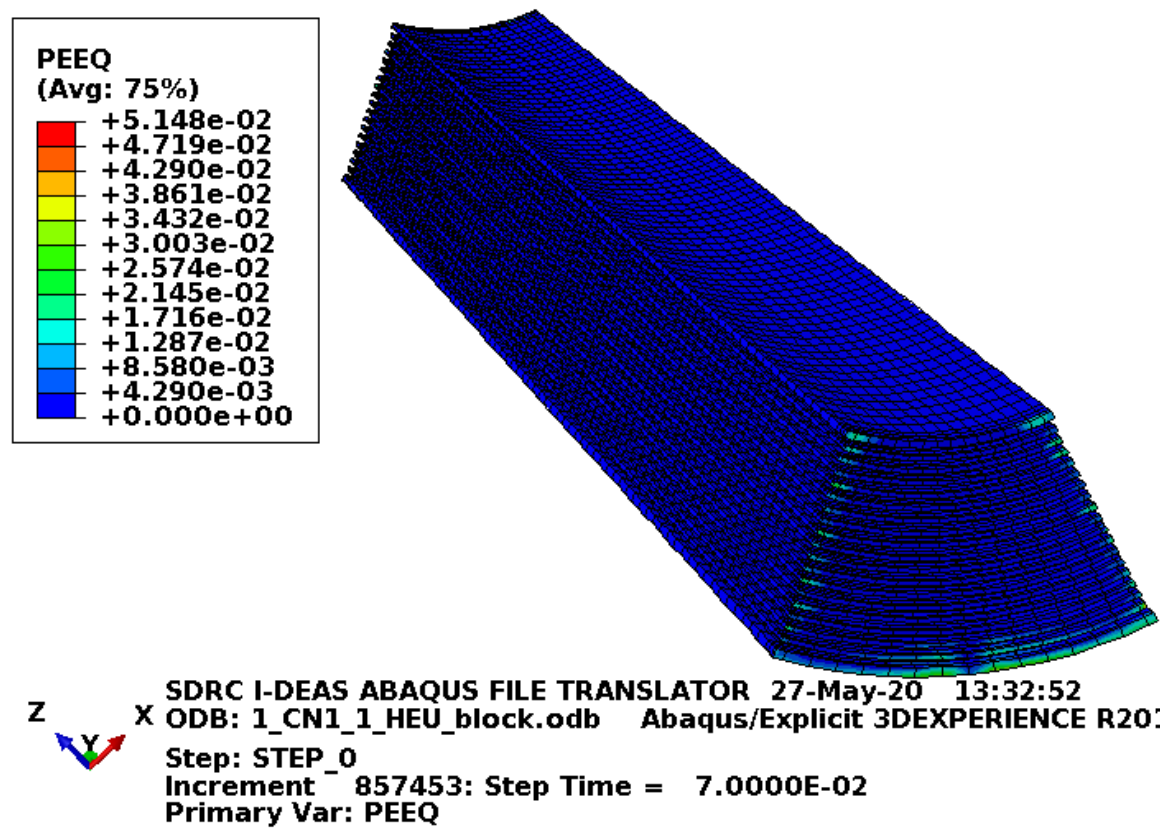

Figure D-19. Scope Part 1c (Table 3), Test 1 (Table 2) fuel plate equivalent strain. 
Figure D-19 shows the equivalent plastic strain in the fuel plates. Failure in these elements occurs at an equivalent plastic strain of $0.205 \mathrm{in}$./in. If element failure were to occur, the element would be removed from the model (thereby excluding its equivalent plastic strain from the maximum equivalent plastic strain for the plot). However, the missing element would be visible in the plot. Figure D-19 shows no failure in the fuel plates with margin.

\section{D2.1.4 Results for Scope Part 1d (Table 3), Test 1 (Table 2)}

The FEA model results for the Scope Part 1d (Table 3), Test 1 (Table 2) model are shown below in Figure D-20 to Figure D-22. The fuel element weighs $22.1 \mathrm{lbf}$ and the drop scenario is modeled with minimum material properties except the enclosure and end boxes, which are modeled with relatively tough material properties. Though ATR FFSC SAR (2017) shows the Scope Part 1 (Table 3) drop scenarios to be acceptable, the results shown (for information) in this section include the blocks as added fuel plate protection.

[x1.E3]

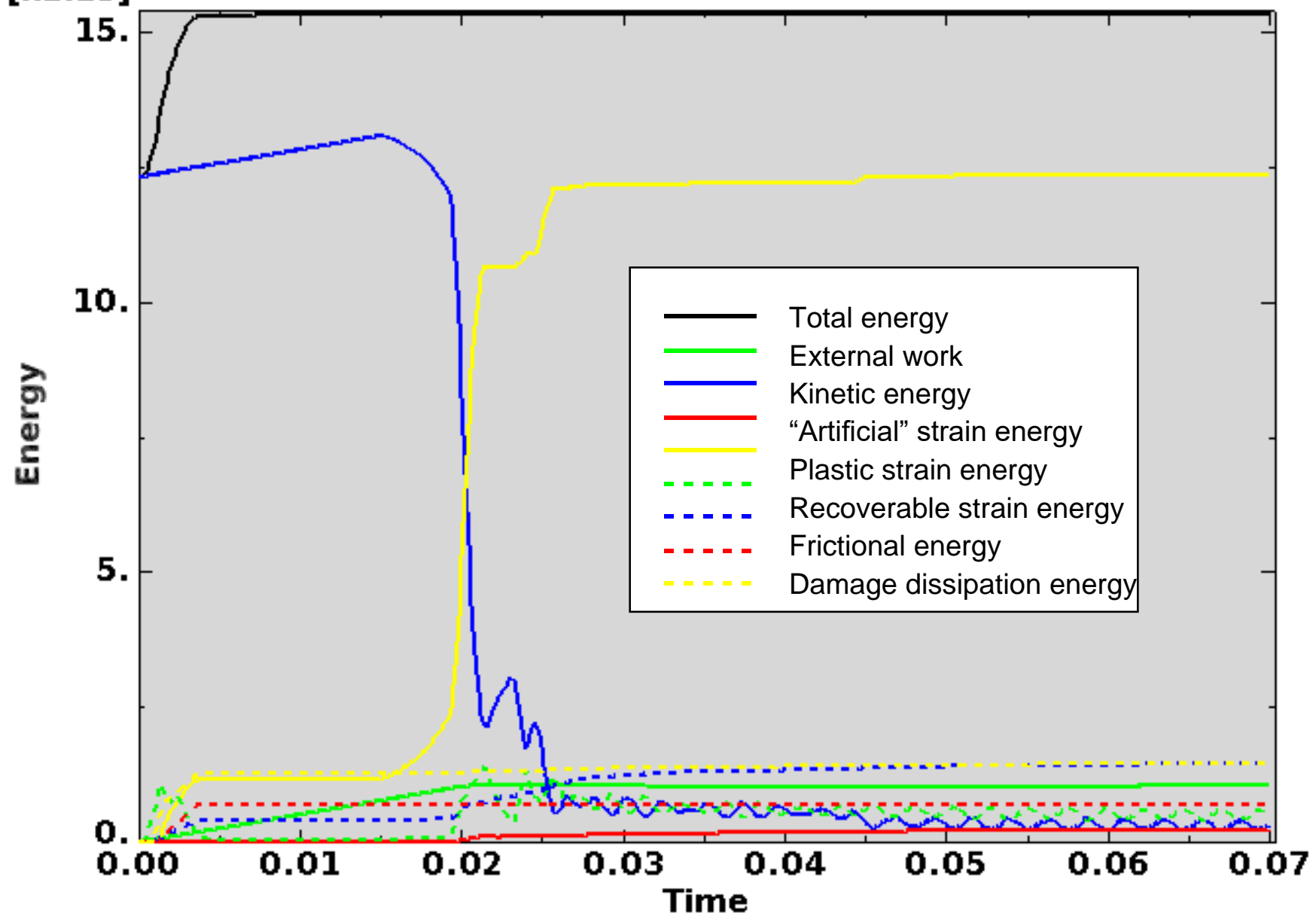

Figure D-20. Scope Part 1d (Table 3), Test 1 (Table 2) energy curves. 
Figure D-20 shows the energy curves for Scope Part 1d (Table 3), Test 1 (Table 2) drop scenario. These curves exhibit a stable shape. Artificial strain energy represents the energy required to keep reduced integration elements from taking on a zero-energy hourglass shape. As shown in Figure D-20, the artificial energy at the end of the model run is $1.6 \%$ of the total energy. Therefore, the potential error associated with artificial energy is not considered to be significant.
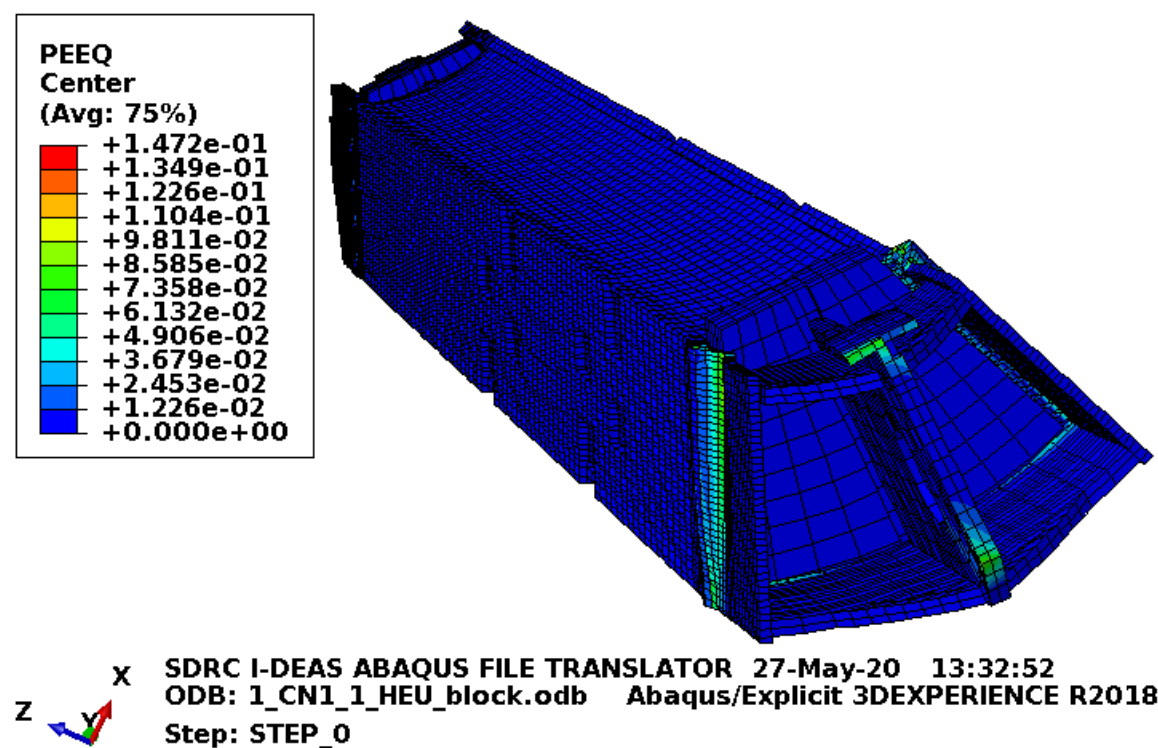

SDRC I-DEAS ABAQUS FILE TRANSLATOR 27-May-20 13:32:52

ODB: 1_CN1_1_HEU_block.odb Abaqus/Explicit 3DEXPERIENCE R2018x

Step: STEP_o

Increment ${ }^{-}$858935: Step Time $=7.0000 \mathrm{E}-02$

Primary Var: PEEQ

Figure D-21. Scope Part 1d (Table 3), Test 1 (Table 2) fuel element plastic equivalent strain.

Figure D-21 shows the equivalent plastic strain in the fuel element. Failure in the end box elements occurs at an equivalent plastic strain of $0.08 \mathrm{in./in.} \mathrm{(for} \mathrm{the} \mathrm{relatively} \mathrm{tough} \mathrm{material} \mathrm{properties).} \mathrm{Failure} \mathrm{in} \mathrm{the} \mathrm{end}$ box weld elements occurs at an equivalent plastic strain of $0.115 \mathrm{in}$./in. (for the relatively tough material properties). Failure in the side plate and comb elements occurs at an equivalent plastic strain of $0.152 \mathrm{in}$./in. Failure in the side plate weld elements occurs at an equivalent plastic strain of $0.205 \mathrm{in}$./in. If element failure were to occur, the element would be removed from the model (thereby excluding its equivalent plastic strain from the maximum equivalent plastic strain for the plot). However, the missing element would be visible in the plot. Figure D-21 shows no failure in the fuel element or blocks, but there is visible plasticity. 
ENGINEERING CALCULATIONS AND ANALYSIS

Drop Analysis of the Advanced Test Reactor Fresh Fuel Shipping Container with Heavier Low-Enriched Uranium Fuel Contents

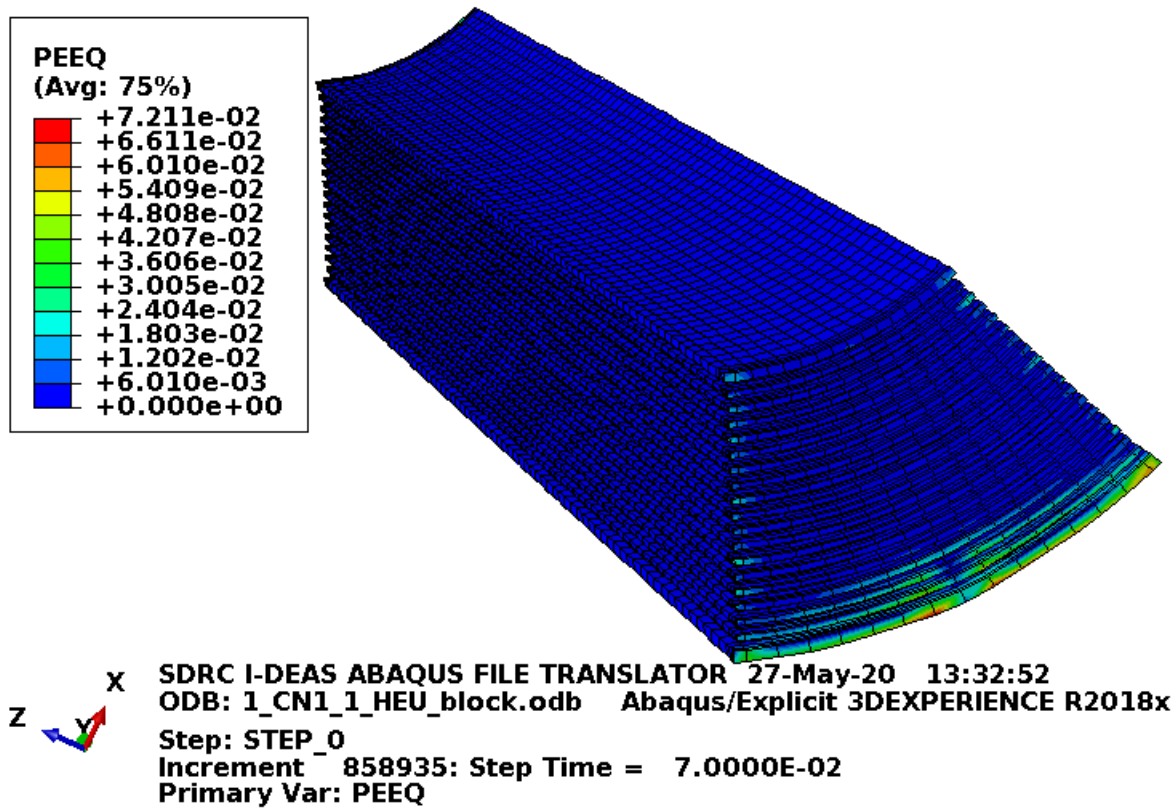

Figure D-22. Scope Part 1d (Table 3), Test 1 (Table 2) fuel plate equivalent strain.

Figure D-22 shows the equivalent plastic strain in the fuel plates. Failure in these elements occurs at an equivalent plastic strain of $0.205 \mathrm{in}$./in. If element failure were to occur, the element would be removed from the model (thereby excluding its equivalent plastic strain from the maximum equivalent plastic strain for the plot). However, the missing element would be visible in the plot. Figure D-22 shows no failure in the fuel plates with margin.

\section{D2.2 Results for Scope Part 1 (Table 3), Test 2 (Table 2)}

The drop scenario considered in this section is a $30 \mathrm{ft}$ drop where the loaded ATR FFSC impacts flat on its side with the pocket side down. It is identified as CD1-1 in the ATR FFSC SAR (2017).

\section{D2.2.1 Results for Scope Part 1a (Table 3), Test 2 (Table 2)}

The FEA model results for the Scope Part 1a (Table 3), Test 2 (Table 2) model are shown below in Figure D-23 to Figure D-25. The fuel element weighs $22.1 \mathrm{lbf}$ and the whole model is modeled with minimum material properties. 


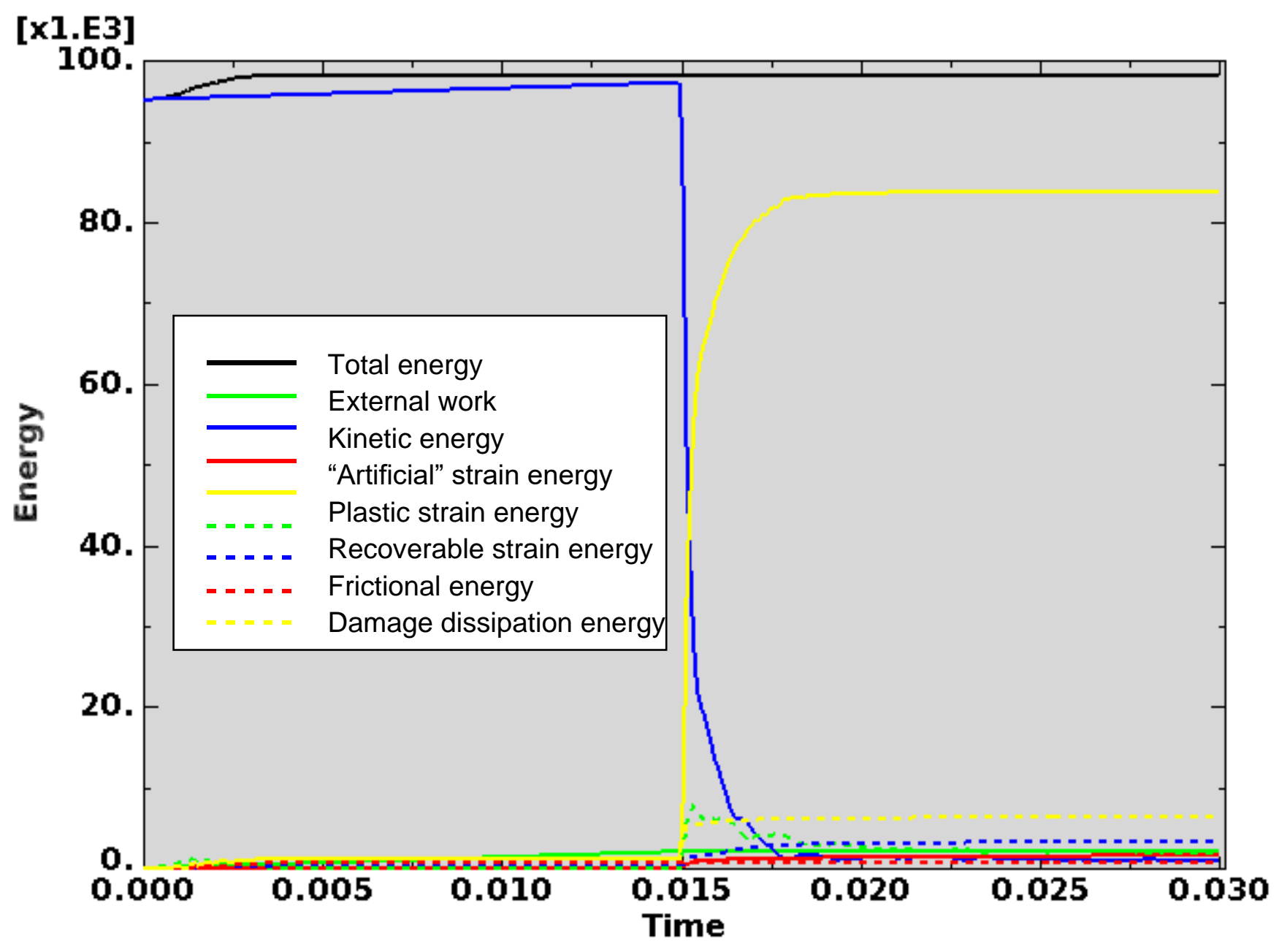

Figure D-23. Scope Part 1a (Table 3), Test 2 (Table 2) energy curves.

Figure D-23 shows the energy curves for Scope Part 1a (Table 3), Test 2 (Table 2) drop scenario. These curves exhibit a stable shape. Artificial strain energy represents the energy required to keep reduced integration elements from taking on a zero-energy hourglass shape. As shown in Figure D-23, the artificial energy at the end of the model run is $1.7 \%$ of the total energy. Therefore, the potential error associated with artificial energy is not considered to be significant. 
ENGINEERING CALCULATIONS AND ANALYSIS

Drop Analysis of the Advanced Test Reactor Fresh Fuel Shipping Container with Heavier Low-Enriched Uranium Fuel Contents

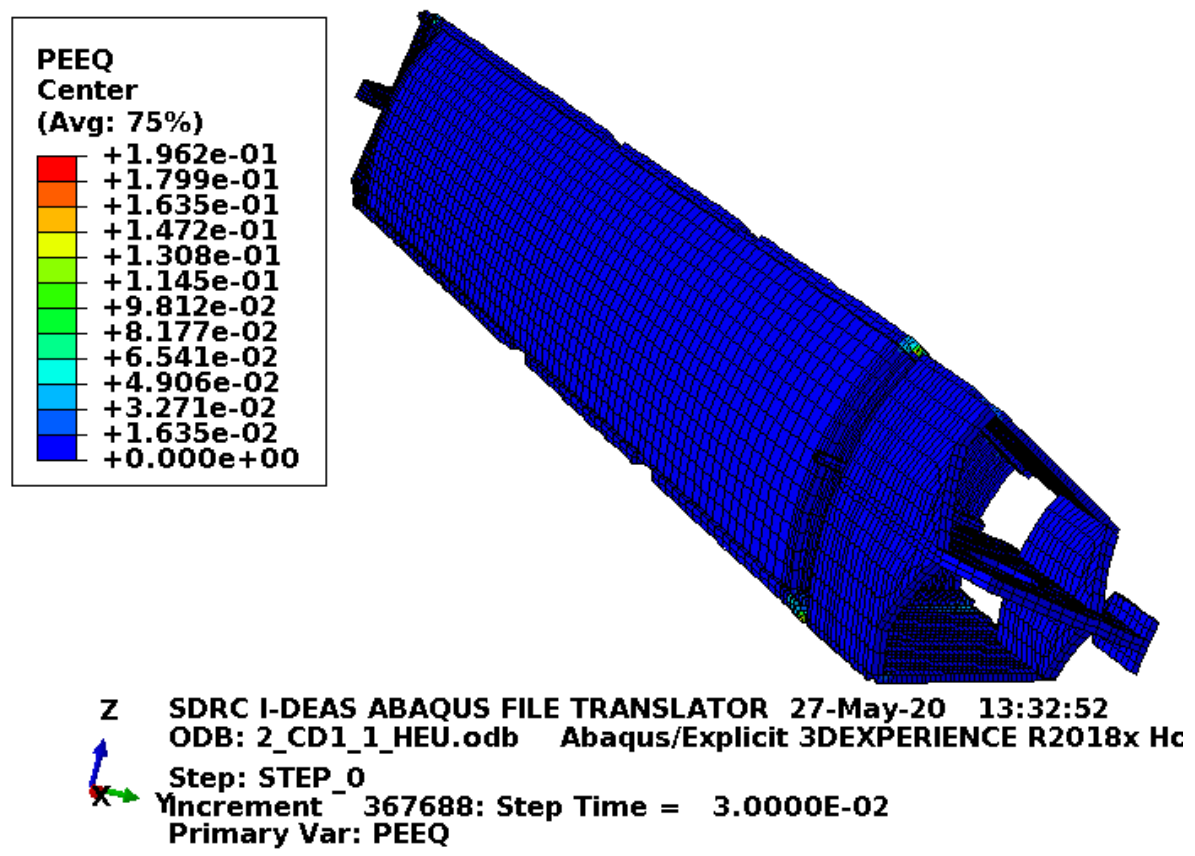

Figure D-24. Scope Part 1a (Table 3), Test 2 (Table 2) fuel element plastic equivalent strain.

Figure D-24 shows the equivalent plastic strain in the fuel element. Failure in the end box elements occurs at an equivalent plastic strain of $0.027 \mathrm{in}$./in. Failure in the end box weld elements occurs at an equivalent plastic strain of $0.032 \mathrm{in}$./in. Failure in the side plate and comb elements occurs at an equivalent plastic strain of $0.152 \mathrm{in} . / \mathrm{in}$. Failure in the side plate weld elements occurs at an equivalent plastic strain of $0.205 \mathrm{in}$./in. If element failure were to occur, the element would be removed from the model (thereby excluding its equivalent plastic strain from the maximum equivalent plastic strain for the plot). However, the missing element would be visible in the plot. Figure D-24 shows a few failed elements in the end boxes and end box welds nearest the impact. Considering the discussion of physical drop results (see Section D2), there was no visible damage in the fuel element after the consecutive Tests 1 and 2 (Table 2) physical drops. Consequently, end box damage shown in Figure D-24 is conservatively high. 
ENGINEERING CALCULATIONS AND ANALYSIS

Drop Analysis of the Advanced Test Reactor Fresh Fuel Shipping Container with Heavier Low-Enriched Uranium Fuel Contents

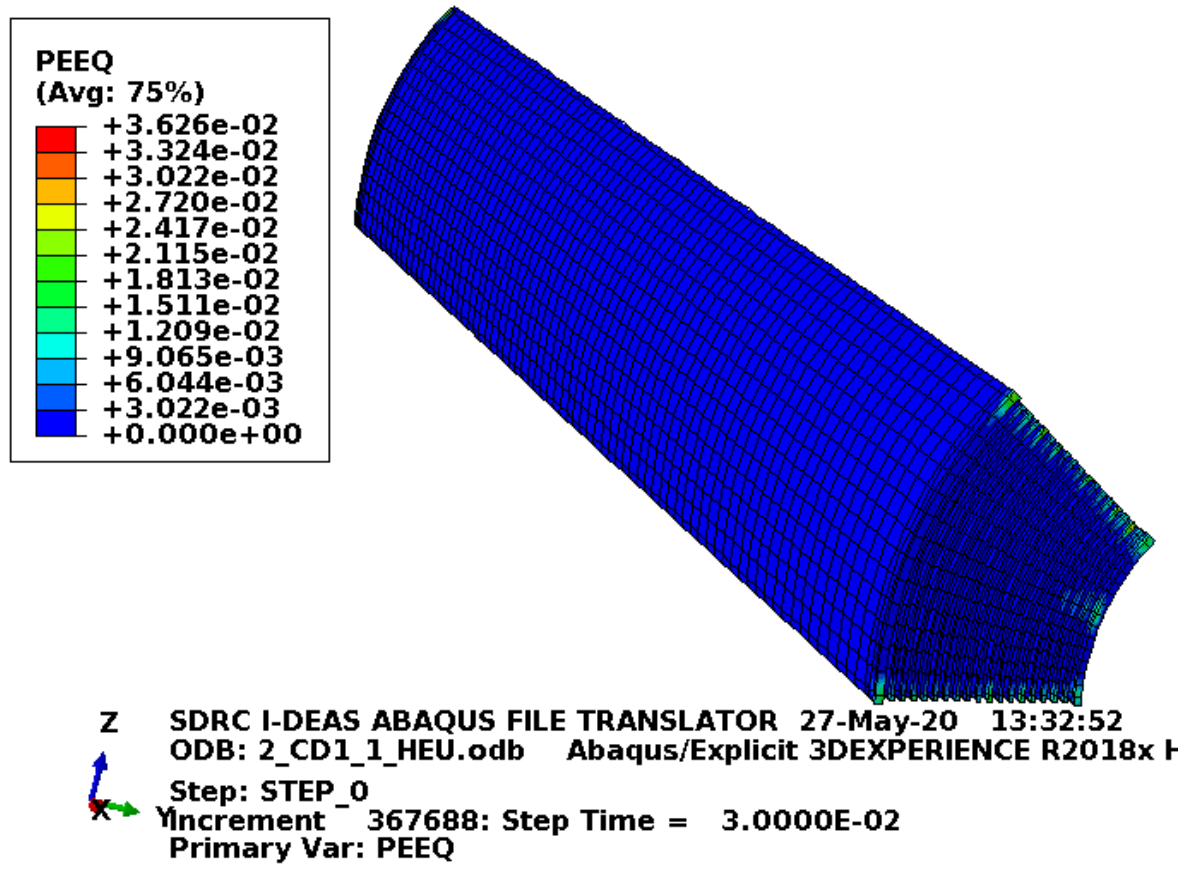

Figure D-25. Scope Part 1 a (Table 3), Test 2 (Table 2) fuel plate equivalent strain.

Figure D-25 shows the equivalent plastic strain in the fuel plates. Failure in these elements occurs at an equivalent plastic strain of 0.205 in./in. If element failure were to occur, the element would be removed from the model (thereby excluding its equivalent plastic strain from the maximum equivalent plastic strain for the plot). However, the missing element would be visible in the plot. Figure D-25 shows no failure in the fuel plates with margin.

\section{D2.2.2 Results for Scope Part 1b (Table 3), Test 2 (Table 2)}

The FEA model results for the Scope Part 1b (Table 3), Test 2 (Table 2) model are shown below in Figure D-26 to Figure D-28. The fuel element weighs $22.1 \mathrm{lbf}$ and the drop scenario is modeled with minimum material properties except the enclosure and end boxes, which are modeled with relatively tough material properties. 


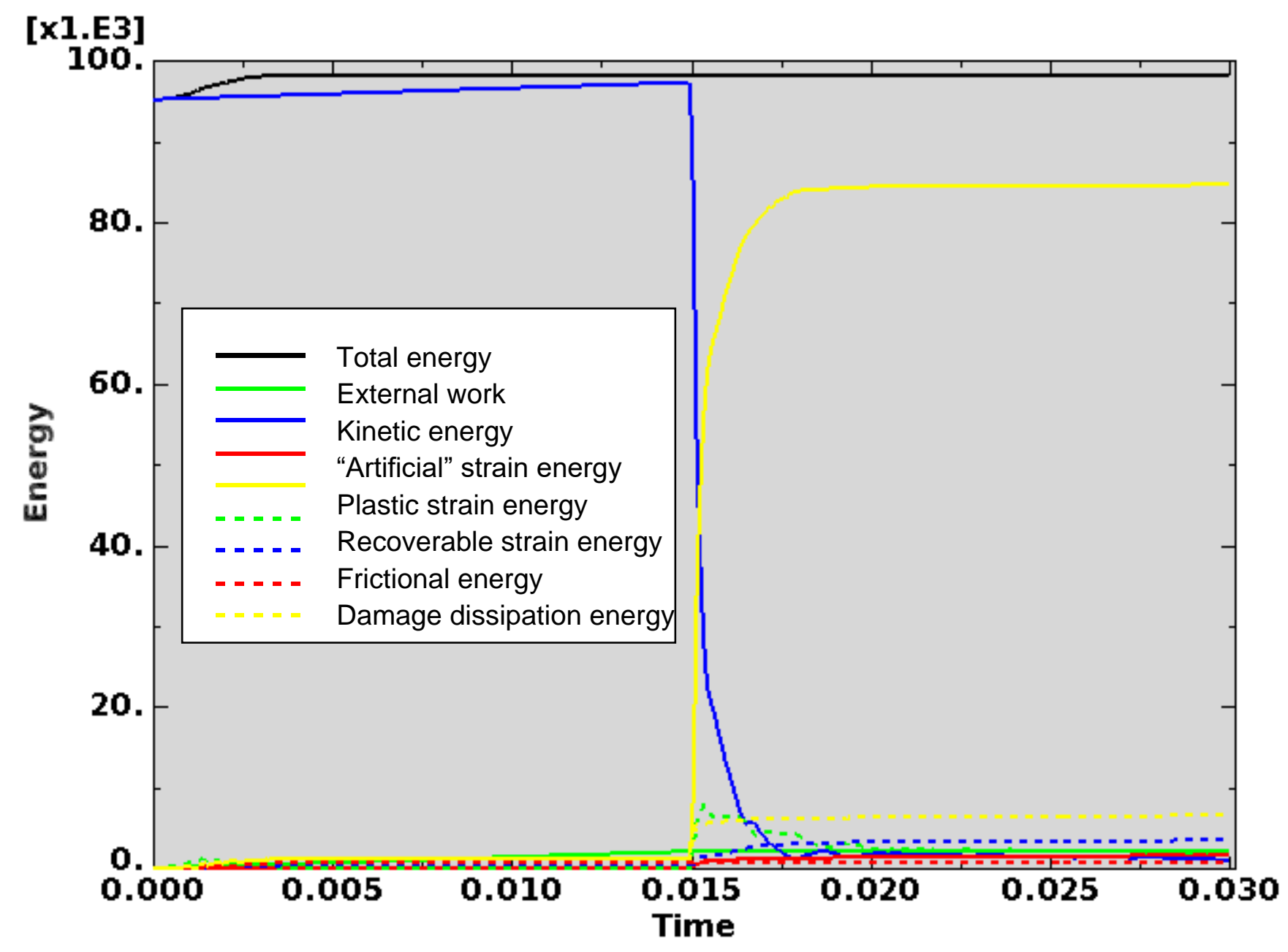

Figure D-26. Scope Part 1b (Table 3), Test 2 (Table 2) energy curves.

Figure D-26 shows the energy curves for Scope Part 1b (Table 3), Test 2 (Table 2) drop scenario. These curves exhibit a stable shape. Artificial strain energy represents the energy required to keep reduced integration elements from taking on a zero-energy hourglass shape. As shown in Figure D-26, the artificial energy at the end of the model run is $1.7 \%$ of the total energy. Therefore, the potential error associated with artificial energy is not considered to be significant. 
ENGINEERING CALCULATIONS AND ANALYSIS

Drop Analysis of the Advanced Test Reactor Fresh Fuel Shipping Container with Heavier Low-Enriched Uranium Fuel Contents

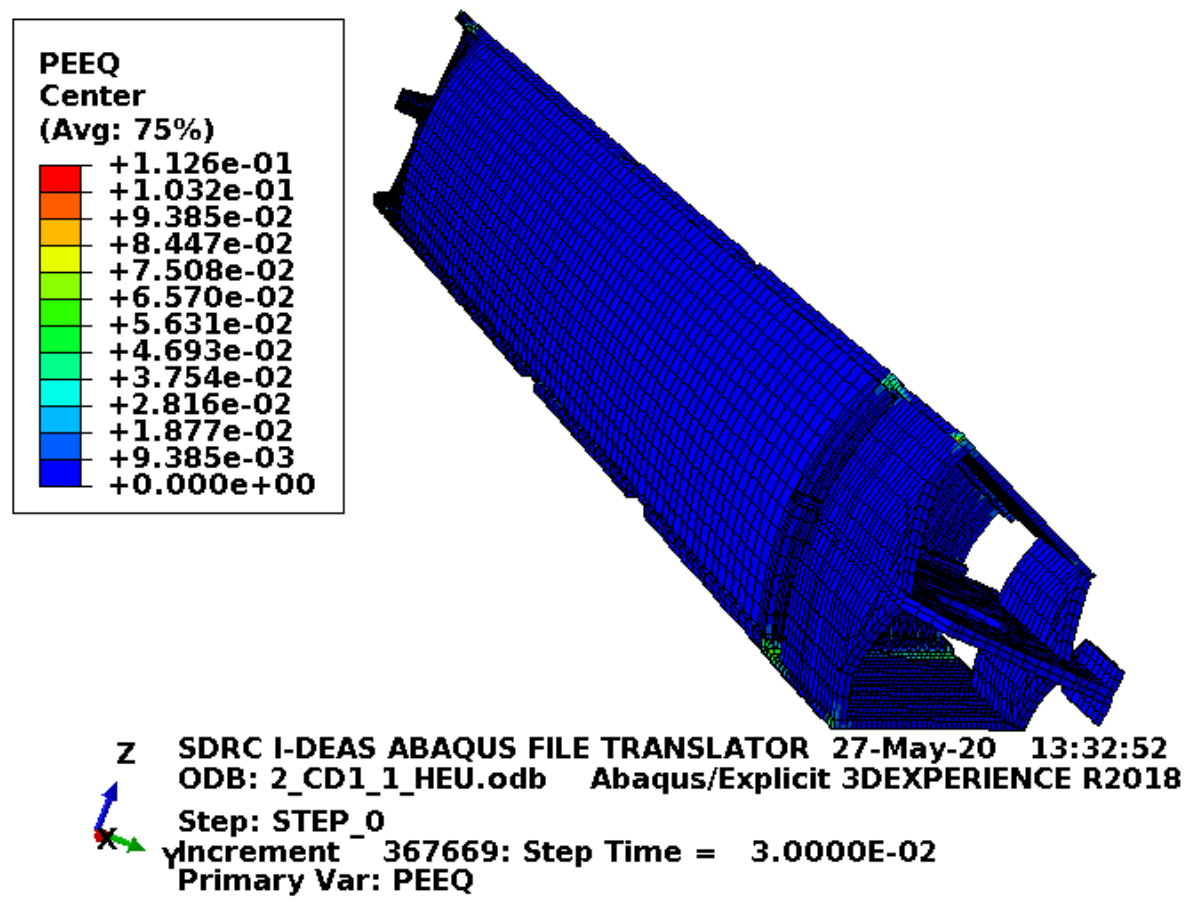

Figure D-27. Scope Part 1b (Table 3), Test 2 (Table 2) fuel element plastic equivalent strain.

Figure D-27 shows the equivalent plastic strain in the fuel element. Failure in the end box elements occurs at an equivalent plastic strain of $0.08 \mathrm{in}$./in. (for the relatively tough material properties). Failure in the end box weld elements occurs at an equivalent plastic strain of $0.115 \mathrm{in}$./in. (for the relatively tough material properties). Failure in the side plate and comb elements occurs at an equivalent plastic strain of $0.152 \mathrm{in}$./in. Failure in the side plate weld elements occurs at an equivalent plastic strain of $0.205 \mathrm{in}$./in. If element failure were to occur, the element would be removed from the model (thereby excluding its equivalent plastic strain from the maximum equivalent plastic strain for the plot). However, the missing element would be visible in the plot. Figure D-27 shows no failure in the fuel element. There is significant plasticity, but it might not be visually obvious. Though there is obvious damage in the Test 1 version of this model. Considering the discussion of physical drop results (see Section D2), there was no visible damage in the fuel element after the consecutive Tests 1 and 2 (Table 2) physical drops. Consequently, end box damage shown in Figure D-27 is conservatively high. 
ENGINEERING CALCULATIONS AND ANALYSIS

Drop Analysis of the Advanced Test Reactor Fresh Fuel Shipping Container with Heavier Low-Enriched Uranium Fuel Contents
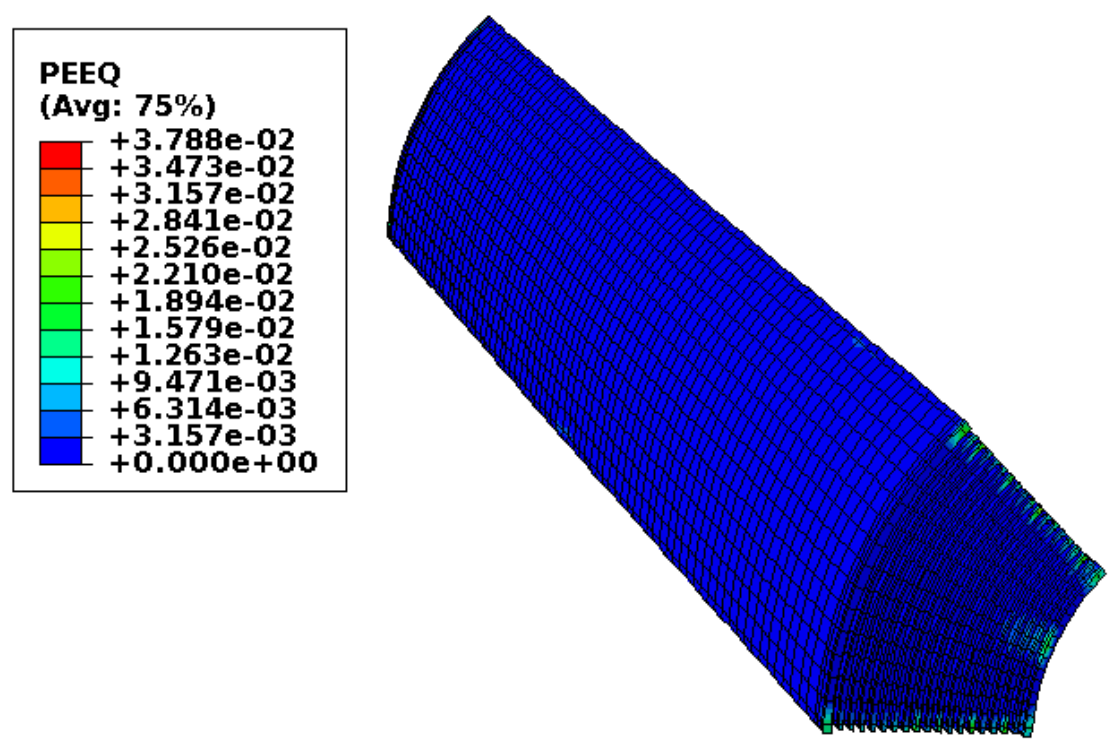

$Z$ SDRC I-DEAS ABAQUS FILE TRANSLATOR 27-May-20 13:32:52

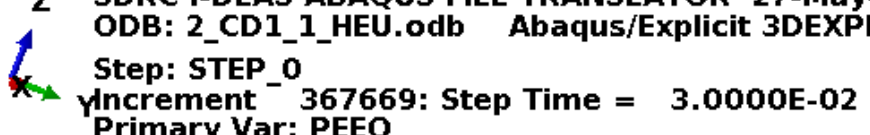

Figure D-28. Scope Part 1b (Table 3), Test 2 (Table 2) fuel plate equivalent strain.

Figure D-28 shows the equivalent plastic strain in the fuel plates. Failure in these elements occurs at an equivalent plastic strain of $0.205 \mathrm{in}$./in. If element failure were to occur, the element would be removed from the model (thereby excluding its equivalent plastic strain from the maximum equivalent plastic strain for the plot). However, the missing element would be visible in the plot. Figure D-28 shows no failure in the fuel plates with margin.

\section{D2.2.3 Results for Scope Part 1c (Table 3), Test 2 (Table 2)}

The FEA model results for the Scope Part 1c (Table 3), Test 2 (Table 2) model are shown below in Figure D-29 to Figure D-31. The fuel element weighs $22.1 \mathrm{lbf}$ and the whole model is modeled with minimum material properties. Though ATR FFSC SAR (2017) shows the Scope Part 1 (Table 3) drop scenarios to be acceptable, the results shown (for information) in this section include the blocks as added fuel plate protection. 


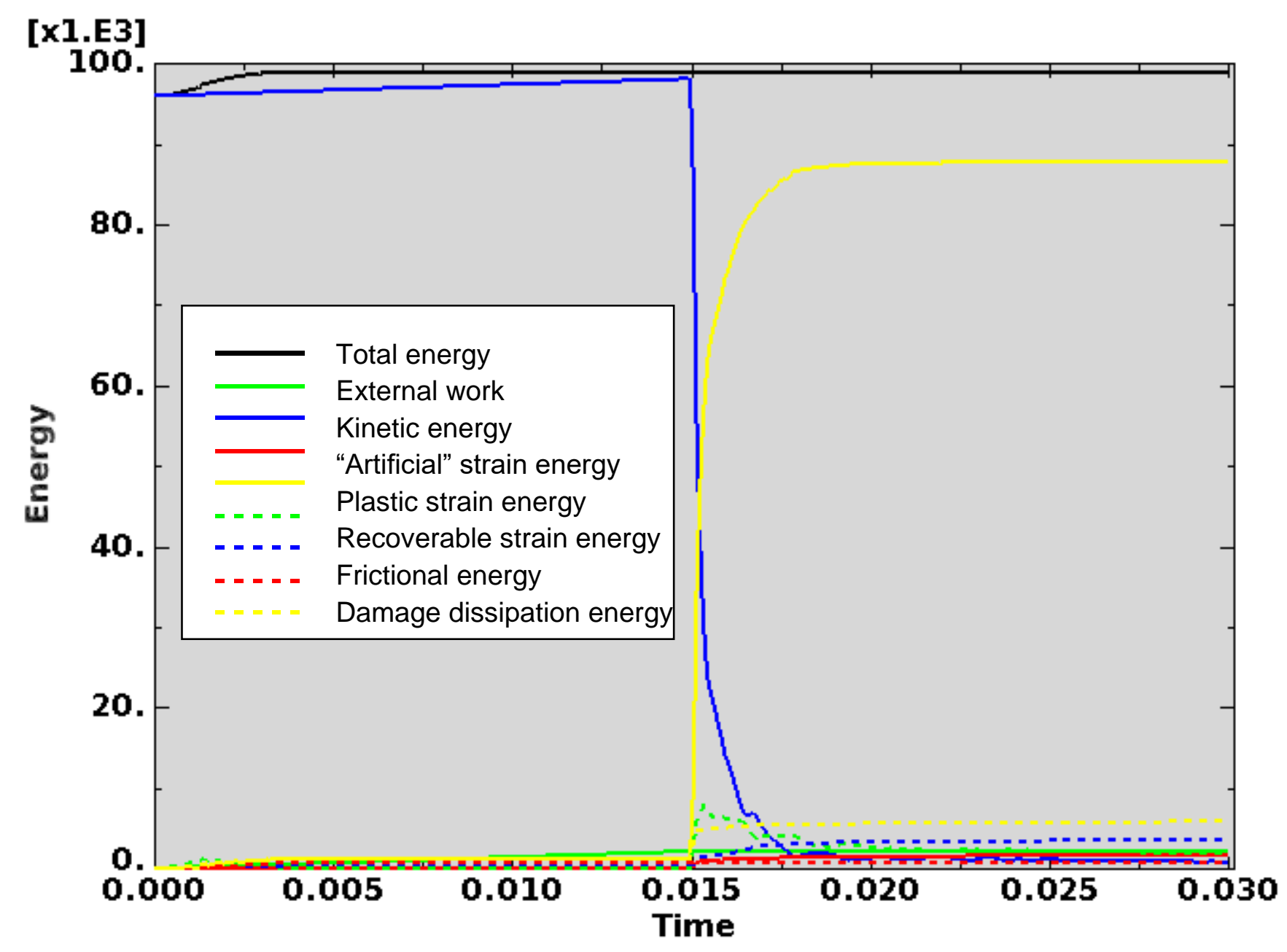

Figure D-29. Scope Part 1c (Table 3), Test 2 (Table 2) energy curves.

Figure D-29 shows the energy curves for Scope Part 1c (Table 3), Test 2 (Table 2) drop scenario. These curves exhibit a stable shape. Artificial strain energy represents the energy required to keep reduced integration elements from taking on a zero-energy hourglass shape. As shown in Figure D-29, the artificial energy at the end of the model run is $1.8 \%$ of the total energy. Therefore, the potential error associated with artificial energy is not considered to be significant. 
ENGINEERING CALCULATIONS AND ANALYSIS

Drop Analysis of the Advanced Test Reactor Fresh Fuel Shipping Container with Heavier Low-Enriched Uranium Fuel Contents
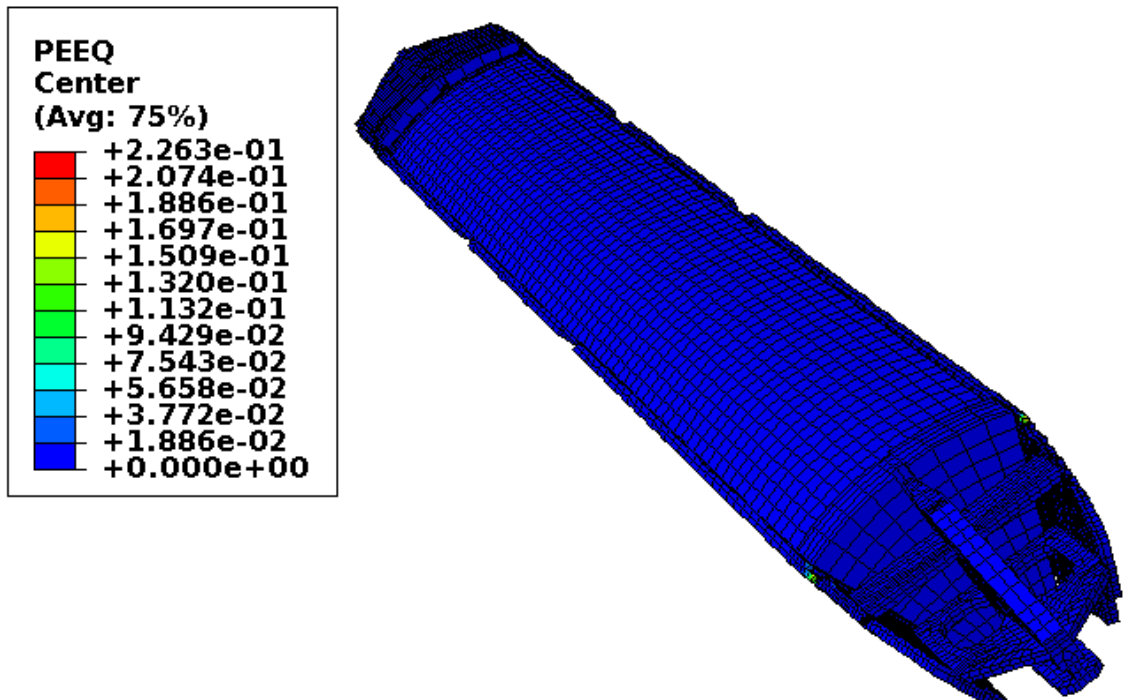

SDRC I-DEAS ABAQUS FILE TRANSLATOR 27-May-20 13:32:52 ODB: 2_CD1_1_HEU_block.odb Abaqus/Explicit 3DEXPERIENCE I<smiles>[Y]C([Z])[X]</smiles>
Step: STEP 0 Increment $367650:$ Step Time $=3.0000 \mathrm{E}-02$ Primary Var: PEEQ

Figure D-30. Scope Part 1c (Table 3), Test 2 (Table 2) fuel element plastic equivalent strain.

Figure D-30 shows the equivalent plastic strain in the fuel element. Failure in the end box elements occurs at an equivalent plastic strain of $0.027 \mathrm{in}$./in. Failure in the end box weld elements occurs at an equivalent plastic strain of $0.032 \mathrm{in}$./in. Failure in the side plate and comb elements occurs at an equivalent plastic strain of $0.152 \mathrm{in}$./in. Failure in the side plate weld elements occurs at an equivalent plastic strain of $0.205 \mathrm{in}$./in. If element failure were to occur, the element would be removed from the model (thereby excluding its equivalent plastic strain from the maximum equivalent plastic strain for the plot). However, the missing element would be visible in the plot. Figure D-30 shows a few failed elements in the end boxes and end box welds nearest the impact. 
ENGINEERING CALCULATIONS AND ANALYSIS

Drop Analysis of the Advanced Test Reactor Fresh Fuel Shipping Container with Heavier Low-Enriched Uranium Fuel Contents

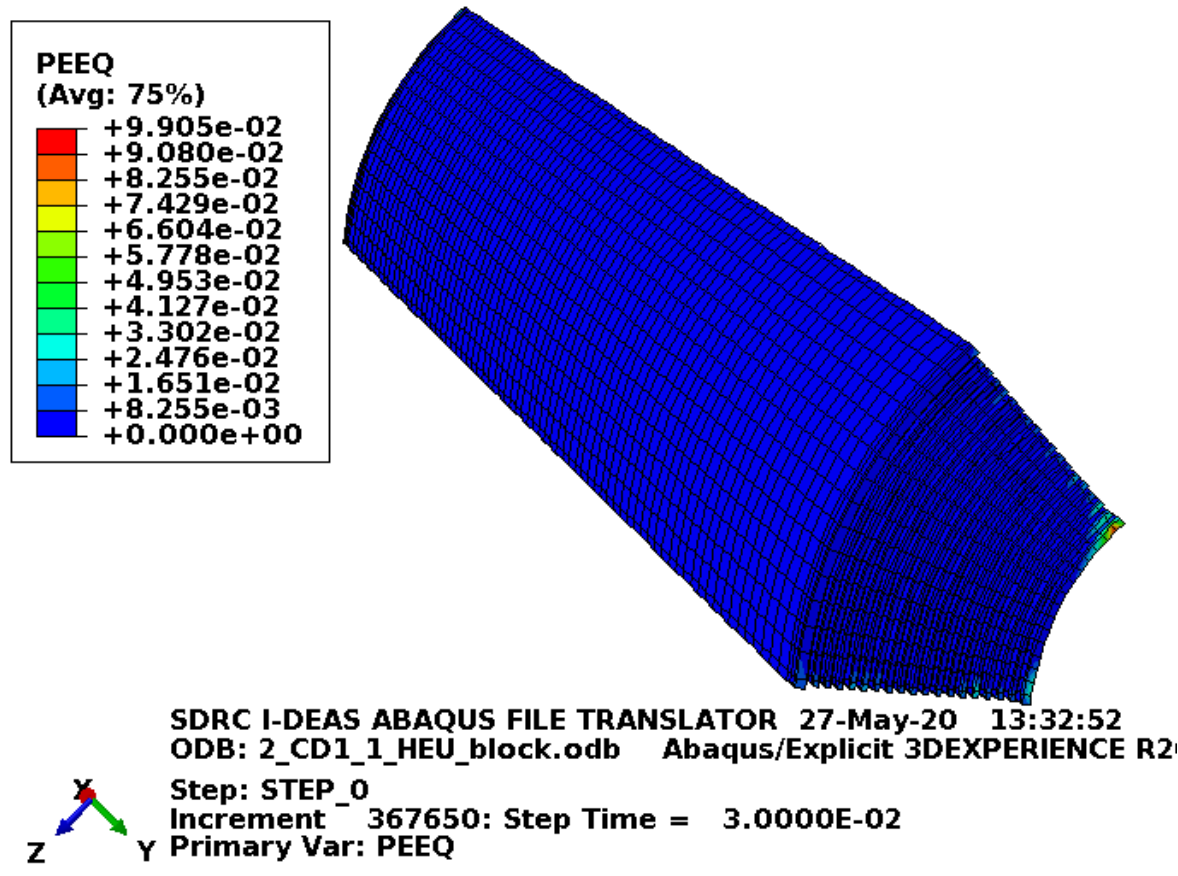

Figure D-31. Scope Part 1c (Table 3), Test 2 (Table 2) fuel plate equivalent strain.

Figure D-31 shows the equivalent plastic strain in the fuel plates. Failure in these elements occurs at an equivalent plastic strain of $0.205 \mathrm{in}$./in. If element failure were to occur, the element would be removed from the model (thereby excluding its equivalent plastic strain from the maximum equivalent plastic strain for the plot). However, the missing element would be visible in the plot. Figure D-31 shows no failure in the fuel plates with margin.

\section{D2.2.4 Results for Scope Part 1d (Table 3), Test 2 (Table 2)}

The FEA model results for the Scope Part 1d (Table 3), Test 2 (Table 2) model are shown below in Figure D-32 to Figure D-34. The fuel element weighs $22.1 \mathrm{lbf}$ and the drop scenario is modeled with minimum material properties except the enclosure and end boxes, which are modeled with relatively tough material properties. Though ATR FFSC SAR (2017) shows the Scope Part 1 (Table 3) drop scenarios to be acceptable, the results shown (for information) in this section include the blocks as added fuel plate protection. 


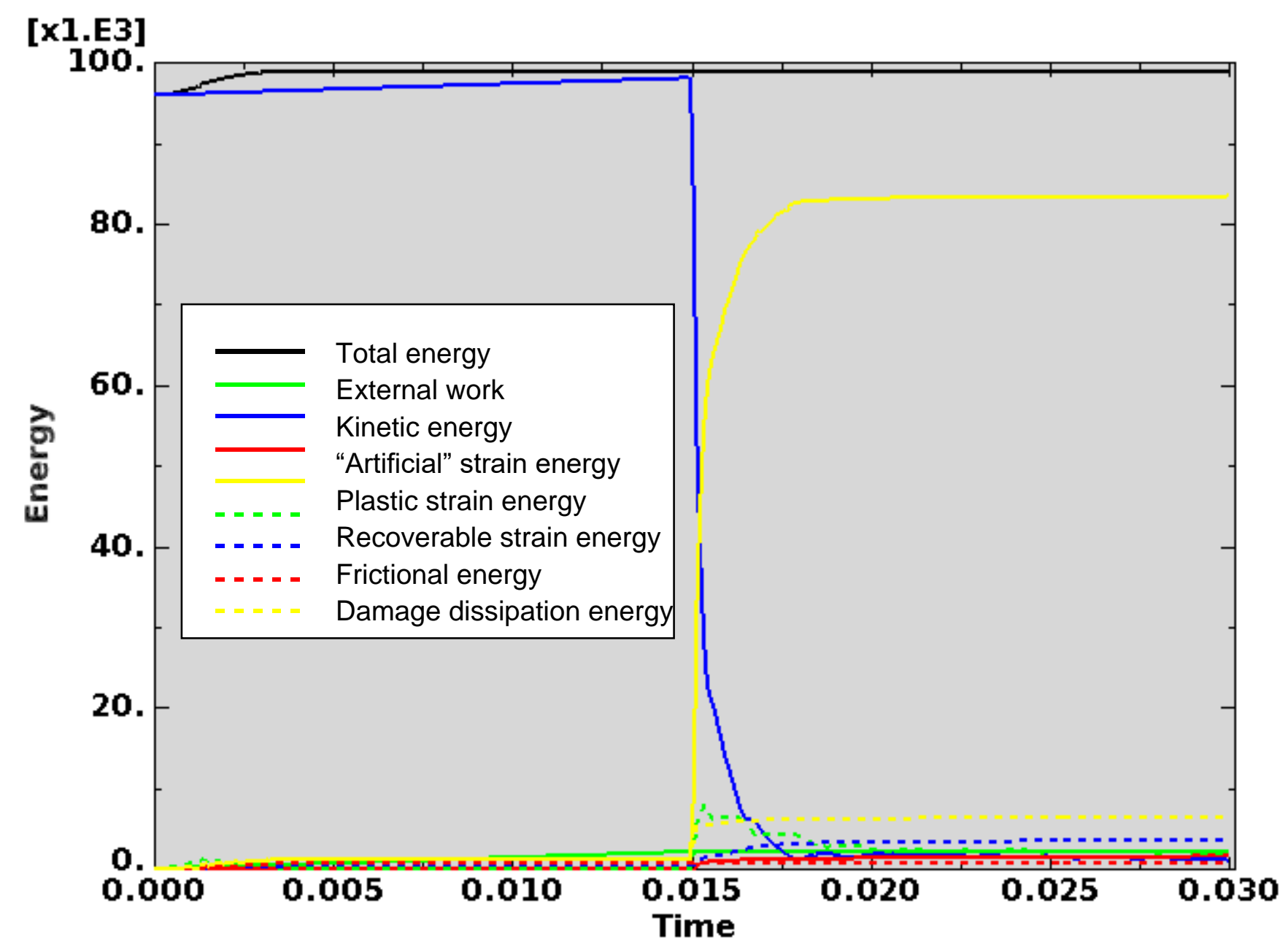

Figure D-32. Scope Part 1d (Table 3), Test 2 (Table 2) energy curves.

Figure D-32 shows the energy curves for Scope Part 1d (Table 3), Test 2 (Table 2) drop scenario. These curves exhibit a stable shape. Artificial strain energy represents the energy required to keep reduced integration elements from taking on a zero-energy hourglass shape. As shown in Figure D-32, the artificial energy at the end of the model run is $1.6 \%$ of the total energy. Therefore, the potential error associated with artificial energy is not considered to be significant. 
ENGINEERING CALCULATIONS AND ANALYSIS

Drop Analysis of the Advanced Test Reactor Fresh Fuel Shipping Container with Heavier Low-Enriched Uranium Fuel Contents

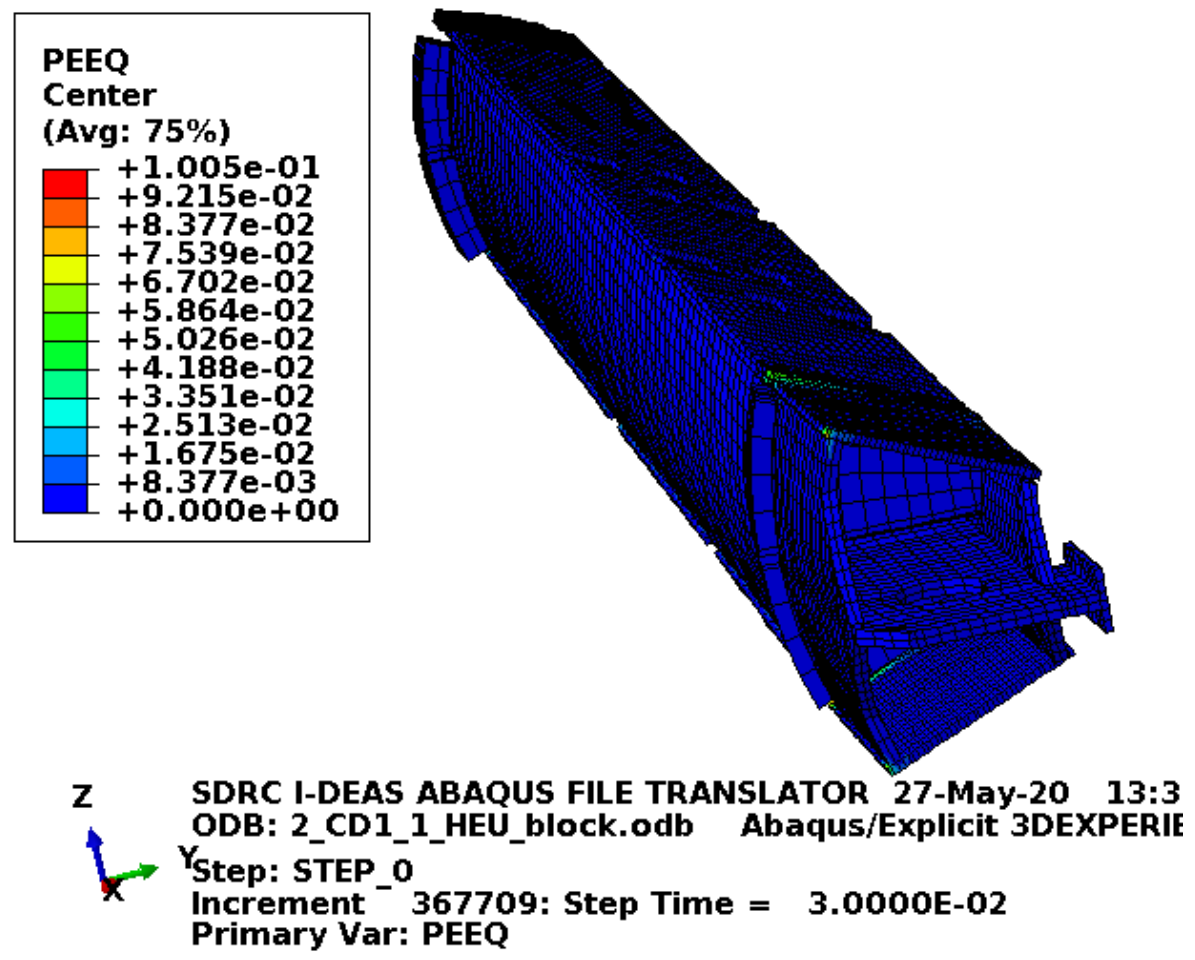

Figure D-33. Scope Part 1d (Table 3), Test 2 (Table 2) fuel element plastic equivalent strain.

Figure D-33 shows the equivalent plastic strain in the fuel element. Failure in the end box elements occurs at an equivalent plastic strain of $0.08 \mathrm{in./in.} \mathrm{(for} \mathrm{the} \mathrm{relatively} \mathrm{tough} \mathrm{material} \mathrm{properties).} \mathrm{Failure} \mathrm{in} \mathrm{the} \mathrm{end}$ box weld elements occurs at an equivalent plastic strain of $0.115 \mathrm{in}$./in. (for the relatively tough material properties). Failure in the side plate and comb elements occurs at an equivalent plastic strain of 0.152 in./in. Failure in the side plate weld elements occurs at an equivalent plastic strain of $0.205 \mathrm{in}$./in. If element failure were to occur, the element would be removed from the model (thereby excluding its equivalent plastic strain from the maximum equivalent plastic strain for the plot). However, the missing element would be visible in the plot. Figure D-33 shows no failure in the fuel element or blocks. 
ENGINEERING CALCULATIONS AND ANALYSIS

Drop Analysis of the Advanced Test Reactor Fresh Fuel Shipping Container with Heavier Low-Enriched Uranium Fuel Contents

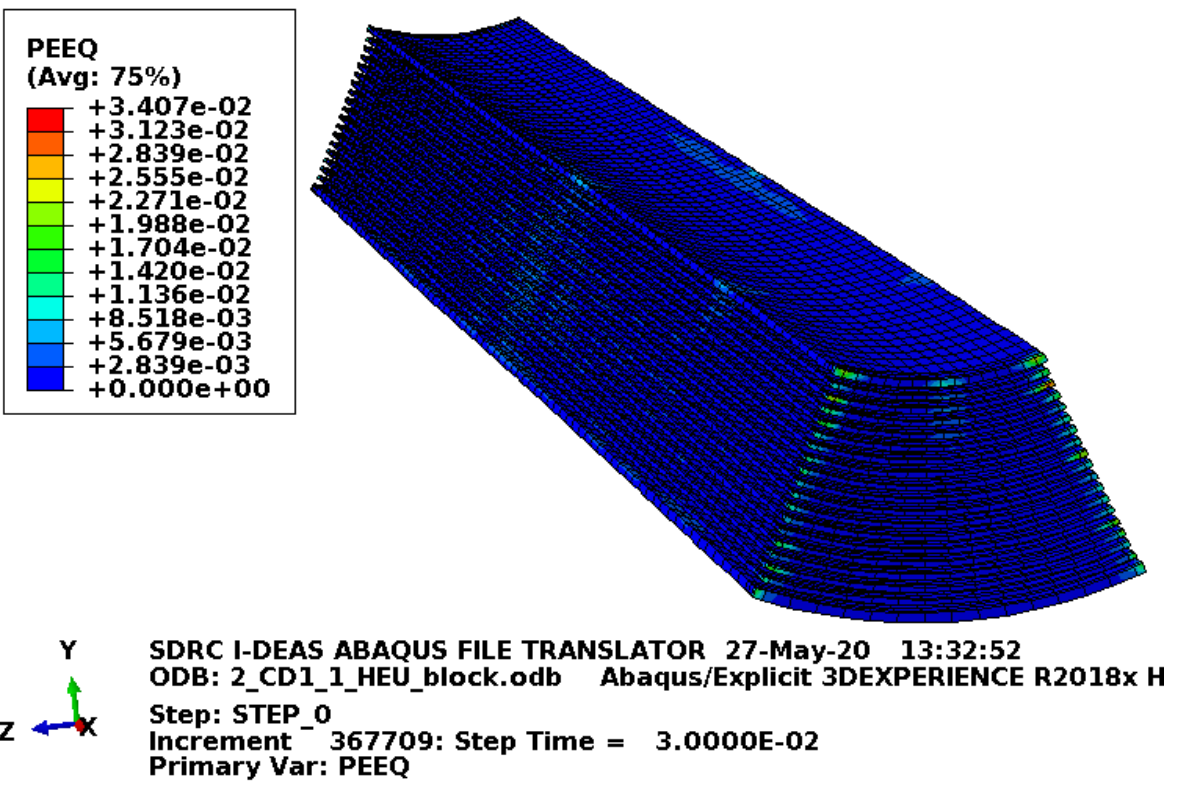

Figure D-34. Scope Part 1d (Table 3), Test 2 (Table 2) fuel plate equivalent strain.

Figure D-34 shows the equivalent plastic strain in the fuel plates. Failure in these elements occurs at an equivalent plastic strain of $0.205 \mathrm{in}$./in. If element failure were to occur, the element would be removed from the model (thereby excluding its equivalent plastic strain from the maximum equivalent plastic strain for the plot). However, the missing element would be visible in the plot. Figure D-34 shows no failure in the fuel plates with margin.

\section{D2.3 Results for Scope Part 1 (Table 3), Test 3 (Table 2)}

The drop scenario considered in this section is a $30 \mathrm{ft}$ drop modeled as a side drop with the index lugs facing downward and the edge impacting slightly before the index lugs. It is identified as CD2.A-1 in the ATR FFSC SAR (2017). Though physical drops CD2.B-1 and CD2.D-1 in the ATR FFSC SAR (2017) are similar. All three drops had rotation and the first two had a lot of rotation, so unlike Section D2.2, the FEA model was adjusted to try to reasonably capture the rotation.

\section{D2.3.1 Results for Scope Part 1a (Table 3), Test 3 (Table 2)}

The FEA model results for the Scope Part 1a (Table 3), Test 3 (Table 2) model are shown below in Figure D-35 to Figure D-37. The fuel element weighs $22.1 \mathrm{lbf}$ and the whole model is modeled with minimum material properties. 


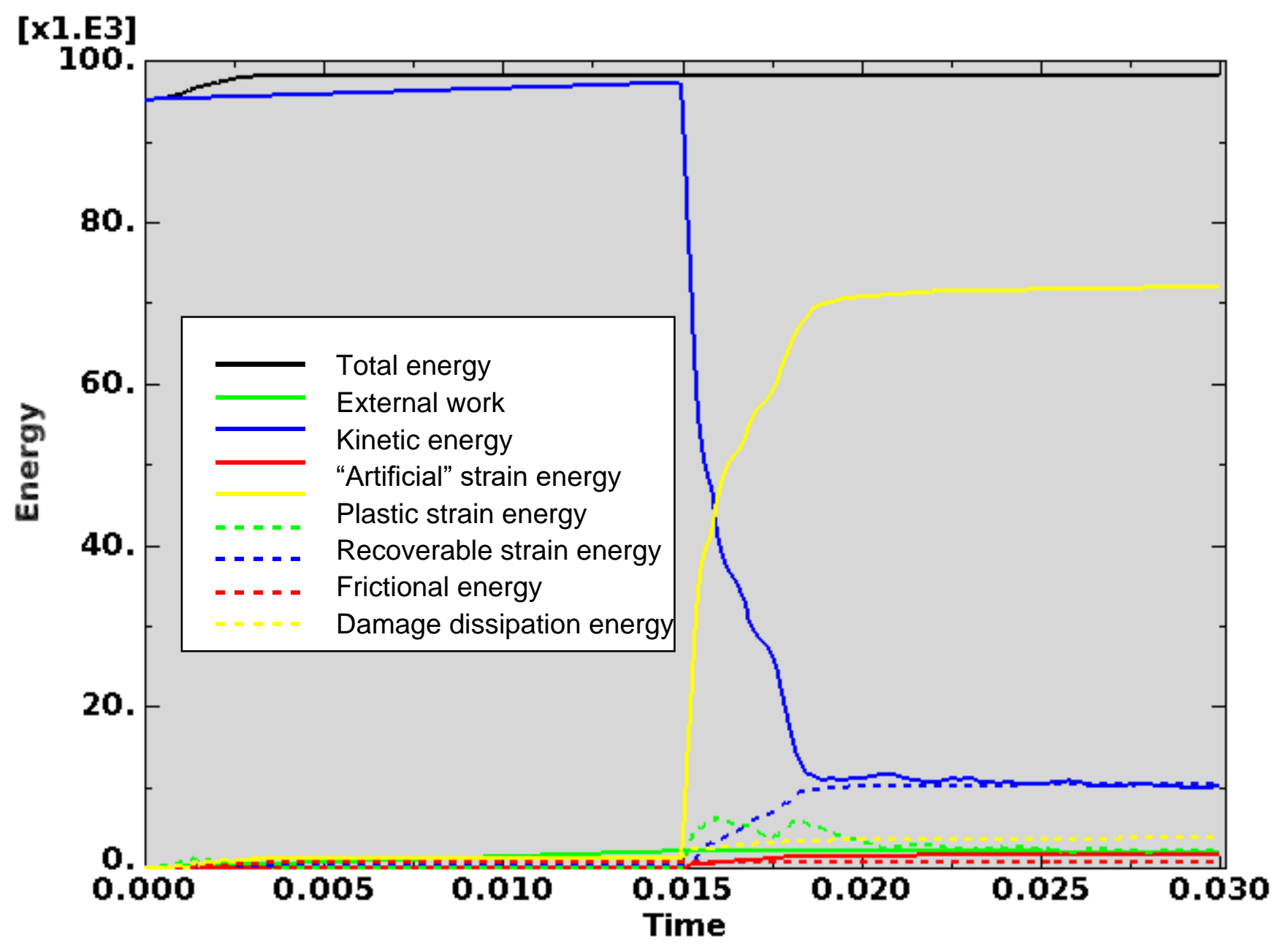

Figure D-35. Scope Part 1a (Table 3), Test 3 (Table 2) energy curves.

Figure D-35 shows the energy curves for Scope Part 1a (Table 3), Test 3 (Table 2) drop scenario. These curves exhibit a stable shape. Artificial strain energy represents the energy required to keep reduced integration elements from taking on a zero-energy hourglass shape. As shown in Figure D-35, the artificial energy at the end of the model run is $1.8 \%$ of the total energy. Therefore, the potential error associated with artificial energy is not considered to be significant. 
ENGINEERING CALCULATIONS AND ANALYSIS

Drop Analysis of the Advanced Test Reactor Fresh Fuel Shipping Container with Heavier Low-Enriched Uranium Fuel Contents

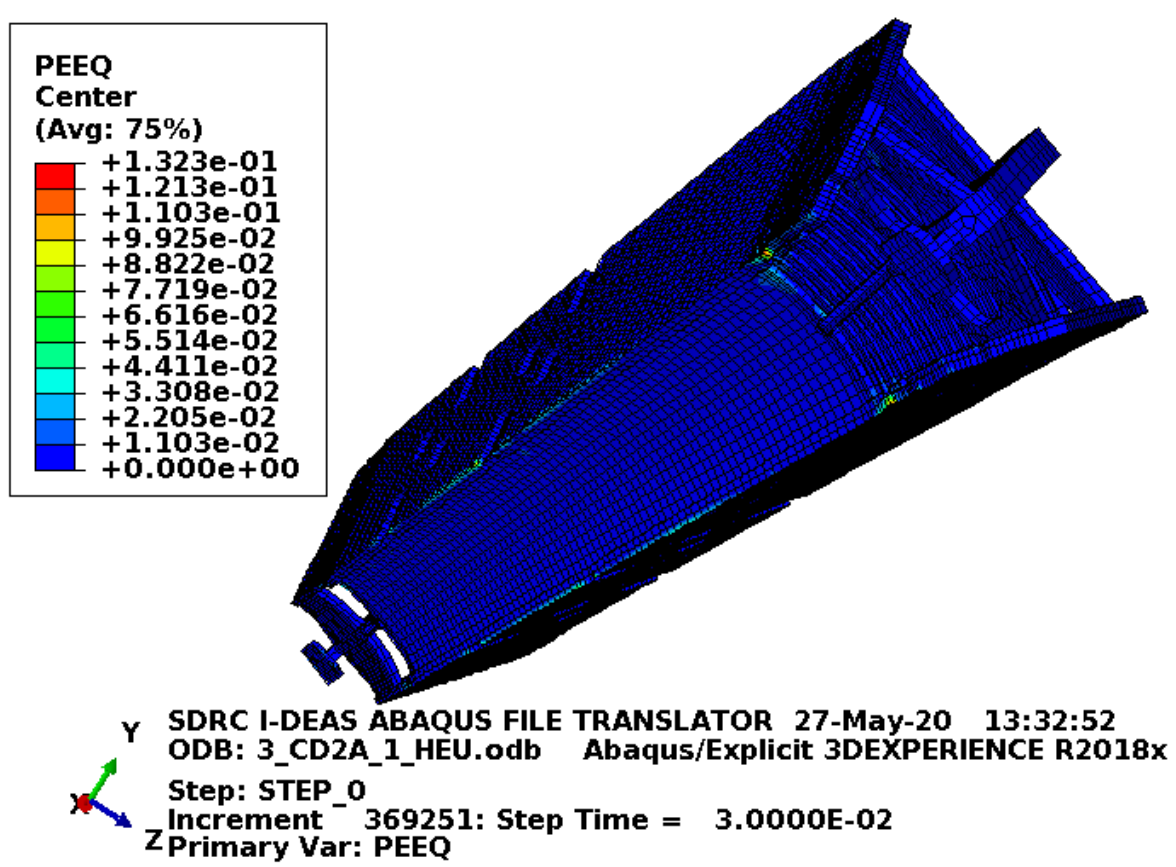

Figure D-36. Scope Part 1a (Table 3), Test 3 (Table 2) fuel element plastic equivalent strain.

Figure D-36 shows the equivalent plastic strain in the fuel element. Failure in the end box elements occurs at an equivalent plastic strain of $0.027 \mathrm{in}$./in. Failure in the end box weld elements occurs at an equivalent plastic strain of $0.032 \mathrm{in}$./in. Failure in the side plate and comb elements occurs at an equivalent plastic strain of 0.152 in./in. Failure in the side plate weld elements occurs at an equivalent plastic strain of $0.205 \mathrm{in./in.} \mathrm{If} \mathrm{element} \mathrm{failure} \mathrm{were} \mathrm{to} \mathrm{occur,} \mathrm{the} \mathrm{element} \mathrm{would} \mathrm{be} \mathrm{removed} \mathrm{from} \mathrm{the} \mathrm{model} \mathrm{(thereby}$ excluding its equivalent plastic strain from the maximum equivalent plastic strain for the plot). However, the missing element would be visible in the plot. Figure D-36 shows a few failed elements in the end boxes and end box welds nearest the impact. Considering the discussion of physical drop results (see Section D2), it is difficult to establish what kind of fuel element damage might have happened in this drop scenario. 
ENGINEERING CALCULATIONS AND ANALYSIS

Drop Analysis of the Advanced Test Reactor Fresh Fuel Shipping Container with Heavier Low-Enriched Uranium Fuel Contents

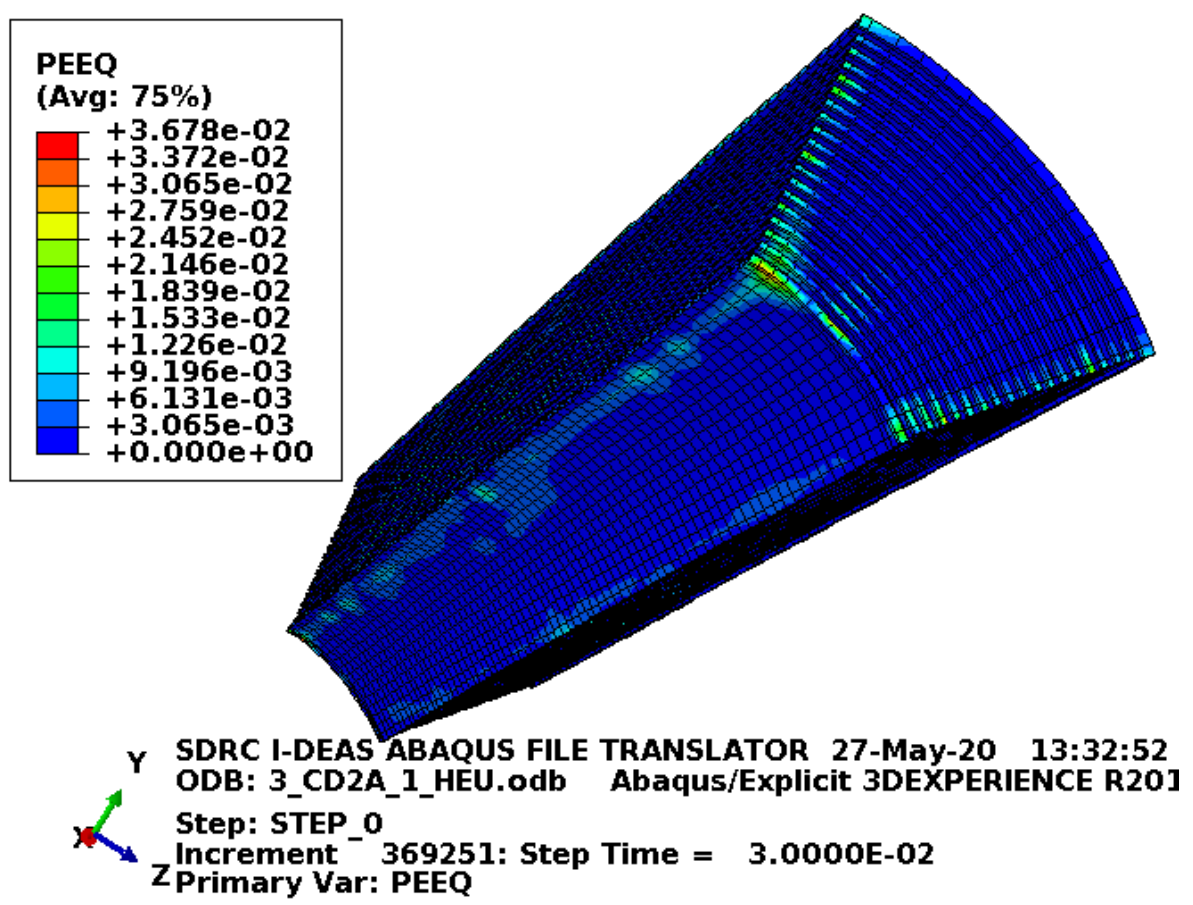

Figure D-37. Scope Part 1a (Table 3), Test 3 (Table 2) fuel plate equivalent strain.

Figure D-37 shows the equivalent plastic strain in the fuel plates. Failure in these elements occurs at an equivalent plastic strain of $0.205 \mathrm{in}$./in. If element failure were to occur, the element would be removed from the model (thereby excluding its equivalent plastic strain from the maximum equivalent plastic strain for the plot). However, the missing element would be visible in the plot. Figure D-37 shows no failure in the fuel plates with margin.

\section{D2.3.2 Results for Scope Part 1b (Table 3), Test 3 (Table 2)}

The FEA model results for the Scope Part 1b (Table 3), Test 3 (Table 2) model are shown below in Figure D-38 to Figure D-40. The fuel element weighs $22.1 \mathrm{lbf}$ and the drop scenario is modeled with minimum material properties except the enclosure and end boxes, which are modeled with relatively tough material properties. 


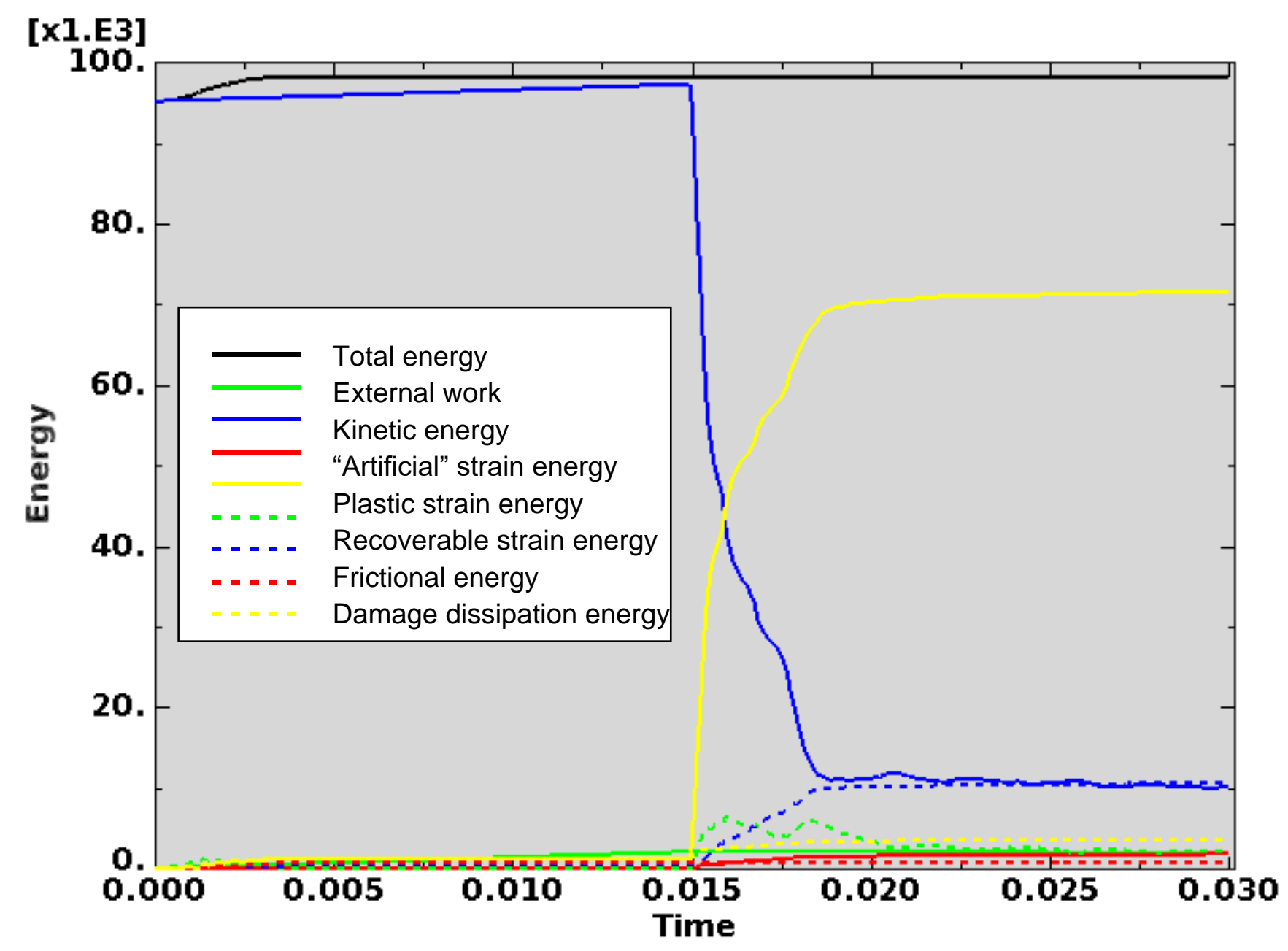

Figure D-38. Scope Part 1b (Table 3), Test 3 (Table 2) energy curves.

Figure D-38 shows the energy curves for Scope Part 1b (Table 3), Test 3 (Table 2) drop scenario. These curves exhibit a stable shape. Artificial strain energy represents the energy required to keep reduced integration elements from taking on a zero-energy hourglass shape. As shown in Figure D-38, the artificial energy at the end of the model run is $1.8 \%$ of the total energy. Therefore, the potential error associated with artificial energy is not considered to be significant. 


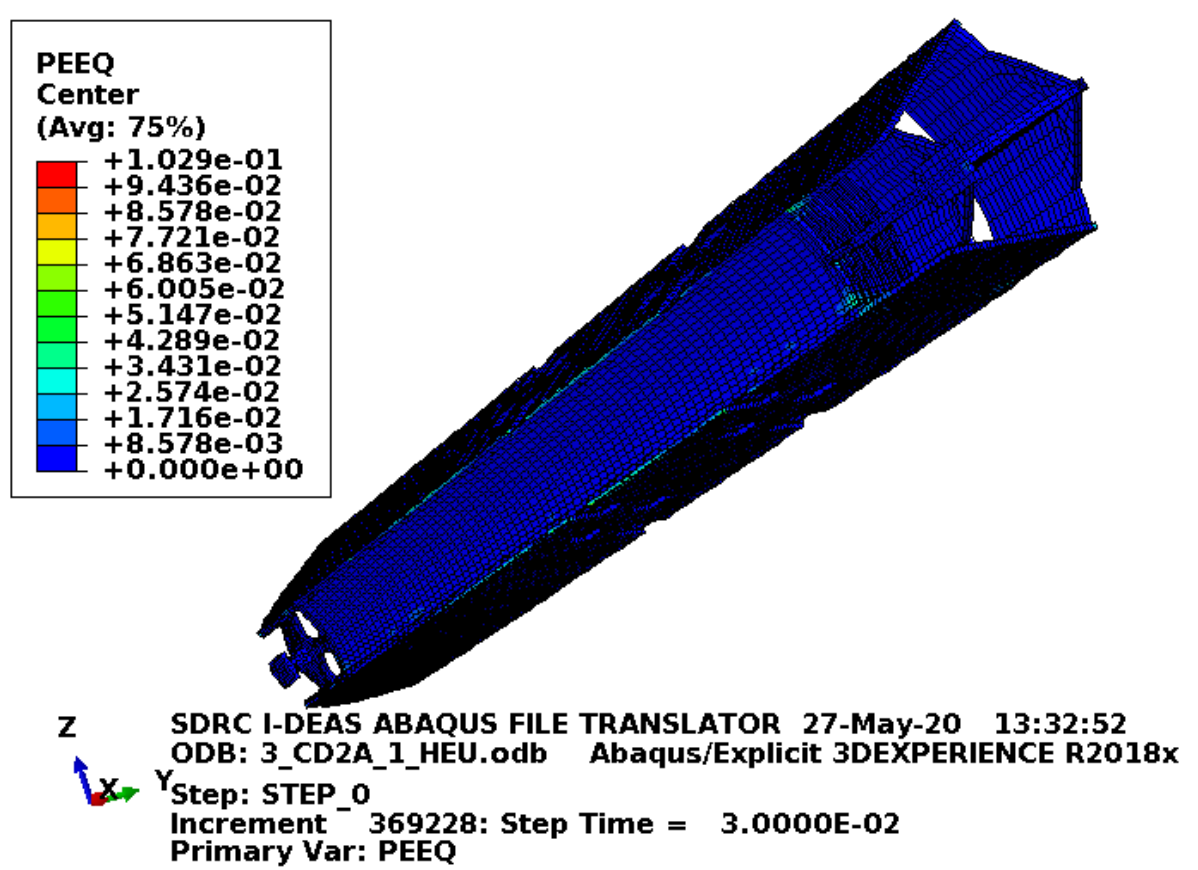

Figure D-39. Scope Part 1b (Table 3), Test 3 (Table 2) fuel element plastic equivalent strain.

Figure D-39 shows the equivalent plastic strain in the fuel element. Failure in the end box elements occurs at an equivalent plastic strain of $0.08 \mathrm{in./in.} \mathrm{(for} \mathrm{the} \mathrm{relatively} \mathrm{tough} \mathrm{material} \mathrm{properties).} \mathrm{Failure} \mathrm{in} \mathrm{the} \mathrm{end}$ box weld elements occurs at an equivalent plastic strain of $0.115 \mathrm{in}$./in. (for the relatively tough material properties). Failure in the side plate and comb elements occurs at an equivalent plastic strain of 0.152 in./in. Failure in the side plate weld elements occurs at an equivalent plastic strain of $0.205 \mathrm{in}$./in. If element failure were to occur, the element would be removed from the model (thereby excluding its equivalent plastic strain from the maximum equivalent plastic strain for the plot). However, the missing element would be visible in the plot. Figure D-39 shows no failure in the fuel element. There is significant plasticity, but it might not be visually obvious. Considering the discussion of physical drop results (see Section D2), it is difficult to establish what kind of fuel element damage might have happened in this drop scenario. 
ENGINEERING CALCULATIONS AND ANALYSIS

Drop Analysis of the Advanced Test Reactor Fresh Fuel Shipping Container with Heavier Low-Enriched Uranium Fuel Contents

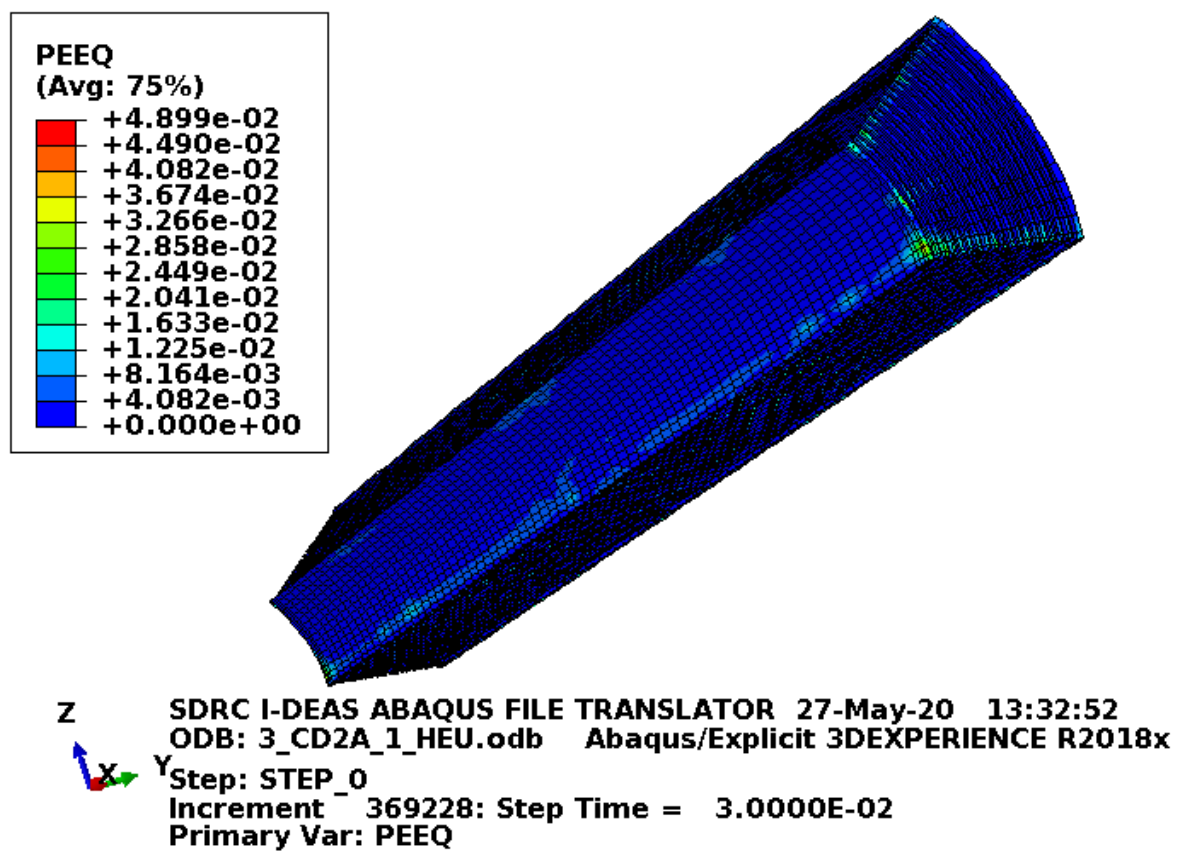

Figure D-40. Scope Part 1b (Table 3), Test 3 (Table 2) fuel plate equivalent strain.

Figure D-40 shows the equivalent plastic strain in the fuel plates. Failure in these elements occurs at an equivalent plastic strain of 0.205 in./in. If element failure were to occur, the element would be removed from the model (thereby excluding its equivalent plastic strain from the maximum equivalent plastic strain for the plot). However, the missing element would be visible in the plot. Figure D-40 shows no failure in the fuel plates with margin.

\section{D2.3.3 Results for Scope Part 1c (Table 3), Test 3 (Table 2)}

The FEA model results for the Scope Part 1c (Table 3), Test 3 (Table 2) model are shown below in Figure D-41 to Figure D-43. The fuel element weighs $22.1 \mathrm{lbf}$ and the whole model is modeled with minimum material properties. Though ATR FFSC SAR (2017) shows the Scope Part 1 (Table 3) drop scenarios to be acceptable, the results shown (for information) in this section include the blocks as added fuel plate protection. 


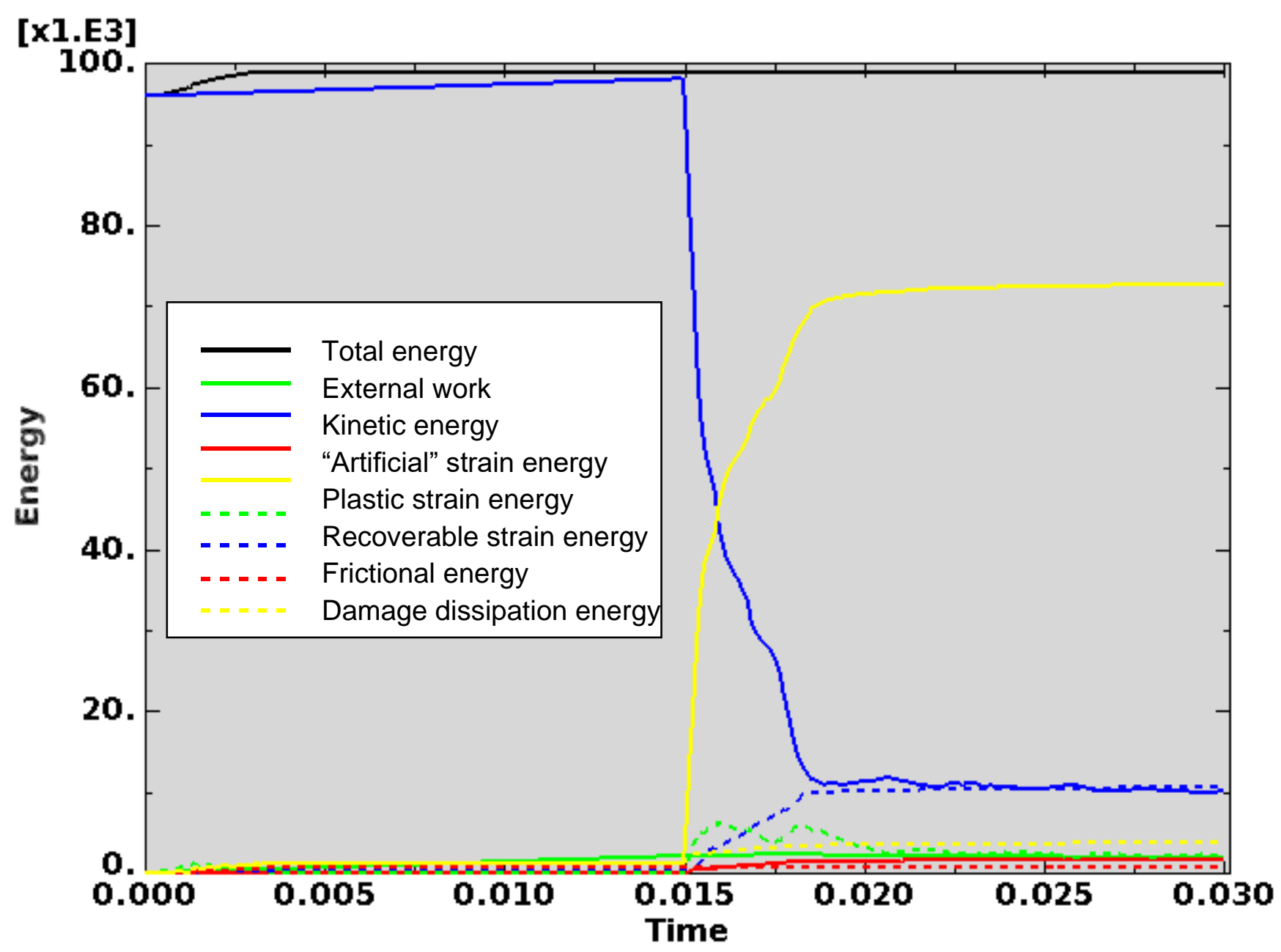

Figure D-41. Scope Part 1c (Table 3), Test 3 (Table 2) energy curves.

Figure D-41 shows the energy curves for Scope Part 1c (Table 3), Test 3 (Table 2) drop scenario. These curves exhibit a stable shape. Artificial strain energy represents the energy required to keep reduced integration elements from taking on a zero-energy hourglass shape. As shown in Figure D-41, the artificial energy at the end of the model run is $1.8 \%$ of the total energy. Therefore, the potential error associated with artificial energy is not considered to be significant. 
ENGINEERING CALCULATIONS AND ANALYSIS

Drop Analysis of the Advanced Test Reactor Fresh Fuel Shipping Container with Heavier Low-Enriched Uranium Fuel Contents

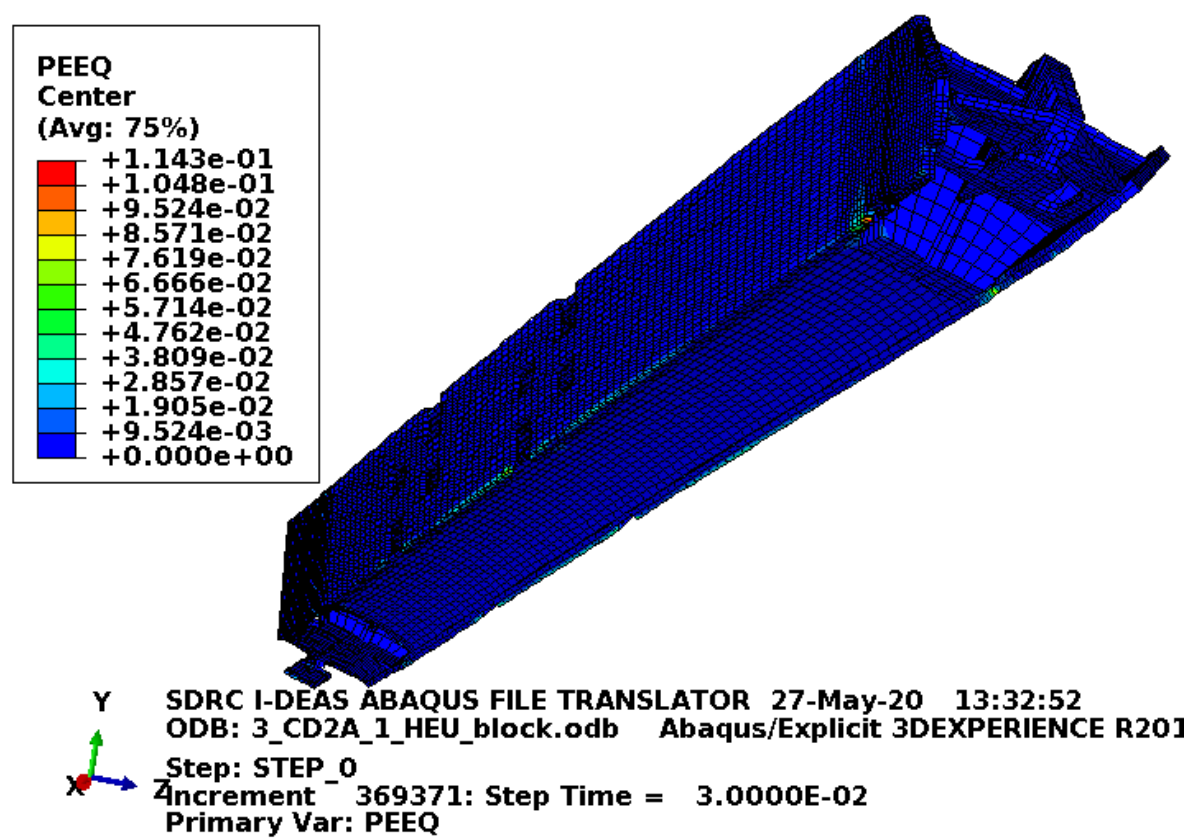

Figure D-42. Scope Part 1c (Table 3), Test 3 (Table 2) fuel element plastic equivalent strain.

Figure D-42 shows the equivalent plastic strain in the fuel element. Failure in the end box elements occurs at an equivalent plastic strain of $0.027 \mathrm{in}$./in. Failure in the end box weld elements occurs at an equivalent plastic strain of $0.032 \mathrm{in}$./in. Failure in the side plate and comb elements occurs at an equivalent plastic strain of $0.152 \mathrm{in} . / \mathrm{in}$. Failure in the side plate weld elements occurs at an equivalent plastic strain of $0.205 \mathrm{in./in.} \mathrm{If} \mathrm{element} \mathrm{failure} \mathrm{were} \mathrm{to} \mathrm{occur,} \mathrm{the} \mathrm{element} \mathrm{would} \mathrm{be} \mathrm{removed} \mathrm{from} \mathrm{the} \mathrm{model} \mathrm{(thereby}$ excluding its equivalent plastic strain from the maximum equivalent plastic strain for the plot). However, the missing element would be visible in the plot. Figure D-42 shows a few failed elements in the end boxes and end box welds nearest the impact. 


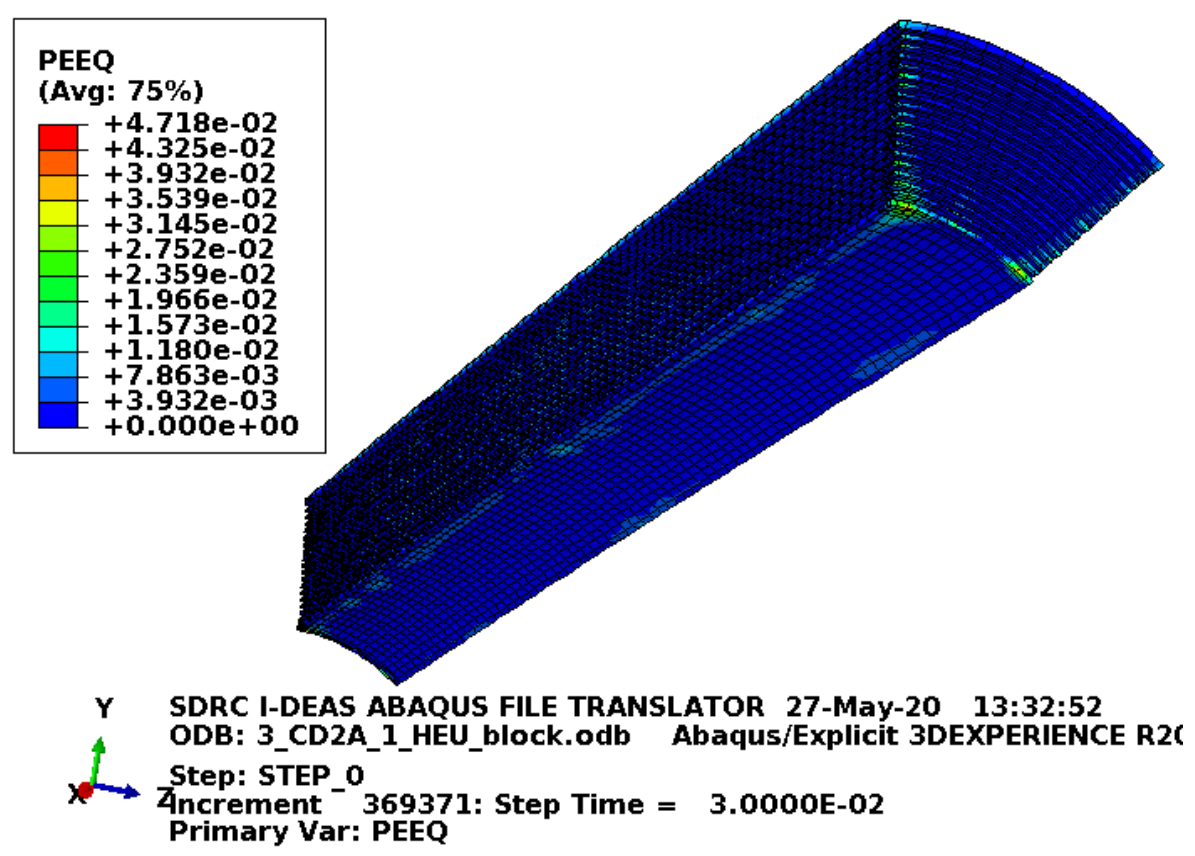

Figure D-43. Scope Part 1c (Table 3), Test 3 (Table 2) fuel plate equivalent strain.

Figure D-43 shows the equivalent plastic strain in the fuel plates. Failure in these elements occurs at an equivalent plastic strain of $0.205 \mathrm{in}$./in. If element failure were to occur, the element would be removed from the model (thereby excluding its equivalent plastic strain from the maximum equivalent plastic strain for the plot). However, the missing element would be visible in the plot. Figure D-43 shows no failure in the fuel plates with margin.

\section{D2.3.4 Results for Scope Part 1d (Table 3), Test 3 (Table 2)}

The FEA model results for the Scope Part 1d (Table 3), Test 3 (Table 2) model are shown below in Figure D-44 to Figure D-46. The fuel element weighs $22.1 \mathrm{lbf}$ and the drop scenario is modeled with minimum material properties except the enclosure and end boxes, which are modeled with relatively tough material properties. Though ATR FFSC SAR (2017) shows the Scope Part 1 (Table 3) drop scenarios to be acceptable, the results shown (for information) in this section include the blocks as added fuel plate protection. 


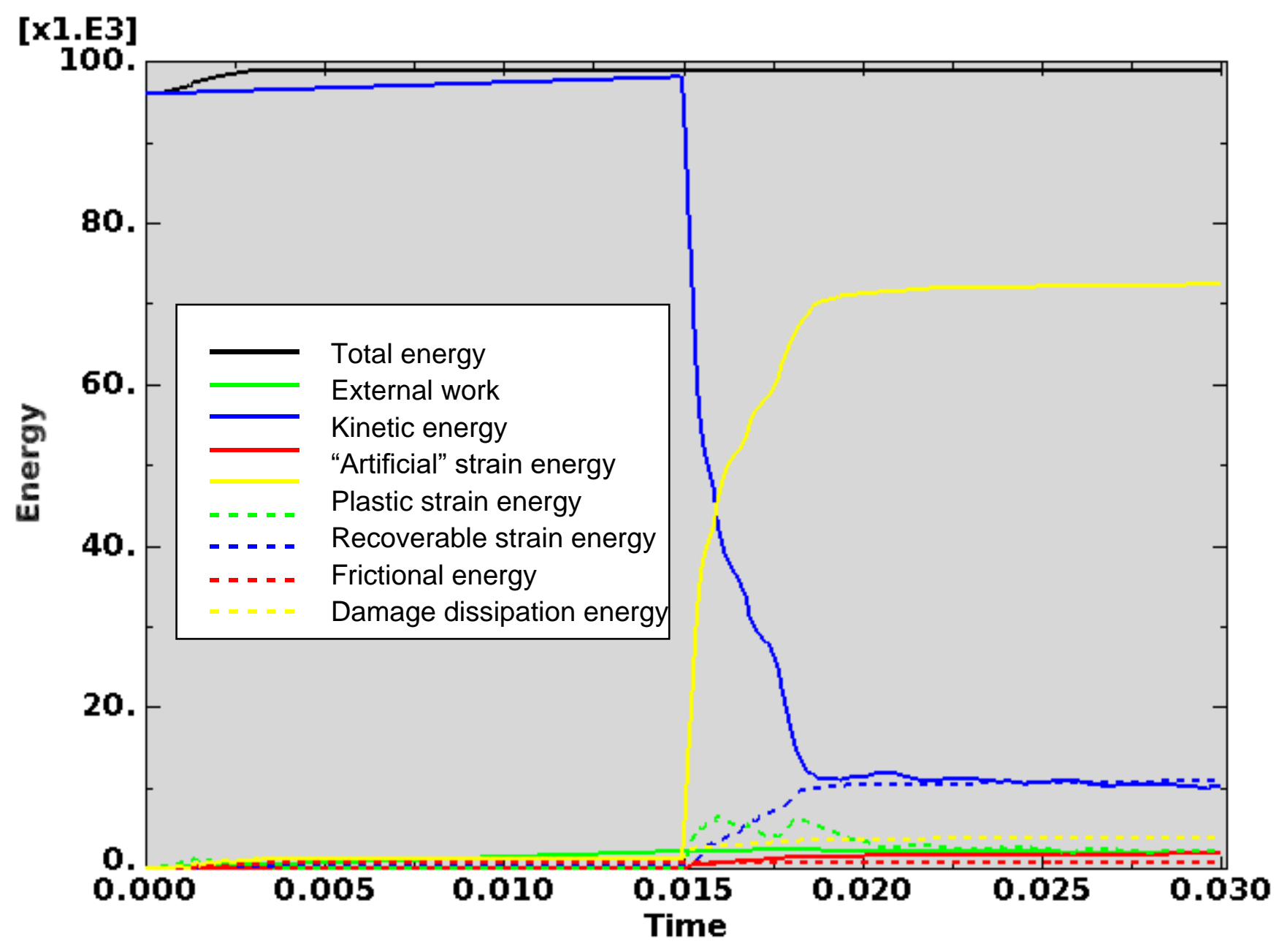

Figure D-44. Scope Part 1d (Table 3), Test 3 (Table 2) energy curves.

Figure D-44 shows the energy curves for Scope Part 1d (Table 3), Test 3 (Table 2) drop scenario. These curves exhibit a stable shape. Artificial strain energy represents the energy required to keep reduced integration elements from taking on a zero-energy hourglass shape. As shown in Figure D-44, the artificial energy at the end of the model run is $1.8 \%$ of the total energy. Therefore, the potential error associated with artificial energy is not considered to be significant. 
ENGINEERING CALCULATIONS AND ANALYSIS

Drop Analysis of the Advanced Test Reactor Fresh Fuel Shipping Container with Heavier Low-Enriched Uranium Fuel Contents

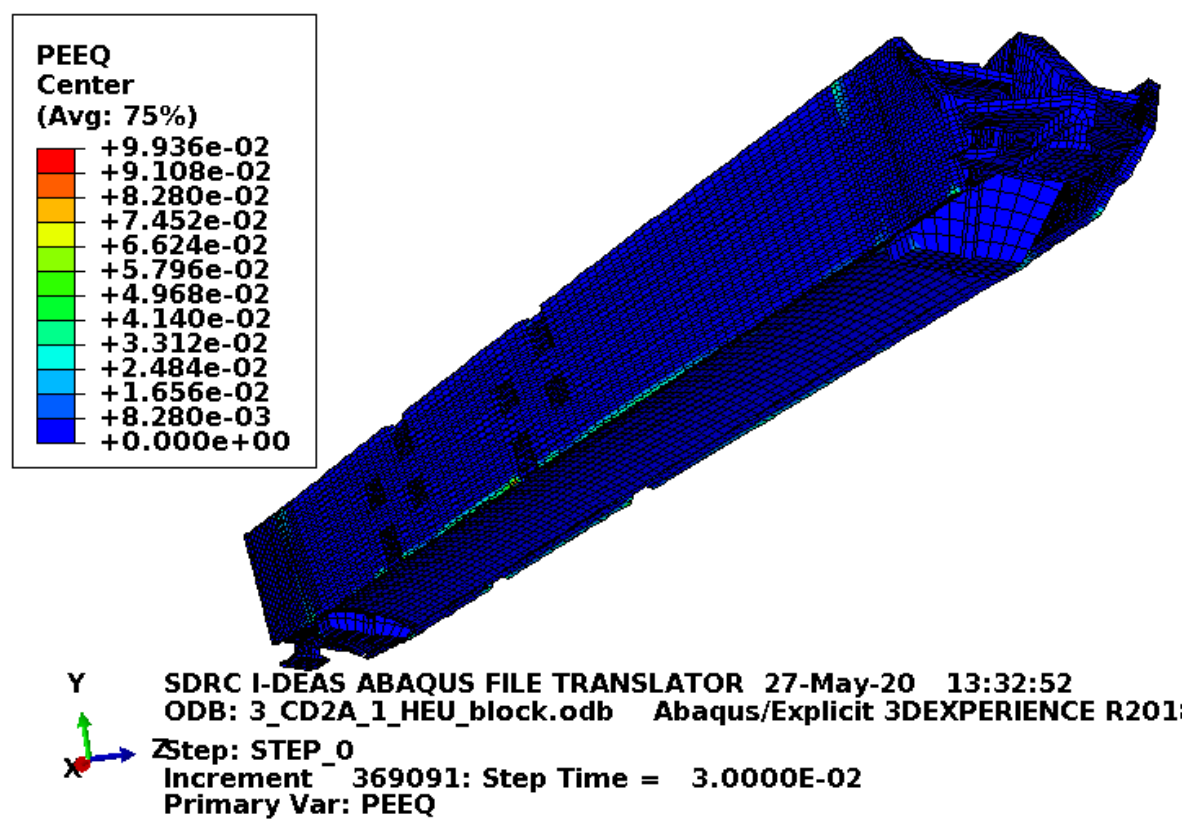

Figure D-45. Scope Part 1d (Table 3), Test 3 (Table 2) fuel element plastic equivalent strain.

Figure D-45 shows the equivalent plastic strain in the fuel element. Failure in the end box elements occurs at an equivalent plastic strain of $0.08 \mathrm{in./in.} \mathrm{(for} \mathrm{the} \mathrm{relatively} \mathrm{tough} \mathrm{material} \mathrm{properties).} \mathrm{Failure} \mathrm{in} \mathrm{the} \mathrm{end}$ box weld elements occurs at an equivalent plastic strain of $0.115 \mathrm{in}$./in. (for the relatively tough material properties). Failure in the side plate and comb elements occurs at an equivalent plastic strain of $0.152 \mathrm{in}$./in. Failure in the side plate weld elements occurs at an equivalent plastic strain of $0.205 \mathrm{in}$./in. If element failure were to occur, the element would be removed from the model (thereby excluding its equivalent plastic strain from the maximum equivalent plastic strain for the plot). However, the missing element would be visible in the plot. Figure D-45 shows no failure in the fuel element or blocks.

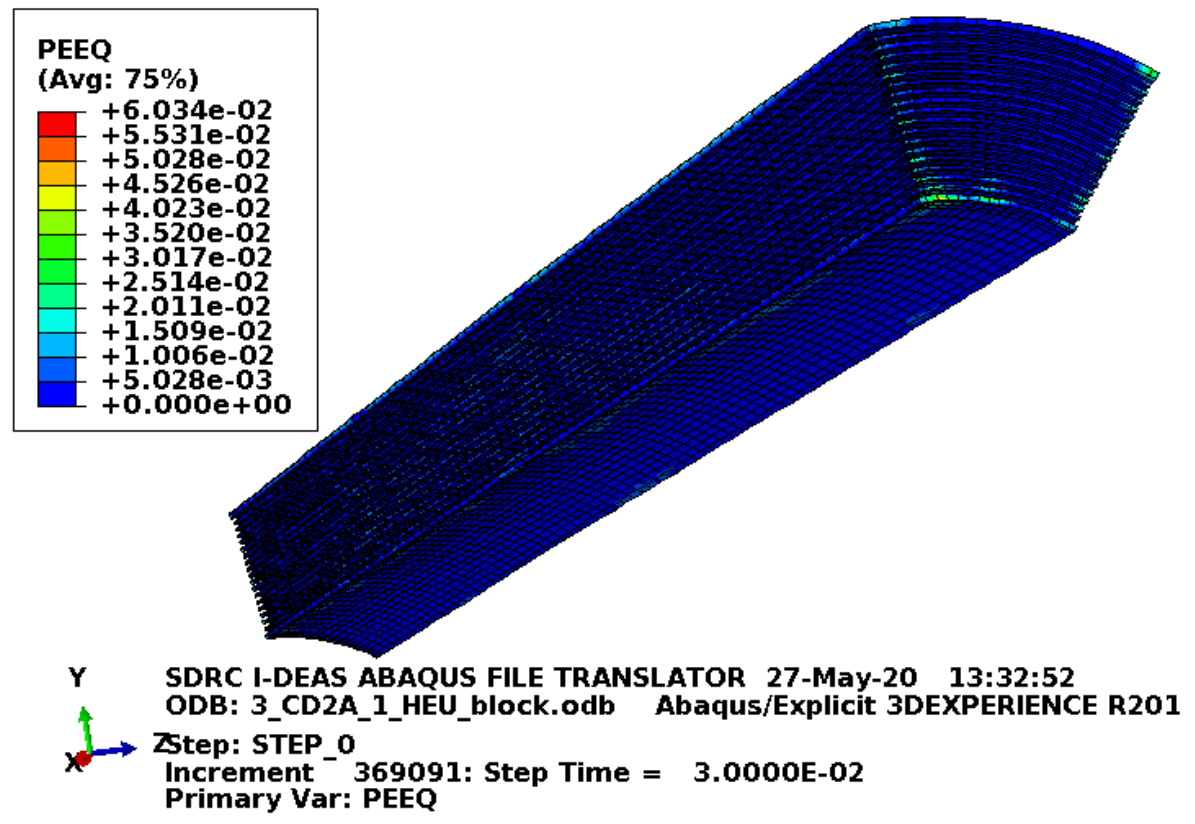

Figure D-46. Scope Part 1d (Table 3), Test 3 (Table 2) fuel plate equivalent strain. 
Figure D-46 shows the equivalent plastic strain in the fuel plates. Failure in these elements occurs at an equivalent plastic strain of $0.205 \mathrm{in}$./in. If element failure were to occur, the element would be removed from the model (thereby excluding its equivalent plastic strain from the maximum equivalent plastic strain for the plot). However, the missing element would be visible in the plot. Figure D-46 shows no failure in the fuel plates with margin.

\section{D2.4 Results for Scope Part 1 (Table 3), Test 5 (Table 2)}

The drop scenario considered in this section is a $30 \mathrm{ft}$ drop modeled as a flat side drop with the pockets and index lugs on the sides. It is identified as CD3-1 in the ATR FFSC SAR (2017).

\section{D2.4.1 Results for Scope Part 1a (Table 3), Test 5 (Table 2)}

The FEA model results for the Scope Part 1a (Table 3), Test 5 (Table 2) model are shown below in Figure D-47 to Figure D-49. The fuel element weighs $22.1 \mathrm{lbf}$ and the whole model is modeled with minimum material properties.

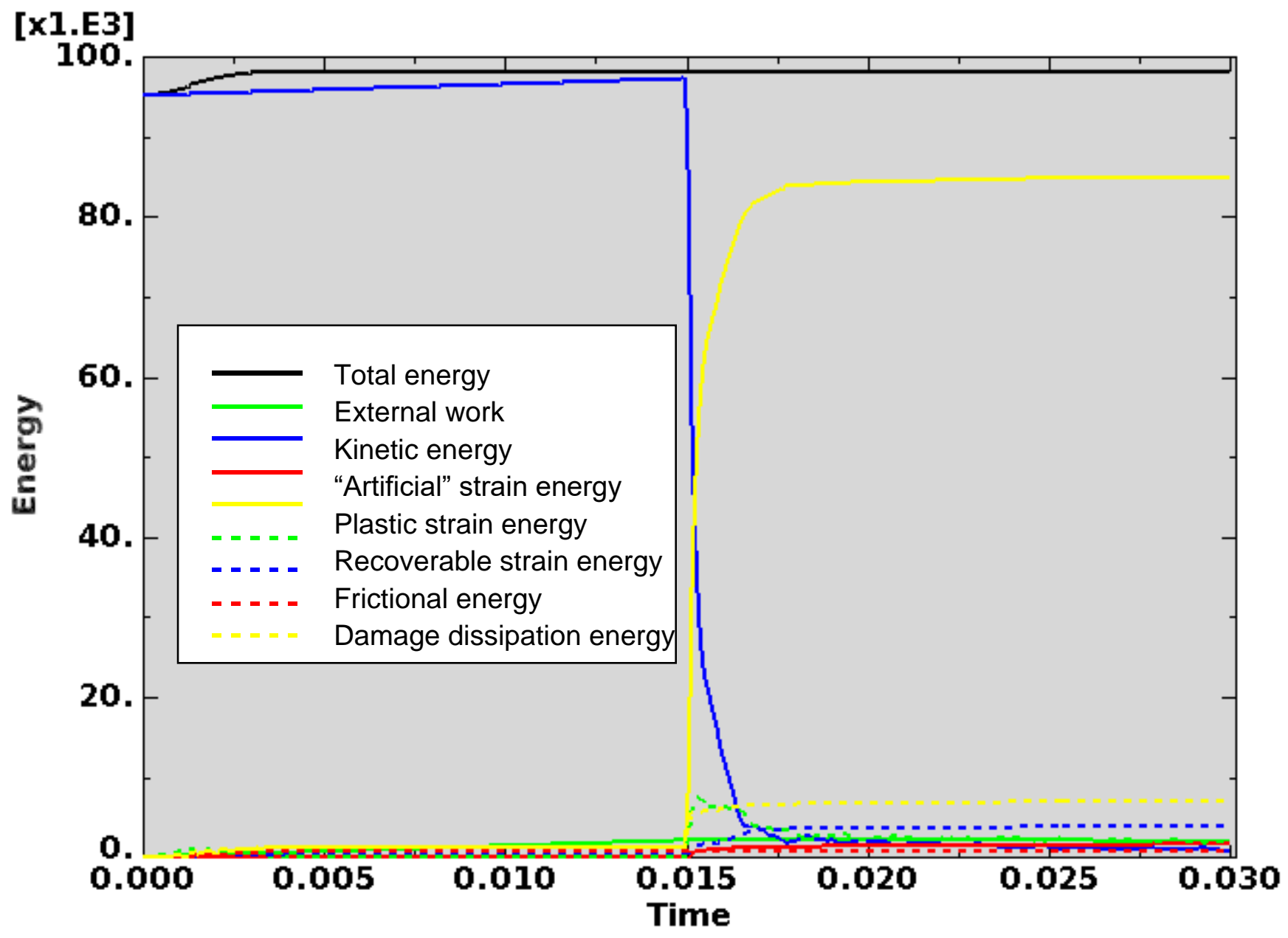

Figure D-47. Scope Part 1a (Table 3), Test 5 (Table 2) energy curves. 
Figure D-47 shows the energy curves for Scope Part 1a (Table 3), Test 5 (Table 2) drop scenario. These curves exhibit a stable shape. Artificial strain energy represents the energy required to keep reduced integration elements from taking on a zero-energy hourglass shape. As shown in Figure D-47, the artificial energy at the end of the model run is $1.7 \%$ of the total energy. Therefore, the potential error associated with artificial energy is not considered to be significant.

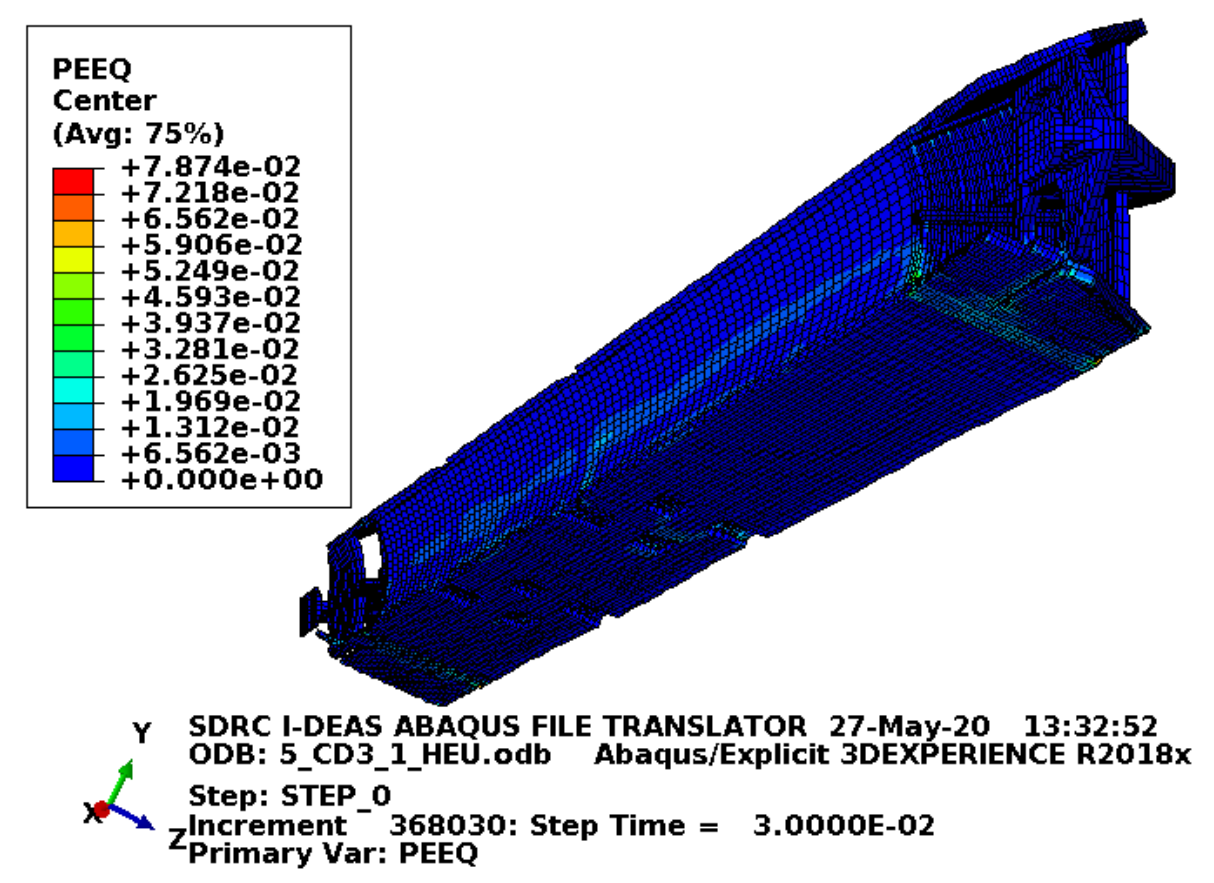

Figure D-48. Scope Part 1a (Table 3), Test 5 (Table 2) fuel element plastic equivalent strain.

Figure D-48 shows the equivalent plastic strain in the fuel element. Failure in the end box elements occurs at an equivalent plastic strain of $0.027 \mathrm{in}$./in. Failure in the end box weld elements occurs at an equivalent plastic strain of $0.032 \mathrm{in}$./in. Failure in the side plate and comb elements occurs at an equivalent plastic strain of $0.152 \mathrm{in./in.} \mathrm{Failure} \mathrm{in} \mathrm{the} \mathrm{side} \mathrm{plate} \mathrm{weld} \mathrm{elements} \mathrm{occurs} \mathrm{at} \mathrm{an} \mathrm{equivalent} \mathrm{plastic} \mathrm{strain} \mathrm{of}$ $0.205 \mathrm{in./in.} \mathrm{If} \mathrm{element} \mathrm{failure} \mathrm{were} \mathrm{to} \mathrm{occur,} \mathrm{the} \mathrm{element} \mathrm{would} \mathrm{be} \mathrm{removed} \mathrm{from} \mathrm{the} \mathrm{model} \mathrm{(thereby}$ excluding its equivalent plastic strain from the maximum equivalent plastic strain for the plot). However, the missing element would be visible in the plot. Figure D-48 shows failed elements in the end boxes and end box welds nearest the impact. Considering the discussion of physical drop results (see Section D2), it is difficult to establish what kind of fuel element damage might have happened in this drop scenario. 


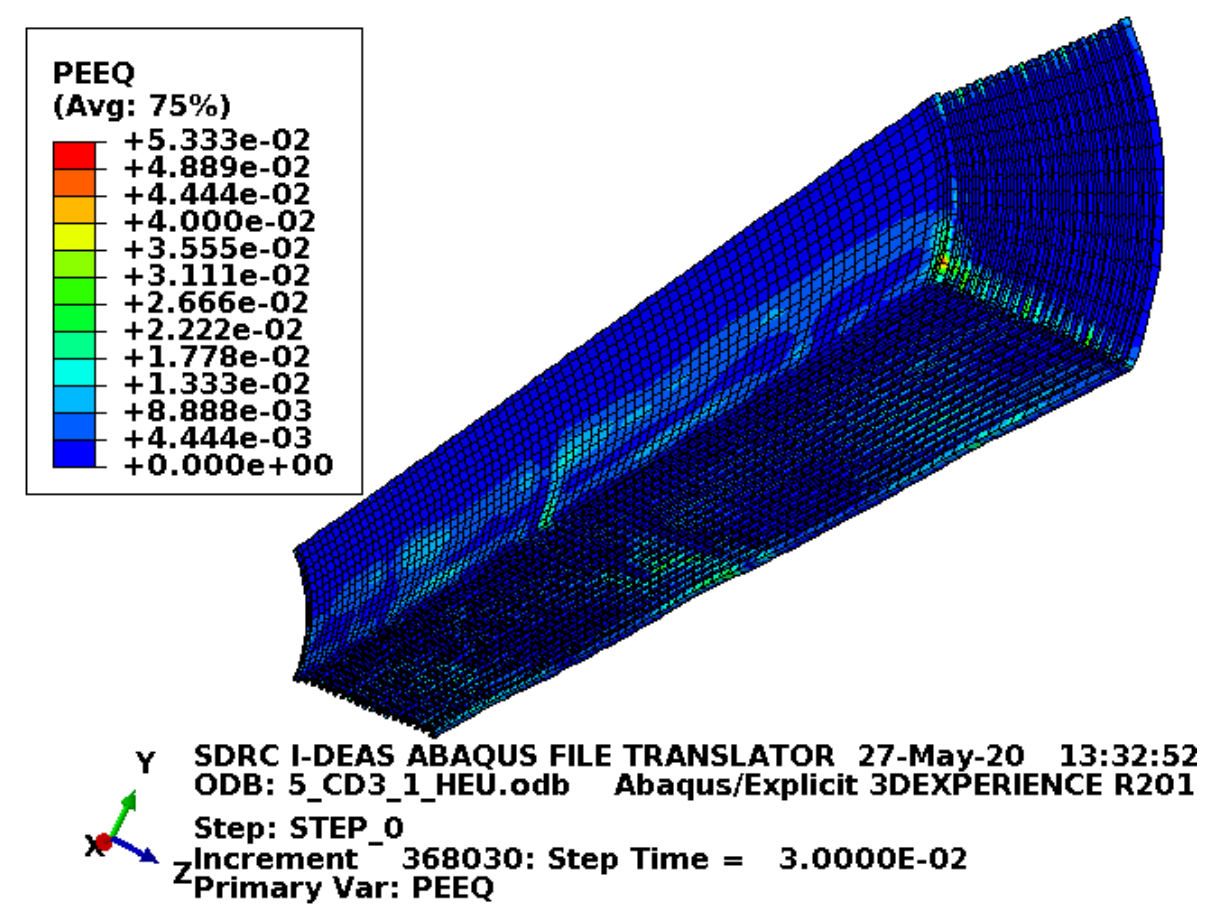

Figure D-49. Scope Part 1a (Table 3), Test 5 (Table 2) fuel plate equivalent strain.

Figure D-49 shows the equivalent plastic strain in the fuel plates. Failure in these elements occurs at an equivalent plastic strain of $0.205 \mathrm{in}$./in. If element failure were to occur, the element would be removed from the model (thereby excluding its equivalent plastic strain from the maximum equivalent plastic strain for the plot). However, the missing element would be visible in the plot. Figure D-49 shows no failure in the fuel plates with margin.

\section{D2.4.2 Results for Scope Part 1b (Table 3), Test 5 (Table 2)}

The FEA model results for the Scope Part $1 \mathrm{~b}$ (Table 3), Test 5 (Table 2) model are shown below in Figure D-50 to Figure D-52. The fuel element weighs $22.1 \mathrm{lbf}$ and the drop scenario is modeled with minimum material properties except the enclosure and end boxes, which are modeled with relatively tough material properties. 


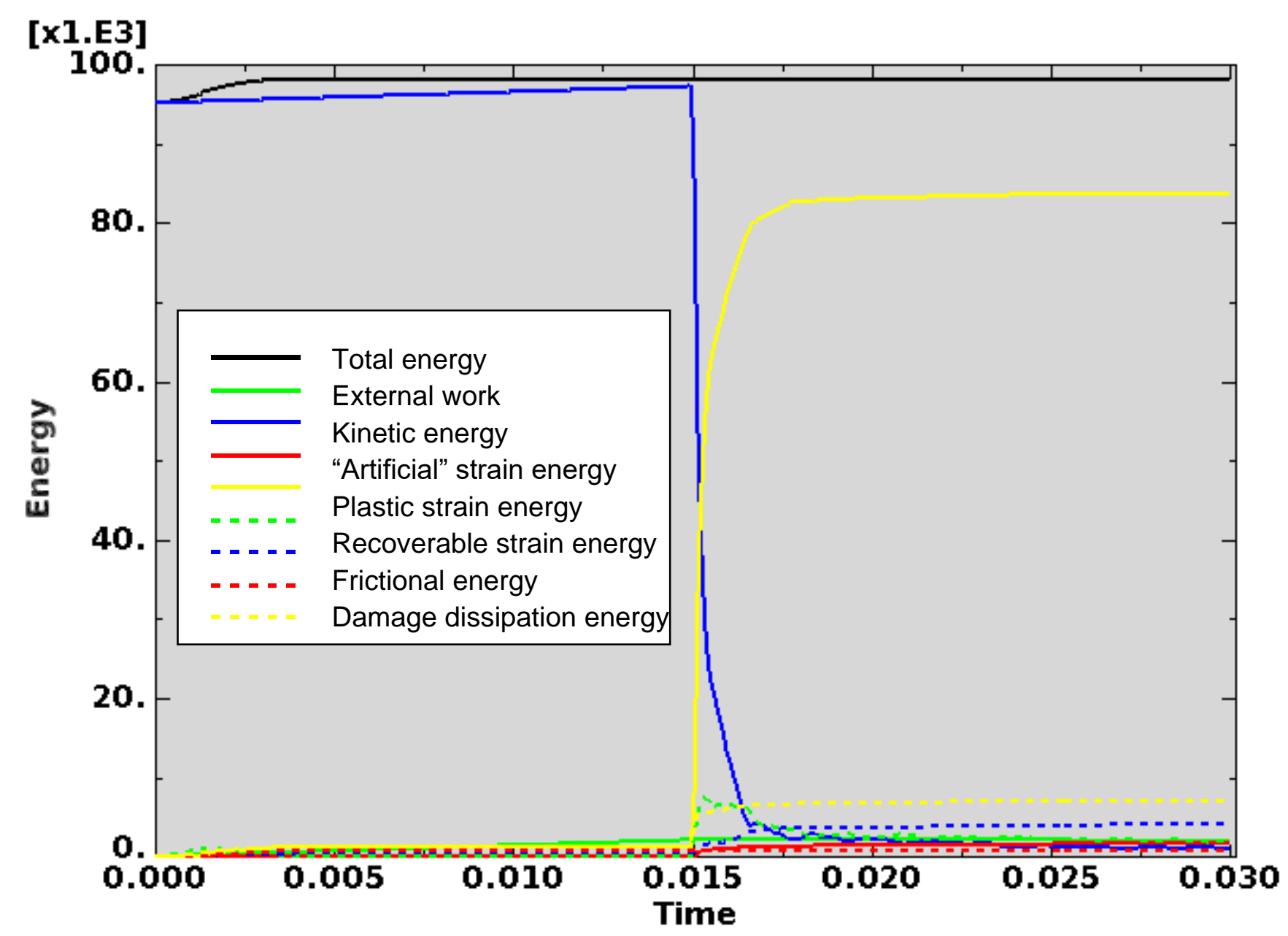

Figure D-50. Scope Part 1b (Table 3), Test 5 (Table 2) energy curves.

Figure D-50 shows the energy curves for Scope Part 1b (Table 3), Test 5 (Table 2) drop scenario. These curves exhibit a stable shape. Artificial strain energy represents the energy required to keep reduced integration elements from taking on a zero-energy hourglass shape. As shown in Figure D-50, the artificial energy at the end of the model run is $1.7 \%$ of the total energy. Therefore, the potential error associated with artificial energy is not considered to be significant. 
ENGINEERING CALCULATIONS AND ANALYSIS

Drop Analysis of the Advanced Test Reactor Fresh Fuel Shipping Container with Heavier Low-Enriched Uranium Fuel Contents

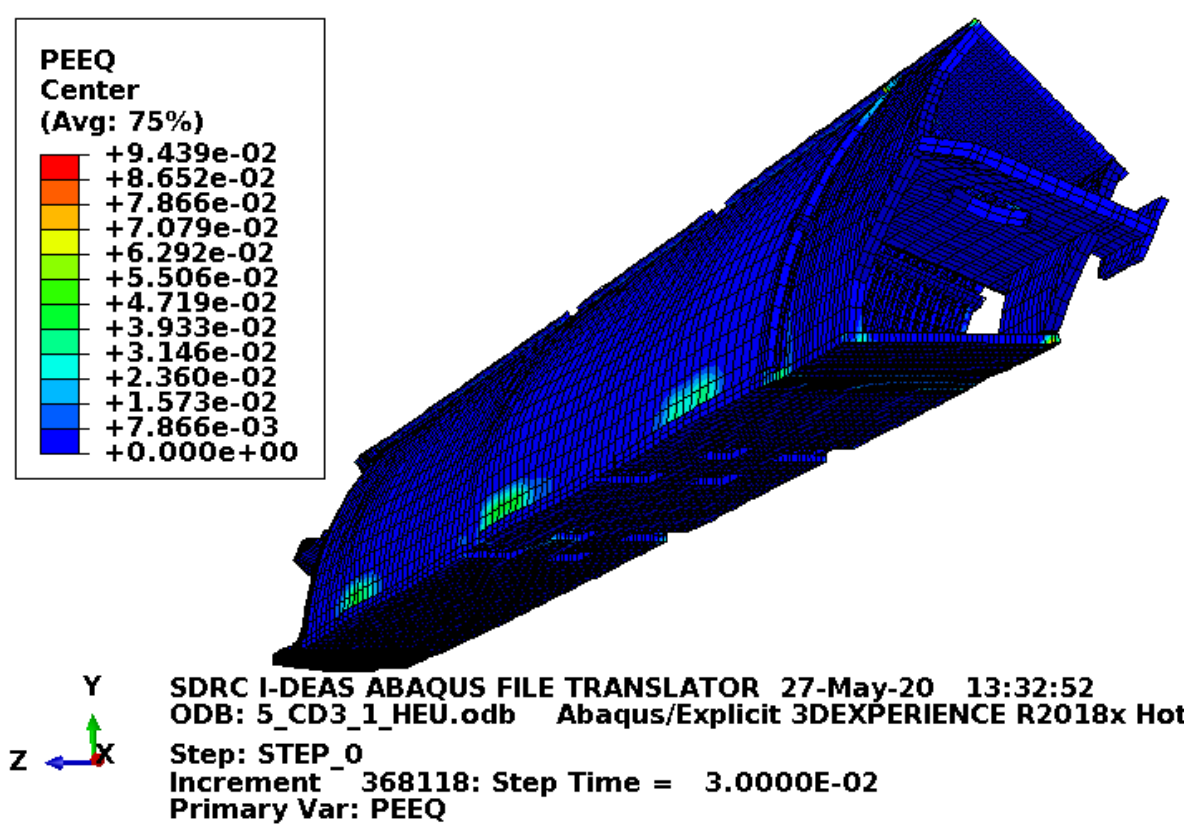

Figure D-51. Scope Part 1b (Table 3), Test 5 (Table 2) fuel element plastic equivalent strain.

Figure D-51 shows the equivalent plastic strain in the fuel element. Failure in the end box elements occurs at an equivalent plastic strain of $0.08 \mathrm{in./in.} \mathrm{(for} \mathrm{the} \mathrm{relatively} \mathrm{tough} \mathrm{material} \mathrm{properties).} \mathrm{Failure} \mathrm{in} \mathrm{the} \mathrm{end}$ box weld elements occurs at an equivalent plastic strain of $0.115 \mathrm{in}$./in. (for the relatively tough material properties). Failure in the side plate and comb elements occurs at an equivalent plastic strain of 0.152 in./in. Failure in the side plate weld elements occurs at an equivalent plastic strain of $0.205 \mathrm{in}$./in. If element failure were to occur, the element would be removed from the model (thereby excluding its equivalent plastic strain from the maximum equivalent plastic strain for the plot). However, the missing element would be visible in the plot. Figure D-51 shows no failure in the fuel element. There is significant plasticity, but it might not be visually obvious. Considering the discussion of physical drop results (see Section D2), it is difficult to establish what kind of fuel element damage might have happened in this drop scenario. 
ENGINEERING CALCULATIONS AND ANALYSIS

Drop Analysis of the Advanced Test Reactor Fresh Fuel Shipping Container with Heavier Low-Enriched Uranium Fuel Contents

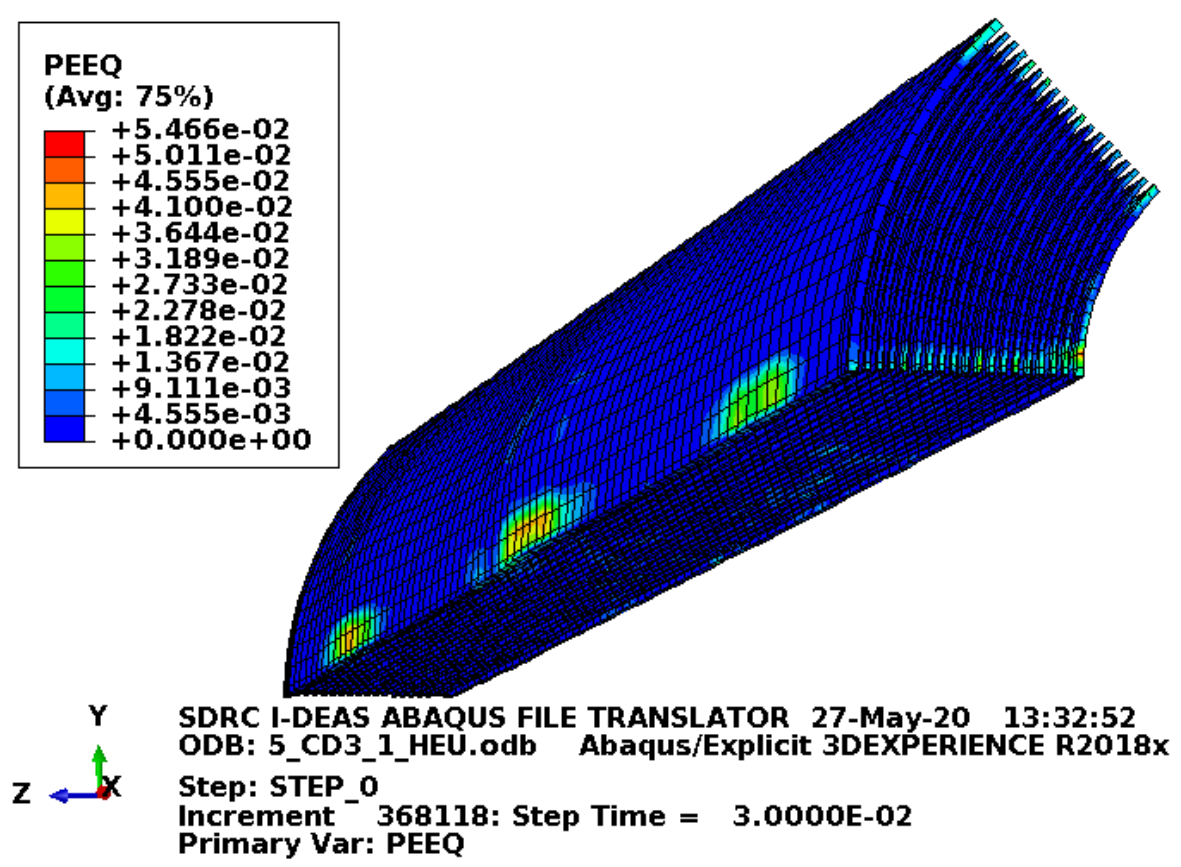

Figure D-52. Scope Part 1b (Table 3), Test 5 (Table 2) fuel plate equivalent strain.

Figure D-52 shows the equivalent plastic strain in the fuel plates. Failure in these elements occurs at an equivalent plastic strain of 0.205 in./in. If element failure were to occur, the element would be removed from the model (thereby excluding its equivalent plastic strain from the maximum equivalent plastic strain for the plot). However, the missing element would be visible in the plot. Figure D-52 shows no failure in the fuel plates with margin.

The three high strain locations in the outer plate (shown in Figure D-52) are where the ribs (in the body) give additional stiffness during the impact. This occurs in all of the Test 5 (Table 2) drop scenarios and can explain (at least in part) the deformations shown in the Figure D-9 and Figure D-10 of the physical drops. Figure D-9 and Figure D-10 only show fuel plate plasticity where it can be seen through the side plate vents. The location of the side vents relative to the fuel plate plasticity can be seen in Figure D-51.

\section{D2.4.3 Results for Scope Part 1c (Table 3), Test 5 (Table 2)}

The FEA model results for the Scope Part 1c (Table 3), Test 5 (Table 2) model are shown below in Figure D-53 to Figure D-55. The fuel element weighs $22.1 \mathrm{lbf}$ and the whole model is modeled with minimum material properties. Though ATR FFSC SAR (2017) shows the Scope Part 1 (Table 3) drop scenarios to be acceptable, the results shown (for information) in this section include the blocks as added fuel plate protection. 


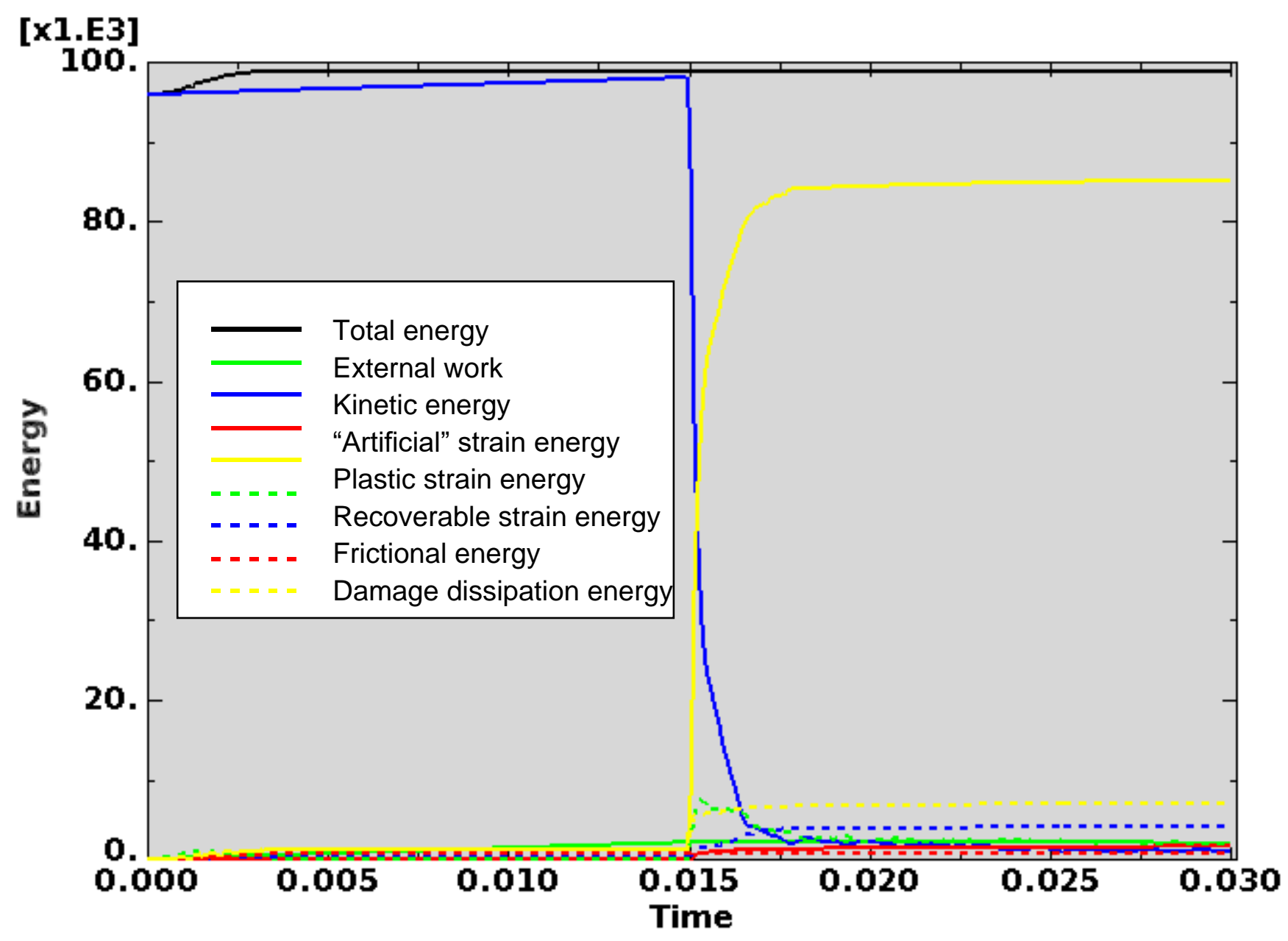

Figure D-53. Scope Part 1c (Table 3), Test 5 (Table 2) energy curves.

Figure D-53 shows the energy curves for Scope Part 1c (Table 3), Test 5 (Table 2) drop scenario. These curves exhibit a stable shape. Artificial strain energy represents the energy required to keep reduced integration elements from taking on a zero-energy hourglass shape. As shown in Figure D-53, the artificial energy at the end of the model run is $1.7 \%$ of the total energy. Therefore, the potential error associated with artificial energy is not considered to be significant. 
ENGINEERING CALCULATIONS AND ANALYSIS

Drop Analysis of the Advanced Test Reactor Fresh Fuel Shipping Container with Heavier Low-Enriched Uranium Fuel Contents

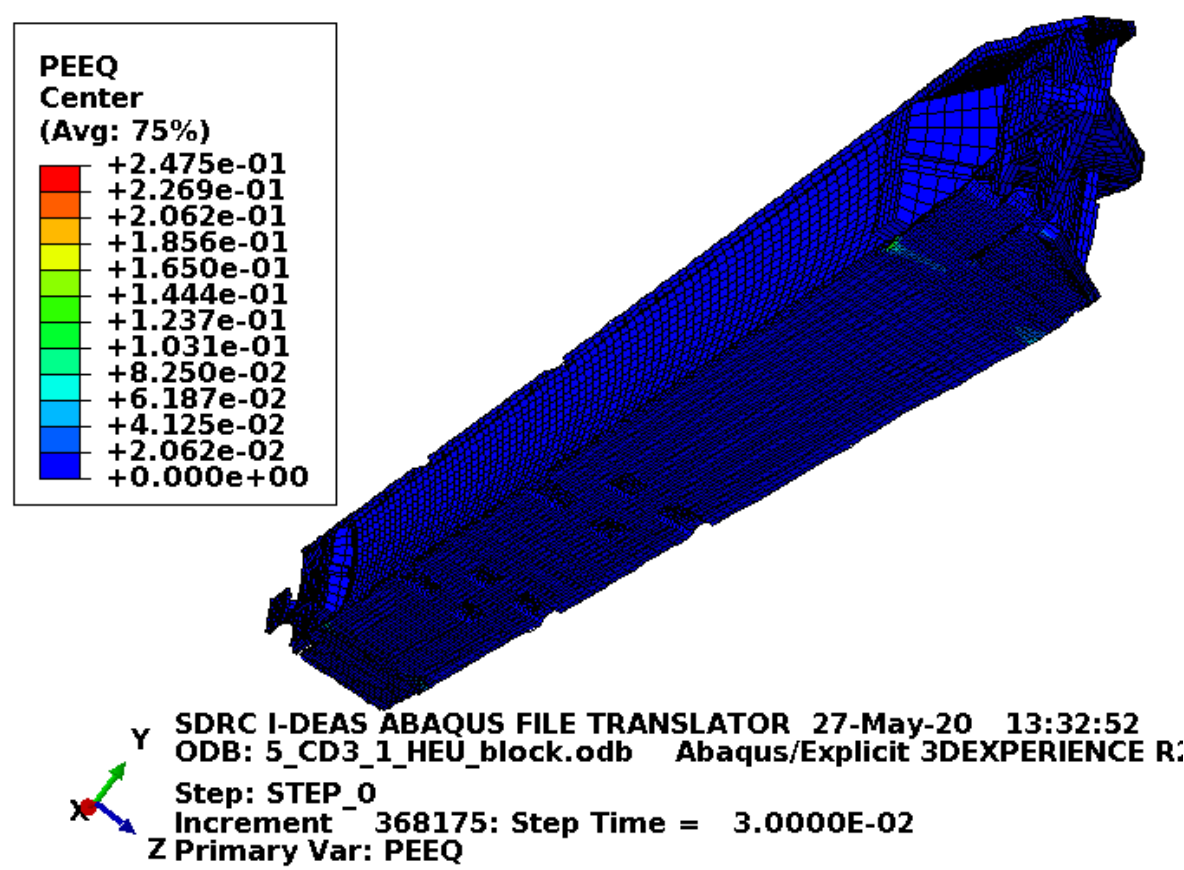

Figure D-54. Scope Part 1c (Table 3), Test 5 (Table 2) fuel element plastic equivalent strain.

Figure D-54 shows the equivalent plastic strain in the fuel element. Failure in the end box elements occurs at an equivalent plastic strain of $0.027 \mathrm{in}$./in. Failure in the end box weld elements occurs at an equivalent plastic strain of $0.032 \mathrm{in}$./in. Failure in the side plate and comb elements occurs at an equivalent plastic strain of $0.152 \mathrm{in} . / \mathrm{in}$. Failure in the side plate weld elements occurs at an equivalent plastic strain of $0.205 \mathrm{in}$./in. If element failure were to occur, the element would be removed from the model (thereby excluding its equivalent plastic strain from the maximum equivalent plastic strain for the plot). However, the missing element would be visible in the plot. Figure D-54 shows failed elements in the end boxes and end box welds nearest the impact. 
ENGINEERING CALCULATIONS AND ANALYSIS

Drop Analysis of the Advanced Test Reactor Fresh Fuel Shipping Container with Heavier Low-Enriched Uranium Fuel Contents

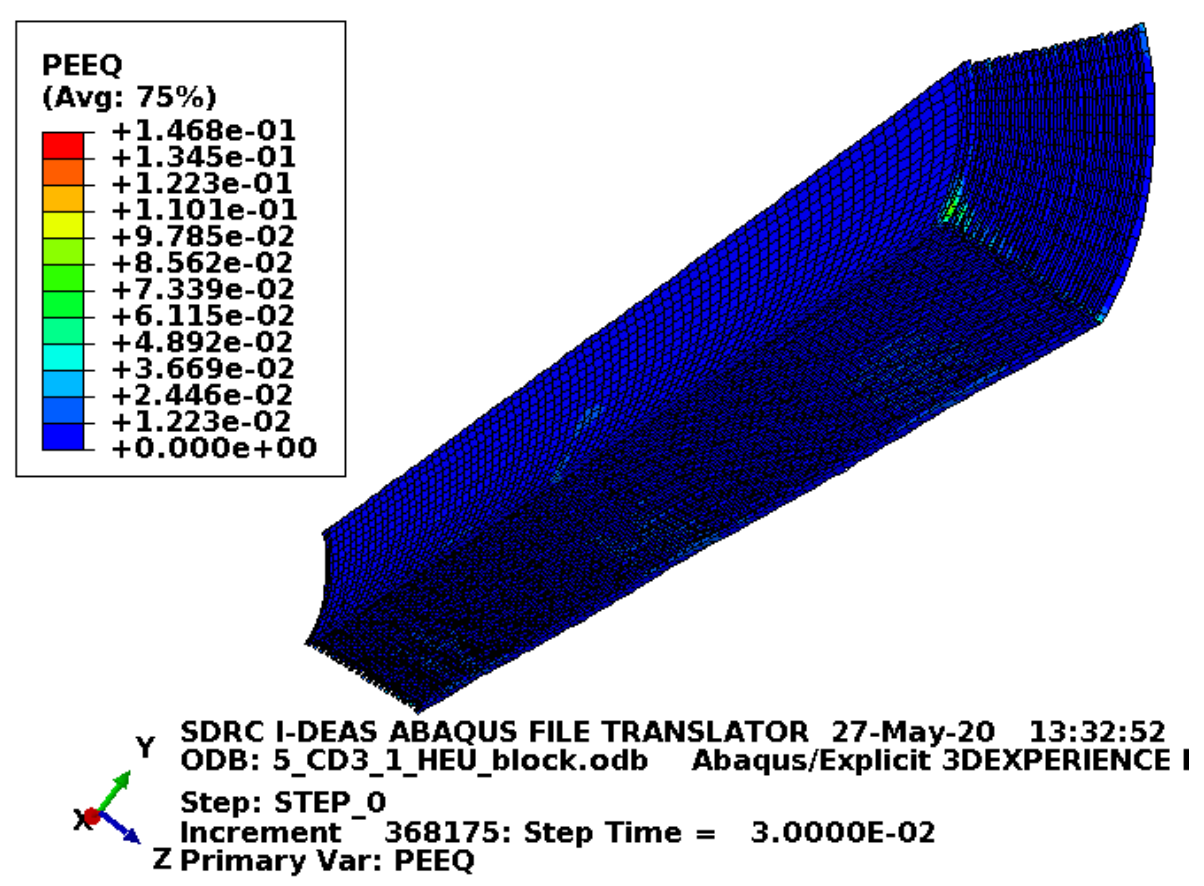

Figure D-55. Scope Part 1c (Table 3), Test 5 (Table 2) fuel plate equivalent strain.

Figure D-55 shows the equivalent plastic strain in the fuel plates. Failure in these elements occurs at an equivalent plastic strain of $0.205 \mathrm{in}$./in. If element failure were to occur, the element would be removed from the model (thereby excluding its equivalent plastic strain from the maximum equivalent plastic strain for the plot). However, the missing element would be visible in the plot. Figure D-55 shows no failure in the fuel plates with margin.

\section{D2.4.4 Results for Scope Part 1d (Table 3), Test 5 (Table 2)}

The FEA model results for the Scope Part 1d (Table 3), Test 5 (Table 2) model are shown below in Figure D-56 to Figure D-58. The fuel element weighs $22.1 \mathrm{lbf}$ and the drop scenario is modeled with minimum material properties except the enclosure and end boxes, which are modeled with relatively tough material properties. Though ATR FFSC SAR (2017) shows the Scope Part 1 (Table 3) drop scenarios to be acceptable, the results shown (for information) in this section include the blocks as added fuel plate protection. 


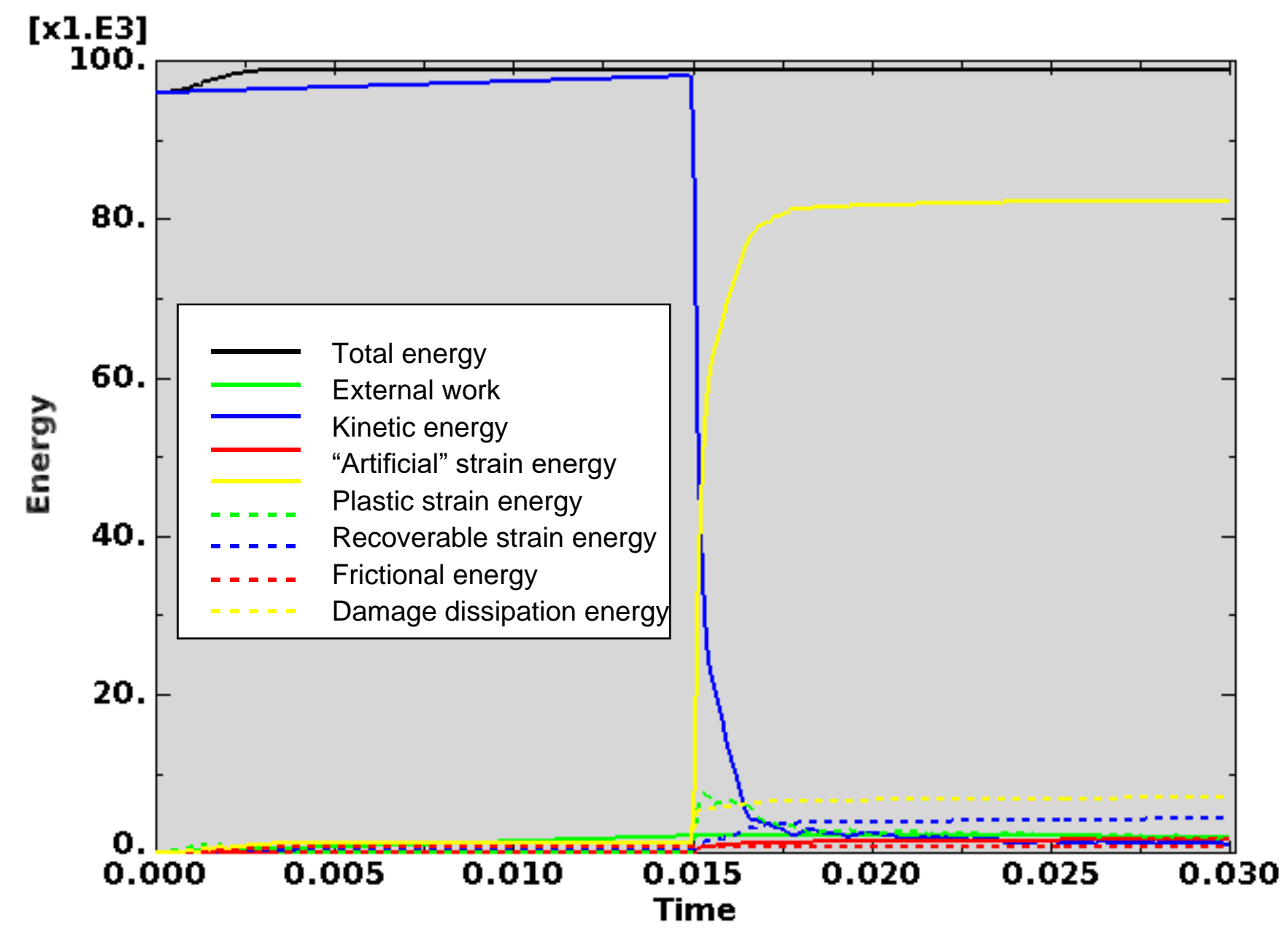

Figure D-56. Scope Part 1d (Table 3), Test 5 (Table 2) energy curves.

Figure D-56 shows the energy curves for Scope Part 1d (Table 3), Test 5 (Table 2) drop scenario. These curves exhibit a stable shape. Artificial strain energy represents the energy required to keep reduced integration elements from taking on a zero-energy hourglass shape. As shown in Figure D-56, the artificial energy at the end of the model run is $1.7 \%$ of the total energy. Therefore, the potential error associated with artificial energy is not considered to be significant. 
ENGINEERING CALCULATIONS AND ANALYSIS

Drop Analysis of the Advanced Test Reactor Fresh Fuel Shipping Container with Heavier Low-Enriched Uranium Fuel Contents

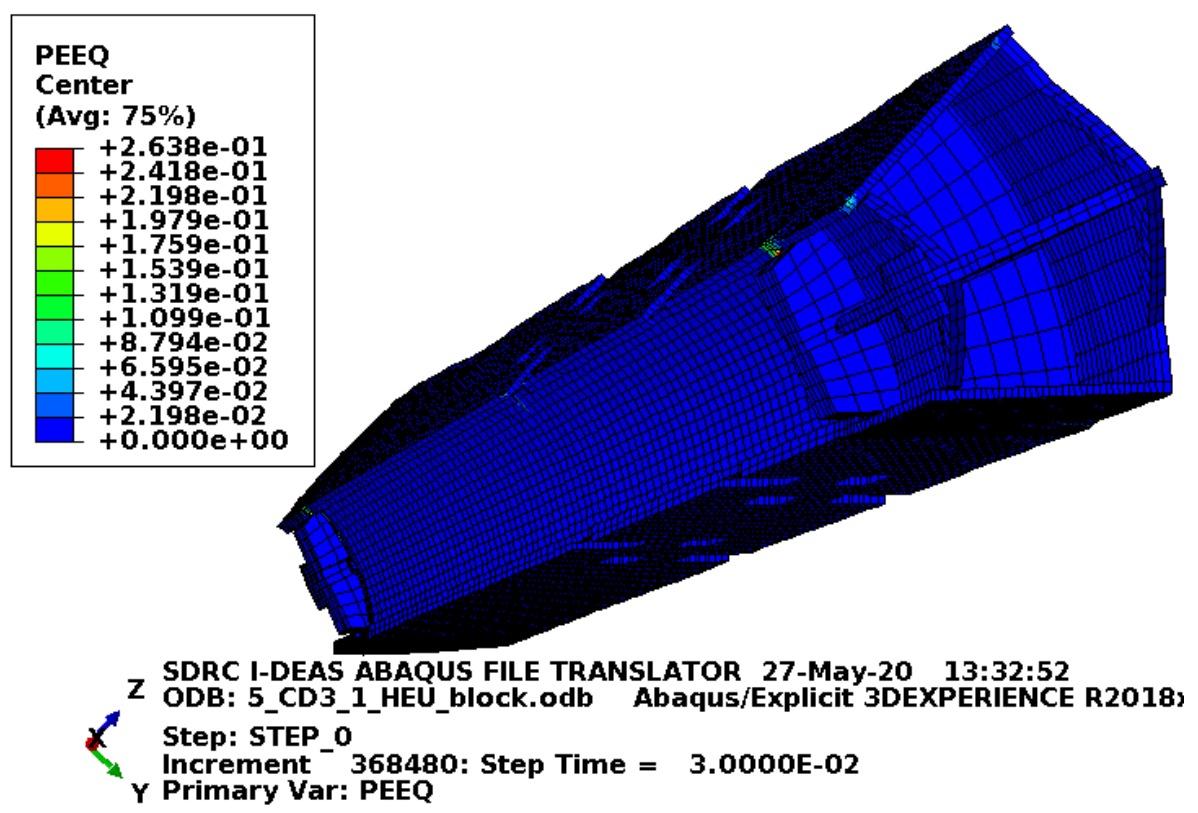

Figure D-57. Scope Part 1d (Table 3), Test 5 (Table 2) fuel element plastic equivalent strain.

Figure D-57 shows the equivalent plastic strain in the fuel element. Failure in the end box elements occurs at an equivalent plastic strain of $0.08 \mathrm{in./in.} \mathrm{(for} \mathrm{the} \mathrm{relatively} \mathrm{tough} \mathrm{material} \mathrm{properties).} \mathrm{Failure} \mathrm{in} \mathrm{the} \mathrm{end}$ box weld elements occurs at an equivalent plastic strain of $0.115 \mathrm{in}$./in. (for the relatively tough material properties). Failure in the side plate and comb elements occurs at an equivalent plastic strain of 0.152 in./in. Failure in the side plate weld elements occurs at an equivalent plastic strain of $0.205 \mathrm{in}$./in. If element failure were to occur, the element would be removed from the model (thereby excluding its equivalent plastic strain from the maximum equivalent plastic strain for the plot). However, the missing element would be visible in the plot. Figure D-57 shows no failure in the fuel element or blocks, but an above failure strain value is shown in an end box weld element. This very local strain results from impact with the block. The strains shown above the failure strain likely result from extrapolation (as integration point strains are the important strains for failure). It is of no consequence if this element were considered as having failed. 
ENGINEERING CALCULATIONS AND ANALYSIS

Drop Analysis of the Advanced Test Reactor Fresh Fuel Shipping Container with Heavier Low-Enriched Uranium Fuel Contents

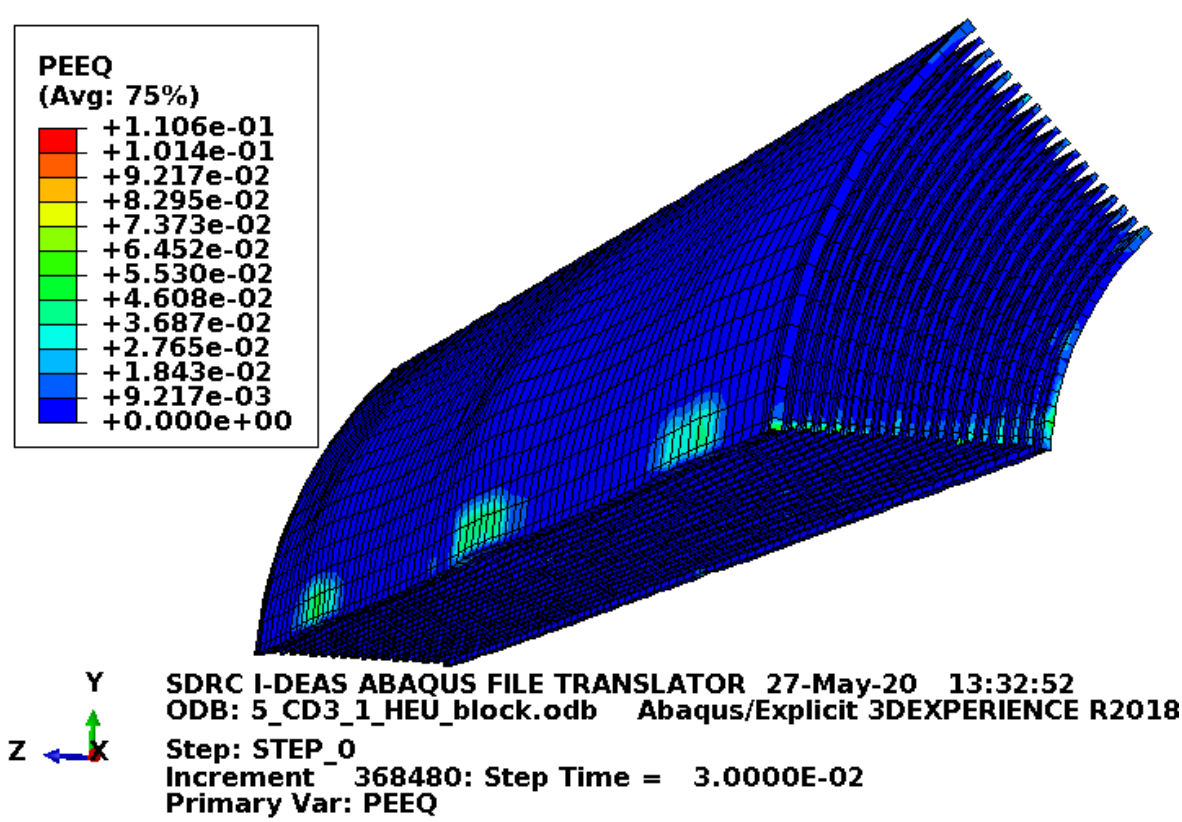

Figure D-58. Scope Part 1d (Table 3), Test 5 (Table 2) fuel plate equivalent strain.

Figure D-58 shows the equivalent plastic strain in the fuel plates. Failure in these elements occurs at an equivalent plastic strain of $0.205 \mathrm{in}$./in. If element failure were to occur, the element would be removed from the model (thereby excluding its equivalent plastic strain from the maximum equivalent plastic strain for the plot). However, the missing element would be visible in the plot. Figure D-58 shows no failure in the fuel plates with margin.

\section{D2.5 Results for Scope Part 1 (Table 3), Test 6 (Table 2)}

The drop scenario considered in this section is a $30 \mathrm{ft}$ drop modeled as a vertical bottom impact. It is identified as CD4-1 in the ATR FFSC SAR (2017).

For this drop scenario, Abaqus (2018) appears to have trouble with some models. The problems seem to result from interaction between partially failed fuel element components near the end of a model run. While the motion of the models appears to remain stable, the total energy begins to rise. In some cases where the contact is complex between failed components, there are some localized places where contact should occur, but it appears to be missed. This may reduce damage in some places that should have occurred. Though globally, there is always sufficient contact in these areas to produce rebound. Therefore, the overall energy that is causing damage is applied. This problem does not seem to be remedied with the applied mesh refinement. Also, internal face contact and added nodal contact scoping models did not seem to remedy the problem. Additionally, scoping models indicated that running a model for an extended time could produce added damage when no significant interaction is occurring. Consequently, the problematic models do appear to be heading toward an unstable solution. It is likely that significant error does not occur until significantly after rebound. 
In the physical drops, this was the only bottom drop. It was preceded by a $4 \mathrm{ft}$ center of gravity over the top corner and four $30 \mathrm{ft}$ side drops. After the first side drop, the ATR FFSC SAR (2017) stated that there was no visible damage to the fuel element (as discussed in Section D2). Given this limited information, the damage shown in Figure D-7 and Figure D-8 is credited to this drop scenario. Even with the FEA model energy curve trouble in the models that best represent the physical drop, the results still compare well with the physical drop. Consequently, the results will be considered even with the FEA models having some energy curve trouble. For models showing a total energy increase, output is shown at the first output frame after fuel element rebound. This is done to minimize rise in total energy while capturing the important damage. Ultimately, the desire is to demonstrate that the FEA models produce reasonable and conservative results when compared to the physical drop results. This then lends confidence of getting reasonable and conservative results when the fuel element weight is increased for the LOWE fuel element.

\section{D2.5.1 Results for Scope Part 1a (Table 3), Test 6 (Table 2)}

The FEA model results for the Scope Part 1a (Table 3), Test 6 (Table 2) model are shown below in Figure D-59 to Figure D-63. The fuel element weighs $22.1 \mathrm{lbf}$ and the whole model is modeled with minimum material properties.

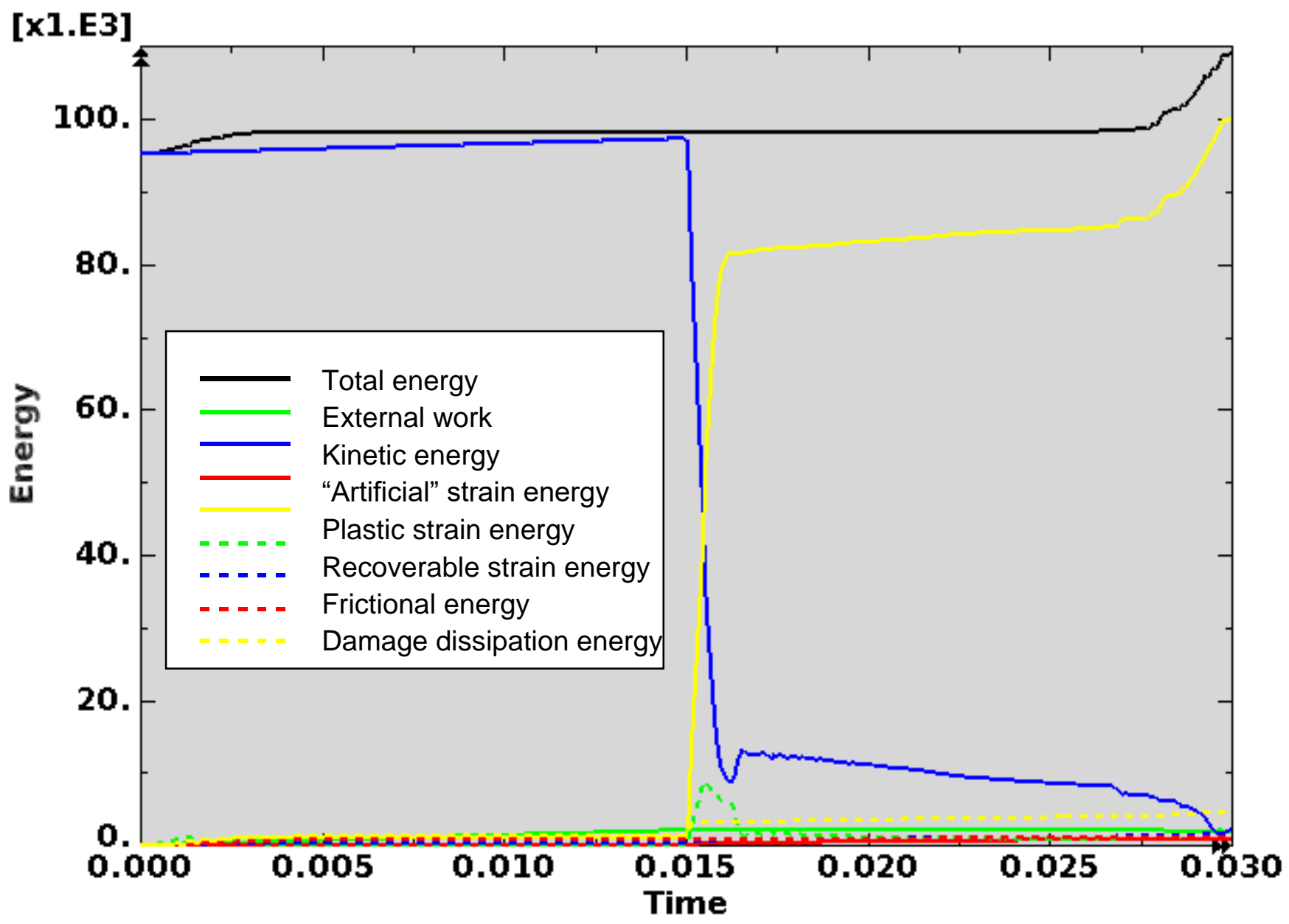

Figure D-59. Scope Part 1a (Table 3), Test 6 (Table 2) energy curves. 
Figure D-59 shows the energy curves for Scope Part 1a (Table 3), Test 6 (Table 2) drop scenario. These curves exhibit mostly stable behavior. Near the end of the model run, the total energy and plastic strain energy start to show undesirable behavior. As discussed in Section D2.5 this appears to result from contact difficultly between failed portions of the fuel element. Consequently, output is shown at the first output frame after fuel element rebound ( 0.030 second) to try to minimize potential error associated with this.

Artificial strain energy represents the energy required to keep reduced integration elements from taking on a zero-energy hourglass shape. As shown in Figure D-59, the artificial energy at the end of the model run is $1.0 \%$ of the total energy. Therefore, the potential error associated with artificial energy is not considered to be significant.

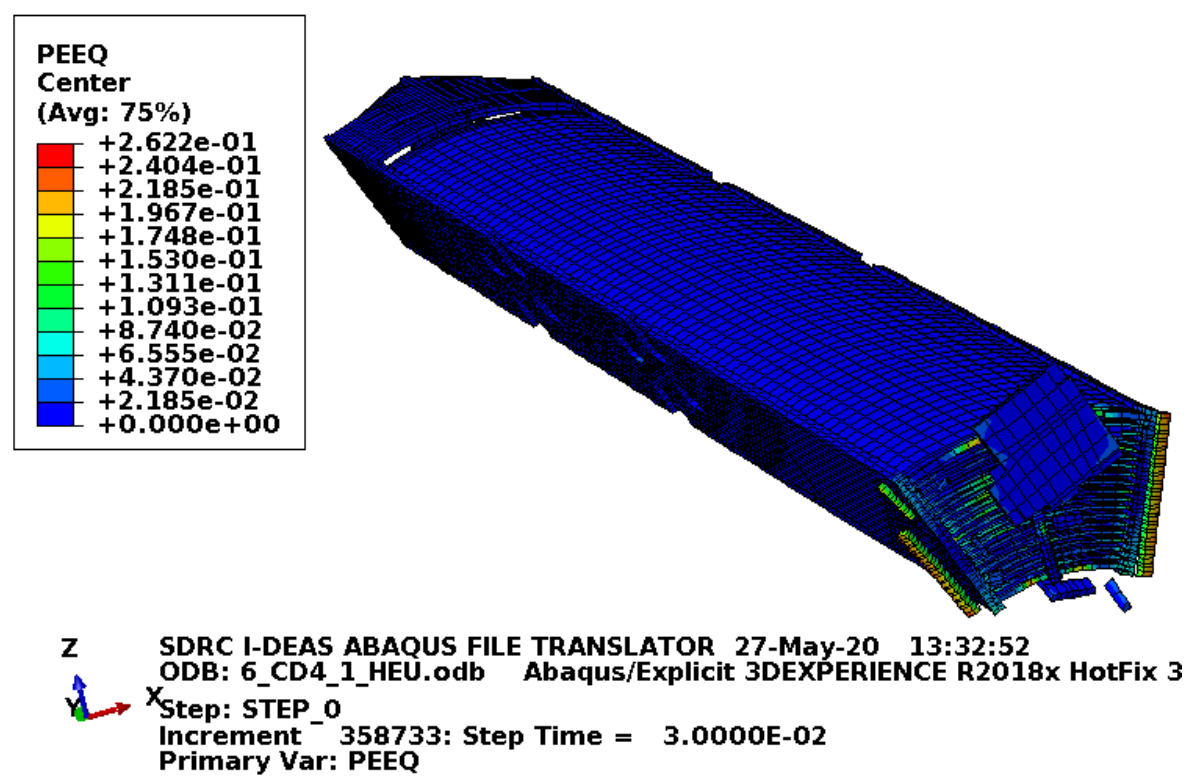

Figure D-60. Scope Part 1a (Table 3), Test 6 (Table 2) fuel element plastic equivalent strain.

Figure D-60 shows the equivalent plastic strain in the fuel element. Failure in the end box elements occurs at an equivalent plastic strain of $0.027 \mathrm{in}$./in. Failure in the end box weld elements occurs at an equivalent plastic strain of $0.032 \mathrm{in}$./in. Failure in the side plate and comb elements occurs at an equivalent plastic strain of $0.152 \mathrm{in}$./in. Failure in the side plate weld elements occurs at an equivalent plastic strain of 0.205 in./in. Figure D-60 shows extensive failure in the end box and fuel plates nearest the impact. 
ENGINEERING CALCULATIONS AND ANALYSIS

Drop Analysis of the Advanced Test Reactor Fresh Fuel Shipping Container with Heavier Low-Enriched Uranium Fuel Contents
ECAR-5224, Rev. 0

Page D56 of D293

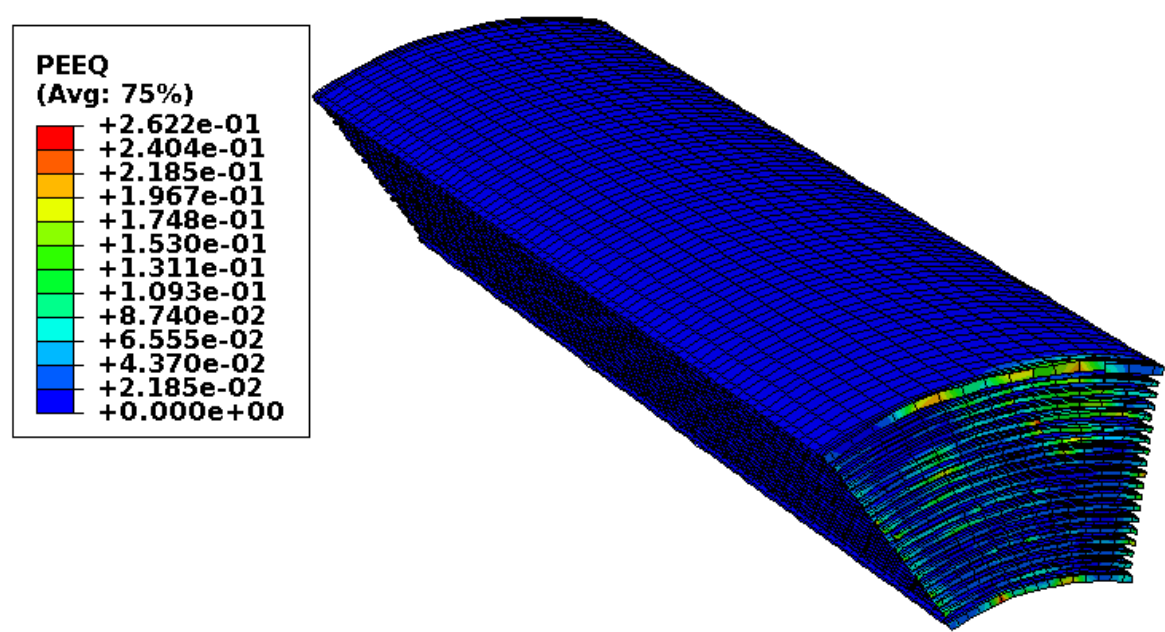

$Z \quad$ SDRC I-DEAS ABAQUS FILE TRANSLATOR 27-May-20 13:32:52

ODB: 6_CD4_1_HEU.odb Abaqus/Explicit 3DEXPERIENCE R2018x HotFix

$X_{\text {Step: STEP_o }}$

Increment 358733: Step Time $=3.0000 \mathrm{E}-02$

Primary Var: PEEQ

Figure D-61. Scope Part 1a (Table 3), Test 6 (Table 2) fuel plate equivalent strain.

Figure D-61 shows the equivalent plastic strain in the fuel plates. Failure in these elements occurs at an equivalent plastic strain of $0.205 \mathrm{in}$./in. If element failure were to occur, the element would be removed from the model (thereby excluding its equivalent plastic strain not included in the maximum equivalent plastic strain for the plot). However, the missing element would be visible in the plot. Figure D-61 shows some element failure in the end nearest the impact. 


\section{ENGINEERING CALCULATIONS AND ANALYSIS}

Drop Analysis of the Advanced Test Reactor Fresh Fuel Shipping Container with Heavier Low-Enriched Uranium Fuel Contents
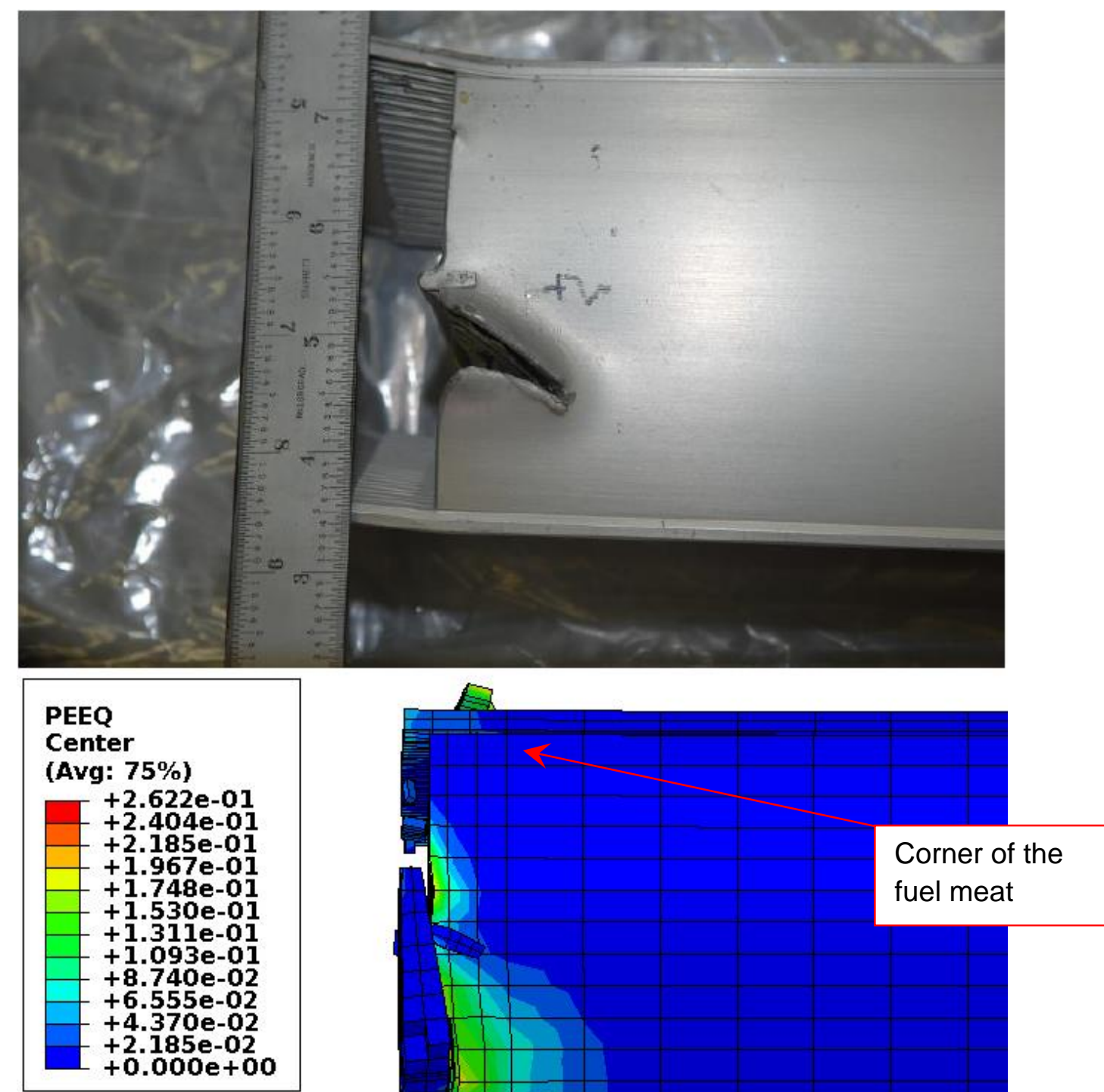

SDRC I-DEAS ABAQUS FILE TRANSLATOR 27-May-20 13:32:52 ODB: 6_CD4_1_HEU.odb Abaqus/Explicit 3DEXPERIENCE R2018:

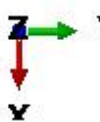
Step: STEP 0 Increment 358733 : Step Time $=3.0000 E-02$ Primary Var: PEEQ

Figure D-62. Scope Part 1a (Table 3), Test 6 (Table 2) damage comparison with Figure D-8.

The FEA model in Figure D-62 is the fuel element with only failed elements not visible. The damage comparison shows that the end box did not stay together well enough or did not get properly trapped such that it cut into the fuel plates similar to the physical drop. 
ENGINEERING CALCULATIONS AND ANALYSIS

Drop Analysis of the Advanced Test Reactor Fresh Fuel Shipping Container with Heavier Low-Enriched Uranium Fuel Contents
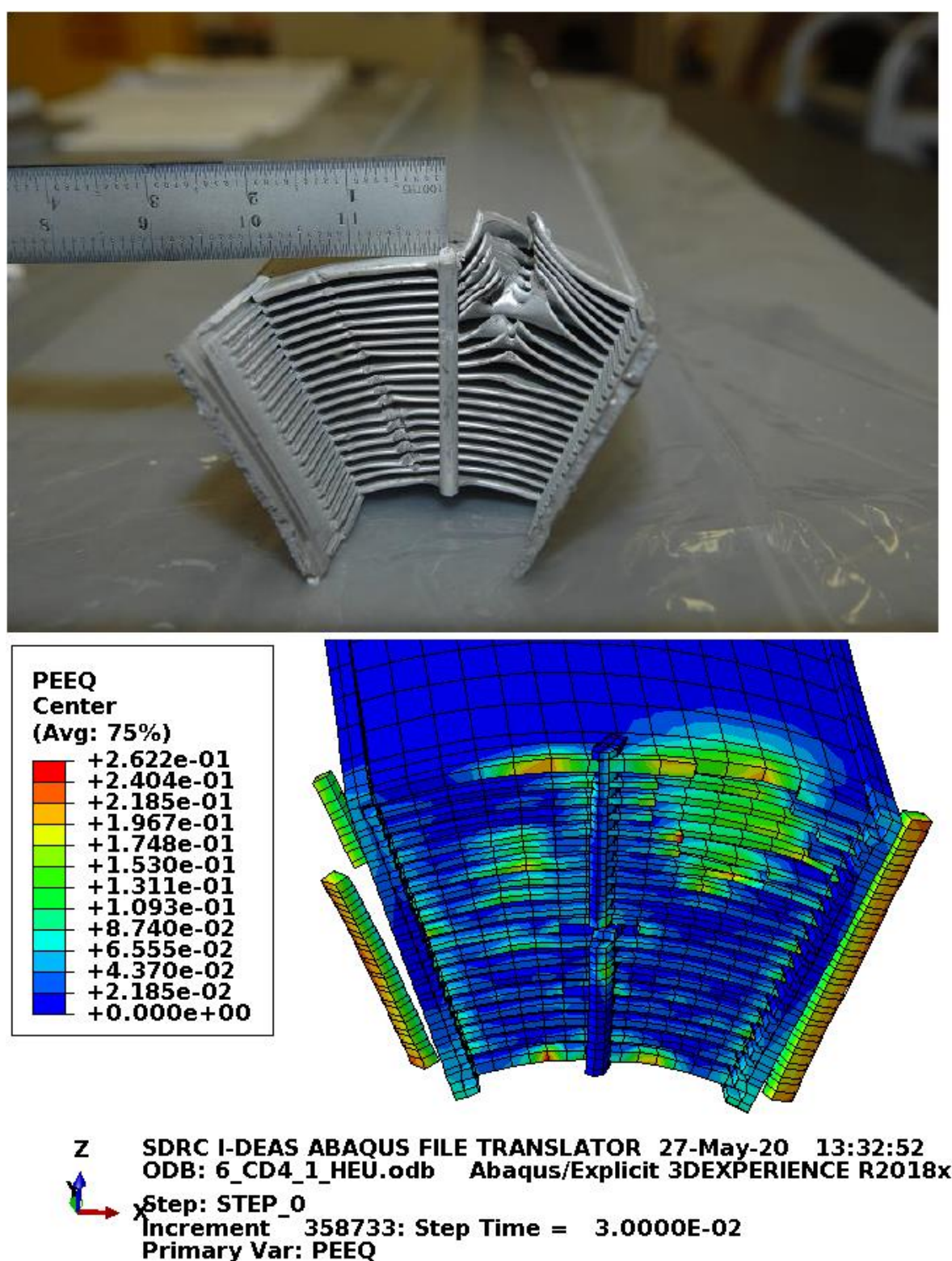

Figure D-63. Scope Part 1a (Table 3), Test 6 (Table 2) damage comparison with Figure D-7.

The FEA model in Figure D-63 has the end boxes and end box welds removed. The damage comparison shows much less plastic deformation in the FEA model. Though, the volume of failed elements might be similar to the physical drop failed volume. With minimum material properties in the end box, it did not appear to hold together well enough to do damage like in the physical drop.

\section{D2.5.2 Results for Scope Part 1a (Table 3), Test 6 (Table 2) Fine Mesh}

The FEA model results for the Scope Part 1a (Table 3), Test 6 (Table 2) fine mesh model are shown below in Figure D-64 to Figure D-68. The fuel element weighs $22.1 \mathrm{lbf}$ and the whole model is modeled with minimum material properties. 


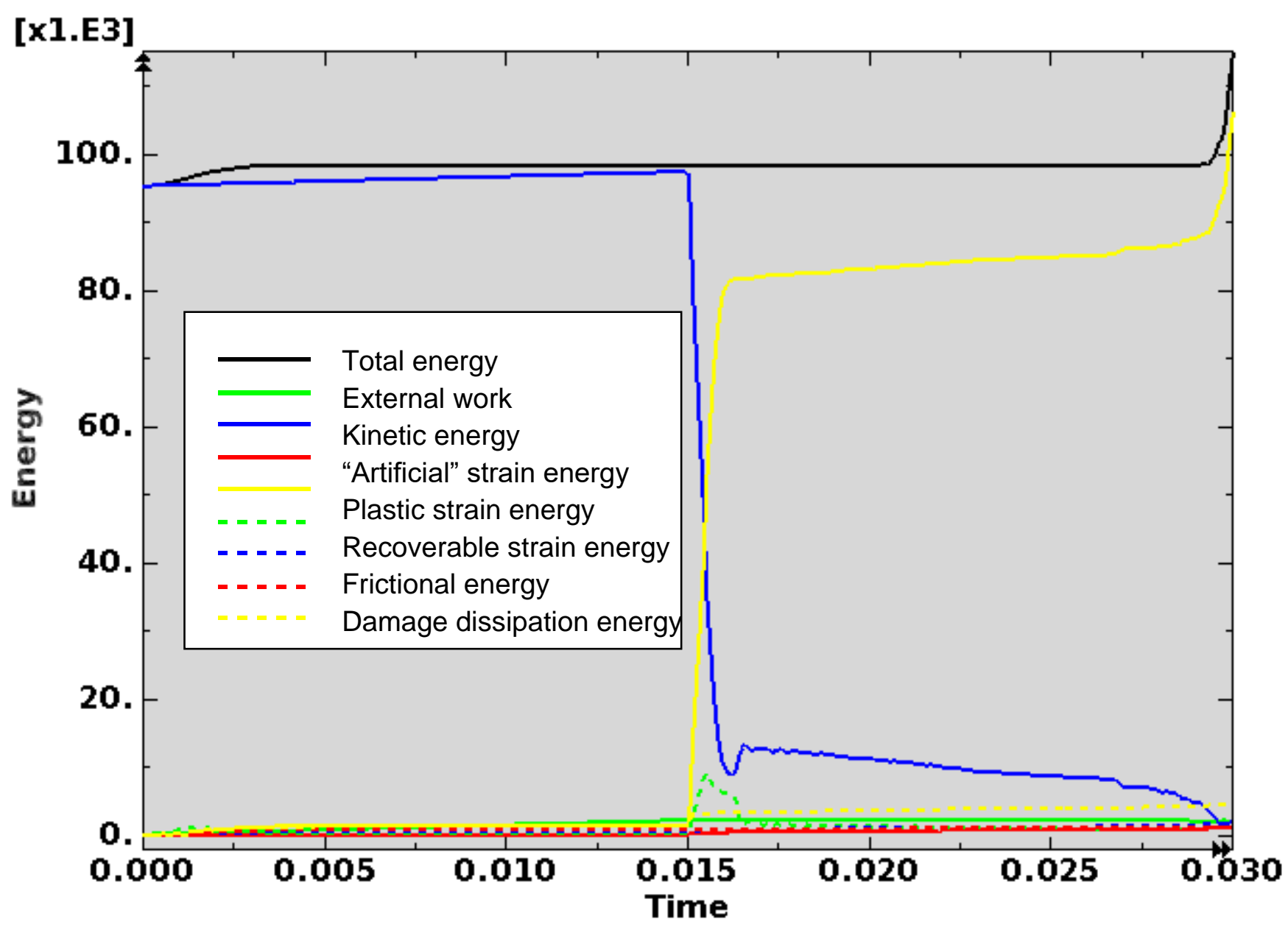

Figure D-64. Scope Part 1a (Table 3), Test 6 (Table 2) fine mesh energy curves.

Figure D-64 shows the energy curves for Scope Part 1a (Table 3), Test 6 (Table 2) fine mesh drop scenario. These curves exhibit mostly stable behavior. Near the end of the model run, the total energy and plastic strain energy start to show undesirable behavior. As discussed in Section D2.5 this appears to result from contact difficultly between failed portions of the fuel element. Consequently, output is shown at the first output frame after fuel element rebound $(0.030$ second) to try to minimize potential error associated with this.

Artificial strain energy represents the energy required to keep reduced integration elements from taking on a zero-energy hourglass shape. As shown in Figure D-64, the artificial energy at the end of the model run is $0.8 \%$ of the total energy. Therefore, the potential error associated with artificial energy is not considered to be significant. 
ENGINEERING CALCULATIONS AND ANALYSIS

Drop Analysis of the Advanced Test Reactor Fresh Fuel Shipping Container with Heavier Low-Enriched Uranium Fuel Contents

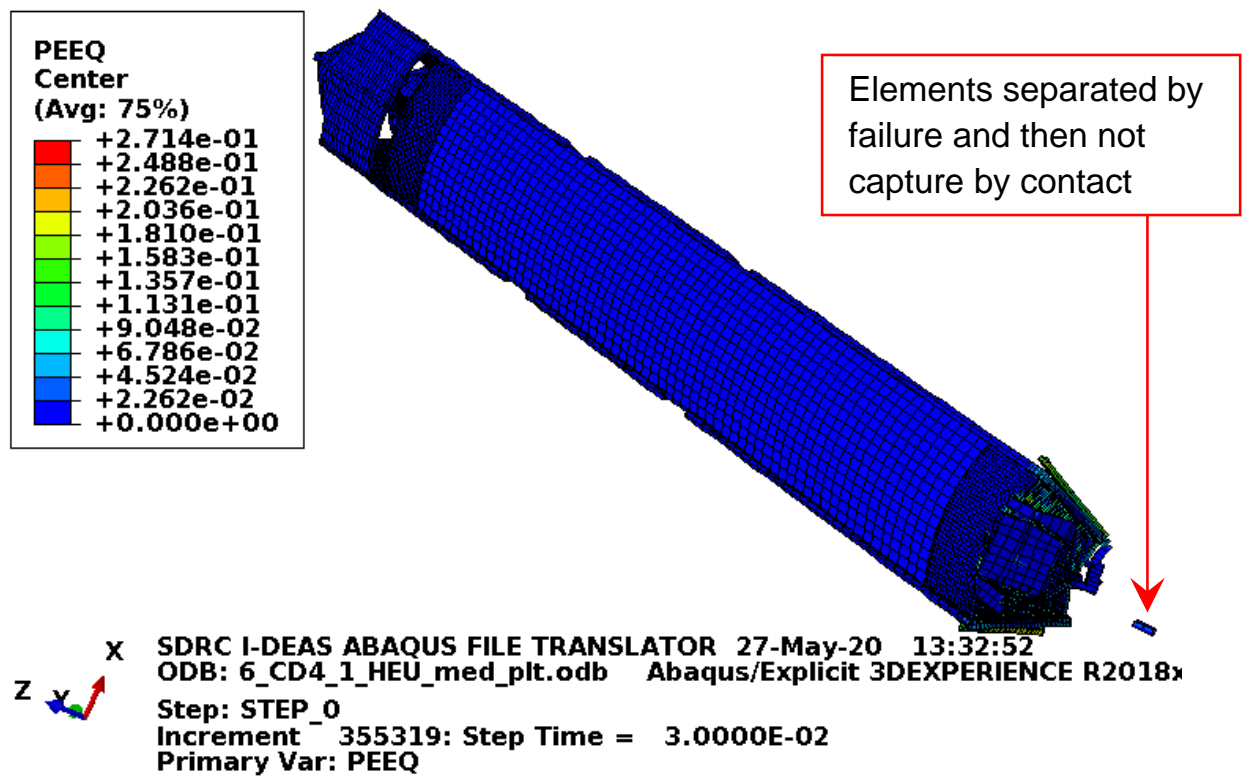

Figure D-65. Scope Part 1a (Table 3), Test 6 (Table 2) fine mesh fuel element plastic equivalent strain.

Figure D-65 shows the equivalent plastic strain in the fuel element. Failure in the end box elements occurs at an equivalent plastic strain of $0.027 \mathrm{in}$./in. Failure in the end box weld elements occurs at an equivalent plastic strain of $0.032 \mathrm{in}$./in. Failure in the side plate and comb elements occurs at an equivalent plastic strain of $0.152 \mathrm{in} . / \mathrm{in}$. Failure in the side plate weld elements occurs at an equivalent plastic strain of $0.205 \mathrm{in}$./in. Figure D-65 shows extensive failure in the end box and fuel plates nearest the impact. A few elements were separated by failure and then not captured by contact. The overall model error associated with this is not considered to be significant.

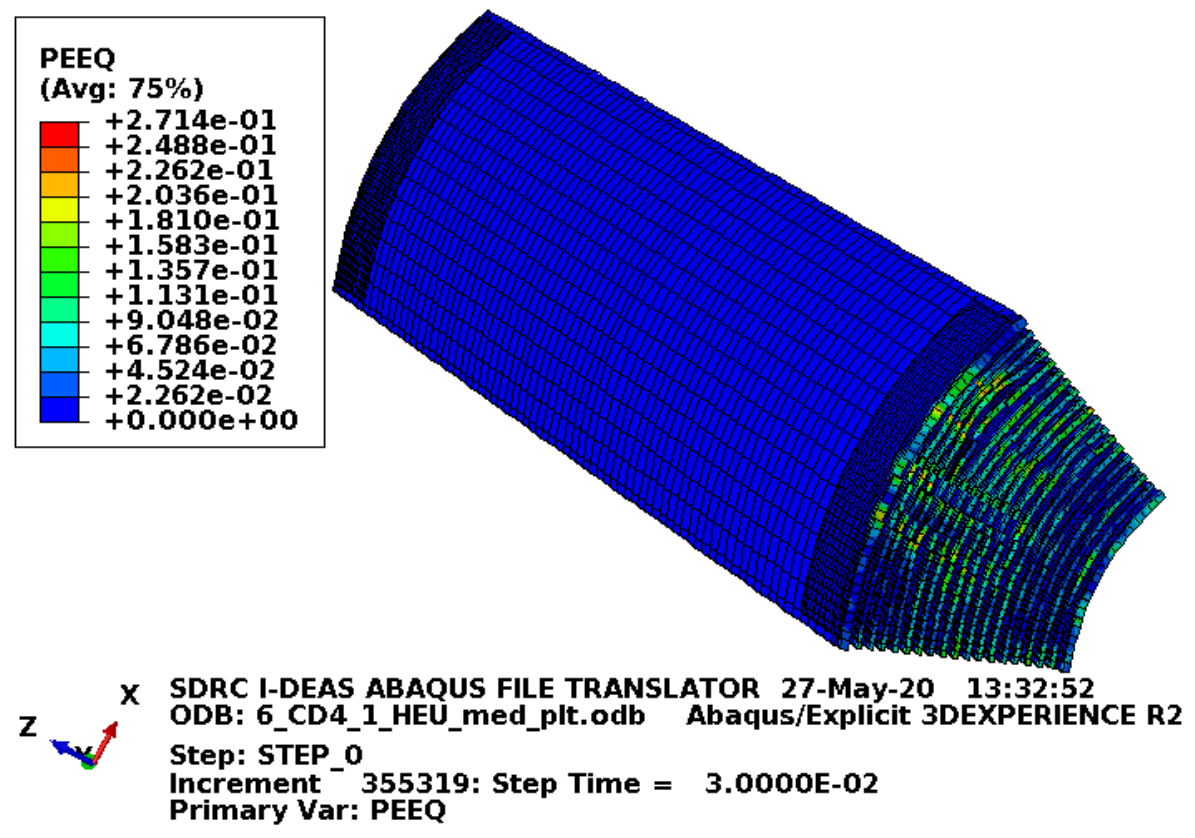

Figure D-66. Scope Part 1a (Table 3), Test 6 (Table 2) fine mesh fuel plate equivalent strain. 
Figure D-66 shows the equivalent plastic strain in the fuel plates. Failure in these elements occurs at an equivalent plastic strain of $0.205 \mathrm{in}$./in. If element failure were to occur, the element would be removed from the model (thereby excluding its equivalent plastic strain from the maximum equivalent plastic strain for the plot). However, the missing element would be visible in the plot. Figure D-66 shows some element failure in the end nearest the impact.
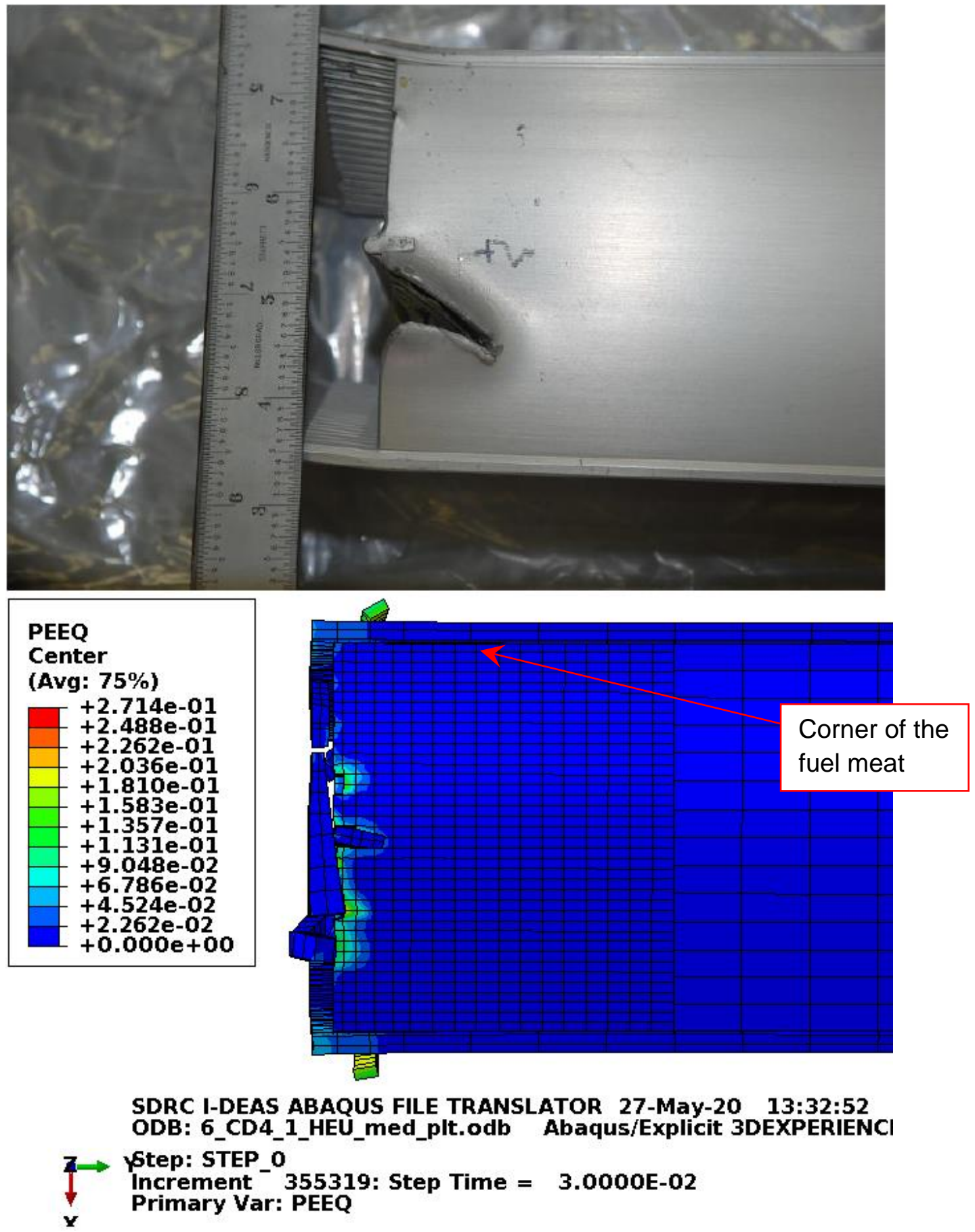

Figure D-67. Scope Part 1a (Table 3), Test 6 (Table 2) fine mesh damage comparison with Figure D-8. 
Drop Analysis of the Advanced Test Reactor Fresh Fuel Shipping Container with Heavier Low-Enriched Uranium Fuel Contents

The FEA model in Figure D-67 is the fuel element with only failed elements not visible. The damage comparison shows that the end box did not stay together well enough or did not get properly trapped such that it cut into the fuel plate similar to the physical drop.
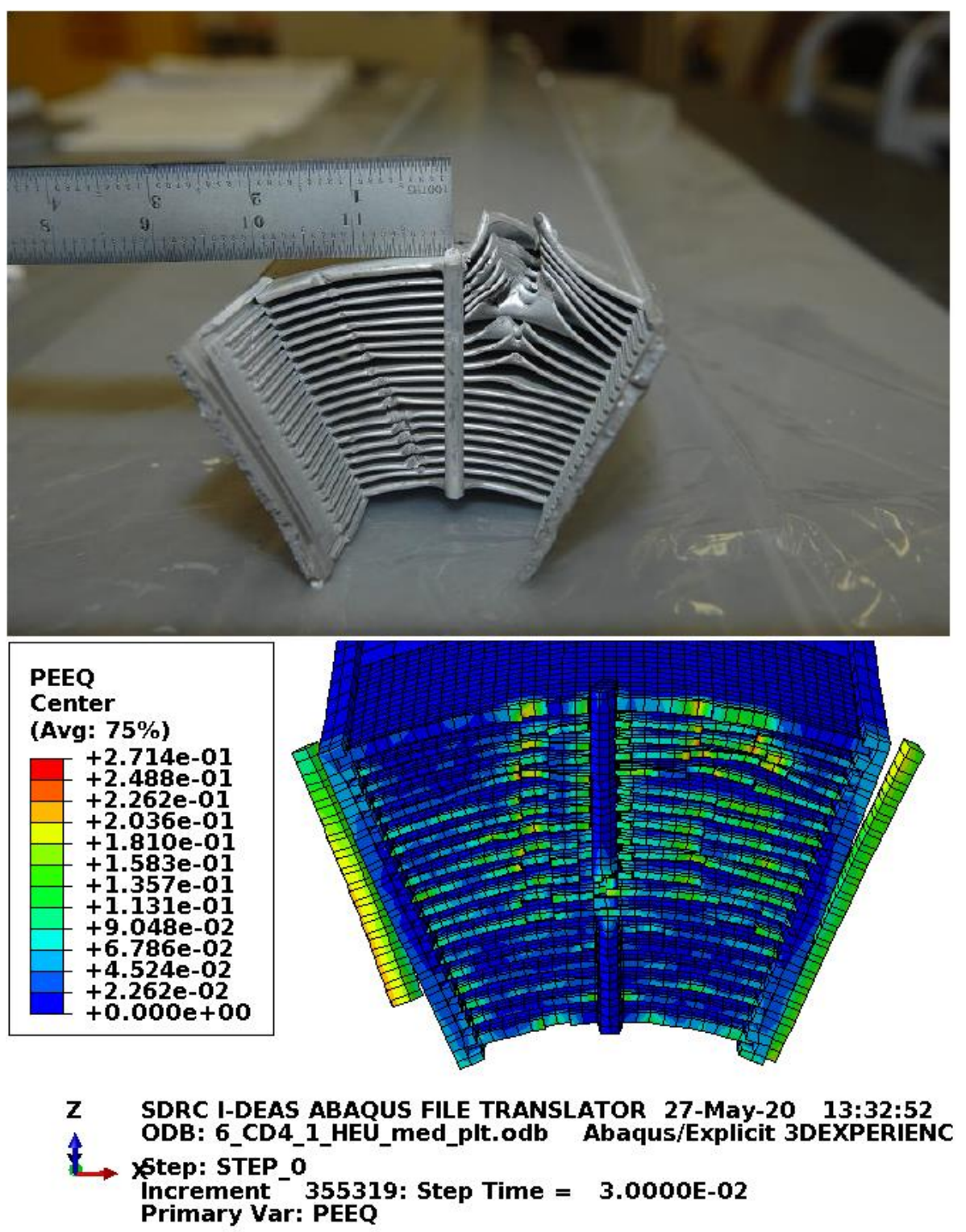

Figure D-68. Scope Part 1a (Table 3), Test 6 (Table 2) fine mesh damage comparison with Figure D-7.

The FEA model in Figure D-68 has the end boxes and end box welds removed. The damage comparison shows much less plastic deformation in the FEA model. Though, the volume of failed elements might be similar to the physical drop failed volume. With minimum material properties in the end box, it did not appear to hold together well enough to do damage like in the physical drop. 


\section{D2.5.3 Results for Scope Part 1b (Table 3), Test 6 (Table 2)}

The FEA model results for the Scope Part 1b (Table 3), Test 6 (Table 2) model are shown below in Figure D-69 to Figure D-73. The fuel element weighs $22.1 \mathrm{lbf}$ and the drop scenario is modeled with minimum material properties except the enclosure and end boxes, which are modeled with relatively tough material properties.

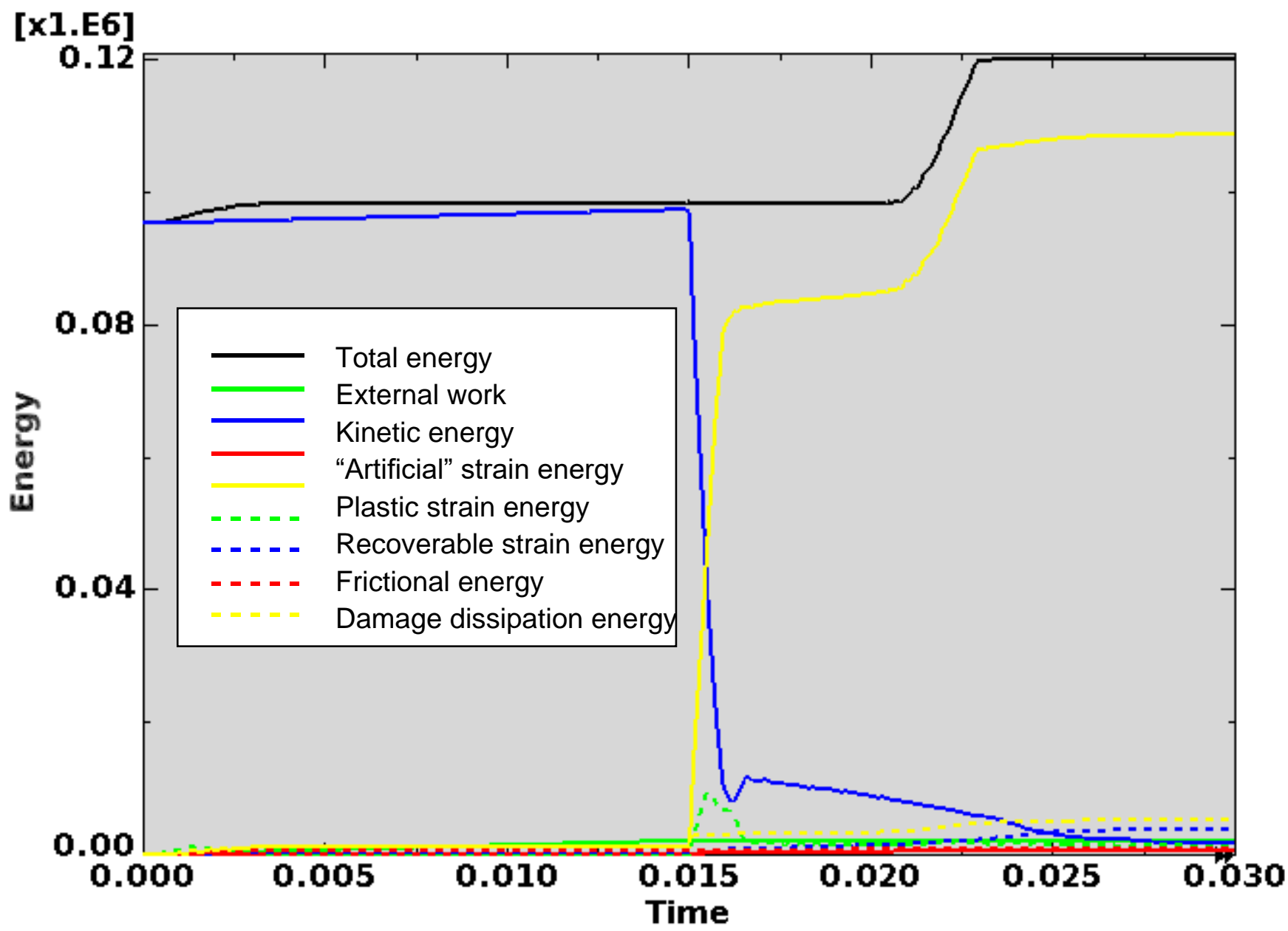

Figure D-69. Scope Part 1b (Table 3), Test 6 (Table 2) energy curves.

Figure D-69 shows the energy curves for Scope Part 1b (Table 3), Test 6 (Table 2) drop scenario. These curves exhibit mostly stable behavior. After the ATR FFSC impact, the total energy and plastic strain energy start to show undesirable behavior but appear to stabilize somewhat by the end of the model run. As discussed in Section D2.5 this appears to result from contact difficultly between failed portions of the fuel element. Consequently, output is shown at the first output frame after fuel element rebound ( 0.030 second) to try to minimize potential error associated with this.

Artificial strain energy represents the energy required to keep reduced integration elements from taking on a zero-energy hourglass shape. As shown in Figure D-69, the artificial energy at the end of the model run is $0.7 \%$ of the total energy. Therefore, the potential error associated with artificial energy is not considered to be significant. 
ENGINEERING CALCULATIONS AND ANALYSIS

Drop Analysis of the Advanced Test Reactor Fresh Fuel Shipping Container with Heavier Low-Enriched Uranium Fuel Contents
ECAR-5224, Rev. 0

Page D64 of D293

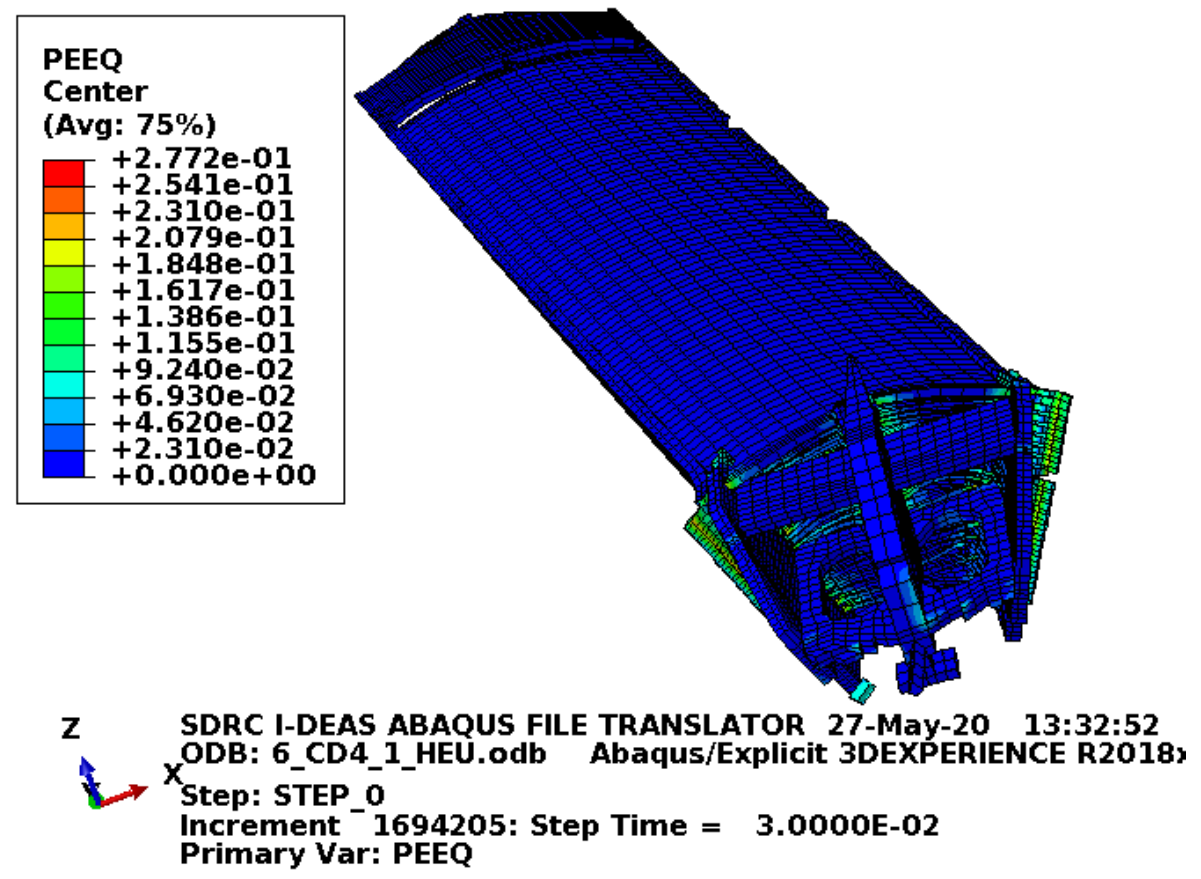

Figure D-70. Scope Part 1b (Table 3), Test 6 (Table 2) fuel element plastic equivalent strain.

Figure D-70 shows the equivalent plastic strain in the fuel element. Failure in the end box elements occurs at an equivalent plastic strain of $0.08 \mathrm{in./in.} \mathrm{(for} \mathrm{the} \mathrm{relatively} \mathrm{tough} \mathrm{material} \mathrm{properties).} \mathrm{Failure} \mathrm{in} \mathrm{the} \mathrm{end}$ box weld elements occurs at an equivalent plastic strain of $0.115 \mathrm{in}$./in. (for the relatively tough material properties). Failure in the side plate and comb elements occurs at an equivalent plastic strain of 0.152 in./in. Failure in the side plate weld elements occurs at an equivalent plastic strain of 0.205 in./in. Figure D-70 shows extensive failure in the end box and fuel plates nearest the impact.

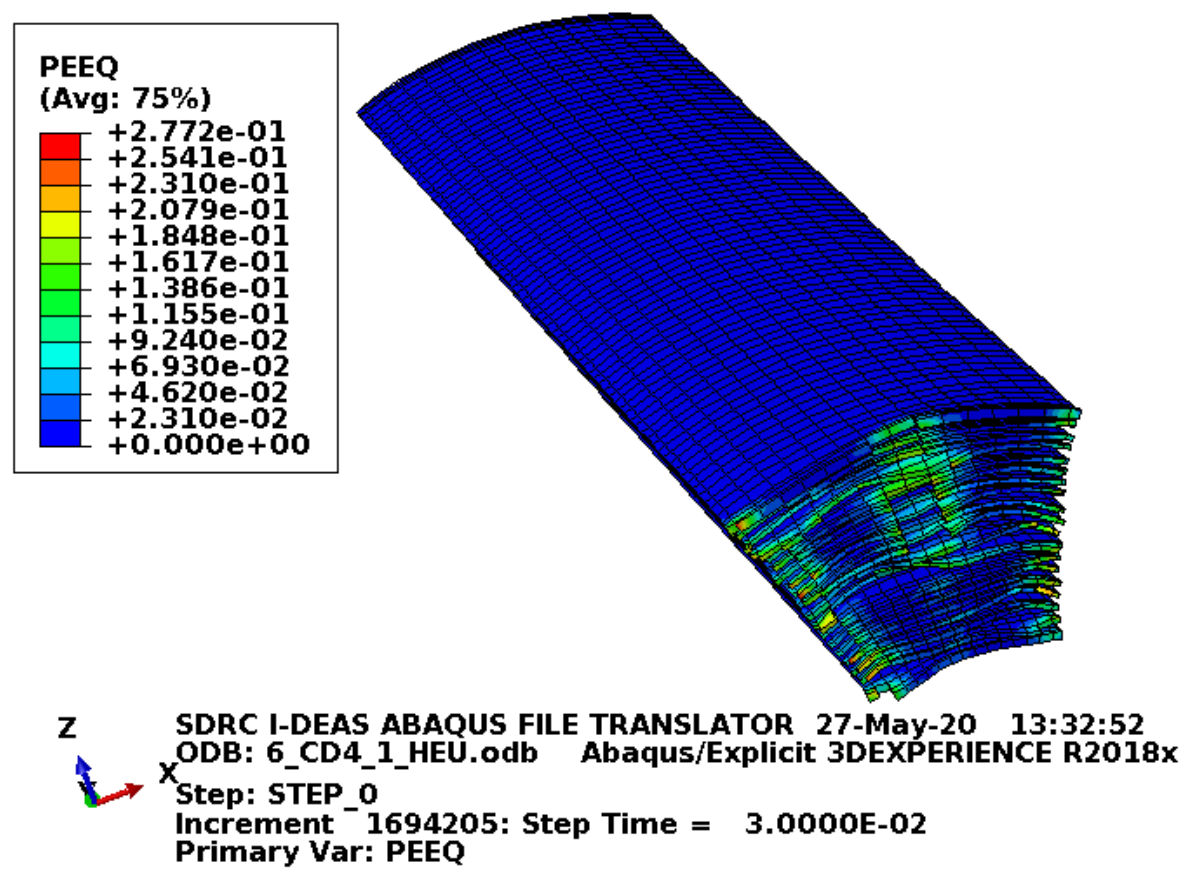

Figure D-71. Scope Part 1b (Table 3), Test 6 (Table 2Table 2) fuel plate equivalent strain. 
Figure D-71 shows the equivalent plastic strain in the fuel plates. Failure in these elements occurs at an equivalent plastic strain of $0.205 \mathrm{in}$./in. If element failure were to occur, the element would be removed from the model (thereby excluding its equivalent plastic strain from the maximum equivalent plastic strain for the plot). However, the missing element would be visible in the plot. Figure D-71 shows element failure in the end nearest the impact. 

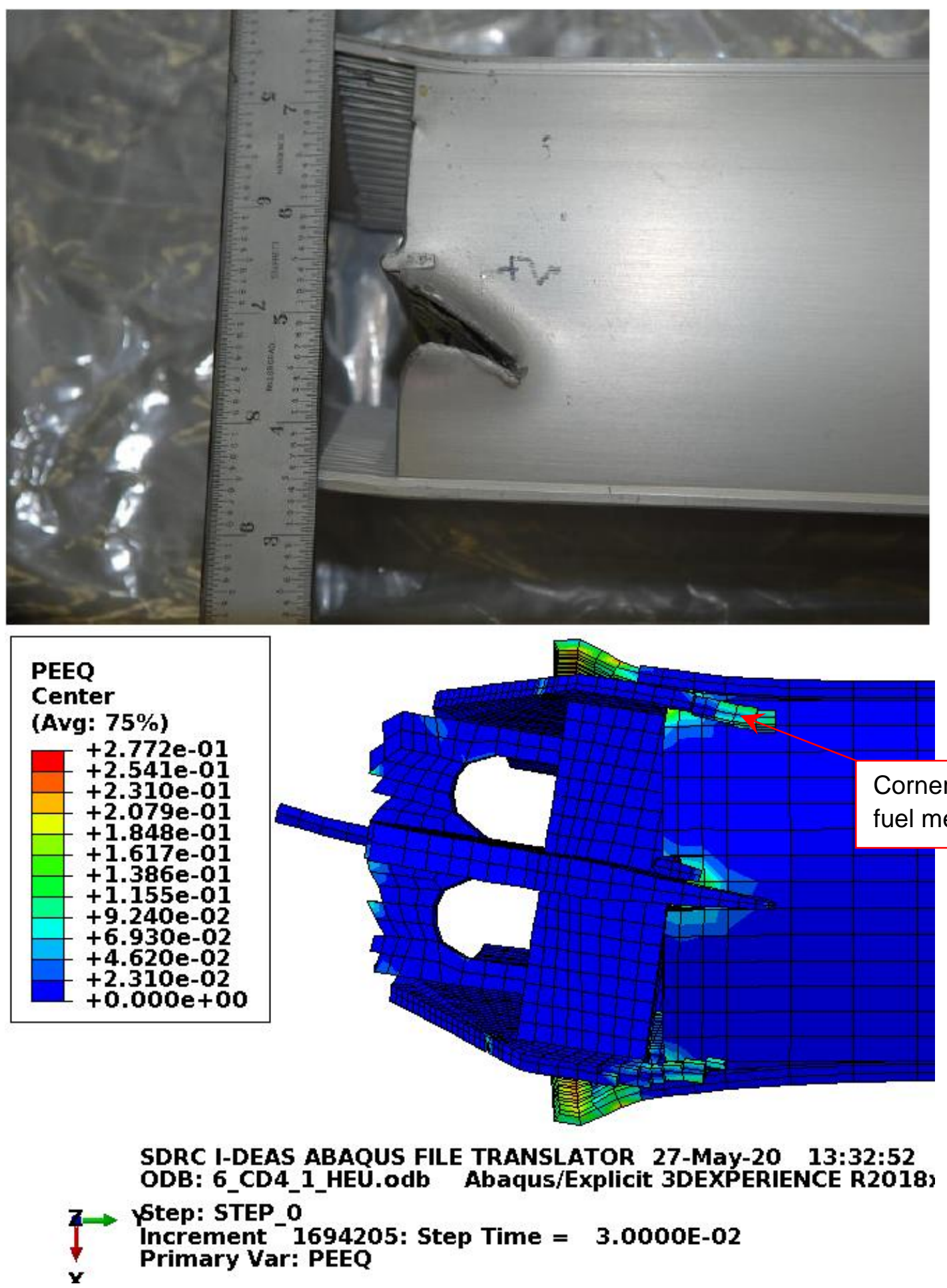

Figure D-72. Scope Part 1b (Table 3), Test 6 (Table 2) damage comparison with Figure D-8.

The FEA model in Figure D-72 is the fuel element with only failed elements not visible. The damage comparison shows that the end box stayed together too well compared to the physical drop but came very close to making the center cut as the physical drop. In this case, there is very complex contact and some of it was missed. 

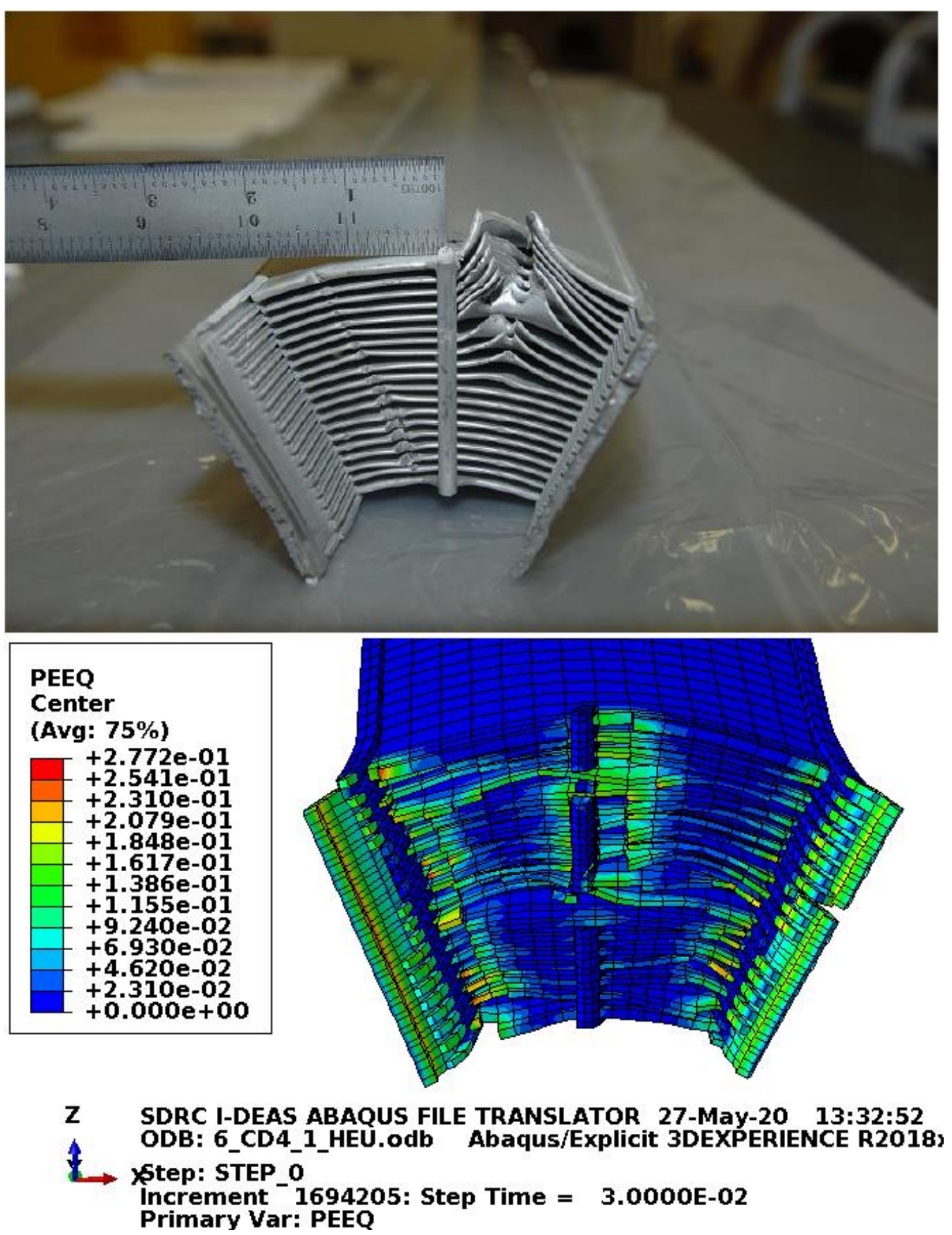

Figure D-73. Scope Part 1b (Table 3), Test 6 (Table 2) damage comparison with Figure D-7.

The FEA model in Figure D-73 has the end boxes and end box welds removed. The damage comparison shows significant plastic deformation in the FEA model but not the same pattern as the physical drop. Also, the volume of failed elements in the FEA model appears to be significantly more than in the physical drop failed volume, but the failures occur in different locations. With relatively tough material properties in the end box, it appeared to hold together too well when compared to the physical drop. Though, given the very nonlinear nature of this drop, the general behavior of the FEA model is representative of the physical drop. 


\section{D2.5.4 Results for Scope Part 1b (Table 3), Test 6 (Table 2) Fine Mesh}

The FEA model results for the Scope Part $1 \mathrm{~b}$ (Table 3), Test 6 (Table 2) fine mesh model are shown below in Figure D-74 to Figure D-78. The fuel element weighs $22.1 \mathrm{lbf}$ and the drop scenario is modeled with minimum material properties except the enclosure and end boxes, which are modeled with relatively tough material properties.

\section{[x1.E6]}

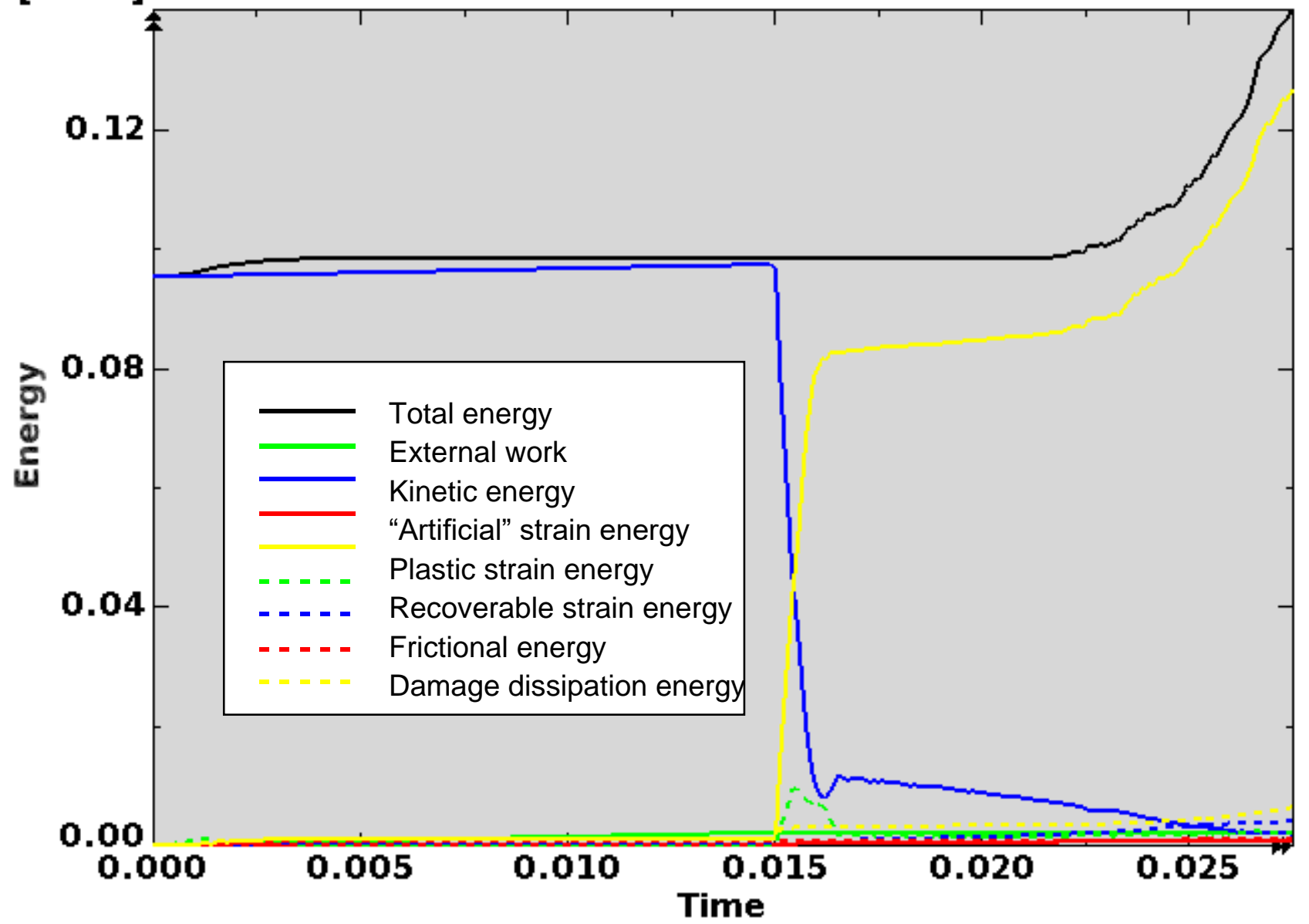

Figure D-74. Scope Part 1b (Table 3), Test 6 (Table 2) fine mesh energy curves.

Figure D-74 shows the energy curves for Scope Part 1b (Table 3), Test 6 (Table 2) fine mesh drop scenario. These curves exhibit mostly stable behavior. Near the end of the model run, the total energy and plastic strain energy start to show undesirable behavior. As discussed in Section D2.5 this appears to result from contact difficultly between failed portions of the fuel element. Consequently, output is shown at the first output frame after fuel element rebound $(0.0275$ second $)$ to try to minimize potential error associated with this.

Artificial strain energy represents the energy required to keep reduced integration elements from taking on a zero-energy hourglass shape. As shown in Figure D-74, the artificial energy at the end of the model run is $0.5 \%$ of the total energy. Therefore, the potential error associated with artificial energy is not considered to be significant. 
ENGINEERING CALCULATIONS AND ANALYSIS

Drop Analysis of the Advanced Test Reactor Fresh Fuel Shipping Container with Heavier Low-Enriched Uranium Fuel Contents
ECAR-5224, Rev. 0

Page D69 of D293

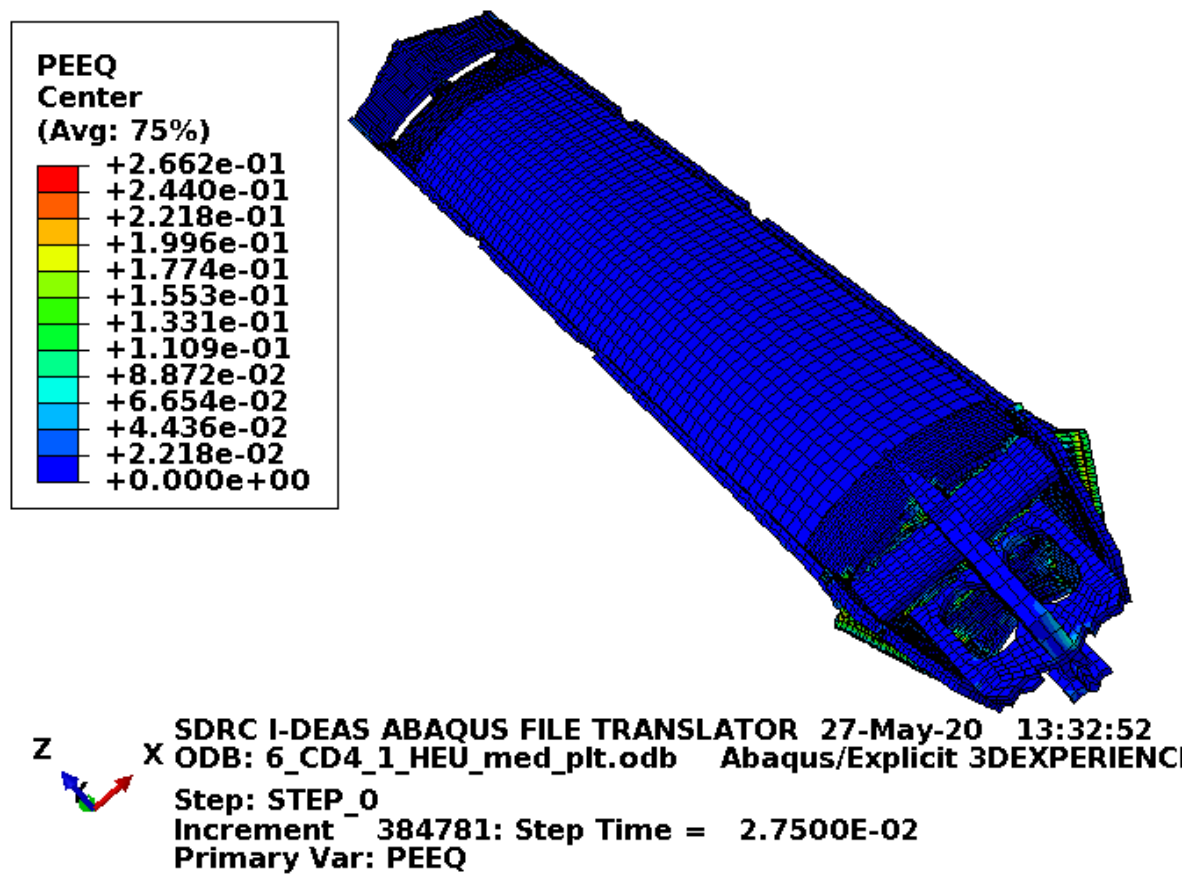

Figure D-75. Scope Part 1b (Table 3), Test 6 (Table 2) fine mesh fuel element plastic equivalent strain.

Figure D-75 shows the equivalent plastic strain in the fuel element. Failure in the end box elements occurs at an equivalent plastic strain of $0.08 \mathrm{in./in.} \mathrm{(for} \mathrm{the} \mathrm{relatively} \mathrm{tough} \mathrm{material} \mathrm{properties).} \mathrm{Failure} \mathrm{in} \mathrm{the} \mathrm{end}$ box weld elements occurs at an equivalent plastic strain of $0.115 \mathrm{in}$./in. (for the relatively tough material properties). Failure in the side plate and comb elements occurs at an equivalent plastic strain of $0.152 \mathrm{in}$./in. Failure in the side plate weld elements occurs at an equivalent plastic strain of 0.205 in./in. Figure D-75 shows extensive failure in the end box and fuel plates nearest the impact.

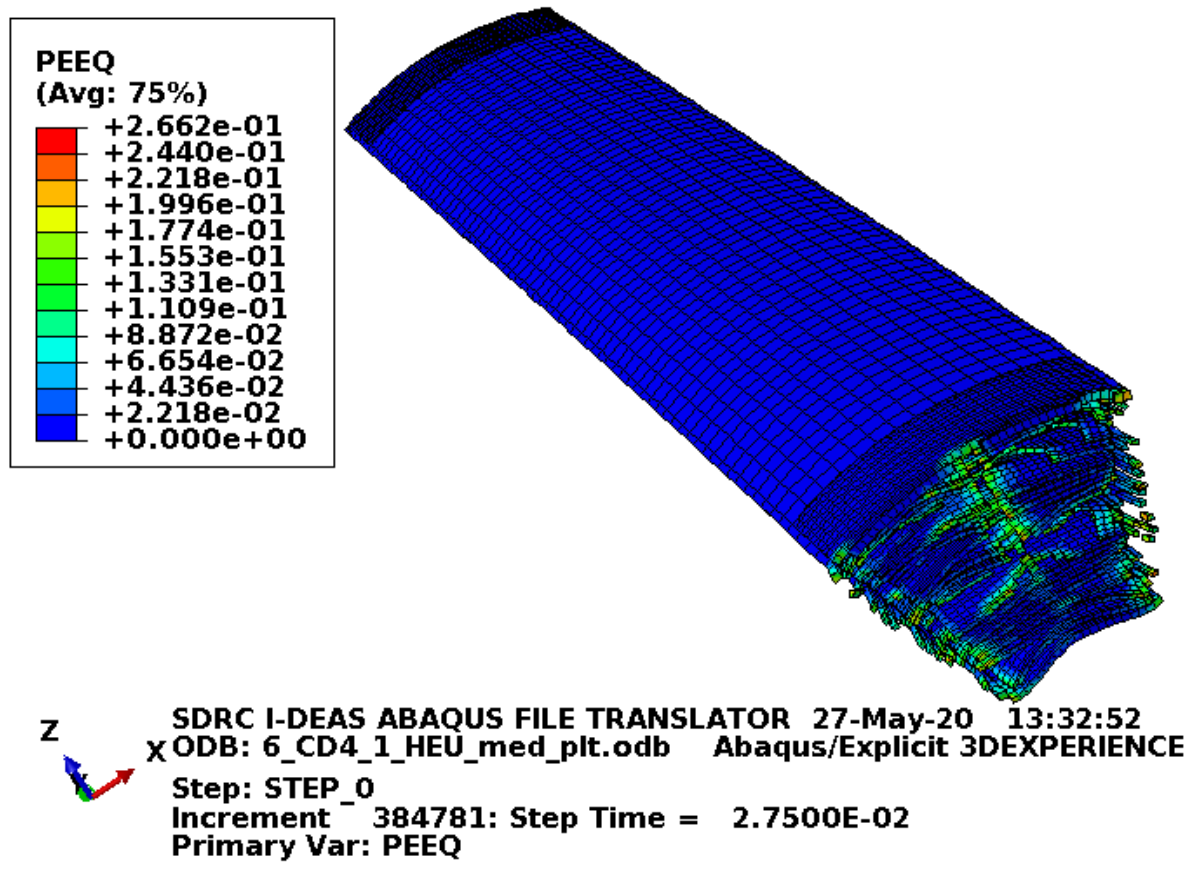

Figure D-76. Scope Part 1b (Table 3), Test 6 (Table 2) fine mesh fuel plate equivalent strain. 
Figure D-76 shows the equivalent plastic strain in the fuel plates. Failure in these elements occurs at an equivalent plastic strain of $0.205 \mathrm{in}$./in. If element failure were to occur, the element would be removed from the model (thereby excluding its equivalent plastic strain from the maximum equivalent plastic strain for the plot). However, the missing element would be visible in the plot. Figure D-76 shows significant element failure in the end nearest the impact.
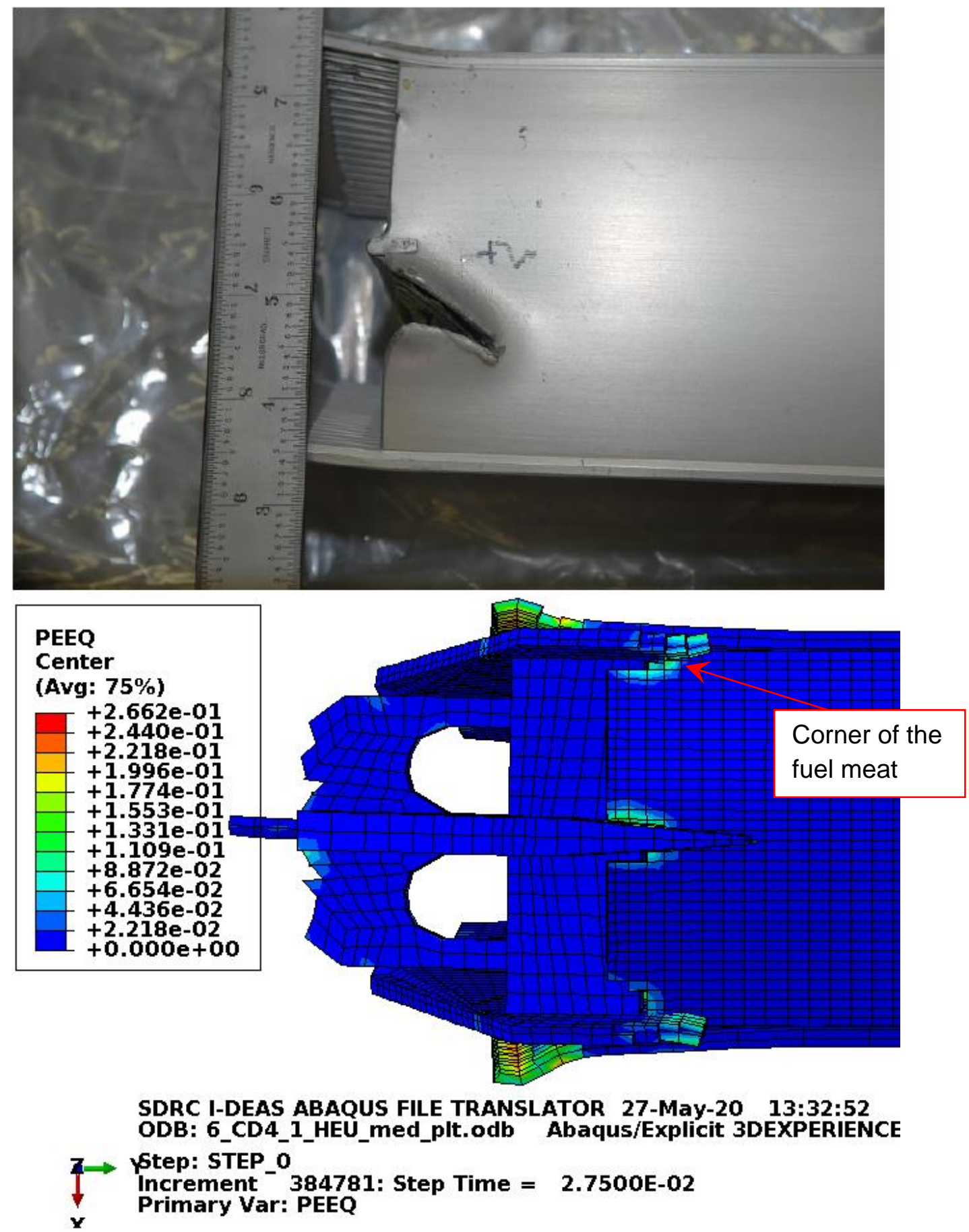

Figure D-77. Scope Part 1b (Table 3), Test 6 (Table 2) fine mesh damage comparison with Figure D-8. 
The FEA model in Figure D-77 is the fuel element with only failed elements not visible. The damage comparison shows that the end box stayed together too well compared to the physical drop but came very close to making the center cut as with the physical drop. In this case, there is very complex contact and some of it was missed. The level of damage in the FEA model is conservative to the point of showing unacceptable damage to the fuel meat.
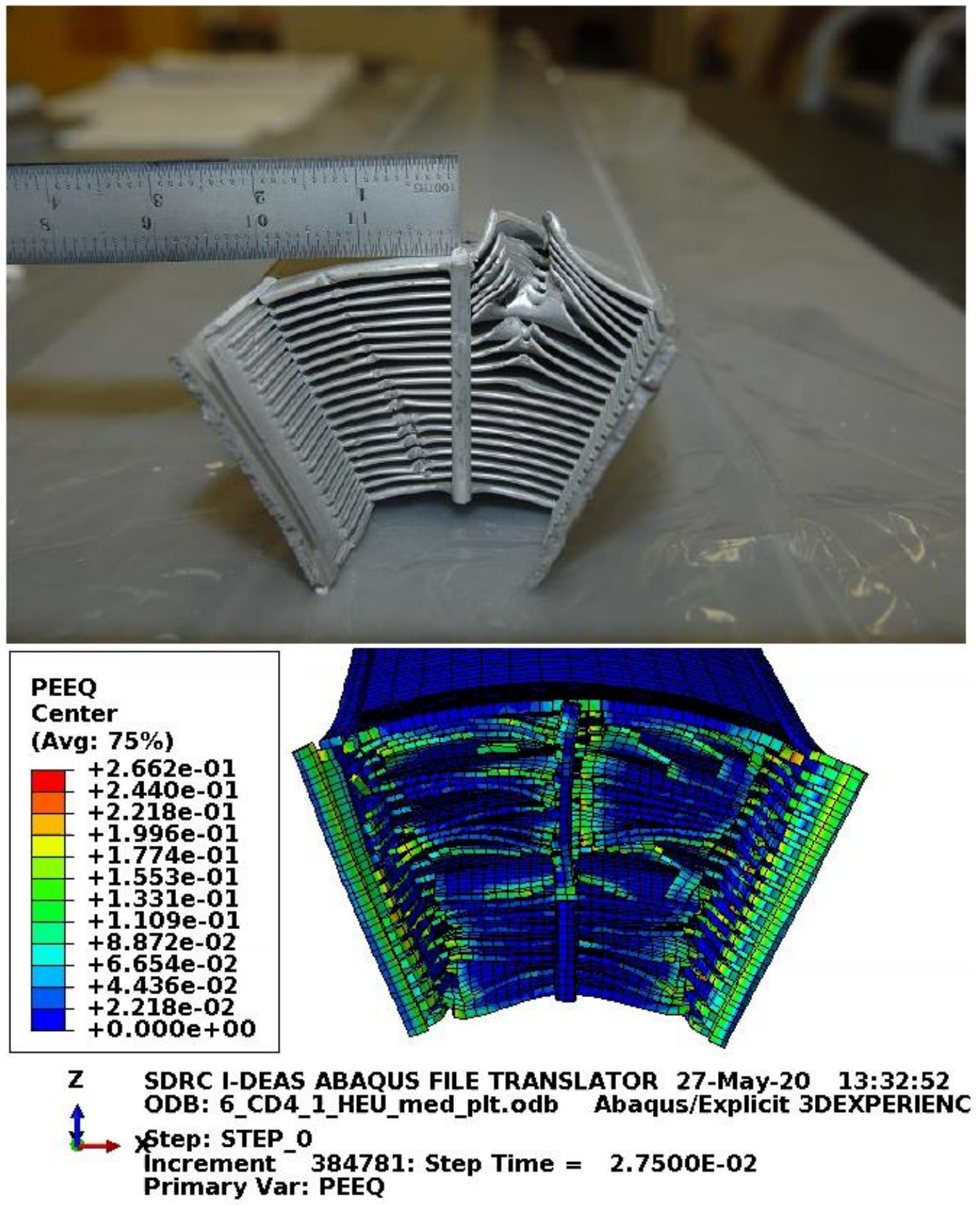

Figure D-78. Scope Part 1b (Table 3), Test 6 (Table 2) fine mesh damage comparison with Figure D-7. 
The FEA model in Figure D-78 has the end boxes and end box welds removed. The damage comparison shows significant plastic deformation in the FEA model but not the same pattern as the physical drop. Also, the volume of failed elements in the FEA model appears to be significantly more than in the physical drop failed volume, but the failures occur in different locations. With relatively tough material properties in the end box, it appeared to hold together too well when compared to the physical drop. Though, given the very nonlinear nature of this drop, the general behavior of the FEA model is representative and conservative of the physical drop.

\section{D2.5.5 Results for Scope Part 1c (Table 3), Test 6 (Table 2)}

The FEA model results for the Scope Part 1c (Table 3), Test 6 (Table 2) model are shown below in Figure D-79 to Figure D-81. The fuel element weighs $22.1 \mathrm{lbf}$ and the whole model is modeled with minimum material properties. Though ATR FFSC SAR (2017) shows the Scope Part 1 (Table 3) drop scenarios to be acceptable, the results shown (for information) in this section include the blocks as added fuel plate protection.

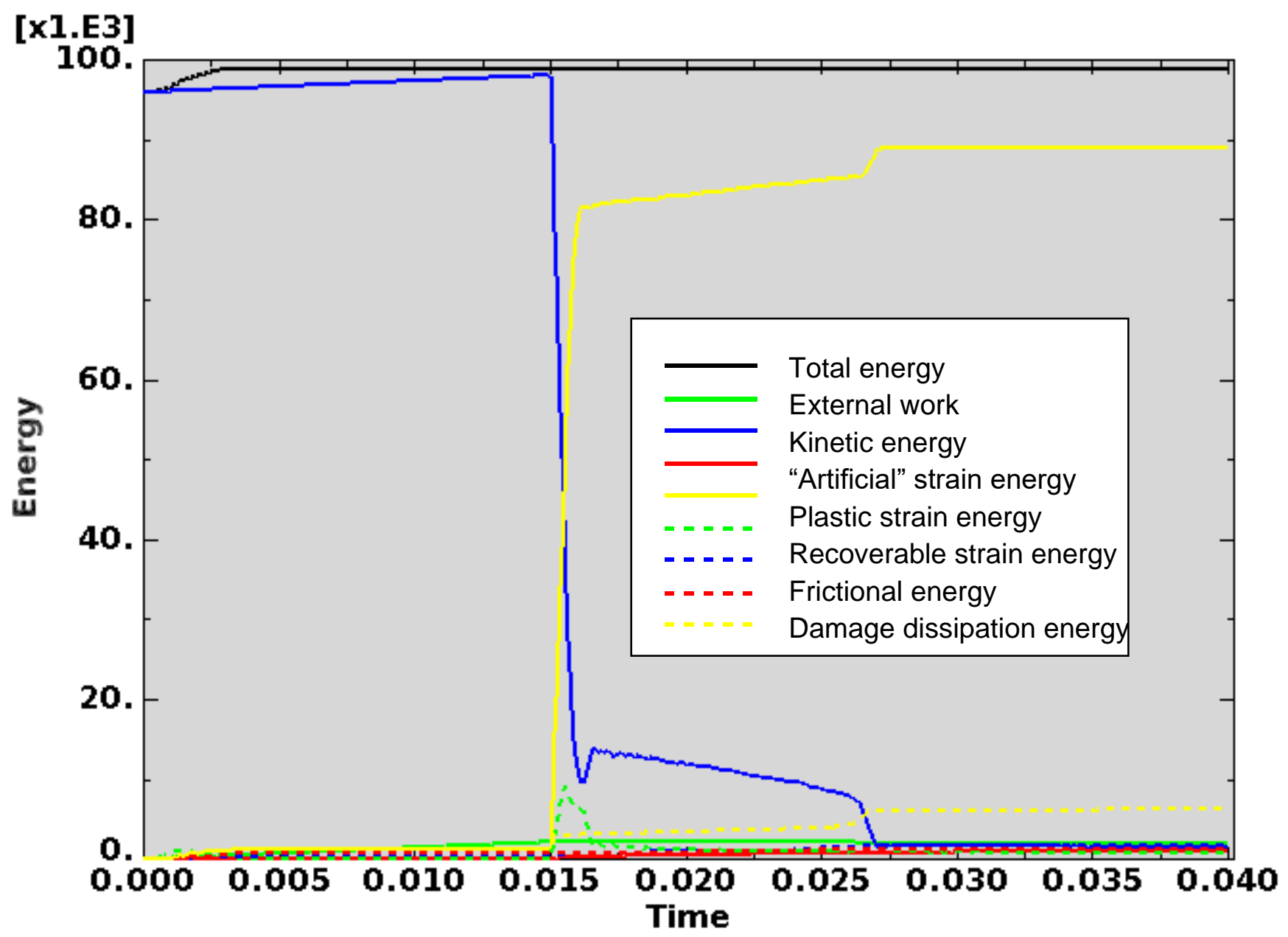

Figure D-79. Scope Part 1c (Table 3), Test 6 (Table 2) energy curves. 
Figure D-79 shows the energy curves for Scope Part 1c (Table 3), Test 6 (Table 2) drop scenario. These curves exhibit a stable shape. Artificial strain energy represents the energy required to keep reduced integration elements from taking on a zero-energy hourglass shape. As shown in Figure D-79, the artificial energy at the end of the model run is $1.0 \%$ of the total energy. Therefore, the potential error associated with artificial energy is not considered to be significant.

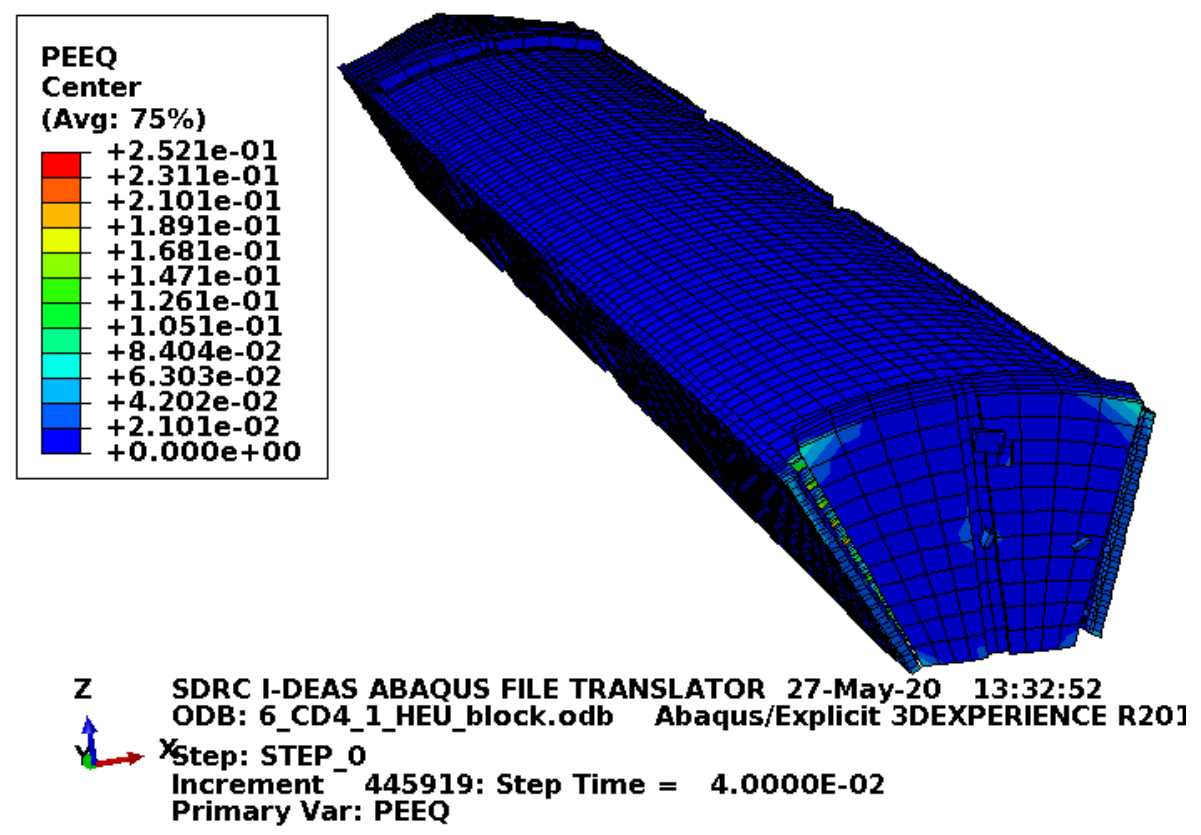

Figure D-80. Scope Part 1c (Table 3), Test 6 (Table 2) fuel element plastic equivalent strain.

Figure D-80 shows the equivalent plastic strain in the fuel element. Failure in the end box elements occurs at an equivalent plastic strain of $0.027 \mathrm{in}$./in. Failure in the end box weld elements occurs at an equivalent plastic strain of $0.032 \mathrm{in}$./in. Failure in the side plate and comb elements occurs at an equivalent plastic strain of $0.152 \mathrm{in./in.} \mathrm{Figure} \mathrm{D-80} \mathrm{shows} \mathrm{nearly} \mathrm{complete} \mathrm{failure} \mathrm{of} \mathrm{the} \mathrm{end} \mathrm{box} \mathrm{and} \mathrm{end} \mathrm{box} \mathrm{welds} \mathrm{nearest}$ the impact. 

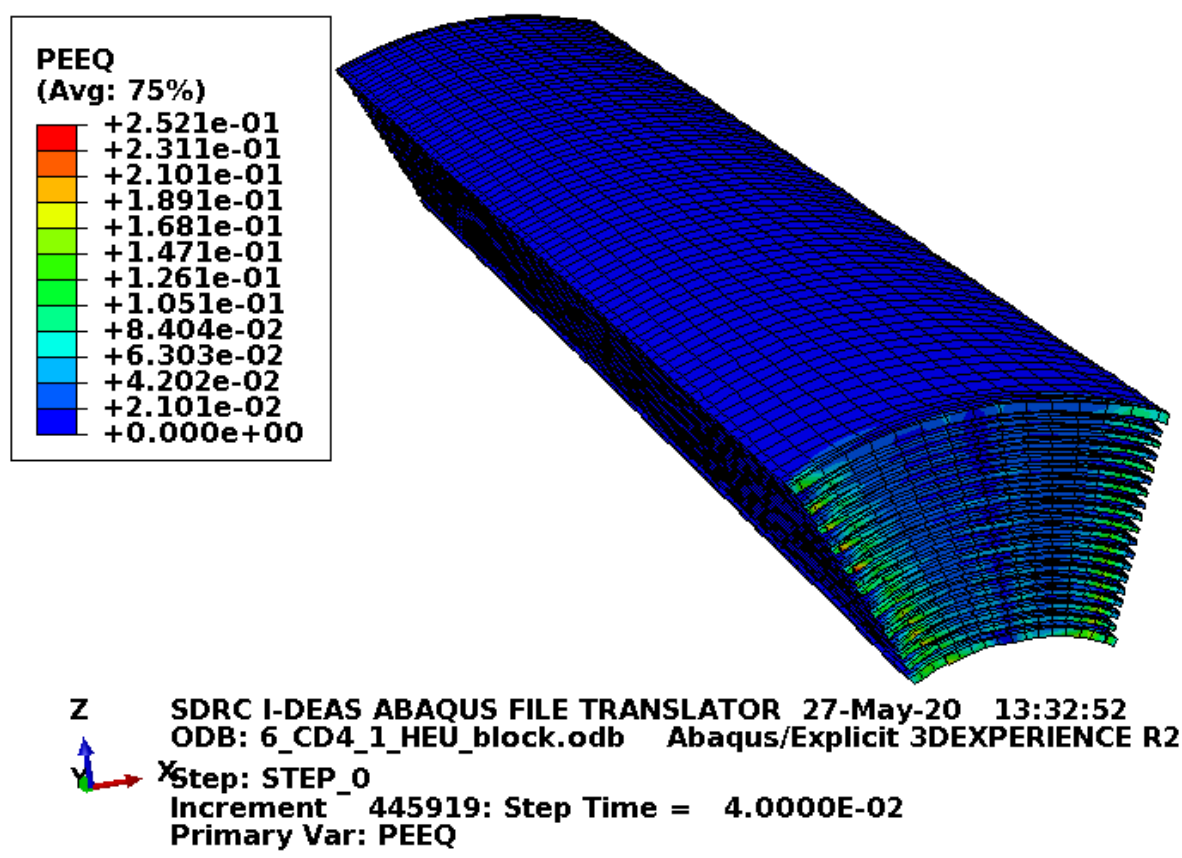

Figure D-81. Scope Part 1c (Table 3), Test 6 (Table 2) fuel plate equivalent strain.

Figure D-81 shows the equivalent plastic strain in the fuel plates. Failure in these elements occurs at an equivalent plastic strain of $0.205 \mathrm{in}$./in. If element failure were to occur, the element would be removed from the model (thereby excluding its equivalent plastic strain from the maximum equivalent plastic strain for the plot). However, the missing element would be visible in the plot. Figure D-81 shows some compressive failure in a few places, one element deep (about $0.15 \mathrm{in}$.), which is acceptable.

\section{D2.5.6 Results for Scope Part 1c (Table 3), Test 6 (Table 2) Fine Mesh}

The FEA model results for the Scope Part 1c (Table 3), Test 6 (Table 2) fine mesh model are shown below in Figure D-82 to Figure D-84. The fuel element weighs $22.1 \mathrm{lbf}$ and the whole model is modeled with minimum material properties. Though ATR FFSC SAR (2017) shows the Scope Part 1 (Table 3) drop scenarios to be acceptable, the results shown (for information) in this section include the blocks as added fuel plate protection. 


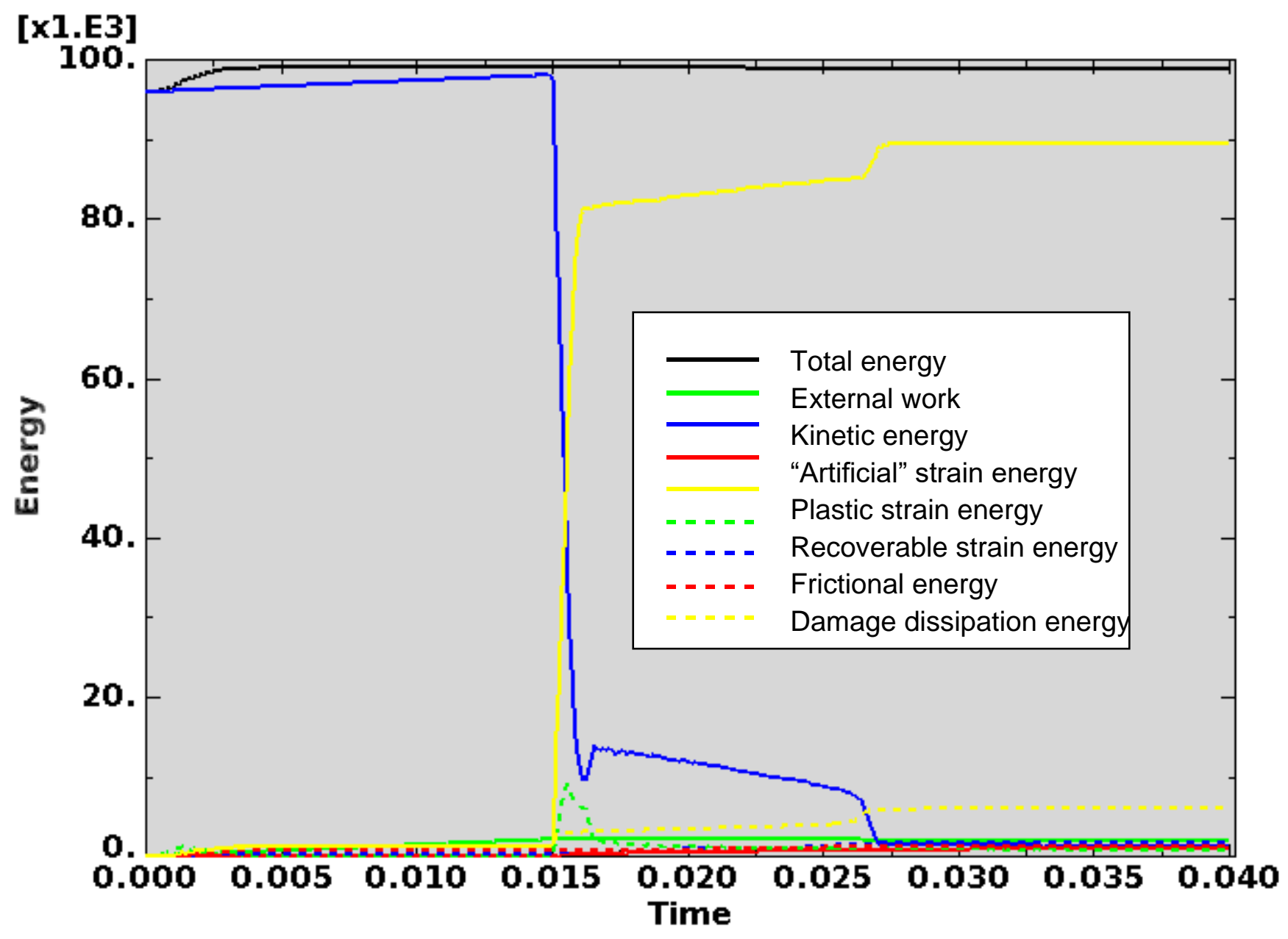

Figure D-82. Scope Part 1c (Table 3), Test 6 (Table 2) fine mesh energy curves.

Figure D-82 shows the energy curves for Scope Part 1c (Table 3), Test 6 (Table 2) fine mesh drop scenario. These curves exhibit a stable shape. Artificial strain energy represents the energy required to keep reduced integration elements from taking on a zero-energy hourglass shape. As shown in Figure D-82, the artificial energy at the end of the model run is $0.9 \%$ of the total energy. Therefore, the potential error associated with artificial energy is not considered to be significant. 
ENGINEERING CALCULATIONS AND ANALYSIS

Drop Analysis of the Advanced Test Reactor Fresh Fuel Shipping Container with Heavier Low-Enriched Uranium Fuel Contents

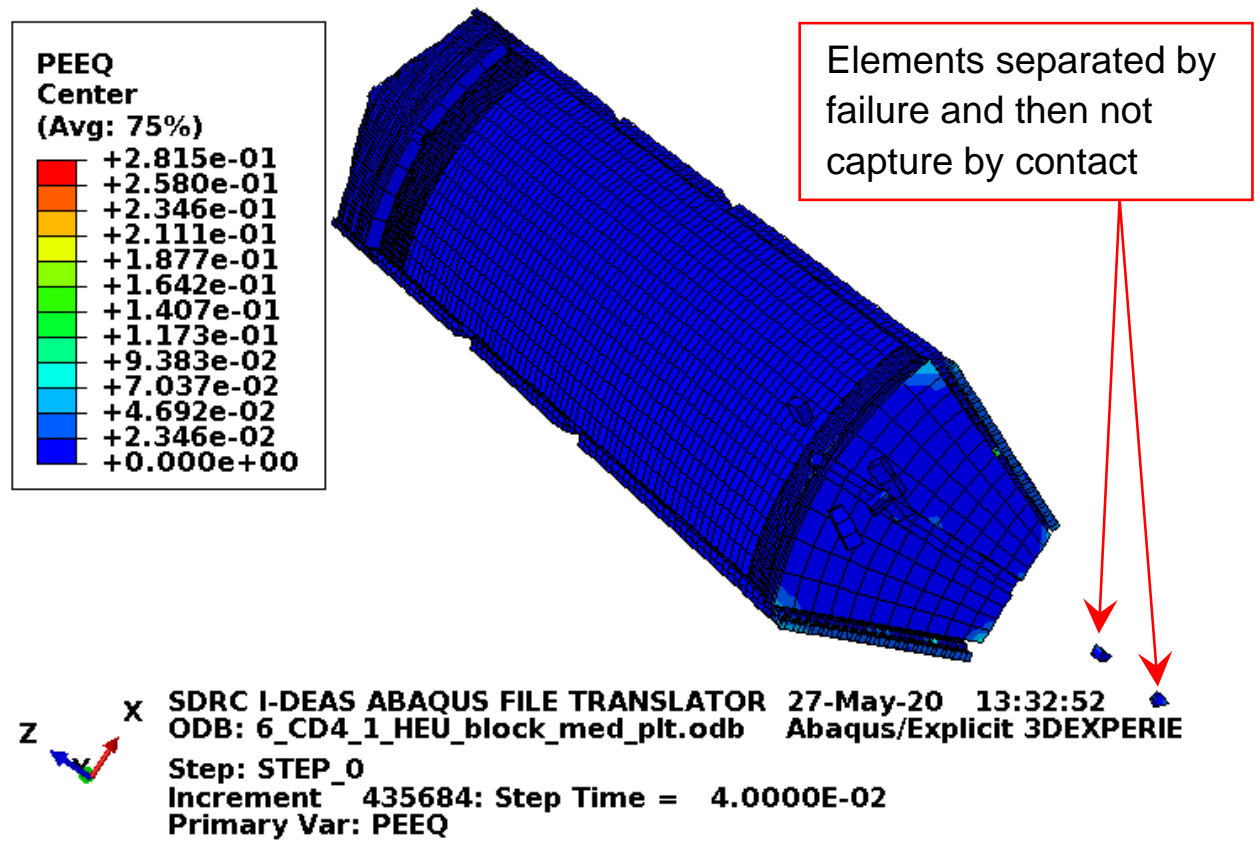

Figure D-83. Scope Part 1c (Table 3), Test 6 (Table 2) fine mesh fuel element plastic equivalent strain.

Figure D-83 shows the equivalent plastic strain in the fuel element. Failure in the end box elements occurs at an equivalent plastic strain of $0.027 \mathrm{in}$./in. Failure in the end box weld elements occurs at an equivalent plastic strain of $0.032 \mathrm{in}$./in. Failure in the side plate and comb elements occurs at an equivalent plastic strain of $0.152 \mathrm{in} . / \mathrm{in}$. Failure in the side plate weld elements occurs at an equivalent plastic strain of 0.205 in./in. Figure D-83 shows nearly complete failure of the end box and end box welds nearest the impact. A couple elements were separated by failure and then not captured by contact. The overall model error associated with this is not considered to be significant.

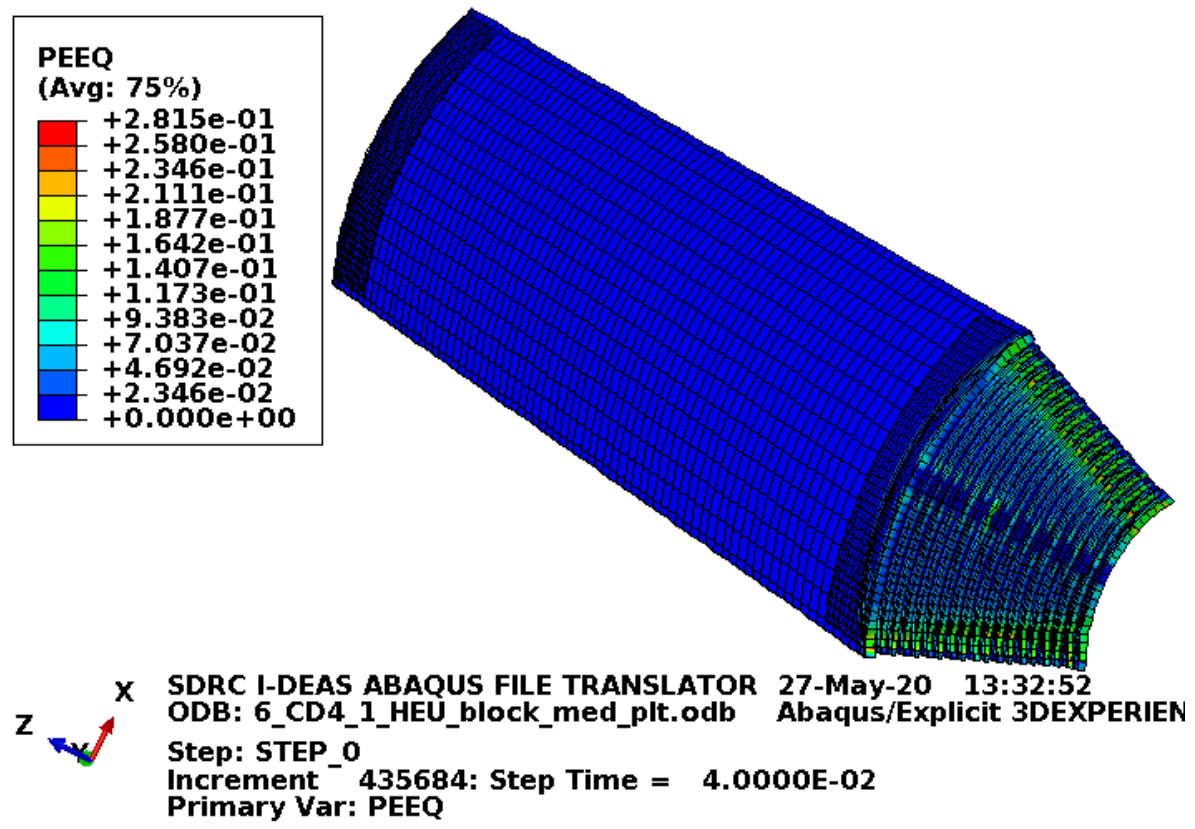

Figure D-84. Scope Part 1c (Table 3), Test 6 (Table 2) fine mesh fuel plate equivalent strain. 
Figure D-84 shows the equivalent plastic strain in the fuel plates. Failure in these elements occurs at an equivalent plastic strain of $0.205 \mathrm{in}$./in. If element failure were to occur, the element would be removed from the model (thereby excluding its equivalent plastic strain not included in the maximum equivalent plastic strain for the plot). However, the missing element would be visible in the plot. Figure D-84 shows some compressive failure in a few places, one element deep (about $0.09 \mathrm{in}$ ), which is acceptable.

\section{D2.5.7 Results for Scope Part 1d (Table 3), Test 6 (Table 2)}

The FEA model results for the Scope Part 1d (Table 3), Test 6 (Table 2) model are shown below in Figure D-85 to Figure D-87. The fuel element weighs $22.1 \mathrm{lbf}$ and the drop scenario is modeled with minimum material properties except the enclosure and end boxes, which are modeled with relatively tough material properties. Though ATR FFSC SAR (2017) shows the Scope Part 1 (Table 3) drop scenarios to be acceptable, the results shown (for information) in this section include the blocks as added fuel plate protection.

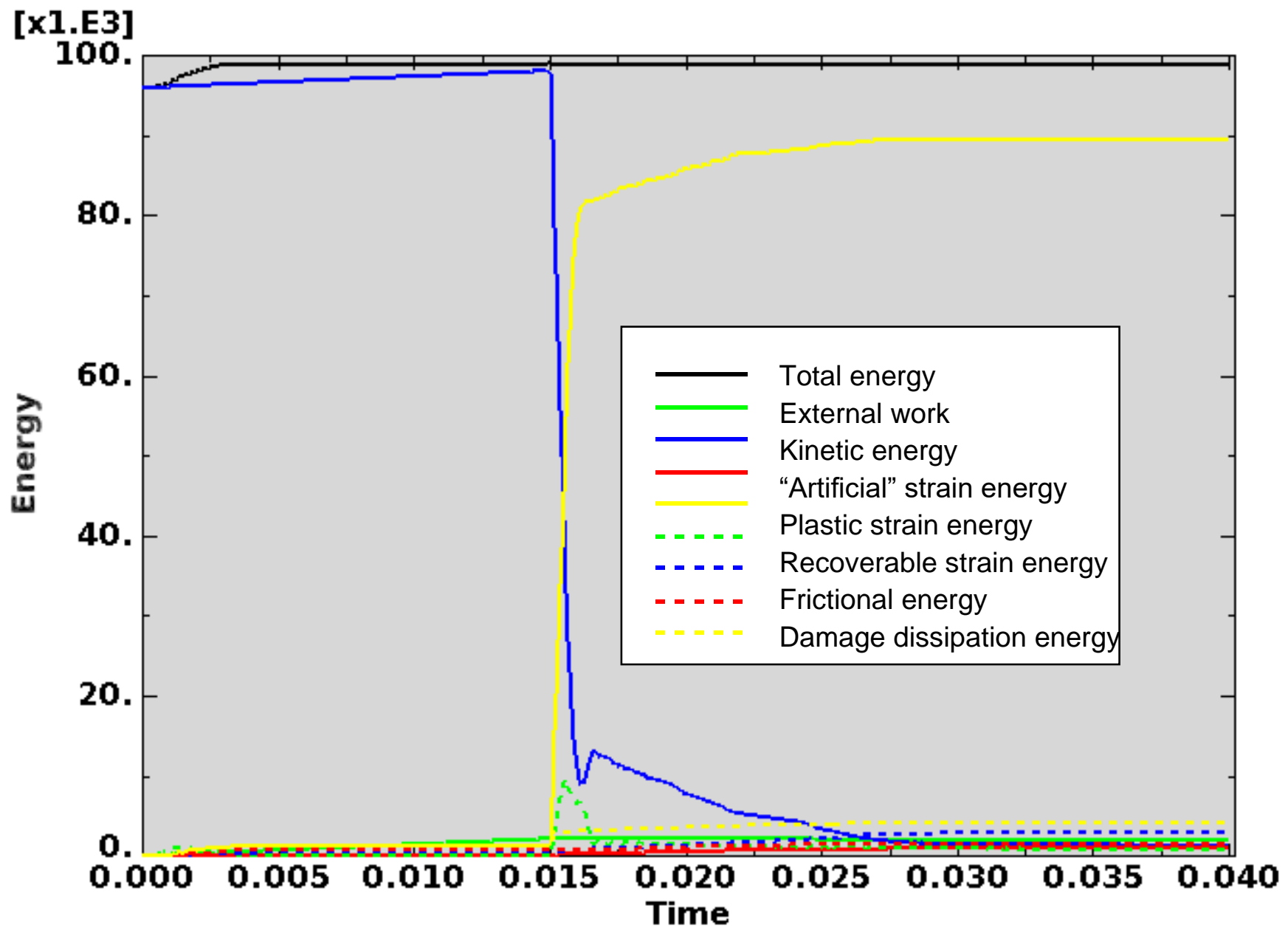

Figure D-85. Scope Part 1d (Table 3), Test 6 (Table 2) energy curves. 
Figure D-85 shows the energy curves for Scope Part 1d (Table 3), Test 6 (Table 2) drop scenario. These curves exhibit a stable shape. Artificial strain energy represents the energy required to keep reduced integration elements from taking on a zero-energy hourglass shape. As shown in Figure D-85, the artificial energy at the end of the model run is $1.0 \%$ of the total energy. Therefore, the potential error associated with artificial energy is not considered to be significant.

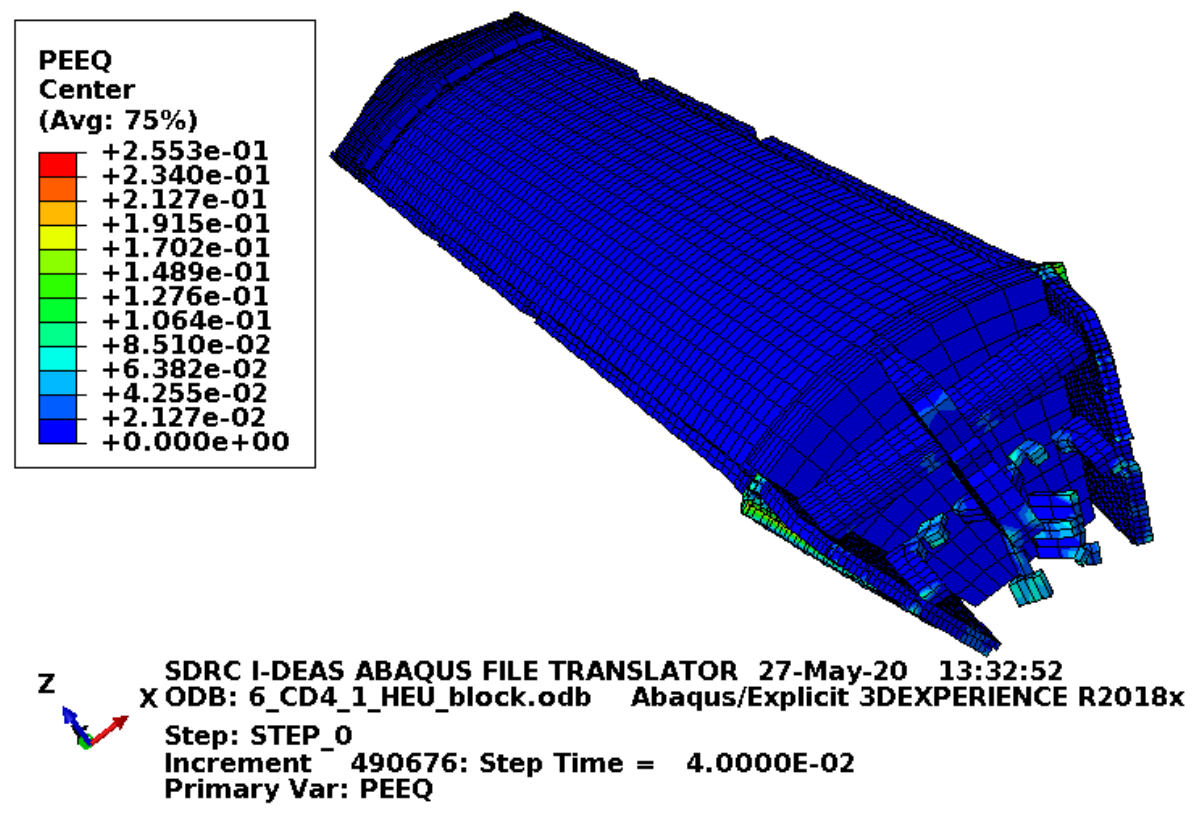

Figure D-86. Scope Part 1d (Table 3), Test 6 (Table 2) fuel element plastic equivalent strain.

Figure D-86 shows the equivalent plastic strain in the fuel element. Failure in the end box elements occurs at an equivalent plastic strain of $0.08 \mathrm{in./in.} \mathrm{(for} \mathrm{the} \mathrm{relatively} \mathrm{tough} \mathrm{material} \mathrm{properties).} \mathrm{Failure} \mathrm{in} \mathrm{the} \mathrm{end}$ box weld elements occurs at an equivalent plastic strain of $0.115 \mathrm{in}$./in. (for the relatively tough material properties). Failure in the side plate and comb elements occurs at an equivalent plastic strain of 0.152 in./in. Failure in the side plate weld elements occurs at an equivalent plastic strain of 0.205 in./in. Figure D-86 shows substantial failure of the end box and end box welds nearest the impact. 
ENGINEERING CALCULATIONS AND ANALYSIS

Drop Analysis of the Advanced Test Reactor Fresh Fuel Shipping Container with Heavier Low-Enriched Uranium Fuel Contents

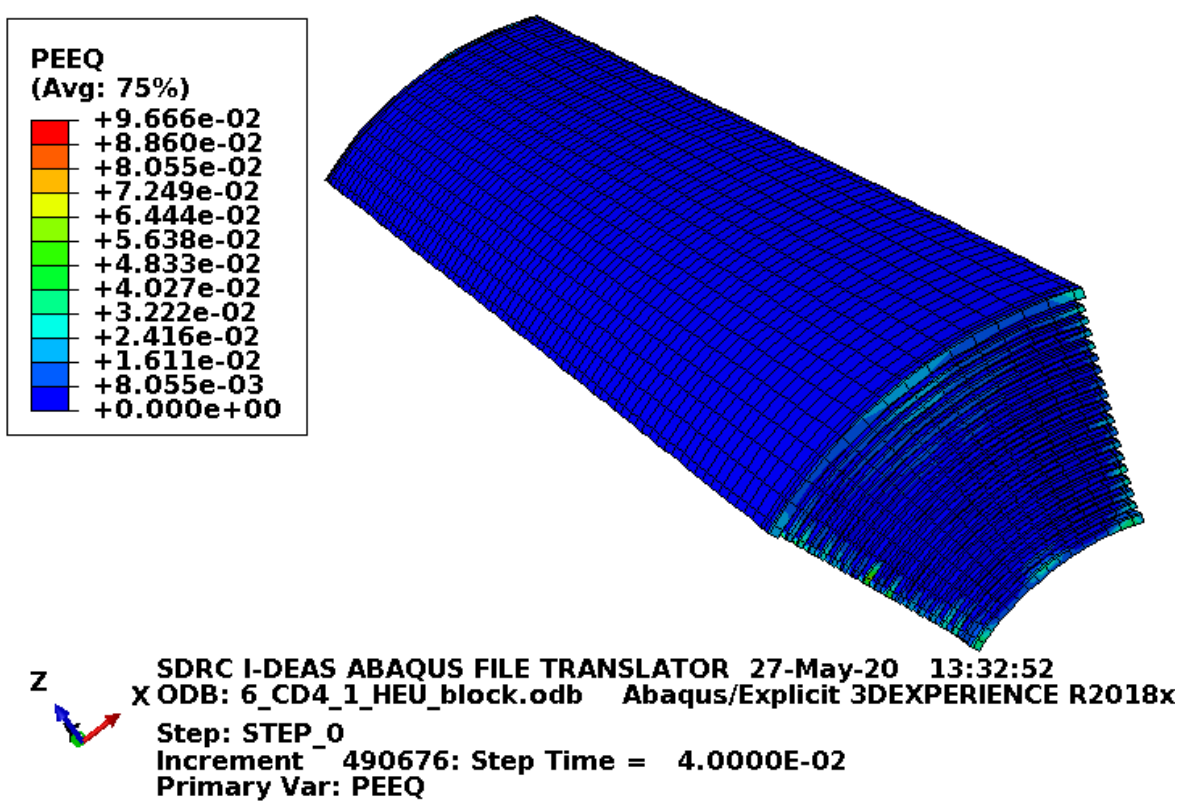

Figure D-87. Scope Part 1d (Table 3), Test 6 (Table 2) fuel plate equivalent strain.

Figure D-87 shows the equivalent plastic strain in the fuel plates. Failure in these elements occurs at an equivalent plastic strain of $0.205 \mathrm{in}$./in. If element failure were to occur, the element would be removed from the model (thereby excluding its equivalent plastic strain from the maximum equivalent plastic strain for the plot). However, the missing element would be visible in the plot. Figure D-87 shows no failure in the fuel plates with margin.

\section{D2.5.8 Results for Scope Part 1d (Table 3), Test 6 (Table 2) Fine Mesh}

The FEA model results for the Scope Part 1d (Table 3), Test 6 (Table 2) fine mesh model are shown below in Figure D-88 to Figure D-90. The fuel element weighs $22.1 \mathrm{lbf}$ and the drop scenario is modeled with minimum material properties except the enclosure and end boxes, which are modeled with relatively tough material properties. Though ATR FFSC SAR (2017) shows the Scope Part 1 (Table 3) drop scenarios to be acceptable, the results shown (for information) in this section include the blocks as added fuel plate protection. 


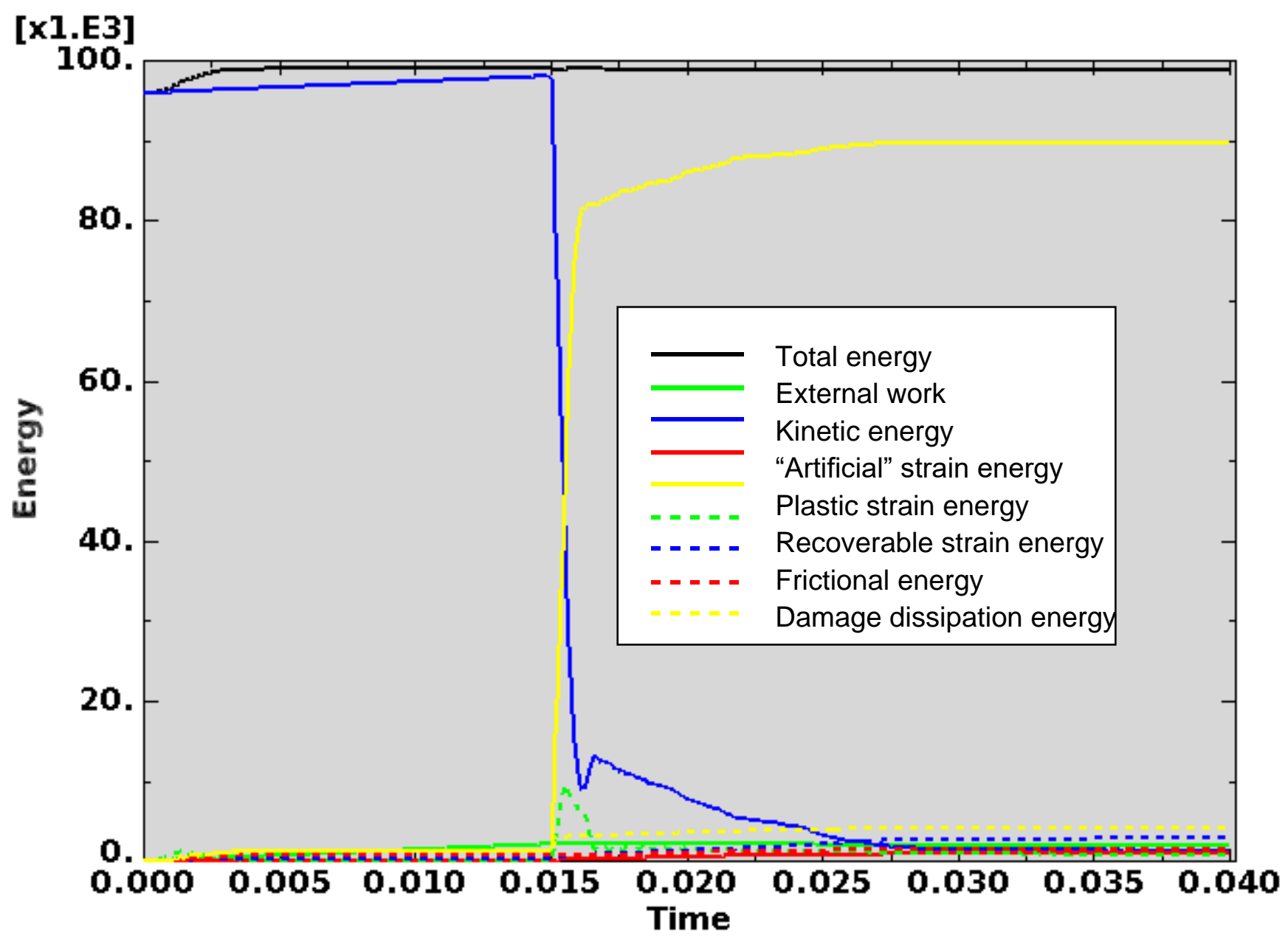

Figure D-88. Scope Part 1d (Table 3), Test 6 (Table 2) fine mesh energy curves.

Figure D-88 shows the energy curves for Scope Part 1d (Table 3), Test 6 (Table 2) fine mesh drop scenario. These curves exhibit a stable shape. Artificial strain energy represents the energy required to keep reduced integration elements from taking on a zero-energy hourglass shape. As shown in Figure D-88, the artificial energy at the end of the model run is $1.0 \%$ of the total energy. Therefore, the potential error associated with artificial energy is not considered to be significant. 
ENGINEERING CALCULATIONS AND ANALYSIS

Drop Analysis of the Advanced Test Reactor Fresh Fuel Shipping Container with Heavier Low-Enriched Uranium Fuel Contents
ECAR-5224, Rev. 0

Page D81 of D293

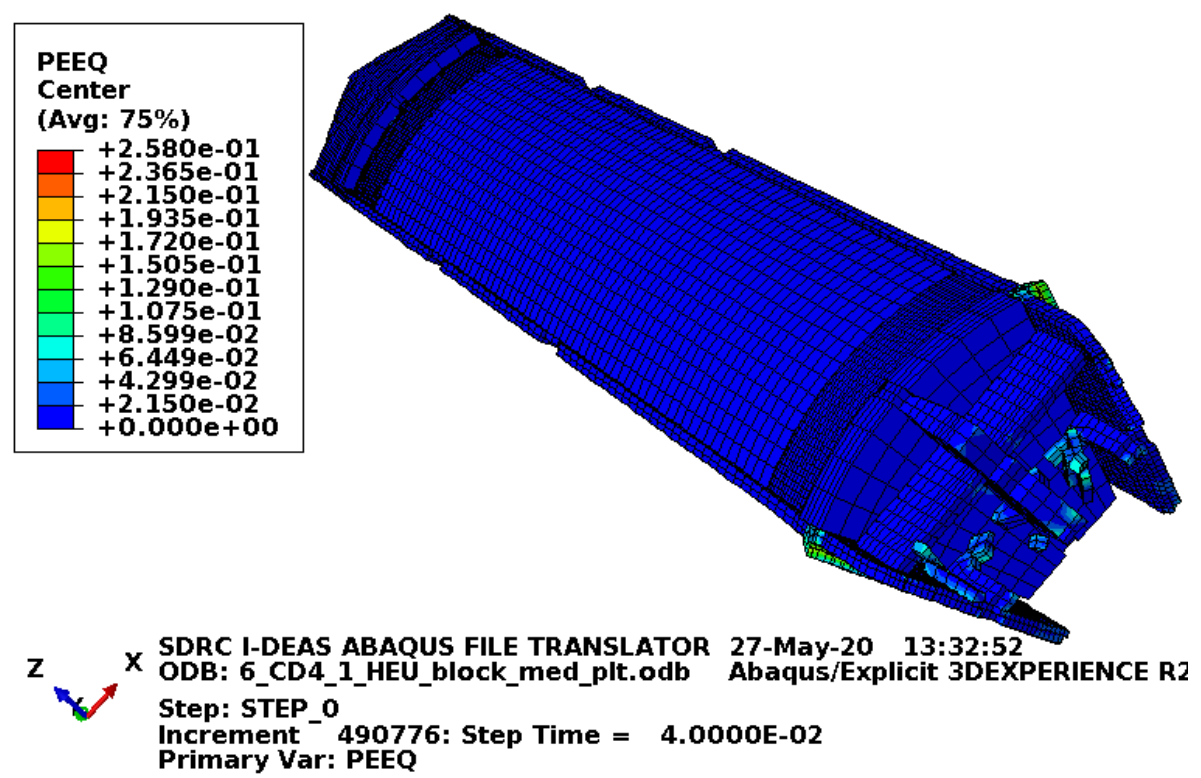

Figure D-89. Scope Part 1d (Table 3), Test 6 (Table 2) fine mesh fuel element plastic equivalent strain.

Figure D-89 shows the equivalent plastic strain in the fuel element. Failure in the end box elements occurs at an equivalent plastic strain of $0.08 \mathrm{in./in.} \mathrm{(for} \mathrm{the} \mathrm{relatively} \mathrm{tough} \mathrm{material} \mathrm{properties).} \mathrm{Failure} \mathrm{in} \mathrm{the} \mathrm{end}$ box weld elements occurs at an equivalent plastic strain of $0.115 \mathrm{in}$./in. (for the relatively tough material properties). Failure in the side plate and comb elements occurs at an equivalent plastic strain of 0.152 in./in. Failure in the side plate weld elements occurs at an equivalent plastic strain of 0.205 in./in. Figure D-89 shows substantial failure of the end box and end box welds nearest the impact.

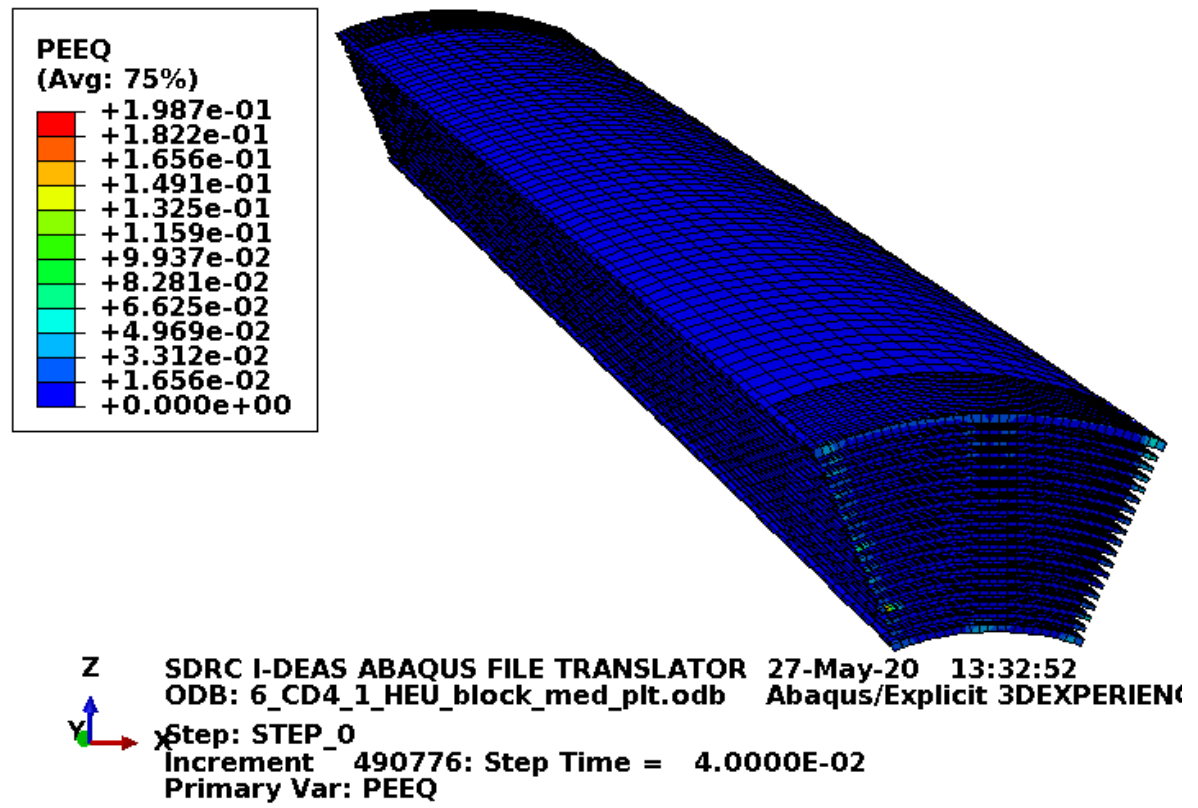

Figure D-90. Scope Part 1d (Table 3), Test 6 (Table 2) fine mesh fuel plate equivalent strain. 
Figure D-90 shows the equivalent plastic strain in the fuel plates. Failure in these elements occurs at an equivalent plastic strain of $0.205 \mathrm{in}$./in. If element failure were to occur, the element would be removed from the model (thereby excluding its equivalent plastic strain from the maximum equivalent plastic strain for the plot). However, the missing element would be visible in the plot. Figure D-90 shows no failure in the fuel plates with margin.

\section{D2.6 Results for Scope Part 1 (Table 3), Test 8 (Table 2)}

The drop scenario considered in this section is a $30 \mathrm{ft}$ drop modeled as a center of gravity over the top corner impact. It is identified as CD5-1 in the ATR FFSC SAR (2017).

In the physical drops, this was only top drop from $30 \mathrm{ft}$. It was preceded by a $4 \mathrm{ft}$ center of gravity over the top corner. After the $4 \mathrm{ft}$ center of gravity over the top corner and a $30 \mathrm{ft}$ side drop, the ATR FFSC SAR (2017) stated that there was no visible damage to the fuel element (as discussed in Section D2). Given this limited information, the damage shown in Figure D-6 is primarily credited to this $30 \mathrm{ft}$ drop scenario.

\section{D2.6.1 Results for Scope Part 1a (Table 3), Test 8 (Table 2)}

The FEA model results for the Scope Part 1a (Table 3), Test 8 (Table 2) model are shown below in Figure D-91 to Figure D-94. The fuel element weighs $22.1 \mathrm{lbf}$ and the whole model is modeled with minimum material properties. 


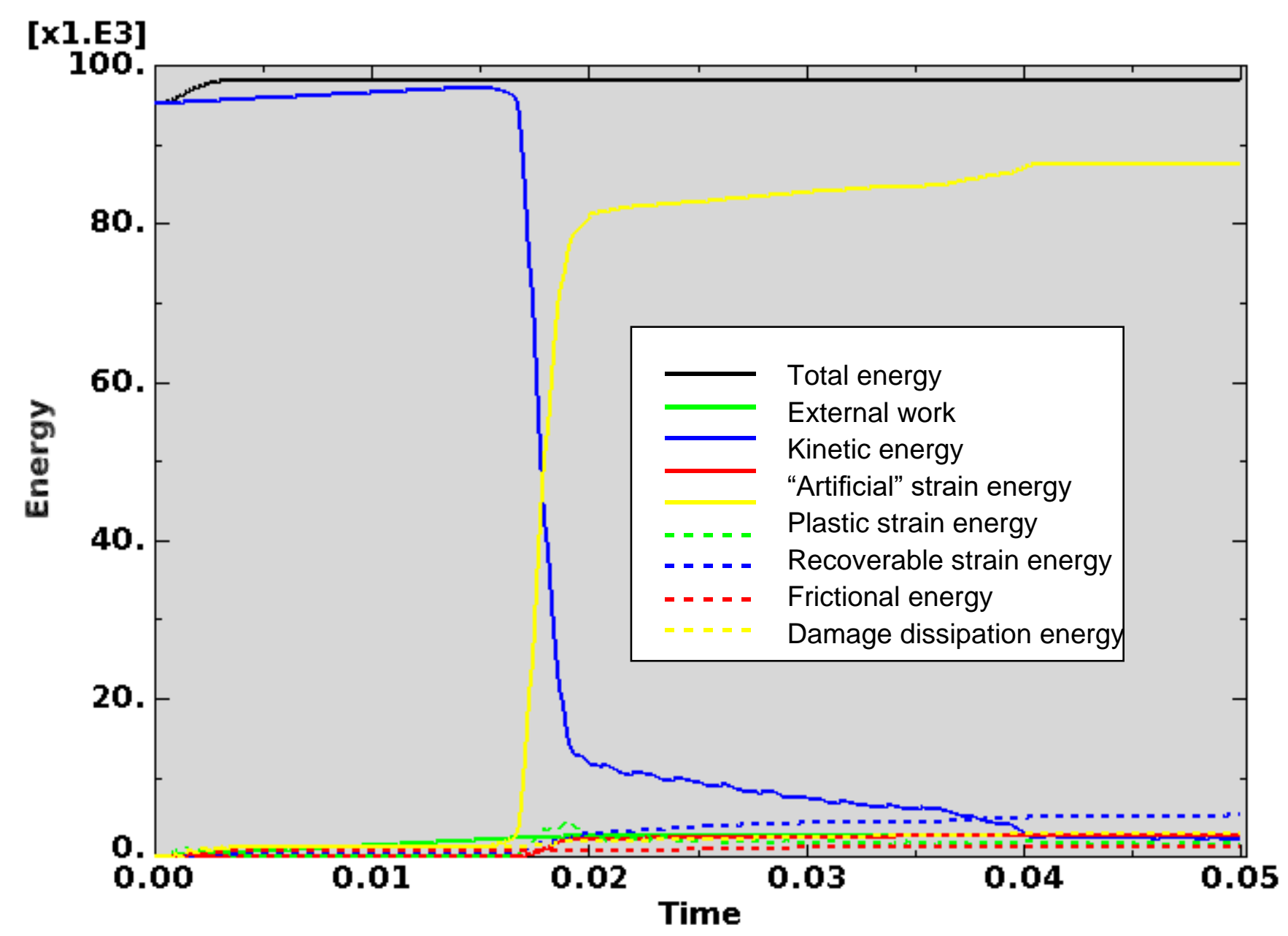

Figure D-91. Scope Part 1a (Table 3), Test 8 (Table 2) energy curves.

Figure D-91 shows the energy curves for Scope Part 1a (Table 3), Test 8 (Table 2) drop scenario. These curves exhibit a stable shape. Artificial strain energy represents the energy required to keep reduced integration elements from taking on a zero-energy hourglass shape. As shown in Figure D-91, the artificial energy at the end of the model run is $2.8 \%$ of the total energy. Therefore, the potential error associated with artificial energy is not considered to be significant. 
ENGINEERING CALCULATIONS AND ANALYSIS

Drop Analysis of the Advanced Test Reactor Fresh Fuel Shipping Container with Heavier Low-Enriched Uranium Fuel Contents
ECAR-5224, Rev. 0

Page D84 of D293

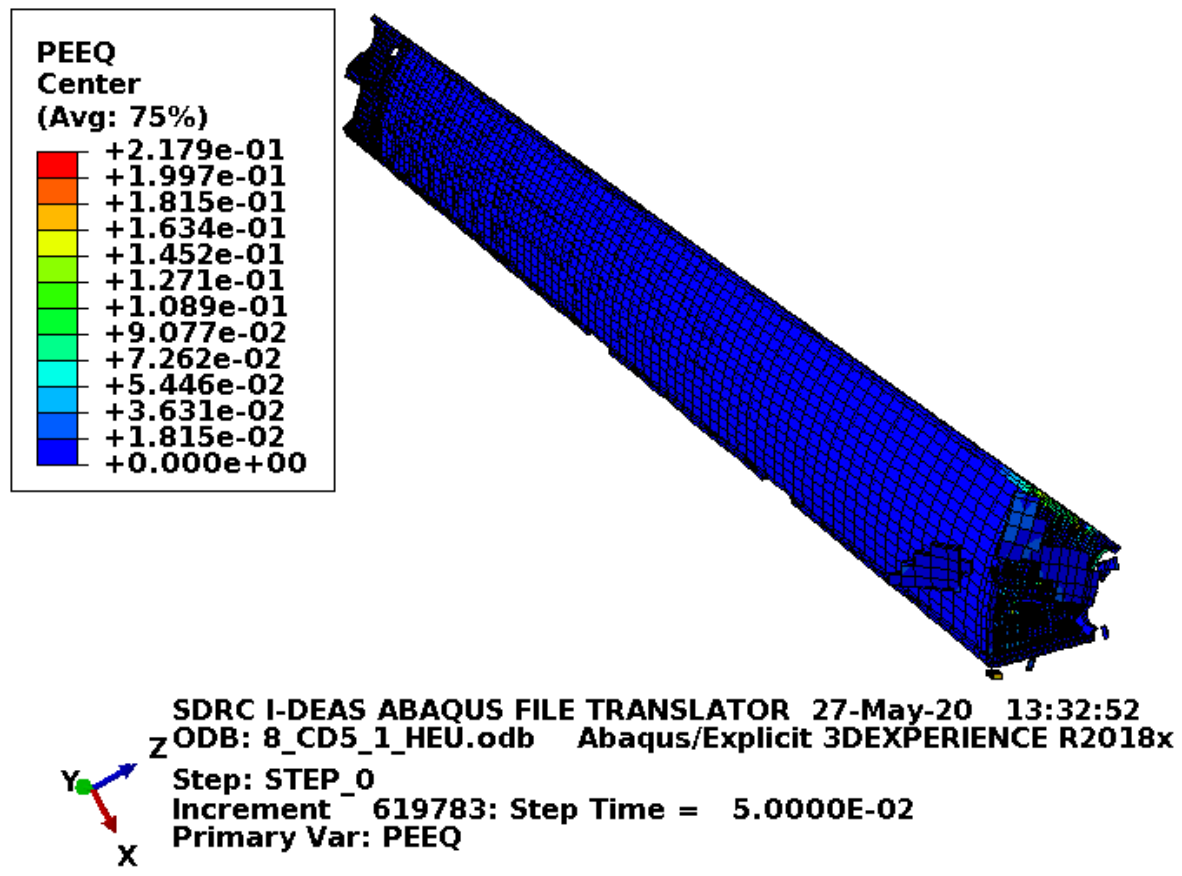

Figure D-92. Scope Part 1a (Table 3), Test 8 (Table 2) fuel element plastic equivalent strain.

Figure D-92 shows the equivalent plastic strain in the fuel element. Failure in the end box elements occurs at an equivalent plastic strain of $0.027 \mathrm{in}$./in. Failure in the end box weld elements occurs at an equivalent plastic strain of $0.032 \mathrm{in}$./in. Failure in the side plate and comb elements occurs at an equivalent plastic strain of $0.152 \mathrm{in}$./in. Failure in the side plate weld elements occurs at an equivalent plastic strain of 0.205 in./in. Figure D-92 shows substantial failure of the end box and end box welds nearest the impact.
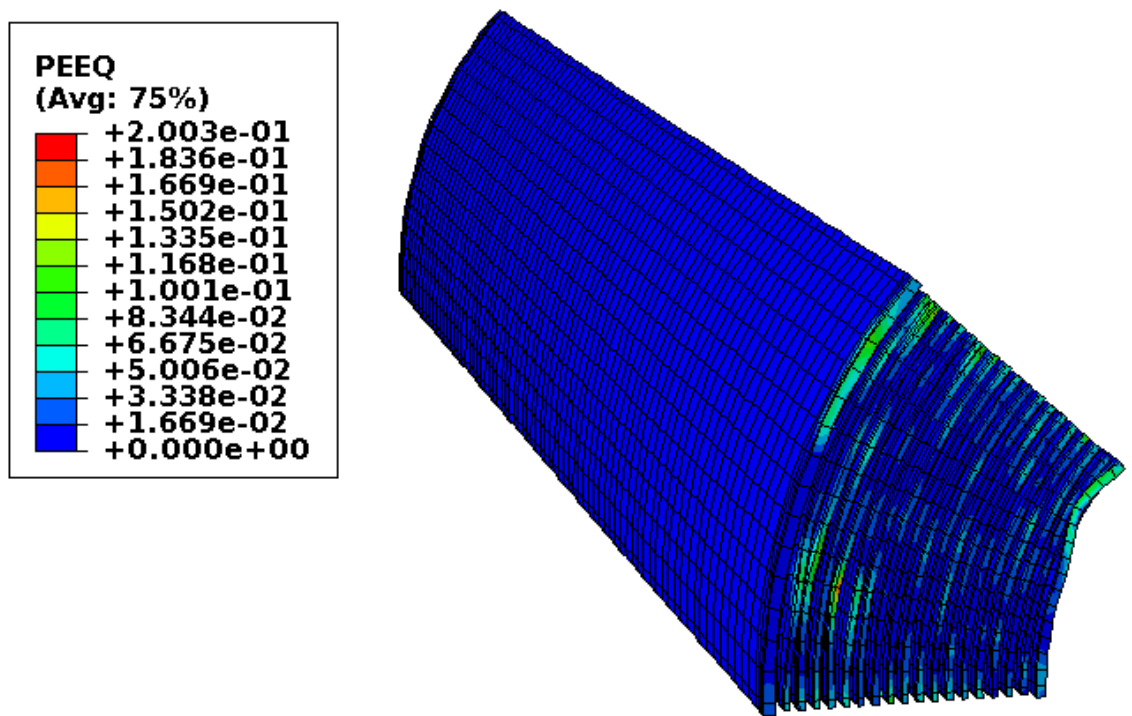

SDRC I-DEAS ABAQUS FILE TRANSLATOR 27-May-20 13:32:52 ODB: 8_CD5_1_HEU.odb Abaqus/Explicit 3DEXPERIENCE R2018x Step: STEP_o

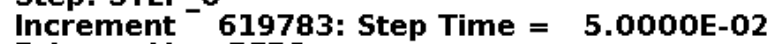

Figure D-93. Scope Part 1a (Table 3), Test 8 (Table 2) fuel plate equivalent strain. 
Figure D-93 shows the equivalent plastic strain in the fuel plates. Failure in these elements occurs at an equivalent plastic strain of $0.205 \mathrm{in}$./in. If element failure were to occur, the element would be removed from the model (thereby excluding its equivalent plastic strain from the maximum equivalent plastic strain for the plot). However, the missing element would be visible in the plot. Figure D-93 shows no element failure.
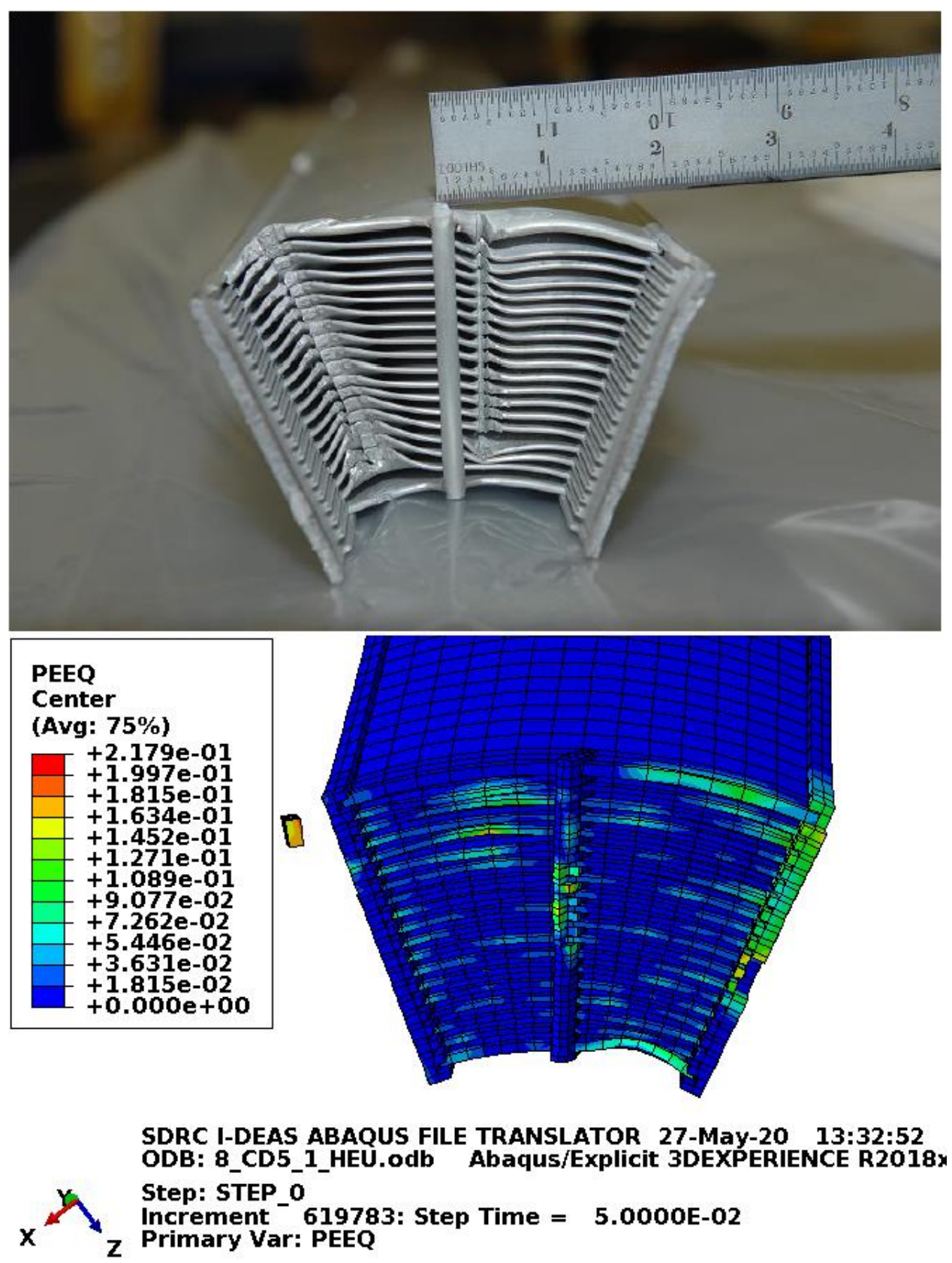

Figure D-94. Scope Part 1a (Table 3), Test 8 (Table 2) damage comparison with Figure D-6.

The FEA model in Figure D-94 has the end boxes and end box welds removed. The damage comparison shows some plastic deformation in the FEA model, but much less and not the same pattern as the physical drop. In this scenario, the end box is much weaker than that of the physical drop. 


\section{D2.6.2 Results for Scope Part 1b (Table 3), Test 8 (Table 2)}

The FEA model results for the Scope Part $1 \mathrm{~b}$ (Table 3), Test 8 (Table 2) model are shown below in Figure D-95 to Figure D-98. The fuel element weighs $22.1 \mathrm{lbf}$ and the drop scenario is modeled with minimum material properties except the enclosure and end boxes, which are modeled with relatively tough material properties.

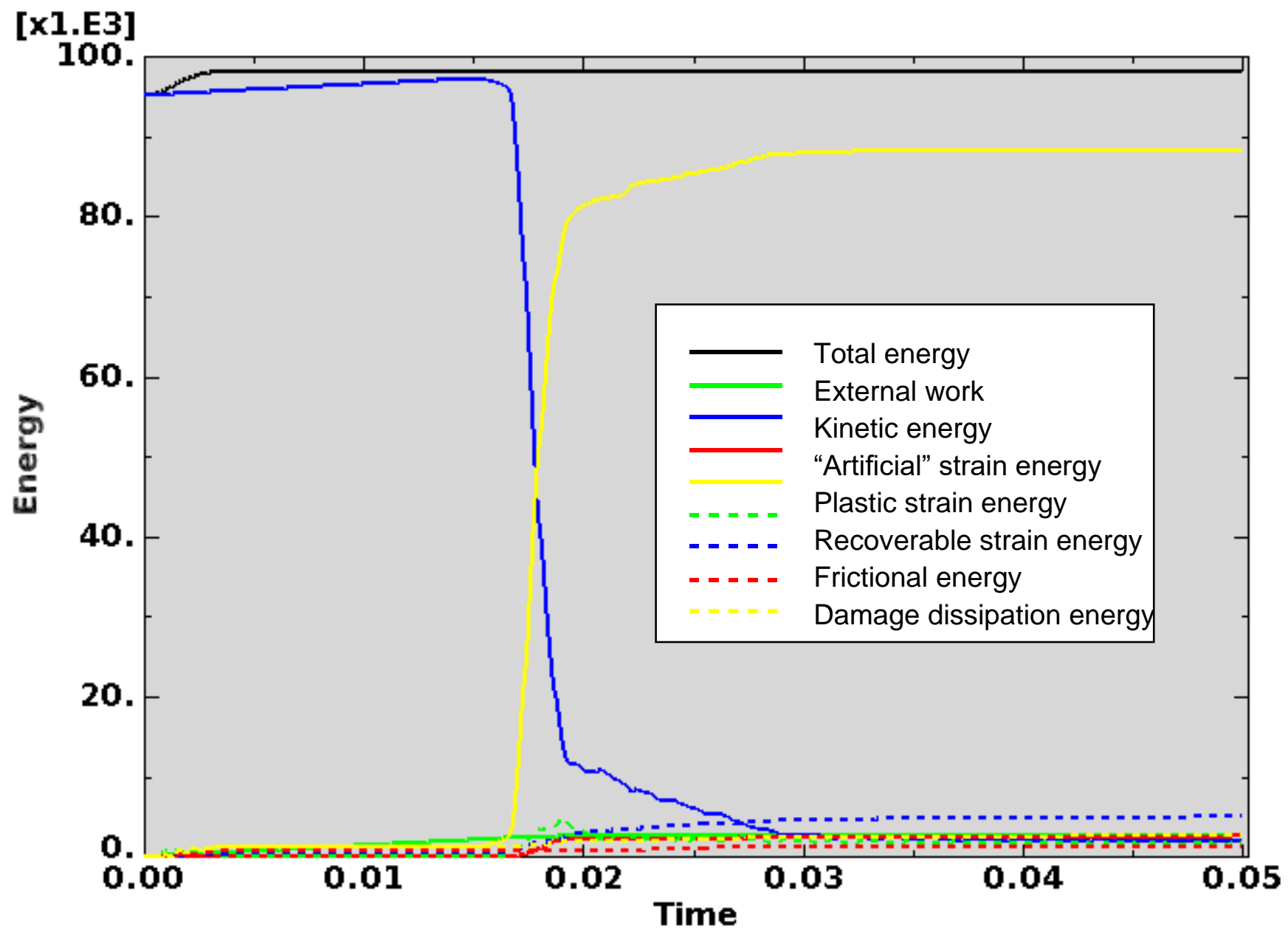

Figure D-95. Scope Part 1b (Table 3), Test 8 (Table 2) energy curves.

Figure D-95 shows the energy curves for Scope Part 1b (Table 3), Test 8 (Table 2) drop scenario. These curves exhibit a stable shape. Artificial strain energy represents the energy required to keep reduced integration elements from taking on a zero-energy hourglass shape. As shown in Figure D-95, the artificial energy at the end of the model run is $2.6 \%$ of the total energy. Therefore, the potential error associated with artificial energy is not considered to be significant. 
ENGINEERING CALCULATIONS AND ANALYSIS

Drop Analysis of the Advanced Test Reactor Fresh Fuel Shipping Container with Heavier Low-Enriched Uranium Fuel Contents

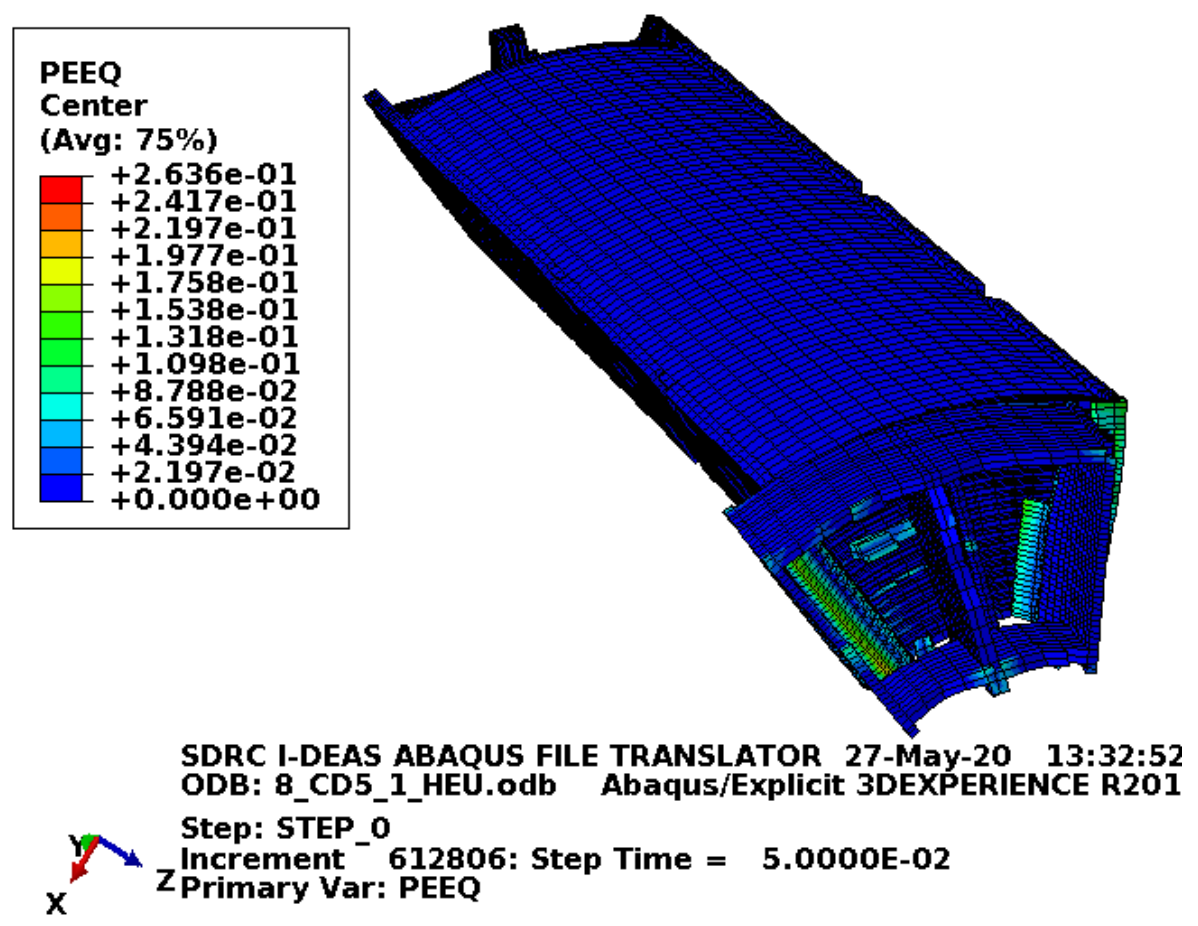

Figure D-96. Scope Part 1b (Table 3), Test 8 (Table 2) fuel element plastic equivalent strain.

Figure D-96 shows the equivalent plastic strain in the fuel element. Failure in the end box elements occurs at an equivalent plastic strain of $0.08 \mathrm{in}$./in. (for the relatively tough material properties). Failure in the end box weld elements occurs at an equivalent plastic strain of $0.115 \mathrm{in}$./in. (for the relatively tough material properties). Failure in the side plate and comb elements occurs at an equivalent plastic strain of $0.152 \mathrm{in}$./in. Failure in the side plate weld elements occurs at an equivalent plastic strain of $0.205 \mathrm{in}$./in. Figure D-96 shows failure in the end box and end box welds. 
ENGINEERING CALCULATIONS AND ANALYSIS

Drop Analysis of the Advanced Test Reactor Fresh Fuel Shipping Container with Heavier Low-Enriched Uranium Fuel Contents
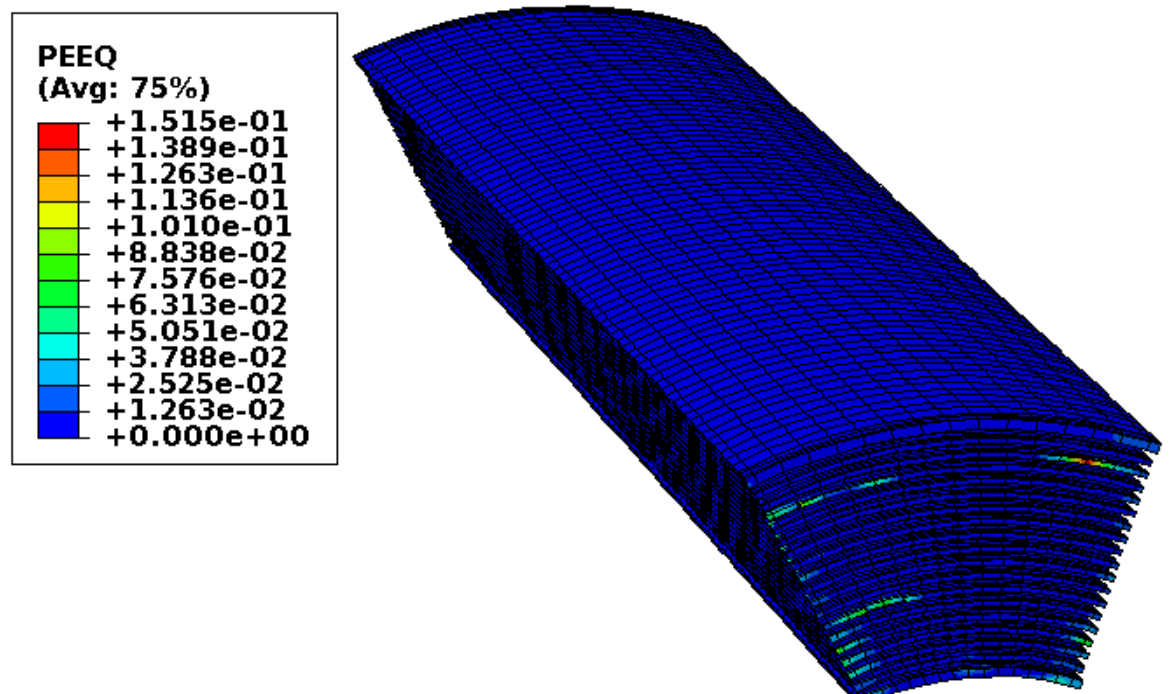

SDRC I-DEAS ABAQUS FILE TRANSLATOR 27-May-20 13:32:52

ODB: 8_CD5_1_HEU.odb Abaqus/Explicit 3DEXPERIENCE R2018x

Step: STEP_o

Increment 612806: Step Time = 5.0000E-02

Primary Var: PEEQ

Figure D-97. Scope Part 1b (Table 3), Test 8 (Table 2) fuel plate equivalent strain.

Figure D-97 shows the equivalent plastic strain in the fuel plates. Failure in these elements occurs at an equivalent plastic strain of 0.205 in./in. If element failure were to occur, the element would be removed from the model (thereby excluding its equivalent plastic strain from the maximum equivalent plastic strain for the plot). However, the missing element would be visible in the plot. Figure D-97 shows no element failure. 

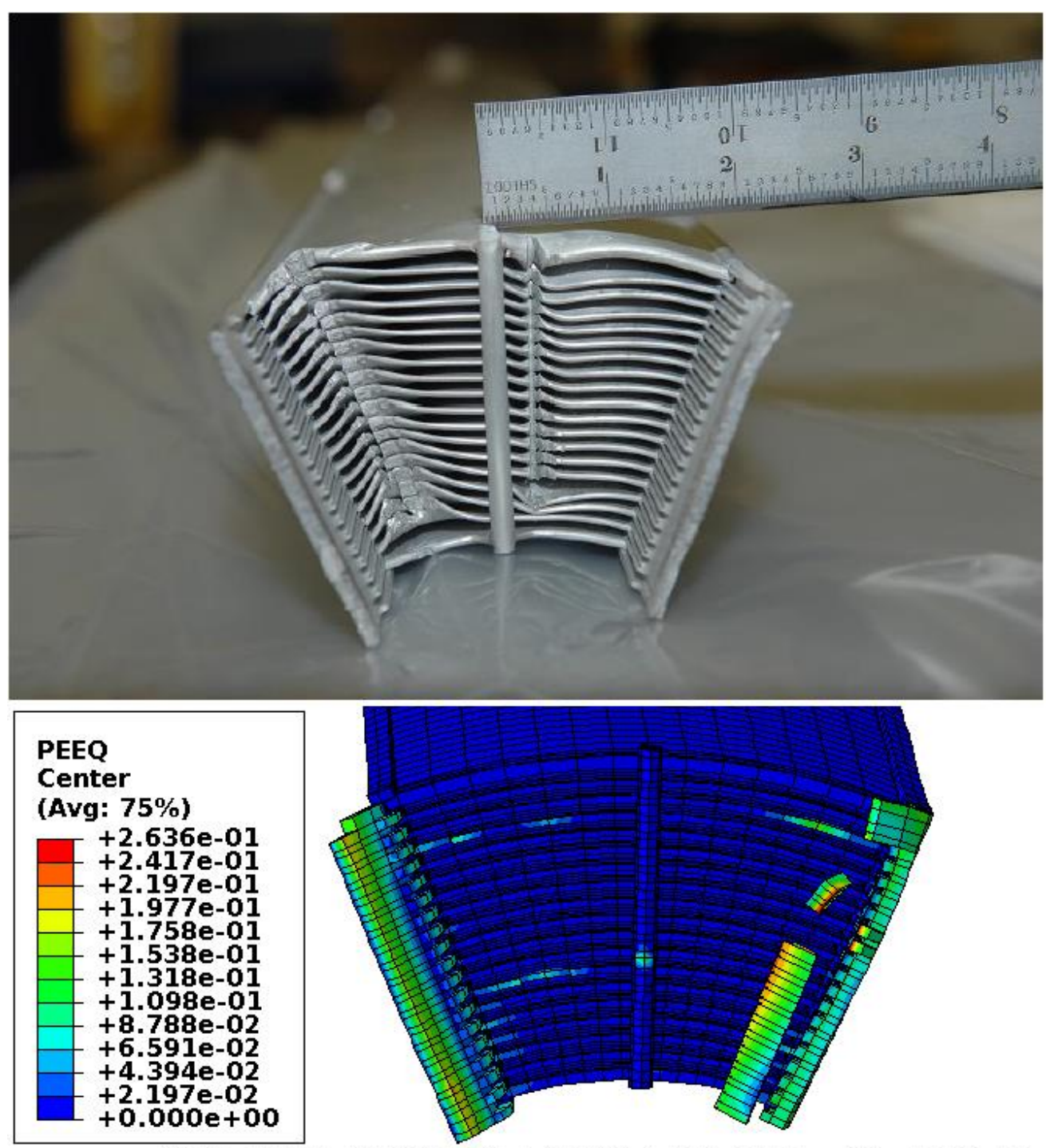

SDRC I-DEAS ABAQUS FILE TRANSLATOR 27-May-20 13:32:52

ODB: 8_CD5_1_HEU.odb Abaqus/Explicit 3DEXPERIENCE R2018,

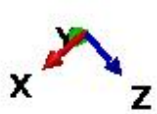

Step: STEP_o

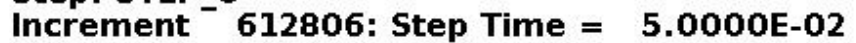
Z Primary Var: PEEQ

Figure D-98. Scope Part 1b (Table 3), Test 8 (Table 2) damage comparison with Figure D-6.

The FEA model in Figure D-98 has the end boxes and end box welds removed. The damage comparison shows that the tougher end box and end box weld material properties did not allow the end box to fully break free. Consequently, the end box could not impact the fuel plates. However, it should be noted that the FEA model damage for the $4 \mathrm{ft}$ top corner drop is conservative. Considering the model with relatively tough end boxes (see Section D2.1.2), there is significant weld damage (as shown in Figure D-15). If this damaged model were then run for the drop scenario in this section, more reasonable and conservative damage could be expected. This evaluation considers only a single drop accident as credible. Also, this evaluation adds FEA model results for a flat top drop (see Section D2.9) which is a more violent fuel element impact than in this drop scenario. 


\section{D2.6.3 Results for Scope Part 1c (Table 3), Test 8 (Table 2)}

The FEA model results for the Scope Part 1c (Table 3), Test 8 (Table 2) model are shown below in Figure D-99 to Figure D-101. The fuel element weighs $22.1 \mathrm{lbf}$ and the whole model is modeled with minimum material properties. Though ATR FFSC SAR (2017) shows the Scope Part 1 (Table 3) drop scenarios to be acceptable, the results shown (for information) in this section include the blocks as added fuel plate protection.

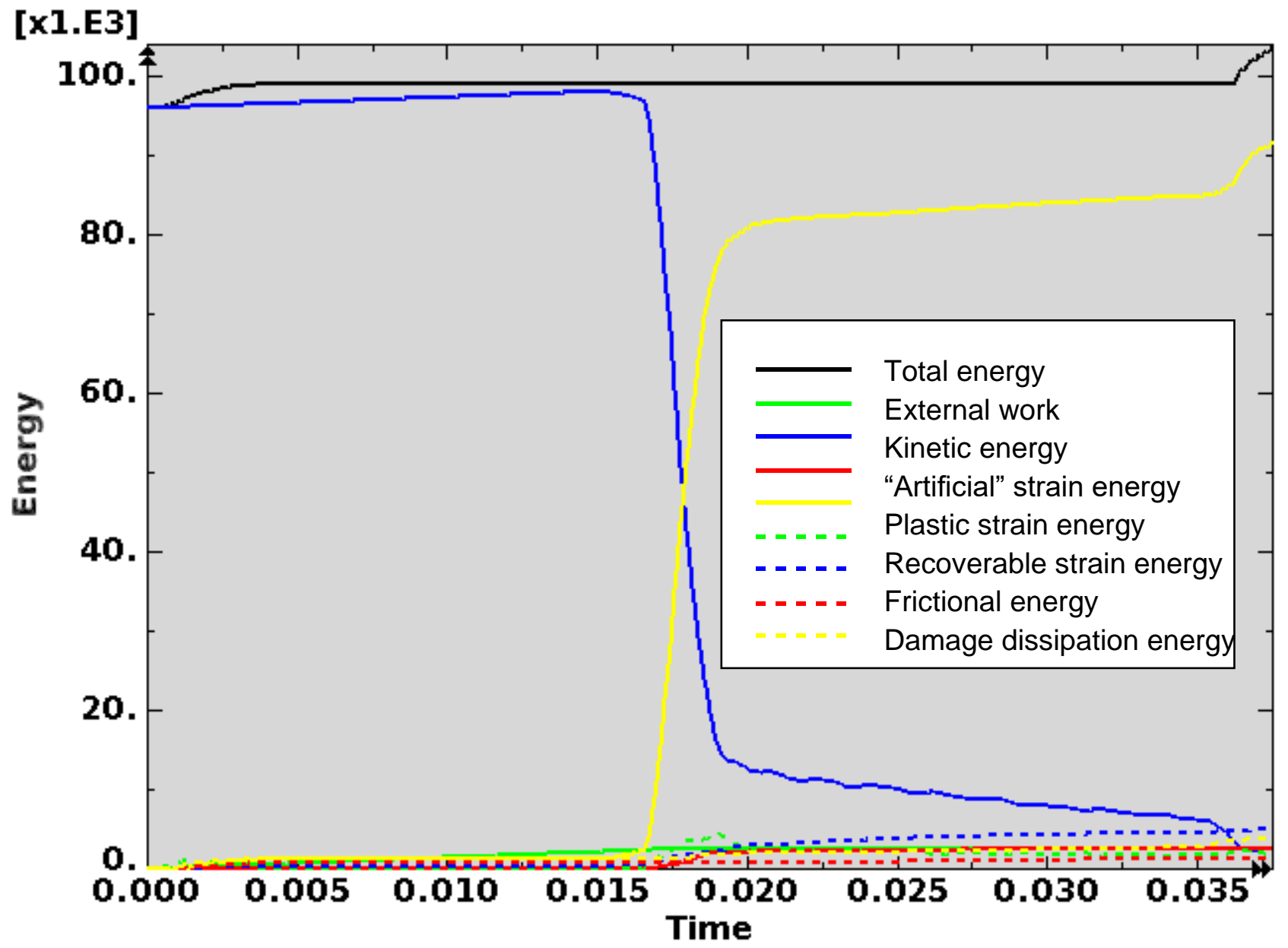

Figure D-99. Scope Part 1c (Table 3), Test 8 (Table 2) energy curves.

Figure D-99 shows the energy curves for Scope Part 1c (Table 3), Test 8 (Table 2) drop scenario. These curves exhibit mostly stable behavior. Near the end of the model run, the total energy and plastic strain energy start to show undesirable behavior. As discussed in Section D2.5 this appears to result from contact difficultly between failed portions of the fuel element. Consequently, output is shown at the first output frame after fuel element rebound ( 0.0375 second) to try to minimize potential error associated with this.

Artificial strain energy represents the energy required to keep reduced integration elements from taking on a zero-energy hourglass shape. As shown in Figure D-99, the artificial energy at the end of the model run is $2.6 \%$ of the total energy. Therefore, the potential error associated with artificial energy is not considered to be significant. 
ENGINEERING CALCULATIONS AND ANALYSIS

Drop Analysis of the Advanced Test Reactor Fresh Fuel Shipping Container with Heavier Low-Enriched Uranium Fuel Contents
ECAR-5224, Rev. 0

Page D91 of D293
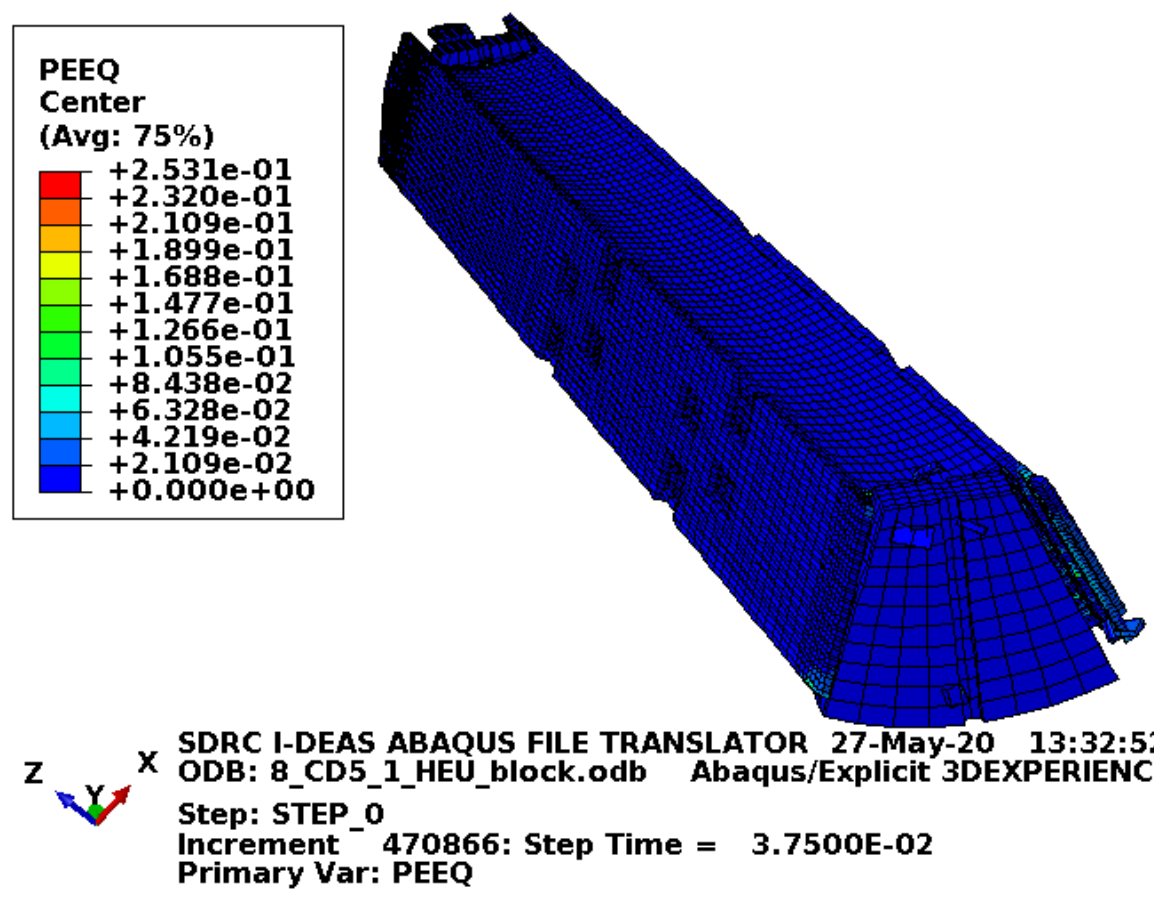

Figure D-100. Scope Part 1c (Table 3), Test 8 (Table 2) fuel element plastic equivalent strain.

Figure D-100 shows the equivalent plastic strain in the fuel element. Failure in the end box elements occurs at an equivalent plastic strain of $0.027 \mathrm{in}$./in. Failure in the end box weld elements occurs at an equivalent plastic strain of $0.032 \mathrm{in}$./in. Failure in the side plate and comb elements occurs at an equivalent plastic strain of $0.152 \mathrm{in} . / \mathrm{in}$. Failure in the side plate weld elements occurs at an equivalent plastic strain of 0.205 in./in. Figure D-100 shows substantial failure of the end box and end box welds nearest the impact.

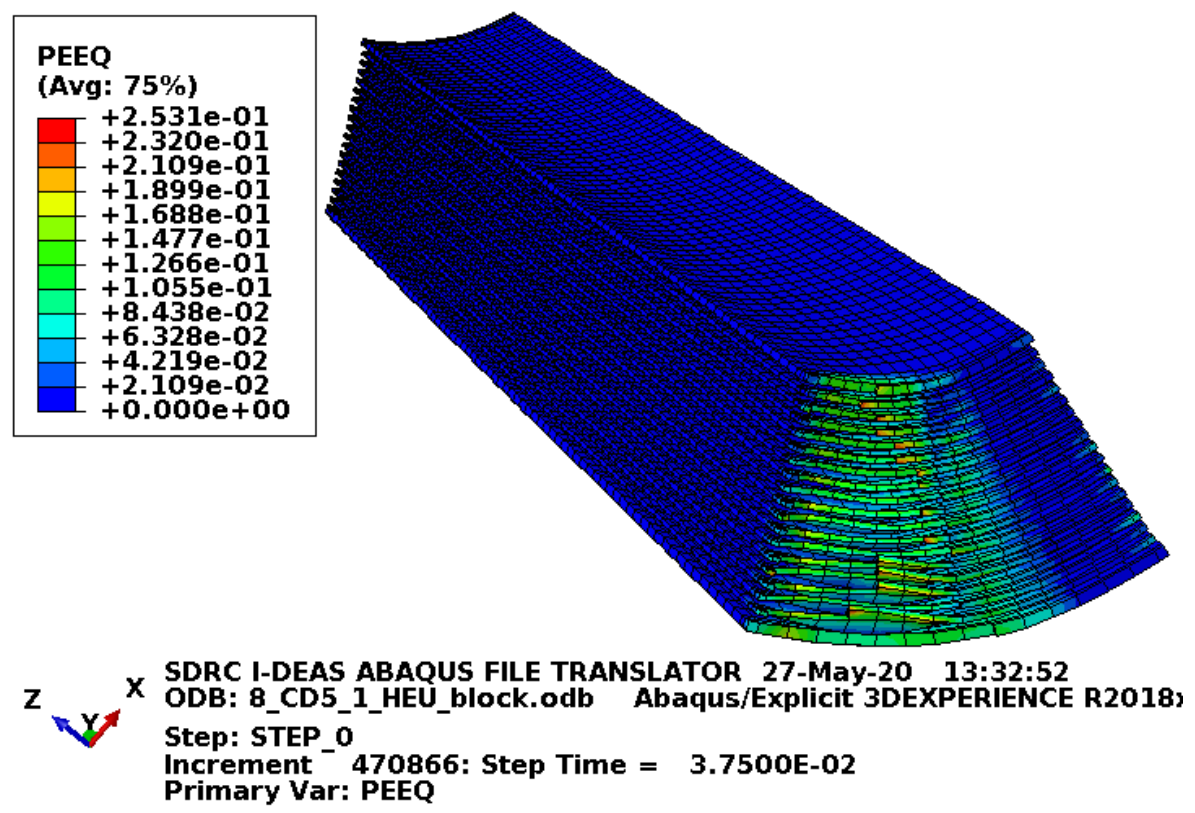

Figure D-101. Scope Part 1c (Table 3), Test 8 (Table 2) fuel plate equivalent strain. 
Figure D-101 shows the equivalent plastic strain in the fuel plates. Failure in these elements occurs at an equivalent plastic strain of $0.205 \mathrm{in}$./in. If element failure were to occur, the element would be removed from the model (thereby excluding its equivalent plastic strain from the maximum equivalent plastic strain for the plot). However, the missing element would be visible in the plot. Figure D-101 shows some compressive failure in a few places, one element deep (about 0.09 in.), which is acceptable. In this situation where the end box is weak, having the block reduces the crush zone thereby making the fuel plate absorb more of the impact energy. Having the blocks is still desirable because the damage is more predictable and compressive (rather than cutting).

\section{D2.6.4 Results for Scope Part 1c (Table 3), Test 8 (Table 2) Fine Mesh}

The FEA model results for the Scope Part 1c (Table 3), Test 8 (Table 2) fine mesh model are shown below in Figure D-102 to Figure D-104. The fuel element weighs $22.1 \mathrm{lbf}$ and the whole model is modeled with minimum material properties. Though ATR FFSC SAR (2017) shows the Scope Part 1 (Table 3) drop scenarios to be acceptable, the results shown (for information) in this section include the blocks as added fuel plate protection.

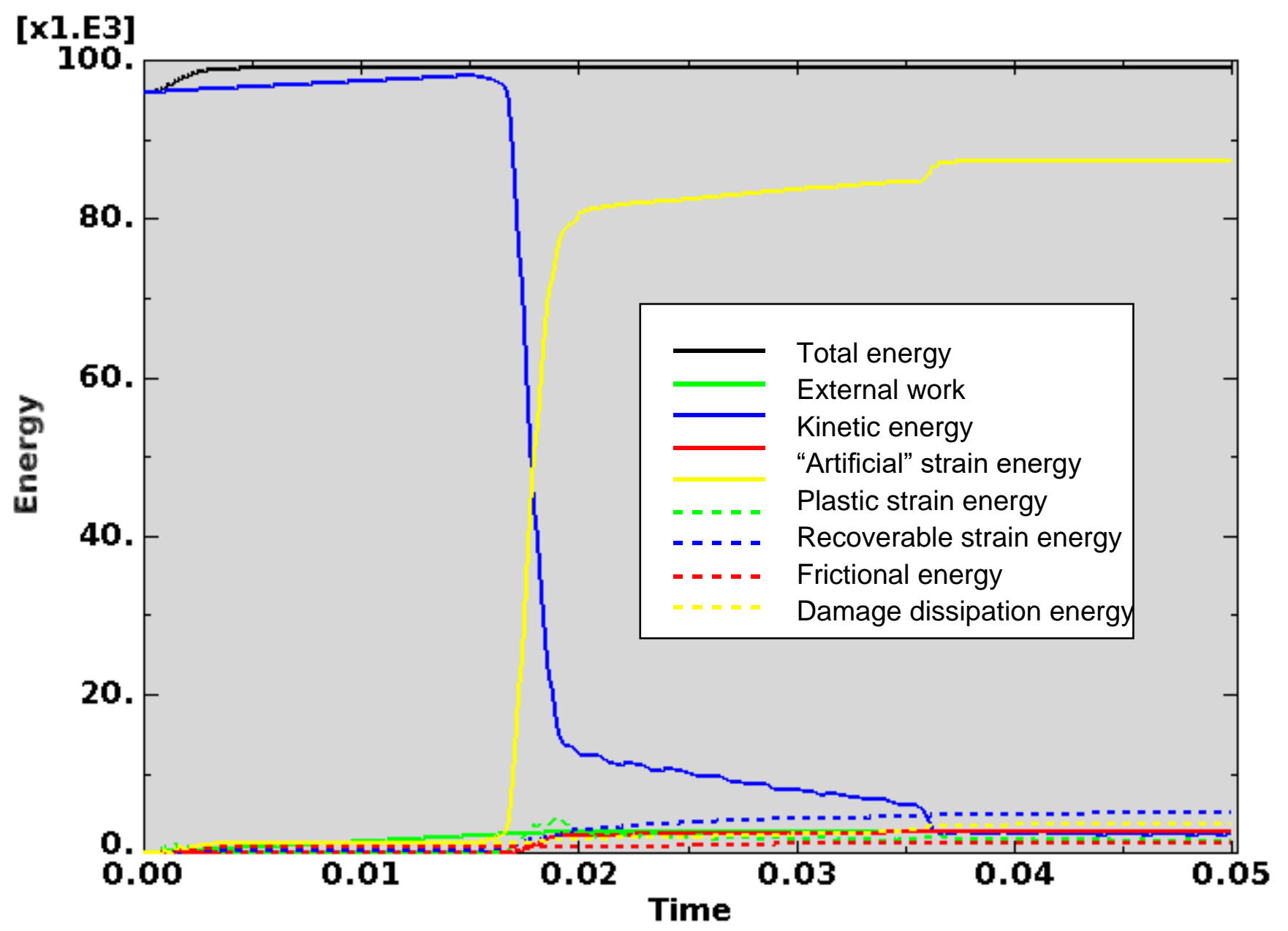

Figure D-102. Scope Part 1c (Table 3), Test 8 (Table 2) fine mesh energy curves. 
Figure D-102 shows the energy curves for Scope Part 1c (Table 3), Test 8 (Table 2) fine mesh drop scenario. These curves exhibit a stable shape. Artificial strain energy represents the energy required to keep reduced integration elements from taking on a zero-energy hourglass shape. As shown in Figure D-102, the artificial energy at the end of the model run is $2.7 \%$ of the total energy. Therefore, the potential error associated with artificial energy is not considered to be significant.
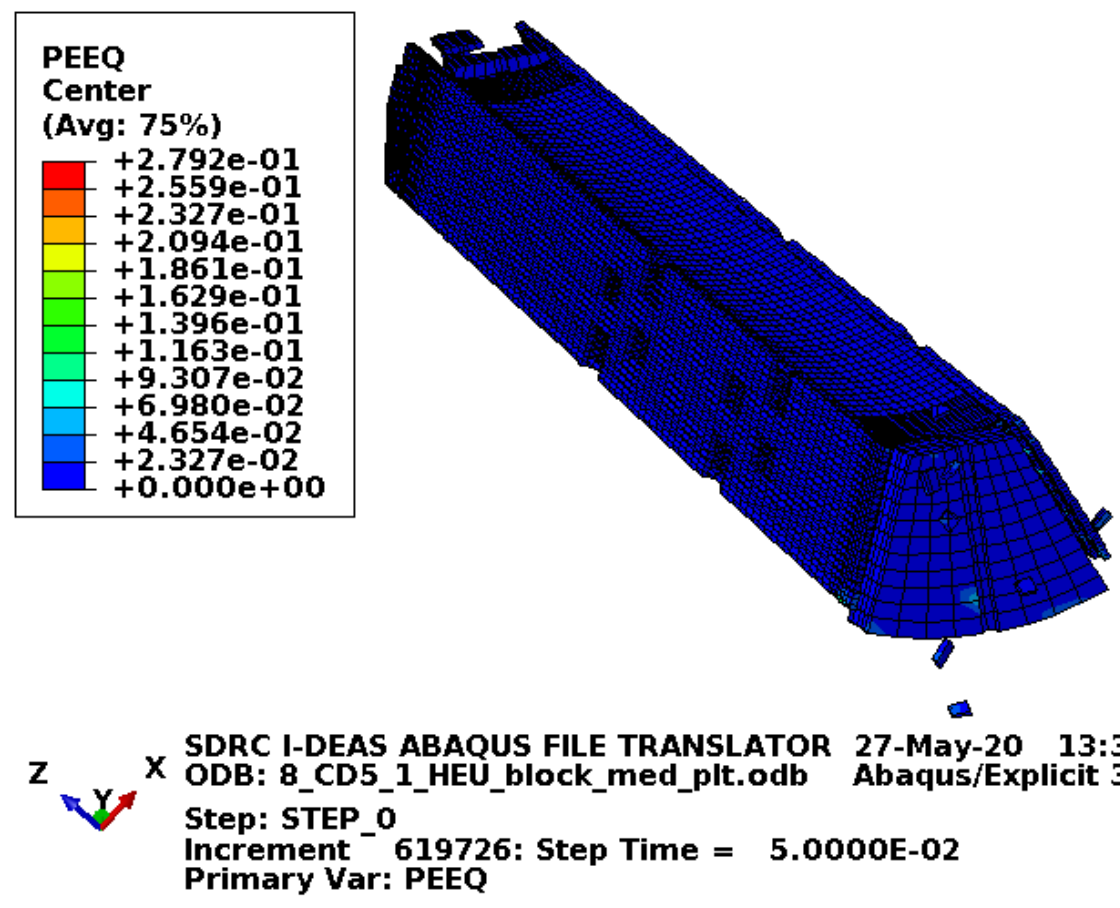

Figure D-103. Scope Part 1c (Table 3), Test 8 (Table 2) fine mesh fuel element plastic equivalent strain.

Figure D-103 shows the equivalent plastic strain in the fuel element. Failure in the end box elements occurs at an equivalent plastic strain of $0.027 \mathrm{in}$./in. Failure in the end box weld elements occurs at an equivalent plastic strain of $0.032 \mathrm{in}$./in. Failure in the side plate and comb elements occurs at an equivalent plastic strain of $0.152 \mathrm{in}$./in. Failure in the side plate weld elements occurs at an equivalent plastic strain of 0.205 in./in. Figure D-103 shows substantial failure of the end box and end box welds nearest the impact. 


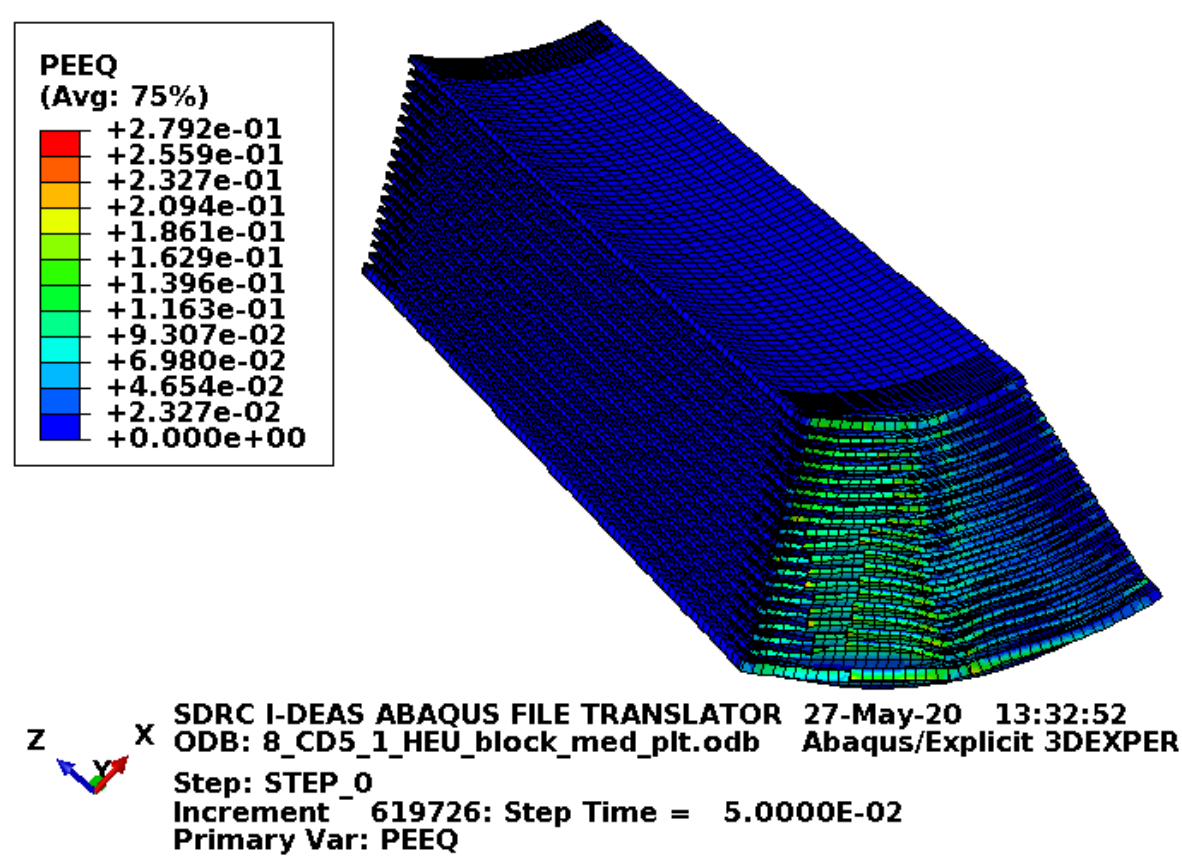

Figure D-104. Scope Part 1c (Table 3), Test 8 (Table 2) fine mesh fuel plate equivalent strain.

Figure D-104 shows the equivalent plastic strain in the fuel plates. Failure in these elements occurs at an equivalent plastic strain of $0.205 \mathrm{in}$./in. If element failure were to occur, the element would be removed from the model (thereby excluding its equivalent plastic strain from the maximum equivalent plastic strain for the plot). However, the missing element would be visible in the plot. Figure D-104 shows compressive failure in the fuel plates to a little less than 0.22 in. deep from the fuel plate ends. Also, above failure strain values are shown in many other fuel plate elements. These local high strain results are likely from extrapolation (as integration point strains are the important strains for failure). If the elements having strains above failure are considered as failed, the maximum failure depth would remain unchanged and the failure is acceptable because it does not reach the fuel meat.

\section{D2.6.5 Results for Scope Part 1d (Table 3), Test 8 (Table 2)}

The FEA model results for the Scope Part 1d (Table 3), Test 8 (Table 2) model are shown below in Figure D-105 to Figure D-107. The fuel element weighs $22.1 \mathrm{lbf}$ and the drop scenario is modeled with minimum material properties except the enclosure and end boxes, which are modeled with relatively tough material properties. Though ATR FFSC SAR (2017) shows the Scope Part 1 (Table 3) drop scenarios to be acceptable, the results shown (for information) in this section include the blocks as added fuel plate protection. 


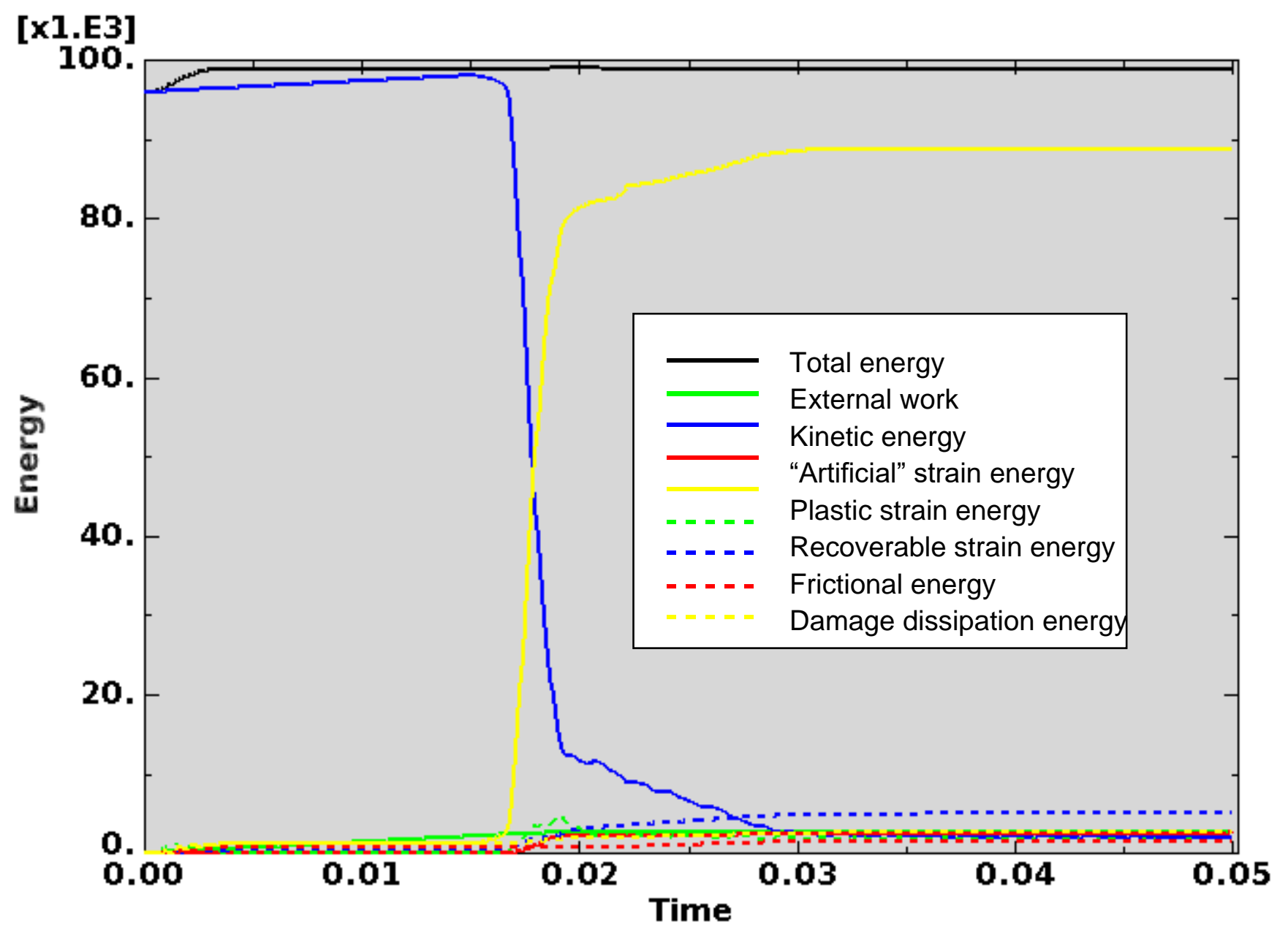

Figure D-105. Scope Part 1d (Table 3), Test 8 (Table 2) energy curves.

Figure D-105 shows the energy curves for Scope Part 1d (Table 3), Test 8 (Table 2) drop scenario. These curves exhibit a stable shape. Artificial strain energy represents the energy required to keep reduced integration elements from taking on a zero-energy hourglass shape. As shown in Figure D-105, the artificial energy at the end of the model run is $2.6 \%$ of the total energy. Therefore, the potential error associated with artificial energy is not considered to be significant. 
ENGINEERING CALCULATIONS AND ANALYSIS

Drop Analysis of the Advanced Test Reactor Fresh Fuel Shipping Container with Heavier Low-Enriched Uranium Fuel Contents
ECAR-5224, Rev. 0

Page D96 of D293

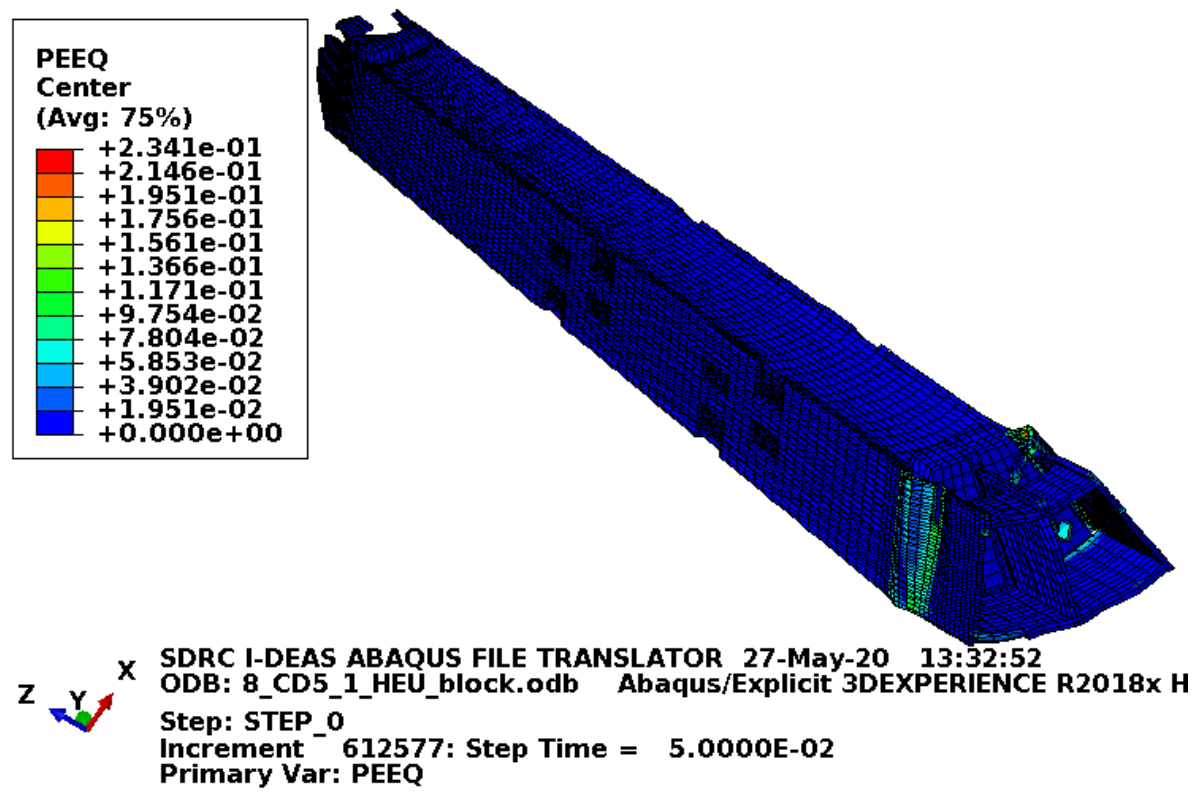

Figure D-106. Scope Part 1d (Table 3), Test 8 (Table 2) fuel element plastic equivalent strain.

Figure D-106 shows the equivalent plastic strain in the fuel element. Failure in the end box elements occurs at an equivalent plastic strain of $0.08 \mathrm{in./in.} \mathrm{(for} \mathrm{the} \mathrm{relatively} \mathrm{tough} \mathrm{material} \mathrm{properties).} \mathrm{Failure} \mathrm{in} \mathrm{the} \mathrm{end}$ box weld elements occurs at an equivalent plastic strain of $0.115 \mathrm{in}$./in. (for the relatively tough material properties). Failure in the side plate and comb elements occurs at an equivalent plastic strain of 0.152 in./in. Failure in the side plate weld elements occurs at an equivalent plastic strain of 0.205 in./in. Figure D-106 shows some failure in the end box and end box weld nearest the impacted surface.

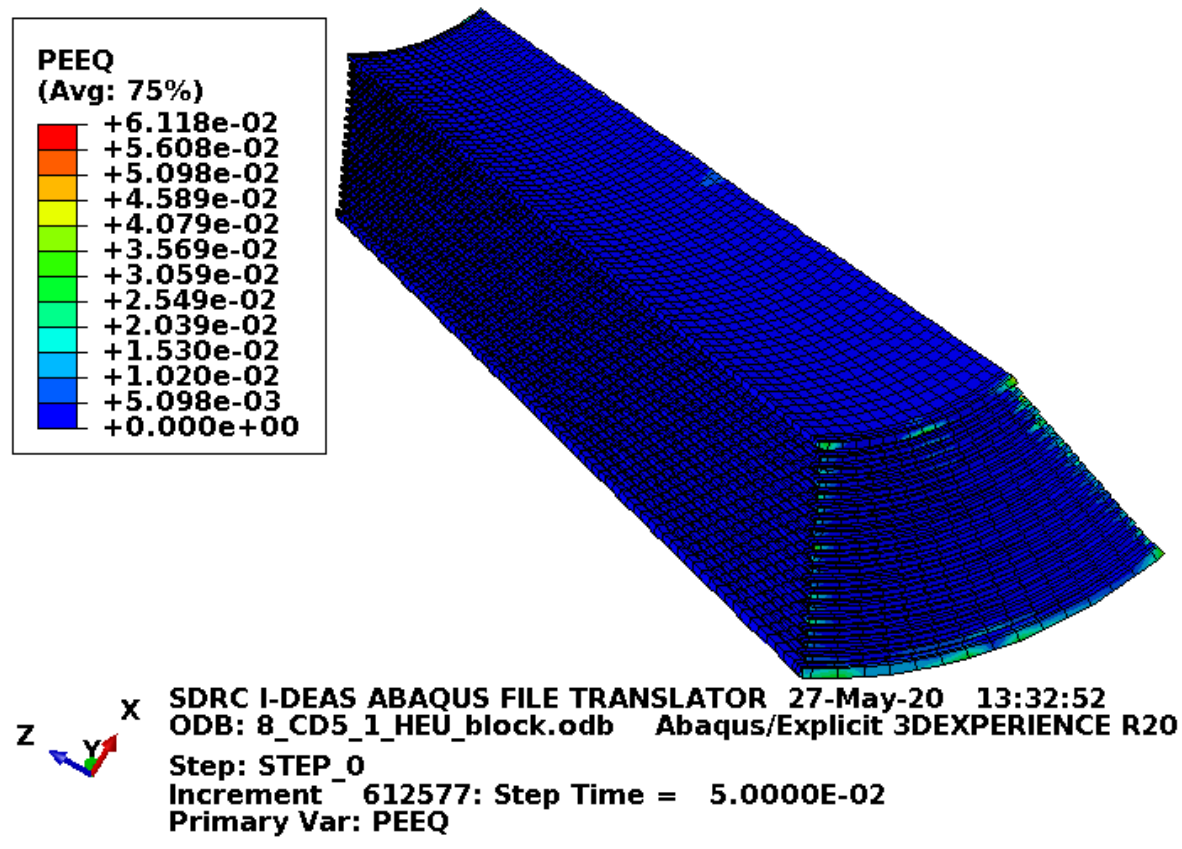

Figure D-107. Scope Part 1d (Table 3), Test 8 (Table 2) fuel plate equivalent strain. 
Figure D-107 shows the equivalent plastic strain in the fuel plates. Failure in these elements occurs at an equivalent plastic strain of $0.205 \mathrm{in}$./in. If element failure were to occur, the element would be removed from the model (thereby excluding its equivalent plastic strain from the maximum equivalent plastic strain for the plot). However, the missing element would be visible in the plot. Figure D-107 shows no failure in the fuel plates with margin.

\section{D2.6.6 Results for Scope Part 1d (Table 3), Test 8 (Table 2) Fine Mesh}

The FEA model results for the Scope Part 1d (Table 3), Test 8 (Table 2) fine mesh model are shown below in Figure D-108 to Figure D-110. The fuel element weighs $22.1 \mathrm{lbf}$ and the drop scenario is modeled with minimum material properties except the enclosure and end boxes, which are modeled with relatively tough material properties. Though ATR FFSC SAR (2017) shows the Scope Part 1 (Table 3) drop scenarios to be acceptable, the results shown (for information) in this section include the blocks as added fuel plate protection.

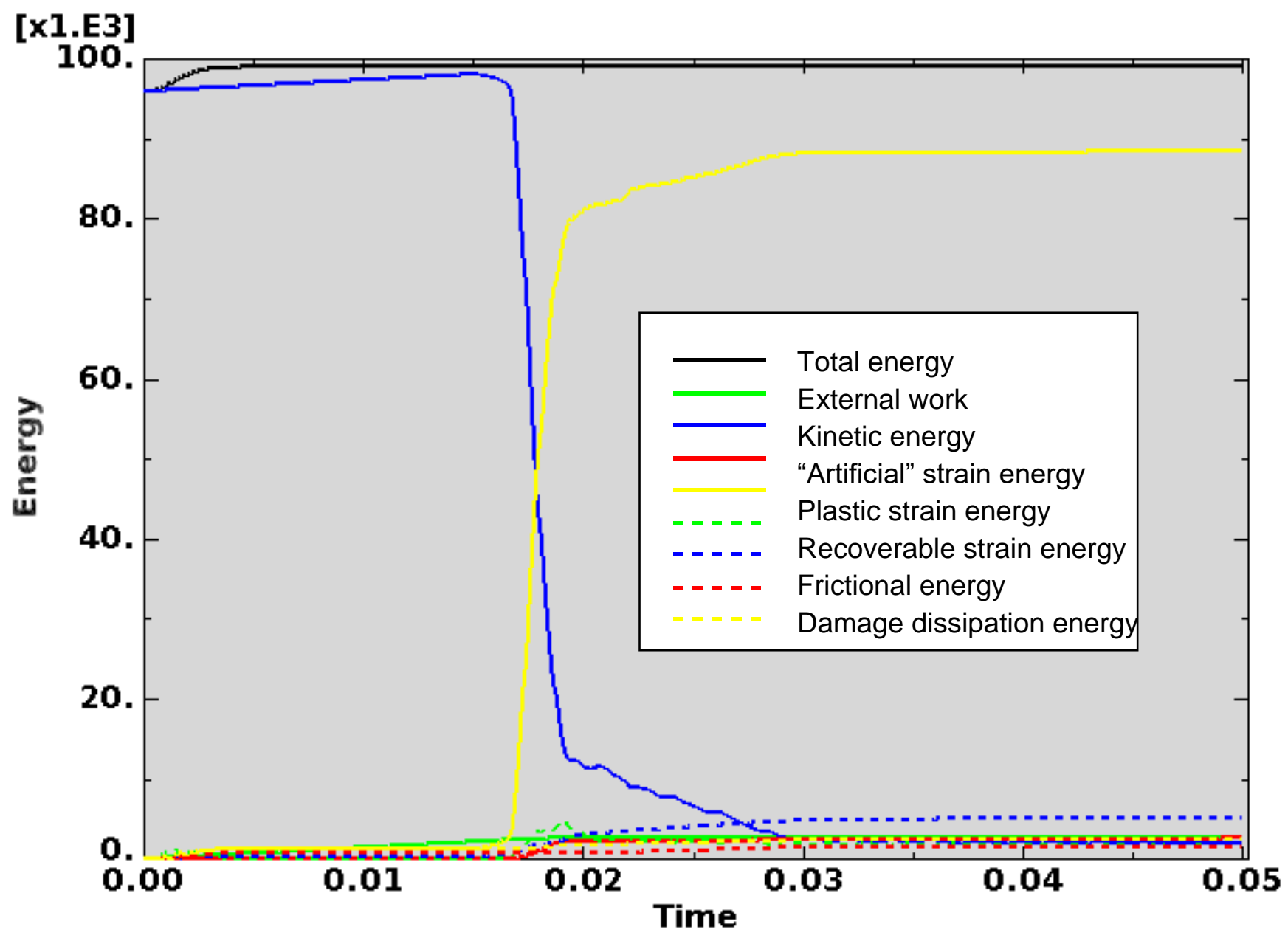

Figure D-108. Scope Part 1d (Table 3), Test 8 (Table 2) fine mesh energy curves. 
Figure D-108 shows the energy curves for Scope Part 1d (Table 3), Test 8 (Table 2) fine mesh drop scenario. These curves exhibit a stable shape. Artificial strain energy represents the energy required to keep reduced integration elements from taking on a zero-energy hourglass shape. As shown in Figure D-108, the artificial energy at the end of the model run is $2.6 \%$ of the total energy. Therefore, the potential error associated with artificial energy is not considered to be significant.

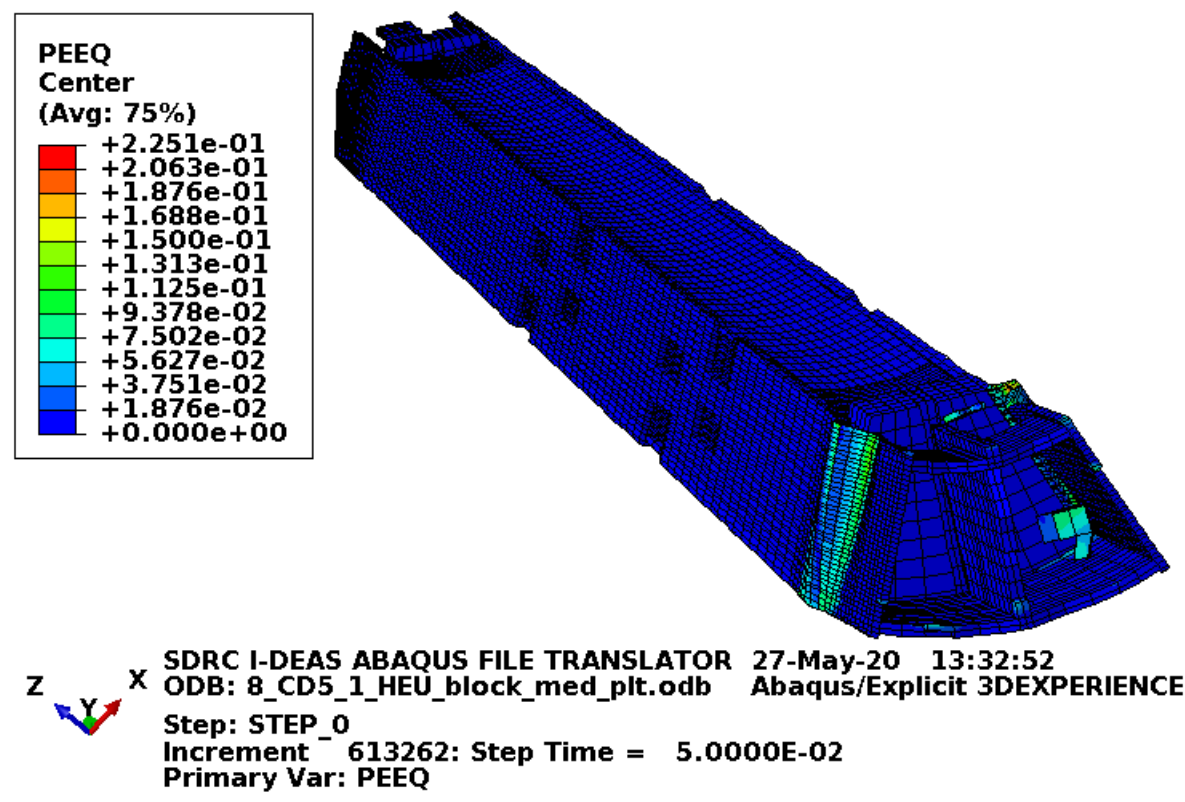

Figure D-109. Scope Part 1d (Table 3), Test 8 (Table 2) fine mesh fuel element plastic equivalent strain.

Figure D-109 shows the equivalent plastic strain in the fuel element. Failure in the end box elements occurs at an equivalent plastic strain of $0.08 \mathrm{in./in.} \mathrm{(for} \mathrm{the} \mathrm{relatively} \mathrm{tough} \mathrm{material} \mathrm{properties).} \mathrm{Failure} \mathrm{in} \mathrm{the} \mathrm{end}$ box weld elements occurs at an equivalent plastic strain of $0.115 \mathrm{in}$./in. (for the relatively tough material properties). Failure in the side plate and comb elements occurs at an equivalent plastic strain of 0.152 in./in. Failure in the side plate weld elements occurs at an equivalent plastic strain of 0.205 in./in. Figure D-109 shows some failure in the end box and end box weld nearest the impacted surface. 


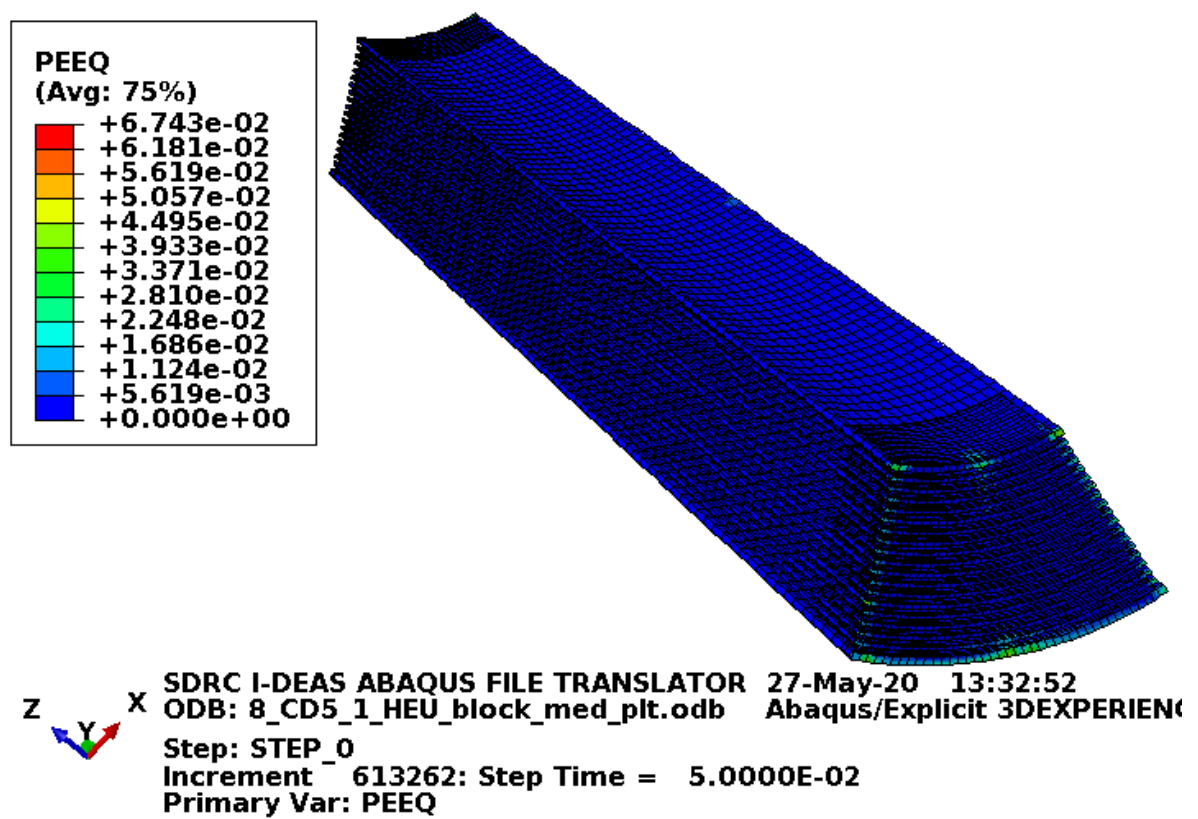

Figure D-110. Scope Part 1d (Table 3), Test 8 (Table 2) fine mesh fuel plate equivalent strain.

Figure D-110 shows the equivalent plastic strain in the fuel plates. Failure in these elements occurs at an equivalent plastic strain of 0.205 in./in. If element failure were to occur, the element would be removed from the model (thereby excluding its equivalent plastic strain from the maximum equivalent plastic strain for the plot). However, the missing element would be visible in the plot. Figure D-110 shows no failure in the fuel plates with margin.

\section{D2.7 Results for Scope Part 1 (Table 3), Test 10 (Table 2)}

The drop scenario considered in this section is a 40 in. drop modeled as a 30 degrees off horizontal, center of gravity over a 6 in. diameter puncture bar. It is identified as CP2-1 in the ATR FFSC SAR (2017).

\section{D2.7.1 Results for Scope Part 1a (Table 3), Test 10 (Table 2)}

The FEA model results for the Scope Part 1a (Table 3), Test 10 (Table 2) model are shown below in Figure D-111 to Figure D-113. The fuel element weighs $22.1 \mathrm{lbf}$ and the whole model is modeled with minimum material properties. 


\section{[X1.E3]}
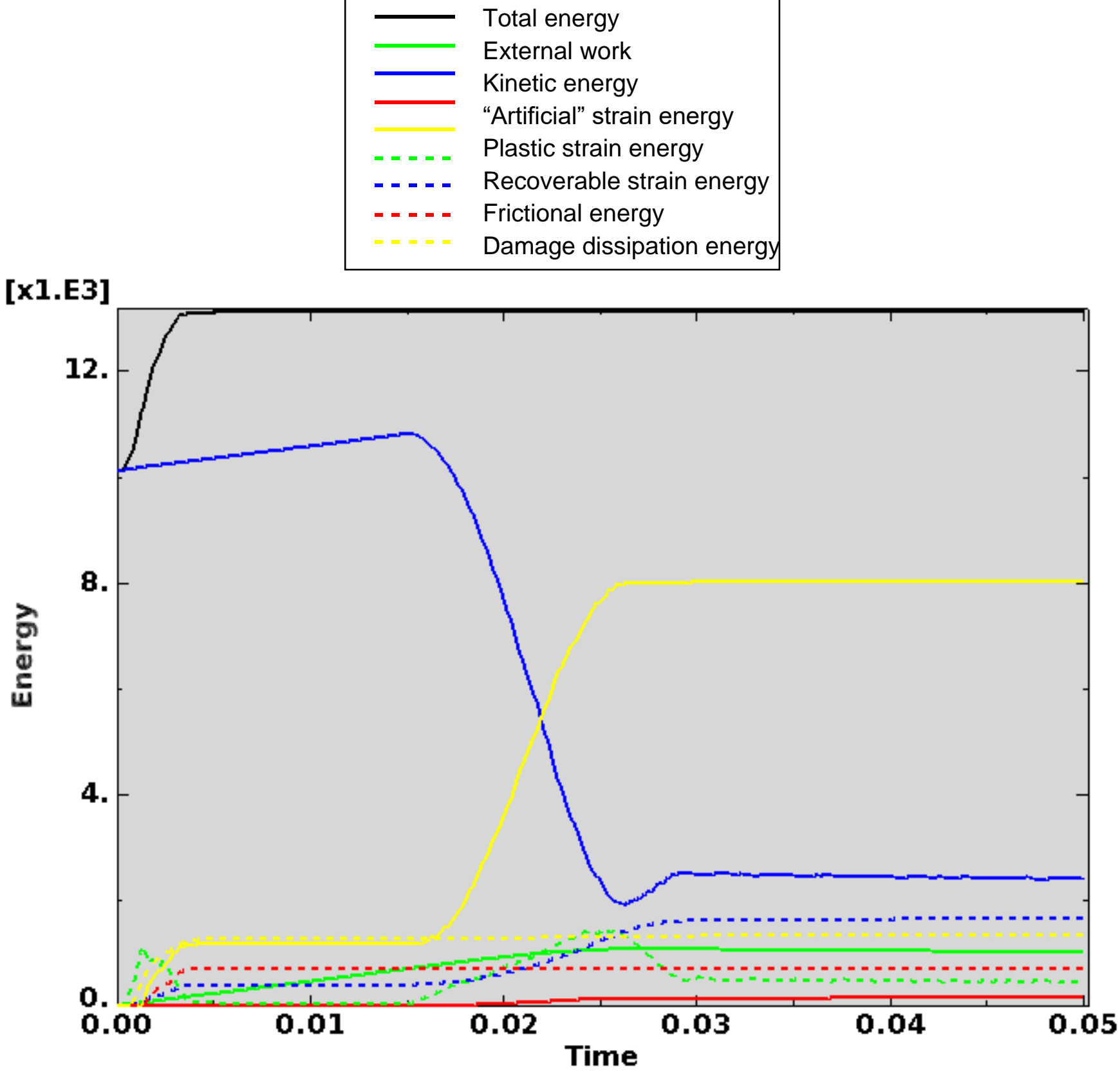

Figure D-111. Scope Part 1a (Table 3), Test 10 (Table 2) energy curves.

Figure D-111 shows the energy curves for Scope Part 1a (Table 3), Test 10 (Table 2) drop scenario. These curves exhibit a stable shape. Artificial strain energy represents the energy required to keep reduced integration elements from taking on a zero-energy hourglass shape. As shown in Figure D-111, the artificial energy at the end of the model run is $1.2 \%$ of the total energy. Therefore, the potential error associated with artificial energy is not considered to be significant. 
ENGINEERING CALCULATIONS AND ANALYSIS

Drop Analysis of the Advanced Test Reactor Fresh Fuel Shipping Container with Heavier Low-Enriched Uranium Fuel Contents
ECAR-5224, Rev. 0

Page D101 of D293

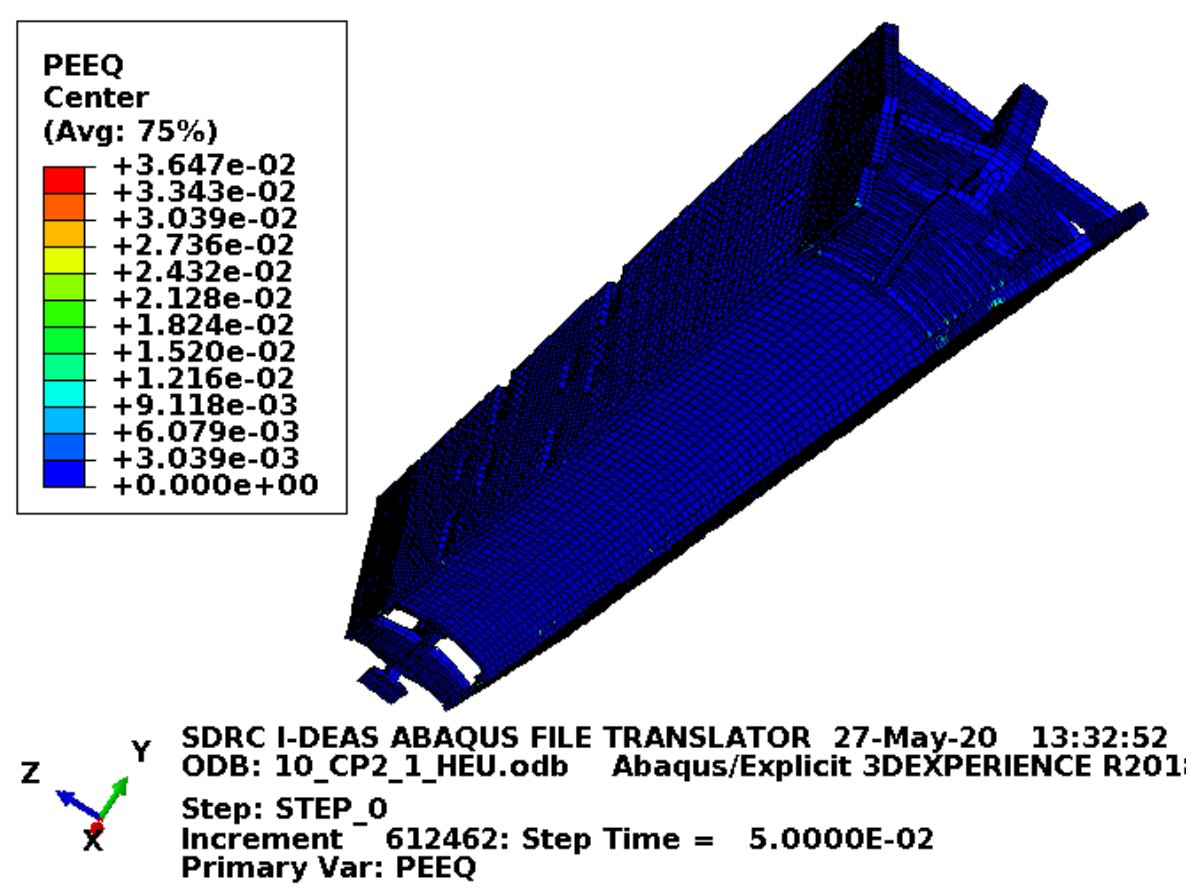

Figure D-112. Scope Part 1a (Table 3), Test 10 (Table 2) fuel element plastic equivalent strain.

Figure D-112 shows the equivalent plastic strain in the fuel element. Failure in the end box elements occurs at an equivalent plastic strain of $0.027 \mathrm{in}$./in. Failure in the end box weld elements occurs at an equivalent plastic strain of $0.032 \mathrm{in}$./in. Failure in the side plate and comb elements occurs at an equivalent plastic strain of $0.152 \mathrm{in./in.} \mathrm{Failure} \mathrm{in} \mathrm{the} \mathrm{side} \mathrm{plate} \mathrm{weld} \mathrm{elements} \mathrm{occurs} \mathrm{at} \mathrm{an} \mathrm{equivalent} \mathrm{plastic} \mathrm{strain} \mathrm{of}$ $0.205 \mathrm{in}$./in. If element failure were to occur, the element would be removed from the model (thereby excluding its equivalent plastic strain from the maximum equivalent plastic strain for the plot). However, the missing element would be visible in the plot. Figure D-112 shows no failure in the fuel element. 
ENGINEERING CALCULATIONS AND ANALYSIS

Drop Analysis of the Advanced Test Reactor Fresh Fuel Shipping Container with Heavier Low-Enriched Uranium Fuel Contents
ECAR-5224, Rev. 0

Page D102 of D293

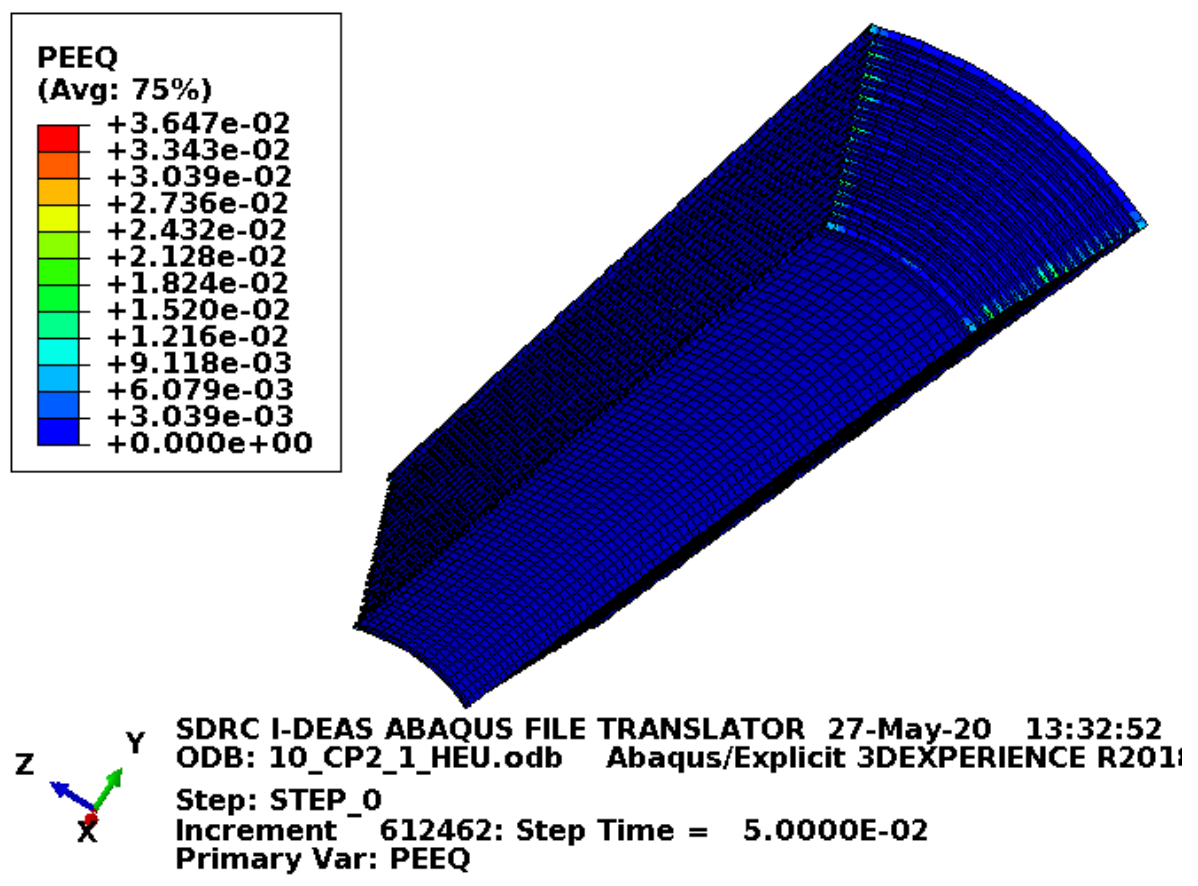

Figure D-113. Scope Part 1a (Table 3), Test 10 (Table 2) fuel plate equivalent strain.

Figure D-113 shows the equivalent plastic strain in the fuel plates. Failure in these elements occurs at an equivalent plastic strain of 0.205 in./in. If element failure were to occur, the element would be removed from the model (thereby excluding its equivalent plastic strain from the maximum equivalent plastic strain for the plot). However, the missing element would be visible in the plot. Figure D-113 shows no failure in the fuel plates with margin.

\section{D2.7.2 Results for Scope Part 1b (Table 3), Test 10 (Table 2)}

The FEA model results for the Scope Part 1b (Table 3), Test 10 (Table 2) model are shown below in Figure D-114 to Figure D-116. The fuel element weighs $22.1 \mathrm{lbf}$ and the drop scenario is modeled with minimum material properties except the enclosure and end boxes, which are modeled with relatively tough material properties. 
[X1.E3]

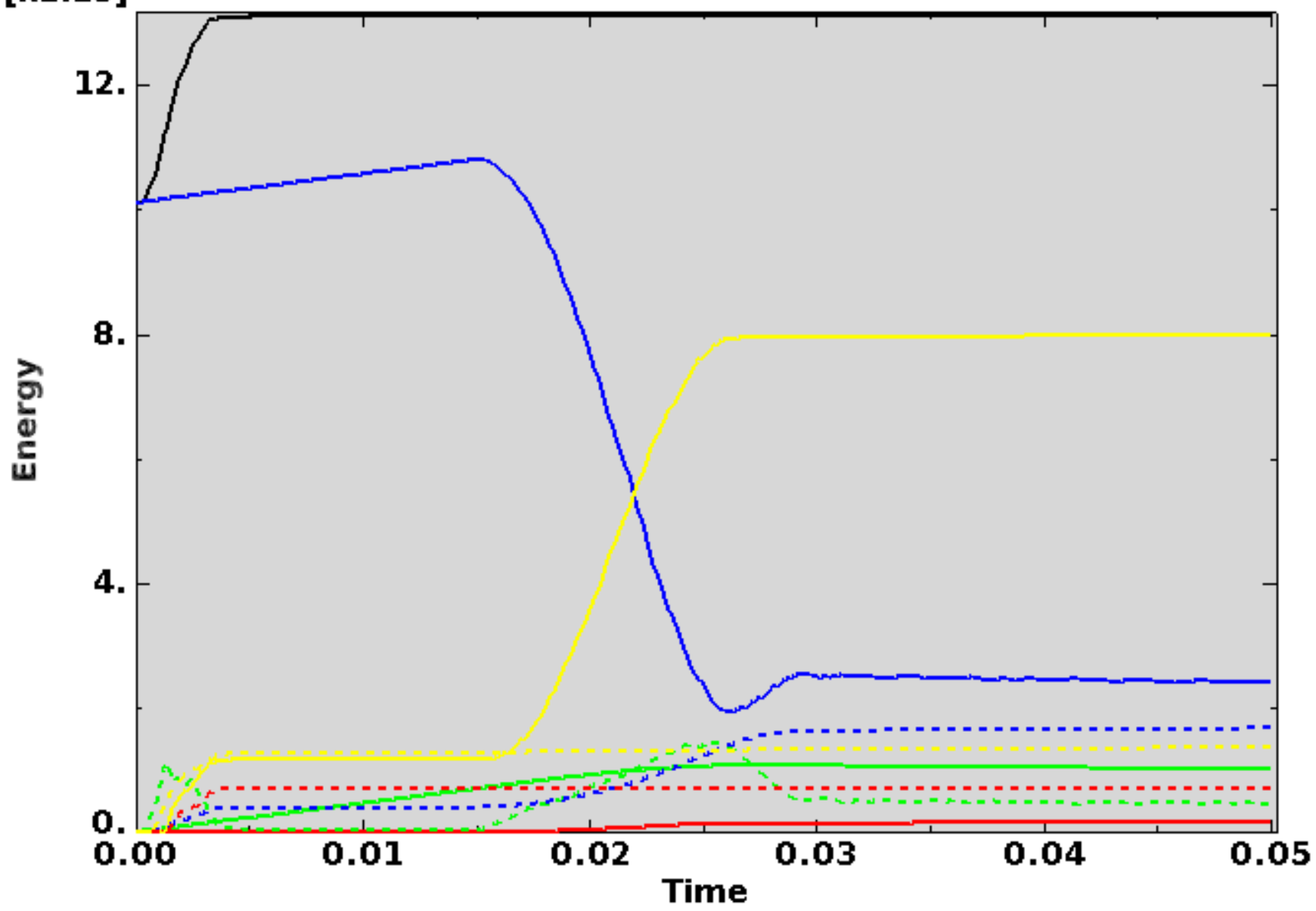

Figure D-114. Scope Part 1b (Table 3), Test 10 (Table 2) energy curves.

Figure D-114 shows the energy curves for Scope Part 1b (Table 3), Test 10 (Table 2) drop scenario. These curves exhibit a stable shape. Artificial strain energy represents the energy required to keep reduced integration elements from taking on a zero-energy hourglass shape. As shown in Figure D-114, the artificial energy at the end of the model run is $1.3 \%$ of the total energy. Therefore, the potential error associated with artificial energy is not considered to be significant. 
ENGINEERING CALCULATIONS AND ANALYSIS

Drop Analysis of the Advanced Test Reactor Fresh Fuel Shipping Container with Heavier Low-Enriched Uranium Fuel Contents
ECAR-5224, Rev. 0

Page D104 of D293

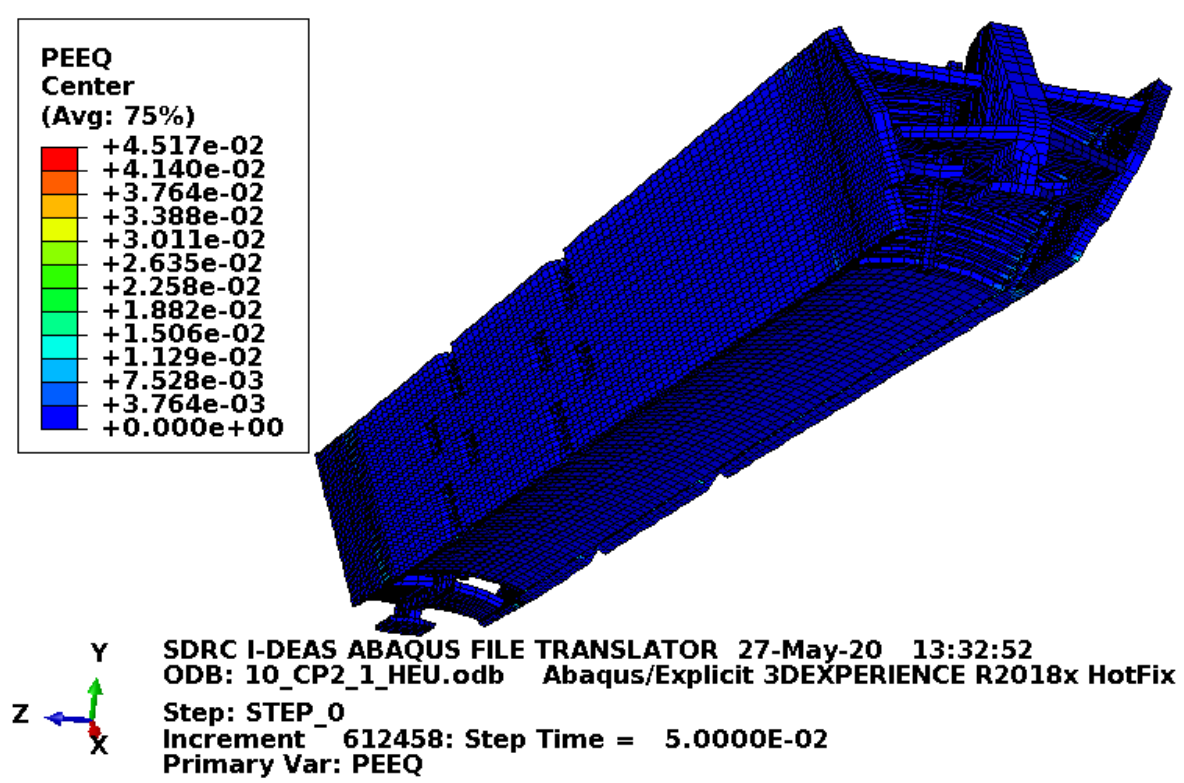

Figure D-115. Scope Part 1b (Table 3), Test 10 (Table 2) fuel element plastic equivalent strain.

Figure D-115 shows the equivalent plastic strain in the fuel element. Failure in the end box elements occurs at an equivalent plastic strain of $0.08 \mathrm{in./in.} \mathrm{(for} \mathrm{the} \mathrm{relatively} \mathrm{tough} \mathrm{material} \mathrm{properties).} \mathrm{Failure} \mathrm{in} \mathrm{the} \mathrm{end}$ box weld elements occurs at an equivalent plastic strain of $0.115 \mathrm{in}$./in. (for the relatively tough material properties). Failure in the side plate and comb elements occurs at an equivalent plastic strain of 0.152 in./in. Failure in the side plate weld elements occurs at an equivalent plastic strain of $0.205 \mathrm{in}$./in. If element failure were to occur, the element would be removed from the model (thereby excluding its equivalent plastic strain from the maximum equivalent plastic strain for the plot). However, the missing element would be visible in the plot. Figure D-115 shows no failure in the fuel element.

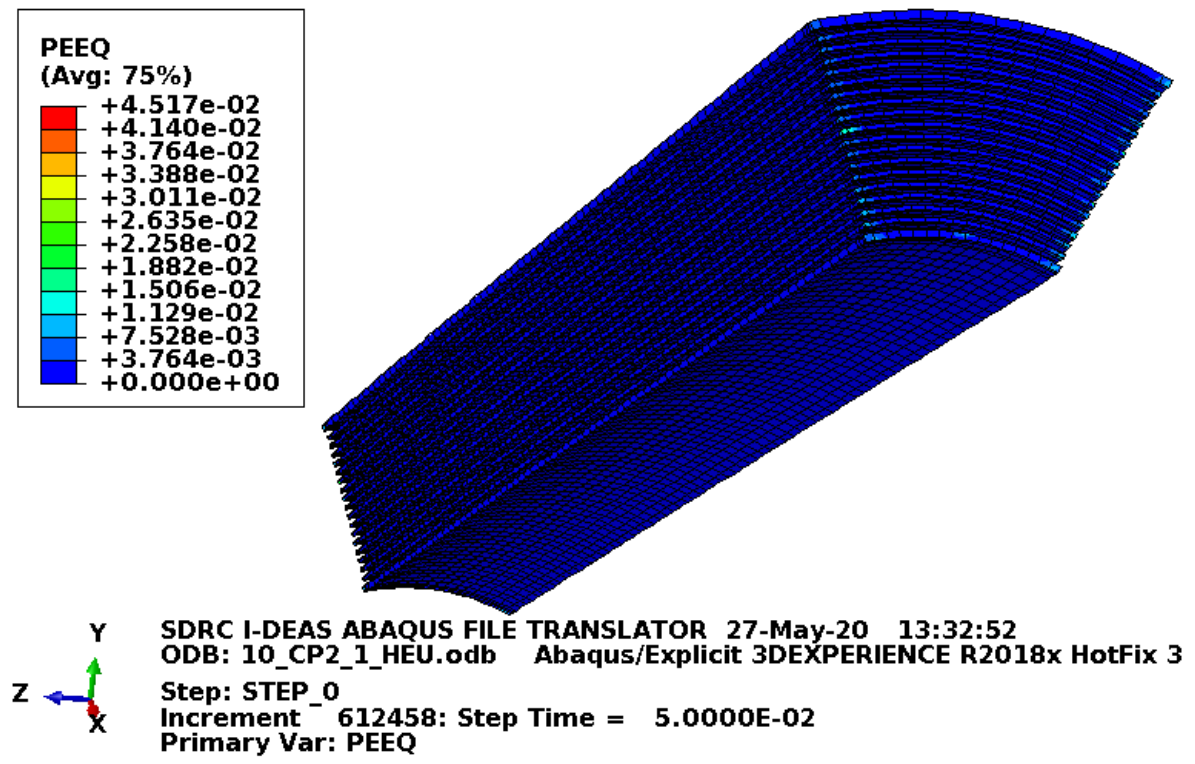

Figure D-116. Scope Part 1b (Table 3), Test 10 (Table 2) fuel plate equivalent strain. 
Figure D-116 shows the equivalent plastic strain in the fuel plates. Failure in these elements occurs at an equivalent plastic strain of $0.205 \mathrm{in}$./in. If element failure were to occur, the element would be removed from the model (thereby excluding its equivalent plastic strain from the maximum equivalent plastic strain for the plot). However, the missing element would be visible in the plot. Figure D-116 shows no failure in the fuel plates with margin.

\section{D2.7.3 Results for Scope Part 1c (Table 3), Test 10 (Table 2)}

The FEA model results for the Scope Part 1c (Table 3), Test 10 (Table 2) model are shown below in Figure D-117 to Figure D-119. The fuel element weighs $22.1 \mathrm{lbf}$ and the whole model is modeled with minimum material properties. Though ATR FFSC SAR (2017) shows the Scope Part 1 (Table 3) drop scenarios to be acceptable, the results shown (for information) in this section include the blocks as added fuel plate protection. 


\section{[X1.E3]}
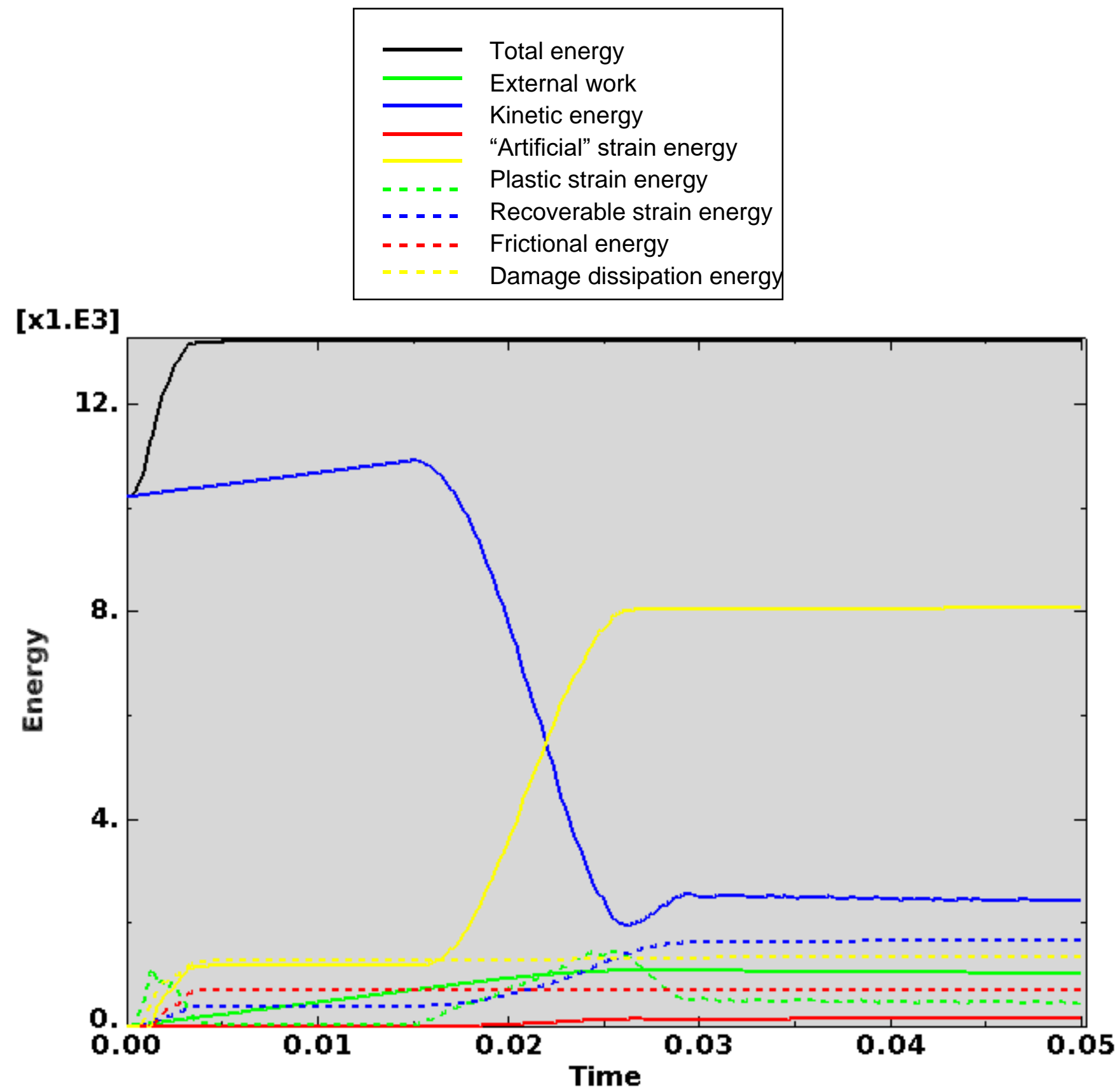

Figure D-117. Scope Part 1c (Table 3), Test 10 (Table 2) energy curves.

Figure D-117 shows the energy curves for Scope Part 1c (Table 3), Test 10 (Table 2) drop scenario. These curves exhibit a stable shape. Artificial strain energy represents the energy required to keep reduced integration elements from taking on a zero-energy hourglass shape. As shown in Figure D-117, the artificial energy at the end of the model run is $1.3 \%$ of the total energy. Therefore, the potential error associated with artificial energy is not considered to be significant. 
ENGINEERING CALCULATIONS AND ANALYSIS

Drop Analysis of the Advanced Test Reactor Fresh Fuel Shipping Container with Heavier Low-Enriched Uranium Fuel Contents
ECAR-5224, Rev. 0

Page D107 of D293

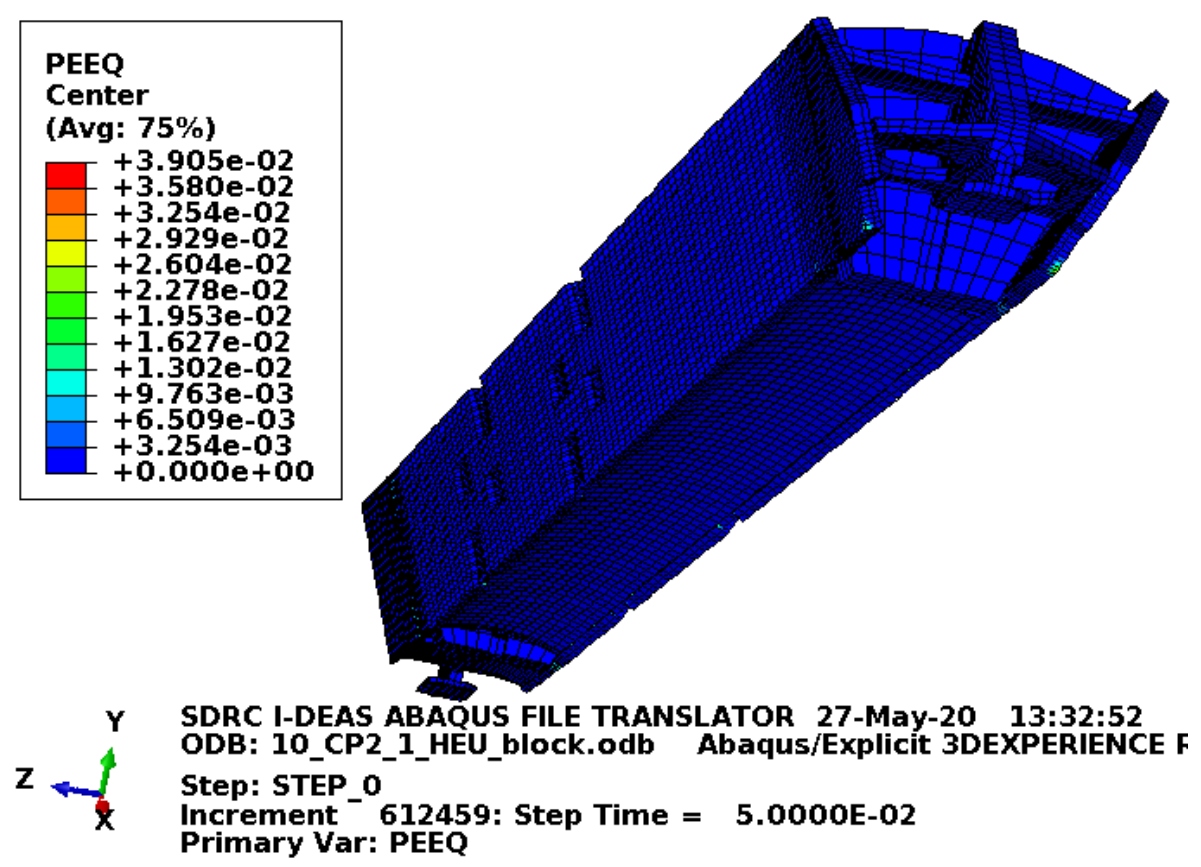

Figure D-118. Scope Part 1c (Table 3), Test 10 (Table 2) fuel element plastic equivalent strain.

Figure D-118 shows the equivalent plastic strain in the fuel element. Failure in the end box elements occurs at an equivalent plastic strain of $0.027 \mathrm{in}$./in. Failure in the end box weld elements occurs at an equivalent plastic strain of $0.032 \mathrm{in}$./in. Failure in the side plate and comb elements occurs at an equivalent plastic strain of $0.152 \mathrm{in./in.} \mathrm{Failure} \mathrm{in} \mathrm{the} \mathrm{side} \mathrm{plate} \mathrm{weld} \mathrm{elements} \mathrm{occurs} \mathrm{at} \mathrm{an} \mathrm{equivalent} \mathrm{plastic} \mathrm{strain} \mathrm{of}$ $0.205 \mathrm{in}$./in. If element failure were to occur, the element would be removed from the model (thereby excluding its equivalent plastic strain from the maximum equivalent plastic strain for the plot). However, the missing element would be visible in the plot. Figure D-118 shows no failure in the fuel element or block.

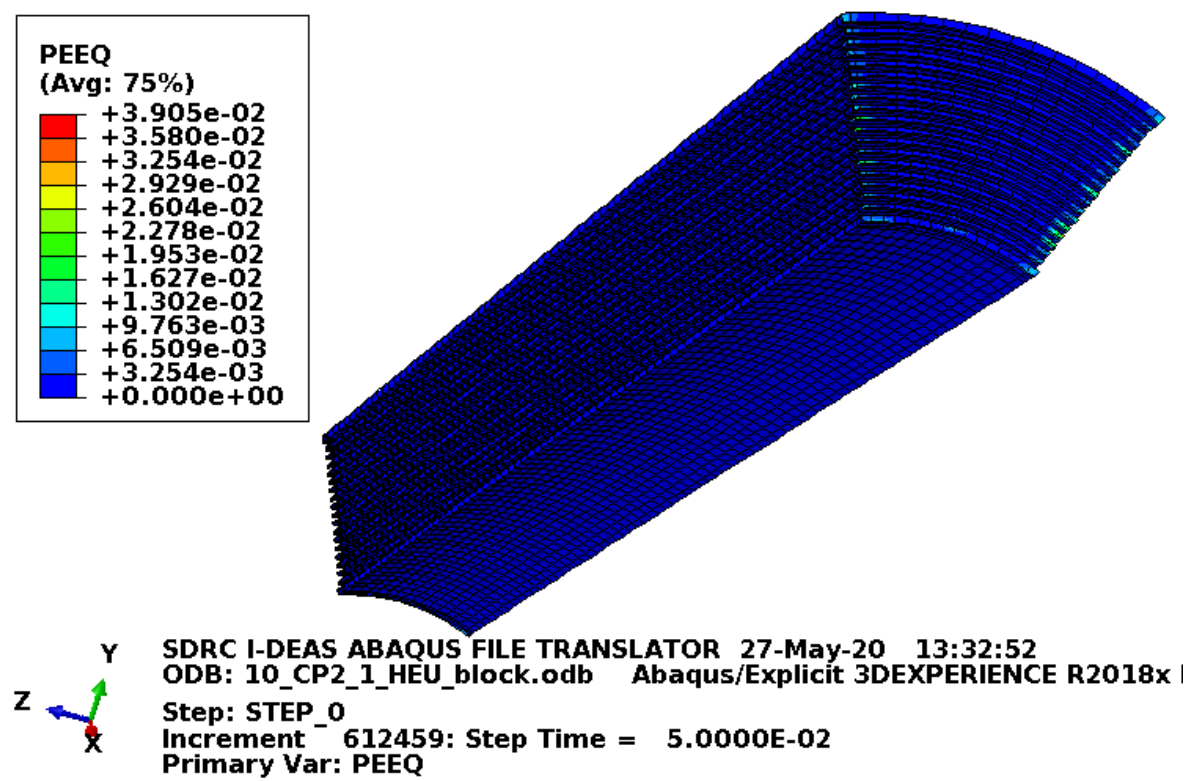

Figure D-119. Scope Part 1c (Table 3), Test 10 (Table 2) fuel plate equivalent strain. 
Figure D-119 shows the equivalent plastic strain in the fuel plates. Failure in these elements occurs at an equivalent plastic strain of $0.205 \mathrm{in}$./in. If element failure were to occur, the element would be removed from the model (thereby excluding its equivalent plastic strain from the maximum equivalent plastic strain for the plot). However, the missing element would be visible in the plot. Figure D-119 shows no failure in the fuel plates with margin.

\section{D2.7.4 Results for Scope Part 1d (Table 3), Test 10 (Table 2)}

The FEA model results for the Scope Part 1d (Table 3), Test 10 (Table 2) model are shown below in Figure D-120 to Figure D-122. The fuel element weighs $22.1 \mathrm{lbf}$ and the drop scenario is modeled with minimum material properties except the enclosure and end boxes, which are modeled with relatively tough material properties. Though ATR FFSC SAR (2017) shows the Scope Part 1 (Table 3) drop scenarios to be acceptable, the results shown (for information) in this section include the blocks as added fuel plate protection. 


\section{[x1.E3]}
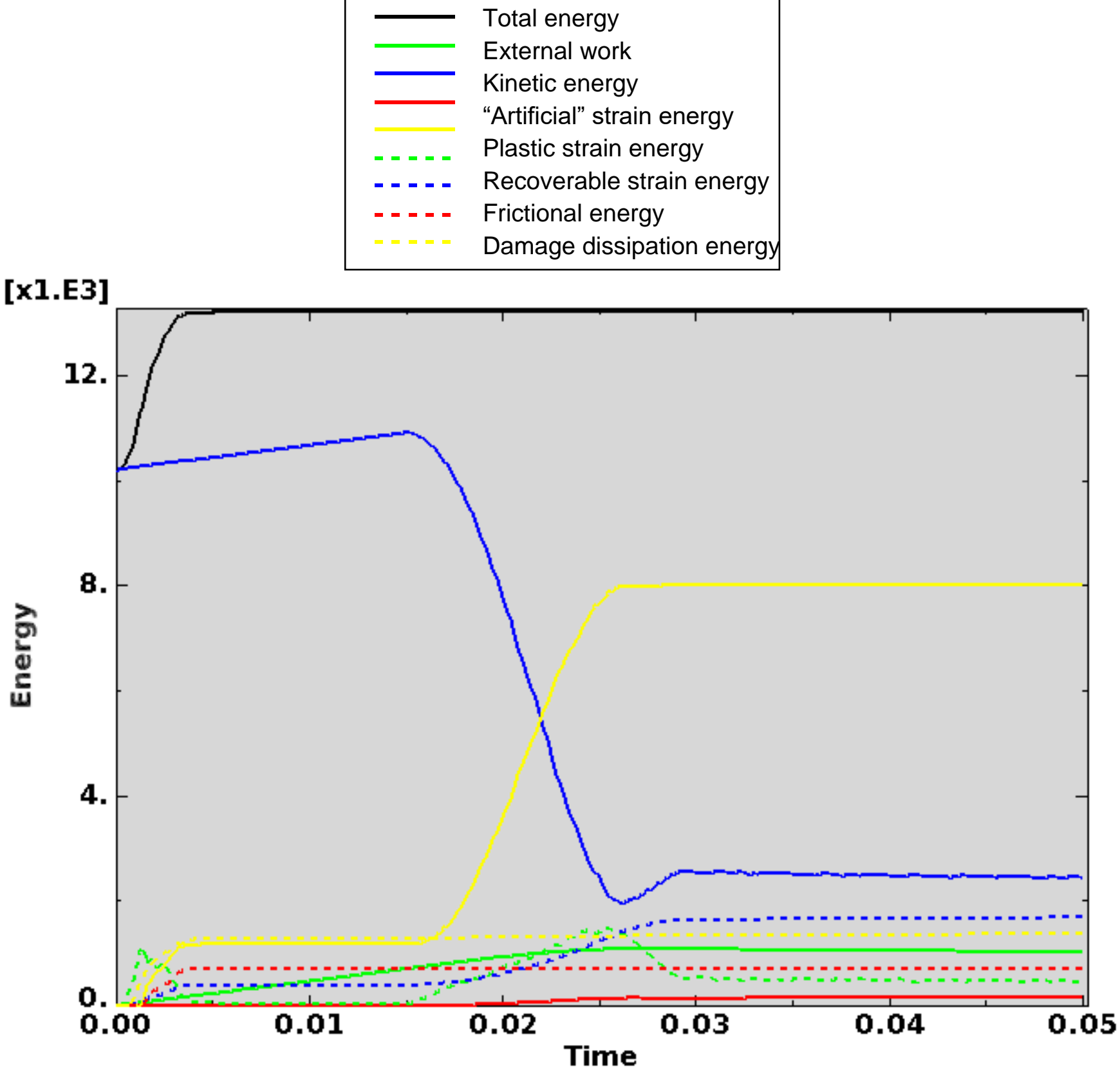

Figure D-120. Scope Part 1d (Table 3), Test 10 (Table 2) energy curves.

Figure D-120 shows the energy curves for Scope Part 1d (Table 3), Test 10 (Table 2) drop scenario. These curves exhibit a stable shape. Artificial strain energy represents the energy required to keep reduced integration elements from taking on a zero-energy hourglass shape. As shown in Figure D-120, the artificial energy at the end of the model run is $1.3 \%$ of the total energy. Therefore, the potential error associated with artificial energy is not considered to be significant. 
ENGINEERING CALCULATIONS AND ANALYSIS

Drop Analysis of the Advanced Test Reactor Fresh Fuel Shipping Container with Heavier Low-Enriched Uranium Fuel Contents
ECAR-5224, Rev. 0 Page D110 of D293

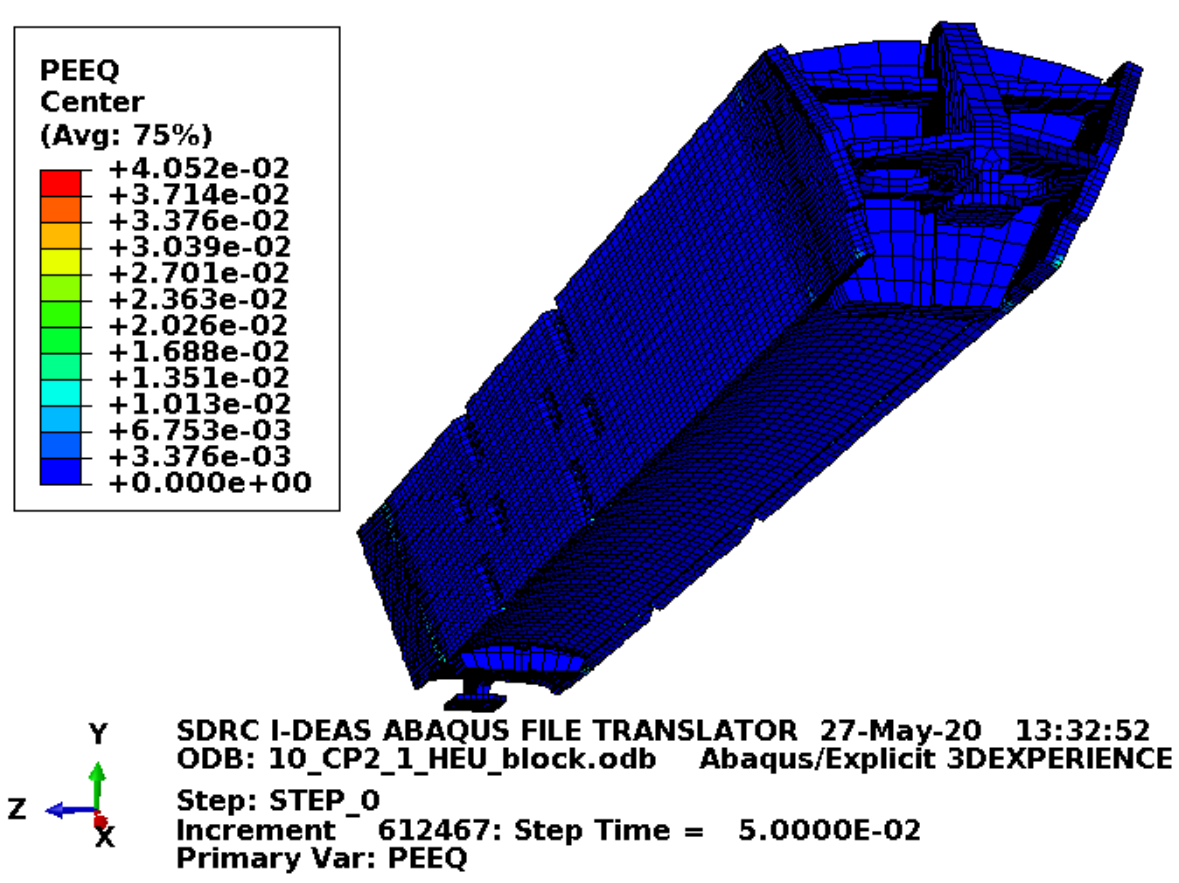

Figure D-121. Scope Part 1d (Table 3), Test 10 (Table 2) fuel element plastic equivalent strain.

Figure D-121 shows the equivalent plastic strain in the fuel element. Failure in the end box elements occurs at an equivalent plastic strain of $0.08 \mathrm{in./in.} \mathrm{(for} \mathrm{the} \mathrm{relatively} \mathrm{tough} \mathrm{material} \mathrm{properties).} \mathrm{Failure} \mathrm{in} \mathrm{the} \mathrm{end}$ box weld elements occurs at an equivalent plastic strain of $0.115 \mathrm{in}$./in. (for the relatively tough material properties). Failure in the side plate and comb elements occurs at an equivalent plastic strain of $0.152 \mathrm{in}$./in. Failure in the side plate weld elements occurs at an equivalent plastic strain of $0.205 \mathrm{in}$./in. If element failure were to occur, the element would be removed from the model (thereby excluding its equivalent plastic strain from the maximum equivalent plastic strain for the plot). However, the missing element would be visible in the plot. Figure D-121 shows no failure in the fuel element or blocks. 
ENGINEERING CALCULATIONS AND ANALYSIS

Drop Analysis of the Advanced Test Reactor Fresh Fuel Shipping Container with Heavier Low-Enriched Uranium Fuel Contents
ECAR-5224, Rev. 0

Page D111 of D293

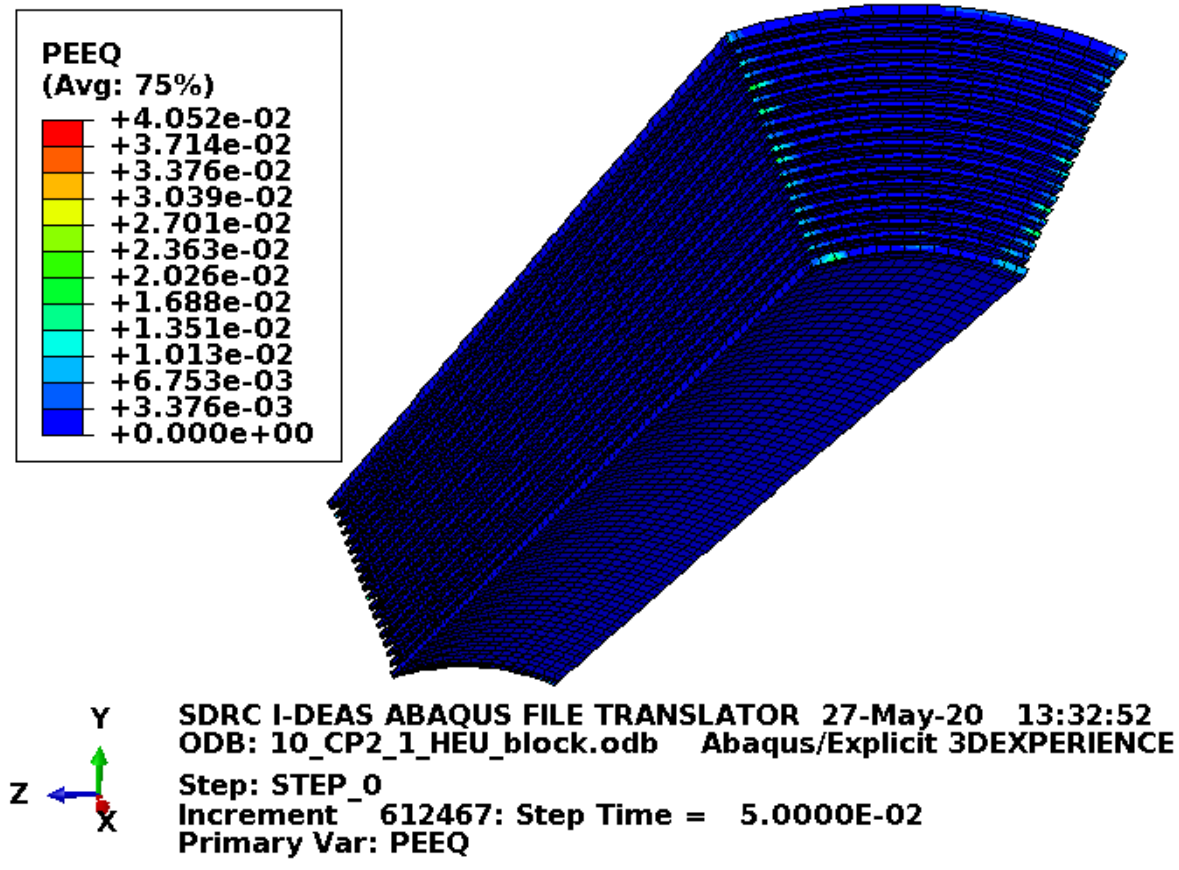

Figure D-122. Scope Part 1d (Table 3), Test 10 (Table 2) fuel plate equivalent strain.

Figure D-122 shows the equivalent plastic strain in the fuel plates. Failure in these elements occurs at an equivalent plastic strain of $0.205 \mathrm{in}$./in. If element failure were to occur, the element would be removed from the model (thereby excluding its equivalent plastic strain from the maximum equivalent plastic strain for the plot). However, the missing element would be visible in the plot. Figure D-122 shows no failure in the fuel plates with margin.

\section{D2.8 Results for Scope Part 1 (Table 3), Test 11 (Table 2)}

The drop scenario considered in this section is a 40 in. drop modeled as a vertical top drop with the lid centered over a 6 in. diameter puncture bar. It is identified as CP1-1 in the ATR FFSC SAR (2017).

\section{D2.8.1 Results for Scope Part 1a (Table 3), Test 11 (Table 2)}

The FEA model results for the Scope Part 1a (Table 3), Test 11 (Table 2) model are shown below in Figure D-123 to Figure D-125. The fuel element weighs $22.1 \mathrm{lbf}$ and the whole model is modeled with minimum material properties. 


\section{[X1.E3]}

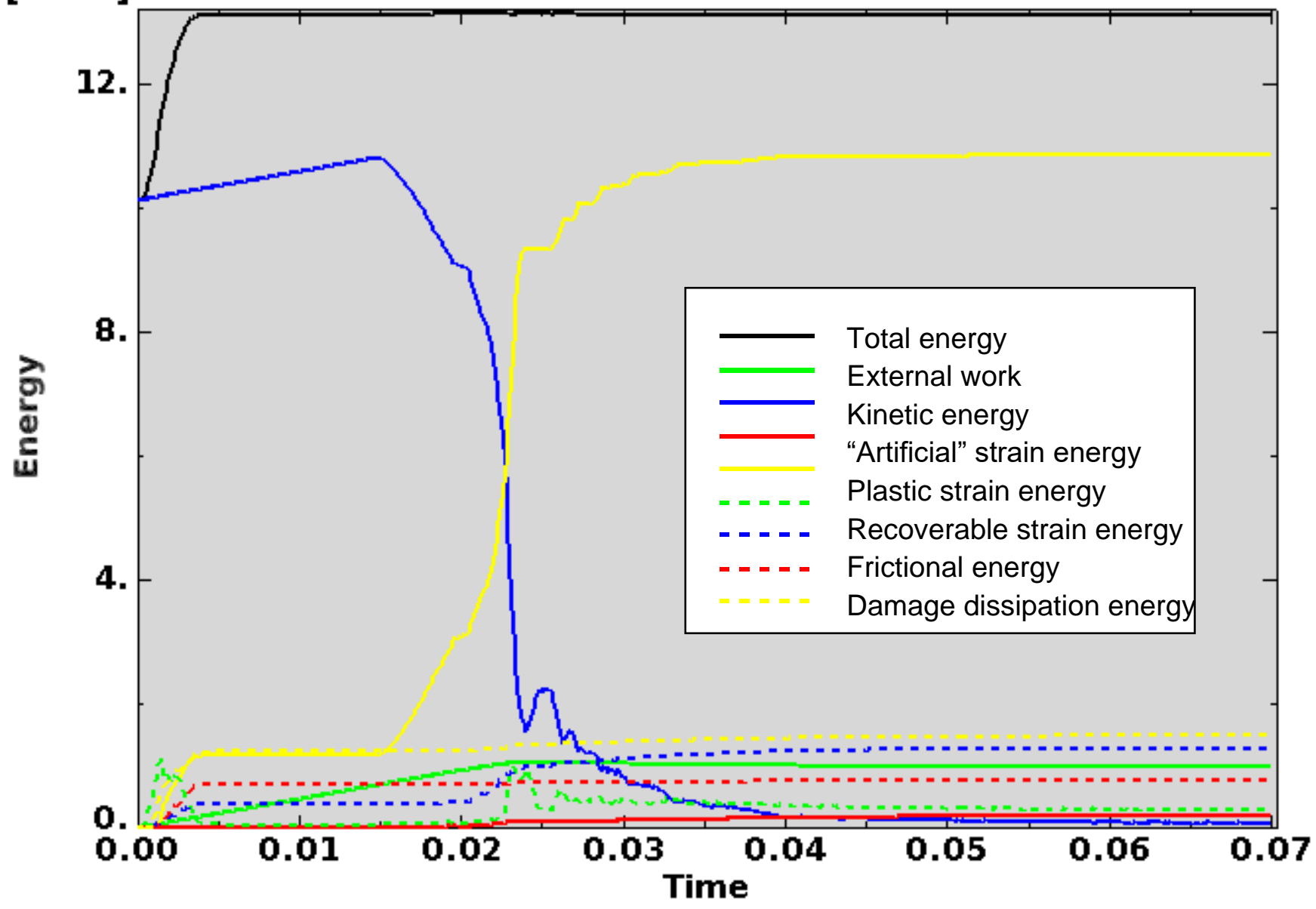

Figure D-123. Scope Part 1a (Table 3), Test 11 (Table 2) energy curves.

Figure D-123 shows the energy curves for Scope Part 1a (Table 3), Test 11 (Table 2) drop scenario. These curves exhibit a stable shape. Artificial strain energy represents the energy required to keep reduced integration elements from taking on a zero-energy hourglass shape. As shown in Figure D-123, the artificial energy at the end of the model run is $1.6 \%$ of the total energy. Therefore, the potential error associated with artificial energy is not considered to be significant. 
ENGINEERING CALCULATIONS AND ANALYSIS

Drop Analysis of the Advanced Test Reactor Fresh Fuel Shipping Container with Heavier Low-Enriched Uranium Fuel Contents

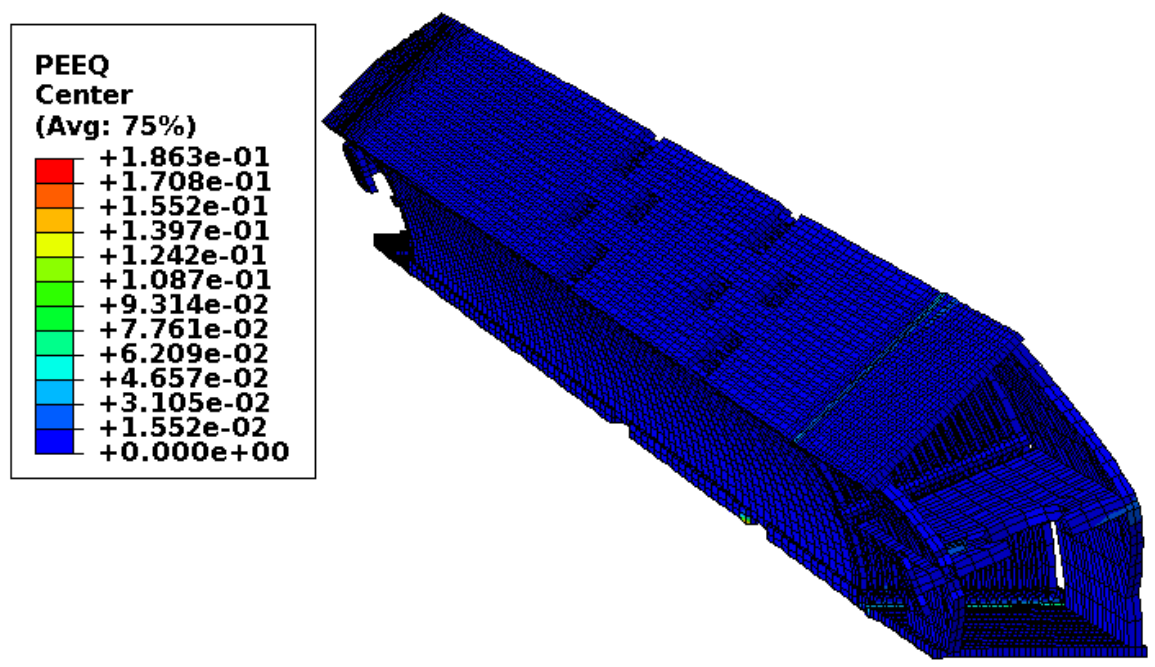

SDRC I-DEAS ABAQUS FILE TRANSLATOR 27-May-20 13:32:52

ODB: 11_CP1_1_HEU.odb Abaqus/Explicit 3DEXPERIENCE R2018x Hot

Step: STEP_o

Increment 857622 : Step Time $=7.0000 \mathrm{E}-02$

$\mathbf{x}$

Primary Var: PEEQ

Figure D-124. Scope Part 1a (Table 3), Test 11 (Table 2) fuel element plastic equivalent strain.

Figure D-124 shows the equivalent plastic strain in the fuel element. Failure in the end box elements occurs at an equivalent plastic strain of $0.027 \mathrm{in}$./in. Failure in the end box weld elements occurs at an equivalent plastic strain of $0.032 \mathrm{in}$./in. Failure in the side plate and comb elements occurs at an equivalent plastic strain of $0.152 \mathrm{in./in.} \mathrm{Failure} \mathrm{in} \mathrm{the} \mathrm{side} \mathrm{plate} \mathrm{weld} \mathrm{elements} \mathrm{occurs} \mathrm{at} \mathrm{an} \mathrm{equivalent} \mathrm{plastic} \mathrm{strain} \mathrm{of}$ $0.205 \mathrm{in./in.} \mathrm{If} \mathrm{element} \mathrm{failure} \mathrm{were} \mathrm{to} \mathrm{occur,} \mathrm{the} \mathrm{element} \mathrm{would} \mathrm{be} \mathrm{removed} \mathrm{from} \mathrm{the} \mathrm{model} \mathrm{(thereby}$ excluding its equivalent plastic strain from the maximum equivalent plastic strain for the plot). However, the missing element would be visible in the plot. Figure D-124 shows some failure in the end box nearest the impact which is acceptable. 
ENGINEERING CALCULATIONS AND ANALYSIS

Drop Analysis of the Advanced Test Reactor Fresh Fuel Shipping Container with Heavier Low-Enriched Uranium Fuel Contents
ECAR-5224, Rev. 0

Page D114 of D293

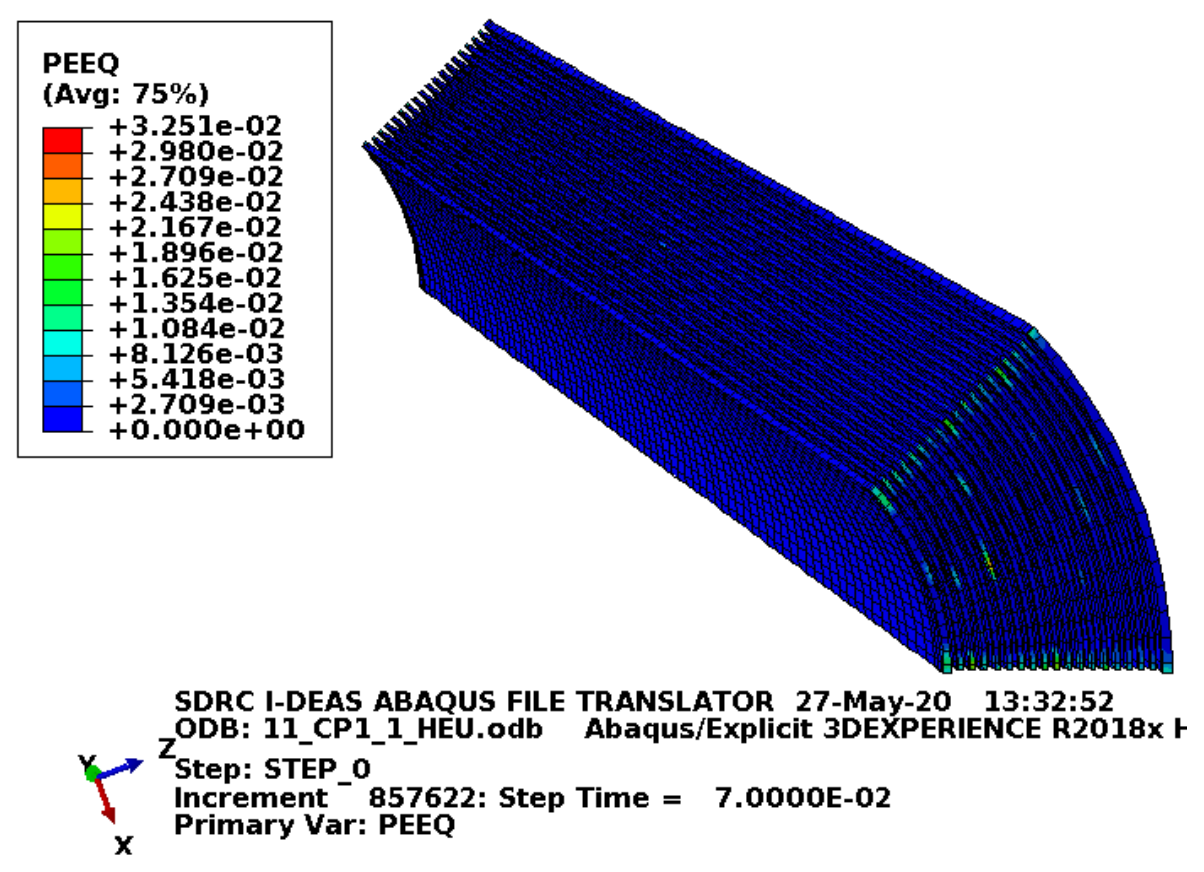

Figure D-125. Scope Part 1 a (Table 3), Test 11 (Table 2) fuel plate equivalent strain.

Figure D-125 shows the equivalent plastic strain in the fuel plates. Failure in these elements occurs at an equivalent plastic strain of 0.205 in./in. If element failure were to occur, the element would be removed from the model (thereby excluding its equivalent plastic strain from the maximum equivalent plastic strain for the plot). However, the missing element would be visible in the plot. Figure D-125 shows no failure in the fuel plates with margin.

\section{D2.8.2 Results for Scope Part 1b (Table 3), Test 11 (Table 2)}

The FEA model results for the Scope Part $1 \mathrm{~b}$ (Table 3), Test 11 (Table 2) model are shown below in Figure D-126 to Figure D-128. The fuel element weighs $22.1 \mathrm{lbf}$ and the drop scenario is modeled with minimum material properties except the enclosure and end boxes, which are modeled with relatively tough material properties. 


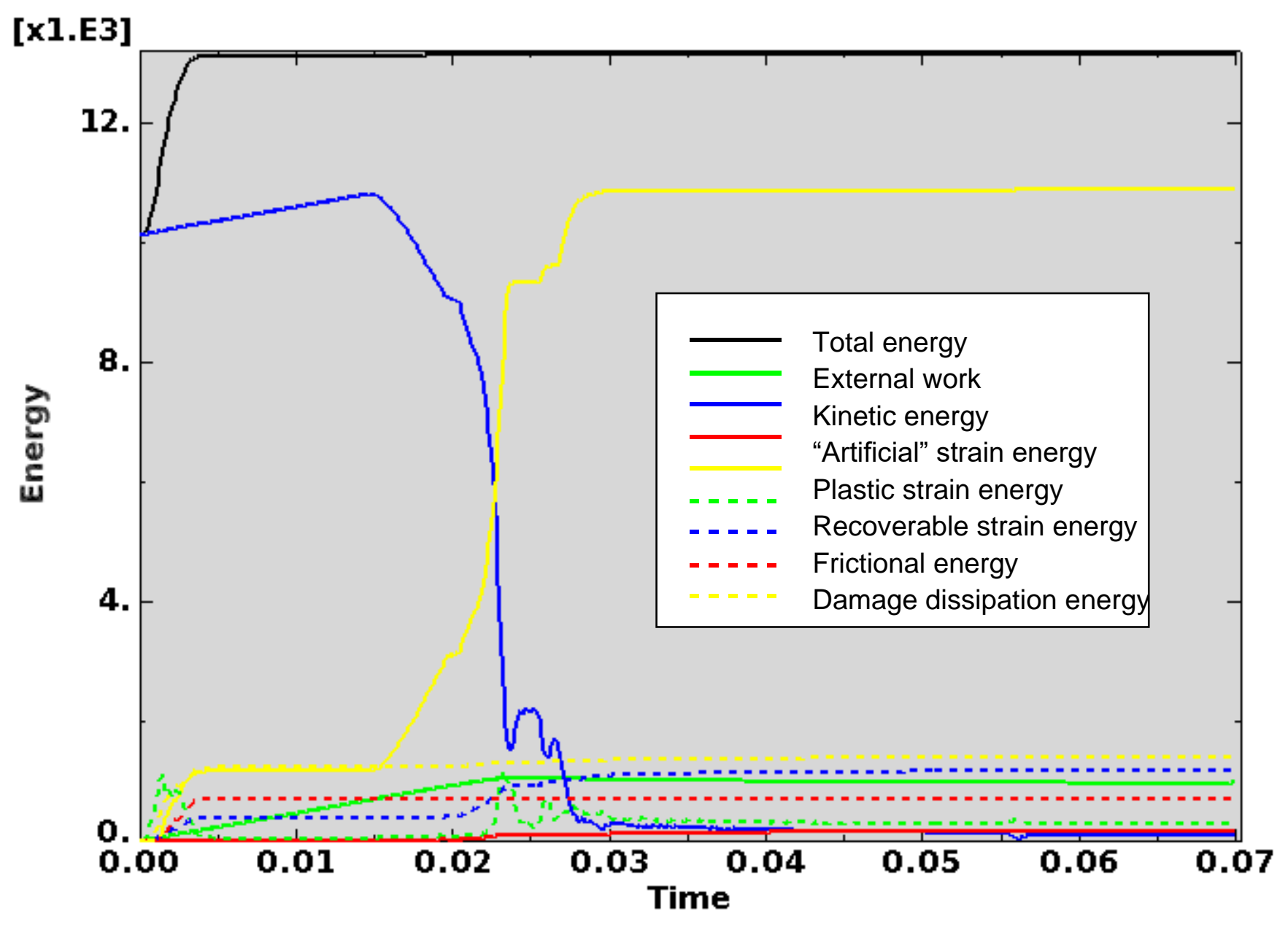

Figure D-126. Scope Part 1b (Table 3), Test 11 (Table 2) energy curves.

Figure D-126 shows the energy curves for Scope Part 1b (Table 3), Test 11 (Table 2) drop scenario. These curves exhibit a stable shape. Artificial strain energy represents the energy required to keep reduced integration elements from taking on a zero-energy hourglass shape. As shown in Figure D-126, the artificial energy at the end of the model run is $1.3 \%$ of the total energy. Therefore, the potential error associated with artificial energy is not considered to be significant. 
ENGINEERING CALCULATIONS AND ANALYSIS

Drop Analysis of the Advanced Test Reactor Fresh Fuel Shipping Container with Heavier Low-Enriched Uranium Fuel Contents

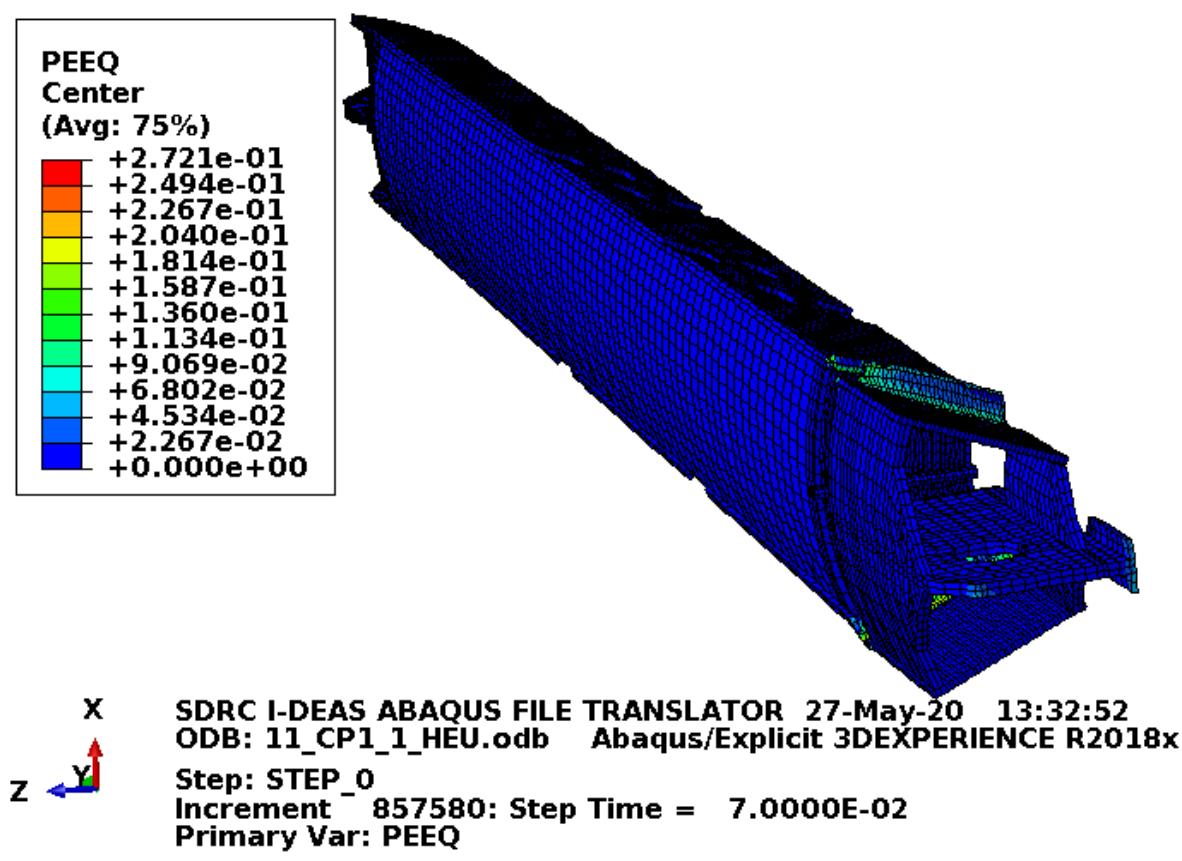

Figure D-127. Scope Part 1b (Table 3), Test 11 (Table 2) fuel element plastic equivalent strain.

Figure D-127 shows the equivalent plastic strain in the fuel element. Failure in the end box elements occurs at an equivalent plastic strain of $0.08 \mathrm{in}$./in. (for the relatively tough material properties). Failure in the end box weld elements occurs at an equivalent plastic strain of $0.115 \mathrm{in}$./in. (for the relatively tough material properties). Failure in the side plate and comb elements occurs at an equivalent plastic strain of $0.152 \mathrm{in}$./in. Failure in the side plate weld elements occurs at an equivalent plastic strain of $0.205 \mathrm{in}$./in. If element failure were to occur, the element would be removed from the model (thereby excluding its equivalent plastic strain from the maximum equivalent plastic strain for the plot). However, the missing element would be visible in the plot. Figure D-127 shows some failure in the end box welds nearest the impact which is acceptable. 
ENGINEERING CALCULATIONS AND ANALYSIS

Drop Analysis of the Advanced Test Reactor Fresh Fuel Shipping Container with Heavier Low-Enriched Uranium Fuel Contents
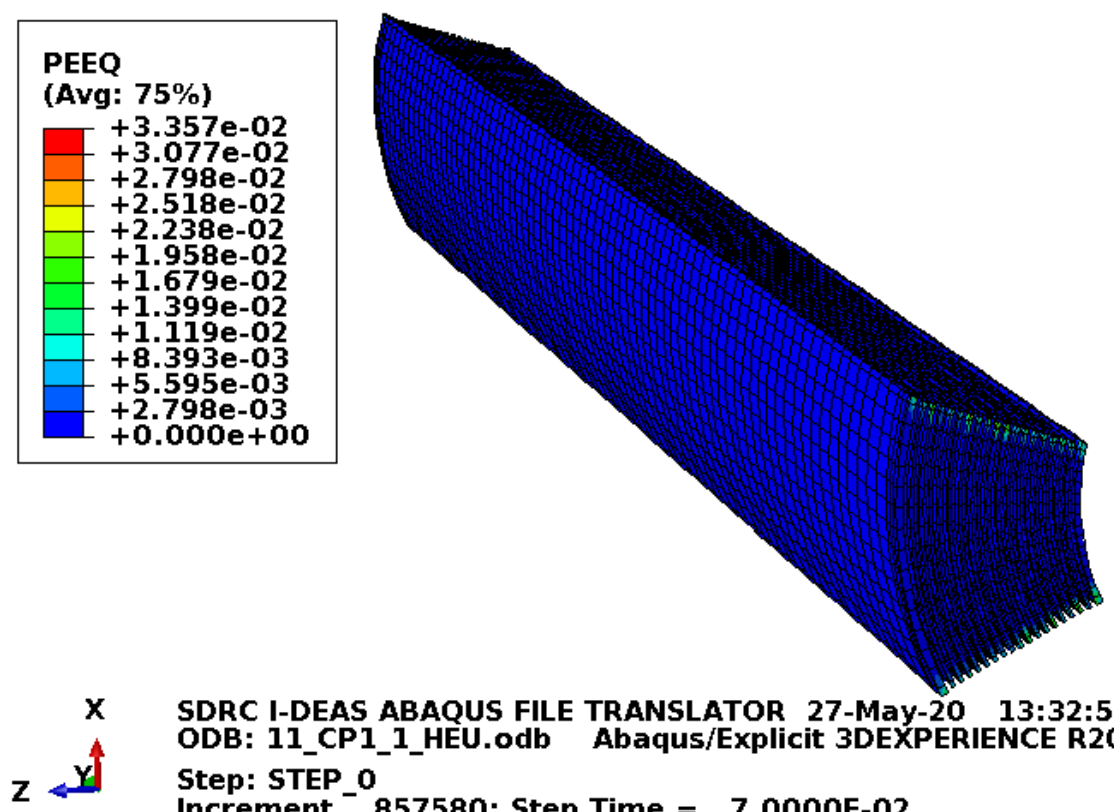

SDRC I-DEAS ABAQUS FILE TRANSLATOR 27-May-20 13:32:52

ODB: 11_CP1_1_HEU.odb Abaqus/Explicit 3DEXPERIENCE R2018x

Step: STEP_o

Increment 857580: Step Time $=$ 7.0000E-02

Primary Var: PEEQ

Figure D-128. Scope Part 1b (Table 3), Test 11 (Table 2) fuel plate equivalent strain.

Figure D-128 shows the equivalent plastic strain in the fuel plates. Failure in these elements occurs at an equivalent plastic strain of $0.205 \mathrm{in}$./in. If element failure were to occur, the element would be removed from the model (thereby excluding its equivalent plastic strain from the maximum equivalent plastic strain for the plot). However, the missing element would be visible in the plot. Figure D-128 shows no failure in the fuel plates with margin.

\section{D2.8.3 Results for Scope Part 1c (Table 3), Test 11 (Table 2)}

The FEA model results for the Scope Part 1c (Table 3), Test 11 (Table 2) model are shown below in Figure D-129 to Figure D-131. The fuel element weighs $22.1 \mathrm{lbf}$ and the whole model is modeled with minimum material properties. Though ATR FFSC SAR (2017) shows the Scope Part 1 (Table 3) drop scenarios to be acceptable, the results shown (for information) in this section include the blocks as added fuel plate protection. 


\section{[x1.E3]}

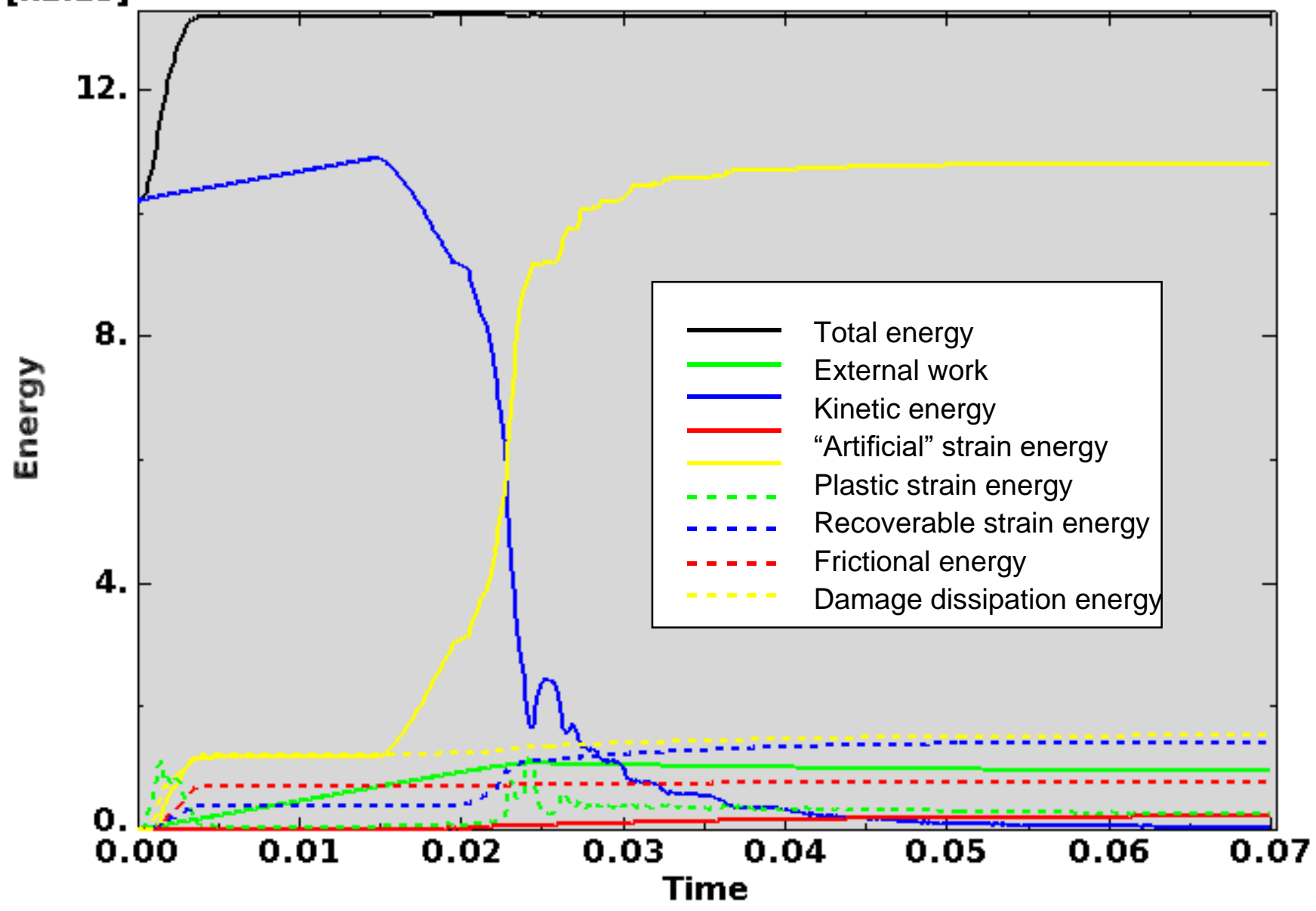

Figure D-129. Figure D-2.8.3-1. Scope Part 1c (Table 3), Test 11 (Table 2) energy curves.

Figure D-129 shows the energy curves for Scope Part 1c (Table 3), Test 11 (Table 2) drop scenario. These curves exhibit a stable shape. Artificial strain energy represents the energy required to keep reduced integration elements from taking on a zero-energy hourglass shape. As shown in Figure D-129, the artificial energy at the end of the model run is $1.6 \%$ of the total energy. Therefore, the potential error associated with artificial energy is not considered to be significant. 
ENGINEERING CALCULATIONS AND ANALYSIS

Drop Analysis of the Advanced Test Reactor Fresh Fuel Shipping Container with Heavier Low-Enriched Uranium Fuel Contents

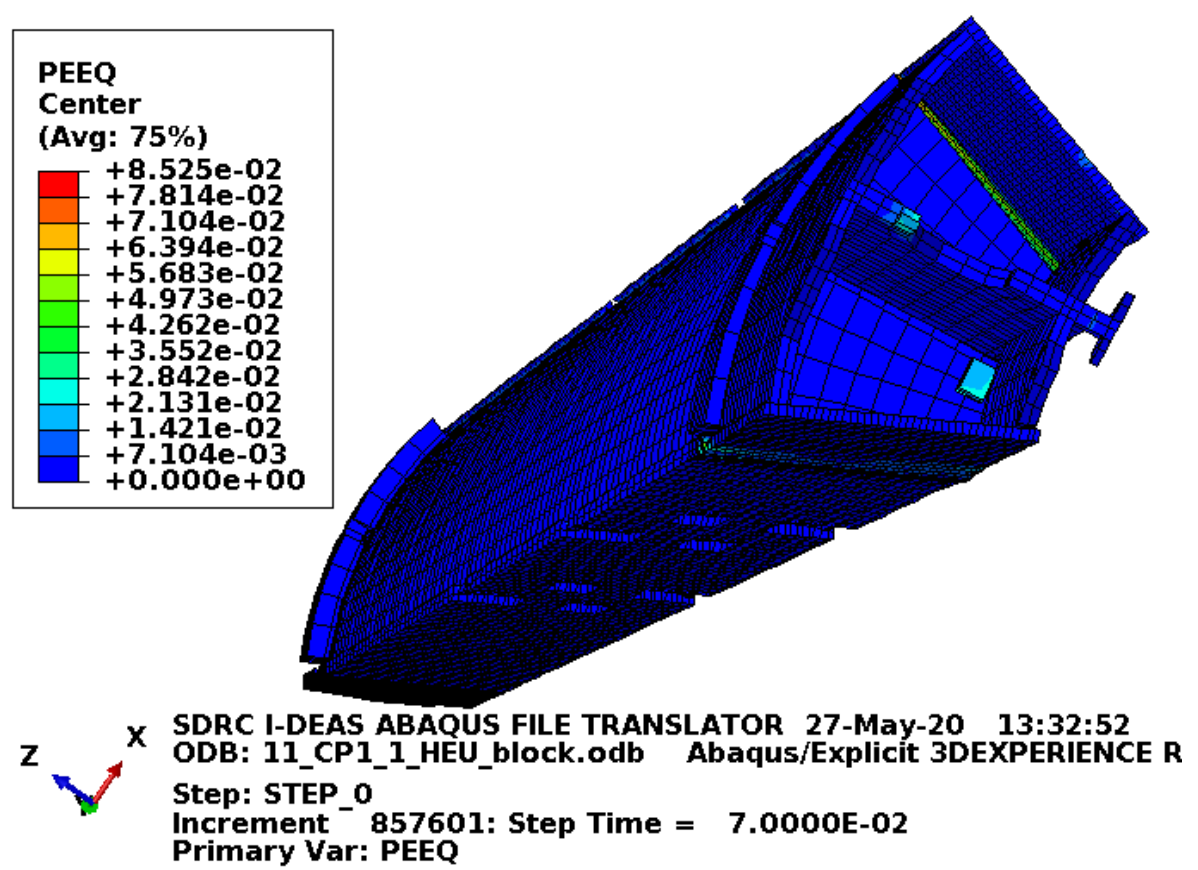

Figure D-130. Scope Part 1c (Table 3), Test 11 (Table 2) fuel element plastic equivalent strain.

Figure D-130 shows the equivalent plastic strain in the fuel element. Failure in the end box elements occurs at an equivalent plastic strain of $0.027 \mathrm{in}$./in. Failure in the end box weld elements occurs at an equivalent plastic strain of $0.032 \mathrm{in./in.} \mathrm{Failure} \mathrm{in} \mathrm{the} \mathrm{side} \mathrm{plate} \mathrm{and} \mathrm{comb} \mathrm{elements} \mathrm{occurs} \mathrm{at} \mathrm{an} \mathrm{equivalent} \mathrm{plastic}$ strain of $0.152 \mathrm{in}$./in. Failure in the side plate weld elements occurs at an equivalent plastic strain of $0.205 \mathrm{in./in.} \mathrm{If} \mathrm{element} \mathrm{failure} \mathrm{were} \mathrm{to} \mathrm{occur,} \mathrm{the} \mathrm{element} \mathrm{would} \mathrm{be} \mathrm{removed} \mathrm{from} \mathrm{the} \mathrm{model} \mathrm{(thereby}$ excluding its equivalent plastic strain from the maximum equivalent plastic strain for the plot). However, the missing element would be visible in the plot. Figure D-130 shows some failure in the end box nearest the impact which is acceptable. 
ENGINEERING CALCULATIONS AND ANALYSIS

Drop Analysis of the Advanced Test Reactor Fresh Fuel Shipping Container with Heavier Low-Enriched Uranium Fuel Contents
ECAR-5224, Rev. 0 Page D120 of D293

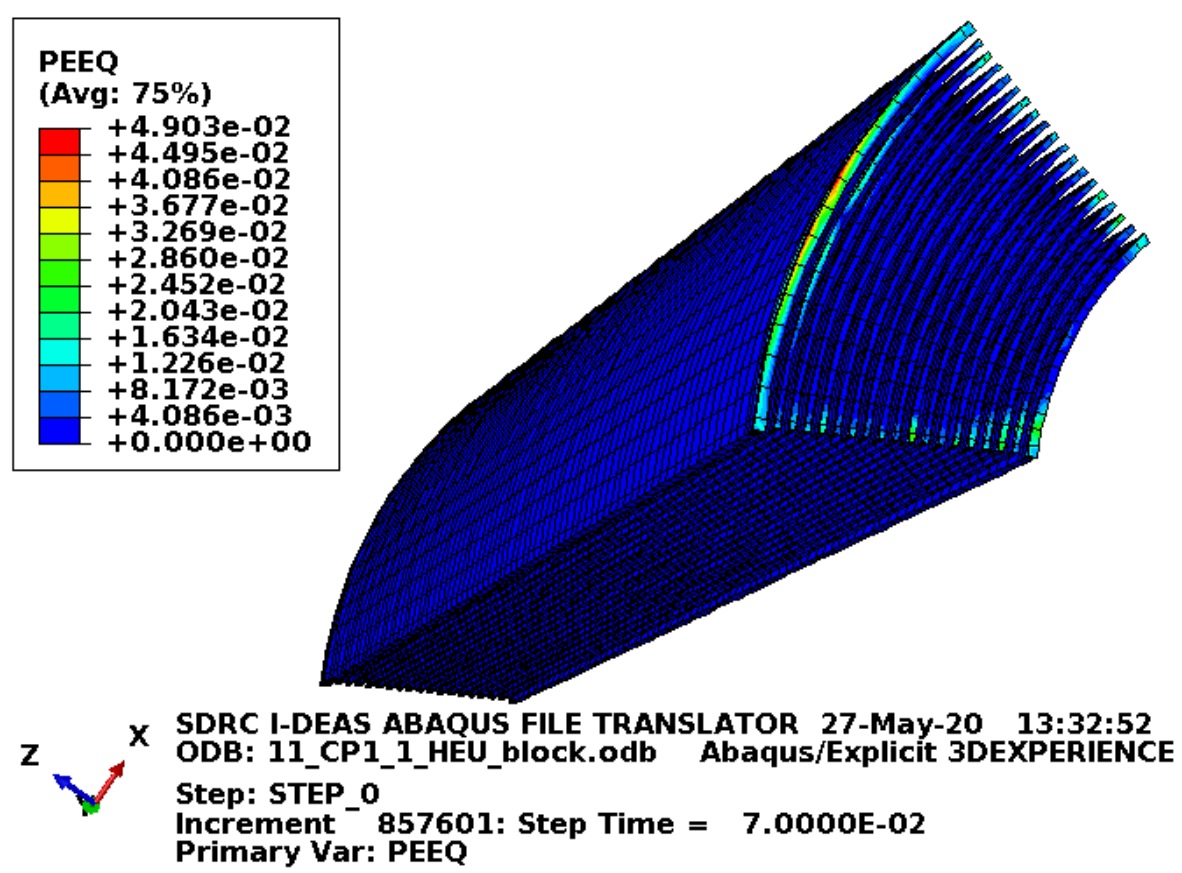

Figure D-131. Scope Part 1c (Table 3), Test 11 (Table 2) fuel plate equivalent strain.

Figure D-131 shows the equivalent plastic strain in the fuel plates. Failure in these elements occurs at an equivalent plastic strain of 0.205 in./in. If element failure were to occur, the element would be removed from the model (thereby excluding its equivalent plastic strain from the maximum equivalent plastic strain for the plot). However, the missing element would be visible in the plot. Figure D-131 shows no failure in the fuel plates with margin.

\section{D2.8.4 Results for Scope Part 1d (Table 3), Test 11 (Table 2)}

The FEA model results for the Scope Part 1d (Table 3), Test 11 (Table 2) model are shown below in Figure D-132 to Figure D-134. The fuel element weighs $22.1 \mathrm{lbf}$ and the drop scenario is modeled with minimum material properties except the enclosure and end boxes, which are modeled with relatively tough material properties. Though ATR FFSC SAR (2017) shows the Scope Part 1 (Table 3) drop scenarios to be acceptable, the results shown (for information) in this section include the blocks as added fuel plate protection. 


\section{[X1.E3]}

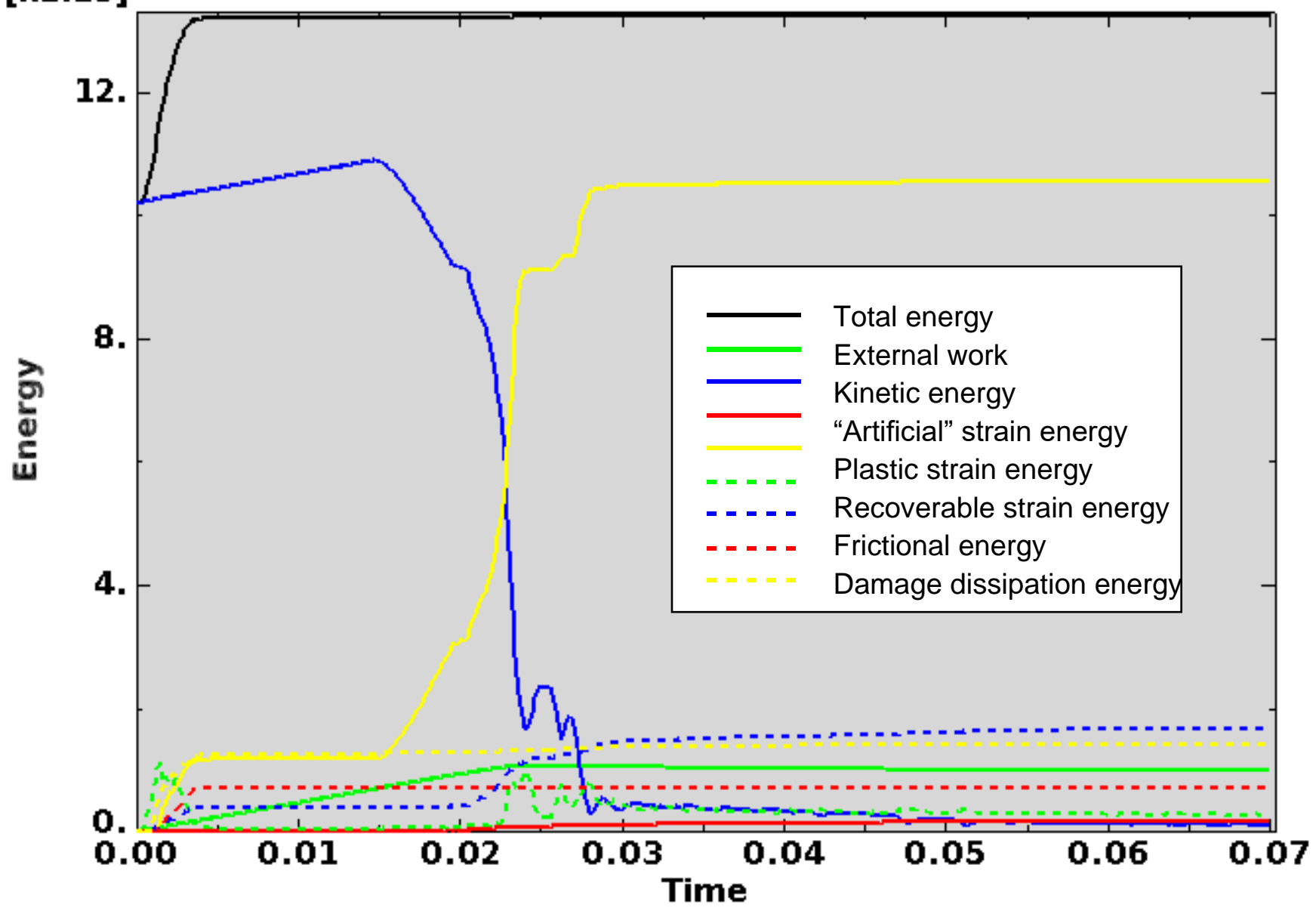

Figure D-132. Scope Part 1d (Table 3), Test 11 (Table 2) energy curves.

Figure D-132 shows the energy curves for Scope Part 1d (Table 3), Test 11 (Table 2) drop scenario. These curves exhibit a stable shape. Artificial strain energy represents the energy required to keep reduced integration elements from taking on a zero-energy hourglass shape. As shown in Figure D-132, the artificial energy at the end of the model run is $1.3 \%$ of the total energy. Therefore, the potential error associated with artificial energy is not considered to be significant. 
ENGINEERING CALCULATIONS AND ANALYSIS

Drop Analysis of the Advanced Test Reactor Fresh Fuel Shipping Container with Heavier Low-Enriched Uranium Fuel Contents
ECAR-5224, Rev. 0

Page D122 of D293

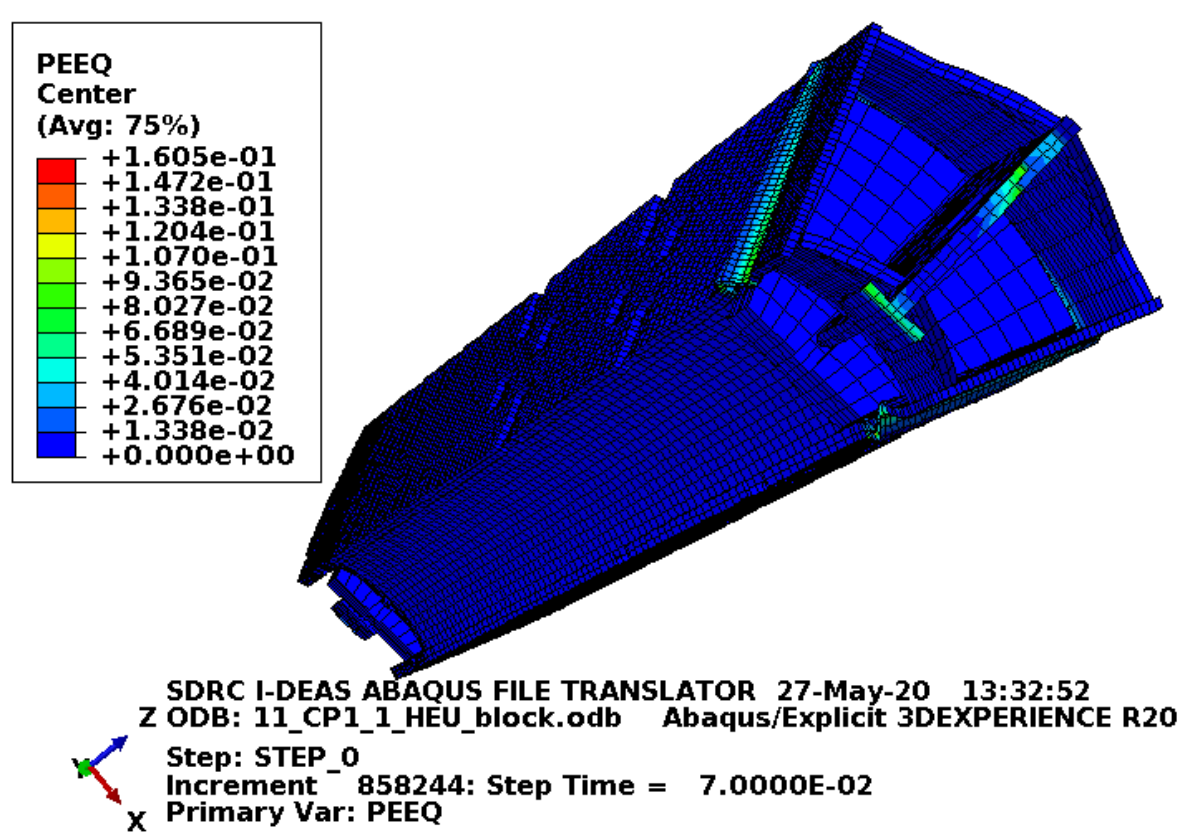

Figure D-133. Scope Part 1d (Table 3), Test 11 (Table 2) fuel element plastic equivalent strain.

Figure D-133 shows the equivalent plastic strain in the fuel element. Failure in the end box elements occurs at an equivalent plastic strain of $0.08 \mathrm{in./in.} \mathrm{(for} \mathrm{the} \mathrm{relatively} \mathrm{tough} \mathrm{material} \mathrm{properties).} \mathrm{Failure} \mathrm{in} \mathrm{the} \mathrm{end}$ box weld elements occurs at an equivalent plastic strain of $0.115 \mathrm{in}$./in. (for the relatively tough material properties). Failure in the side plate and comb elements occurs at an equivalent plastic strain of $0.152 \mathrm{in}$./in. Failure in the side plate weld elements occurs at an equivalent plastic strain of $0.205 \mathrm{in}$./in. If element failure were to occur, the element would be removed from the model (thereby excluding its equivalent plastic strain from the maximum equivalent plastic strain for the plot). However, the missing element would be visible in the plot. Figure D-133 shows some failure in the end box nearest the impact which is acceptable. While there is significant plasticity in the end box welds, there is no failure in the end box welds. 
ENGINEERING CALCULATIONS AND ANALYSIS

Drop Analysis of the Advanced Test Reactor Fresh Fuel Shipping Container with Heavier Low-Enriched Uranium Fuel Contents

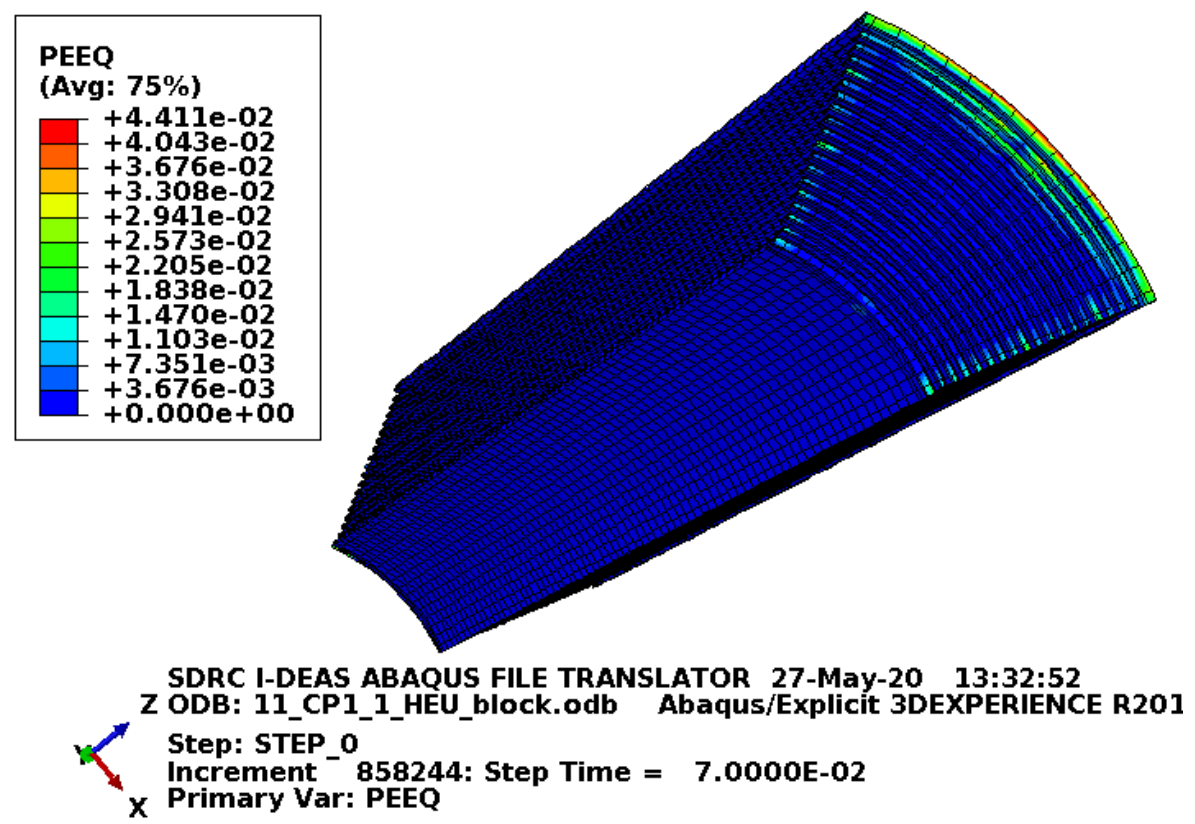

Figure D-134. Scope Part 1d (Table 3), Test 11 (Table 2) fuel plate equivalent strain.

Figure D-134 shows the equivalent plastic strain in the fuel plates. Failure in these elements occurs at an equivalent plastic strain of $0.205 \mathrm{in}$./in. If element failure were to occur, the element would be removed from the model (thereby excluding its equivalent plastic strain from the maximum equivalent plastic strain for the plot). However, the missing element would be visible in the plot. Figure D-134 shows no failure in the fuel plates with margin.

\section{D2.9 Results for Scope Part 1 (Table 3), Test 12 (Table 2)}

The drop scenario considered in this section is a $30 \mathrm{ft}$ drop modeled as a vertical top impact.

\section{D2.9.1 Results for Scope Part 1a (Table 3), Test 12 (Table 2)}

The FEA model results for the Scope Part 1a (Table 3), Test 12 (Table 2) model are shown below in Figure D-135 to Figure D-138. The fuel element weighs $22.1 \mathrm{lbf}$ and the whole model is modeled with minimum material properties. 


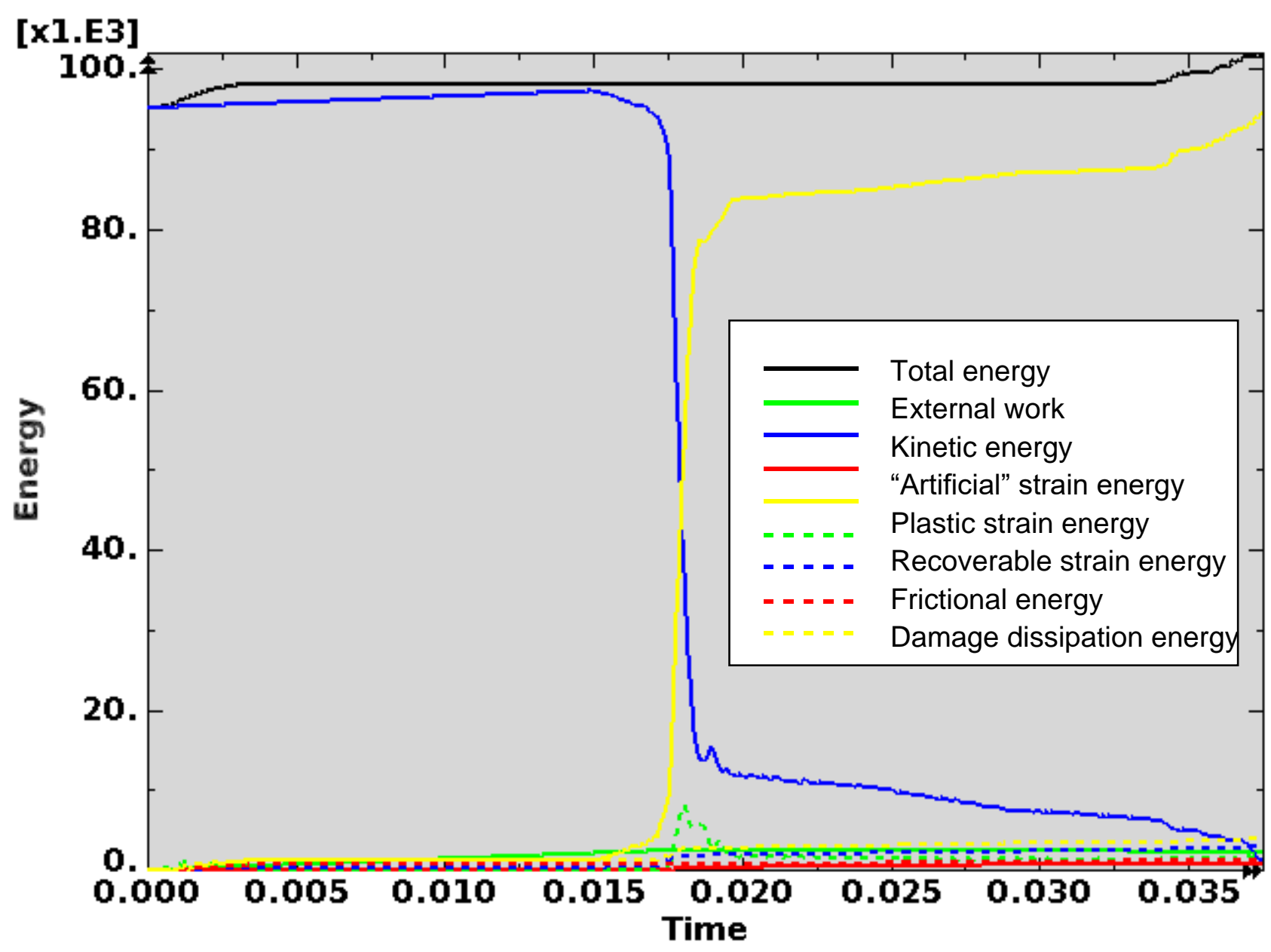

Figure D-135. Scope Part 1a (Table 3), Test 12 (Table 2) energy curves.

Figure D-135 shows the energy curves for Scope Part 1a (Table 3), Test 12 (Table 2) drop scenario. These curves exhibit mostly stable behavior. Near the end of the model run, the total energy and plastic strain energy start to show undesirable behavior. As discussed in Section D2.5 this appears to result from contact difficultly between failed portions of the fuel element. Consequently, output is shown at the first output frame after fuel element rebound $(0.0375$ second) to try to minimize potential error associated with this.

Artificial strain energy represents the energy required to keep reduced integration elements from taking on a zero-energy hourglass shape. As shown in Figure D-135, the artificial energy at the end of the model run is $0.9 \%$ of the total energy. Therefore, the potential error associated with artificial energy is not considered to be significant. 
ENGINEERING CALCULATIONS AND ANALYSIS

Drop Analysis of the Advanced Test Reactor Fresh Fuel Shipping Container with Heavier Low-Enriched Uranium Fuel Contents
ECAR-5224, Rev. 0

Page D125 of D293

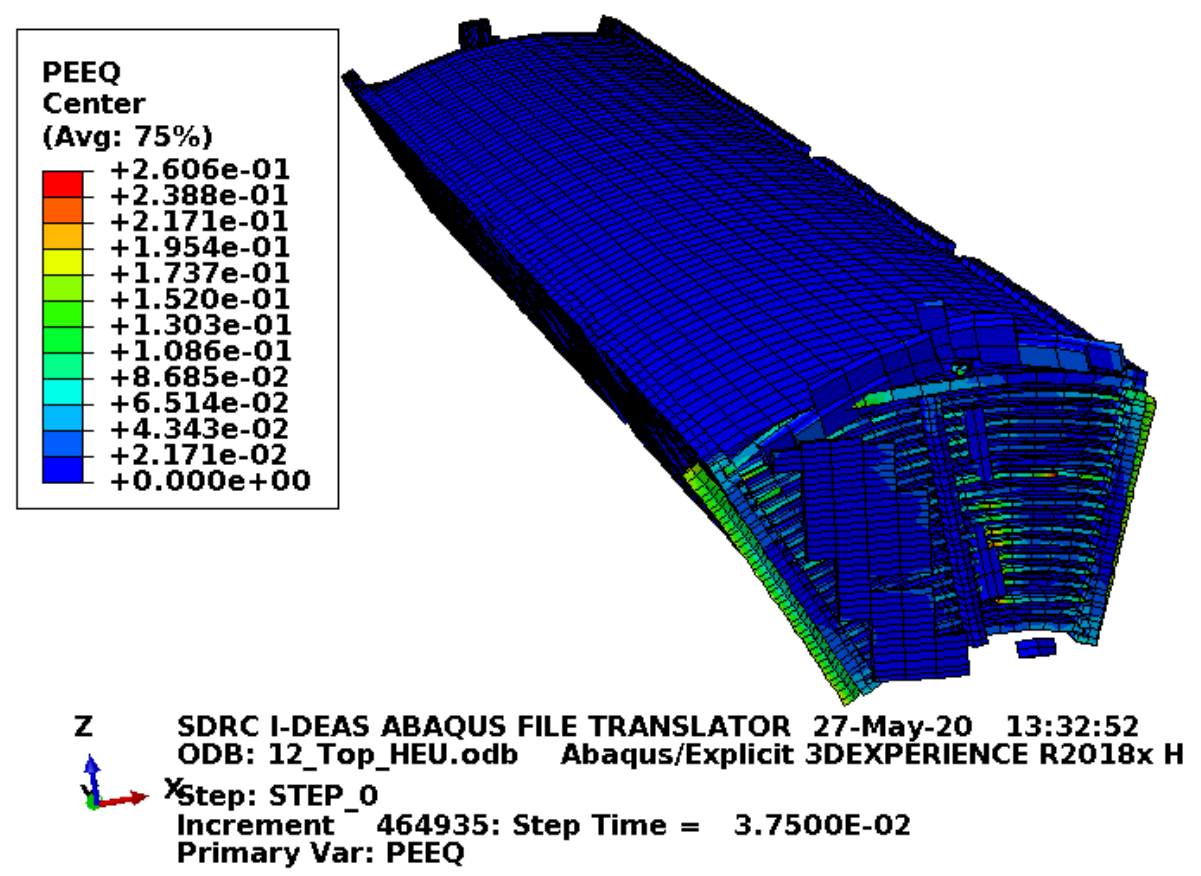

Figure D-136. Scope Part 1a (Table 3), Test 12 (Table 2) fuel element plastic equivalent strain.

Figure D-136 shows the equivalent plastic strain in the fuel element. Failure in the end box elements occurs at an equivalent plastic strain of $0.027 \mathrm{in}$./in. Failure in the end box weld elements occurs at an equivalent plastic strain of $0.032 \mathrm{in}$./in. Failure in the side plate and comb elements occurs at an equivalent plastic strain of $0.152 \mathrm{in}$./in. Failure in the side plate weld elements occurs at an equivalent plastic strain of 0.205 in./in. Figure D-136 shows substantial failure of the end box and end box welds nearest the impact.

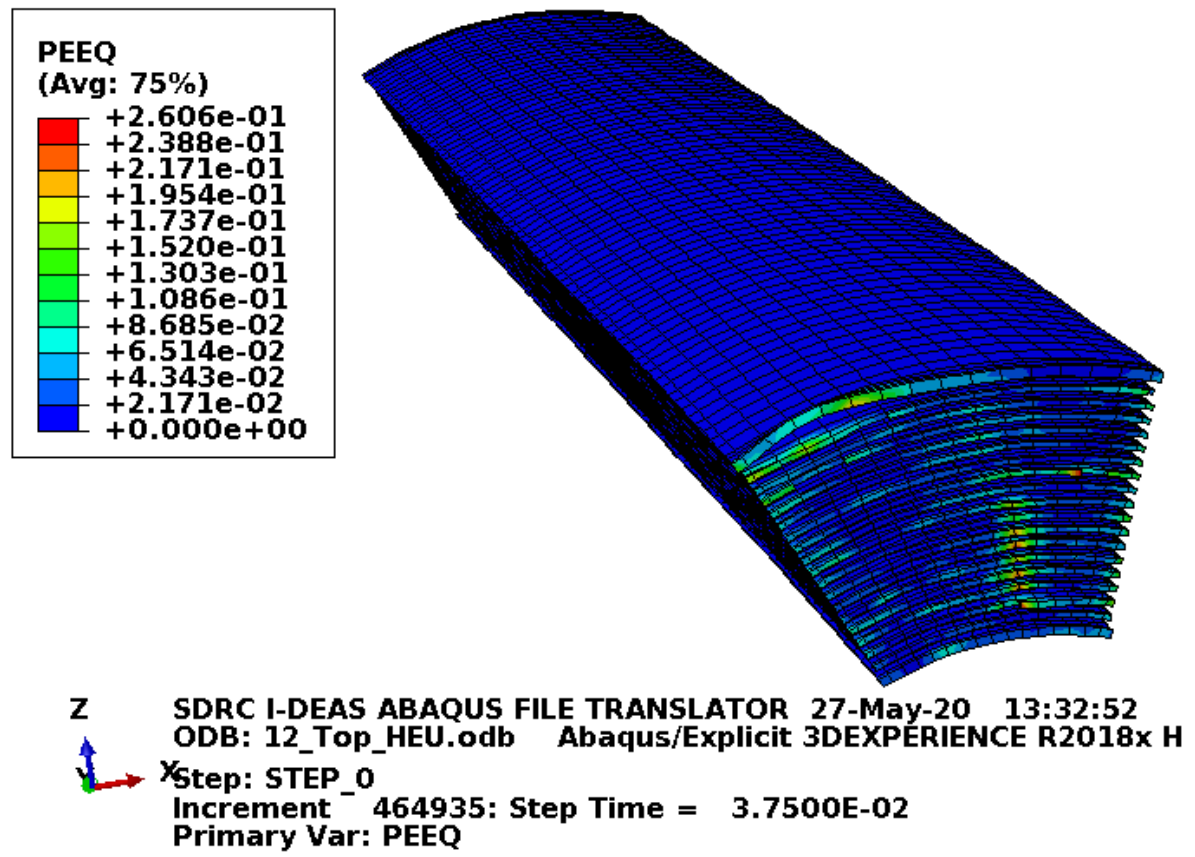

Figure D-137. Figure D-2.9.1-3. Scope Part 1a (Table 3), Test 12 (Table 2) fuel plate equivalent strain. 
ENGINEERING CALCULATIONS AND ANALYSIS

Drop Analysis of the Advanced Test Reactor Fresh Fuel Shipping Container with Heavier Low-Enriched Uranium Fuel Contents
ECAR-5224, Rev. 0

Page D126 of D293

Figure D-137 shows the equivalent plastic strain in the fuel plates. Failure in these elements occurs at an equivalent plastic strain of $0.205 \mathrm{in}$./in. If element failure were to occur, the element would be removed from the model (thereby excluding its equivalent plastic strain from the maximum equivalent plastic strain for the plot). However, the missing element would be visible in the plot. Figure D-137 shows some compressive failure in a few places, one element deep (about 0.15 in.), which is acceptable.
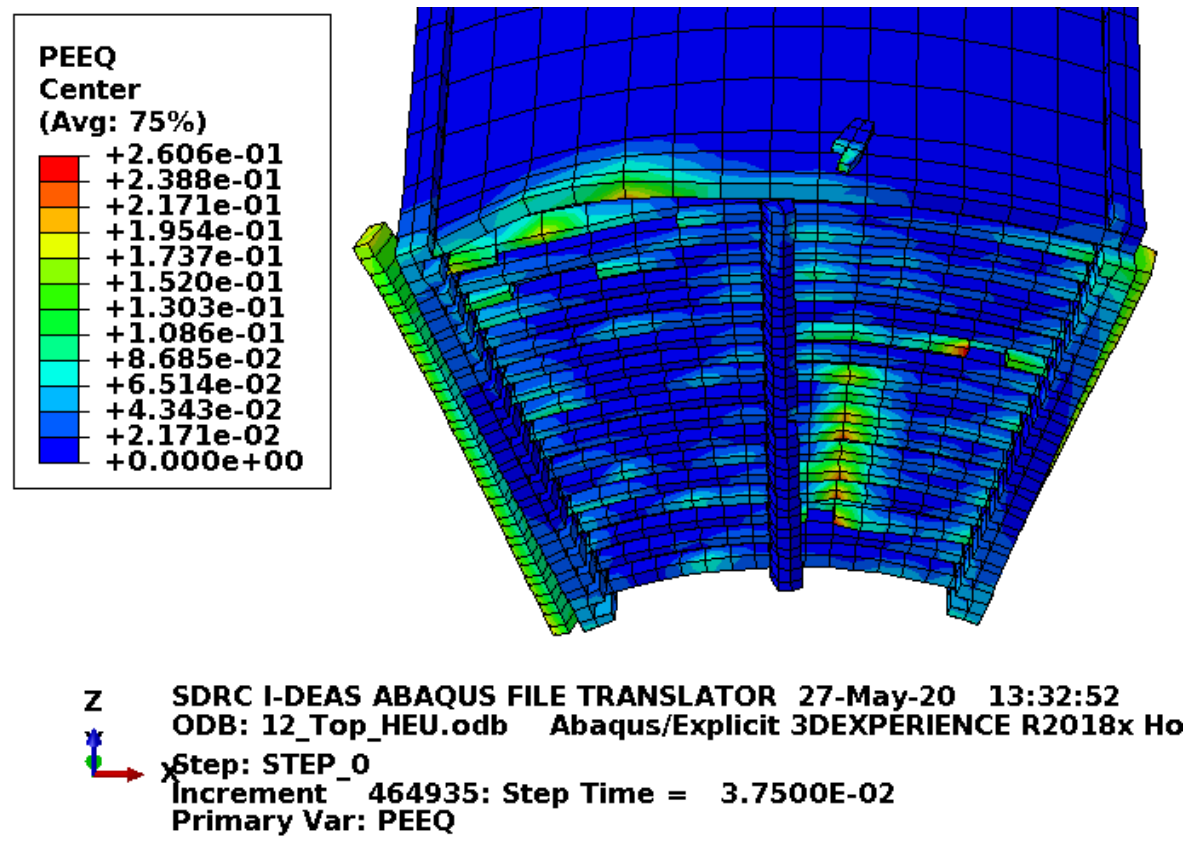

Figure D-138. Scope Part 1a (Table 3), Test 12 (Table 2) fuel element end damage.

For information, Figure D-138 shows a zoomed view of the fuel element with the end boxes and end box welds removed.

\section{D2.9.2 Results for Scope Part 1b (Table 3), Test 12 (Table 2)}

The FEA model results for the Scope Part 1b (Table 3), Test 12 (Table 2) model are shown below in Figure D-139 to Figure D-142. The fuel element weighs $22.1 \mathrm{lbf}$ and the drop scenario is modeled with minimum material properties except the enclosure and end boxes, which are modeled with relatively tough material properties. 


\section{[X1.E3]}

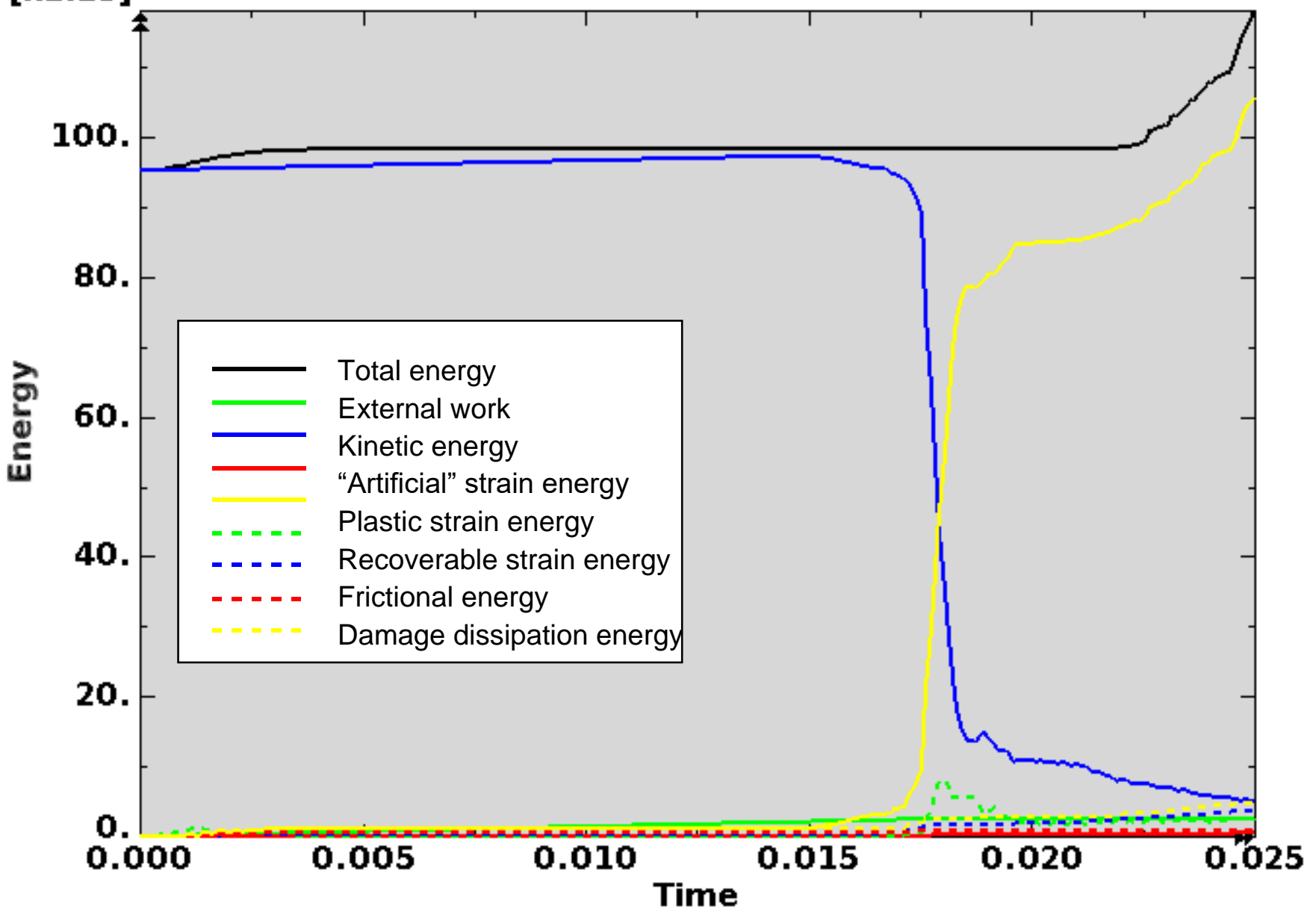

Figure D-139. Scope Part 1b (Table 3), Test 12 (Table 2) energy curves.

Figure D-139 shows the energy curves for Scope Part 1b (Table 3), Test 12 (Table 2) drop scenario. These curves exhibit initially stable behavior. Near the end of the model run, the total energy and plastic strain energy show the undesirable behavior of increasing very substantially. As discussed in Section D2.5 this appears to result from contact difficultly between failed portions of the fuel element. Also, as in Section D2.5.4, these results should be conservative and they show unacceptable damage to the fuel meat. Consequently, this model is shown for information. A similar model with the block design included (see Sections D2.9.4 and D2.9.5) is used to show the conservative acceptability of this drop scenario with blocks. For this model, rebound occurs at 0.035 second. At 0.035 second, substantial instability is demonstrated by the energy curves. At 0.025 second, unacceptable damage has occurred and the energy curves are still somewhat reasonable. Consequently, output is shown at 0.025 second where the model is more stable, and the same conclusions can be drawn.

Artificial strain energy represents the energy required to keep reduced integration elements from taking on a zero-energy hourglass shape. As shown in Figure D-139, the artificial energy at the end of the model run is $0.4 \%$ of the total energy. Therefore, the potential error associated with artificial energy is not considered to be significant. 
ENGINEERING CALCULATIONS AND ANALYSIS

Drop Analysis of the Advanced Test Reactor Fresh Fuel Shipping Container with Heavier Low-Enriched Uranium Fuel Contents
ECAR-5224, Rev. 0

Page D128 of D293

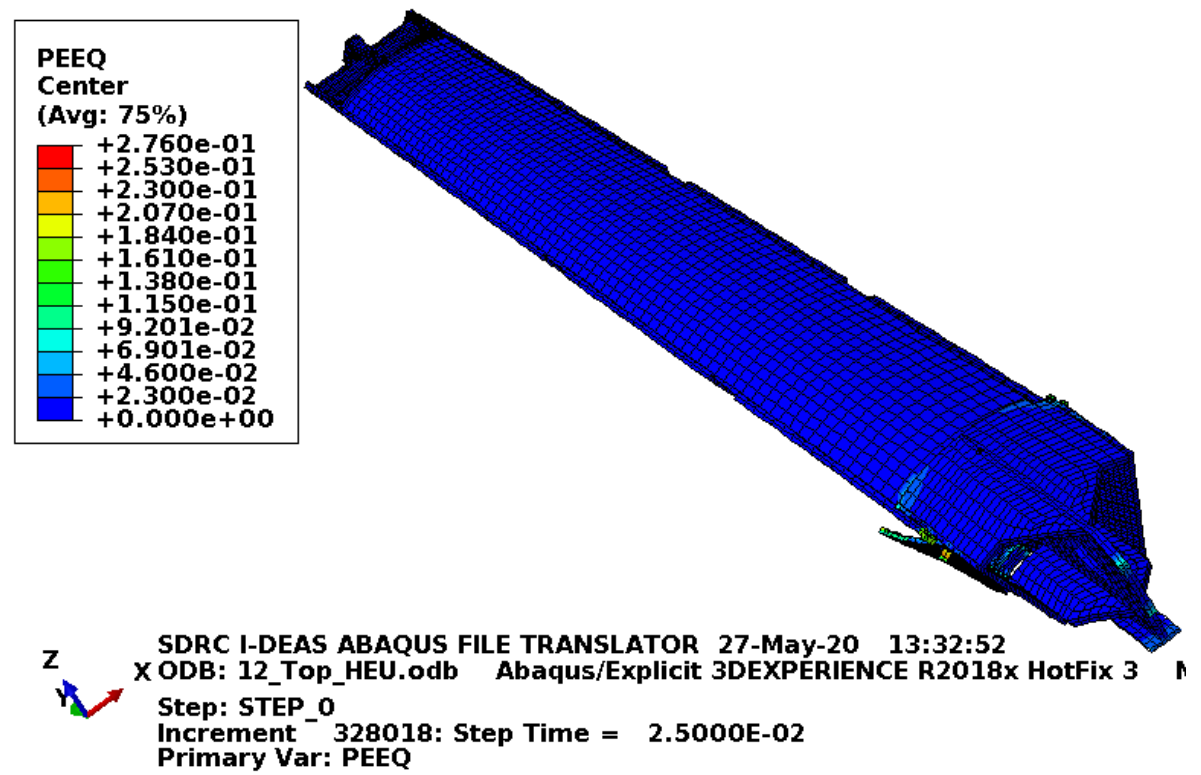

Figure D-140. Scope Part 1b (Table 3), Test 12 (Table 2) fuel element plastic equivalent strain.

Figure D-140 shows the equivalent plastic strain in the fuel element. Failure in the end box elements occurs at an equivalent plastic strain of $0.08 \mathrm{in}$./in. (for the relatively tough material properties). Failure in the end box weld elements occurs at an equivalent plastic strain of $0.115 \mathrm{in}$./in. (for the relatively tough material properties). Failure in the side plate and comb elements occurs at an equivalent plastic strain of $0.152 \mathrm{in}$./in. Failure in the side plate weld elements occurs at an equivalent plastic strain of $0.205 \mathrm{in}$./in. Figure D-140 shows failure in the end box and complete failure of the end box welds. Similar to Section D2.5.4, the damage should be conservative.

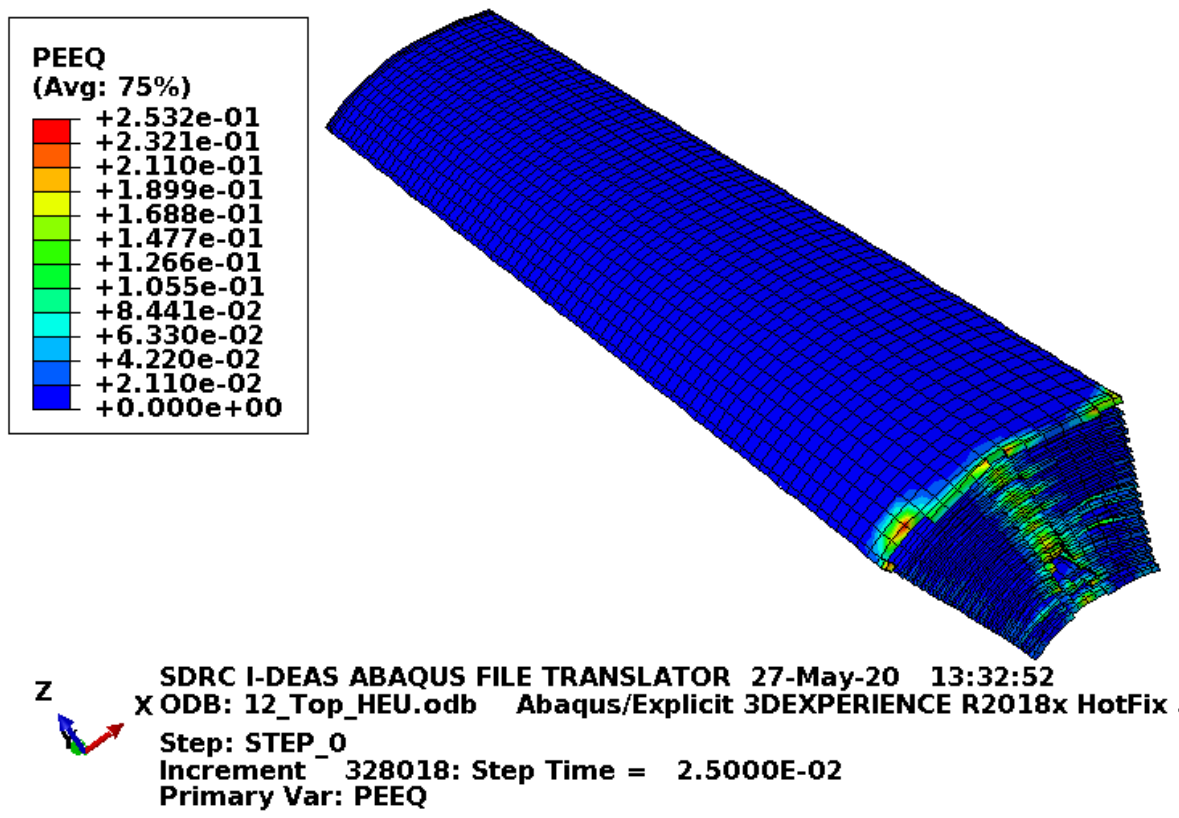

Figure D-141. Scope Part 1b (Table 3), Test 12 (Table 2) fuel plate equivalent strain. 
Figure D-141 shows the equivalent plastic strain in the fuel plates. Failure in these elements occurs at an equivalent plastic strain of $0.205 \mathrm{in}$./in. Figure D-141 shows significant failure in the fuel plates nearest the impact. By the inconsistent damage, it is clear that Abaqus (2018) is having trouble establishing contact correctly. Also, though the level of damage should be conservative, the fuel plates have unacceptable damage to the fuel meat (shown in Figure D-141). There are also strain results shown above the failure strain that likely result from extrapolation (as integration point strains are the important strains for failure). If the elements with high strains are considered as failed, it just adds to the already unacceptable damage.

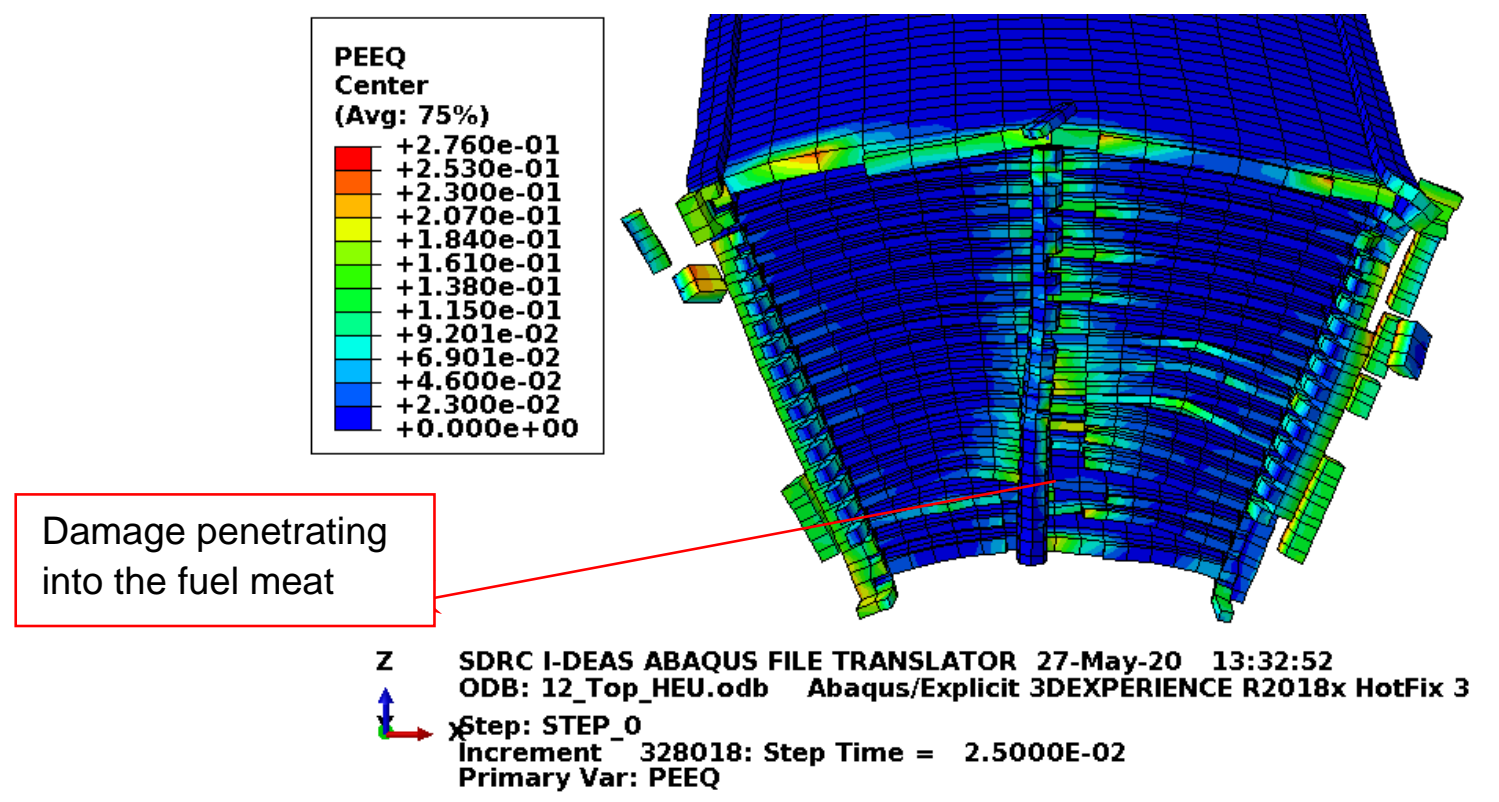

Figure D-142. Scope Part 1b (Table 3), Test 12 (Table 2) fuel element end damage.

For information, Figure D-142 shows a zoomed view of the fuel element with the end boxes and end box welds removed.

\section{D2.9.3 Results for Scope Part 1c (Table 3), Test 12 (Table 2)}

The FEA model results for the Scope Part 1c (Table 3), Test 12 (Table 2) model are shown below in Figure D-143 to Figure D-146. The fuel element weighs $22.1 \mathrm{lbf}$ and the whole model is modeled with minimum material properties. Though ATR FFSC SAR (2017) shows the Scope Part 1 (Table 3) drop scenarios to be acceptable, the results shown (for information) in this section include the blocks as added fuel plate protection. 


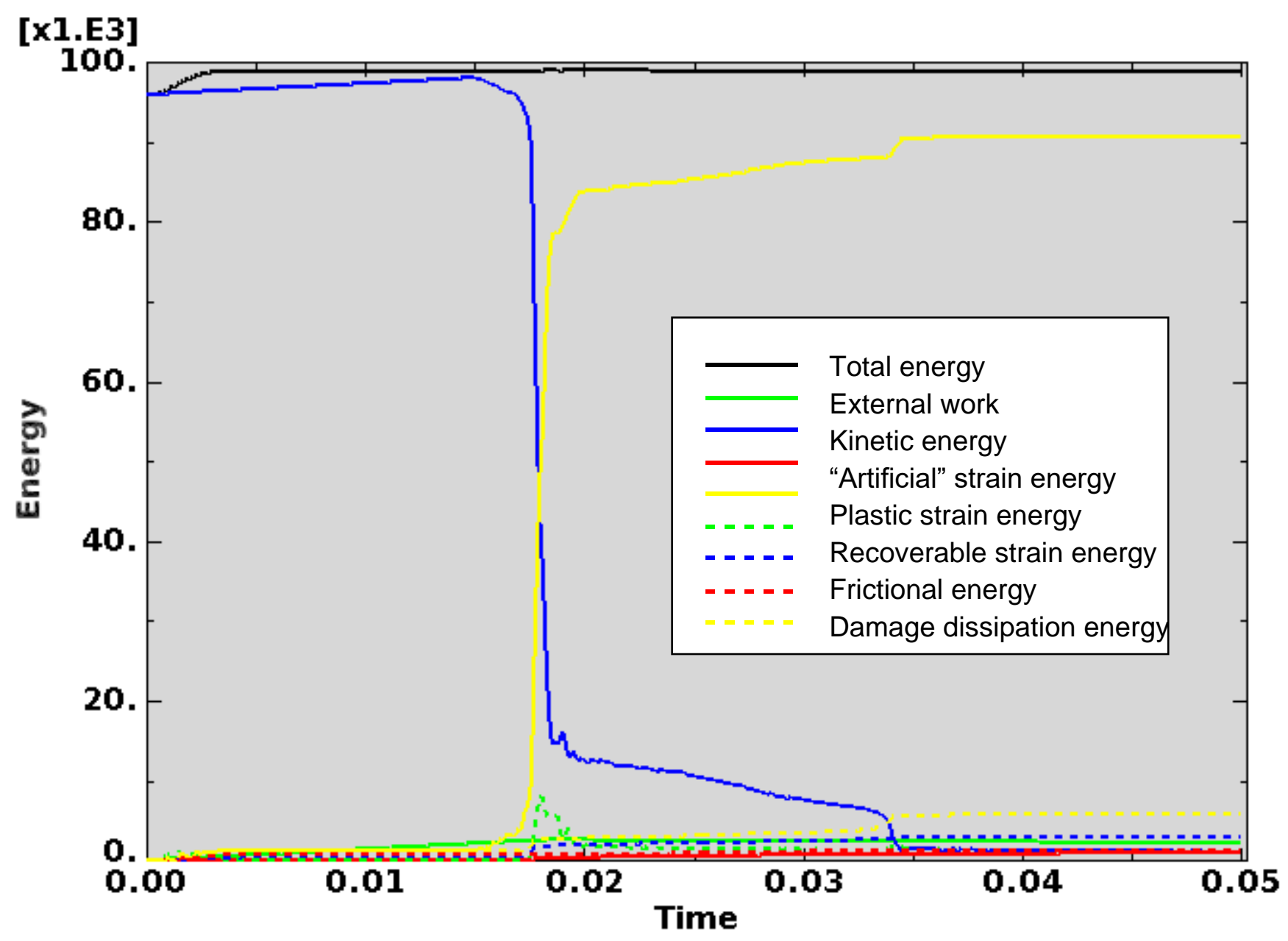

Figure D-143. Scope Part 1c (Table 3), Test 12 (Table 2) energy curves.

Figure D-143 shows the energy curves for Scope Part 1c (Table 3), Test 12 (Table 2) drop scenario. These curves exhibit a stable shape. Artificial strain energy represents the energy required to keep reduced integration elements from taking on a zero-energy hourglass shape. As shown in Figure D-143, the artificial energy at the end of the model run is $0.9 \%$ of the total energy. Therefore, the potential error associated with artificial energy is not considered to be significant. 
ENGINEERING CALCULATIONS AND ANALYSIS

Drop Analysis of the Advanced Test Reactor Fresh Fuel Shipping Container with Heavier Low-Enriched Uranium Fuel Contents
ECAR-5224, Rev. 0

Page D131 of D293

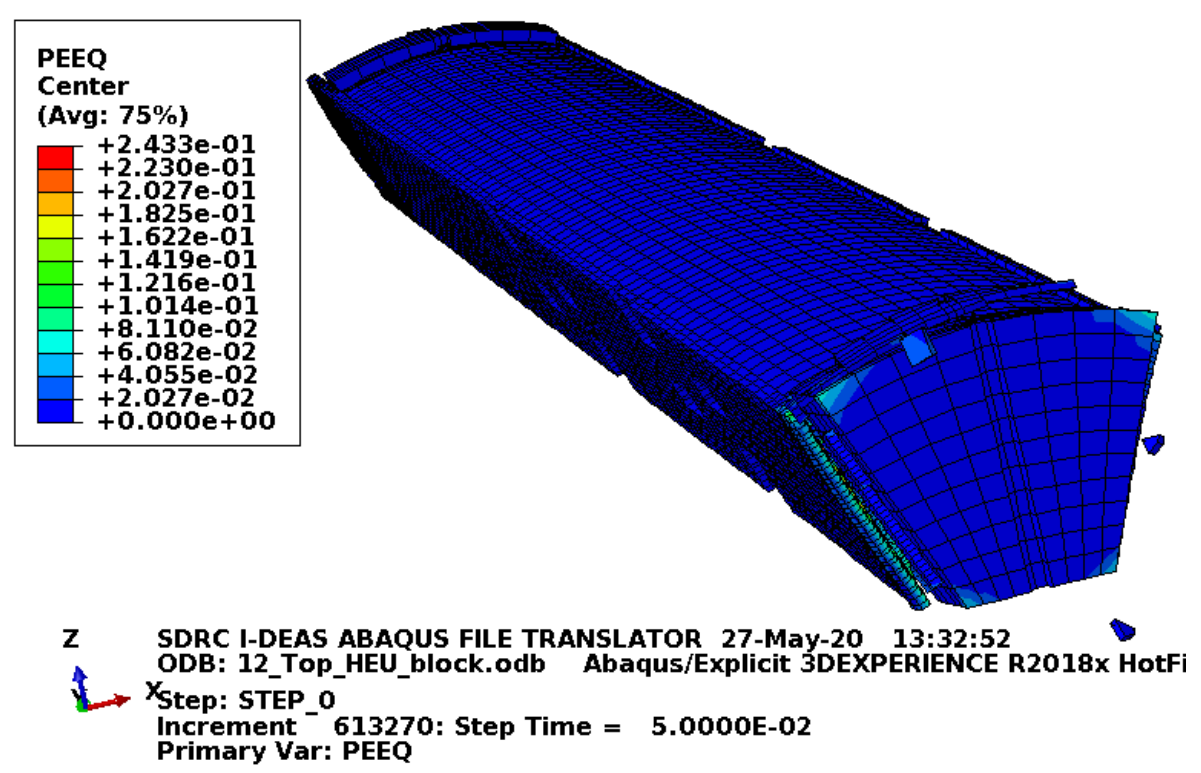

Figure D-144. Scope Part 1c (Table 3), Test 12 (Table 2) fuel element plastic equivalent strain.

Figure D-144 shows the equivalent plastic strain in the fuel element. Failure in the end box elements occurs at an equivalent plastic strain of $0.027 \mathrm{in.}$./in. Failure in the end box weld elements occurs at an equivalent plastic strain of 0.032 in./in. Failure in the side plate and comb elements occurs at an equivalent plastic strain of $0.152 \mathrm{in./in}$. Failure in the side plate weld elements occurs at an equivalent plastic strain of 0.205 in./in. Figure D-144 shows substantial failure of the end box and end box welds nearest the impact.

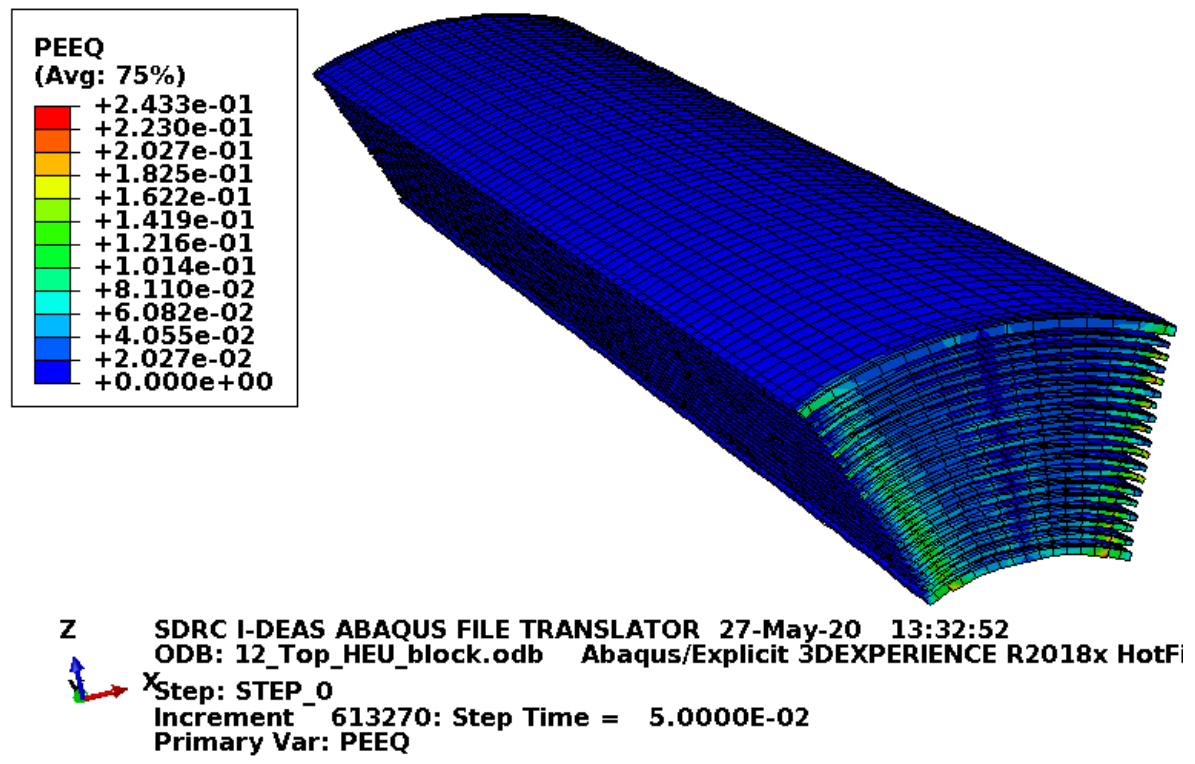

Figure D-145. Figure D-2.9.3-3. Scope Part 1c (Table 3), Test 12 (Table 2) fuel plate equivalent strain. 
Figure D-145 shows the equivalent plastic strain in the fuel plates. Failure in these elements occurs at an equivalent plastic strain of $0.205 \mathrm{in}$./in. If element failure were to occur, the element would be removed from the model (thereby excluding its equivalent plastic strain from the maximum equivalent plastic strain for the plot). However, the missing element would be visible in the plot. Figure D-145 shows some compressive failure in a few places, one element deep (about $0.15 \mathrm{in}$.), which is acceptable. In this situation where the end box is weak, having the block reduces the crush zone thereby making the fuel plate absorb more of the impact energy. Having the blocks is still desirable because the damage is more predictable and compressive (rather than cutting).

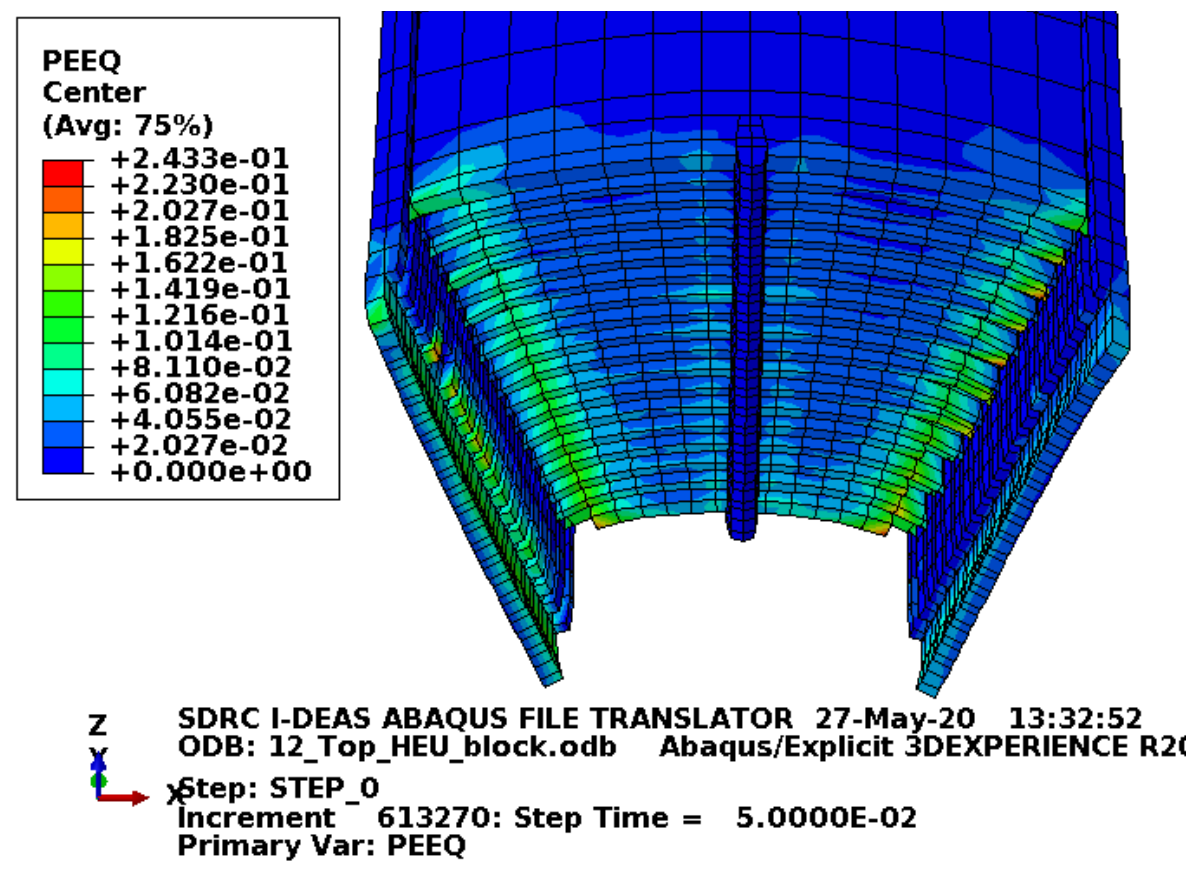

Figure D-146. Scope Part 1c (Table 3), Test 12 (Table 2) fuel element end damage.

For information, Figure D-146 shows a zoomed view of the fuel element with the end boxes and end box welds removed.

\section{D2.9.4 Results for Scope Part 1c (Table 3), Test 12 (Table 2) Fine Mesh}

The FEA model results for the Scope Part 1c (Table 3), Test 12 (Table 2) fine mesh model are shown below in Figure D-147 to Figure D-150. The fuel element weighs $22.1 \mathrm{lbf}$ and the whole model is modeled with minimum material properties. Though ATR FFSC SAR (2017) shows the Scope Part 1 (Table 3) drop scenarios to be acceptable, the results shown (for information) in this section include the blocks as added fuel plate protection. 


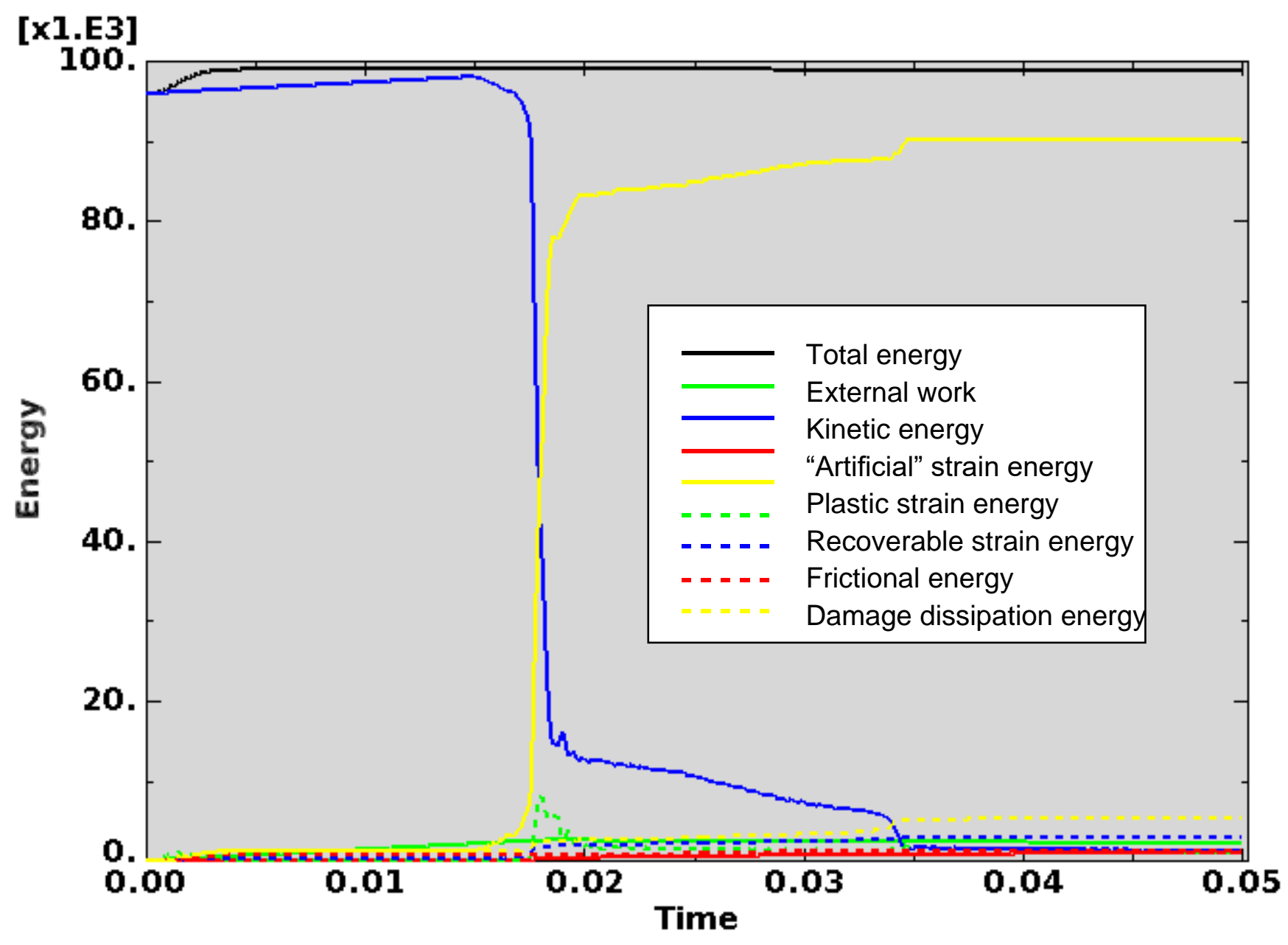

Figure D-147. Scope Part 1c (Table 3), Test 12 (Table 2) fine mesh energy curves.

Figure D-147 shows the energy curves for Scope Part 1c (Table 3), Test 12 (Table 2) fine mesh drop scenario. These curves exhibit a stable shape. Artificial strain energy represents the energy required to keep reduced integration elements from taking on a zero-energy hourglass shape. As shown in Figure D-147, the artificial energy at the end of the model run is $0.9 \%$ of the total energy. Therefore, the potential error associated with artificial energy is not considered to be significant. 


\section{ENGINEERING CALCULATIONS AND ANALYSIS}

Drop Analysis of the Advanced Test Reactor Fresh Fuel Shipping Container with Heavier Low-Enriched Uranium Fuel Contents
ECAR-5224, Rev. 0

Page D134 of D293

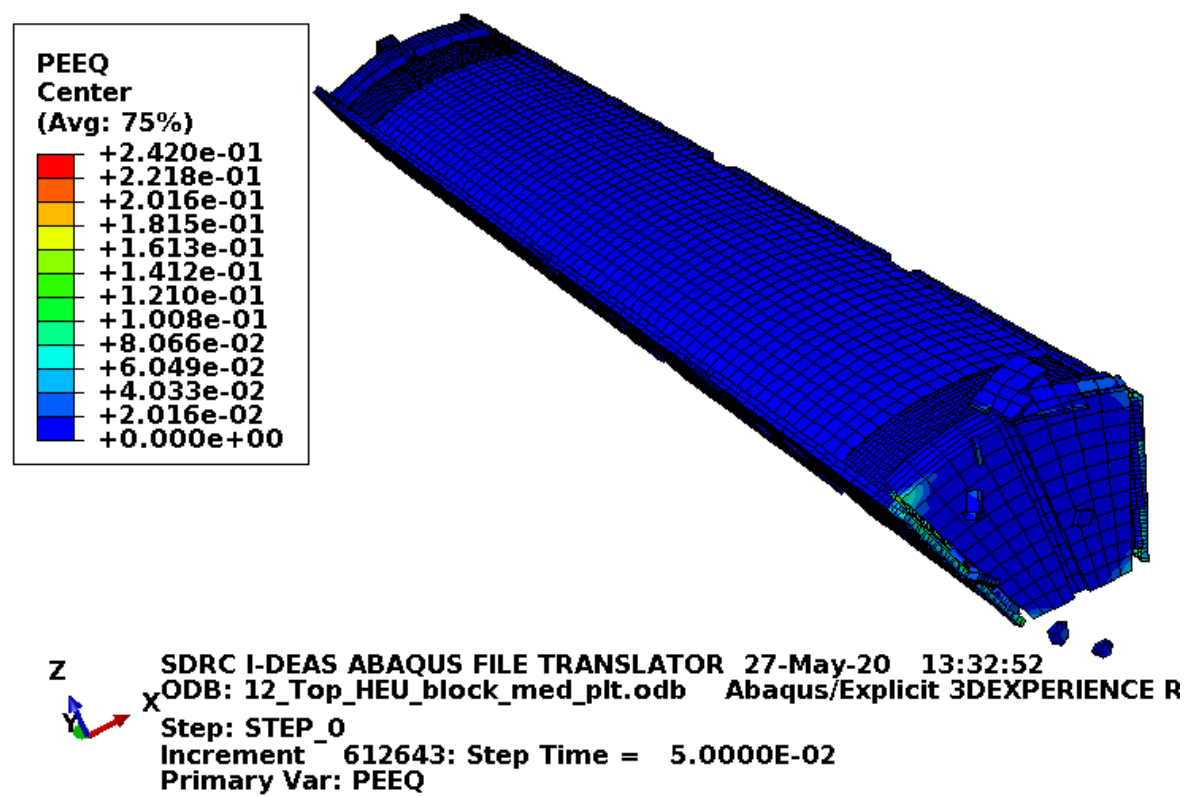

Figure D-148. Scope Part 1c (Table 3), Test 12 (Table 2) fine mesh fuel element plastic equivalent strain.

Figure D-148 shows the equivalent plastic strain in the fuel element. Failure in the end box elements occurs at an equivalent plastic strain of $0.027 \mathrm{in}$./in. Failure in the end box weld elements occurs at an equivalent plastic strain of $0.032 \mathrm{in}$./in. Failure in the side plate and comb elements occurs at an equivalent plastic strain of $0.152 \mathrm{in}$./in. Failure in the side plate weld elements occurs at an equivalent plastic strain of 0.205 in./in. Figure D-148 shows substantial failure of the end box and end box welds nearest the impact.

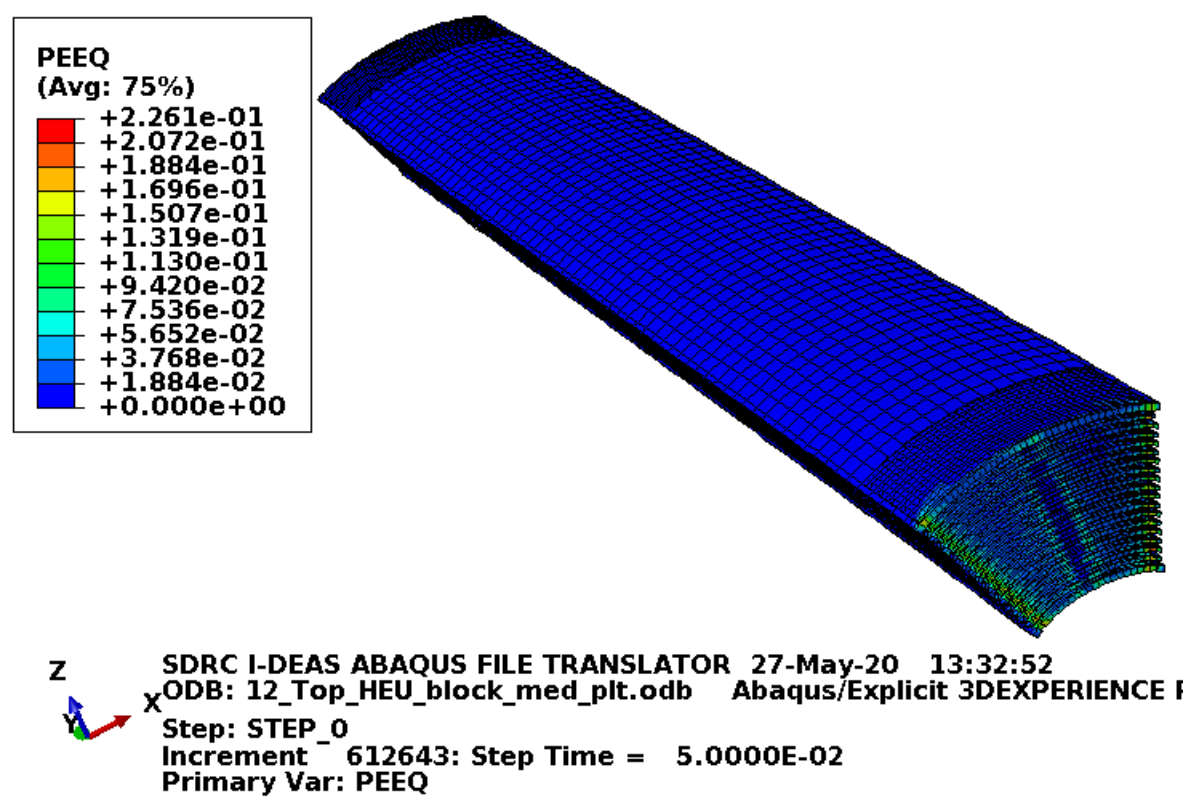

Figure D-149. Scope Part 1c (Table 3), Test 12 (Table 2) fine mesh fuel plate equivalent strain. 
Figure D-149 shows the equivalent plastic strain in the fuel plates. Failure in these elements occurs at an equivalent plastic strain of $0.205 \mathrm{in}$./in. If element failure were to occur, the element would be removed from the model (thereby excluding its equivalent plastic strain from the maximum equivalent plastic strain for the plot). However, the missing element would be visible in the plot. Figure D-149 shows some compressive failure in a couple places, one element deep (about 0.09 in.), which is acceptable.
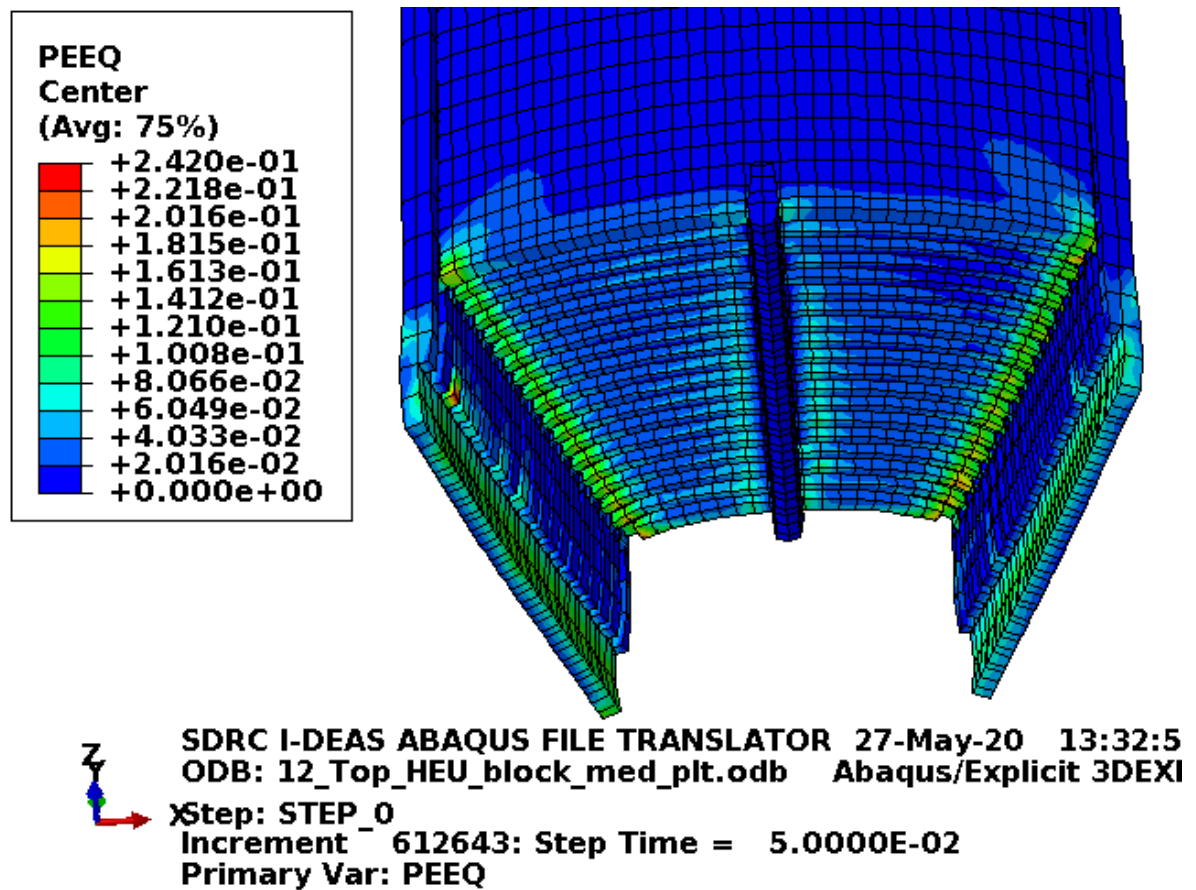

Figure D-150. Scope Part 1c (Table 3), Test 12 (Table 2) fine mesh fuel element end damage.

For information, Figure D-150 shows a zoomed view of the fuel element with the end boxes and end box welds removed.

\section{D2.9.5 Results for Scope Part 1d (Table 3), Test 12 (Table 2)}

The FEA model results for the Scope Part 1d (Table 3), Test 12 (Table 2) model are shown below in Figure D-151 to Figure D-154. The fuel element weighs $22.1 \mathrm{lbf}$ and the drop scenario is modeled with minimum material properties except the enclosure and end boxes, which are modeled with relatively tough material properties. Though ATR FFSC SAR (2017) shows the Scope Part 1 (Table 3) drop scenarios to be acceptable, the results shown (for information) in this section include the blocks as added fuel plate protection. 


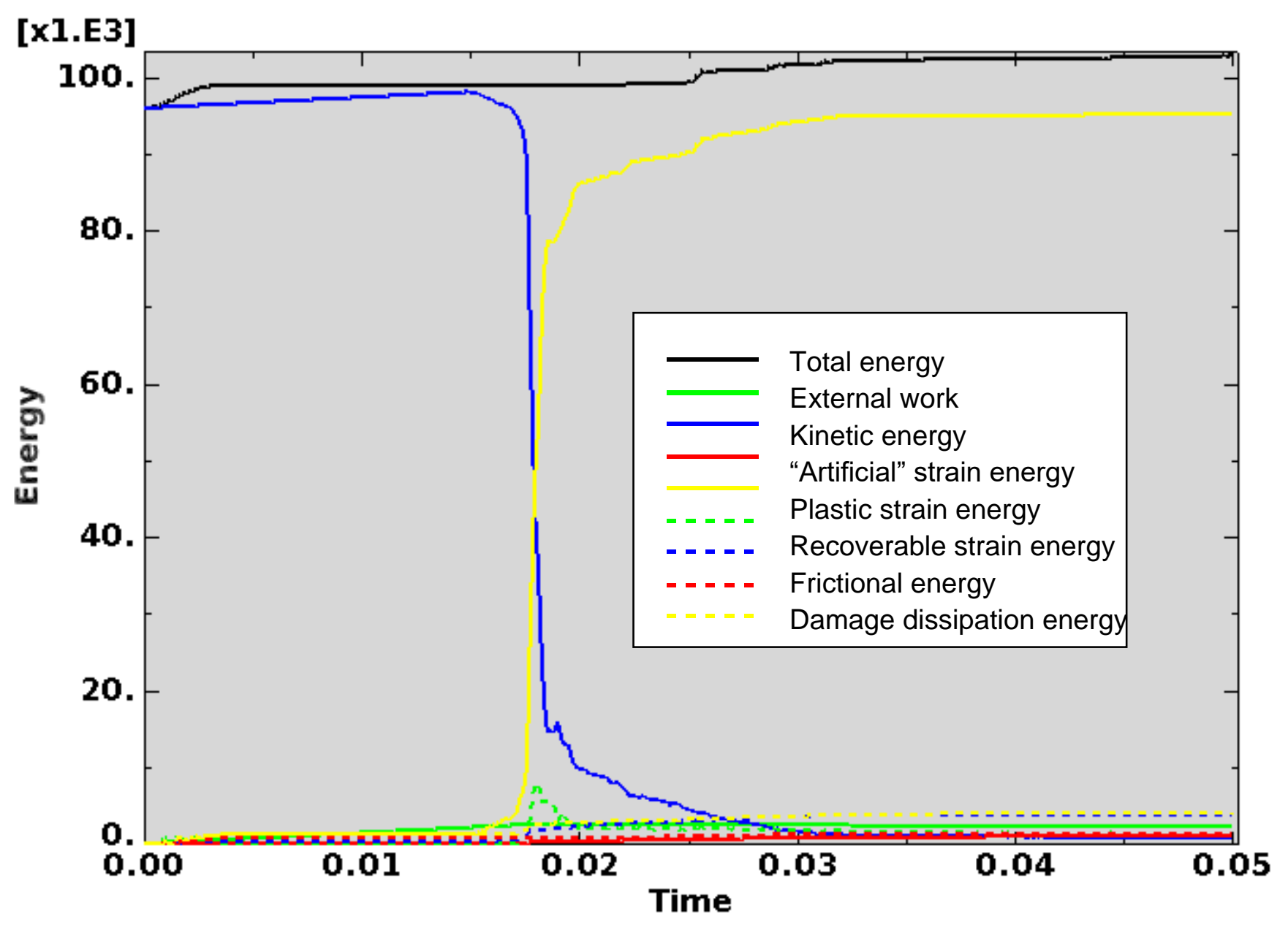

Figure D-151. Scope Part 1d (Table 3), Test 12 (Table 2) energy curves.

Figure D-151 shows the energy curves for Scope Part 1d (Table 3), Test 12 (Table 2) drop scenario. These curves exhibit somewhat stable behavior. The total energy and plastic strain energy show a small amount of undesirable behavior midway through the model run. As discussed in Section D2.5 this appears to result from contact difficultly between failed portions of the fuel element. Because there is not substantial undesirable behavior, the model results are given at the end of the model run.

Artificial strain energy represents the energy required to keep reduced integration elements from taking on a zero-energy hourglass shape. As shown in Figure D-151, the artificial energy at the end of the model run is $0.9 \%$ of the total energy. Therefore, the potential error associated with artificial energy is not considered to be significant. 
ENGINEERING CALCULATIONS AND ANALYSIS

Drop Analysis of the Advanced Test Reactor Fresh Fuel Shipping Container with Heavier Low-Enriched Uranium Fuel Contents
ECAR-5224, Rev. 0

Page D137 of D293

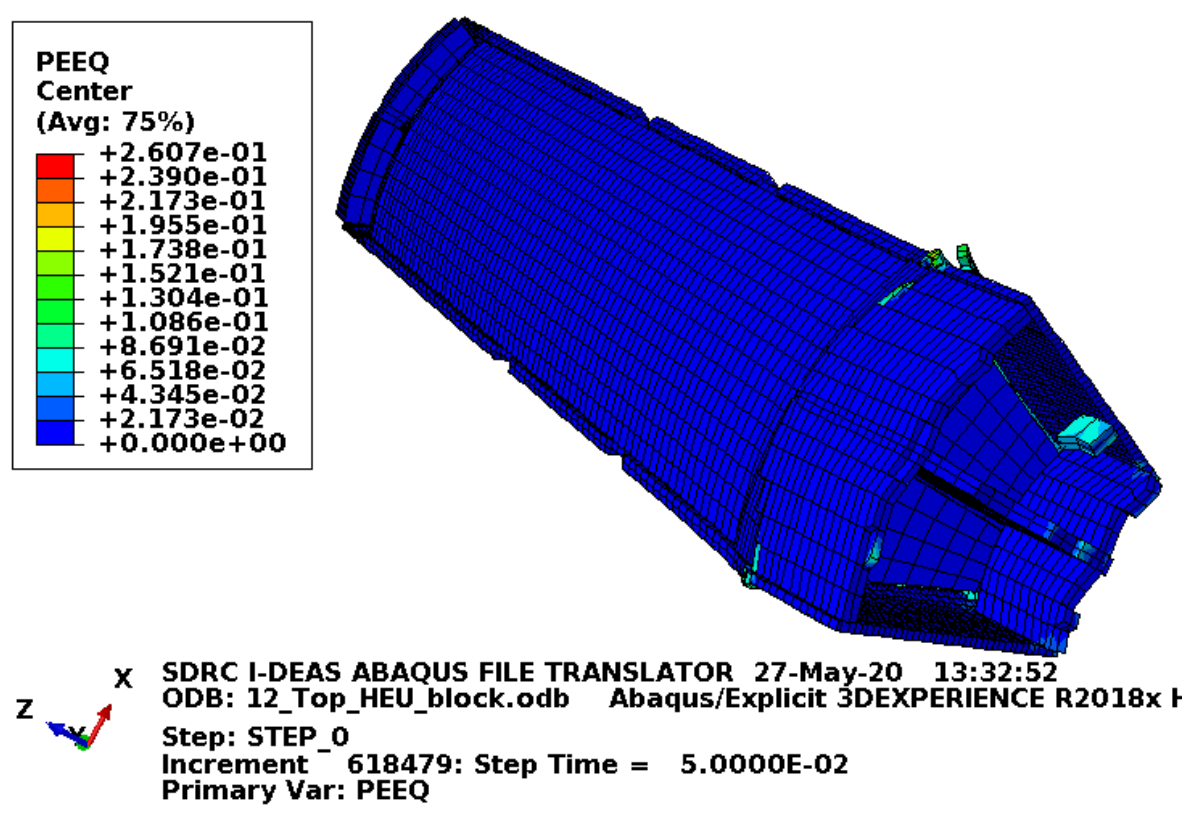

Figure D-152. Scope Part 1d (Table 3), Test 12 (Table 2) fuel element plastic equivalent strain.

Figure D-152 shows the equivalent plastic strain in the fuel element. Failure in the end box elements occurs at an equivalent plastic strain of $0.08 \mathrm{in}$./in. (for the relatively tough material properties). Failure in the end box weld elements occurs at an equivalent plastic strain of $0.115 \mathrm{in}$./in. (for the relatively tough material properties). Failure in the side plate and comb elements occurs at an equivalent plastic strain of $0.152 \mathrm{in}$./in. Failure in the side plate weld elements occurs at an equivalent plastic strain of $0.205 \mathrm{in}$./in. Figure D-152 shows significant failure in the end box and end box weld nearest the impacted surface.

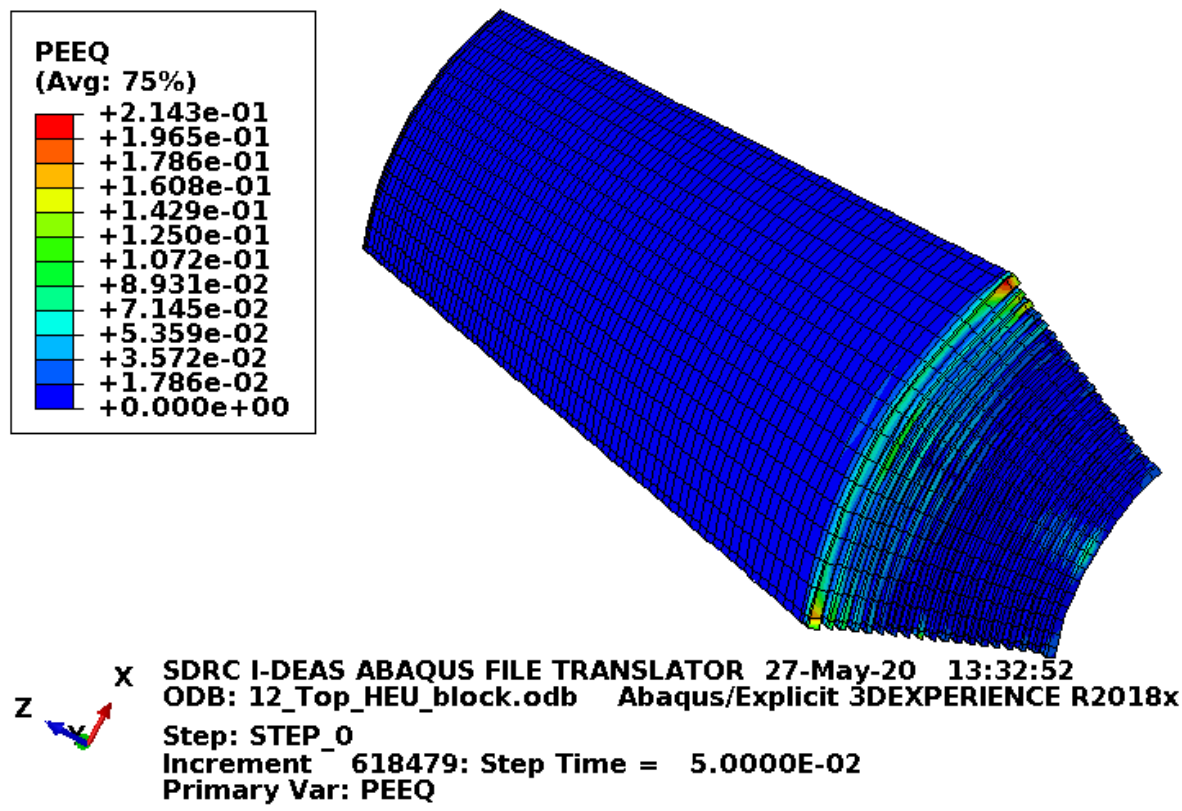

Figure D-153. Scope Part 1d (Table 3), Test 12 (Table 2) fuel plate equivalent strain. 
Figure D-153 shows the equivalent plastic strain in the fuel plates. Failure in these elements occurs at an equivalent plastic strain of $0.205 \mathrm{in}$./in. If element failure were to occur, the element would be removed from the model (thereby excluding its equivalent plastic strain from the maximum equivalent plastic strain for the plot). However, the missing element would be visible in the plot. Figure D-153 shows no element failure though a couple elements at the end of one fuel plate show strains above failure. The strains shown above the failure strain likely result from extrapolation (as integration point strains are the important strains for failure). Even if the elements with high strain were removed as being failed, the failure would be acceptable as the high strained elements do not represent fuel meat.

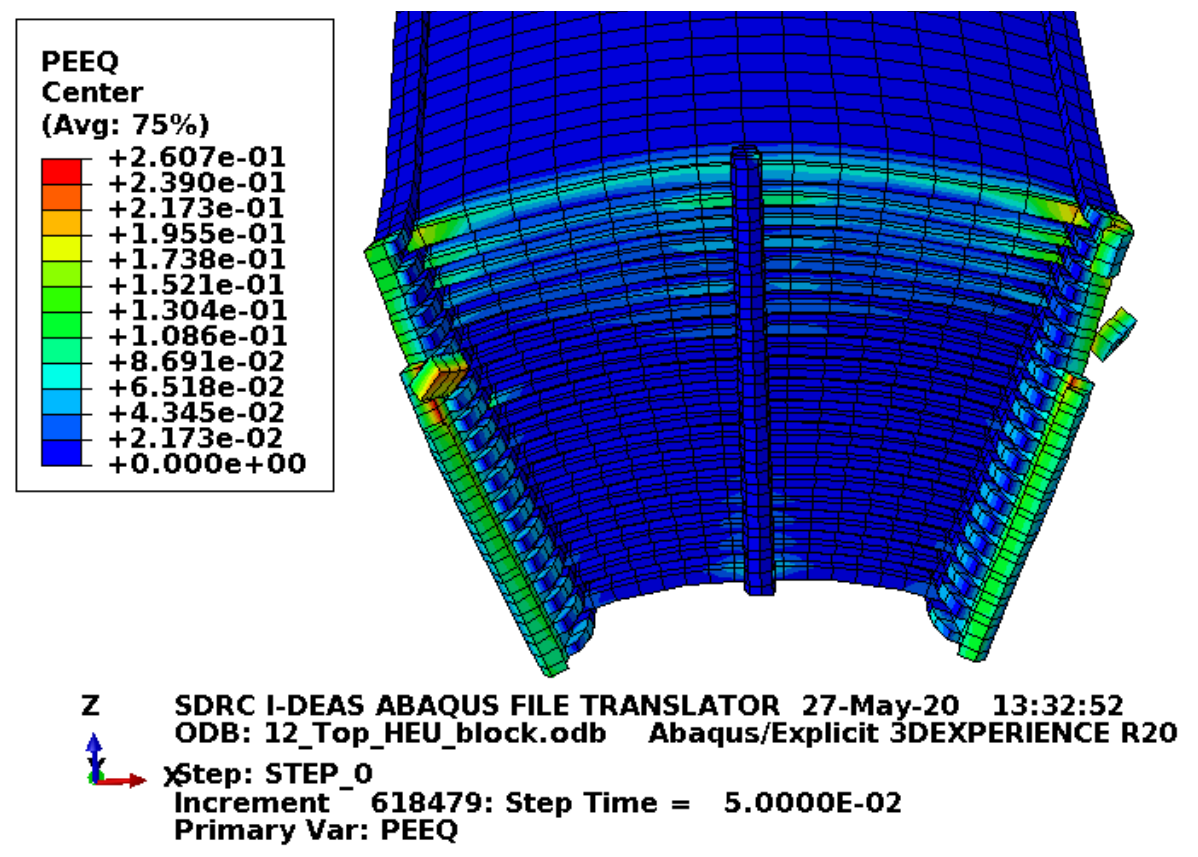

Figure D-154. Scope Part 1d (Table 3), Test 12 (Table 2) fuel element end damage.

For information, Figure D-154 shows a zoomed view of the fuel element with the end boxes and end box welds removed.

\section{D2.9.6 Results for Scope Part 1d (Table 3), Test 12 (Table 2) Fine Mesh}

The FEA model results for the Scope Part 1d (Table 3), Test 12 (Table 2) fine mesh model are shown below in Figure D-155 to Figure D-158. The fuel element weighs $22.1 \mathrm{lbf}$ and the drop scenario is modeled with minimum material properties except the enclosure and end boxes, which are modeled with relatively tough material properties. Though ATR FFSC SAR (2017) shows the Scope Part 1 (Table 3) drop scenarios to be acceptable, the results shown (for information) in this section include the blocks as added fuel plate protection. 


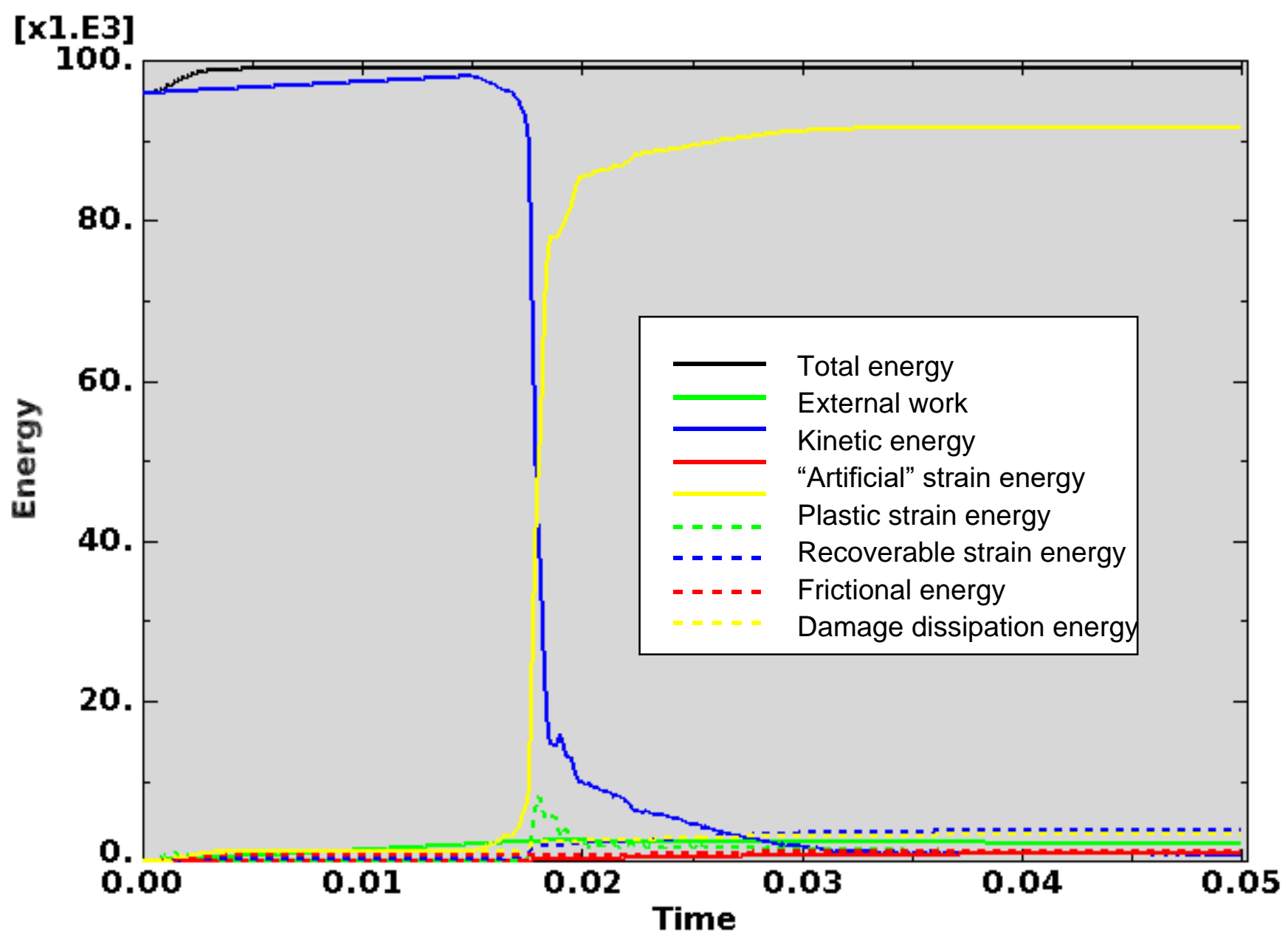

Figure D-155. Scope Part 1d (Table 3), Test 12 (Table 2) fine mesh energy curves.

Figure D-155 shows the energy curves for Scope Part 1d (Table 3), Test 12 (Table 2) fine mesh drop scenario. These curves exhibit a stable shape. Artificial strain energy represents the energy required to keep reduced integration elements from taking on a zero-energy hourglass shape. As shown in Figure D-155, the artificial energy at the end of the model run is $1.0 \%$ of the total energy. Therefore, the potential error associated with artificial energy is not considered to be significant. 
ENGINEERING CALCULATIONS AND ANALYSIS

Drop Analysis of the Advanced Test Reactor Fresh Fuel Shipping Container with Heavier Low-Enriched Uranium Fuel Contents
ECAR-5224, Rev. 0

Page D140 of D293

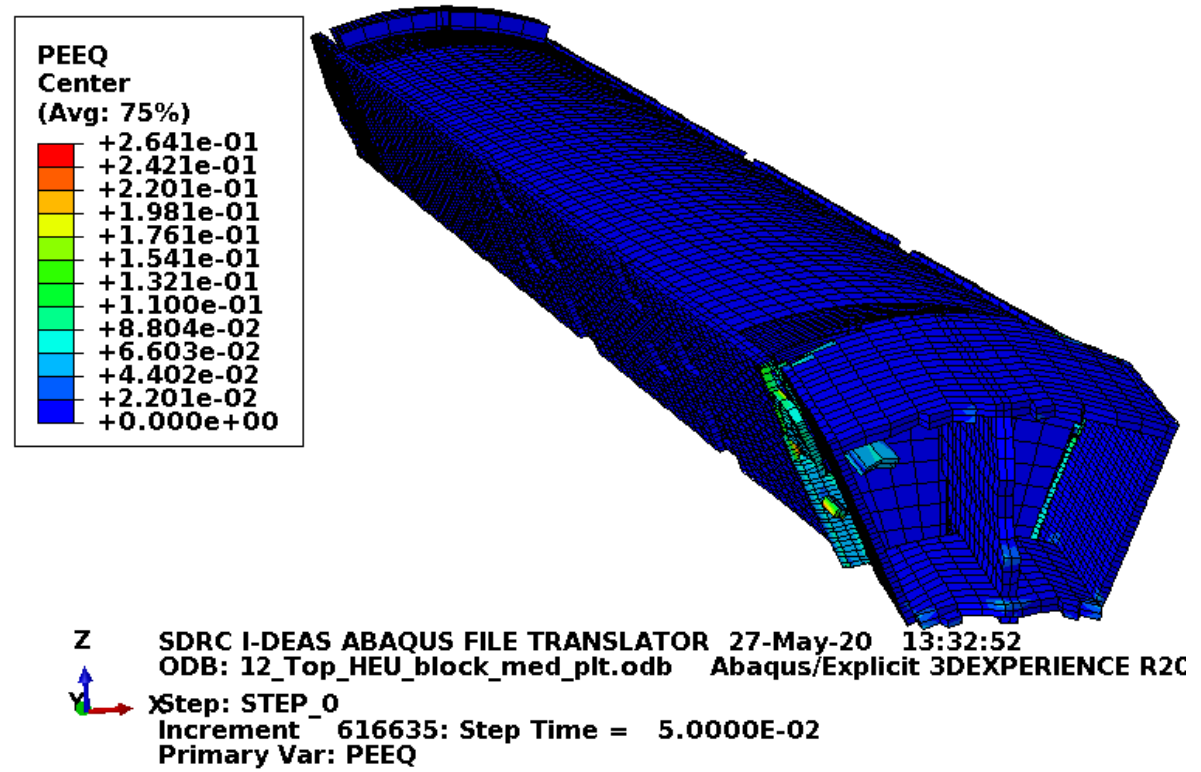

Figure D-156. Scope Part 1d (Table 3), Test 12 (Table 2) fine mesh fuel element plastic equivalent strain.

Figure D-156 shows the equivalent plastic strain in the fuel element. Failure in the end box elements occurs at an equivalent plastic strain of $0.08 \mathrm{in}$./in. (for the relatively tough material properties). Failure in the end box weld elements occurs at an equivalent plastic strain of $0.115 \mathrm{in}$./in. (for the relatively tough material properties). Failure in the side plate and comb elements occurs at an equivalent plastic strain of $0.152 \mathrm{in}$./in. Failure in the side plate weld elements occurs at an equivalent plastic strain of $0.205 \mathrm{in}$./in. Figure D-156 shows significant failure in the end box and end box weld nearest the impacted surface.

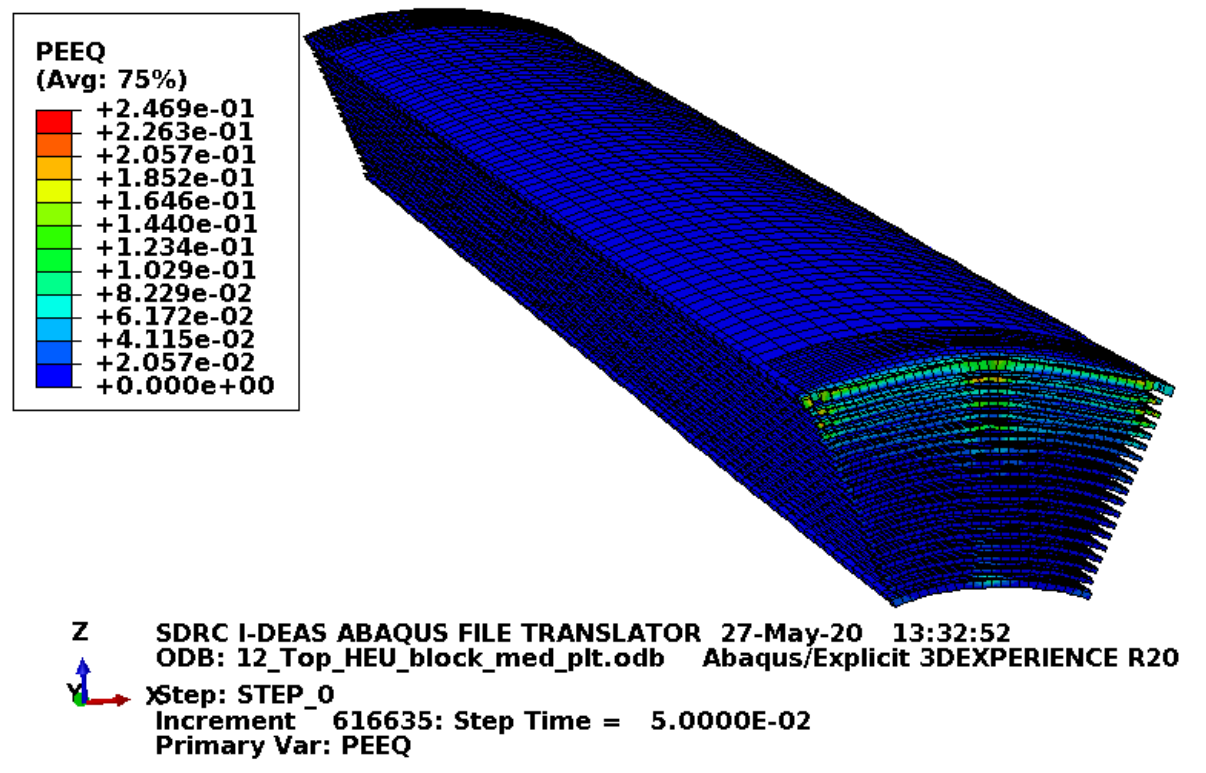

Figure D-157. Scope Part 1d (Table 3), Test 12 (Table 2) fine mesh fuel plate equivalent strain. 
Figure D-157 shows the equivalent plastic strain in the fuel plates. Failure in these elements occurs at an equivalent plastic strain of $0.205 \mathrm{in}$./in. If element failure were to occur, the element would be removed from the model (thereby excluding its equivalent plastic strain from the maximum equivalent plastic strain for the plot). However, the missing element would be visible in the plot. Figure D-157 shows a few failed elements near the end of the fuel plates. Additionally, a couple elements at the end of one fuel plate show strains above failure. The strains shown above the failure strain likely result from extrapolation (as integration point strains are the important strains for failure). Even if the elements with high strain were removed as being failed, the failure would be acceptable as the high strained elements do not represent fuel meat.
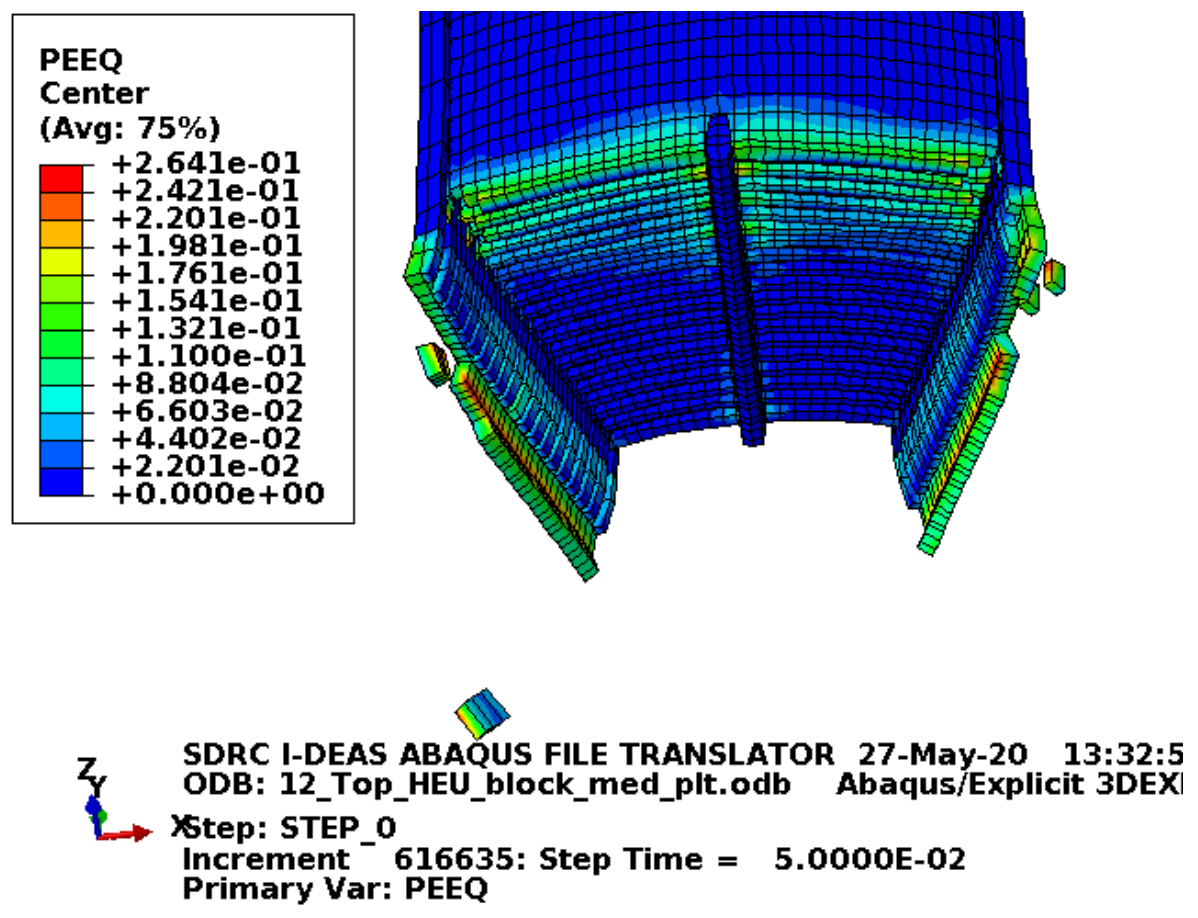

Figure D-158. Scope Part 1d (Table 3), Test 12 (Table 2) fine mesh fuel element end damage.

For information, Figure D-158 shows a zoomed view of the fuel element with the end boxes and end box welds removed.

\section{D2.10 Results for Scope Part 1 (Table 3), Test 13 (Table 2)}

The drop scenario considered in this section is a $30 \mathrm{ft}$ drop modeled as a flat side drop on an edge.

\section{D2.10.1 Results for Scope Part 1a (Table 3), Test 13 (Table 2)}

The FEA model results for the Scope Part 1a (Table 3), Test 13 (Table 2) model are shown below in Figure D-159 to Figure D-161. The fuel element weighs $22.1 \mathrm{lbf}$ and the whole model is modeled with minimum material properties. 


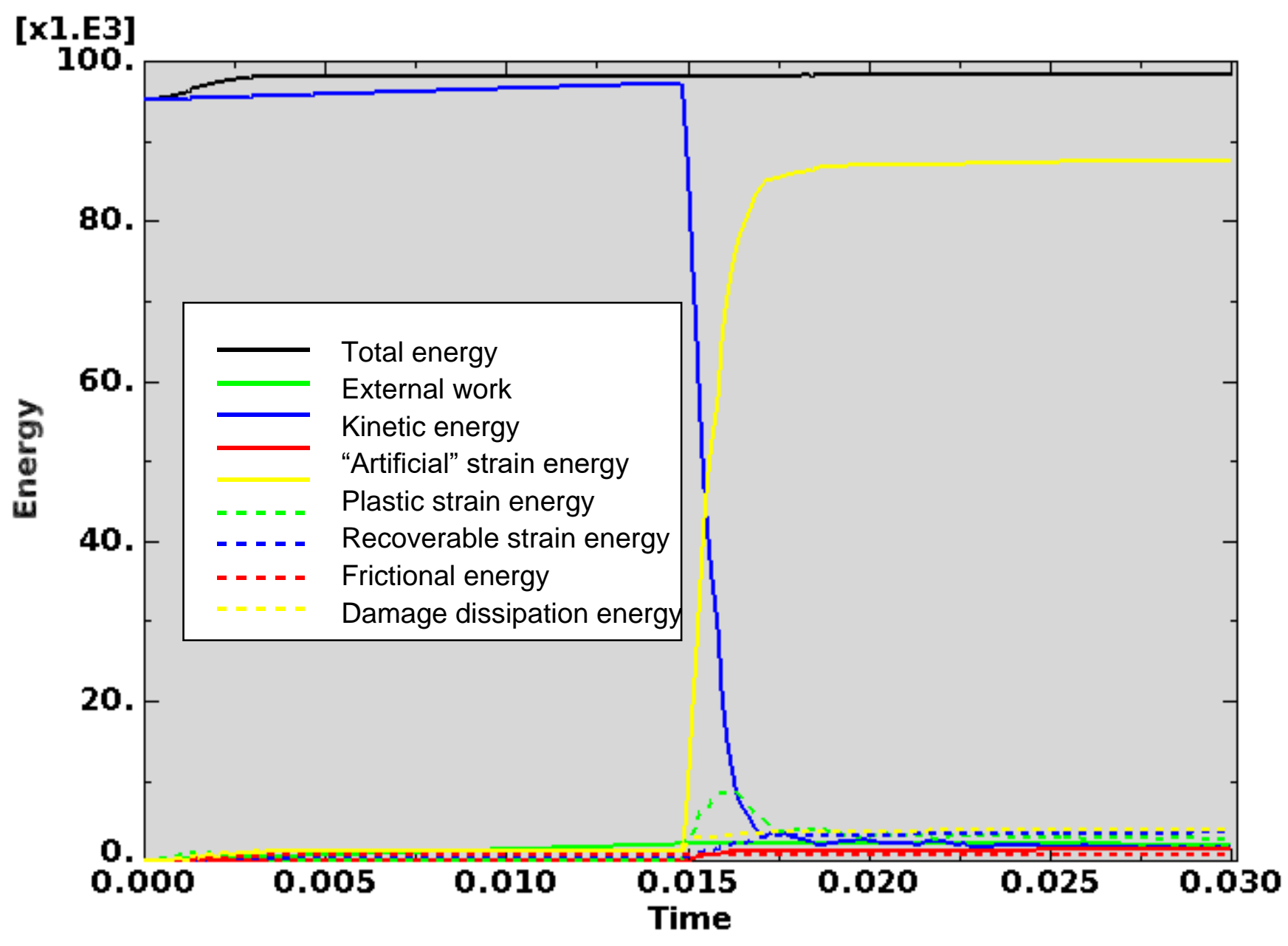

Figure D-159. Scope Part 1a (Table 3), Test 13 (Table 2) energy curves.

Figure D-159 shows the energy curves for Scope Part 1a (Table 3), Test 13 (Table 2) drop scenario. These curves exhibit a stable shape. Artificial strain energy represents the energy required to keep reduced integration elements from taking on a zero-energy hourglass shape. As shown in Figure D-159, the artificial energy at the end of the model run is $1.5 \%$ of the total energy. Therefore, the potential error associated with artificial energy is not considered to be significant. 
ENGINEERING CALCULATIONS AND ANALYSIS

Drop Analysis of the Advanced Test Reactor Fresh Fuel Shipping Container with Heavier Low-Enriched Uranium Fuel Contents
ECAR-5224, Rev. 0 Page D143 of D293

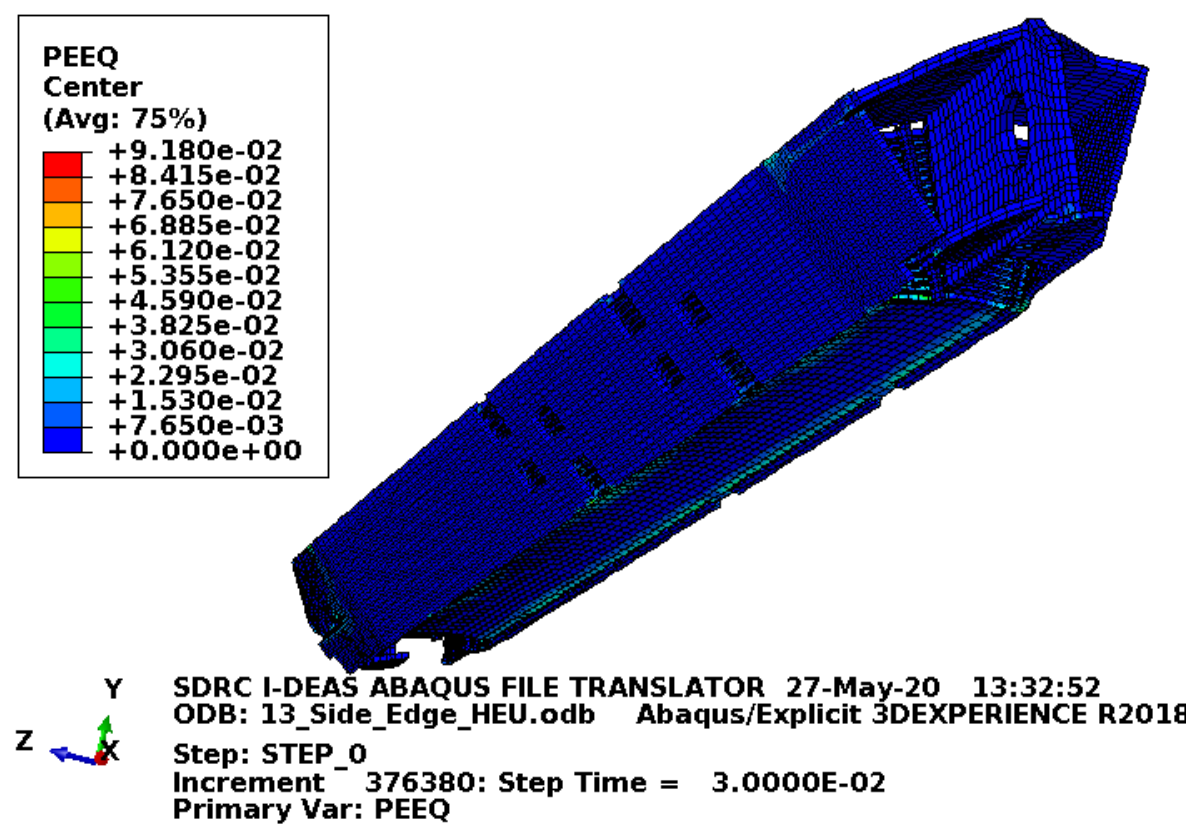

Figure D-160. Scope Part 1a (Table 3), Test 13 (Table 2) fuel element plastic equivalent strain.

Figure D-160 shows the equivalent plastic strain in the fuel element. Failure in the end box elements occurs at an equivalent plastic strain of $0.027 \mathrm{in}$./in. Failure in the end box weld elements occurs at an equivalent plastic strain of $0.032 \mathrm{in}$./in. Failure in the side plate and comb elements occurs at an equivalent plastic strain of $0.152 \mathrm{in} . / \mathrm{in}$. Failure in the side plate weld elements occurs at an equivalent plastic strain of $0.205 \mathrm{in}$./in. If element failure were to occur, the element would be removed from the model (thereby excluding its equivalent plastic strain from the maximum equivalent plastic strain for the plot). However, the missing element would be visible in the plot. Figure D-160 shows some end box failure.

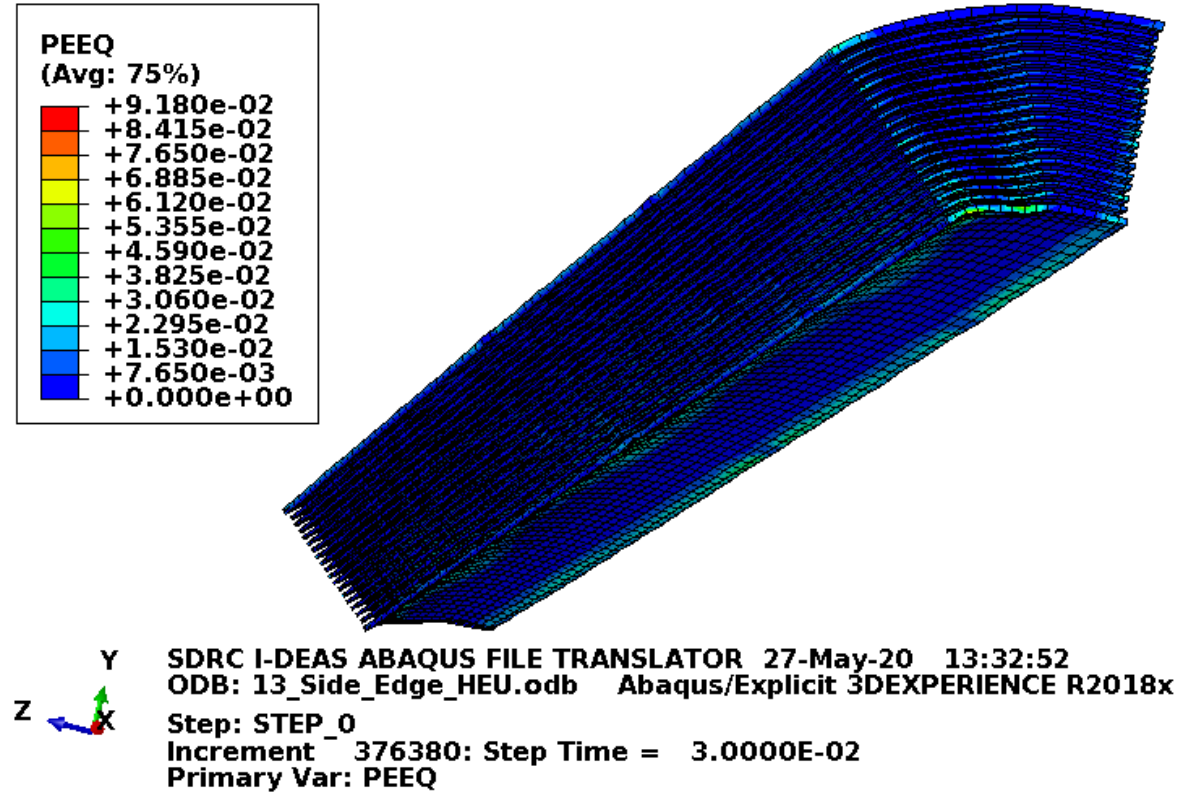

Figure D-161. Scope Part 1a (Table 3), Test 13 (Table 2) fuel plate equivalent strain. 
Figure D-161 shows the equivalent plastic strain in the fuel plates. Failure in these elements occurs at an equivalent plastic strain of $0.205 \mathrm{in}$./in. If element failure were to occur, the element would be removed from the model (thereby excluding its equivalent plastic strain from the maximum equivalent plastic strain for the plot). However, the missing element would be visible in the plot. Figure D-161 shows no failure in the fuel plates with margin.

\section{D2.10.2 Results for Scope Part 1b (Table 3), Test 13 (Table 2)}

The FEA model results for the Scope Part 1b (Table 3), Test 13 (Table 2) model are shown below in Figure D-162 to Figure D-164. The fuel element weighs $22.1 \mathrm{lbf}$ and the drop scenario is modeled with minimum material properties except the enclosure and end boxes, which are modeled with relatively tough material properties.

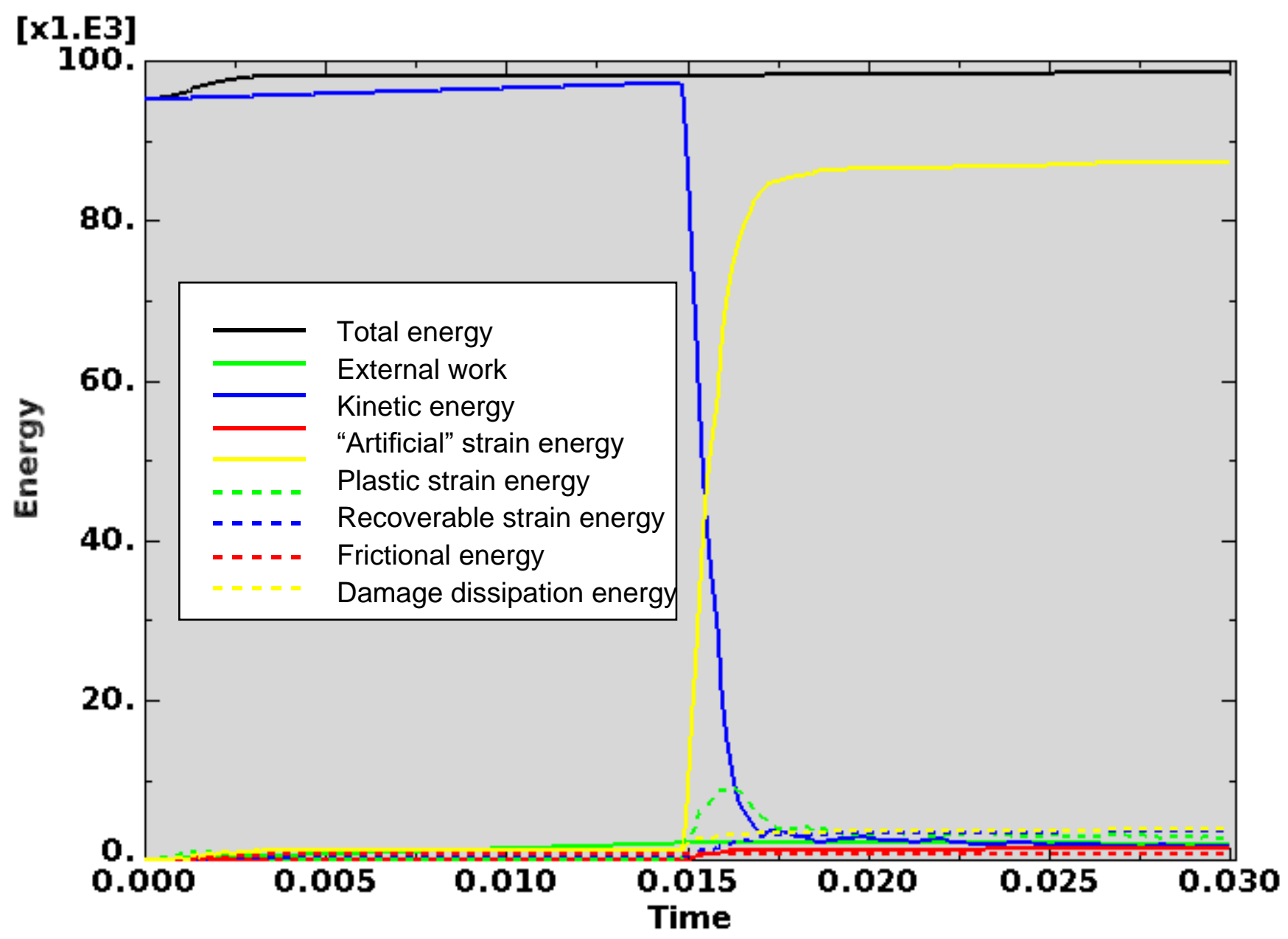

Figure D-162. Scope Part 1b (Table 3), Test 13 (Table 2) energy curves.

Figure D-162 shows the energy curves for Scope Part 1b (Table 3), Test 13 (Table 2) drop scenario. These curves exhibit a stable shape. Artificial strain energy represents the energy required to keep reduced integration elements from taking on a zero-energy hourglass shape. As shown in Figure D-162, the artificial energy at the end of the model run is $1.5 \%$ of the total energy. Therefore, the potential error associated with artificial energy is not considered to be significant. 
ENGINEERING CALCULATIONS AND ANALYSIS

Drop Analysis of the Advanced Test Reactor Fresh Fuel Shipping Container with Heavier Low-Enriched Uranium Fuel Contents
ECAR-5224, Rev. 0

Page D145 of D293

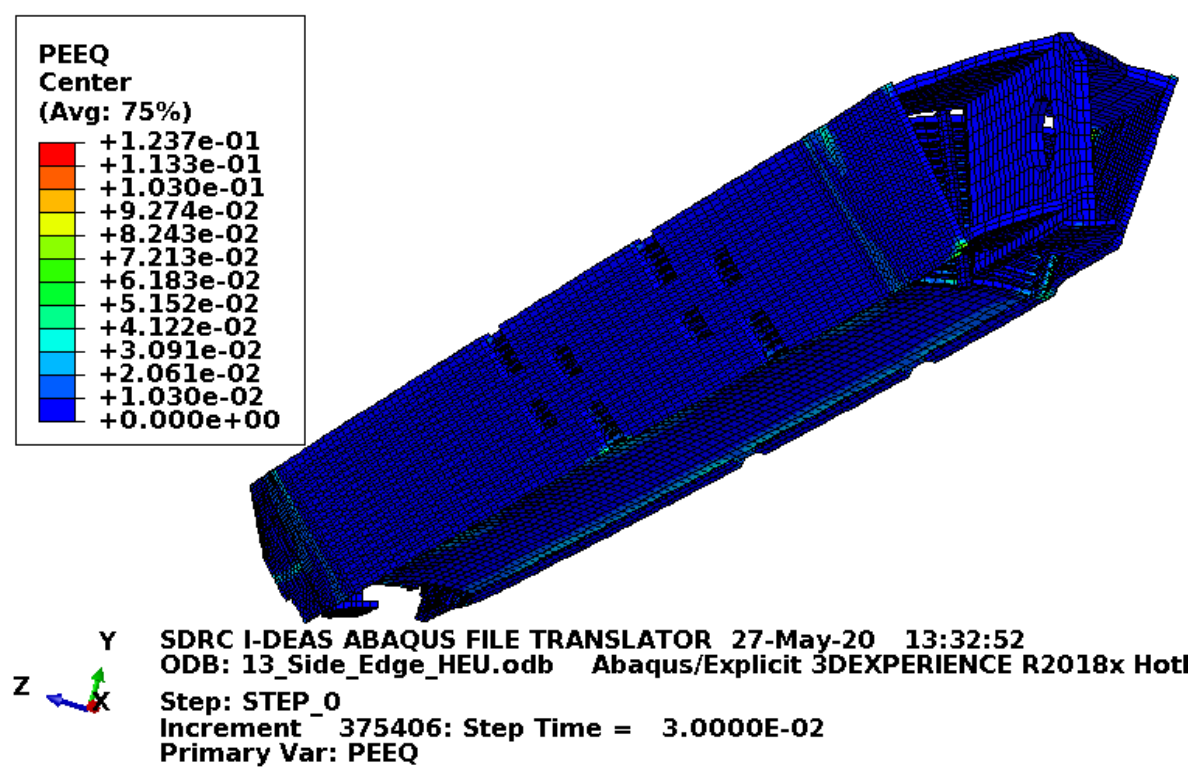

Figure D-163. Scope Part 1b (Table 3), Test 13 (Table 2) fuel element plastic equivalent strain.

Figure D-163 shows the equivalent plastic strain in the fuel element. Failure in the end box elements occurs at an equivalent plastic strain of $0.08 \mathrm{in./in.} \mathrm{(for} \mathrm{the} \mathrm{relatively} \mathrm{tough} \mathrm{material} \mathrm{properties).} \mathrm{Failure} \mathrm{in} \mathrm{the} \mathrm{end}$ box weld elements occurs at an equivalent plastic strain of $0.115 \mathrm{in}$./in. (for the relatively tough material properties). Failure in the side plate and comb elements occurs at an equivalent plastic strain of $0.152 \mathrm{in}$./in. Failure in the side plate weld elements occurs at an equivalent plastic strain of $0.205 \mathrm{in}$./in. If element failure were to occur, the element would be removed from the model (thereby excluding its equivalent plastic strain from the maximum equivalent plastic strain for the plot). However, the missing element would be visible in the plot. Figure D-163 shows minimal end box failure.

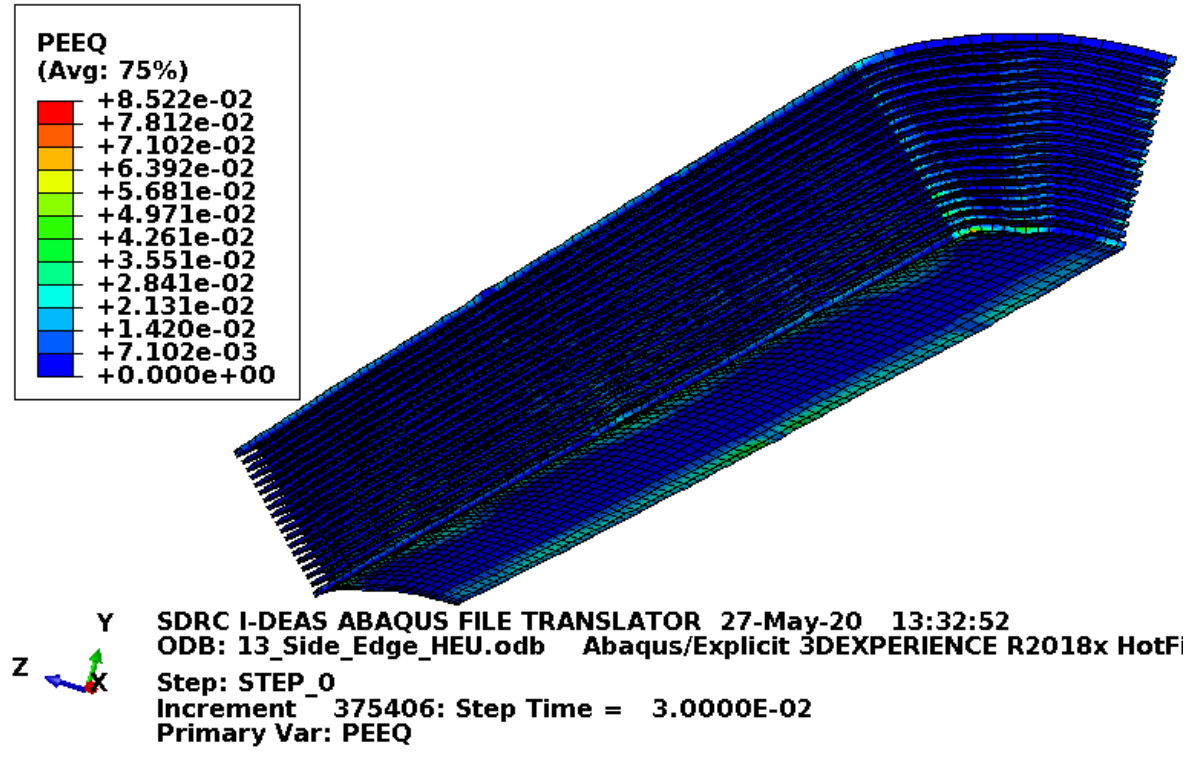

Figure D-164. Scope Part 1b (Table 3), Test 13 (Table 2) fuel plate equivalent strain. 
ENGINEERING CALCULATIONS AND ANALYSIS

Drop Analysis of the Advanced Test Reactor Fresh Fuel Shipping Container with Heavier Low-Enriched Uranium Fuel Contents
ECAR-5224, Rev. 0

Page D146 of D293

Figure D-164 shows the equivalent plastic strain in the fuel plates. Failure in these elements occurs at an equivalent plastic strain of $0.205 \mathrm{in}$./in. If element failure were to occur, the element would be removed from the model (thereby excluding its equivalent plastic strain from the maximum equivalent plastic strain for the plot). However, the missing element would be visible in the plot. Figure D-164 shows no failure in the fuel plates with margin.

\section{D2.10.3 Results for Scope Part 1c (Table 3), Test 13 (Table 2)}

The FEA model results for the Scope Part 1c (Table 3), Test 13 (Table 2) model are shown below in Figure D-165 to Figure D-167. The fuel element weighs $22.1 \mathrm{lbf}$ and the whole model is modeled with minimum material properties. Though ATR FFSC SAR (2017) shows the Scope Part 1 (Table 3) drop scenarios to be acceptable, the results shown (for information) in this section include the blocks as added fuel plate protection.

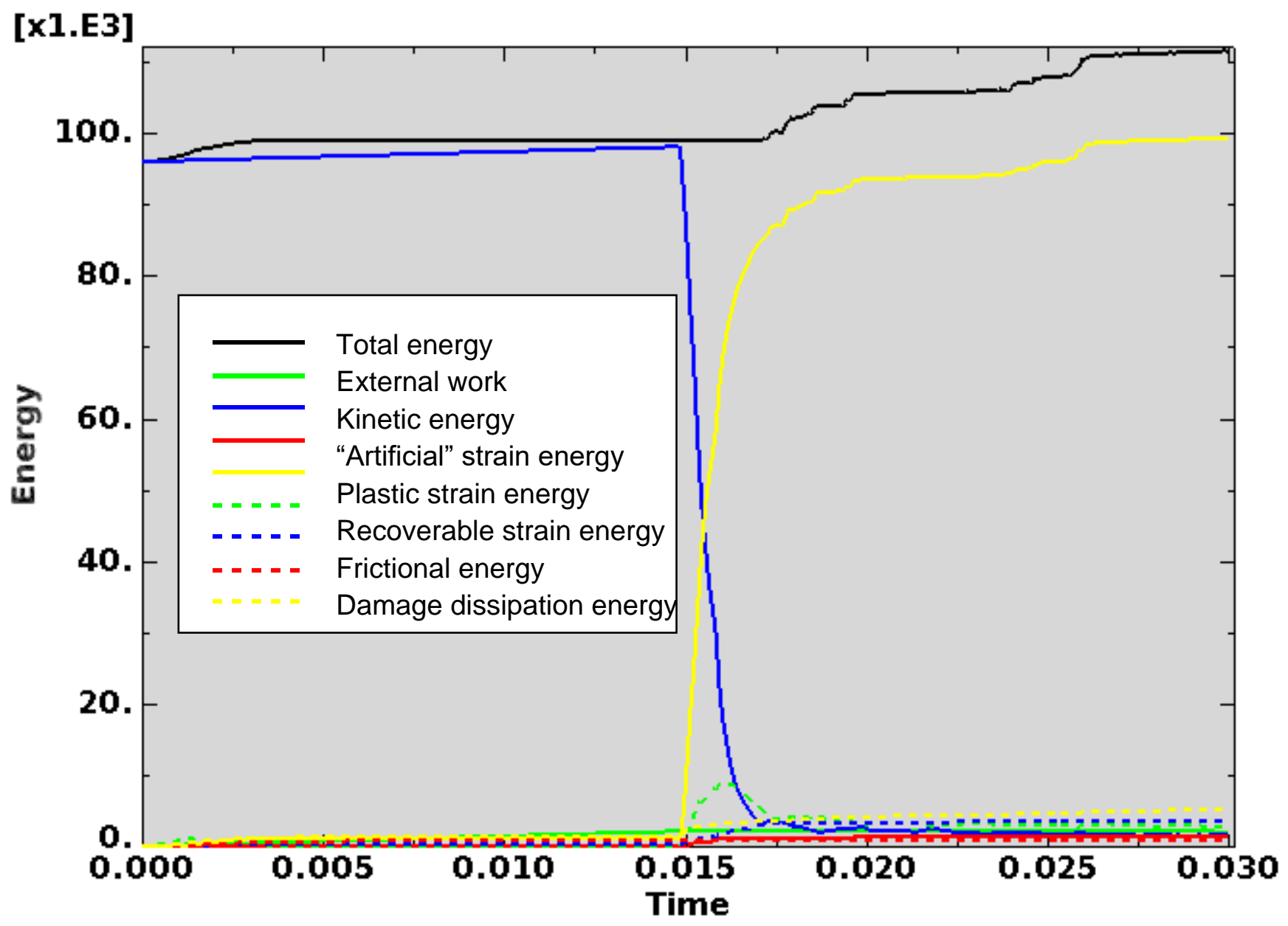

Figure D-165. Scope Part 1c (Table 3), Test 13 (Table 2) energy curves. 
Figure D-165 shows the energy curves for Scope Part 1c (Table 3), Test 13 (Table 2) drop scenario. These curves exhibit somewhat stable behavior. The total energy and plastic strain energy show some undesirable behavior midway through the model run. This model run provides results very similar to that in Section D2.10.1. This drop scenario differs from that in Section D2.10.1 only with the inclusion of the block design. The increase in damage caused by the blocks is not substantial. Considering the similarity, the model results are considered reasonable and they are given at the end of the model run.

Artificial strain energy represents the energy required to keep reduced integration elements from taking on a zero-energy hourglass shape. As shown in Figure D-165, the artificial energy at the end of the model run is $1.3 \%$ of the total energy. Therefore, the potential error associated with artificial energy is not considered to be significant.

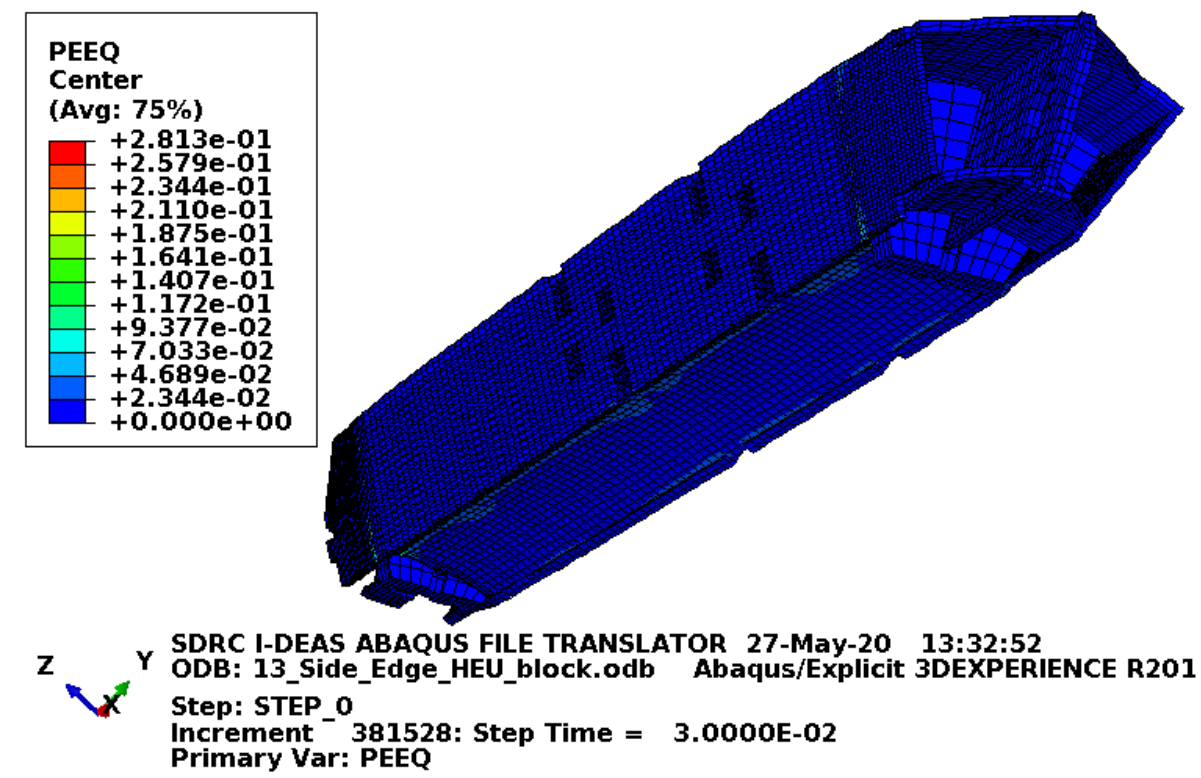

Figure D-166. Scope Part 1c (Table 3), Test 13 (Table 2) fuel element plastic equivalent strain.

Figure D-166 shows the equivalent plastic strain in the fuel element. Failure in the end box elements occurs at an equivalent plastic strain of $0.027 \mathrm{in}$./in. Failure in the end box weld elements occurs at an equivalent plastic strain of $0.032 \mathrm{in}$./in. Failure in the side plate and comb elements occurs at an equivalent plastic strain of $0.152 \mathrm{in./in.} \mathrm{Failure} \mathrm{in} \mathrm{the} \mathrm{side} \mathrm{plate} \mathrm{weld} \mathrm{elements} \mathrm{occurs} \mathrm{at} \mathrm{an} \mathrm{equivalent} \mathrm{plastic} \mathrm{strain} \mathrm{of}$ $0.205 \mathrm{in}$./in. If element failure were to occur, the element would be removed from the model (thereby excluding its equivalent plastic strain from the maximum equivalent plastic strain for the plot). However, the missing element would be visible in the plot. Figure D-166 shows end box failure. 
ENGINEERING CALCULATIONS AND ANALYSIS

Drop Analysis of the Advanced Test Reactor Fresh Fuel Shipping Container with Heavier Low-Enriched Uranium Fuel Contents
ECAR-5224, Rev. 0 Page D148 of D293

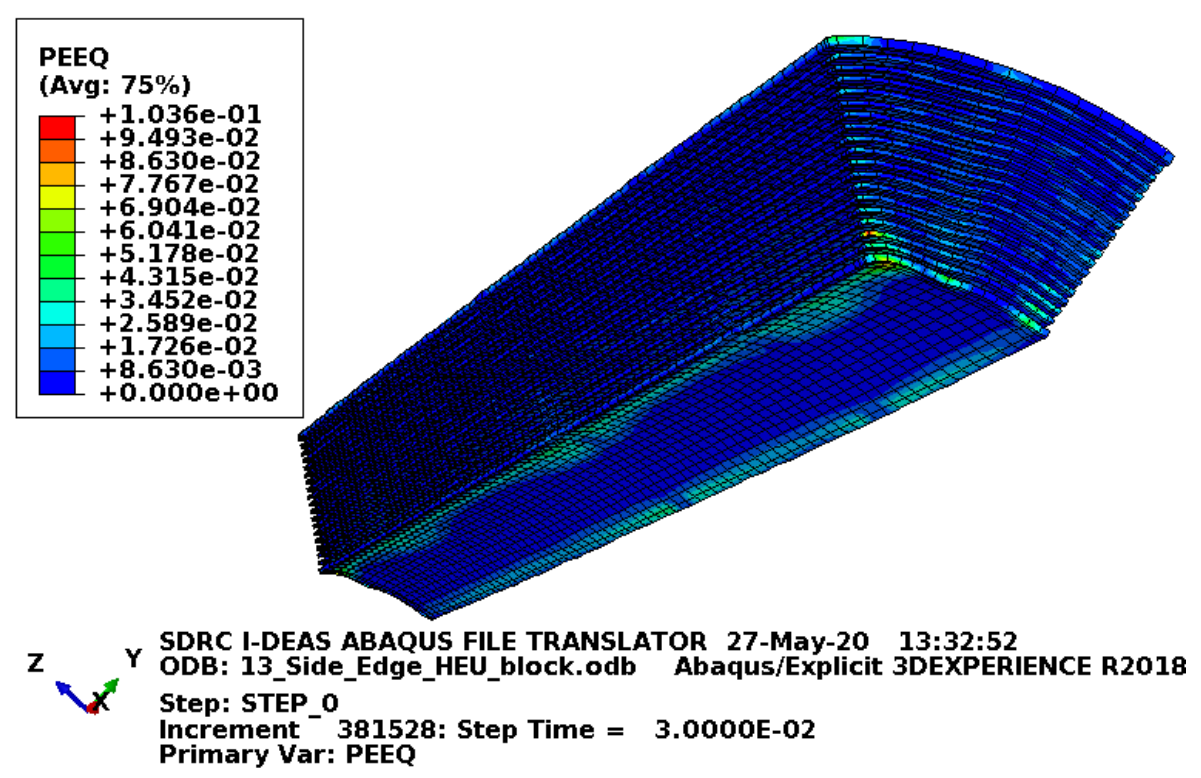

Figure D-167. Scope Part 1c (Table 3), Test 13 (Table 2) fuel plate equivalent strain.

Figure D-167 shows the equivalent plastic strain in the fuel plates. Failure in these elements occurs at an equivalent plastic strain of $0.205 \mathrm{in}$./in. If element failure were to occur, the element would be removed from the model (thereby excluding its equivalent plastic strain from the maximum equivalent plastic strain for the plot). However, the missing element would be visible in the plot. Figure D-167 shows no failure in the fuel plates with margin.

\section{D2.10.4 Results for Scope Part 1d (Table 3), Test 13 (Table 2)}

The FEA model results for the Scope Part 1d (Table 3), Test 13 (Table 2) model are shown below in Figure D-168 to Figure D-170. The fuel element weighs $22.1 \mathrm{lbf}$ and the drop scenario is modeled with minimum material properties except the enclosure and end boxes, which are modeled with relatively tough material properties. Though ATR FFSC SAR (2017) shows the Scope Part 1 (Table 3) drop scenarios to be acceptable, the results shown (for information) in this section include the blocks as added fuel plate protection. 


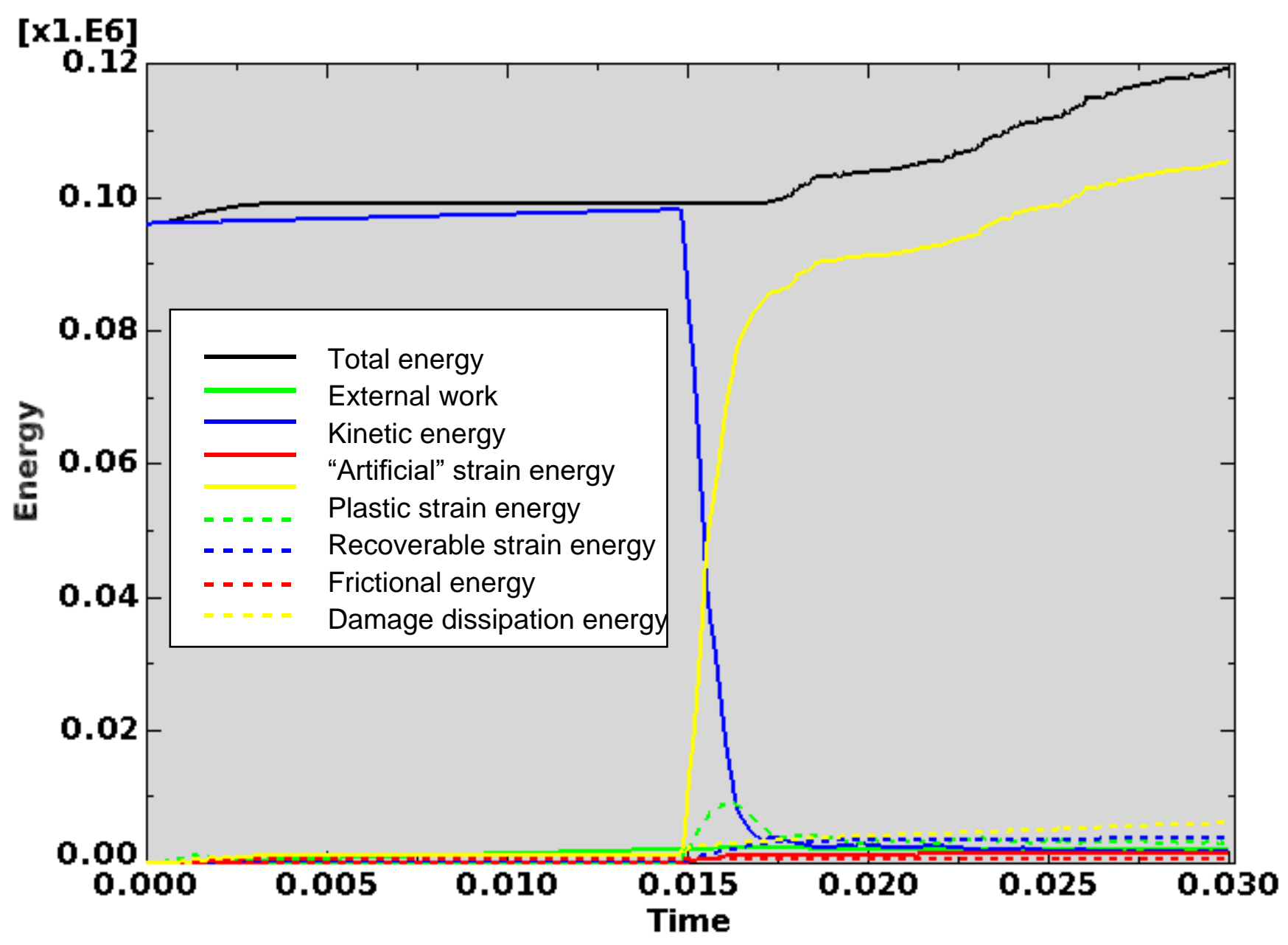

Figure D-168. Scope Part 1d (Table 3), Test 13 (Table 2) energy curves.

Figure D-168 shows the energy curves for Scope Part 1d (Table 3), Test 13 (Table 2) drop scenario. These curves exhibit somewhat stable behavior. The total energy and plastic strain energy show some undesirable behavior midway through the model run. This model run provides results very similar to that in Section D2.10.2. This drop scenario differs from that in Section D2.10.1 only with the inclusion of the block design. The increase in damage caused by the blocks is not substantial. Considering the similarity, the model results are considered reasonable and they are given at the end of the model run.

Artificial strain energy represents the energy required to keep reduced integration elements from taking on a zero-energy hourglass shape. As shown in Figure D-168, the artificial energy at the end of the model run is $1.2 \%$ of the total energy. Therefore, the potential error associated with artificial energy is not considered to be significant. 
ENGINEERING CALCULATIONS AND ANALYSIS

Drop Analysis of the Advanced Test Reactor Fresh Fuel Shipping Container with Heavier Low-Enriched Uranium Fuel Contents
ECAR-5224, Rev. 0 Page D150 of D293

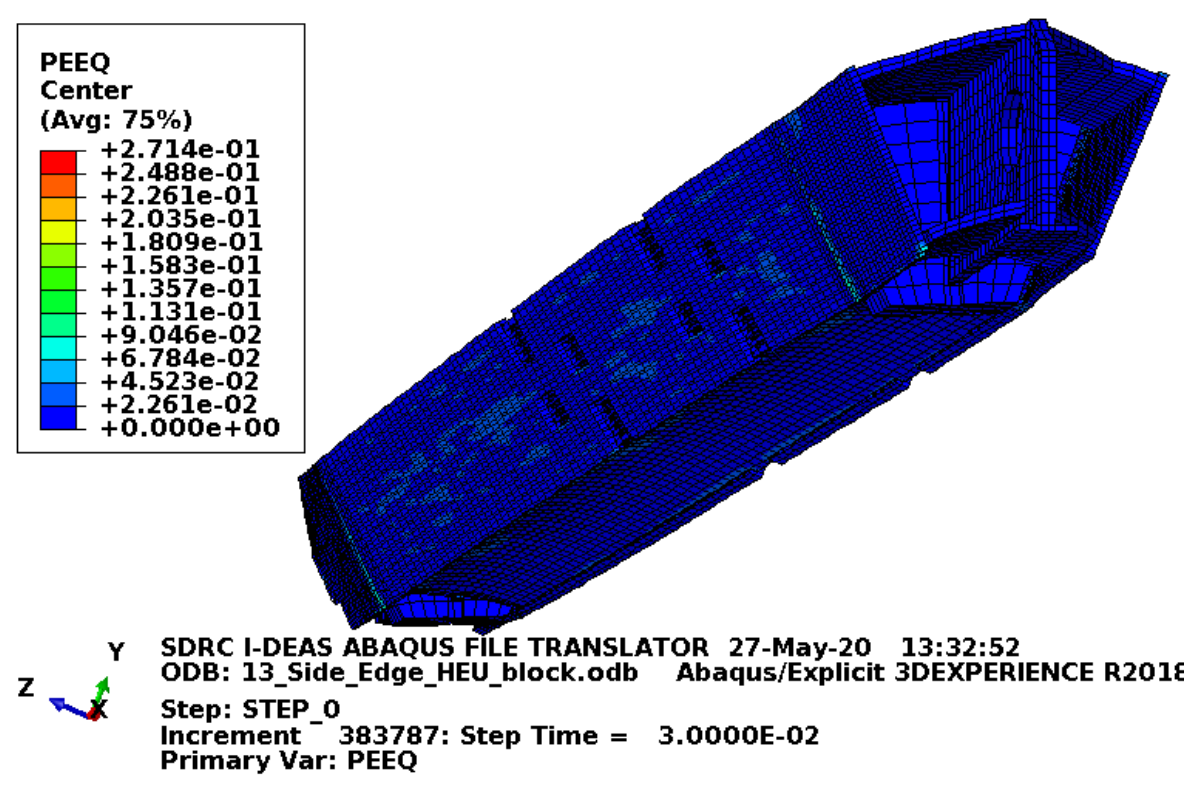

Figure D-169. Scope Part 1d (Table 3), Test 13 (Table 2) fuel element plastic equivalent strain.

Figure D-169 shows the equivalent plastic strain in the fuel element. Failure in the end box elements occurs at an equivalent plastic strain of $0.08 \mathrm{in./in.} \mathrm{(for} \mathrm{the} \mathrm{relatively} \mathrm{tough} \mathrm{material} \mathrm{properties).} \mathrm{Failure} \mathrm{in} \mathrm{the} \mathrm{end}$ box weld elements occurs at an equivalent plastic strain of $0.115 \mathrm{in}$./in. (for the relatively tough material properties). Failure in the side plate and comb elements occurs at an equivalent plastic strain of 0.152 in./in. Failure in the side plate weld elements occurs at an equivalent plastic strain of $0.205 \mathrm{in}$./in. If element failure were to occur, the element would be removed from the model (thereby excluding its equivalent plastic strain from the maximum equivalent plastic strain for the plot). However, the missing element would be visible in the plot. Figure D-169 shows minimal end box failure.

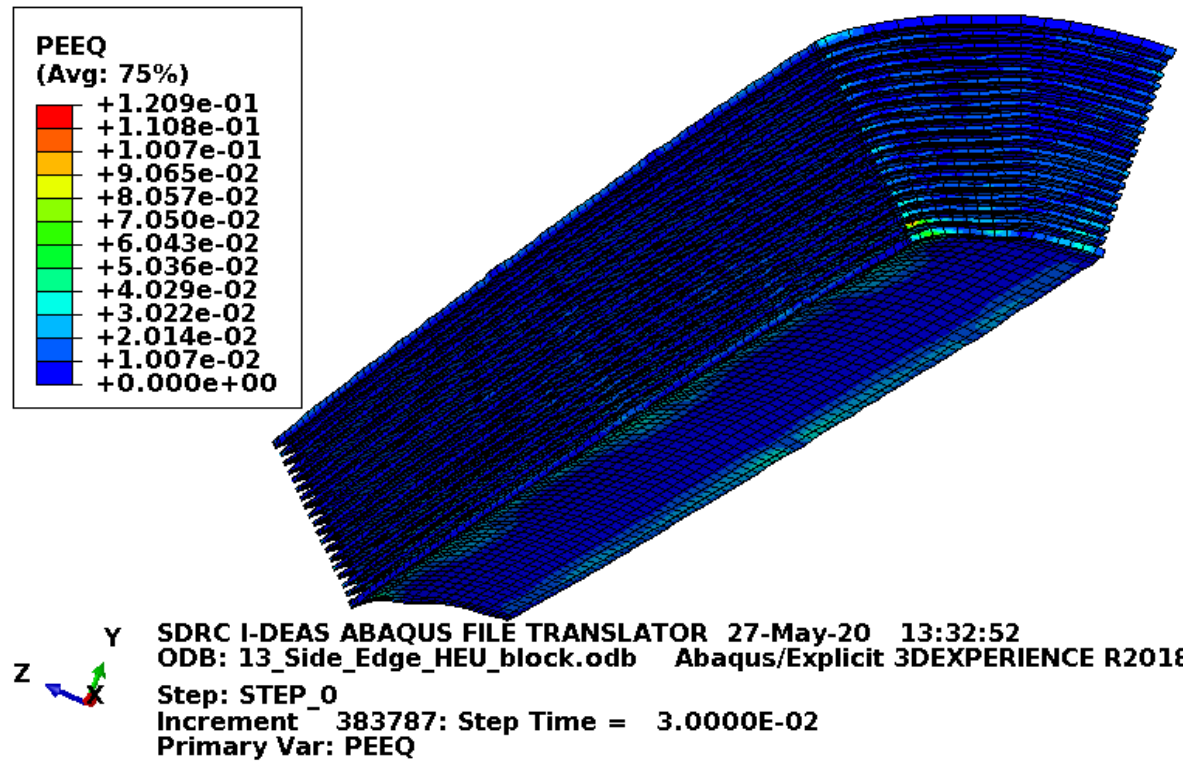

Figure D-170. Scope Part 1d (Table 3), Test 13 (Table 2) fuel plate equivalent strain. 
Figure D-170 shows the equivalent plastic strain in the fuel plates. Failure in these elements occurs at an equivalent plastic strain of $0.205 \mathrm{in}$./in. If element failure were to occur, the element would be removed from the model (thereby excluding its equivalent plastic strain from the maximum equivalent plastic strain for the plot). However, the missing element would be visible in the plot. Figure D-170 shows no failure in the fuel plates with margin.

\section{D2.11 Results for Scope Part 1 (Table 3), Test 14 (Table 2)}

The drop scenario considered in this section is a $30 \mathrm{ft}$ slap-down drop with pockets and index lugs on the sides. The impact orientation is 20 degrees off horizontal with the ATR FFSC bottom hitting first.

\section{D2.11.1 Results for Scope Part 1a (Table 3), Test 14 (Table 2)}

The FEA model results for the Scope Part 1a (Table 3), Test 14 (Table 2) model are shown below in Figure D-171 to Figure D-173. The fuel element weighs $22.1 \mathrm{lbf}$ and the whole model is modeled with minimum material properties. 


\section{[X1.E3]}

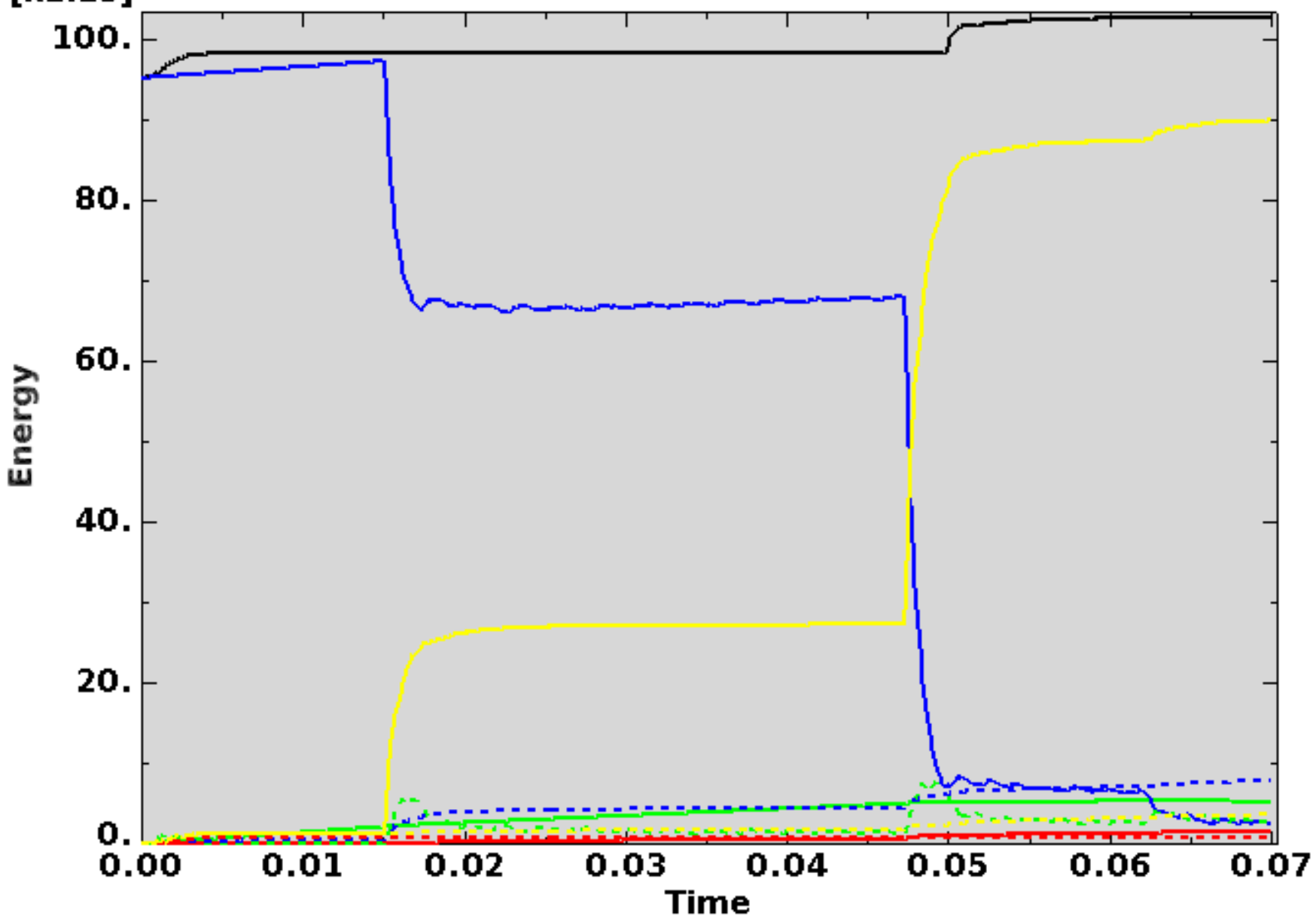

Figure D-171. Scope Part 1a (Table 3), Test 14 (Table 2) energy curves.

Figure D-171 shows the energy curves for Scope Part 1a (Table 3), Test 14 (Table 2) drop scenario. These curves exhibit a somewhat stable shape. There is a small amount of undesirable increase in total and plastic strain energy, but it is not considered significantly detrimental to the validity of the results. As discussed in Section D2.5 this appears to result from contact difficultly between failed portions of the fuel element. Artificial strain energy represents the energy required to keep reduced integration elements from taking on a zero-energy hourglass shape. As shown in Figure D-171, the artificial energy at the end of the model run is $1.5 \%$ of the total energy. Therefore, the potential error associated with artificial energy is not considered to be significant. 
ENGINEERING CALCULATIONS AND ANALYSIS

Drop Analysis of the Advanced Test Reactor Fresh Fuel Shipping Container with Heavier Low-Enriched Uranium Fuel Contents
ECAR-5224, Rev. 0

Page D153 of D293

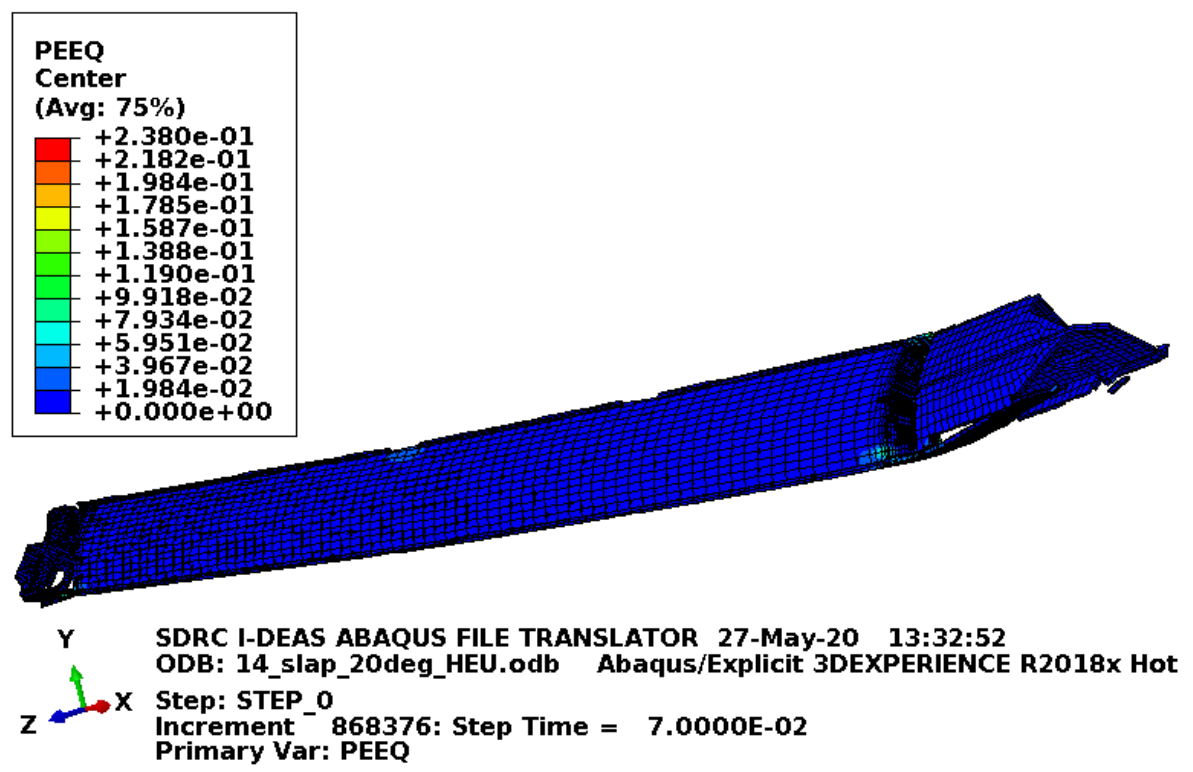

Figure D-172. Scope Part 1a (Table 3), Test 14 (Table 2) fuel element plastic equivalent strain.

Figure D-172 shows the equivalent plastic strain in the fuel element. Failure in the end box elements occurs at an equivalent plastic strain of $0.027 \mathrm{in}$./in. Failure in the end box weld elements occurs at an equivalent plastic strain of $0.032 \mathrm{in}$./in. Failure in the side plate and comb elements occurs at an equivalent plastic strain of $0.152 \mathrm{in}$./in. Failure in the side plate weld elements occurs at an equivalent plastic strain of $0.205 \mathrm{in}$./in. If element failure were to occur, the element would be removed from the model (thereby excluding its equivalent plastic strain from the maximum equivalent plastic strain for the plot). However, the missing element would be visible in the plot. Figure D-172 shows significant end box failure.

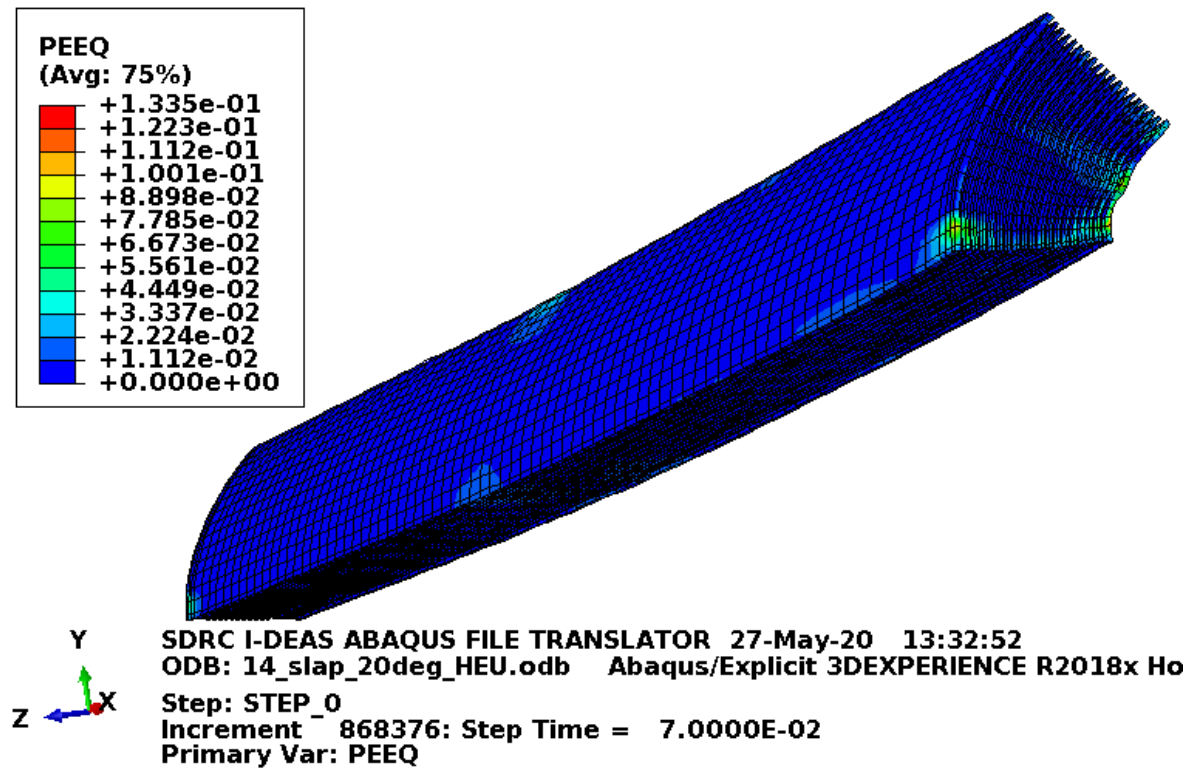

Figure D-173. Scope Part 1a (Table 3), Test 14 (Table 2) fuel plate equivalent strain. 
Figure D-173 shows the equivalent plastic strain in the fuel plates. Failure in these elements occurs at an equivalent plastic strain of $0.205 \mathrm{in}$./in. If element failure were to occur, the element would be removed from the model (thereby excluding its equivalent plastic strain from the maximum equivalent plastic strain for the plot). However, the missing element would be visible in the plot. Figure D-173 shows no failure in the fuel plates with margin.

\section{D2.11.2 Results for Scope Part 1b (Table 3), Test 14 (Table 2)}

The FEA model results for the Scope Part $1 b$ (Table 3), Test 14 (Table 2) model are shown below in Figure D-174 to Figure D-176. The fuel element weighs $22.1 \mathrm{lbf}$ and the drop scenario is modeled with minimum material properties except the enclosure and end boxes, which are modeled with relatively tough material properties. 


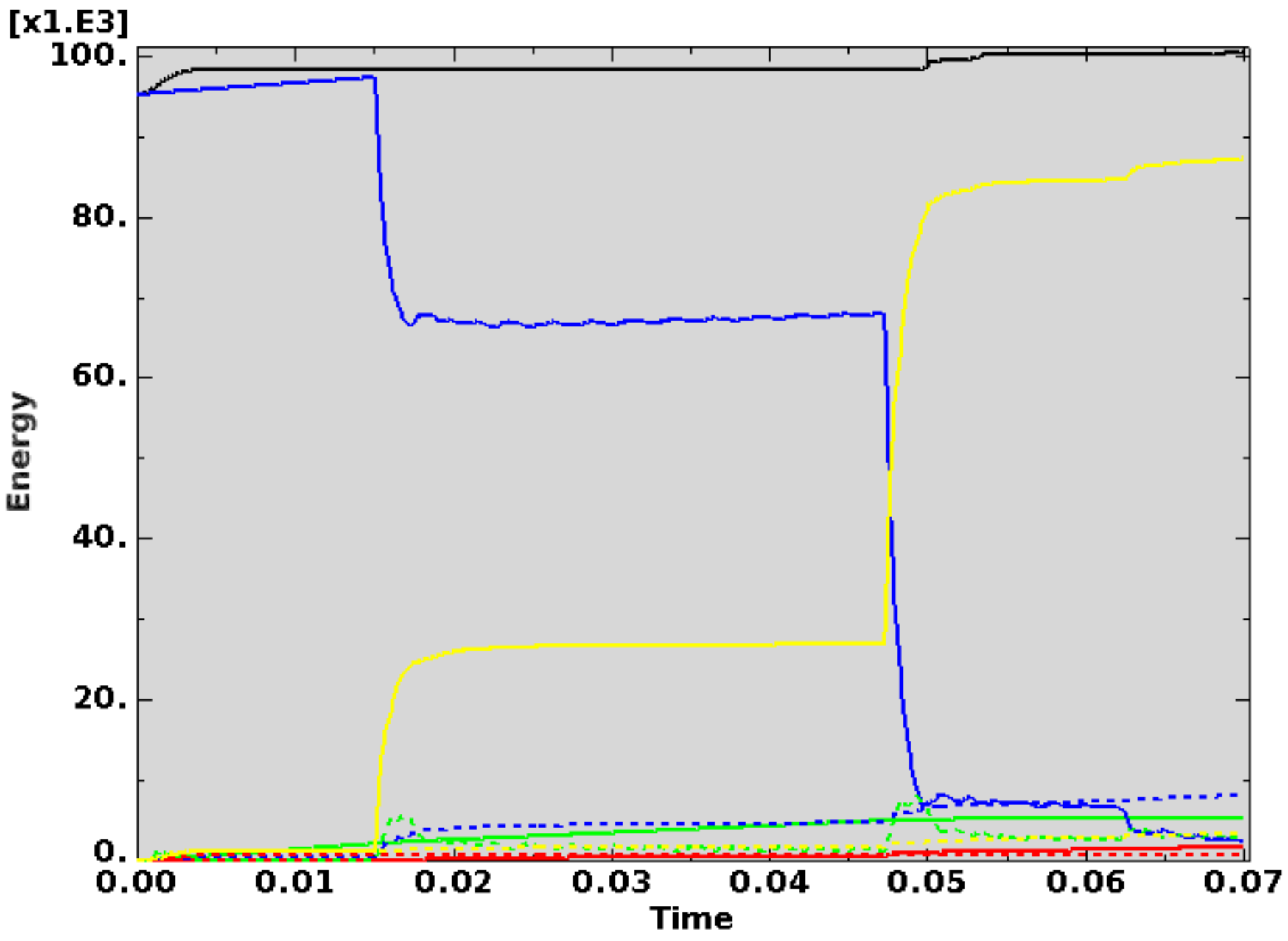

Figure D-174. Scope Part 1b (Table 3), Test 14 (Table 2) energy curves.

Figure D-174 shows the energy curves for Scope Part 1b (Table 3), Test 14 (Table 2) drop scenario. These curves exhibit a somewhat stable shape. There is a small amount of undesirable increase in total and plastic strain energy, but it is not considered significantly detrimental to the validity of the results. Artificial strain energy represents the energy required to keep reduced integration elements from taking on a zero-energy hourglass shape. As shown in Figure D-174, the artificial energy at the end of the model run is $1.7 \%$ of the total energy. Therefore, the potential error associated with artificial energy is not considered to be significant. 
ENGINEERING CALCULATIONS AND ANALYSIS

Drop Analysis of the Advanced Test Reactor Fresh Fuel Shipping Container with Heavier Low-Enriched Uranium Fuel Contents
ECAR-5224, Rev. 0

Page D156 of D293

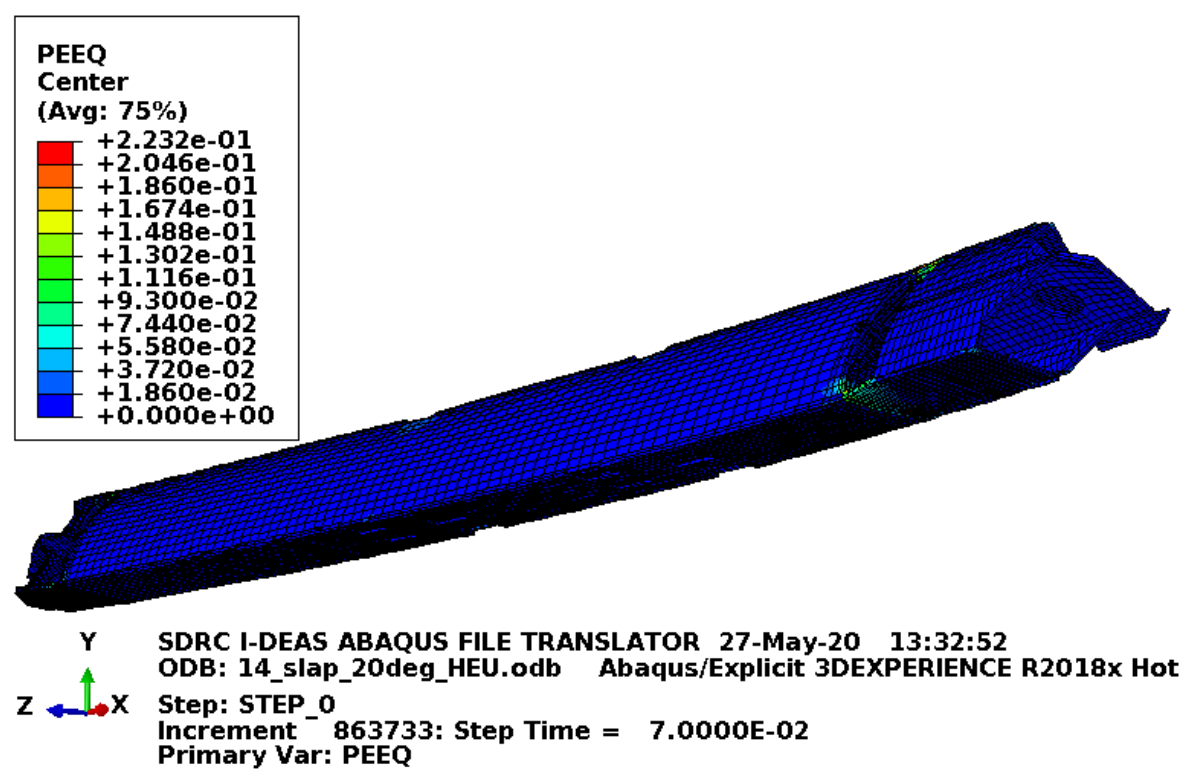

Figure D-175. Scope Part 1b (Table 3), Test 14 (Table 2) fuel element plastic equivalent strain.

Figure D-175 shows the equivalent plastic strain in the fuel element. Failure in the end box elements occurs at an equivalent plastic strain of $0.08 \mathrm{in./in.} \mathrm{(for} \mathrm{the} \mathrm{relatively} \mathrm{tough} \mathrm{material} \mathrm{properties).} \mathrm{Failure} \mathrm{in} \mathrm{the} \mathrm{end}$ box weld elements occurs at an equivalent plastic strain of $0.115 \mathrm{in}$./in. (for the relatively tough material properties). Failure in the side plate and comb elements occurs at an equivalent plastic strain of $0.152 \mathrm{in}$./in. Failure in the side plate weld elements occurs at an equivalent plastic strain of $0.205 \mathrm{in}$./in. If element failure were to occur, the element would be removed from the model (thereby excluding its equivalent plastic strain from the maximum equivalent plastic strain for the plot). However, the missing element would be visible in the plot. Figure D-175 shows minimal end box failure.

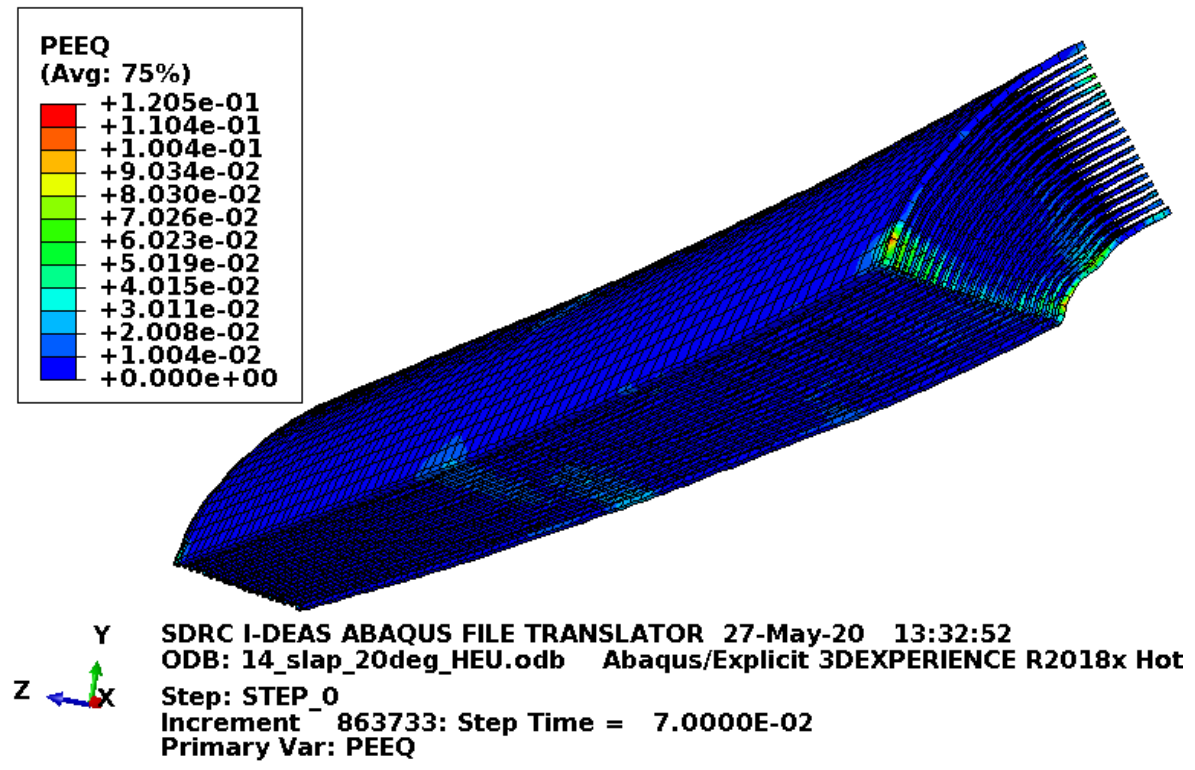

Figure D-176. Scope Part 1b (Table 3), Test 14 (Table 2) fuel plate equivalent strain. 
Figure D-176 shows the equivalent plastic strain in the fuel plates. Failure in these elements occurs at an equivalent plastic strain of $0.205 \mathrm{in}$./in. If element failure were to occur, the element would be removed from the model (thereby excluding its equivalent plastic strain from the maximum equivalent plastic strain for the plot). However, the missing element would be visible in the plot. Figure D-176 shows no failure in the fuel plates with margin.

\section{D2.11.3 Results for Scope Part 1c (Table 3), Test 14 (Table 2)}

The FEA model results for the Scope Part 1c (Table 3), Test 14 (Table 2) model are shown below in Figure D-177 to Figure D-179. The fuel element weighs $22.1 \mathrm{lbf}$ and the whole model is modeled with minimum material properties. 
[X1.E3]

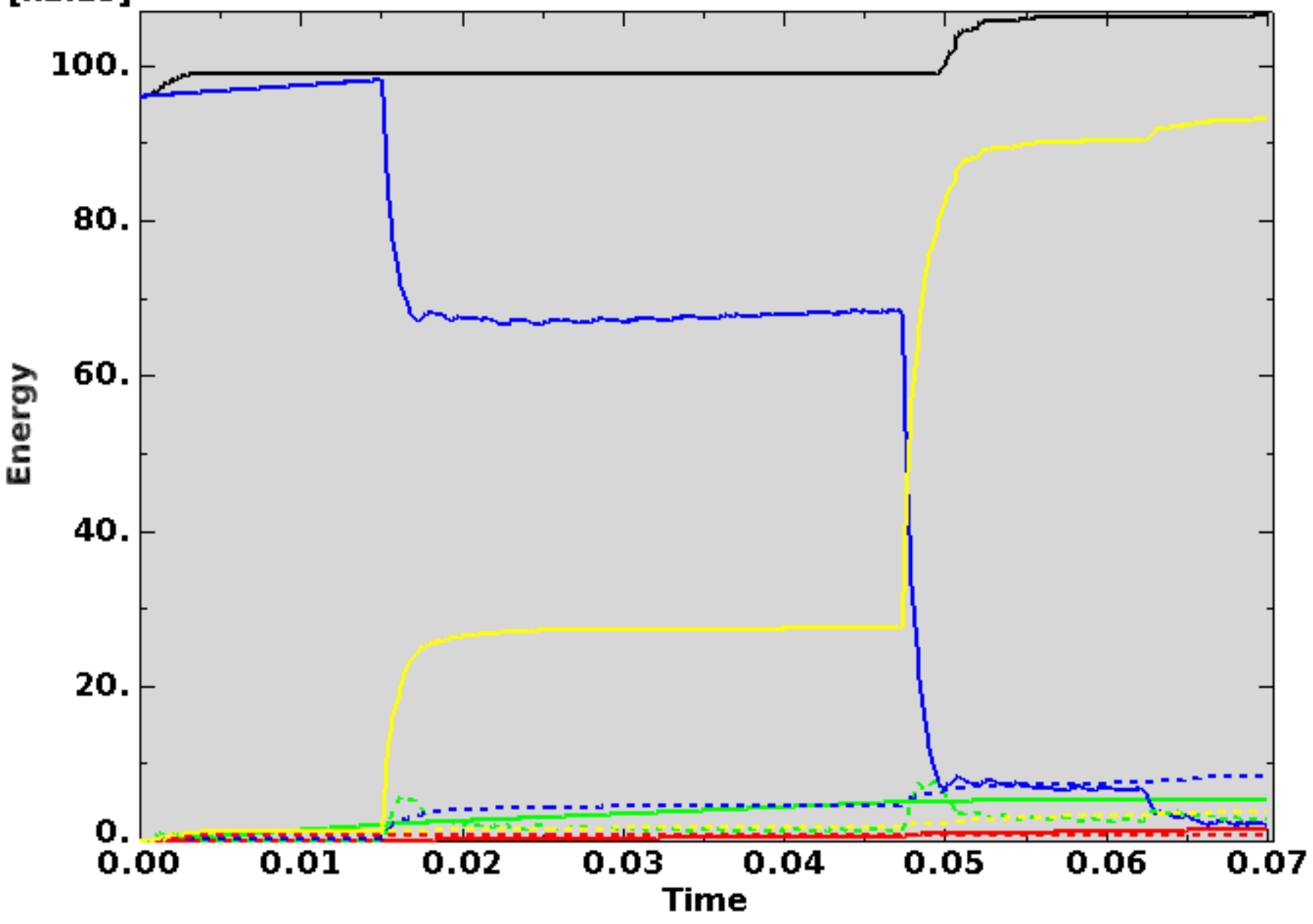

Figure D-177. Scope Part 1c (Table 3), Test 14 (Table 2) energy curves.

Figure D-177 shows the energy curves for Scope Part 1c (Table 3), Test 14 (Table 2) drop scenario. These curves exhibit a somewhat stable shape. There is some undesirable increase in total and plastic strain energy, but it is not considered significantly detrimental to the validity of the results. As discussed in Section D2.5 this appears to result from contact difficultly between failed portions of the fuel element. Artificial strain energy represents the energy required to keep reduced integration elements from taking on a zero-energy hourglass shape. As shown in Figure D-177, the artificial energy at the end of the model run is $1.5 \%$ of the total energy. Therefore, the potential error associated with artificial energy is not considered to be significant. 
ENGINEERING CALCULATIONS AND ANALYSIS

Drop Analysis of the Advanced Test Reactor Fresh Fuel Shipping Container with Heavier Low-Enriched Uranium Fuel Contents
ECAR-5224, Rev. 0

Page D159 of D293

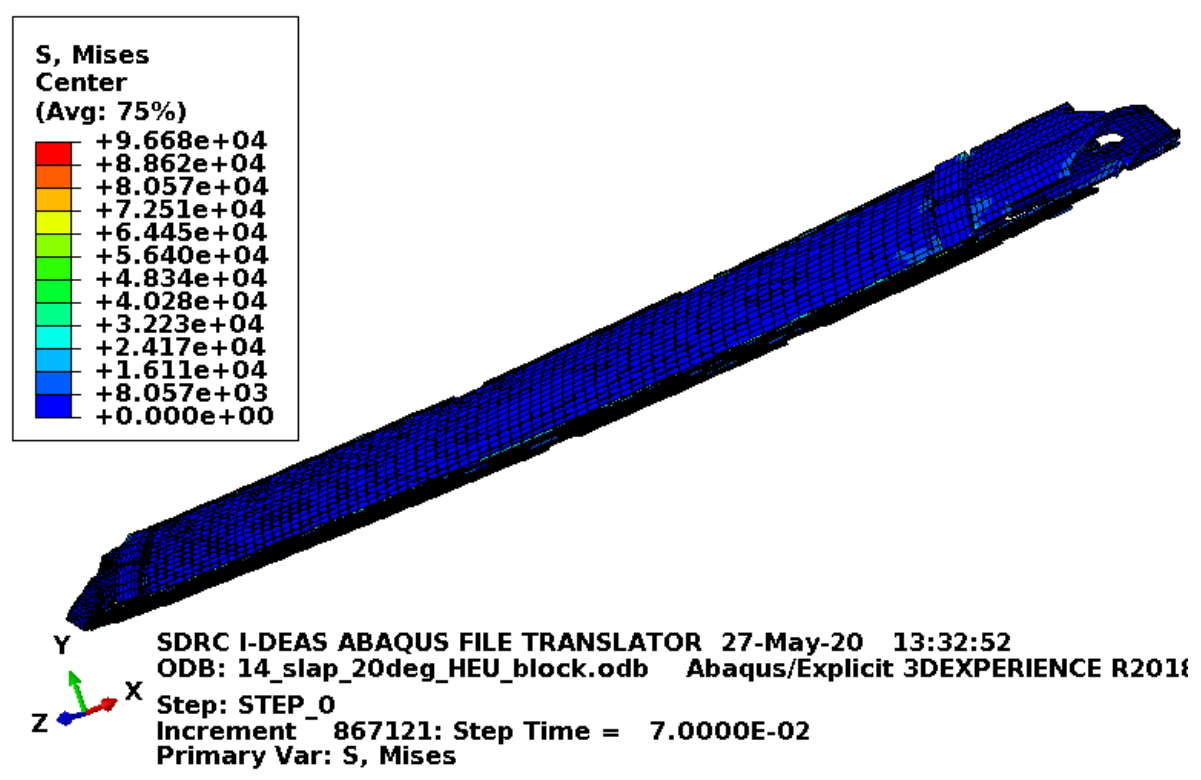

Figure D-178. Scope Part 1c (Table 3), Test 14 (Table 2) fuel element plastic equivalent strain.

Figure D-178 shows the equivalent plastic strain in the fuel element. Failure in the end box elements occurs at an equivalent plastic strain of $0.027 \mathrm{in}$./in. Failure in the end box weld elements occurs at an equivalent plastic strain of $0.032 \mathrm{in}$./in. Failure in the side plate and comb elements occurs at an equivalent plastic strain of $0.152 \mathrm{in}$./in. Failure in the side plate weld elements occurs at an equivalent plastic strain of $0.205 \mathrm{in./in.} \mathrm{If} \mathrm{element} \mathrm{failure} \mathrm{were} \mathrm{to} \mathrm{occur,} \mathrm{the} \mathrm{element} \mathrm{would} \mathrm{be} \mathrm{removed} \mathrm{from} \mathrm{the} \mathrm{model} \mathrm{(thereby}$ excluding its equivalent plastic strain from the maximum equivalent plastic strain for the plot). However, the missing element would be visible in the plot. Figure D-178 shows some end box failure.

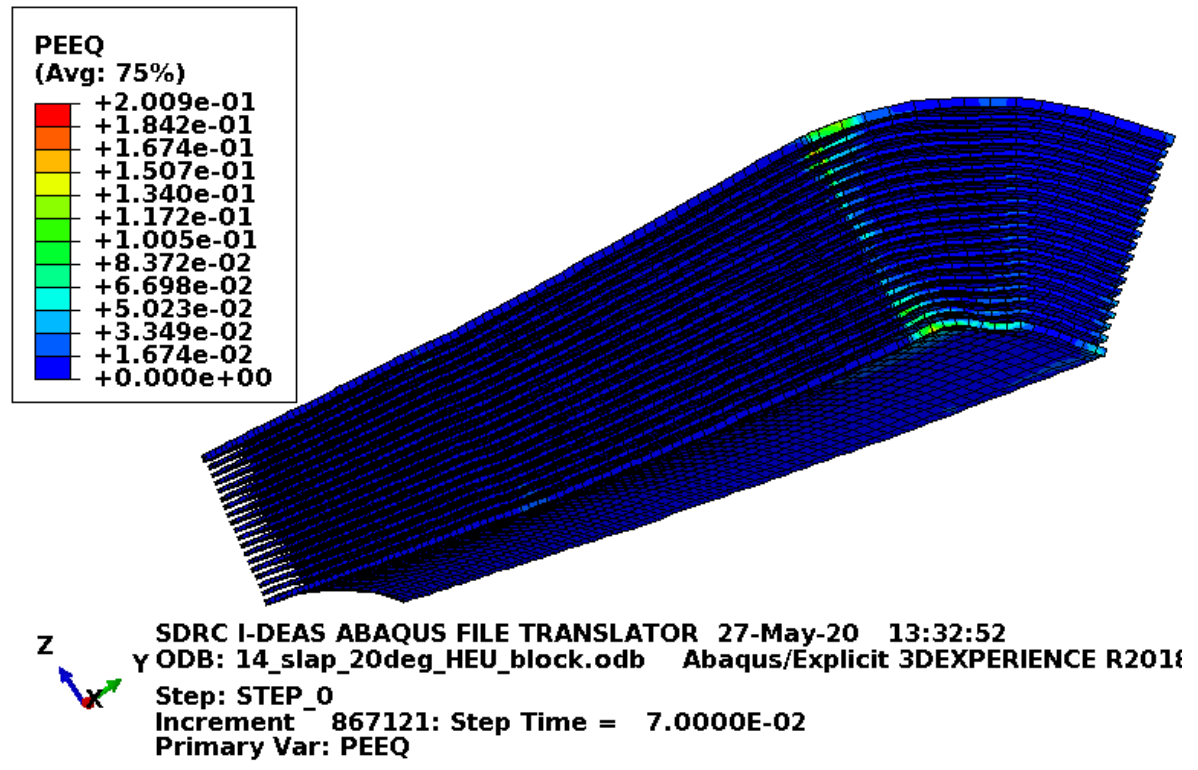

Figure D-179. Scope Part 1c (Table 3), Test 14 (Table 2) fuel plate equivalent strain.

Figure D-179 shows the equivalent plastic strain in the fuel plates. Failure in these elements occurs at an equivalent plastic strain of 0.205 in./in. If element failure were to occur, the element would be removed from 
the model (thereby excluding its equivalent plastic strain from the maximum equivalent plastic strain for the plot). However, the missing element would be visible in the plot. Figure D-179 shows no element failure.

\section{D2.11.4 Results for Scope Part 1d (Table 3), Test 14 (Table 2)}

The FEA model results for the Scope Part 1d (Table 3), Test 14 (Table 2) model are shown below in Figure D-180 to Figure D-182. The fuel element weighs $22.1 \mathrm{lbf}$ and the drop scenario is modeled with minimum material properties except the enclosure and end boxes, which are modeled with relatively tough material properties.

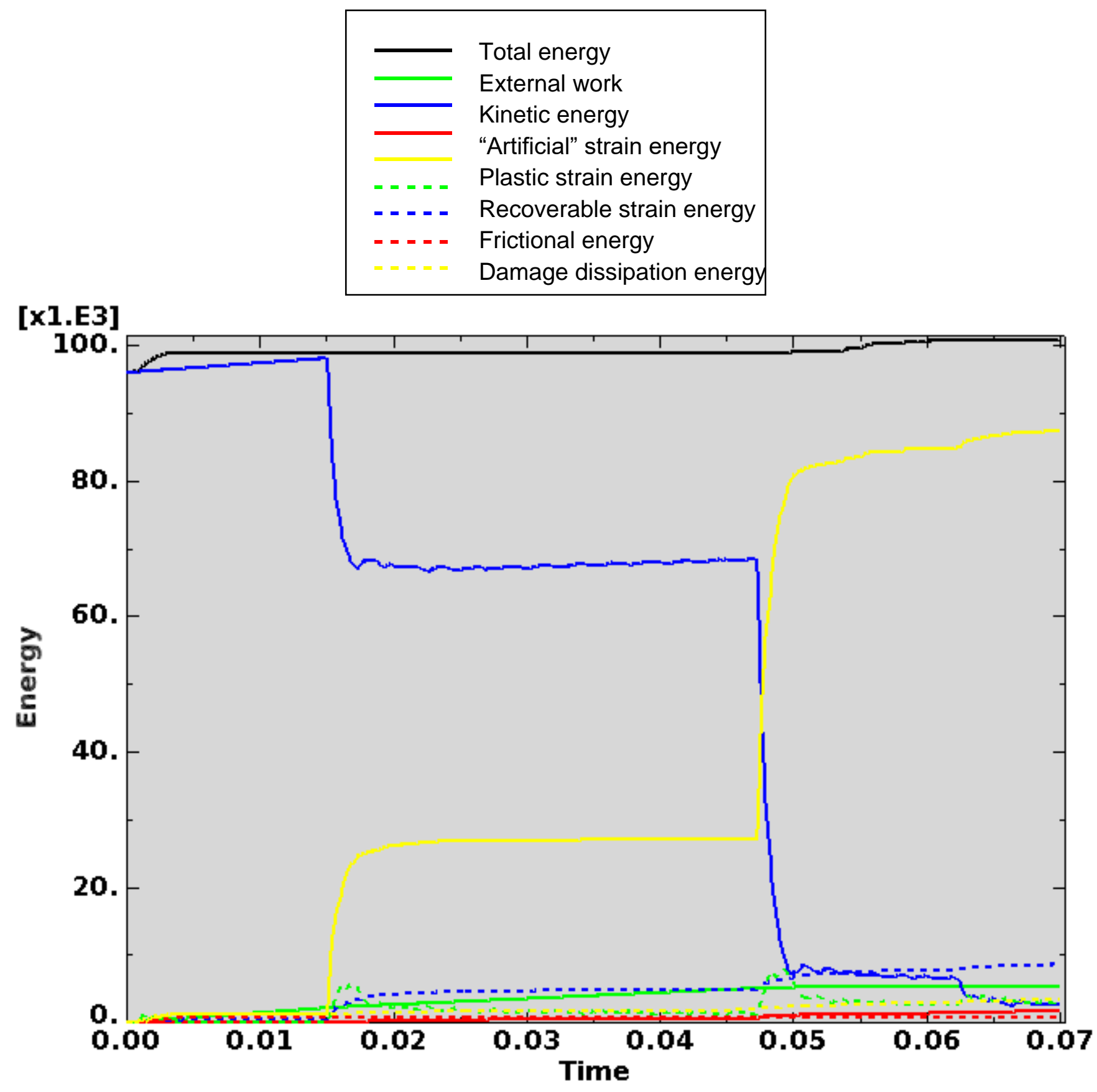

Figure D-180. Scope Part 1d (Table 3), Test 14 (Table 2) energy curves. 
Figure D-180 shows the energy curves for Scope Part 1d (Table 3), Test 14 (Table 2) drop scenario. These curves exhibit a somewhat stable shape. There is a small amount of undesirable increase in total and plastic strain energy, but it is not considered significantly detrimental to the validity of the results. Artificial strain energy represents the energy required to keep reduced integration elements from taking on a zeroenergy hourglass shape. As shown in Figure D-180, the artificial energy at the end of the model run is $1.6 \%$ of the total energy. Therefore, the potential error associated with artificial energy is not considered to be significant.

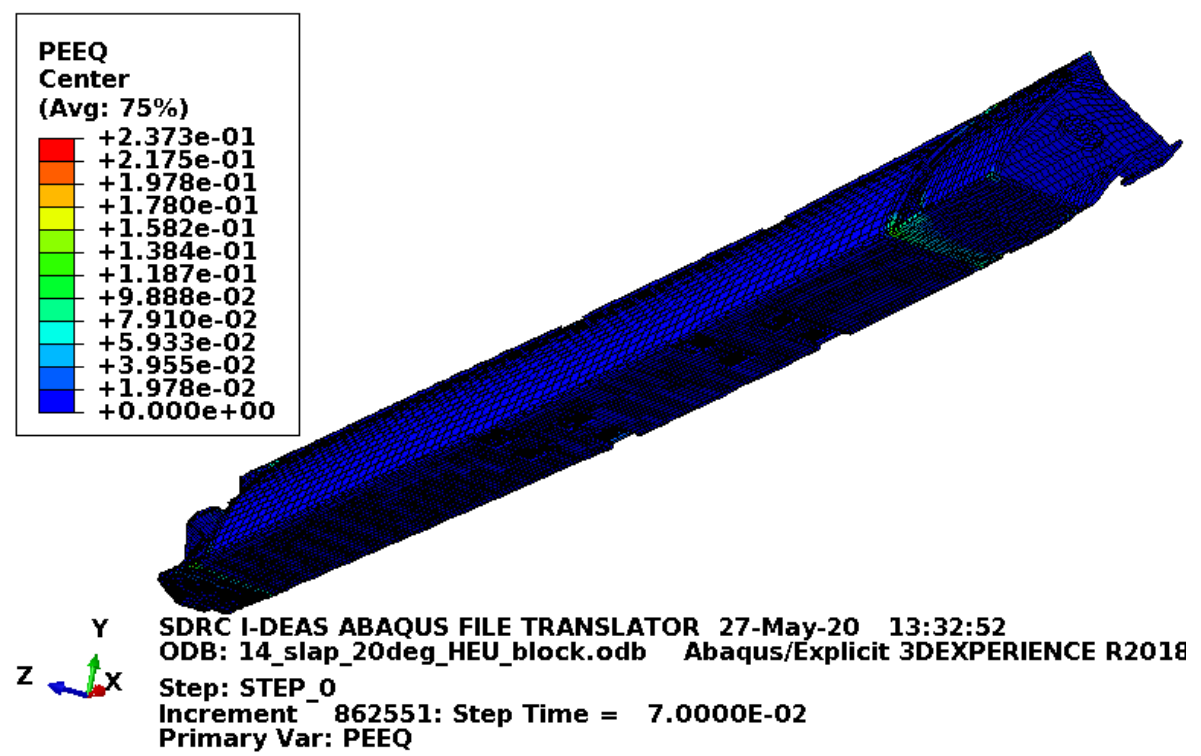

Figure D-181. Scope Part 1d (Table 3), Test 14 (Table 2) fuel element plastic equivalent strain.

Figure D-181 shows the equivalent plastic strain in the fuel element. Failure in the end box elements occurs at an equivalent plastic strain of $0.08 \mathrm{in./in.} \mathrm{(for} \mathrm{the} \mathrm{relatively} \mathrm{tough} \mathrm{material} \mathrm{properties).} \mathrm{Failure} \mathrm{in} \mathrm{the} \mathrm{end}$ box weld elements occurs at an equivalent plastic strain of $0.115 \mathrm{in}$./in. (for the relatively tough material properties). Failure in the side plate and comb elements occurs at an equivalent plastic strain of 0.152 in./in. Failure in the side plate weld elements occurs at an equivalent plastic strain of $0.205 \mathrm{in}$./in. If element failure were to occur, the element would be removed from the model (thereby excluding its equivalent plastic strain from the maximum equivalent plastic strain for the plot). However, the missing element would be visible in the plot. Figure D-181 shows minimal end box failure. 
ENGINEERING CALCULATIONS AND ANALYSIS

Drop Analysis of the Advanced Test Reactor Fresh Fuel Shipping Container with Heavier Low-Enriched Uranium Fuel Contents
ECAR-5224, Rev. 0

Page D162 of D293

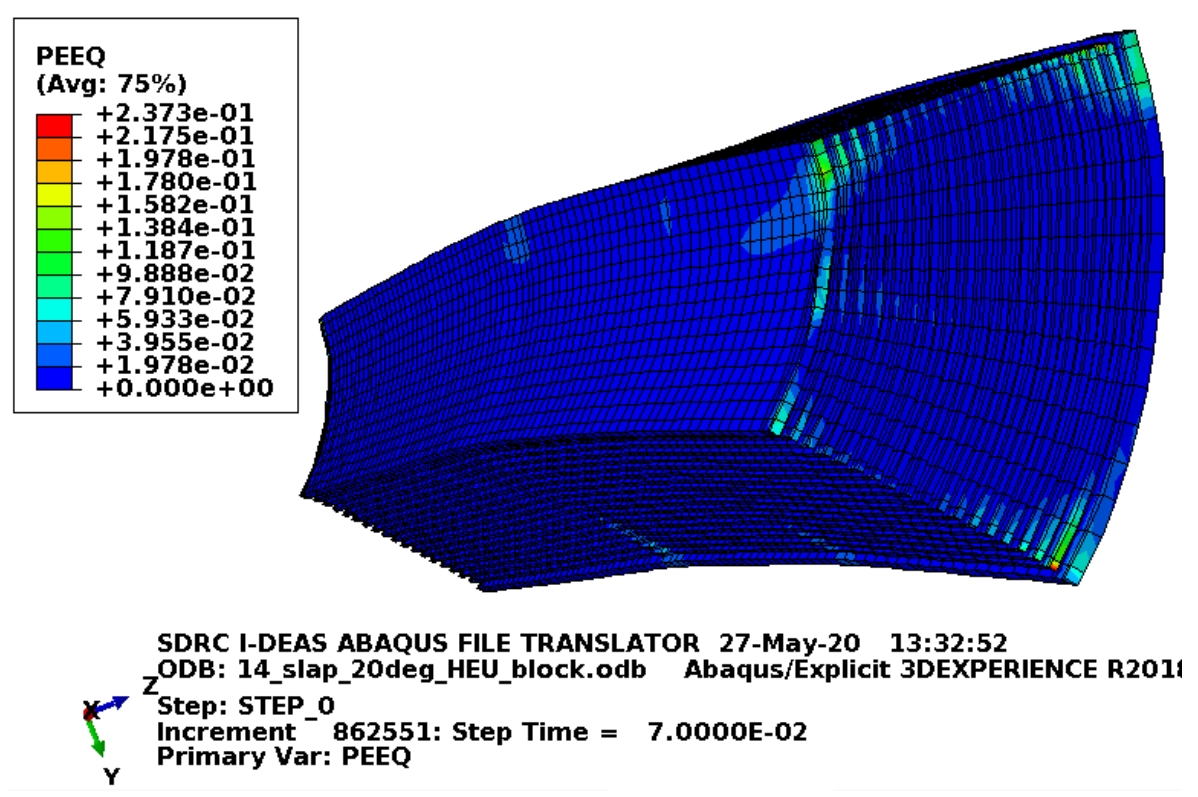

Figure D-182. Scope Part 1d (Table 3), Test 14 (Table 2) fuel plate equivalent strain.

Figure D-182 shows the equivalent plastic strain in the fuel plates. Failure in these elements occurs at an equivalent plastic strain of $0.205 \mathrm{in}$./in. If element failure were to occur, the element would be removed from the model (thereby excluding its equivalent plastic strain from the maximum equivalent plastic strain for the plot). However, the missing element would be visible in the plot. Figure D-182 shows no element failure, but one element at the end of one fuel plate show strains above failure. The strains shown above the failure strain likely result from extrapolation (as integration point strains are the important strains for failure). Even if the element with high strain were removed as being failed, its failure would be acceptable as it does not represent fuel meat.

\section{D2.12 Summary of Results for Scope Part 1 (Table 3)}

The Scope Part 1a (Table 3) results demonstrate that the FEA models produce reasonable and conservative results compared to the physical drops. All of the drops were performed with and without the new block design. Given that the ATR FFSC SAR (2017) provides acceptance of the physically dropped fuel element without the block, the FEA model results with the blocks are provided as information. Though, the blocks could be added as defense in depth making these results more useful.

Unlike the ATR FFSC discussion of physical drops (provided in Appendix C), fuel element damage was only discussed after the second physical drop and after all the drops were performed. The first inspection happened after the $4 \mathrm{ft}$ drop with the center of gravity over the top corner and the $30 \mathrm{ft}$ flat side drop with the pocket side down. Per the ATR FFSC SAR (2017), Section 2.12.1.4.1.2, there was no visible damage to the fuel element for the first inspection. The FEA models (see Sections D2.1 and D2.2) showed some failure but acceptable results. Consequently, the damage shown in the FEA models was conservative.

After all the physical drops, there was significant damage to the fuel element. Damage such as that shown in Figure D-9 and Figure D-10 is difficult to attribute to a particular drop scenario. Section D2.4 provided evidence that a $30 \mathrm{ft}$ side drop could contribute to this fuel plate deformation. Also, the end drop scenarios (see Sections D2.5 and D2.6) could further contribute to buckling the fuel plates if successive FEA model drops were performed. However, this evaluation is based on damage seen in a single drop. 
Damage to the bottom of the fuel element shown in Figure D-7 and Figure D-8 is attributed to the bottom drop (see Section D2.5). In the physical drops, this was the only bottom drop. It was preceded by a $4 \mathrm{ft}$ center of gravity over the top corner and four $30 \mathrm{ft}$ side drops. As noted above, there was no visible damage to the fuel element after the first $30 \mathrm{ft}$ side drop. Though this is very limited information, it is reasonable that the damage shown in Figure D-7 and Figure D-8 is primarily from the bottom drop (see Section D2.5). In Sections D2.5.1 and D2.5.2, having all minimum material properties caused the end box nearest the impacted surface to shatter. It did not cut into the fuel plate as shown in Figure D-7 and Figure D-8. Though the end box behavior appears weaker than in the physical drops, these results are still considered. With weaker end boxes, less impact energy is absorbed by the end box and more impact energy is absorbed by the fuel plates. Sections D2.5.3 and D2.5.4 provided results for the relatively tough material properties for the end boxes. In these results, the end box did cut into the fuel meat; though, the end box held together too well (relative to the physical drops) and caused more damage to the sides of the fuel plates. The contact in these models became complex due to the multitude of failed surfaces in contact and some local contact got missed. However, globally the contact was sufficient to cause rebound. The cutting path followed by the center of the end box in Section D2.5.3 is very close to that of the physical drop cut. To help ensure conservatism, the refined mesh in Section D2.5.4 is used. The damage shown in this section is conservative to the point of causing unacceptable fuel meat damage. This is a desirable result because if the same mesh can be used to show acceptable results for the LOWE fuel element, then the acceptability of the LOWE model has additional credibility. (The expectation is that the LOWE fuel element would be acceptable with the added block design.) Adding the block design (see Sections D2.5.5 to D2.5.8) produced acceptable results even with the added conservatism of the fine mesh.

Damage to the top of the fuel element shown in Figure D-6 is attributed primarily to the top corner drop (see Section D2.6). In the physical drops, this was the only $30 \mathrm{ft}$ top drop. An identical version of this drop is performed as the first drop from $4 \mathrm{ft}$, but as mentioned above, there was no visible damage. Though, it is possible that some plasticity did occur. The final damage to the fuel element top was much less severe than the damage to the bottom. This can be expected because a flat end drop is a stiffer impact for the fuel element. For this FEA model drop scenario, the relatively weak and relatively tough material property results provided less damage than seen in the final damage from the physical drops. The models having all minimum material properties (see Section D2.6.1) again shattered the end box and did not line up a fragment to cut into the fuel plates. The models having results for end boxes with relatively tough material properties (see Section D2.6.2) resulted in the end box not being completely disconnect from the rest of the fuel element. Consequently, the end box could not impact the fuel plates. However, it should be noted that the FEA model damage for the $4 \mathrm{ft}$ top corner drop is conservative. Considering the model with relatively tough end boxes (see Section D2.1.2), there is significant weld damage (as shown in Figure D-15). If this damaged model were then run in the $30 \mathrm{ft}$ drop scenario, more reasonable and conservative damage could be expected. However, this evaluation considers only a single drop accident as credible. Though, as an attempt to produce conservative damage to the top of the fuel element, a flat top drop FEA model is added in Section D2.9. This drop was not performed in the physical drops but provides the worst-case FEA model results. Similar to the flat bottom results, the flat bottom FEA model produces unacceptable damage to the fuel meat (see Section D2.9.2). However, adding the block design (see Sections D2.9.3 to D2.9.6) produced acceptable results even with the added conservatism of the fine mesh. 
The sections not specifically mentioned were included for completeness but did not produce notably different results. All FEA models with the new block design included showed acceptable results. Having the blocks in place reduces the useable crush zone at the ends of the fuel plates which results in more compressive load potentially being applied to the fuel plate ends. And, having the blocks nearly eliminates the possibility of a failed end box piece cutting into the end of the fuel plates as occurred with the physical drops.

(As discussed in Section D2.1, it should be noted that failure parameters are based on tensile failure. Therefore, compressive failure like that in the fuel plates from the blocks is predicted with significant conservatism. This is because sufficient data are not currently available to include triaxiality effects for the materials used in the evaluation.)

\section{D3 LOWE FUEL ELEMENT RESULTS (SCOPE PART 2, TABLE 3)}

Sections D3.1-D3.11 show the FEA model results for the Scope Part 2 (Table 3) drop scenarios (with a fuel element weight of $44 \mathrm{lbf}$ ). Section D3.12 provides a summary of the results for the Scope Part 2 (Table 3) drop scenarios. The FEA model used for these results is the same as that used in Section D2 except the fuel plate density has been modified to increase the mass. It is considered reasonable and conservative based on the results comparison with physical drops in Section D2.

NOTE: $\quad$ As discussed in Table 2 of the main body, Test 4, 7, and 9 are not performed with an FEA model.

\section{D3.1 Results for Scope Part 2 (Table 3), Test 1 (Table 2)}

The drop scenario considered in this section is a $4 \mathrm{ft}$ drop where the loaded ATR FFSC impacts with its center of gravity over the top corner. The FEA models for this drop were run. However, the results for Scope Part 2 (Table 3), Test 8 (Table 2) shown in Section D3.6 are for the same drop orientation from $30 \mathrm{ft}$ Because the Scope Part 2 (Table 3), Test 8 (Table 2) results are easily enveloping, they are the only results documented for this drop orientation.

\section{D3.2 Results for Scope Part 2 (Table 3), Test 2 (Table 2)}

The drop scenario considered in this section is a $30 \mathrm{ft}$ drop where the loaded ATR FFSC impacts flat on its side drop with the pocket side down.

\section{D3.2.1 Results for Scope Part 2a (Table 3), Test 2 (Table 2)}

The FEA model results for the Scope Part 2a (Table 3), Test 2 (Table 2) model are shown below in Figure D-183 to Figure D-185. The fuel element weighs $44 \mathrm{lbf}$ and the whole model is modeled with minimum material properties. 


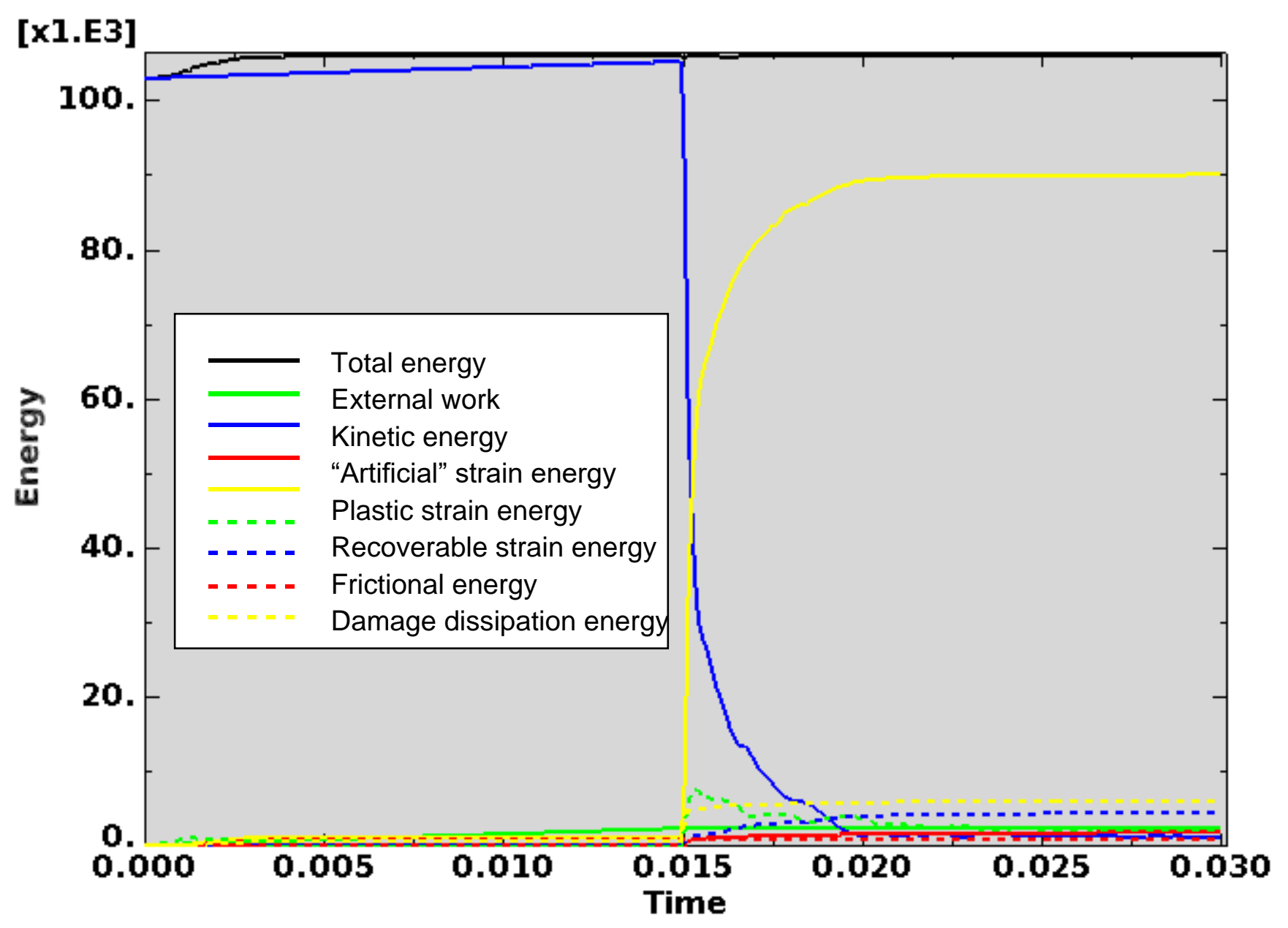

Figure D-183. Scope Part 2a (Table 3), Test 2 (Table 2) energy curves.

Figure D-183 shows the energy curves for Scope Part 2a (Table 3), Test 2 (Table 2) drop scenario. These curves exhibit a stable shape. Artificial strain energy represents the energy required to keep reduced integration elements from taking on a zero-energy hourglass shape. As shown in Figure D-183, the artificial energy at the end of the model run is $1.7 \%$ of the total energy. Therefore, the potential error associated with artificial energy is not considered to be significant. 


\section{ENGINEERING CALCULATIONS AND ANALYSIS}

Drop Analysis of the Advanced Test Reactor Fresh Fuel Shipping Container with Heavier Low-Enriched Uranium Fuel Contents
ECAR-5224, Rev. 0

Page D166 of D293
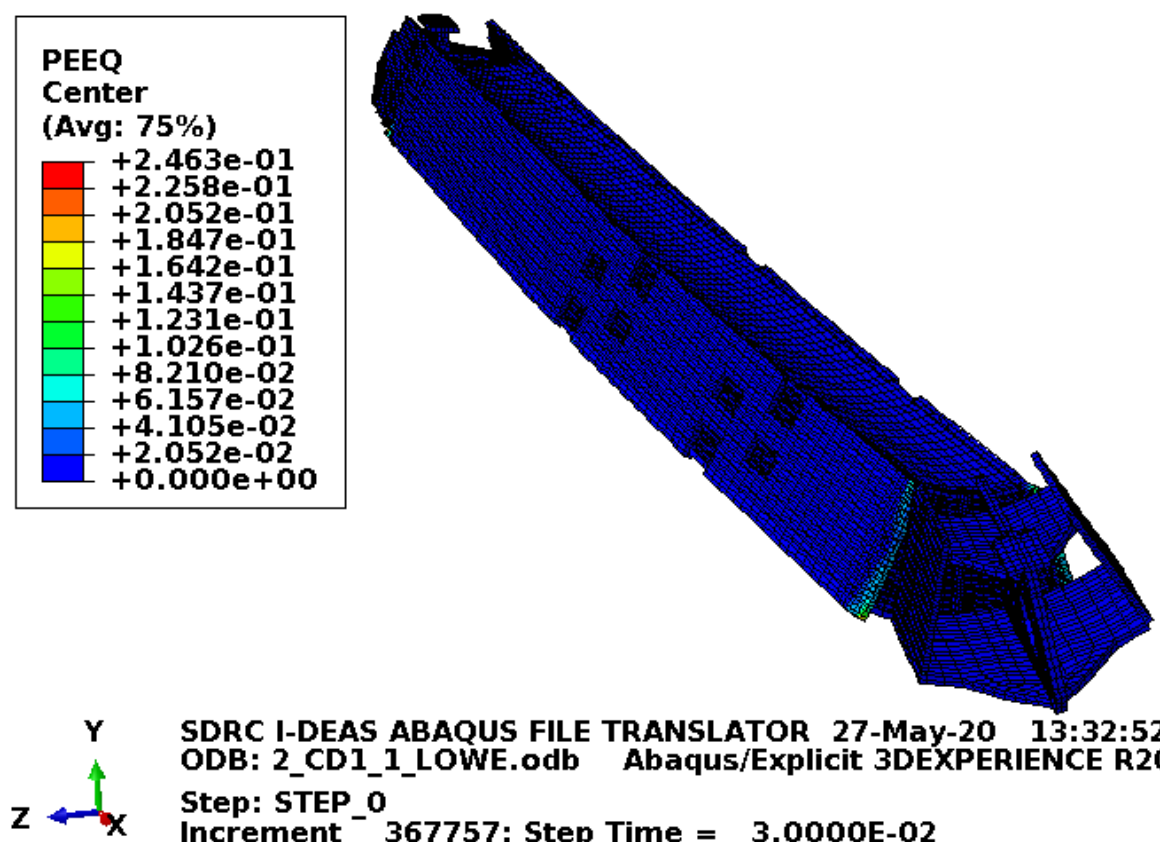

SDRC I-DEAS ABAQUS FILE TRANSLATOR 27-May-20 13:32:52 ODB: 2_CD1_1_LOWE.odb Abaqus/Explicit 3DEXPERIENCE R20:

Step: STEP_o

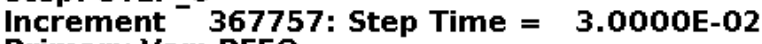

Primary Var: PEEQ

Figure D-184. Scope Part 2a (Table 3), Test 2 (Table 2) fuel element plastic equivalent strain.

Figure D-184 shows the equivalent plastic strain in the fuel element. Failure in the end box elements occurs at an equivalent plastic strain of $0.027 \mathrm{in}$./in. Failure in the end box weld elements occurs at an equivalent plastic strain of $0.032 \mathrm{in}$./in. Failure in the side plate and comb elements occurs at an equivalent plastic strain of $0.152 \mathrm{in./in.} \mathrm{Failure} \mathrm{in} \mathrm{the} \mathrm{side} \mathrm{plate} \mathrm{weld} \mathrm{elements} \mathrm{occurs} \mathrm{at} \mathrm{an} \mathrm{equivalent} \mathrm{plastic} \mathrm{strain} \mathrm{of}$ 0.205 in./in. Figure D-184 shows a failure in the end boxes and end box welds. Failure in the welds for one end box causes the end box to be separated from the rest of the fuel element.

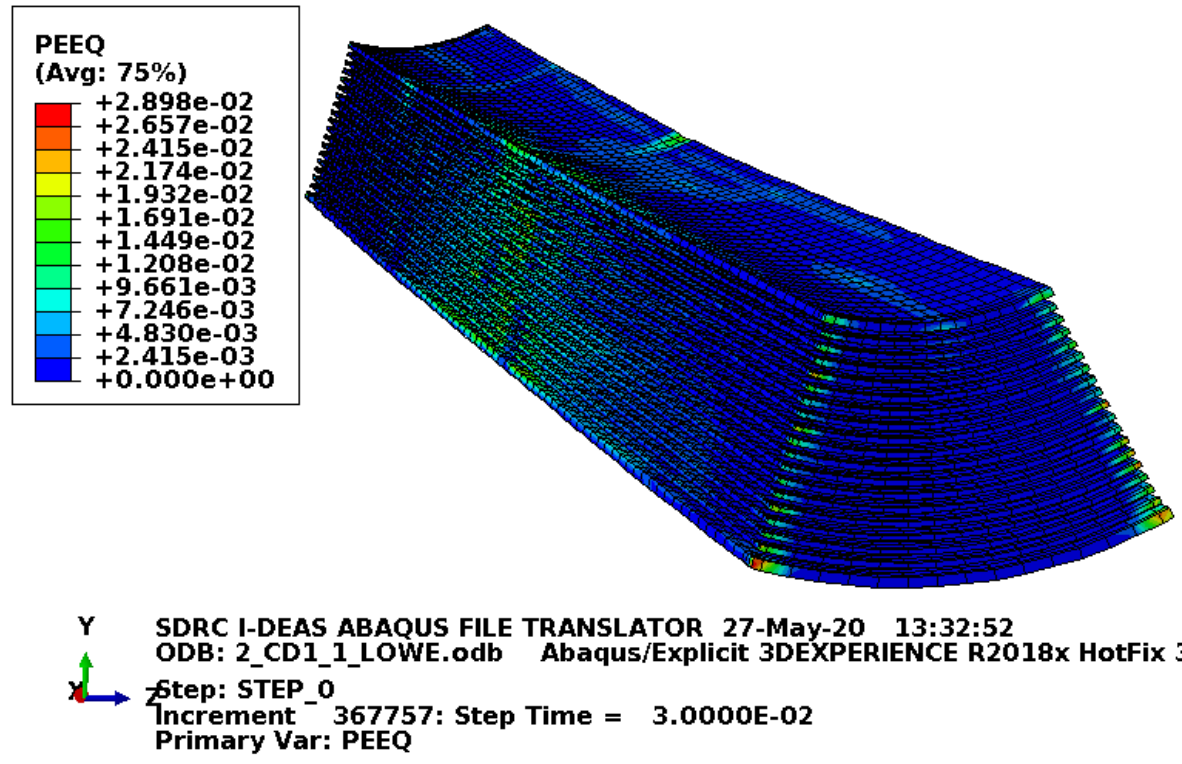

Figure D-185. Scope Part 2a (Table 3), Test 2 (Table 2) fuel plate equivalent strain. 
Figure D-185 shows the equivalent plastic strain in the fuel plates. Failure in these elements occurs at an equivalent plastic strain of $0.205 \mathrm{in}$./in. If element failure were to occur, the element would be removed from the model (thereby excluding its equivalent plastic strain from the maximum equivalent plastic strain for the plot). However, the missing element would be visible in the plot. Figure D-185 shows no failure in the fuel plates, but above failure strain values are shown in a few localized places at the ends of the fuel plates. The strains shown above the failure strain likely result from extrapolation (as integration point strains are the important strains for failure). It is of no consequence if these elements were considered as having failed.

\section{D3.2.2 Results for Scope Part $2 b$ (Table 3), Test 2 (Table 2)}

The FEA model results for the Scope Part $2 b$ (Table 3), Test 2 (Table 2) model are shown below in Figure D-186 to Figure D-188. The fuel element weighs $44 \mathrm{lbf}$ and the drop scenario is modeled with minimum material properties except the enclosure and end boxes, which are modeled with relatively tough material properties.

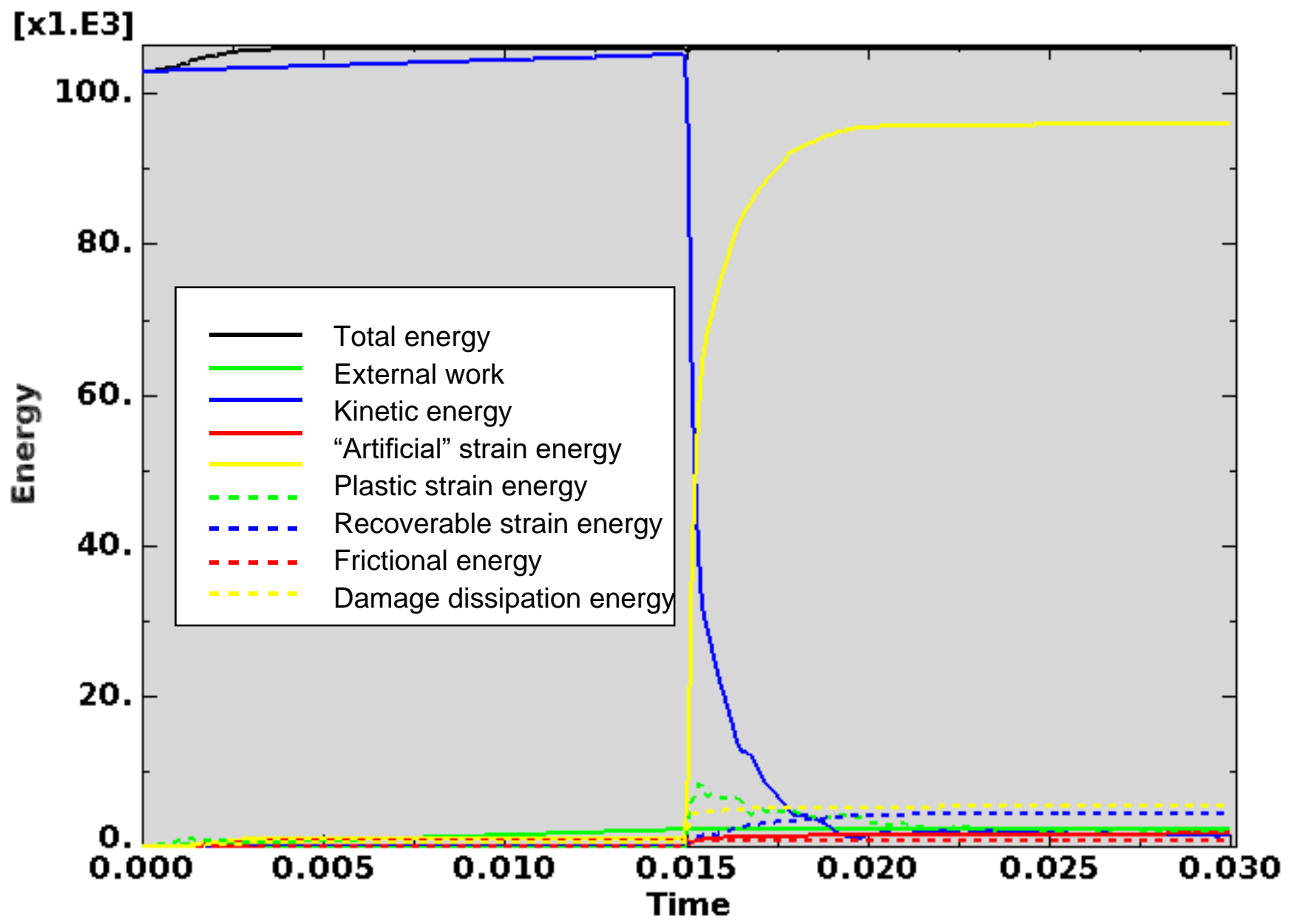

Figure D-186. Scope Part 2b (Table 3), Test 2 (Table 2) energy curves. 
Figure D-186 shows the energy curves for Scope Part 2b (Table 3), Test 2 (Table 2) drop scenario. These curves exhibit a stable shape. Artificial strain energy represents the energy required to keep reduced integration elements from taking on a zero-energy hourglass shape. As shown in Figure D-186, the artificial energy at the end of the model run is $1.6 \%$ of the total energy. Therefore, the potential error associated with artificial energy is not considered to be significant.
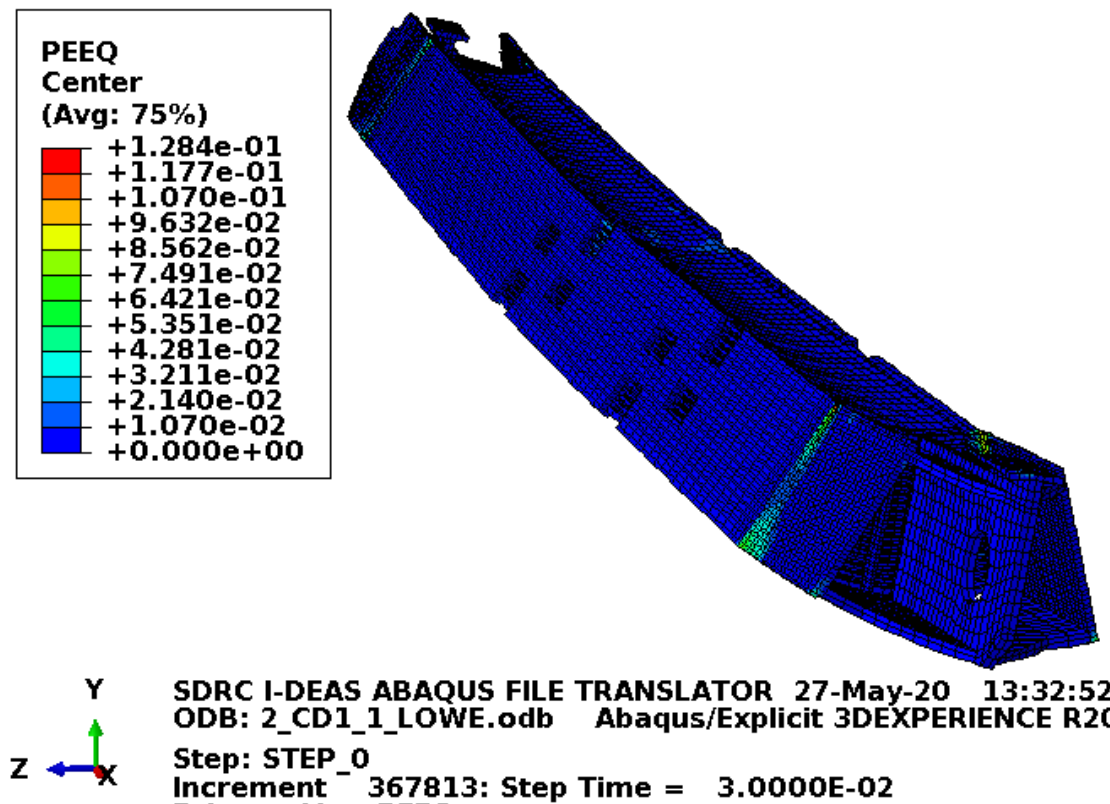

SDRC I-DEAS ABAQUS FILE TRANSLATOR 27-May-20 13:32:52

ODB: 2_CD1_1_LOWE.odb Abaqus/Explicit 3DEXPERIENCE R2018x

Step: STEP_o

Increment $367813:$ Step Time $=3.0000 E-02$

Primary Var: PEEQ

Figure D-187. Scope Part 2b (Table 3), Test 2 (Table 2) fuel element plastic equivalent strain.

Figure D-187 shows the equivalent plastic strain in the fuel element. Failure in the end box elements occurs at an equivalent plastic strain of $0.08 \mathrm{in}$./in. (for the relatively tough material properties). Failure in the end box weld elements occurs at an equivalent plastic strain of $0.115 \mathrm{in}$./in. (for the relatively tough material properties). Failure in the side plate and comb elements occurs at an equivalent plastic strain of 0.152 in./in. Failure in the side plate weld elements occurs at an equivalent plastic strain of 0.205 in./in. Figure D-187 shows a few failed elements in the end boxes which is acceptable. 
ENGINEERING CALCULATIONS AND ANALYSIS

Drop Analysis of the Advanced Test Reactor Fresh Fuel Shipping Container with Heavier Low-Enriched Uranium Fuel Contents
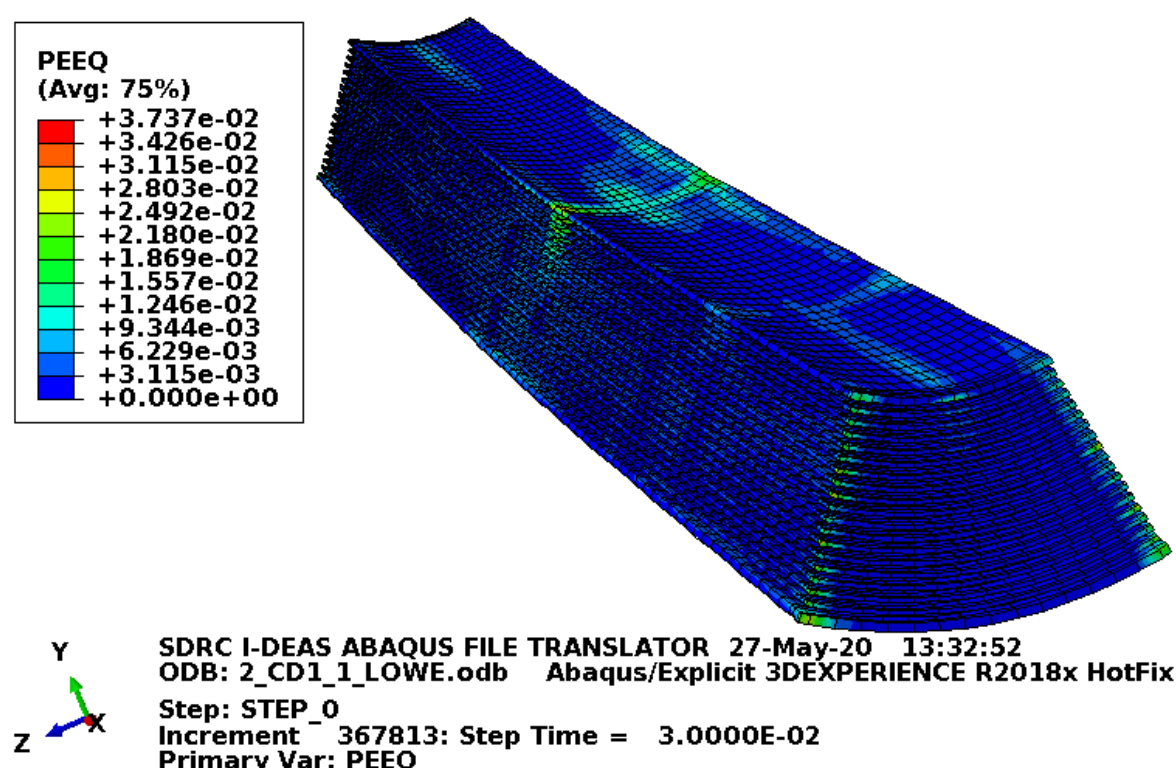

SDRC I-DEAS ABAQUS FILE TRANSLATOR 27-May-20 13:32:52

ODB: 2_CD1_1_LOWE.odb Abaqus/Explicit 3DEXPERIENCE R2018x HotFix

Step: STEP 0

Increment 367813 : Step Time $=3.0000 \mathrm{E}-02$

Primary Var: PEEQ

Figure D-188. Scope Part 2b (Table 3), Test 2 (Table 2) fuel plate equivalent strain.

Figure D-188 shows the equivalent plastic strain in the fuel plates. Failure in these elements occurs at an equivalent plastic strain of 0.205 in./in. If element failure were to occur, the element would be removed from the model (thereby excluding its equivalent plastic strain from the maximum equivalent plastic strain for the plot). However, the missing element would be visible in the plot. Figure D-188 shows no failure in the fuel plates with margin.

\section{D3.2.3 Results for Scope Part 2c (Table 3), Test 2 (Table 2)}

The FEA model results for the Scope Part 2c (Table 3), Test 2 (Table 2) model are shown below in Figure D-189 to Figure D-191. The fuel element weighs $44 \mathrm{lbf}$ and the whole model is modeled with minimum material properties. This section includes the blocks as added fuel plate protection. 


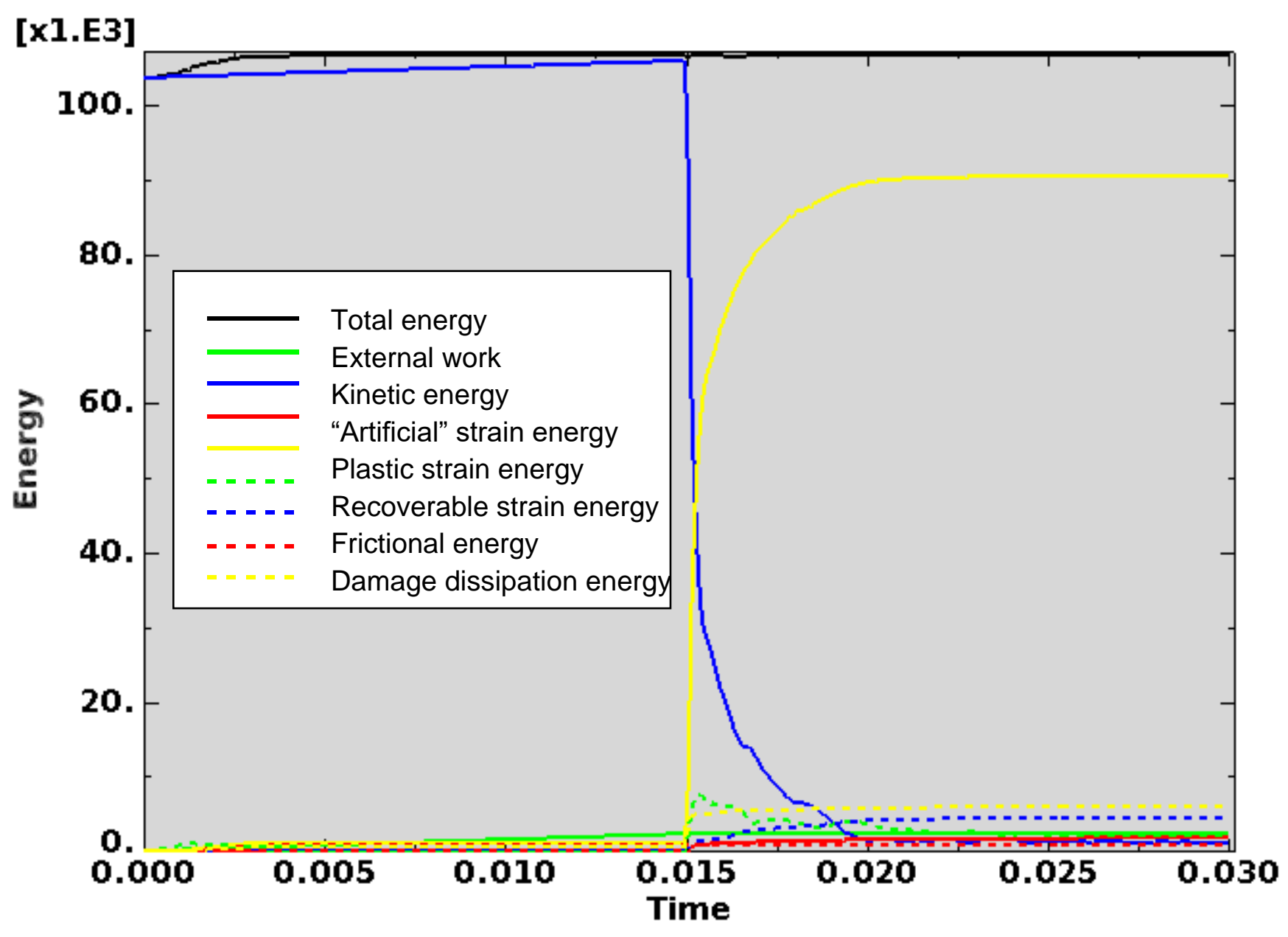

Figure D-189. Scope Part 2c (Table 3), Test 2 (Table 2) energy curves.

Figure D-189 shows the energy curves for Scope Part 2c (Table 3), Test 2 (Table 2) drop scenario. These curves exhibit a stable shape. Artificial strain energy represents the energy required to keep reduced integration elements from taking on a zero-energy hourglass shape. As shown in Figure D-189, the artificial energy at the end of the model run is $1.7 \%$ of the total energy. Therefore, the potential error associated with artificial energy is not considered to be significant. 
ENGINEERING CALCULATIONS AND ANALYSIS

Drop Analysis of the Advanced Test Reactor Fresh Fuel Shipping Container with Heavier Low-Enriched Uranium Fuel Contents
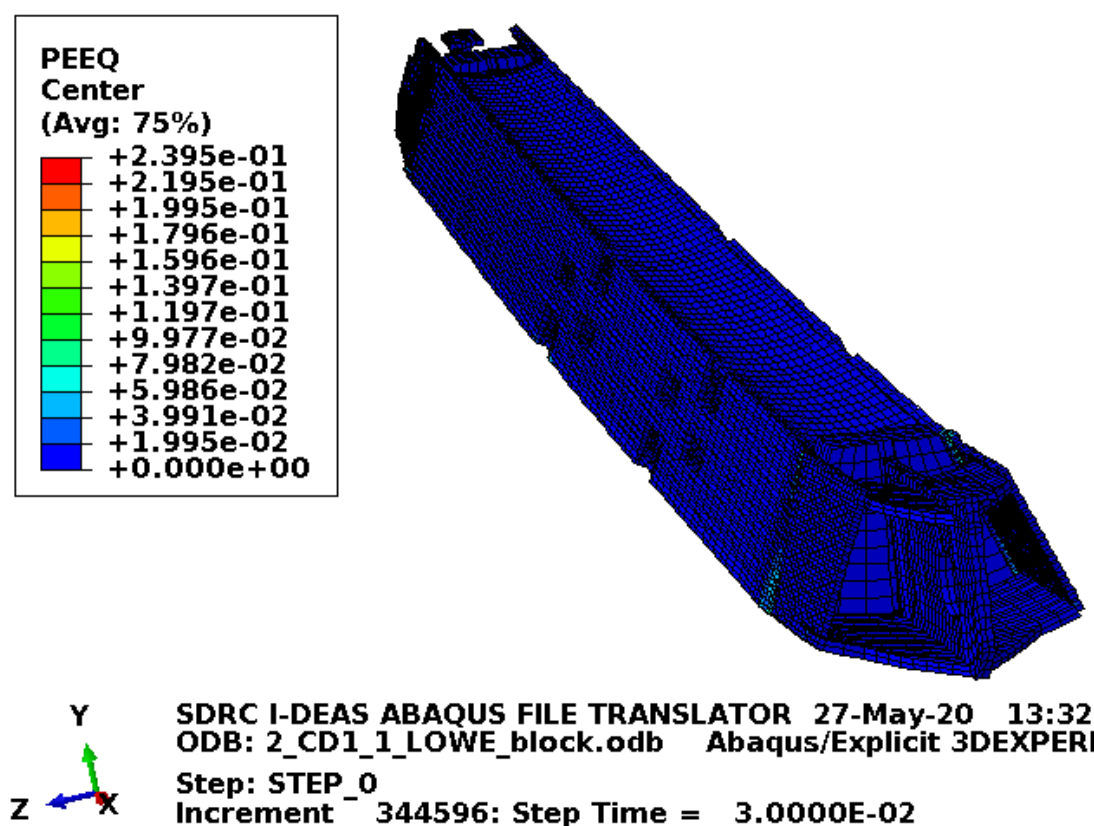

SDRC I-DEAS ABAQUS FILE TRANSLATOR 27-May-20 13:32:52 ODB: 2_CD1_1_LOWE_block.odb Abaqus/Explicit 3DEXPERIENCE

Step: STEP 0

Increment ${ }^{-}$344596: Step Time $=$3.0000E-02

Primary Var: PEEQ

Figure D-190. Scope Part 2c (Table 3), Test 2 (Table 2) fuel element plastic equivalent strain.

Figure D-190 shows the equivalent plastic strain in the fuel element. Failure in the end box elements occurs at an equivalent plastic strain of $0.027 \mathrm{in}$./in. Failure in the end box weld elements occurs at an equivalent plastic strain of $0.032 \mathrm{in./in.} \mathrm{Failure} \mathrm{in} \mathrm{the} \mathrm{side} \mathrm{plate} \mathrm{and} \mathrm{comb} \mathrm{elements} \mathrm{occurs} \mathrm{at} \mathrm{an} \mathrm{equivalent} \mathrm{plastic}$ strain of $0.152 \mathrm{in./in.} \mathrm{Failure} \mathrm{in} \mathrm{the} \mathrm{side} \mathrm{plate} \mathrm{weld} \mathrm{elements} \mathrm{occurs} \mathrm{at} \mathrm{an} \mathrm{equivalent} \mathrm{plastic} \mathrm{strain} \mathrm{of}$ $0.205 \mathrm{in}$./in. If element failure were to occur, the element would be removed from the model (thereby excluding its equivalent plastic strain from the maximum equivalent plastic strain for the plot). However, the missing element would be visible in the plot. Figure D-190 shows a few failed elements in the end boxes and end box welds nearest the impact. 
ENGINEERING CALCULATIONS AND ANALYSIS

Drop Analysis of the Advanced Test Reactor Fresh Fuel Shipping Container with Heavier Low-Enriched Uranium Fuel Contents

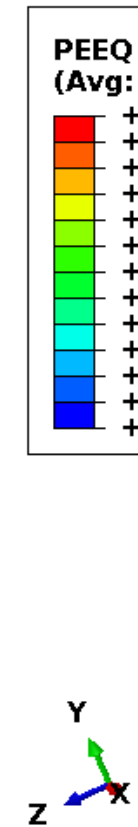

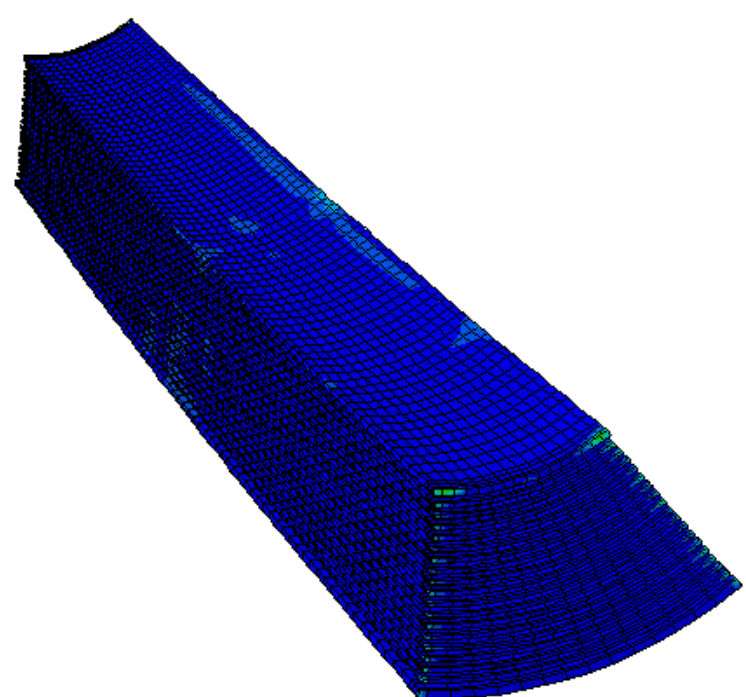

SDRC I-DEAS ABAOUS FILE TRANSLATOR 27-May-20 13:32:52 ODB: 2_CD1_1_LOWE_block.odb Abaqus/Explicit 3DEXPERIENCE Step: STEP 0

Increment ${ }^{-344596: \text { Step Time }=3.0000 E-02}$

Primary Var: PEEQ
ECAR-5224, Rev. 0 Page D172 of D293

Figure D-191. Scope Part 2c (Table 3), Test 2 (Table 2) fuel plate equivalent strain.

Figure D-191 shows the equivalent plastic strain in the fuel plates. Failure in these elements occurs at an equivalent plastic strain of 0.205 in./in. If element failure were to occur, the element would be removed from the model (thereby excluding its equivalent plastic strain from the maximum equivalent plastic strain for the plot). However, the missing element would be visible in the plot. Figure D-191 shows no failure in the fuel plates with margin.

\section{D3.2.4 Results for Scope Part 2d (Table 3), Test 2 (Table 2)}

The FEA model results for the Scope Part 2d (Table 3), Test 2 (Table 2) model are shown below in Figure D-192 to Figure D-194. The fuel element weighs $44 \mathrm{lbf}$ and the drop scenario is modeled with minimum material properties except the enclosure and end boxes, which are modeled with relatively tough material properties. This section includes the blocks as added fuel plate protection. 


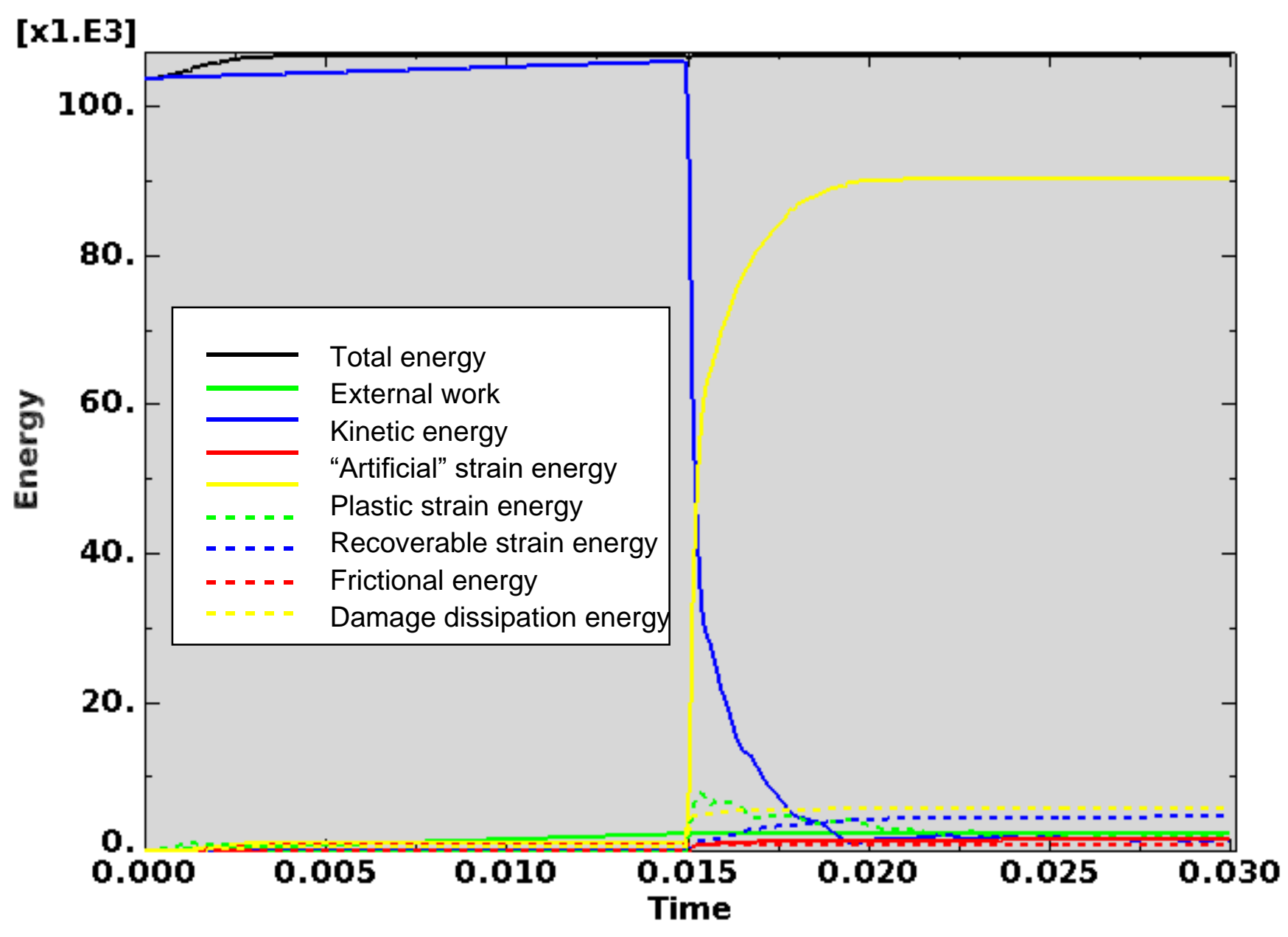

Figure D-192. Scope Part 2d (Table 3), Test 2 (Table 2) energy curves.

Figure D-192 shows the energy curves for Scope Part 2d (Table 3), Test 2 (Table 2) drop scenario. These curves exhibit a stable shape. Artificial strain energy represents the energy required to keep reduced integration elements from taking on a zero-energy hourglass shape. As shown in Figure D-192, the artificial energy at the end of the model run is $1.5 \%$ of the total energy. Therefore, the potential error associated with artificial energy is not considered to be significant. 


\section{ENGINEERING CALCULATIONS AND ANALYSIS}

Drop Analysis of the Advanced Test Reactor Fresh Fuel Shipping Container with Heavier Low-Enriched Uranium Fuel Contents
ECAR-5224, Rev. 0

Page D174 of D293
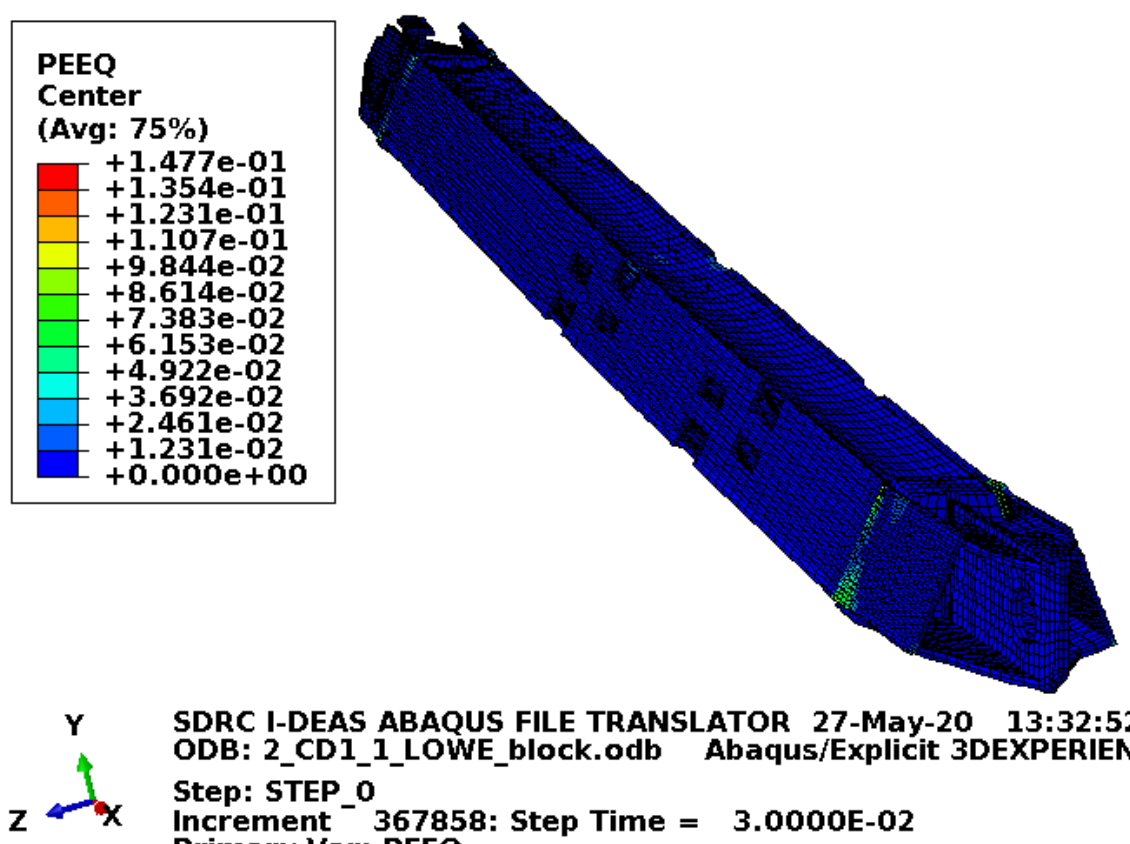

SDRC I-DEAS ABAOUS FILE TRANSLATOR 27-May-20 13:32:52 ODB: 2_CD1_1_LOWE_block.odb Abaqus/Explicit 3DEXPERIENCE Step: STEP o

Increment ${ }^{-}$367858: Step Time $=3.0000 E-02$

Primary Var: PEEQ

Figure D-193. Scope Part 2d (Table 3), Test 2 (Table 2) fuel element plastic equivalent strain.

Figure D-193 shows the equivalent plastic strain in the fuel element. Failure in the end box elements occurs at an equivalent plastic strain of $0.08 \mathrm{in./in.} \mathrm{(for} \mathrm{the} \mathrm{relatively} \mathrm{tough} \mathrm{material} \mathrm{properties).} \mathrm{Failure} \mathrm{in} \mathrm{the} \mathrm{end}$ box weld elements occurs at an equivalent plastic strain of $0.115 \mathrm{in}$./in. (for the relatively tough material properties). Failure in the side plate and comb elements occurs at an equivalent plastic strain of $0.152 \mathrm{in}$./in. Failure in the side plate weld elements occurs at an equivalent plastic strain of 0.205 in./in. Figure D-193 shows some failure in the end boxes which is acceptable.
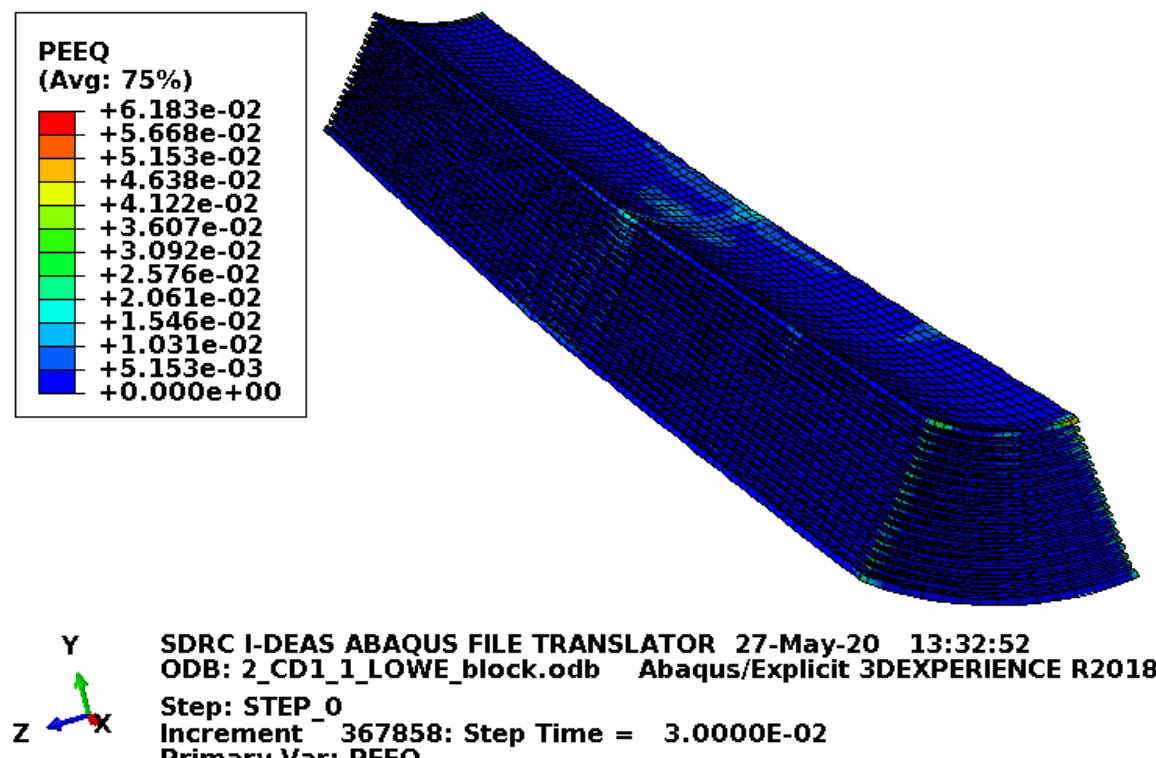

SDRC I-DEAS ABAQUS FILE TRANSLATOR 27-May-20 13:32:52 ODB: 2_CD1_1_LOWE_block.odb Abaqus/Explicit 3DEXPERIENCE R2018x

Step: STEP_o

Increment ${ }^{-367858: \text { Step Time }=3.0000 E-02}$

Primary Var: PEEQ

Figure D-194. Scope Part 2d (Table 3), Test 2 (Table 2) fuel plate equivalent strain. 
Figure D-194 shows the equivalent plastic strain in the fuel plates. Failure in these elements occurs at an equivalent plastic strain of $0.205 \mathrm{in}$./in. If element failure were to occur, the element would be removed from the model (thereby excluding its equivalent plastic strain from the maximum equivalent plastic strain for the plot). However, the missing element would be visible in the plot. Figure D-194 shows no failure in the fuel plates with margin.

\section{D3.3 Results for Scope Part 2 (Table 3), Test 3 (Table 2)}

The drop scenario considered in this section is a $30 \mathrm{ft}$ drop modeled as a side drop with the index lugs facing downward and the edge impacting slightly before the index lugs.

\section{D3.3.1 Results for Scope Part 2a (Table 3), Test 3 (Table 2)}

The FEA model results for the Scope Part $2 a$ (Table 3), Test 3 (Table 2) model are shown below in Figure D-195 to Figure D-197. The fuel element weighs $44 \mathrm{lbf}$ and the whole model is modeled with minimum material properties.

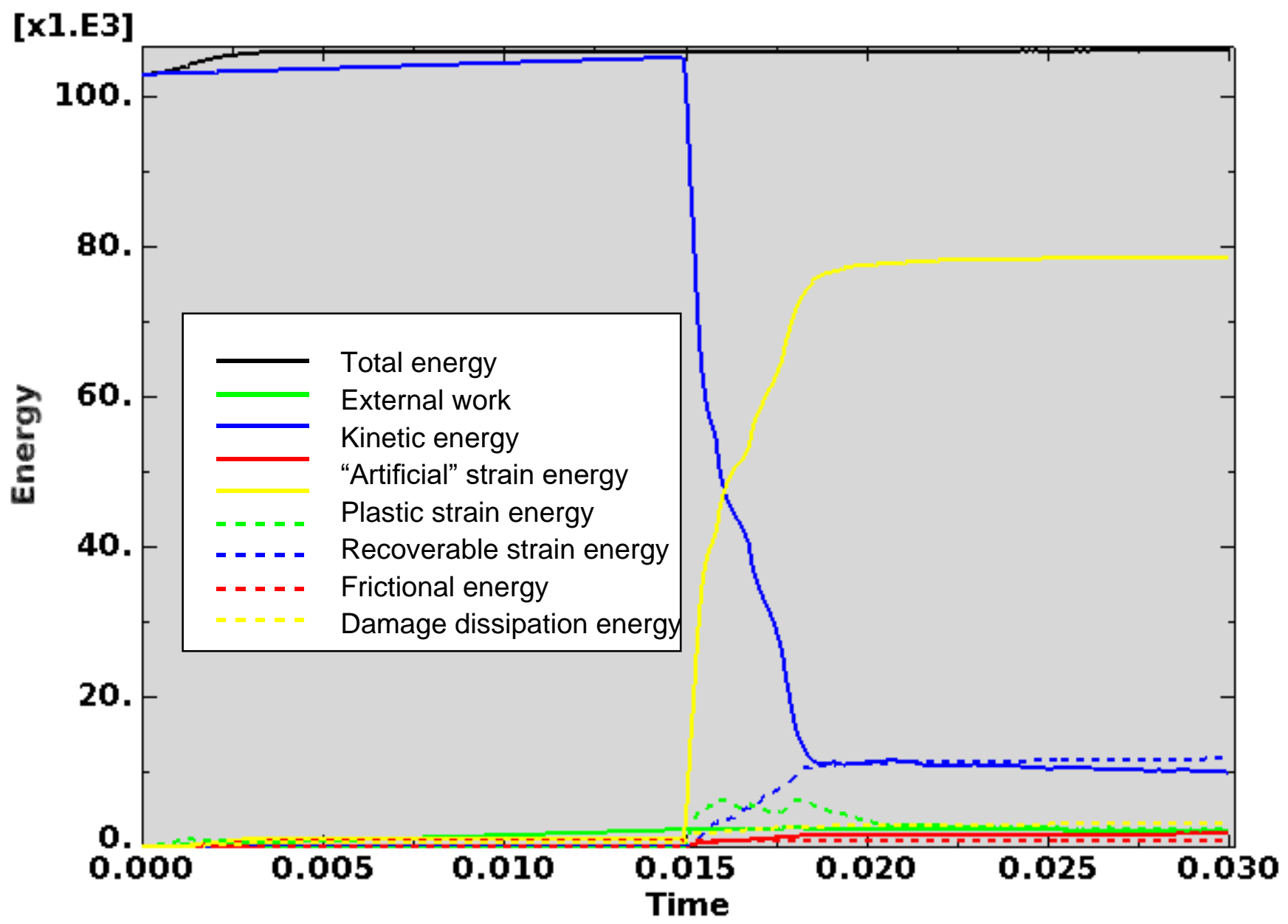

Figure D-195. Scope Part 2a (Table 3), Test 3 (Table 2) energy curves. 
Figure D-195 shows the energy curves for Scope Part 2a (Table 3), Test 3 (Table 2) drop scenario. These curves exhibit a stable shape. Artificial strain energy represents the energy required to keep reduced integration elements from taking on a zero-energy hourglass shape. As shown in Figure D-195, the artificial energy at the end of the model run is $1.6 \%$ of the total energy. Therefore, the potential error associated with artificial energy is not considered to be significant.

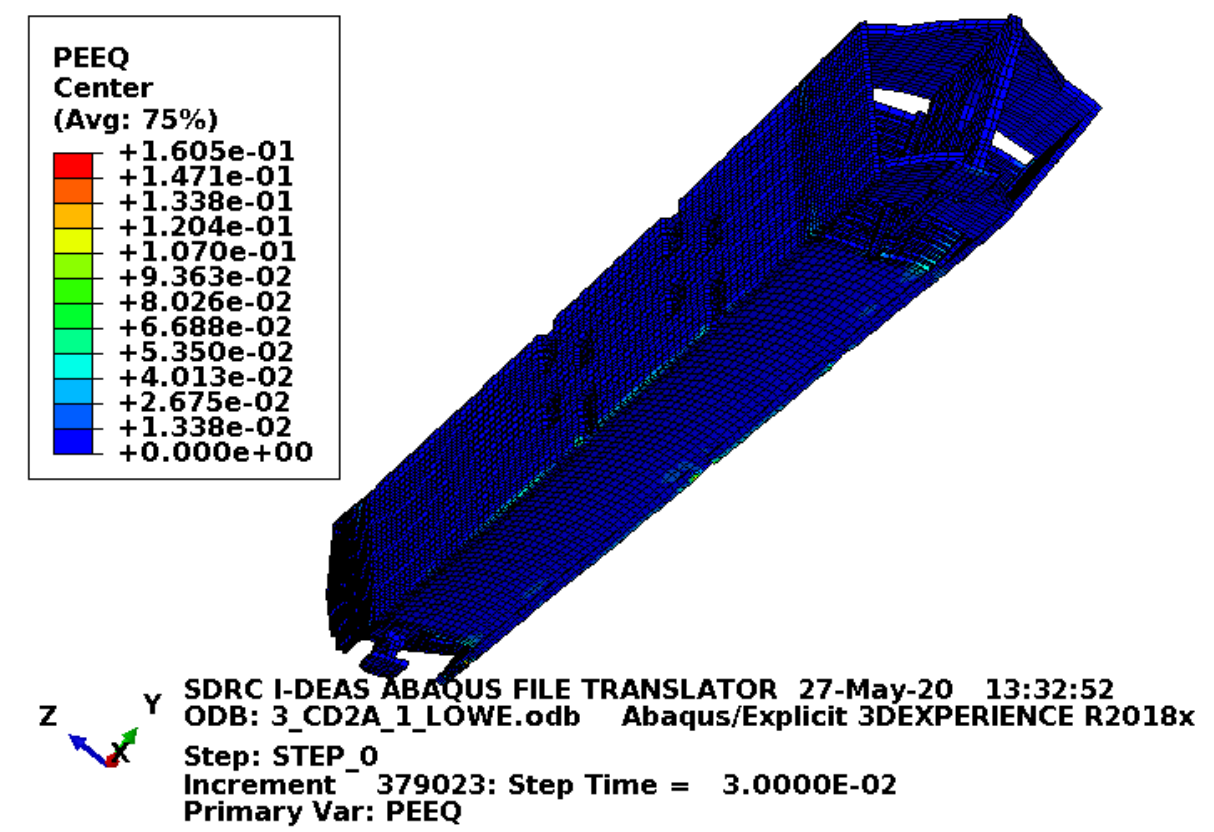

Figure D-196. Scope Part 2a (Table 3), Test 3 (Table 2) fuel element plastic equivalent strain.

Figure D-196 shows the equivalent plastic strain in the fuel element. Failure in the end box elements occurs at an equivalent plastic strain of $0.027 \mathrm{in}$./in. Failure in the end box weld elements occurs at an equivalent plastic strain of $0.032 \mathrm{in}$./in. Failure in the side plate and comb elements occurs at an equivalent plastic strain of $0.152 \mathrm{in}$./in. Failure in the side plate weld elements occurs at an equivalent plastic strain of 0.205 in./in. Figure D-196 shows a few failed elements in the end boxes and end box welds nearest the impact which is acceptable. 
ENGINEERING CALCULATIONS AND ANALYSIS

Drop Analysis of the Advanced Test Reactor Fresh Fuel Shipping Container with Heavier Low-Enriched Uranium Fuel Contents
ECAR-5224, Rev. 0 Page D177 of D293

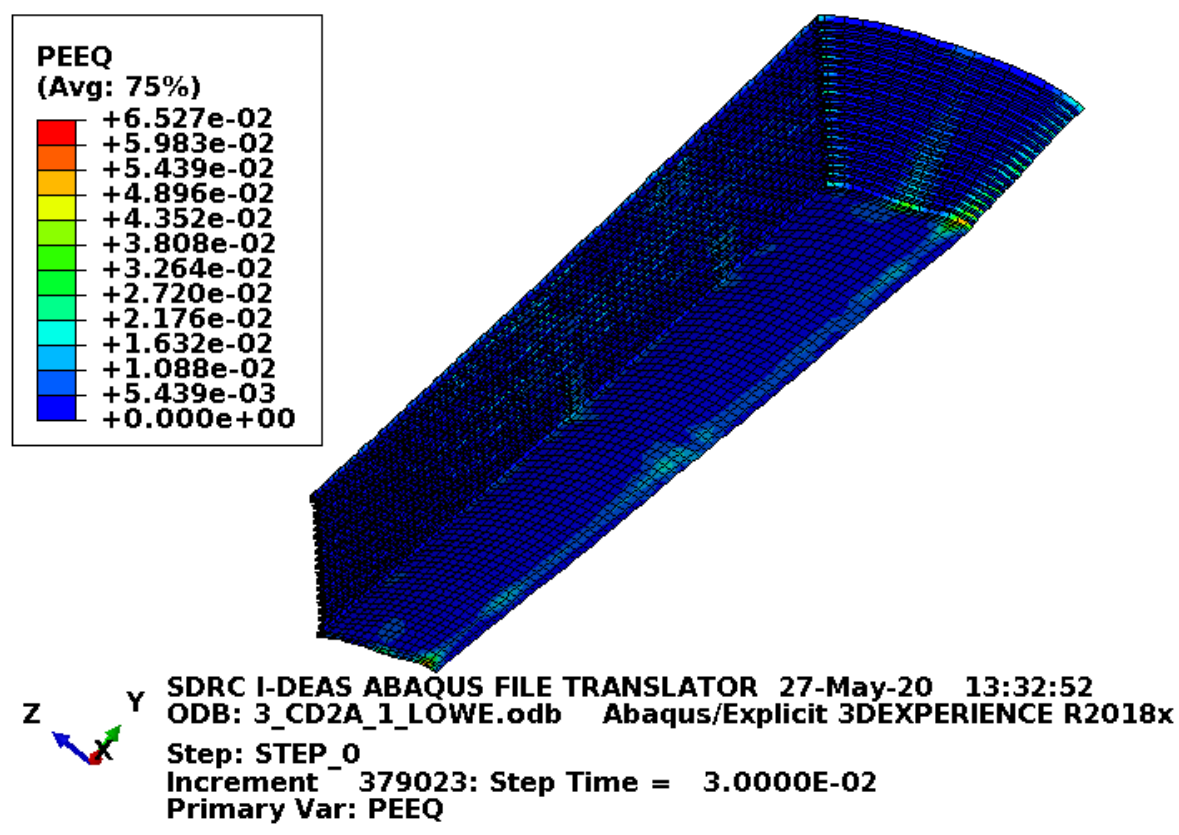

Figure D-197. Scope Part 2a (Table 3), Test 3 (Table 2) fuel plate equivalent strain.

Figure D-197 shows the equivalent plastic strain in the fuel plates. Failure in these elements occurs at an equivalent plastic strain of $0.205 \mathrm{in}$./in. If element failure were to occur, the element would be removed from the model (thereby excluding its equivalent plastic strain from the maximum equivalent plastic strain for the plot). However, the missing element would be visible in the plot. Figure D-197 shows no failure in the fuel plates with margin.

\section{D3.3.2 Results for Scope Part 2b (Table 3), Test 3 (Table 2)}

The FEA model results for the Scope Part $2 b$ (Table 3), Test 3 (Table 2) model are shown below in Figure D-198 to Figure D-200. The fuel element weighs $44 \mathrm{lbf}$ and the drop scenario is modeled with minimum material properties except the enclosure and end boxes, which are modeled with relatively tough material properties. 


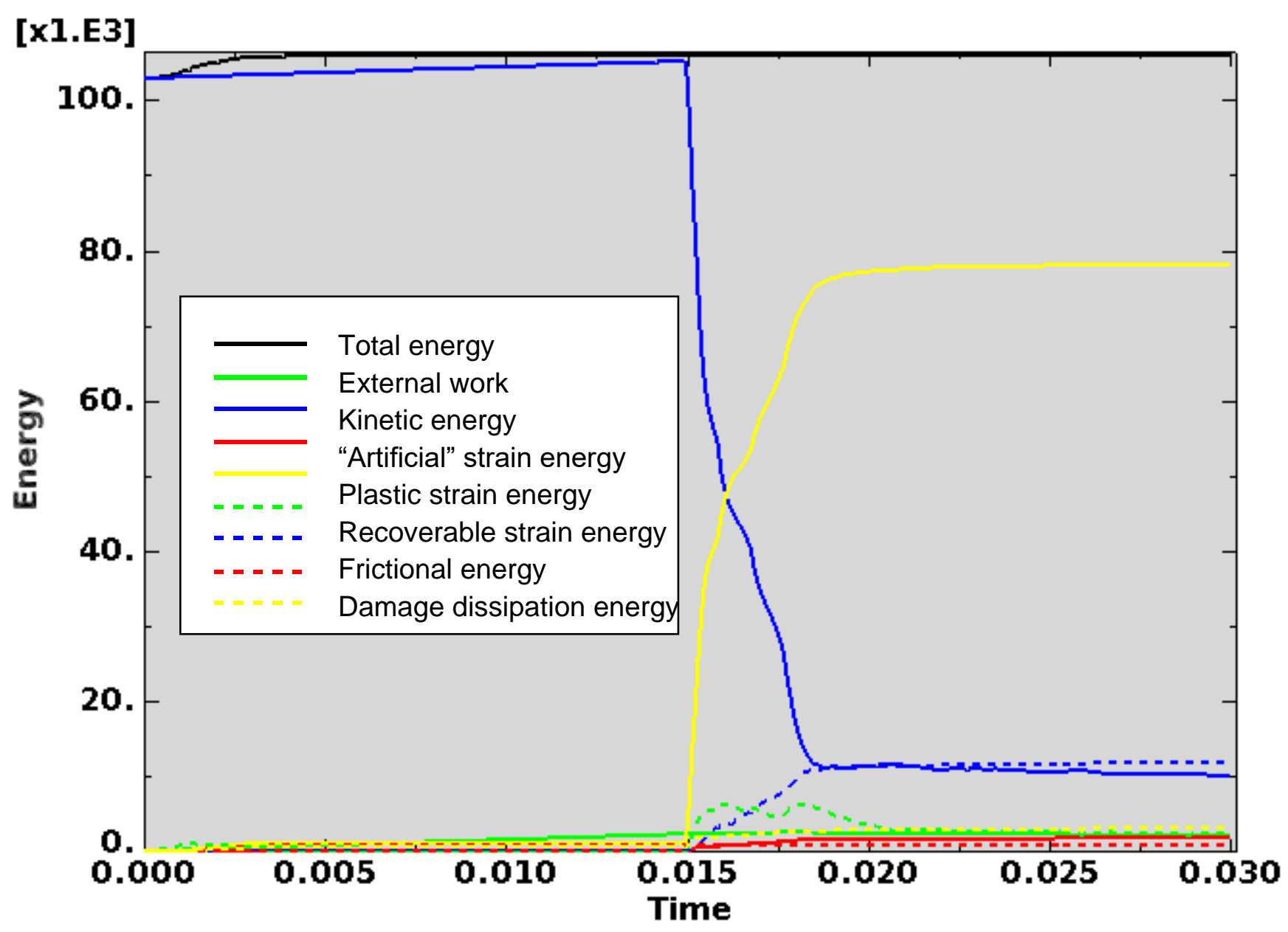

Figure D-198. Scope Part 2b (Table 3), Test 3 (Table 2) energy curves.

Figure D-198 shows the energy curves for Scope Part $2 b$ (Table 3), Test 3 (Table 2) drop scenario. These curves exhibit a stable shape. Artificial strain energy represents the energy required to keep reduced integration elements from taking on a zero-energy hourglass shape. As shown in Figure D-198, the artificial energy at the end of the model run is $1.7 \%$ of the total energy. Therefore, the potential error associated with artificial energy is not considered to be significant. 
ENGINEERING CALCULATIONS AND ANALYSIS

Drop Analysis of the Advanced Test Reactor Fresh Fuel Shipping Container with Heavier Low-Enriched Uranium Fuel Contents
ECAR-5224, Rev. 0

Page D179 of D293

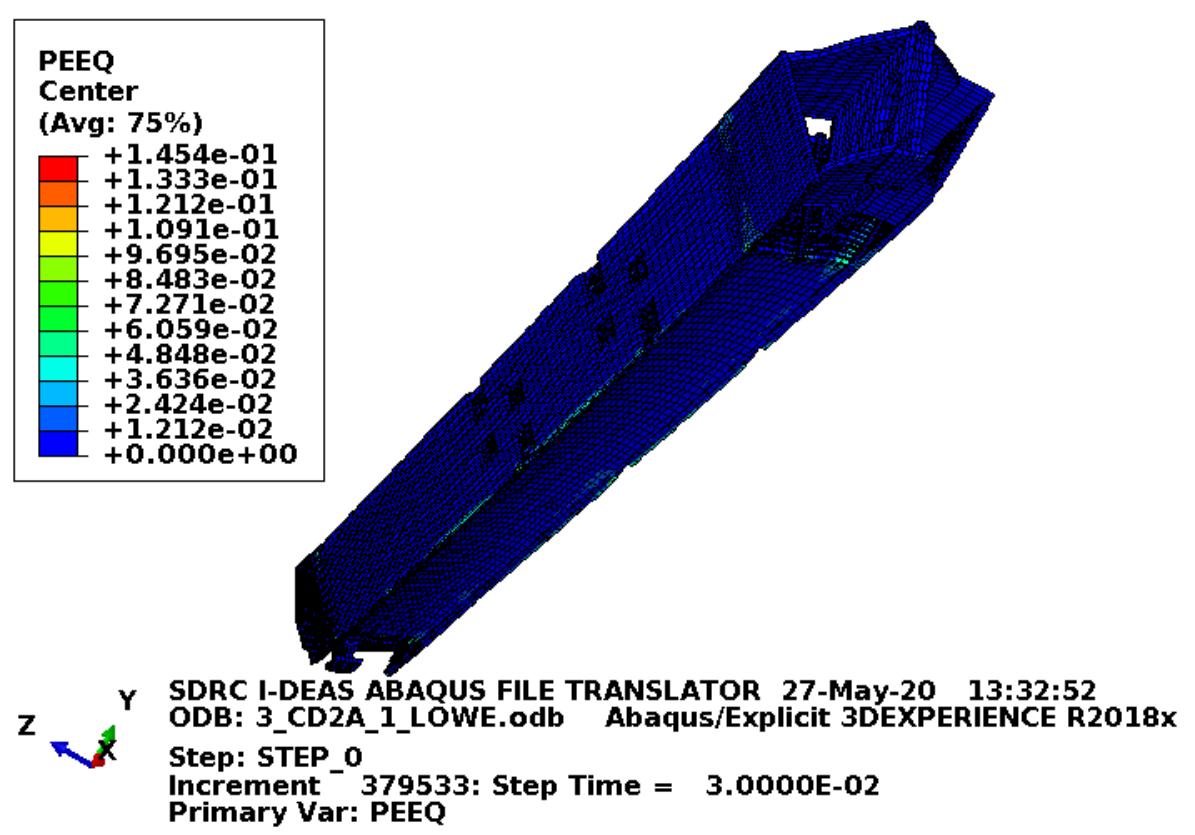

Figure D-199. Scope Part 2b (Table 3), Test 3 (Table 2) fuel element plastic equivalent strain.

Figure D-199 shows the equivalent plastic strain in the fuel element. Failure in the end box elements occurs at an equivalent plastic strain of $0.08 \mathrm{in./in.} \mathrm{(for} \mathrm{the} \mathrm{relatively} \mathrm{tough} \mathrm{material} \mathrm{properties).} \mathrm{Failure} \mathrm{in} \mathrm{the} \mathrm{end}$ box weld elements occurs at an equivalent plastic strain of $0.115 \mathrm{in}$./in. (for the relatively tough material properties). Failure in the side plate and comb elements occurs at an equivalent plastic strain of $0.152 \mathrm{in}$./in. Failure in the side plate weld elements occurs at an equivalent plastic strain of $0.205 \mathrm{in}$./in. If element failure were to occur, the element would be removed from the model (thereby excluding its equivalent plastic strain from the maximum equivalent plastic strain for the plot). However, the missing element would be visible in the plot. Figure D-199 shows no failure in the fuel element.

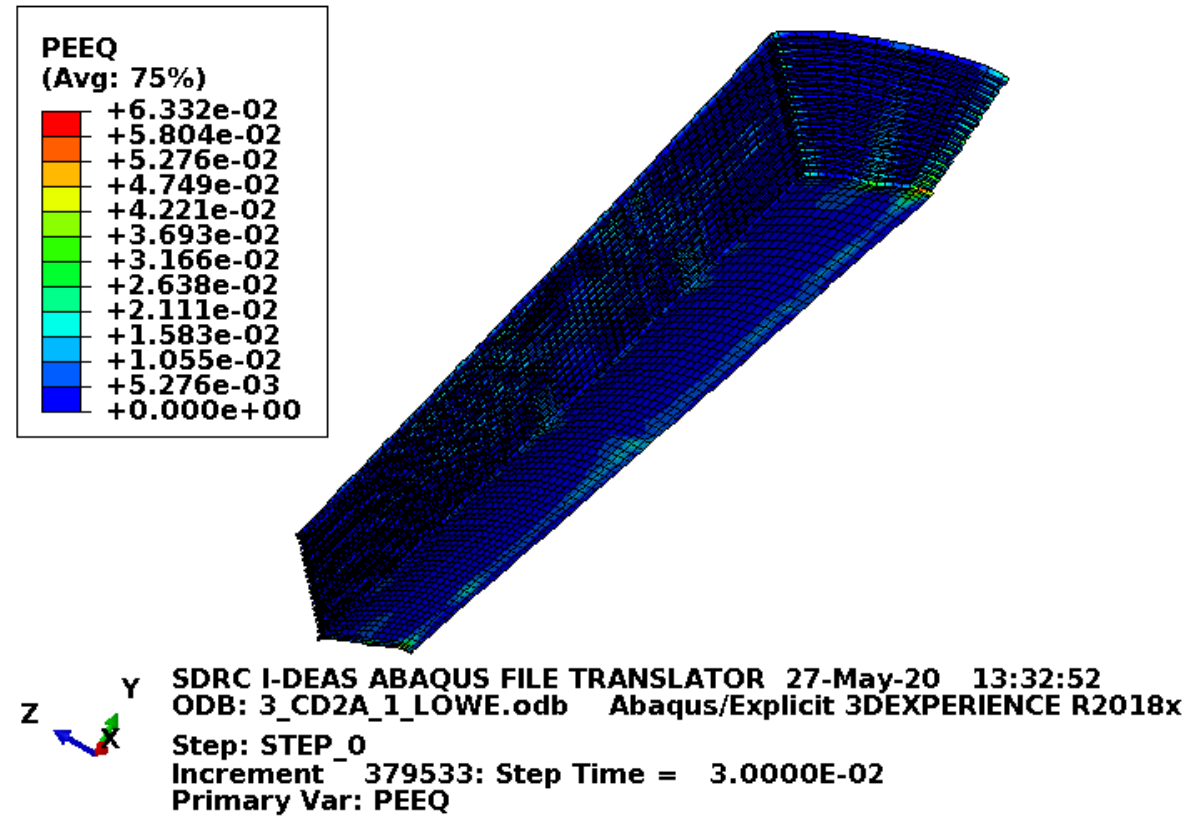

Figure D-200. Scope Part 2b (Table 3), Test 3 (Table 2) fuel plate equivalent strain. 
Figure D-200 shows the equivalent plastic strain in the fuel plates. Failure in these elements occurs at an equivalent plastic strain of $0.205 \mathrm{in}$./in. If element failure were to occur, the element would be removed from the model (thereby excluding its equivalent plastic strain from the maximum equivalent plastic strain for the plot). However, the missing element would be visible in the plot. Figure D-200 shows no failure in the fuel plates with margin.

\section{D3.3.3 Results for Scope Part 2c (Table 3), Test 3 (Table 2)}

The FEA model results for the Scope Part 2c (Table 3), Test 3 (Table 2) model are shown below in Figure D-201 to Figure D-203. The fuel element weighs $44 \mathrm{lbf}$ and the whole model is modeled with minimum material properties. This section includes the blocks as added fuel plate protection.

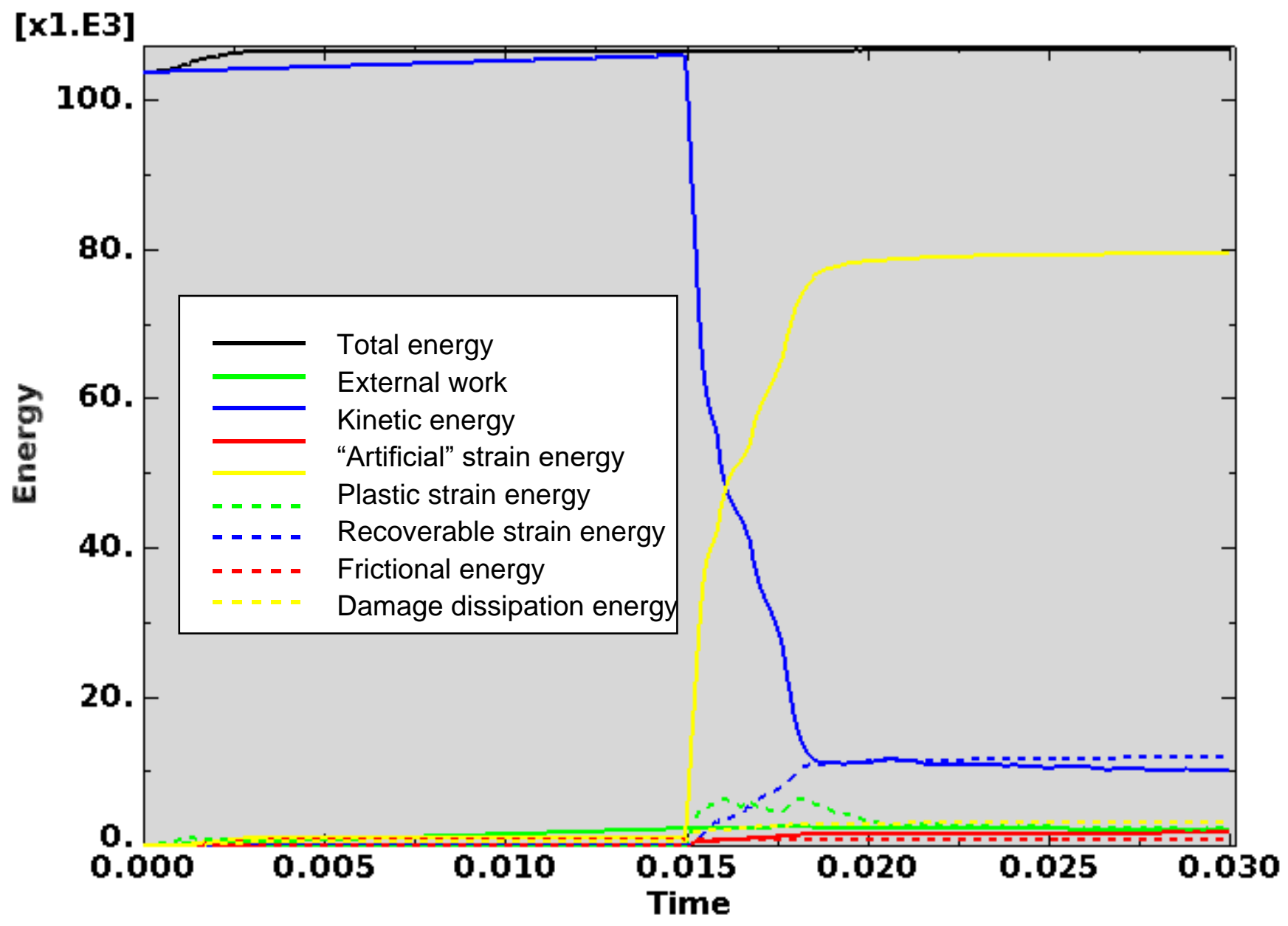

Figure D-201. Scope Part 2c (Table 3), Test 3 (Table 2) energy curves.

Figure D-201 shows the energy curves for Scope Part 2c (Table 3), Test 3 (Table 2) drop scenario. These curves exhibit a stable shape. Artificial strain energy represents the energy required to keep reduced integration elements from taking on a zero-energy hourglass shape. As shown in Figure D-201, the artificial energy at the end of the model run is $1.6 \%$ of the total energy. Therefore, the potential error associated with artificial energy is not considered to be significant. 
ENGINEERING CALCULATIONS AND ANALYSIS

Drop Analysis of the Advanced Test Reactor Fresh Fuel Shipping Container with Heavier Low-Enriched Uranium Fuel Contents
ECAR-5224, Rev. 0

Page D181 of D293

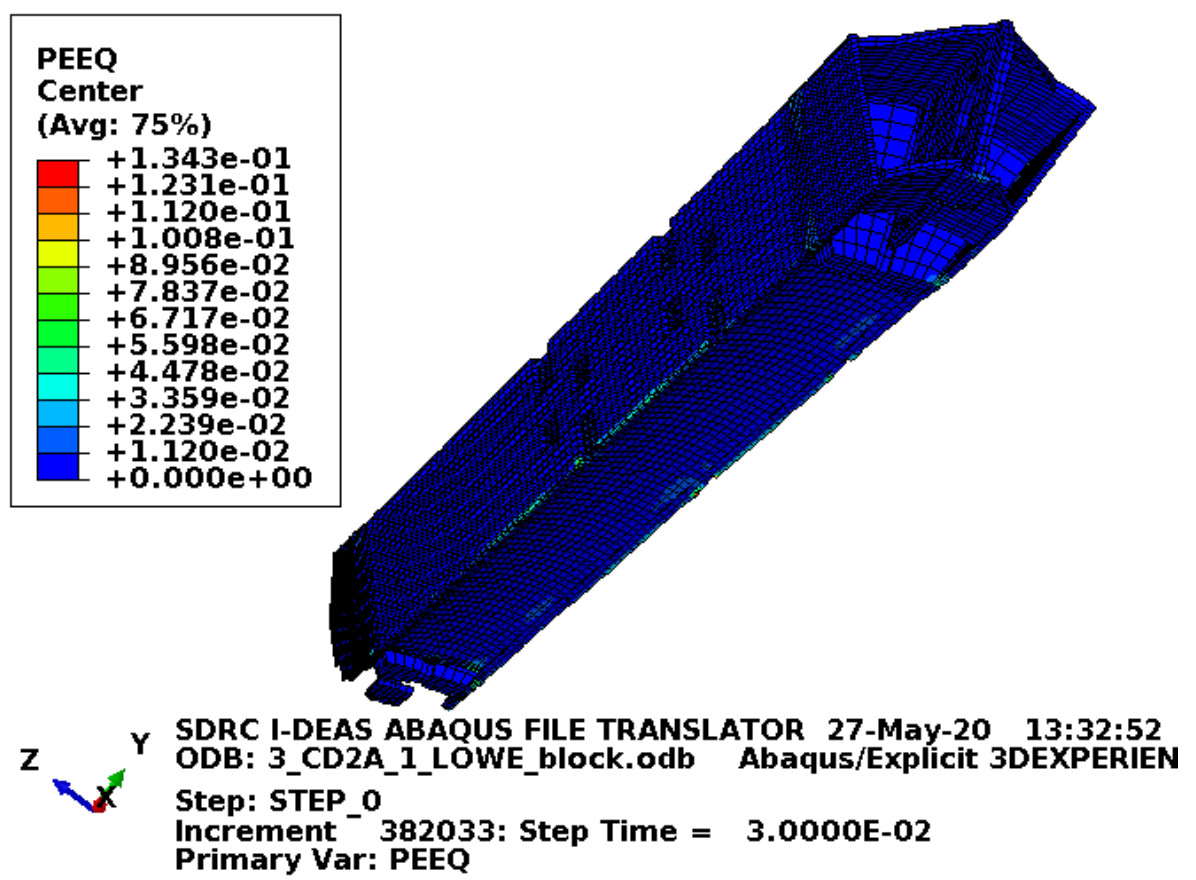

Figure D-202. Scope Part 2c (Table 3), Test 3 (Table 2) fuel element plastic equivalent strain.

Figure D-202 shows the equivalent plastic strain in the fuel element. Failure in the end box elements occurs at an equivalent plastic strain of $0.027 \mathrm{in}$./in. Failure in the end box weld elements occurs at an equivalent plastic strain of $0.032 \mathrm{in}$./in. Failure in the side plate and comb elements occurs at an equivalent plastic strain of $0.152 \mathrm{in./in.} \mathrm{Failure} \mathrm{in} \mathrm{the} \mathrm{side} \mathrm{plate} \mathrm{weld} \mathrm{elements} \mathrm{occurs} \mathrm{at} \mathrm{an} \mathrm{equivalent} \mathrm{plastic} \mathrm{strain} \mathrm{of}$ $0.205 \mathrm{in}$./in. If element failure were to occur, the element would be removed from the model (thereby excluding its equivalent plastic strain from the maximum equivalent plastic strain for the plot). However, the missing element would be visible in the plot. Figure D-202 shows a few failed elements in the end boxes and end box welds nearest the impact. 
ENGINEERING CALCULATIONS AND ANALYSIS

Drop Analysis of the Advanced Test Reactor Fresh Fuel Shipping Container with Heavier Low-Enriched Uranium Fuel Contents
ECAR-5224, Rev. 0

Page D182 of D293

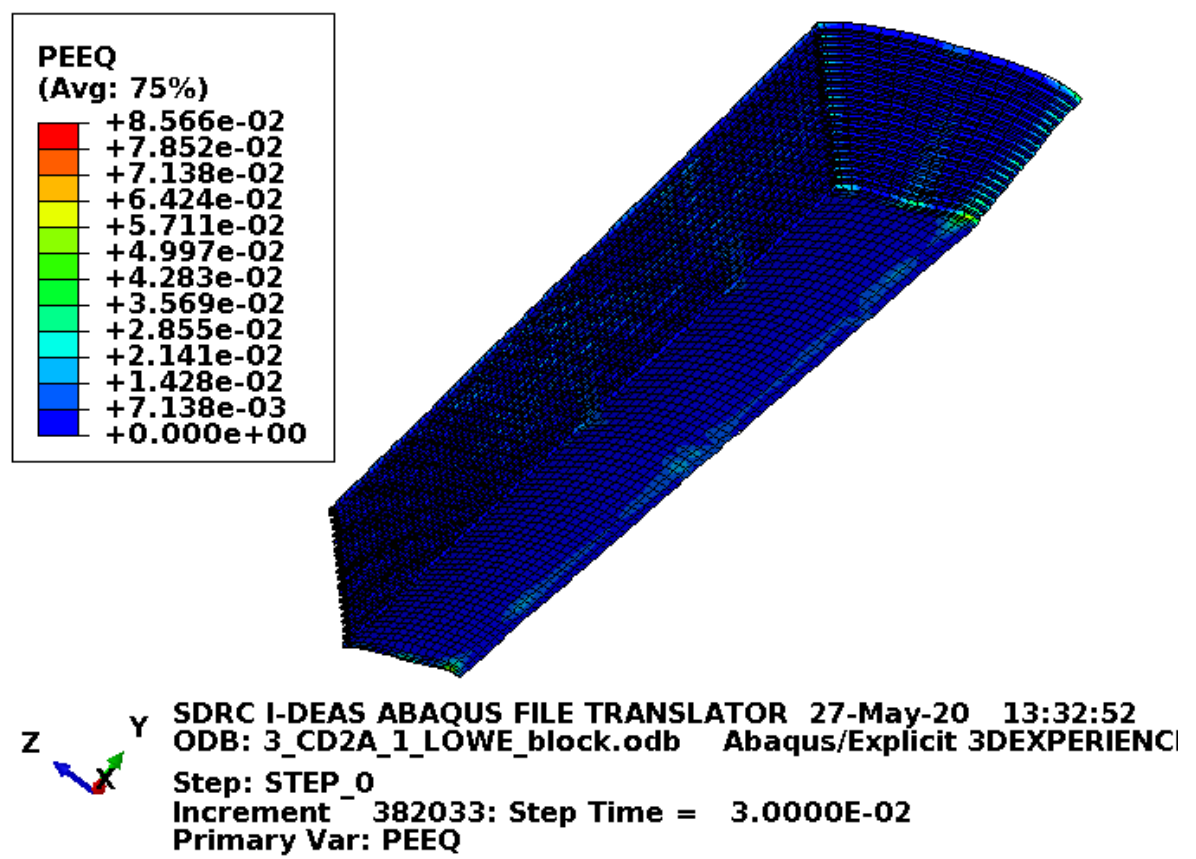

Figure D-203. Scope Part 2c (Table 3), Test 3 (Table 2) fuel plate equivalent strain.

Figure D-203 shows the equivalent plastic strain in the fuel plates. Failure in these elements occurs at an equivalent plastic strain of $0.205 \mathrm{in}$./in. If element failure were to occur, the element would be removed from the model (thereby excluding its equivalent plastic strain from the maximum equivalent plastic strain for the plot). However, the missing element would be visible in the plot. Figure D-203 shows no failure in the fuel plates with margin.

\section{D3.3.4 Results for Scope Part 2d (Table 3), Test 3 (Table 2)}

The FEA model results for the Scope Part 2d (Table 3), Test 3 (Table 2) model are shown below in Figure D-204 to Figure D-206. The fuel element weighs $44 \mathrm{lbf}$ and the drop scenario is modeled with minimum material properties except the enclosure and end boxes, which are modeled with relatively tough material properties. This section includes the blocks as added fuel plate protection. 


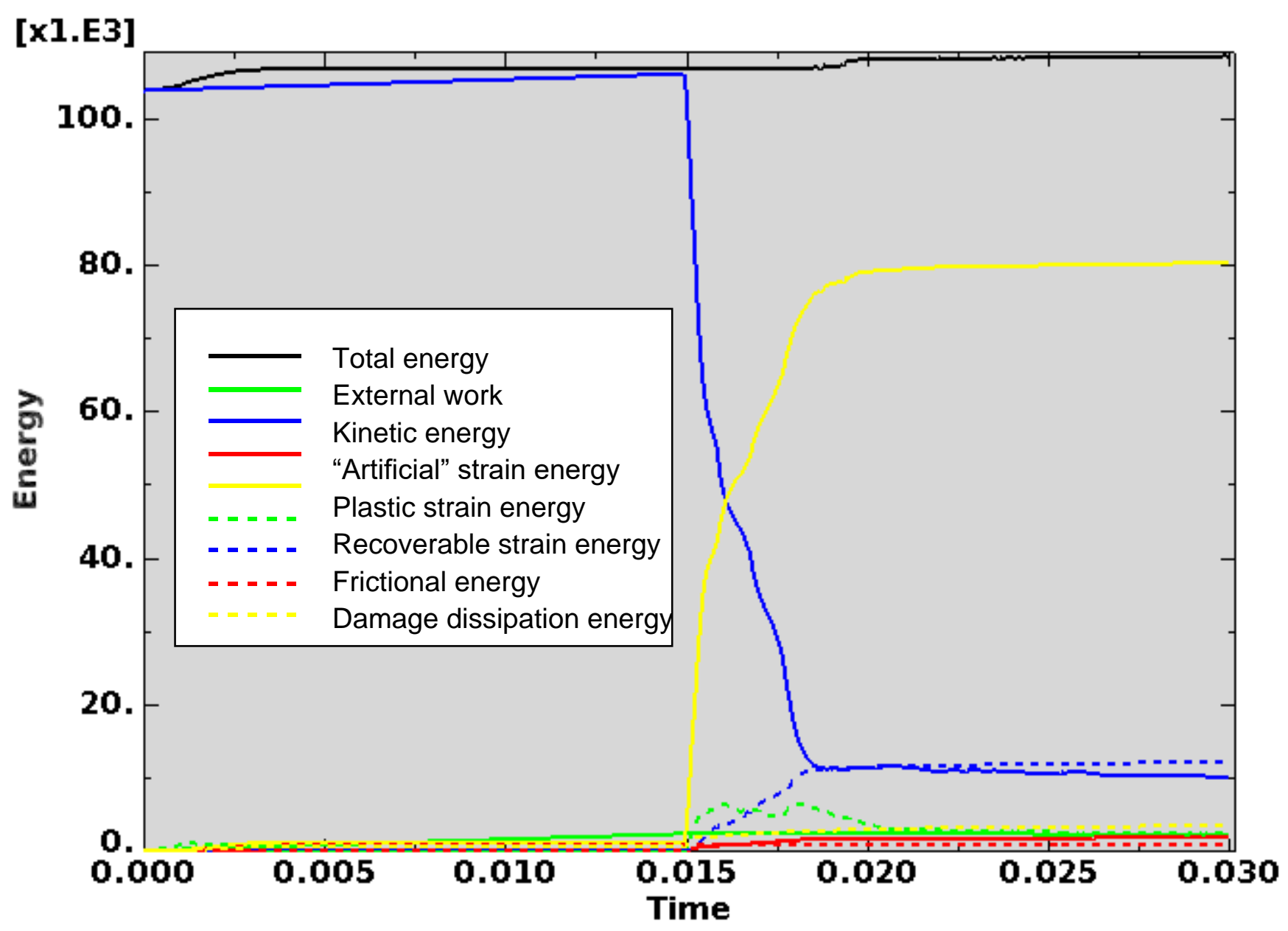

Figure D-204. Scope Part 2d (Table 3), Test 3 (Table 2) energy curves.

Figure D-204 shows the energy curves for Scope Part 2d (Table 3), Test 3 (Table 2) drop scenario. These curves exhibit a stable shape. Artificial strain energy represents the energy required to keep reduced integration elements from taking on a zero-energy hourglass shape. As shown in Figure D-204, the artificial energy at the end of the model run is $1.7 \%$ of the total energy. Therefore, the potential error associated with artificial energy is not considered to be significant. 
ENGINEERING CALCULATIONS AND ANALYSIS

Drop Analysis of the Advanced Test Reactor Fresh Fuel Shipping Container with Heavier Low-Enriched Uranium Fuel Contents
ECAR-5224, Rev. 0 Page D184 of D293

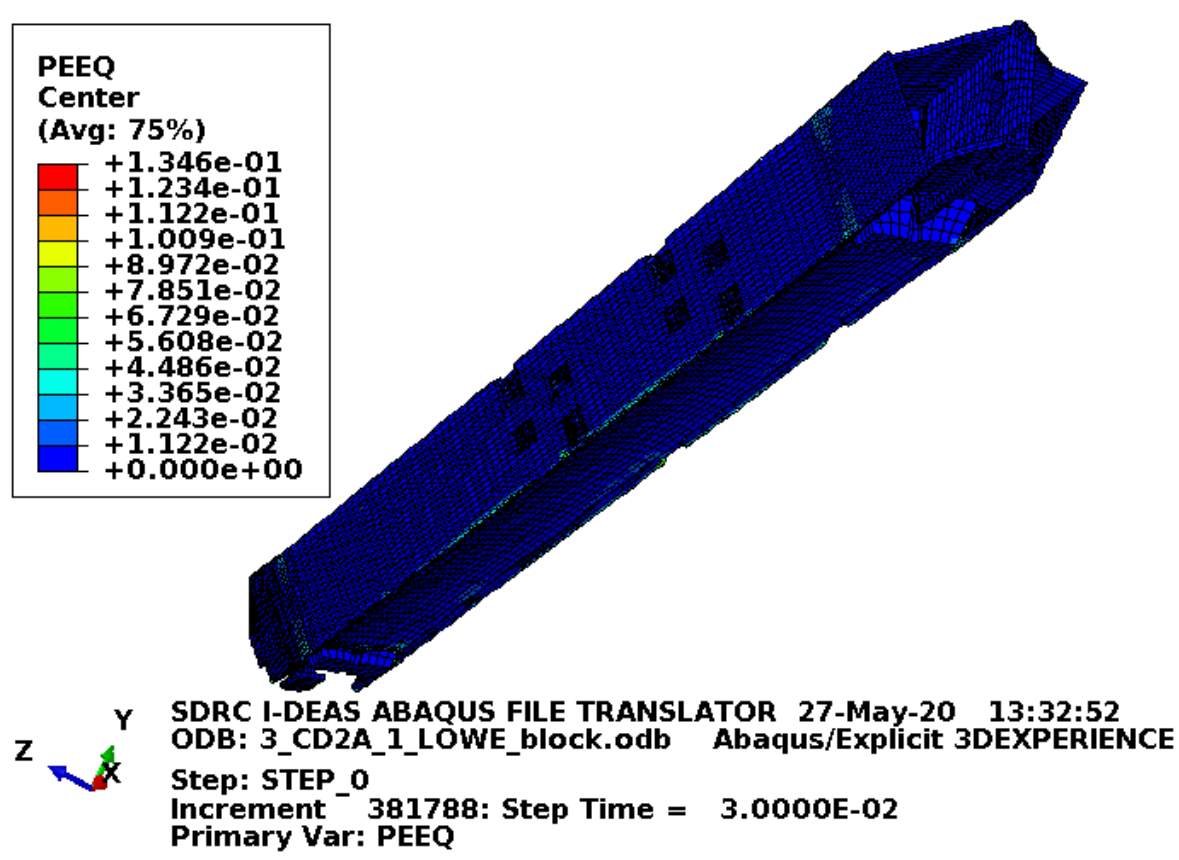

Figure D-205. Scope Part 2d (Table 3), Test 3 (Table 2) fuel element plastic equivalent strain.

Figure D-205 shows the equivalent plastic strain in the fuel element. Failure in the end box elements occurs at an equivalent plastic strain of $0.08 \mathrm{in./in.} \mathrm{(for} \mathrm{the} \mathrm{relatively} \mathrm{tough} \mathrm{material} \mathrm{properties).} \mathrm{Failure} \mathrm{in} \mathrm{the} \mathrm{end}$ box weld elements occurs at an equivalent plastic strain of $0.115 \mathrm{in}$./in. (for the relatively tough material properties). Failure in the side plate and comb elements occurs at an equivalent plastic strain of $0.152 \mathrm{in}$./in. Failure in the side plate weld elements occurs at an equivalent plastic strain of $0.205 \mathrm{in}$./in. If element failure were to occur, the element would be removed from the model (thereby excluding its equivalent plastic strain from the maximum equivalent plastic strain for the plot). However, the missing element would be visible in the plot. Figure D-205 shows no failure in the fuel element or blocks.

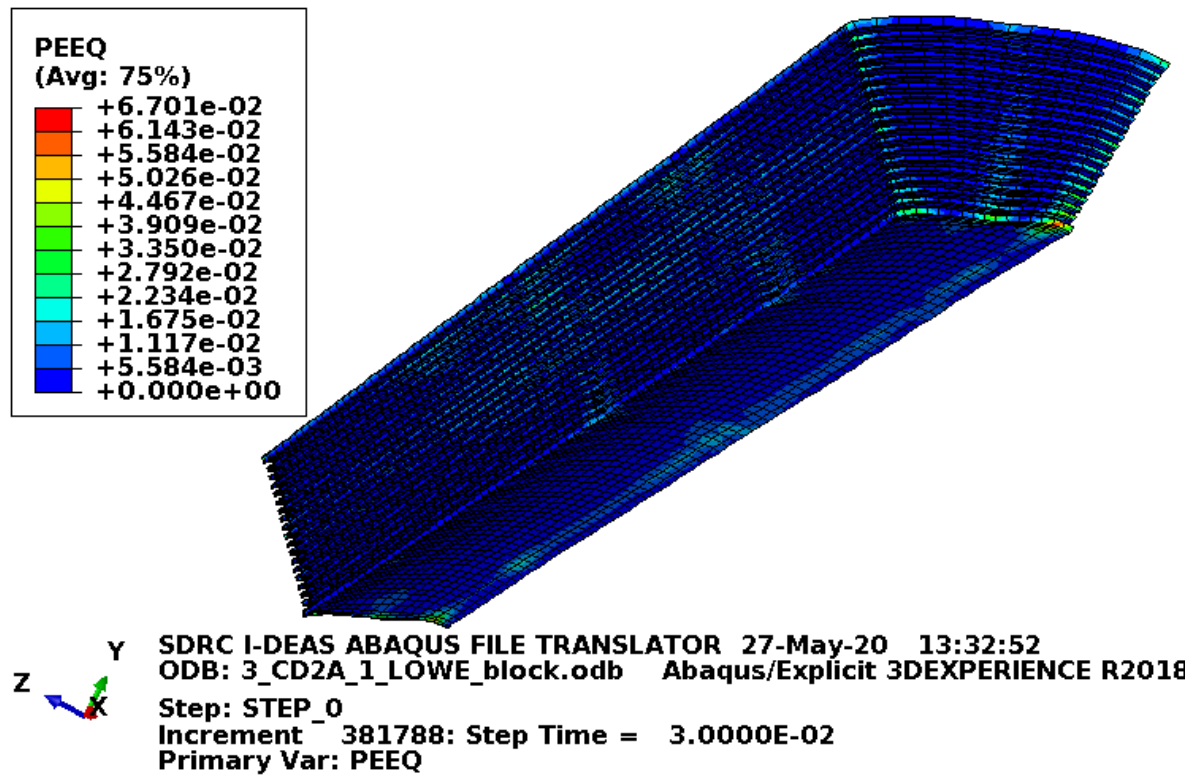

Figure D-206. Scope Part 2d (Table 3), Test 3 (Table 2) fuel plate equivalent strain. 
Figure D-206 shows the equivalent plastic strain in the fuel plates. Failure in these elements occurs at an equivalent plastic strain of $0.205 \mathrm{in}$./in. If element failure were to occur, the element would be removed from the model (thereby excluding its equivalent plastic strain from the maximum equivalent plastic strain for the plot). However, the missing element would be visible in the plot. Figure D-206 shows no failure in the fuel plates with margin.

\section{D3.4 Results for Scope Part 2 (Table 3), Test 5 (Table 2)}

The drop scenario considered in this section is a $30 \mathrm{ft}$ drop modeled as a flat side drop with the pockets and index lugs on the sides.

\section{D3.4.1 Results for Scope Part 2a (Table 3), Test 5 (Table 2)}

The FEA model results for the Scope Part $2 a$ (Table 3), Test 5 (Table 2) model are shown below in Figure D-207 to Figure D-209. The fuel element weighs $44 \mathrm{lbf}$ and the whole model is modeled with minimum material properties.

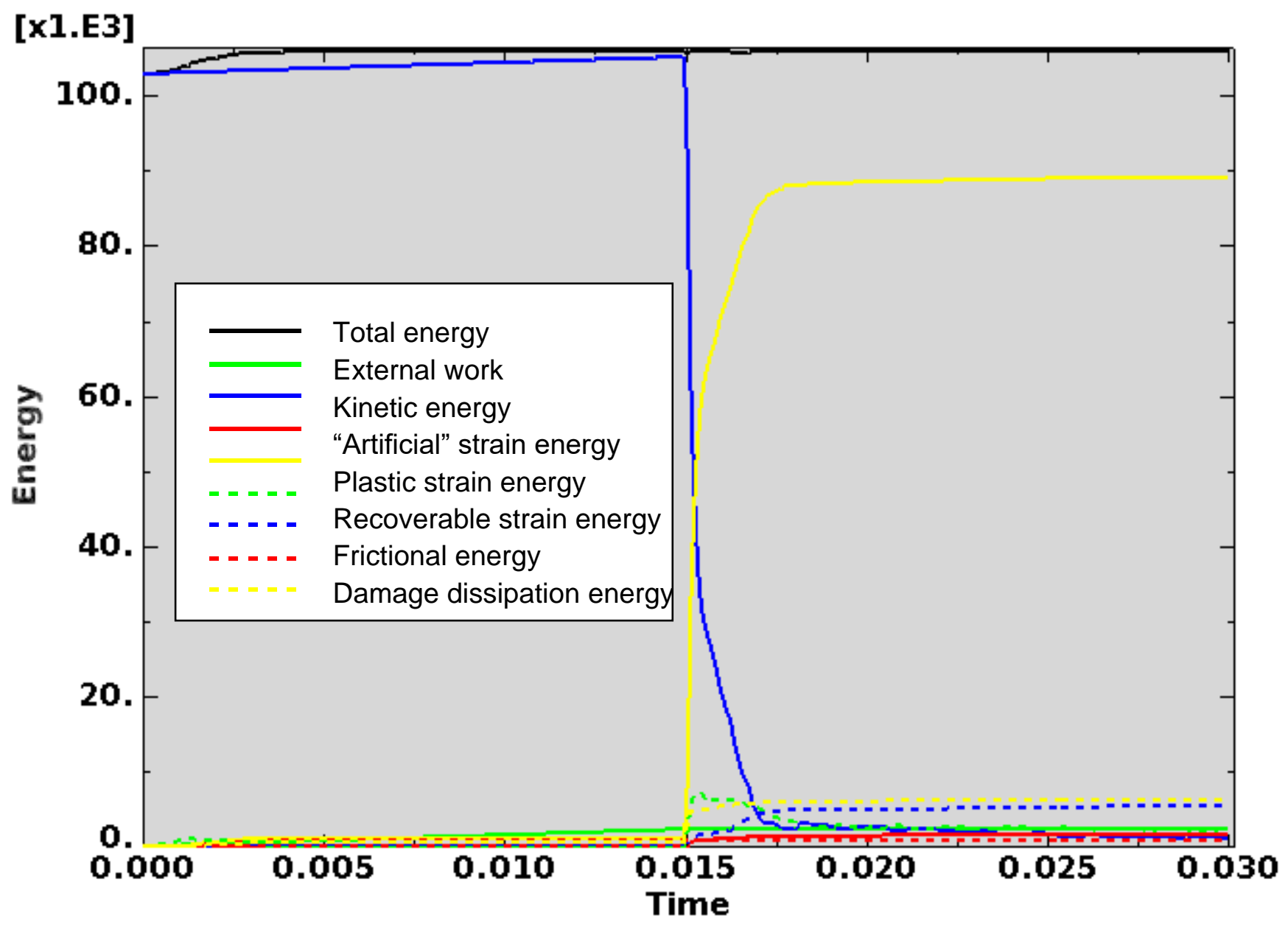

Figure D-207. Scope Part 2a (Table 3), Test 5 (Table 2) energy curves. 
Figure D-207 shows the energy curves for Scope Part 2a (Table 3), Test 5 (Table 2) drop scenario. These curves exhibit a stable shape. Artificial strain energy represents the energy required to keep reduced integration elements from taking on a zero-energy hourglass shape. As shown in Figure D-207, the artificial energy at the end of the model run is $1.6 \%$ of the total energy. Therefore, the potential error associated with artificial energy is not considered to be significant.

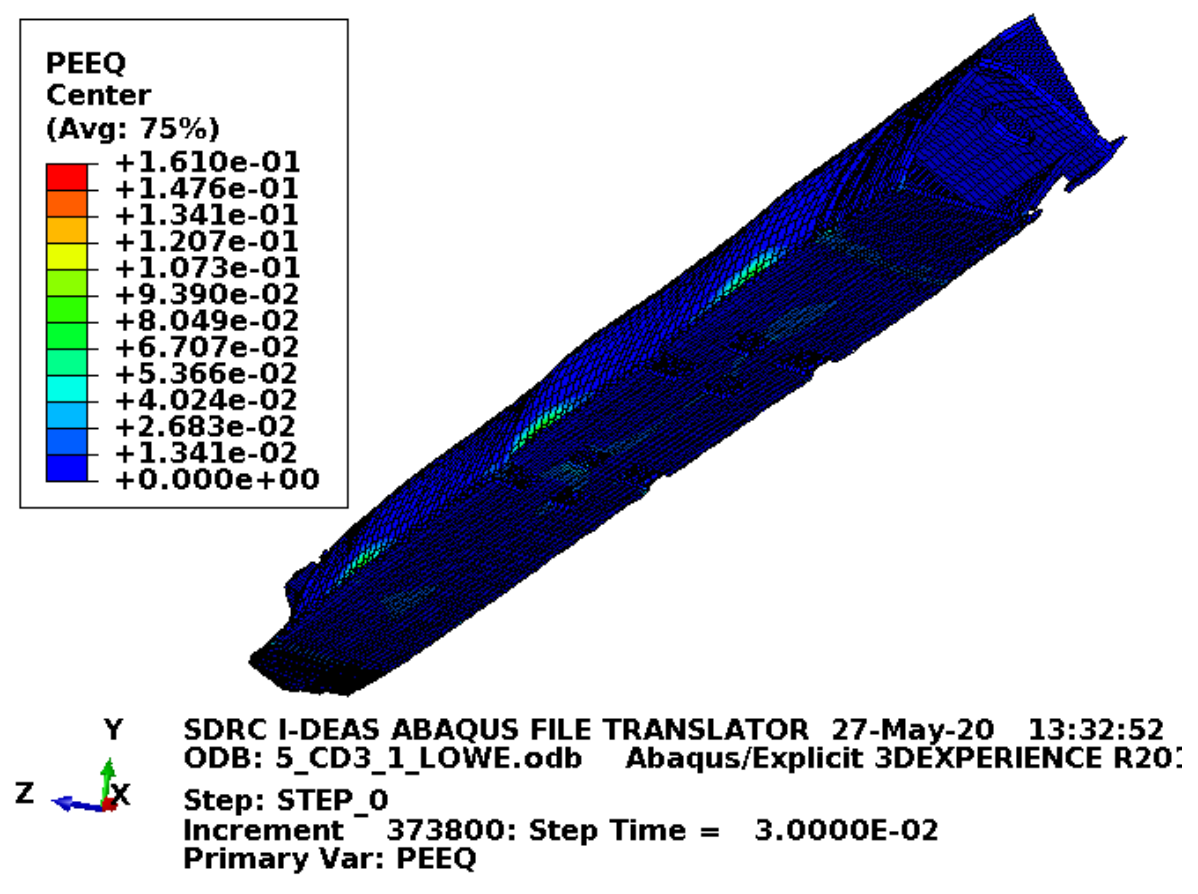

Figure D-208. Scope Part 2a (Table 3), Test 5 (Table 2) fuel element plastic equivalent strain.

Figure D-208 shows the equivalent plastic strain in the fuel element. Failure in the end box elements occurs at an equivalent plastic strain of $0.027 \mathrm{in}$./in. Failure in the end box weld elements occurs at an equivalent plastic strain of $0.032 \mathrm{in}$./in. Failure in the side plate and comb elements occurs at an equivalent plastic strain of $0.152 \mathrm{in./in.} \mathrm{Failure} \mathrm{in} \mathrm{the} \mathrm{side} \mathrm{plate} \mathrm{weld} \mathrm{elements} \mathrm{occurs} \mathrm{at} \mathrm{an} \mathrm{equivalent} \mathrm{plastic} \mathrm{strain} \mathrm{of}$ $0.205 \mathrm{in./in.} \mathrm{If} \mathrm{element} \mathrm{failure} \mathrm{were} \mathrm{to} \mathrm{occur,} \mathrm{the} \mathrm{element} \mathrm{would} \mathrm{be} \mathrm{removed} \mathrm{from} \mathrm{the} \mathrm{model} \mathrm{(thereby}$ excluding its equivalent plastic strain from the maximum equivalent plastic strain for the plot). However, the missing element would be visible in the plot. Figure D-208 shows failed elements in the end boxes which is acceptable. 
ENGINEERING CALCULATIONS AND ANALYSIS

Drop Analysis of the Advanced Test Reactor Fresh Fuel Shipping Container with Heavier Low-Enriched Uranium Fuel Contents

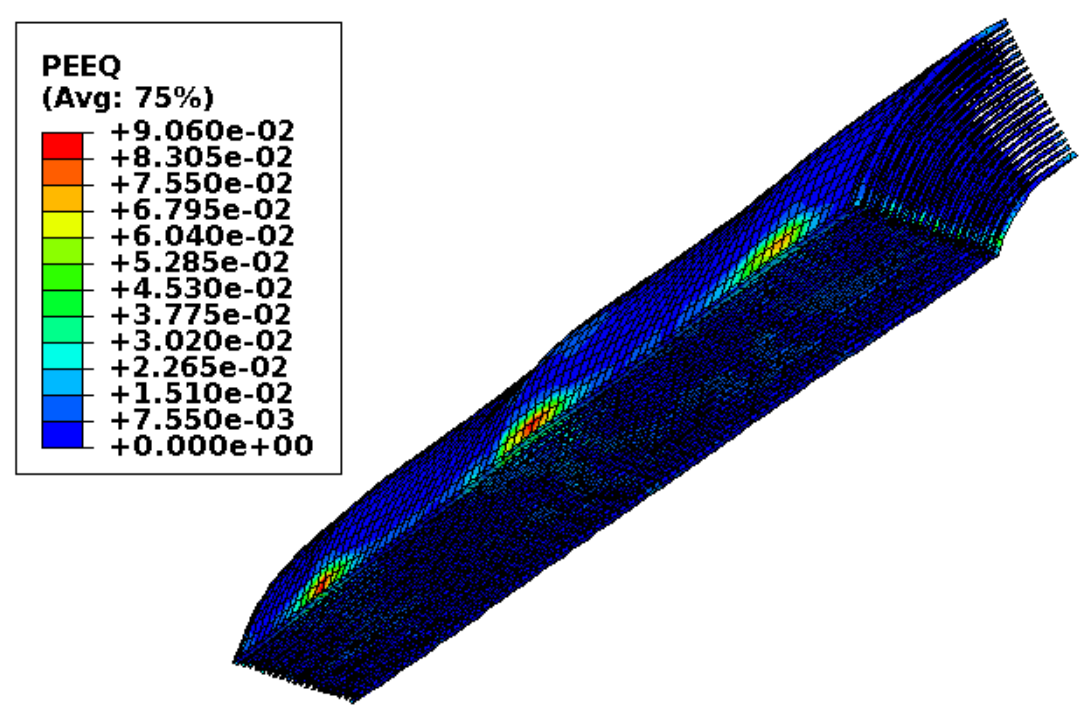

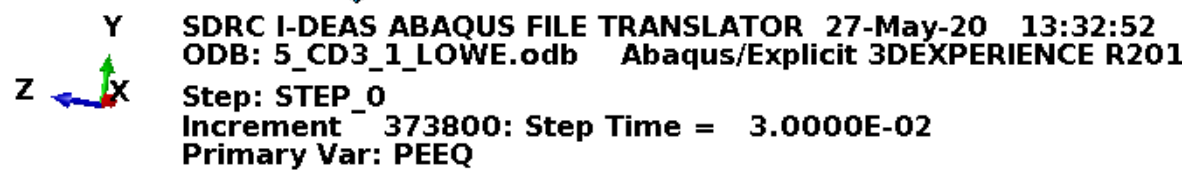

Figure D-209. Scope Part 2a (Table 3), Test 5 (Table 2) fuel plate equivalent strain.

Figure D-209 shows the equivalent plastic strain in the fuel plates. Failure in these elements occurs at an equivalent plastic strain of $0.205 \mathrm{in}$./in. If element failure were to occur, the element would be removed from the model (thereby excluding its equivalent plastic strain from the maximum equivalent plastic strain for the plot). However, the missing element would be visible in the plot. Figure D-209 shows no failure in the fuel plates with margin.

\section{D3.4.2 Results for Scope Part 2b (Table 3), Test 5 (Table 2)}

The FEA model results for the Scope Part $2 \mathrm{~b}$ (Table 3), Test 5 (Table 2) model are shown below in Figure D-210 to Figure D-212. The fuel element weighs $44 \mathrm{lbf}$ and the drop scenario is modeled with minimum material properties except the enclosure and end boxes, which are modeled with relatively tough material properties. 


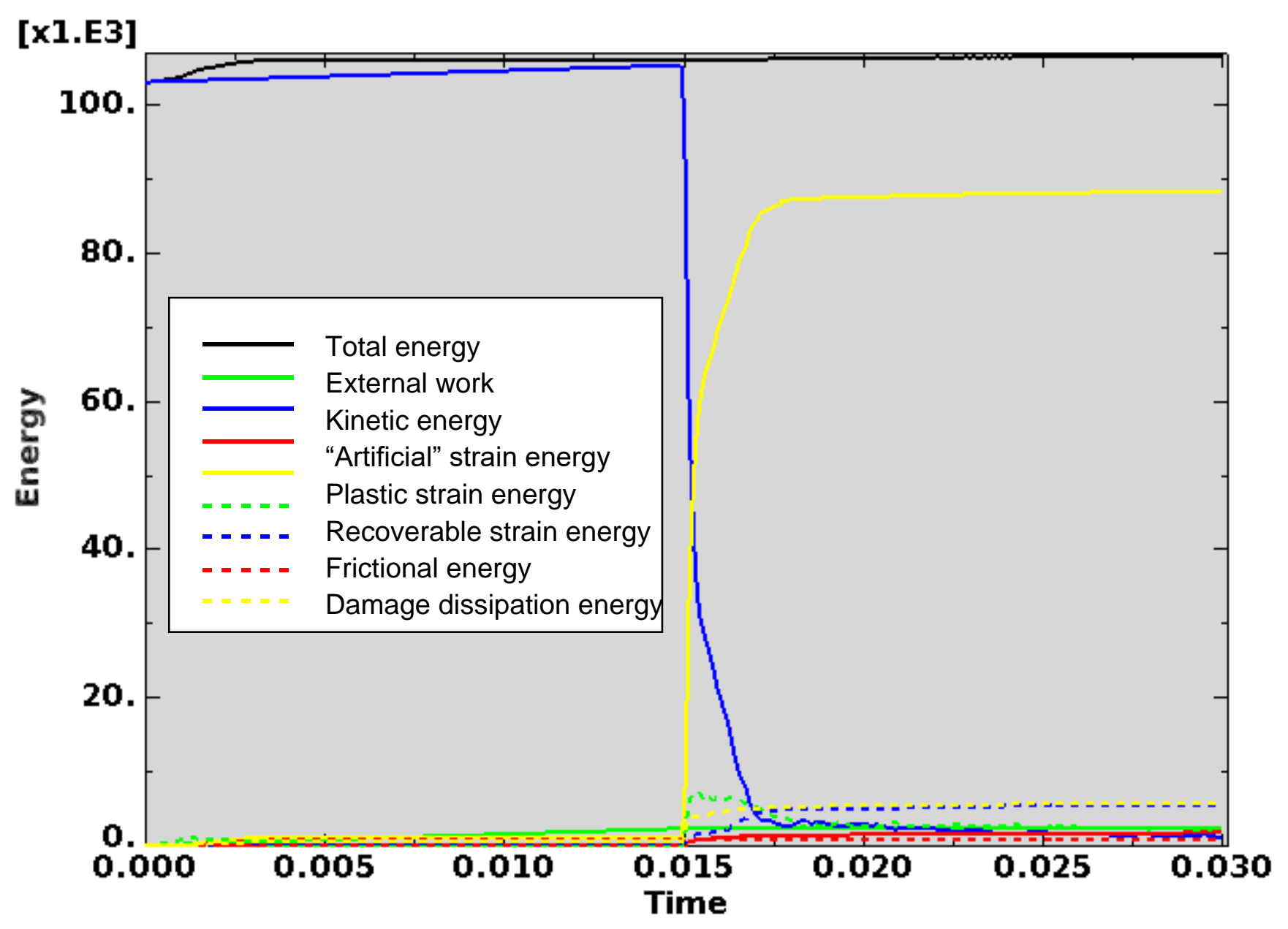

Figure D-210. Scope Part 2b (Table 3), Test 5 (Table 2) energy curves.

Figure D-210 shows the energy curves for Scope Part $2 b$ (Table 3), Test 5 (Table 2) drop scenario. These curves exhibit a stable shape. Artificial strain energy represents the energy required to keep reduced integration elements from taking on a zero-energy hourglass shape. As shown in Figure D-210, the artificial energy at the end of the model run is $1.6 \%$ of the total energy. Therefore, the potential error associated with artificial energy is not considered to be significant. 
ENGINEERING CALCULATIONS AND ANALYSIS

Drop Analysis of the Advanced Test Reactor Fresh Fuel Shipping Container with Heavier Low-Enriched Uranium Fuel Contents

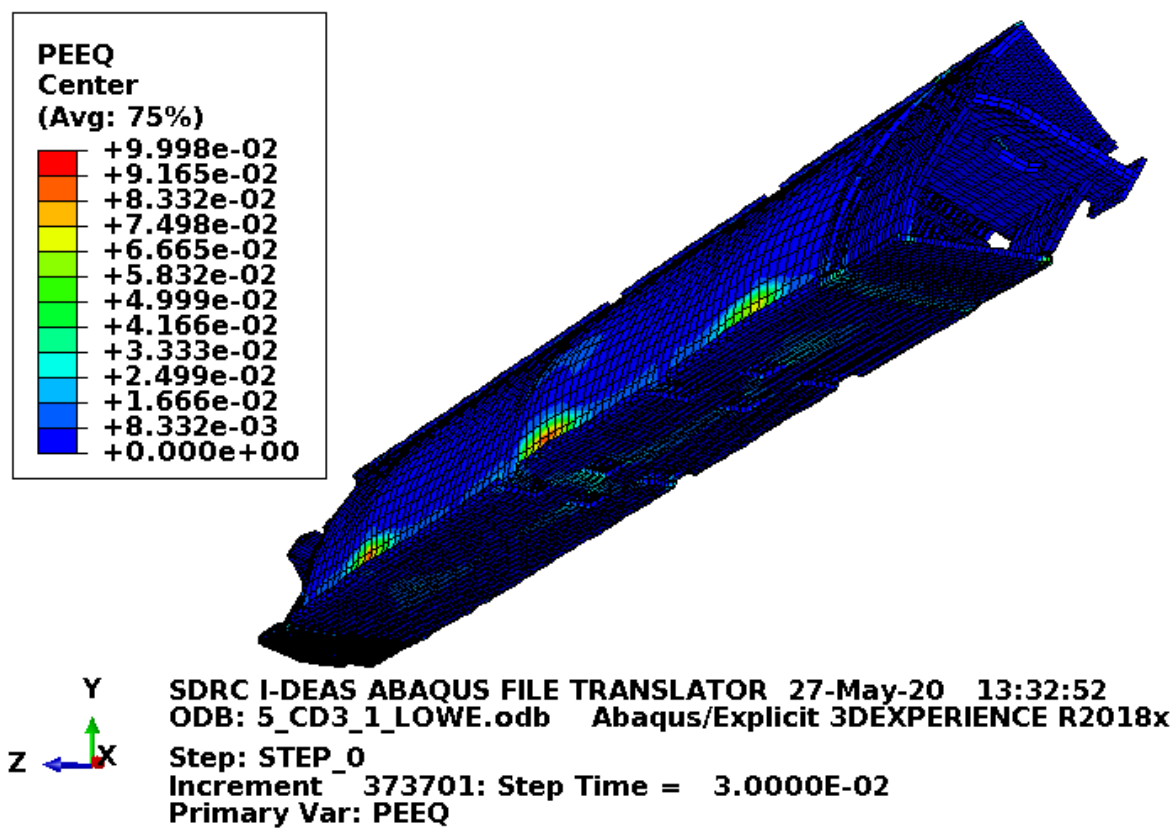

Figure D-211. Scope Part 2b (Table 3), Test 5 (Table 2) fuel element plastic equivalent strain.

Figure D-211 shows the equivalent plastic strain in the fuel element. Failure in the end box elements occurs at an equivalent plastic strain of $0.08 \mathrm{in./in.} \mathrm{(for} \mathrm{the} \mathrm{relatively} \mathrm{tough} \mathrm{material} \mathrm{properties).} \mathrm{Failure} \mathrm{in} \mathrm{the} \mathrm{end}$ box weld elements occurs at an equivalent plastic strain of $0.115 \mathrm{in}$./in. (for the relatively tough material properties). Failure in the side plate and comb elements occurs at an equivalent plastic strain of $0.152 \mathrm{in}$./in. Failure in the side plate weld elements occurs at an equivalent plastic strain of $0.205 \mathrm{in}$./in. If element failure were to occur, the element would be removed from the model (thereby excluding its equivalent plastic strain from the maximum equivalent plastic strain for the plot). However, the missing element would be visible in the plot. Figure D-211 shows no failure in the fuel element. 


\section{ENGINEERING CALCULATIONS AND ANALYSIS}

Drop Analysis of the Advanced Test Reactor Fresh Fuel Shipping Container with Heavier Low-Enriched Uranium Fuel Contents

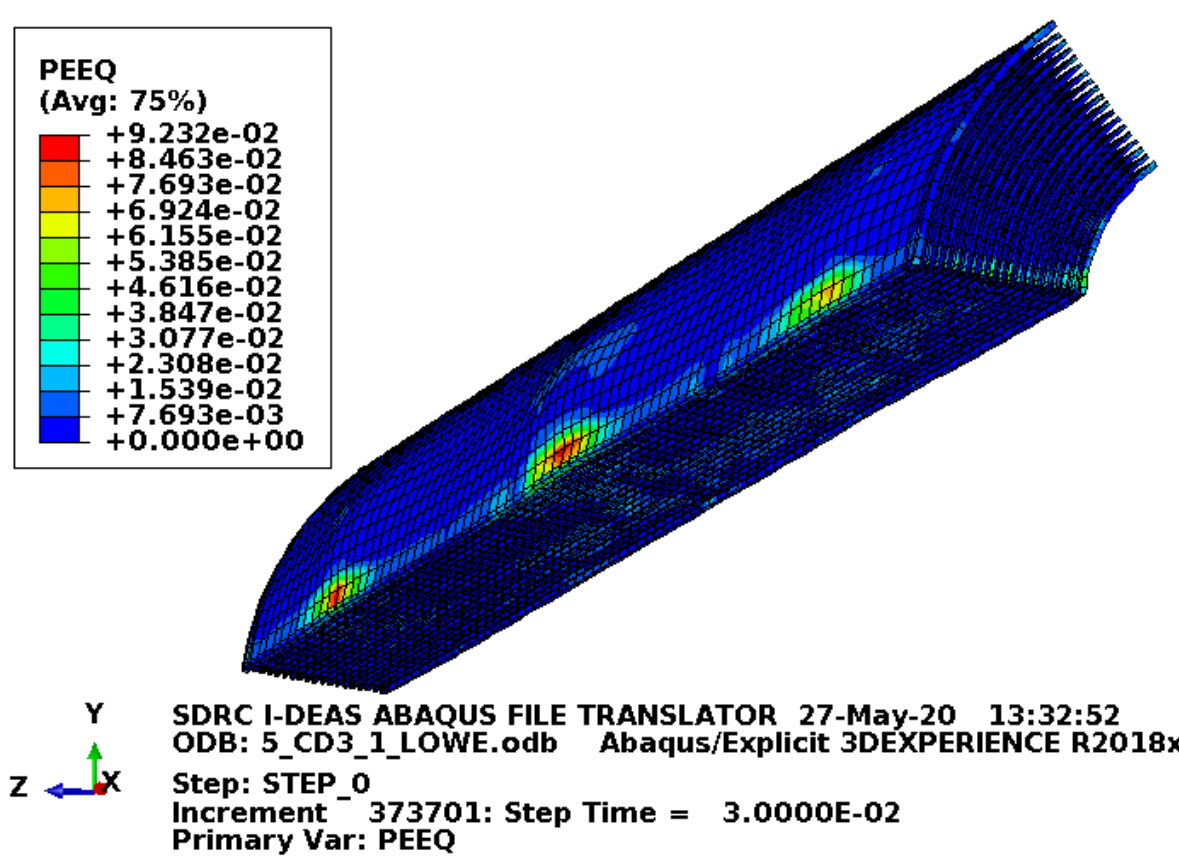

Figure D-212. Scope Part 2b (Table 3), Test 5 (Table 2) fuel plate equivalent strain.

Figure D-212 shows the equivalent plastic strain in the fuel plates. Failure in these elements occurs at an equivalent plastic strain of $0.205 \mathrm{in}$./in. If element failure were to occur, the element would be removed from the model (thereby excluding its equivalent plastic strain from the maximum equivalent plastic strain for the plot). However, the missing element would be visible in the plot. Figure D-212 shows no failure in the fuel plates with margin.

\section{D3.4.3 Results for Scope Part 2c (Table 3), Test 5 (Table 2)}

The FEA model results for the Scope Part 2c (Table 3), Test 5 (Table 2) model are shown below in Figure D-213 to Figure D-215. The fuel element weighs $44 \mathrm{lbf}$ and the whole model is modeled with minimum material properties. This section includes the blocks as added fuel plate protection. 


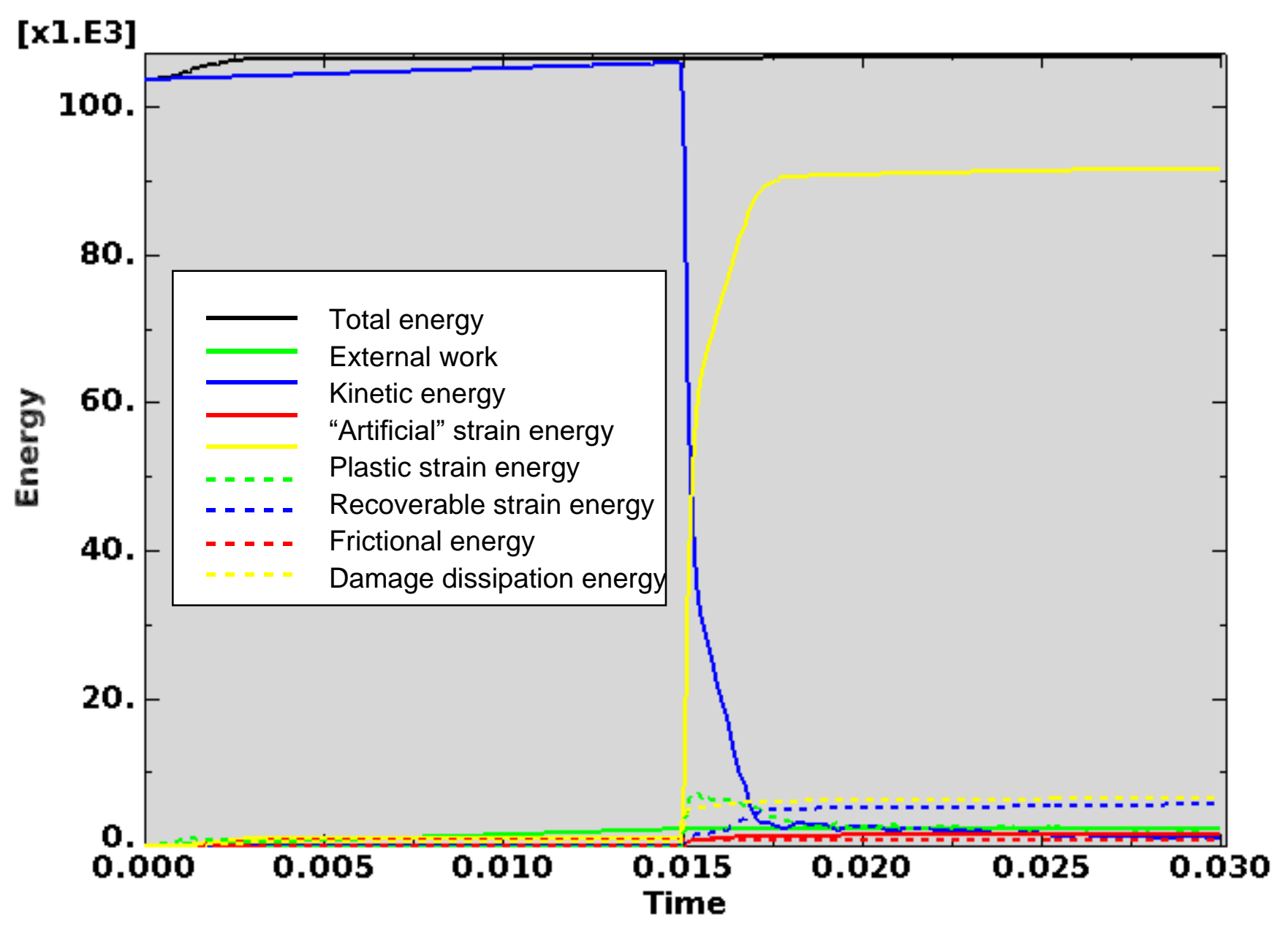

Figure D-213. Scope Part 2c (Table 3), Test 5 (Table 2) energy curves.

Figure D-213 shows the energy curves for Scope Part 2c (Table 3), Test 5 (Table 2) drop scenario. These curves exhibit a stable shape. Artificial strain energy represents the energy required to keep reduced integration elements from taking on a zero-energy hourglass shape. As shown in Figure D-213, the artificial energy at the end of the model run is $1.6 \%$ of the total energy. Therefore, the potential error associated with artificial energy is not considered to be significant. 
ENGINEERING CALCULATIONS AND ANALYSIS

Drop Analysis of the Advanced Test Reactor Fresh Fuel Shipping Container with Heavier Low-Enriched Uranium Fuel Contents

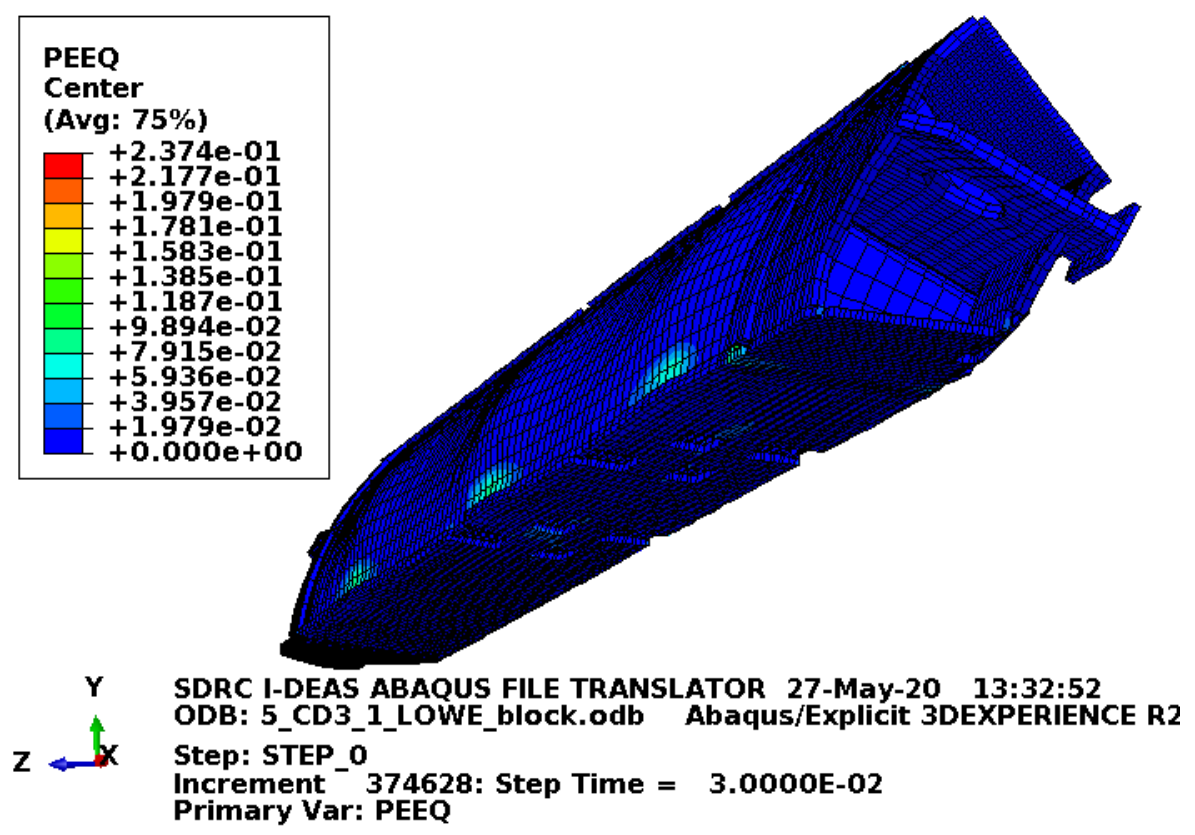

Figure D-214. Scope Part 2c (Table 3), Test 5 (Table 2) fuel element plastic equivalent strain.

Figure D-214 shows the equivalent plastic strain in the fuel element. Failure in the end box elements occurs at an equivalent plastic strain of $0.027 \mathrm{in}$./in. Failure in the end box weld elements occurs at an equivalent plastic strain of 0.032 in./in. Failure in the side plate and comb elements occurs at an equivalent plastic strain of $0.152 \mathrm{in./in.} \mathrm{Failure} \mathrm{in} \mathrm{the} \mathrm{side} \mathrm{plate} \mathrm{weld} \mathrm{elements} \mathrm{occurs} \mathrm{at} \mathrm{an} \mathrm{equivalent} \mathrm{plastic} \mathrm{strain} \mathrm{of}$ $0.205 \mathrm{in./in.} \mathrm{If} \mathrm{element} \mathrm{failure} \mathrm{were} \mathrm{to} \mathrm{occur,} \mathrm{the} \mathrm{element} \mathrm{would} \mathrm{be} \mathrm{removed} \mathrm{from} \mathrm{the} \mathrm{model} \mathrm{(thereby}$ excluding its equivalent plastic strain from the maximum equivalent plastic strain for the plot). However, the missing element would be visible in the plot. Figure D-214 shows failed elements in the end boxes and end box welds nearest the impact. 
ENGINEERING CALCULATIONS AND ANALYSIS

Drop Analysis of the Advanced Test Reactor Fresh Fuel Shipping Container with Heavier Low-Enriched Uranium Fuel Contents

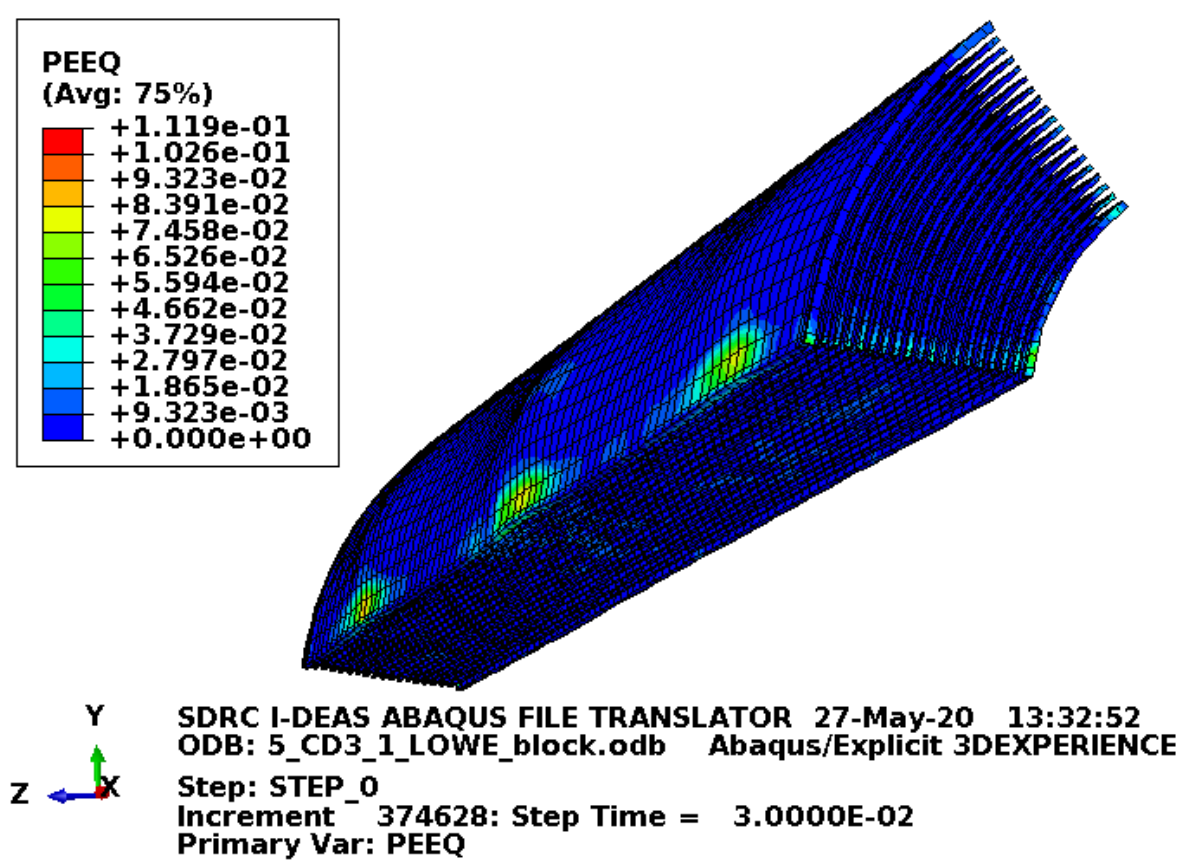

Figure D-215. Scope Part 2c (Table 3), Test 5 (Table 2) fuel plate equivalent strain.

Figure D-215 shows the equivalent plastic strain in the fuel plates. Failure in these elements occurs at an equivalent plastic strain of $0.205 \mathrm{in}$./in. If element failure were to occur, the element would be removed from the model (thereby excluding its equivalent plastic strain from the maximum equivalent plastic strain for the plot). However, the missing element would be visible in the plot. Figure D-215 shows no failure in the fuel plates with margin.

\section{D3.4.4 Results for Scope Part 2d (Table 3), Test 5 (Table 2)}

The FEA model results for the Scope Part 2d (Table 3), Test 5 (Table 2) model are shown below in Figure D-216 to Figure D-218. The fuel element weighs $44 \mathrm{lbf}$ and the drop scenario is modeled with minimum material properties except the enclosure and end boxes, which are modeled with relatively tough material properties. This section includes the blocks as added fuel plate protection. 


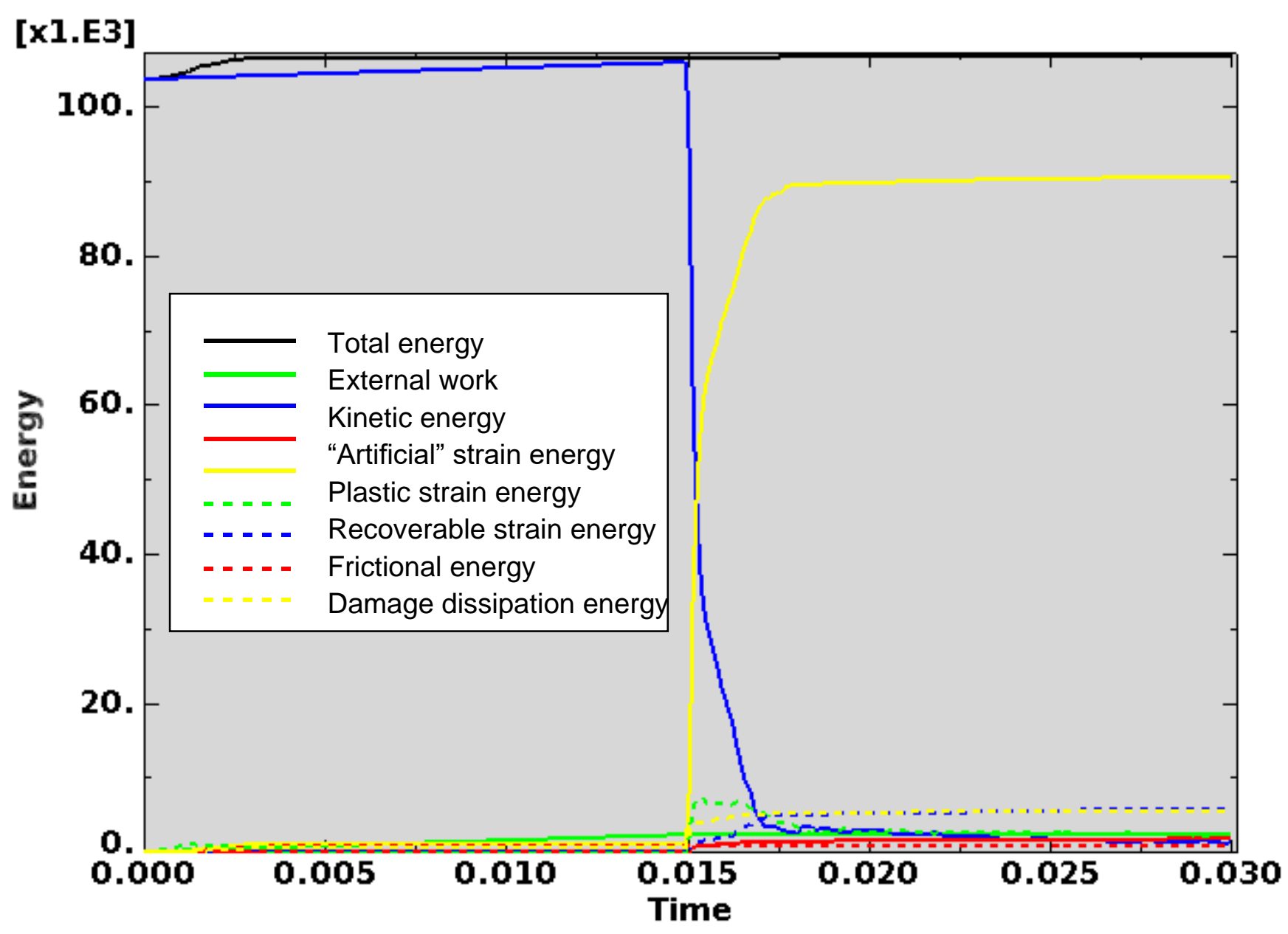

Figure D-216. Scope Part 2d (Table 3), Test 5 (Table 2) energy curves.

Figure D-216 shows the energy curves for Scope Part 2d (Table 3), Test 5 (Table 2) drop scenario. These curves exhibit a stable shape. Artificial strain energy represents the energy required to keep reduced integration elements from taking on a zero-energy hourglass shape. As shown in Figure D-216, the artificial energy at the end of the model run is $1.6 \%$ of the total energy. Therefore, the potential error associated with artificial energy is not considered to be significant. 
ENGINEERING CALCULATIONS AND ANALYSIS

Drop Analysis of the Advanced Test Reactor Fresh Fuel Shipping Container with Heavier Low-Enriched Uranium Fuel Contents

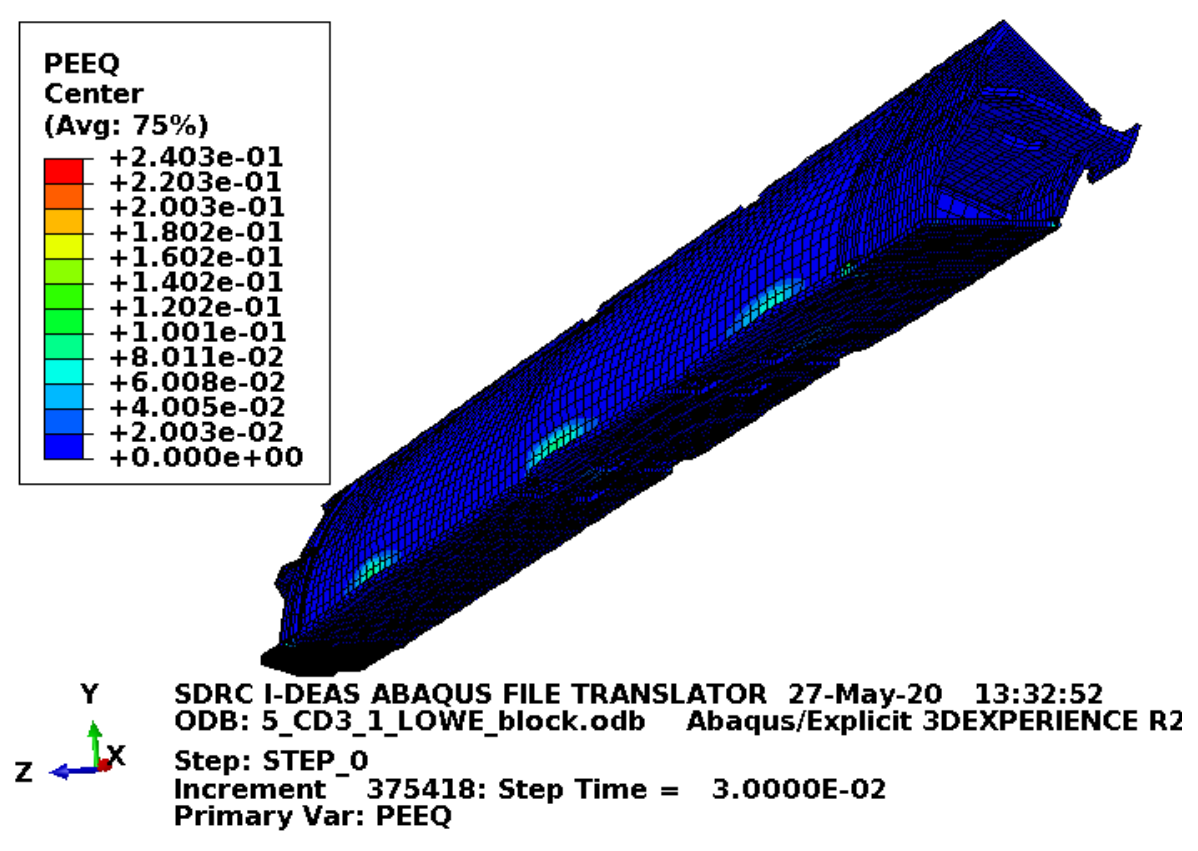

Figure D-217. Scope Part 2d (Table 3), Test 5 (Table 2) fuel element plastic equivalent strain.

Figure D-217 shows the equivalent plastic strain in the fuel element. Failure in the end box elements occurs at an equivalent plastic strain of $0.08 \mathrm{in./in.} \mathrm{(for} \mathrm{the} \mathrm{relatively} \mathrm{tough} \mathrm{material} \mathrm{properties).} \mathrm{Failure} \mathrm{in} \mathrm{the} \mathrm{end}$ box weld elements occurs at an equivalent plastic strain of $0.115 \mathrm{in}$./in. (for the relatively tough material properties). Failure in the side plate and comb elements occurs at an equivalent plastic strain of $0.152 \mathrm{in}$./in. Failure in the side plate weld elements occurs at an equivalent plastic strain of 0.205 in./in. Figure D-217 shows some failure in the end boxes and an above failure strain value occurs in the end box weld zone. This very local strain results from impact with the block. The strains shown above the failure strain likely result from extrapolation (as integration point strains are the important strains for failure). Strains in the fuel plates are the important strains and they are shown in Figure D-218. The failed elements and elements that could be counted as failed (due to the high displayed strains) in the rest of the fuel element are acceptable. 
ENGINEERING CALCULATIONS AND ANALYSIS

Drop Analysis of the Advanced Test Reactor Fresh Fuel Shipping Container with Heavier Low-Enriched Uranium Fuel Contents

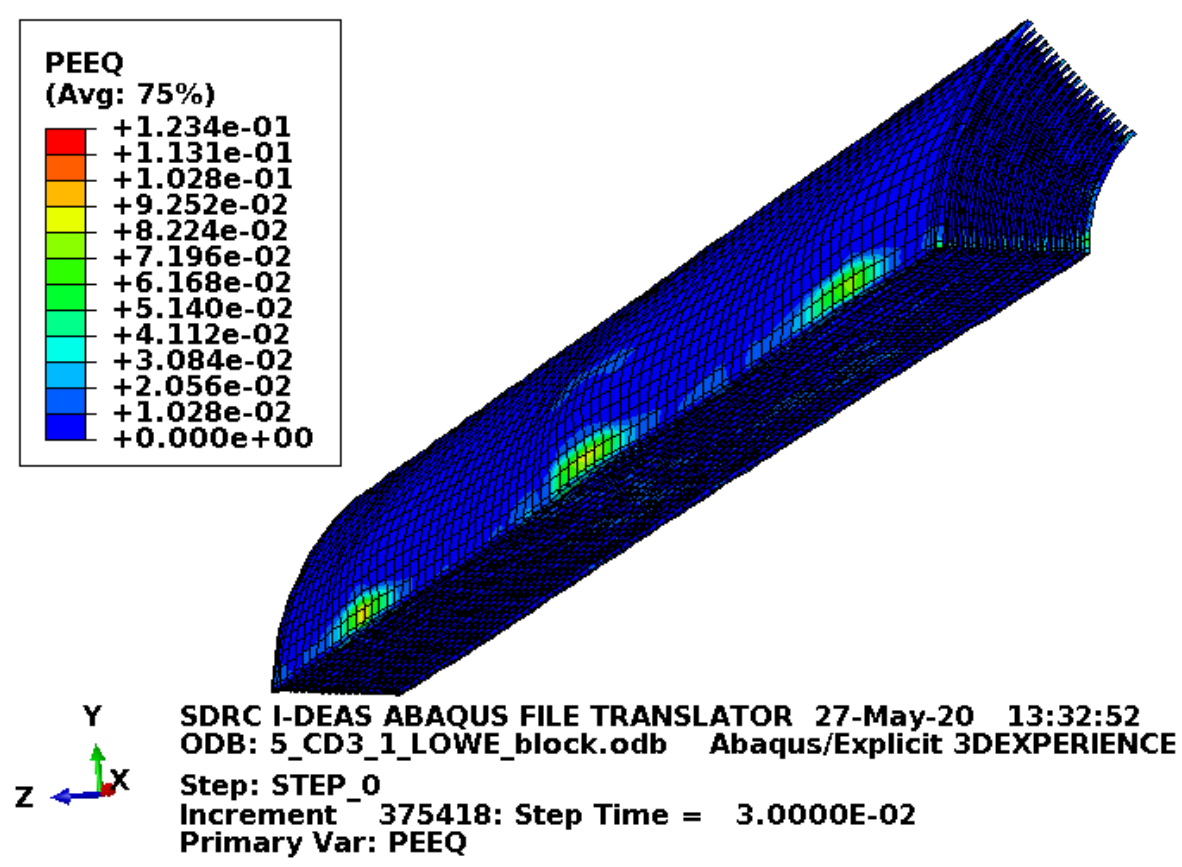

Figure D-218. Scope Part 2d (Table 3), Test 5 (Table 2) fuel plate equivalent strain.

Figure D-218 shows the equivalent plastic strain in the fuel plates. Failure in these elements occurs at an equivalent plastic strain of $0.205 \mathrm{in}$./in. If element failure were to occur, the element would be removed from the model (thereby excluding its equivalent plastic strain from the maximum equivalent plastic strain for the plot). However, the missing element would be visible in the plot. Figure D-218 shows no failure in the fuel plates with margin.

\section{D3.5 Results for Scope Part 2 (Table 3), Test 6 (Table 2)}

The drop scenario considered in this section is a $30 \mathrm{ft}$ drop modeled as a vertical bottom impact.

As in Section D2.5, Abaqus (2018) appears to have trouble with some models in this drop scenario. The problems seem to result from interaction between partially failed fuel element components near the end of a model run. While the motion of the models appears to remain stable, the total energy begins to rise. In some cases where the contact is complex between failed components, there are some localized places where contact should occur, but it appears to be missed. This may reduce damage in some places that should have occurred. Though globally, there is always sufficient contact in these areas to produce rebound. Therefore, the overall energy that is causing damage is applied. This problem does not seem to be remedied with the applied mesh refinement. Additionally, scoping models indicated that running a model for an extended time could produce added damage when no significant interaction is occurring.

Consequently, the problematic models do appear to be heading toward an unstable solution. It is likely that significant error does not occur until significantly after rebound.

\section{D3.5.1 Results for Scope Part 2a (Table 3), Test 6 (Table 2)}

The FEA model results for the Scope Part 2a (Table 3), Test 6 (Table 2) model are shown below in Figure D-219 to Figure D-223. The fuel element weighs $44 \mathrm{lbf}$ and the whole model is modeled with minimum material properties. 


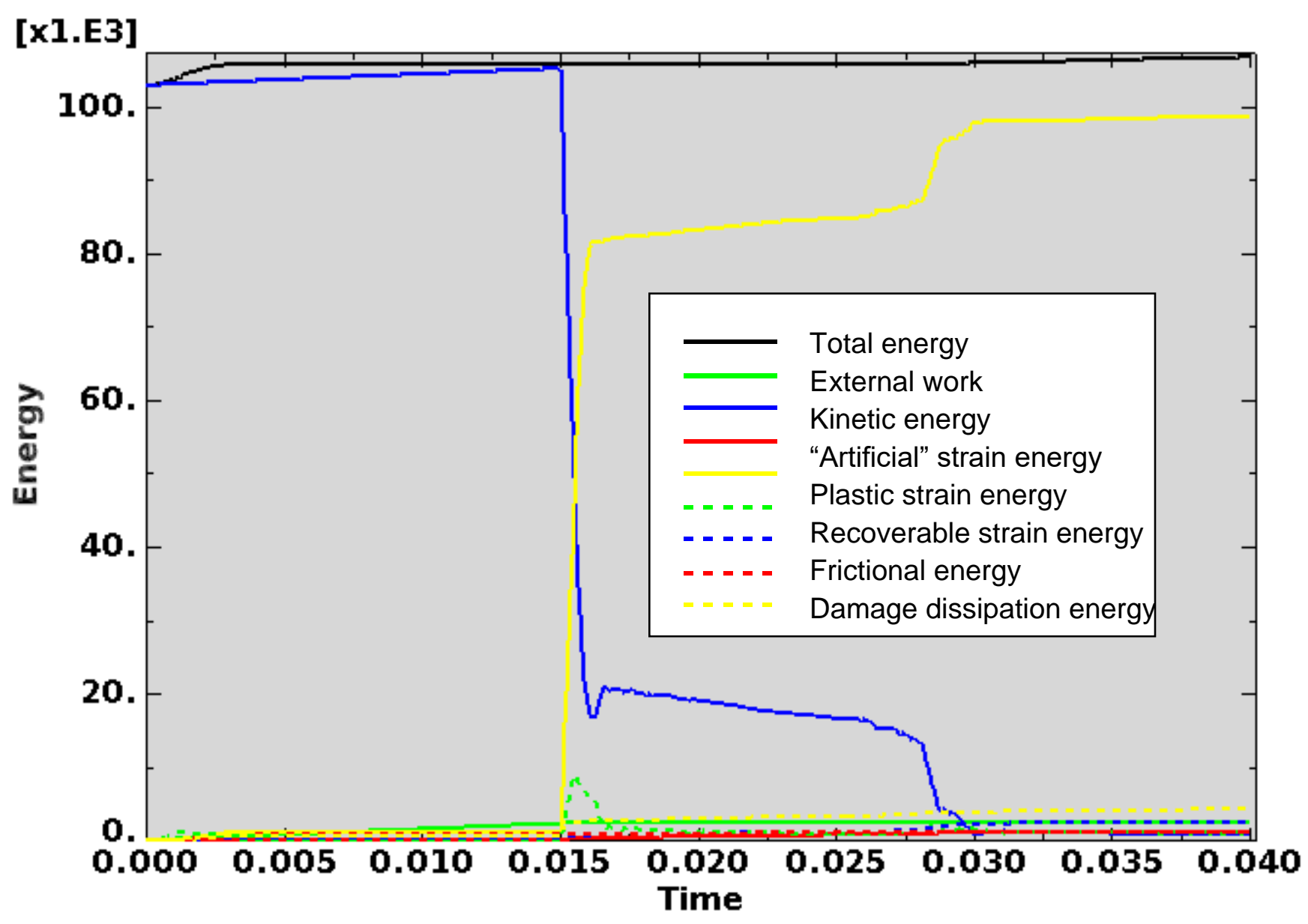

Figure D-219. Scope Part 2a (Table 3), Test 6 (Table 2) energy curves.

Figure D-219 shows the energy curves for Scope Part 2a (Table 3), Test 6 (Table 2) drop scenario. These curves exhibit mostly stable behavior. Near the end of the model run, the total energy and plastic strain energy start to show minimal undesirable behavior. As discussed in Section D3.5 this appears to result from contact difficultly between failed portions of the fuel element. Because the undesirable behavior is minimal, the results are given at the end of the model run.

Artificial strain energy represents the energy required to keep reduced integration elements from taking on a zero-energy hourglass shape. As shown in Figure D-219, the artificial energy at the end of the model run is $1.1 \%$ of the total energy. Therefore, the potential error associated with artificial energy is not considered to be significant. 
ENGINEERING CALCULATIONS AND ANALYSIS

Drop Analysis of the Advanced Test Reactor Fresh Fuel Shipping Container with Heavier Low-Enriched Uranium Fuel Contents
ECAR-5224, Rev. 0

Page D198 of D293

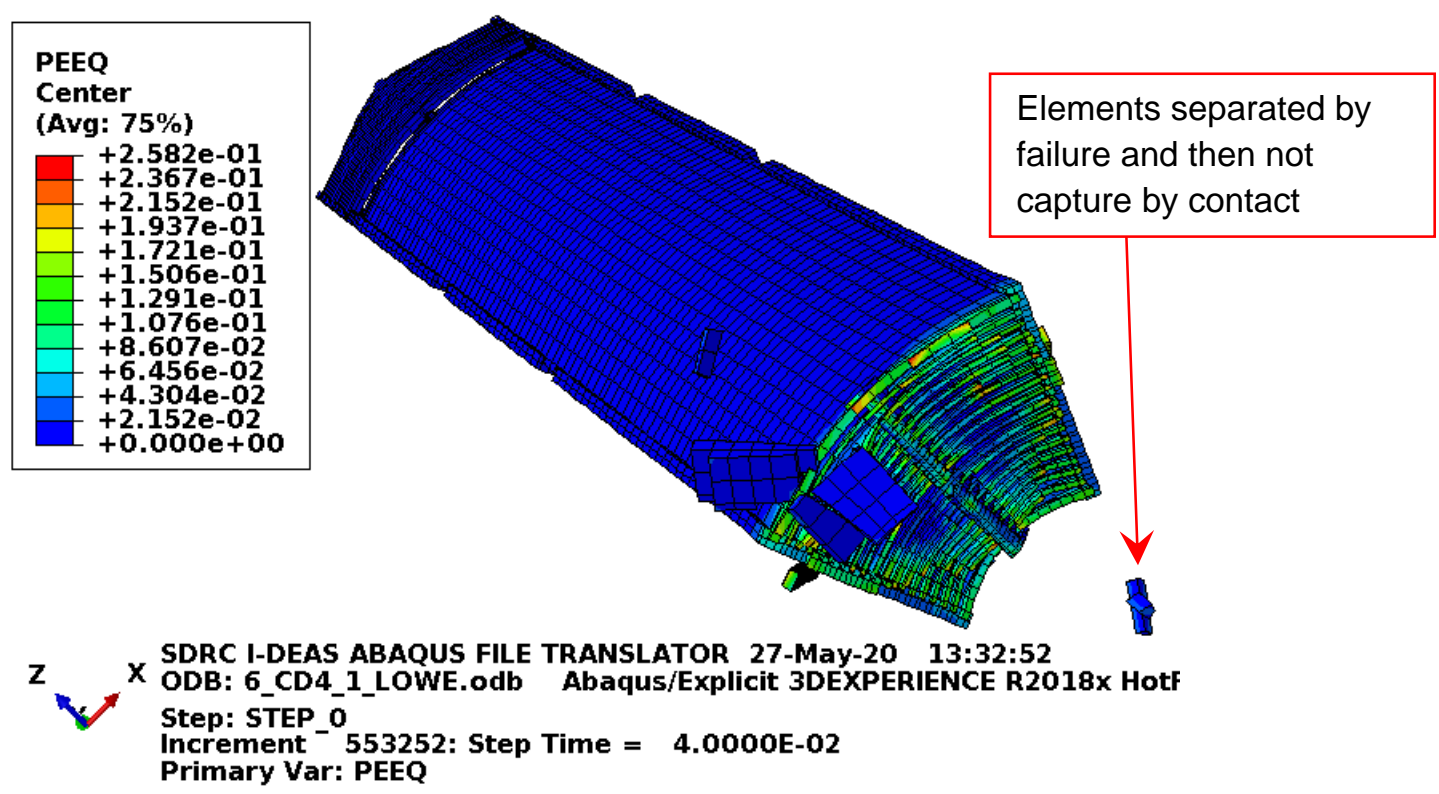

Figure D-220. Scope Part 2a (Table 3), Test 6 (Table 2) fuel element plastic equivalent strain.

Figure D-220 shows the equivalent plastic strain in the fuel element. Failure in the end box elements occurs at an equivalent plastic strain of $0.027 \mathrm{in}$./in. Failure in the end box weld elements occurs at an equivalent plastic strain of $0.032 \mathrm{in./in.} \mathrm{Failure} \mathrm{in} \mathrm{the} \mathrm{side} \mathrm{plate} \mathrm{and} \mathrm{comb} \mathrm{elements} \mathrm{occurs} \mathrm{at} \mathrm{an} \mathrm{equivalent} \mathrm{plastic}$ strain of $0.152 \mathrm{in./in}$. Failure in the side plate weld elements occurs at an equivalent plastic strain of $0.205 \mathrm{in}$./in. Figure D-220 shows extensive failure in the end box and fuel plates nearest the impact. A few elements were separated by failure and then not captured by contact. The overall model error associated with this is not considered to be significant.
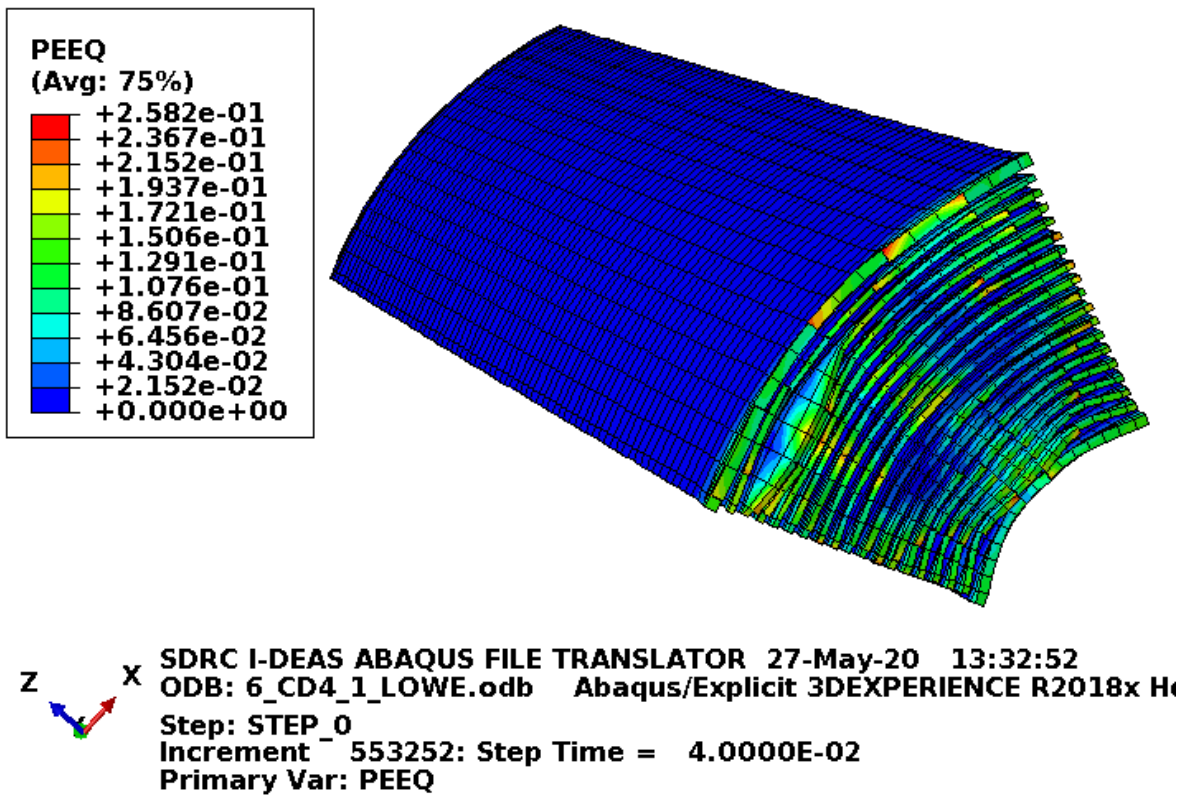

Figure D-221. Scope Part 2a (Table 3), Test 6 (Table 2) fuel plate equivalent strain. 
ENGINEERING CALCULATIONS AND ANALYSIS

Drop Analysis of the Advanced Test Reactor Fresh Fuel Shipping Container with Heavier Low-Enriched Uranium Fuel Contents
ECAR-5224, Rev. 0

Page D199 of D293

Figure D-221 shows the equivalent plastic strain in the fuel plates. Failure in these elements occurs at an equivalent plastic strain of $0.205 \mathrm{in}$./in. Figure D-221 shows some element failure in the end nearest the impact. The strains shown above the failure strain likely result from extrapolation (as integration point strains are the important strains for failure). Even if the elements with high strain were removed as being failed, the failure does not extend into the fuel meat.
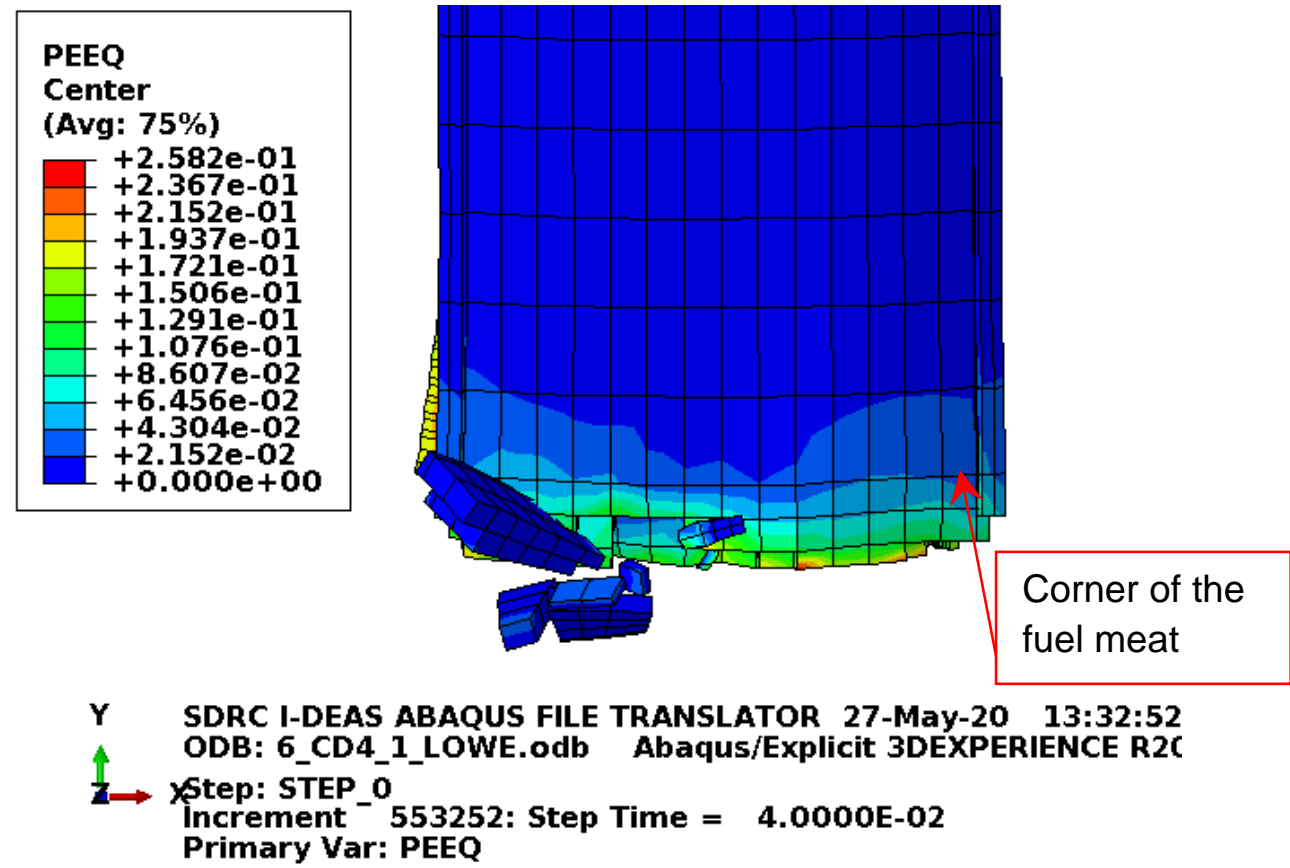

Figure D-222. Scope Part 2a (Table 3), Test 6 (Table 2) zoomed view of the damage.

The FEA model in Figure D-222 is the fuel element with only failed elements not visible. The damage shows that the end box did not stay together well enough or did not get properly trapped such that it cut into the fuel plates. This plot is done similar to that of Figure D-8 for information. 
ENGINEERING CALCULATIONS AND ANALYSIS

Drop Analysis of the Advanced Test Reactor Fresh Fuel Shipping Container with Heavier Low-Enriched Uranium Fuel Contents
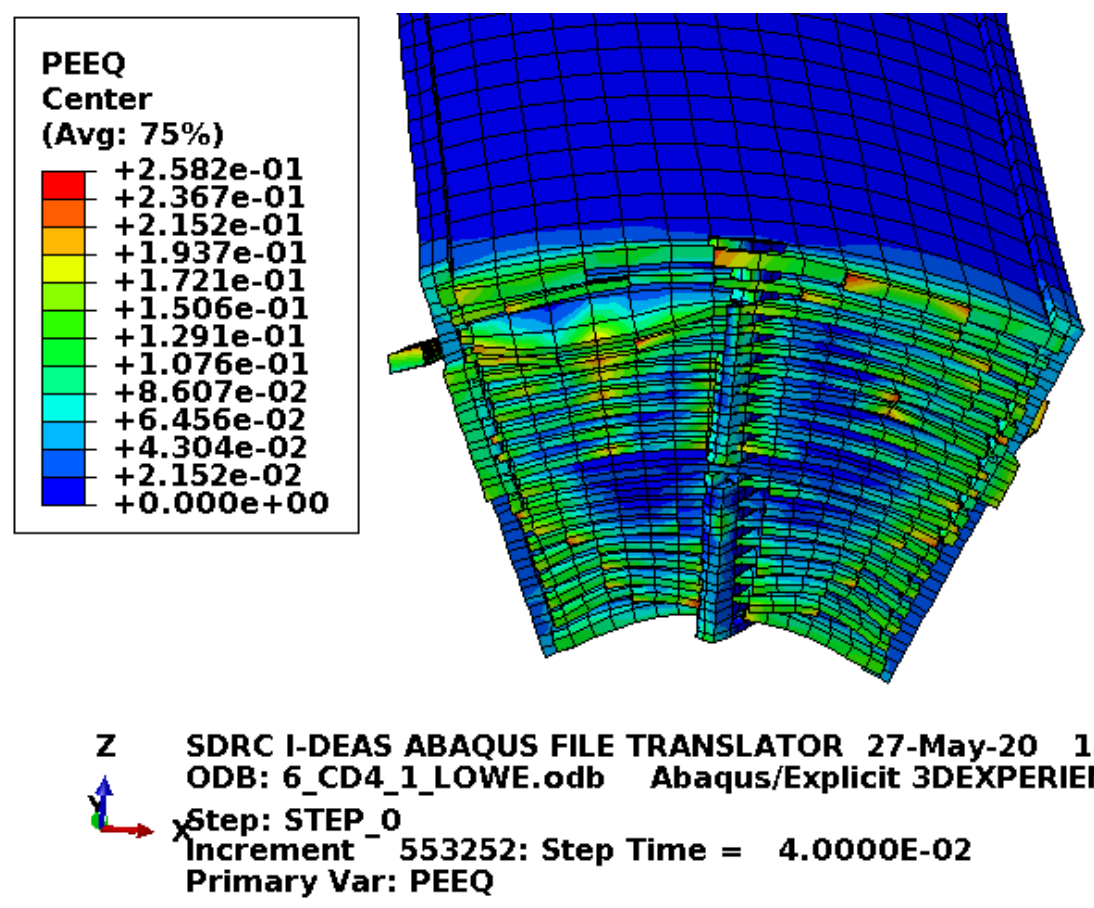

Figure D-223. Scope Part 2a (Table 3), Test 6 (Table 2) zoomed view of the damage without the end box.

The FEA model in Figure D-223 has the end boxes and end box welds removed. This plot is done similar to that of Figure D-7 for information.

\section{D3.5.2 Results for Scope Part 2a (Table 3), Test 6 (Table 2) Fine Mesh}

The FEA model results for the Scope Part 2a (Table 3), Test 6 (Table 2) fine mesh model are shown below in Figure D-224 to Figure D-228. The fuel element weighs $44 \mathrm{lbf}$ and the whole model is modeled with minimum material properties. 


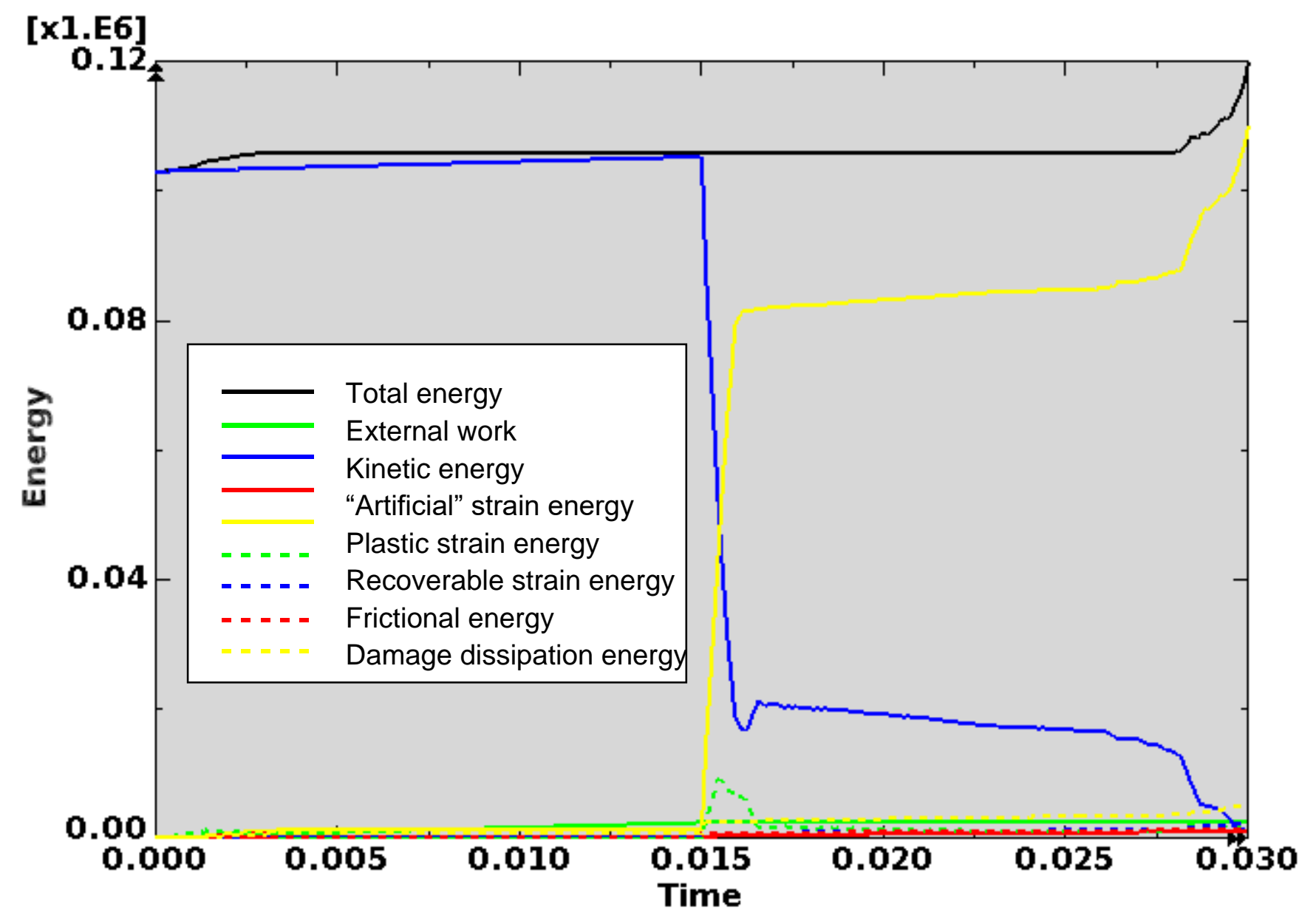

Figure D-224. Scope Part 2a (Table 3), Test 6 (Table 2) fine mesh energy curves.

Figure D-224 shows the energy curves for Scope Part 2a (Table 3), Test 6 (Table 2) fine mesh drop scenario. These curves exhibit mostly stable behavior. Near the end of the model run, the total energy and plastic strain energy start to show undesirable behavior. The full model run went to 0.04 seconds, the energy curves went up sharply, and damage started happening in places not being impacted (as though erroneous, high magnitude shockwaves were passing through the model). As discussed in Section D3.5 this appears to result from contact difficultly between failed portions of the fuel element. Rebound of the fuel element happens just after 0.03 seconds. There is not an obvious change in fuel element damage at 0.0325 seconds (the next output frame), but the energy curves rise substantially. Consequently, the output is shown at 0.03 second. Given that this is not a recommended configuration (the recommended configuration being with blocks) for LOWE fuel elements, this model is just for information. So, more emphasis is put on results that are as accurate as possible rather than as enveloping as possible.

Artificial strain energy represents the energy required to keep reduced integration elements from taking on a zero-energy hourglass shape. As shown in Figure D-224, the artificial energy at the end of the model run is $0.9 \%$ of the total energy. Therefore, the potential error associated with artificial energy is not considered to be significant. 
Drop Analysis of the Advanced Test Reactor Fresh Fuel Shipping Container with Heavier Low-Enriched Uranium Fuel Contents

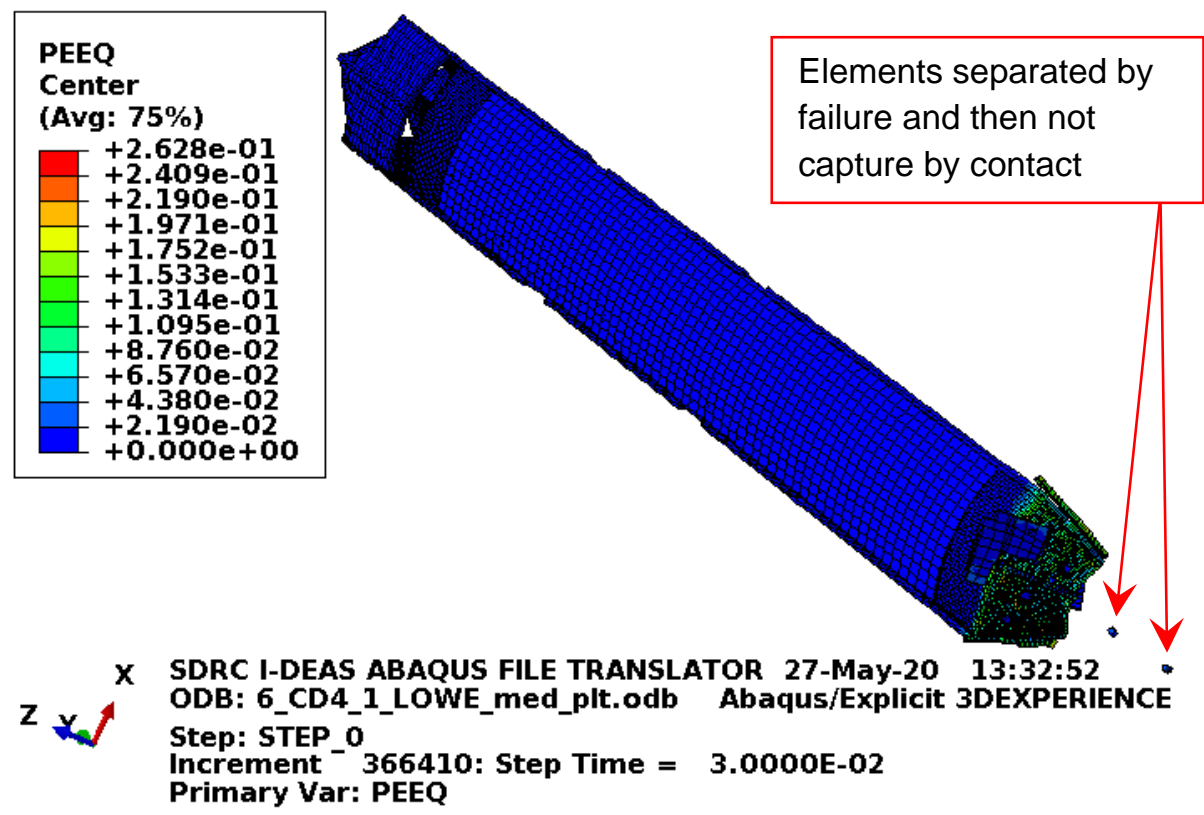

Figure D-225. Scope Part 2a (Table 3), Test 6 (Table 2) fine mesh fuel element plastic equivalent strain.

Figure D-225 shows the equivalent plastic strain in the fuel element. Failure in the end box elements occurs at an equivalent plastic strain of $0.027 \mathrm{in}$./in. Failure in the end box weld elements occurs at an equivalent plastic strain of $0.032 \mathrm{in}$./in. Failure in the side plate and comb elements occurs at an equivalent plastic strain of $0.152 \mathrm{in./in}$. Failure in the side plate weld elements occurs at an equivalent plastic strain of $0.205 \mathrm{in}$./in. Figure D-225 shows extensive failure in the end box and fuel plates nearest the impact. A few elements were separated by failure and then not captured by contact. The overall model error associated with this is not considered to be significant.
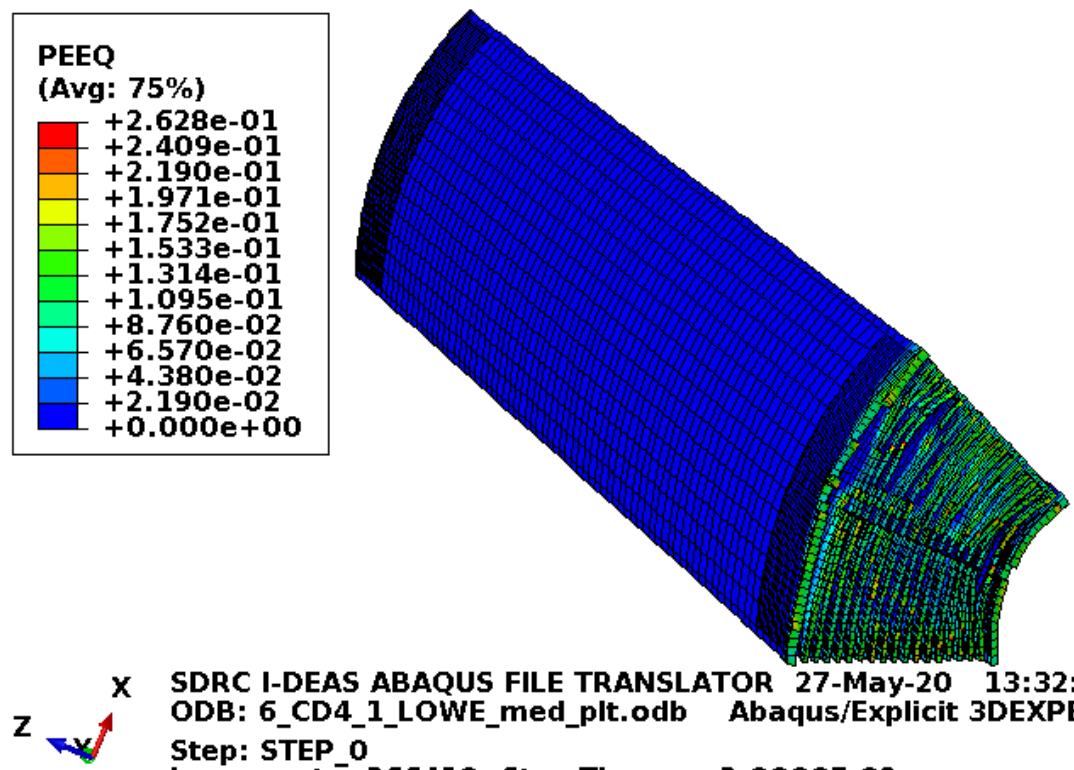

$\mathbf{X}$

SDRC I-DEAS ABAQUS FILE TRANSLATOR 27-May-20 13:32:52

ODB: 6_CD4_1_LOWE_med_plt.odb Abaqus/Explicit 3DEXPERIENCE

Step: STEP_0

Increment ${ }^{-}$366410: Step Time $=3.0000 E-02$

Primary Var: PEEQ

Figure D-226. Scope Part 2a (Table 3), Test 6 (Table 2) fine mesh fuel plate equivalent strain. 
ENGINEERING CALCULATIONS AND ANALYSIS

Drop Analysis of the Advanced Test Reactor Fresh Fuel Shipping Container with Heavier Low-Enriched Uranium Fuel Contents
ECAR-5224, Rev. 0

Page D203 of D293

Figure D-226 shows the equivalent plastic strain in the fuel plates. Failure in these elements occurs at an equivalent plastic strain of 0.205 in./in. Figure D-226 shows element failure in the end nearest the impact. Though, the failure does not extend into the fuel meat.

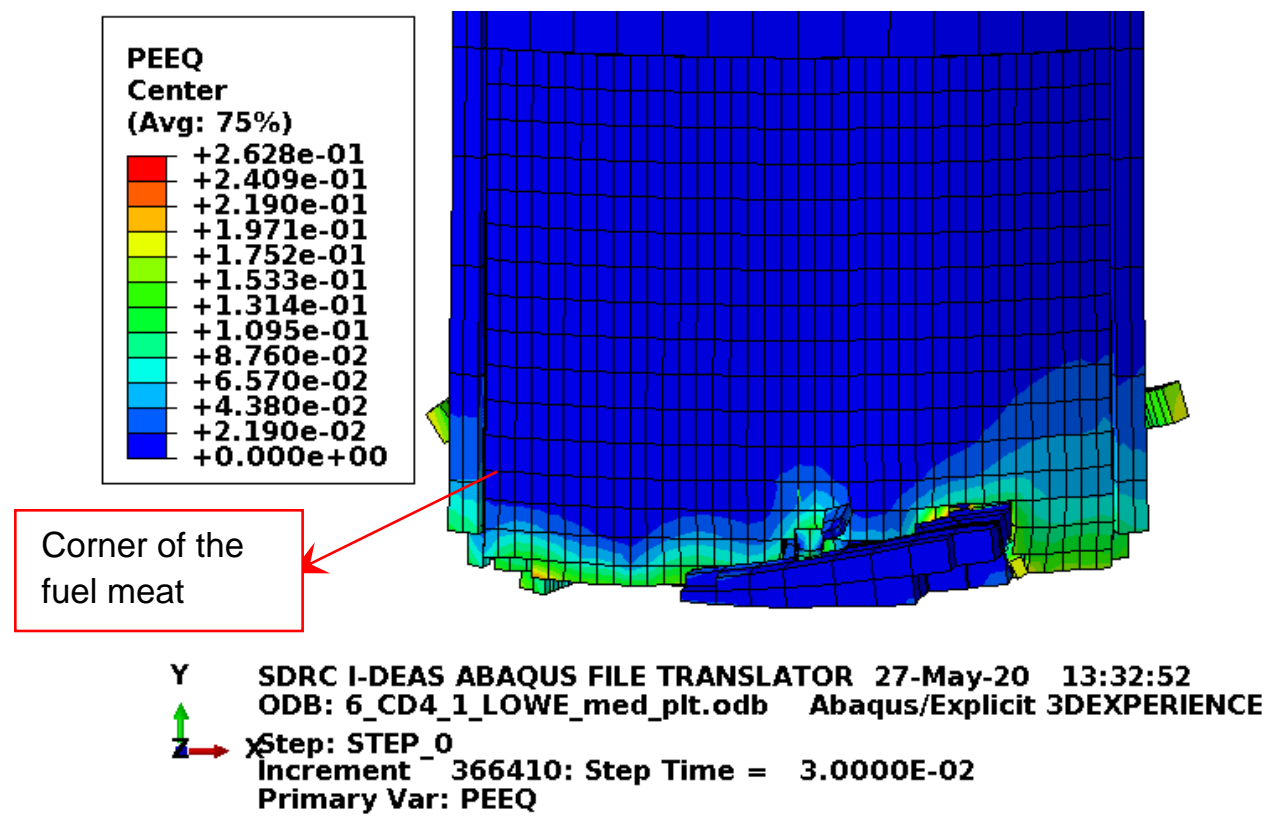

Figure D-227. Scope Part 2a (Table 3), Test 6 (Table 2) fine mesh zoomed view of the damage.

The FEA model in Figure D-227 is the fuel element with only failed elements not visible. The damage shows that the end box did not stay together well enough or did not get properly trapped such that it cut into the fuel plates. This plot is done similar to that of Figure D-8 for information.
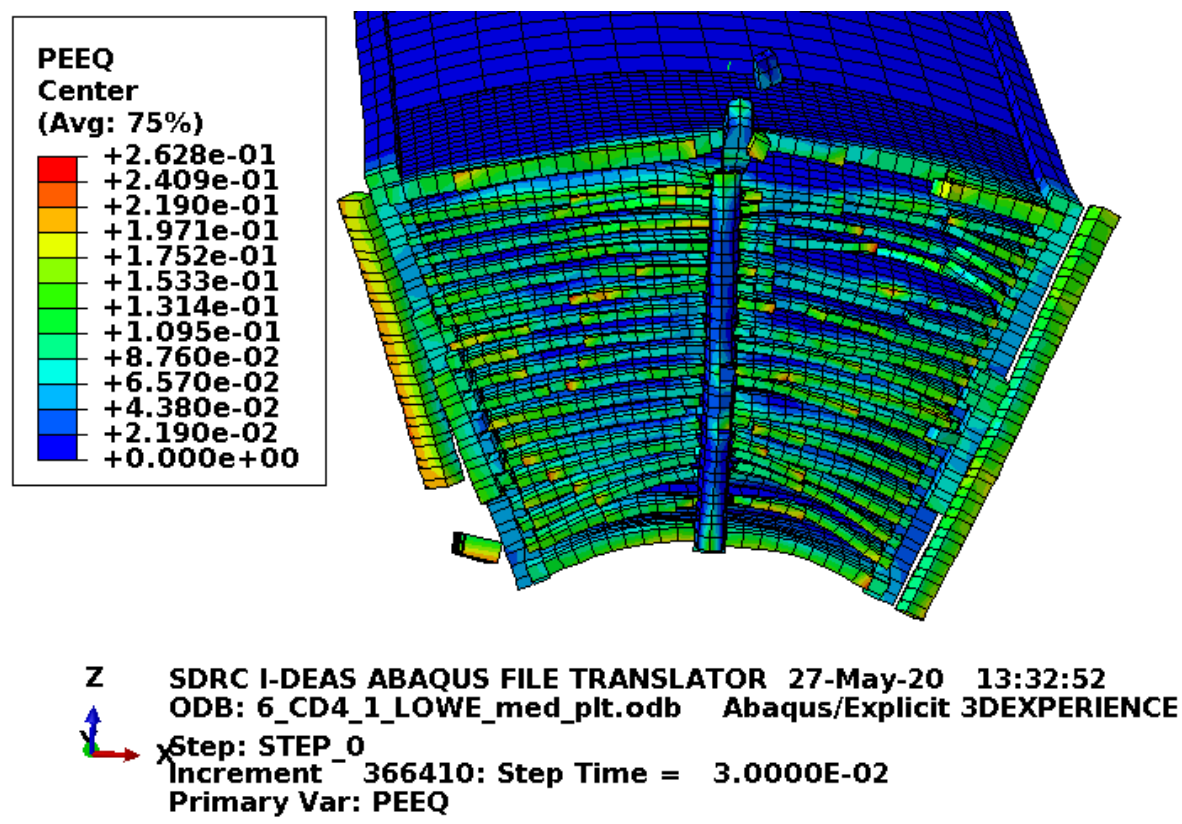

Figure D-228. Scope Part 2a (Table 3), Test 6 (Table 2) fine mesh zoomed view of the damage without the end box. 
The FEA model in Figure D-228 has the end boxes and end box welds removed This plot is done similar to that of Figure D-7 for information.

\section{D3.5.3 Results for Scope Part 2b (Table 3), Test 6 (Table 2)}

The FEA model results for the Scope Part $2 b$ (Table 3), Test 6 (Table 2) model are shown below in Figure D-229 to Figure D-233. The fuel element weighs $44 \mathrm{lbf}$ and the drop scenario is modeled with minimum material properties except the enclosure and end boxes, which are modeled with relatively tough material properties.

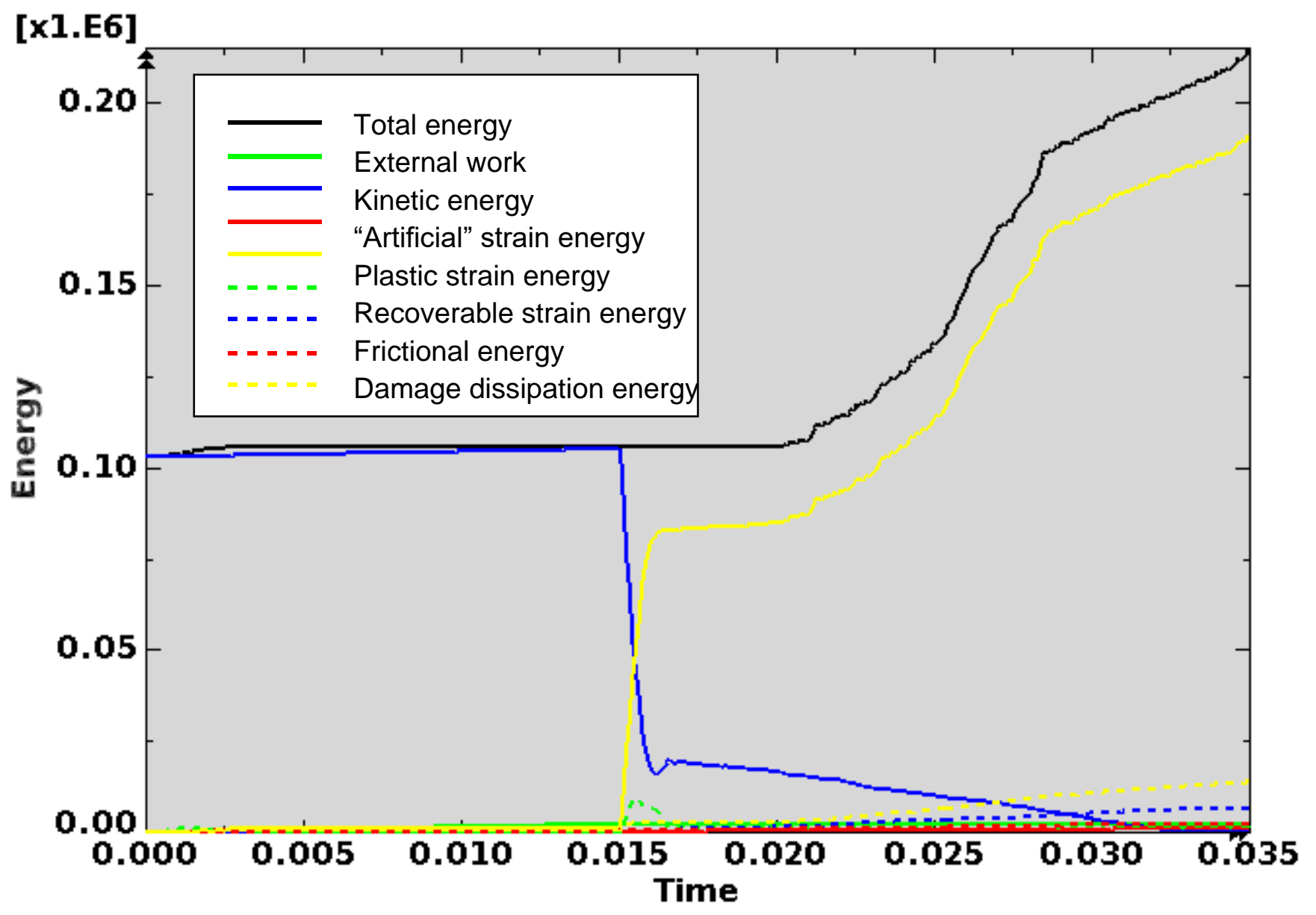

Figure D-229. Scope Part 2b (Table 3), Test 6 (Table 2) energy curves.

Figure D-229 shows the energy curves for Scope Part 2b (Table 3), Test 6 (Table 2) drop scenario. These curves exhibit stable behavior for the initial impact of the ATR FFSC. As the fuel element impacts and is badly damaged, the total energy and plastic strain energy increase substantially which is undesirable. As discussed in Section D3.5 this appears to result from contact difficultly between failed portions of the fuel element. Output is shown at the first output frame after fuel element rebound $(0.035$ second) to try to minimize potential error associated with this. Though the energy curves show substantial problems with the model run, the results are provided for information. This is not a recommended configuration (the recommended configuration being with blocks) for LOWE fuel elements and the model is showing unacceptable damage to the fuel meat. 
Artificial strain energy represents the energy required to keep reduced integration elements from taking on a zero-energy hourglass shape. As shown in Figure D-229, the artificial energy at the end of the model run is $0.5 \%$ of the total energy. Therefore, the potential error associated with artificial energy is not considered to be significant.

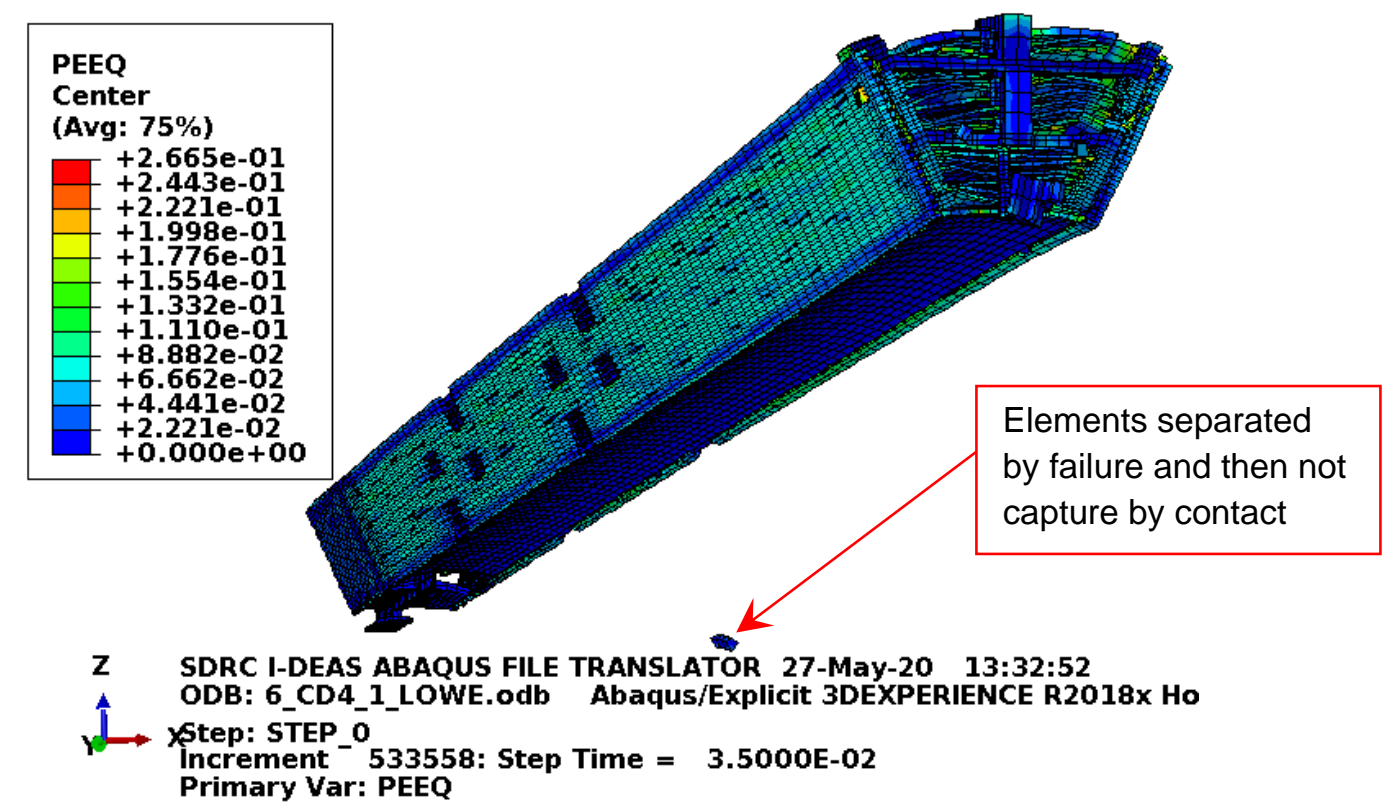

Figure D-230. Scope Part 2b (Table 3), Test 6 (Table 2) fuel element plastic equivalent strain.

Figure D-230 shows the equivalent plastic strain in the fuel element. Failure in the end box elements occurs at an equivalent plastic strain of $0.08 \mathrm{in}$./in. (for the relatively tough material properties). Failure in the end box weld elements occurs at an equivalent plastic strain of $0.115 \mathrm{in.} / \mathrm{in}$. (for the relatively tough material properties). Failure in the side plate and comb elements occurs at an equivalent plastic strain of 0.152 in./in. Failure in the side plate weld elements occurs at an equivalent plastic strain of 0.205 in./in. Figure D-230 shows extensive failure in the end box and fuel plates nearest the impact. A few elements were separated by failure and then not captured by contact. The overall model error associated with this is not considered to be significant. 
ENGINEERING CALCULATIONS AND ANALYSIS

Drop Analysis of the Advanced Test Reactor Fresh Fuel Shipping Container with Heavier Low-Enriched Uranium Fuel Contents
ECAR-5224, Rev. 0

Page D206 of D293

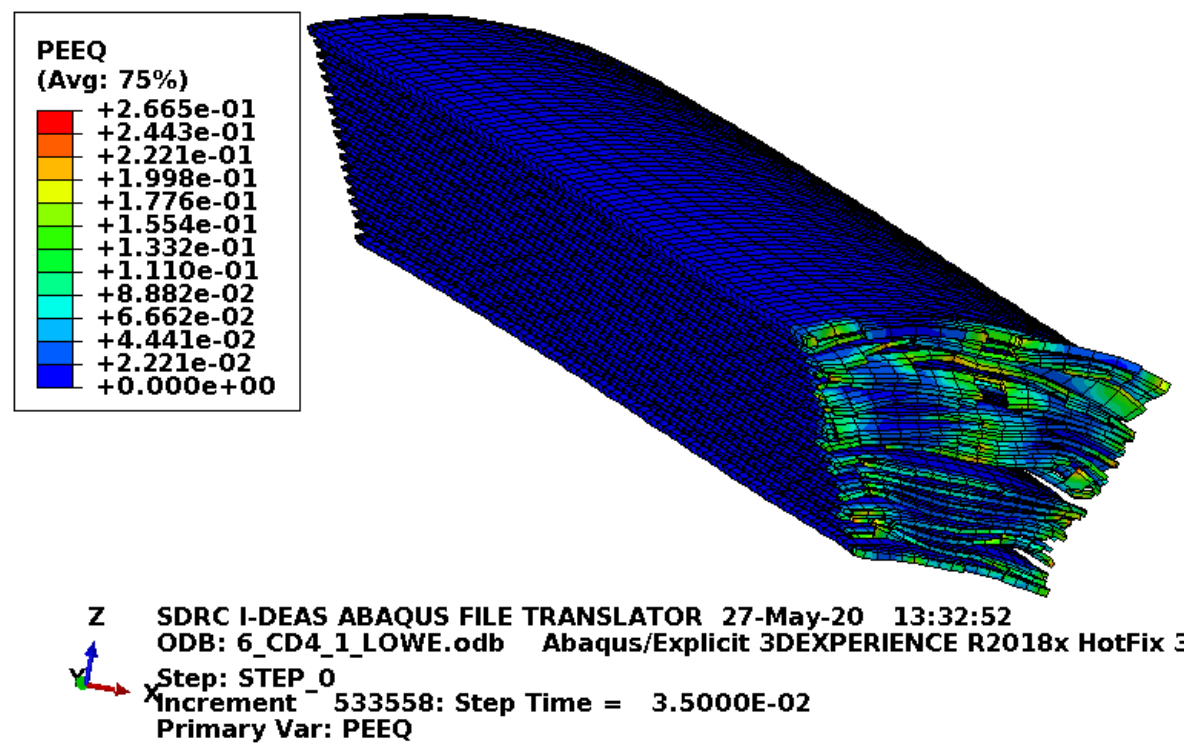

Figure D-231. Scope Part 2b (Table 3), Test 6 (Table 2) fuel plate equivalent strain.

Figure D-231 shows the equivalent plastic strain in the fuel plates. Failure in these elements occurs at an equivalent plastic strain of 0.205 in./in. Figure D-231 shows significant element failure in the end nearest the impact causing unacceptable damage to the fuel meat.
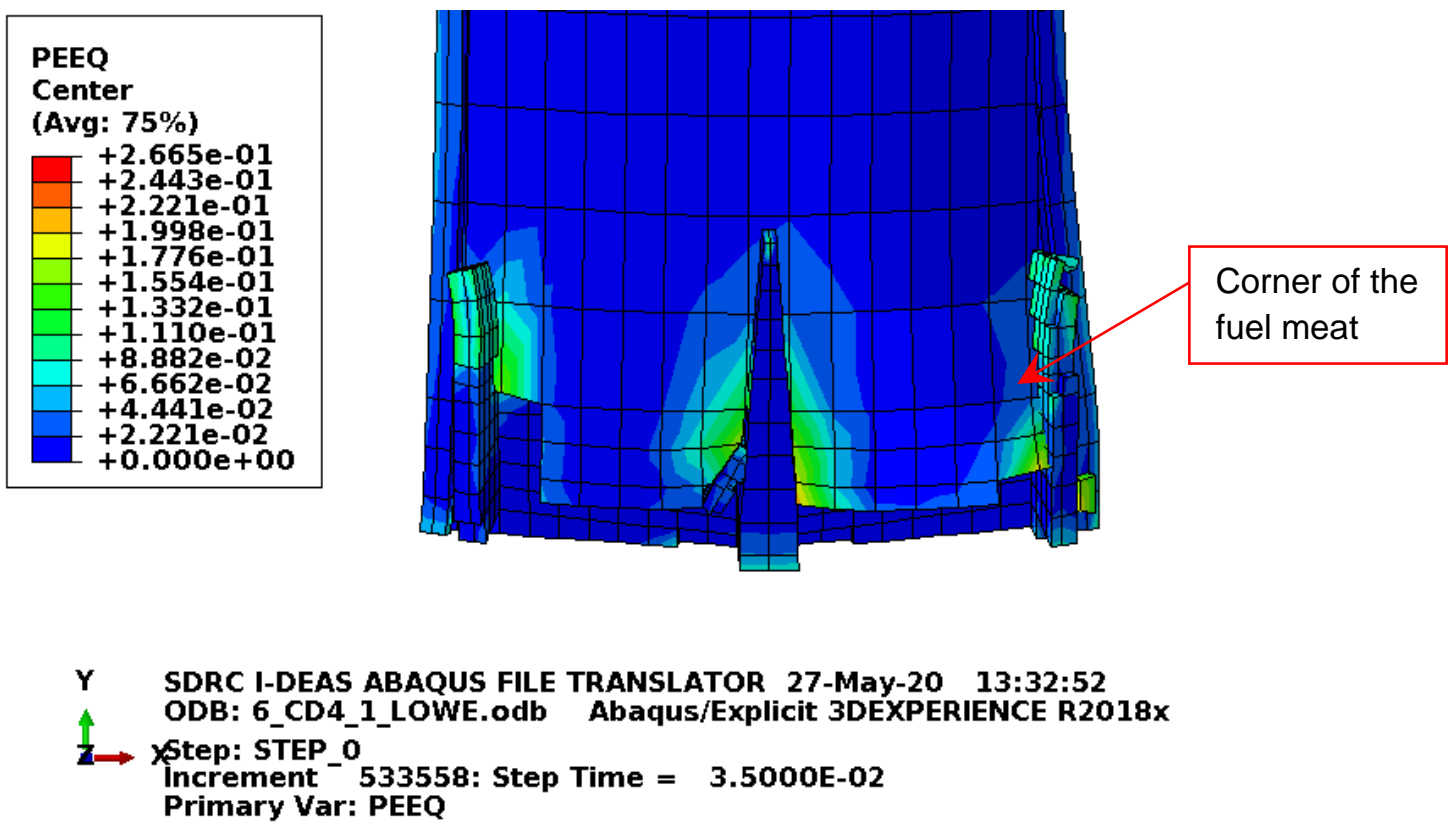

Figure D-232. Scope Part 2b (Table 3), Test 6 (Table 2) zoomed view of the damage.

The FEA model in Figure D-232 is the fuel element with only failed elements not visible. The damage shows that the end box stayed together well enough to unacceptably cut into the fuel meat. This plot is done similar to that of Figure D-8 for information. 
ENGINEERING CALCULATIONS AND ANALYSIS

Drop Analysis of the Advanced Test Reactor Fresh Fuel Shipping Container with Heavier Low-Enriched Uranium Fuel Contents
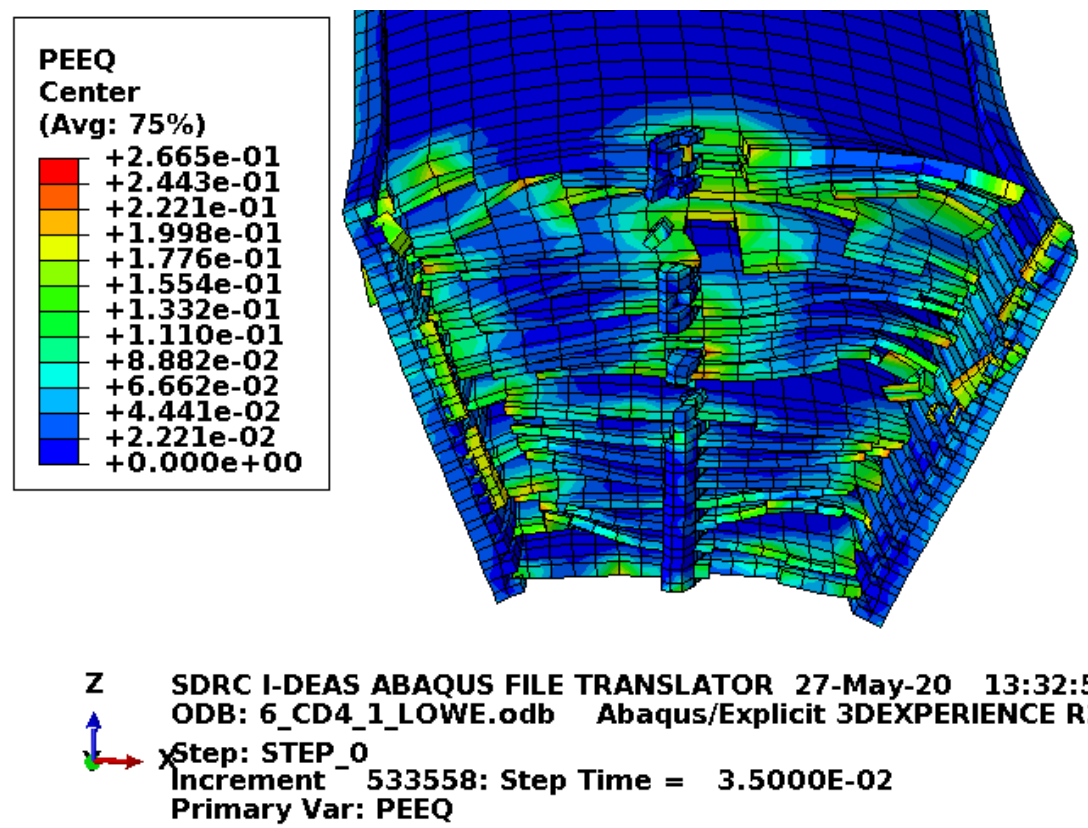

Figure D-233. Scope Part 2b (Table 3), Test 6 (Table 2) zoomed view of the damage without the end box.

The FEA model in Figure D-233 has the end boxes and end box welds removed. This plot is done similar to that of Figure D-7 for information.

\section{D3.5.4 Results for Scope Part 2b (Table 3), Test 6 (Table 2) Fine Mesh}

The FEA model results for the Scope Part $2 b$ (Table 3), Test 6 (Table 2) fine mesh model are shown below in Figure D-234 to Figure D-238. The fuel element weighs $44 \mathrm{lbf}$ and the drop scenario is modeled with minimum material properties except the enclosure and end boxes, which are modeled with relatively tough material properties. 


\section{[X1.E6]}

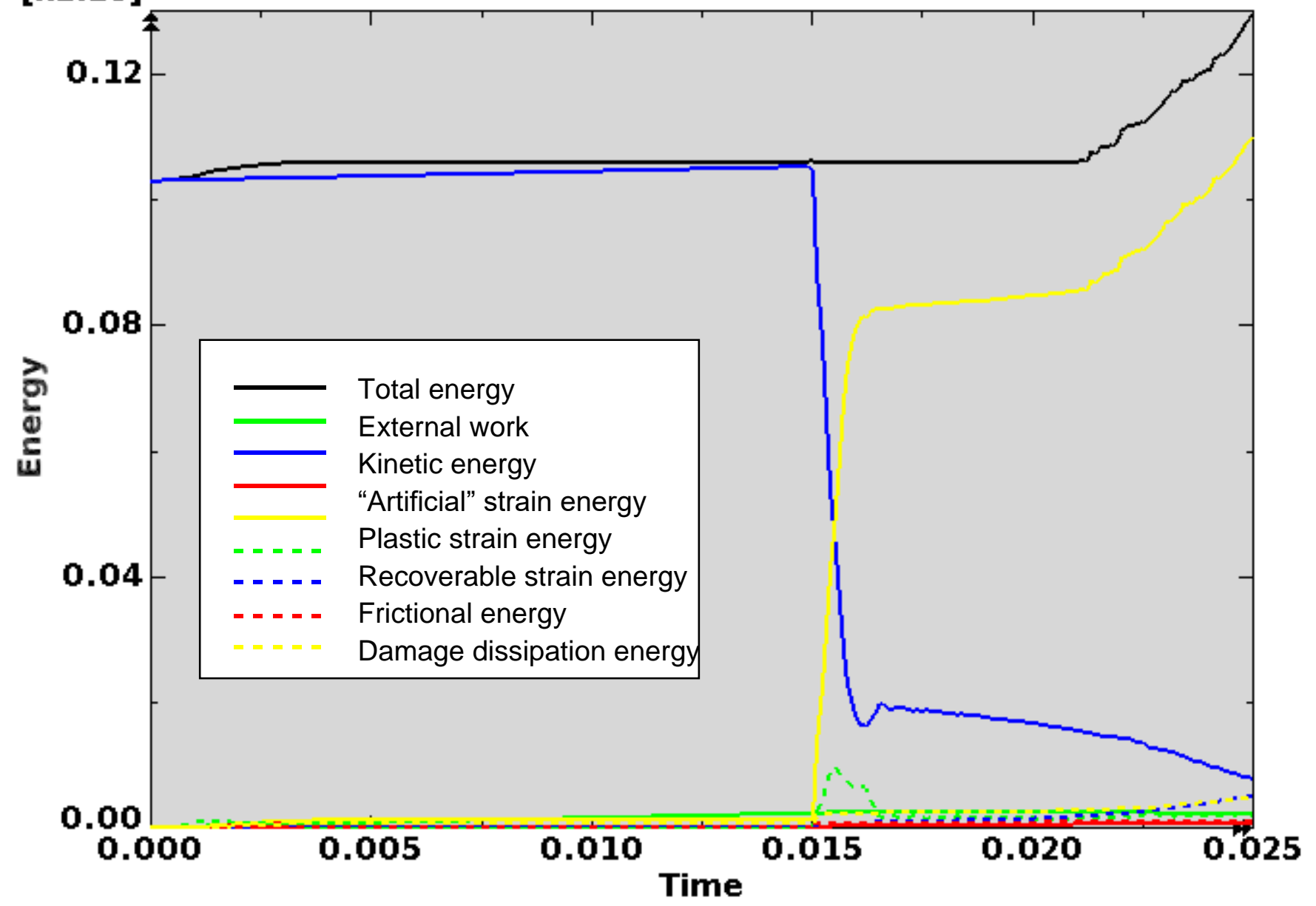

Figure D-234. Scope Part 2b (Table 3), Test 6 (Table 2) fine mesh energy curves.

Figure D-234 shows the energy curves for Scope Part 2b (Table 3), Test 6 (Table 2) fine mesh drop scenario. These curves exhibit stable behavior for the initial impact of the ATR FFSC. As the fuel element impacts and is badly damaged, the total energy and plastic strain energy increase substantially which is undesirable. As discussed in Section D3.5 this appears to result from contact difficultly between failed portions of the fuel element. This model shows unacceptable damage to the fuel meat. Consequently, this model is shown for information. This is not a recommended configuration (the recommended configuration being with blocks) for LOWE fuel elements.

For this model, rebound occurs at 0.0325 second. At 0.0325 second, substantial instability is demonstrated by the energy curves. At 0.025 second, unacceptable damage has occurred and the energy curves are still somewhat reasonable. Consequently, output is shown at 0.025 second where the model is more stable and the same conclusions can be drawn. Though the damage gets progressively worse up to rebound.

Artificial strain energy represents the energy required to keep reduced integration elements from taking on a zero-energy hourglass shape. As shown in Figure D-234, the artificial energy at the end of the model run is $0.5 \%$ of the total energy. Therefore, the potential error associated with artificial energy is not considered to be significant. 
ENGINEERING CALCULATIONS AND ANALYSIS

Drop Analysis of the Advanced Test Reactor Fresh Fuel Shipping Container with Heavier Low-Enriched Uranium Fuel Contents
ECAR-5224, Rev. 0

Page D209 of D293

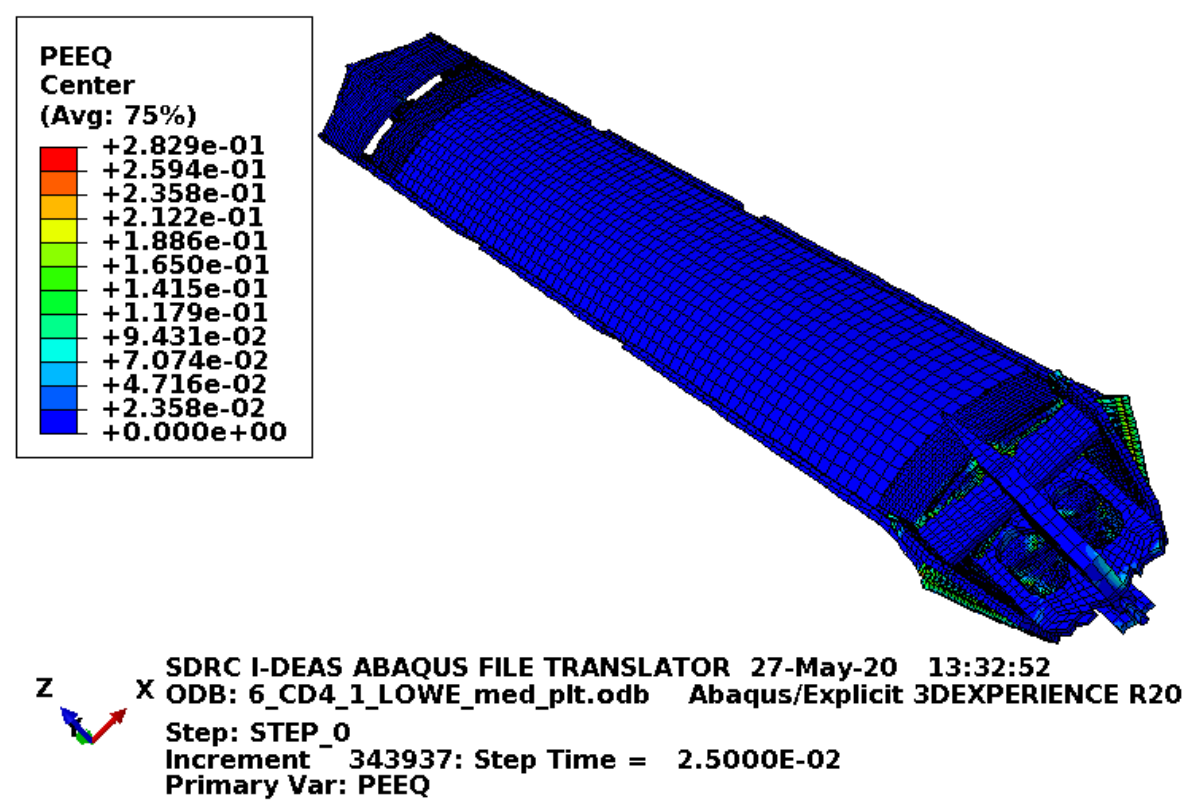

Figure D-235. Scope Part 2b (Table 3), Test 6 (Table 2) fine mesh fuel element plastic equivalent strain.

Figure D-235 shows the equivalent plastic strain in the fuel element. Failure in the end box elements occurs at an equivalent plastic strain of $0.08 \mathrm{in}$./in. (for the relatively tough material properties). Failure in the end box weld elements occurs at an equivalent plastic strain of $0.115 \mathrm{in}$./in. (for the relatively tough material properties). Failure in the side plate and comb elements occurs at an equivalent plastic strain of $0.152 \mathrm{in}$./in. Failure in the side plate weld elements occurs at an equivalent plastic strain of $0.205 \mathrm{in}$./in. Figure D-235 shows extensive failure in the end box and fuel plates nearest the impact.

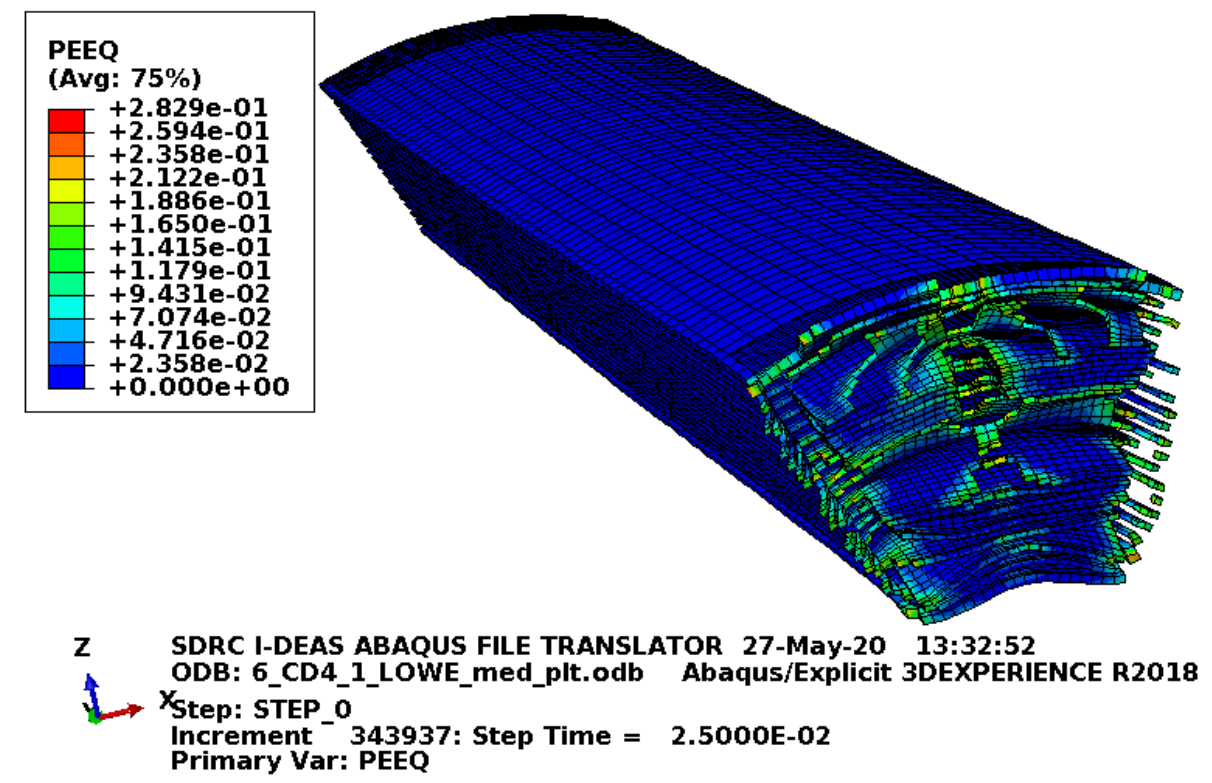

Figure D-236. Scope Part 2b (Table 3), Test 6 (Table 2) fine mesh fuel plate equivalent strain. 
Figure D-236 shows the equivalent plastic strain in the fuel plates. Failure in these elements occurs at an equivalent plastic strain of $0.205 \mathrm{in}$./in. If element failure were to occur, the element would be removed from the model (thereby excluding its equivalent plastic strain from the maximum equivalent plastic strain for the plot). However, the missing element would be visible in the plot. Figure D-236 shows significant element failure in the end nearest the impact causing unacceptable damage to the fuel meat. This is shown before rebound. Therefore, worse damage occurs than is shown here.

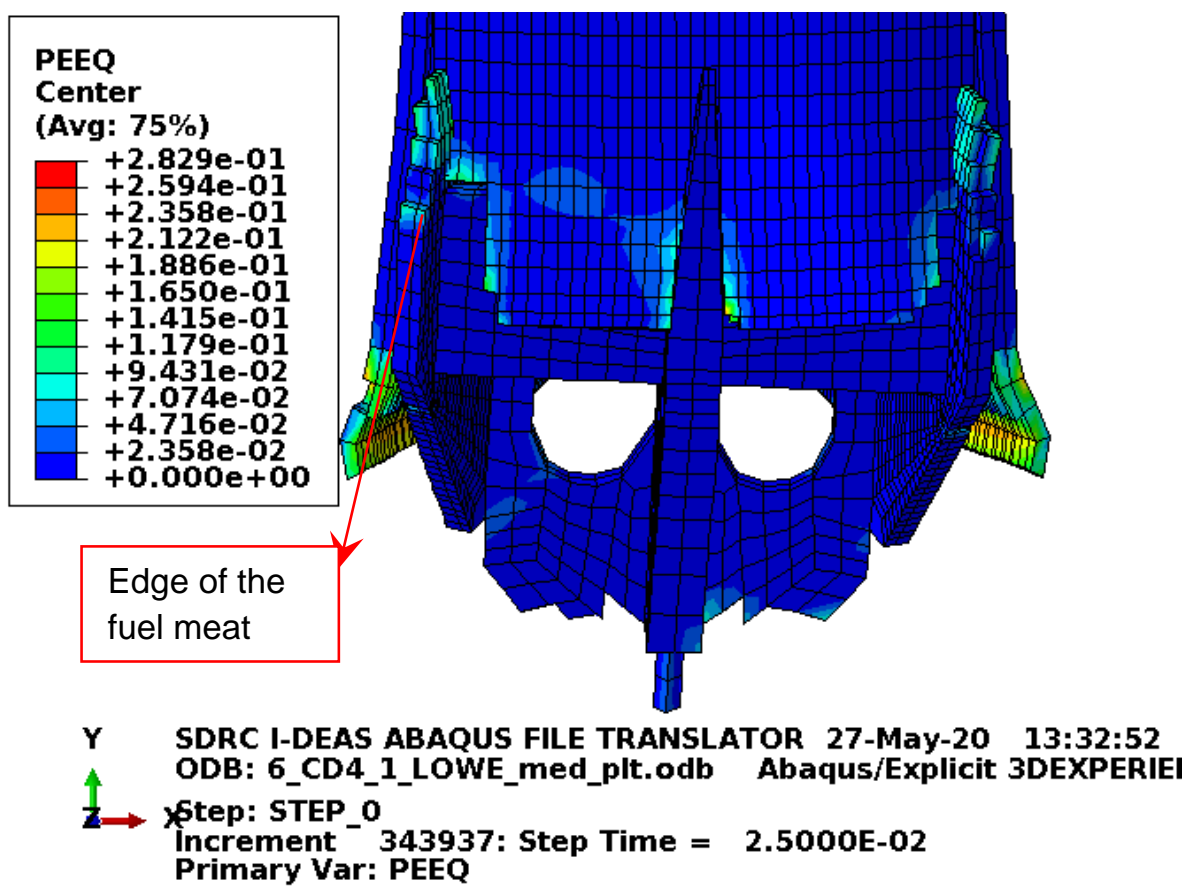

Figure D-237. Scope Part 2b (Table 3), Test 6 (Table 2) fine mesh zoomed view of the damage.

The FEA model in Figure D-237 is the fuel element with only failed elements not visible. The damage shows that the end box stayed together well enough to unacceptably cut into the fuel meat. This plot is done similar to that of Figure D-8 for information. This is shown before rebound. So, worse damage occurs, but the damage shown is already unacceptable. 
ENGINEERING CALCULATIONS AND ANALYSIS

Drop Analysis of the Advanced Test Reactor Fresh Fuel Shipping Container with Heavier Low-Enriched Uranium Fuel Contents
ECAR-5224, Rev. 0

Page D211 of D293

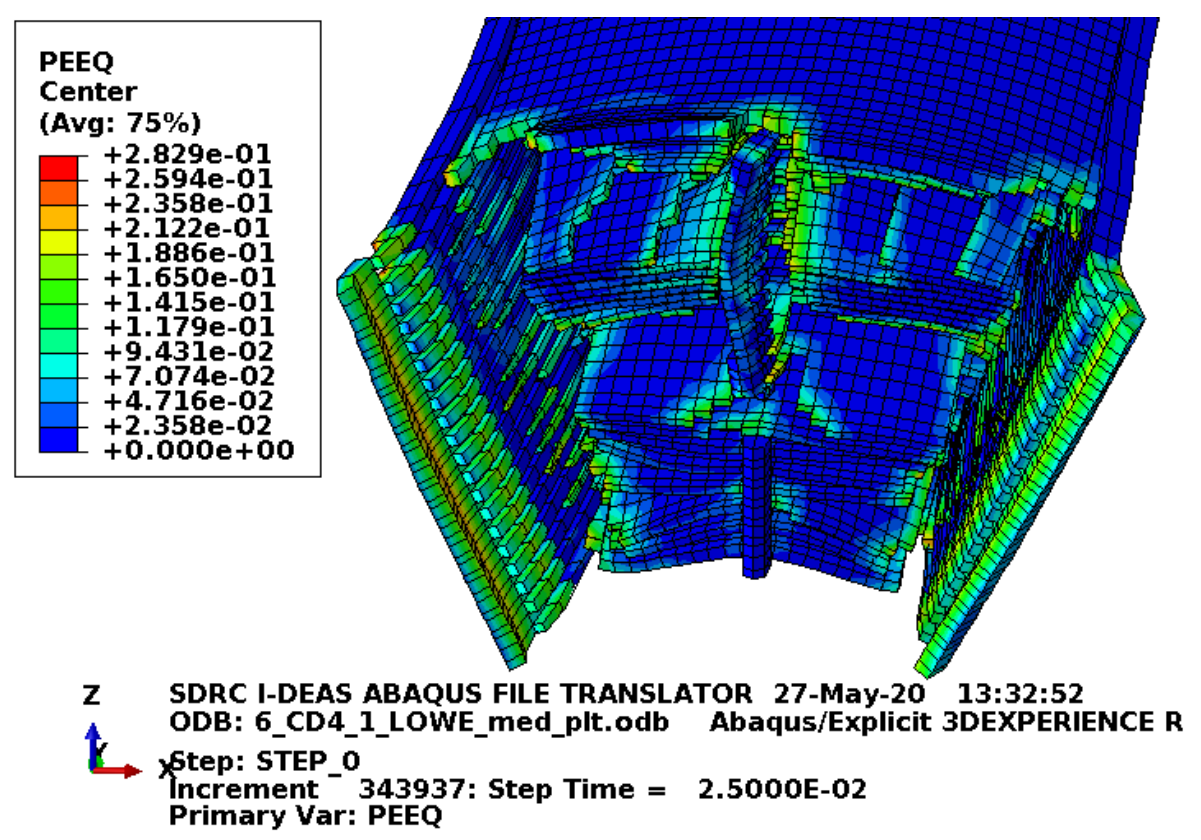

Figure D-238. Scope Part 2b (Table 3), Test 6 (Table 2) fine mesh zoomed view of the damage without the end box.

The FEA model in Figure D-238 has the end boxes and end box welds removed. This plot is done similar to that of Figure D-7 for information. This is shown before rebound. So, worse damage occurs, but the damage shown is already unacceptable.

\section{D3.5.5 Results for Scope Part 2c (Table 3), Test 6 (Table 2)}

The FEA model results for the Scope Part 2c (Table 3), Test 6 (Table 2) model are shown below in Figure D-239 to Figure D-241. The fuel element weighs $44 \mathrm{lbf}$ and the whole model is modeled with minimum material properties. This section includes the blocks as added fuel plate protection. 


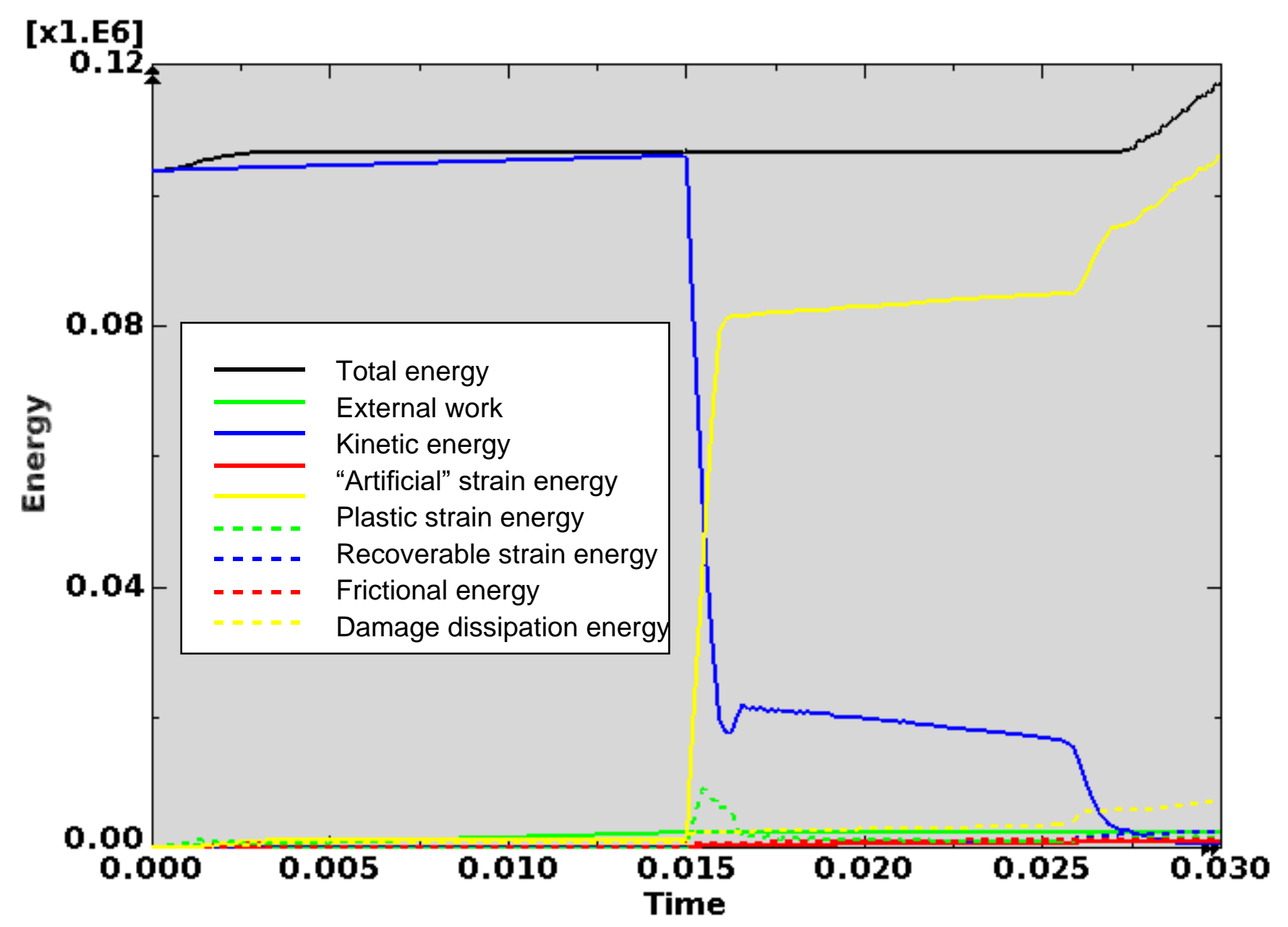

Figure D-239. Scope Part 2c (Table 3), Test 6 (Table 2) energy curves.

Figure D-239 shows the energy curves for Scope Part 2c (Table 3), Test 6 (Table 2) drop scenario. These curves exhibit mostly stable behavior. Near the end of the model run, the total energy and plastic strain energy start to show undesirable behavior. As discussed in Section D3.5 this appears to result from contact difficultly between failed portions of the fuel element. Consequently, output is shown at the first output frame after fuel element rebound $(0.03$ second) to try to minimize potential error associated with this. The results are considered reasonable and conservative considering that the results compared with physical drops (see Section D2.5) had more of an energy rise and still produced reasonable and conservative results.

Artificial strain energy represents the energy required to keep reduced integration elements from taking on a zero-energy hourglass shape. As shown in Figure D-239, the artificial energy at the end of the model run is $0.8 \%$ of the total energy. Therefore, the potential error associated with artificial energy is not considered to be significant. 
ENGINEERING CALCULATIONS AND ANALYSIS

Drop Analysis of the Advanced Test Reactor Fresh Fuel Shipping Container with Heavier Low-Enriched Uranium Fuel Contents
ECAR-5224, Rev. 0

Page D213 of D293

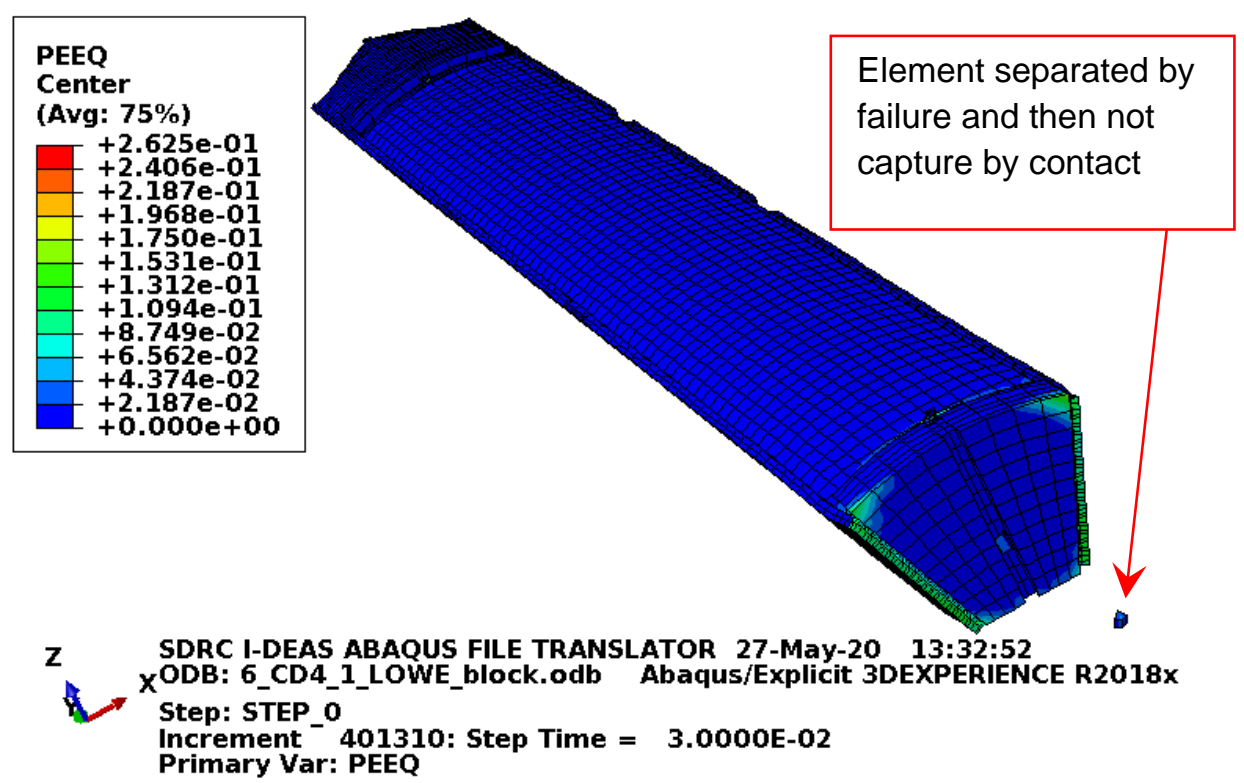

Figure D-240. Scope Part 2c (Table 3), Test 6 (Table 2) fuel element plastic equivalent strain.

Figure D-240 shows the equivalent plastic strain in the fuel element. Failure in the end box elements occurs at an equivalent plastic strain of $0.027 \mathrm{in}$./in. Failure in the end box weld elements occurs at an equivalent plastic strain of $0.032 \mathrm{in}$./in. Failure in the side plate and comb elements occurs at an equivalent plastic strain of $0.152 \mathrm{in}$./in. Figure D-240 shows nearly complete failure of the end box and end box welds nearest the impact. An element was separated by failure and then not captured by contact. The overall model error associated with this is not considered to be significant.

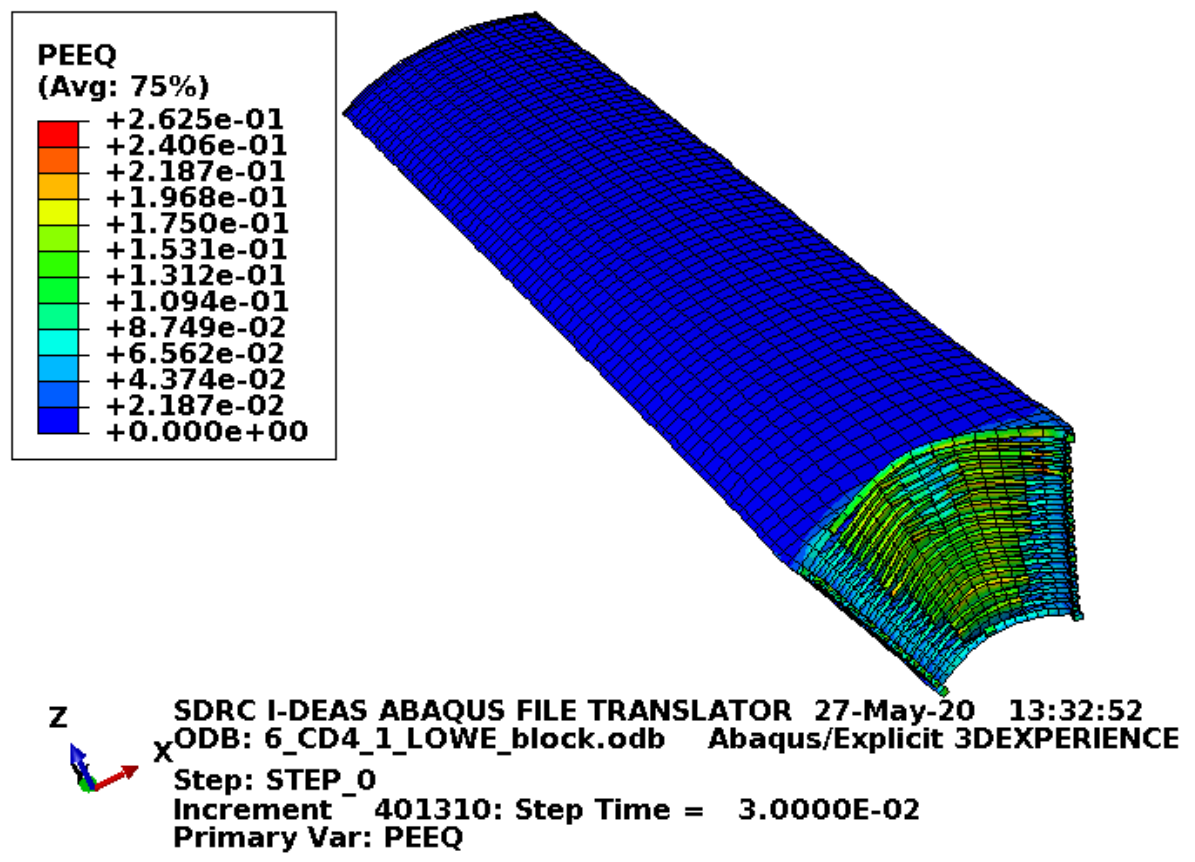

Figure D-241. Scope Part 2c (Table 3), Test 6 (Table 2) fuel plate equivalent strain. 
Figure D-241 shows the equivalent plastic strain in the fuel plates. Failure in these elements occurs at an equivalent plastic strain of 0.205 in./in. Figure D-241 shows element failure extends close to the fuel meat in the end of the fuel plates. Additionally, a couple elements at the end of one fuel plate show strains above failure. The strains shown above the failure strain likely result from extrapolation (as integration point strains are the important strains for failure). Even if the elements with high strain were removed as being failed, the failure would be acceptable as the failed and high strained elements do not represent fuel meat.

\section{D3.5.6 Results for Scope Part 2c (Table 3), Test 6 (Table 2) Fine Mesh}

The FEA model results for the Scope Part 2c (Table 3), Test 6 (Table 2) fine mesh model are shown below in Figure D-242 to Figure D-244. The fuel element weighs $44 \mathrm{lbf}$ and the whole model is modeled with minimum material properties. This section includes the blocks as added fuel plate protection.

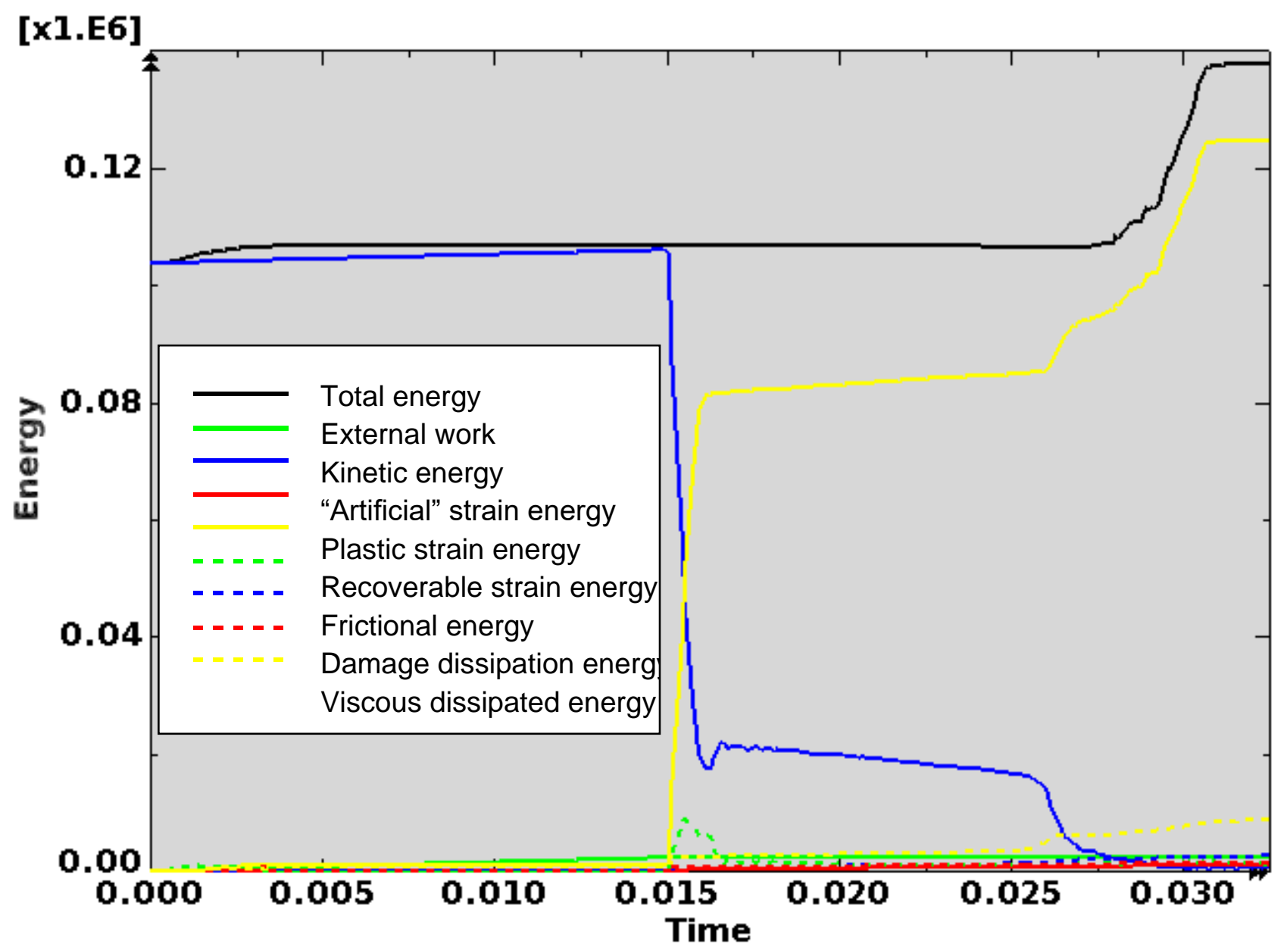

Figure D-242. Scope Part 2c (Table 3), Test 6 (Table 2) fine mesh energy curves.

Figure D-242 shows the energy curves for Scope Part 2c (Table 3), Test 6 (Table 2) fine mesh drop scenario. These curves exhibit mostly stable behavior. Near the end of the model run, the total energy and plastic strain energy start to show undesirable behavior. As discussed in Section D3.5 this appears to result from contact difficultly between failed portions of the fuel element. Consequently, output is shown at the first output frame after fuel element rebound $(0.0325$ second $)$ to try to minimize potential error associated with this. 
The results are considered reasonable and conservative considering that the results compared with physical drops (see Section D2.5) had more of an energy rise and still produced reasonable and conservative results. Rebound for this model occurred just after 0.03 seconds. Consequently, more undesirable behavior is shown than is needed. If a model rerun were performed to closer to just after rebound, then this curve would look similar to that in Figure D-239. However, at 0.0325 seconds no obvious additional damage has occurred and the model results are intended to envelope the damage.

Artificial strain energy represents the energy required to keep reduced integration elements from taking on a zero-energy hourglass shape. As shown in Figure D-242, the artificial energy at the end of the model run is $0.7 \%$ of the total energy. Therefore, the potential error associated with artificial energy is not considered to be significant.

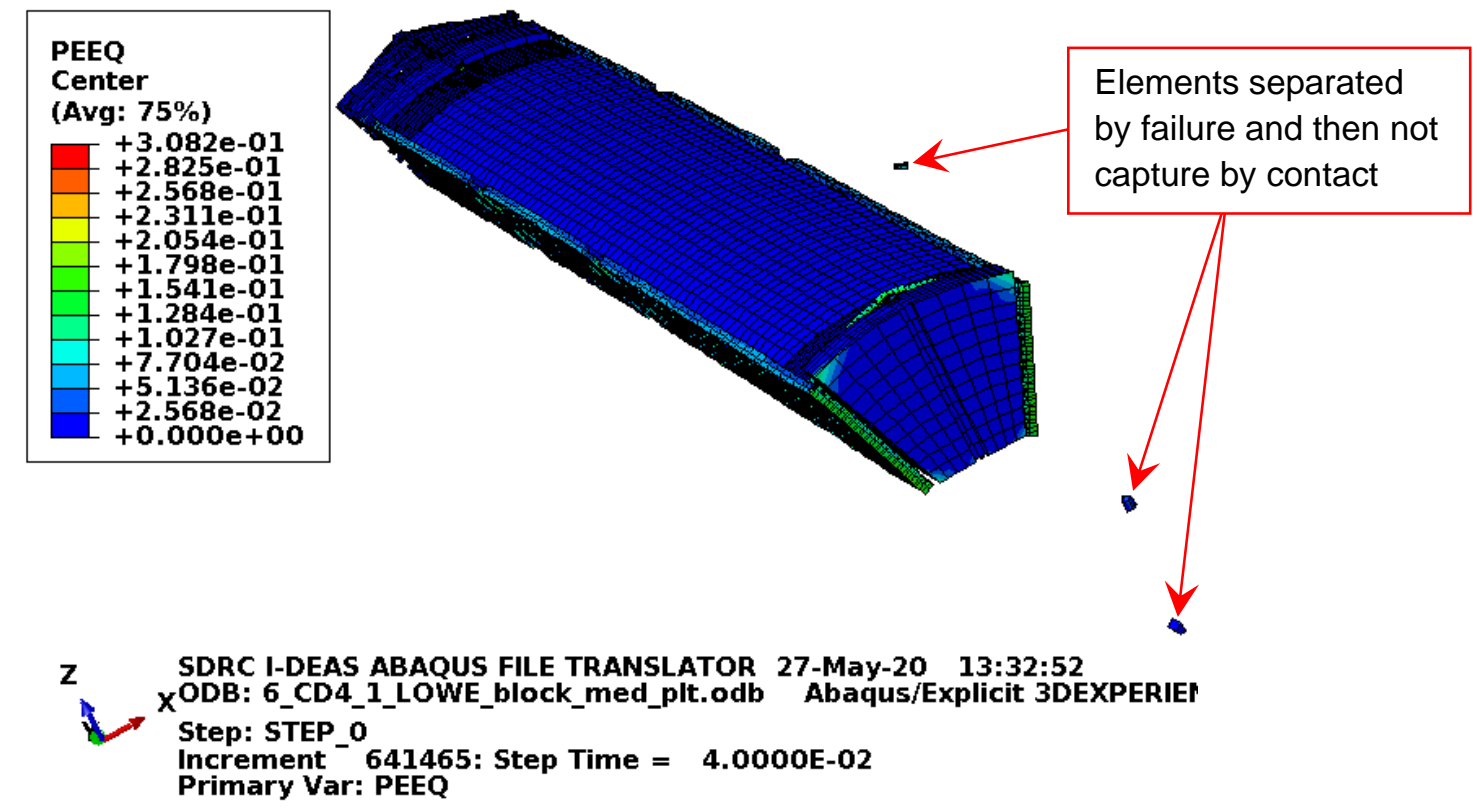

Figure D-243. Scope Part 2c (Table 3), Test 6 (Table 2) fine mesh fuel element plastic equivalent strain.

Figure D-243 shows the equivalent plastic strain in the fuel element. Failure in the end box elements occurs at an equivalent plastic strain of $0.027 \mathrm{in.} / \mathrm{in}$. Failure in the end box weld elements occurs at an equivalent plastic strain of $0.032 \mathrm{in}$./in. Failure in the side plate and comb elements occurs at an equivalent plastic strain of $0.152 \mathrm{in./in.} \mathrm{Failure} \mathrm{in} \mathrm{the} \mathrm{side} \mathrm{plate} \mathrm{weld} \mathrm{elements} \mathrm{occurs} \mathrm{at} \mathrm{an} \mathrm{equivalent} \mathrm{plastic} \mathrm{strain} \mathrm{of}$ $0.205 \mathrm{in}$./in. Figure D-243 shows nearly complete failure of the end box and end box welds nearest the impact. A couple elements were separated by failure and then not captured by contact. The overall model error associated with this is not considered to be significant. 
ENGINEERING CALCULATIONS AND ANALYSIS

Drop Analysis of the Advanced Test Reactor Fresh Fuel Shipping Container with Heavier Low-Enriched Uranium Fuel Contents
ECAR-5224, Rev. 0

Page D216 of D293

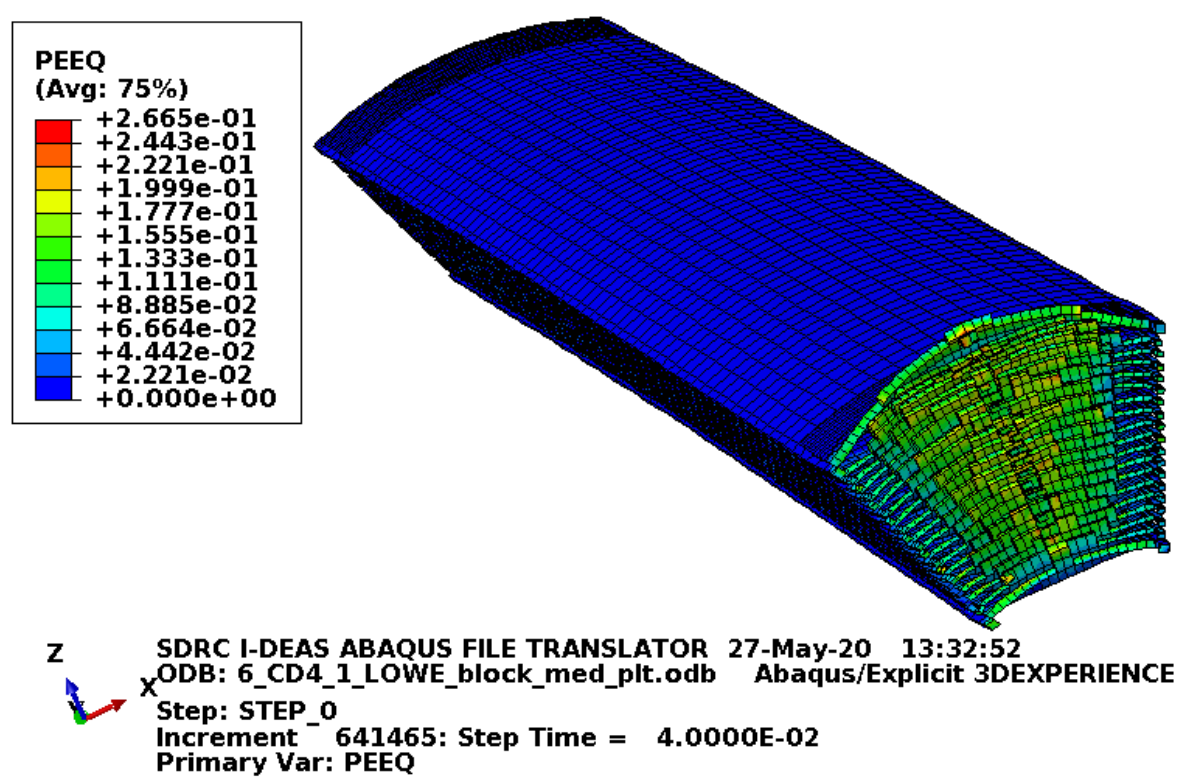

Figure D-244. Scope Part 2c (Table 3), Test 6 (Table 2) fine mesh fuel plate equivalent strain.

Figure D-244 shows the equivalent plastic strain in the fuel plates. Failure in these elements occurs at an equivalent plastic strain of $0.205 \mathrm{in}$./in. Figure D-244 shows element failure in the ends of the fuel plates, but it does not extend into the fuel meat. Additionally, a few elements at the fuel plate ends show strains above failure. The strains shown above the failure strain likely result from extrapolation (as integration point strains are the important strains for failure). Even if the elements with high strain were removed as being failed, the failure would be acceptable as the failed and high strained elements do not represent fuel meat.

\section{D3.5.7 Results for Scope Part 2d (Table 3), Test 6 (Table 2)}

The FEA model results for the Scope Part 2d (Table 3), Test 6 (Table 2) model are shown below in Figure D-245 to Figure D-247. The fuel element weighs $44 \mathrm{lbf}$ and the drop scenario is modeled with minimum material properties except the enclosure and end boxes, which are modeled with relatively tough material properties. This section includes the blocks as added fuel plate protection. 


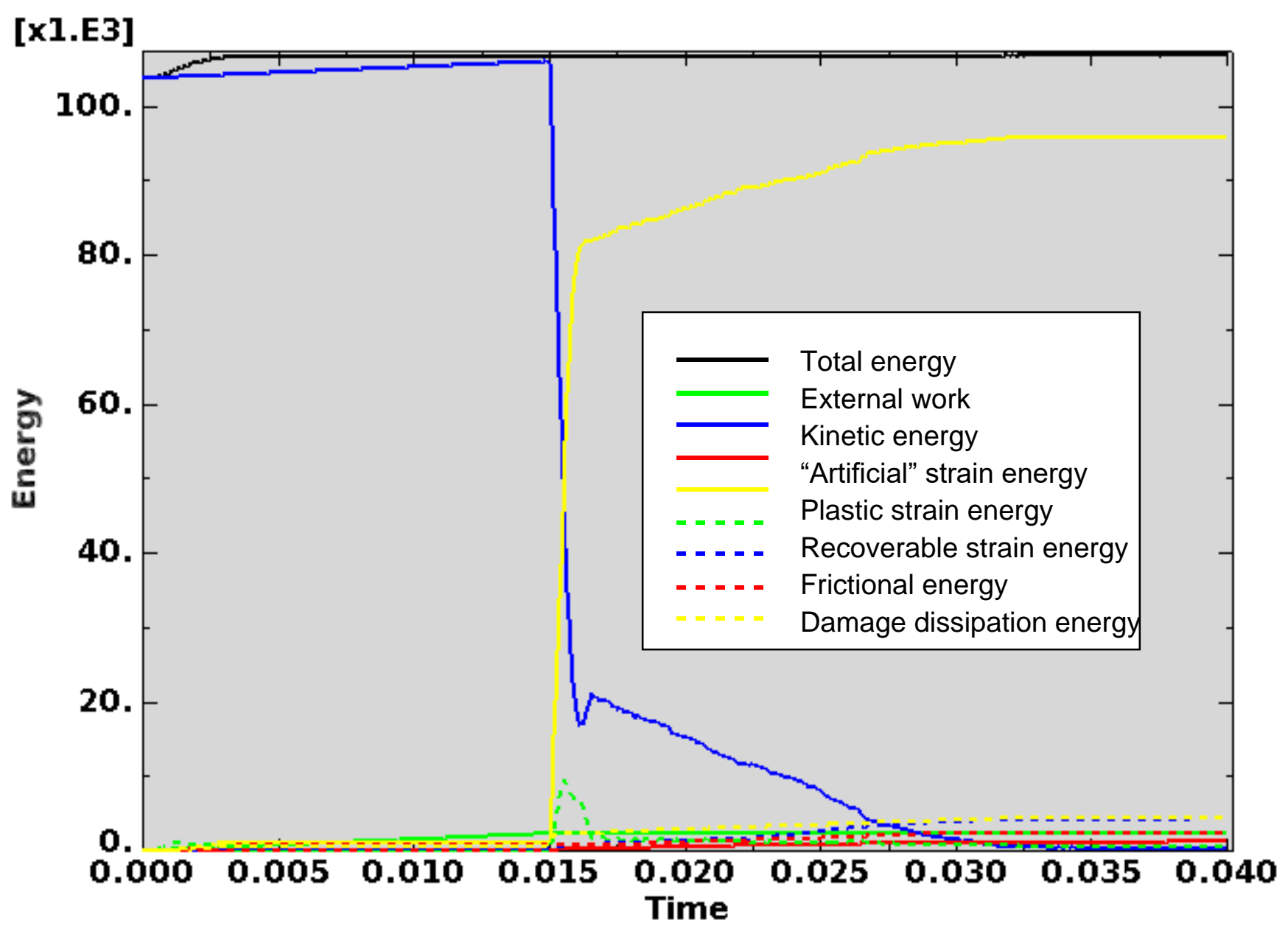

Figure D-245. Scope Part 2d (Table 3), Test 6 (Table 2) energy curves.

Figure D-245 shows the energy curves for Scope Part 2d (Table 3), Test 6 (Table 2) drop scenario. These curves exhibit a stable shape. Artificial strain energy represents the energy required to keep reduced integration elements from taking on a zero-energy hourglass shape. As shown in Figure D-245, the artificial energy at the end of the model run is $1.1 \%$ of the total energy. Therefore, the potential error associated with artificial energy is not considered to be significant. 
ENGINEERING CALCULATIONS AND ANALYSIS

Drop Analysis of the Advanced Test Reactor Fresh Fuel Shipping Container with Heavier Low-Enriched Uranium Fuel Contents
ECAR-5224, Rev. 0

Page D218 of D293

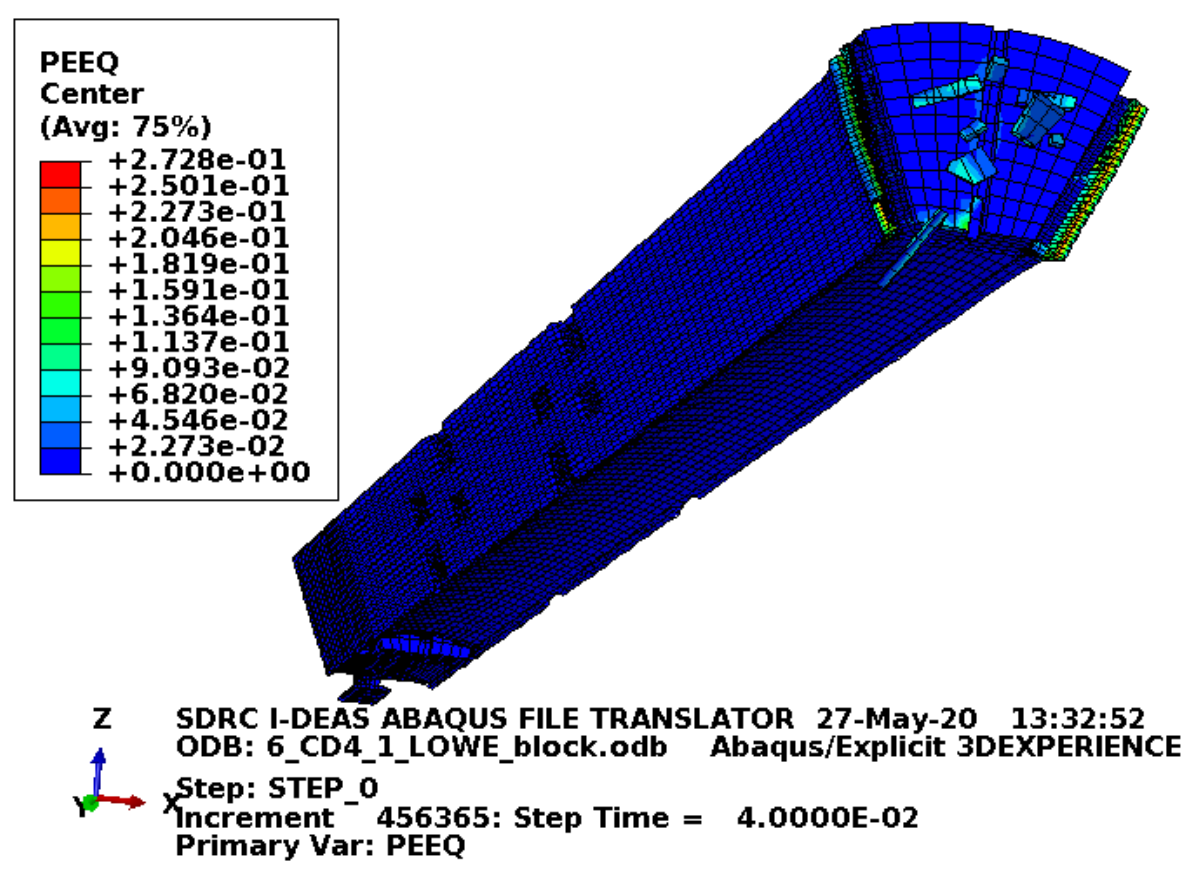

Figure D-246. Scope Part 2d (Table 3), Test 6 (Table 2) fuel element plastic equivalent strain.

Figure D-246 shows the equivalent plastic strain in the fuel element. Failure in the end box elements occurs at an equivalent plastic strain of $0.08 \mathrm{in./in.} \mathrm{(for} \mathrm{the} \mathrm{relatively} \mathrm{tough} \mathrm{material} \mathrm{properties).} \mathrm{Failure} \mathrm{in} \mathrm{the} \mathrm{end}$ box weld elements occurs at an equivalent plastic strain of $0.115 \mathrm{in}$./in. (for the relatively tough material properties). Failure in the side plate and comb elements occurs at an equivalent plastic strain of $0.152 \mathrm{in}$./in. Failure in the side plate weld elements occurs at an equivalent plastic strain of 0.205 in./in. Figure D-246 shows nearly complete failure of the end box and end box welds nearest the impact.

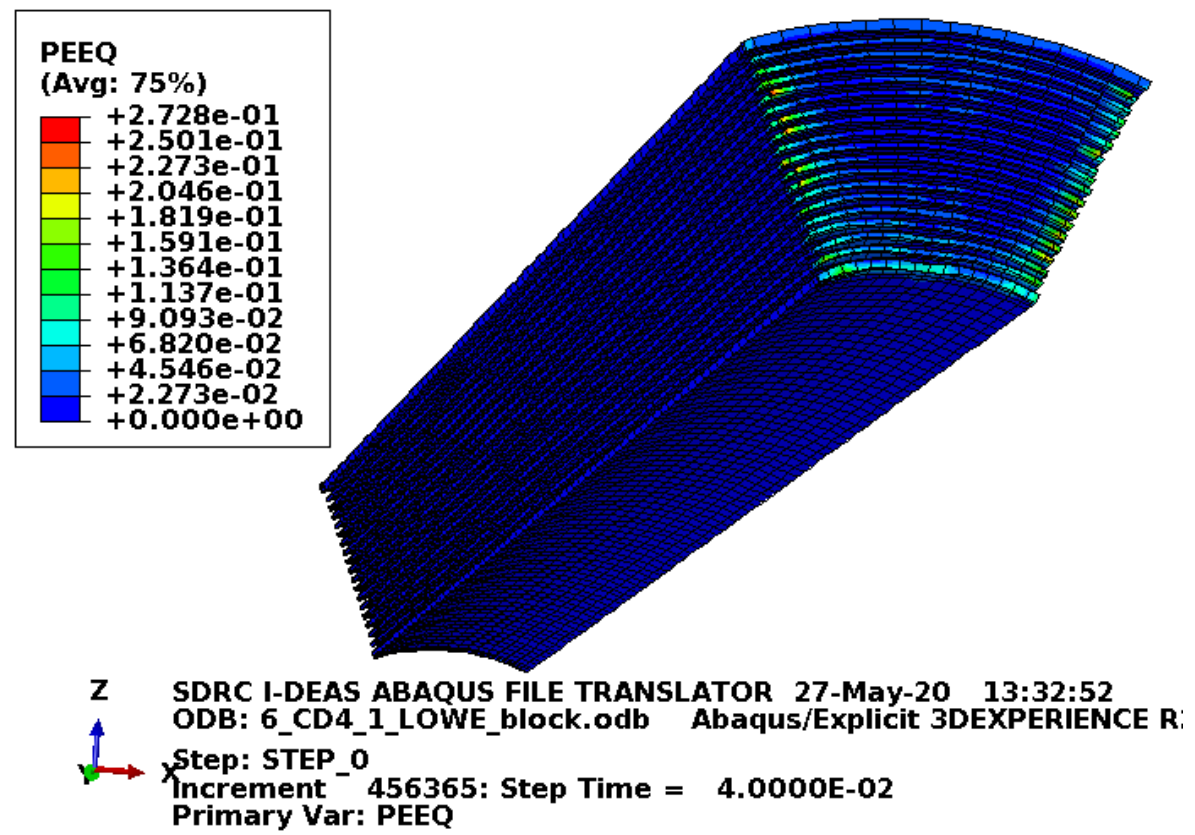

Figure D-247. Scope Part 2d (Table 3), Test 6 (Table 2) fuel plate equivalent strain. 
Figure D-247 shows the equivalent plastic strain in the fuel plates. Failure in these elements occurs at an equivalent plastic strain of $0.205 \mathrm{in}$./in. Figure D-247 shows element failure in the ends of the fuel plates nearest the impact. The failure results from failed pieces of the end box sides trying to wedge down next to the block and between the fuel plates and side plate. The damage is mostly shallow but extends to about $0.4 \mathrm{in}$. in one location near the plate edges. Additionally, a few elements at the end of the fuel plates show strains above failure. The strains shown above the failure strain likely result from extrapolation (as integration point strains are the important strains for failure). Even if the elements with high strain were removed as being failed, they would not cause the failure to be closer to the fuel meat than failed elements already caused. Consequently, the failure would be acceptable as the failed and high strained elements remain significantly distant from the fuel meat.

\section{D3.5.8 Results for Scope Part 2d (Table 3), Test 6 (Table 2) Fine Mesh}

The FEA model results for the Scope Part 2d (Table 3), Test 6 (Table 2) fine mesh model are shown below in Figure D-248 to Figure D-250. The fuel element weighs $44 \mathrm{lbf}$ and the drop scenario is modeled with minimum material properties except the enclosure and end boxes, which are modeled with relatively tough material properties. This section includes the blocks as added fuel plate protection.

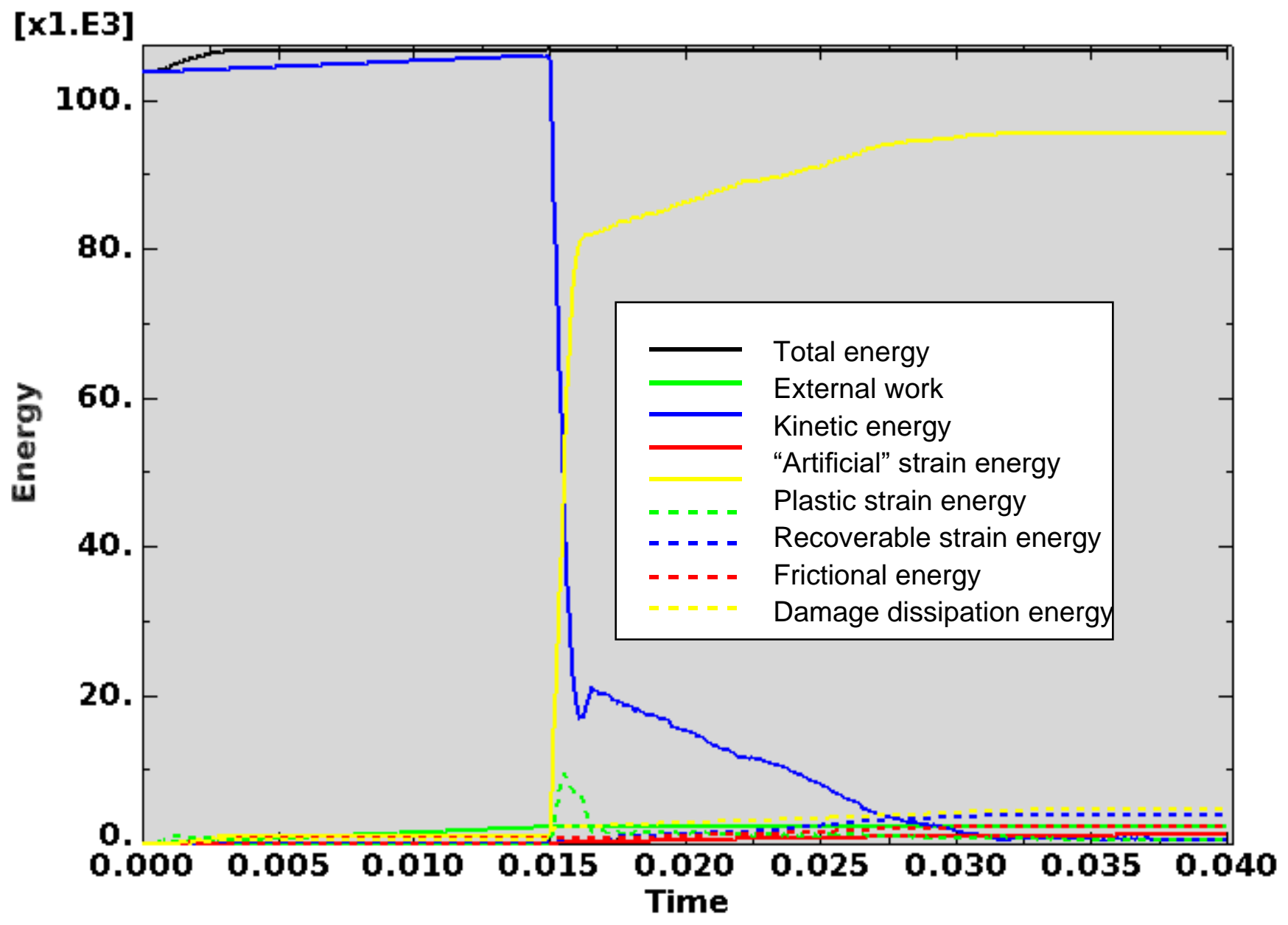

Figure D-248. Scope Part 2d (Table 3), Test 6 (Table 2) fine mesh energy curves. 
Figure D-248 shows the energy curves for Scope Part 2d (Table 3), Test 6 (Table 2) fine mesh drop scenario. These curves exhibit a stable shape. Artificial strain energy represents the energy required to keep reduced integration elements from taking on a zero-energy hourglass shape. As shown in Figure D-248, the artificial energy at the end of the model run is $1.2 \%$ of the total energy. Therefore, the potential error associated with artificial energy is not considered to be significant.

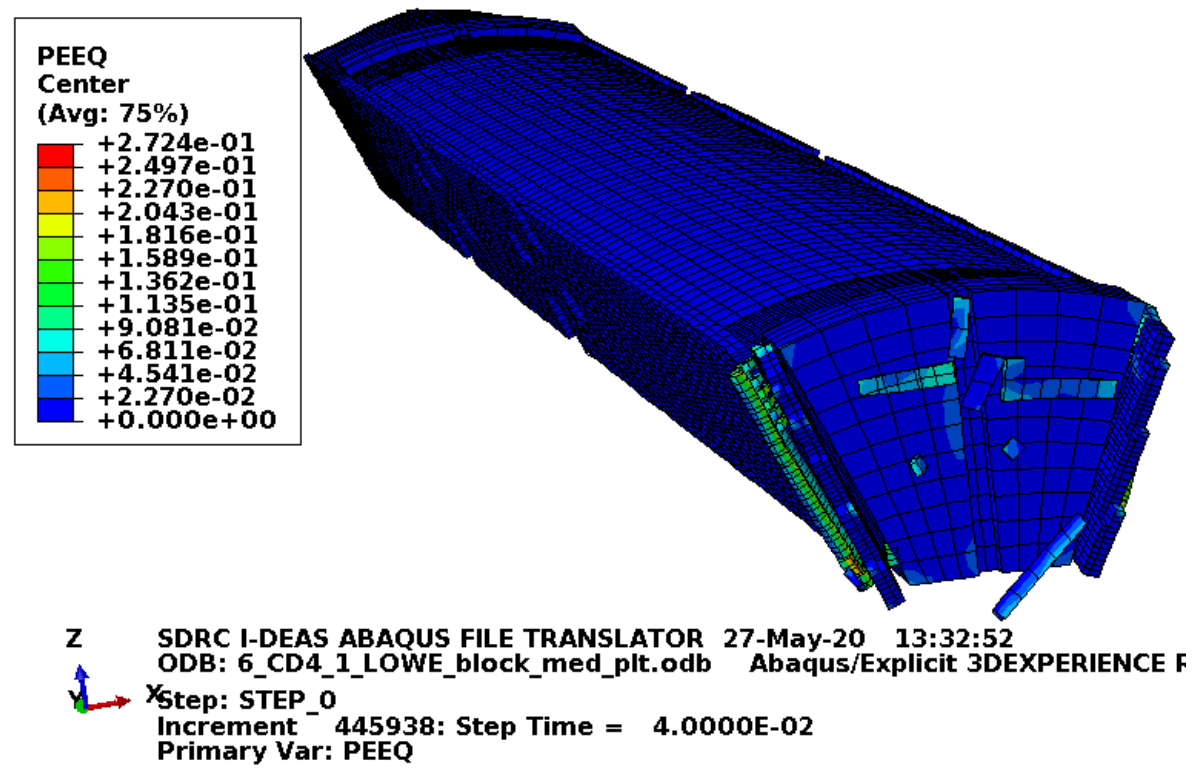

Figure D-249. Scope Part 2d (Table 3), Test 6 (Table 2) fine mesh fuel element plastic equivalent strain.

Figure D-249 shows the equivalent plastic strain in the fuel element. Failure in the end box elements occurs at an equivalent plastic strain of $0.08 \mathrm{in./in.} \mathrm{(for} \mathrm{the} \mathrm{relatively} \mathrm{tough} \mathrm{material} \mathrm{properties).} \mathrm{Failure} \mathrm{in} \mathrm{the} \mathrm{end}$ box weld elements occurs at an equivalent plastic strain of $0.115 \mathrm{in}$./in. (for the relatively tough material properties). Failure in the side plate and comb elements occurs at an equivalent plastic strain of 0.152 in./in. Failure in the side plate weld elements occurs at an equivalent plastic strain of 0.205 in./in. Figure D-249 shows nearly complete failure of the end box and end box welds nearest the impact. 


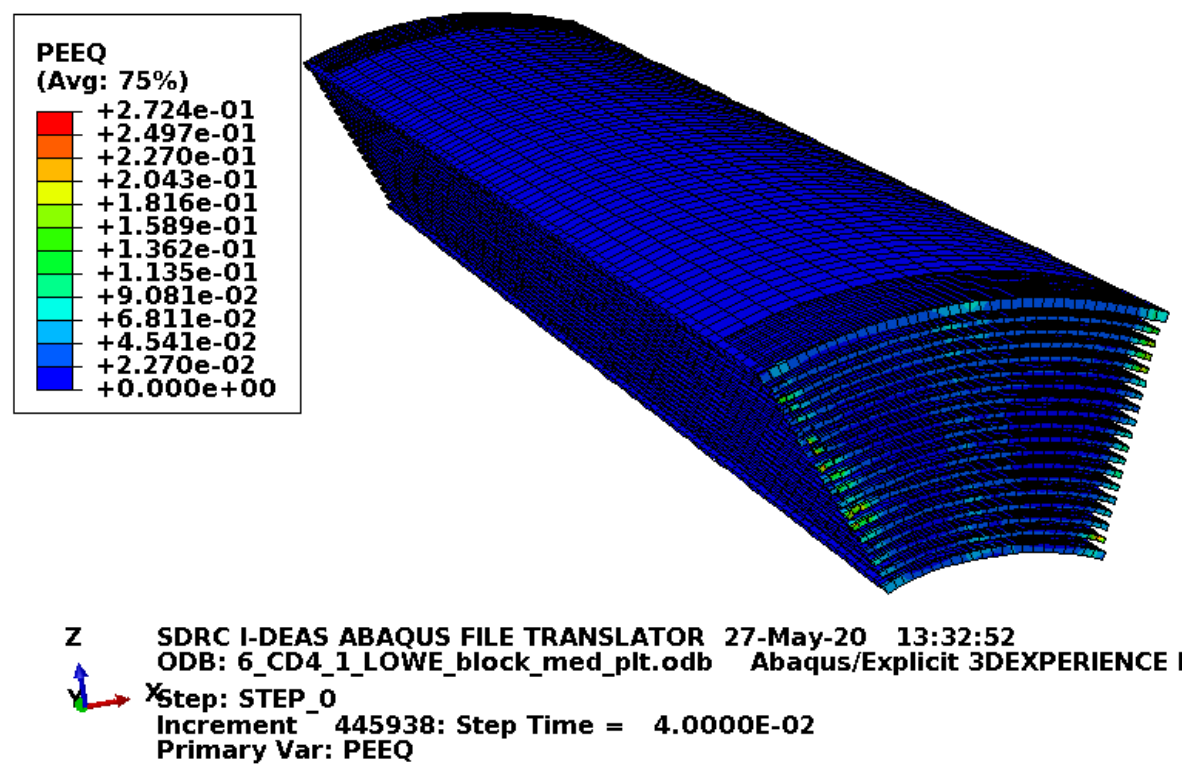

Figure D-250. Scope Part 2d (Table 3), Test 6 (Table 2) fine mesh fuel plate equivalent strain.

Figure D-250 shows the equivalent plastic strain in the fuel plates. Failure in these elements occurs at an equivalent plastic strain of 0.205 in./in. Figure D-250 shows element failure in the ends of the fuel plates nearest the impact. The failure results from failed pieces of the end box sides trying to wedge down next to the block and between the fuel plates and side plate. The damage is mostly shallow but extends to about $0.3 \mathrm{in}$. in one location near the plate edges. Additionally, a few elements at the end of the fuel plates show strains above failure. The strains shown above the failure strain likely result from extrapolation (as integration point strains are the important strains for failure). Even if the elements with high strain were removed as being failed, they would not cause the failure to be closer to the fuel meat than failed elements already caused. Consequently, the failure would be acceptable as the failed and high strained elements remain significantly distant from the fuel meat. It is notable that the finer mesh should damage relatively easier than the coarse mesh shown in Figure D-247 yet there is less damage shown in the finer mesh. Also, the failure pattern of the fine meshed model is on the edge of the fuel plates. Consequently, extension of the failure pattern well past the $0.75 \mathrm{in}$. depth of the upper fuel meat edge would be acceptable because the damage would be to the side of the fuel meat (rather than in the fuel meat).

\section{D3.6 Results for Scope Part 2 (Table 3), Test 8 (Table 2)}

The drop scenario considered in this section is a $30 \mathrm{ft}$ drop modeled as a center of gravity over the top corner impact.

\section{D3.6.1 Results for Scope Part 2a (Table 3), Test 8 (Table 2)}

The FEA model results for the Scope Part 2a (Table 3), Test 8 (Table 2) model are shown below in Figure D-251 to Figure D-253. The fuel element weighs $44 \mathrm{lbf}$ and the whole model is modeled with minimum material properties. 


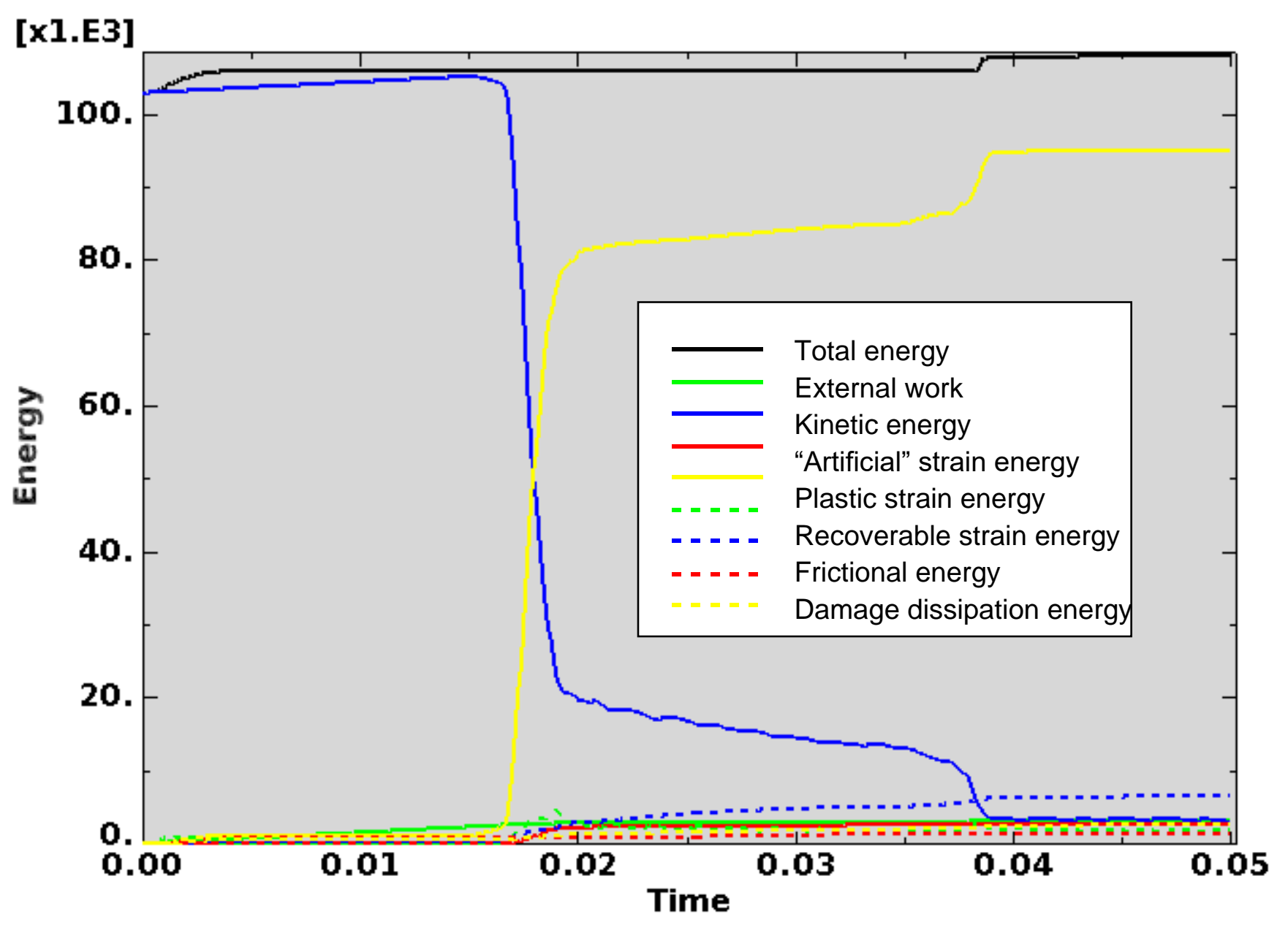

Figure D-251. Scope Part 2a (Table 3), Test 8 (Table 2) energy curves.

Figure D-251 shows the energy curves for Scope Part 2a (Table 3), Test 8 (Table 2) drop scenario. These curves exhibit mostly stable behavior. Near the end of the model run, the total energy and plastic strain energy start to show minimal undesirable behavior. As discussed in Section D3.5 this appears to result from contact difficultly between failed portions of the fuel element. Because the undesirable behavior in the total energy is minimal, the results are given at the end of the model run.

Artificial strain energy represents the energy required to keep reduced integration elements from taking on a zero-energy hourglass shape. As shown in Figure D-251, the artificial energy at the end of the model run is $2.6 \%$ of the total energy. Therefore, the potential error associated with artificial energy is not considered to be significant. 
ENGINEERING CALCULATIONS AND ANALYSIS

Drop Analysis of the Advanced Test Reactor Fresh Fuel Shipping Container with Heavier Low-Enriched Uranium Fuel Contents
ECAR-5224, Rev. 0

Page D223 of D293

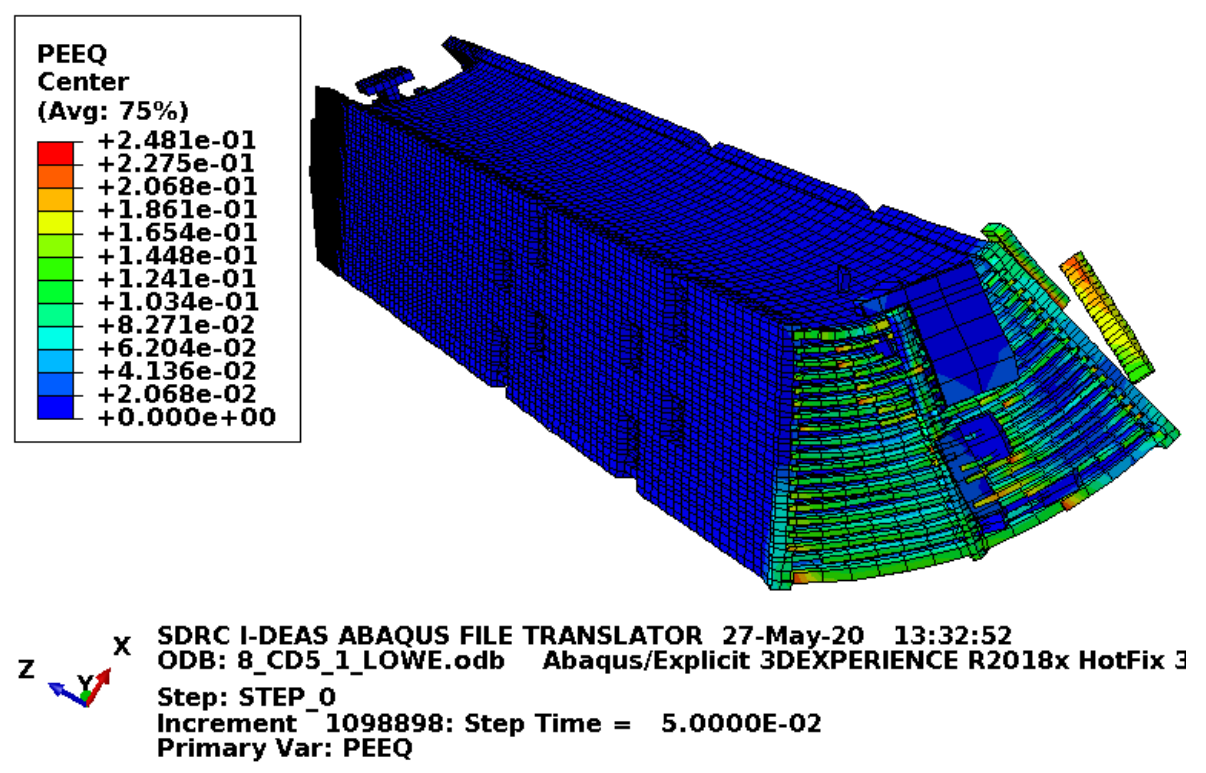

Figure D-252. Scope Part 2a (Table 3), Test 8 (Table 2) fuel element plastic equivalent strain.

Figure D-252 shows the equivalent plastic strain in the fuel element. Failure in the end box elements occurs at an equivalent plastic strain of $0.027 \mathrm{in}$./in. Failure in the end box weld elements occurs at an equivalent plastic strain of 0.032 in./in. Failure in the side plate and comb elements occurs at an equivalent plastic strain of $0.152 \mathrm{in}$./in. Failure in the side plate weld elements occurs at an equivalent plastic strain of $0.205 \mathrm{in}$./in. Figure D-252 shows nearly complete failure of the end box and end box welds nearest the impact.

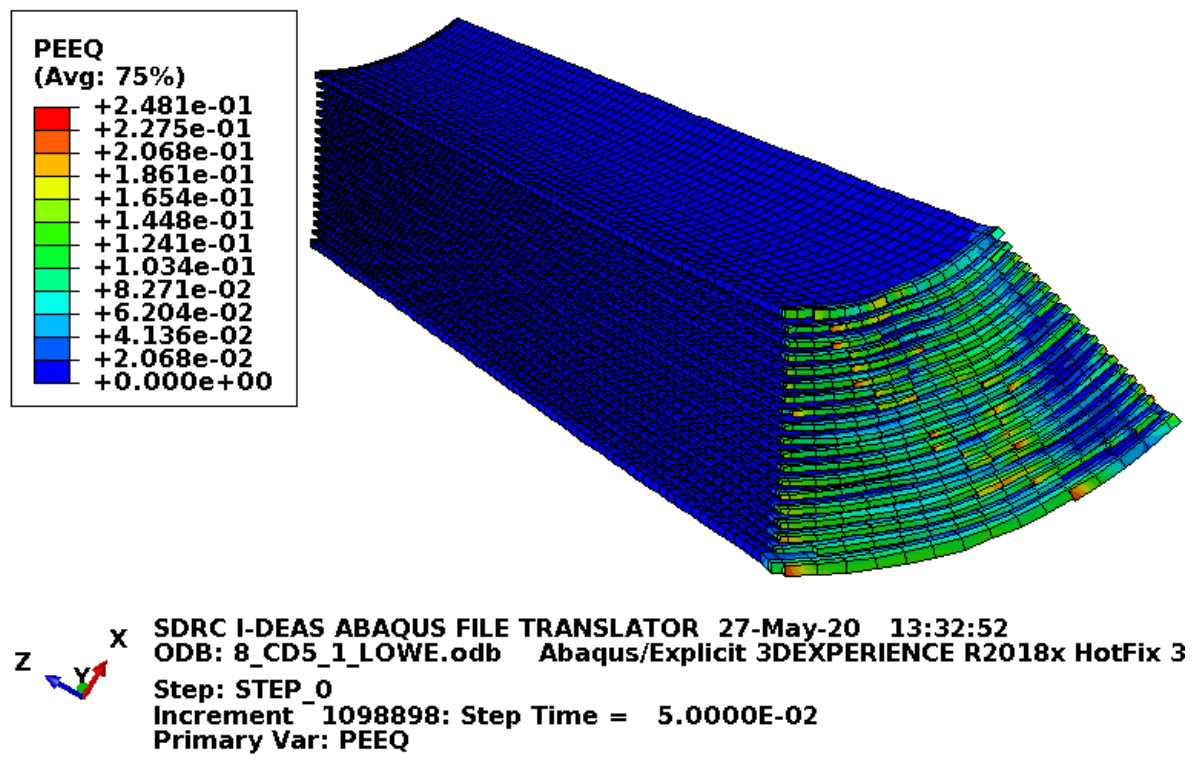

Figure D-253. Scope Part 2a (Table 3), Test 8 (Table 2) fuel plate equivalent strain. 
ENGINEERING CALCULATIONS AND ANALYSIS

Drop Analysis of the Advanced Test Reactor Fresh Fuel Shipping Container with Heavier Low-Enriched Uranium Fuel Contents
ECAR-5224, Rev. 0

Page D224 of D293

Figure D-253 shows the equivalent plastic strain in the fuel plates. Failure in these elements occurs at an equivalent plastic strain of 0.205 in./in. Figure D-253 shows element failure in the end of the fuel plates. Additionally, a few elements at the end of one fuel plate show strains above failure. The strains shown above the failure strain likely result from extrapolation (as integration point strains are the important strains for failure). Even if the elements with high strain were removed as being failed, the failure would be acceptable as the failed and high strained elements do not represent fuel meat.

\section{D3.6.2 Results for Scope Part 2b (Table 3), Test 8 (Table 2)}

The FEA model results for the Scope Part 2b (Table 3), Test 8 (Table 2) model are shown below in Figure D-254 to Figure D-256. The fuel element weighs $44 \mathrm{lbf}$ and the drop scenario is modeled with minimum material properties except the enclosure and end boxes, which are modeled with relatively tough material properties.

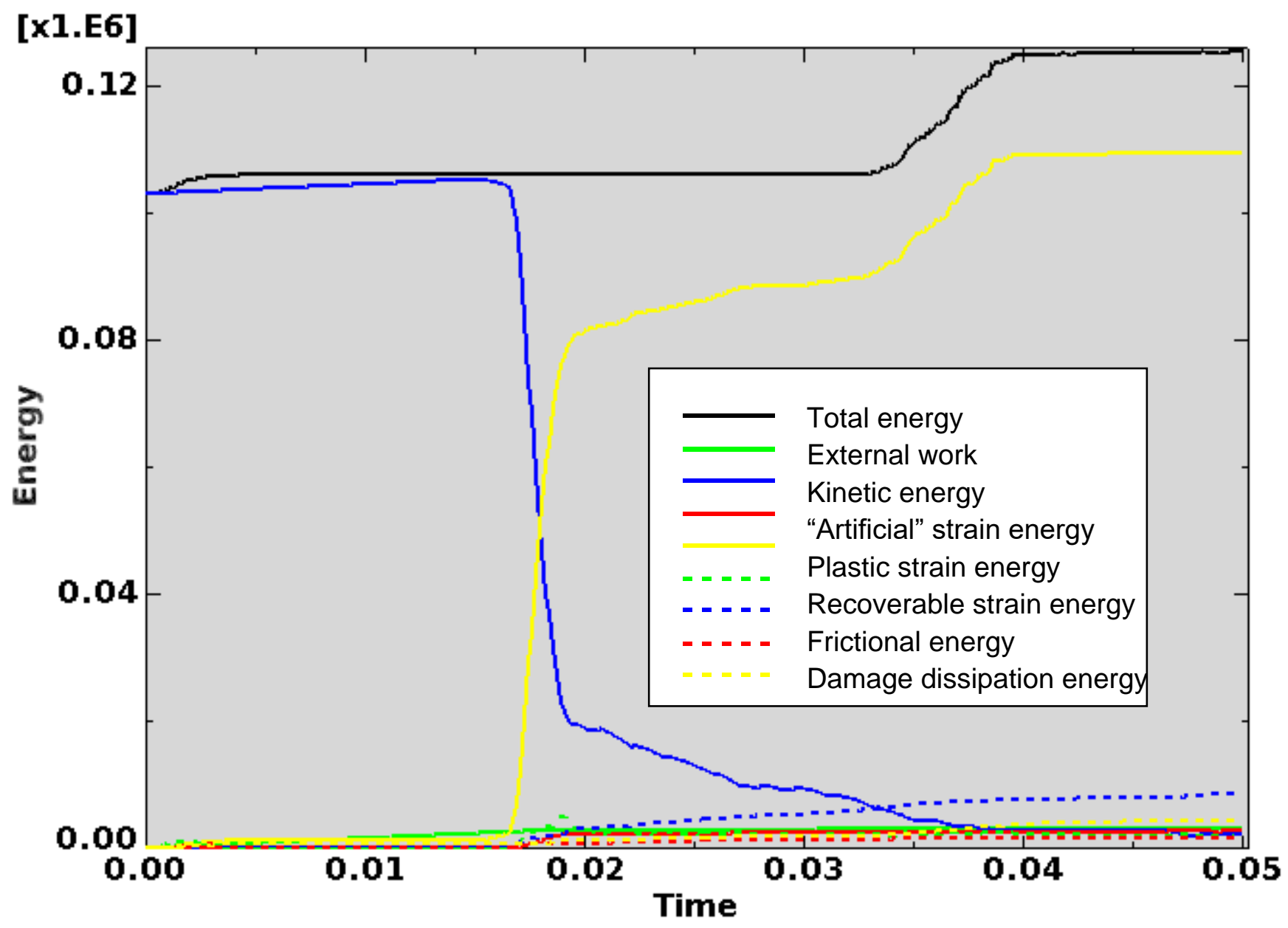

Figure D-254. Scope Part 2b (Table 3), Test 8 (Table 2) energy curves. 
Figure D-254 shows the energy curves for Scope Part 2b (Table 3), Test 8 (Table 2) drop scenario. These curves exhibit stable behavior for the initial impact of the ATR FFSC. As the fuel element impacts and is badly damaged, the total energy and plastic strain energy increase significantly which is undesirable. As discussed in Section D3.5 this appears to result from contact difficultly between failed portions of the fuel element. Though the energy curves show significant problems with the model run, the results are provided for information. This is not a recommended configuration (the recommended configuration being with blocks) for LOWE fuel elements and the model is showing unacceptable damage to the fuel meat.

Artificial strain energy represents the energy required to keep reduced integration elements from taking on a zero-energy hourglass shape. As shown in Figure D-254, the artificial energy at the end of the model run is $2.1 \%$ of the total energy. Therefore, the potential error associated with artificial energy is not considered to be significant.

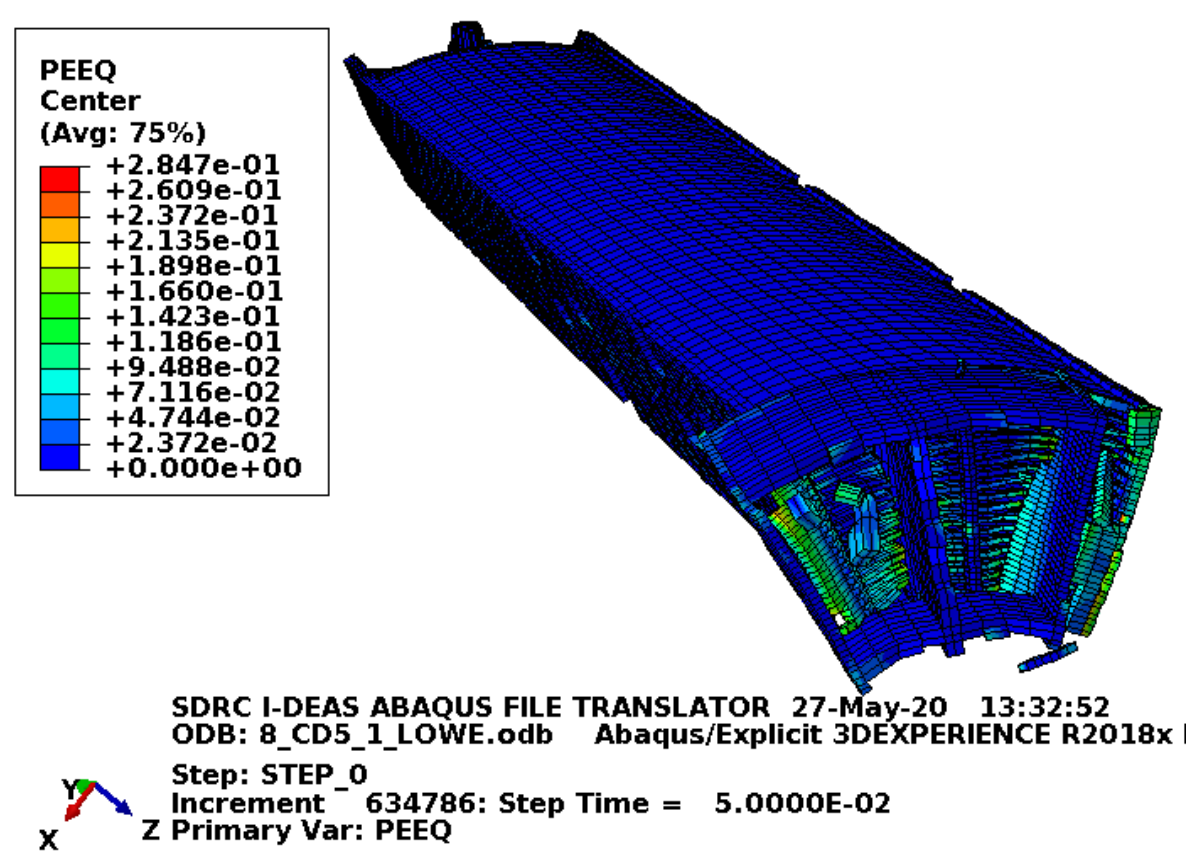

Figure D-255. Scope Part 2b (Table 3), Test 8 (Table 2) fuel element plastic equivalent strain.

Figure D-255 shows the equivalent plastic strain in the fuel element. Failure in the end box elements occurs at an equivalent plastic strain of $0.08 \mathrm{in./in.} \mathrm{(for} \mathrm{the} \mathrm{relatively} \mathrm{tough} \mathrm{material} \mathrm{properties).} \mathrm{Failure} \mathrm{in} \mathrm{the} \mathrm{end}$ box weld elements occurs at an equivalent plastic strain of $0.115 \mathrm{in}$./in. (for the relatively tough material properties). Failure in the side plate and comb elements occurs at an equivalent plastic strain of $0.152 \mathrm{in}$./in. Failure in the side plate weld elements occurs at an equivalent plastic strain of $0.205 \mathrm{in}$./in. Figure D-255 shows failure in the end box such that it has broken free and is impacting the fuel plates. Some local contact is being missed where end box pieces with failure contact fuel plates with failure. However, globally the contact is sufficient to produce reasonable rebound. 
ENGINEERING CALCULATIONS AND ANALYSIS

Drop Analysis of the Advanced Test Reactor Fresh Fuel Shipping Container with Heavier Low-Enriched Uranium Fuel Contents
ECAR-5224, Rev. 0

Page D226 of D293

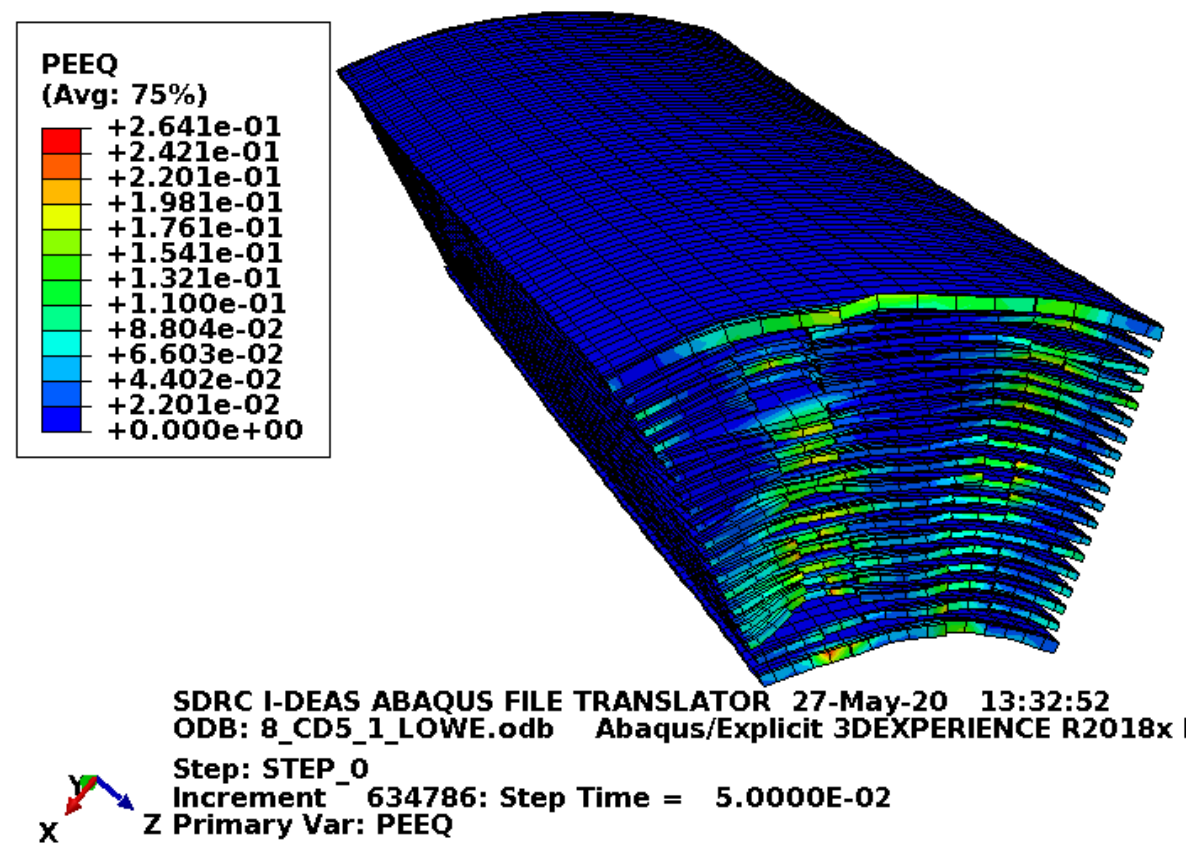

Figure D-256. Scope Part 2b (Table 3), Test 8 (Table 2) fuel plate equivalent strain.

Figure D-256 shows the equivalent plastic strain in the fuel plates. Failure in these elements occurs at an equivalent plastic strain of 0.205 in./in. Figure D-256 shows unacceptable fuel meat failure.

\section{D3.6.3 Results for Scope Part 2c (Table 3), Test 8 (Table 2)}

The FEA model results for the Scope Part 2c (Table 3), Test 8 (Table 2) model are shown below in Figure D-257 to Figure D-259. The fuel element weighs $44 \mathrm{lbf}$ and the whole model is modeled with minimum material properties. This section includes the blocks as added fuel plate protection. 


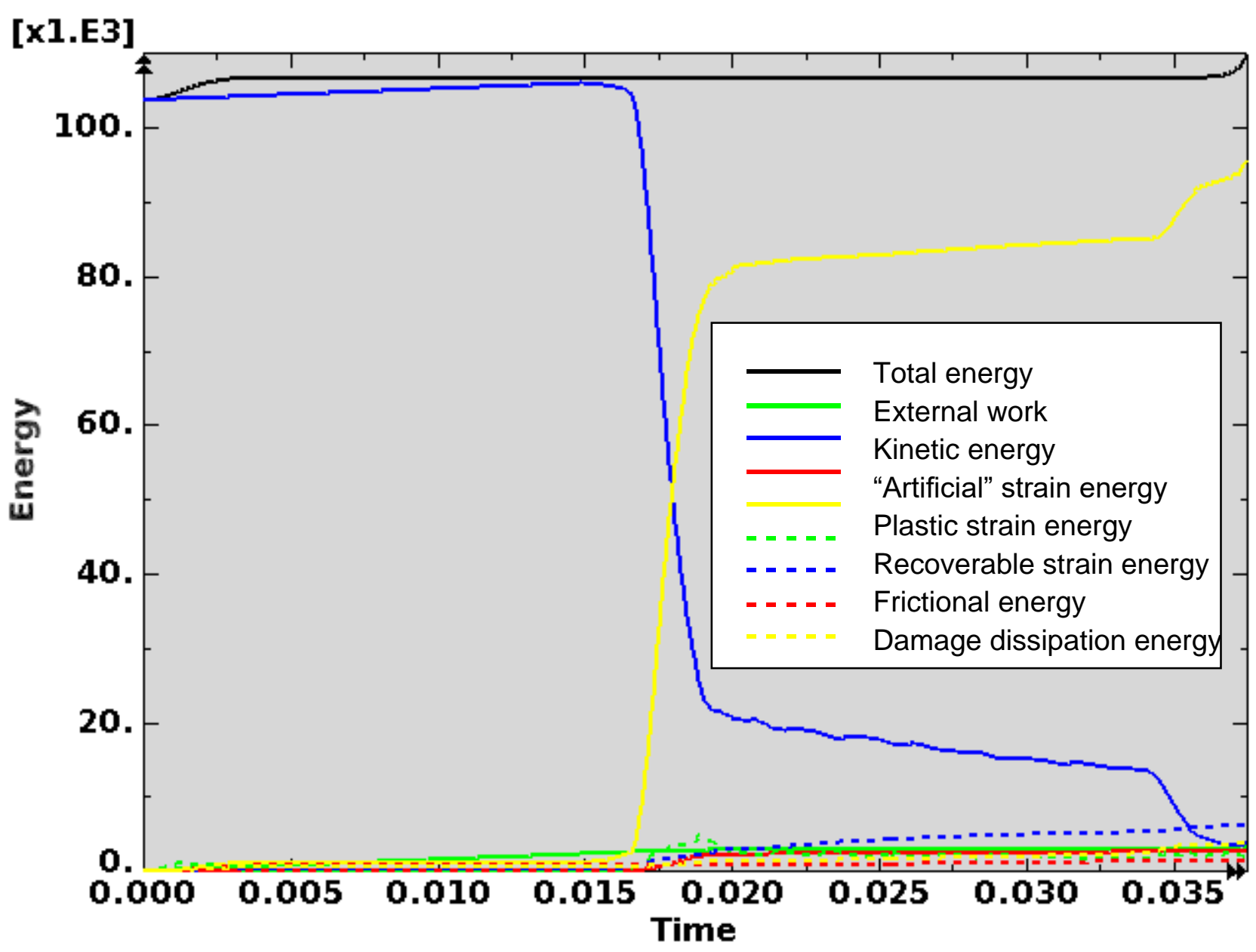

Figure D-257. Scope Part 2c (Table 3), Test 8 (Table 2) energy curves.

Figure D-257 shows the energy curves for Scope Part 2c (Table 3), Test 8 (Table 2) drop scenario. These curves exhibit stable behavior for the initial ATR FFSC impact and much of the fuel element impact. At a time of 0.0375 seconds, the kinetic energy has dropped to near zero and a strong argument can be made that the reasonable damage accumulation has ended. Though because of angular motions, the bottom of the fuel element does not show significant positive vertical velocities (used to indicate rebound in other models) until 0.0425 seconds. At a time of 0.0425 seconds, the total energy and plastic strain energy are showing significant rise which is undesirable behavior. However, from the time of 0.0375 seconds to the time of 0.0425 seconds, the fuel plates do not acquire any more failure and the peak plastic strain does not increase. Given this information, results are given at a time of 0.0375 seconds due to the fuel plate peak damage being achieved with relatively stable energy curves. Additionally, the results are considered reasonable and conservative considering that the results compared with physical drops (see Section D2.5) had more of an energy rise and still produced reasonable and conservative results.

Artificial strain energy represents the energy required to keep reduced integration elements from taking on a zero-energy hourglass shape. As shown in Figure D-257, the artificial energy at the end of the model run is $2.5 \%$ of the total energy. Therefore, the potential error associated with artificial energy is not considered to be significant. 
ENGINEERING CALCULATIONS AND ANALYSIS

Drop Analysis of the Advanced Test Reactor Fresh Fuel Shipping Container with Heavier Low-Enriched Uranium Fuel Contents
ECAR-5224, Rev. 0

Page D228 of D293
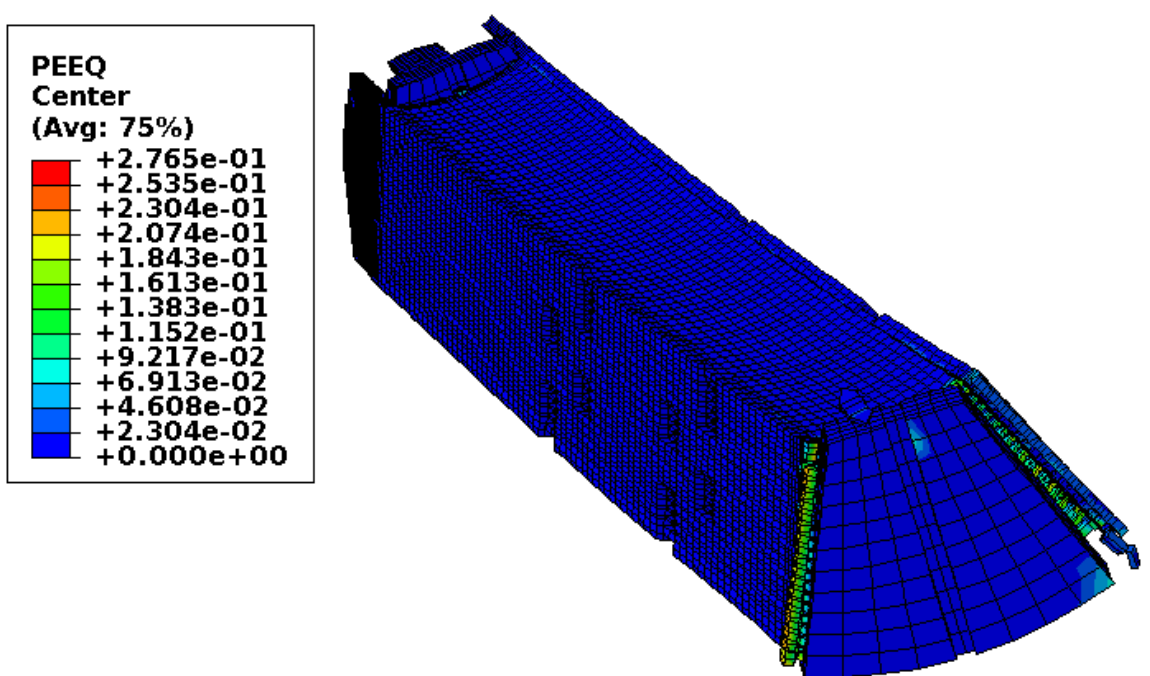

SDRC I-DEAS ABAQUS FILE TRANSLATOR 27-May-20 13:32:52

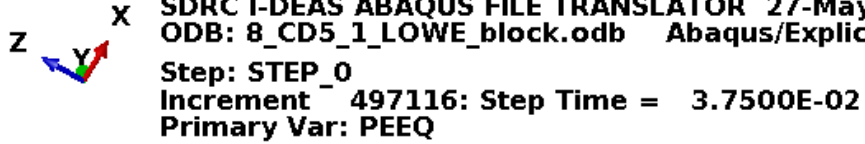

Figure D-258. Scope Part 2c (Table 3), Test 8 (Table 2) fuel element plastic equivalent strain.

Figure D-258 shows the equivalent plastic strain in the fuel element. Failure in the end box elements occurs at an equivalent plastic strain of $0.027 \mathrm{in}$./in. Failure in the end box weld elements occurs at an equivalent plastic strain of $0.032 \mathrm{in./in.} \mathrm{Failure} \mathrm{in} \mathrm{the} \mathrm{side} \mathrm{plate} \mathrm{and} \mathrm{comb} \mathrm{elements} \mathrm{occurs} \mathrm{at} \mathrm{an} \mathrm{equivalent} \mathrm{plastic}$ strain of $0.152 \mathrm{in./in.} \mathrm{Failure} \mathrm{in} \mathrm{the} \mathrm{side} \mathrm{plate} \mathrm{weld} \mathrm{elements} \mathrm{occurs} \mathrm{at} \mathrm{an} \mathrm{equivalent} \mathrm{plastic} \mathrm{strain} \mathrm{of}$ $0.205 \mathrm{in}$./in. Figure D-258 shows nearly complete failure of the end box and end box welds nearest the impact.
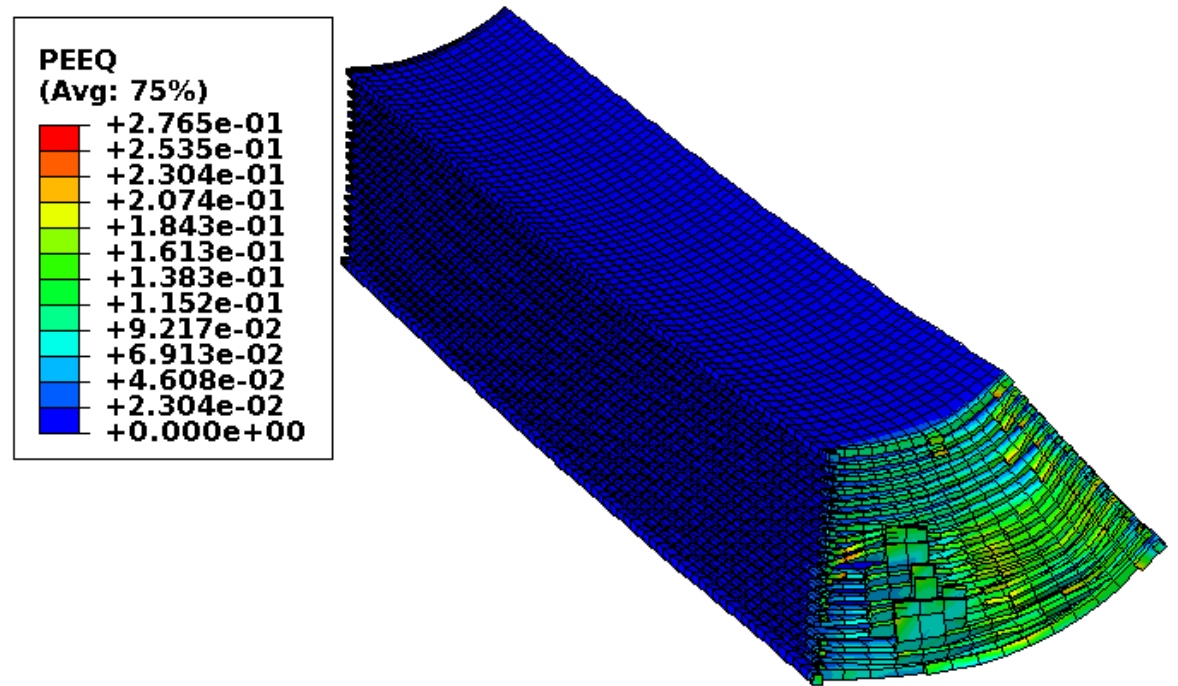

SDRC I-DEAS ABAOUS FILE TRANSLATOR 27-May-20 13:32:52

$\mathrm{x}$ ODB: 8_CD5_1_LOWE_block.odb Abaqus/Explicit 3DEXPERIENCE F

Step: STEP 0

Increment ${ }^{-}$497116: Step Time $=3.7500 \mathrm{E}-02$

Primary var: PEEQ

Figure D-259. Scope Part 2c (Table 3), Test 8 (Table 2) fuel plate equivalent strain. 
Figure D-259 shows the equivalent plastic strain in the fuel plates. Failure in these elements occurs at an equivalent plastic strain of 0.205 in./in. Figure D-259 shows some compressive failure in a few places up to about 0.66 in. Additionally, a couple elements at the end of one fuel plate show strains above failure. The strains shown above the failure strain likely result from extrapolation (as integration point strains are the important strains for failure). Even if the elements with high strain were removed as being failed, the failure would be acceptable as the failed and high strained elements do not reach the fuel meat.

\section{D3.6.4 Results for Scope Part 2c (Table 3), Test 8 (Table 2) Fine Mesh}

The FEA model results for the Scope Part 2c (Table 3), Test 8 (Table 2) fine mesh model are shown below in Figure D-260 to Figure D-262. The fuel element weighs $44 \mathrm{lbf}$ and the whole model is modeled with minimum material properties. This section includes the blocks as added fuel plate protection.

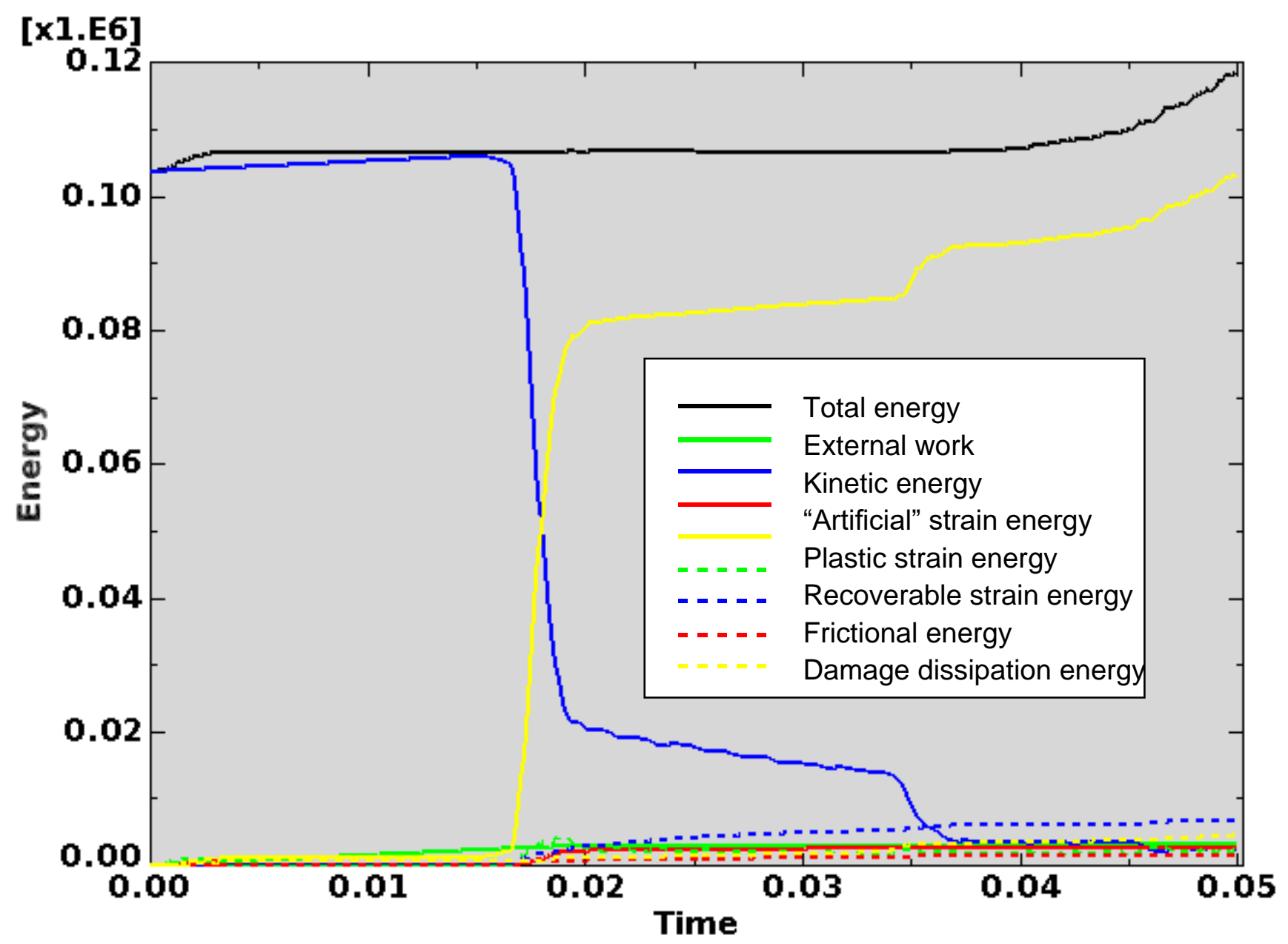

Figure D-260. Scope Part 2c (Table 3), Test 8 (Table 2) fine mesh energy curves.

Figure D-260 shows the energy curves for Scope Part 2c (Table 3), Test 8 (Table 2) fine mesh drop scenario. These curves exhibit mostly stable behavior. Near the end of the model run, the total energy and plastic strain energy start to show undesirable behavior. As discussed in Section D3.5 this appears to result from contact difficultly between failed portions of the fuel element. At a time of 0.04 seconds, the kinetic energy has dropped to near zero and a strong argument can be made that the reasonable damage accumulation has ended. Though because of angular motions, the bottom of the fuel element does not 
show significant positive vertical velocities (used to indicate rebound in other models) until 0.05 seconds. Due to the energy curves not dramatically rising, the results are conservatively given at 0.05 seconds. Additionally, the results are considered reasonable and conservative considering that the results compared with physical drops (see Section D2.5) had more of an energy rise and still produced reasonable and conservative results.

Artificial strain energy represents the energy required to keep reduced integration elements from taking on a zero-energy hourglass shape. As shown in Figure D-260, the artificial energy at the end of the model run is $2.3 \%$ of the total energy. Therefore, the potential error associated with artificial energy is not considered to be significant.

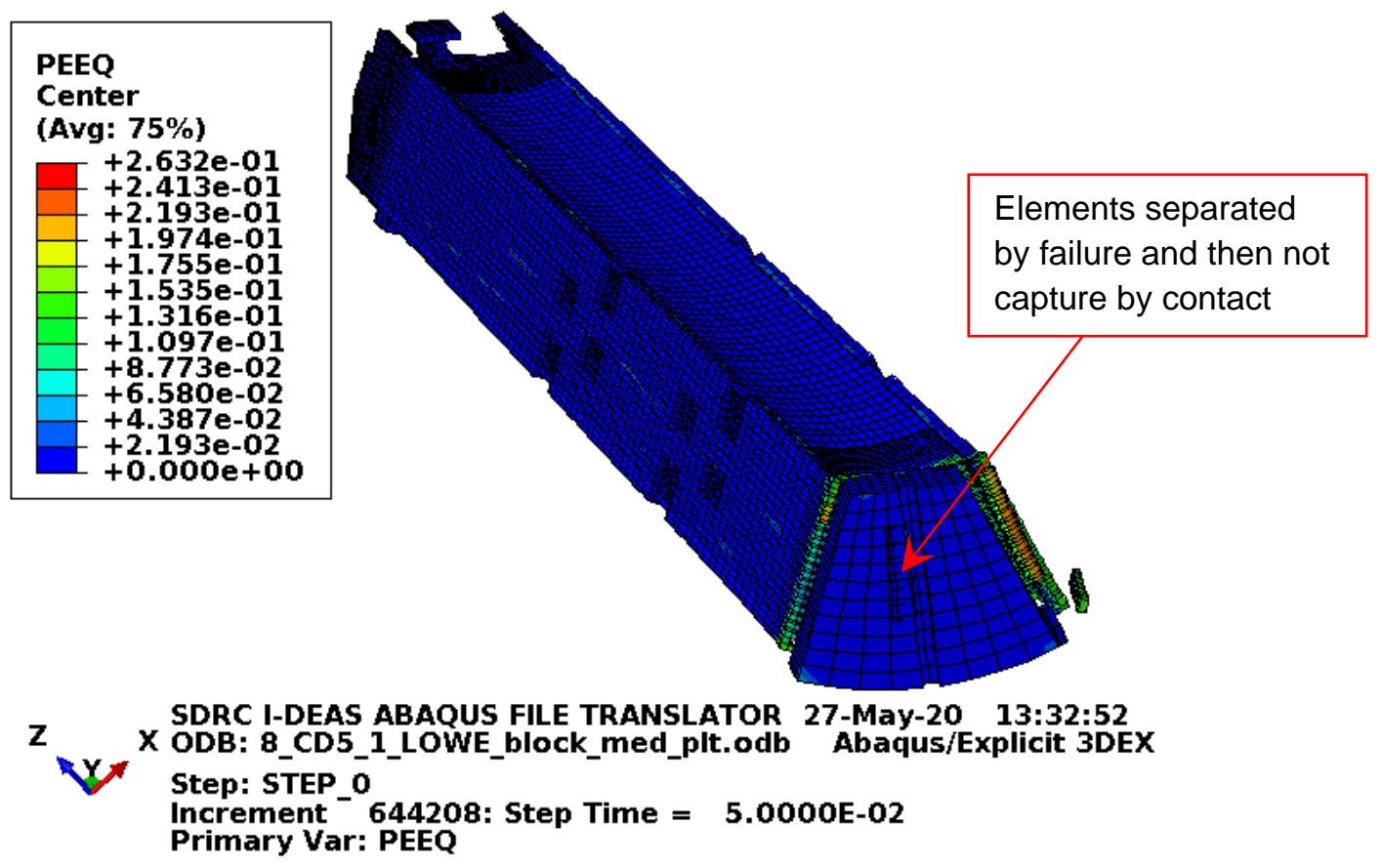

Figure D-261. Scope Part 2c (Table 3), Test 8 (Table 2) fine mesh fuel element plastic equivalent strain.

Figure D-261 shows the equivalent plastic strain in the fuel element. Failure in the end box elements occurs at an equivalent plastic strain of $0.027 \mathrm{in}$./in. Failure in the end box weld elements occurs at an equivalent plastic strain of $0.032 \mathrm{in}$./in. Failure in the side plate and comb elements occurs at an equivalent plastic strain of $0.152 \mathrm{in./in.} \mathrm{Failure} \mathrm{in} \mathrm{the} \mathrm{side} \mathrm{plate} \mathrm{weld} \mathrm{elements} \mathrm{occurs} \mathrm{at} \mathrm{an} \mathrm{equivalent} \mathrm{plastic} \mathrm{strain} \mathrm{of}$ $0.205 \mathrm{in}$./in. Figure D-261 shows nearly complete failure of the end box and end box welds nearest the impact. A few end box elements were separated by failure and then not properly put into contact with the block (thereby appearing to embed themselves into the block). The overall model error associated with this is not considered to be significant. 
ENGINEERING CALCULATIONS AND ANALYSIS

Drop Analysis of the Advanced Test Reactor Fresh Fuel Shipping Container with Heavier Low-Enriched Uranium Fuel Contents
ECAR-5224, Rev. 0

Page D231 of D293

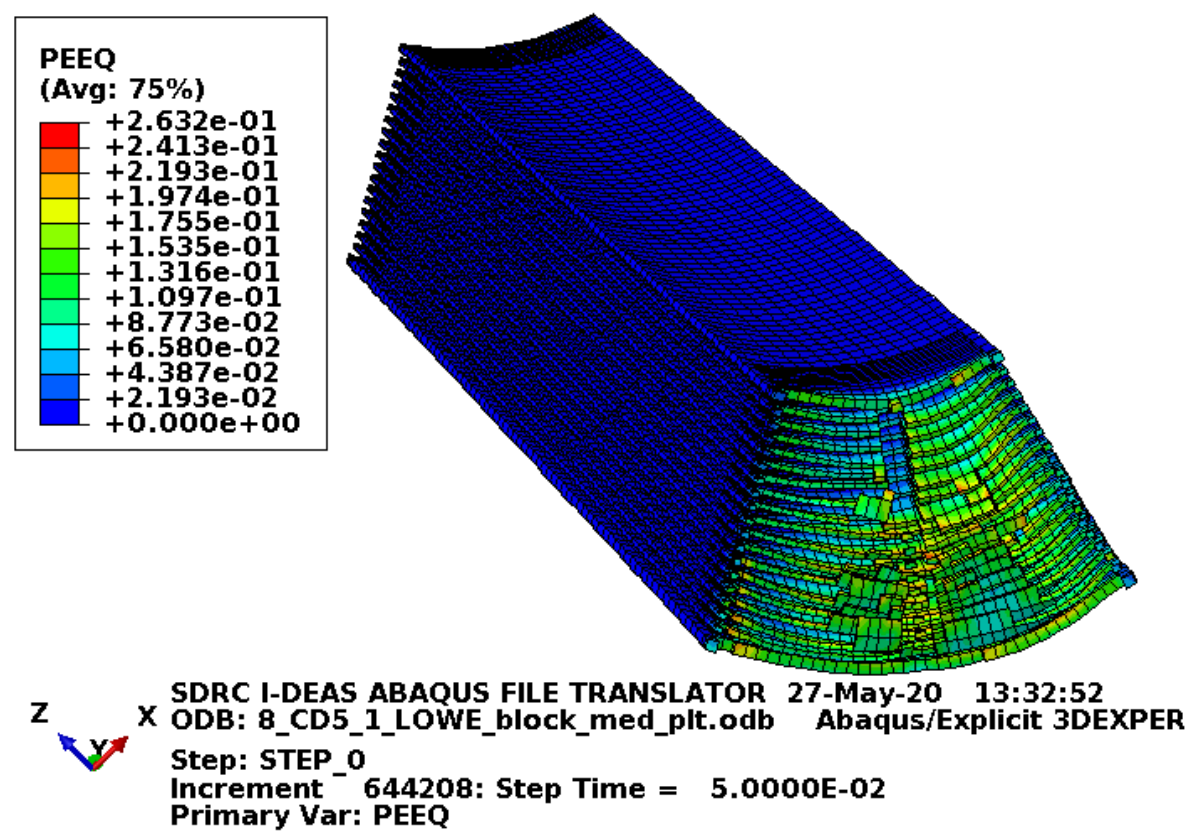

Figure D-262. Scope Part 2c (Table 3), Test 8 (Table 2) fine mesh fuel plate equivalent strain.

Figure D-262 shows the equivalent plastic strain in the fuel plates. Failure in these elements occurs at an equivalent plastic strain of 0.205 in./in. Figure D-262 shows element failure extending to but not into the fuel meat in the end of the fuel plates. Additionally, a few elements at the ends of the fuel plates show strains above failure. The strains shown above the failure strain likely result from extrapolation (as integration point strains are the important strains for failure). Even if the elements with high strain were removed as being failed, the failure would be acceptable as the failed and high strained elements do not represent fuel meat.

\section{D3.6.5 Results for Scope Part 2d (Table 3), Test 8 (Table 2)}

The FEA model results for the Scope Part 2d (Table 3), Test 8 (Table 2) model are shown below in Figure D-263 to Figure D-265. The fuel element weighs $44 \mathrm{lbf}$ and the drop scenario is modeled with minimum material properties except the enclosure and end boxes, which are modeled with relatively tough material properties. This section includes the blocks as added fuel plate protection. 


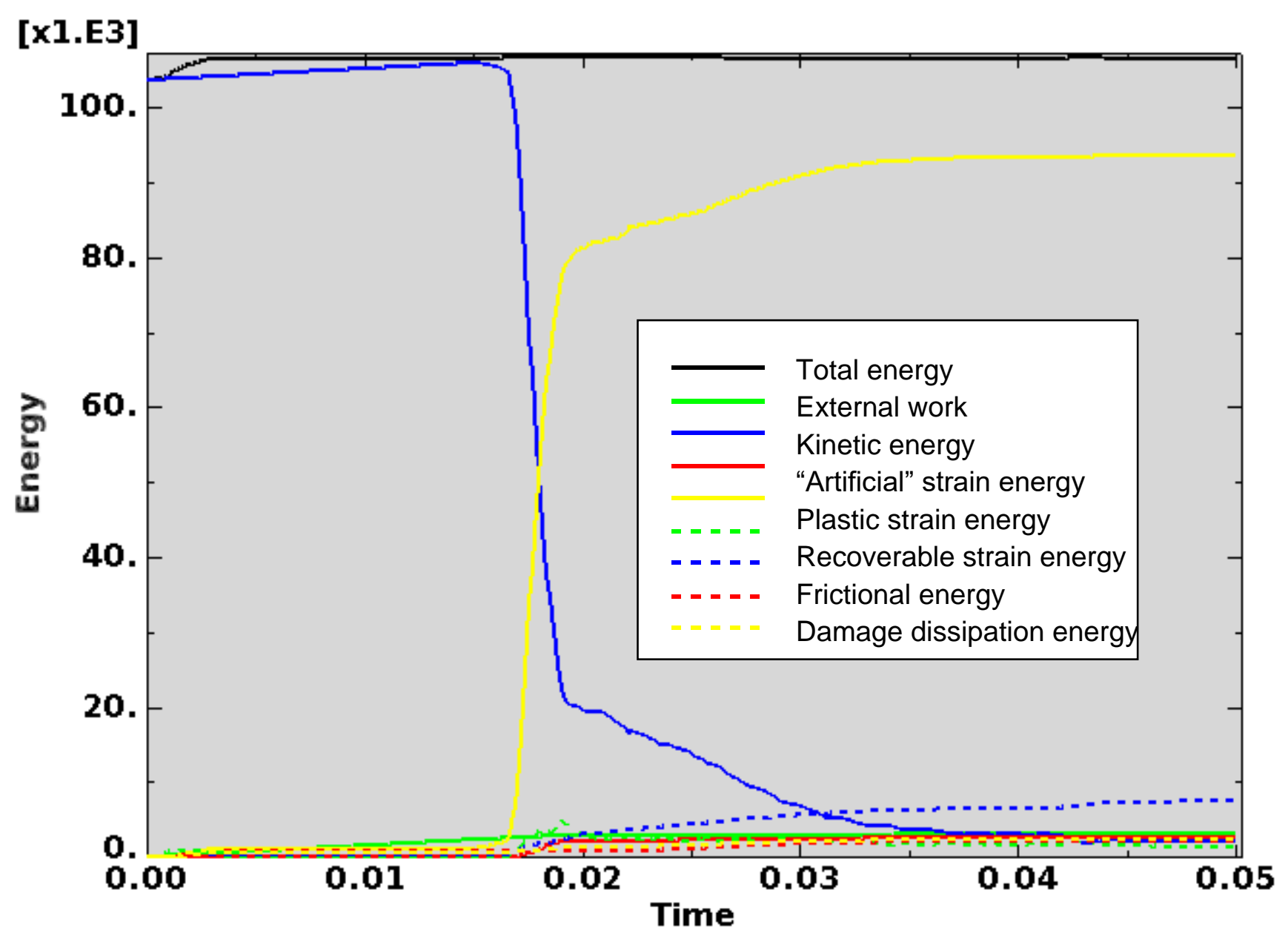

Figure D-263. Scope Part 2d (Table 3), Test 8 (Table 2) energy curves.

Figure D-263 shows the energy curves for Scope Part 2d (Table 3), Test 8 (Table 2) drop scenario. These curves exhibit a stable shape. Artificial strain energy represents the energy required to keep reduced integration elements from taking on a zero-energy hourglass shape. As shown in Figure D-263, the artificial energy at the end of the model run is $2.5 \%$ of the total energy. Therefore, the potential error associated with artificial energy is not considered to be significant. 
ENGINEERING CALCULATIONS AND ANALYSIS

Drop Analysis of the Advanced Test Reactor Fresh Fuel Shipping Container with Heavier Low-Enriched Uranium Fuel Contents

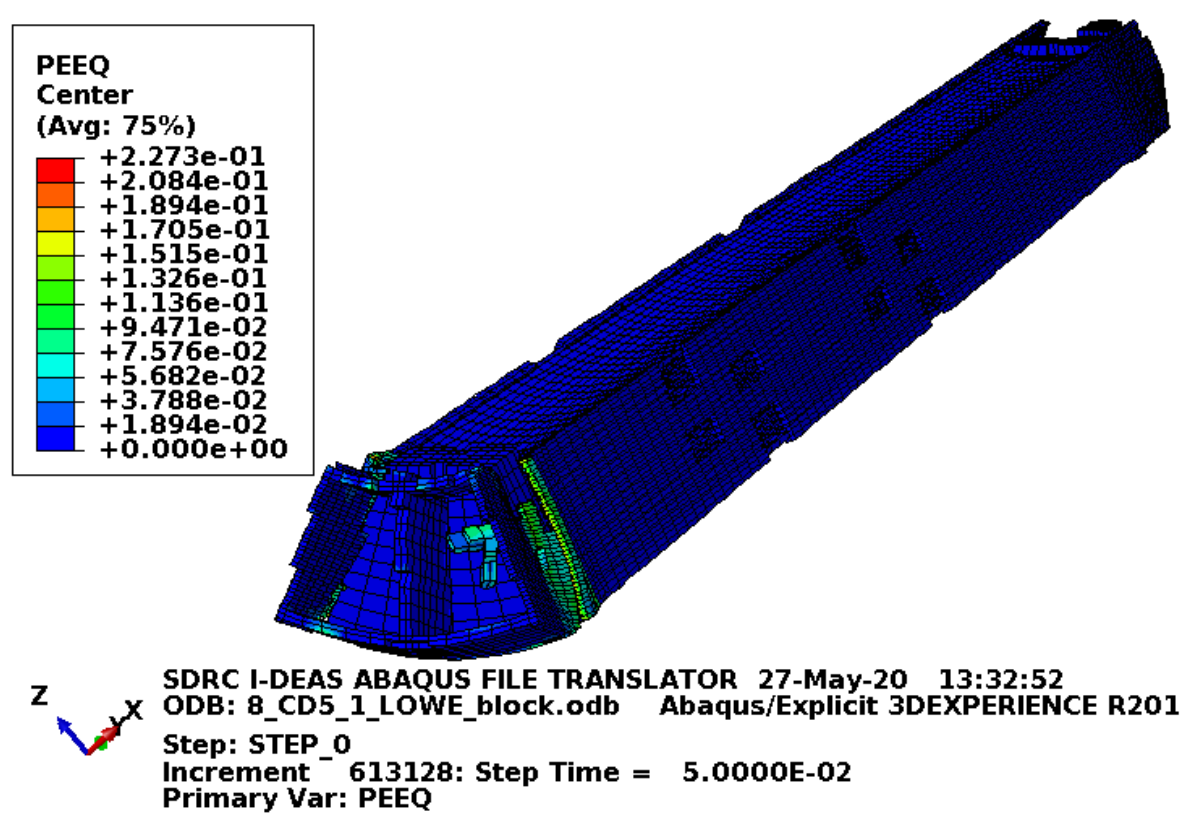

Figure D-264. Scope Part 2d (Table 3), Test 8 (Table 2) fuel element plastic equivalent strain.

Figure D-264 shows the equivalent plastic strain in the fuel element. Failure in the end box elements occurs at an equivalent plastic strain of $0.08 \mathrm{in./in.} \mathrm{(for} \mathrm{the} \mathrm{relatively} \mathrm{tough} \mathrm{material} \mathrm{properties).} \mathrm{Failure} \mathrm{in} \mathrm{the} \mathrm{end}$ box weld elements occurs at an equivalent plastic strain of $0.115 \mathrm{in}$./in. (for the relatively tough material properties). Failure in the side plate and comb elements occurs at an equivalent plastic strain of 0.152 in./in. Failure in the side plate weld elements occurs at an equivalent plastic strain of 0.205 in./in. Figure D-264 shows significant failure in the end box. Also, the end box welds failed sufficiently to free the end box from the rest of the fuel element. However, the block prevents the end box from impacting the fuel plates.

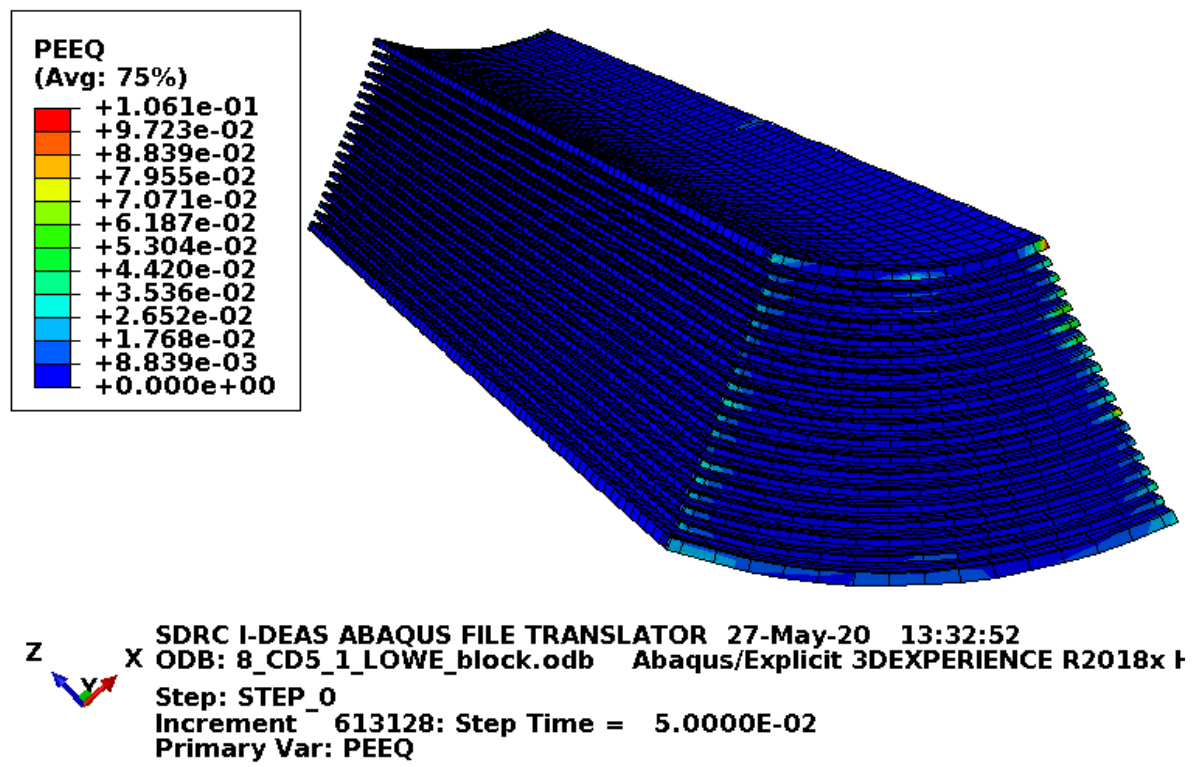

Figure D-265. Scope Part 2d (Table 3), Test 8 (Table 2) fuel plate equivalent strain. 
Figure D-265 shows the equivalent plastic strain in the fuel plates. Failure in these elements occurs at an equivalent plastic strain of $0.205 \mathrm{in}$./in. If element failure were to occur, the element would be removed from the model (thereby excluding its equivalent plastic strain from the maximum equivalent plastic strain for the plot). However, the missing element would be visible in the plot. Figure D-265 shows no failure in the fuel plates with margin.

\section{D3.6.6 Results for Scope Part 2d (Table 3), Test 8 (Table 2) Fine Mesh}

The FEA model results for the Scope Part 2d (Table 3), Test 8 (Table 2) fine mesh model are shown below in Figure D-242 to Figure D-244. The fuel element weighs $44 \mathrm{lbf}$ and the drop scenario is modeled with minimum material properties except the enclosure and end boxes, which are modeled with relatively tough material properties. This section includes the blocks as added fuel plate protection.

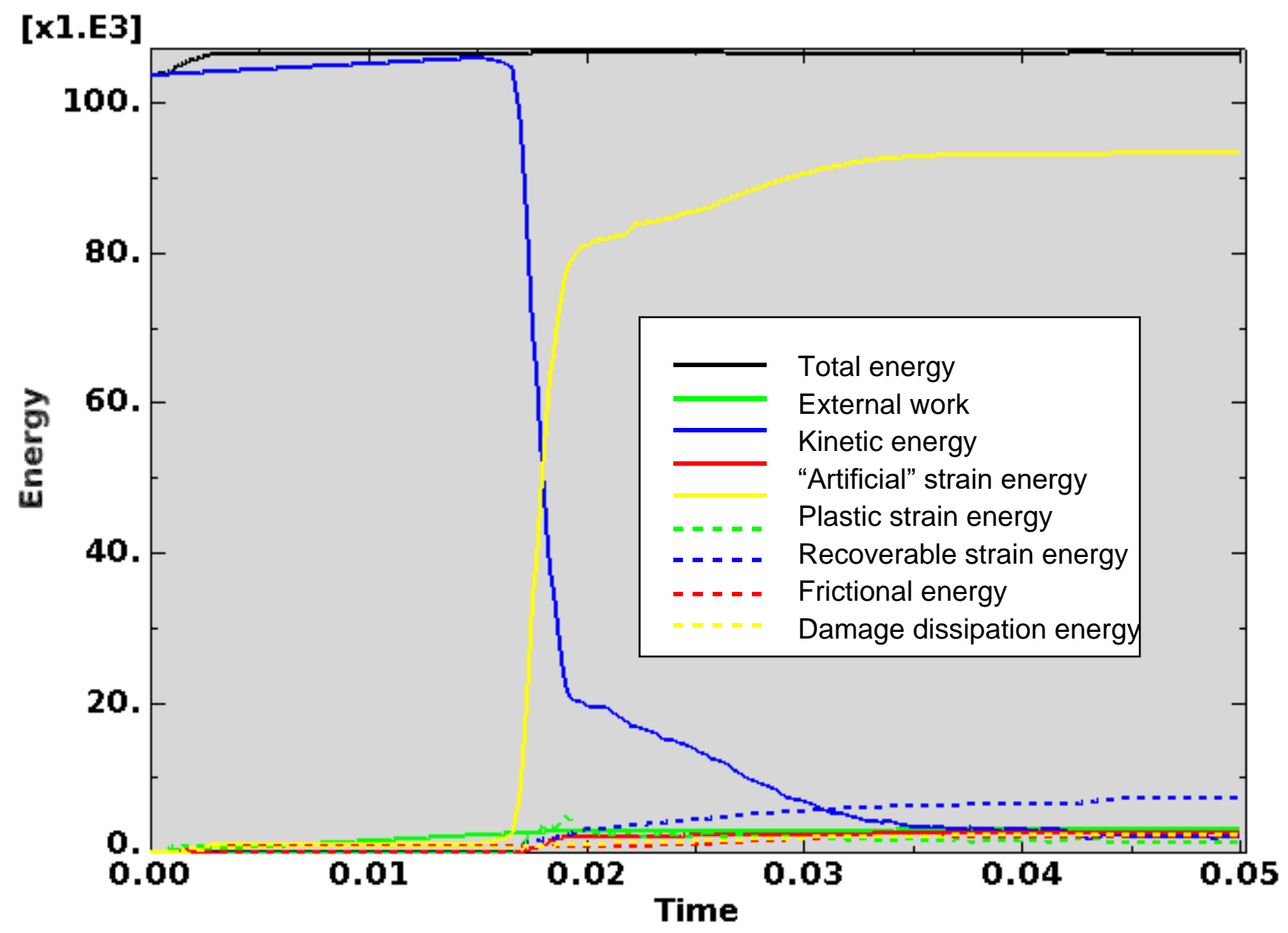

Figure D-266. Scope Part 2d (Table 3), Test 8 (Table 2) fine mesh energy curves.

Figure D-266 shows the energy curves for Scope Part 2d (Table 3), Test 8 (Table 2) fine mesh drop scenario. These curves exhibit a stable shape. Artificial strain energy represents the energy required to keep reduced integration elements from taking on a zero-energy hourglass shape. As shown in

Figure D-266, the artificial energy at the end of the model run is $2.5 \%$ of the total energy. Therefore, the potential error associated with artificial energy is not considered to be significant. 
ENGINEERING CALCULATIONS AND ANALYSIS

Drop Analysis of the Advanced Test Reactor Fresh Fuel Shipping Container with Heavier Low-Enriched Uranium Fuel Contents
ECAR-5224, Rev. 0

Page D235 of D293

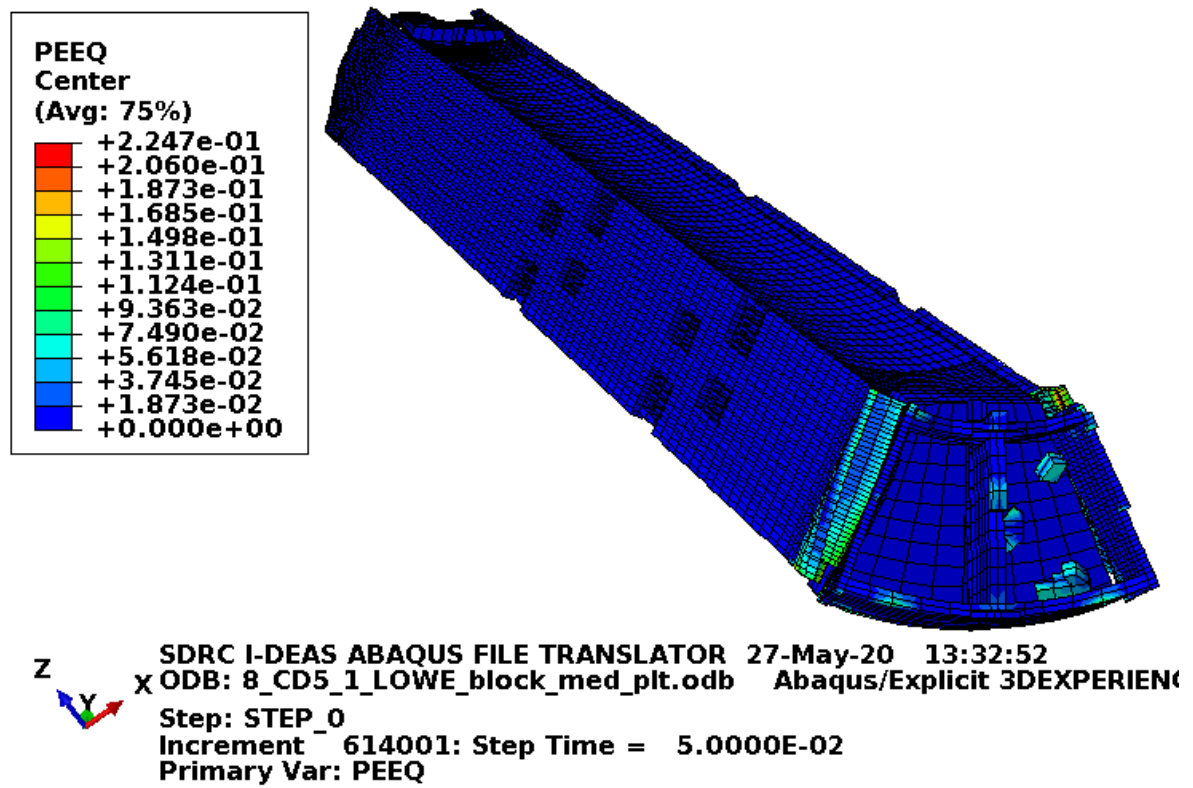

Figure D-267. Scope Part 2d (Table 3), Test 8 (Table 2) fine mesh fuel element plastic equivalent strain.

Figure D-267 shows the equivalent plastic strain in the fuel element. Failure in the end box elements occurs at an equivalent plastic strain of $0.08 \mathrm{in}$./in. (for the relatively tough material properties). Failure in the end box weld elements occurs at an equivalent plastic strain of $0.115 \mathrm{in}$./in. (for the relatively tough material properties). Failure in the side plate and comb elements occurs at an equivalent plastic strain of $0.152 \mathrm{in}$./in. Failure in the side plate weld elements occurs at an equivalent plastic strain of $0.205 \mathrm{in}$./in. Figure D-267 shows significant failure in the end box. Also, the end box welds failed sufficiently to free the end box from the rest of the fuel element. However, the block prevents the end box from impacting the fuel plates.

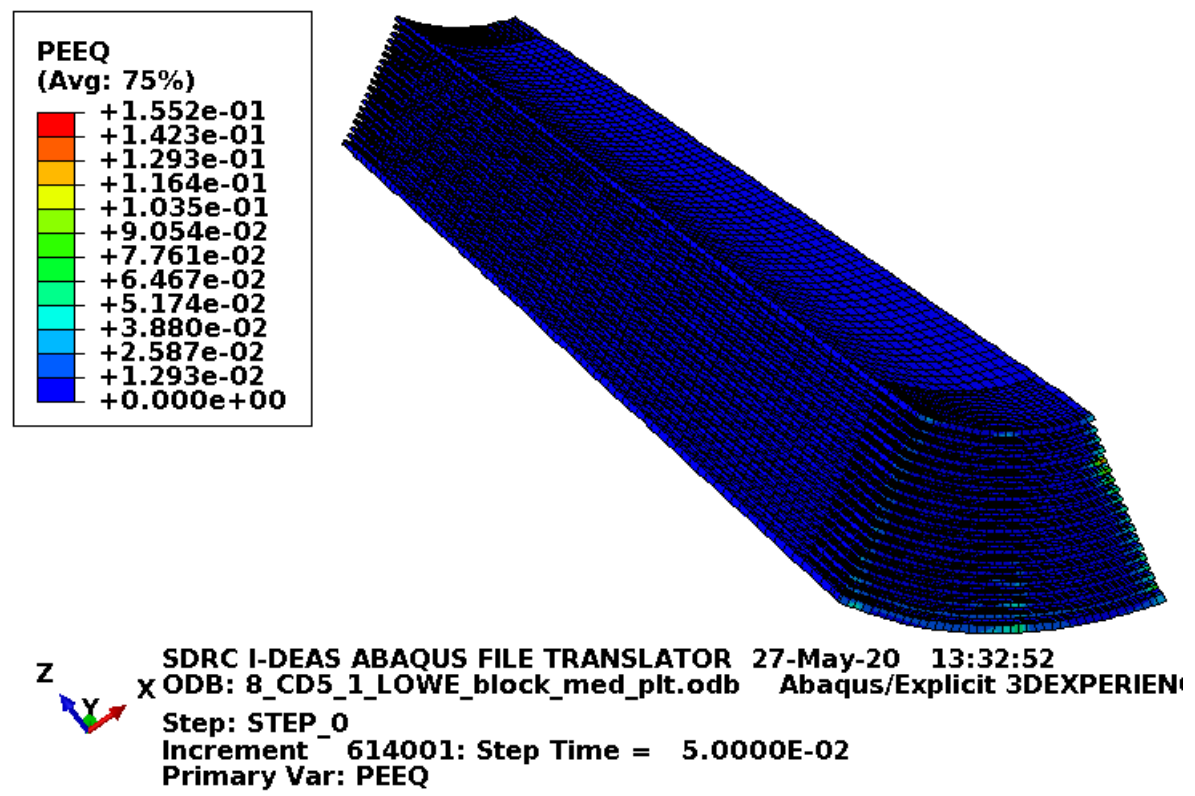

Figure D-268. Scope Part 2d (Table 3), Test 8 (Table 2) fine mesh fuel plate equivalent strain. 
Figure D-268 shows the equivalent plastic strain in the fuel plates. Failure in these elements occurs at an equivalent plastic strain of $0.205 \mathrm{in}$./in. If element failure were to occur, the element would be removed from the model (thereby excluding its equivalent plastic strain from the maximum equivalent plastic strain for the plot). However, the missing element would be visible in the plot. Figure D-268 shows no failure in the fuel plates with margin.

\section{D3.7 Results for Scope Part 2 (Table 3), Test 10 (Table 2)}

The drop scenario considered in this section is a 40 in drop modeled as a 30 degrees off horizontal, center of gravity over a 6 in. diameter puncture bar.

\section{D3.7.1 Results for Scope Part 2a (Table 3), Test 10 (Table 2)}

The FEA model results for the Scope Part 2a (Table 3), Test 10 (Table 2) model are shown below in Figure D-269 to Figure D-271. The fuel element weighs $44 \mathrm{lbf}$ and the whole model is modeled with minimum material properties. 


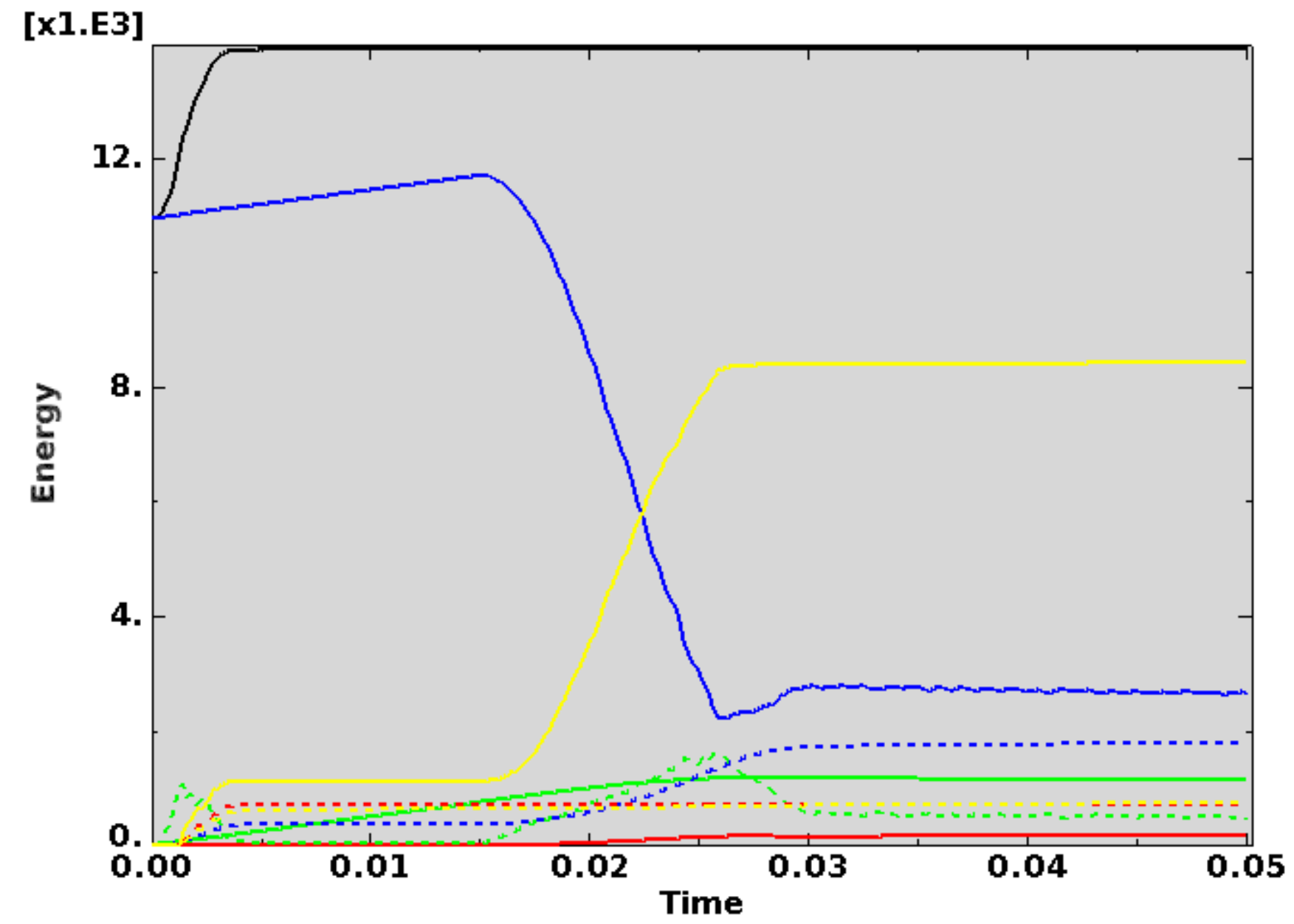

Figure D-269. Scope Part 2a (Table 3), Test 10 (Table 2) energy curves.

Figure D-269 shows the energy curves for Scope Part 2a (Table 3), Test 10 (Table 2) drop scenario. These curves exhibit a stable shape. Artificial strain energy represents the energy required to keep reduced integration elements from taking on a zero-energy hourglass shape. As shown in Figure D-269, the artificial energy at the end of the model run is $1.3 \%$ of the total energy. Therefore, the potential error associated with artificial energy is not considered to be significant. 
ENGINEERING CALCULATIONS AND ANALYSIS

Drop Analysis of the Advanced Test Reactor Fresh Fuel Shipping Container with Heavier Low-Enriched Uranium Fuel Contents
ECAR-5224, Rev. 0

Page D238 of D293

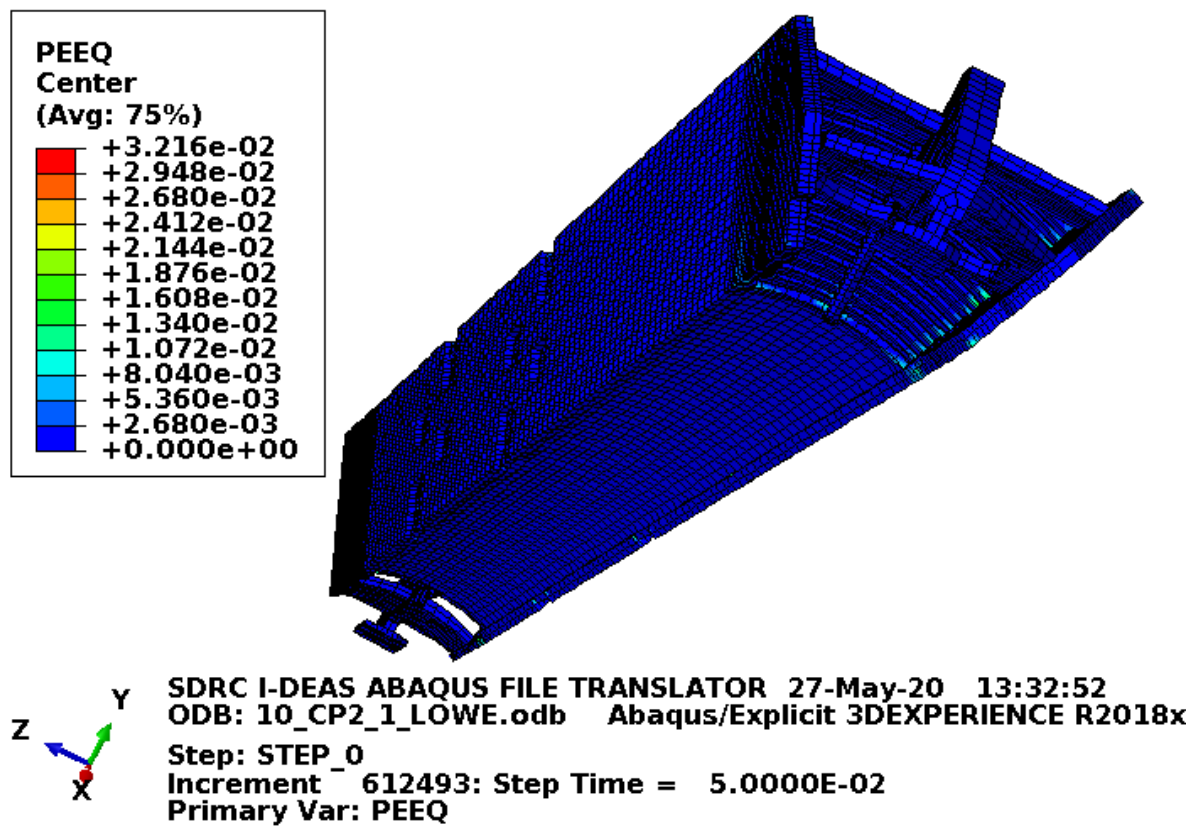

Figure D-270. Scope Part 2a (Table 3), Test 10 (Table 2) fuel element plastic equivalent strain.

Figure D-270 shows the equivalent plastic strain in the fuel element. Failure in the end box elements occurs at an equivalent plastic strain of $0.027 \mathrm{in}$./in. Failure in the end box weld elements occurs at an equivalent plastic strain of $0.032 \mathrm{in}$./in. Failure in the side plate and comb elements occurs at an equivalent plastic strain of $0.152 \mathrm{in}$./in. Failure in the side plate weld elements occurs at an equivalent plastic strain of $0.205 \mathrm{in./in.} \mathrm{If} \mathrm{element} \mathrm{failure} \mathrm{were} \mathrm{to} \mathrm{occur,} \mathrm{the} \mathrm{element} \mathrm{would} \mathrm{be} \mathrm{removed} \mathrm{from} \mathrm{the} \mathrm{model} \mathrm{(thereby}$ excluding its equivalent plastic strain from the maximum equivalent plastic strain for the plot). However, the missing element would be visible in the plot. Figure D-270 shows no failure in the fuel element.

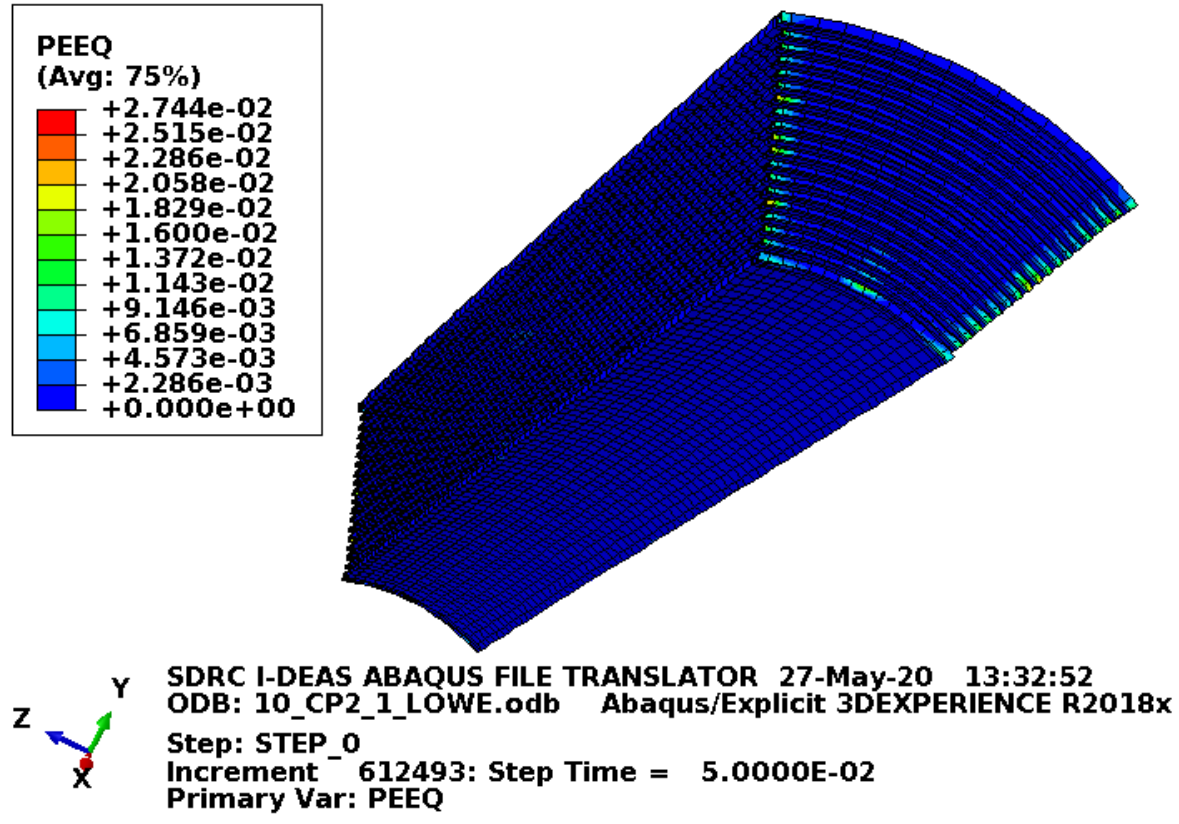

Figure D-271. Scope Part 2a (Table 3), Test 10 (Table 2) fuel plate equivalent strain. 
Figure D-271 shows the equivalent plastic strain in the fuel plates. Failure in these elements occurs at an equivalent plastic strain of $0.205 \mathrm{in}$./in. If element failure were to occur, the element would be removed from the model (thereby excluding its equivalent plastic strain from the maximum equivalent plastic strain for the plot). However, the missing element would be visible in the plot. Figure D-271 shows no element failure, but a few elements at the ends of the fuel plates show strains above failure. The strains shown above the failure strain likely result from extrapolation (as integration point strains are the important strains for failure). Even if the elements with high strain were removed as being failed, the failure would be acceptable as they are far from the fuel meat.

\section{D3.7.2 Results for Scope Part 2b (Table 3), Test 10 (Table 2)}

The FEA model results for the Scope Part 2b (Table 3), Test 10 (Table 2) model are shown below in Figure D-272 to Figure D-274. The fuel element weighs $44 \mathrm{lbf}$ and the drop scenario is modeled with minimum material properties except the enclosure and end boxes, which are modeled with relatively tough material properties. 


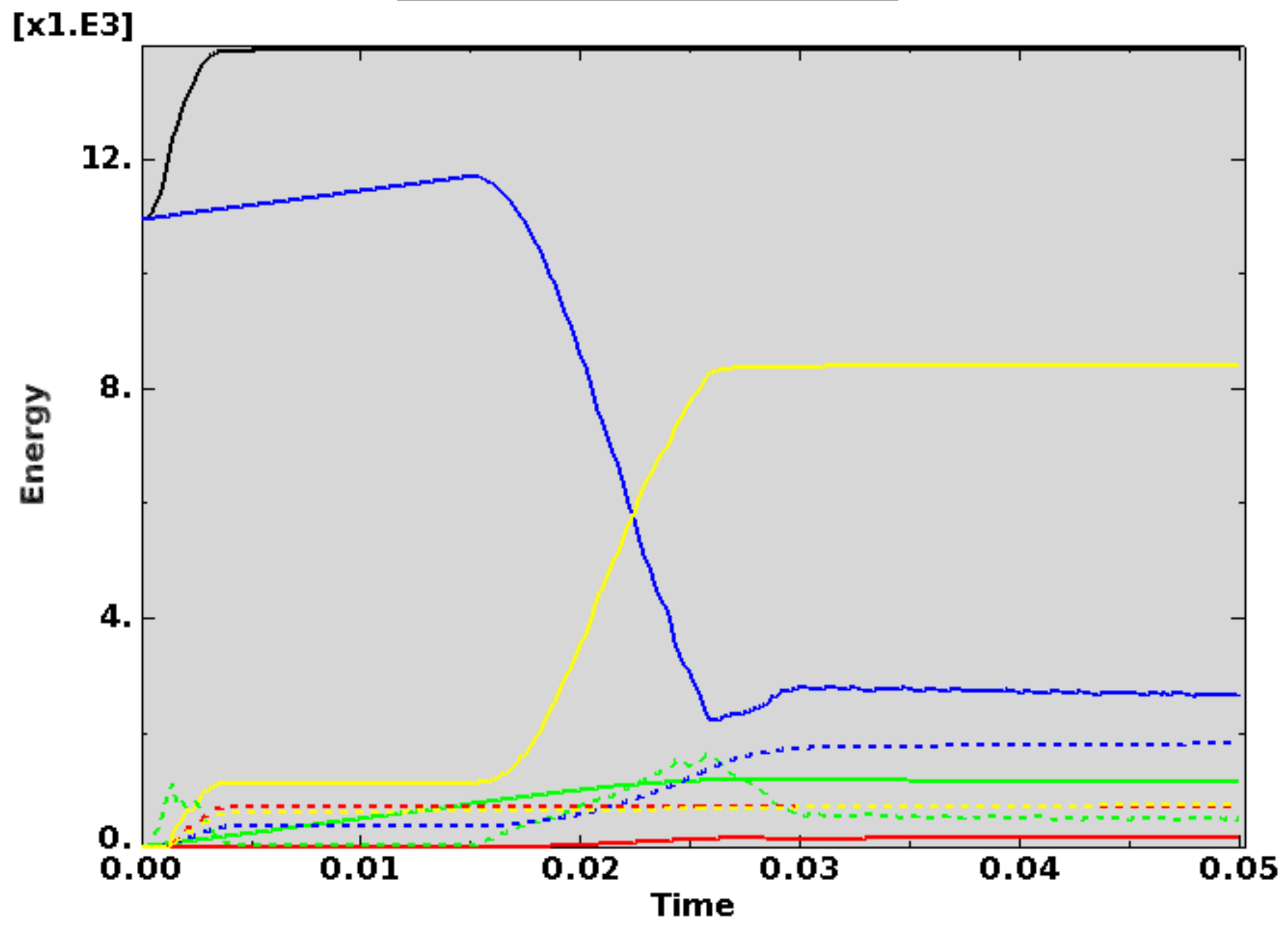

Figure D-272. Scope Part 2b (Table 3), Test 10 (Table 2) energy curves.

Figure D-272 shows the energy curves for Scope Part 2b (Table 3), Test 10 (Table 2) drop scenario. These curves exhibit a stable shape. Artificial strain energy represents the energy required to keep reduced integration elements from taking on a zero-energy hourglass shape. As shown in Figure D-272, the artificial energy at the end of the model run is $1.3 \%$ of the total energy. Therefore, the potential error associated with artificial energy is not considered to be significant. 
ENGINEERING CALCULATIONS AND ANALYSIS

Drop Analysis of the Advanced Test Reactor Fresh Fuel Shipping Container with Heavier Low-Enriched Uranium Fuel Contents
ECAR-5224, Rev. 0

Page D241 of D293

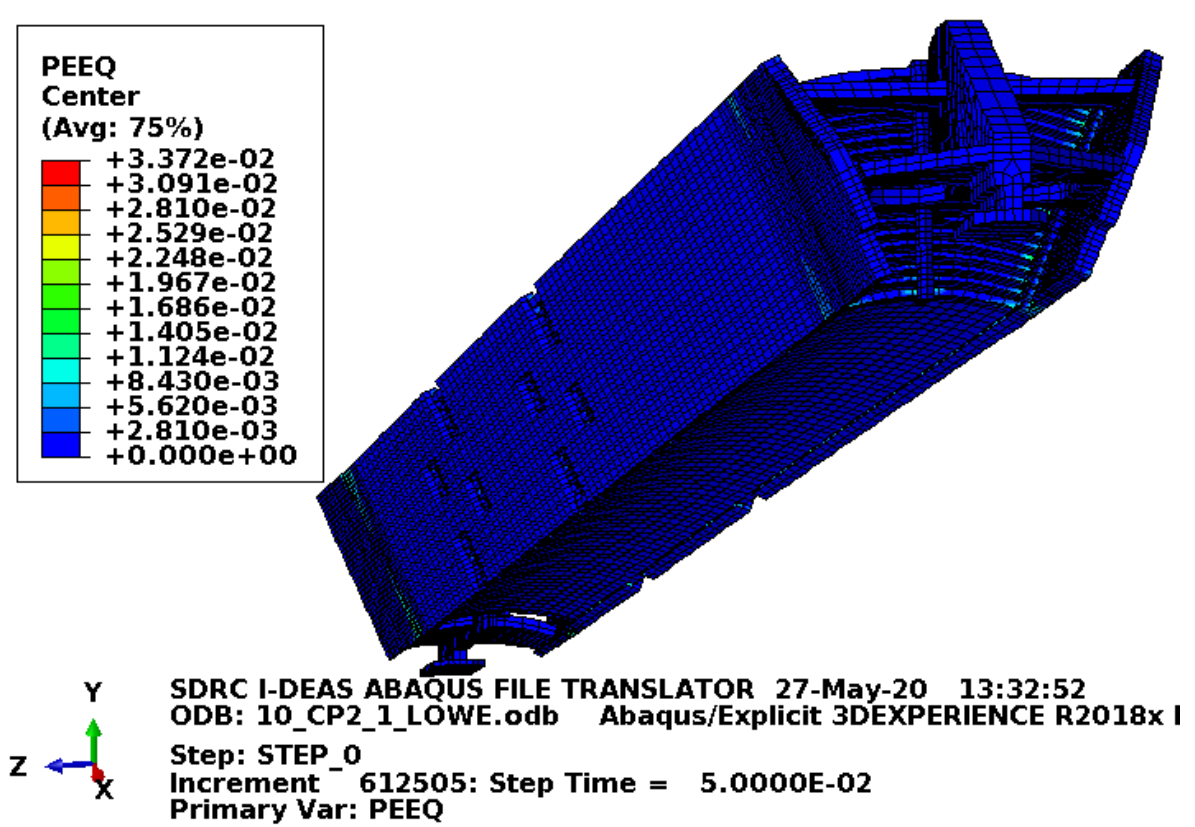

Figure D-273. Scope Part 2b (Table 3), Test 10 (Table 2) fuel element plastic equivalent strain.

Figure D-273 shows the equivalent plastic strain in the fuel element. Failure in the end box elements occurs at an equivalent plastic strain of $0.08 \mathrm{in./in.} \mathrm{(for} \mathrm{the} \mathrm{relatively} \mathrm{tough} \mathrm{material} \mathrm{properties).} \mathrm{Failure} \mathrm{in} \mathrm{the} \mathrm{end}$ box weld elements occurs at an equivalent plastic strain of $0.115 \mathrm{in}$./in. (for the relatively tough material properties). Failure in the side plate and comb elements occurs at an equivalent plastic strain of 0.152 in./in. Failure in the side plate weld elements occurs at an equivalent plastic strain of $0.205 \mathrm{in}$./in. If element failure were to occur, the element would be removed from the model (thereby excluding its equivalent plastic strain from the maximum equivalent plastic strain for the plot). However, the missing element would be visible in the plot. Figure D-273 shows no failure in the fuel element.

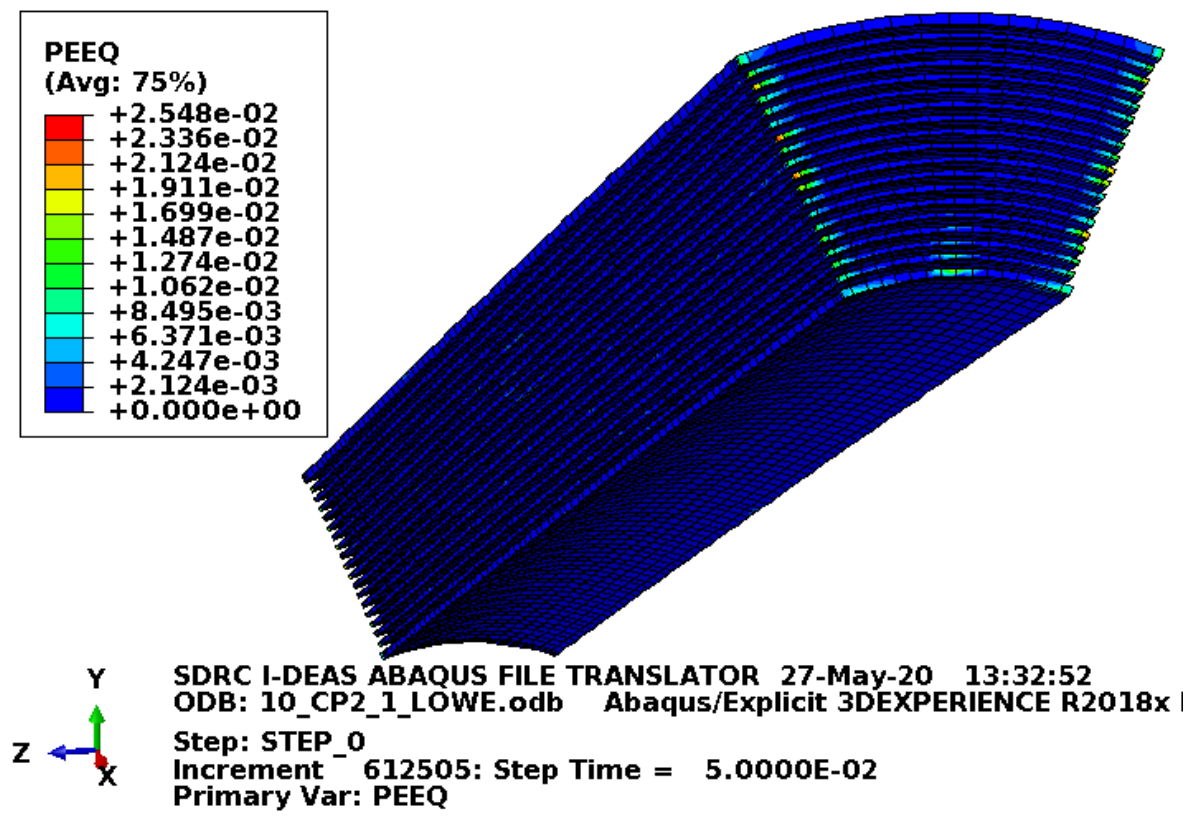

Figure D-274. Scope Part 2b (Table 3), Test 10 (Table 2) fuel plate equivalent strain. 
Figure D-274 shows the equivalent plastic strain in the fuel plates. Failure in these elements occurs at an equivalent plastic strain of $0.205 \mathrm{in}$./in. If element failure were to occur, the element would be removed from the model (thereby excluding its equivalent plastic strain from the maximum equivalent plastic strain for the plot). However, the missing element would be visible in the plot. Figure D-274 shows no failure in the fuel plates with margin.

\section{D3.7.3 Results for Scope Part 2c (Table 3), Test 10 (Table 2)}

The FEA model results for the Scope Part 2c (Table 3), Test 10 (Table 2) model are shown below in Figure D-275 to Figure D-277. The fuel element weighs $44 \mathrm{lbf}$ and the whole model is modeled with minimum material properties. This section includes the blocks as added fuel plate protection. 
[X1.E3]

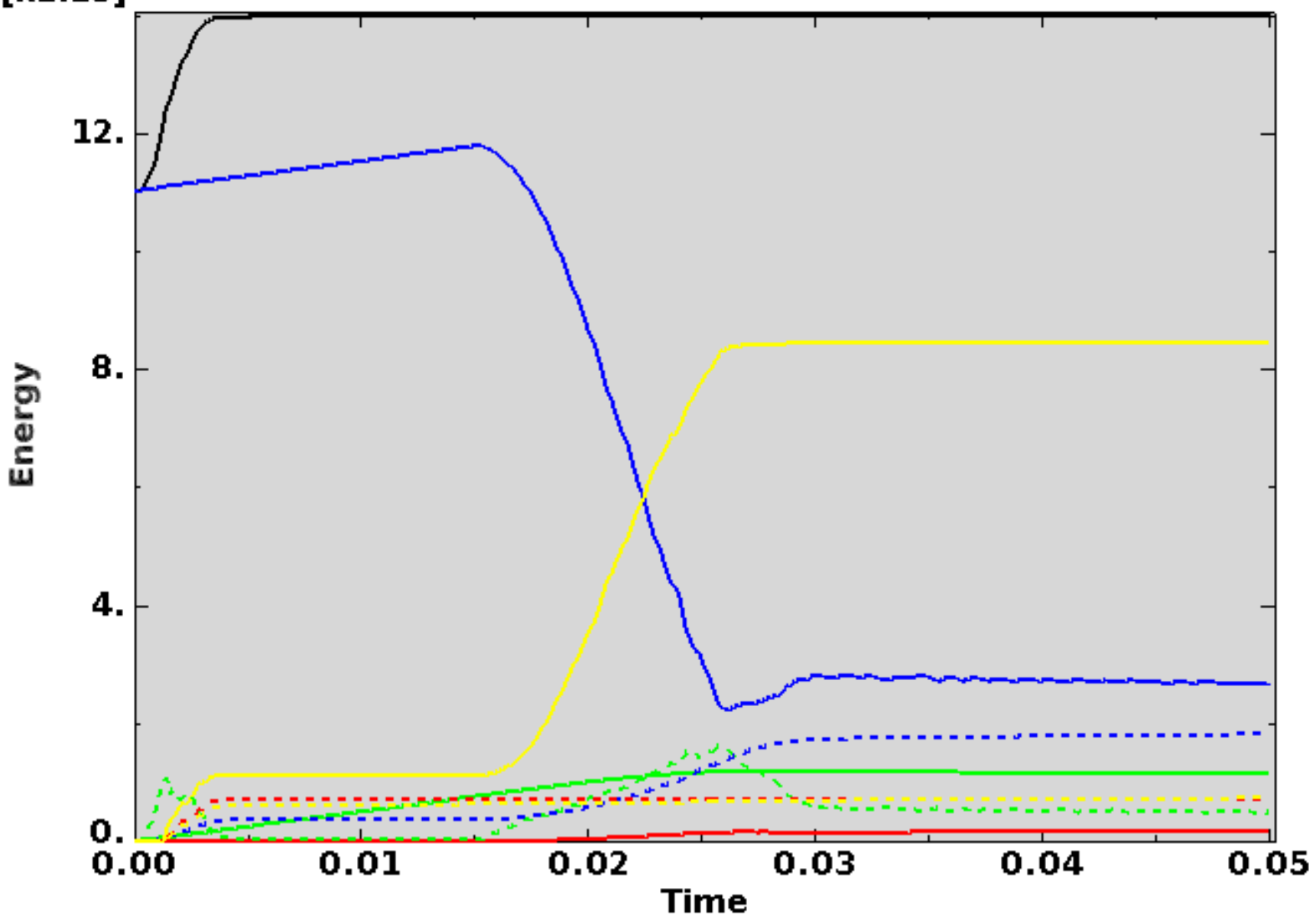

Figure D-275. Scope Part 2c (Table 3), Test 10 (Table 2) energy curves.

Figure D-275 shows the energy curves for Scope Part 2c (Table 3), Test 10 (Table 2) drop scenario. These curves exhibit a stable shape. Artificial strain energy represents the energy required to keep reduced integration elements from taking on a zero-energy hourglass shape. As shown in Figure D-275, the artificial energy at the end of the model run is $1.3 \%$ of the total energy. Therefore, the potential error associated with artificial energy is not considered to be significant. 
ENGINEERING CALCULATIONS AND ANALYSIS

Drop Analysis of the Advanced Test Reactor Fresh Fuel Shipping Container with Heavier Low-Enriched Uranium Fuel Contents
ECAR-5224, Rev. 0 Page D244 of D293

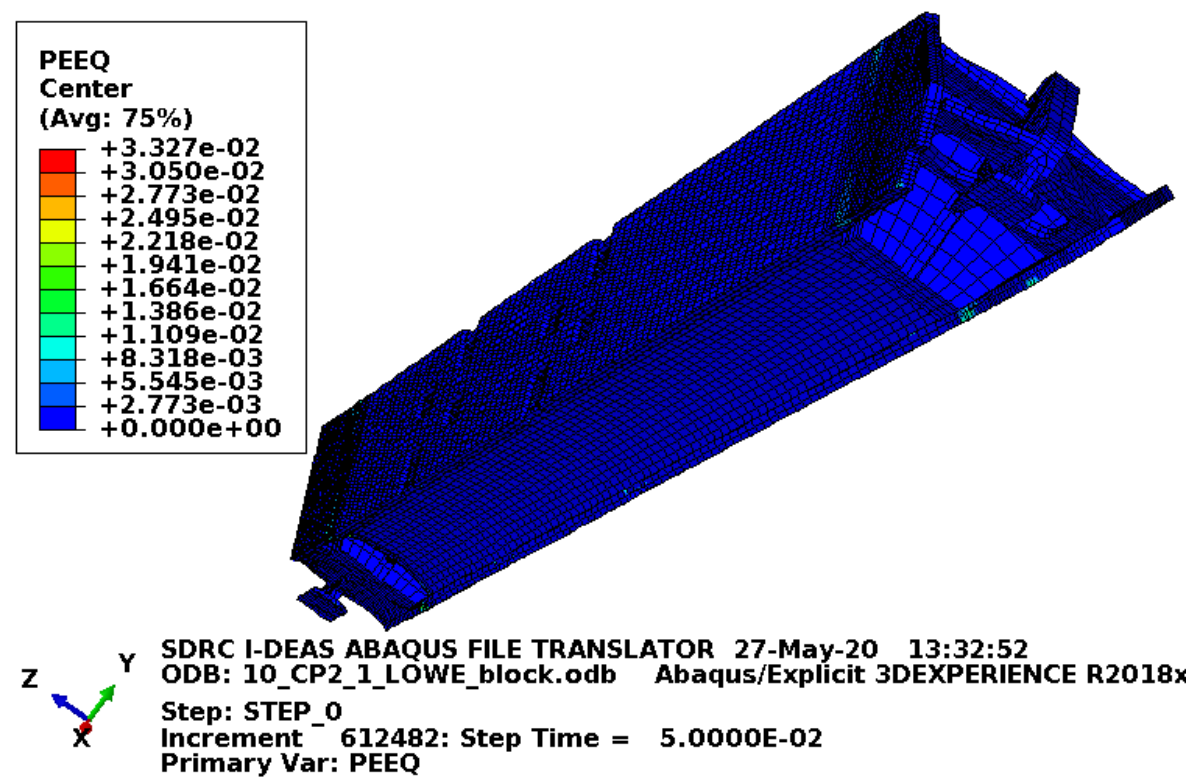

Figure D-276. Scope Part 2c (Table 3), Test 10 (Table 2) fuel element plastic equivalent strain.

Figure D-276 shows the equivalent plastic strain in the fuel element. Failure in the end box elements occurs at an equivalent plastic strain of $0.027 \mathrm{in}$./in. Failure in the end box weld elements occurs at an equivalent plastic strain of $0.032 \mathrm{in}$./in. Failure in the side plate and comb elements occurs at an equivalent plastic strain of $0.152 \mathrm{in./in.} \mathrm{Failure} \mathrm{in} \mathrm{the} \mathrm{side} \mathrm{plate} \mathrm{weld} \mathrm{elements} \mathrm{occurs} \mathrm{at} \mathrm{an} \mathrm{equivalent} \mathrm{plastic} \mathrm{strain} \mathrm{of}$ $0.205 \mathrm{in./in.} \mathrm{If} \mathrm{element} \mathrm{failure} \mathrm{were} \mathrm{to} \mathrm{occur,} \mathrm{the} \mathrm{element} \mathrm{would} \mathrm{be} \mathrm{removed} \mathrm{from} \mathrm{the} \mathrm{model} \mathrm{(thereby}$ excluding its equivalent plastic strain from the maximum equivalent plastic strain for the plot). However, the missing element would be visible in the plot. Figure D-276 shows no failure in the fuel element or block.

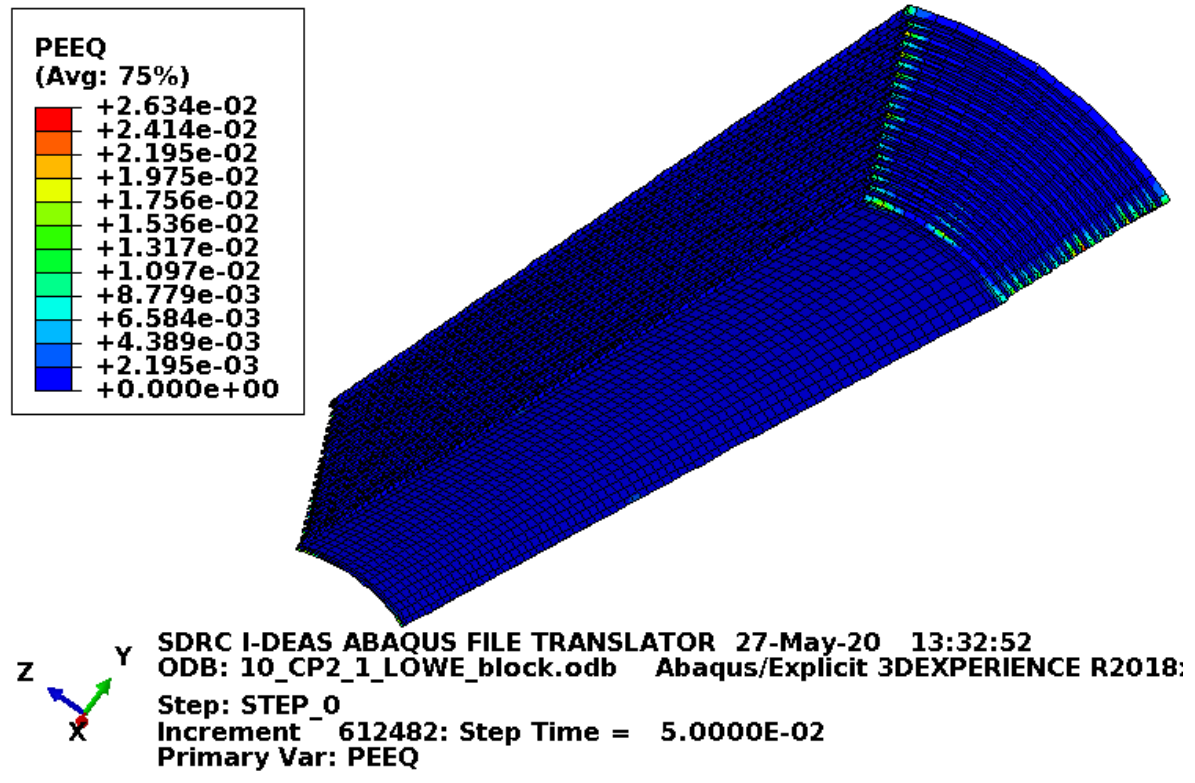

Figure D-277. Scope Part 2c (Table 3), Test 10 (Table 2) fuel plate equivalent strain. 
Figure D-277 shows the equivalent plastic strain in the fuel plates. Failure in these elements occurs at an equivalent plastic strain of $0.205 \mathrm{in}$./in. If element failure were to occur, the element would be removed from the model (thereby excluding its equivalent plastic strain from the maximum equivalent plastic strain for the plot). However, the missing element would be visible in the plot. Figure D-277 shows no failure in the fuel plates with margin.

\section{D3.7.4 Results for Scope Part 2d (Table 3), Test 10 (Table 2)}

The FEA model results for the Scope Part 2d (Table 3), Test 10 (Table 2) model are shown below in Figure D-278 to Figure D-280. The fuel element weighs $44 \mathrm{lbf}$ and the drop scenario is modeled with minimum material properties except the enclosure and end boxes, which are modeled with relatively tough material properties. This section includes the blocks as added fuel plate protection. 


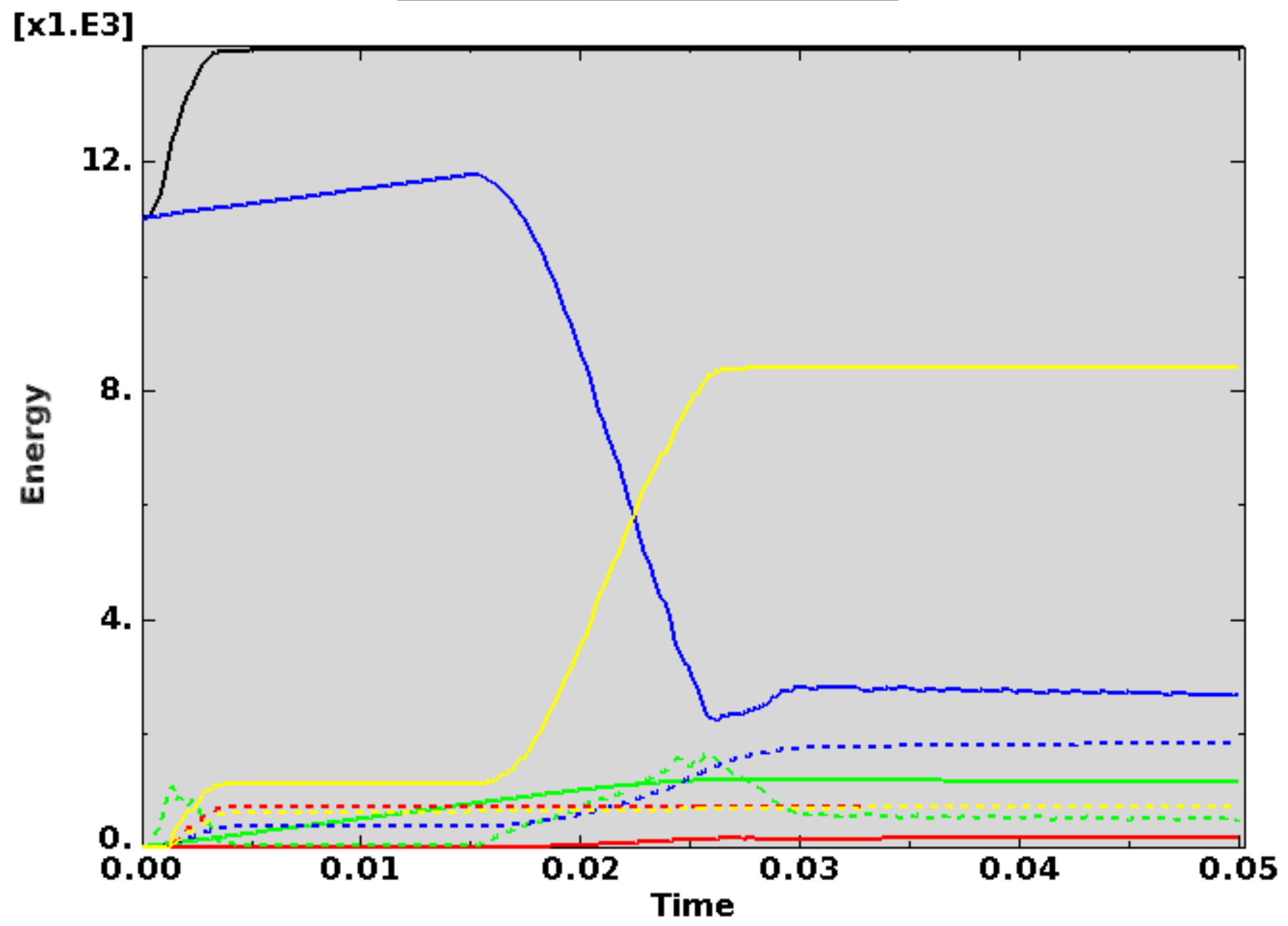

Figure D-278. Scope Part 2d (Table 3), Test 10 (Table 2) energy curves.

Figure D-278 shows the energy curves for Scope Part 2d (Table 3), Test 10 (Table 2) drop scenario. These curves exhibit a stable shape. Artificial strain energy represents the energy required to keep reduced integration elements from taking on a zero-energy hourglass shape. As shown in Figure D-278, the artificial energy at the end of the model run is $1.3 \%$ of the total energy. Therefore, the potential error associated with artificial energy is not considered to be significant. 
ENGINEERING CALCULATIONS AND ANALYSIS

Drop Analysis of the Advanced Test Reactor Fresh Fuel Shipping Container with Heavier Low-Enriched Uranium Fuel Contents
ECAR-5224, Rev. 0

Page D247 of D293

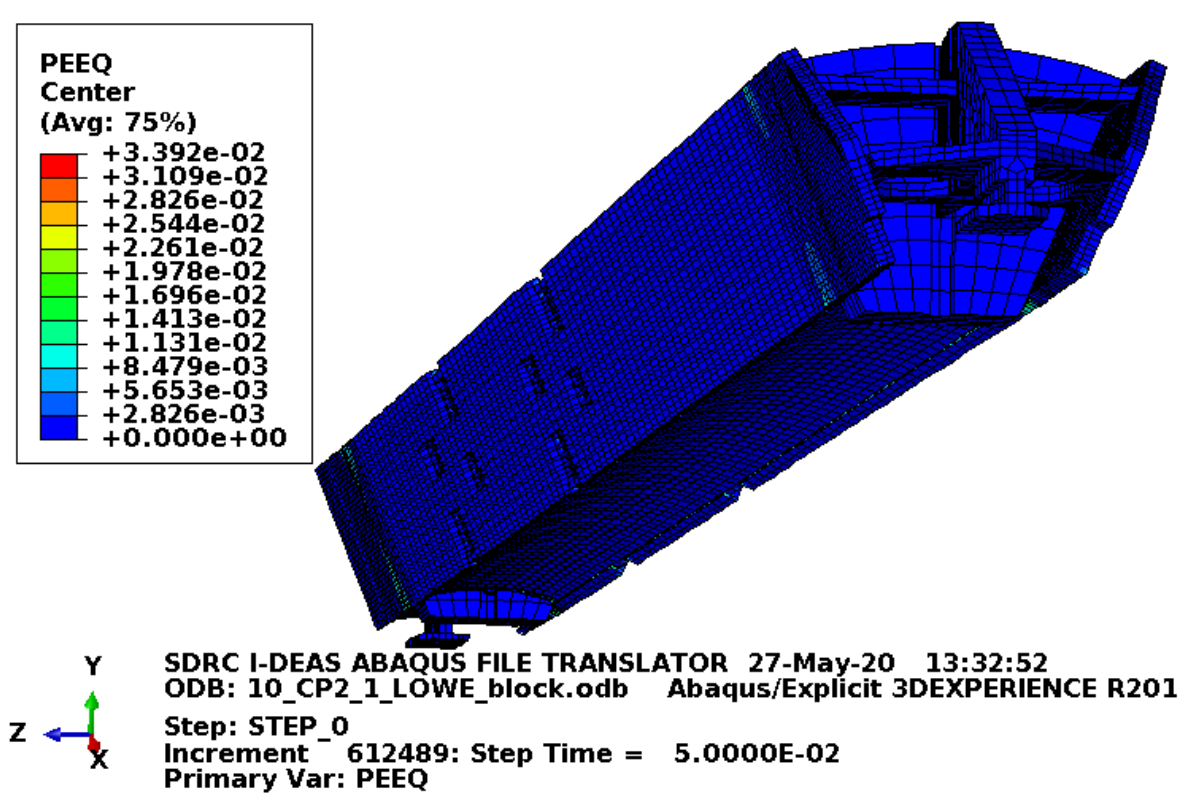

Figure D-279. Scope Part 2d (Table 3), Test 10 (Table 2) fuel element plastic equivalent strain.

Figure D-279 shows the equivalent plastic strain in the fuel element. Failure in the end box elements occurs at an equivalent plastic strain of $0.08 \mathrm{in./in.} \mathrm{(for} \mathrm{the} \mathrm{relatively} \mathrm{tough} \mathrm{material} \mathrm{properties).} \mathrm{Failure} \mathrm{in} \mathrm{the} \mathrm{end}$ box weld elements occurs at an equivalent plastic strain of $0.115 \mathrm{in}$./in. (for the relatively tough material properties). Failure in the side plate and comb elements occurs at an equivalent plastic strain of $0.152 \mathrm{in}$./in. Failure in the side plate weld elements occurs at an equivalent plastic strain of $0.205 \mathrm{in}$./in. If element failure were to occur, the element would be removed from the model (thereby excluding its equivalent plastic strain from the maximum equivalent plastic strain for the plot). However, the missing element would be visible in the plot. Figure D-279 shows no failure in the fuel element or blocks.

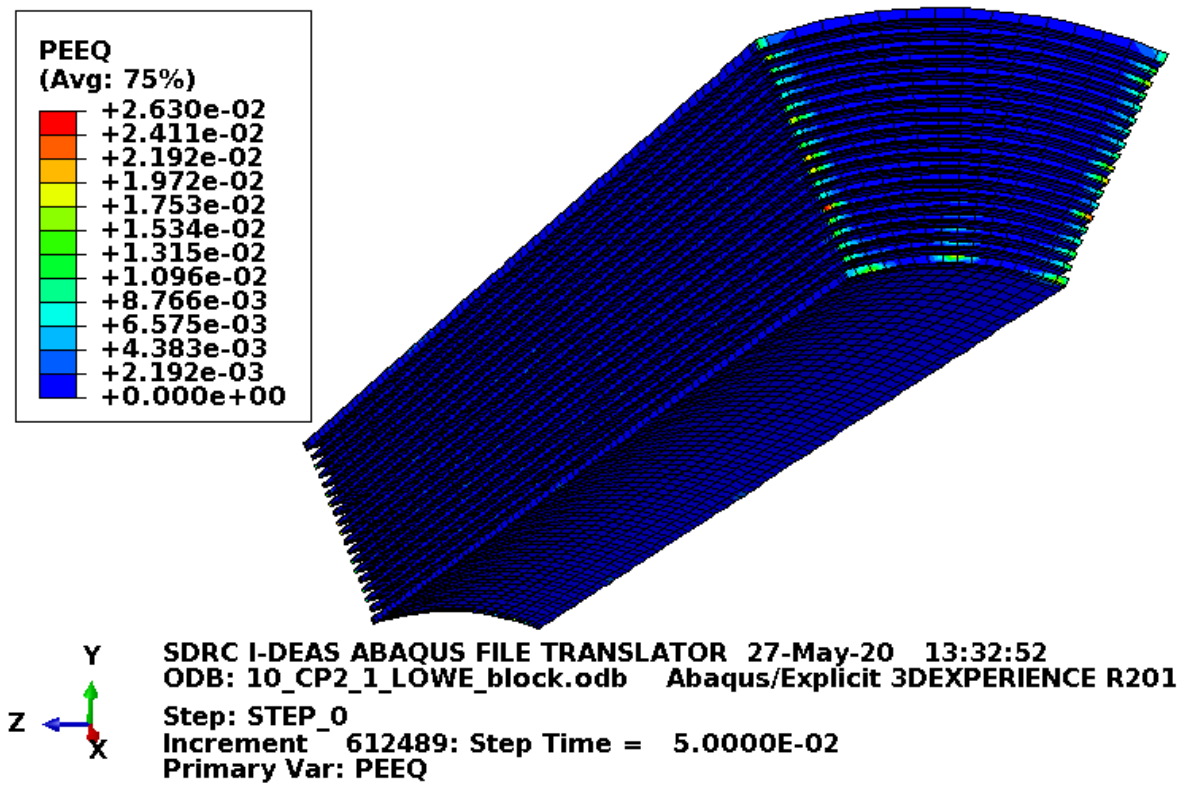

Figure D-280. Scope Part 2d (Table 3), Test 10 (Table 2) fuel plate equivalent strain. 
ENGINEERING CALCULATIONS AND ANALYSIS

Drop Analysis of the Advanced Test Reactor Fresh Fuel Shipping Container with Heavier Low-Enriched Uranium Fuel Contents
ECAR-5224, Rev. 0

Page D248 of D293

Figure D-280 shows the equivalent plastic strain in the fuel plates. Failure in these elements occurs at an equivalent plastic strain of $0.205 \mathrm{in}$./in. If element failure were to occur, the element would be removed from the model (thereby excluding its equivalent plastic strain from the maximum equivalent plastic strain for the plot). However, the missing element would be visible in the plot. Figure D-280 shows no failure in the fuel plates with margin.

\section{D3.8 Results for Scope Part 2 (Table 3), Test 11 (Table 2)}

The drop scenario considered in this section is a 40 in drop modeled as a vertical top drop with the lid centered over a 6 in. diameter puncture bar.

\section{D3.8.1 Results for Scope Part 2a (Table 3), Test 11 (Table 2)}

The FEA model results for the Scope Part 2a (Table 3), Test 11 (Table 2) model are shown below in Figure D-281 to Figure D-283. The fuel element weighs $44 \mathrm{lbf}$ and the whole model is modeled with minimum material properties.

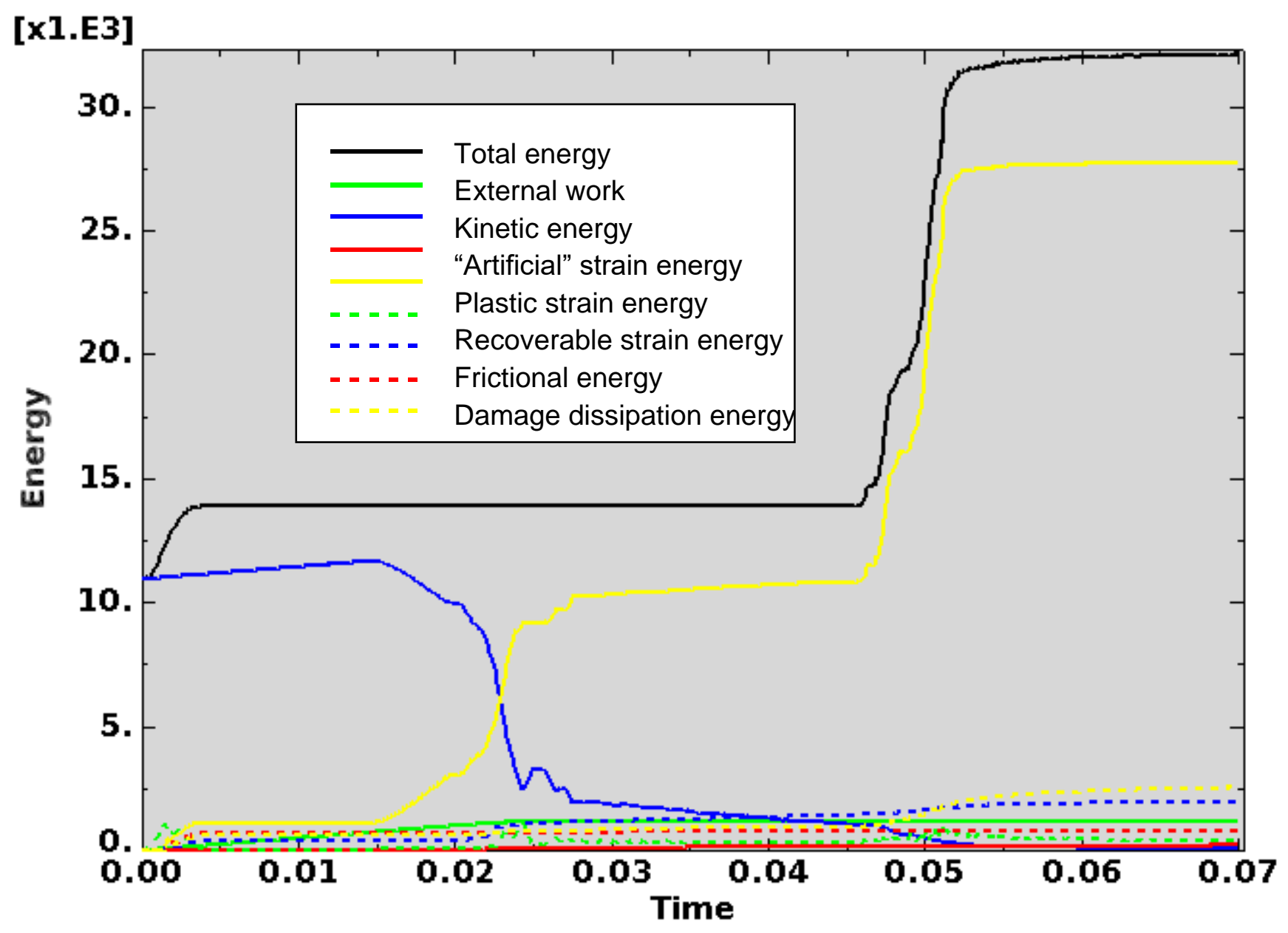

Figure D-281. Scope Part 2a (Table 3), Test 11 (Table 2) energy curves. 
Figure D-281 shows the energy curves for Scope Part 2a (Table 3), Test 11 (Table 2) drop scenario. These curves exhibit stable behavior up until significant failure occurs in the fuel element. At this point, the total energy and plastic strain energy show undesirable behavior. As discussed in Section D3.5 this appears to result from contact difficultly between failed portions of the fuel element. Given that this is not a recommended configuration (the recommended configuration being with blocks) for LOWE fuel elements, this model is just for information. Consequently, results are provided at the end of the model run.

Artificial strain energy represents the energy required to keep reduced integration elements from taking on a zero-energy hourglass shape. As shown in Figure D-281, the artificial energy at the end of the model run is $0.6 \%$ of the total energy. Therefore, the potential error associated with artificial energy is not considered to be significant.

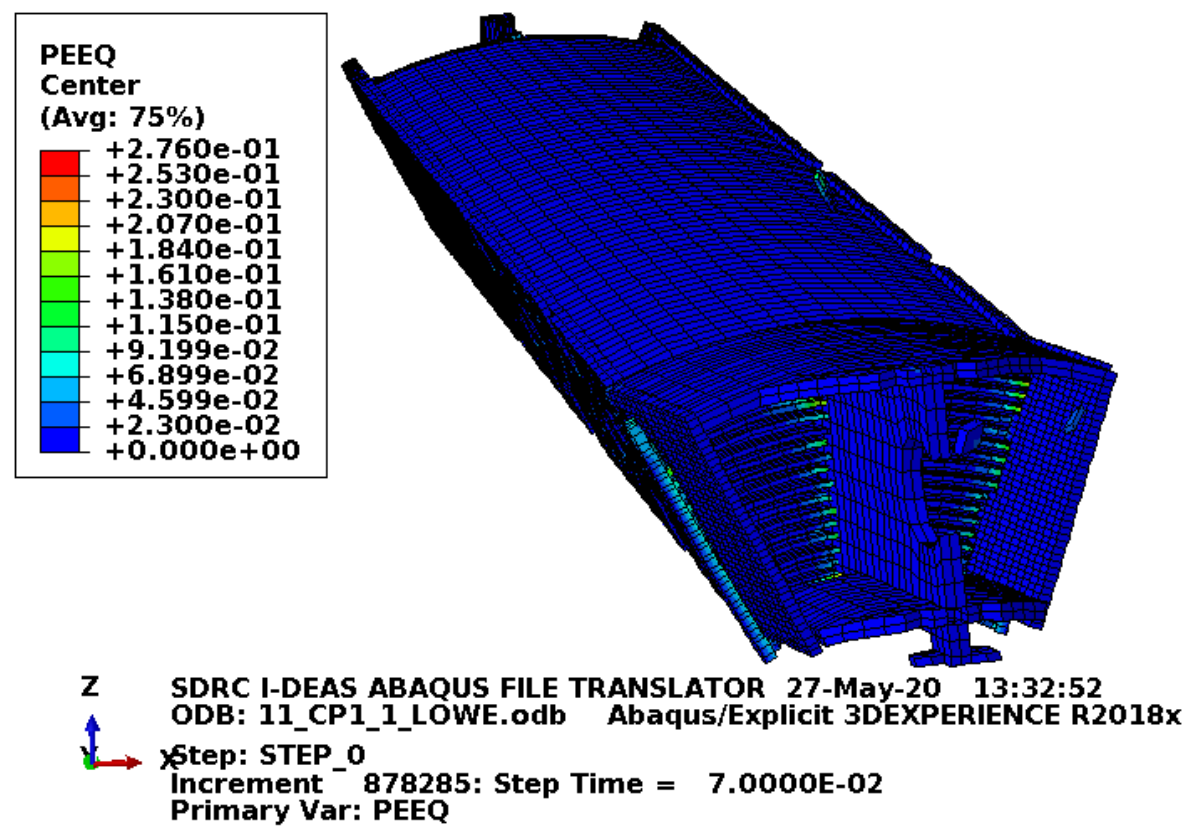

Figure D-282. Scope Part 2a (Table 3), Test 11 (Table 2) fuel element plastic equivalent strain.

Figure D-282 shows the equivalent plastic strain in the fuel element. Failure in the end box elements occurs at an equivalent plastic strain of $0.027 \mathrm{in}$./in. Failure in the end box weld elements occurs at an equivalent plastic strain of $0.032 \mathrm{in}$./in. Failure in the side plate and comb elements occurs at an equivalent plastic strain of $0.152 \mathrm{in./in.} \mathrm{Failure} \mathrm{in} \mathrm{the} \mathrm{side} \mathrm{plate} \mathrm{weld} \mathrm{elements} \mathrm{occurs} \mathrm{at} \mathrm{an} \mathrm{equivalent} \mathrm{plastic} \mathrm{strain} \mathrm{of}$ 0.205 in./in. Figure D-282 shows significant failure in the end box nearest the impacted surface. Also, the end box welds failed sufficiently to free the end box from the rest of the fuel element. When impacting the fuel plates, it appears that Abaqus (2018) has trouble establishing contact. Consequently, the end box penetrates the fuel meat region. This would need to be considered as unacceptable damage. If this were a recommended configuration (the recommended configuration being with blocks) for LOWE fuel elements, further study could be performed to improve the accuracy of the results. However, since this is only for information, no further study is performed. 
ENGINEERING CALCULATIONS AND ANALYSIS

Drop Analysis of the Advanced Test Reactor Fresh Fuel Shipping Container with Heavier Low-Enriched Uranium Fuel Contents
ECAR-5224, Rev. 0

Page D250 of D293
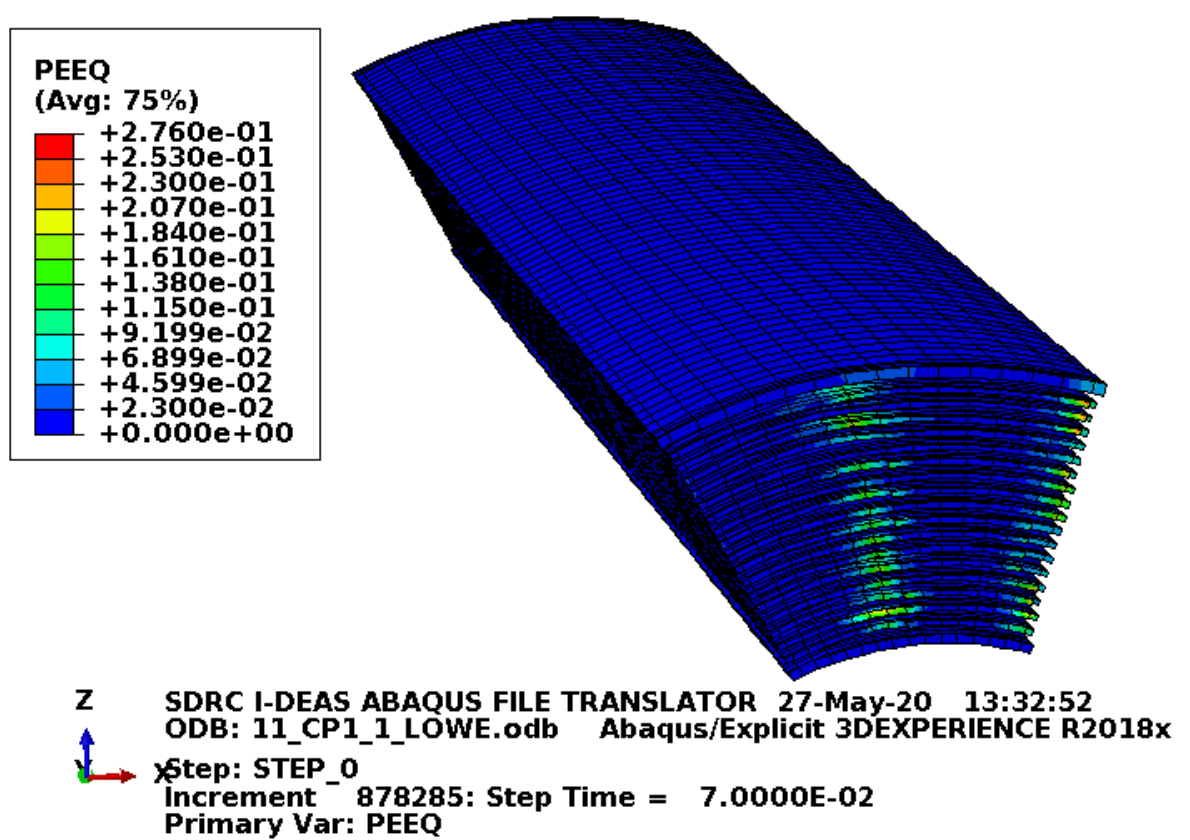

Figure D-283. Scope Part 2a (Table 3), Test 11 (Table 2) fuel plate equivalent strain.

Figure D-283 shows the equivalent plastic strain in the fuel plates. Failure in these elements occurs at an equivalent plastic strain of $0.205 \mathrm{in}$./in. If element failure were to occur, the element would be removed from the model (thereby excluding its equivalent plastic strain from the maximum equivalent plastic strain for the plot). However, the missing element would be visible in the plot. Figure D-283 shows some compressive failure in a few places one element deep (about $0.15 \mathrm{in}$.). Additionally, a few elements at the end of the fuel plates show strains above failure. The strains shown above the failure strain likely result from extrapolation (as integration point strains are the important strains for failure). Considering the discussion with Figure D-283, Abaqus (2018) had some problems with contact and there should have been damage further into the fuel plates. Therefore, this would need to be considered as unacceptable damage. If this were a recommended configuration (the recommended configuration being with blocks) for LOWE fuel elements, further study could be performed to improve the accuracy of the results. However, since this is only for information, no further study is performed.

\section{D3.8.2 Results for Scope Part 2b (Table 3), Test 11 (Table 2)}

The FEA model results for the Scope Part $2 b$ (Table 3), Test 11 (Table 2) model are shown below in Figure D-284 to Figure D-286. The fuel element weighs $44 \mathrm{lbf}$ and the drop scenario is modeled with minimum material properties except the enclosure and end boxes, which are modeled with relatively tough material properties. 


\section{[x1.E3]}

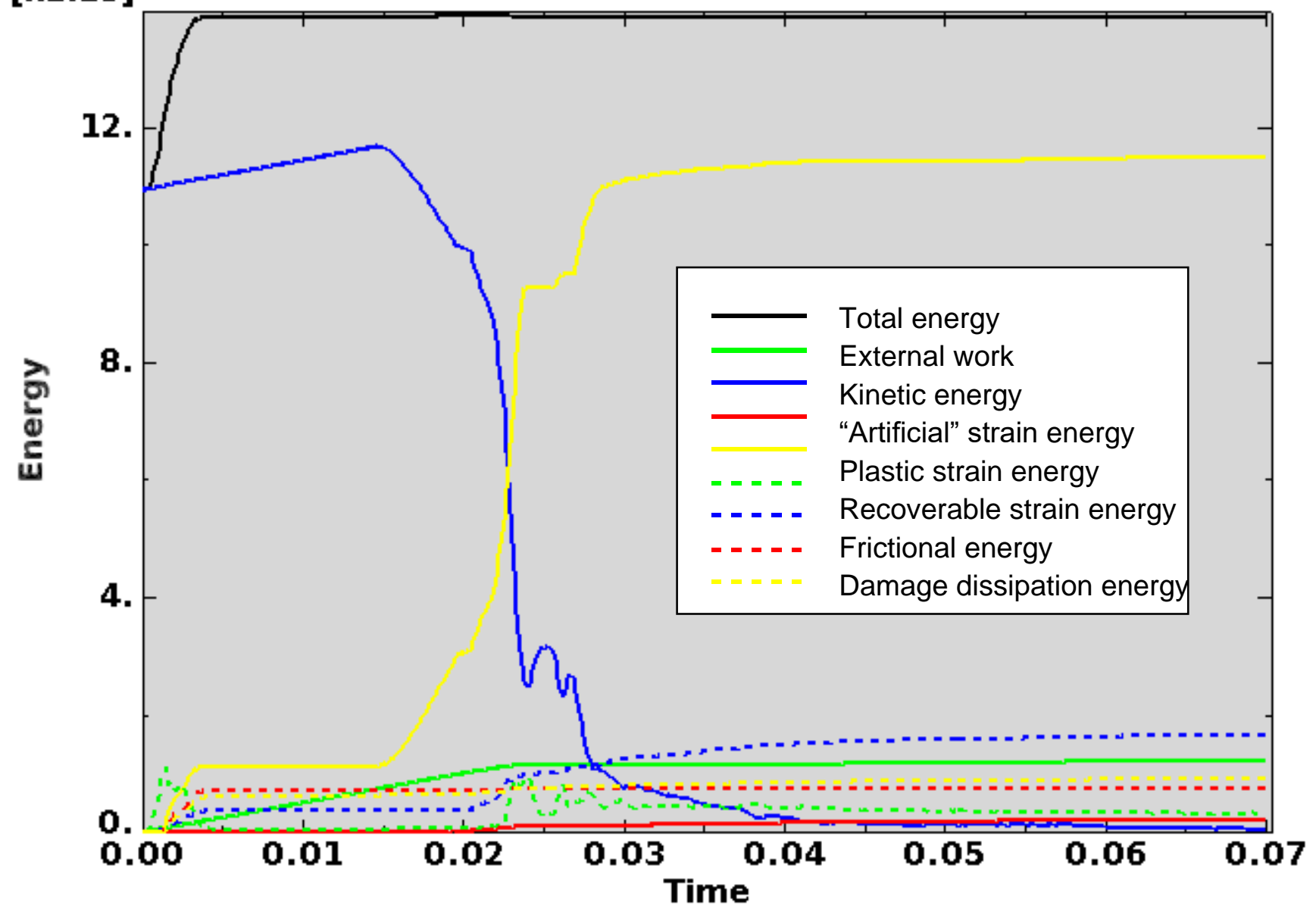

Figure D-284. Scope Part 2b (Table 3), Test 11 (Table 2) energy curves.

Figure D-284 shows the energy curves for Scope Part 2b (Table 3), Test 11 (Table 2) drop scenario. These curves exhibit a stable shape. Artificial strain energy represents the energy required to keep reduced integration elements from taking on a zero-energy hourglass shape. As shown in Figure D-284, the artificial energy at the end of the model run is $1.5 \%$ of the total energy. Therefore, the potential error associated with artificial energy is not considered to be significant. 
ENGINEERING CALCULATIONS AND ANALYSIS

Drop Analysis of the Advanced Test Reactor Fresh Fuel Shipping Container with Heavier Low-Enriched Uranium Fuel Contents
ECAR-5224, Rev. 0

Page D252 of D293

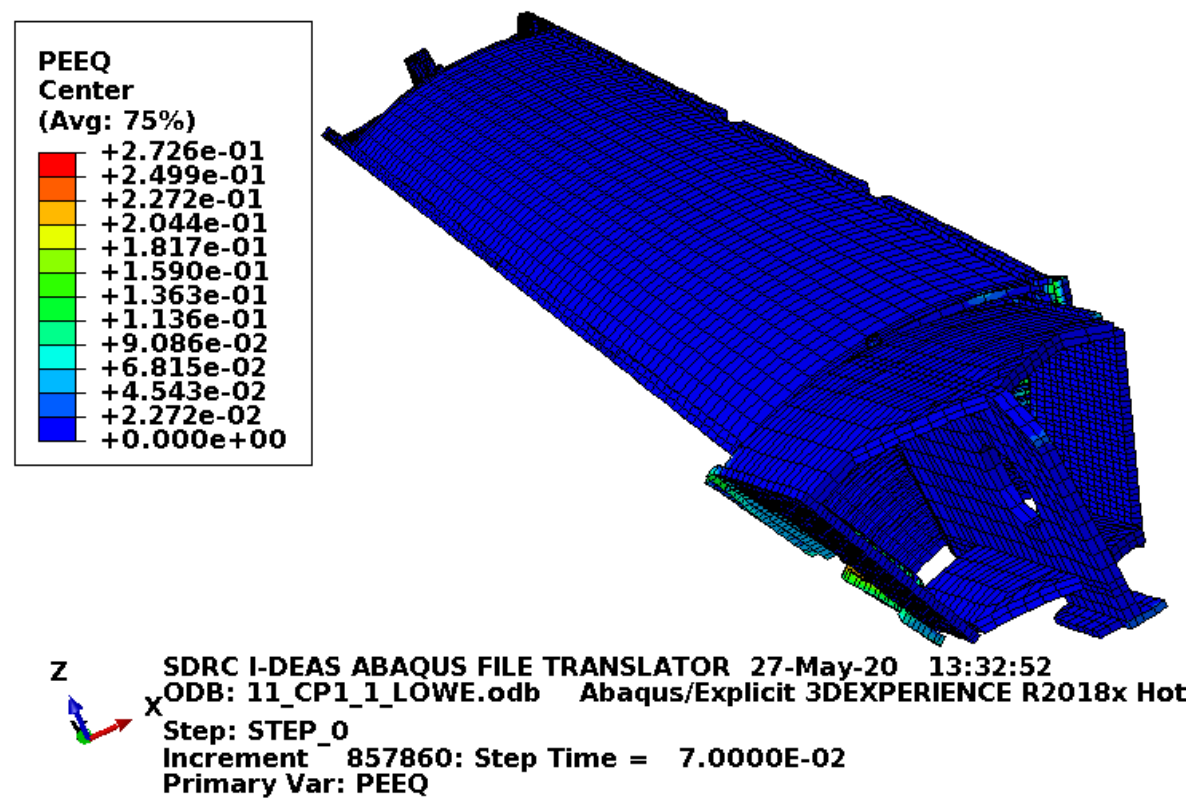

Figure D-285. Scope Part 2b (Table 3), Test 11 (Table 2) fuel element plastic equivalent strain.

Figure D-285 shows the equivalent plastic strain in the fuel element. Failure in the end box elements occurs at an equivalent plastic strain of $0.08 \mathrm{in./in.} \mathrm{(for} \mathrm{the} \mathrm{relatively} \mathrm{tough} \mathrm{material} \mathrm{properties).} \mathrm{Failure} \mathrm{in} \mathrm{the} \mathrm{end}$ box weld elements occurs at an equivalent plastic strain of $0.115 \mathrm{in}$./in. (for the relatively tough material properties). Failure in the side plate and comb elements occurs at an equivalent plastic strain of 0.152 in./in. Failure in the side plate weld elements occurs at an equivalent plastic strain of 0.205 in./in. Figure D-285 shows some failure in the end box nearest the impacted surface. Also, the end box welds failed sufficiently to free the end box from the rest of the fuel element. However, the end box welds absorb most of the energy of impact. So, the end box impact with the fuel plates does not do much damage.

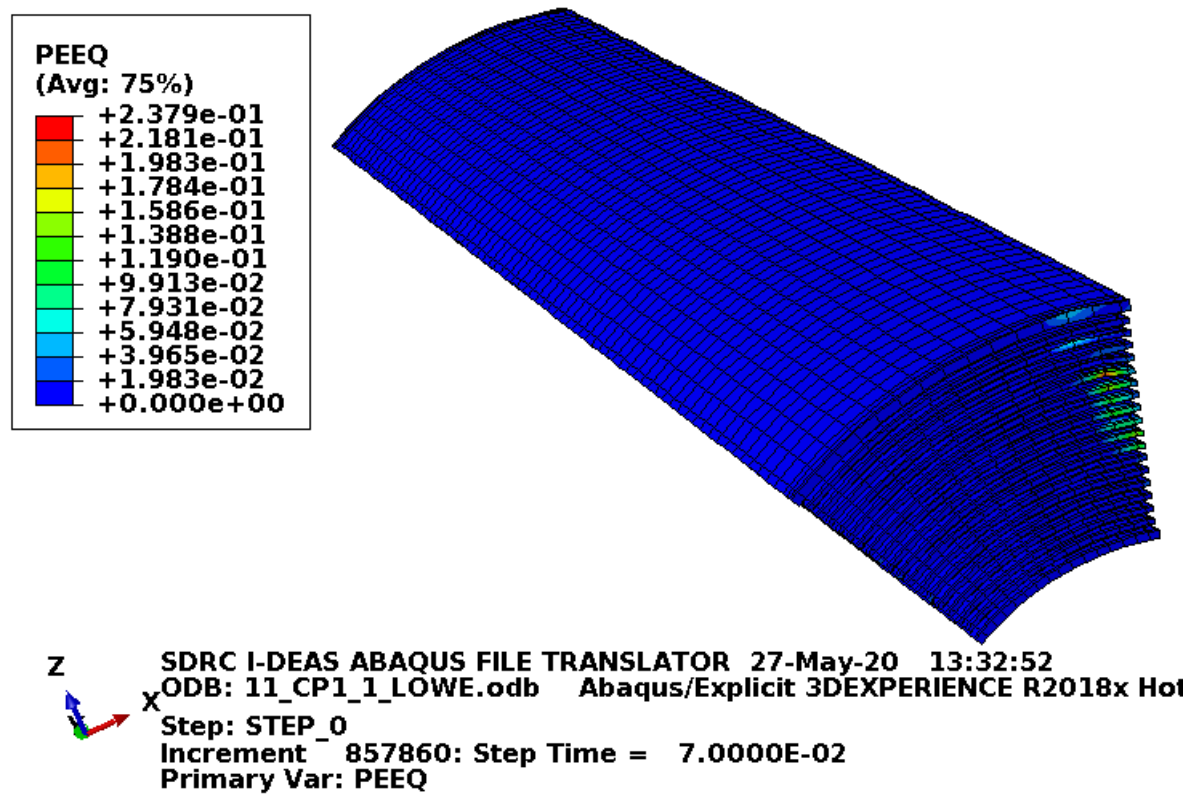

Figure D-286. Scope Part 2b (Table 3), Test 11 (Table 2) fuel plate equivalent strain. 
Figure D-286 shows the equivalent plastic strain in the fuel plates. Failure in these elements occurs at an equivalent plastic strain of $0.205 \mathrm{in}$./in. Figure D-286 shows no element failure, but a couple elements at the end of one fuel plate show strains above failure. The strains shown above the failure strain likely result from extrapolation (as integration point strains are the important strains for failure). Even if the elements with high strain were removed as being failed, their failure would be acceptable as they do not represent fuel meat.

\section{D3.8.3 Results for Scope Part 2c (Table 3), Test 11 (Table 2)}

The FEA model results for the Scope Part 2c (Table 3), Test 11 (Table 2) model are shown below in Figure D-287 to Figure D-289. The fuel element weighs $44 \mathrm{lbf}$ and the whole model is modeled with minimum material properties. This section includes the blocks as added fuel plate protection.

[X1.E3]

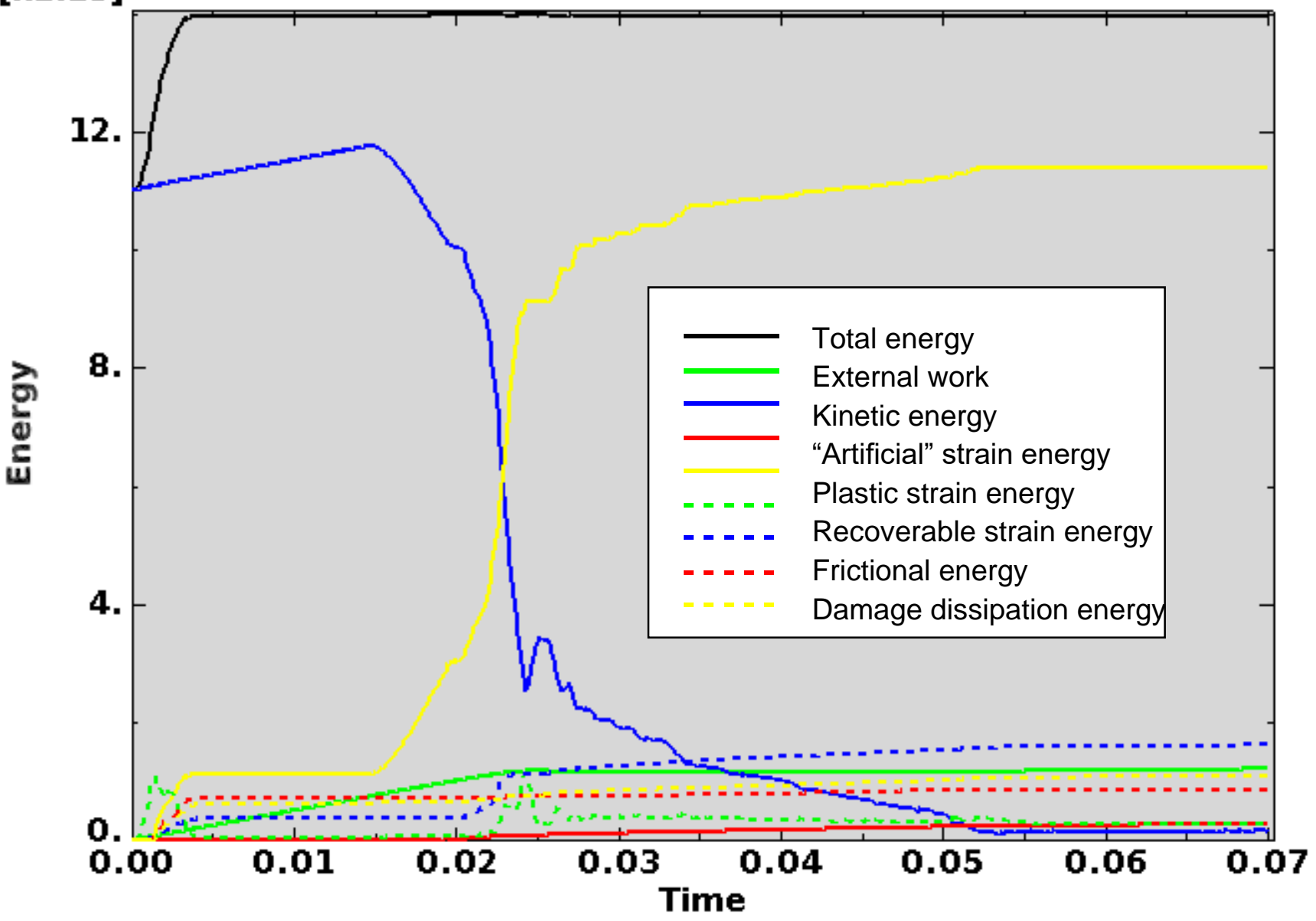

Figure D-287. Scope Part 2c (Table 3), Test 11 (Table 2) energy curves.

Figure D-287 shows the energy curves for Scope Part 2c (Table 3), Test 11 (Table 2) drop scenario. These curves exhibit a stable shape. Artificial strain energy represents the energy required to keep reduced integration elements from taking on a zero-energy hourglass shape. As shown in Figure D-287, the artificial energy at the end of the model run is $1.9 \%$ of the total energy. Therefore, the potential error associated with artificial energy is not considered to be significant. 


\section{ENGINEERING CALCULATIONS AND ANALYSIS}

Drop Analysis of the Advanced Test Reactor Fresh Fuel Shipping Container with Heavier Low-Enriched Uranium Fuel Contents
ECAR-5224, Rev. 0

Page D254 of D293

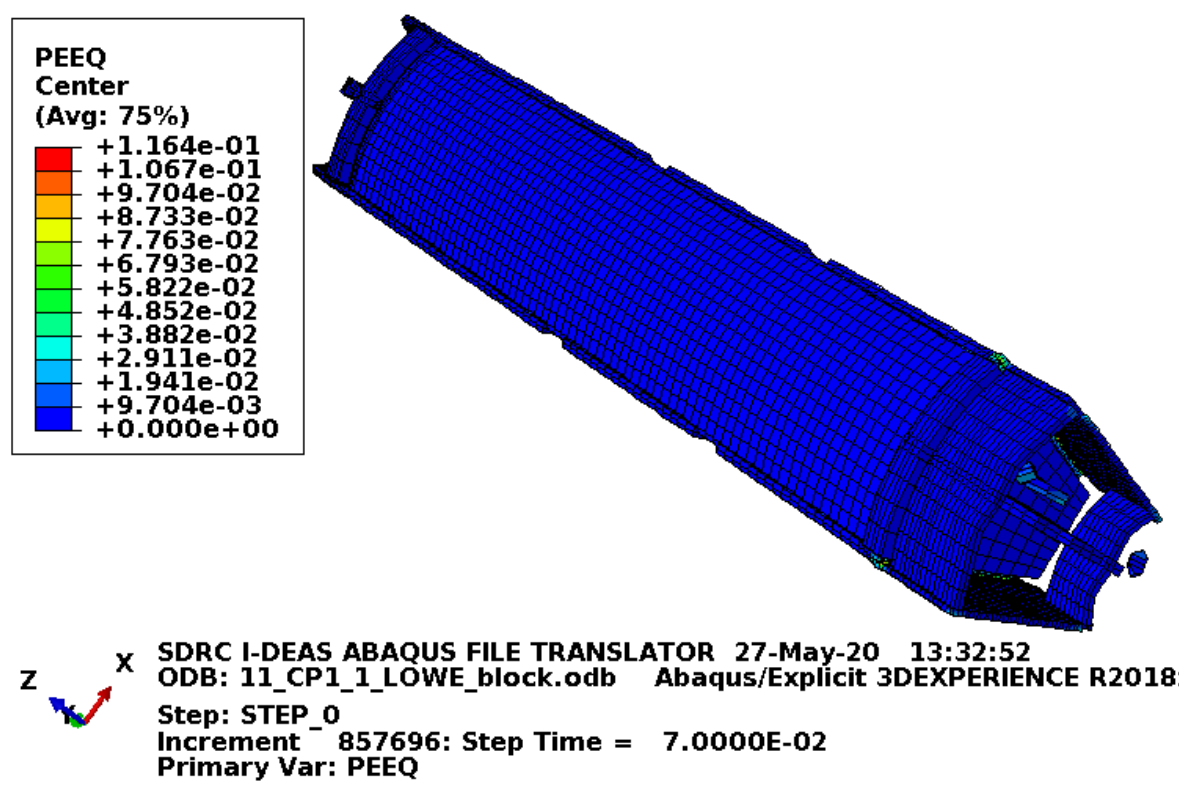

Figure D-288. Scope Part 2c (Table 3), Test 11 (Table 2) fuel element plastic equivalent strain.

Figure D-288 shows the equivalent plastic strain in the fuel element. Failure in the end box elements occurs at an equivalent plastic strain of $0.027 \mathrm{in}$./in. Failure in the end box weld elements occurs at an equivalent plastic strain of $0.032 \mathrm{in}$./in. Failure in the side plate and comb elements occurs at an equivalent plastic strain of $0.152 \mathrm{in./in.} \mathrm{Failure} \mathrm{in} \mathrm{the} \mathrm{side} \mathrm{plate} \mathrm{weld} \mathrm{elements} \mathrm{occurs} \mathrm{at} \mathrm{an} \mathrm{equivalent} \mathrm{plastic} \mathrm{strain} \mathrm{of}$ 0.205 in./in. Figure D-288 shows failure in the end box and partial failure in the end box welds nearest the impact which is acceptable.
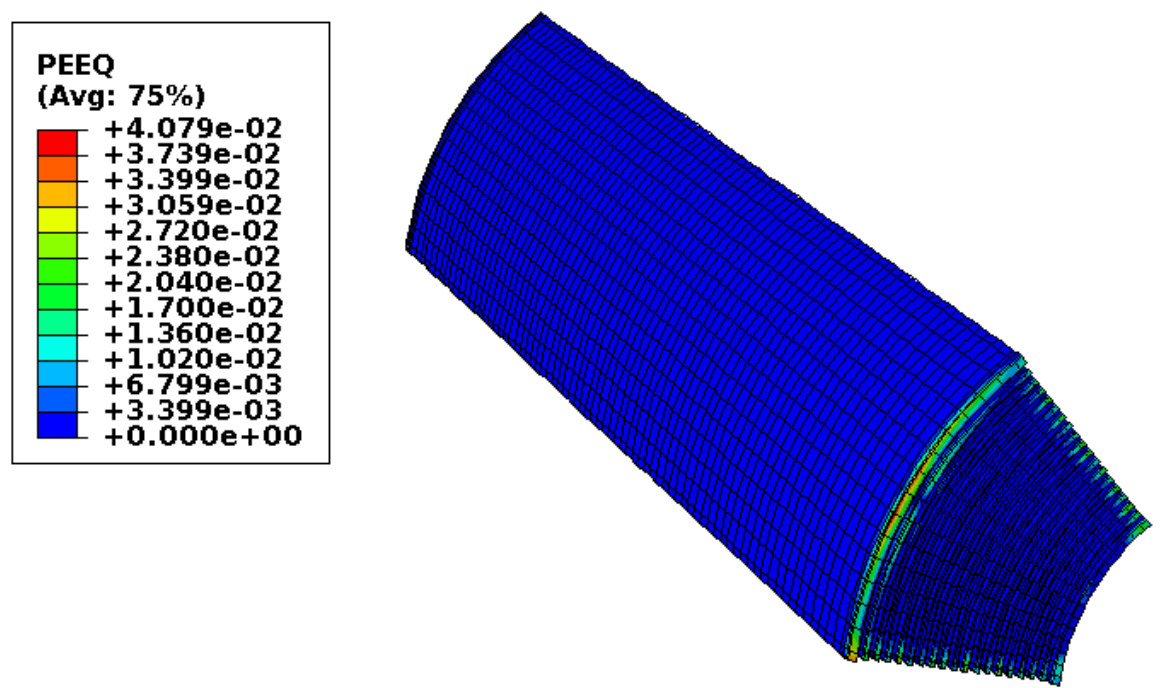

SDRC I-DEAS ABAQUS FILE TRANSLATOR 27-May-20 13:32:52 ODB: 11_CP1_1_LOWE_block.odb Abaqus/Explicit 3DEXPERIENCE

Step: STEP_o

Increment ${ }^{-857696: \text { Step Time }=7.0000 E-02}$

Primary Var: PEEQ

Figure D-289. Scope Part 2c (Table 3), Test 11 (Table 2) fuel plate equivalent strain. 
Figure D-289 shows the equivalent plastic strain in the fuel plates. Failure in these elements occurs at an equivalent plastic strain of $0.205 \mathrm{in}$./in. If element failure were to occur, the element would be removed from the model (thereby excluding its equivalent plastic strain from the maximum equivalent plastic strain for the plot). However, the missing element would be visible in the plot. Figure D-289 shows no failure in the fuel plates with margin.

\section{D3.8.4 Results for Scope Part 2d (Table 3), Test 11 (Table 2)}

The FEA model results for the Scope Part 2d (Table 3), Test 11 (Table 2) model are shown below in Figure D-290 to Figure D-292. The fuel element weighs $44 \mathrm{lbf}$ and the drop scenario is modeled with minimum material properties except the enclosure and end boxes, which are modeled with relatively tough material properties. This section includes the blocks as added fuel plate protection.

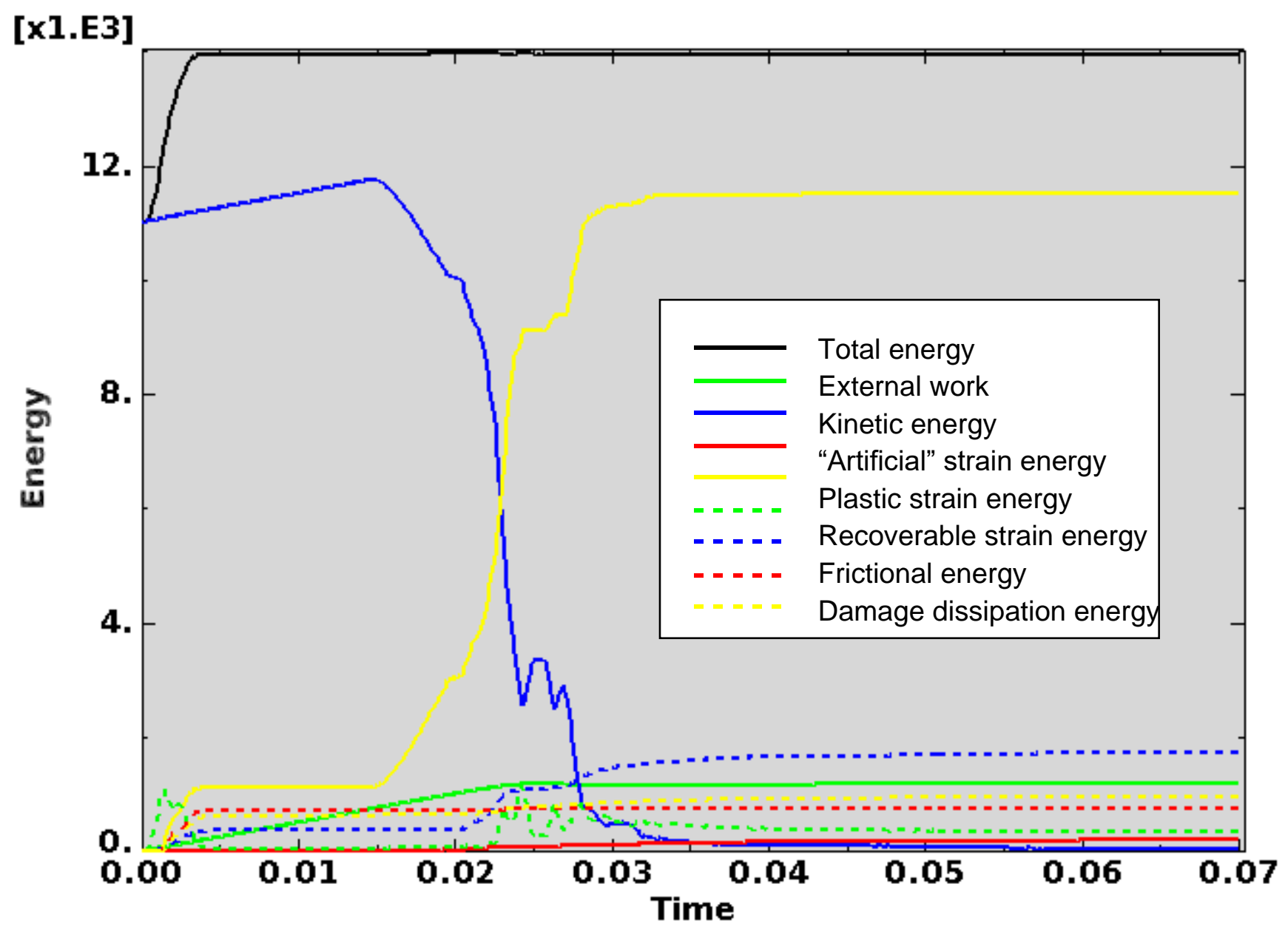

Figure D-290. Scope Part 2d (Table 3), Test 11 (Table 2) energy curves.

Figure D-290 shows the energy curves for Scope Part 2d (Table 3), Test 11 (Table 2) drop scenario. These curves exhibit a stable shape. Artificial strain energy represents the energy required to keep reduced integration elements from taking on a zero-energy hourglass shape. As shown in Figure D-290, the artificial energy at the end of the model run is $1.4 \%$ of the total energy. Therefore, the potential error associated with artificial energy is not considered to be significant. 
ENGINEERING CALCULATIONS AND ANALYSIS

Drop Analysis of the Advanced Test Reactor Fresh Fuel Shipping Container with Heavier Low-Enriched Uranium Fuel Contents
ECAR-5224, Rev. 0

Page D256 of D293

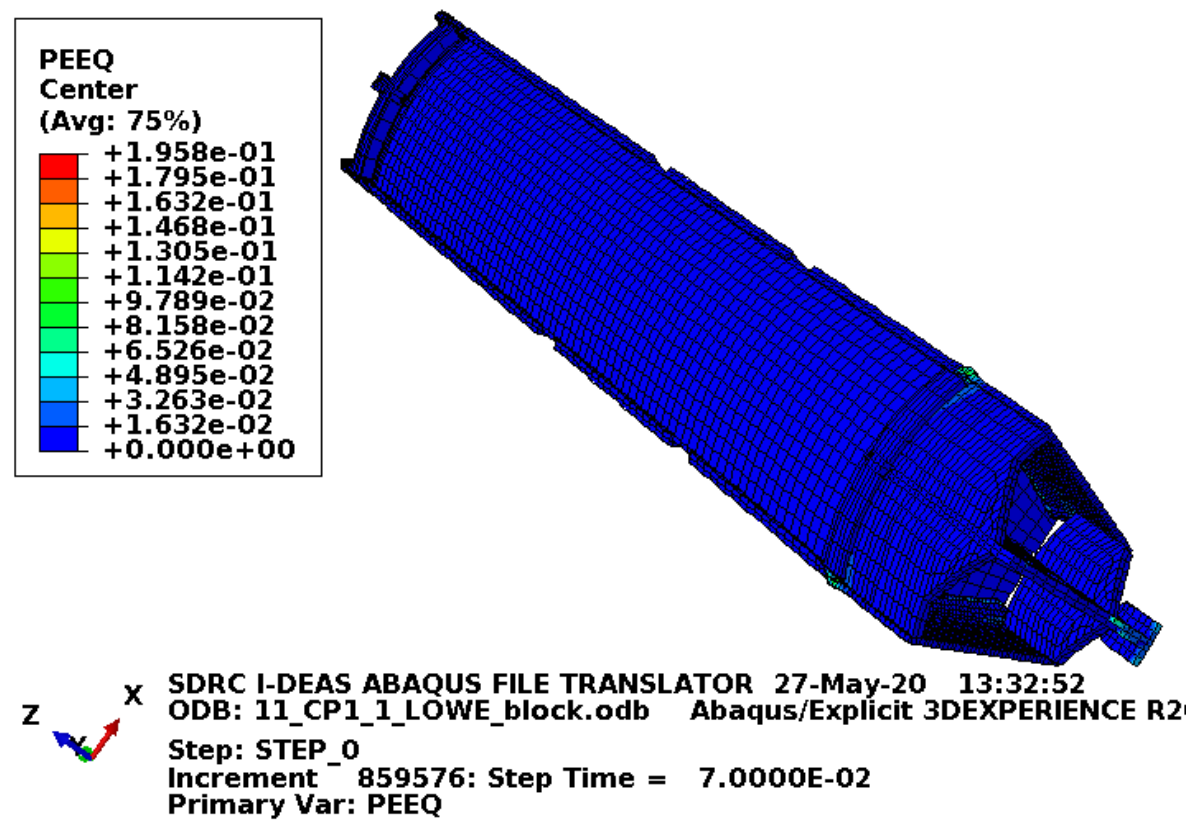

Figure D-291. Scope Part 2d (Table 3), Test 11 (Table 2) fuel element plastic equivalent strain.

Figure D-291 shows the equivalent plastic strain in the fuel element. Failure in the end box elements occurs at an equivalent plastic strain of $0.08 \mathrm{in}$./in. (for the relatively tough material properties). Failure in the end box weld elements occurs at an equivalent plastic strain of $0.115 \mathrm{in}$./in. (for the relatively tough material properties). Failure in the side plate and comb elements occurs at an equivalent plastic strain of $0.152 \mathrm{in}$./in. Failure in the side plate weld elements occurs at an equivalent plastic strain of 0.205 in./in. Figure D-291 shows some failure in the end box nearest the impact which is acceptable.

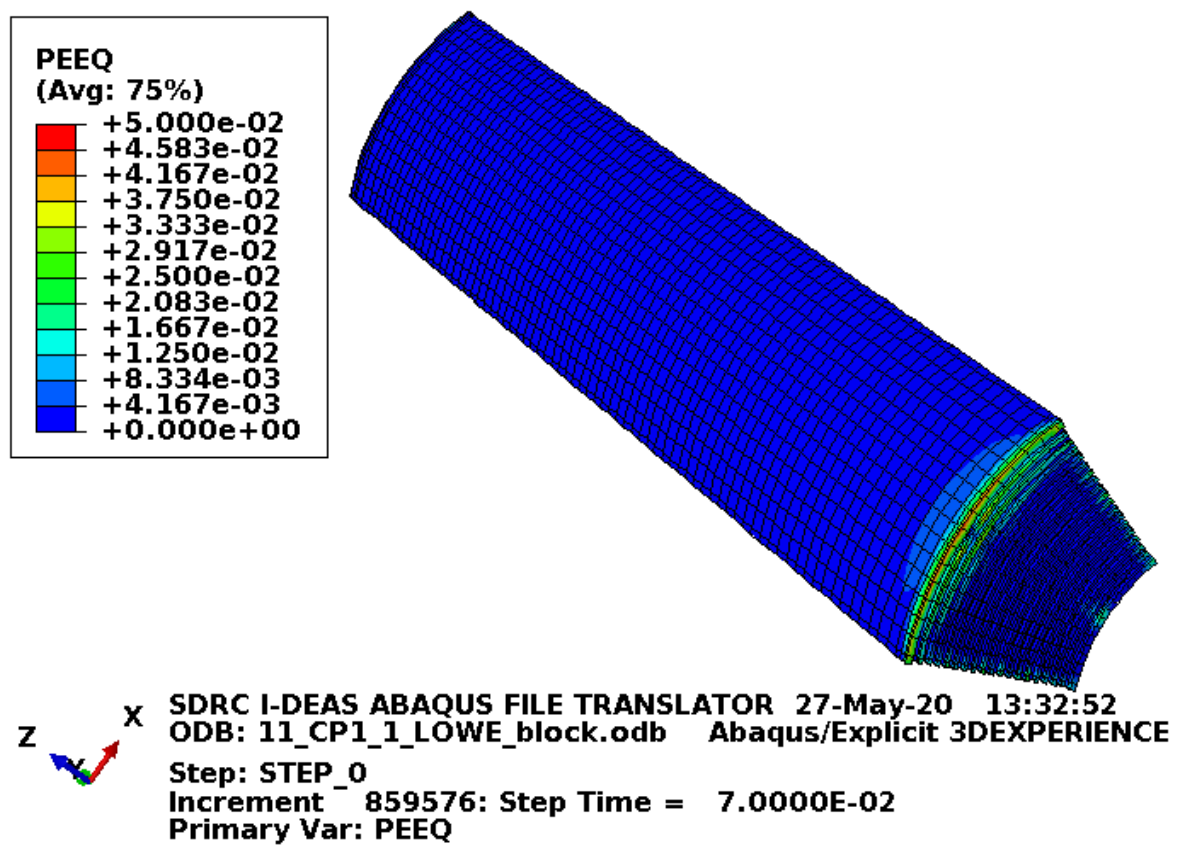

Figure D-292. Scope Part 2d (Table 3), Test 11 (Table 2) fuel plate equivalent strain. 
ENGINEERING CALCULATIONS AND ANALYSIS

Drop Analysis of the Advanced Test Reactor Fresh Fuel Shipping Container with Heavier Low-Enriched Uranium Fuel Contents
ECAR-5224, Rev. 0

Page D257 of D293

Figure D-292 shows the equivalent plastic strain in the fuel plates. Failure in these elements occurs at an equivalent plastic strain of $0.205 \mathrm{in}$./in. If element failure were to occur, the element would be removed from the model (thereby excluding its equivalent plastic strain from the maximum equivalent plastic strain for the plot). However, the missing element would be visible in the plot. Figure D-292 shows no failure in the fuel plates with margin.

\section{D3.9 Results for Scope Part 2 (Table 3), Test 12 (Table 2)}

The drop scenario considered in this section is a $30 \mathrm{ft}$ drop modeled as a vertical top impact.

\section{D3.9.1 Results for Scope Part 2a (Table 3), Test 12 (Table 2)}

The FEA model results for the Scope Part 2a (Table 3), Test 12 (Table 2) model are shown below in Figure D-293 to Figure D-295. The fuel element weighs $44 \mathrm{lbf}$ and the whole model is modeled with minimum material properties.

\section{[x1.E3]}

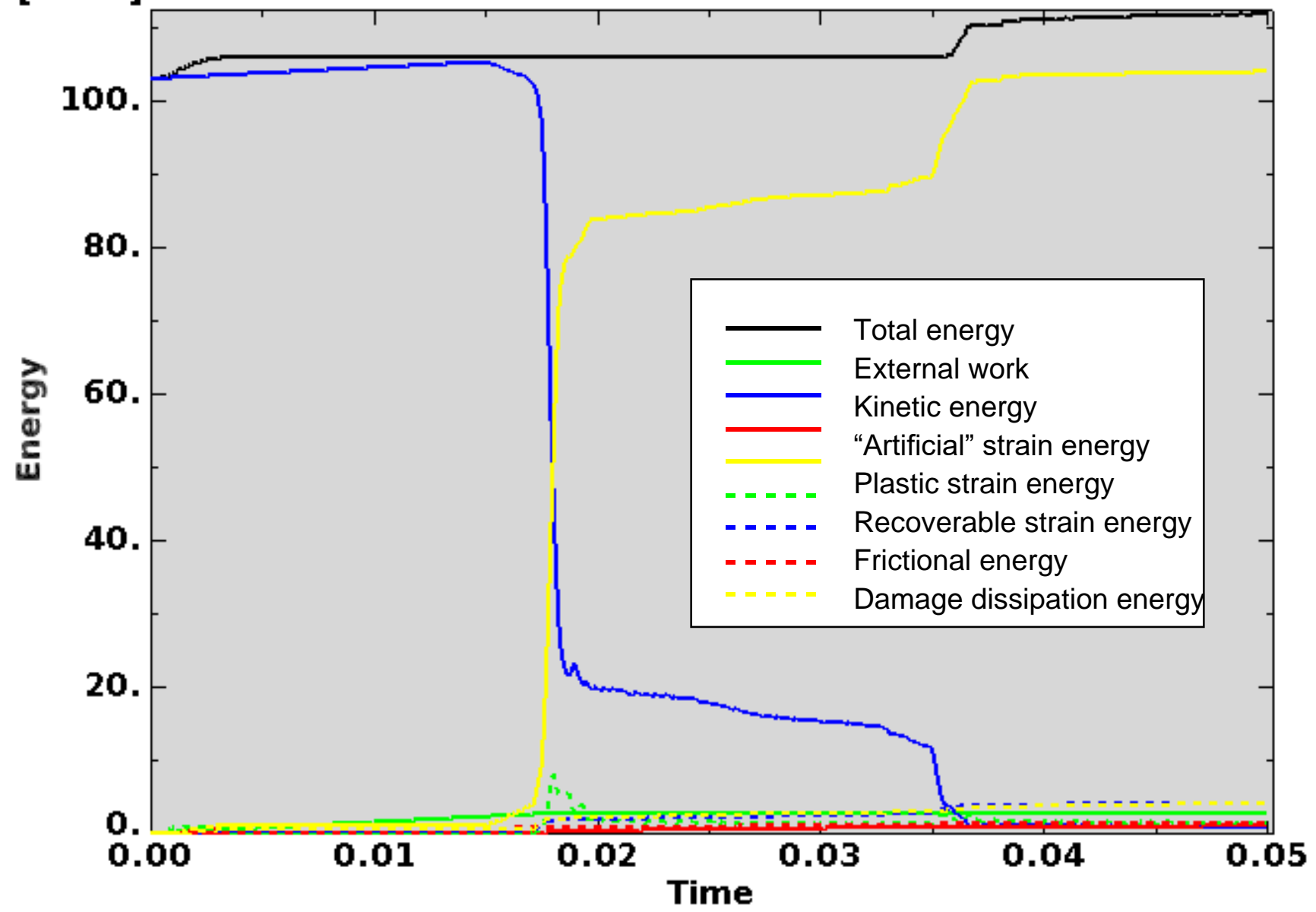

Figure D-293. Scope Part 2a (Table 3), Test 12 (Table 2) energy curves. 
Figure D-293 shows the energy curves for Scope Part 2a (Table 3), Test 12 (Table 2) drop scenario. These curves exhibit stable behavior up until significant failure occurs in the fuel element. At this point, the total energy and plastic strain energy show some undesirable behavior. As discussed in Section D3.5 this appears to result from contact difficultly between failed portions of the fuel element. Given that this is not a recommended configuration (the recommended configuration being with blocks) for LOWE fuel elements, this model is just for information. The results are provided at the end of the model run.

Artificial strain energy represents the energy required to keep reduced integration elements from taking on a zero-energy hourglass shape. As shown in Figure D-293, the artificial energy at the end of the model run is $0.9 \%$ of the total energy. Therefore, the potential error associated with artificial energy is not considered to be significant.

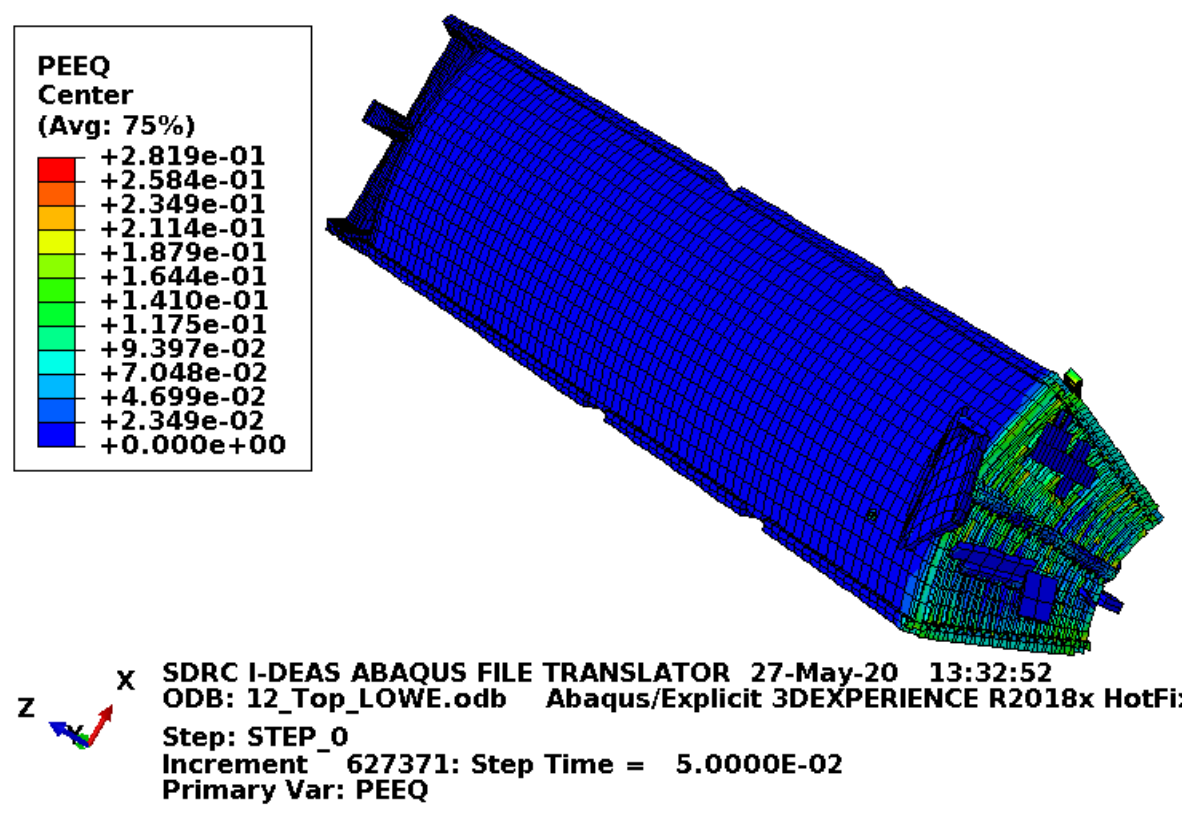

Figure D-294. Scope Part 2a (Table 3), Test 12 (Table 2) fuel element plastic equivalent strain.

Figure D-294 shows the equivalent plastic strain in the fuel element. Failure in the end box elements occurs at an equivalent plastic strain of $0.027 \mathrm{in}$./in. Failure in the end box weld elements occurs at an equivalent plastic strain of $0.032 \mathrm{in}$./in. Failure in the side plate and comb elements occurs at an equivalent plastic strain of $0.152 \mathrm{in}$./in. Failure in the side plate weld elements occurs at an equivalent plastic strain of 0.205 in./in. Figure D-294 shows substantial failure of the end box and end box welds nearest the impact. 
ENGINEERING CALCULATIONS AND ANALYSIS

Drop Analysis of the Advanced Test Reactor Fresh Fuel Shipping Container with Heavier Low-Enriched Uranium Fuel Contents

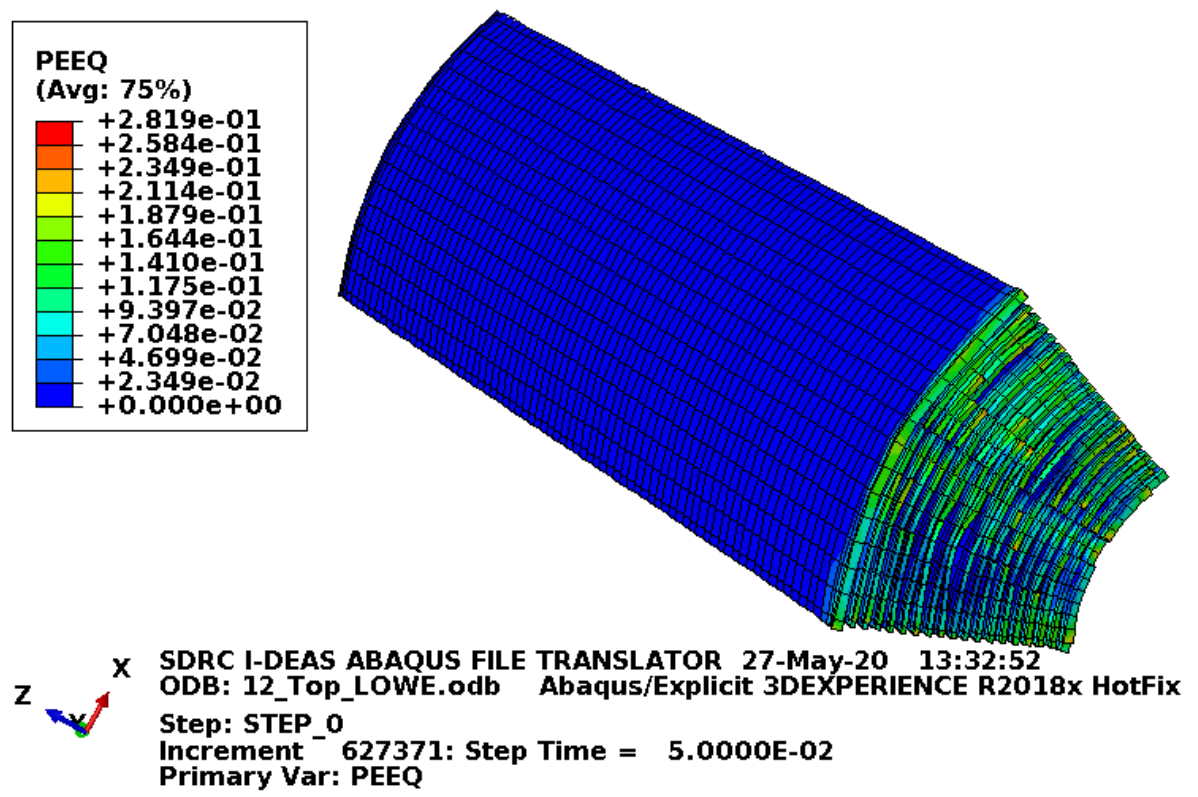

Figure D-295. Scope Part 2a (Table 3), Test 12 (Table 2) fuel plate equivalent strain.

Figure D-295 shows the equivalent plastic strain in the fuel plates. Failure in these elements occurs at an equivalent plastic strain of $0.205 \mathrm{in}$./in. Figure D-295 shows some compressive failure in a few places, one element deep (about 0.15 in.), which is acceptable.

\section{D3.9.2 Results for Scope Part 2b (Table 3), Test 12 (Table 2)}

The FEA model results for the Scope Part $2 b$ (Table 3), Test 12 (Table 2) model are shown below in Figure D-296 to Figure D-298. The fuel element weighs $44 \mathrm{lbf}$ and the drop scenario is modeled with minimum material properties except the enclosure and end boxes, which are modeled with relatively tough material properties. 


\section{[x1.E6]}

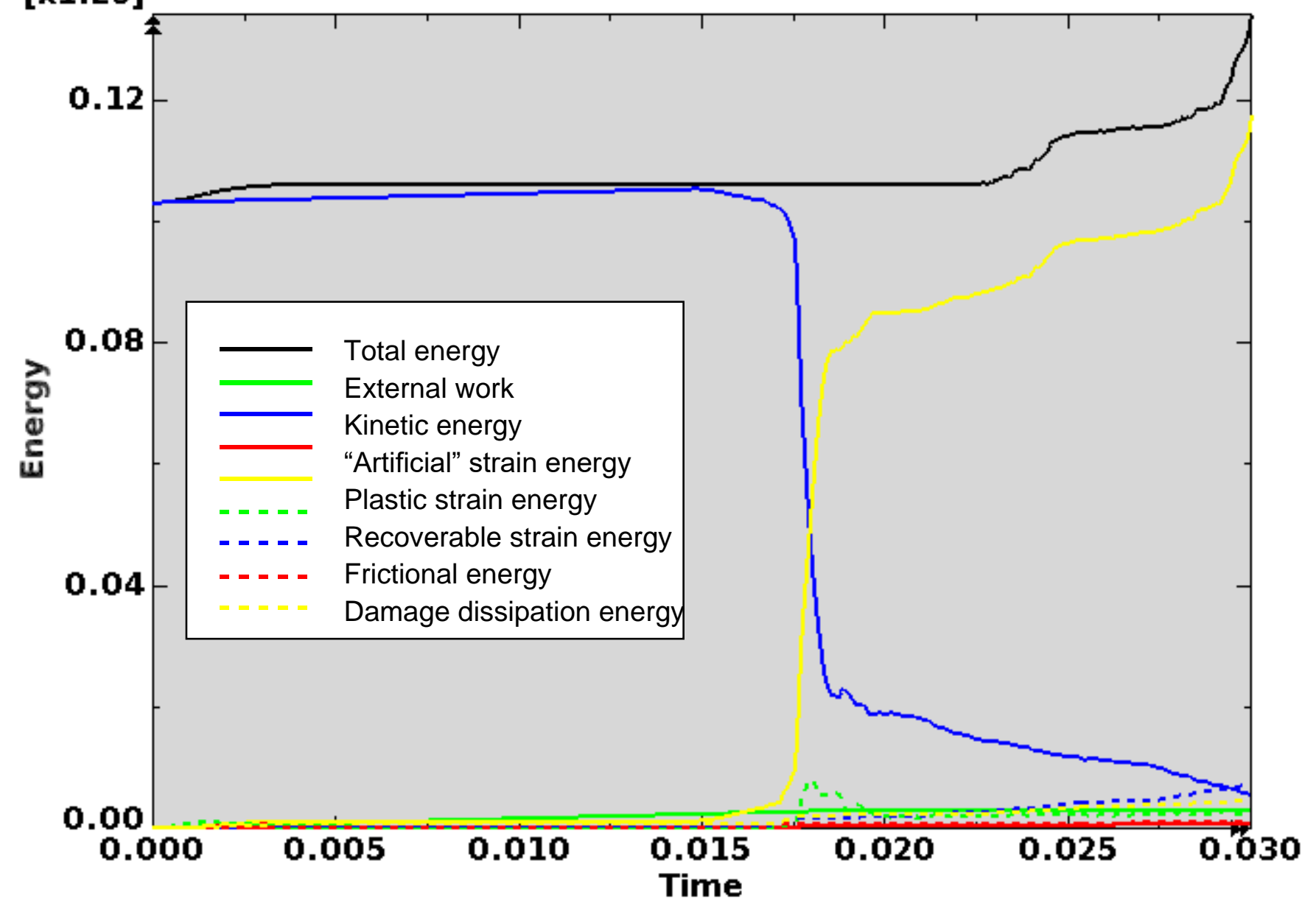

Figure D-296. Scope Part 2b (Table 3), Test 12 (Table 2) energy curves.

Figure D-296 shows the energy curves for Scope Part 2b (Table 3), Test 12 (Table 2) drop scenario. These curves exhibit initially stable behavior. When the fuel element begins to fail, the total energy and plastic strain energy show the undesirable behavior of increasing very substantially. As discussed in Section D3.5 this appears to result from contact difficultly between failed portions of the fuel element.

These curves exhibit stable behavior for the initial impact of the ATR FFSC. As the fuel element impacts and is badly damaged, the total energy and plastic strain energy increase substantially which is undesirable. As discussed in Section D3.5 this appears to result from contact difficultly between failed portions of the fuel element. Output is shown at 0.030 second as this is close to rebound and the model becomes obviously unstable after this time. (Instability is observed as substantial element failure occurring in elements well away from the impact and seeing no interaction). Though the energy curves show substantial problems with the model run, the results are provided for information. This is not a recommended configuration (the recommended configuration being with blocks) for LOWE fuel elements and the model is showing unacceptable damage to the fuel meat. 
Artificial strain energy represents the energy required to keep reduced integration elements from taking on a zero-energy hourglass shape. As shown in Figure D-296, the artificial energy at the end of the model run is $0.5 \%$ of the total energy. Therefore, the potential error associated with artificial energy is not considered to be significant.

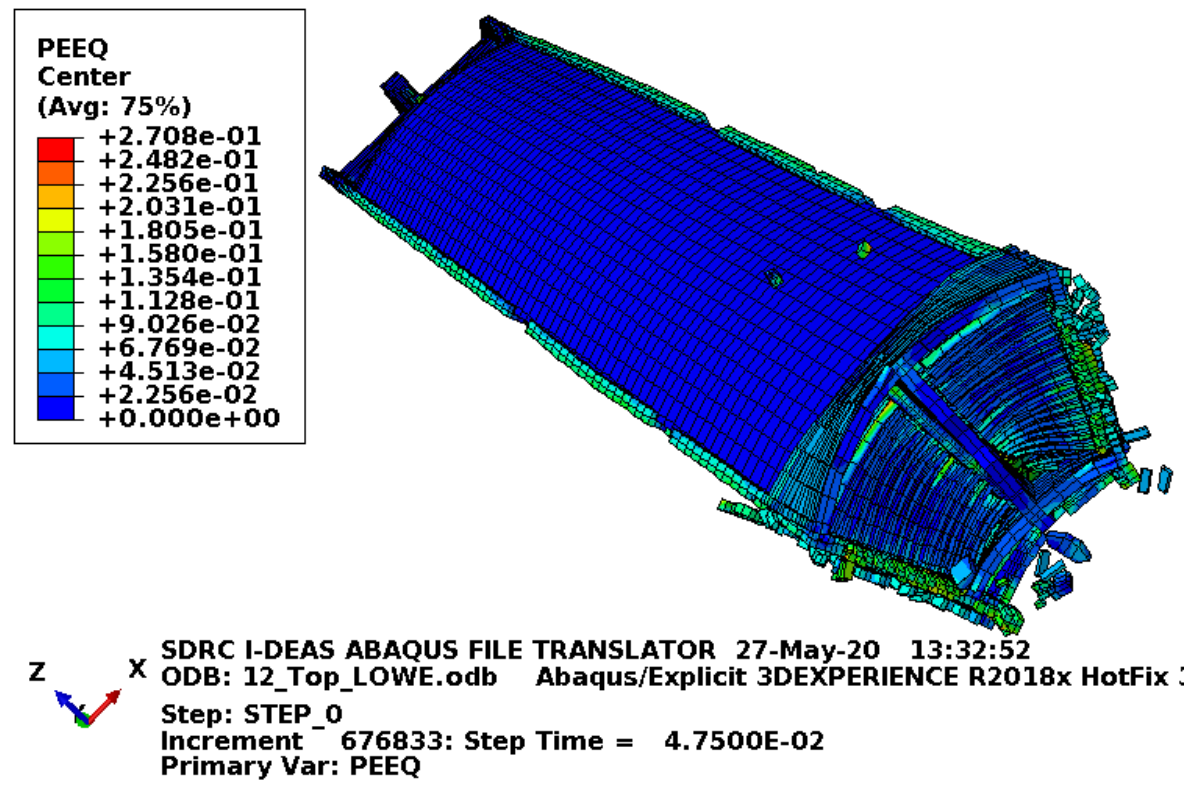

Figure D-297. Scope Part 2b (Table 3), Test 12 (Table 2) fuel element plastic equivalent strain.

Figure D-297 shows the equivalent plastic strain in the fuel element. Failure in the end box elements occurs at an equivalent plastic strain of $0.08 \mathrm{in./in.} \mathrm{(for} \mathrm{the} \mathrm{relatively} \mathrm{tough} \mathrm{material} \mathrm{properties).} \mathrm{Failure} \mathrm{in} \mathrm{the} \mathrm{end}$ box weld elements occurs at an equivalent plastic strain of $0.115 \mathrm{in}$./in. (for the relatively tough material properties). Failure in the side plate and comb elements occurs at an equivalent plastic strain of 0.152 in./in. Failure in the side plate weld elements occurs at an equivalent plastic strain of 0.205 in./in. Figure D-297 shows failure in the end box and complete failure of the end box welds. Also, the end box cuts substantially into the fuel elements. 
ENGINEERING CALCULATIONS AND ANALYSIS

Drop Analysis of the Advanced Test Reactor Fresh Fuel Shipping Container with Heavier Low-Enriched Uranium Fuel Contents
ECAR-5224, Rev. 0

Page D262 of D293

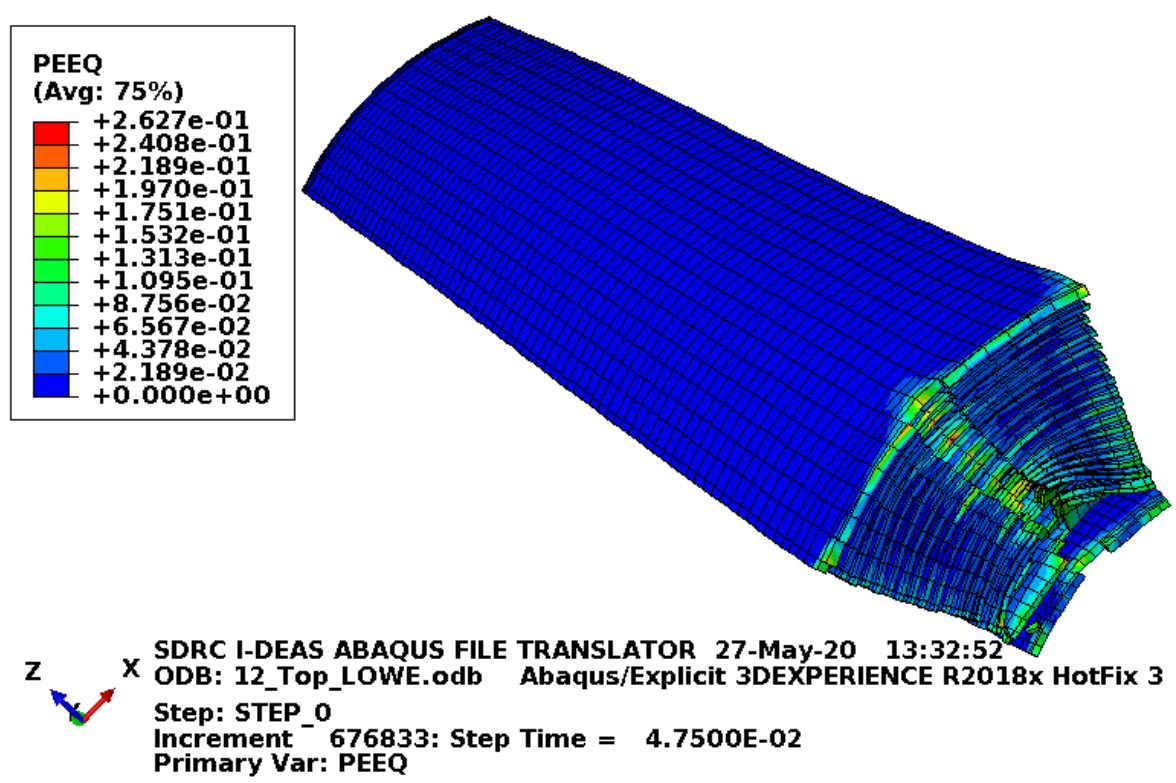

Figure D-298. Scope Part 2b (Table 3), Test 12 (Table 2) fuel plate equivalent strain.

Figure D-298 shows the equivalent plastic strain in the fuel plates. Failure in these elements occurs at an equivalent plastic strain of 0.205 in./in. Figure D-298 shows significant failure in the fuel plates nearest the impact. By the inconsistent damage, it is clear that Abaqus (2018) is having trouble establishing contact correctly. Though, the fuel plates have unacceptable damage well into the fuel meat (shown in Figure D-298).

\section{D3.9.3 Results for Scope Part 2c (Table 3), Test 12 (Table 2)}

The FEA model results for the Scope Part 2c (Table 3), Test 12 (Table 2) model are shown below in Figure D-299 to Figure D-301. The fuel element weighs $44 \mathrm{lbf}$ and the whole model is modeled with minimum material properties. This section includes the blocks as added fuel plate protection. 


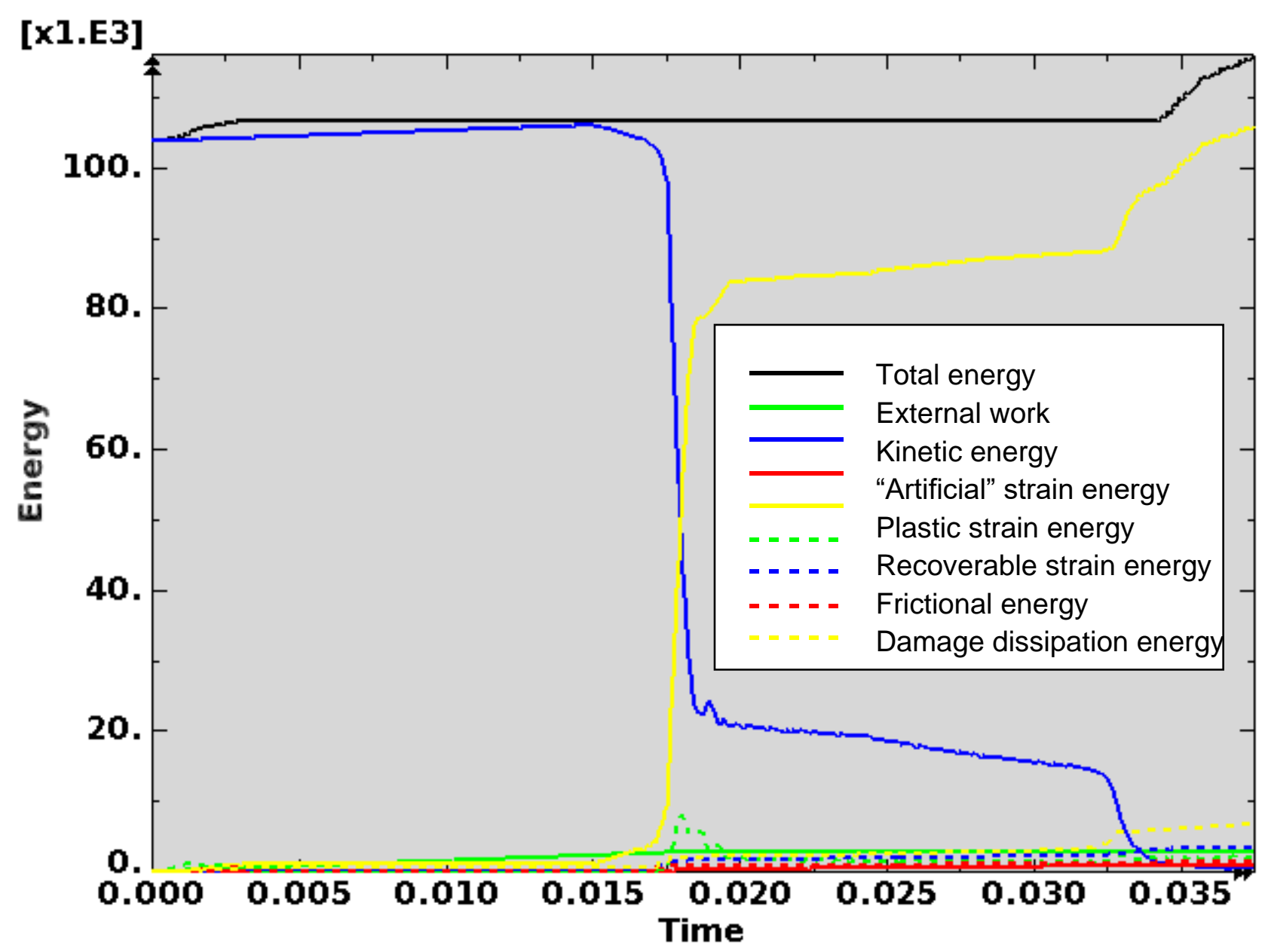

Figure D-299. Scope Part 2c (Table 3), Test 12 (Table 2) energy curves.

Figure D-299 shows the energy curves for Scope Part 2c (Table 3), Test 12 (Table 2) drop scenario. These curves exhibit mostly stable behavior. Near the end of the model run, the total energy and plastic strain energy start to show undesirable behavior. As discussed in Section D3.5 this appears to result from contact difficultly between failed portions of the fuel element. Consequently, output is shown at the first output frame after fuel element rebound $(0.0375$ second) to try to minimize potential error associated with this. The results are considered reasonable and conservative considering that the results compared with physical drops (see Section D2.5) had more of an energy rise and still produced reasonable and conservative results.

Artificial strain energy represents the energy required to keep reduced integration elements from taking on a zero-energy hourglass shape. As shown in Figure D-299, the artificial energy at the end of the model run is $0.8 \%$ of the total energy. Therefore, the potential error associated with artificial energy is not considered to be significant. 
ENGINEERING CALCULATIONS AND ANALYSIS

Drop Analysis of the Advanced Test Reactor Fresh Fuel Shipping Container with Heavier Low-Enriched Uranium Fuel Contents
ECAR-5224, Rev. 0

Page D264 of D293

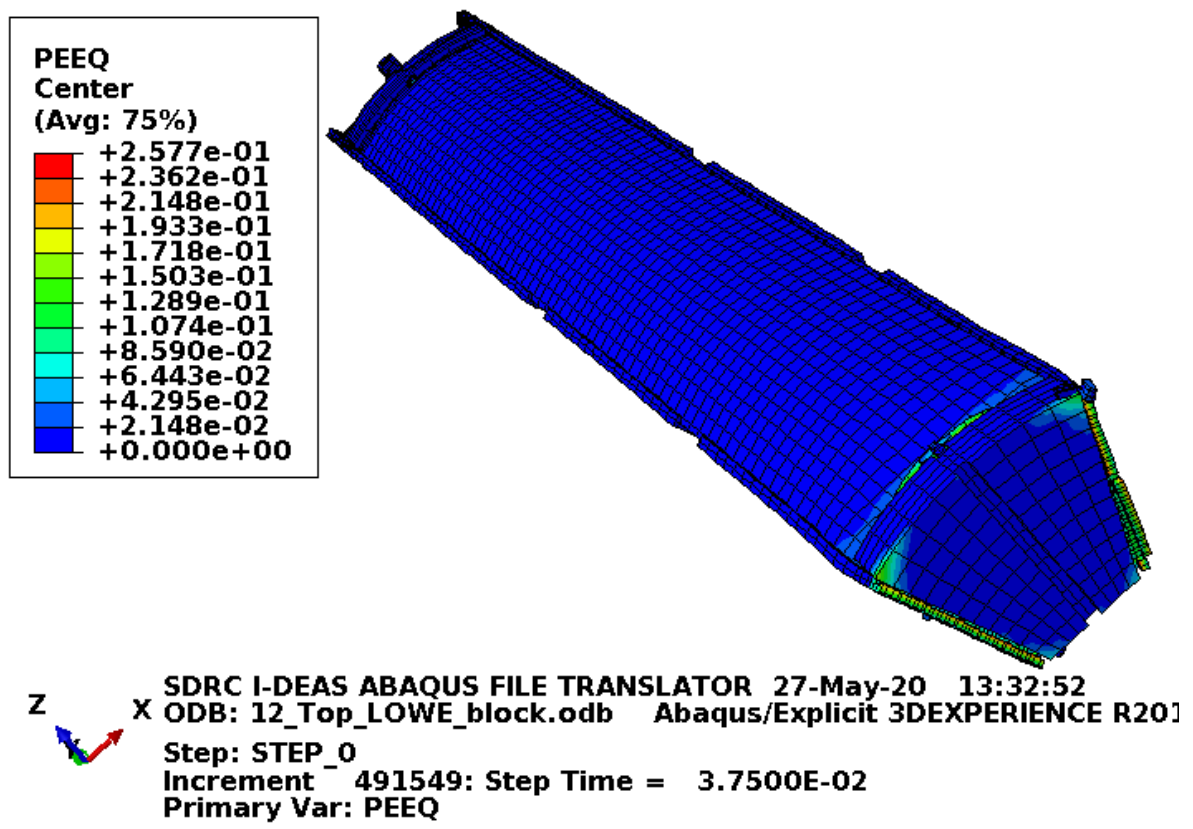

Figure D-300. Scope Part 2c (Table 3), Test 12 (Table 2) fuel element plastic equivalent strain.

Figure D-300 shows the equivalent plastic strain in the fuel element. Failure in the end box elements occurs at an equivalent plastic strain of $0.027 \mathrm{in}$./in. Failure in the end box weld elements occurs at an equivalent plastic strain of $0.032 \mathrm{in}$./in. Failure in the side plate and comb elements occurs at an equivalent plastic strain of $0.152 \mathrm{in}$./in. Failure in the side plate weld elements occurs at an equivalent plastic strain of 0.205 in./in. Figure D-300 shows nearly complete failure of the end box and end box welds nearest the impact.
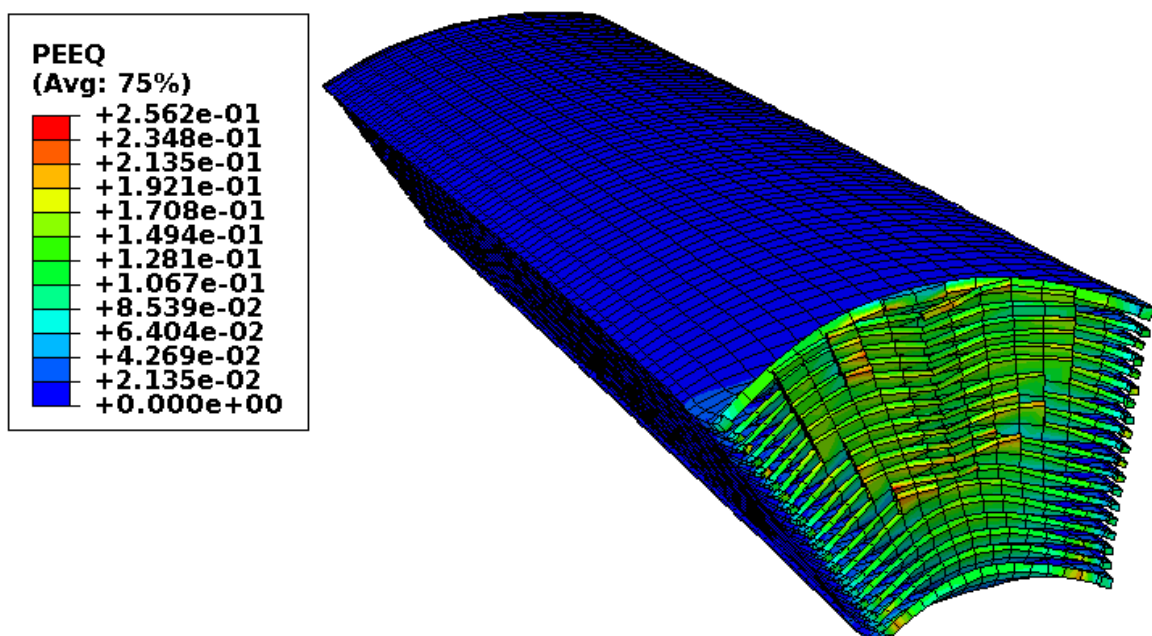

$Z$ SDRC I-DEAS ABAQUS FILE TRANSLATOR 27-May-20 13:32:52

ODB: 12_Top_LOWE_block.odb Abaqus/Explicit 3DEXPERIENCE R2018:

$X_{\text {Step: STEP_o }}$

Increment ${ }^{-}$491549: Step Time $=3.7500 \mathrm{E}-02$

Primary Var: PEEQ

Figure D-301. Scope Part 2c (Table 3), Test 12 (Table 2) fuel plate equivalent strain. 
Figure D-301 shows the equivalent plastic strain in the fuel plates. Failure in these elements occurs at an equivalent plastic strain of $0.205 \mathrm{in}$./in. Figure D-301 shows compressive failure two elements deep (about $0.41 \mathrm{in}$.) in the ends of the fuel plates which is acceptable. Additionally, a few elements at the ends of the fuel plates show strains above failure. The strains shown above the failure strain likely result from extrapolation (as integration point strains are the important strains for failure). Even if the elements with high strain were removed as being failed, the failure would be acceptable as the failed and high strained elements are far from the fuel meat.

\section{D3.9.4 Results for Scope Part 2c (Table 3), Test 12 (Table 2) Fine Mesh}

The FEA model results for the Scope Part 2c (Table 3), Test 12 (Table 2) fine mesh model are shown below in Figure D-302 to Figure D-304. The fuel element weighs $44 \mathrm{lbf}$ and the whole model is modeled with minimum material properties. This section includes the blocks as added fuel plate protection.

This model is run with a 0.9 scale factor on the time step. Results such as those in Sections D2.9.5, D3.2.1, D3.7.1, and this section showed higher strains relative to other similar model runs as though a numerical instability or odd shockwave produced unrealistically high results. In Sections D2.9.5, D3.2.1, and D3.7.1, the higher than expected strains did not produce unacceptable results so the results were given as they were produced. The model in this section was one of the models that was rerun to correct properties on two elements in the end box (discussed with Figure B-15). When rerun, there were a few extra elements that failed away from the vicinity of the modified elements. Consequently, the model was rerun with a 0.9 scale factor on the time step. This model again produced results like the original model run and is documented in this section. 


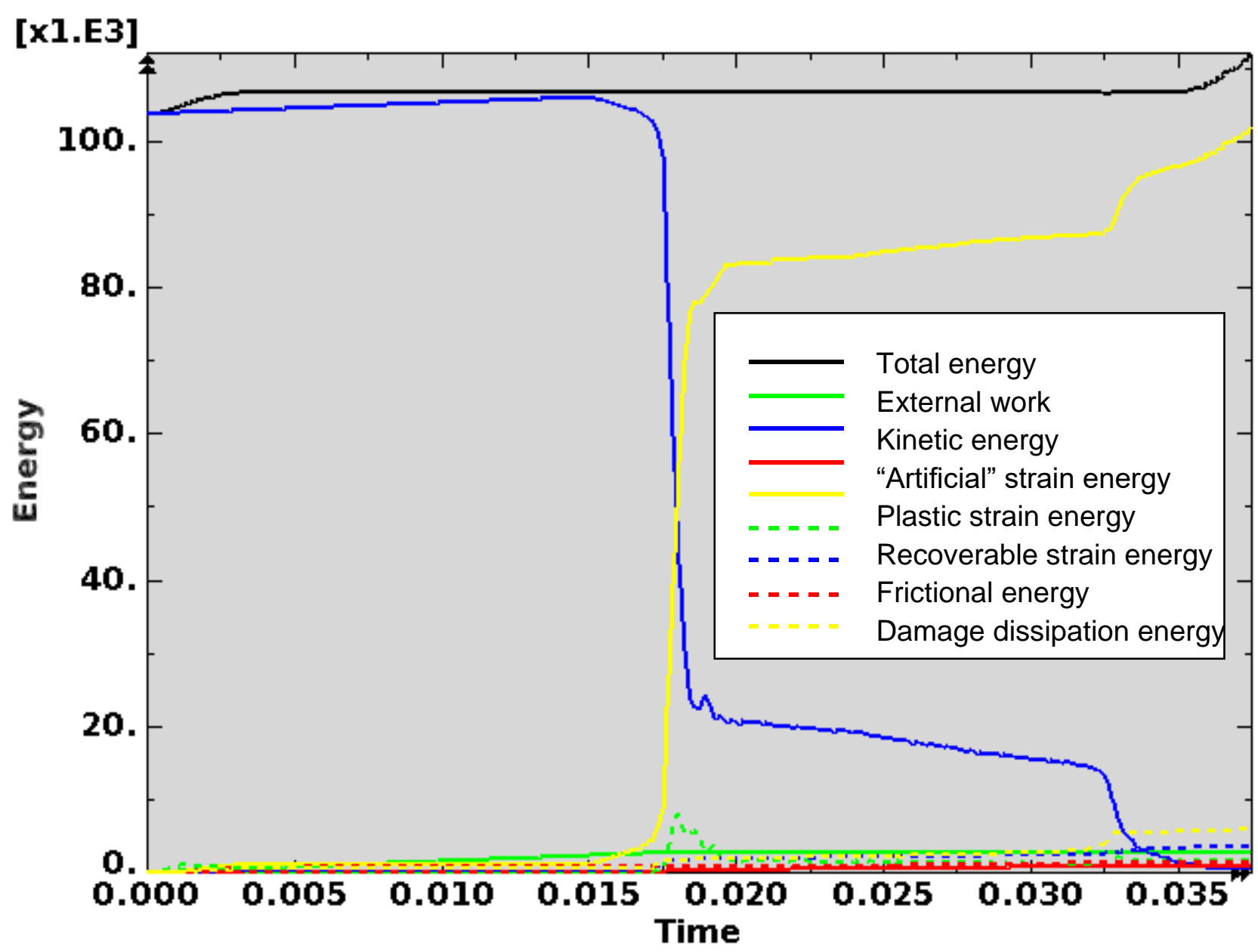

Figure D-302. Scope Part 2c (Table 3), Test 12 (Table 2) fine mesh energy curves.

Figure D-302 shows the energy curves for Scope Part 2c (Table 3), Test 12 (Table 2) fine mesh drop scenario. These curves exhibit mostly stable behavior. Near the end of the model run, the total energy and plastic strain energy start to show undesirable behavior. As discussed in Section D3.5 this appears to result from contact difficultly between failed portions of the fuel element. Consequently, output is shown at the first output frame after fuel element rebound $(0.0375$ second) to try to minimize potential error associated with this. The results are considered reasonable and conservative considering that the results compared with physical drops (see Section D2.5) had more of an energy rise and still produced reasonable and conservative results.

Artificial strain energy represents the energy required to keep reduced integration elements from taking on a zero-energy hourglass shape. As shown in Figure D-302, the artificial energy at the end of the model run is $0.9 \%$ of the total energy. Therefore, the potential error associated with artificial energy is not considered to be significant. 
ENGINEERING CALCULATIONS AND ANALYSIS

Drop Analysis of the Advanced Test Reactor Fresh Fuel Shipping Container with Heavier Low-Enriched Uranium Fuel Contents
ECAR-5224, Rev. 0

Page D267 of D293

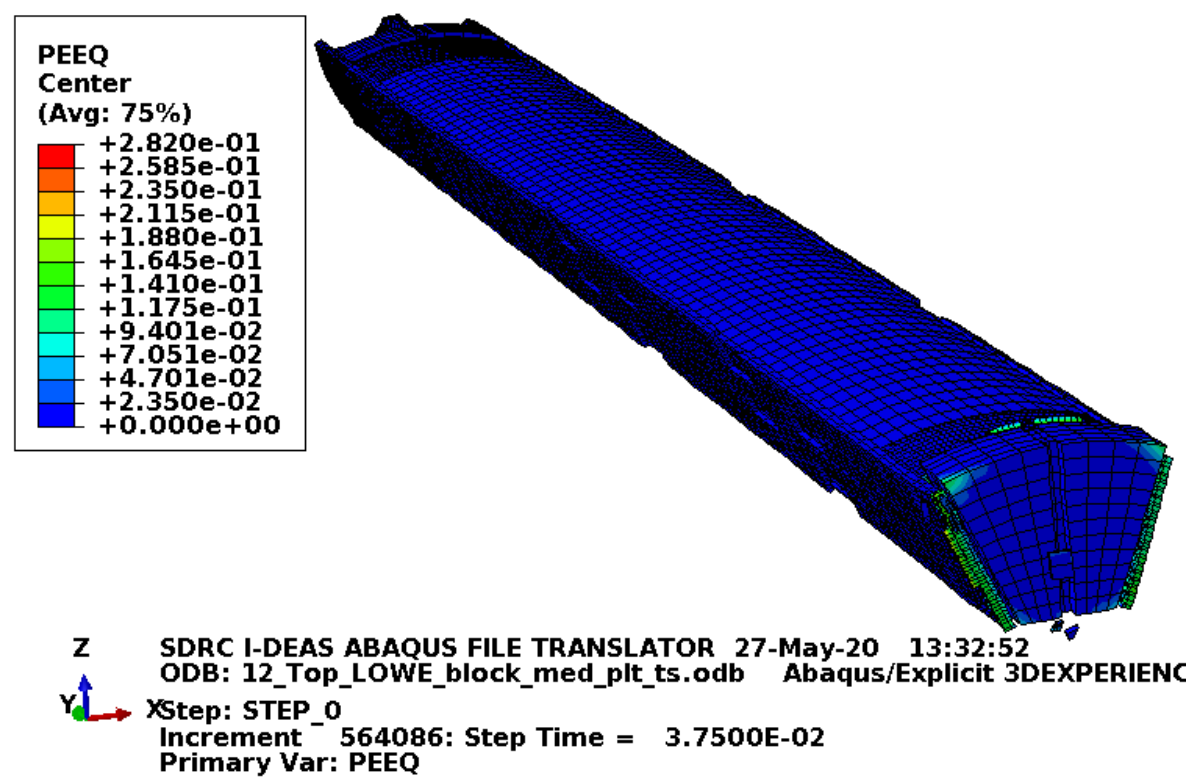

Figure D-303. Scope Part 2c (Table 3), Test 12 (Table 2) fine mesh fuel element plastic equivalent strain.

Figure D-303 shows the equivalent plastic strain in the fuel element. Failure in the end box elements occurs at an equivalent plastic strain of $0.027 \mathrm{in}$./in. Failure in the end box weld elements occurs at an equivalent plastic strain of $0.032 \mathrm{in}$./in. Failure in the side plate and comb elements occurs at an equivalent plastic strain of $0.152 \mathrm{in}$./in. Failure in the side plate weld elements occurs at an equivalent plastic strain of 0.205 in./in. Figure D-303 shows nearly complete failure of the end box and end box welds nearest the impact.
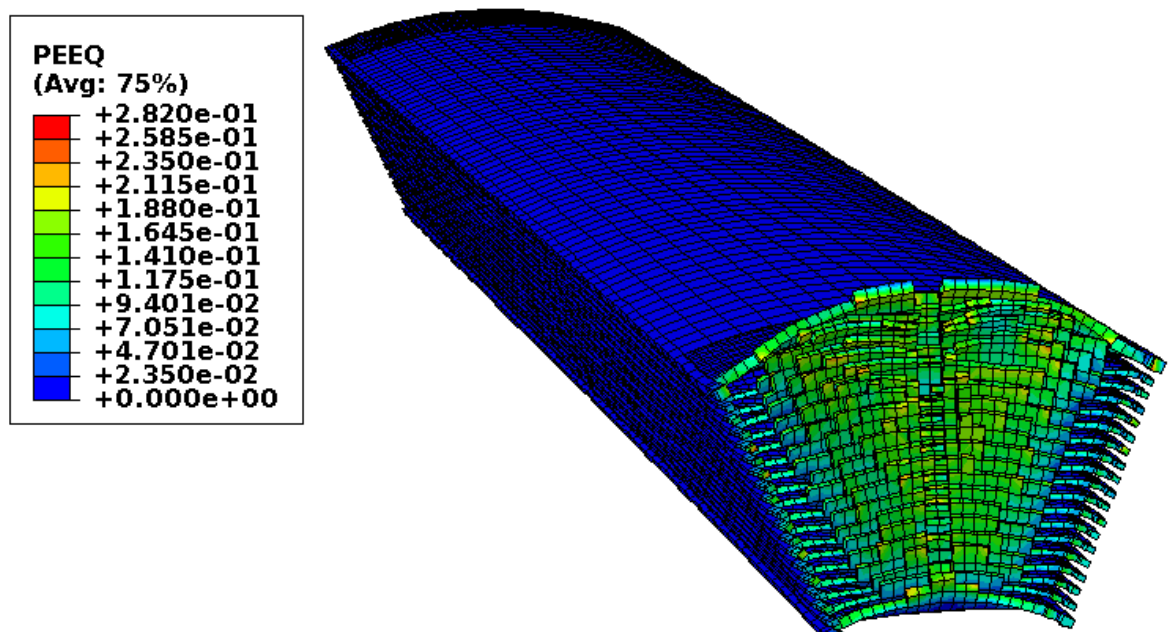

$Z$ SDRC I-DEAS ABAQUS FILE TRANSLATOR 27-May-20 13:32:52

ODB: 12_Top_LOWE_block_med_plt_ts.odb Abaqus/Explicit 3DEXPERIEN

$\checkmark$ XStep: STEP_o

XStep: STEP_O

Primary Var: PEEQ

Figure D-304. Scope Part 2c (Table 3), Test 12 (Table 2) fine mesh fuel plate equivalent strain. 
Figure D-304 shows the equivalent plastic strain in the fuel plates. Failure in these elements occurs at an equivalent plastic strain of $0.205 \mathrm{in}$./in. Figure D-304 shows compressive failure to the fuel meat in the ends of the fuel plates. Additionally, a few elements at the end of the fuel plates show strains above failure. The strains shown above the failure strain likely result from extrapolation (as integration point strains are the important strains for failure). Even if the elements with high strain were removed as being failed, the failure would be acceptable as the failed and high strained elements do not represent fuel meat.

\section{D3.9.5 Results for Scope Part 2d (Table 3), Test 12 (Table 2)}

The FEA model results for the Scope Part 2d (Table 3), Test 12 (Table 2) model are shown below in Figure D-305 to Figure D-307. The fuel element weighs $44 \mathrm{lbf}$ and the drop scenario is modeled with minimum material properties except the enclosure and end boxes, which are modeled with relatively tough material properties. This section includes the blocks as added fuel plate protection.

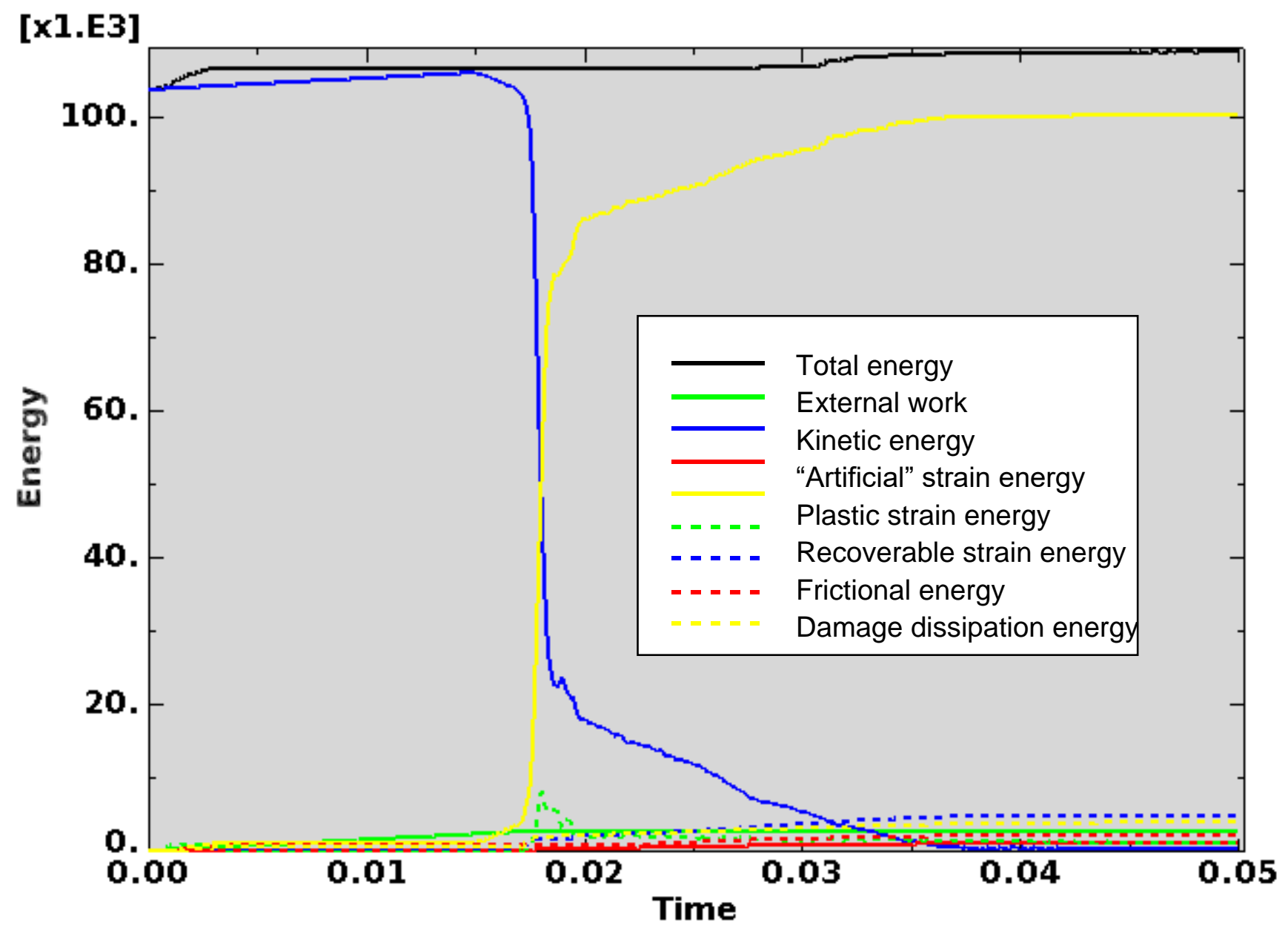

Figure D-305. Scope Part 2d (Table 3), Test 12 (Table 2) energy curves. 
Figure D-305 shows the energy curves for Scope Part 2d (Table 3), Test 12 (Table 2) drop scenario. These curves exhibit mostly stable behavior. When significant fuel element damage occurs, the total energy and plastic strain energy show some undesirable behavior. As discussed in Section D3.5 this appears to result from contact difficultly between failed portions of the fuel element. The results are considered reasonable and conservative considering that the results compared with physical drops (see Section D2.5) had more of an energy rise and still produced reasonable and conservative results. The model results are given at the end of the model run.

Artificial strain energy represents the energy required to keep reduced integration elements from taking on a zero-energy hourglass shape. As shown in Figure D-305, the artificial energy at the end of the model run is $1.0 \%$ of the total energy. Therefore, the potential error associated with artificial energy is not considered to be significant.

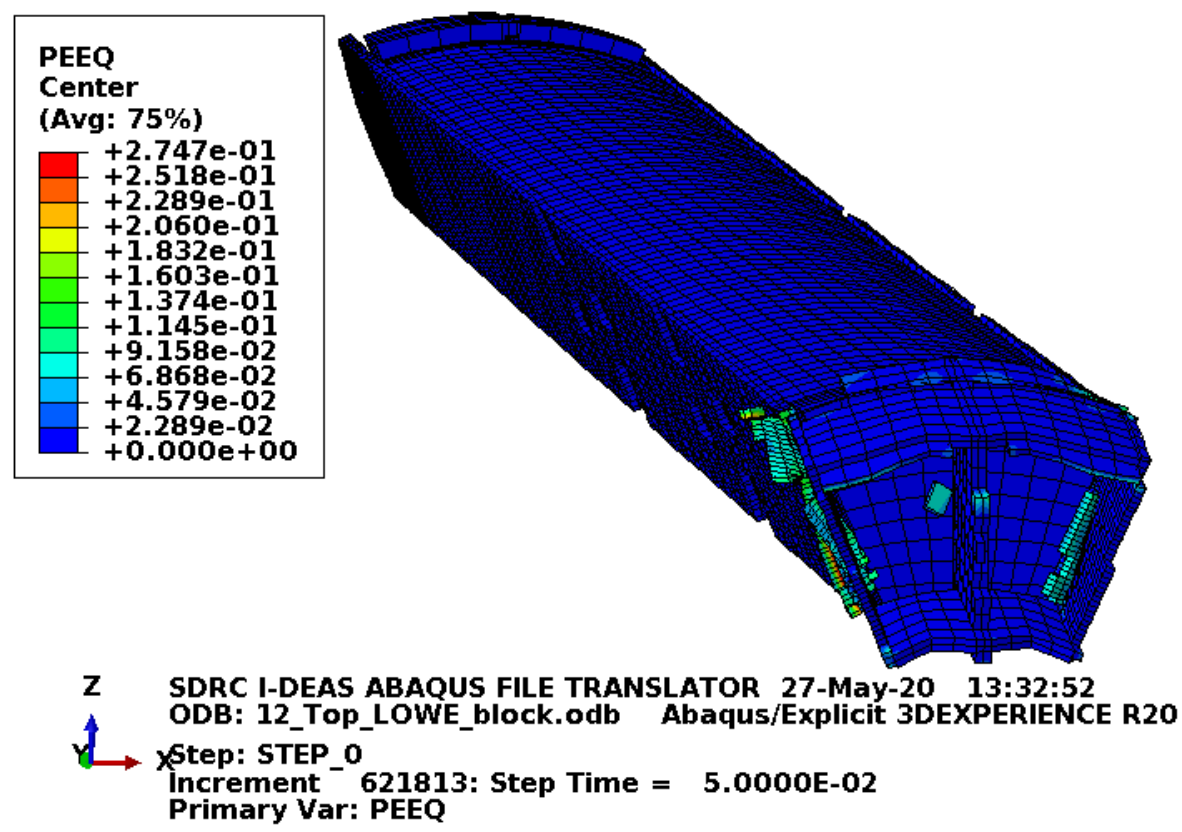

Figure D-306. Scope Part 2d (Table 3), Test 12 (Table 2) fuel element plastic equivalent strain.

Figure D-306 shows the equivalent plastic strain in the fuel element. Failure in the end box elements occurs at an equivalent plastic strain of $0.08 \mathrm{in./in.} \mathrm{(for} \mathrm{the} \mathrm{relatively} \mathrm{tough} \mathrm{material} \mathrm{properties).} \mathrm{Failure} \mathrm{in} \mathrm{the} \mathrm{end}$ box weld elements occurs at an equivalent plastic strain of $0.115 \mathrm{in}$./in. (for the relatively tough material properties). Failure in the side plate and comb elements occurs at an equivalent plastic strain of $0.152 \mathrm{in}$./in. Failure in the side plate weld elements occurs at an equivalent plastic strain of 0.205 in./in. Figure D-306 shows significant failure in the end box nearest the impacted surface. Also, the end box welds failed sufficiently to free the end box from the rest of the fuel element. However, the block prevents the end box from impacting the fuel plates. 
ENGINEERING CALCULATIONS AND ANALYSIS

Drop Analysis of the Advanced Test Reactor Fresh Fuel Shipping Container with Heavier Low-Enriched Uranium Fuel Contents
ECAR-5224, Rev. 0

Page D270 of D293

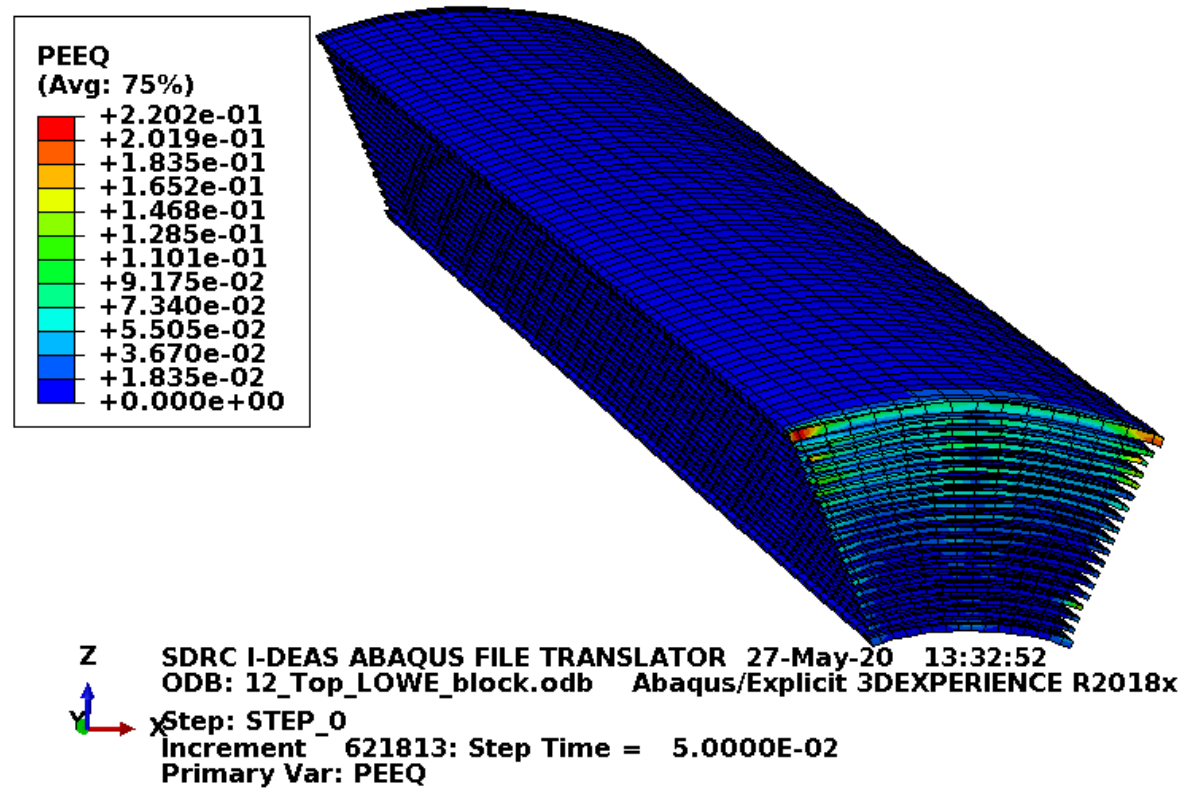

Figure D-307. Scope Part 2d (Table 3), Test 12 (Table 2) fuel plate equivalent strain.

Figure D-307 shows the equivalent plastic strain in the fuel plates. Failure in these elements occurs at an equivalent plastic strain of $0.205 \mathrm{in}$./in. Figure D-307 shows compressive failure in a few places, one element deep (about $0.15 \mathrm{in}$.). Additionally, a couple elements at the end of one fuel plate show strains above failure. The strains shown above the failure strain likely result from extrapolation (as integration point strains are the important strains for failure). Even if the elements with high strain were removed as being failed, the failure would be acceptable as the failed and high strained elements are far from the fuel meat.

\section{D3.9.6 Results for Scope Part 2d (Table 3), Test 12 (Table 2) Fine Mesh}

The FEA model results for the Scope Part 2d (Table 3), Test 12 (Table 2) fine mesh model are shown below in Figure D-308 to Figure D-310. The fuel element weighs $44 \mathrm{lbf}$ and the drop scenario is modeled with minimum material properties except the enclosure and end boxes, which are modeled with relatively tough material properties. This section includes the blocks as added fuel plate protection. 


\section{[X1.E3]}

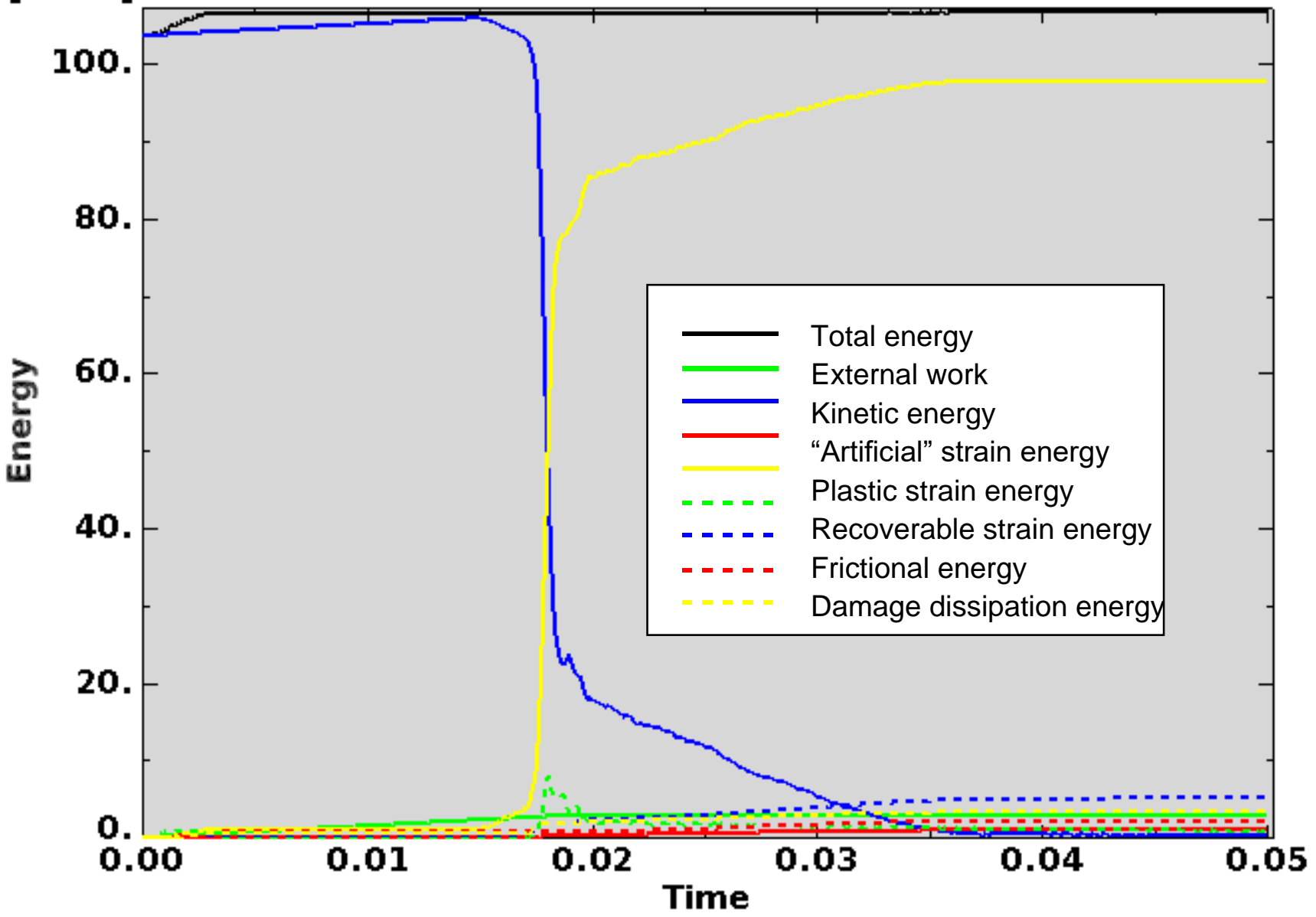

Figure D-308. Scope Part 2d (Table 3), Test 12 (Table 2) fine mesh energy curves.

Figure D-308 shows the energy curves for Scope Part 2d (Table 3), Test 12 (Table 2) fine mesh drop scenario. These curves exhibit a stable shape. Artificial strain energy represents the energy required to keep reduced integration elements from taking on a zero-energy hourglass shape. As shown in Figure D-308, the artificial energy at the end of the model run is $1.0 \%$ of the total energy. Therefore, the potential error associated with artificial energy is not considered to be significant. 
ENGINEERING CALCULATIONS AND ANALYSIS

Drop Analysis of the Advanced Test Reactor Fresh Fuel Shipping Container with Heavier Low-Enriched Uranium Fuel Contents
ECAR-5224, Rev. 0

Page D272 of D293

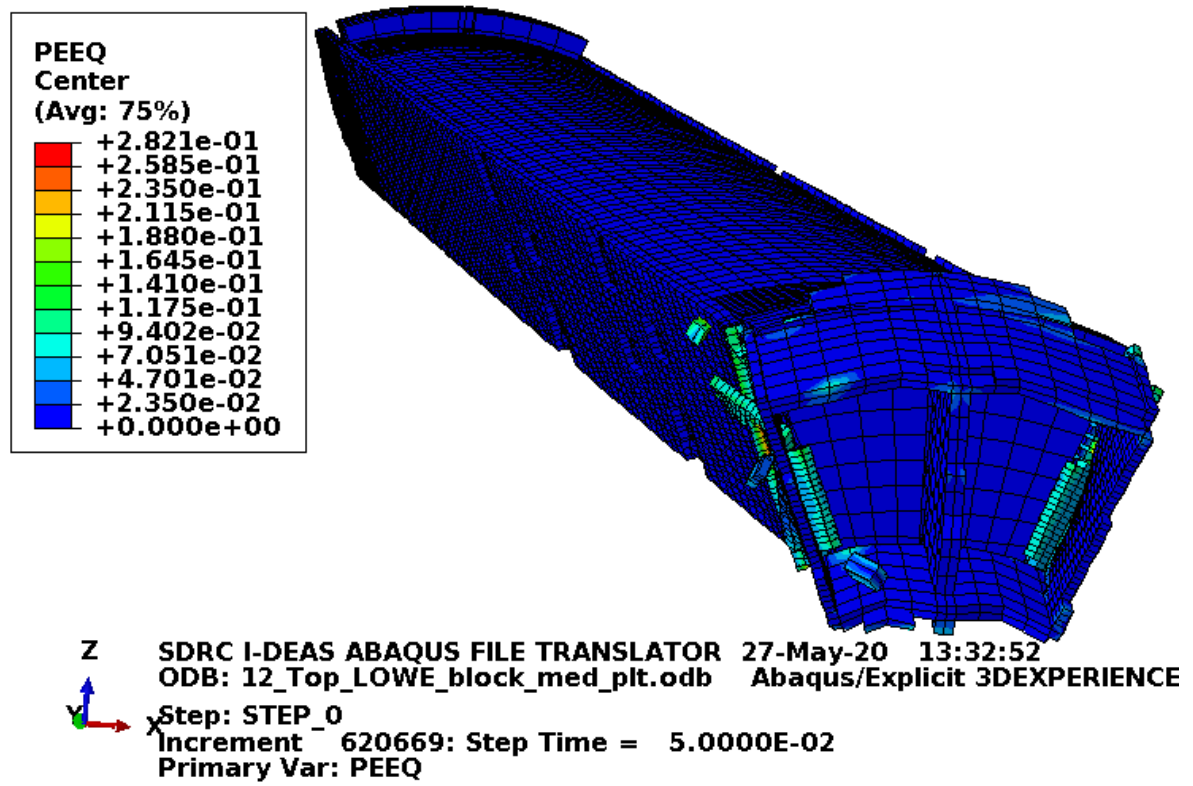

Figure D-309. Scope Part 2d (Table 3), Test 12 (Table 2) fine mesh fuel element plastic equivalent strain.

Figure D-309 shows the equivalent plastic strain in the fuel element. Failure in the end box elements occurs at an equivalent plastic strain of $0.08 \mathrm{in./in.} \mathrm{(for} \mathrm{the} \mathrm{relatively} \mathrm{tough} \mathrm{material} \mathrm{properties).} \mathrm{Failure} \mathrm{in} \mathrm{the} \mathrm{end}$ box weld elements occurs at an equivalent plastic strain of $0.115 \mathrm{in}$./in. (for the relatively tough material properties). Failure in the side plate and comb elements occurs at an equivalent plastic strain of 0.152 in./in. Failure in the side plate weld elements occurs at an equivalent plastic strain of $0.205 \mathrm{in}$./in. Figure D-309 shows significant failure in the end box nearest the impacted surface. Also, the end box welds failed sufficiently to free the end box from the rest of the fuel element. However, the block prevents the end box from impacting the fuel plates.

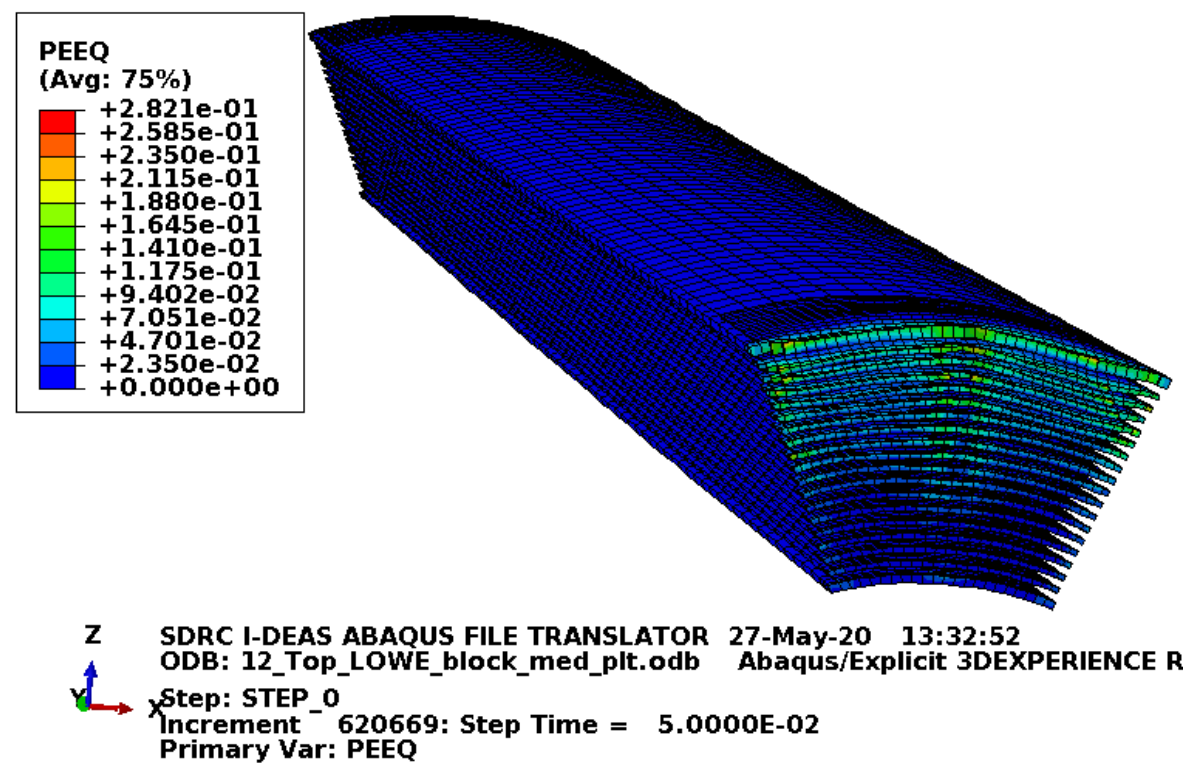

Figure D-310. Scope Part 2d (Table 3), Test 12 (Table 2) fine mesh fuel plate equivalent strain. 
Figure D-310 shows the equivalent plastic strain in the fuel plates. Failure in these elements occurs at an equivalent plastic strain of $0.205 \mathrm{in}$./in. Figure D-310 shows compressive failure two elements deep (about $0.22 \mathrm{in}$.) in the ends of a few fuel plates. Additionally, a few elements at the ends of the fuel plates show strains above failure. The strains shown above the failure strain likely result from extrapolation (as integration point strains are the important strains for failure). Even if the elements with high strain were removed as being failed, the failure would be acceptable as the failed and high strained elements are far from the fuel meat.

\section{D3.10 Results for Scope Part 2 (Table 3), Test 13 (Table 2)}

The drop scenario considered in this section is a $30 \mathrm{ft}$ drop modeled as a flat side drop on an edge.

\section{D3.10.1 Results for Scope Part 2a (Table 3), Test 13 (Table 2)}

The FEA model results for the Scope Part 2a (Table 3), Test 13 (Table 2) model are shown below in Figure D-311 to Figure D-313. The fuel element weighs $44 \mathrm{lbf}$ and the whole model is modeled with minimum material properties.

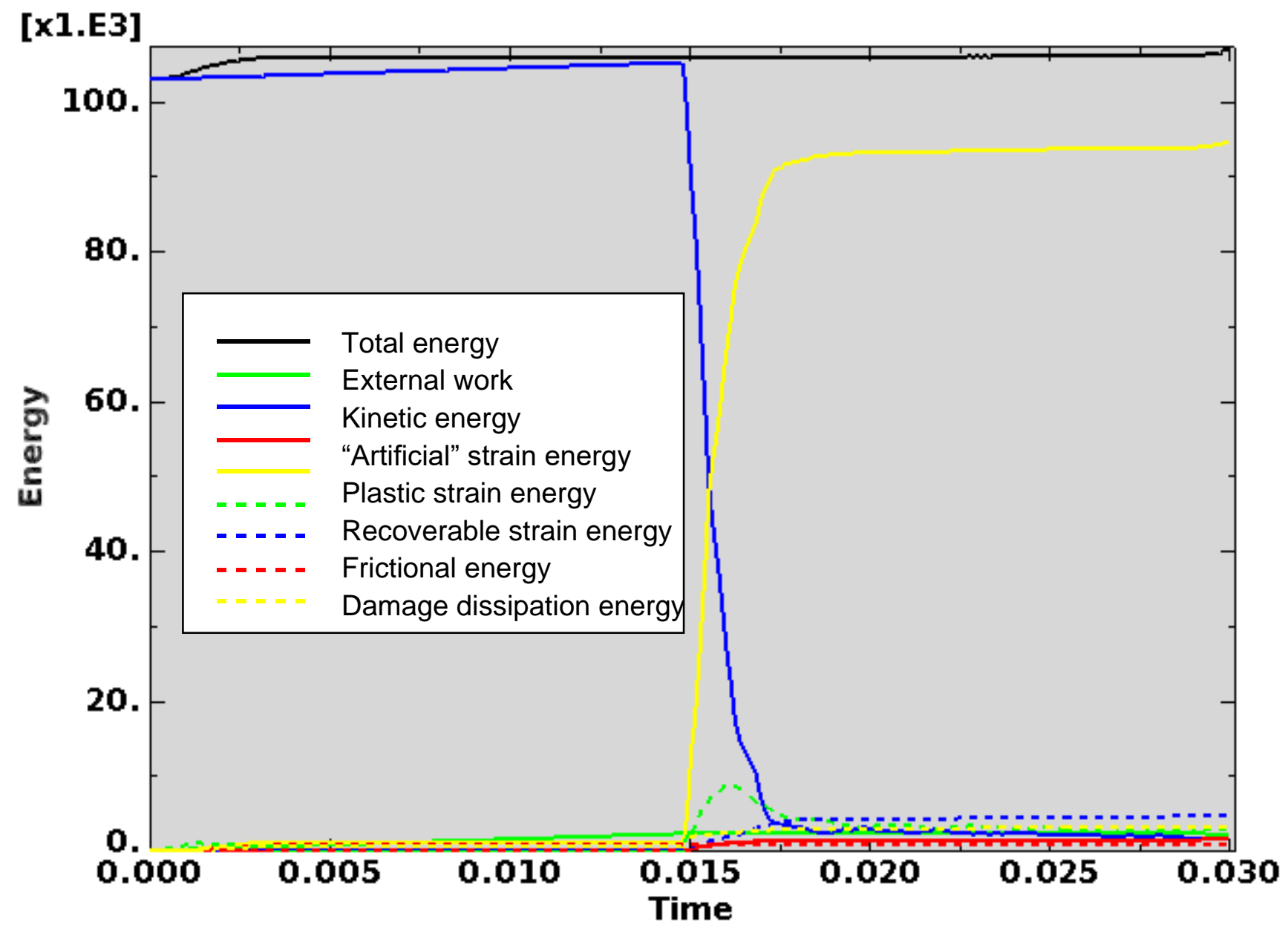

Figure D-311. Scope Part 2a (Table 3), Test 13 (Table 2) energy curves. 
Figure D-311 shows the energy curves for Scope Part 2a (Table 3), Test 13 (Table 2) drop scenario. These curves exhibit a stable shape. Artificial strain energy represents the energy required to keep reduced integration elements from taking on a zero-energy hourglass shape. As shown in Figure D-311, the artificial energy at the end of the model run is $1.4 \%$ of the total energy. Therefore, the potential error associated with artificial energy is not considered to be significant.

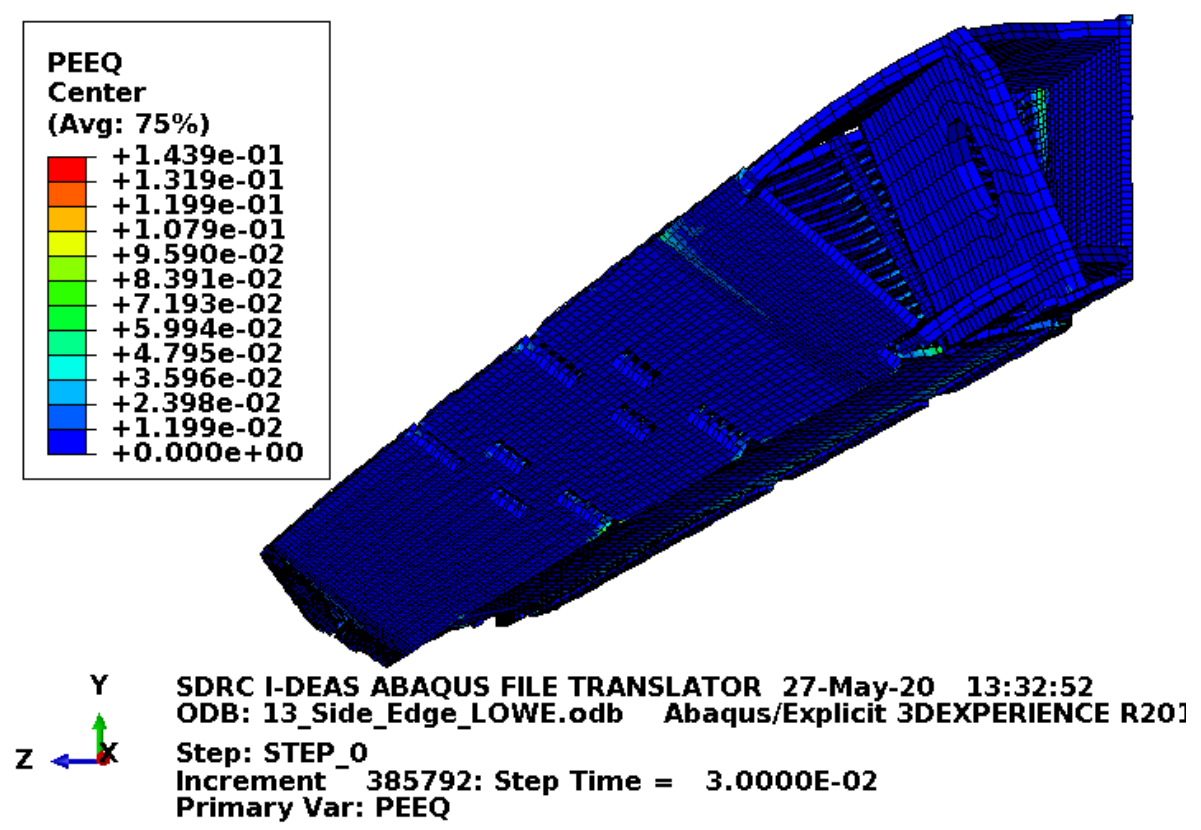

Figure D-312. Scope Part 2a (Table 3), Test 13 (Table 2) fuel element plastic equivalent strain.

Figure D-312 shows the equivalent plastic strain in the fuel element. Failure in the end box elements occurs at an equivalent plastic strain of $0.027 \mathrm{in.} / \mathrm{in}$. Failure in the end box weld elements occurs at an equivalent plastic strain of $0.032 \mathrm{in}$./in. Failure in the side plate and comb elements occurs at an equivalent plastic strain of $0.152 \mathrm{in./in.} \mathrm{Failure} \mathrm{in} \mathrm{the} \mathrm{side} \mathrm{plate} \mathrm{weld} \mathrm{elements} \mathrm{occurs} \mathrm{at} \mathrm{an} \mathrm{equivalent} \mathrm{plastic} \mathrm{strain} \mathrm{of}$ 0.205 in./in. Figure D-312 shows some end box failure. 
ENGINEERING CALCULATIONS AND ANALYSIS

Drop Analysis of the Advanced Test Reactor Fresh Fuel Shipping Container with Heavier Low-Enriched Uranium Fuel Contents

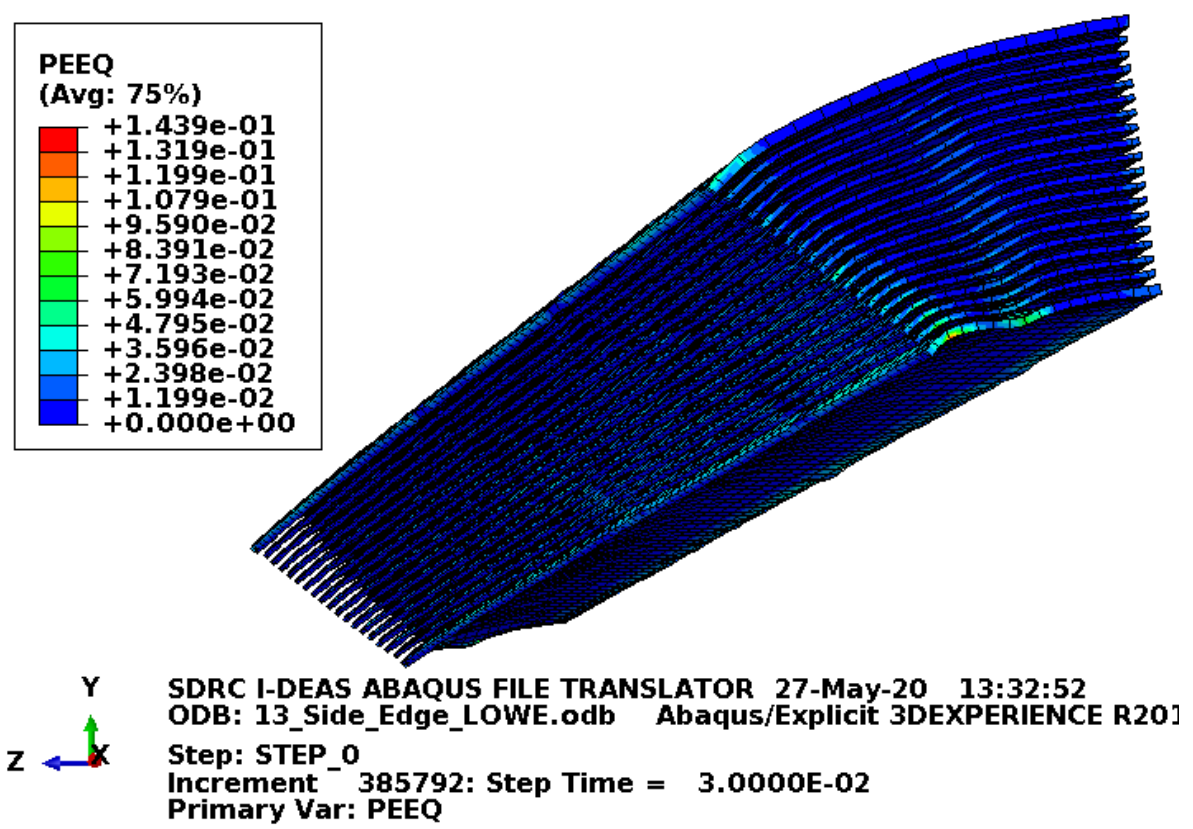

Figure D-313. Scope Part 2a (Table 3), Test 13 (Table 2) fuel plate equivalent strain.

Figure D-313 shows the equivalent plastic strain in the fuel plates. Failure in these elements occurs at an equivalent plastic strain of $0.205 \mathrm{in}$./in. Figure D-313 shows no failure in the fuel plates with margin.

\section{D3.10.2 Results for Scope Part 2b (Table 3), Test 13 (Table 2)}

The FEA model results for the Scope Part $2 b$ (Table 3), Test 13 (Table 2) model are shown below in Figure D-314 to Figure D-316. The fuel element weighs $44 \mathrm{lbf}$ and the drop scenario is modeled with minimum material properties except the enclosure and end boxes, which are modeled with relatively tough material properties. 


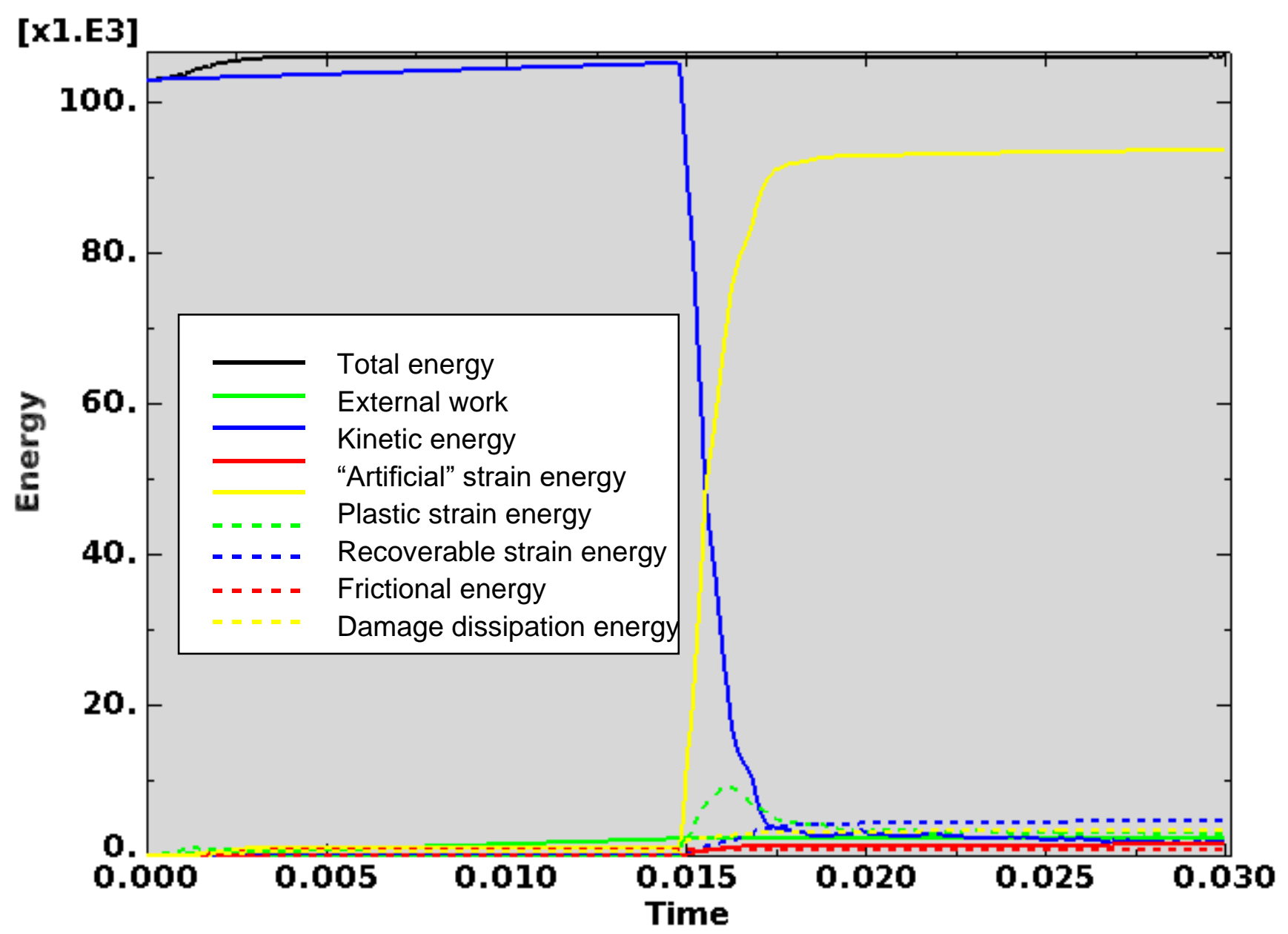

Figure D-314. Scope Part 2b (Table 3), Test 13 (Table 2) energy curves.

Figure D-314 shows the energy curves for Scope Part 2b (Table 3), Test 13 (Table 2) drop scenario. These curves exhibit a stable shape. Artificial strain energy represents the energy required to keep reduced integration elements from taking on a zero-energy hourglass shape. As shown in Figure D-314, the artificial energy at the end of the model run is $1.4 \%$ of the total energy. Therefore, the potential error associated with artificial energy is not considered to be significant. 
ENGINEERING CALCULATIONS AND ANALYSIS

Drop Analysis of the Advanced Test Reactor Fresh Fuel Shipping Container with Heavier Low-Enriched Uranium Fuel Contents
ECAR-5224, Rev. 0

Page D277 of D293

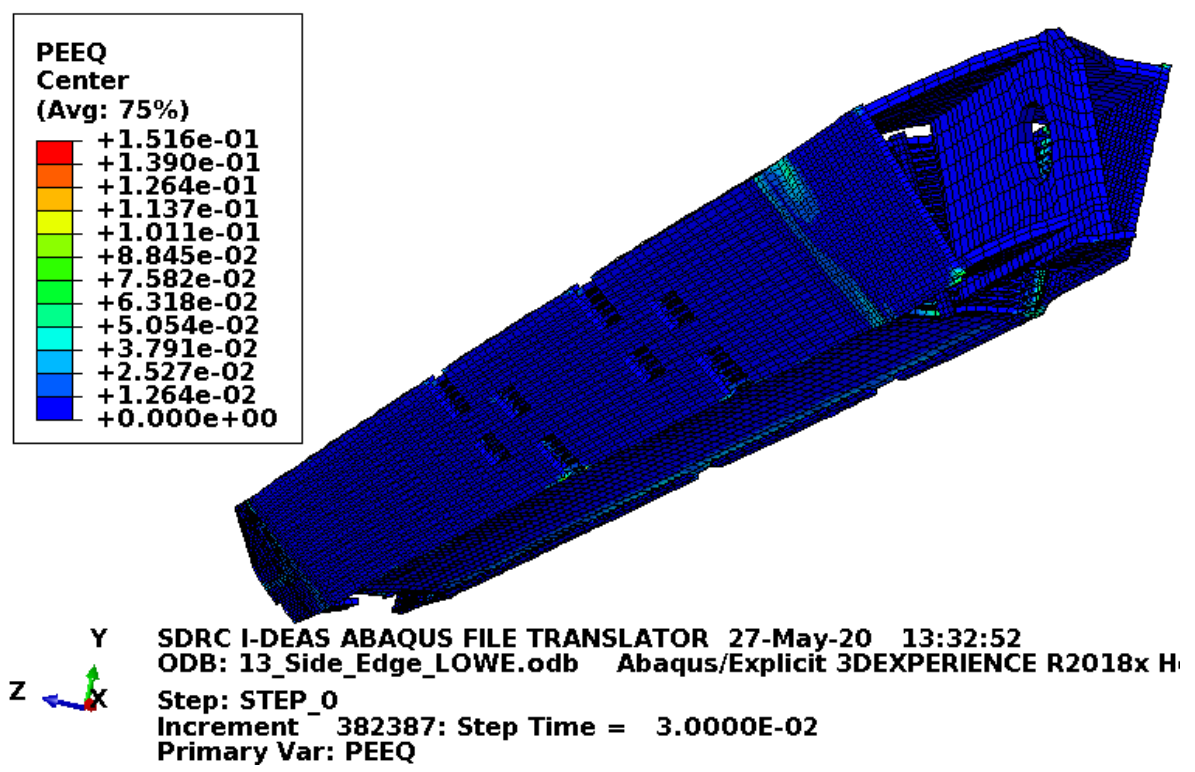

Figure D-315. Scope Part 2b (Table 3), Test 13 (Table 2) fuel element plastic equivalent strain.

Figure D-315 shows the equivalent plastic strain in the fuel element. Failure in the end box elements occurs at an equivalent plastic strain of $0.08 \mathrm{in}$./in. (for the relatively tough material properties). Failure in the end box weld elements occurs at an equivalent plastic strain of $0.115 \mathrm{in}$./in. (for the relatively tough material properties). Failure in the side plate and comb elements occurs at an equivalent plastic strain of $0.152 \mathrm{in}$./in. Failure in the side plate weld elements occurs at an equivalent plastic strain of $0.205 \mathrm{in}$./in. Figure D-315 shows minimal end box failure.

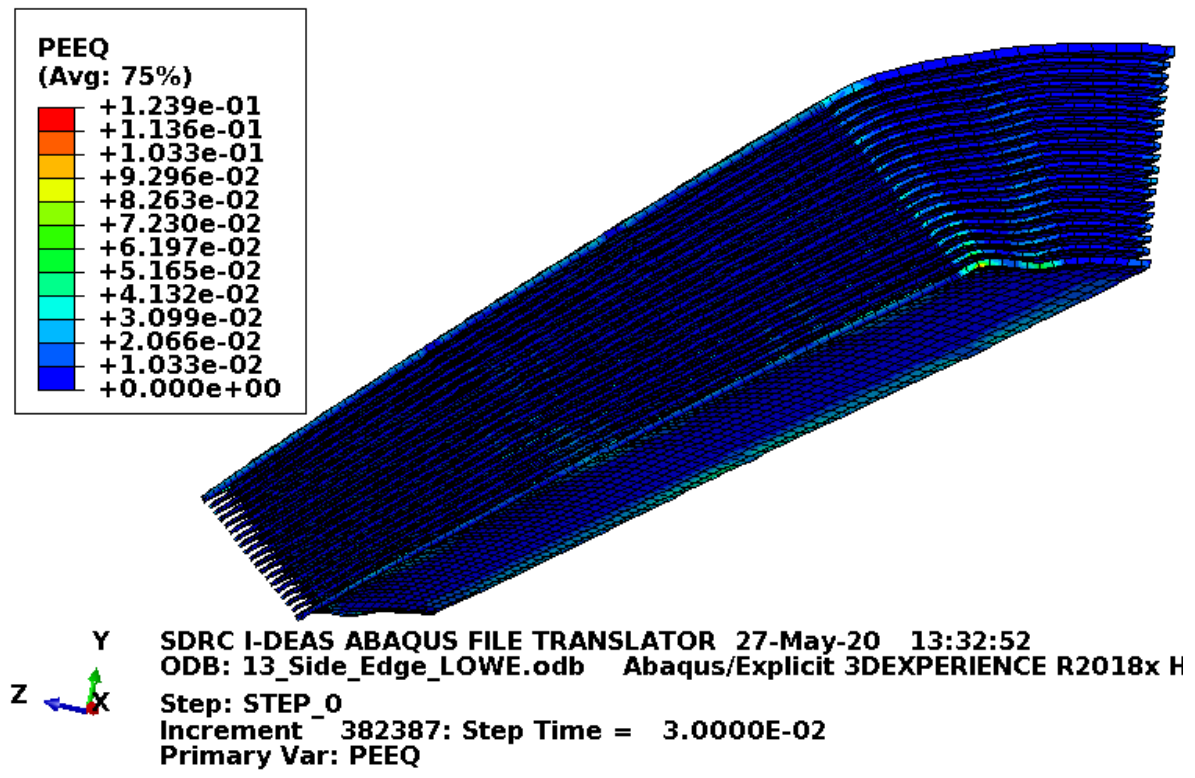

Figure D-316. Scope Part 2b (Table 3), Test 13 (Table 2) fuel plate equivalent strain.

Figure D-316 shows the equivalent plastic strain in the fuel plates. Failure in these elements occurs at an equivalent plastic strain of $0.205 \mathrm{in}$./in. Figure D-316 shows no failure in the fuel plates with margin. 


\section{D3.10.3 Results for Scope Part 2c (Table 3), Test 13 (Table 2)}

The FEA model results for the Scope Part 2c (Table 3), Test 13 (Table 2) model are shown below in Figure D-317 to Figure D-319. The fuel element weighs $44 \mathrm{lbf}$ and the whole model is modeled with minimum material properties. This section includes the blocks as added fuel plate protection.

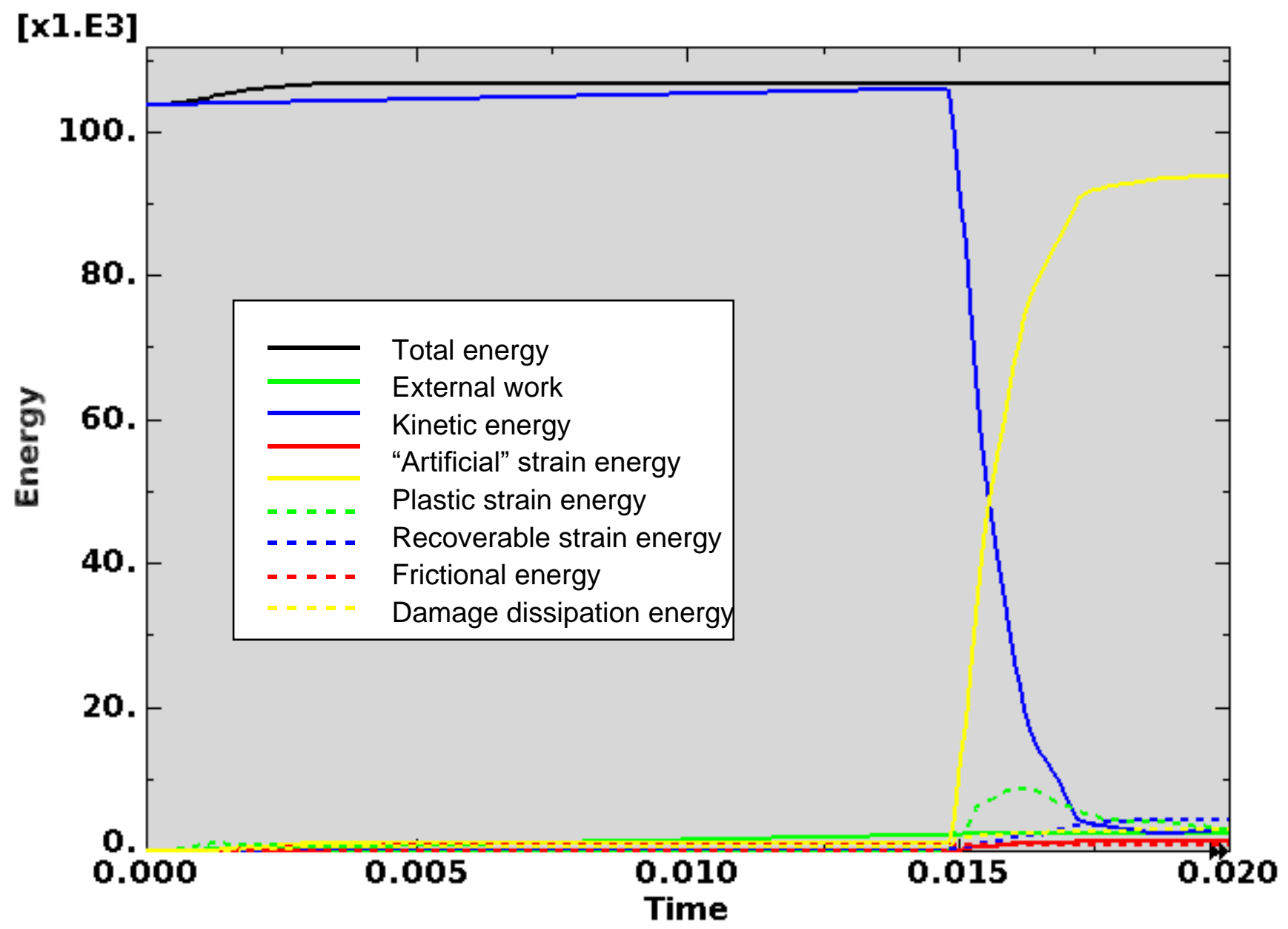

Figure D-317. Scope Part 2c (Table 3), Test 13 (Table 2) energy curves.

Figure D-317 shows the energy curves for Scope Part 2c (Table 3), Test 13 (Table 2) drop scenario. These curves exhibit stable behavior. The original model run was performed for 0.03 seconds and a small amount of undesirable rise in total energy and plastic strain energy did occur near the end. However, rebound has occurred at 0.02 seconds and the curves are stable. Consequently, output is given at 0.02 seconds.

Artificial strain energy represents the energy required to keep reduced integration elements from taking on a zero-energy hourglass shape. As shown in Figure D-317, the artificial energy at the end of the model run is $1.3 \%$ of the total energy. Therefore, the potential error associated with artificial energy is not considered to be significant. 
ENGINEERING CALCULATIONS AND ANALYSIS

Drop Analysis of the Advanced Test Reactor Fresh Fuel Shipping Container with Heavier Low-Enriched Uranium Fuel Contents
ECAR-5224, Rev. 0

Page D279 of D293

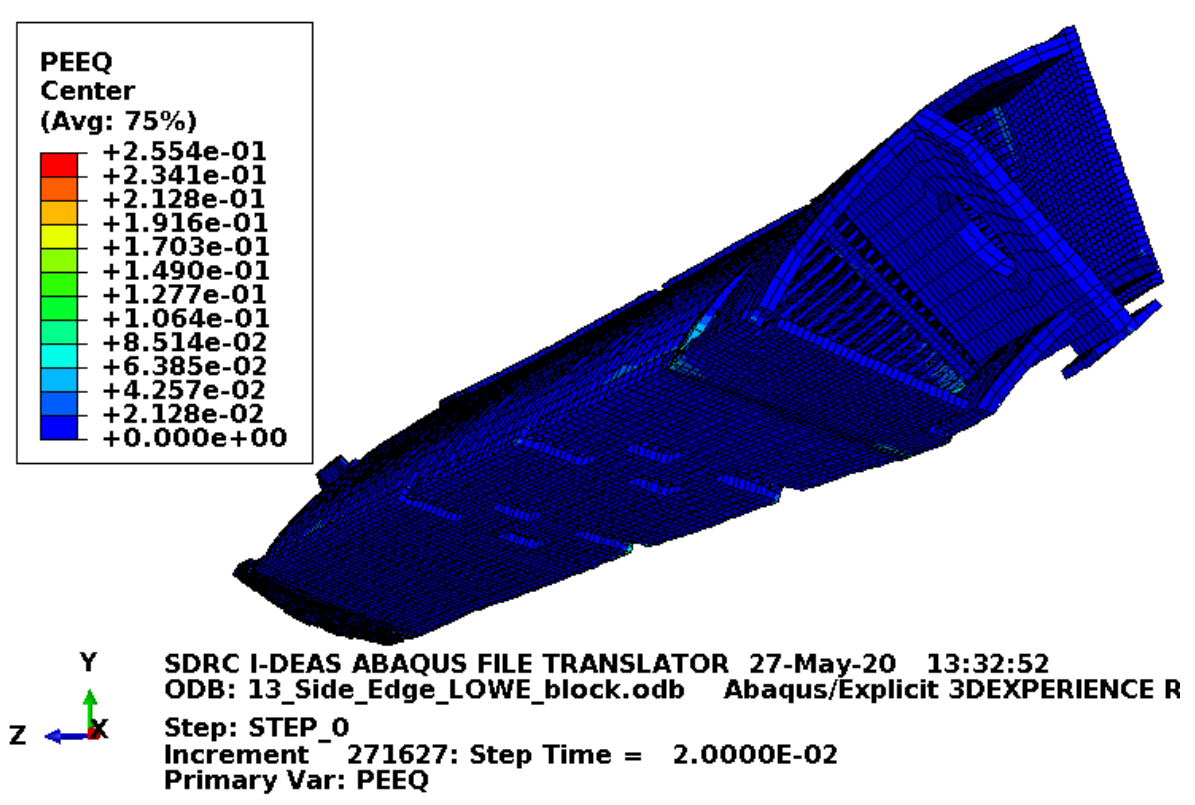

Figure D-318. Scope Part 2c (Table 3), Test 13 (Table 2) fuel element plastic equivalent strain.

Figure D-318 shows the equivalent plastic strain in the fuel element. Failure in the end box elements occurs at an equivalent plastic strain of $0.027 \mathrm{in}$./in. Failure in the end box weld elements occurs at an equivalent plastic strain of $0.032 \mathrm{in}$./in. Failure in the side plate and comb elements occurs at an equivalent plastic strain of $0.152 \mathrm{in./in.} \mathrm{Failure} \mathrm{in} \mathrm{the} \mathrm{side} \mathrm{plate} \mathrm{weld} \mathrm{elements} \mathrm{occurs} \mathrm{at} \mathrm{an} \mathrm{equivalent} \mathrm{plastic} \mathrm{strain} \mathrm{of}$ 0.205 in./in. Figure D-318 shows some end box failure.

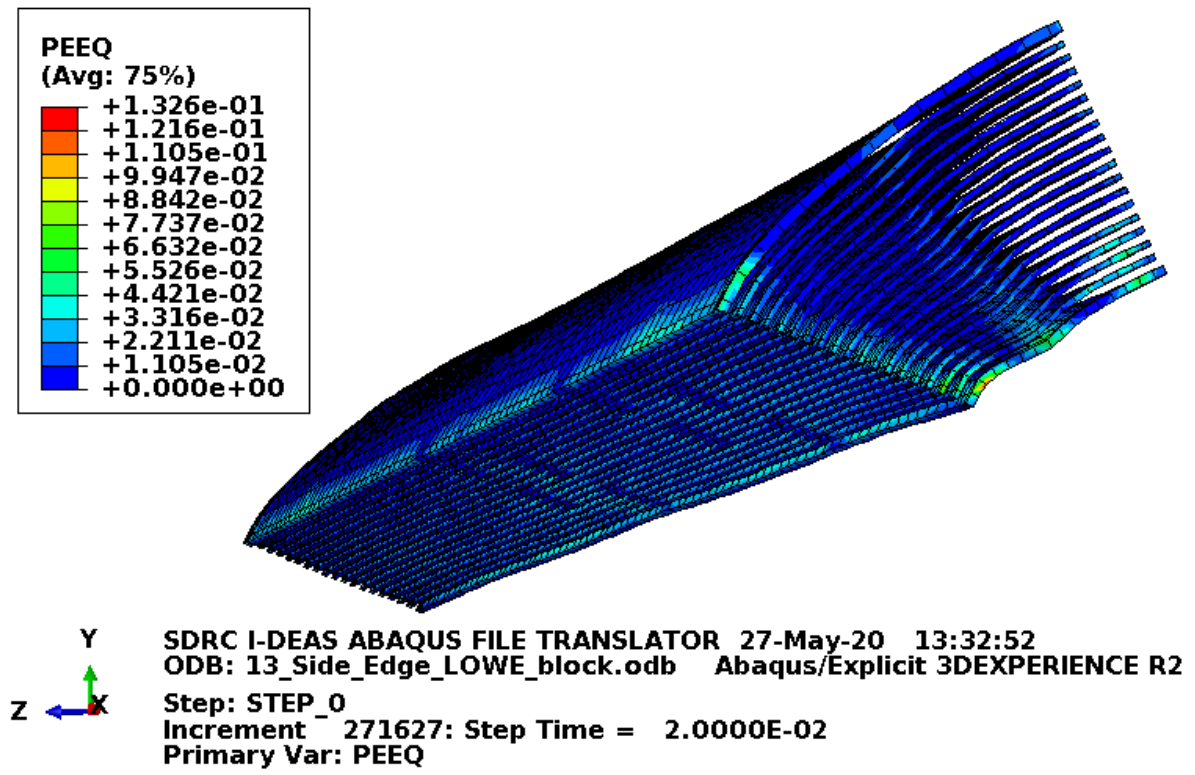

Figure D-319. Scope Part 2c (Table 3), Test 13 (Table 2) fuel plate equivalent strain.

Figure D-319 shows the equivalent plastic strain in the fuel plates. Failure in these elements occurs at an equivalent plastic strain of 0.205 in./in. Figure D-319 shows no failure in the fuel plates with margin. 


\section{D3.10.4 Results for Scope Part 2d (Table 3), Test 13 (Table 2)}

The FEA model results for the Scope Part 2d (Table 3), Test 13 (Table 2) model are shown below in Figure D-320 to Figure D-322. The fuel element weighs $44 \mathrm{lbf}$ and the drop scenario is modeled with minimum material properties except the enclosure and end boxes, which are modeled with relatively tough material properties. This section includes the blocks as added fuel plate protection.

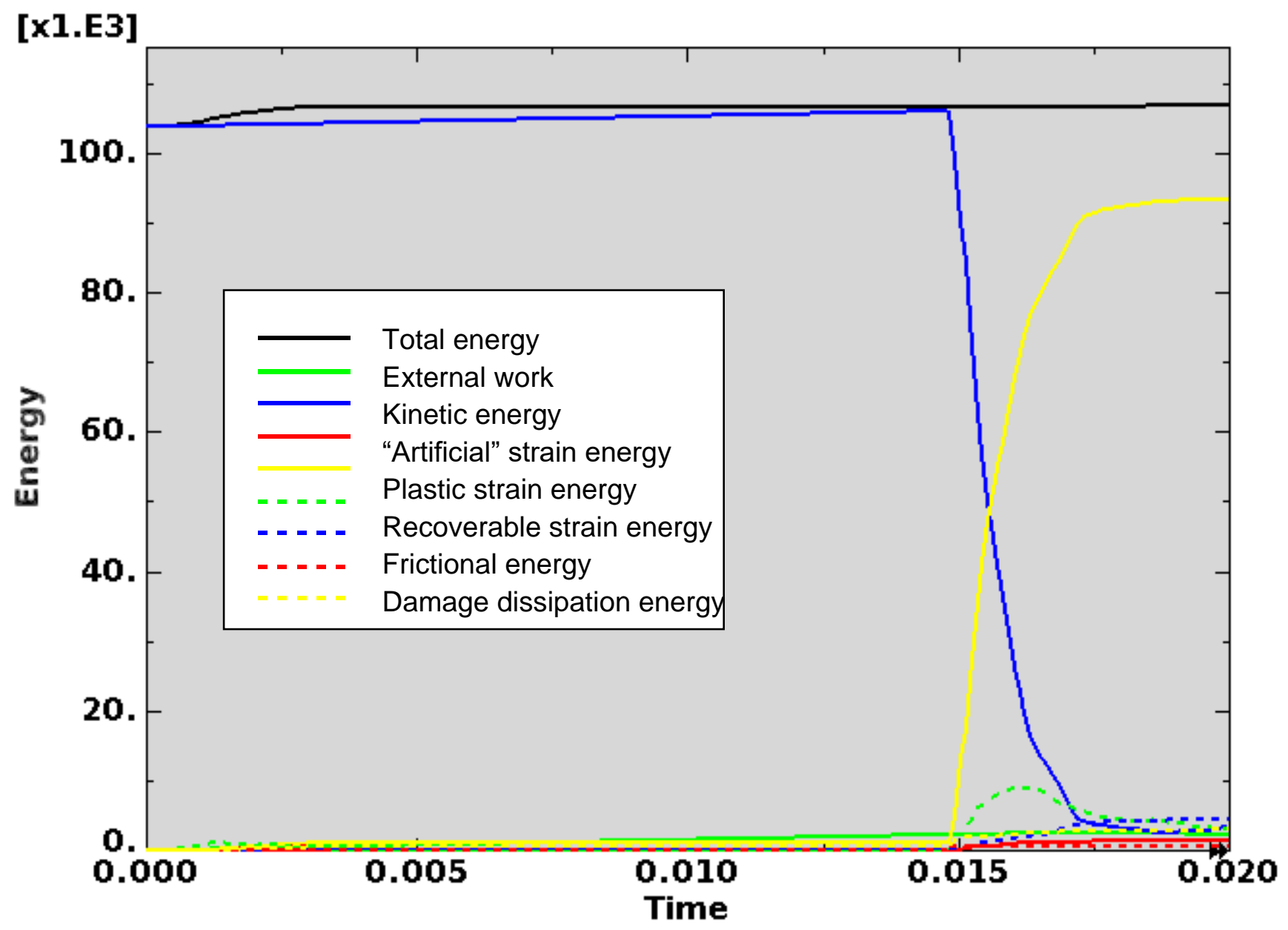

Figure D-320. Scope Part 2d (Table 3), Test 13 (Table 2) energy curves.

Figure D-320 shows the energy curves for Scope Part 2d (Table 3), Test 13 (Table 2) drop scenario. These curves exhibit stable behavior. The original model run was performed for 0.03 seconds and a small amount of undesirable rise in total energy and plastic strain energy did occur near the end. However, rebound has occurred at 0.02 seconds and the curves are stable. Consequently, output is given at 0.02 seconds.

Artificial strain energy represents the energy required to keep reduced integration elements from taking on a zero-energy hourglass shape. As shown in Figure D-320, the artificial energy at the end of the model run is $1.3 \%$ of the total energy. Therefore, the potential error associated with artificial energy is not considered to be significant. 
ENGINEERING CALCULATIONS AND ANALYSIS

Drop Analysis of the Advanced Test Reactor Fresh Fuel Shipping Container with Heavier Low-Enriched Uranium Fuel Contents
ECAR-5224, Rev. 0

Page D281 of D293

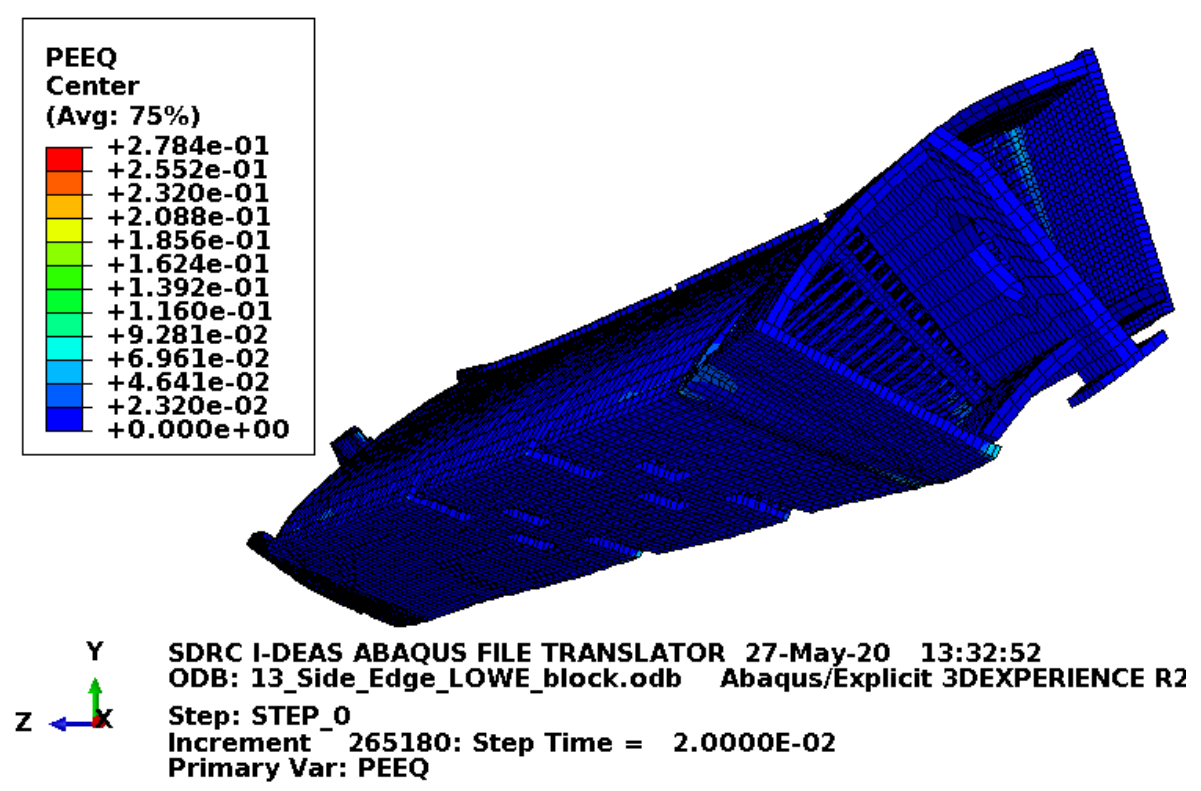

Figure D-321. Scope Part 2d (Table 3), Test 13 (Table 2) fuel element plastic equivalent strain.

Figure D-321 shows the equivalent plastic strain in the fuel element. Failure in the end box elements occurs at an equivalent plastic strain of $0.08 \mathrm{in./in.} \mathrm{(for} \mathrm{the} \mathrm{relatively} \mathrm{tough} \mathrm{material} \mathrm{properties).} \mathrm{Failure} \mathrm{in} \mathrm{the} \mathrm{end}$ box weld elements occurs at an equivalent plastic strain of $0.115 \mathrm{in}$./in. (for the relatively tough material properties). Failure in the side plate and comb elements occurs at an equivalent plastic strain of $0.152 \mathrm{in}$./in. Failure in the side plate weld elements occurs at an equivalent plastic strain of 0.205 in./in. Figure D-321 shows minimal failure in the vicinity of the end box.

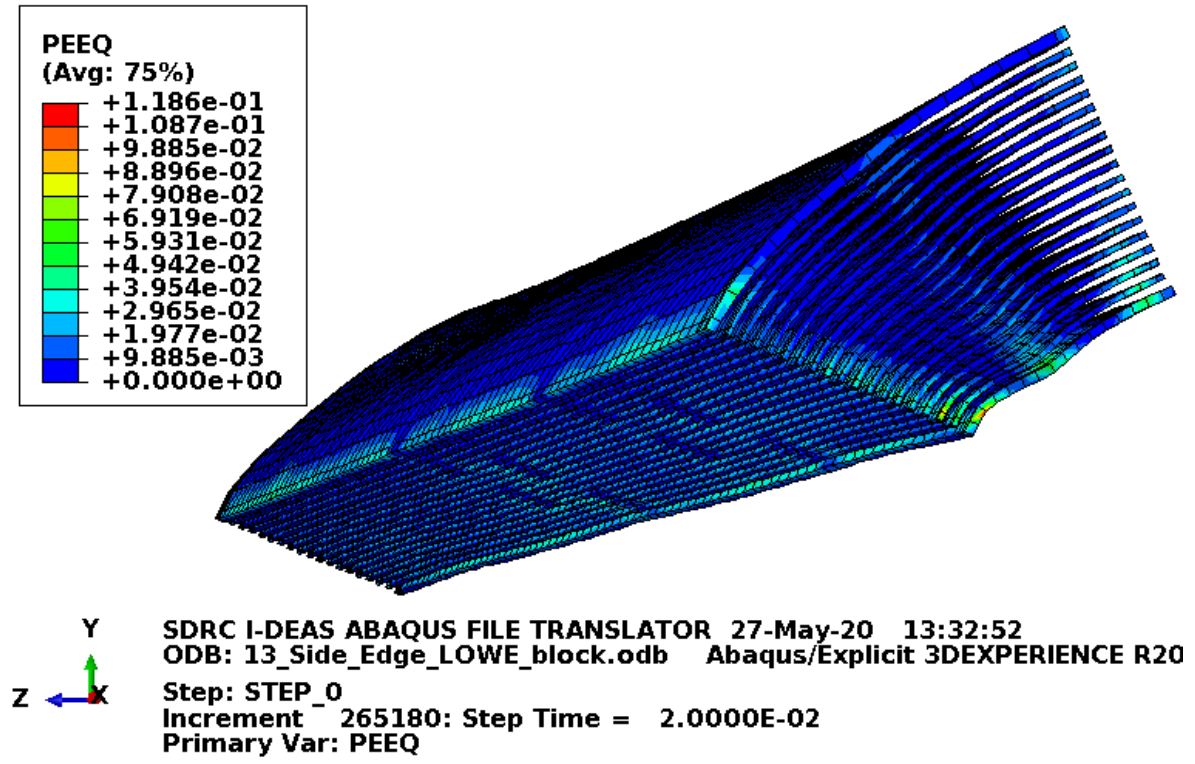

Figure D-322. Scope Part 2d (Table 3), Test 13 (Table 2) fuel plate equivalent strain.

Figure D-322 shows the equivalent plastic strain in the fuel plates. Failure in these elements occurs at an equivalent plastic strain of 0.205 in./in. Figure D-322 shows no failure in the fuel plates with margin. 


\section{D3.11 Results for Scope Part 2 (Table 3), Test 14 (Table 2)}

The drop scenario considered in this section is a $30 \mathrm{ft}$ slap-down drop with pockets and index lugs on the sides. The impact orientation is 20 degrees off horizontal with the ATR FFSC bottom hitting first.

\section{D3.11.1 Results for Scope Part 2a (Table 3), Test 14 (Table 2)}

The FEA model results for the Scope Part 2a (Table 3), Test 14 (Table 2) model are shown below in Figure D-323 to Figure D-325. The fuel element weighs $44 \mathrm{lbf}$ and the whole model is modeled with minimum material properties.

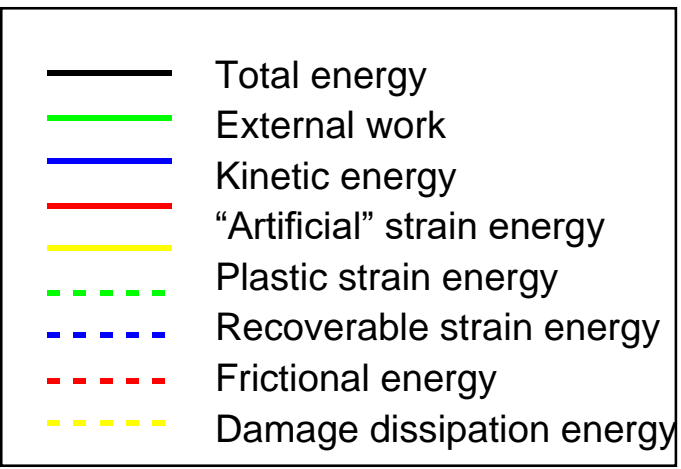

[X1.E3]

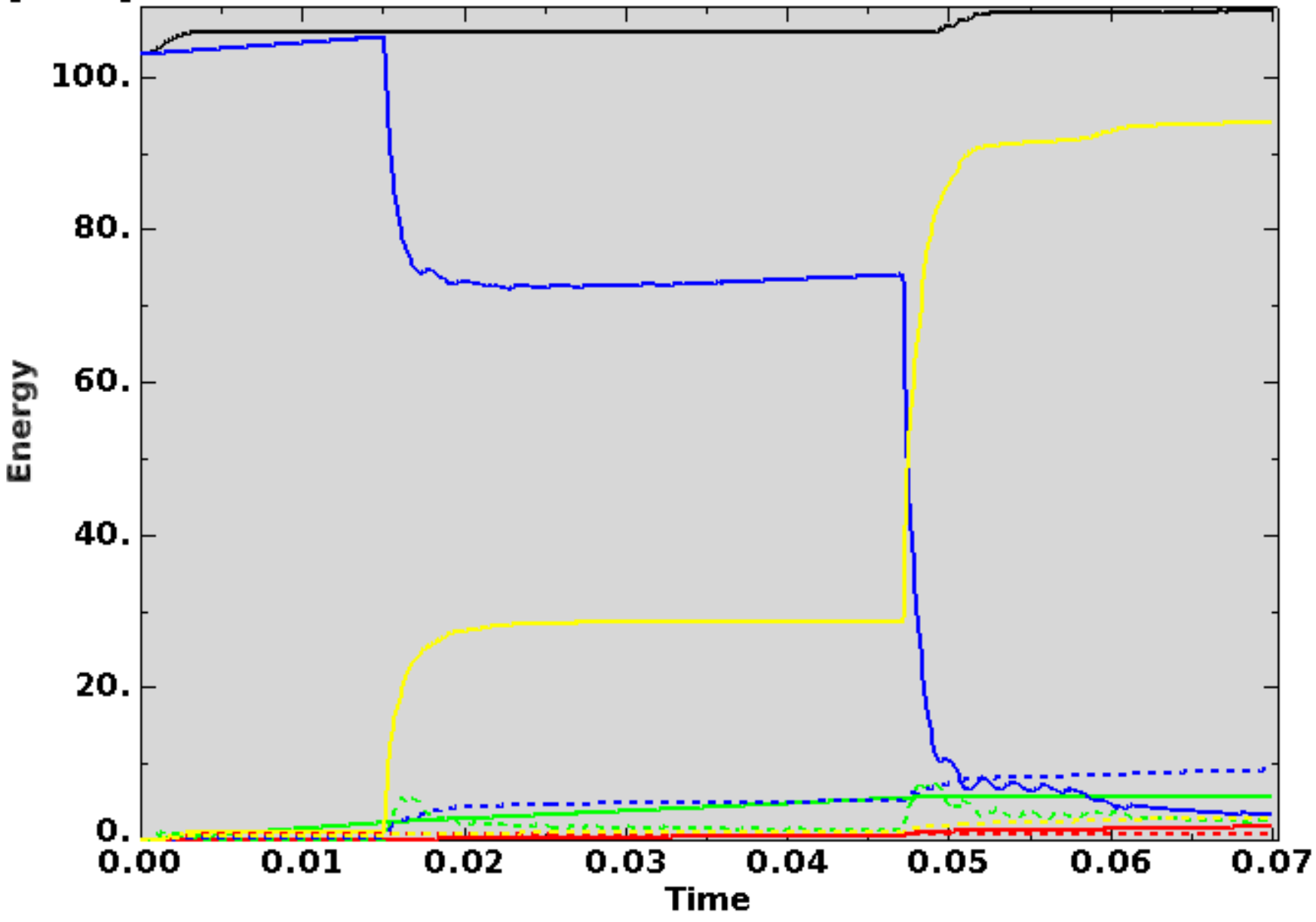

Figure D-323. Scope Part 2a (Table 3), Test 14 (Table 2) energy curves. 
Figure D-323 shows the energy curves for Scope Part 2a (Table 3), Test 14 (Table 2) drop scenario. These curves exhibit a somewhat stable shape. There is a small amount of undesirable increase in total and plastic strain energy, but it is not considered significantly detrimental to the validity of the results. As discussed in Section D2.5 this appears to result from contact difficultly between failed portions of the fuel element. Artificial strain energy represents the energy required to keep reduced integration elements from taking on a zero-energy hourglass shape. As shown in Figure D-323, the artificial energy at the end of the model run is $1.6 \%$ of the total energy. Therefore, the potential error associated with artificial energy is not considered to be significant.

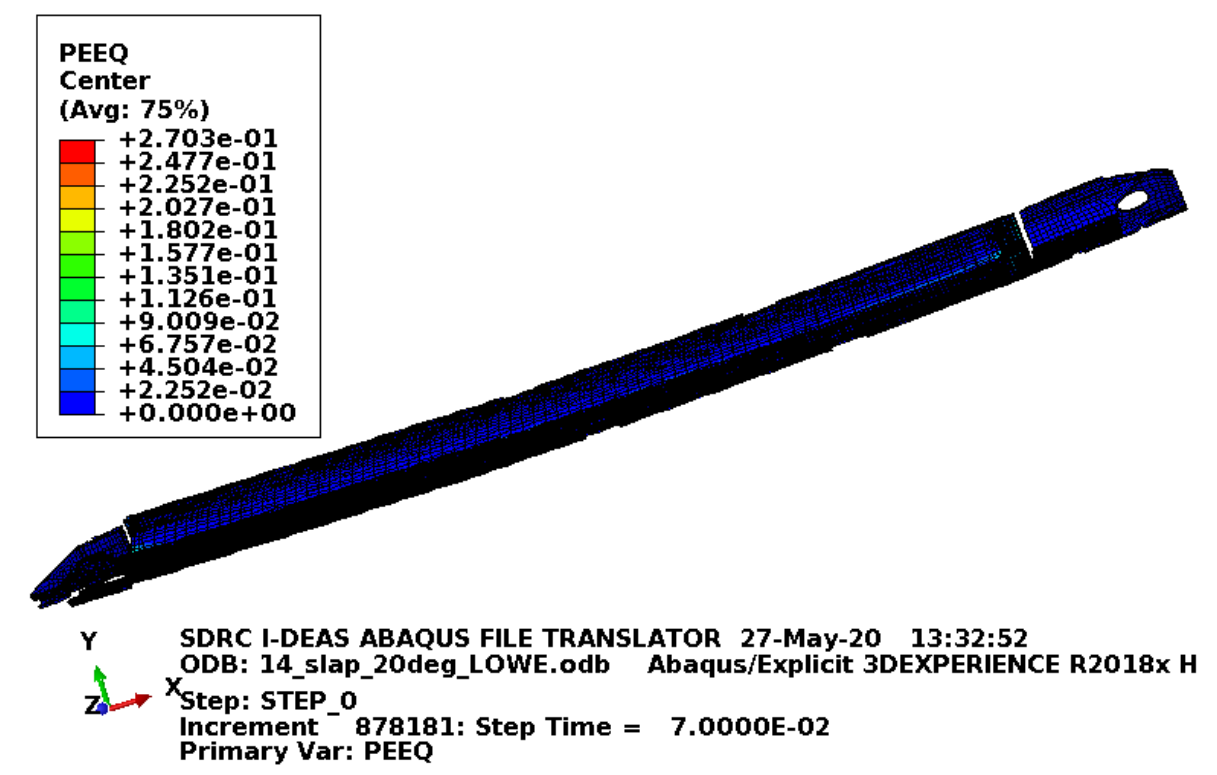

Figure D-324. Scope Part 2a (Table 3), Test 14 (Table 2) fuel element plastic equivalent strain.

Figure D-324 shows the equivalent plastic strain in the fuel element. Failure in the end box elements occurs at an equivalent plastic strain of $0.027 \mathrm{in}$./in. Failure in the end box weld elements occurs at an equivalent plastic strain of $0.032 \mathrm{in}$./in. Failure in the side plate and comb elements occurs at an equivalent plastic strain of $0.152 \mathrm{in./in.} \mathrm{Failure} \mathrm{in} \mathrm{the} \mathrm{side} \mathrm{plate} \mathrm{weld} \mathrm{elements} \mathrm{occurs} \mathrm{at} \mathrm{an} \mathrm{equivalent} \mathrm{plastic} \mathrm{strain} \mathrm{of}$ 0.205 in./in. Figure D-324 shows some end box failure. 
ENGINEERING CALCULATIONS AND ANALYSIS

Drop Analysis of the Advanced Test Reactor Fresh Fuel Shipping Container with Heavier Low-Enriched Uranium Fuel Contents

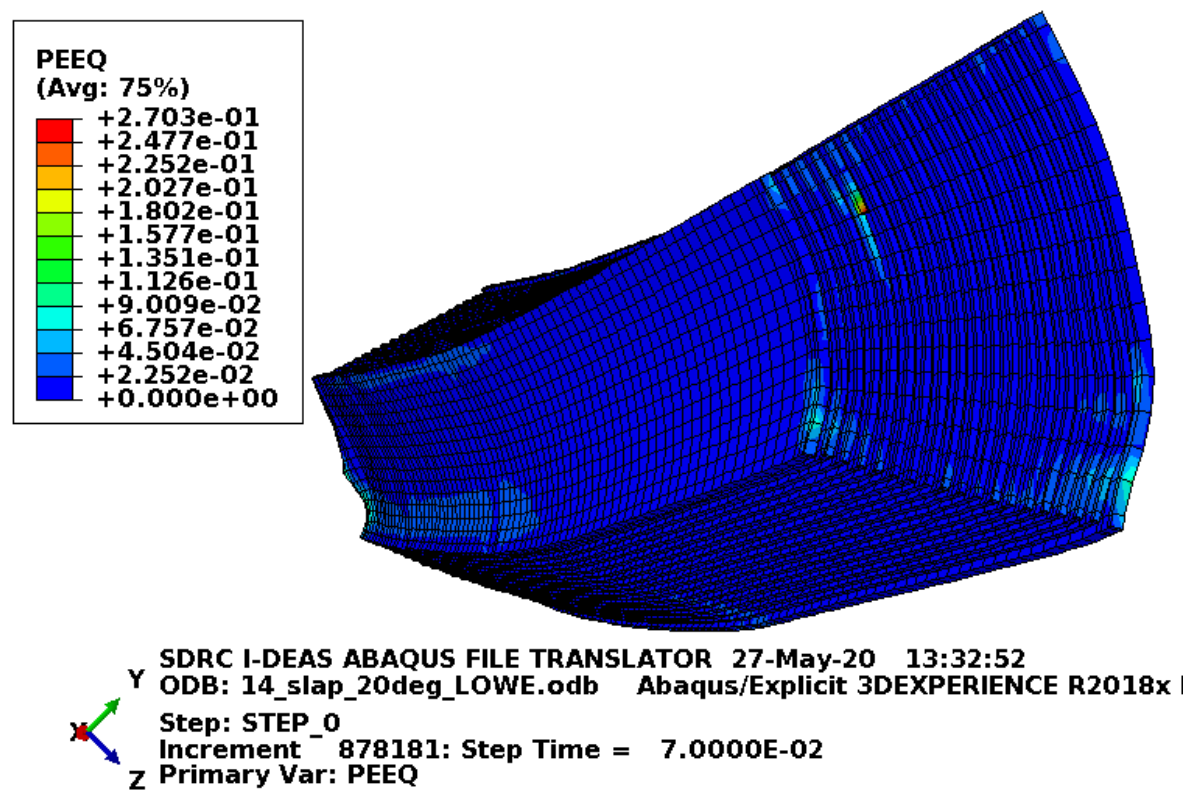

Figure D-325. Scope Part 2a (Table 3), Test 14 (Table 2) fuel plate equivalent strain.

Figure D-325 shows the equivalent plastic strain in the fuel plates. Failure in these elements occurs at an equivalent plastic strain of $0.205 \mathrm{in}$./in. Figure D-325 shows some failure one element deep (about $0.15 \mathrm{in}$.) in the end of one fuel plate. Additionally, one element at the end of the same fuel plate (next to the failed region) shows strains above failure. The strains shown above the failure strain likely result from extrapolation (as integration point strains are the important strains for failure). Even if the elements with high strain were removed as being failed, the failure is acceptable because it does not extend into the fuel meat.

\section{D3.11.2 Results for Scope Part 2b (Table 3), Test 14 (Table 2)}

The FEA model results for the Scope Part $2 b$ (Table 3), Test 14 (Table 2) model are shown below in Figure D-326 to Figure D-328. The fuel element weighs $44 \mathrm{lbf}$ and the drop scenario is modeled with minimum material properties except the enclosure and end boxes, which are modeled with relatively tough material properties. 


\section{[X1.E3]}
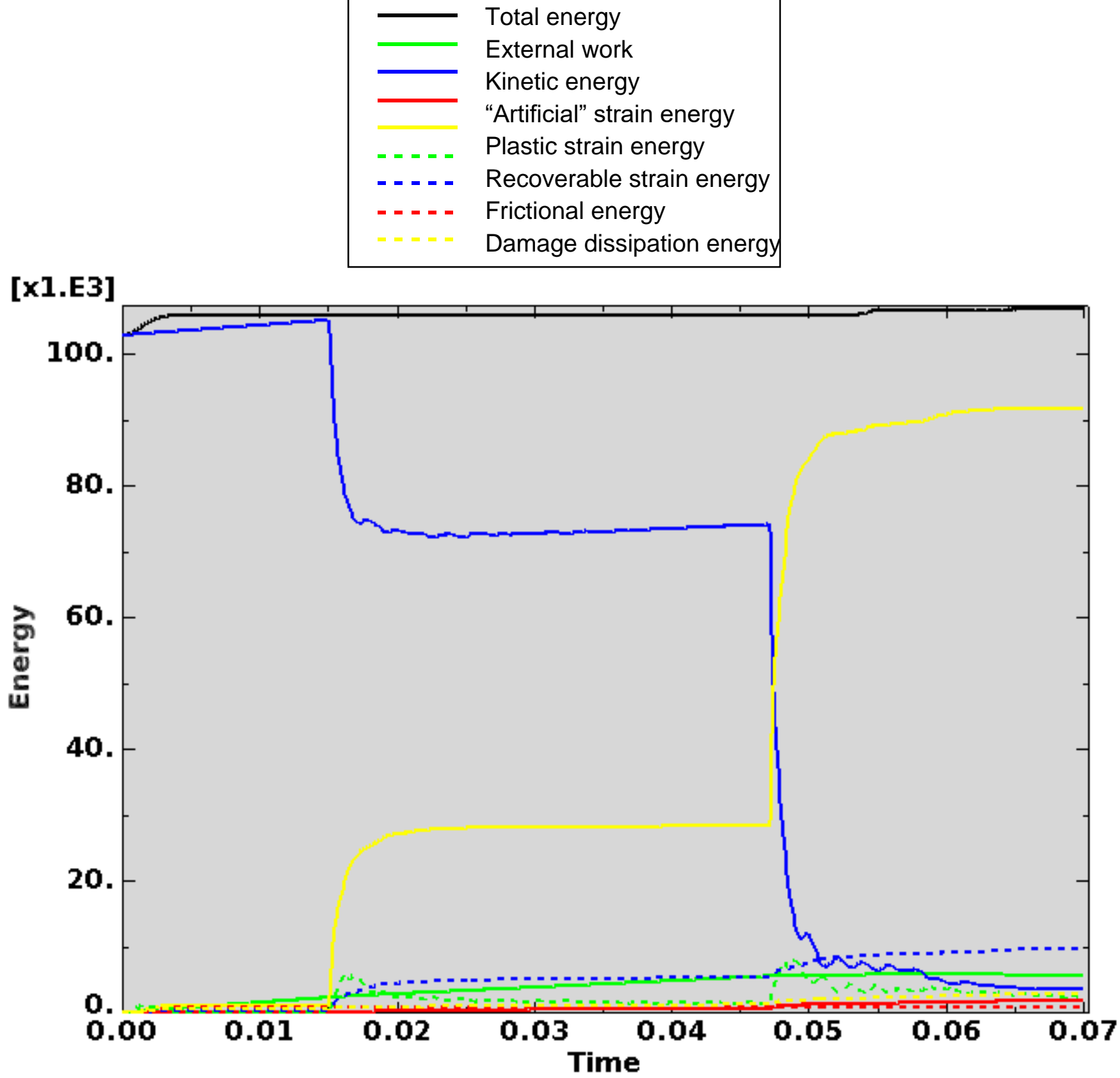

Figure D-326. Scope Part 2b (Table 3), Test 14 (Table 2) energy curves.

Figure D-326 shows the energy curves for Scope Part 2b (Table 3), Test 14 (Table 2) drop scenario. These curves exhibit a somewhat stable shape. There is a small amount of undesirable increase in total and plastic strain energy, but it is not considered significantly detrimental to the validity of the results. Artificial strain energy represents the energy required to keep reduced integration elements from taking on a zero-energy hourglass shape. As shown in Figure D-326, the artificial energy at the end of the model run is $1.7 \%$ of the total energy. Therefore, the potential error associated with artificial energy is not considered to be significant. 


\section{ENGINEERING CALCULATIONS AND ANALYSIS}

Drop Analysis of the Advanced Test Reactor Fresh Fuel Shipping Container with Heavier Low-Enriched Uranium Fuel Contents
ECAR-5224, Rev. 0

Page D286 of D293

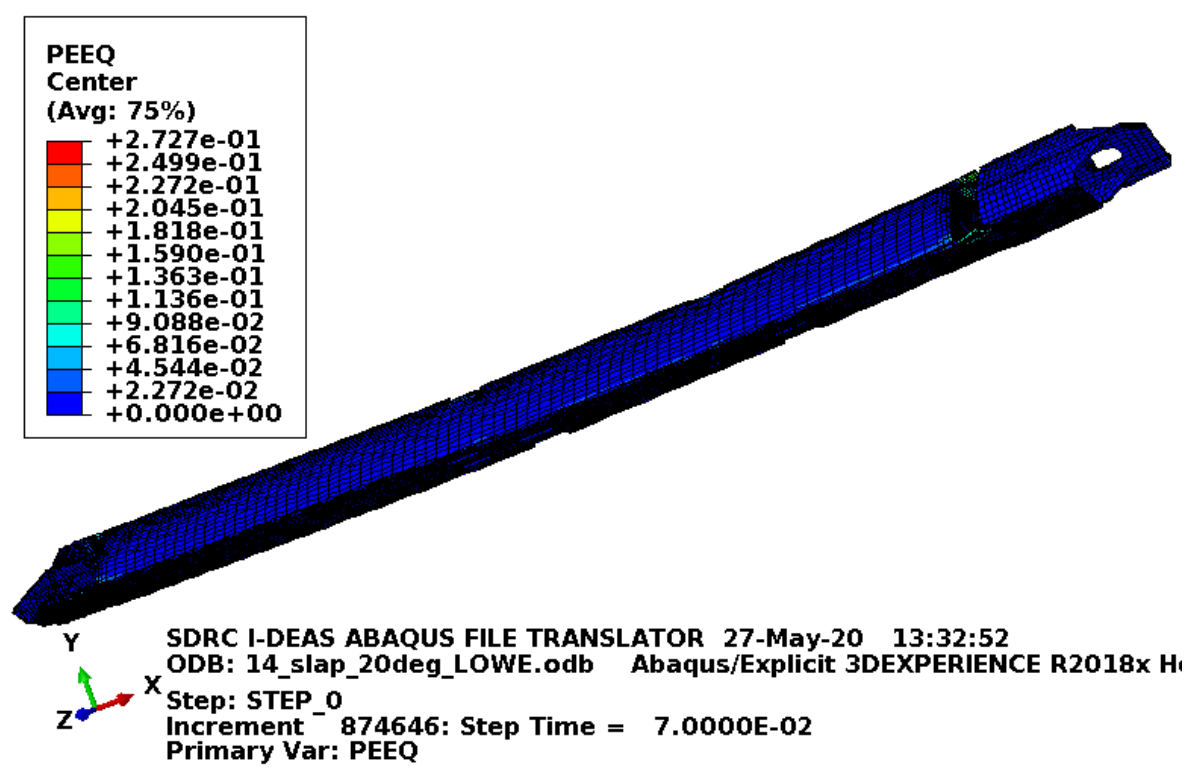

Figure D-327. Scope Part 2b (Table 3), Test 14 (Table 2) fuel element plastic equivalent strain.

Figure D-327 shows the equivalent plastic strain in the fuel element. Failure in the end box elements occurs at an equivalent plastic strain of $0.08 \mathrm{in./in.} \mathrm{(for} \mathrm{the} \mathrm{relatively} \mathrm{tough} \mathrm{material} \mathrm{properties).} \mathrm{Failure} \mathrm{in} \mathrm{the} \mathrm{end}$ box weld elements occurs at an equivalent plastic strain of $0.115 \mathrm{in}$./in. (for the relatively tough material properties). Failure in the side plate and comb elements occurs at an equivalent plastic strain of $0.152 \mathrm{in}$./in. Failure in the side plate weld elements occurs at an equivalent plastic strain of 0.205 in./in. Figure D-327 shows minimal end box failure.

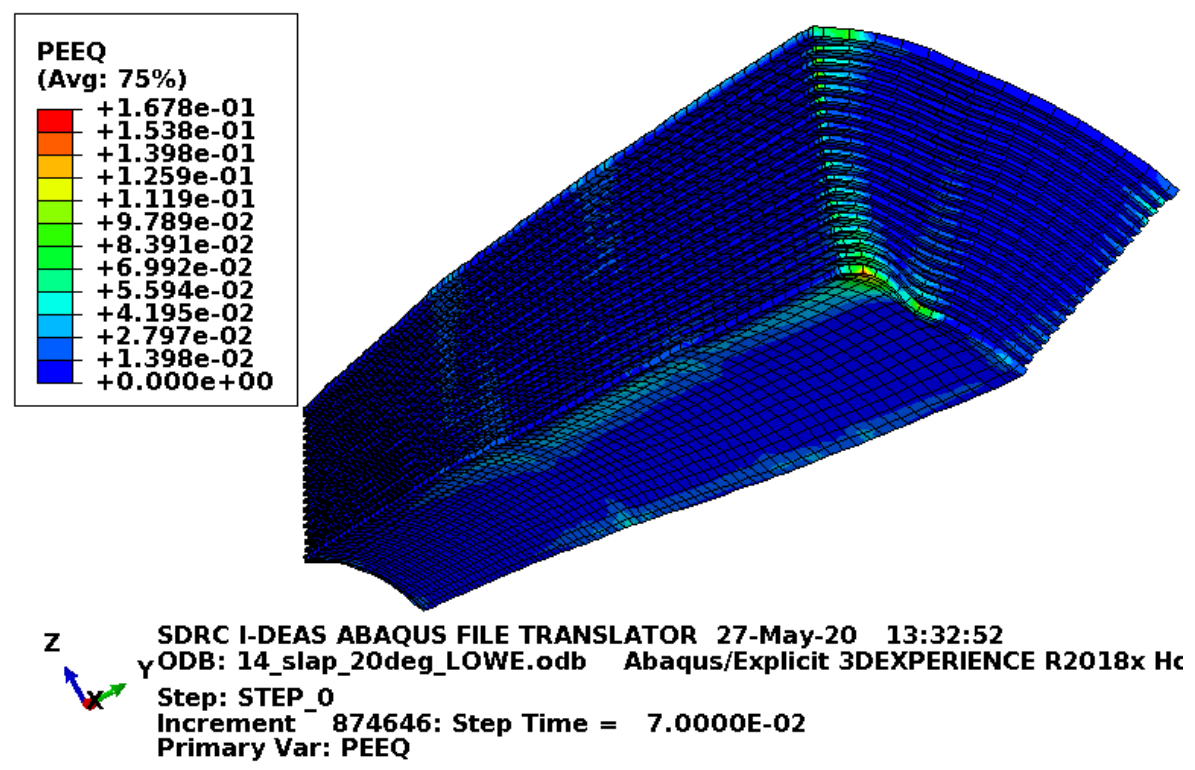

Figure D-328. Scope Part 2b (Table 3), Test 14 (Table 2) fuel plate equivalent strain.

Figure D-328 shows the equivalent plastic strain in the fuel plates. Failure in these elements occurs at an equivalent plastic strain of 0.205 in./in. Figure D-328 shows no element failure. 


\section{D3.11.3 Results for Scope Part 2c (Table 3), Test 14 (Table 2)}

The FEA model results for the Scope Part 2c (Table 3), Test 14 (Table 2) model are shown below in Figure D-329 to Figure D-331. The fuel element weighs $44 \mathrm{lbf}$ and the whole model is modeled with minimum material properties. This section includes the blocks as added fuel plate protection.

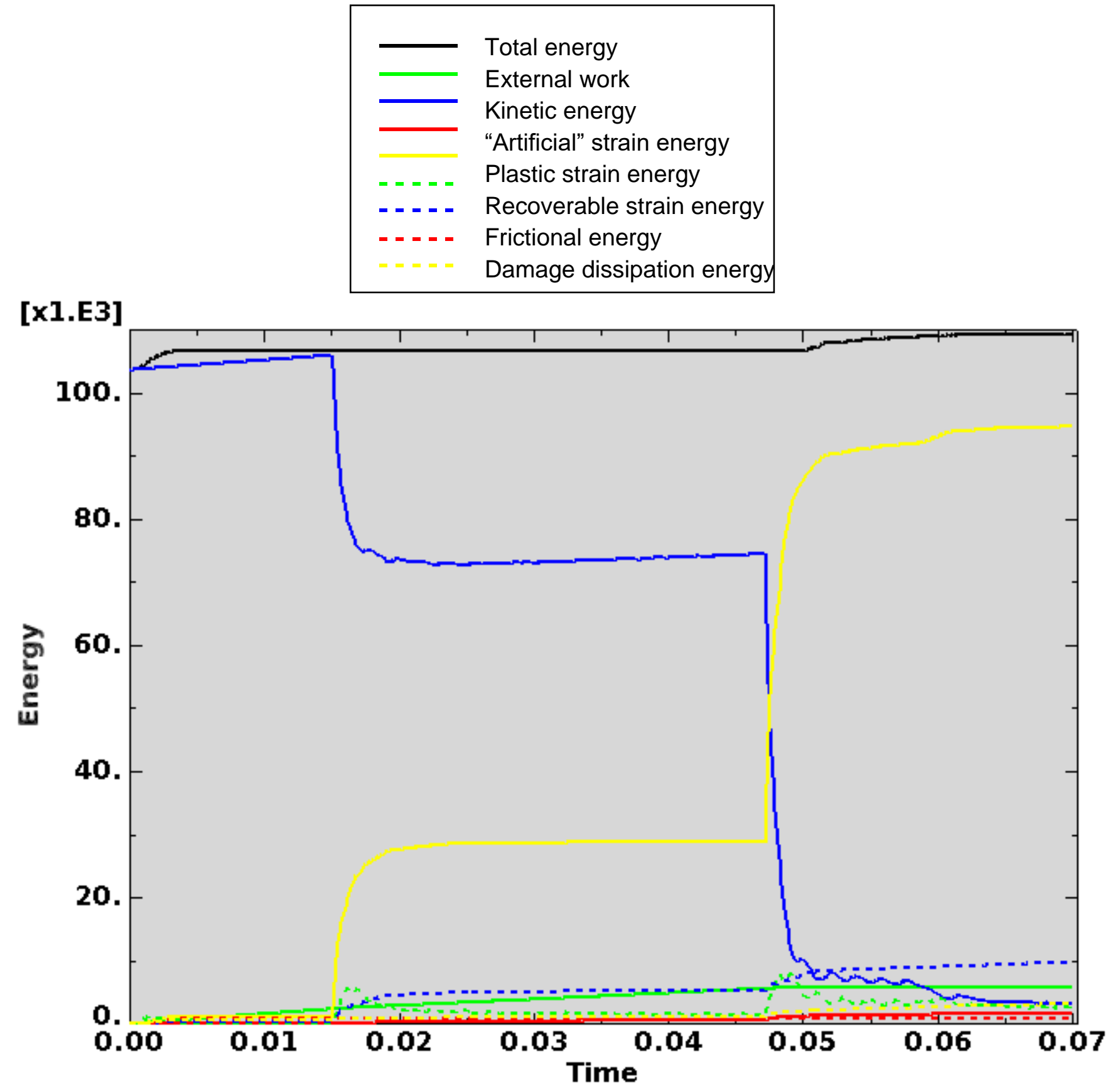

Figure D-329. Scope Part 2c (Table 3), Test 14 (Table 2) energy curves. 
Figure D-329 shows the energy curves for Scope Part 2c (Table 3), Test 14 (Table 2) drop scenario. These curves exhibit a somewhat stable shape. There is a small amount of undesirable increase in total and plastic strain energy, but it is not considered significantly detrimental to the validity of the results. Artificial strain energy represents the energy required to keep reduced integration elements from taking on a zero-energy hourglass shape. As shown in Figure D-329, the artificial energy at the end of the model run is $1.6 \%$ of the total energy. Therefore, the potential error associated with artificial energy is not considered to be significant.

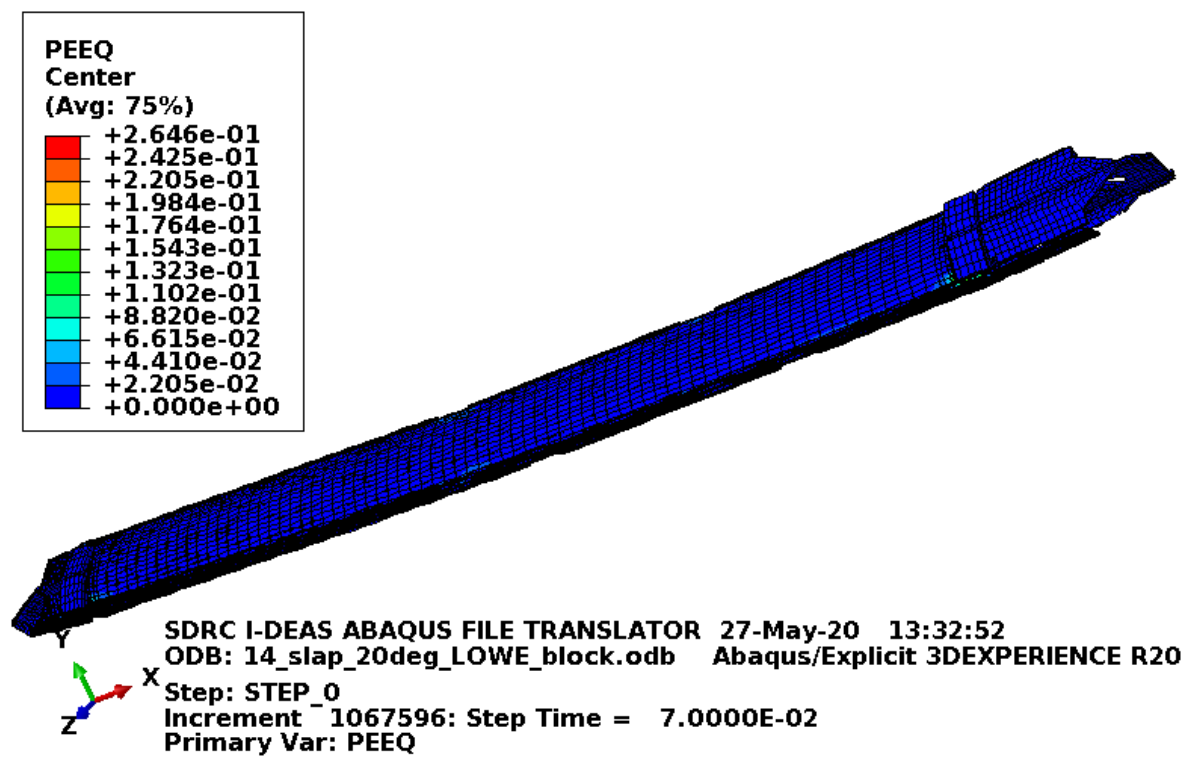

Figure D-330. Scope Part 2c (Table 3), Test 14 (Table 2) fuel element plastic equivalent strain.

Figure D-330 shows the equivalent plastic strain in the fuel element. Failure in the end box elements occurs at an equivalent plastic strain of $0.027 \mathrm{in}$./in. Failure in the end box weld elements occurs at an equivalent plastic strain of $0.032 \mathrm{in}$./in. Failure in the side plate and comb elements occurs at an equivalent plastic strain of $0.152 \mathrm{in./in.} \mathrm{Failure} \mathrm{in} \mathrm{the} \mathrm{side} \mathrm{plate} \mathrm{weld} \mathrm{elements} \mathrm{occurs} \mathrm{at} \mathrm{an} \mathrm{equivalent} \mathrm{plastic} \mathrm{strain} \mathrm{of}$ 0.205 in./in. Figure D-330 shows some end box failure. 
ENGINEERING CALCULATIONS AND ANALYSIS

Drop Analysis of the Advanced Test Reactor Fresh Fuel Shipping Container with Heavier Low-Enriched Uranium Fuel Contents

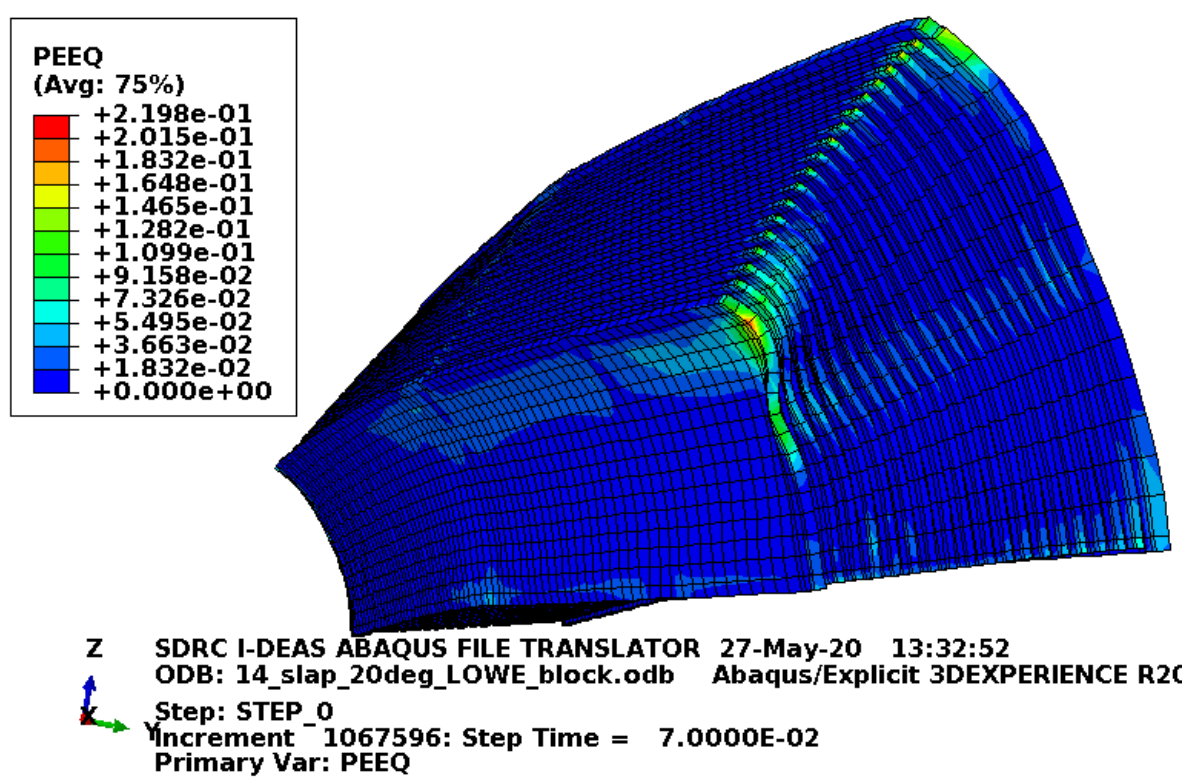

Figure D-331. Scope Part 2c (Table 3), Test 14 (Table 2) fuel plate equivalent strain.

Figure D-331 shows the equivalent plastic strain in the fuel plates. Failure in these elements occurs at an equivalent plastic strain of $0.205 \mathrm{in}$./in. Figure D-331 shows failure in one element (about $0.15 \mathrm{in}$. deep) in the end of one fuel plate. Additionally, one element at the end of a different fuel plate shows strains above failure. The strains shown above the failure strain likely result from extrapolation (as integration point strains are the important strains for failure). Even if the elements with high strain were removed as being failed, the failure is acceptable because it does not extend into the fuel meat.

\section{D3.11.4 Results for Scope Part 2d (Table 3), Test 14 (Table 2)}

The FEA model results for the Scope Part 2d (Table 3), Test 14 (Table 2) model are shown below in Figure D-332 to Figure D-334. The fuel element weighs $44 \mathrm{lbf}$ and the drop scenario is modeled with minimum material properties except the enclosure and end boxes, which are modeled with relatively tough material properties. This section includes the blocks as added fuel plate protection. 


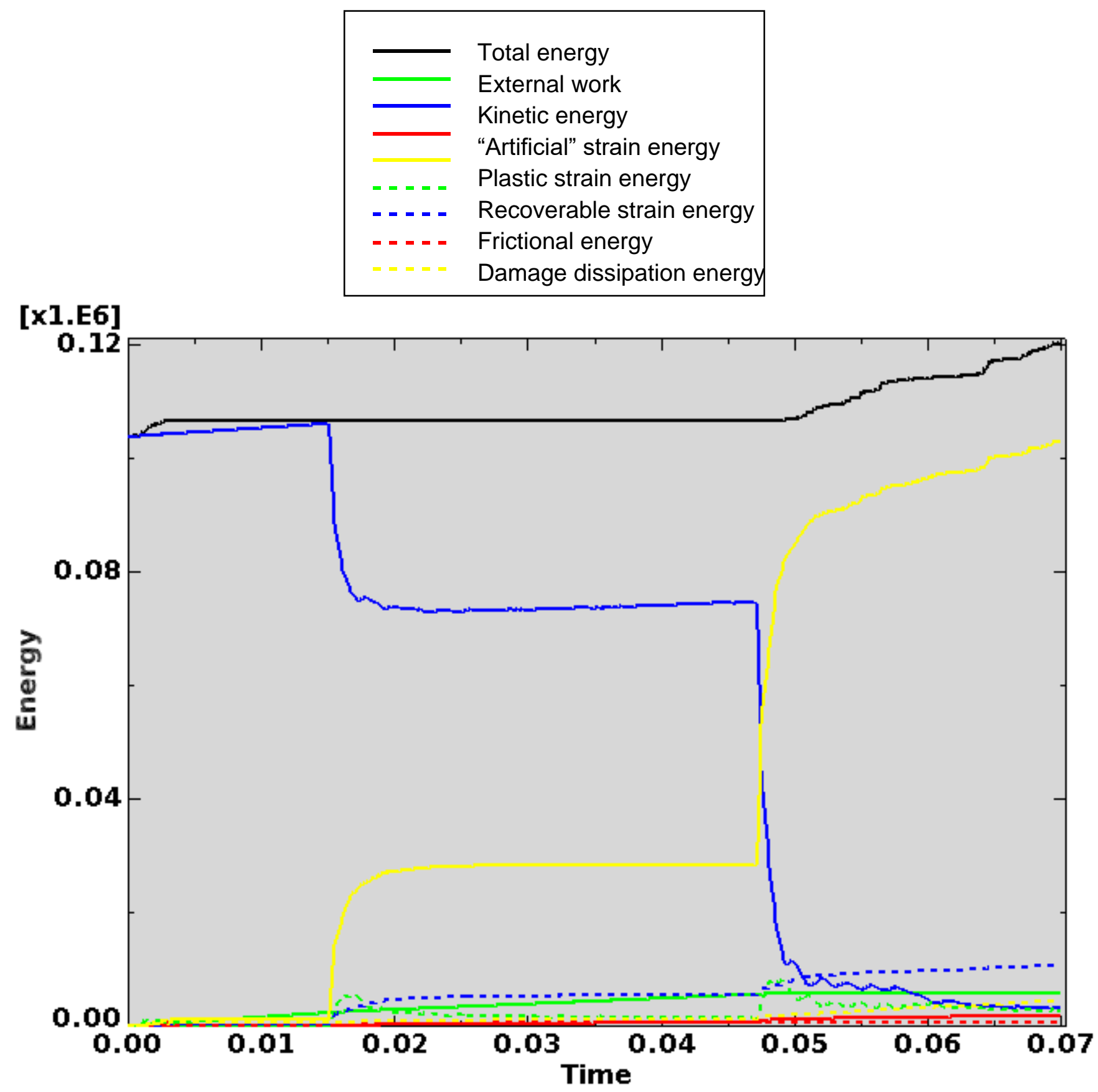

Figure D-332. Scope Part 2d (Table 3), Test 14 (Table 2) energy curves.

Figure D-332 shows the energy curves for Scope Part 2d (Table 3), Test 14 (Table 2) drop scenario. These curves exhibit a somewhat stable shape. There is some undesirable increase in total and plastic strain energy, but it is not considered significantly detrimental to the validity of the results. Additionally, this model differs from the model in Section D3.11.2 only with the addition of blocks and the results are similar. Artificial strain energy represents the energy required to keep reduced integration elements from taking on a zero-energy hourglass shape. As shown in Figure D-332, the artificial energy at the end of the model run is $1.5 \%$ of the total energy. Therefore, the potential error associated with artificial energy is not considered to be significant. 
ENGINEERING CALCULATIONS AND ANALYSIS

Drop Analysis of the Advanced Test Reactor Fresh Fuel Shipping Container with Heavier Low-Enriched Uranium Fuel Contents
ECAR-5224, Rev. 0

Page D291 of D293

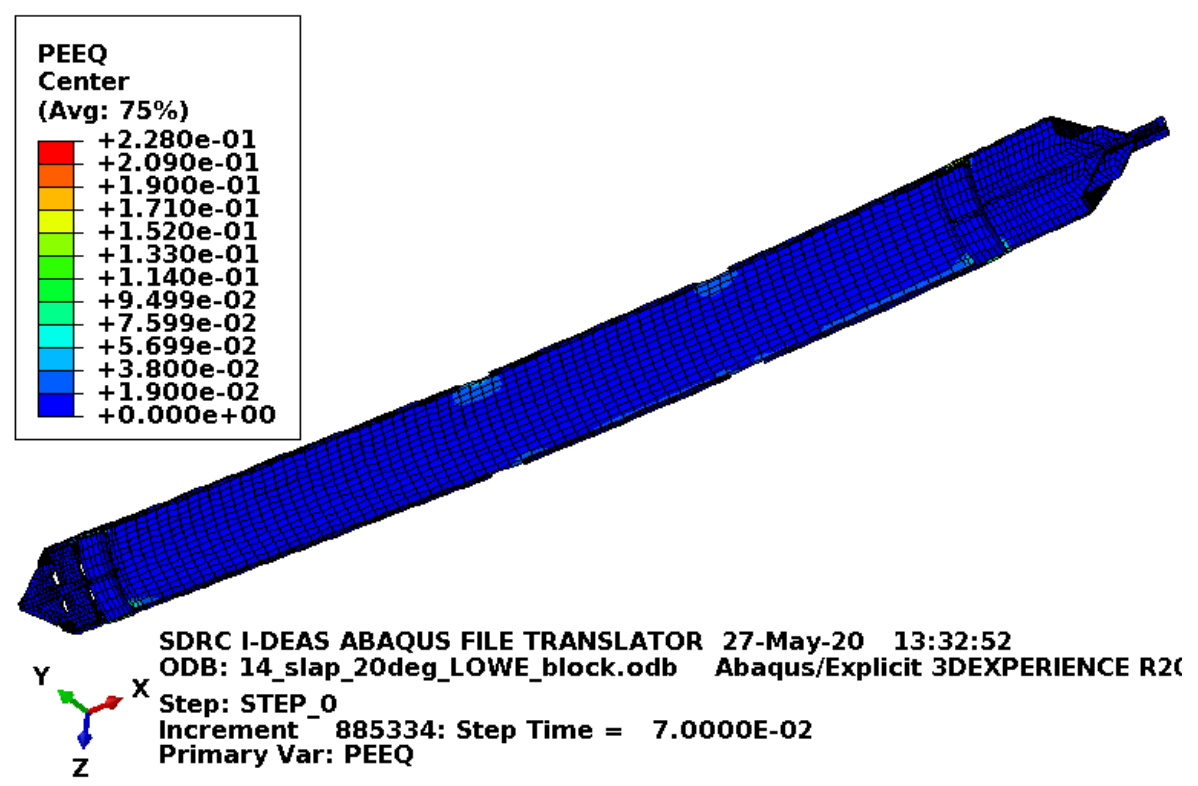

Figure D-333. Scope Part 2d (Table 3), Test 14 (Table 2) fuel element plastic equivalent strain.

Figure D-333 shows the equivalent plastic strain in the fuel element. Failure in the end box elements occurs at an equivalent plastic strain of $0.08 \mathrm{in./in.} \mathrm{(for} \mathrm{the} \mathrm{relatively} \mathrm{tough} \mathrm{material} \mathrm{properties).} \mathrm{Failure} \mathrm{in} \mathrm{the} \mathrm{end}$ box weld elements occurs at an equivalent plastic strain of $0.115 \mathrm{in}$./in. (for the relatively tough material properties). Failure in the side plate and comb elements occurs at an equivalent plastic strain of 0.152 in./in. Failure in the side plate weld elements occurs at an equivalent plastic strain of 0.205 in./in. Figure D-333 shows minimal failure in the vicinity of the end box.

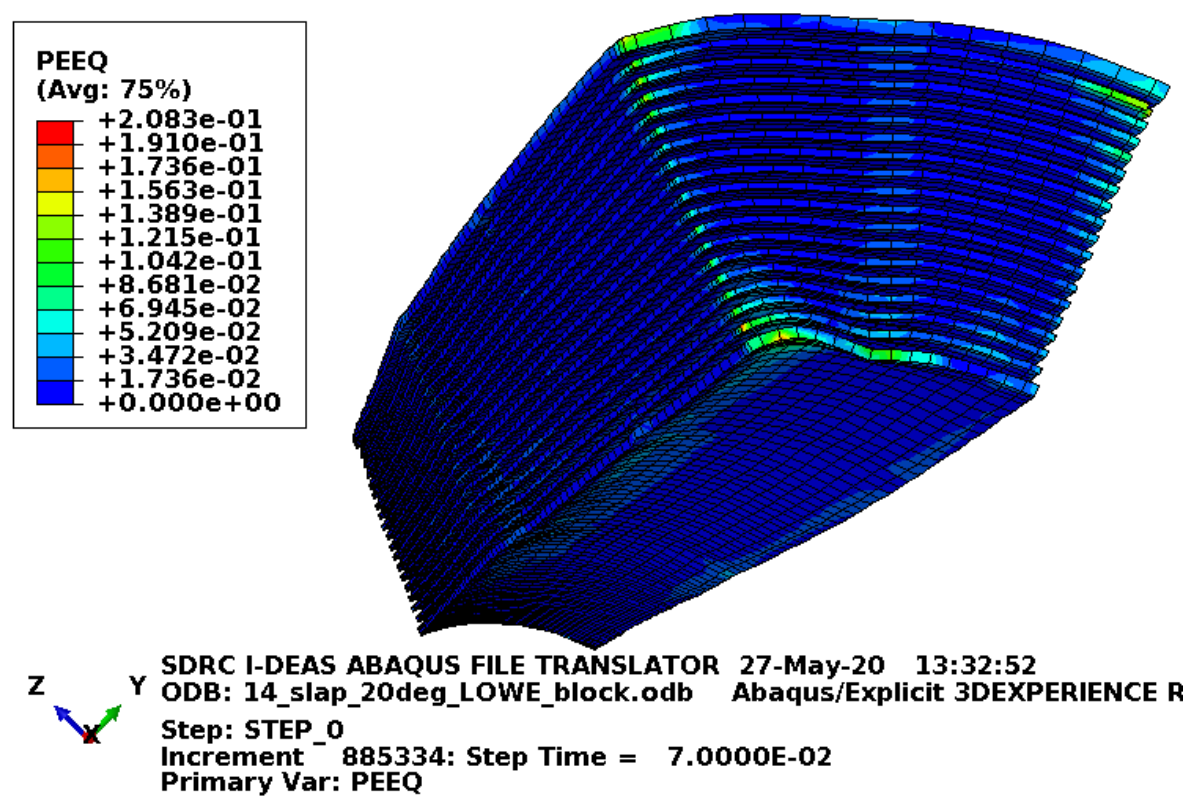

Figure D-334. Scope Part 2d (Table 3), Test 14 (Table 2) fuel plate equivalent strain. 
Figure D-334 shows the equivalent plastic strain in the fuel plates. Failure in these elements occurs at an equivalent plastic strain of $0.205 \mathrm{in}$./in. Figure D-334 shows failure in one element (about $0.15 \mathrm{in}$. deep) in the end of one fuel plate. Additionally, one element at the end of a different fuel plate shows strains above failure. The strains shown above the failure strain likely result from extrapolation (as integration point strains are the important strains for failure). Even if the elements with high strain were removed as being failed, the failure is acceptable because it does not extend into the fuel meat.

\section{D3.12 Summary of Results for Scope Part 2 (Table 3)}

The Scope Part 1 (Table 3) results (see Section D2) demonstrate that the FEA models produce reasonable and conservative results compared to the physical drops. The Scope Part 2 (Table 3) results (using the same FEA models with increased LOWE fuel weight) showed that the LOWE fuel element with the new block design produced acceptable results for all the drop scenarios. It did not produce acceptable results for all drop scenarios without the blocks.

The single notable drawback of the blocks is that they reduce the crush zone for an end impact of the fuel element. Though this is greatly outweighed by the benefit of providing fuel plate protection from being cut by fractured pieces of the end boxes. Also, they provide a smooth flat surface which can uniformly compress against the fuel plates in an end impact.

For the considered drop scenarios, the flat bottom (see Section D3.5) and flat top (see Section D3.9) drop scenarios provide the most fuel plate damage that is potentially harmful to the fuel meat. Similar to Section D2, minimum material properties are used for the fuel plate and fine meshed models of the fuel plates provides added conservatism. The end box behavior is very important in end impacts as they absorb impact energy, but failed pieces can cut into the fuel plates. In an attempt to bracket the response, minimum and relatively tough material properties are considered for the end boxes. With minimum material properties for the end boxes, a minimum amount of energy is absorbed by the end boxes and the addition of the blocks compounds this by reducing the crush zone. This conservatively puts more strain energy into the fuel plates. For the acceptable LOWE fuel element with blocks results, Figure D-244 and Figure D-304 show the worst fuel plate damage. In these models, compressive failure is shown up to but not in the fuel meat. As noted in Section D2.11, compressive failure in the fuel plates is predicted with significant conservatism using the defined failure parameter in Abaqus (2018). Abaqus (2018) is capable of a more accurate solution, but test data for all the needed parameters are not currently available for the materials in these models.

For the relatively tough end boxes, there is a higher risk of a piece of the end box cutting into the fuel plates. These models showed the most damage for the unacceptable models having the LOWE fuel element without blocks (see Sections D3.5.3, D3.5.4, and D3.9.2). However, for the acceptable models having the LOWE fuel element with blocks, this produced less fuel plate damage than those with the minimum material property end boxes. This is because the end boxes absorbed more impact energy and the blocks offered protection to the fuel plates from failed pieces of the end boxes. Sections D3.5.7 and D3.5.8 did show the possibility of weld failure occurring low enough on the end box that the end box sides could go around the block and do some fuel plate damage. The damage shown is a local outward push of the side plate and damage to the fuel plate near the edge. Given the damage in the fine meshed model (Section D3.5.8), the damage is near enough to the fuel plate edge that if it were extended further along the fuel plate, it would miss the fuel meat. 
In general, the side drop scenarios caused LOWE fuel element plasticity, but no model showed failed fuel plate elements. The slap-down drop did cause minimal failure in the end of some fuel plates, though this failure did not extend beyond the solid aluminum edges and into the fuel meat. The sections not specifically mentioned were included for completeness but did not produce notable results. 